\title{
LEGAL AND REGULATORY ASPECTS OF MOBILE FINANCIAL SERVICES
}

\author{
by \\ Leon Joseph Perlman \\ submitted in accordance with the requirements for the \\ degree of \\ DOCTOR OF LAWS \\ at the \\ UNIVERSITY OF SOUTH AFRICA
}

PROMOTER: PROF JT PRETORIUS

November 2012 


\section{DEDICATION}

For my mother, Doreen.

For my wife, Lauren. 


\section{THESIS SUMMARY}

The thesis deals with the emergence of bank and non-bank entities that provide a range of unique transaction-based payment services broadly called Mobile Financial Services (MFS) to unbanked, underserved and underbanked persons via mobile phones.

Models of MFS from Mobile Network Operators (MNOs), banks, combinations of MNOs and banks, and independent Mobile Financial Services Providers are covered. Provision by non-banks of 'bank-type' services via mobile phones has been termed 'transformational banking' versus the 'additive banking' services from banks. All involve the concept of 'branchless banking' whereby 'cash-in/cash out' services are provided through 'agents.'

Funds for MFS payments may available through a Stored Value Product (SVP), particularly through a Stored Value Account SVP variant offered by MNOs where value is stored as a redeemable fiat- or mobile 'airtime'-based Store of Value.

The competitive, legal, technical and regulatory nature of non-bank versus bank MFS models is discussed, in particular the impact of banking, payments, money laundering, telecommunications, e-commerce and consumer protection laws. Whether funding mechanisms for SVPs may amount to deposit-taking such that entities could be engaged in the 'business of banking' is discussed. The continued use of 'deposit' as the traditional trigger for the 'business of banking' is investigated, alongside whether transaction and paymentcentric MFS rises to the 'business of banking.'

An extensive evaluation of 'money' based on the Orthodox and Claim School economic theories is undertaken in relation to SVPs used in MFS, their legal associations and import, and whether they may be deemed 'money' in law.

Consumer protection for MFS and payments generally through current statute, contract, and payment law and common law condictiones are found to be wanting. Possible regulatory arbitrage in relation to MFS in South African law is discussed.

The legal and regulatory regimes in the European Union, Kenya and the United States of America are compared with South Africa. The need for a coordinated payments-specific law that has consumer protections, enables proportional risk-based licensing of new non-bank providers of MFS, and allows for a regulator for retail payments is recommended. The use of trust companies and trust accounts is recommended for protection of user funds. 


\section{KEY TERMS}

Additive Banking; Agents; Airtime; Airtime Transfer; Airtime-based SOV; Allocation of Loss; Allocation of Risk; AML; Anti-Money Laundering (AML); Aristotle; Austrian School; Auto-subscription; Banks; Banks Act; Bilateral Juristic Act; Bottom of Pyramid; Branchless Banking; BSD; Business of Banking; Cash-In/Cash Out; Central Bank; Claim School; Competition Commission; Condictiones; Consumer Protection; Consumer Protection Act (CPA); Contract Law; Convergence; CTF; Dedicated Banks Bill; Delict; Regulatory Philosophies; Deposits; Deposit-taking; Directives; Dodd-Frank; Electronic Commerce (e-commerce); Electronic Communications and Transactions Act (ECTA); Electronic Funds Transfer (EFT); Electronic Money (e-Money); Electronic Money Directive (EMD); EMD; EU; European Union (EU); FA Mann; Fiat; Fiat-based SOV; FICA; Financial Inclusion; Financial Literacy; Foley v Hill; Hacking; ICASA; Kenya; KYC; Legal Capacity; m-Banking; Means of Exchange; Means of Payment; MFS; MFSP; Miller v Race; Minors; MNO; Mobile Banking (m-banking); Mobile Commerce (mcommerce); Mobile Financial Services (MFS); Mobile Financial Services Provider (MFSP); Mobile Financial Services Providers (MFSPs); Mobile Network Operator (MNO); Mobile Payments; Mobile Payments (m-payments); Mobile Purse; Mobile Wallet; Money; Money Laundering (ML); m-Payments; mpesa; National Consumer Commission; National Payment System; National Payment System Act (NPSA); Non-Banks; NPSA; Orthodox School; Oversight; Payment Instrument; Payment Service Providers (PSP); Payment Services Providers Law (PSPL); Payment Services Directive (PSD); Payment Services Regulatory Authority (PSRA); Payments Law; Pooled Accounts; Position Paper; Proportional Regulation; Prudential Regulation; PSD; PSPL; PSRA; Redeemable Funds; Regulator's Dilemma; Regulatory Arbitrage; Regulatory Capture; Remittances; Regulation of Interception of Communications Act (South Africa); (RICA) (South Africa); Security; SIM Card; SIPS; South African Reserve Bank; SOV; Specie; Store of Value (SOV); Stored Value Account (SVA); Stored Value Product (SVP); Subscriber; Supervision; Systemic Risk; Telecommunications; Transformational Banking; Trust Accounts; Unbanked; Underserved; Underbanked; Unit of Account; United Dominions Trust (UDT); Unjustified Enrichment; USA; Value Added Services (VAS); Wallet; WASP; WASPA 


\section{ACKNOWLEDGEMENTS}

A huge thank you to my promoter, Professor Jopie T. Pretorius, for his patience, support and sage guidance over the years. I have learnt much from you.

My eternal love and gratitude to my dear mother, Doreen, for your love and perennial faith in me.

To my wife and love of my life, Lauren, thank you so much for your unwavering support and love, and for the many sacrifices you made in giving me the space to complete this thesis.

I am very lucky to have my sister, Heather White, in my life, who has always provided me with much love, support, and encouragement to complete this and other degrees.

I am very grateful and thankful to my parents-in-law, Leonard and Rita Lavitt, for their love and support, and for the space and nourishment in their home over many seasons.

I appreciate and am thankful for all the encouragement and support from all my family around the world over many years.

Much gratitude and thanks goes to my proof-reader, Karen Breckon, for her hard work, diligence, dedication, and words of advice. Thank you so much.

Thank you to all my friends all over the world who provided me with encouragement, writing space, understanding and support.

I am grateful to BankSETA for their support and funding.

Thank you to all those many experts in their respective fields, academics, businessmen, colleagues, government officials and numerous others around the world, all of whom generously gave of their time and expertise in the course of research for this thesis and without whose insights it would not have been complete. 


\section{DECLARATION}

I declare that LEGAL AND REGULATORY ASPECTS OF MOBILE FINANCIAL SERVICES is my own work, and that all the sources that I have used or quoted have been indicated and acknowledged by means of complete references.

Leon Joseph Perlman

SIGNATURE
30 November 2012

DATE

Leon Joseph Perlman

Unisa Student Number 674-299-8 


\section{TABLE OF CONTENTS}

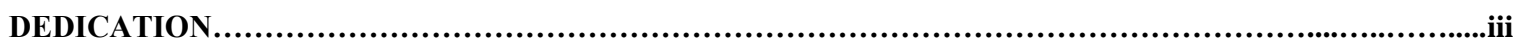

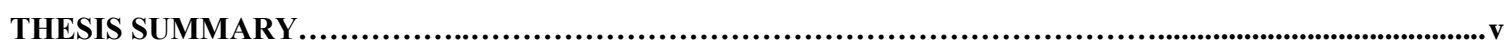

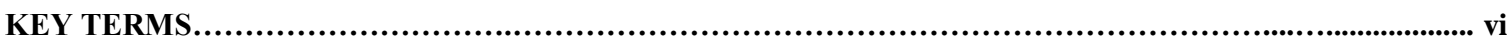

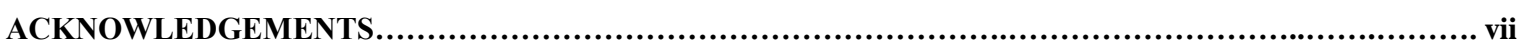

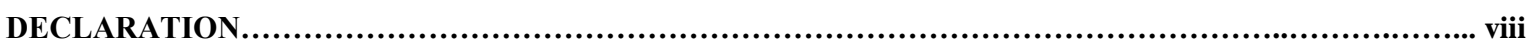

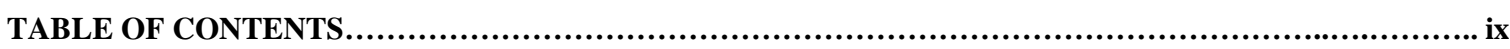

CHAPTER 1: SCOPE, STRUCTURE AND RESEARCH METHODOLOGY.................................. 1

$\begin{array}{ll}\text { A. } & \text { Overview } \mathbf{O f} \text { Thesis } \\ 1.1 & \text { Introduction } \ldots \ldots \ldots\end{array}$

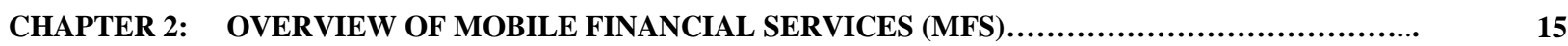

2.1

Exhibit A

2.2

2.3
Introduction

Stylised structure and transaction flows of a dual-SVA SVP

The Rationale for MFS

The Scope of MFS

Services Available In MFS

Structure and Participants in MFS Schemes

Overview....

Use Of Agents.

Comparisons with other Systems and Internet E-Commerce 


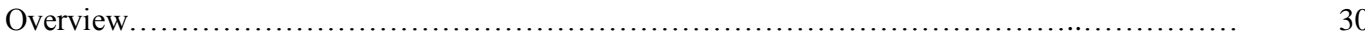

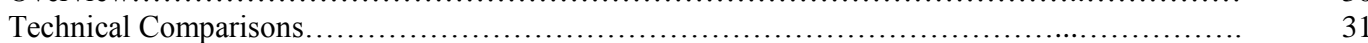

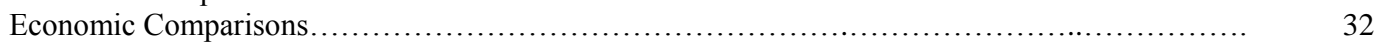

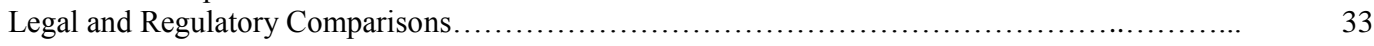

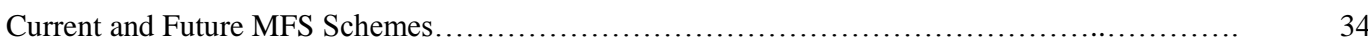

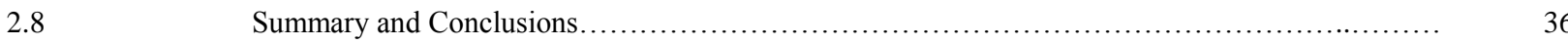

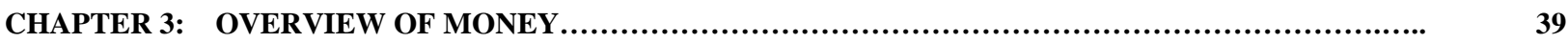

3.1

3.1 .1

3.1 .2

3.2

3.2 .1

3.2 .2

3.2.3

3.2.3.1

3.2.3.2

3.2.3.3

3.2.3.4

3.2.3.5

3.2 .4

Introduction.

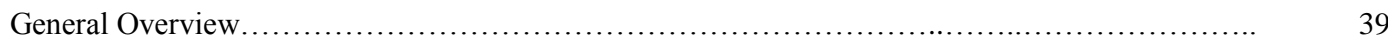

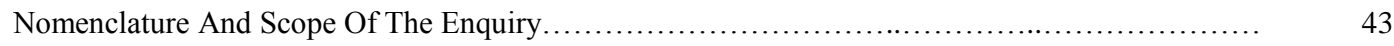

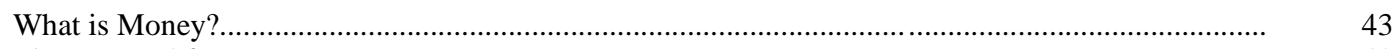

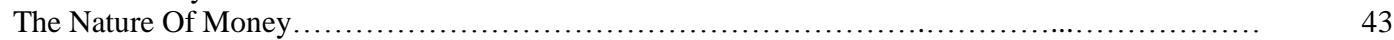

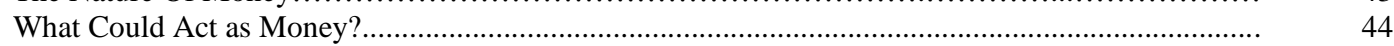

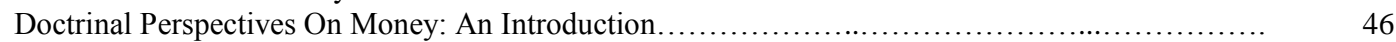

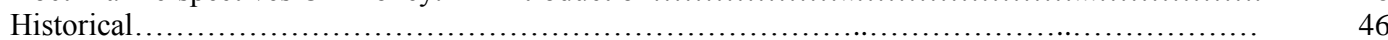

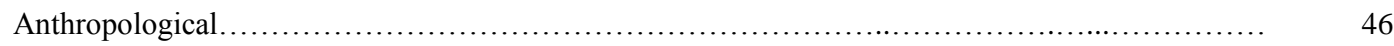

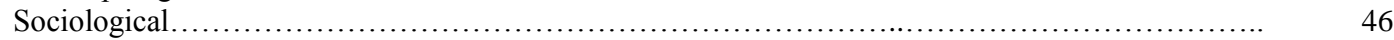

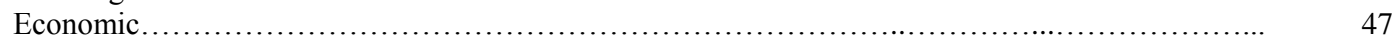

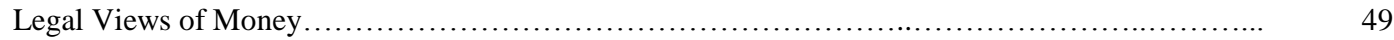

Additional Foundational Perspectives Relating To Money ......................................... 50

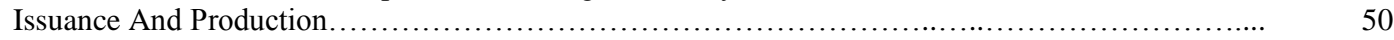

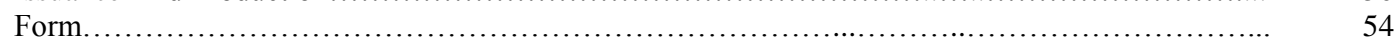

Initial Analysis of The Doctrines \& Perspectives Of Money...................................... 55

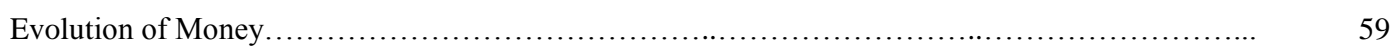

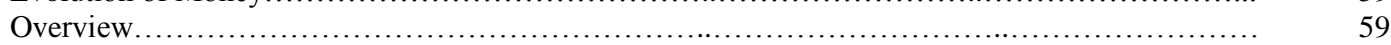

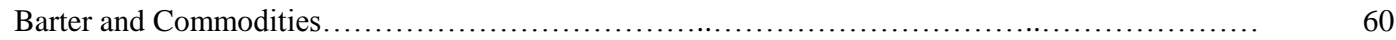

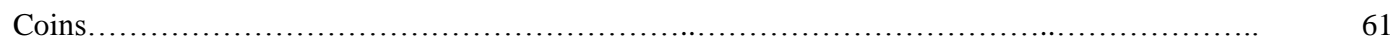

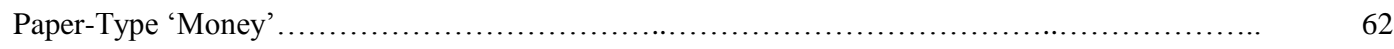

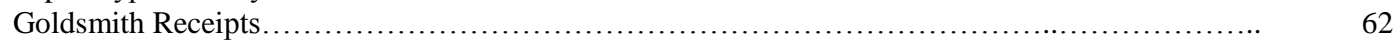

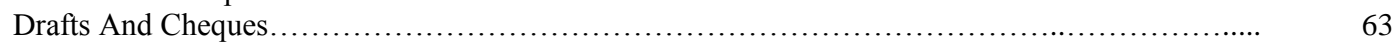

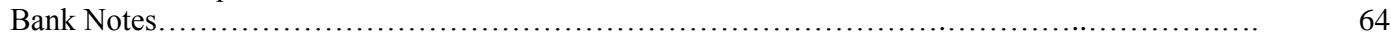

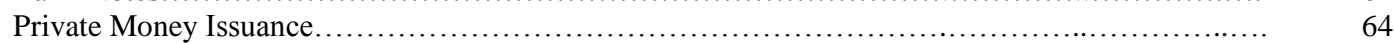

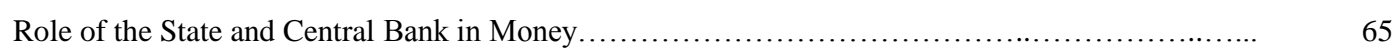

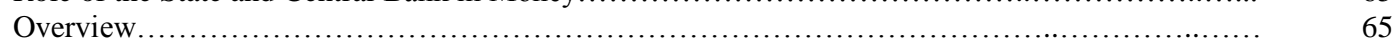

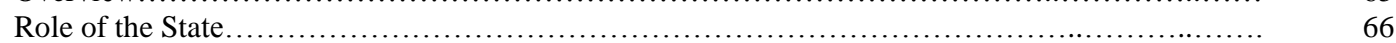

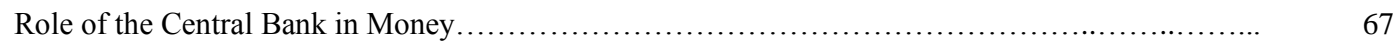

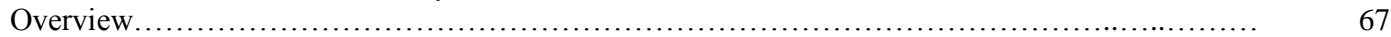

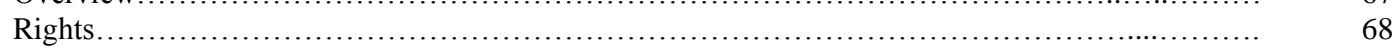

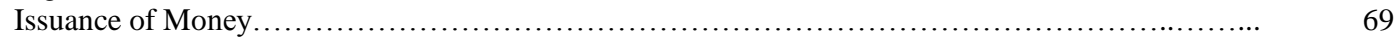

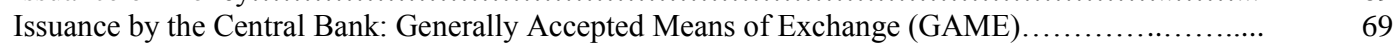

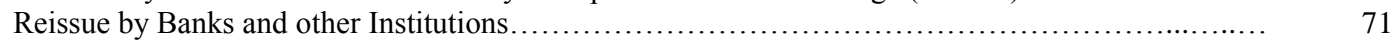

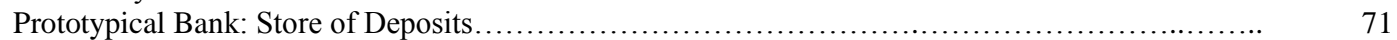

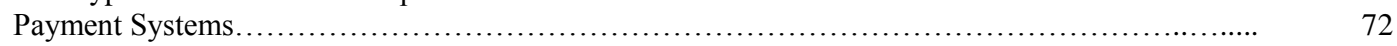

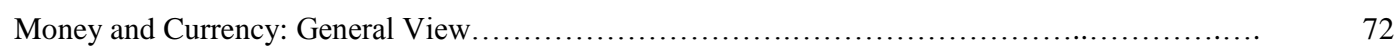

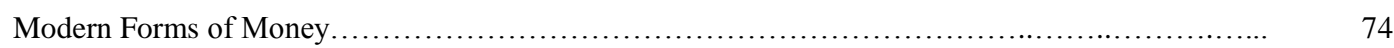

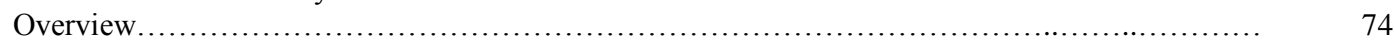

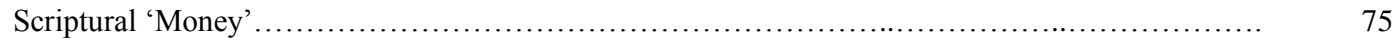

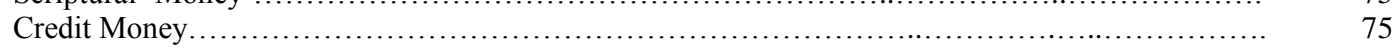

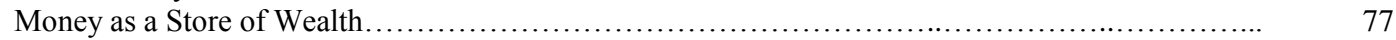

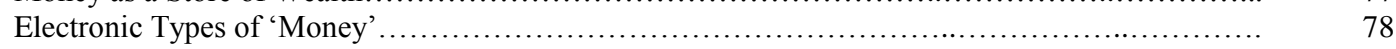

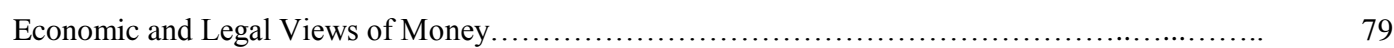

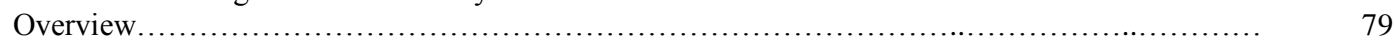

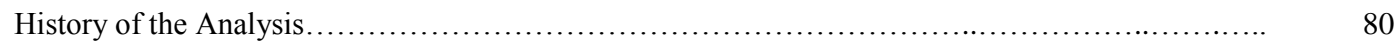

Economic Views Of Money........................................................... 
Orthodox School

Overview

Components of Orthodox-type Money.

Unit Of Account....

A Store of Value...

Claim School.

Overview....

Components of 'Claim' Money

Unit of Account.

'Money'.....

Means of Payment.

Interplay Between 'Money' Theories.................................................... 94

Legal View.

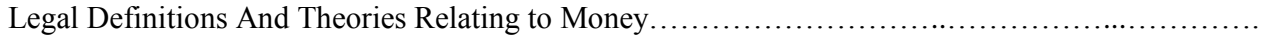

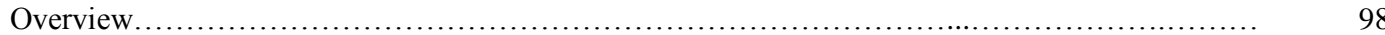

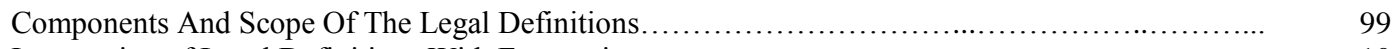

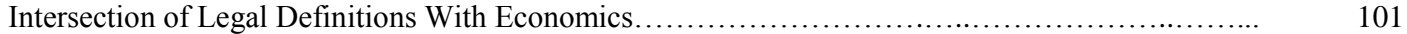

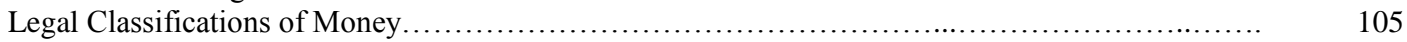

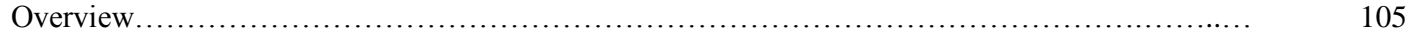

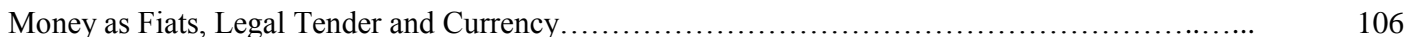

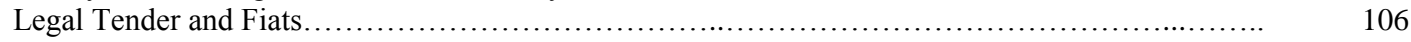

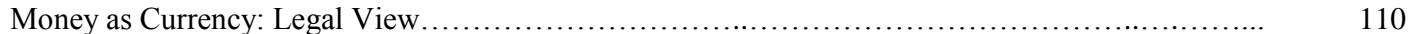

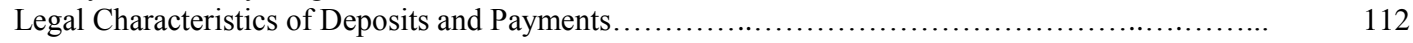

The Common Law and Banking......

Deposits.

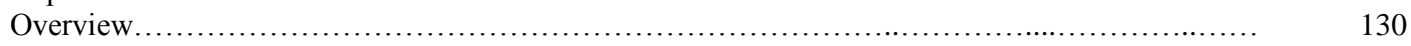

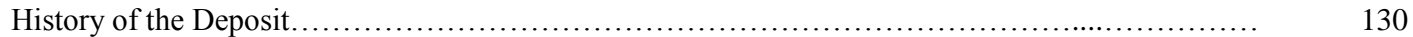

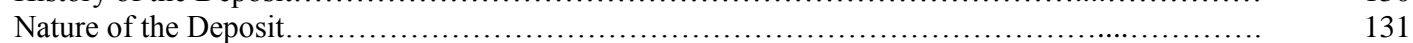

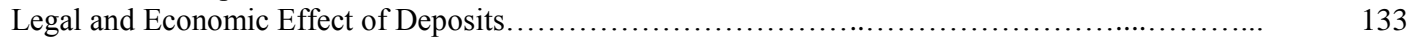

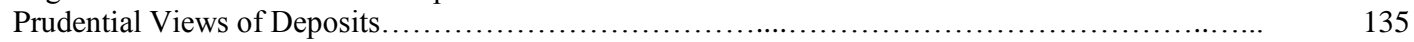

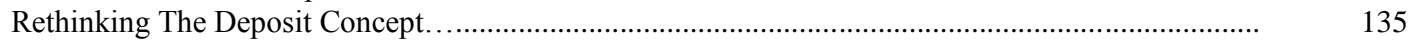

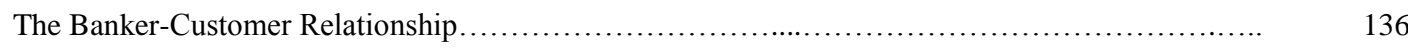

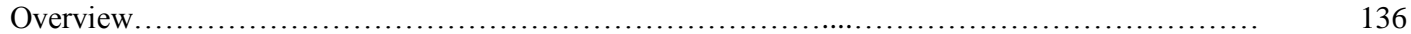

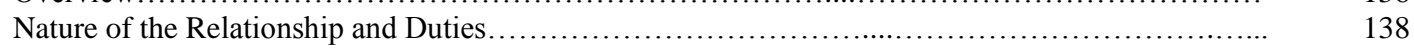




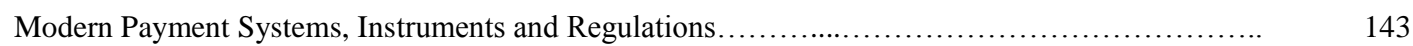

Overview..

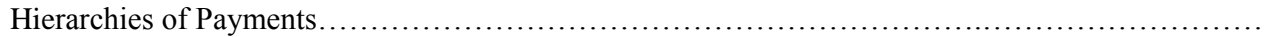

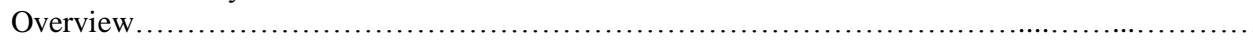

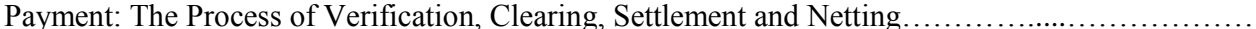

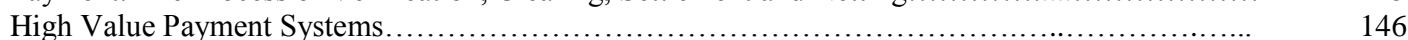

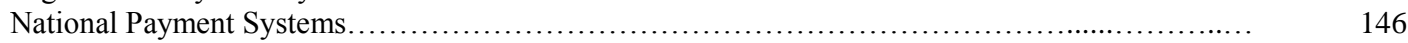

Participants in a Payment System............................................................... 147

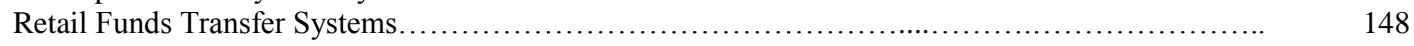

Low Value Payments: Macro-payments...................................................... 148

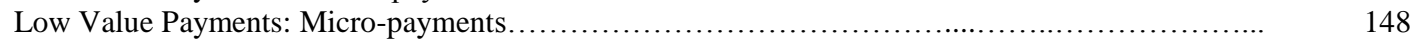

Payment Methodologies and Characteristics.................................................... 149

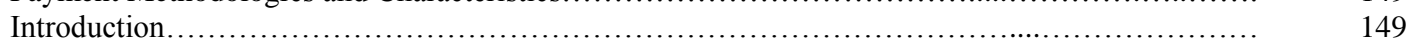

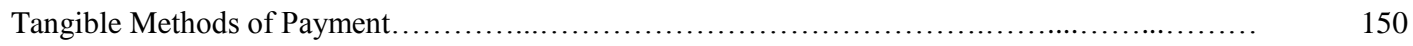

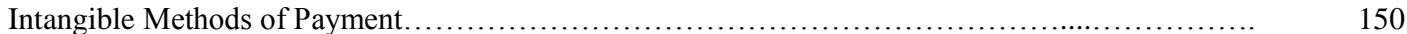

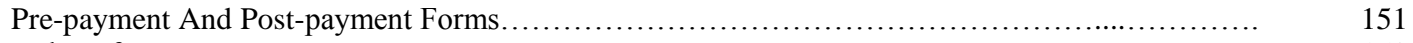

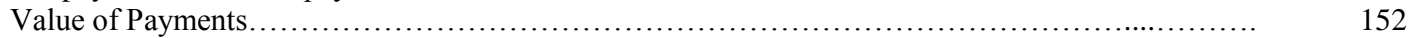

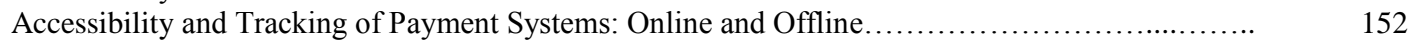

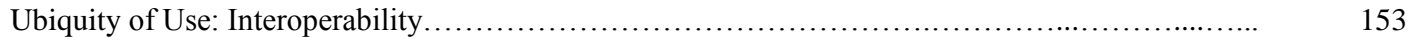

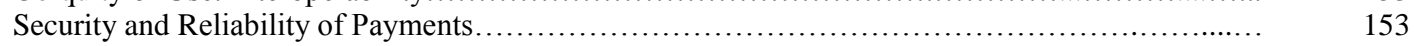

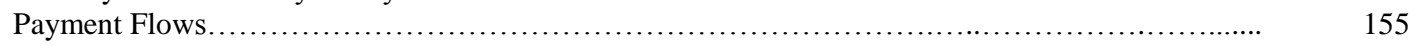

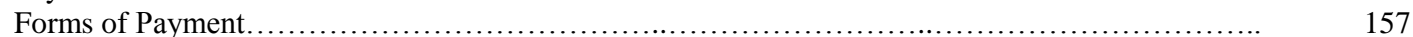

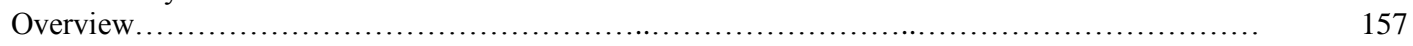

Electronic Fund Transfers (EFTs) And Similar Forms....................................... 158

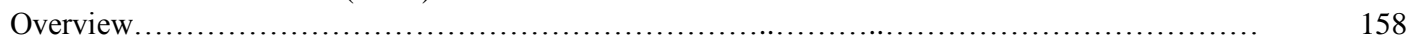

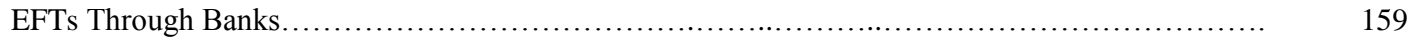

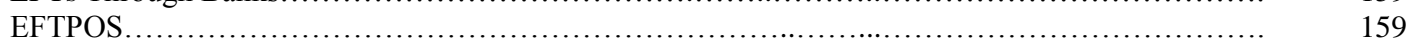

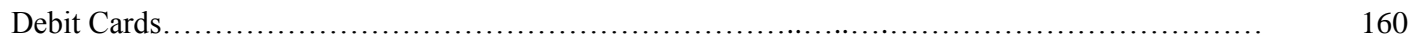

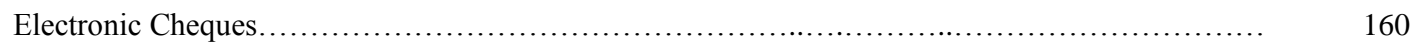

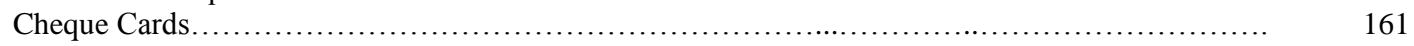

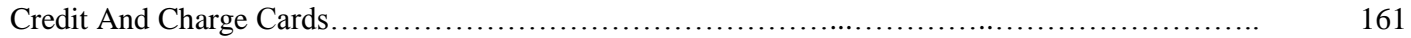

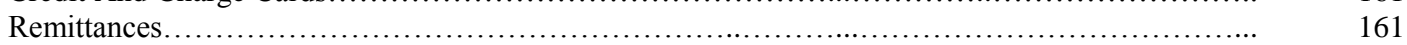

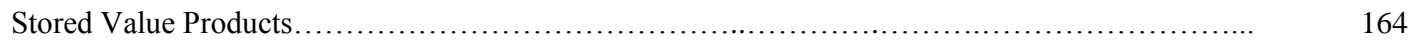

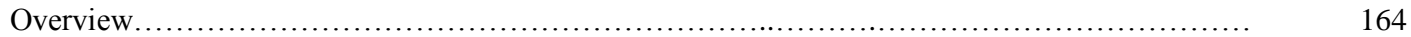

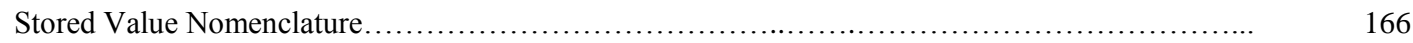

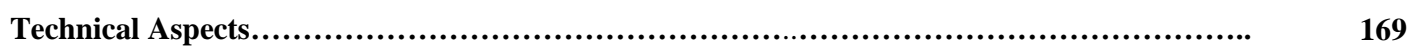

Technical Aspects.

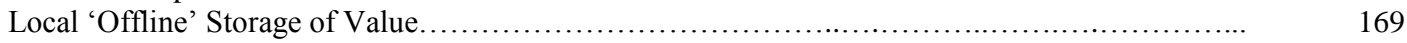

'Online' Storage of Value................................................................. 170

Commercial Aspects................................................................... 170

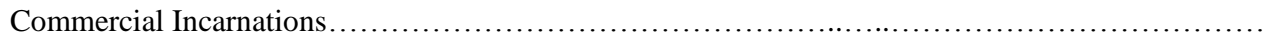

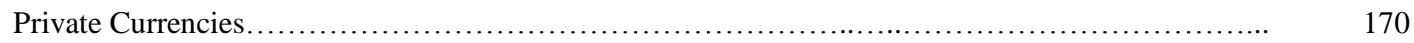

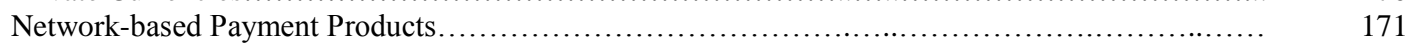

4.8.4.4.4.2

4.8.4.4.4.3

4.8.4.4.4.4

4.8.4.4.4.5

Mobile-type SVPS......

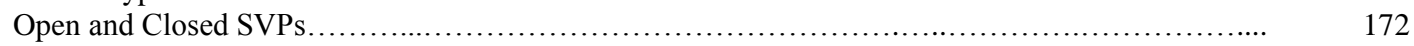

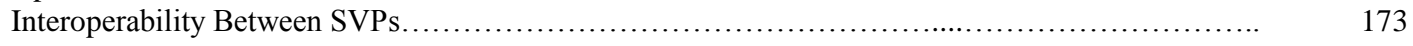

\section{C}

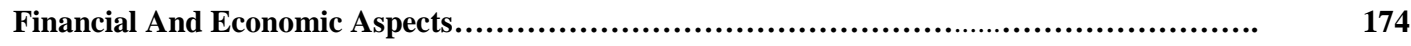

Underlying Financial Relationships.

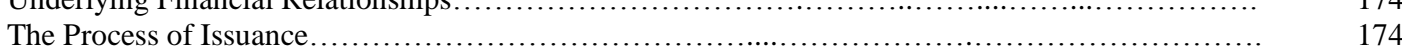

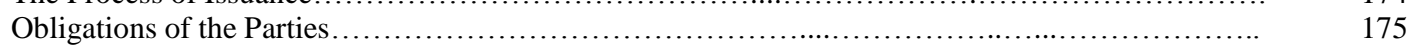

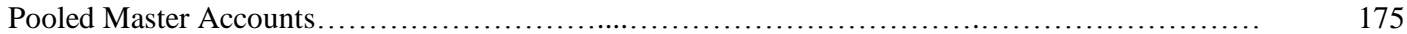

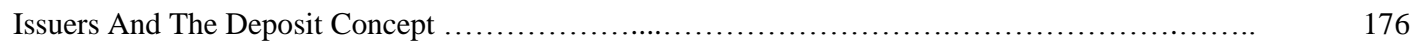

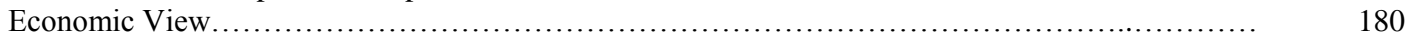

Nature of the Transaction and Settlement.................................................... 181

Legal and Prudential Aspects........................................................... 184

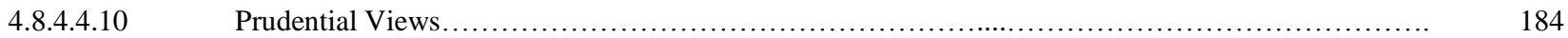




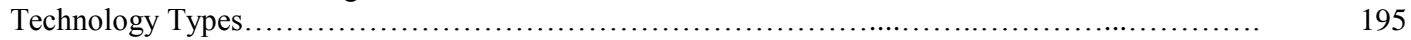

User Access to Mobile Networks..................................................................

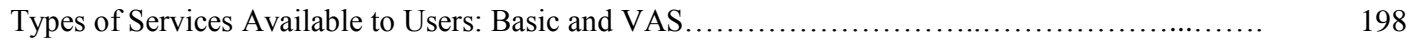

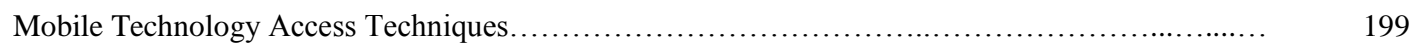

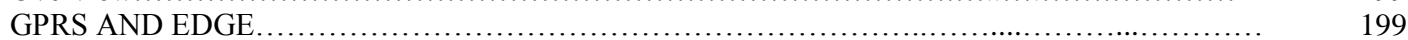

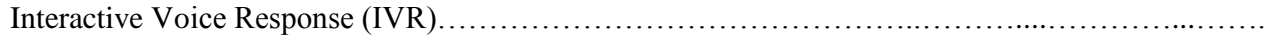

Short Message Service (SMS) and Shortcodes......

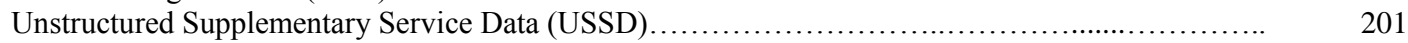

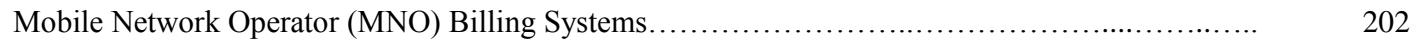

Overview.

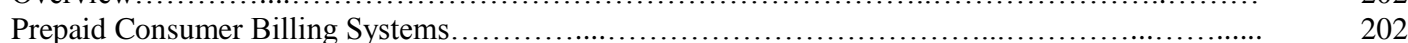

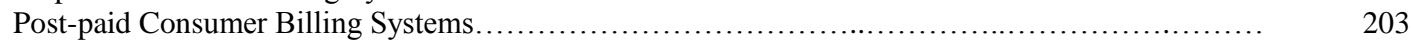

Mobile Network Transaction Billing Mechanisms........................................... 203

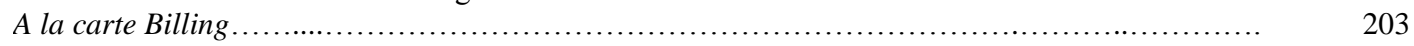

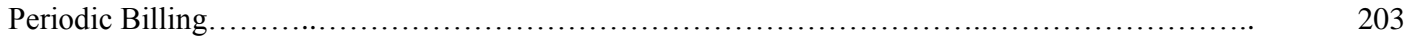

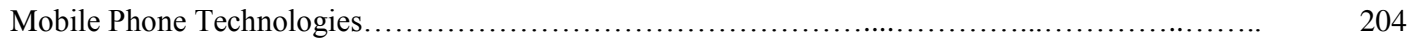

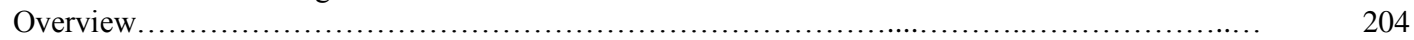

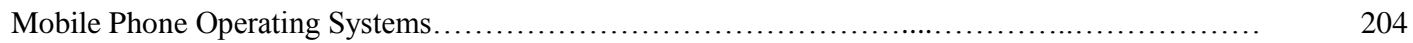

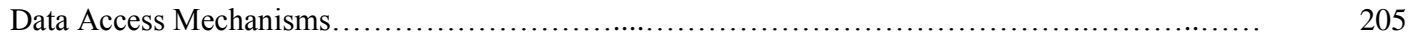

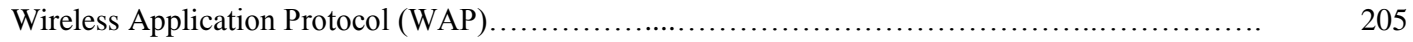

S@T Mobile Phone Navigation Menus for MFS ............................................ 205

Mobile Phone Applications.................................................................. 206

Mobile Phone User Interfaces Best Suited to MFS .......................................... 207

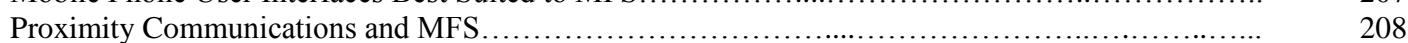

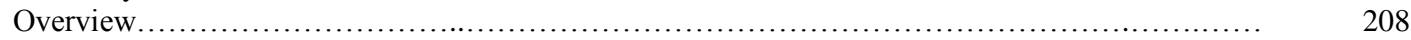

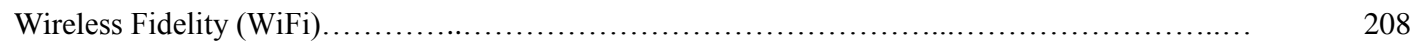

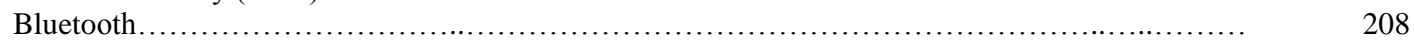

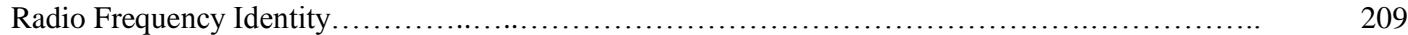

Near Field Communication............................................................. 209

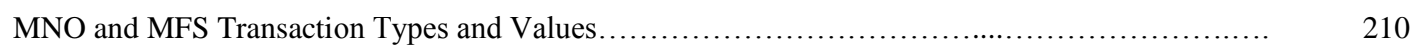

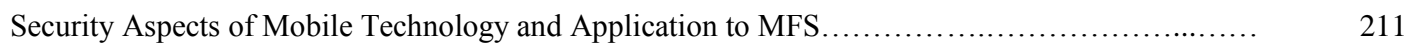

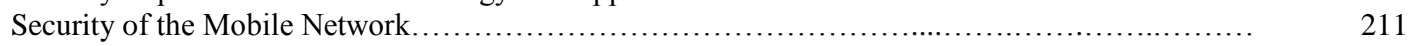

User Aspects of the Mobile Handset...................................................... 211

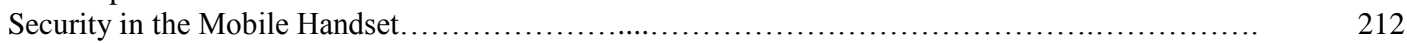

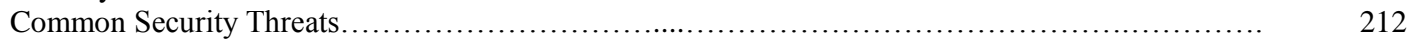

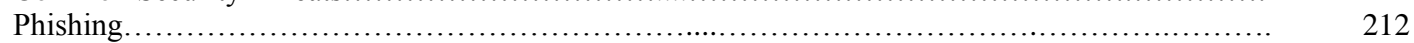

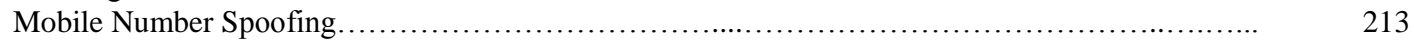

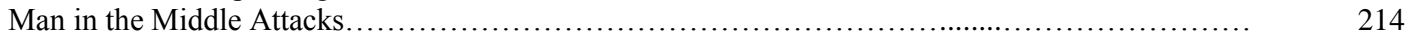

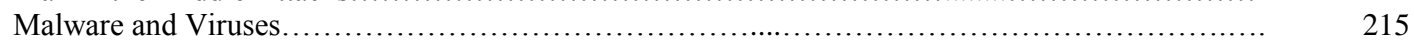

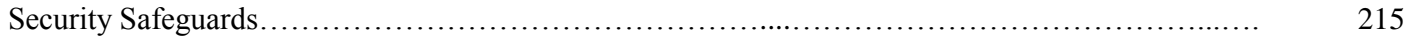


Relationships and Types of Models in the MFS Ecosystem.

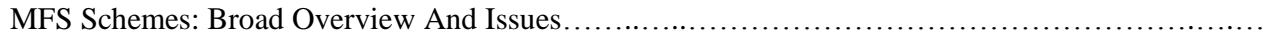

Overview.....

Licensed-Bank Branchless Banking Model.......

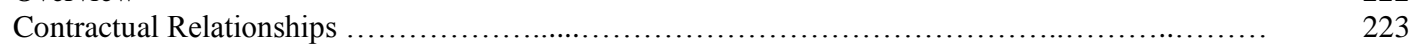

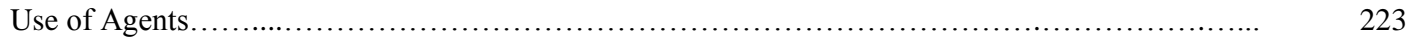

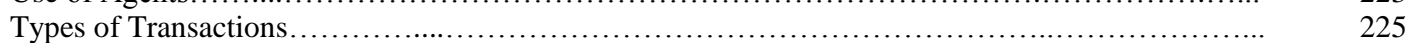

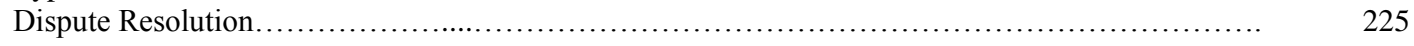

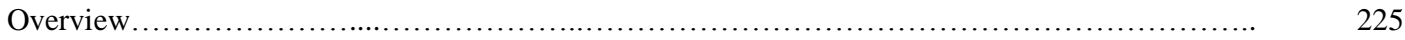

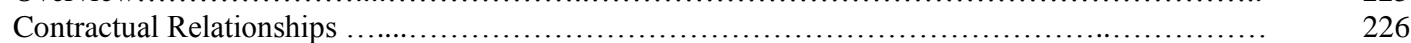

Use of Agents.

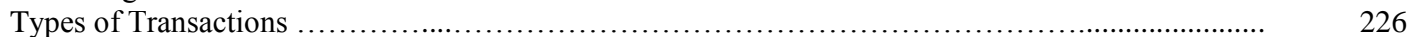

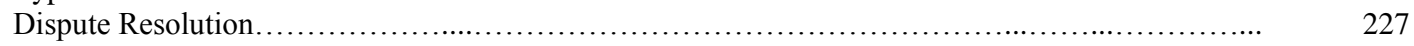

Licensed Bank-MFSP Model.

Overview

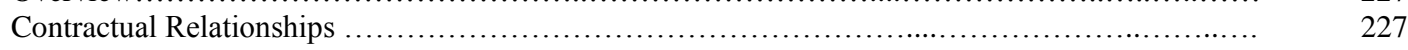

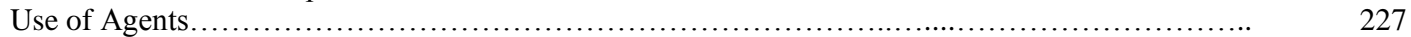

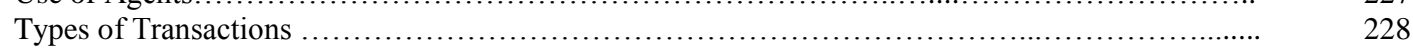

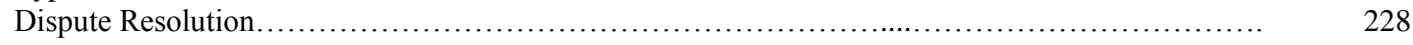

MNO-Led Models.

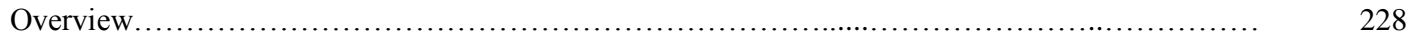

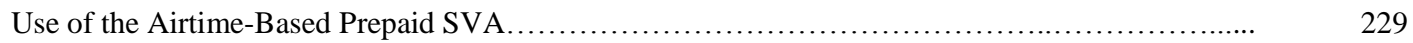

Use of the Airtime-Based Prepaid SVA in Transactions...................................... 230

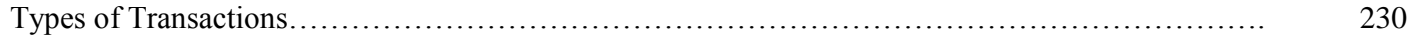

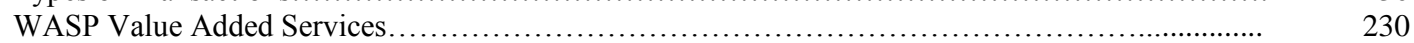

Relationships in the WASP And VAS Environment......................................... 231

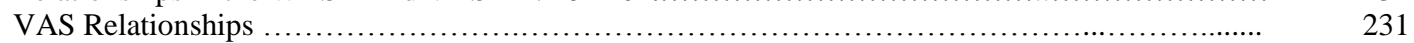

Payment Methodologies............................................................. 233

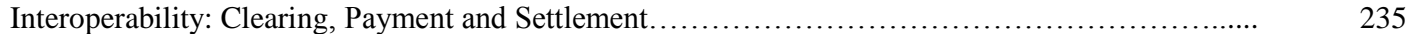

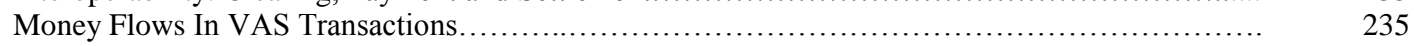

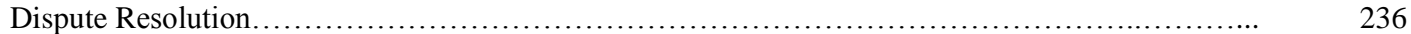

Mobile Airtime Transfer................................................................. 237

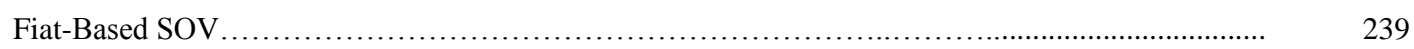


6.5.5.3

6.5.5.3.1

6.5.5.3.2

6.5.5.4

6.5.5.5

6.5.5.6

6.5.5.7

C

6.6

6.6 .1

6.6 .2

6.6 .3

6.6 .4

6.7

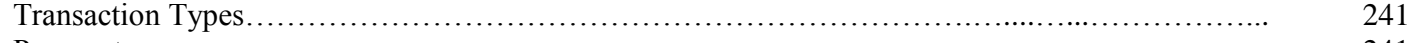

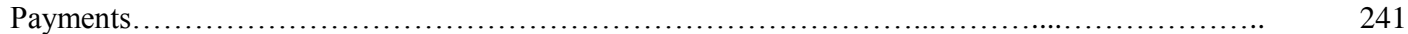

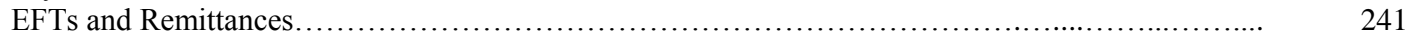

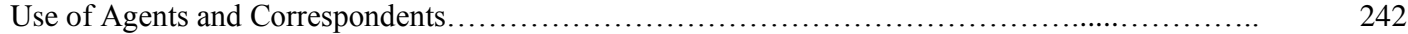

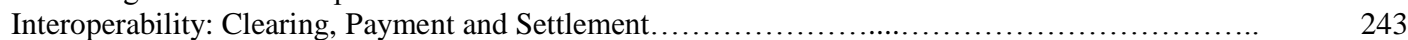

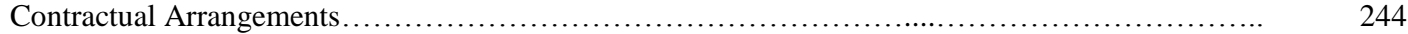

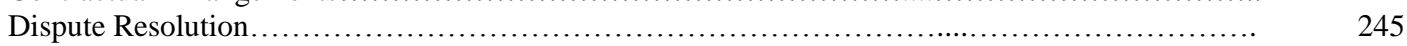

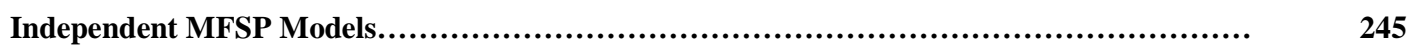

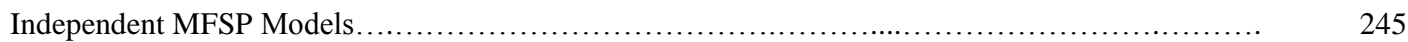

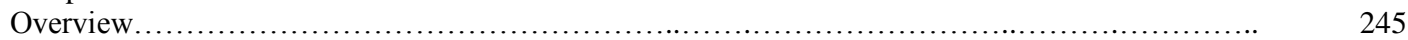

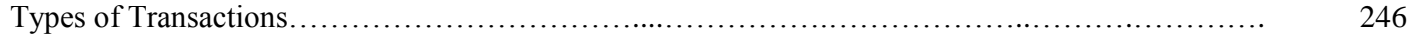

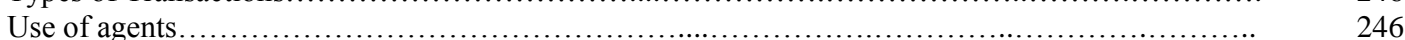

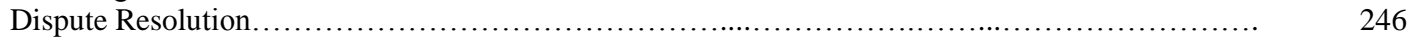

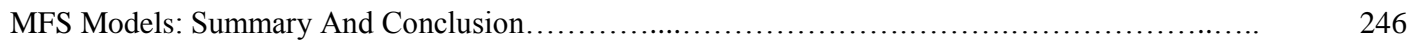

CHAPTER 7: $\quad$ LEGAL NATURE, CHARACTERISTICS OF MOBILE FINANCIAL SERVICES..................

Introduction.

Contracts.

Contracts

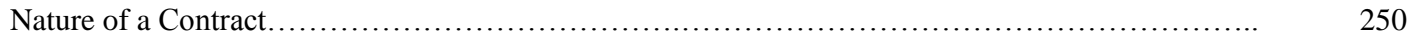

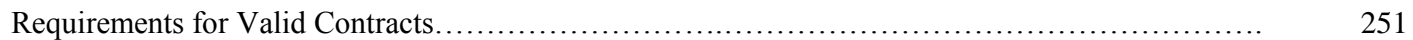

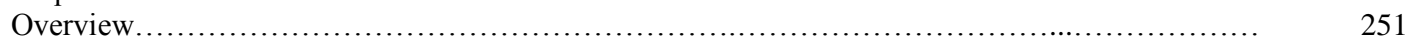

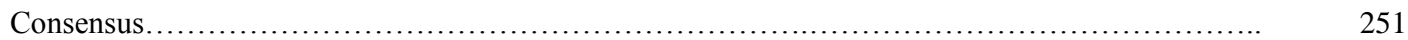

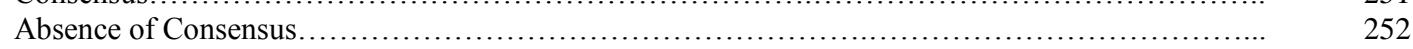

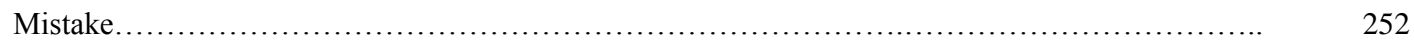

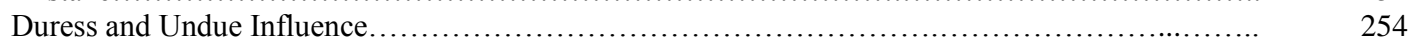

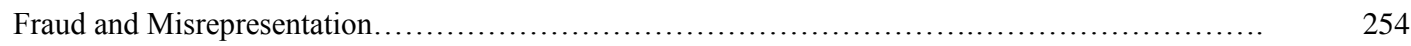

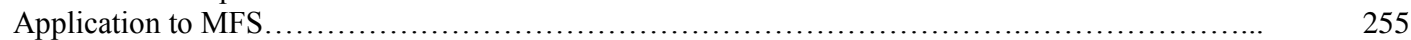

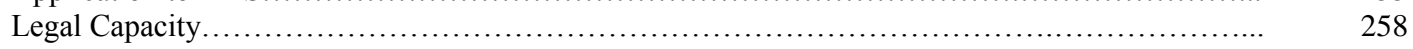

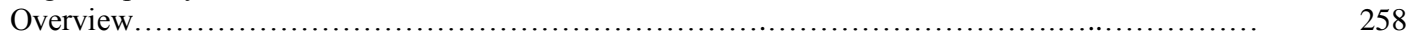

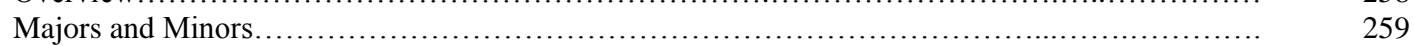

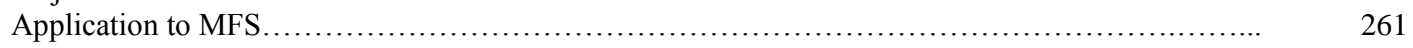

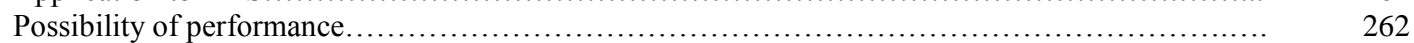

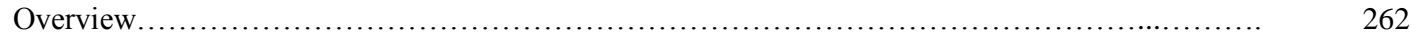

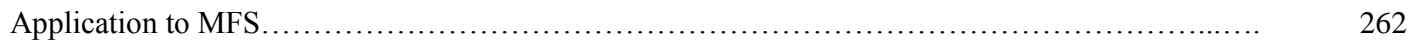

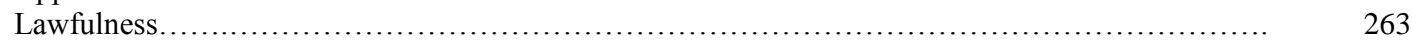

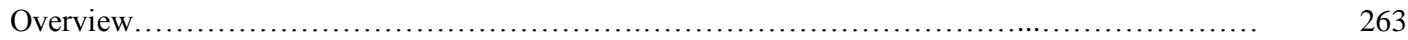

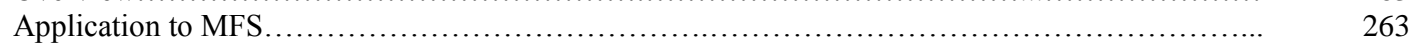

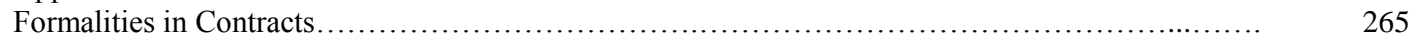

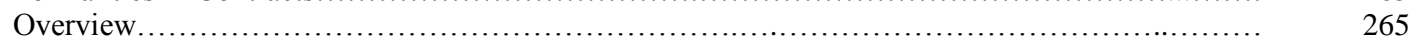

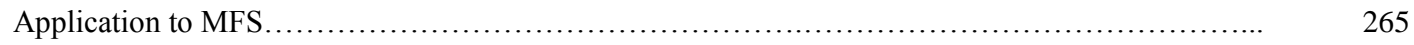

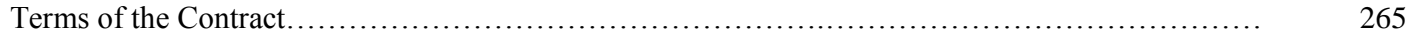

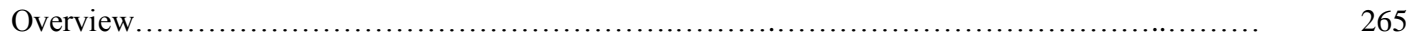

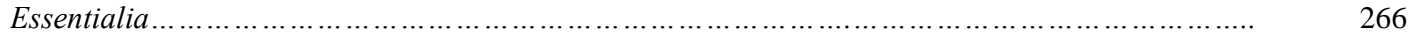

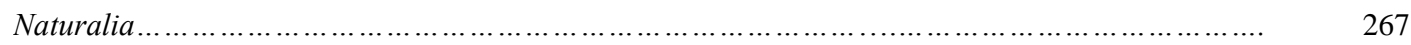

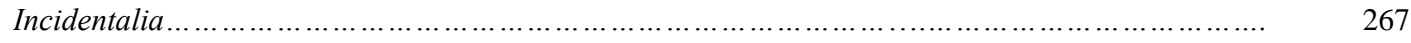

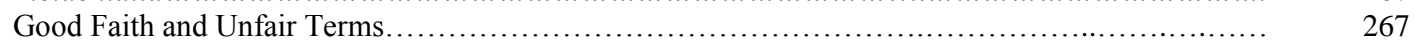

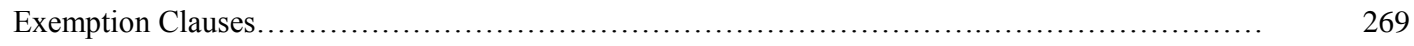

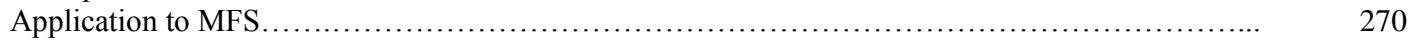

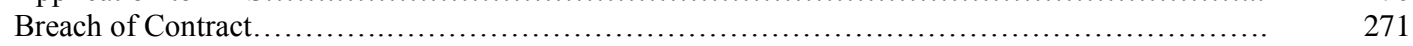

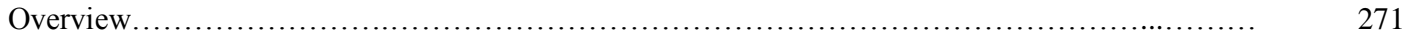


7.2.5.2

7.2.5.3

7.2 .6

7.2.6.1

7.2 .6 .2

7.2.6.3

7.2.6.3.1

7.2.6.3.2

7.2.6.4

7.2.6.4.1

7.2.6.4.2

7.2.6.4.3

7.2.7

\section{B}

7.3

7.3.1

7.3.2

7.3.2.1

7.3.2.2

7.3.2.2.1

7.3.2.2.2

7.3.2.2.3

7.3.3

7.3.3.1

7.3.3.2

7.3.4

7.3.4.1

7.3.4.2

7.3.5

7.3.5.1

7.3.5.2

7.3.6

7.3.6.1

7.3.6.2

7.3.6.3

7.3.6.4

7.3.6.5

7.3.6.5.1

7.3.6.5.2

7.3.6.5.3

7.3.6.5.3.1

7.3.6.5.3.2

7.3.6.5.3.3

7.3.6.5.4

7.3.6.5.5

7.3.6.5.6

7.3.6.5.6.1

7.3.6.5.6.2

7.3.6.5.6.3

7.3.6.6

7.3 .6 .7

7.3.6.8

7.3.6.8.1

7.3.6.8.2

7.3.6.8.3

7.3.6.8.4

7.3.6.8.5

7.3.6.8.6

7.3.6.9

7.4

7.4 .1

7.4 .2

7.4 .3
Breach of Contract Versus Delict

272

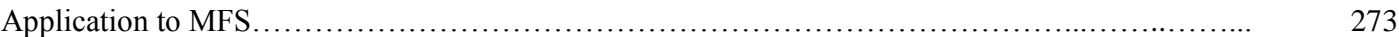

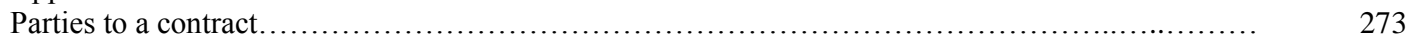

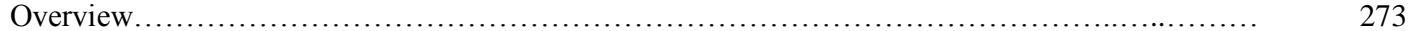

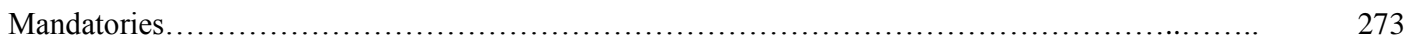

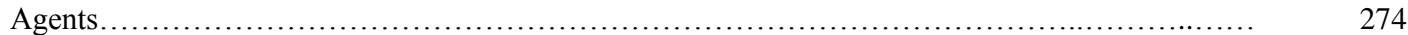

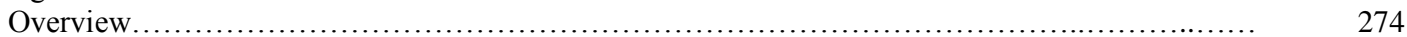

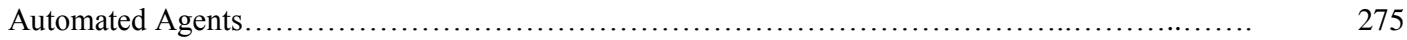

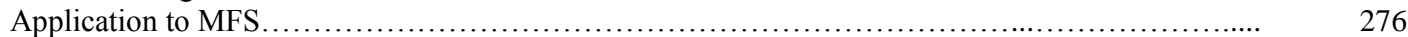

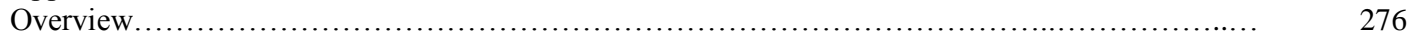

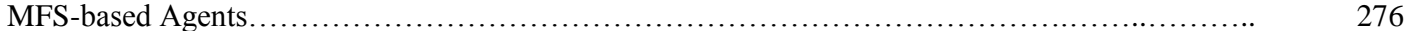

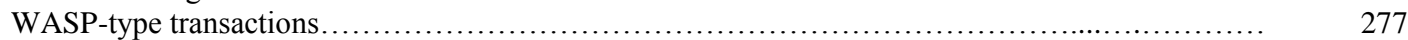

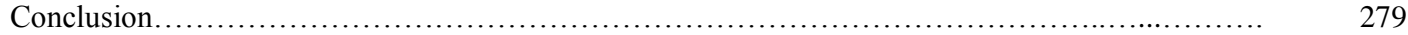

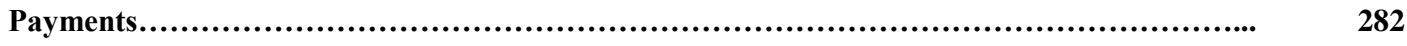

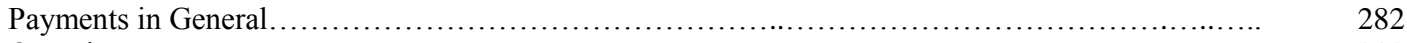

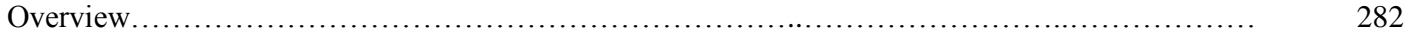

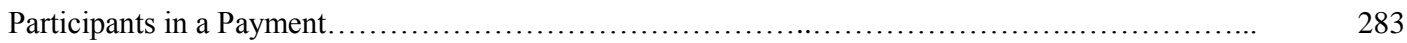

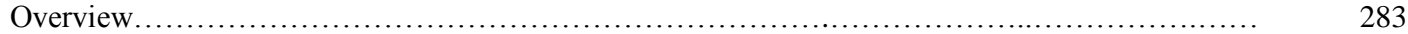

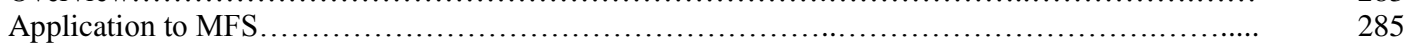

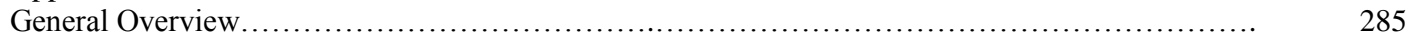

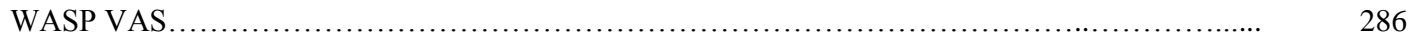

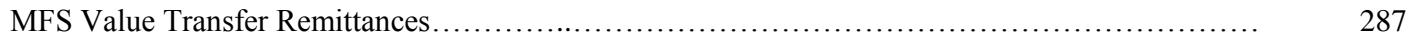

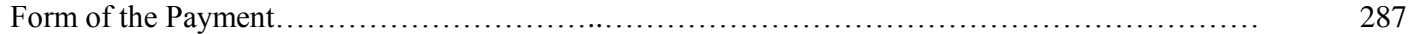

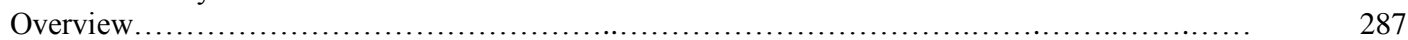

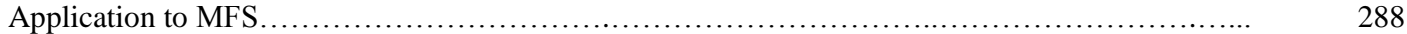

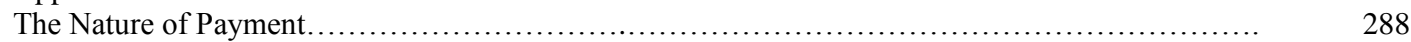

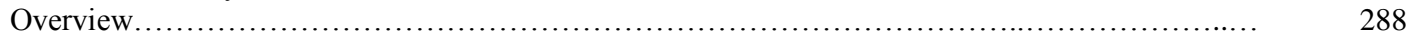

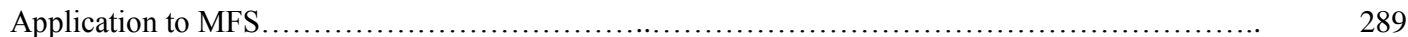

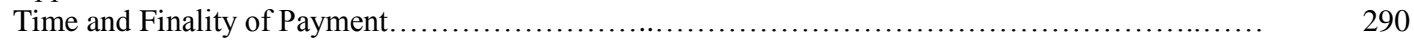

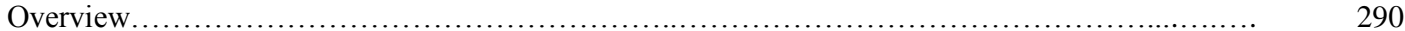

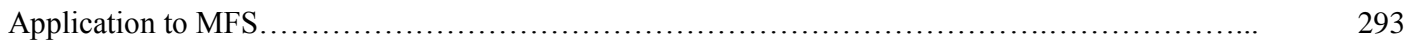

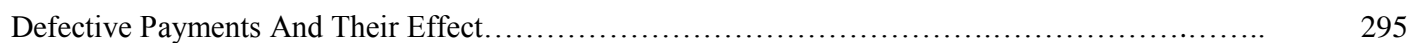

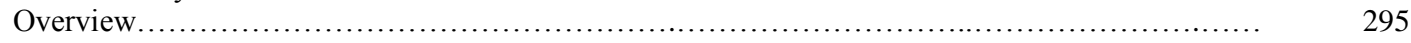

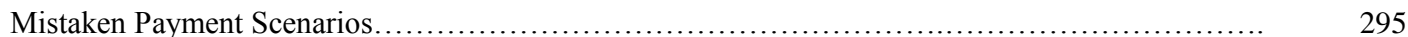

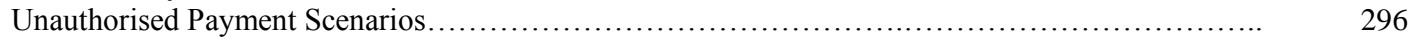

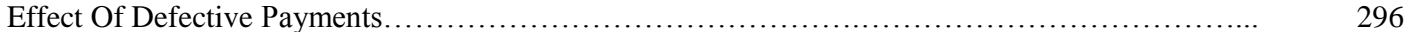

Allocation of Risk, Loss and Liability...................................................... 297

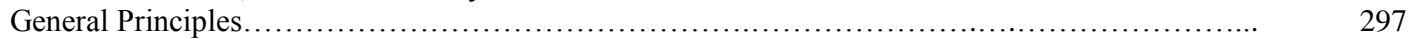

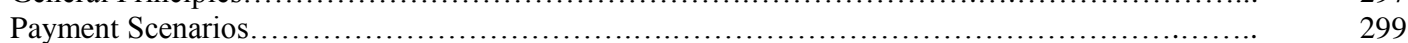

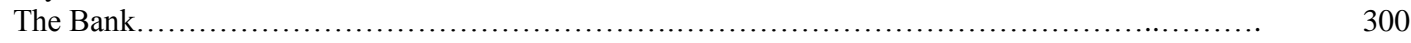

Nature Of A Bank's Activities................................................................ 300

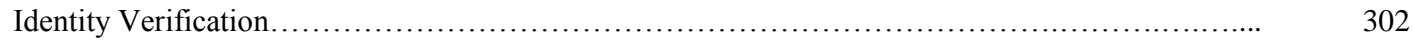

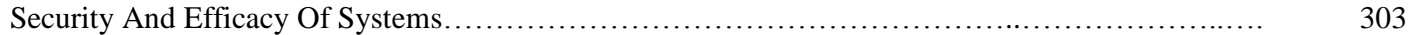

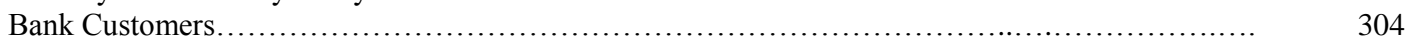

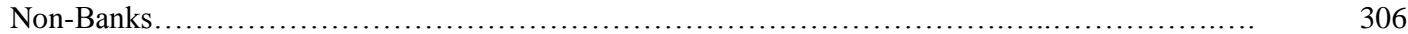

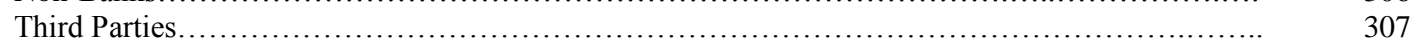

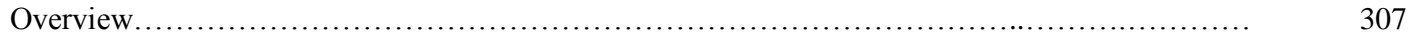

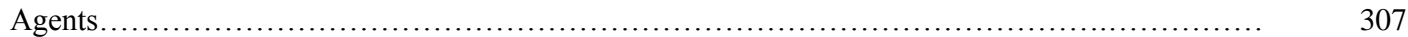

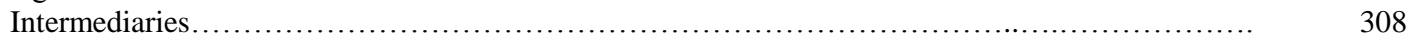

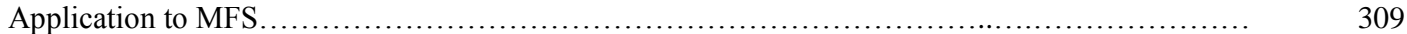

Unjustified Enrichment.................................................................. 311

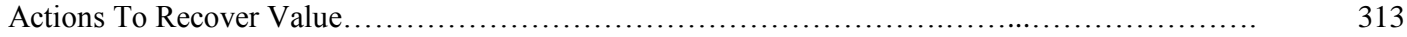

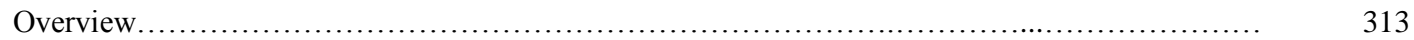

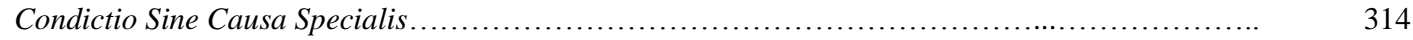

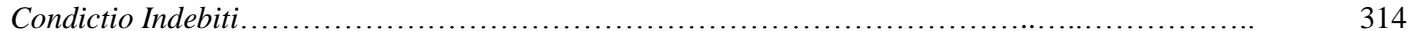

Condictio Ob Turpem Vel Iniustam Causam...............................................

Condictio Causa Data Causa Non Secuta ..................................................... 315

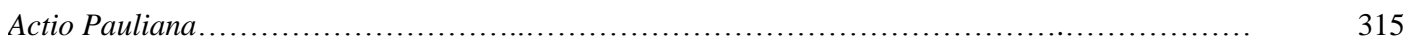

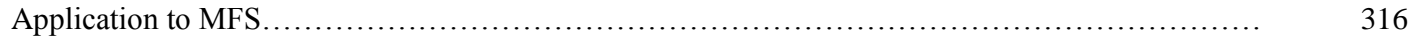

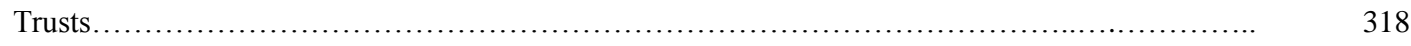

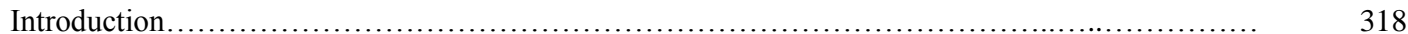

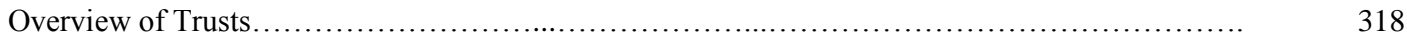

Creation of a Trust............................................................................ 320 


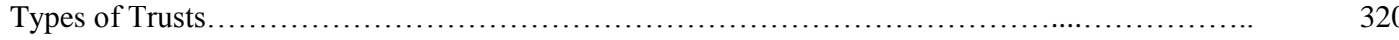

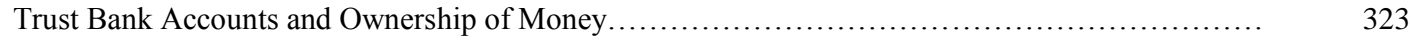

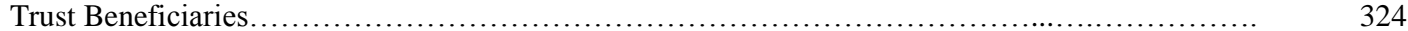

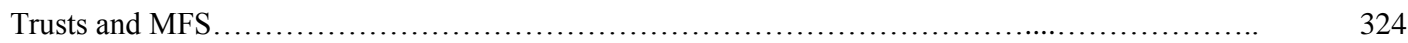

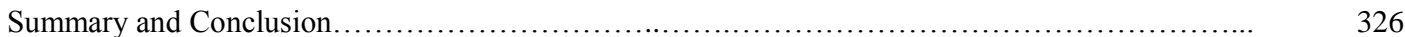

Terms.

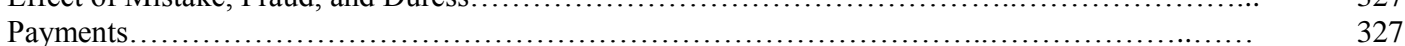

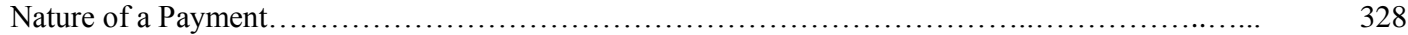

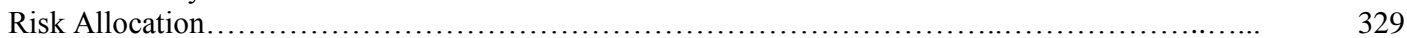

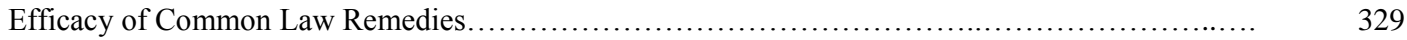

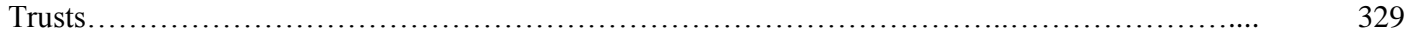




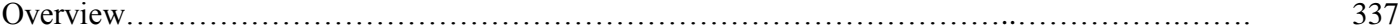

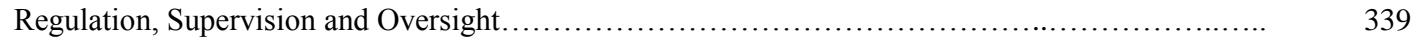

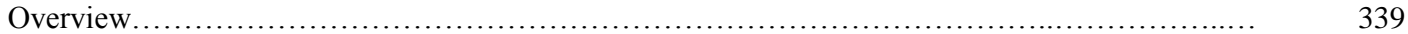

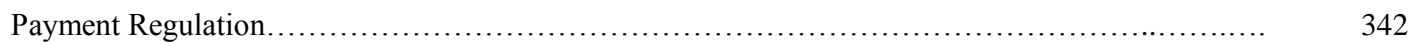

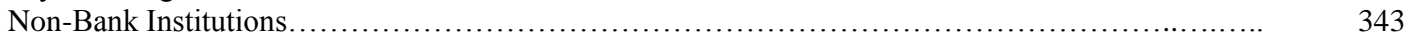

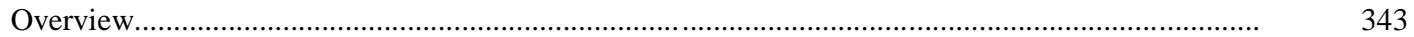

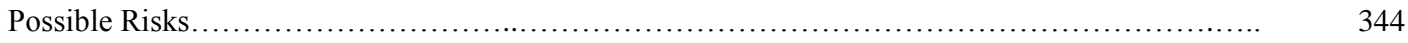

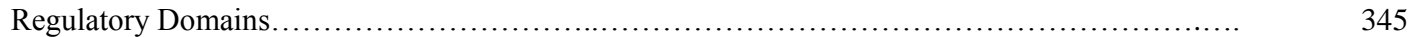

Examples of Consumer-Based Financial Regulation..................................... 346

Anti-Money Laundering, Terrorist Financing and Customer Due Diligence Laws and Regulations

EU Legislation.

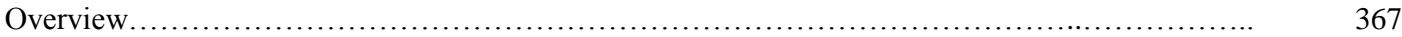

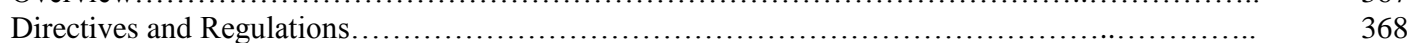

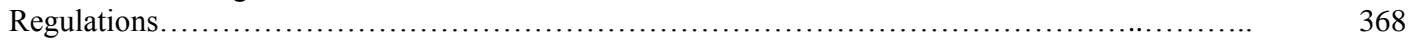

The Prudential Landscape for Financial Products and Services in the EU.

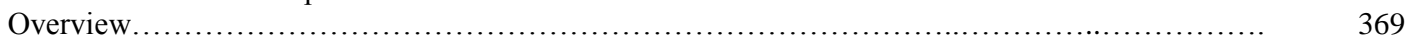

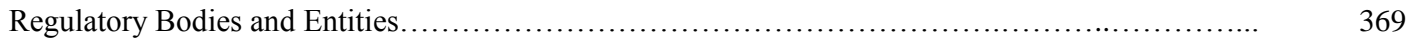

Regulatory, Licensing and General Oversight Regimes........................................... 370

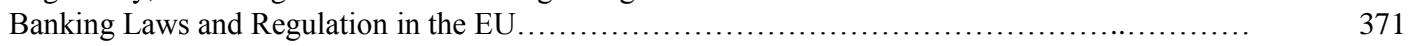

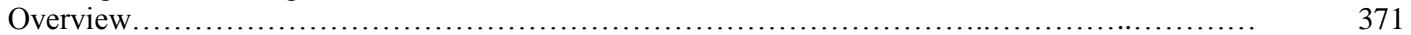

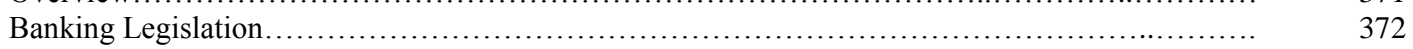

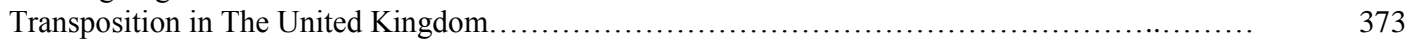

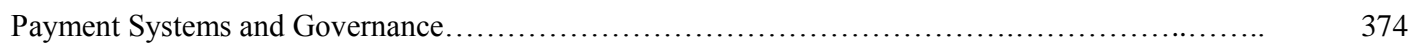

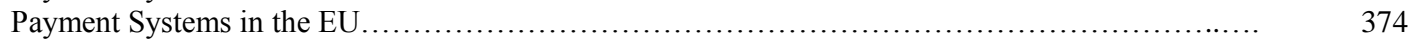

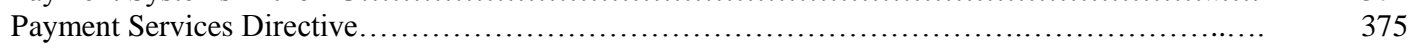

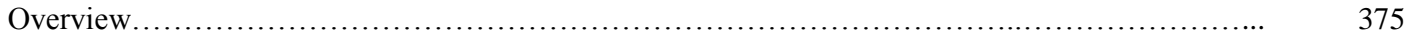

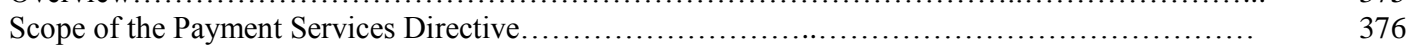

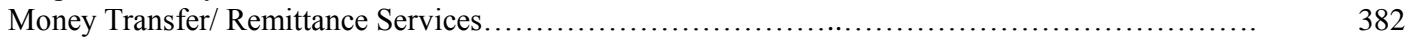

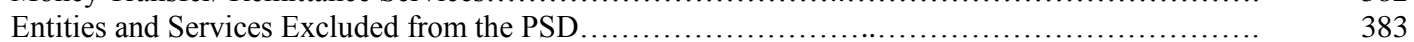

Transactional Rules and Liability Allocation in the PSD .................................. 384 
Liability Allocation and Obligations of the Parties......

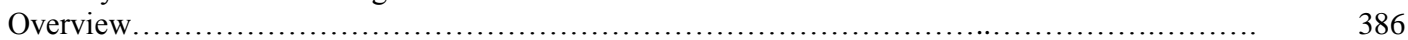

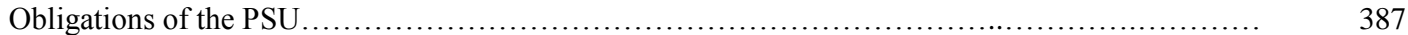

Obligations of the PSP

Liability Allocation between PSP and its Technical Providers......................................

Loss from Lost or Stolen Instruments...

$9.6 .2 .5 \cdot 2.5 .2$

Loss for Transactions Pre-notification of Loss/Theft. .

Loss for Transactions Post-notification of Loss/Theft.

Loss for Transactions of 'Offline' Payment Instruments. ...

Loss from Cloned/Forged Payment Instruments. ...

Effect of Gross Negligence by the PSU

9.6.2.5.4

9.6.2.5.5

Effect of Fraud by the PSU.

9.6.2.5.6

9.6.2.5.7

Possible Reduction of PSU Liability....

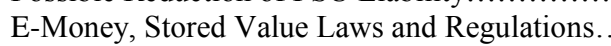

Background.

Second Electronic Money Directive

Overview....

Scope.

New Definition of e-Money.

'Deposits'

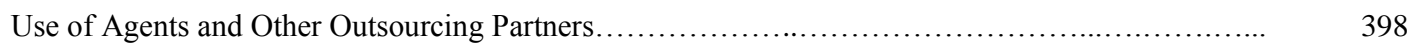

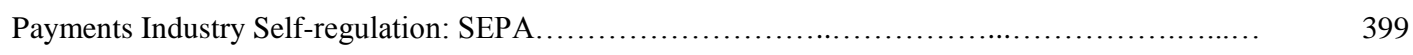

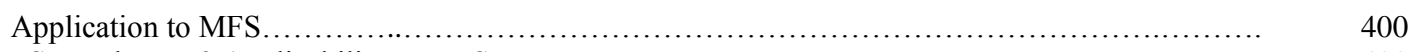

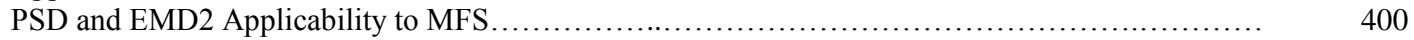

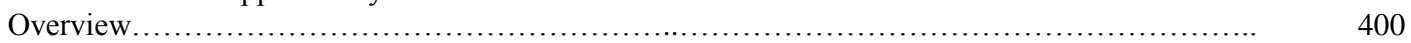

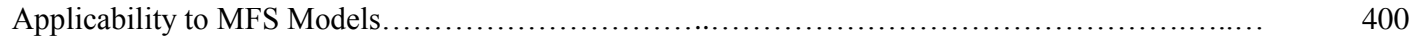

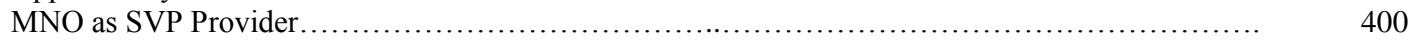

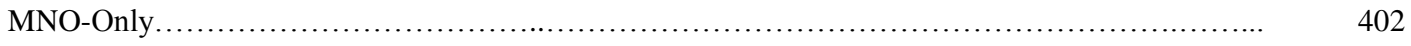

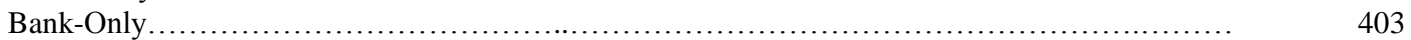

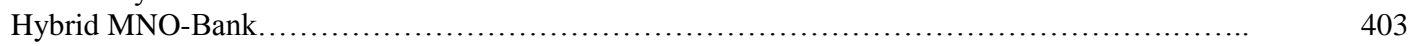

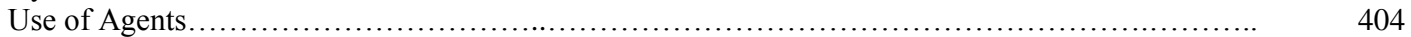

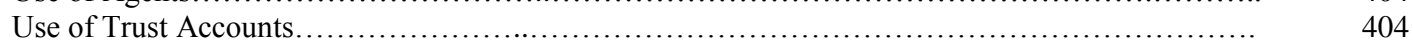

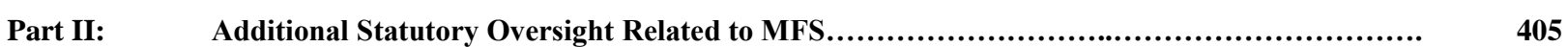

9.10 Anti-Money Laundering, Terrorist Financing and Customer Due Diligence Laws and Regulations.... 405

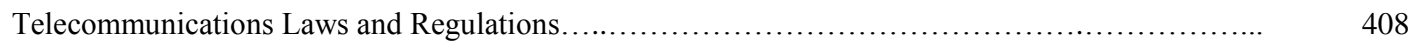

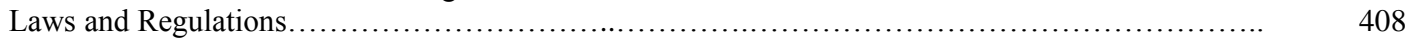

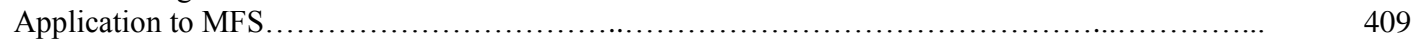

E-commerce and Associated Laws.

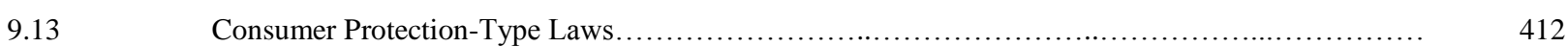

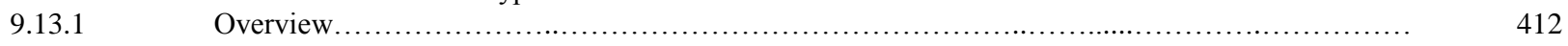

Application to MFS $\quad$ A.13.2

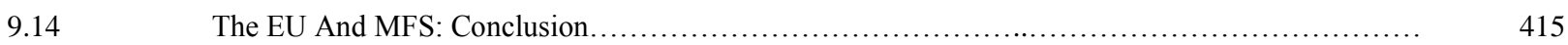

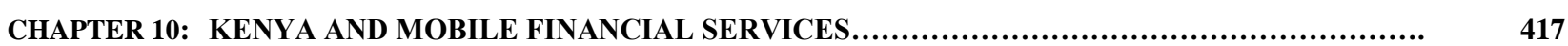

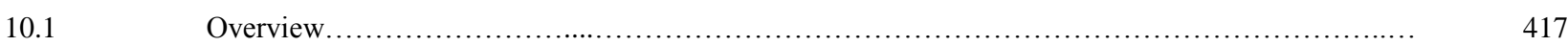

A Money, Banking, \& Payments Laws \& Guidelines.................................................. 
Overview

Regulatory Bodies

Banking Laws and Regulations in Kenya

Banking Act. ...

Business of Banking.

10.2.3.1.2

Deposits.

Microfinance Act...

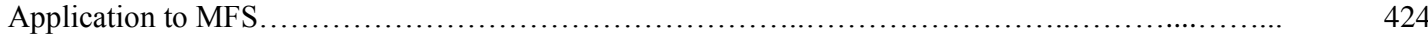

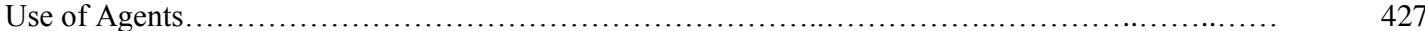

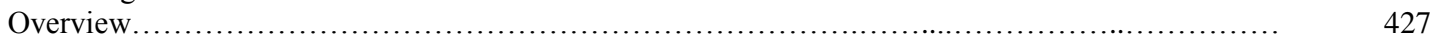

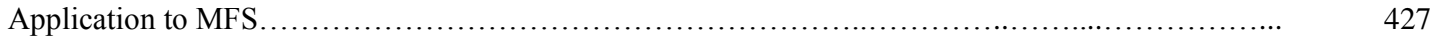

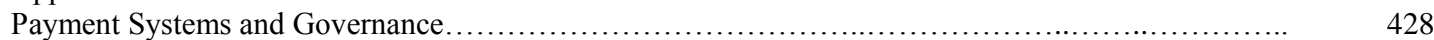

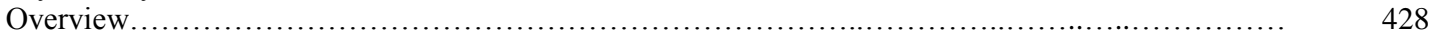

10.2.5.1

10.2.5.2

Application to MFS.

Anti-Money Laundering, Terrorist Financing and Customer Due Diligence Laws and Regulations....... 
State Overview......

A.

B.

C.
Federal.

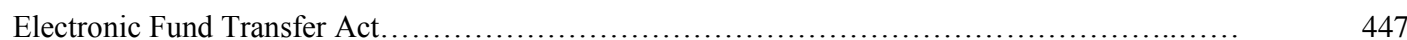

Dodd-Frank Wall Street Reform and Consumer Protection Act................................. 450

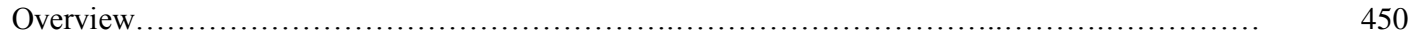

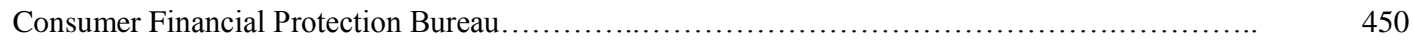

Additional Consumer Protection Legislation................................................... 451

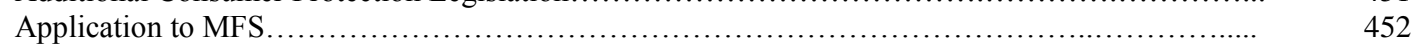

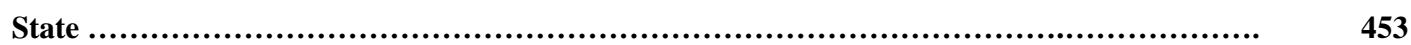

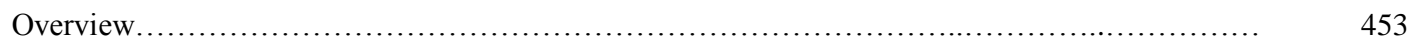

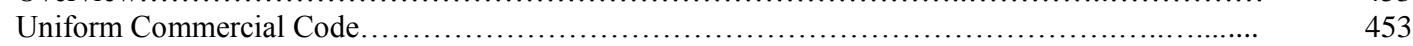

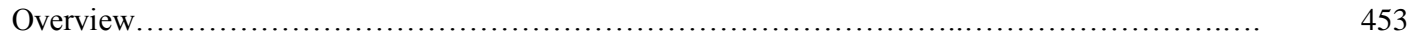

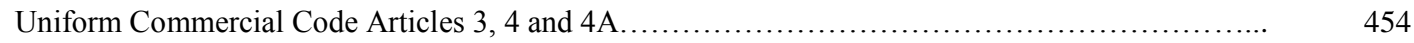

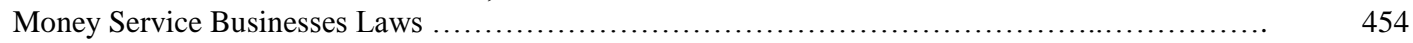

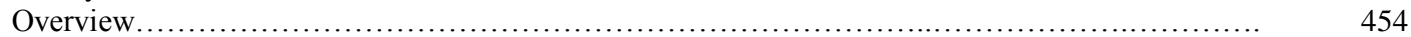

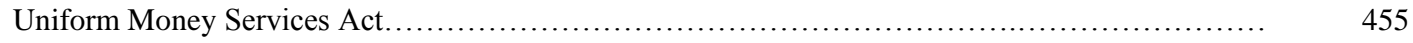

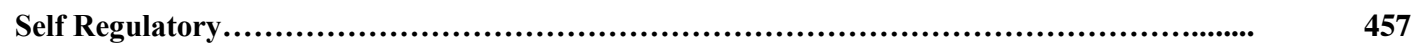

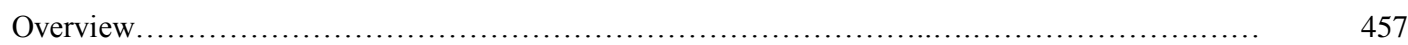

National Automated Clearing House Association........................................ 457

Credit Card Networks.......................................................................... 457

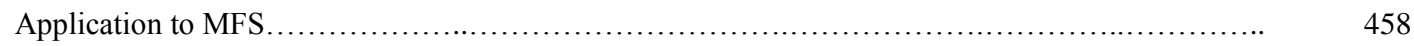

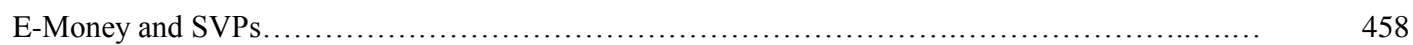

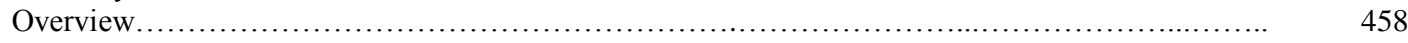

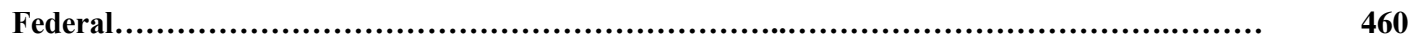

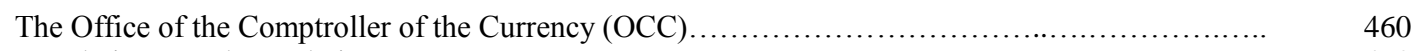

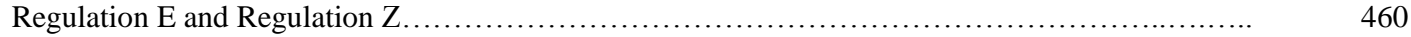

The Federal Deposit Insurance Corporation (FDIC) and Deposits............................ 461

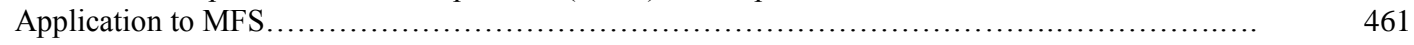

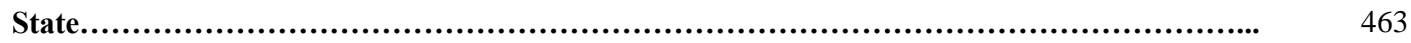

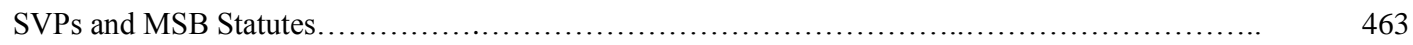

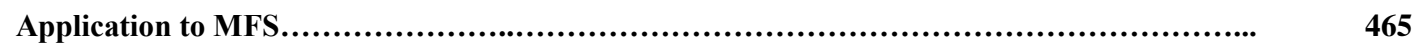

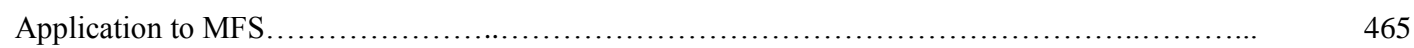

Additional Statutory Oversight Related To MFS.............................................. 468

Anti-Money Laundering, Terrorist Financing and Customer Due Diligence Laws and Regulations... 468

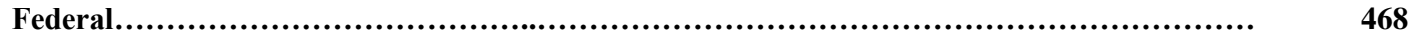

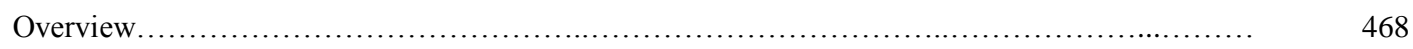

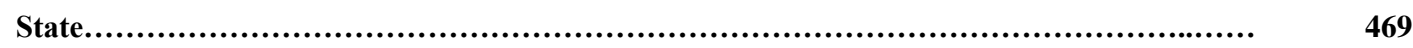

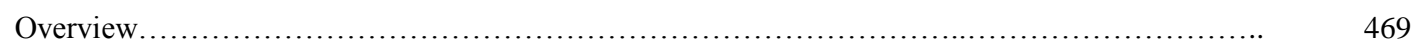

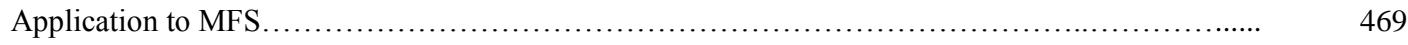

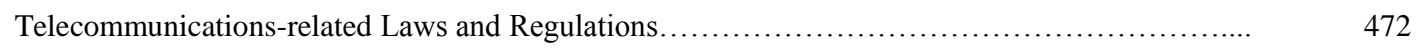

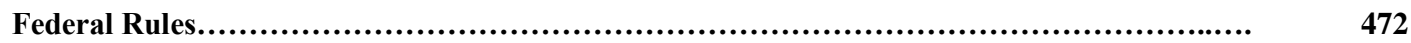


11.4 .1

11.4.2

B.

11.4.3

C.

11.4.4

11.4.5

11.5

A.

11.5.1

B.

11.5.2

11.5.3

11.6

11.6.1

11.6.2

11.7
Overview......

Truth-in-Billing Rules

State Rules.

Overview

Private Rules.

Self-regulatory

Application to MFS

Electronic Commerce Laws and Regulations

Federal Rules.

Federal Laws.

State Rules

State Laws

Application to MFS

Consumer Protection.

Overview

Application to MFS

USA And MFS: Summary And Conclusion.
CHAPTER 12: SOUTH AFRICA AND MOBILE FINANCIAL SERVICES.

Part I:

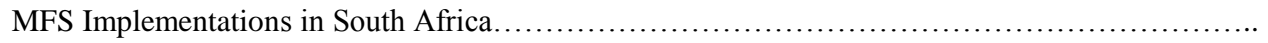

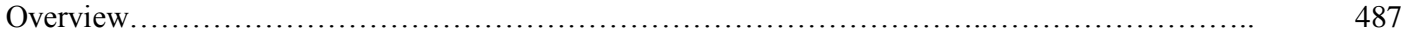

Wireless Application Service Providers VAS .................................................. 487

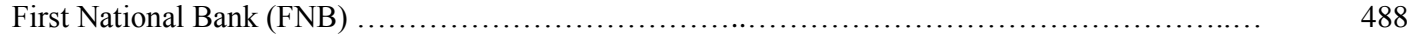

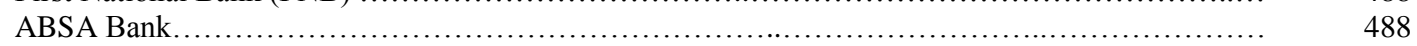

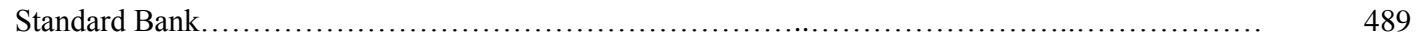

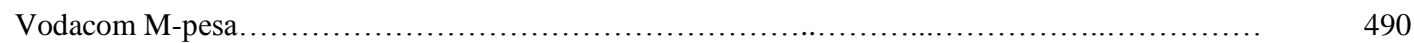

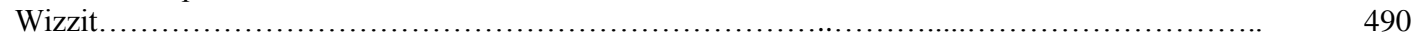

UBank

Money, Banking, \& Payments Laws, Bodies And Guidelines.................................... 491

The Prudential Landscape for Financial Products and Services in SA.......................... 491

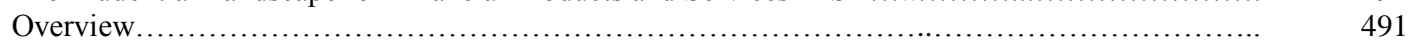

Financial-related Regulatory and Advisory Bodies in South Africa........................... 491

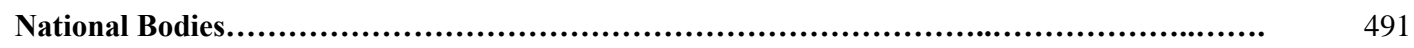

South African Reserve Bank (SARB)

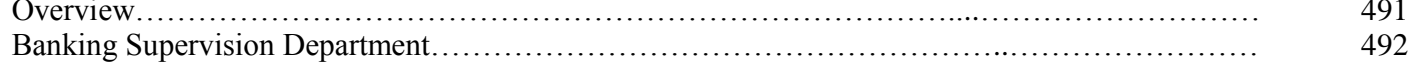

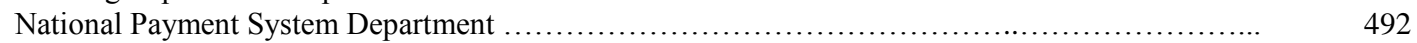

Financial Surveillance Department....................................................... 493

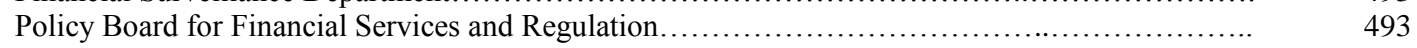

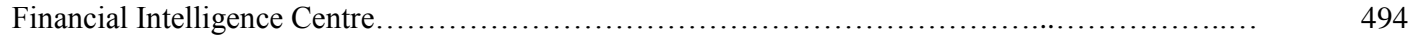

Financial Services Board.................................................................. 494

The Office of the Ombud for Financial Service Providers...................................... 494

The National Consumer Commission And National Consumer Tribunal........................... 494

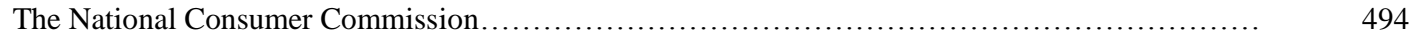

The National Consumer Tribunal .......................................................... 495

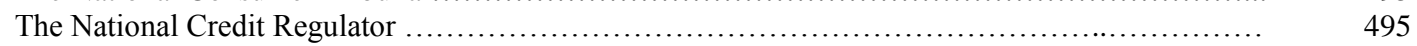

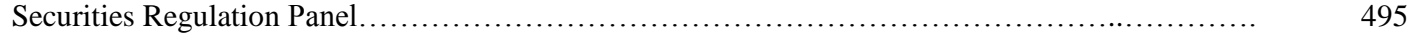


Advisory Boards

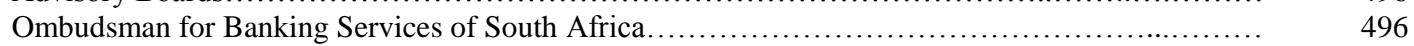

12.3.2.11

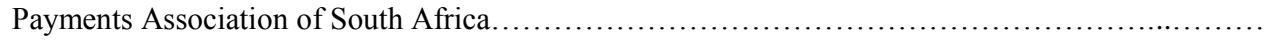

The NPSSB and NPSOF.

12.3.2.13

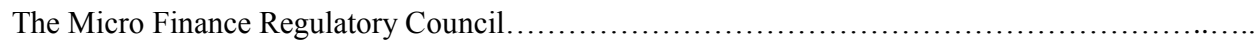

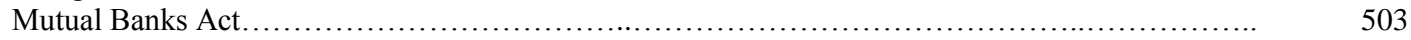

Dedicated Banks Bill..................................................................... 503

Implications of Registering as a Bank.....

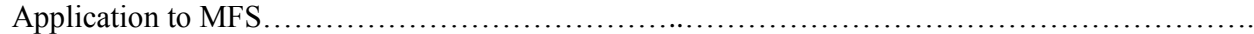

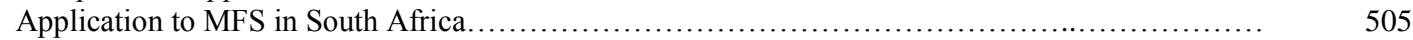

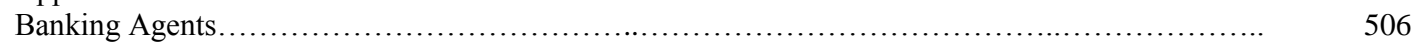

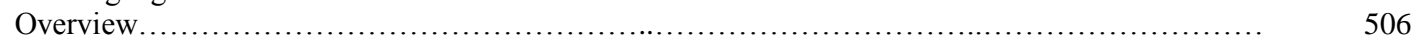

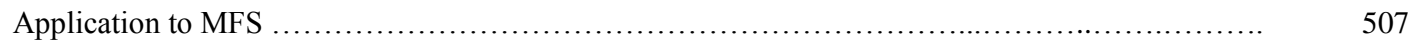

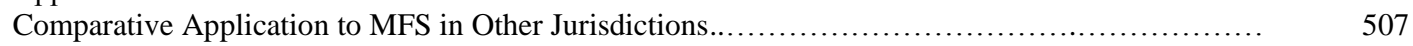

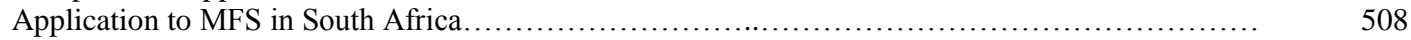

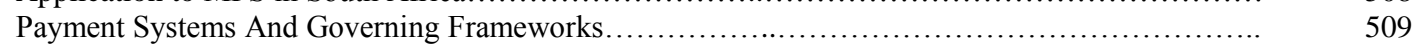

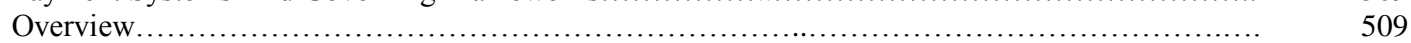

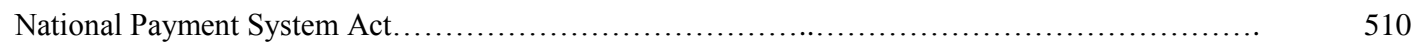

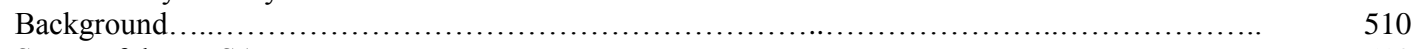

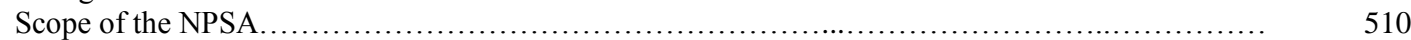

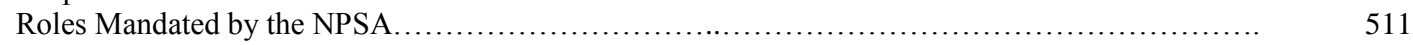

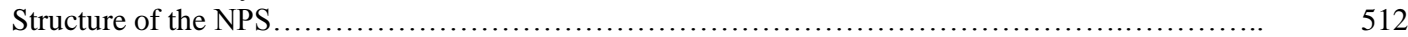

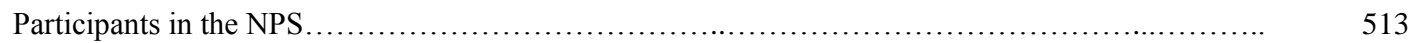

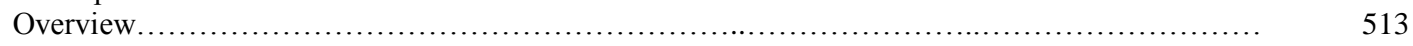

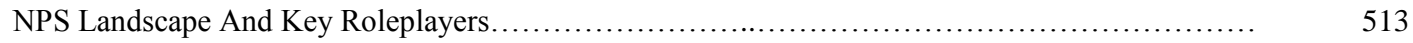

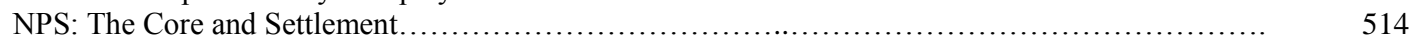

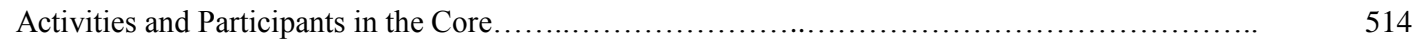

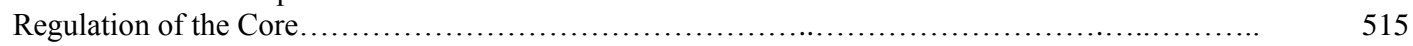

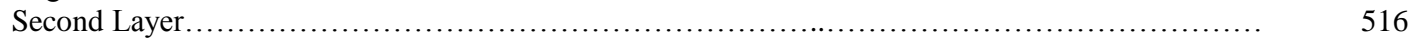

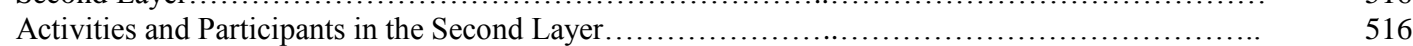

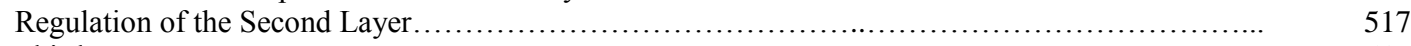

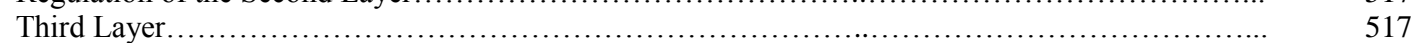

Activities and Participants in the Third Layer..................................................... 517

Regulation of the Third Layer........................................................... 517

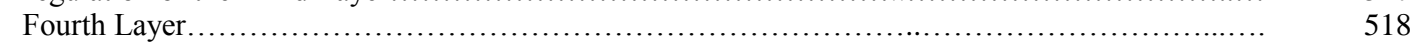

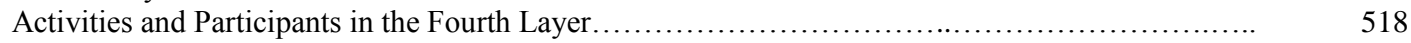

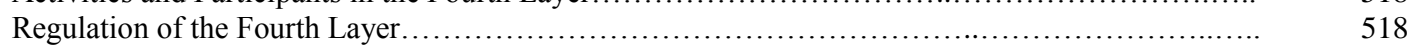

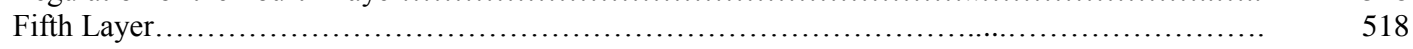

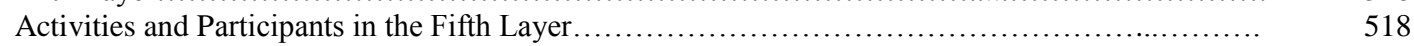

Rules and Regulations of the Fifth Layer......................................................... 519

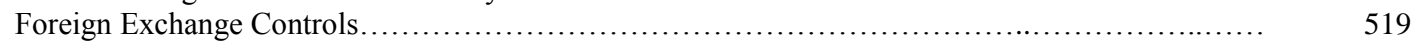

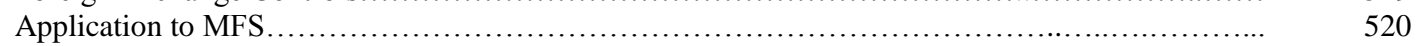

Comparative Application to MFS in Other Jurisdictions................................... 520 
E-Money in South Africa...........

12.4.2.2

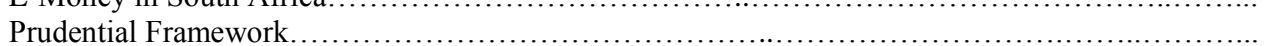

Issuance and Redemption...

'Monetary Value'

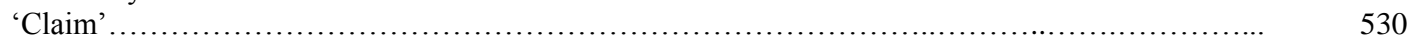

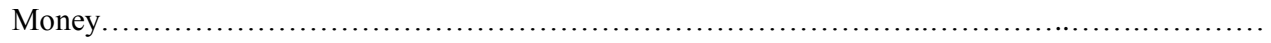

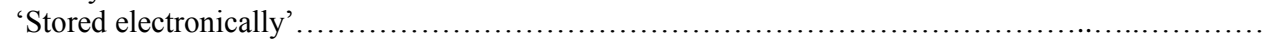

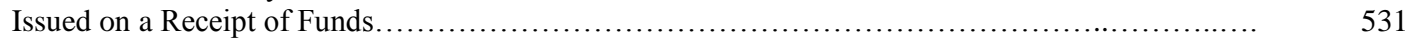

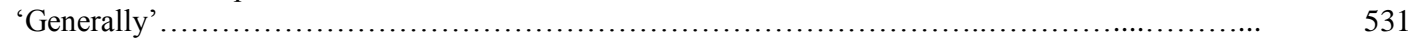

12.4 .3 .2 .7

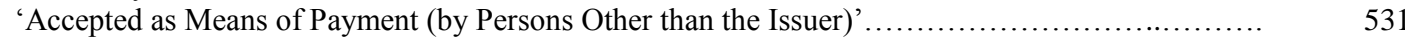

'(Accepted as Means of Payment) by Persons Other than the Issuer' ............................ 531

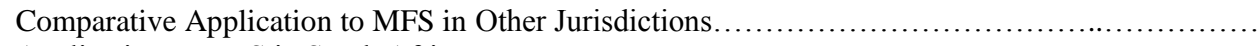

Telecommunications-related Laws and Regulations.

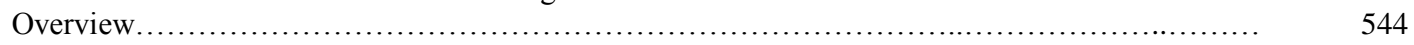

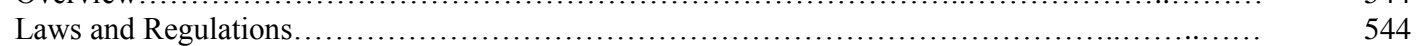

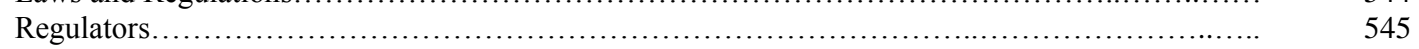

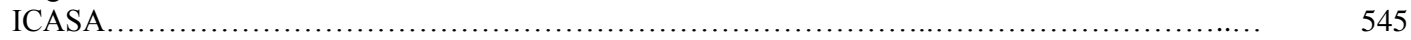

WASPA.

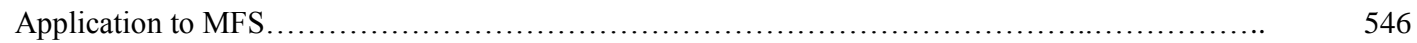

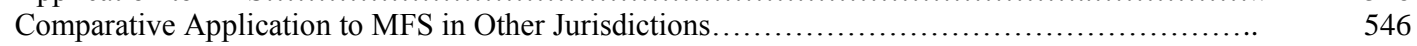

Application to MFS in South Africa ............................................................ 547

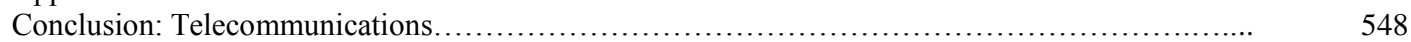

E-Commerce Laws....... 
12.9.2.2.2

12.9.2.2.3

12.9.2.2.4

B

12.9.2.2.5

12.9.2.2.6

12.9.2.2.7

12.9.2.2.8

12.9.3

12.10

12.10 .1

12.10 .2

12.10.2.1

12.10.2.2

12.10.2.2.1

12.10.2.2.2

12.10.2.2.3

12.10.2.2.4

12.10.2.2.5

12.10.2.2.6

12.10.2.2.7

12.10 .3

12.11

12.12

12.12 .1

12.12 .2

12.12 .3
Legal Capacity

Mistake In Transactions.

Specific Consumer Protection Clauses in the ECTA.

Information Requirements for the Validity of a Transaction

Storage Requirements.

Transaction Security And Payment Systems......

Cooling Off Period Available for Some Services.

Conclusion: E-Commerce Laws

Consumer Protection Laws.

Overview

Application To MFS

Comparative Application to MFS in Other Jurisdictions...

Application to MFS In South Africa.

Agreements by Persons Lacking Legal Capacity

Ownership of MFS SOV.

Access to Service Facilities.

Liability for Loss of MFS SVP Value

Enforcement of Rights by Consumers.

Interplay of the CPA with the ECTA.

Jurisdictional Issues Between the NCC and Other Regulatory Bodies

Conclusion: Consumer Protection Laws.

Consumer Protection And Loss Allocation With Respect to Payments.

South Africa: General Summary and Conclusions.

General Observations of The Regulatory Structure ....

General Observations on Consumer Protection.

General Observations on Security Aspects
Formation of Contracts By Users Contracting with Electronic Agents

552

552

CHAPTER 13: RE-EVALUATION OF MONEY

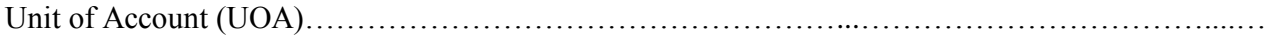

Role as a Means of Exchange (MOE)

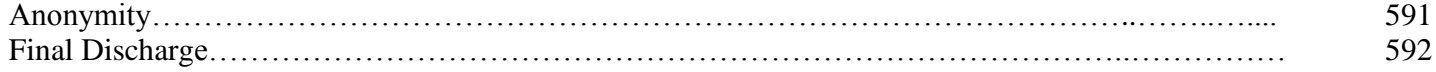

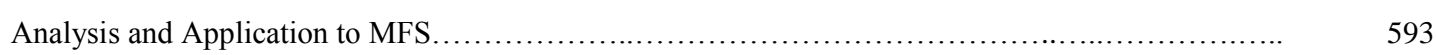

Claim School View Of Money.......................................................... 595

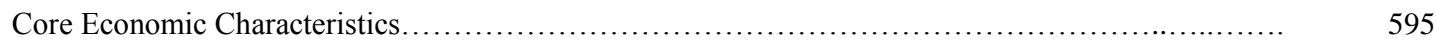

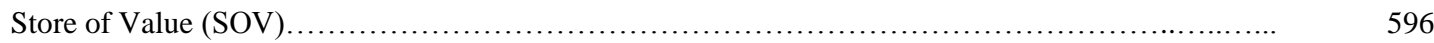

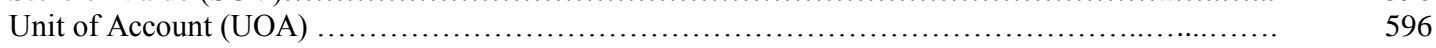

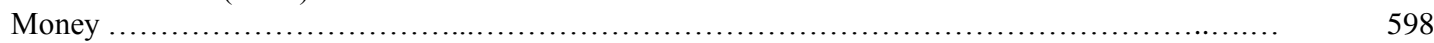

A 'Thing' as the Money ..................................................................... 598

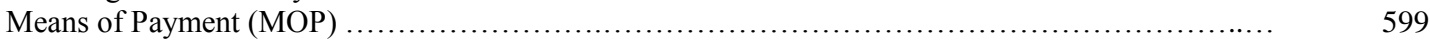


13.6

13.6.1

13.6.2

13.6.3

13.6.4

13.6.5

13.6.6

13.7

13.8

13.8 .1

A

13.8.2

13.8.2.1

13.8.2.2

13.8.2.3

B.

13.8.3

13.8.3.1

13.8.3.2

13.8.3.3

13.8.3.4

13.8.3.5

13.9

Exhibit A
Legal Characteristics Based on the Claim School.

601

601

601

602

603

604

605

608

Analysis And Application to MFS.

611

611

Overview.

612

612

612

613

613

616

616

616

617

619

619

620

621

624

CHAPTER 14: RESEARCH SUMMARIES, CONCLUSIONS AND RECOMMENDATIONS.

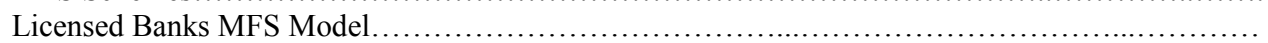

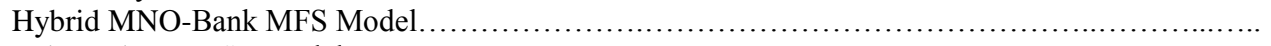

Banks' Services versus MNO Mobile Financial Services.................................... 635

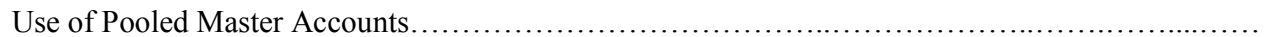

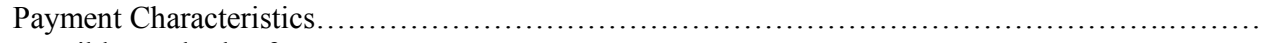


14.3.4.4

14.3.4.5

14.3.4.6

14.3.4.7

14.3.4.7.1

14.3.4.7.2

14.3.4.7.3

14.3.4.8

14.3.4.8.1

14.3.4.8.1.1

14.3.4.8.1.2

14.3.4.8.1.3

14.3.4.8.1.4

14.3.5

14.4

14.4.1

14.4 .2

14.4 .3

14.4.4

14.4 .5

14.4.6

14.4.7

14.4.8

14.5

14.5.1

14.5.2

14.5.2.1

14.5.2.2

14.5.2.3

14.5.2.4

14.5.2.4.1

14.5.2.4.2

14.5.2.4.3

14.5.2.5

14.5.2.5.1

14.5.2.5.2

14.5.2.5.2.1.

14.5.2.5.2.2

14.5.2.5.2.3

14.5.2.5.2.4

14.5.2.5.3

14.5.2.5.3.1

14.5.2.5.3.2

14.5.2.5.3.3

14.5.2.5.3.4

14.5.3

14.5.3.1

Part I.

14.5.3.2

14.5.3.3

14.5.3.4

Part II.

14.5.3.5

14.5.3.6

14.5.3.7

Part III.

14.5.4

14.5.4.1

14.5.4.2

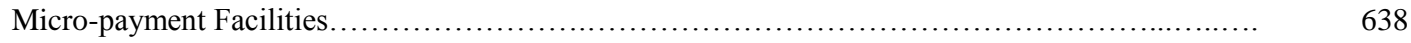

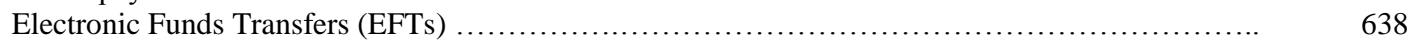

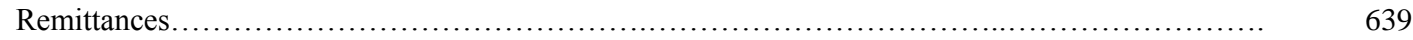

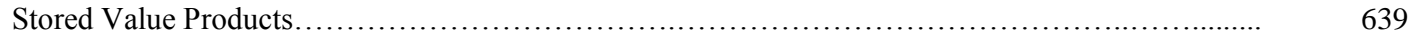

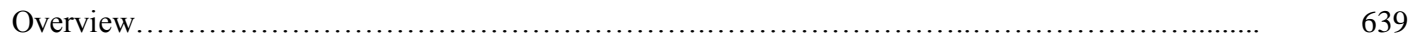

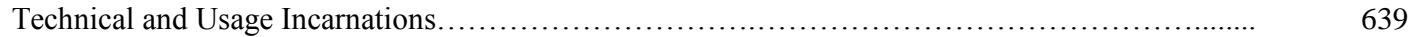

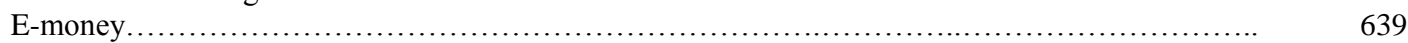

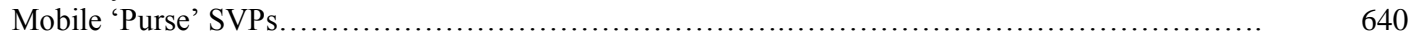

Comparison with other Payment Methodologies, and Internet e-Commerce....................... 640

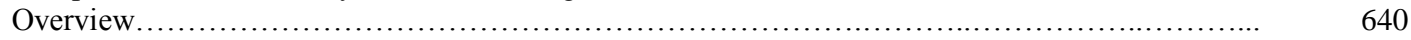

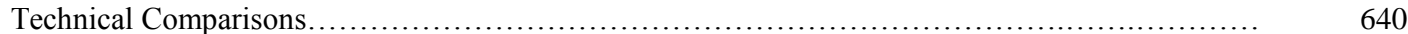

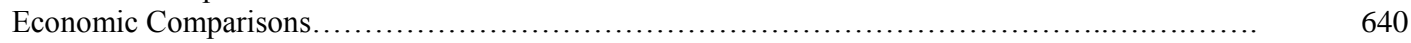

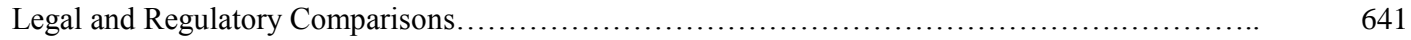

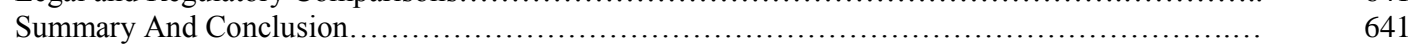

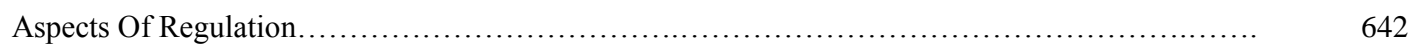

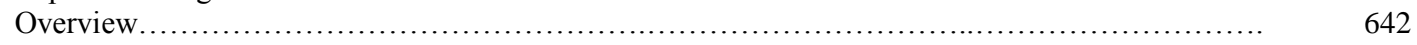

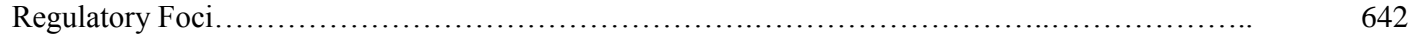

Philosophies Behind Regulation..................................................... 642

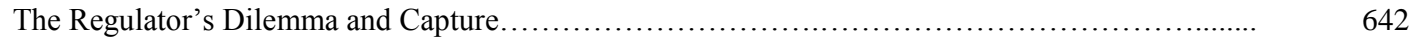

Functional versus Institutional Approaches............................................ 643

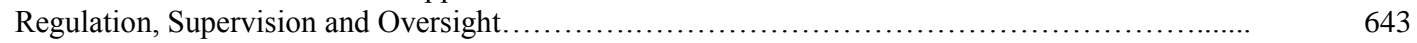

Financial Inclusion versus Financial Integrity.............................................. 643

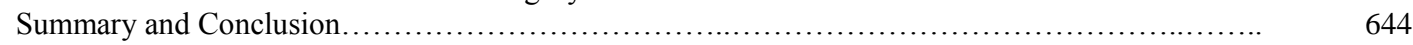

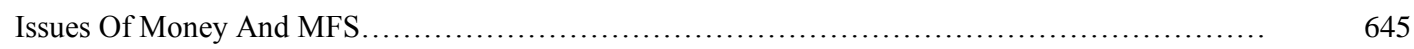

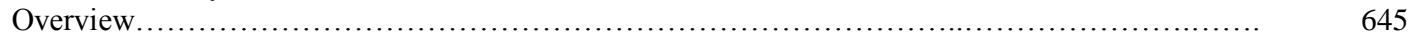

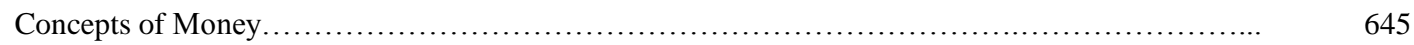

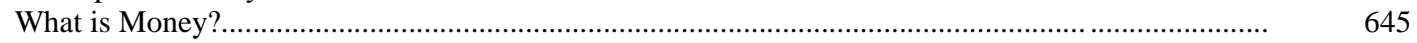

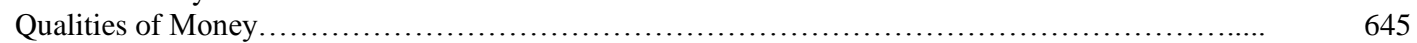

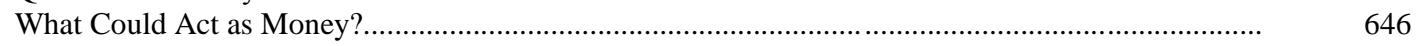

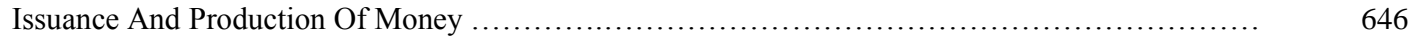

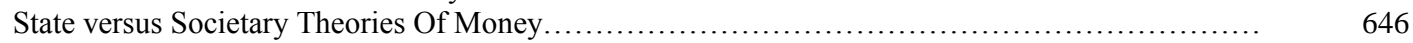

Specific Role of the State and Central Bank in Money....................................... 646

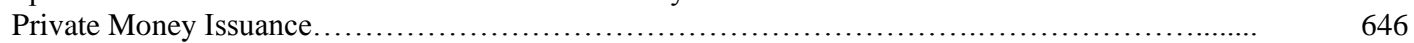

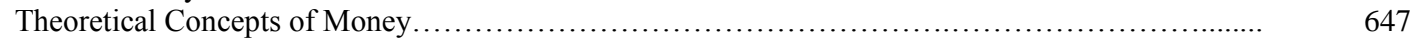

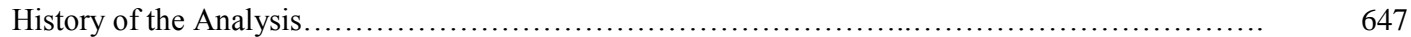

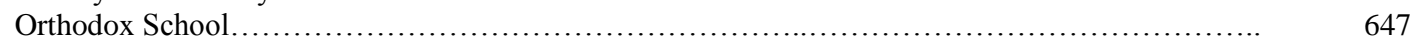

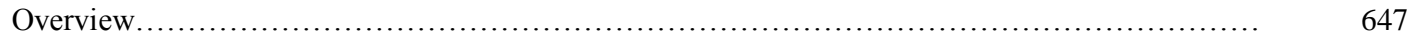

Unit of Account . . .

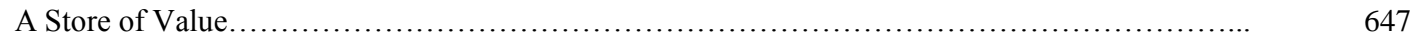

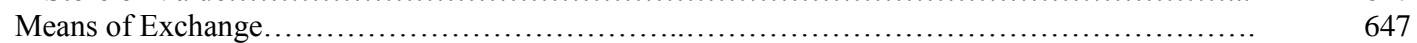

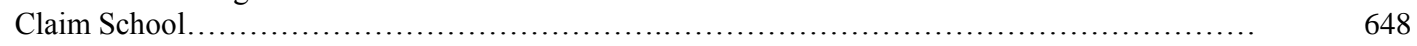

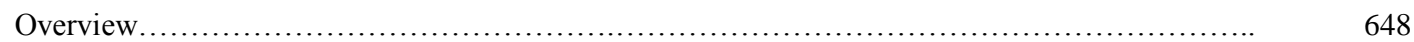

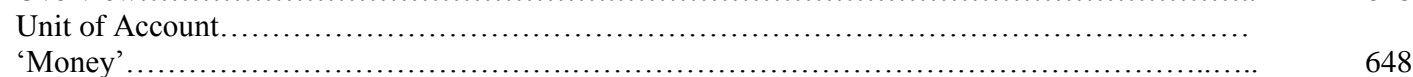

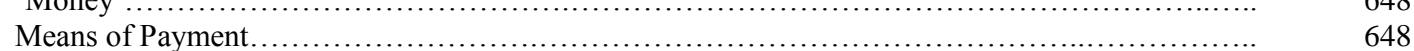

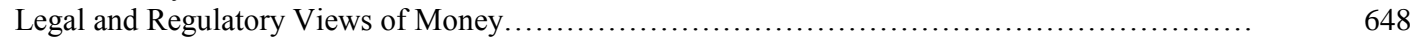

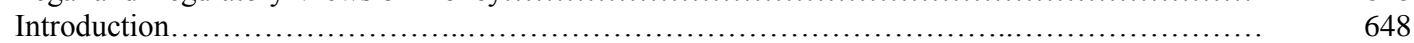

Leading Cases And Works on Money ....................................................... 649

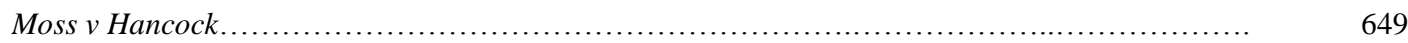

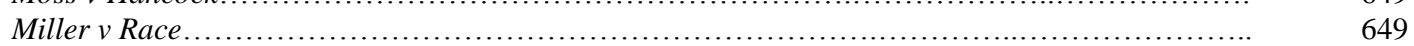

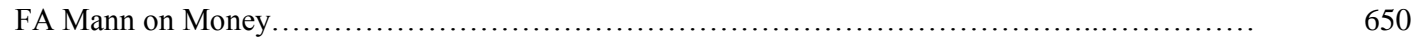

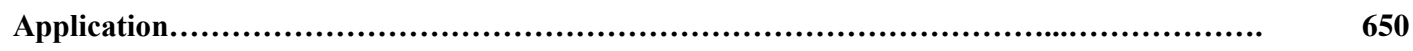

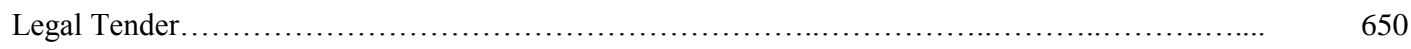

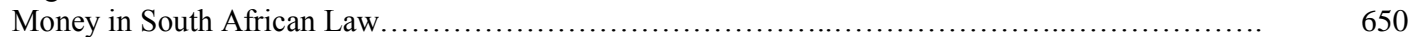

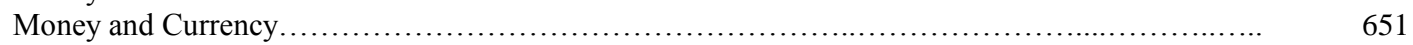

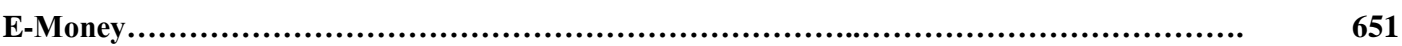

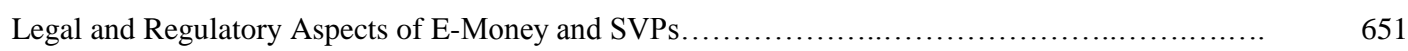

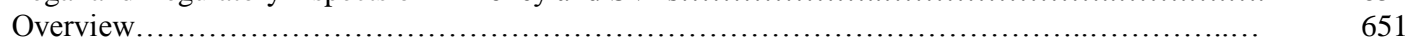

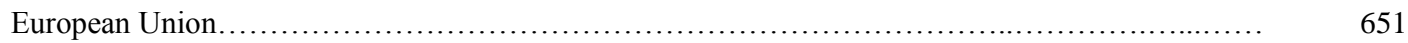


14.5.4.3

14.5.4.4

14.5.4.5

14.5.4.6

14.5.4.7

14.5.4.7.1

14.5.4.7.2

14.6

14.6.1

Part I.

14.6.2

14.6.3

14.6.4

14.6.5

Part II.

14.6.6

14.6.6.1

14.6.6.2

14.6.6.3

14.6.6.4

Part III.

14.6.7

14.6.8

14.7

PART I.

14.7.1

14.7.2

14.7 .3

14.7.4

14.7.5

Part II.

14.7.6

Part III.

14.7 .7

14.7 .8

Part IV.

14.7.10

A.

Kenya

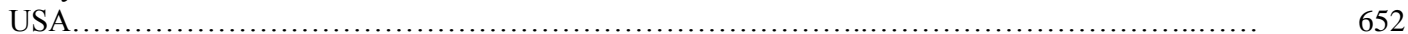

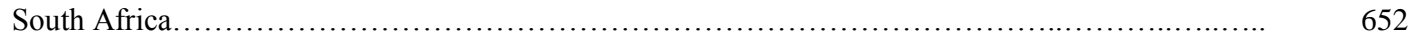

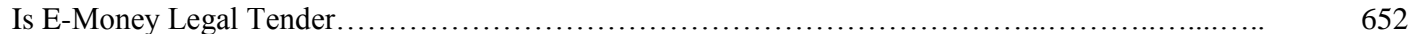

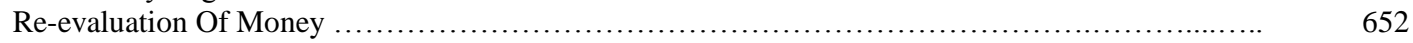

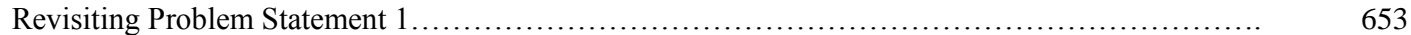

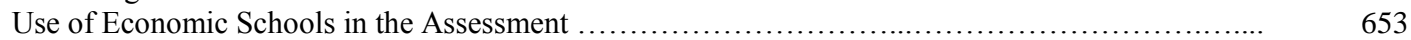

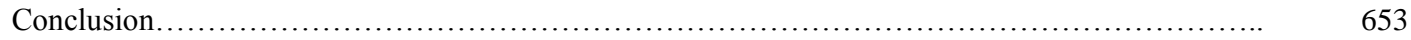

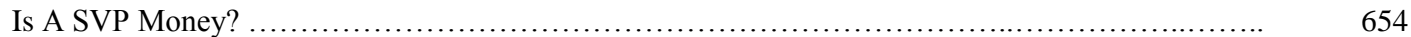

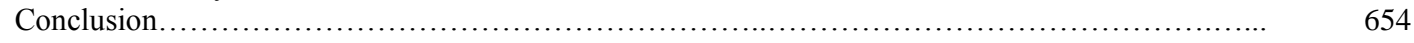

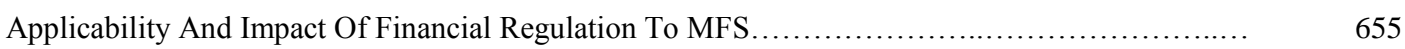

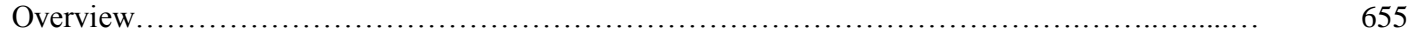

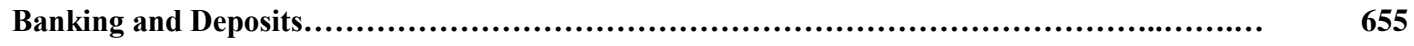

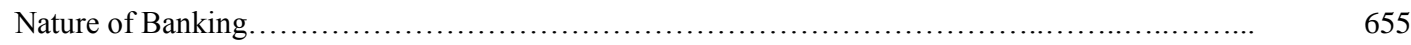

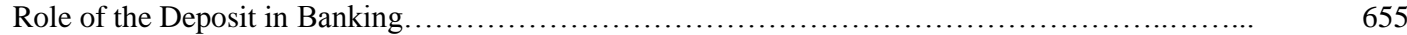

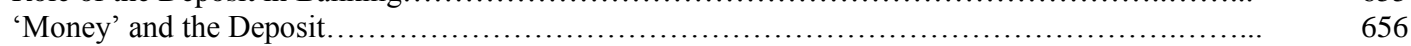

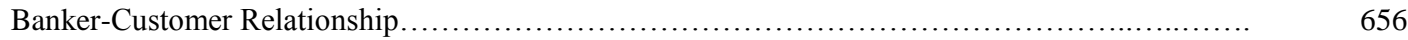

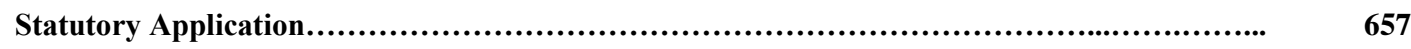

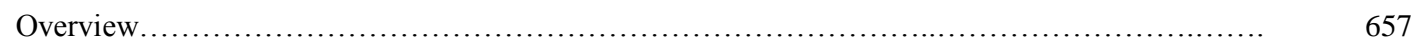

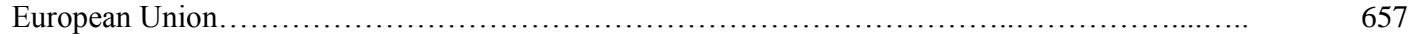

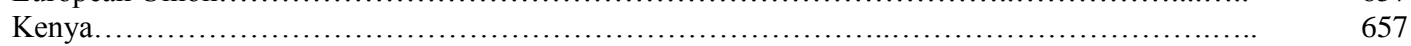

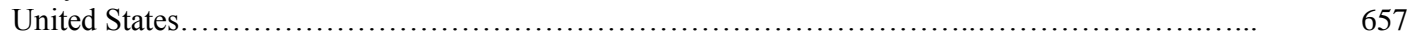

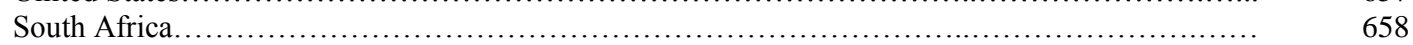

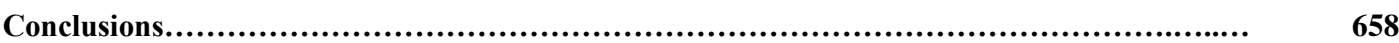

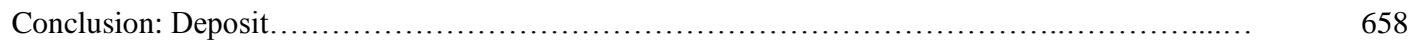

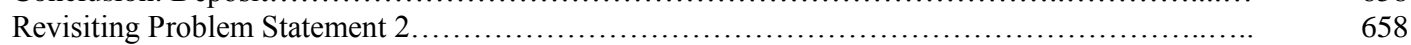

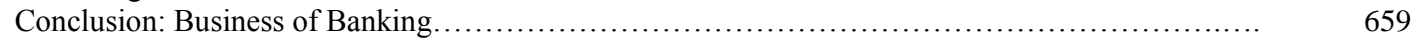

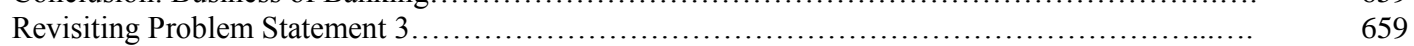

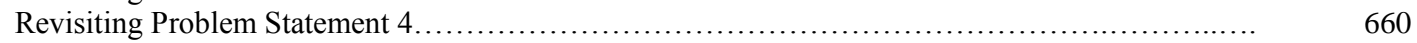

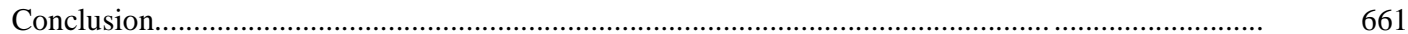

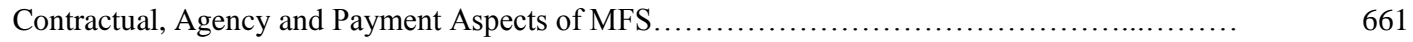

Contracts..................................................................................

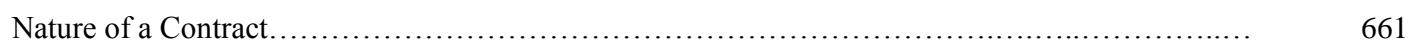

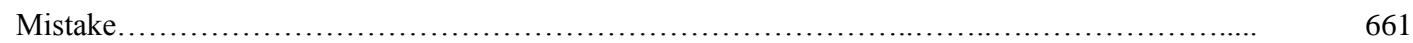

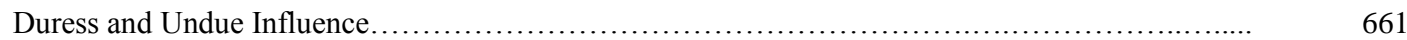

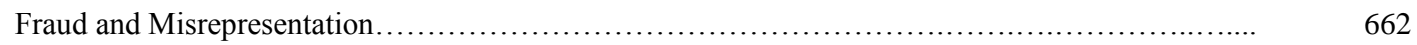

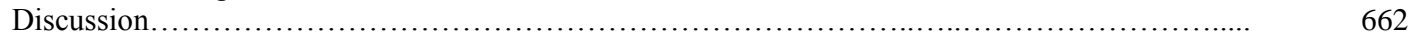

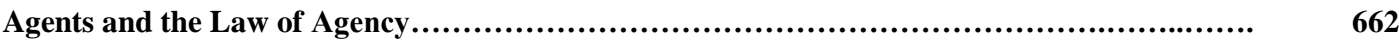

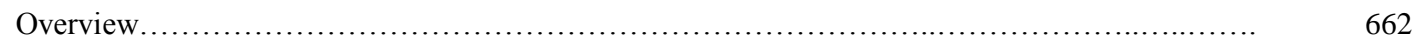

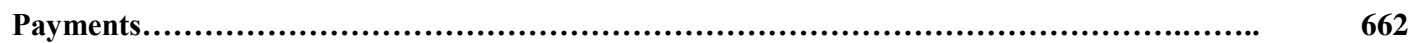

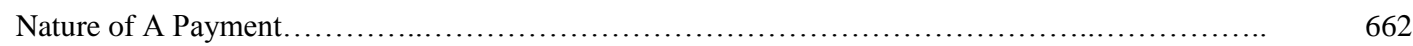

Allocation of Risk in Contracts and Payments.............................................. 663

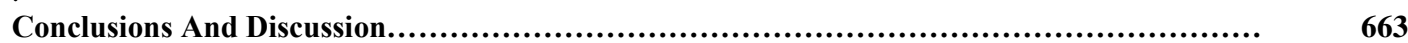

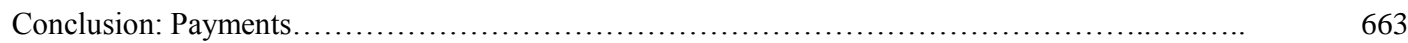

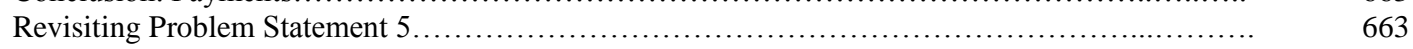

Payment Regulation and Protections...................................................... 664

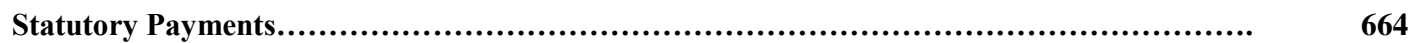

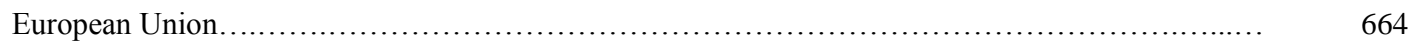


14.7.10.1.1

14.7.10.1.2

14.7.10.2

14.7.10.2.1

14.7.10.2.2

14.7.10.3

14.7.10.3.1

14.7.10.3.2

14.7.10.4

14.7.10.4.1

14.7.10.4.2

B

14.7.11

14.7.12

14.8

14.8 .1

A

14.8 .2

14.8 .3

14.8.4

14.8 .5

14.8.6

B

14.8 .7

14.8 .8

14.8 .9

14.8 .10

14.8.11

C

14.8.12

14.8 .13

14.8.14

14.8.15

D

14.8.16

14.8 .17

14.8 .18

14.8 .19

14.8 .20

14.9

14.9.1

A.

B.

14.9.2

A.

B.
Overview

Specific Consumer Protections.

Kenya.......

Overview....

Specific Consumer Protections.

United States.

Overview....

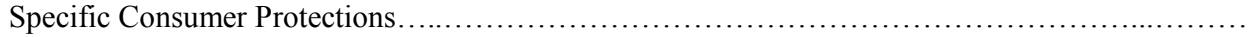

South Africa. ...

Overview

Specific Consumer Protections.

Common Law.

664

665

665

665

665

665

665

666

666

666

666

667

Common Law Protections: Condictiones

667

667

667

669

Revisiting Problem Statement 6

Conclusion.

Overview

European Union

669

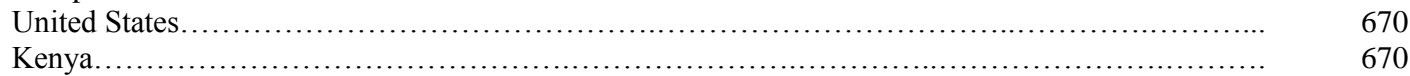

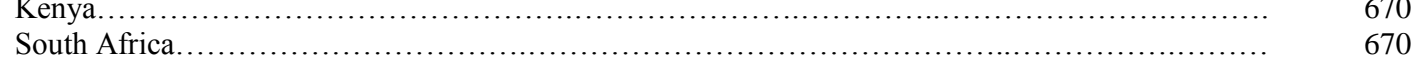

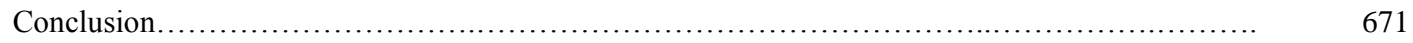

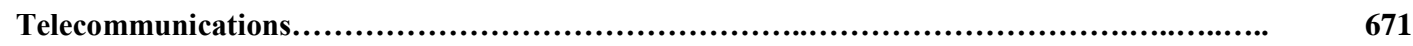

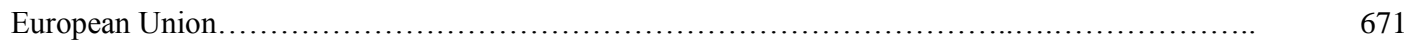

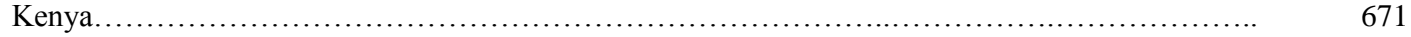

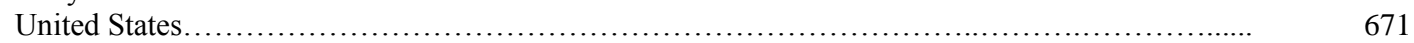

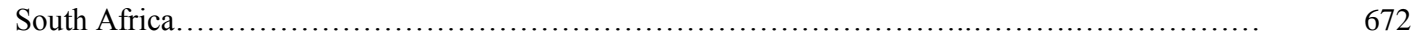

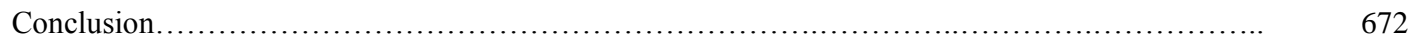

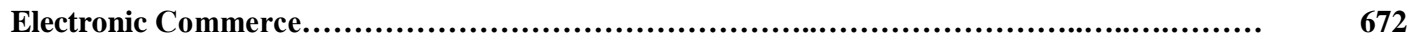

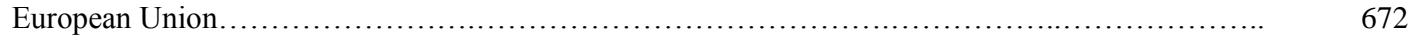

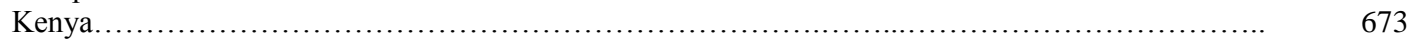

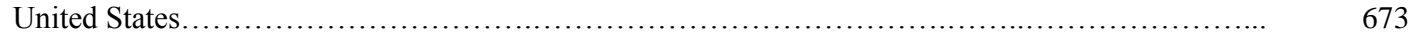

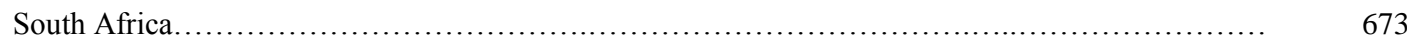

Consumer Protection.................................................................. 674

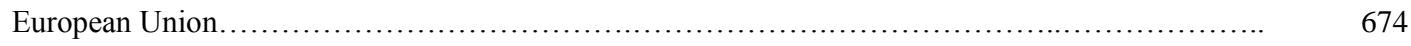

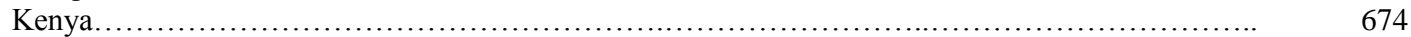

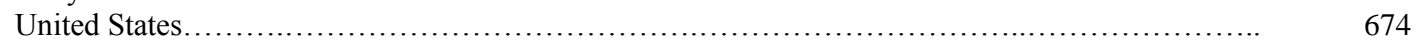

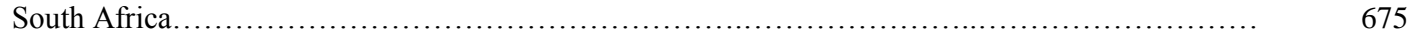

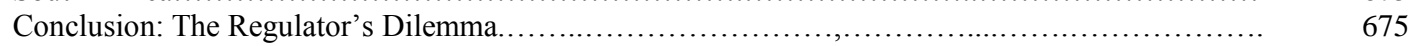

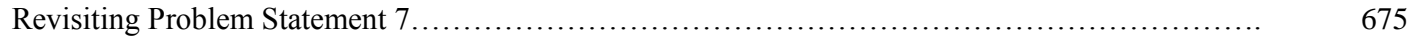

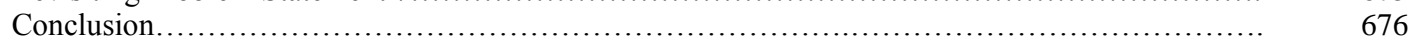

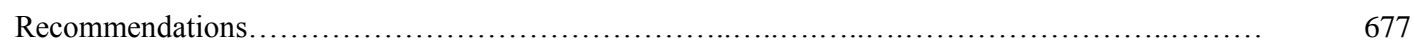

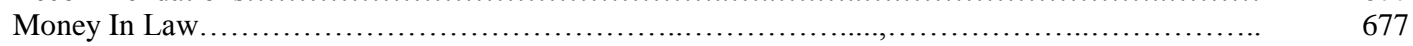

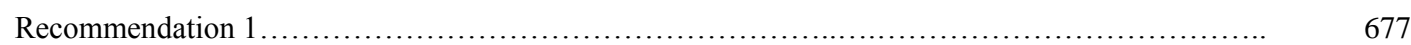

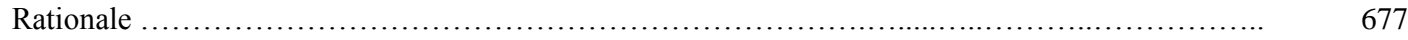

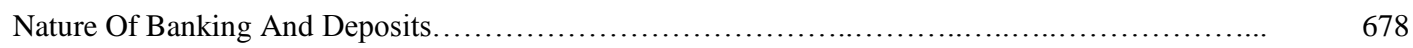

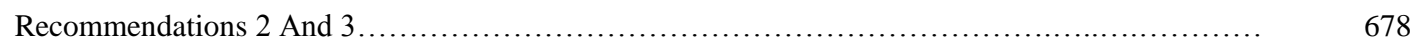

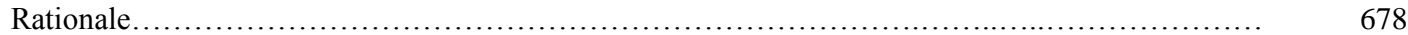




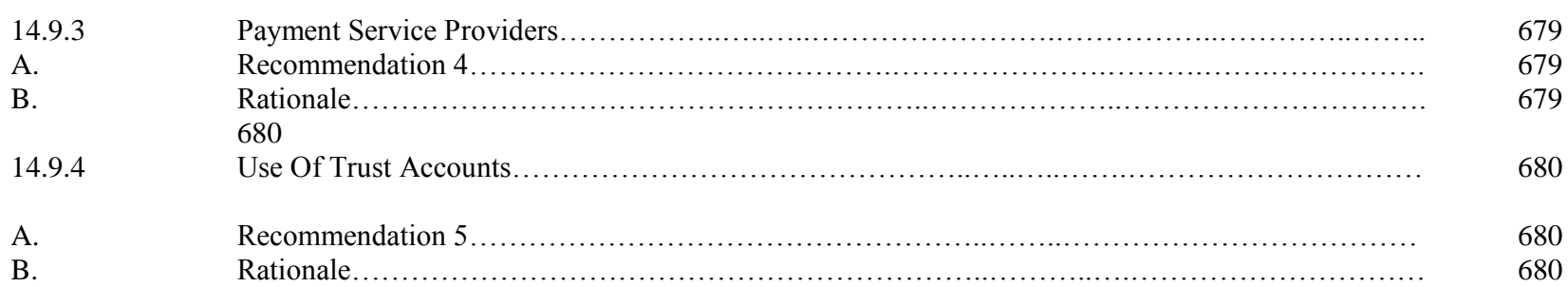

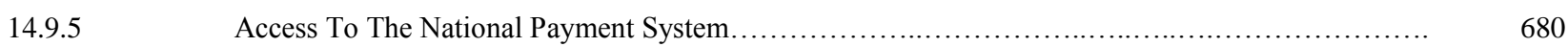

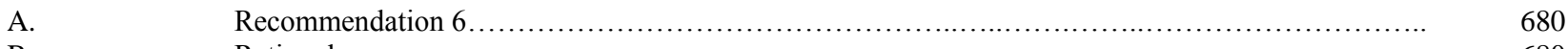

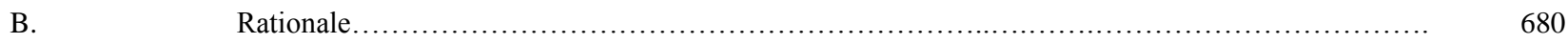

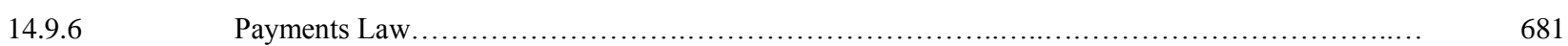

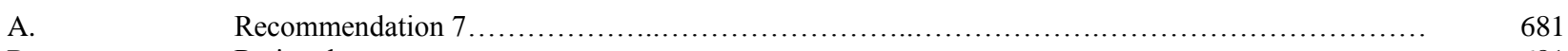

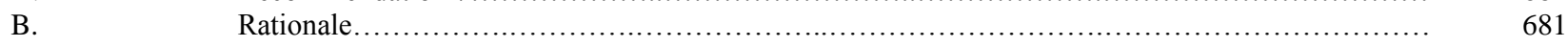

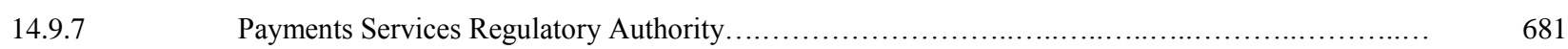

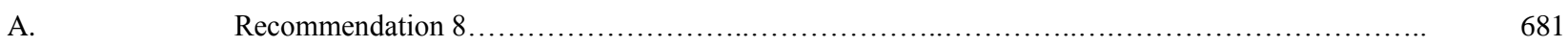

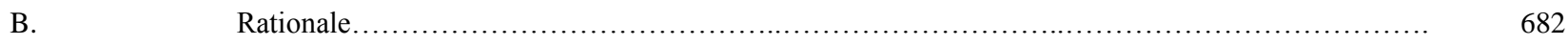

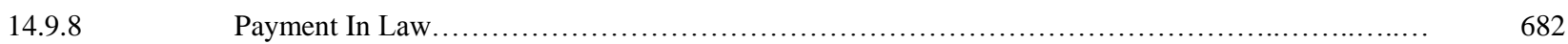

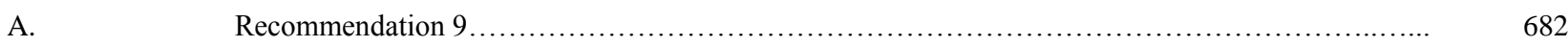

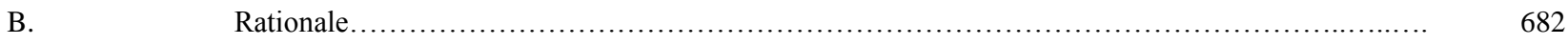

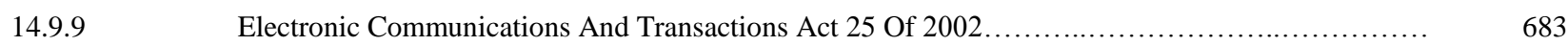

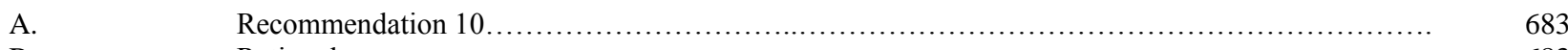

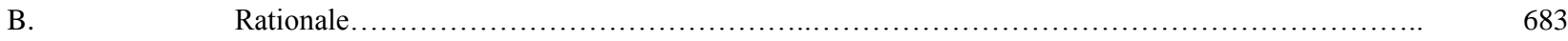

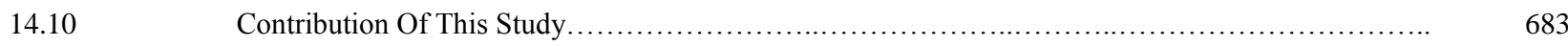

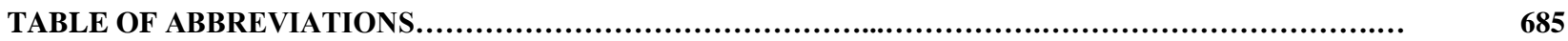

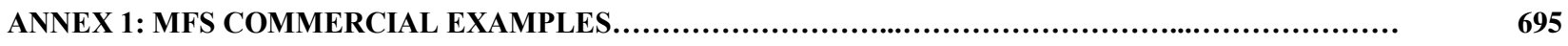

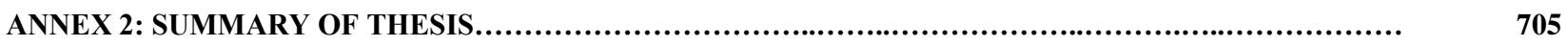

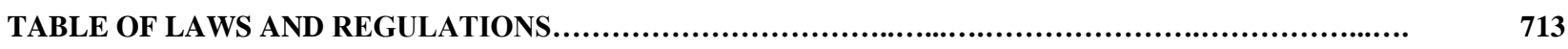

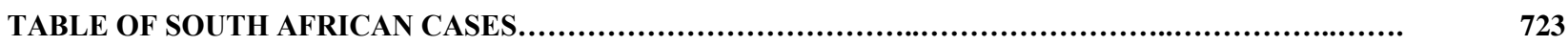

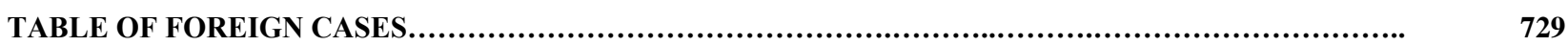

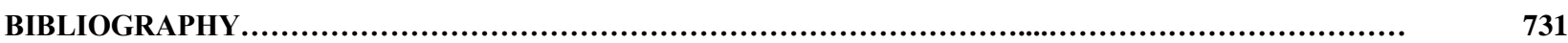

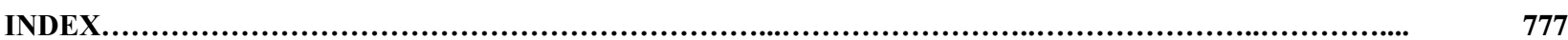




\section{CHAPTER 1}

\section{SCOPE, STRUCTURE AND RESEARCH METHODOLOGY}

\section{A. \\ Overview Of Thesis}

1.1

\section{Introduction}

The study deals with the emergence of entities that provide a range of transaction-based payment services via mobile phones to primarily 'unbanked,' 'underserved,' and 'underbanked' persons who are at the bottom of the financial pyramid (hereafter BOP) so as to enable and promote Financial Inclusion (hereafter FI). ${ }^{1}$ These services are broadly called Mobile Financial Services (MFS) and include ${ }^{2}$ payments for goods and services, for Value Added Services (hereafter VAS), ${ }^{3}$ and for sending remittances. ${ }^{4}$

There are a number of MFS commercial models that are covered, including those from:

- $\quad$ Mobile Network Operators (hereafter MNOs);

- $\quad$ Licensed banks;

- $\quad$ A combination of MNOs and licensed banks;

- $\quad$ Mobile Financial Service Providers (hereafter MFSPs);

- Wireless Application Service Providers (hereafter WASPs).

There are currently over 100 MFS systems worldwide, the most successful being the eponymous 'M-pesa' - 'mobile money' in Swahili - MFS system operated by Kenyan MNO Safaricom. ${ }^{5}$

Many of these models - particularly those offered by entities which are not licensed banks - are examples of the evolving concept of 'branchless banking' whereby many financial services available through a mobile phone are augmented by financial services provided in situ by 'agents' - also known as cash merchants - who may inter alia offer what are known as 'cash-in/cash-out' facilities to users of MFS systems. ${ }^{6}$ The competitive, legal and regulatory nature of these "transformational ${ }^{7}$ non-bank MFS models

\footnotetext{
${ }^{1}$ See ch 2, s2.1.

${ }^{2}$ For pictorial examples of services covered under MFS and discussed in this study, see Exhibits A-J in Annex 1.

${ }^{3}$ See ch 2, s2.6 on Premium Rated Services.

${ }^{4}$ See ch 4, s4.8.4.3 on remittances.

5 See ch 10 passim on MFS in Kenya and the discussion on the hugely successful M-pesa MFS system run by MNO Safaricom, seen as a bellwether of MFS globally. See specifically www.safaricom.co.ke on M-pesa. Notably, it does not have a Kenyan banking license.

${ }^{6}$ See ch 2, s2.5.1.2 on MFS agents.

${ }^{7}$ See ch 2, s2.3 on MFS.
} 
versus the 'additive ${ }^{8}$ MFS model offered by licensed banks providing similar services is discussed, as are the various technical enablers of MFS.

Funds for these MFS transactions may be stored in electronic 'purses' - also known as a Stored Value Accounts (hereafter SVA) ${ }^{9}$ - derived from either the value as a non-redeemable mobile airtime-based ${ }^{10}$ Store of Value (hereafter SOV) or from redeemable fiat-based ${ }^{11}$ SOVs. Both types may be offered by MNOs. These products are known as being species of the family of Stored Value Products (hereafter SVPs). ${ }^{12}$ The study examines if, and then how, each should be regulated and whether the funding mechanism for the SVPs falls within the scope of the definition of deposit-taking such that the entity taking those funds could be viewed as doing the "business of banking. ${ }^{13}$ In so far as proportionality in regulation ${ }^{14}$ may be desirable, coincident investigations are undertaken as to whether the 'deposit' is still an appropriate trigger for determining the 'business of banking,' as is the applicability of the concept of the 'business of banking' itself in relation to describing transaction and payment-centric entities providing MFS using SVPs where there is ephemeral, transient storage of any value.

Further, with regard to money being the traditional ingredient for a 'deposit,' an assessment is undertaken as to whether some of the SVP incarnations used in MFS could even be classified as money using current legal views of money, founded as they currently are on the commodity-based Orthodox School economic view of money derived from Aristotle. There is a further investigation of whether a new method of legal classification of money - coincident with relatively new economic theories of money proffered by the competing Claim School economic view of money - may be required instead and be more appropriate. The implications for deposit-taking anti-money laundering (hereafter AML) measures, and rights sounding in money where a SOV is not seen as money are discussed.

Since there are not yet any specific laws that focus specifically or directly on MFS in the jurisdictions under review in this study, this study uses extrapolation from the common law and existing laws and regulations that could have general or specific applicability to MFS.

The study then looks at potential legal and regulatory valencies in relation, inter alia, to AML and general security-type laws, banking law, payments law, e-commerce laws, telecommunication laws, and consumer protection laws and measures so as to understand on a comparative basis the legal and regulatory ecosystem MFS may encounter and to recommend any improvements. The regulatory framework - where it could be applied - for 'branchless banking' and use of agents, as with as the identified valencies, in the

\footnotetext{
${ }^{8}$ See ch 2, ss2.2 titled The Rationale for MFS, 2.3 titled The Scope of MFS and 2.4 titled Services Available in MFS.

${ }^{9}$ See ch 4, s4.8.4.4.2 titled Stored Value Nomenclature; and ch 2, s2.1 titled Introduction and Exhibit A therein for application thereof. For their relative interactions and terminological use in this study, see ch 1, s1.6 titled Terminology.

${ }^{10}$ On mobile 'airtime', see ch 5, s5.2.2 titled User Access to Mobile Networks. On the terminological use of 'airtime' in this study, see ch 1, s1.6 titled Terminology.

${ }^{11}$ Fiat is the order of the state. See further on fiats, ch 3, s3.5.1 titled Overview; and on terminological use in this study, see ch 1, s1.6.

${ }^{12}$ See ch 4, s4.8.4.4 titled Stored Value Products. See ch 4, s4.8.4.4.2 on the taxonomical hierarchies that characterise SVPs.

${ }^{13}$ See ch 4, s4.3.2 titled Characteristics of Banking.

${ }^{14}$ See ch 8, s8.9 titled Conclusion, on proportional regulation.
} 
European Union (hereafter EU), ${ }^{15}$ Kenya, ${ }^{16}$ the United States of America (hereafter USA) ${ }^{17}$ and South Africa (hereafter SA) ${ }^{18}$ is extensively covered.

In so far as MFS may have implications for consumer protection, the existing common law remedies using condictiones used to reclaim values lost, ${ }^{19}$ as well as those related to unjustified enrichment, are discussed alongside the efficacy of statutory facilities and measures as they may be applied to MFS. Due to financial literacy and technical concerns it is found inter alia, that there is a need for robust and dedicated consumer protection of payment services, falling under the remit of what this study proposes as a new Payment Services Providers Law (PSPL) for $\mathrm{SA}^{20}$ that licenses the non-bank MFS entities acting as Payment Service Providers (hereafter PSPs) whose primary focus is transactional payments. The potential for a new regulator in SA for payment services - a proposed Payment Services Regulatory Authority (hereafter PSRA $)^{21}-$ is also investigated and then proposed. The discussion on payments also includes an assessment of whether MFS challenges the requirement in South African law for a payment to be 'bilateral'.

The use of special trust companies vehicles and accounts to store pooled user funds housed by the PSPs as a safety and soundness measure is also discussed and then proposed. ${ }^{22}$ The legal regulatory rationale and philosophies for all these proposals are discussed, as is the need to revise current e-commerce and consumer protection laws where these are found to be ineffective in their application to MFS.

\subsection{Structure of the Thesis and Brief Summaries}

The study provides a technical, commercial, economic and legal and regulatory overview of MFS and money on a comparative basis between the EU, Kenya, the USA, and SA.

The chapters generally cover the problem statements and any composite doctrinal interactions thereto as outlined in ch1, s1.8 below.

Chapter 1 serves as the introductory chapter, where the various Problem Statements are described.

Chapter 2 offers an overview of MFS, and concludes that there is a need to boost FI for those at the BOP, and that MFS may provide an elegant and ubiquitous solution to the challenges posed in promoting FI.

\footnotetext{
${ }^{15}$ See ch 9 on the EU and MFS.

${ }^{16}$ See ch 10 on Kenya and MFS.

${ }^{17}$ See ch 12 on the US and MFS.

${ }^{18}$ See ch 12 on South Africa and MFS.

${ }^{19}$ See ch 7, s7.3.6.8 titled Actions to Recover Value on the condictiones.

${ }^{20}$ See ch 12, s12.12 titled South Africa: General Summary and Conclusion.

${ }^{21}$ Ibid.

${ }^{22}$ See ch 7, s7.4 titled Trusts.
} 
Chapter 3 is the first of two chapters that focus specifically on money, the other being a re-evaluation of money in chapter 13. Chapter 3 contains a historical overview of money ${ }^{23}$ and the money theories developed over time ${ }^{24}$ alongside their legal application. It discusses under what circumstances, if any, the electronic SOV used in MFS could possibly amount to money. Chapter 3 concludes $^{25}$ that in the light of new, intangible forms of what could possibly be considered money, the legal system's reliance on the familiar Orthodox School economic view of money ${ }^{26}$ may need to be revised to use instead the competing Claim School view of money. ${ }^{27}$

Chapter 4 deals with banking and payments, and provides an extensive overview of the various types of electronic payments available - such as $\mathrm{SVPs}^{28}$ and electronic (hereafter e-money). ${ }^{29}$ It also discusses the potential challenges MFS poses to the nature of the concept of deposit, ${ }^{30}$ the deposit's ubiquitous, covalent relationship to the 'business of banking, ${ }^{31}$ and similarly, whether MNOs or MFSPs may be engaged in the 'business of banking.' Chapter 4 concludes ${ }^{32}$ that the 'business of banking' is undergoing a metamorphosis from what this study concludes may be dated common-law criteria, in that acceptance of funds used primarily for transactional payment purposes should not necessarily amount to a deposit and that the deposit as it is known in banking law should rather be termed the 'deposit concept'. This may mean then that most MFS activities would not amount to the 'business of banking' and hence should not be subject to the full gamut of domestic banking regulation.

Chapter 5 looks at mobile technology employed in MFS and concomitant security ${ }^{33}$ aspects. Chapter 5 concludes $^{34}$ that while the mobile technology and mobile phones available for use with MFS are well suited, there are some potential security risks that may place user funds at risk.

Chapter 6 provides a more comprehensive overview of MFS business models offered by banks ${ }^{35}$ and nonbanks $^{36}$ and some hybrids ${ }^{37}$ of the two, highlighting concomitant components, services, participants, and possible regulatory effects. Chapter 6 concludes $^{38}$ that some MFS models, particularly those services offered by non-banks, suggest a transformational change to the interaction of unbanked, underserved and underbanked consumers with their primary financial institution, although these may pose some regulatory challenges.

\footnotetext{
${ }^{23}$ See ch 3, s3.4 titled Evolution of Money.

${ }^{24}$ See ch 3, s3.2.3 titled Doctrinal Perspectives on Money: An Introduction.

${ }^{25}$ See ch 3, s3.14 titled Summary and Conclusion.

${ }^{26}$ See ch 3, s3.9 on the Orthodox School view of money.

${ }^{27}$ See ch 3, s3.10 on the Claim School view of money.

${ }^{28}$ See ch 4 , s4.8.4.4 on SVPs.

${ }^{29}$ See ch 4, s4.8.4.4.2 titled Stored Value Nomenclature.

${ }^{30}$ See ch 4, s4.4 titled Deposits.

${ }^{31}$ See ch 4, s4.3.2 titled Characteristics of Banking.

${ }^{32}$ See ch 4, s4.10 titled Summary And Conclusions.

${ }^{33}$ See ch 5, s5.7 titled Security Aspects of MFS.

${ }^{34}$ See ch 5, s5.8 titled Conclusions.

${ }^{35}$ See ch 6, s6.4 titled Licensed Bank-led Model.

${ }^{36}$ See ch 6, s6.5 titled MNO-led Models.

${ }^{37}$ See ch 6, s6.6 titled Independent MFSP Models.

${ }^{38}$ See ch 6, s6.7 titled MFS Models: Summary and Conclusion.
} 
Chapter 7 provides an overview of the legal nature of MFS in regard to contracts ${ }^{39}$ used in MFS, ${ }^{40}$ the nature of payment relationships, ${ }^{41}$ the various condictiones ${ }^{42}$ ostensibly available for redress in case of unintended or fraudulent transactions, as well as an overview of the use of trusts in relation to safeguarding stored funds in MFS. Chapter 7 concludes $^{43}$ that the need in South African law for a payment to be 'bilateral' is buffeted by the unilateral and multilateral mechanism of value transfer employed in MFS. With regard to payment protections, those at the BOP may be affected by informational asymmetries that impact on their risks and rights in cases of mistake, fraud or duress, and where existing common law condictiones remedies may be insufficient. Trusts, ${ }^{44}$ as a means to safeguard user funds placed with MNO or MFSPs by users, may be an option as a proportionately adequate prudential safety and soundness measure.

Chapter 8 provides another vantage point for MFS regulation in relation to if and how, AML, ${ }^{45}$ electronic commerce, ${ }^{46}$ telecommunications, ${ }^{47}$ and consumer protection ${ }^{48}$ sector laws and regulations - and the regulatory philosophies ${ }^{49}$ behind them - may have relevance to MFS. Chapter 8 concludes $^{50}$ that there is a 'regulator's dilemma' in how to balance motives to enhance FI with the realities of the need for financial integrity, and further, that concurrent jurisdiction by multiple regulators over the component parts of the MFS ecosystem may create regulatory arbitrage. This, it was found, may set the stage for the emergence of a (proposed) retail payments-specific law and regulator for South Africa. ${ }^{51}$

Chapter 9 looks at the potential applicability to MFS in the EU in relation to the application of banking, ${ }^{52}$ payments, ${ }^{53}$ AML, ${ }^{54}$ telecommunications,${ }^{55}$ e-commerce, ${ }^{56}$ consumer protection, ${ }^{57}$ and e-money ${ }^{58}$ laws and regulations. Chapter 9 concludes $^{59}$ with the observation that the stratified and proportional regulatory banking and retail payments regime enabled by 'bank-lite' EU directives like the Electronic Money Directive $^{60}$ and the Payment Services Directive ${ }^{61}$ appear ideally suited to MFS, and could be employed in a manner in SA.

\footnotetext{
${ }^{39}$ See ch 7, s7.2 titled Contracts.

${ }^{40}$ See ch 7, s7.2.2.4 titled Application to MFS.

${ }^{41}$ See ch 7, s7.3 titled Payment in General.

${ }^{42}$ See ch 7, s7.3.6.8 titled Actions To Recover Value.

${ }^{43}$ See ch 7, s7.5 titled Summary and Conclusion.

${ }^{44}$ See ch 7, s7.4 titled Trusts.

${ }^{45}$ See ch 8, s8.5 titled Anti-Money Laundering, Terrorist Financing and Customer Due Diligence Laws and Regulations.

${ }^{46}$ See ch 8, s8.7 titled E-Commerce Laws and Regulations.

${ }^{47}$ See ch 8, s8.6 titled Telecommunications Laws and Regulations.

${ }^{48}$ See ch 8, s8.8 titled Consumer Protection-type Laws.

${ }^{49}$ See ch 8, s8.2 titled Philosophies behind Regulation.

${ }^{50}$ See ch 8 , s8.9 titled Conclusions.

${ }^{51}$ See ch 12, s12.12 titled South Africa: General Summary and Conclusion.

${ }_{53}^{52}$ See ch 9, s9.5.4 titled Banking Laws and Regulation in the EU.

${ }^{53}$ See ch 9, s9.6 titled Payment Systems and Governance.

${ }_{55}^{54}$ See ch 9, s9.10 titled Anti-Money Laundering, Terrorist Financing and Customer Due Diligence Laws and Regulations.

${ }_{55}^{5}$ See ch 9, s9.11 titled Telecommunications Laws and Regulations.

${ }^{56}$ See ch 9, s9.12 titled E-Commerce And Associated Laws.

${ }_{58}^{57}$ See ch 9, s9.13 titled Consumer Protection-Type and Regulations.

${ }^{58}$ See ch 9, s9.6.3 titled E-Money, Stored Value Laws and Regulations.

${ }^{59}$ See ch 9, s9.14 titled The EU and MFS: Conclusion.

${ }^{60}$ Directive 2000/46/EC on the Taking up, Pursuit of and Prudential Supervision of the Business of Electronic Money Institutions; and later Directive 2009/110/EC On The Taking Up, Pursuit And Prudential Supervision Of The Business Of Electronic Money Institutions. See a discussion thereof in ch 9, s9.6.3 titled E-money, Stored Value Laws and Regulations.

${ }^{61}$ Directive 2007/64/EC on Payment Services in the Internal Market. See ch 9, s9.6.2 titled Payment Services Directive.
} 
Chapter 10 looks at the potential applicability to MFS in Kenya in relation to banking, ${ }^{62}$ payments, ${ }^{63}$ AML, ${ }^{64}$ telecommunications, ${ }^{65}$ e-commerce, ${ }^{66}$ consumer protection ${ }^{67}$ laws and regulations. Chapter 10 concludes ${ }^{68}$ with the observation that the seminal and laudable policy goals of FI employed by prudential regulators in Kenya have been the basis for the huge success of the M-pesa MFS system. The successful use of trust accounts to house pooled funds of M-pesa in Kenya is similarly suggested as a prudential safety and soundness mechanism to facilitate non-bank core participation in MFS activities in SA.

Chapter 11 looks at the potential applicability to MFS in the USA at state and federal level in relation to banking, ${ }^{69}$ payments, ${ }^{70}$ AML,${ }^{71}$ telecommunications, ${ }^{72}$ e-commerce, ${ }^{73}$ consumer protection, ${ }^{74}$ and SVP or emoney-type ${ }^{75}$ laws and regulations. Chapter 11 concludes $^{76}$ that the payment instrument-based approach to regulation in the US is unsuitable in the midst of emerging payment methodologies like MFS, although the dedicated, emerging federal Consumer Financial Protection Bureau (hereafter CFPB) with its ability to adjudicate on consumer payment matters and its rule-making ability provides a good model for consumer protection of retail payments. Concurrent jurisdiction by multiple regulators and laws over MFS may create undesirable regulatory arbitrage.

Chapter 12 looks at in relation to banking, ${ }^{77}$ payments, ${ }^{78}$ AML,${ }^{79}$ telecommunications, ${ }^{80}$ e-commerce,${ }^{81}$ consumer protection, ${ }^{82}$ and SVP or e-money-type ${ }^{83}$ laws and regulations, the potential applicability to MFS in SA along with a brief comparative overview of each sector to the EU, the USA and Kenya. Chapter 12 concludes $^{84}$ with indications that there is a need for a robust, dedicated and enabling payments law to allow non-banks to accept funds for primarily transactional purposes without being subject to the full bore of banking regulation. Consumer protection of payment services, falling under the remit of a proposed new PSPL would license non-bank MFS entities acting as PSPs whose primary focus would be transactional payments and not intermediation. A new regulator for payment services, a PSRA, is proposed. Trust company vehicles could be used to safeguard funds where non-banks are involved. Some measure of

\footnotetext{
${ }^{62}$ See ch 10, s10.2 titled Prudential and Financial Services.

${ }^{63}$ See ch 10, s10.2.5 titled Payment Systems and Governance.

${ }^{64}$ See ch 10, s10.3 titled Anti-Money Laundering, Terrorist Financing and Customer Due Diligence Laws and Regulations.

${ }^{65}$ See ch 10, s10.4 titled Telecommunications-related Laws and Regulations.

${ }^{66}$ See ch 10, s10.5 titled E-Commerce.

${ }^{67}$ See ch 10, s10.6 titled Consumer Protection.

${ }^{68}$ See ch 10, s10.7 titled Kenya and MFS: Conclusions.

${ }^{69}$ See ch 11, s11.2.3 titled Banking Laws and Regulations.

${ }^{70}$ See ch 11, s11.2.4 titled Payment Systems and Governing Frameworks.

${ }^{71}$ See ch 11, s11.3 titled Anti-Money Laundering, Terrorist Financing and Customer Due Diligence Laws and Regulations.

${ }^{72}$ See ch 11, s11.4 titled Telecommunications-related Laws and Regulations.

${ }^{73}$ See ch 11, s11.5 titled E-Commerce Laws and Regulations.

${ }^{74}$ See ch 11, s11.6 titled Consumer Protection.

${ }^{75}$ See ch 11, s11.2.5 titled E-Money and SVPs.

${ }^{76}$ See ch 11, s11.7 USA and MFS: Summary and Conclusion.

${ }^{77}$ See ch 12, s12.3.5 titled Banking Laws and Regulations in South Africa.

${ }^{78}$ See ch 12, s12.3.7 titled Payment Systems and Governing Frameworks.

${ }^{79}$ See ch 12, s12.7 titled Anti-Money Laundering, Terrorist Financing and Customer Due Diligence Laws and Regulations.

${ }^{80}$ See ch 12, s12.8 titled Telecommunications-related Laws and Regulations.

${ }^{81}$ See ch 12, s12.9 titled E-Commerce Laws.

${ }^{82}$ See ch 12, s12.10 titled Consumer Protection Laws.

${ }^{83}$ See ch 12, s12.4 titled E-Money And Stored Value.

${ }^{84}$ See ch 12, s12.12 titled South Africa: General Summary and Conclusions
} 
regulatory arbitrage is also found in relation to the combined working of telecommunications, e-commerce and consumer protection laws, and revisions are suggested in their application to MFS.

Chapter 13 assimilates the technical, commercial and legal information and analysis on MFS in preceding chapters and asks whether the SOVs used in the various MFS incarnations amounts to 'money.' It then reevaluates $^{85}$ the qualitative and legal nature of money based on an equilibration analysis with the locus classicus on money, Moss v Hancock. ${ }^{86}$ Chapter 13 concludes $^{87}$ that the Claim School view of money is better suited to, and should be adopted by, the legal system in relation to a more modern legal assessment of money, particularly in relation to intangible forms of payment and SOVs, such as those used in MFS. Applying legal precepts of money to new non-fiat SVP and MFS systems indicates that in many cases they may not (legally) amount to money. ${ }^{88}$

Chapter 14 is a comparative summary of the thesis, and also then makes recommendations relating to:

- The legal basis of money,

- The nature and scope of the 'business of banking',

- The use of deposits as a pivot in determining whether an entity is engaged in the "business of banking',

- The regulation of non-banks,

- The need for a dedicated payment services law that provides consumer protection measures for payments,

- Licensing of non-bank MFSPs to provide specialised payment services,

- A need for a dedicated payment services regulatory agency, and

- The impact of some SOVs used in MFS on AML measures and the South African Electronic Communications and Transactions Act.

B.

\section{Research Scope}

1.3

\section{Research Methodology and Sources}

A large proportion of the research for this study is based on literature reviews, analysis of commercial models, analysis of laws, regulations and similar instruments, attendance and participation at MFS and similar conferences around the world, interviews and interactions with major commercial participants and practitioners in MFS globally, interactions with security experts, interviews with financial, AML, central bank, consumer protection, telecommunications and e-commerce sector regulators and practitioners in all

\footnotetext{
${ }^{85}$ See ch 13, s13.7 titled Analysis and Application to MFS.

${ }^{86}$ Moss $v$ Hancock (1899) 2 QB 111

${ }^{87}$ See ch 13, s13.9 titled Summary and Conclusions.

${ }^{88}$ Exhibit $\mathrm{A}$ in ch 13, s13.9 shows the putative taxonomical relationships between debt and money.
} 
countries analysed in this study, and analysis and information provided to the author by these sector regulators. ${ }^{89}$

The author has also tested a number of MFS products from a user-perspective in the countries covered in this study. As such, many of the insights in this study are as a result of an in situ process of investigation and testing of commercial and evolving MFS products and services.

\section{4 \\ Comparative Jurisdictions}

This analysis of MFS is predicated on an interpretation of the existing laws, regulations, competition issues, and general regulatory philosophies in SA that could have general or specific applicability to MFS, compared with those in the EU, the USA and Kenya.

The jurisdictions under review were chosen to reflect a mix of developing and developed world economies.

1.5

Periods Covered

Case law, legislation and legal writings for the following countries were considered as at:

$\begin{array}{lll}\text { - } & \text { EU }^{90} & \text { Up to November } 302011 \\ \text { - } & \text { Kenya }^{91} & \text { Up to November } 302011 \\ \text { - } & \text { USA }^{92} & \text { Up to November } 302011 \\ \text { - } & \text { SA }^{93} & \text { Up to February 29 2012 }\end{array}$

1.6

Terminology

As the subject matter of this study is evolving, there is no consistently used term to describe financial transactions and activities using a mobile phone. As noted above, the process is commercially variously known as MFS $^{94}$, but may also be known as mobile commerce (m-commerce), mobile payments (mpayments), or mobile banking (m-banking). Therefore, the term 'MFS' was selected as the term most descriptive of all the models used and, indeed, it appears to have become the preferred commercial appellation for the process. Thus MFS will be used as the primary term throughout the study, with the

\footnotetext{
${ }^{89}$ The author is also the founder of the Wireless Application Service Providers' Association (WASPA) that oversees micropayments used for mobile VAS, discussed in the thesis in relation to mobile VAS and its self-regulation in South Africa. See the official site of WASPA at www.waspa.org.za. Some key lessons from his participation in this body have also been included in this thesis. See further ch 6, s6.5.4.2 on WASP VAS.

${ }^{90}$ See ch 9 on the EU and MFS.

${ }^{91}$ See ch 10 on Kenya and MFS.

${ }^{92}$ See ch 11 on the USA and MFS.

${ }^{93}$ See ch 12 on SA and MFS.

${ }^{94}$ See ch 2, s2.1 on an introduction to MFS.
} 
other terms noted as specific incarnations or usage variations. Where the mobile phone and the MNO or MFSP become the primary means of transacting in a country, this is termed 'transformational'. When a licensed bank uses the mobile phone to allow its existing depositors remote access to their accounts and for payments, this is termed 'additive'. ${ }^{95}$ In many cases, the MNOs and MFSPs provide much the same services but in different guises, but usually share the same or similar regulatory impacts and operating environments. As such, the terms MNOs and MFSPs are used interchangeably, but where MFS in a MNO context is discussed, the term MNO is then specifically used.

As noted above, the source of funds for payments in both cases may be termed an electronic 'purse', or 'wallet' 'SVA' or even a 'SOV', although these may be incarnations of the more descriptive term which is used throughout the study, namely, the prefunded 'SVPs'. ${ }^{96}$

The terminology surrounding the interaction and relationships between the family of SVPs and its components, it must be noted, is non-standard in literature and in commercial application.

In the context of this MFS-based study however, the following hierarchy and terminology is followed: the family of prefunded MFS SVPs have genera of SVAs ${ }^{97}$ operated by an MNO that can be used to pay for calls and other services. These SVAs may be said to be 'online ${ }^{98}$ in that they are usually constantly in contact with the MNO over the MNOs network: a mobile phone may be said to 'access' an online SVA. There may be multiple types of SVAs offered, each containing a particular type of SOV, and where each SOV may be denominated in particular Unit of Account (hereafter UOA).

For example, there may be the MNO's (private) 'mobile airtime'-based UOA ${ }^{99}$ denominated in values such as mobile airtime minutes. The term 'airtime' reflects a common commercial usage to describe the SOV available in a MNO-operated SVA for a user to pay for use of an MNO's services. Thus where there is an airtime component to a SOV, SVA or SVP, this is referred to as an 'airtime-based' SOV, SVA or SVP, depending on context. There may also be a SVA with a SOV denominated in a UOA relating to national (fiat) currencies such as the SA Rand (ZAR) or Euro $(€)$. Thus where the SVP is based on a redeemable value using a specific national currency issued by a state via a fiat ${ }^{100}$ or decree, this is referred to as a 'fiatbased' SOV, SVA or SVP, depending on context. ${ }^{101}$

\footnotetext{
${ }^{95}$ See ch 2, s2.1 titled Introduction.

${ }^{96}$ This is shown in Exhibit A in this section. For stored value and component nomenclature usage and the interaction between them, see ch 4, s4.8.4.4.2.

${ }^{97}$ See ch 4, s4.8.4.4 titled Stored Value Products. 'Prefunded' may also mean 'prepaid,' the latter being of commercial and popular use. The terms are used interchangeably throughout this study, depending on the context. They both simply mean that users can only use a SVA for transactions if they have placed value in them. No credit ('overdrafts') is given. Another genus of SVP may be the Stored Value Card (hereafter SVC) where value may be stored locally and 'offline' only. See ch 4, s4.8.4.4.3.1 titled Local 'Offline' Storage of Value.

${ }^{98}$ See ch 4, s4.8.4.4.3.2 titled 'Online' Storage of Value.

${ }^{99}$ See ch 3, s3.2.3.4 on an overview of UOAs.

${ }^{100}$ See 'Fiat' (2011) Merriam-Webster, available at http://goo.gl//32Nd.

${ }^{101}$ Fiat is the order of the state. See further on fiats, ch 3, s3.5.1 titled Overview.
} 
In some commercial and popular descriptor of MFS, a fiat-based or airtime-based SOV is said to be 'mobile money' (hereafter m-money). ${ }^{102}$ Mobile money, and its non-mobile (usually fiat) analogue, 'emoney', are then said to be species of SVPs. ${ }^{103}$

In so far as a SVP and the value stored within a SVA as a SOV may amount to 'money', this is analysed according to the various legal and economic components of money. In this regard, there is what is termed in aggregate as the 'Orthodox School' economic view of money noted above which refers to money as being a UOA, SOV, and Means of Exchange (hereafter MOE). There is the more recent and 'Claim School' economic view of money which refers to money as being a UOA, SOV, and a Means of Payment (hereafter MOP).

Since much of the focus of the study revolves around mobile and associated technologies and their integration into the financial arena, it is necessary to outline the relevant mobile and related technologies, payment instruments and payment systems and their extensive roles in enabling MFS. Chapter $5^{104}$ is therefore dedicated to the technologies involved and their roles in MFS, and the Table of Abbreviations provides a valuable guide for the numerous and necessary technical acronyms when reading the study.

Where an abbreviation could have different meanings depending on the jurisdiction, context or application, this has been noted.

The financial focus of the study utilises the conventional terminology used in payments and banking law and commercial operations, although where a deviation is needed owing to the use of evolving technologies, this is fully explained in the particular context in which it is used.

\section{7}

\section{Reference Style}

Many of the sources used in the literature review were drawn from sources publically available on websites and from the subscription databases of the University of South Africa (Unisa) Library available to registered students.

A trend among authors has been noted. They periodically update the scholarly papers they make freely available on the Internet, while at the same time retaining the paper's initial date of publication. Owing to the additions made by this updating process, the pagination of papers will correspond to the original version and may differ slightly from updated version(s), or the paper may have no page numbers at all.

\footnotetext{
${ }^{102}$ As discussed in ch 3 and ch 13, the word 'money' has legal and economic connotations and as such 'm-money' is not used liberally in this study and is used only for context.

${ }^{103}$ The hierarchy then is SVP (family); then SVA (Genus); and E/M-money (species). As indicated in Exhibit A in ch 13, s13.9, the family SVPs may be part of the order 'Payment,' and in turn part of the class 'Debt'.

${ }^{104}$ See ch 5 on mobile technologies.
} 
The links provided to such papers used in the study reflect the version downloaded by this author at the time, and therefore may differ slightly from the current version if that paper has been updated after the submission of this study.

As many of these links to online documents contain excessively long Internet addresses, and in the interests of clarity and brevity in the footnotes, this study uses the persistent Internet website link-truncating service offered by Google Inc. ${ }^{105}$ which shortens any extended website link to no more than 15 characters using a standard 'http://goo.gl'’ prefix.

When typing in or clicking on this Google-created link, Google's service will automatically redirect the user to the expanded, original link. The original, complete web link may be discovered by readers typing the truncated link into the following Google website: http://www.goo.gl. All links used in this thesis were tested and accessed during September 2012 to November 2012.

The study generally abides by the citation style used in the SA Mercantile Law Journal. Exceptions to the style may include the use of italics for foreign words and expressions, and the use of abbreviations in the text.

Words used in the singular may also mean the plural, and vice versa.

Words in the masculine also indicate the feminine.

C.

\section{Problem Statements}

Overview

The nature of MFS means that a number of seemingly disparate doctrinal disciplines may be involved. The problem statements thereto as identified in this study are described below.

\subsubsection{MFS and Money}

Discussions around 'money' track centuries-old and seemingly perennial doctrinal debates and divisions within the disciplines of economics, sociology, anthropology and law. 'Money' in law follows both a common law view and an Aristotelian-derived Orthodox economic view, or theory, of 'money' based on an assumption that some tangible thing acts as the reason a 'money' may be seen to be valuable to others.

Chapters 3 and 13 discuss whether the Orthodox view is still an appropriate descriptor of 'money' in law in the face of non-tangible, dematerialised forms of value that may amount to money, and if and how this may

\footnotetext{
${ }^{105}$ See www.google.com.
} 
impact statutes and regulations sounding in 'money' - particularly those that relate to AML and the money nature of deposits.

The use of the airtime-based SOV in particular frames the Problem Statement as to:

\section{Problem Statement 1}

Whether the MNO airtime-based SOV, fiat and other private currencies used in closed-loop MFS systems legally amount to 'money'? 106

\subsection{2}

\section{MFS and the Nature of Banking and Deposits}

The role of Micro Finance Institutions (hereafter MFIs), MFSPs, and MNOs in providing transactionalfocused MFS is trumpeted commercially as 'transformational banking', and it is there to provide 'banking' services where banks have been unable or unwilling to provide many of these services. In all, the fluid nature of banking; new forms of storing values that could potentially be seen as a 'deposit-taking'; the introduction of new non-bank entities engaged in MFS with their focus on taking user funds not for intermediation purposes but primarily and narrowly for transaction purposes all speak to the broader issue, and frames two problem statements:

Problem Statement 2:

\section{Problem Statement 2}

What is the nature of a deposit, and how does this impact on determining if those engaged in MFS are 'deposit-taking' entities? ${ }^{107}$

Problem Statement 3:

\section{Problem Statement 3}

Is the nature of the 'business of banking' and its traditional trigger by a 'deposit' challenged through the emergence of MFS $?^{108}$

\footnotetext{
${ }^{106}$ For findings thereto, see ch 3, s3.13 Summary and Conclusions; and ch 13, s13.9 Summary and Conclusions, ch 14, 14.5.4.7 on Reassessment of Money in Law; and specifically ch 14, s14.5.4.7.1 on Use of the Claim School. See also a Recommendation thereto in ch 14, s14.5.4.7 on Reassessment of Money in Law; and ch 14, s14.9.1 on Recommendation: Money in Law (Recommendation 1).

${ }^{107}$ For findings and Recommendations thereto, see ch 4, s4.8.6 on Summary and Conclusions; ch 14, s14.6.2 on the Nature of Banking; ch 14, s14.6.3 on the Role of the Deposit in Banking; and ch 14, s14.6.7 on Conclusion: Deposit; ch 14, s14.6.8 on Conclusions: Business of Banking; and ch 14, s14.9.2 on Recommendations: Nature of Banking and Deposits: (Recommendations 2 and 3).

${ }^{108}$ Ibid.
} 


\subsection{3}

Role and Effect of Payment Regulation

As noted above, a need for systemic reliability underlies the regulators' dilemma in promoting FI, for example, where mandatory implementation of international compliance standards may raise the cost threshold at which formal financial services can be viably offered to the poor. Further and similarly, applying the same financial regulatory regime(s) used for traditional banking activities - that is, intermediation - is also open to investigation. Some other regime to allow proportional regulation could be possible.

This leads to Problem Statement 4 as to:

\section{Problem Statement 4}

Whether existing general and statutory categorisations and licensing of entities involved in taking value from the public are appropriate, and if so, whether a new categorisation or licensing regime should be considered? ${ }^{109}$

\subsection{4} Nature of the Payment in MFS

The payment characteristics of MFS bring into focus the common law and prudential views of payments, particularly the need in South African law for a payment to be a 'bilateral juristic act'.

This leads to Problem Statement 5 as to:

\section{Problem Statement 5}

Whether the disembodied nature of MFS and its coincident transaction types challenge the notion in South African law of a payment needing to be 'bilateral'. ${ }^{110}$

\footnotetext{
109 For findings and Recommendations thereto, see ch 12, s12.12 on South Africa: Chapter General Summary and Conclusions; ch 14, s14.9.3 on Recommendations: Payment Providers (Recommendation 4); ch 14, s14.9.4 Recommendations: Use of Trust Accounts (Recommendation 5); and ch 14, s14.9.5 Recommendations: Access to NPS (Recommendation 6).

${ }^{110}$ For findings and Recommendations thereto, see ch 14, s14.7.9 on Conclusion: Payments; and ch 14, s14.7.8 on Recommendations: Payment in Law (Recommendation 9).
} 
While MFS fills a critical need for consumers and promotes FI, because much of the contracting is done at a distance, such services raise important issues of consumer disclosure, education, technical and financial literacy, and allocation of risk. Informational asymmetries between users of MFS, MNO, banks and MFSPs may place consumers at a disadvantage especially in incidents of mistake and fraud in transactions. Redress is potentially offered through Roman-Dutch condictiones in the macro-payment environment, while some redress is offered at the self-regulatory level. Redress though is not always available, accessible, obvious or even viable.

This leads to Problem Statement 6 as to:

\section{Problem Statement 6}

What rights and redress, if any, are available to retail users of MFS and retail payments generally, and are they adequate? ${ }^{111}$

1.8.6

Role and Effect of Additional Regulatory Oversight of MFS

Since in many cases there are not yet any specific laws that deal with MFS, analysis is predicated on an interpretation of existing laws and regulations that could have general or specific applicability to MFS, possibly however leading to regulatory arbitrage and over-burdensome regulation.

This leads to Problem Statement 7 as to:

\section{Problem Statement 7}

How do regulators militate against the 'dilemma' in promoting financial inclusion while protecting financial integrity in regard to MFS, and how does it manifest in regulatory domains relating to telecommunications, e-commerce, consumer protection and AML? ${ }^{112}$

\footnotetext{
${ }^{111}$ For findings and Recommendations thereto, see ch 7, s7.5 Conclusions; ch 12, s12.12 on South Africa: Chapter General Summary and Conclusions; ch 14, s14.7.12 on Conclusion: Payment Consumer Protection; ch 14, s14.9.6 Payments Law (Recommendation 7); and ch 14, s14.9.7 Payment Services Regulatory Authority (Recommendation 8).

${ }^{112}$ For findings and Recommendations thereto, see ch 8, s8.9 Conclusions; ch 14, s14.8.20 on Conclusion: The Regulator's Dilemma; ch 14, s14.9.6 Recommendation: Payments Law (Recommendation 7) and ch 14, s14.9.7 Recommendation: Payments Regulatory Authority (Recommendation 8). See ch 14, s14.9.9 on changes to the Electronic Commerce and Transactions Act 25 of 2002 (Recommendation 10).
} 


\section{CHAPTER 2}

\section{OVERVIEW OF MOBILE FINANCIAL SERVICES (MFS)}

\section{1}

Introduction

The ability to pay efficiently, reliably and securely is one of the hallmarks of the development of modern economies. Payment and settlement systems play an important role in improving the overall economic efficiency of developed and developing nations. Reducing the costs and the need to make a payment in currency or paper instruments, and instead use ubiquitous electronic channels, is one key to this efficiency.

Lack of access to financial services however can exaggerate the differences between people around the world, especially where a large proportion of poorer customers in developing nations are largely excluded from the ability to take advantage of seamless and efficient savings facilities and payment networks that are the hallmark of developed nations and many developing nations. ${ }^{1}$

The World Bank reports that in the decade running up to the global financial crisis of 2007-2009, the global economy was adding an estimated 150 million (hereafter $\mathrm{mn}$ ) new consumers of financial services each year and that most new consumers were from developing countries where consumer protection and financial literacy are still in their infancy. ${ }^{2}$

As Visser presciently pointed out in relation to payments generally:

'The banking industry has two options to alleviate these problems, namely to introduce technical modifications to the present system while retaining the basic problem established more than 300 years ago, or to introduce a direct-funds-transfer system using computer technology and having no relation to the present collection system or its legal framework. ${ }^{3}$

The broad process of attempting to bring the poor - described in sociological terms as being at the 'Bottom of the Pyramid' (hereafter BOP) ${ }^{4}$ - into the financial fold with products and facilities more suited to their

\footnotetext{
${ }^{1}$ N Ferguson (2008) The Ascent of Money: A Financial History of the World 16.

${ }^{2}$ See SL Rutledge (2010) 'Consumer Protection and Financial Literacy: Lessons from Nine Country Studies' 5, available at http://goo.gl/B0Inw.

${ }^{3}$ C Visser (1989) 'Evolution of Electronic Payment Systems' 1(2) SA Mercantile Law Journal 189, 194.

${ }^{4}$ The term 'Bottom of the Pyramid' or BOP was coined by management author, CK Prahalad, to describe the socio-economic grouping of the poor and underserved section of the market. See CK Prahalad (2006) The Fortune at the Bottom of the Pyramid. This phrase is used by developmental economists and by the World Bank, as well as entities developing new models of doing business targeted at this demographic. The theory among development economists is that providing increased consumption choices to the poor will increase their welfare. According to the World Bank, the BOP has two income poverty lines, that is, an absolute poverty line of people who live on US $\$ 1.00$ per day or less and who reside in the poorest countries of the world, and a second poverty line of people who live on US $\$ 2.00$ per day and who reside in lower to middle income countries. Some $4 \mathrm{bn}$ people, the majority of the world's population, constitute the BOP. Their incomes are less than US $\$ 3.35$ a day in Brazil, US\$2.11 in China, US\$1.89 in Ghana, and US\$1.56 in India. Nevertheless, combined, they have substantial
} 
socio-economic status is, as noted earlier, called 'Financial Inclusion' (hereafter FI), the essence of which is to ensure that a range of appropriate financial services are available to every individual and all those who need these services are made to understand and use what is available to them. FI is usually a composite value, though, and is expressed negatively as 'Financial Exclusion' (hereafter FE). ${ }^{5}$

purchasing power and the BOP constitutes US $\$ 5$ trillion (hereafter tn) of the global consumer market. The slightly wealthier mid-market population segment consists of $1.4 \mathrm{bn}$ people with per capita incomes of between US\$3,000 and US\$20,000, and represents US $\$ 12.5$ tn of the global market. According to the International Finance Corporation (hereafter IFC), this market is largely urban, already relatively well-served and extremely competitive. By contrast, the BOP markets are often rural especially in rapidly growing Asia - very poorly served, dominated by the informal economy, and, as a result, relatively inefficient and uncompetitive. Of the global BOP market, Asia makes up the biggest portion with a market worth US\$3.47tn, followed by Latin America (US\$509bn), Eastern Europe (US\$458bn) and Africa (US\$429bn). The BOP is by far Africa's dominant consumer market, with $71 \%$ of the purchasing power and it consists of $486 \mathrm{mn}$ people or $95 \%$ of the population. See also CGAP's definition of 'low-income' as being broader than the poverty line of US\$1.25 per day used by the World Bank, being the majority of consumers in developing countries who are economically active and may earn up to US\$10 per day. The 'mass market' in most developing countries is comprised of low-income, unbanked people who make up the majority of the population. See C McKay and M Pickens (2010a) 'Branchless Banking Pricing Analysis,' available at http://goo.gl/krLf1; C McKay and M Pickens (2010b) ‘Branchless Banking 2010: Who's Served? At What Price? What's Next?' CGAP Focus Note, available at http://goo.gl/d2bM5; International Finance Corporation (IFC) (2007) 'The Next 4 billion: Market Size and Business Strategy at the Base of the Pyramid', available at http://goo.gl/sqWhF; by 2015, the United Nations' Millennium Development Project aims to halve the number of people who live on less than US\$1.00 per day. See World Bank (2001) World Development Report 2000/2001: Attacking Poverty; and United Nations (UN) (2006) 'Millennium Development Project Report', available at http://goo.gl/hwTgq; A Karnani (2009) 'The Bottom of the Pyramid Strategy for Reducing Poverty: A Failed Promise' UN DESA Working Paper No 80, available at http://goo.gl/3iG5L; J Sachs (2005) The End of Poverty passim; R Kanbur (2004) 'Growth, Inequality and Poverty: Some Hard Questions', available at http://goo.gl/foReT.

${ }^{5}$ On aspects of FE and efforts generally to increase FI around the world, see A Saxena (2009) 'Accelerating Financial Inclusion through Innovative Channels: 10 Obstacles for MFIs Launching Alternative Channels - and What Can Be Done About Them' No 27 InSight, available at http://goo.gl/BwmHj; KPMG (2011) “"Underserved” Market Represents Opportunity for Banks,' available at http://goo.gl/FHzAj; OP Ardic, M Heimann and N Mylenko (2011) 'Access to Financial Services and the Financial Inclusion Agenda around the World: A Cross-Country Analysis with a New Data Set' The World Bank, Financial and Private Sector Development, Financial Access Team of the Consultative Group to Assist the Poor, Policy Research Working Paper No 5537, January, 1-55, available at http://goo.gl/8EZS3 ; T Beck, A Demirgüç-Kunt and A Levine (2007) 'Finance, Inequality, and the Poor' 12(1) Journal of Economic Growth 27-49, available at http://goo.gl/0Pkyi; T Beck, A Demirgüç-Kunt and MS Martinez Peria (2007) 'Reaching Out: Access to and Use of Banking Services Across Countries' 85(1) Journal of Financial Economics 234-266, available at http://goo.gl/5qSSd; T Beck, A Demirgüç-Kunt and MS Martinez Peria (2008) 'Banking Services for Everyone? Barriers to Bank Access and Use Around the World,' 22(3) World Bank Economic Review 397-430, available at http://goo.gl/OUSQD; J Coetzee (2009) 'Personal or remote interaction? Banking the unbanked in South Africa' South African Journal of Economic and Management Sciences NS 448-461; J Caskey, CR Duran and TM Solo (2006) 'The Urban Unbanked in Mexico and the United States' World Bank Policy Research Working Paper No 3835, available at http://goo.gl/e2yO9; S Claessens (2006) 'Access to Financial Services: A Review of the Issues and Public Policy Objectives' 21(2) The World Bank Research Observer 207-240, available at http://goo.gl/2UVq6; A Demirgüç-Kunt, T Beck and P Honohan (2008) 'Finance for All? Policies and Pitfalls in Expanding Access', available at http://goo.gl/4ILM5; G Dymski (2005) 'Banking Strategy and Financial Exclusion: Tracing the Pathways of Globalization' 31 Revista de Economia, 1-29, 107-143, available at http://goo.gl/PKb6i;Federal Deposit Insurance Corporation (FDIC) (2009c) 'FDIC National Survey of Unbanked and Underbanked Households December 2009', available at http://goo.gl/DRqn1; Federal Deposit Insurance Corporation (FDIC) (2010) 'FDIC Advisory Committee on Economic Inclusion: Strategic Plan', available at http://goo.gl/098kY; P Friedman (2005) 'Banking the Unbanked: Helping Low-Income Families Build Financial Assets', available at http://goo.gl/GymU1; D Glajchen (2011) 'A Comparative Analysis of Mobile Phone-Based Payment Services in the United States and South Africa' PhD Dissertation, Northcentral University (Prescott Valley, Arizona); A Hannig and S Jansen (2010) 'Financial Inclusion and Financial Stability: Current Policy Issues' ADBI Working Paper No 259, available at http://goo.gl/7U2k3; P Honohan (2008) 'Cross-Country Variation in Household Access to Financial Services' 32(11) Journal of Banking and Finance 2493-2500, available at http://goo.gl/E0BiF; J Kendall, N Mylenko and A Ponce (2010) 'Measuring Financial Access around the World' Policy Research Working Paper 5253, available at http://goo.gl/p9sf5; TR Lyman, M Pickens and D Porteous (2008) 'Regulating Transformational Branchless Banking: Mobile Phones and Other Technology to Increase Access to Finance' 43 CGAP Focus Note, January, available at http://goo.gl/0jU4b; I Mas (2008) 'Realizing the Potential of Branchless Banking: Challenges Ahead' 50 CGAP Focus Note, available at http://goo.gl/tsvOy; I Mas (2009b) 'The Utility of Retail Payments in Addressing the Financial Inclusion Gap in Developing Countries' 1 Lydian Payments Journal, available at http://goo.gl/QOK3L; I Mas (2010c) 'Savings for the Poor: Banking on Mobile Phones' 11(4) World Economics, available at http://goo.gl/cDFcs; AP Pati (2009) 'Enhancing Financial Inclusion: The Catalytic Role of Self Help Groups' The Management Accountant, available at http://goo.gl/mccjV; R Ramachandran (2010) 'BFSI: Best Practices in Financial Inclusion', available at http://goo.gl/DhGWU; K Ravichandran and K Alkhathlan (2009) 'Financial Inclusion: A Path towards India's Future Economic Growth', available at http://goo.gl/YyGJ5; P Sharma and B Mukhopadhyay (2009) 'Reaching a Billion People: The Electronic Payments Solution', available at http://goo.gl/sojbw; D Subbarao (2009) 'Retail Payments: Perspectives and Way Forward: Valedictory Address delivered at the Regional Seminar on Payment and Settlement Systems, India', available at http://goo.gl/Voc5a; J Leach and D Beghin (2004) 'The Access Propositions', available at http://goo.gl/2p0qQ; A Schoombee (2004) 'South African Banks and the Unbanked: Progress and Prospects', available at http://goo.gl/62kMk; D Porteous (2006a) 'The Enabling Environment for Mobile Banking in Africa', available at http://goo.gl/JDDRn; D Porteous 
It is clear that traditional banking methods using so-called 'brick ' $n$ mortar' facilities have not provided FI - that is, permanent access ${ }^{6}$ and usage ${ }^{7}$ of appropriate financial products and services ${ }^{8}$ - nor have those traditional methods been able to provide products and services in a cost-effective manner or successfully wean the population off the use of cash with its attendant inefficiencies and cost of acquisition. ${ }^{9}$

In South Africa, the level of FE reported in 2010 is around 24-26\%, a higher percentage to that of $2007 .{ }^{10}$ Reported barriers to FI include such structural problems as lack of jobs and financial illiteracy. ${ }^{11}$ Although some $60 \%$ of the adult population have a bank account of sorts, lack of access to these accounts increases the level of FE. Some $10.3 \mathrm{mn}$ or $53 \%$ of the people live in the rural areas and in many cases travel more than 20 kilometres (hereafter $\mathrm{km}$ ) to the nearest bank. ${ }^{12}$ In addition to the banked adults, $4 \%$ of the adult population is formally included ${ }^{13}$ and $10 \%$ of adults use informal products or services. ${ }^{14}$ The proportion of South Africans with savings products improved in 2010, with an increase of 35\% in 2010 versus $29 \%$ and $34 \%$ in 2008 and 2009 respectively. ${ }^{15}$ Even among the banked population, some $29 \%$ do not save or invest at all, indicating that in many cases, banking is mostly a transactional facility. ${ }^{16}$

(2008) 'Mobile Phone Banking: Is m-Banking Advancing Access to Basic Banking Services in South Africa?', available from http://goo.gl/4a1P2.

${ }^{6}$ Access refers to a composite of requirements describing the supply conditions of financial services, such as availability, affordability and appropriateness

${ }^{7}$ Usage refers to the actual consumption of such services and therefore the effective demand for the provision of financial services for all.

${ }^{8}$ This means that they do not use any financial products, formal or informal, to manage their financial lives. P Ndzamela (2010b) 'More South Africans are Using Financial Products', Finmark Trust, News and Media Releases, New Publications, posted on Moneyweb, available at http://goo.gl/sArpi. The survey showed that $76.5 \%$ of South African adults were financially included in 2010 versus $73.9 \%$ and $76.4 \%$ in 2009 and 2008 respectively. The survey said that, in 2010, 24\% of South African adults opted to save through formal savings products versus $21 \%$ in 2009 . Some $18 \%$ used the informal sector compared to $10.5 \%$. In 2009, while $7 \%$ of South African adults saved at home compared to $13 \%$ in 2009 , some $31 \%$ of adults received money from friends and family as a source of income, while $24 \%$ of South African adults are either sending or receiving money to/from family members, parents and children and nearly two thirds of individuals who remit do so through bank accounts. This illustrates that individuals who have access to banks remit and these are individuals in the LSM 6-10, employed with a basic income of between ZAR2,000 and ZAR8,000+. See Finmark Trust (2010) 'FinScope South Africa 2010', available at http://goo.gl/nI7V3.

${ }^{9}$ See also Banda and Mdwazika who note that while the supply side of the cash payment system incurs financial costs, the demand side, namely the general public, uses notes and coins at zero cost. This feature, they say, makes cash the most preferred payment instrument as opposed to account-based payment instruments whose usage is associated with transaction or ledger fees. Further, they believe cash is preferred because of its immediacy of payment, anonymity of transactions and acceptability across the economy by virtue of being a claim over the central bank and the confidence people have in cash due to its long historical usage. See LN Banda and FH Mdwazika (2007) 'Cash and Retail Payment Systems in Developing Countries: Opportunities and Challenges: The Case of Malawi' 2, available at http://goo.gl/jwAeu.

${ }^{10}$ Republic of South Africa, National Treasury (2010) 'Vision for Financial Inclusion', available at http://goo.gl/NgKrw.

${ }^{11}$ For the impact of the lack of financial literacy generally, see A Lusardi and P Tufano (2008) 'Debt Literacy, Financial Experiences and Overindebtedness' NBER Working Paper No 14808, available at http://goo.gl/NTaEF; M Miller et al (2009) 'The Case for Financial Literacy in Developing Countries: Promoting Access to Finance by Empowering Consumers', available at http://goo.gl/nNGLJ; United States, Government Accountability Office (US GAO) (2005) 'Credit Reporting Literacy: Consumers Understood the Basics but Could Benefit from Targeted Educational Efforts', available at http://goo.gl/sSYZq; US GAO (2006) 'Credit Cards: Increased Complexity in Rates and Fees Heightens Need for More Effective Disclosures to Consumers' GAO-06-929, available at http://goo.gl/9AVPe; US GAO (2010) 'Consumer Finance: Factors Affecting the Financial Literacy of Individuals with Limited English Proficiency' GAO-10-518, available at http://goo.gl/90Wzk; T Wilson, N Howell and G Sheehan (2009) 'Protecting the Most Vulnerable in Consumer Credit Transactions' 32(2) Journal of Consumer Policy 117-140, available at http://goo.gl/rXoPj.

${ }^{12}$ Finmark Trust (2005) 'FinScope 2005: A Comprehensive Nationwide Survey of Financial Usage in South Africa', available at http://goo.gl/tEycm.

${ }^{13}$ Meaning that they are in possession of any other formally provided financial service.

${ }^{14}$ This indicates the appetite for financial services, but the inappropriate nature of formal provision.

${ }^{15}$ Most, however, hold their money in a safe place at home and borrow from friends.

${ }^{16}$ Finmark Trust (2007) 'South Africans Shun the Piggy-Bank', available at http://goo.gl/2smnV. 
Given the historically skewed distribution of resources within both the economy and financial sector, the South African National Treasury has noted that the importance of FI to South Africa is clear. It believes though that the well-developed financial sector has produced insufficient social outcomes though and needs to be modified to take into account equity and welfare concerns. ${ }^{17}$

Developing cashless payment systems has been a perennial issue, even in developed nations. The original stimuli for cashless payments were the risks and inconvenience to the public of storing and transporting money. ${ }^{18}$ There have been huge technological advances that partly address these concerns by permitting, inter alia, the ability to withdraw and deposit funds at Automated Teller Machines (hereafter ATMs), and the use non-cash payment instruments and non-bank Point of Sale (hereafter POS) terminals.

The current evolutionary cycle in financial access products includes what are termed Stored Value Products (hereafter SVPs), ${ }^{19}$ which are devices or systems where a value may be electronically stored as an electronic Store of Value (hereafter SOV) either 'offline' locally on some type of electronic chip-based or magnetic-stripe card or Stored Value Card (hereafter SVC) ${ }^{20}$ or device, or 'online' on a centralised system $^{21}$ where account balances and/or a record of all transactions are kept in a Stored Value Account (hereafter SVA). ${ }^{22}$ The SVPs are mostly prepaid (prefunded), meaning that users must first have or provide funds upfront before they can transact. ${ }^{23}$

There are a plethora of SVP types that all contribute to the decline of plastic or paper at the POS. They may be differentiated by whether they are vertically integrated, serving a specific niche with a closed or 'walledgarden' limitation of products and merchants with or without its own private 'currency' issued by the

\footnotetext{
${ }^{17}$ RSA, National Treasury (2010) op cit note 10. See also the results of the Competition Commission enquiry into banking in South Africa detailed in ch 12, s12.5.

${ }^{18}$ IFG Baxter (1974) 'Simple Payment of Money' 24(1) University of Toronto Law Journal 63-95 at 63.

${ }^{19}$ See ch 4, s4.8.4.4 on Stored Value Products.

${ }^{20}$ A SVC is a type of Stored Value Product. See ch 4, s4.8.4.4.3.1 titled Local 'Offline' Storage of Value.

${ }^{21}$ This may then be known as 'electronic money' (hereafter e-money) or when operated by MNOs or MFSPs, as 'mobile money' (hereafter m-money). See the discussion further below in ch 4, s4.8.4.4.2 on SVP nomenclature.

${ }^{22}$ See ch 4, s4.8.4.4.3.2 titled 'Online' Storage of Value. The value, which may be denominated in the country's currency also called the Generally Accepted Means of Exchange (hereafter GAME), or it may be in some other denomination such as mobile airtime minutes - may be spent in a closed system or be generally accepted. See inter alia ch 3, s3.5.3.3.1 on the GAME

${ }^{23}$ See ch 4, s4.8.3.4 titled Pre-payment and Post-payment Forms. Generally, the term 'prepaid card' means different things in different markets. In less developed markets and markets where prepaid mobile users are predominant, it may refer to airtime recharge vouchers, whilst in more developed markets with ubiquitous ATM and POS systems, they may refer to gift cards issued by both retailers and banks, wages or payroll cards, government benefits cards as well as loyalty and incentive cards. In the prepaid card environment, overall growth across key markets worldwide is driven by consumer-oriented applications such as the gift cards and general-purpose cards for the underserved banking population, as well as governments embracing these products to provide payment for social services and benefits. In all, prepaid cards are designed to fulfill the same purposes as bank accounts such that, in countries where they are available, consumers can directly deposit their pay cheques, government payments or other recurring income onto a virtual card account, set up bill payments through the card, and even draw cheques against card funds. See M Jun (2009) 'Prepaid Cards: Second-Tier Bank Account Substitutes: Consumers Union Report', available at http://goo.gl/7fh3V . In the US alone, there were 5 bn prepaid card transactions in 2008, up from 2.5bn transactions in 2003. In 2008, US\$60.42bn was loaded on general-purpose cards, up 54.3\% from US\$39.16bn in 2007. On the general increased use of prepaid cards, see American Association of Retired Persons (AARP) Public Policy Institute (2010) 'Prepaid Cards: Promise and Pitfalls for Consumers', available at http://goo.gl/fMm1g; Center for Financial Services Innovation (2009) 'A Tool for Getting By or Getting Ahead? Consumers' Views on Prepaid Cards', available at http://goo.gl/fCDLz; Federal Deposit Insurance Corporation (FDIC) (2009b) 'National Survey of Unbanked and Underbanked Households December 2009', available at http://goo.gl/m0Kq6; MJ Furletti (2004a) 'Prepaid Card Markets and Regulation' Federal Reserve Bank of Philadelphia Payment Cards Center Discussion Paper 04-01, available at http://goo.gl/3eGbi. See further ch 4, s4.8.4.4.4 titled Open and Closed SVPs.
} 
system operator (hereafter SO), ${ }^{24}$ or horizontal in that they have ubiquitous use and acceptance in an open system where all merchants may participate. ${ }^{25}$ Where the SVA is prefunded by use of the fiat national currency as a SOV and the SOV is denominated in the Unit of Account (hereafter UOA ${ }^{26}$ of the fiat currency, then the SOV stored in the SVA is referred to as fiat-based. It is usually also redeemable at par on demand.

Their differences also relate to the process to add value as a SOV, the feature sets of the system, and the technical and operational requirements to support the system. ${ }^{27}$

Governments have also attempted to kick-start $\mathrm{FI},{ }^{28}$ providing innovations like low cost banking products, the use of so-called 'agents, ${ }^{29}$ simplification of Know Your Customer (hereafter KYC) ${ }^{30}$ procedures for low value, low risk accounts and promoting the use of card-based government payouts. ${ }^{31}$

Ultimately, the effect of the recent evolution in payments has been to leverage the ubiquity of the mobile phone as a SVP. The relatively low cost of an entry-level mobile phone to under US\$20, and the use of prepaid funding to pay for calls, was the inspiration for a new model for the development of alternate and lower-cost banking-like and payment infrastructures that serve economic groups known as the 'unbanked,' 'underserved' and 'underbanked. ${ }^{32}$ In this sense, this presages the emergence of the 'branchless banking' paradigm, where the financial and banking needs of those at the BOP are served not by a bricks and mortar bank branch, but by an electronic replacement, or an electronic-human combination using agents who provide what are known as 'cash in/cash-out' facilities. ${ }^{33}$

\footnotetext{
${ }^{24}$ An example of a private currency would be the airtime-based SOV issued and operated by a Mobile Network Operator (MNO). On private currencies, see ch 4, s4.8.4.4.4.1.

${ }^{25}$ See ch 4, ss4.8.3.7 titled Ubiquity of Use; and 4.8.4.4.4.4 titled Open and Closed SVPs

${ }^{26}$ See ch 3, s3.2.3.4 on an overview of UOAs.

${ }^{27}$ See generally on prepaid systems, JS Cheney (2005) 'Prepaid Card Models: A Study in Diversity' (2005) Federal Reserve Bank of Philadelphia Payment Cards Center Discussion Paper No 05-03, available at http://goo.gl/sJQMS.

${ }^{28}$ See ch 12, s12.1 on the Mzansi low-cost banking product introduced with modest success in to South Africa by local banks. CGAP report that FI policies like offering basic accounts, transferring government payments to individual accounts, and encouraging saving through matched and tax-advantaged savings accounts are concentrated in high-income countries and are far from widespread. In developing countries, they are usually only successful if participating financial institutions see them as a viable business proposition and if they address a binding constraint, be it cost or distance. See CGAP (2009a) 'Financial Access 2009: Measuring Access to Financial Services around the World' 2, available at http://goo.gl/fuBBy.

${ }^{29}$ See ch 2, s2.5.2 below on Agents in MFS, and ch 6 below on the various MFS business models and the role of agents in each model. See Glajchen (2011) op cit note 5 at 27-29.

${ }^{30}$ See ch 8, s8.5 below on AML and KYC procedures. In particular, see the discussion in ch 12, s12.7 of the South African Reserve Bank's (hereafter SARB) so-called 'Exemption 17' which lowered the usually strict identification criteria for users of low-value accounts.

${ }^{31}$ This is largely the situation in South Africa. In India, the government encourages the use of biometric-based ATMs in rural areas to cater to illiterate customers and has removed usage fees on ATMs for use of other Bank ATMs. They have not, however, fully embraced the concept of non-banks providing bank-like services. See R Ramachandran (2010) 'BFSI: Best Practices in Financial Inclusion', available at http://goo.gl/DhGWU.

${ }^{32}$ See ch 2, s2.2 for discussion of the terms 'unbanked,' 'underserved' and 'underbanked.' The 'unbanked' may in some cases also be known as 'underserved.'

${ }^{33}$ CGAP define 'branchless banking' as the delivery of financial services outside conventional bank branches using information and communications technologies and non-bank retail agents, for example, over card-based networks or with mobile phones. McKay and Pickens (2010a) op cit note 4. See also Philippine Institute for Development Studies (2009) 'Transformational Branchless Banking: Blazing New Trails in Delivering Financial Services' 9(1) Economic Issue of the Day, available at http://goo.gl/oxU76. For examples of these facilities, see Annex 1: MFS Commercial Examples, and Exhibits H-J. Exhibit $\mathbf{J}$ in particular shows an example of Wizzit agents - 'Wizzkids' - providing outdoor 'branchless banking' services in a South African township. For details on the Wizzit MFS system operating in South Africa, see ch 12, s12.2.7.
} 
The entire ecosystem that allows basic banking functionality to be provided by non-bank entities such as Mobile Network Operators (hereafter MNOs), the transforming of fiat cash into an electronic SOV, the payment of bills by mobile phone, transferring and receiving money to and from other account holders as a remittance, all without ever setting foot in a bank or bank-like institution, is known as Mobile Financial Services (hereafter MFS).

MFS uses as its inspiration the popular and ubiquitous use of prefunded SOVs housed in SVAs ${ }^{34}$ operated by the MNOs using the MNO's mobile airtime 'currency, ${ }^{35}$ as a SOV to pay for calls and other similar services. The MFS SVAs have SOVs denominated in a MNO's (private) mobile airtime-based UOA as well as in a UOA relating to national, fiat-based ${ }^{36}$ currencies such as the Rand or Euro, and may be said to be genera of the family of prefunded electronic SVPs. ${ }^{37}$

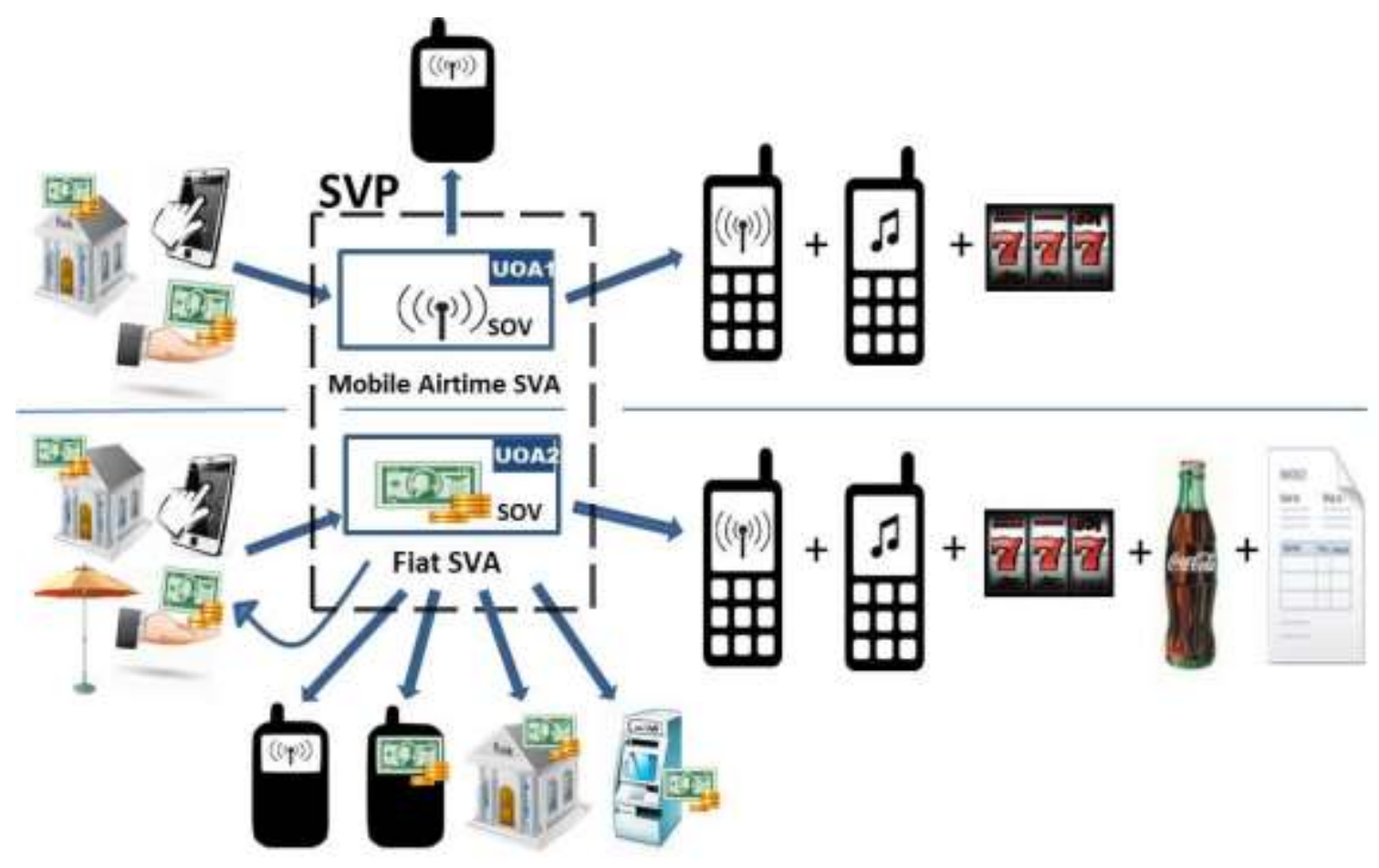

Exhibit A: Stylised structure and transaction flows of a dual-SVA SVP, operated by an MNO doing MFS.

\footnotetext{
${ }^{34}$ See ch 4, s4.8.4.4 on Stored Value Products. Prefunded may also mean 'prepaid,' the latter being of commercial and popular use. The terms are used interchangeably throughout this study, depending on the context. They both simply mean that users can only use a SVA for transactions if they have placed value in them. No credit (overdrafts) is given.

${ }_{35}$ Airtime is the value or 'currency' used by MNOs to allow access to their telecommunication facilities. Users will usually prefund (prepay) their airtime SOV by purchasing an 'airtime voucher' or similarly by using some value or denomination in fiat currency. They may also receive the value via an airtime remittance from another user. The equivalent airtime value is then added electronically for later use by that user. See ch 5, ss 5.2.2 titled User Access to Mobile Networks that discusses SIM cards and prepaid mobile airtime values; and 5.4 on Mobile Network Operator (MNO) Billing Systems;

${ }^{36}$ Fiat is the order of the state. A fiat currency is the national currency issued by a state in a particular jurisdiction, for example, the South African Rand (hereafter ZAR). See 'Fiat' (2011) Merriam-Webster, available at http://goo.gl/I32Nd. On fiat currencies, see ch 3, s3.5 titled Role of the State and Central Bank in Money.

${ }^{37}$ For stored value and component nomenclature usage and the interaction between them, see ch 4, s4.8.4.4.2. On private currencies in a SVP context, see ch 4, s4.8.4.4.4.1. On SVCs as a type of SVP, see ch 4, s4.8.4.4.3.2.
} 
The graphic in Exhibit A shows a MNO operating an SVP with two types of prefunded SVAs containing a mobile airtime- and fiat-based SOV.

The top half shows a mobile airtime-based SVA ('purse') prefunded by cash/card or from a remittance from another MNO user. The SOV can be used, inter alia, for buying data use and access to the MNO services as airtime minutes; for buying incorporeal goods like Value Added Services (hereafter VAS) such as ringtones for use on the mobile phone itself via a Wireless Application Service Provider (hereafter WASP); sending mobile airtime value to another user of the MNO as an airtime remittance; and for entering competitions. Value once inserted in the SVA is usually non-redeemable back into a fiat value. There is often comparatively little financial oversight over this SOV, which is usually subject primarily to a telecommunications Authority who issues a license to the MNO to operate a telecommunications service. ${ }^{38}$

The bottom half shows the fiat-based SVA portion of the SVP denominated in fiat values and which is redeemable back into fiat value. There are numerous ways to prefund the SVA. The umbrella icon signifies the use of a cash-in/cash-out agent in 'branchless banking, ${ }^{39}$ The fiat-based SOV here can be used for the same transactional purposes as the airtime-based SOV in the airtime-based SVA, but now additionally can also be used for purchasing (external) non-corporeal goods and services like food, as well as for doing external bill payments. Fiat value can also be remitted externally or even sent from the mobile phone to an ATM where a third party can withdraw the value remittance as cash. This fiat-based SOV may also be, and is often, termed electronic money (hereafter e-money), and its storage and extent of use is usually subject to central bank control, requiring a financial license of some sort. ${ }^{40}$

In all, the configuration and order then is that there is a SVP offered to users which may contain different types of SVAs (to wit, 'purses'), each SVA with its own type of SOV (to wit, 'money'). These SOVs may for example be or fiat- or airtime-based, denominated in a UOA of the fiat of the national currency such as the Rand; or some other private UOA, such as airtime minutes. ${ }^{41}$

Besides the MNO involvement in MFS, other entities providing MFS services are generally known as Mobile Financial Service Providers (hereafter MFSP). All engage in mobile commerce (hereafter mcommerce) compared to Internet-based PC-only transactions ubiquitously known as electronic commerce

\footnotetext{
${ }^{38}$ On the methodology employed by MNOs to allow prefunding into a SVA for use in access to basic telecommunications services and VAS, see 5.2.2 titled User Access to Mobile Networks. On the types of services - basic telecommunications and VAS - available to users, see ch 5, s5.2.3. On WASPs and the sale of VAS to mobile users, see ch 5, s5.2.3 and ch 6, s6.5.4.2. On the availability and use of mobile airtime remittances (transfer), see ch 6, s6.5.4.3. By comparison, in the case of a stand-alone SVP such as a SVC used in public payphones, there is no account per se, only the embedded SOV on the SVC with the transactional 'credits' available to the user.

${ }^{39}$ See similarly the picture of a 'branchless banking' agent providing MFS in Annex 1, Exhibit J.

${ }^{40}$ On the use of the fiat-based SVA for fiat-based remittances using mobile phones, see ch 6, s6.5.5.3.2. Exhibit A is loosely based on the dual SVA configuration of the eponymous M-pesa MFS system operated by MNO Safaricom and used as a model for MFS worldwide. See generally on M-pesa and MFS in Kenya, ch 10 passim. On the licensing and acceptance of value for transactional purposes, see ch 9, s9.6.2 on the Payment Services Directive (hereafter PSD) in the EU. On the need in South Africa for a banking license to accept funds for use as e-money, see ch 12, s12.4.

${ }^{41}$ The simple act of being able to place, store and use value electronically and directly linked to a mobile phone account for payment of goods and services and for remittances in a MFS context has been given the commercial appellation of 'mobile money,' or 'm-money.' In a non-MFS environment this electronic storage or representation of the value as a SOV in a SVA has become popularly known as e-money. Whether this may actually be legally and economically classed as 'money' is the basis for the discussion in chapters 3 and 13. See generally Lyman, Pickens and Porteous (2008) op cit note 5; I Mas and H Siedek (2008) 'Banking through Networks of Retail Agents' 47 CGAP Focus Note, available at http://goo.gl/4XM4w.
} 
(hereafter e-commerce). Where the mobile phone is used to facilitate payments or to do remittances, this activity is generally known as mobile payments (hereafter m-payments). Many of the services in MFS are said to approximate such 'banking' services as acceptance of funds from users, enabling of payments, and remittance-type services. Hence many MFS schemes have been described as 'mobile banking', or 'mbanking' with non-bank entities that supply these 'branchless banking' services via mobile phones and agents and have been seen as amounting to being 'transformational. ${ }^{42}$ As of December 2011, there were over 100 mainly transformational MFS systems in operation worldwide, with over 90 more planned. ${ }^{43}$

The term 'banking' however does not necessarily imply that the entity offering banking-like services constitutes a bank or carries out the 'business of banking' under domestic regulation in so far as domestic regulation may refer to, and the institution may in some way resemble, the functional characteristics of what may constitute the 'business of banking' in domestic law. ${ }^{44}$ The term is thus used narrowly in respect of the range of financial services that customers may obtain from a non-bank entity. ${ }^{45}$ Where a licensed bank may provide these services via mobile phone and agents, this is termed 'additive banking.'

The products and services offered by non-banks, where there is a comparative benchmark available and where aimed at the same kind of customers, have at one measure been seen to be an average $19 \%$ cheaper than those offered by banks. ${ }^{46}$

It has been noted by Ferguson ${ }^{47}$ that poverty is not necessarily the result of the exploitation of the poor, but is more likely a result of the lack of access to financial institutions, that is, the absence of banks and not necessarily their predatory presence. This is especially so in developing countries, where the economically disadvantaged persons who interact at the BOP where access to the facilities to do so are either non-existent

\footnotetext{
${ }^{42}$ See further ch 2, s2.3 below on the practical distinction between 'transformational' and 'additive' MFS systems; and generally ch 6, s6.3.1 passim on the various types of MFS systems in use. 'Transformational' access to financial services has also been referred broadly to as 'shadow banking,' as a second-tier banking system that shadows the traditional banking system. See FBI Director Robert Mueller referring to SVPs as a shadow banking system in RS Mueller (2010) 'Statement before the House Committee on Appropriations, Subcommittee on Commerce, Justice, Science, and Related Agencies,' available at http://goo.gl/N3vjW. While this may include SVPs, also included are financial intermediaries that conduct banking functions without access to central bank liquidity or public sector credit guarantees, for example investment banks, money-market funds, and mortgage brokers; rather old contracts. See GB Gorton and A Metrick (2010) 'Regulating the Shadow Banking System,' available at http://goo.gl/R72bH;

${ }^{43}$ See further ch 2, s2.7 titled Current and Future MFS Schemes.

${ }^{44}$ See chs 9-12 below for statutory overview of what is considered the 'business of banking' in the European Union (EU), USA, Kenya and South Africa.

${ }^{45}$ Depending on the prudential regime, these activities may fall under the domain of bespoke banking and payment regulation equating to the bank supervision or national payments system division respectively. See ch 4 passim on Banking and Payment Mechanisms.

${ }^{46}$ McKay and Pickens (2010a) op cit note 4. These results from the CGAP study of MFS across eight usage cases in 28 markets, benchmarked services such as sending money transfer; receiving money transfer; short-term safekeeping; mediumterm saving for asset; bill payments; high usage (as a proxy for financial inclusion); average monthly transactions per Kenyan m-pesa user in 2008; average monthly transactions per Kenyan banking customer in 2008.

${ }^{47}$ Ferguson (2008) op cit note 1 at 15 . Ferguson notes that access to these institutions may lead to the granting of credit, allowing money to flow from the idle to the industrious.
} 
or in short supply. ${ }^{48}$ Another likely cause of poverty is a lack of knowledge about and access to traditional banking institutions, which impedes the ability of the poor to build financial assets. ${ }^{49}$

As noted earlier, those at the BOP are often referred to as 'unbanked,' 'underserved,' or 'underbanked.' Specifically, the term 'unbanked' may refer to people who do not have a savings, checking, or any account at a licensed bank or similar depository institution. ${ }^{50}$ There are 2.7 billion (hereafter bn) unbanked adults worldwide. ${ }^{51}$ The 'underbanked' segment may be those who have an account at such entities, but who do not have ready access - be that geographical or technical - to services generally offered. They may also rely for their financial services on other financial services providers such as Micro-Finance Institution (hereafter MFIs) that largely serve low- and moderate-income groups. While the 'unbanked' and 'underbanked' may of course have significant overlaps in their day-to-day financial challenges, the terms are not synonymous. Very simply: the underbanked have an account, the unbanked do not. ${ }^{52}$ The term "underserved ${ }^{53}$ however is sometimes used to describe these two segments as one BOP grouping to emphasise for example the point that while traditional banking in the sense of bank branches and the ability to deposit, lend and pay is not necessarily lacking, it is the ready access to basic facilities for the paying of bills and for sending and receiving value that is lacking. ${ }^{54}$

For the purposes of this thesis however, the terms 'underbanked' and 'unbanked' are used, and used separately so as to acknowledge potential regulatory issues that may arise when using the services of any of the entries that provide it. 'Underbanked' may in certain contexts also mean 'underserved'.

Many of the reasons cited for the existence of these classes of unbanked and underbanked people include the expense of creating and maintaining payment and banking points or branches in remote areas, as well as compliance with security principles. These unbanked, underserved and underbanked groups thus face a

\footnotetext{
${ }^{48}$ See D Collins (2010) 'Consumer Experience of Branchless Banking' Presentation delivered at Windsor 3 Seminar on Regulating Branchless Banking, Windsor, UK, available at http://goo.gl/nEn5W; see also J Chipchase (2010) 'Mobile Banking: Agents as Mediators' CGAP Blog, available at http://goo.gl/cU8E7; G Ivatury, TR Lyman and S Staschen (2006) 'Use Of Agents In Branchless Banking For The Poor: Rewards, Risks, and Regulation' 38 CGAP Focus Note, available at http://goo.gl/sXHMU; Mas and Siedek (2008) op cit note 41; I Medhi, A Ratan and K Toyama (2009) 'Mobile-Banking Adoption and Usage by Low-Literate, Low-Income Users in the Developing World Microsoft Research', available at http://goo.gl/YgOLt; N Hughes and S Lonie (2007) 'M-pesa: Mobile Money for the "Unbanked": Turning Mobile phones into 24-Hour Tellers in Kenya', available at http://goo.gl/KQm6O; FinAccess (2009) 'National Survey 2009: Dynamics of Kenya's Changing Financial Landscape', available at http://goo.gl/XtBYS; Global System for Mobile Communication Association (GSMA) (2010) 'Mobile Money for the Unbanked: Annual Report 2009', available at http://goo.gl/Alu86; B Ngugi, M Pelowski and JG Ogembo (2010) 'M-pesa: A Case Study of the Critical Early Adopters' Role in the Rapid Adoption of Mobile Money Banking in Kenya', available at http://goo.gl/td5rH.

${ }^{49}$ Friedman (2005) op cit note 5. Only about one-quarter of households in developing countries have any form of financial savings with formal banking institutions, for example, 10\% in Kenya, 20\% in Macedonia, 25\% in Mexico and 32\% in Bangladesh. Mas and Siedek (2008) op cit note 41.

${ }^{50}$ FDIC (2009c) op cit note 5; FDIC (2010) op cit note 5. While the FDIC definitions are relatively clear and accepted, there are variations on its definition: the Consultative Group to Assist the Poor (CGAP) defines an 'unbanked' person as one who does not have access to affordable, convenient and secure financial services. CGAP is a World Bank think tank that has done much work on FI and poverty alleviation and its work is cited extensively throughout this thesis.

${ }^{51}$ McKay and Pickens (2010b) op cit note 4; CGAP (2009a) op cit note 28.

${ }^{52}$ NP Retsinas and ES Belsky (2005) 'Building Assets, Building Credit: Creating Wealth in Low-Income Communities' p299 FN 17

${ }^{53}$ The FDIC defines 'underserved' as 'households that are either "unbanked" or "underbanked." See FDIC (2010) op cit note 5. For further explanatory details on the term 'underserved,' see KPMG (2011) op cit note 5. See also KPMG (2011) op cit note 5 .

${ }^{54}$ See Mas and Siedek (2008) op cit note 41.
} 
multitude of challenges ${ }^{55}$ in order to perform basic financial tasks such as paying bills, sending money ${ }^{56}$ to relatives, drawing cash due, in part, to the lack of local banking infrastructure and lack of transport, public or otherwise. The overall cost of transactions, ranging from simple payments to transfer of value, is a further prohibitive factor in their potential engagement. As a result, rural residents may spend 8 to 10 hours a week paying bills in person or obtaining cash. ${ }^{57}$ As Friedman notes, when low-income families turn to alternative financial institutions, they face higher costs for service which makes it even more difficult for them to build up assets. ${ }^{58}$

Poverty usually correlates with low levels of formal education and this raises such issues as the suitability of electronic access to sometimes complex financial services and what user interface is most suitable. ${ }^{59}$ In that context, MFS can leverage off the existing ubiquity of mobile phones and mobile coverage to provide banking-like and payment services at far lower cost than those currently offered by banks and other financial institutions. Along with the use of MFS 'agents' who effectively replace bank branches in handling simple account opening and cash-in/cash-out facilities that approximate to bank deposit and withdrawals respectively, the mobile phone becomes a POS and a general transaction device, allowing users to pay for goods and services and transfer funds instantly and at low cost to recipients where there is mobile coverage. This range of low cost, ubiquitously available services may be the panacea that facilitates a greater level of FI, ${ }^{60}$ and the potential for MFS to enhance FI in South Africa is clear. ${ }^{61}$

With the near ubiquitous coverage of MNOs in rural areas in most developing nations, ${ }^{62}$ each phone, in and of itself, and when enabled with the attendant capabilities, has the potential to become a type of bank 'branch' that frees the owner to pay bills, transfer and receive funds, obtain account information, and generally manage an account, regardless of where they are geographically located. ${ }^{63}$

\footnotetext{
${ }^{55}$ The South African National Treasury definition of FI refers to permanent access and usage of appropriate financial products and services. Access refers to a composite of requirements describing the supply conditions of financial services - such as availability, affordability and appropriateness. Usage refers to the actual consumption of such services and therefore the effective demand for financial services. See RSA, National Treasury (2010) op cit note 10.

${ }^{56}$ Also known as remittances. Many who send remittances do not have bank accounts but use Money Transfer Organisations (MTOs) like Western Union and Moneygram. See ch 4, s4.8.4.3 below on remittances.

${ }^{57}$ Ecomlink (2010) 'Prepaid Cards and the Underserved', available at http://goo.gl/73iPN.

${ }^{58}$ Friedman (2005) op cit note 5.

${ }^{59}$ M Plauche and M Prabaker (2010) 'Text-Free User Interfaces' in Association for Computing Machinery (ACM) Conference on Computer Human Interaction, Montreal, Canada, available at http://goo.gl/OGiwC; Medhi, Ratan and Toyama (2009) op cit note 48; I Medhi, E Cutrell and K Toyama (2010) 'It's Not Just Illiteracy' Microsoft Research, available at http://goo.gl/RKN18.

${ }^{60}$ See also T Keraan (2010) 'Banking the Bottom of the Pyramid,' available at http://goo.gl/qRvlm: who says that '[b]anking at the bottom pyramid cannot be operationalised successfully by overlaying the same business processes of traditional banking offerings. New business processes are needed to realise client centricity and cost effectiveness.'

${ }^{61}$ In relation to the use of MFS generally, and in rural areas specifically, the South African Minister of Finance, Pravin Gordhan, has said that ' $[t]$ hese innovations must surely make it possible to bank more than $70 \%$ of South Africans by 2013', and that they need to be sped up and reinforced. See 'Banks must be more inclusive: Gordhan' (2011) The Citizen, 23 August, available at http://goo.gl/A7abC.

${ }^{62}$ CellularOnline (2011a) 'Africa', available at http://goo.gl/havhZ.

${ }^{63}$ CGAP uses the term 'branchless banking' instead of the more commercially attractive m-money to describe MFS. Generally it sees 'branchless banking' as the use of information communications technology and nonbank retail agents such as retail stores, gas stations, lottery kiosks to deliver financial services to low-income people who are beyond traditional banking channels. For the purposes of this thesis, branchless banking is used as a synonym for MFS. Mobilthinking (2011) 'Fighting Poverty with Mobile Money: Interview with Claudia McKay, Consultative Group to Assist the Poor (CGAP), the
} 
Mas $^{64}$ describes a 'branchless banking' platform as consisting of three key elements. First, there is a (retail) agent network, composed of the collection of retail outlets where transactions are originated. ${ }^{65}$ Second, is a payment network, which aggregates the transactions from the collection of retail outlets and routes them to the appropriate issuer. ${ }^{66}$ And third, there is an account platform, which manages the service logic by authorising individual transactions and maintaining the value of accounts, that is, the SVAs. ${ }^{67}$ These accounts may be issued by institutions recognised and explicitly or implicitly authorised by the banking regulator, although they may not be formally licensed and regulated. ${ }^{68}$

While many banks in the developed and developing world have experimented with 'branchless banking' paradigms, this is seen more as additive banking rather than as a 'transformational' process whereby the bespoke banking business operated by licensed banks provides banking-like services. In the additive paradigm, access mechanisms to banking services using mobile phones that augment access to banking and payment services through secure Internet sites. Thus, these additive access mechanisms do not solve the service access issue of the unbanked, underserved, and underbanked as they simply 'add' access via mobile phone interfaces to an existing bank customer base that is able to visit a bank branch and open or maintain an account. ${ }^{69}$ In addition, any funds almost always flow through a national banking and payments system with its systemic cost structure and, invariably, a closed club of participants. The additive motif is in stark contrast to what has similarly been classed as the cheaper ${ }^{70}$ and more ubiquitous transformational banking paradigm which introduces new non-bank actors - such as MNOs and MFSPs - into the financial landscape to augment licensed banks and their services, or to replace banks and their branches altogether. In the transformational model then, the mobile phone not only replaces the bank branch, but the bank itself. As new entrants, the MNOs and MFSPs provide 'bank-lite' storage of value, payment and remittance services via the mobile phone, augmented by contracted cash-in/cash-out 'agents' acting as human ATMs. ${ }^{71}$

This almost natural choice of the mobile phone as a new stored value and access mechanism is bolstered by a somewhat simple observation: the number of mobile phone users exceeds the number of credit card users by 2 to 1 , and outnumbers those who use ATMs by 2,000 to $1 .^{72}$ The mobile phone has also become an

World Bank,' available at http://goo.gl/Ac8z3. Along with airtime purchases, more than half of mobile banking customers in South Africa also transfer airtime, with rural users (69\%) far more likely to do so than urban users (51\%). The same gap exists in mobile purchases of pre-paid electricity, with 33\% of rural cellphone banking users and only $21 \%$ of urban users doing so via their mobile phones. The pattern is repeated in sending fiat value to other individuals via mobile phone banking: 44\% rural, 34\% urban. World Wide Worx (2012) 'Mobility 2012: The Mobile Consumer in South Africa 2012', available from http://goo.gl/WqVfX.

${ }^{64}$ I Mas (2009a) 'The Economics of Branchless Banking' 4(2) Innovations, available at http://goo.gl/qSXr0.

${ }^{65}$ The retail agent may check a customer's ID and process the transaction on behalf of a non-bank, using either a cell phone or a smart card reader. See Lyman, Ivatury and Staschen (2006) op cit note 48.

${ }^{66}$ The legal aspects of the agent's role in MFS are discussed primarily in chs 10, 11, 12 and 13.

${ }^{67}$ Mas (2009a) op cit note 64.

${ }^{68}$ An example is M-pesa in Kenya. See ch 10 passim on Kenya and MFS.

${ }^{69}$ It is more likely, though, that the 'additive' model applies when used by existing banks and their ability to service only a relatively narrow range of customers who usually reside close to and transact at their nearest bank branch. The mobile channel simply adds an extra level of access to the products, but it may not add more customers as it does not necessarily facilitateFI.

${ }^{70}$ For comparative pricing information between bank, MTO and MFS-based systems across a range of transactions, see McKay and Pickens (2010a) op cit note 4.

${ }^{71}$ See ch 2, s2.5.2 below on the use of agents in MFS systems.

72 Ernst and Young (2009) 'Mobile Money: An Overview for Global Telecommunications Operators' 10, available at http://goo.gl/xAEqS. This report cited GSMA statistics. 
economic necessity for many of those who exist at the BOP. While very poor, they paradoxically have access to some form of mobile network service, be it from a roadside vendor who has a community-type phone, or a reasonably affordable mobile phone with sufficient functionality to access basic MNO and certain MFS services. ${ }^{73}$ However, as Mas and Radcliffe ${ }^{74}$ point out, developing these new (retail) payment systems presents a number of challenges, including network effects (of volumes of users), ${ }^{75}$ the chickenand-egg trap ${ }^{76}$ and trust in the new systems. ${ }^{77}$ Ultimately, consumers will have to be convinced that their MNO or some other non-bank provider of banking-type services is a good and trustworthy substitute for their, or a, bank. ${ }^{78}$ If, however, they have never banked their income, the point may be moot, and consumers may gravitate to the entity with the lowest costs, ubiquitous use and an extensive range of services. ${ }^{79}$

\section{Services Available In MFS}

MFS is said to have the ability to transform not just economies, but also the lives of those at the BOP by providing financial services to those in areas where it has never before been contemplated. ${ }^{80}$ In essence, MFS systems may extend or replace the bank branch concept with new, mostly non-bank actors providing customers with basic services that could be termed 'deposits' of cash into what is ultimately a SVA accessible primarily via the user's mobile phone, withdrawals of that value in fiat cash, as well as payments

\footnotetext{
${ }^{73}$ Even in the US, some $18.5 \mathrm{mn}$ households have no banking relationship which accounts for more than $40 \mathrm{mn}$ people. They rely on cheque cashers, convenience stores and other fringe financial providers to cash pay cheques, pay bills and meet their other financial needs. See National Community Investment Fund (NCIF) (2009) 'Demystifying Prepaid Cards', available at http://goo.gl/giEUb. Some $17.5 \mathrm{mn}$ people with mobile phones in the US do not have a bank account. See F Prior and J Santomá (2010) 'Banking the Unbanked Using Prepaid Platforms and Mobile Telephones' IESE Business School-University of Navarra, available at http://goo.gl/NtOKd.

${ }^{74}$ I Mas and D Radcliffe (2010) 'Mobile Payments go Viral: M-pesa in Kenya', available at http://goo.gl/pCKkO.

${ }^{75} \mathrm{Ibid}$. The value of joining a network is directly proportional to the number of people already belonging to it.

${ }^{76}$ Ibid. They must aggressively and in tandem attract both customers and cash-in/cash-out merchants, or the merchants will stop offering the service due to low transaction revenue and customers will not join the system because they cannot find access to a convenient outlet.

${ }^{77}$ Ibid. Customers must be made to feel comfortable using non-bank retail outlets to meet their cash-in/cash-out needs and to initiate transactions through their mobile phones.

${ }^{78}$ According to Arthur D Little, Mobile use in Brazil, Russia, India, China (hereafter M-BRIC) countries are highly attractive markets for MFS. Currently, only 32mn people in M-BRIC - 42\% of which are in India, $20 \%$ in China, $18 \%$ in Brazil, $12 \%$ in Russia and 8\% in Mexico - use these types of services. They project that this will increase to $290 \mathrm{mn}$ users (10\% of the total M-BRIC population) by 2015 , representing a compound annual growth rate of $58 \%$. These users are expected to conduct a total of 20bn transactions in 2015, with India at 8bn and China at 6.9bn. See AD Little (2010) 'M-Payments in M-BRIC', available at http://goo.gl/nZTUu.

${ }^{79}$ From an adoption and usability perspective, a study by Glajchen, indicated that South Africa was seen to have proceeded more rapidly - as a bellwether of a developing nation - versus the USA because of, inter alia, the lack of access that people have to traditional banking outlets; the high costs of traditional banking compared to the value of the typical transaction size; the desire that people in the developing world to avoid carrying cash for security reasons; the need to do remittances without having to depend on banking locations to convert these funds into cash. South Africa, says Glajchen, is moving toward adoption of these services, but at a much slower pace due to the lack of similar drivers. He also claims that since personal security is ostensibly higher in the USA, carrying cash is not risk; that bank locations are more convenient, and, that the size of typical transactions makes banking more cost effective in the developed world. See Glajchen (2011) op cit note 5 at 128. MFS may be integrated into other mobile-based services, like use of mobile phones for education and health purposes, socalled mobile health. See in relation to MFS and health, M Gencer and J Ranck (2012) 'Advancing the Dialogue on Mobile Finance and Mobile Health: Country Case Studies,' available from http://goo.gl/0DWLa

${ }^{80}$ Financial education programmes for the poor are relatively new in developing and transition countries, although efforts are under way to help micro-finance clients and the poor to improve the management of their assets by building knowledge of key financial concepts and developing the skills they need to make informed financial decisions. See Microfinance Opportunities (2005) 'Assessing the Outcomes of Financial Education', available at http://goo.gl/zUpdM.
} 
for corporeal and non-corporeal goods and services, ${ }^{81}$ remittances ${ }^{82}$ and Electronic Fund Transfers (hereafter EFTs) using mobile phones. ${ }^{83}$

The funds in these systems may - but may also not depending on the type of system employed - flow through a national banking and payment system. ${ }^{84}$ Or the funds may simply travel at low cost though the billing system of the MNO from one user account to another. ${ }^{85}$

Both additive and transformational banking that occurs in the mobile channel may wear the appellation of mobile banking or m-banking. ${ }^{86}$ Mobile banking offers access to a range of facilities such as simple access to balance statements, transfers between accounts and payments to other persons. Broadly, they encompass informational and transactional facilities. They do, at some level, approximate to the 'e-banking' access to traditional bank accounts available via traditional computer-based Internet access.

While mobile technology may offer a seemingly ubiquitous path to FI, other non-bank actors have for many years provided similar - albeit far less technology-focussed - financial services to those at the BOP at lower cost than the banks. These may be big retailers, a small local store cashing in a salary cheque for a regular customer, or providing purchases on informal store credit, or sending - remitting - money informally through systems like the Hawala or other Informal Value Transfer Systems (hereafter IVTS) ${ }^{87}$ These services have been provided on an informal basis to unbanked and underbanked consumers who do not have access to banks or who are in need of banking alternatives because of the cost of the degree of access. ${ }^{88}$ It has become a social good, however, to semi-formalise these disparate systems into MFS and similar types where consumers at the BOP can be provided with fast, convenient, and trustworthy ways to

\footnotetext{
${ }^{81}$ Incorporeal goods and services may include purchase of music and ringtones and similar VAS. See also use of WASPs who sell digital goods and services using so-called Premium Rated Services, in ch 5, s5.2.3 and in ch 6, s6.5.4.2. The single most popular transactional service in mobile phone banking use in South Africa remains airtime purchases, with $74 \%$ of customers using it for this purpose, and only $15 \%$ paying accounts via their phones. Mobile phone-based purchases via the phone of physical products that are delivered to the buyer are made by only $4 \%$ of urban cellphone users, but by no rural users whatsoever. World Wide Worx (2012) op cit note 63.

${ }^{82}$ Glajchen (2011) op cit note 5 at 133. He does not, however, appear to include micro-payments and VAS in his definition of MFS.

${ }^{83}$ On the use of the fiat-based SVA for fiat-based remittances using mobile phones, see ch 6, s6.5.5.3.2.

${ }^{84}$ On national payment systems, see ch 4, s4.8.2.3.1. On the South African National Payment System (hereafter NPS), see ch 12 , s12.3.7.3.

${ }^{85}$ They may also be of relatively low value, so-called micropayments. See ch 4, s4.8.2.4.2 on the value of payments.

${ }^{86}$ The m-banking services the banks provide may be active, such as when a user accesses his account for information or transactional purposes, or passive, such as the bank or financial institution sending SMSs to the user's phone to alert the user to low account balances or account activity like the use of a credit card, or a security notification when a new payment beneficiary has been created on the user's bank account via the bank's website.

${ }^{87}$ Informal Value Transfer Systems (IVTS) are so termed by authorities who deal with AML issues. They are based on the performance and honour of a huge network of informal money brokers. Other informal systems identified in cases of potential money laundering activities include Hundi, black market peso exchange networks, the Asian FeiChien and Door-to-Door. For an overall explanation of the modalities and impact of IVTS, see N Passas (2003) 'Informal Value Transfer Systems, Terrorism and Money Laundering: Report to the National Institute of Justice', available at http://goo.gl/8LZHQ. See ch 8, s8.5 below on inter alia AML. See also on IVTS, ch 6, s6.5.4.2.2.

${ }^{88}$ K Jacob (2005) 'Retailers as Financial Services Providers: The Potential and Pitfalls of This Burgeoning Distribution Channel', available at http://goo.gl/U5yug.
} 
obtain cash, payments, and send money to relatives in remote areas or abroad as remittances. These include the noted 'branchless banking' paradigms where basic transactional, deposit and withdrawal facilities are made available. ${ }^{89}$

The actors in a MFS scheme depend generally on the MFS model employed and the regulations that may or may not govern them. ${ }^{90}$

There are a number of MFS configurations ${ }^{91}$ highlighted in this study, falling under the broad headings of Bank-Led, ${ }^{92}$ MNO-led, ${ }^{93}$ and Independent MFSP models. ${ }^{94}$ Examples highlighted include the Licensed Bank Branchless Banking Model $;{ }^{95}$ the MNO-only model $;{ }^{96}$ the Bank-MNO Model $;{ }^{97}$ and the Independent MFSP model. ${ }^{98}$

Participants in these models may include MNOs, licensed banks, joint ventures (hereafter JVs) between banks and MNOs, third party MFS providers like MFSPs, third party application and content providers like WASPs, ${ }^{99}$ third party service providers that are employed by or contracted to banks or MNOs to provide services to customers at the edge of the MFS scheme, ${ }^{100}$ agents that provide so-called cash-in/cash-out facilities to users of MFS, and trust companies nominally controlled by and accountable to MNOs and which may control the value placed in SVAs. ${ }^{101}$

\subsection{2}

\section{Use of Agents}

Where allowed by regulation, both MNOs and banks are extending the reach of their services through the use of so-called 'agents' as the face of the relatively new 'branchless banking' paradigm. ${ }^{102}$ The agents are commonly known as 'outlets, 103 'correspondents,' 'retail partners' or 'cash merchants. ${ }^{104}$ However, 'agent' is the term that will be used throughout this thesis. It should be noted here that the commercial term

\footnotetext{
${ }^{89}$ For example, there is MNO Safaricom in Kenya, and MNOs Smart Communications and Globe Telecoms in the Philippines who all offer their customers the same services through M-pesa, Smart Money and G-Cash, respectively. In Brazil, customers open bank accounts, make deposits, and pay bills at lottery houses, small retail outlets and post offices equipped with POS terminals. See Philippine Institute for Development Studies (2009) 'Transformational Branchless Banking: Blazing New Trails in Delivering Financial Services' 9(1) Economic Issue of the Day, available at http://goo.gl/oxU76.

${ }^{90}$ See generally on all these models, ch 6 passim.

${ }^{91}$ See for example ch 2 , ss 2.3 and 2.5 .

${ }^{92}$ See ch 6, s6.4 on the bank-led MFS model.

${ }^{93}$ See ch 6, s6.5 on the MNO-led MFS model.

${ }^{94}$ See ch 6, s6.6 on the independent MFS model.

${ }^{95}$ See ch 6, s6.4.2 on the licensed bank branchless banking Model.

${ }^{96}$ See ch 6, s6.5 on the MNO-led MFS model.

${ }^{97}$ See the licensed bank-MNO MFS model described in ch 6, s6.4.3.

${ }^{98}$ See the independent MFSP model described in ch 6, s6.6.

${ }^{99}$ See ch 6, s6.5.4.2 on WASP VAS.

${ }^{100}$ See ch 2, s2.5.2 on agents.

${ }^{101}$ See ch 7, s7.4 on use of trusts and specifically s7.4.8 titled Trusts and MFS.

${ }^{102}$ See ch 7, s7.2.6.4.2 titled MFS-based agents.

${ }^{103}$ See ch 12, s12.2 on MFS implementations in SA.

${ }^{104}$ See Mas (2010c) op cit 5 who suggests that these banking agents, at a high level, should rather be called cash merchants as they provide a service for a fee and for their own accounts and as 'principals' of converting cash into e-money. See also similar comments by George Held of the pan-African and Middle Eastern-based MNO Zain (now called Bharti): 'We don't use the term "agents," but "merchants." The reason we believe the merchant is very important is the sustainability of the business model. If a person sells orange juice or magazines, and at the same time he is using mobile payments as a means of payment, it makes a sustainable business versus if his job is just to perform cash-in and cash-out,' as quoted in P Baptista and S Heitmann (2010) 'Unleashing the Power of Convergence to Advance Mobile Money Ecosystems', available at http://goo.gl/9M1ro.
} 
agent may not necessarily be an accurate legal descriptor. Activities may involve the entity and/or its agent taking cash funds from the public in a non-bricks and mortar setting and converting that cash into an electronic SOV, to wit, mobile money. ${ }^{105}$ The process of taking or disbursing funds in an agency environment may not however be limited to transactions in person, and may have some automated agent component. In some jurisdictions such as Brazil, the human agents are called 'correspondents,' while in South Africa they may depending on the scheme, be called agents or 'outlets.' 106

In many areas the agents may not be engaged exclusively in the provision of MFS services, but may primarily be pharmacies, mobile airtime sale kiosks, lottery kiosks, post offices or grocery stores. ${ }^{107}$ Agents already selling prepaid airtime vouchers may be ideally suited, in terms of technical proficiency and financial literacy, to transition to providing more comprehensive MFS-type services using the same basic infrastructure. They will also have to go through a vetting process for AML purposes. They may be able to offer services such as disbursements of loans or micro-loans approved by banks or by a MFI; disburse government social grants; ${ }^{108}$ effect bill payments and transfers; take deposits and loan payments; allow inquiries on account balances or recent movements of funds; and open savings accounts, loans and debit cards (all with approvals from the bank). They may even be contracted to do additional outsourcing functions. ${ }^{109}$ The agents in the MFS sector earn money on customer registration, and to ensure additional bonuses, are usually encouraged to ensure that customers regularly use the service. ${ }^{110}$ The agent may also be paid per transaction by the MNO or bank where they are authorised to provide deposit and cash-out facilities. In all then, the agent may offer front line customer service; may intermediate bank transactions through its balance sheet, transform cash in-the-till into money-in-the-bank, and vice versa and may need to go to the bank from time to time to rebalance its cash in the till versus its money in a collateral or trust bank account. ${ }^{111}$ MFS thus provide these agents with additional forms of revenue beyond their current forms of income.

Depending on the MFS model employed and the needs assessment of a region, there may also be a hierarchy of agents, for example, in the hybrid MNO-Bank model, the MNO is the agent of a bank, and its airtime kiosks (that provide cash in/out services) may be sub-agents authorised to open accounts, even if the third party providing these services is not necessarily called an agent in their contract. Alternatively, as in Kenya, there may be super-agents who provide (cash) liquidity to agents in the street.

\footnotetext{
${ }^{105}$ See Annex 1: Exhibit F on drawing money from a cash outlet.

${ }^{106}$ Ivatury, Lyman and Staschen (2006) op cit note 48 on Brazil, and on MFS implementations in SA, see ch 6, ss6.4.2.3 and 6.5.5.6; and ch 12, s12.2.

${ }^{107}$ Stores providing services to illiterate customers who require assistance are likely to benefit from repeat business. However, the agent may not always act in the best interests of the consumer, for example, insisting that a moderate sum of money must be sent in 1 or 2 tranches, each of which costs the same set commission. For an overview of agent roles in the MFS context, see Collins (2010) op cit note 48. See also Chipchase (2010) op cit note 48; and Jacob (2005) op cit note 88.

${ }^{108}$ See ch 4, s4.8.4.4.4.4 on Electronic Benefit Transfer (hereafter EBT), also known as Electronic Benefit Cards (hereafter EBCs), where payments are made via individual prepaid magnetic stripe cards preloaded with welfare payments. They are especially popular in the US, UK and South Africa, allowing for example payment to those without bank accounts. The workers can withdraw their salaries from any ATM machine using the card..

${ }^{109}$ See SARB (2004) 'Circular 14/2004: Outsourcing of Functions within Banks,' available at http://goo.gl/BWr81.

${ }^{110}$ As Mas points out, MFS agents must be incentivised adequately for the working capital they have tied up in cash and evalue, for the extra security risks they are running and the cost and inconvenience of going to the bank branch to rebalance. See Microfinance Podcast (2010) 'MFP' at 126, and I Mas (2010a) 'Liquidity Management: Mobile Money', available at http://goo.gl/Zsks2.

${ }^{111}$ Mas and Siedek (2008) op cit note 41.See on pooled master accounts, ch 4, s4.8.4.4.6.
} 
Trust in transactions flowing through agents may be ensured through the use of appropriate technology, backed by a contract between the agent and its bank that specifies how the technology is to be used. ${ }^{112}$ This would of course be codified in a contract that outlines the respective roles and responsibilities of all the parties. As a result of the complexities of the models and the regulatory exigencies, there could be a series of possibly inter-related contracts simultaneously at work, for example, the MNO-agent, agent-super-agent, MNO-super-agent, MNO-bank, customer-MNO or customer-bank. ${ }^{113}$ Liquidity is a key factor for the use of agents in so far as it ensures that the agents have enough cash on hand to provide consistent cash-out facilities, as the lack of cash to pay a customer at any one time may create a negative viral feedback in a community towards local adoption of MFS. ${ }^{114}$

Trust between the bank and the MFS provider, and between the MSF provider and the customer can be created through the electronic recording of all transactions, authentication of all parties, offsetting customer cash transactions against the agent's bank account, real-time authorisation of transactions, automatic receipt generation and real-time authorisation of transactions. ${ }^{115}$

\section{Comparisons with other Systems and Internet E-Commerce}

At a high level, MFS differ, in part, from comparable systems like Internet banking or network-based payments, in the following ways:

- How the services are offered,

- How the devices used,

- How value is placed in an account (if there is an account at all),

- The economics of the loading of value into an account,

- The value-chain in the usage,

- The methods by which value is transferred and by whom, and

- The range of available services.

The most compelling technical and service analogues to the evolving MFS systems are those services and facilities offered by banks, POS systems and devices, national payment systems and the associated

\footnotetext{
112 Ibid.

${ }^{113}$ Ibid. For a general overview of the agent ecosystem, see also M Pickens (2009a) 'Understanding What Drives Profits for Agents: M-pesa', available at http://goo.gl/lg8g5; Mas and Radcliffe (2010) op cit note 74. For an overview of relationships on contract with agents in South Africa, see ch 6, s6.4.3.2.

${ }^{114}$ An agent business can be set up so that neither the customer nor the bank needs to incur settlement risk with, or otherwise financially trust, the agent when transacting through it. See Mas and Siedek (2008) op cit note 41. According to Pickens, Mpesa agents in Kenya incur a host of expenses, including bank charges, transport costs, and fees to aggregators who advance commissions and provide easy float/cash swaps for agents. On average, liquidity management consumes $30 \%$ of total expenses. The typical agent has US $\$ 1,605$ tied up in the agent business, mostly in cash and e-float which is some 12 times greater than the US\$129 capital they had invested in airtime cards for sale. Pickens (2009a) op cit note 113.

${ }^{115}$ Mas and Siedek (2008) op cit note 41.
} 
infrastructure, network-based providers of services, issuers of e-money, money transmitters, issuers of SVPs, and even the ubiquitous cash note.

\subsection{2}

\section{Technical Comparisons}

The additive versus transformational differentiation in service offerings also points to the type of access mechanisms that can be employed in MFS compared to non-mobile methods.

At a technical level many of these systems require the user to have a computer, be computer literate, have a bank account, and have sufficient Internet connectivity. These requirements may be considered part of the additive motif because the service offering assumes the user has access to all these facilities and that there is usually an abundance of either bank branches or connectivity to bank websites via the Internet or via the the so-called mobile Internet, Wireless Application Protocol (hereafter WAP), ${ }^{116}$ or both.

By comparison, making a payment via a website requires a fair amount of literacy in computing and security, as well as access to a bank account, credit or debit account linked to a bank or a credit card company, or a stored value account such as that offered by mainly PC-scale Internet-based payment provider like PayPal. ${ }^{117}$ Invariably in these cases the values being mediated are based on the national fiat currency and are usually redeemable on par and on demand.

As a putative analogue of e-money, prefunded SVAs and their SOV within operated by MNOs have likewise taken on the mantle of payment systems. This did not necessarily occur by design but was an almost accidental artefact that resulted from the novel use of the Short Message Service (hereafter SMS) as a payment mechanism for some goods and services. The MNO offerings may take the form of access through special secure access applications or menus sent to the mobile phone ${ }^{118}$ so that the user does not necessarily have to travel to a bank branch to have the facility placed on their mobile phone. Alternatively, the access to the bank account may be via simple SMS messages to the bank from a registered mobile phone number with discrete codes that trigger a reply back to the phone, such as an SMS $^{119}$ request for balances that are then sent by the bank to the phone. SMS is sometimes used in conjunction with what is known technically as the Unstructured Supplementary Service Data (hereafter USSD) ${ }^{120}$ access mechanism, ${ }^{121}$ or access may be via a so-called WAP link to a page formatted for use on a mobile-phone screen and where the menu structures resemble larger Web page links. ${ }^{122}$

\footnotetext{
${ }^{116}$ See ch 5, s5.5.3.1 on WAP.

${ }^{117}$ See ch 4, s4.8.4.4.4.2 on Network-based Payment Products.

118 The menus are sent via a seamless process known as Over-The-Air (or OTA) to create what are known as S@T menus visible to the user on the mobile phone user interface; see ch 5, s5.5.3.2 on S@T. On SMS, see ch 5, s5.3.4.

${ }^{119}$ See ch 5, s5.3.4 on SMS. See the study on mobile usage in South Africa which showed that while most mobile phone banking is still conducted via SMS, more than a third of customers of these services use WAP access for their banking. See further, World Wide Worx (2012) op cit note 63.

${ }^{120}$ See ch 5 , s5.3.5 on USSD.

${ }^{121}$ This is characterised by sessions using the * [star] and \# [hash or pound] keys on the mobile phone keypad.

${ }^{122}$ See ch 5, s5.5.3.1 on WAP.
} 
There are a number of differences in the economics of the usage between mobile and Internet-based systems. Non-MFS systems are usually used for macro-payments for goods and services and remittances, while MFS are invariably used for low or lower-value micro-payments in kind. ${ }^{123}$ Other fundamental differences revolve around the type and source(s) of funding for SVAs and payments, the cost involved in merchant transactions, what can be purchased and where the purchases can be made. ${ }^{124}$

As noted earlier, ${ }^{125}$ the MNO/MFS prepaid SVP may have two possible SVA incarnations:

- A fiat-based money SVA which can be used for pure payments and remittances, ${ }^{126}$ and which is usually redeemable on-demand;

- A SVA where inter alia fiat money has been 'transformed' into an 'airtime' SOV currency available to the user as a cash replacement that pays for the use of the MNO's basic services ${ }^{127}$ such as telephone calls or relatively more expensive micro-transactions that include purchase of ringtones and music and similar VAS in a closed loop, or 'walled garden, ${ }^{128}$ system with a multitude of merchants approved by the MNO. ${ }^{129}$

Although most MNO-based transactions are seen as small-value micro-transactions, the ability to scale up to macro-transactions on the same or similar platforms is possible. In both cases, the vast majority are prepaid SVAs, such that users must first place value in a redeemable or non-redeemable SVA - that is, prefund - as the case may be, before they can transact. There is usually no 'post-paid' facility where the user essentially defers payment in a type of pseudo credit scheme until the end of a billing cycle and receipt of an invoice from the MNO. Further, while the fiat-based MFS SVAs are usually repayable usually at par, often the airtime-based SVAs are simply seen as being advance payment for goods and services and hence are not redeemable back into fiat currency. ${ }^{130}$

But where the airtime-based SVA incarnations differ fundamentally from pure fiat-based bank deposits and various other SVP schemes is that the ex post nominal value of the prepaid SVA differs from the underlying value received ex ante by the MNO. This is because there is a large wholesale distribution network at work using MNO agents to get the prepaid airtime value into the market. ${ }^{131}$ Hence, for example,

\footnotetext{
${ }^{123}$ See ch 5, s4.8.3.5 titled Value of Payments, which details the differences between micro- and macro-transactions.

${ }^{124}$ See ch 4, ss 4.8.3.7 on ubiquity of use and so-called 'Walled Gardens'; and 4.8.4.4.4.4 titled Open and Closed SVPs.

${ }^{125}$ See Exhibit A in ch 2, s2.1 and the notes thereto.

${ }^{126} \mathrm{New}$ forms of m-payments are m-remittances, which are domestic or international transfers of money initiated by, and sometimes retrieved by, a recipient mobile phone.

${ }^{127}$ See ch 5, s5.2.3 on the types of services available to users.

${ }^{128}$ See ch 4, s4.8.3.7 on ubiquity of use and so-called 'Walled Gardens'.

${ }^{129}$ Some models allow remittances of airtime value between users of the same MNO.

${ }^{130}$ See ch 6, s6.5.4.2 on WASP VAS.

${ }^{131}$ The MNO will usually sell the access codes at wholesale cost to any number of agents (or distributors) or super-distributors who then sell these to retailers or other service providers. Each participant in the value chain takes a certain percentage of the face value of the airtime access for profit, such that although the MNO must provide $100 \%$ of the face value to the user for use in making telecommunications or VAS-type purchases, the MNO will only get a certain percentage of that face value for itself after the distribution and retail costs are considered. See ch 2, s2.5.2 on the use of Agents in MFS distribution chains and in cash-in/cash-out transactions.
} 
whereas a prepaid mobile airtime voucher for the purchase of Premium Rated Services ${ }^{132}$ (hereafter PRS) and goods may be denominated at ZAR10 and many give the purchaser thereof ZAR10's worth of nominal spending power for basic mobile services or VAS, the MNO because of the retail and wholesale channel discounting and other market-related reasons may ultimately only have received ZAR7 for it. ${ }^{133}$ The inflationary effects of an MNO acting as a money issuer providing ZAR10 worth of spending value while receiving only ZAR7 are relatively obvious, and this may even be considered a type of fractional banking. ${ }^{134}$

By comparison, most Internet-based payments fund the payment via use of fiat-based systems such as credit and debit cards, PSPs who have a stored value funded by an electronic funds transfer, or credit/debit cards, or via cheque numbers or bank accounts. Similarly, even where there is no bank involved per se, but rather some type of payment intermediary, it is usually fiat money that is involved in the SOV used for the payment where the source of funding is usually a bank account or some other similar means. Whatever is used as the source of funds, however, is usually, bar any transaction and account maintenance fees that may atrophy the initial deposited value, done at par value. Therefore, ZAR1 deposited provides ZAR1 of value available to be spent or transferred, plus any applicable administrative costs involved in the placement of the value. ${ }^{135}$

The rise of MFS may potentially bring its participants into the purview of banking and payment system regulators. Domestic regulations have not kept pace with the emergence of MFS ecosystems and their resulting legal and economic import, particularly in relation to whether what is done under the broad umbrella of MFS amounts to the 'business of banking, ${ }^{136}$ and whether the SOV in the SVA may be seen as a deposit at both statute and common law. ${ }^{137}$ The multi-faceted nature of MFS appears to create a regulatory void or fog, with governing regulations either completely absent or unable to efficiently regulate hybrid-type systems. ${ }^{138}$ These apparent lacunae portend far larger issues in attempts to extrapolate current legal dogma, either in positive law or derived from the common law, surrounding e-money and even scriptural money to encompass these new forms of payments. There is thus, as noted earlier, a 'regulator's

\footnotetext{
${ }^{132}$ Premium Rated Services mean the cost of access and use is more than a standard Person To Person SMS. PRS are usually associated with VAS such as those offered by WASPs. See ch 6, s6.5.4.2 on WASP VAS.

${ }^{133}$ When digital goods are sold using the airtime-based SOV by WASPs, the MNO usually takes between $30 \%$ and $60 \%$ of the value from the merchant, the so-called 'claw-back,' or 'outpayment.' Thus, while the consumer has ZAR10 spending power, the merchant may only receive from the MNO the smaller value. This so-called 'claw-back' by the MNOs from the transaction value is where MFS when using the airtime SVA, differ fundamentally from pure fiat-based SOVs which usually allow par-value redemption of prepaid SOV value. See further on outpayments, ch 6, s 6.5.4.3 titled Interoperability: Clearing, Payment and Settlement in WASP transactions.

${ }^{134}$ For an example of an outpayment in a purchase of music via a mobile phone, see ch 6, s6.5.4.2.3 and Exhibit C titled Money Flows in VAS Transactions. See also ch 5, 5.2.2 titled User Access to Mobile Networks how users gain access to mobile services via a prepaid or postpaid account. On fractional banking, see ch 3, s3.5.3.3.2 titled Reissue by Banks and other Institutions; and generally, JG Hulsmann (2004) 'Legal Tender Laws and Fractional-Reserve Banking' 18(3) Journal of Libertarian Studies 33-55.

${ }^{135}$ Similarly, if a credit card is used for payment for goods and services, the merchant pay between 1-5\% to parties that include the issuing and acquiring bank (of that credit card).

${ }^{136}$ See ch 4, s4.6 titled Conclusions

${ }^{137}$ Ibid, and further ch 4, s4.8.6 titled Summary and Conclusions.

${ }^{138}$ See thereto, ch 14, s14.1 titled Study Summary And General Conclusions; and in particular on the potential legal and economic impact of new forms of money, ch 13, s13.8.
} 
dilemma ${ }^{139}$ on how to define and regulate these new systems in the midst of FI goals whilst maintaining financial integrity of a nation's financial systems. Protection is also needed to give new consumers' confidence in the formal financial system and any new innovations, especially where existing protections may be seen to be wanting or slanted in favour of those with superior contractual power. ${ }^{140}$ It is also in the interests of financial institutions - whether a bank or a non-bank - to have an informed and confident clientele. $^{141}$

The impact, inter alia, of the following on MFS is discussed below: banking, ${ }^{142}$ payment systems, ${ }^{143}$ contract, ${ }^{144}$ payments, ${ }^{145}$ protections under common law, ${ }^{146}$ security laws, ${ }^{147}$ telecommunications laws, ${ }^{148} \mathrm{e}$ commerce laws ${ }^{149}$ and consumer protection laws. ${ }^{150}$ An assessment of whether a SOV is money for legal purposes is also made. ${ }^{151}$

There are, as noted earlier, broadly three types of MFS schemes. ${ }^{152}$

While many of the fiat-based MFS schemes are evolving, the MNO's airtime-based SVA has served as a role model for MFS, having enabled micro-payments in various incarnations since the late $1990 \mathrm{~s} .{ }^{153}$ This has spurred a plethora of businesses that revolve around micro-payments for digital goods and services offered by WASPs. ${ }^{154}$ There are a number of countries around the world that employ these micro-payment regimes, primarily as more expensive PRS. ${ }^{155}$ In South Africa in 2010, the PRS industry was worth some ZAR4bn. ${ }^{156}$ MNOs have also begun to provide facilities for person to person (P2P) transfers of airtime value from one MNO customer's SVA to another SVA. ${ }^{157}$

\footnotetext{
${ }^{139}$ See ch 8, s8.3 titled Types of Regulation Foci. Put succinctly, this means having to find a proportional regulatory approach to MFS and similar emerging systems through balancing the importance of promoting FI whilst still maintaining financial integrity.

${ }^{140}$ See thereto in summary of the issues, and on a comparative approach to loss allocation, ch 12, s12.11 titled Consumer Protection And Loss Allocation With Respect to Payment.

${ }^{141}$ The World Bank cites unclear costs, hidden fees and charges related to products ranging from payments and remittances to insurance policies and investment funds as cause for concern regarding long-term financial stability. See Rutledge (2010) op cit note 2 at 5.

${ }^{142}$ See ch 4, s 4.2 on banking.

${ }^{143}$ See ch 4, s4.8 on payment systems.

${ }^{144}$ See ch 7, s7.2 on contracts.

${ }^{145}$ See ch 7, s 7.3 on payments.

${ }^{146}$ For example, the common law relating to condictiones and unjustified enrichment. See thereto ch 7, s7.3.6.8.

${ }^{147}$ See ch 8, s 8.5 on AML; and chs 9-12 passim on approaches in the EU, SA, Kenya, and USA.

${ }^{148}$ See ch 8, s8.6 on telecommunications laws, and chs 9-12 on approaches in the EU, SA, Kenya, and USA.

${ }^{149}$ See ch 8, s 8.7 on e-commerce laws, and chs 9-12 on approaches in the EU, SA, Kenya, and USA.

${ }^{150}$ See ch $8, \mathrm{~s} 8.8$ on consumer Protection Laws and chs 9-12 on approaches in the EU, SA, Kenya, and USA.

${ }^{151}$ See chs 3 and 13 on 'money' and its relation to MFS.

${ }^{152}$ See ch 2, s2.5.1 titled Overview.

${ }^{153}$ With the non-redeemable airtime-based currency SVA, the MNO and MFSP act as issuer, treasury, and payment system for clearing and settlement. See ch 6, s 6.5.4.2 on WASP services.

${ }^{154}$ Ibid; and ch 5, s 5.4.4 titled Mobile Network Transaction Billing Mechanisms.

${ }^{155}$ Ibid.

156 This figure is based on the author's own calculations from personal polling of all South African MNOs. Similar largescale values may be found in many other jurisdictions On a comparative study of the values of these PRS, see Analsys Mason (2011) 'Premium Rate Services: International Markets and Regulation: Final Report for PhonepayPlus', available at http://goo.gl/sGQfk. According to this research, France was the largest PRS market benchmarked in terms of total revenues, generating US $\$ 2.66$ bn in 2010 . For 20 benchmarked countries, average PRS revenue per capita in 2010 was US $\$ 4.57$. See further on the values and types of PRS in various markets, Thinktank (2010) 'Current \& future market for Premium Rate
} 
The use of the MNO airtime-based SVA and the airtime as a SOV has, to a large extent, been a 'walled garden' system where only the digital goods and services offered by the MNO or its WASP partners have, through either the judicious implementation of a profitable business model or via regulatory exigencies that involve the delineation of the business model allowed, stayed within the walled garden. However, there is the tantalising possibility of the integration through putative 'exchange rates' of the mobile airtime SVA with other 'private currencies' and even fiat-based systems, particularly those offered by social networking behemoths such as Facebook where users can purchase credits to buy, for example, virtual gifts to send to other Facebook users. ${ }^{158}$ This has meant that the extremities of the bespoke use of the airtime-based SOV may now extend beyond that determined by the MNO. In effect then, the MNO airtime SOV may be used to purchase other private currencies at an exchange rate determined by each SO.

As noted earlier, the more recent incarnation of MFS is via the fiat-based redeemable SOV, which has found huge uptake in the countries in which it has been deployed. In many cases, and in particular South Africa, this is seen not just as more convenient, but also as serving customers' aspirations and a transformational purpose. The operational and developing MFS systems worldwide are spurring new business models and an increasing uptake of active users. Kenya and Asia are, to date, the leaders in MFS. Based on recent analysis, one billion people do not have a bank account but do have a mobile phone and this number will grow hand in hand with population growth, making mobile phones a direct conduit to nearly half of the world's unbanked population. ${ }^{159}$

In Kenya, usage of non-bank financial institutions more than doubled from 7.5\% in 2006 to $17.9 \%$ in 2009. This is attributed mostly to the eponymous M-pesa transformational MFS facility launched by Kenyan MNO Safaricom in 2006. ${ }^{160}$ By July 2011, nearly half (45\%) of the adult population had registered for Mpesa, double the number of those with an account at a licensed bank. ${ }^{161}$ A number of convenience, security and savings reasons have been cited for the uptake of M-pesa, and which are typical for most MFS implementations around the world. Urban users adopted M-pesa because it was cheaper, easy to use, safer than other money transfer options as users do not have to travel with cash, ${ }^{162}$ faster, as the transfer occurs

Services: Report prepared for PhonepayPlus', available at http://goo.gl/Wp595. Many researchers however tend not to include this large PRS industry in their calculations, and indeed in the definition, of 'MFS' - possibly because of the mainly closed loop nature of the airtime-based SVA used in PRS - as if the WASP activities and economies are somehow insignificant. This study however treats the airtime-based SVA and the PRS WASP industry it powers as an integral part of MFS.

${ }^{157}$ See ch 6, s 6.5.4.3 titled Mobile Airtime Transfer.

${ }^{158}$ Facebook is a social networking company and website founded in 2003 with users from around the world. For potential rates of exchange between these private currencies, see ch 4, ss4.8.4.4.1 titled Private Currencies; and 4.8.4.4.4.5 titled Interoperability Between SVPs.

${ }^{159}$ As many as 364mn low-income, unbanked people will use mobile money by 2013 , generating US $\$ 7.8 \mathrm{bn}$ in new revenues for the MFS industry via transaction fees, improved loyalty and more cost-efficient airtime distribution. MFS is still only a fraction of the US\$169bn in revenues by MNOs in developing countries for the year ended March 2009. M Pickens (2009b) 'Window on the Unbanked: Mobile Money in the Philippines' CGAP Briefs, available at http://goo.gl/yMGyQ.

${ }^{160}$ Central Bank of Kenya, Financial Sector Deepening (FSD) (2009) 'FinAccess National Survey 2009: Dynamics of Kenya's Changing Financial Landscape', June, available at http://goo.gl/ousfU.

${ }^{161}$ Ibid. Dependence on only informal financial services declined from $32.7 \%$ to $26.8 \%$ in 2009.

162 Morawczynski and Pickens point out that the M-pesa is used as a SOV by both the banked and unbanked; see O Morawczynski and M Pickens (2009) 'Poor People Using Mobile Financial Services: Observations on Customer Usage and Impact from M-pesa' CGAP Brief, available at http://goo.gl/UuQDD. 
almost instantaneously, easy to access as it is accessible wherever the MNO offers coverage and the availability of numerous cash-in/cash-out points via a large agent network. ${ }^{163}$

The Philippines ${ }^{164}$ has offered MFS since 2005 with the transformational Smart Money and G-Cash MFS services via the MNOs Smart Telecom and Globe Telecom ${ }^{165}$ respectively. The integration of MFS with the general economy of the Philippines is manifest ${ }^{166}$ and schemes have been authorised by the Central Bank, the Bangko Sentral ng Pilipinas. In Brazil, CGAP reports at least 75\% of Brazilians use branchless banking agents, compared to $43 \%$ who have a bank account, while Brazilian banks operate 71,000 deposithandling agents in every municipality of the country. ${ }^{167}$ In Ghana, the Hollard Insurance Group launched an insurance programme with MNO - MTN Ghana - where users can pay premiums as low as one cedi (US\$0.65) per month on their mobile phones through MTN's MFS system. ${ }^{168}$

In South Africa, however, the same type of commercial operation was halted by the SARB in 2010 because it was concerned that the sale of insurance via mobile phones may breach the SARB rules regarding the use of the mobile airtime-based SVA which is limited to the purchase of digital goods and services. ${ }^{169}$ There are a number of MFS incarnations in South Africa though: ${ }^{170}$ the MNOs use their airtime-based SOV successfully in sales of VAS via WASPs, while a fiat-based SOV for use in MFS has been restricted to an 'additive' model by the SARB through its Position Papers on e-money. ${ }^{171}$

The familiar, ubiquitous, reliable, simple and mostly secure interface of the mobile phone provides a powerful stimulus for MNOs and MFSPs to provide MFS to those at the so-called economic BOP. These MFS systems now allow the customer to easily store value in special mobile-based accounts instead of finding and holding cash, to conveniently perform bill payments to merchants, and to transfer and receive funds as remittances locally and abroad.

\footnotetext{
${ }^{163}$ See further ch 10 passim on MFS in Kenya.

${ }^{164}$ In a report on the Philippines' early adoption of MFS, CGAP report that half of active MFS users are unbanked; $68 \%$ of users with multiple SIM cards say their mobile money SIM has become their primary card for calls and texting; Intensive users who do four or more transactions per month are $40 \%$ more likely to live within five minutes of an agent; 1 in 10 unbanked users keeps an average of US\$31 (one-quarter of their family savings) in a mobile SOV; $26 \%$ are poor and living on less than US $\$ 5$ per day, which is the poverty line in the Philippines. Pickens (2009b) op cit note 159.

${ }_{165}$ MFS through Globe are operated through GXChange Inc (hereafter GXI), a wholly owned subsidiary of MNO Globe Telecom.

${ }^{166}$ Since GCASH launched in 2004, it has established a wide network of local and international partners that includes government agencies, utility companies, cooperatives, insurance companies, remittance companies, universities, and commercial establishments which have agreed to accept GCASH as a means of payment for products and services. GCASH users may access GCASH via their mobile phone or via the Internet. See GCASH (2011) 'What is GCash?', available at http://goo.gl/8elXS.

${ }^{167}$ Ibid.

168 South African Press Association (SAPA) (2011) 'MTN Launches Mobile Insurance' Times Live, available from http://goo.gl/NcA7f.

${ }^{169}$ See the discussion thereof in ch 12, s12.3.7.6.2 titled Application to MFS in SA.

${ }^{170}$ See ch 12, s12.2 describing some of these MFS implementations in South Africa.

${ }^{171}$ See ch 12, s12.4.2 on e-Money in South Africa. See also G Ivatury and M Pickens (2006) 'Mobile Phone Banking and Low-Income Customers: Evidence from South Africa', available at http://goo.gl/yWU9d; and CGAP (2010) 'Update on Regulation of Branchless Banking in South Africa January 2010', available at http://goo.gl/IgkwI.
} 
From a usability perspective the overall efficacy of MFS allows participants to be financially included and thus actively participate in the real economy.

From a commercial, as well as a legal and regulatory perspective, many of the new commercial MFS models - using MNOs for access for example - are considered not only to be disruptive to traditional forms of, and participants in, payments and banking, but are also seen as being transformational (to an economy).

They do so, for example, by replacing traditional brick 'n mortar bank branches with 'branchless banking' motifs that include the use of human agents or outlets as the human equivalent of ATMs to provide the equivalent of so-called cash-in/cash-out facilities. ${ }^{172}$

The tangentially similar - but not identical - commercial retail activities of those involved in MFS to those of banks has emboldened the interchangeable use of the term m-banking to be associated with MNOs and MFSOs.

What further confuses the issue is that many of the MFS are said to approximate to 'banking' services, for example, in the receipt - or deposit - of funds from users and payment, EFT and remittance services to the extent that the services provided by the entity may in some way resemble the functional characteristics of what could constitute domestic 'banking activity.'

However, while these entities' activities may generally have banking-based themes, a conclusion can be drawn thus far that they are not necessarily banks needing appropriate banking licenses since they have distinctly different primary commercial foci, for example, the provision of telecommunications services by the MNOs.

However, the issue of 'deposits' in MFS and its role as a seminal pivot in positing an entity's involvement in the 'business of banking' comes to the fore, especially in regard to MNOs and specifically, as to whether the airtime SOV - as well as, where applicable, the fiat-based SOV - used in a general telecommunications setting may be classed as a deposit.

Further, the similar storing of user funds by MFSPs (and even MNOs) primarily to facilitate remittances and bill payments also triggers questions of whether the entities may require banking licenses or need be regulated within the national payment system laws and regulations.

The entry of non-banks that are arguably engaged in what may be termed mobile banking that may require a banking or similar license has raised the additional concern that these entities have the potential to inject a modicum of systemic and fraud risk into a country's financial system.

As will be discussed further, ${ }^{173}$ however, while these risks are manifest they appear to be comparatively low as usually all transactions are prefunded, while anti-fraud and proper AML/KYC procedures are in

\footnotetext{
${ }^{172}$ See ch 2, s2.5.2 on the use of agents.
} 
place alongside real-time recordkeeping. Hence, possible regulation, if any, should be proportional to the risk.

Thus, the important point to make here is that it would appear thus far that the liberal use of the term 'banking' in marketing material does not necessarily imply or mean that the institution offering such services constitutes a bank or carries out the 'business of a bank' as defined under domestic regulation.

The term 'banking' is thus used narrowly in respect of the range of financial services that customers may obtain from a non-bank entity.

The fluid nature of the legal and financial lexicon thus presents for discussion in later chapters the major issue discussed throughout the following chapters in this thesis, namely: that the introduction of MFS is not only transformational and 'disruptive' to the domains of existing banks, but could also create regulatory and legal conundrums that test existing common law precepts and regulatory domains relating inter alia to banking and payments and indeed to the concept of money itself. 


\section{CHAPTER 3}

\section{OVERVIEW OF MONEY}

As indicated earlier, ${ }^{1}$ the commercial appellation 'mobile money' (hereafter m-money) is given to either the mobile airtime-based or fiat-based ${ }^{2}$ Store of Value (hereafter SOV) used in a Stored Value Account (hereafter SVA) used in Mobile Financial Services (hereafter MFS) Stored Value Products (hereafter SVP). This chapter investigates on a foundational basis the intrinsic nature of money and the application thereof to inter alia SOVs used in MFS. ${ }^{3}$

\footnotetext{
${ }^{1}$ See ch 2, s2.1 titled Overview.

${ }^{2}$ Fiat is the order of the state. See Merriam-Webster (2011) 'Fiat', available at http://goo.gl/I32Nd; and FH Capie, DP Tsomocos and E Wood (2003) 'E-Barter Versus Fiat Money: Will Central Banks Survive?' Bank of England Working Paper at 10, available at http://goo.gl/HXTUr. See further on fiats, ch 3, s3.5.1 titled Overview.

${ }^{3}$ For a graphical representation of the relationships between SVPs, SVAs and UOAs, see Exhibit A in ch 2, s2.1. The configuration and order then is that there is a SVP offered to users which may contain different types of SVAs, each with its own type of SOV denominated in a specific UOA. For more on electronic money (or e-money) and Stored Value Products (SVPs), ch 4, s4.8.4.4 titled Stored Value Products; and further G Papadopoulos (2007) 'Electronic Money and the Possibility of a Cashless Society', available at http://goo.gl/lTFzG; N Janson (2001) 'The Development of Electronic Money: Toward the Emergence of Free-Banking?', available at http://goo.gl/ocpDM; R Miller, W Michalski and B Stevens (2002) 'The Future of Money' in Organization for Economic Co-operation and Development (OECD) (2002) The Future of Money, available at http://goo.gl/Gj9cD; S Schmitz (2006) 'eMoney and Monetary Policy: The Role of the Inter-eMoney-Institution Market for Settlement Media and the UOA: A Critical Assessment of the Literature' in Institutional Change in the Payment Systems by Electronic Money Innovations: Implications for Monetary Policy. This chapter will investigate the legal, anthropological, sociological, historical, economic and legal basis for money.
}

Classic works on money include: C Menger (1892) 'On the Origin of Money' 2 Economic Journal 239-255; FA von Hayek (1937) Monetary Nationalism and International Stability; FA von Hayek (1976) Denationalisation of Money: An Analysis of the Theory and Practice of Concurrent Currencies; FA von Hayek (1979) 'Toward a Free Market Monetary System' 3(1) Journal of Libertarian Studies, available at http://goo.gl/ic8BH; FA Walker (1879) Money in its Relation to Trade and Industry; G Simmel (1900) Philosophie des Geldes $5^{\text {th }}$ ed; GF Knapp (1924) The State Theory of Money; H Ellis (1934) German Monetary Theory 1905-1933; H Thornton (1802) An Enquiry into the Nature of the Paper Credit of Great Britain; HD Macleod (1889) The Theory of Credit; JA Schumpeter (1934) The Theory Of Economic Development: An Inquiry into Profits, Capital, Credit, Interest and the Business Cycle; JA Schumpeter (1954) History of Economic Analysis; JA Schumpeter (1970) Das Wesen des Geldes; JM Keynes (1924) A Tract On Monetary Reform; JM Keynes (1930) A Treatise on Money; JM Keynes (1937/1973) The General Theory of Employment, Interest and Money repr in The Collected Writings of John Maynard Keynes Vol VII; JM Keynes (1964) The General Theory; JM Keynes (1971) A Treatise on Money; L von Mises (1912) The Theory of Money and Credit 69-74, available at http://goo.gl/eMRKU; L von Mises (1953) The Theory of Money and Credit; M Weber (1978) Economy and Society; WW Hudson (1895) 'Scientific Standard Money' 2(3) Modern Culture 581.

On more recent or specialised anthropological, historical and sociological approaches to money, see: A Meltzer (2002) 'Money', available at http://goo.gl/1vpr3; A Mitchell-Innes (1913) 'What is Money' 30 The Banking Law Journal 377-408, available at http://goo.gl/Ya1Ck; AM Mitchell-Innes (1914) 'The Credit Theory of Money' 31 The Banking Law Journal 151-168, available at http://goo.gl/DXbDJ; Aristotle $(350 \mathrm{BCb})$ Politics trans B Jowett, available at http://goo.gl/cHjDy (hereafter Aristotle $(350 \mathrm{BCb})$ Politics); Aristotle $(350 \mathrm{BCa})$ Nicomachean Ethics (hereafter Aristotle (350 BCa) Nicomachean); BG Carruthers and S Babb (1996) 'The Color of Money and the Nature of Value: Greenbacks and Gold in Post-Bellum America' American Journal of Sociology, 101(6), 1556-1591; BJ Cohen (2004) The Future of Money; CAE Goodhart (2005b) 'Review of Credit and State Theories of Money: The Contributions of A. Mitchell Innes' History of Political Economy, 37(4) 759-761; D Graeber (2009) 'Debt: The First Five Thousand Years', available at http://goo.gl/glvJs; D Graeber (2011) Debt: The First 5,000 Years; E Lagerspetz (1984) 'Money as a Social Contract' 17(1) Theory and Decision 1-9; EW Younkins (2005) 'Aristotle and Economics', available at http://goo.gl/ptDd4; G Ingham (2002) 'New Monetary Spaces?' in Organization for Economic Co-operation and Development (OECD) The Future of Money, available at http://goo.gl/RTOse; G Ingham (2004) The Nature of Money; G Ingham (2006) 'Further Reflections on the Ontology of 
Money: Responses to Lapavitsas N Dodd' 35(2) Economy and Society 259-278; G Ingham (2007) 'The Specificity of Money' 48 European Journal of Sociology 265-272; H Ganßmann (2009) 'Money, Credit and the Structures of Social Action', available at http://goo.gl/n0gl4; J Smithin (2000) What Is Money?; K Hart (1986) 'Heads or Tails? Two Sides of the Coin' 21(4) Man 637-656; K Hart (2000) Money in an Unequal World: Keith Hart and his Memory Bank; K Hart (2005) 'Notes Towards an Anthropology of Money' 2 Kritikos, available at http://goo.gl/yXXiZ; K Iwai (1997) 'Evolution of Money', available at http://goo.gl/9kMa7; N Dodd (2004) The Sociology of Money: Economics, Reason \& Contemporary Society; N Dodd (2005) 'Laundering "Money": On the Need for Conceptual Clarity within the Sociology of Money' 46(3) Archives Européennes De Sociologie 387-411; N Dodd (2007) 'On Simmel's Pure Concept of Money: A Response to Ingham' 48 European Journal of Sociology 273-294; N Ferguson (2008) The Ascent of Money: A Financial History of the World; P Pilkington (2011) 'What is Debt? - An Interview with Economic Anthropologist David Graeber', available at http://goo.gl/b86br; S Meikle (1994) 'Aristotle on Money '39(1) Phronesis 26-44; VA Zelizer (1994) The Social Meaning of Money: Paychecks, Poor Relief and Other Currencies; VA Zelizer (2007) 'Pasts and Futures of Economic Sociology' 50 American Behavioral Scientist 1056, available at http://goo.gl/93nXO; VA Zelizer (2000) 'Fine Tuning the Zelizer View' 29(3) Economy and Society 383-389.

On economic theory aspects relating to money, see: B Lietaer (2001) The Future of Money: Creating New Wealth, Work and a Wiser World at 41; BA Lietaer (2002) 'The Future of Payment Systems: Unisys Corporation' at 19, available at http://goo.gl/mlb1C; BT McCallum (1985) 'Bank Deregulation, Accounting Systems of Exchange, and the UOA: A Critical Review' NBER Working Paper No 1572, available at http://goo.gl/HFRho at 4-5; C Holtzhausen and C Monnet (2003) 'Money and Payments: A Modern Perspective' at 23, available at http://goo.gl/VdrOo; CAE Goodhart (1989) Money, Information and Uncertainty 2nd ed; CAE Goodhart (2005a) 'The Foundations of Macroeconomics: Theoretical Rigour versus Empirical Realism', paper presented at Louvain-la-Neuve Conference on the History of Economic Thought, Jan 20-22; CW Hermann (2007) 'Contemporary Perspectives on Monetary Sovereignty', available at http://goo.gl/9VYpc; DB Humphrey et al (1996) 'The Evolution of Payments in Europe, Japan, and the United States: Lessons for Emerging Market Economies' at 21, available at http://goo.gl/qh33a; DH Robertson (1928/1932) Money $2^{\text {nd }}$ ed 1928 (repr and rev ed 1932); East and Southern African Banking Group (s.d.) 'Factors leading to the founding of the SARB', available at http://goo.gl/DgEcC; EF Fama (1980) 'Banking in the Theory of Finance' 6 Journal of Monetary Economics 39-57; F Cesarano (1994) 'The New Monetary Economics and Keynes' Theory of Money' 21(3) Journal of Economic Studies at 42; F Maclachlan (2003) 'Max Weber and the State Theory of Money', available at http://goo.gl/GZDtF; F Shostak (2000) 'Why the Present Monetary System cannot be Reformed' Paper delivered at the Austrian Scholars' Conference, March 25, 2000, Auburn, Alabama USA, available at http://goo.gl/3oMn8; GA Davies (1994) History of Money; GA Selgin and LH White (2002b) 'Mengerian Perspectives on the Future of Money', available at http://goo.gl/heT1G; J Kutyn (2005) Nature of Money; J Tobin (1963) 'Commercial Banks as Creators of Money' in D Carson (ed) (1963) Banking and Monetary Studies; JL Jordan (2006) 'Money and Monetary Policy for the Twenty-First Century', available at http://goo.gl/phJVD; JM Ostroy and RM Starr (1990) 'The Transactions Role of Money' in BM Friedman and FH Hahn (eds) Handbook of Monetary Economics; K Wicksell (1906) Vorlesungen über Nationalökonomie transl by E Classen (1967) Lectures on Political Economy Vol 2 Money $2^{\text {nd }}$ ed at 7-8, cited in N Kiyotaki and R Wright (1992) 'Acceptability, Means of Payment, and Media of Exchange' 16(3) Federal Reserve Bank of Minneapolis Quarterly Review (no pagination), available at http://goo.gl/ii167; LR Wray (1998) Understanding Modern Money: The Key to Full Employment and Price Stability; LR Wray (2001b) 'Understanding Modern Money' Paper presented at the Workshop Understanding Unemployment in Australia, Japan and the USA: A Cross Country Analysis 10 and 11 December, available at http://goo.gl/mXabr; LR Wray (2006) 'The Credit Money, State Money, and Endogenous Money Approaches: A Survey and Attempted Integration', available at http://goo.gl/zig59; LR Wray (2011) 'MMP Blog \#20: Effects of Sovereign Government Budget Deficits on Saving, Reserves and Interest Rates, (continued)' New Economic Perspectives, available at http://goo.gl/j0Eky; M Mellor (2011) 'The Confusing World Of Modern Monetary Theory', available at http://goo.gl/p1Ucr; M Messori (2002) 'Credit And Money In Schumpeter's Theory' available at http://goo.gl/SOKr5; M Moini (2001) 'Toward a General Theory of Credit and Money' 14(4) The Review of Austrian Economics 267-317; M Sawyer (2003) 'Money: Means of Payment or Store of Wealth?' in L-P Rochon and S Rossi Modern Theories of Money: The Nature and Role of Money in Capitalist Economies 3-17; M Shubik (2000) 'The Theory of Money' Cowles Foundation Discussion Papers No 1253, available at http://goo.gl/6RmTn; MD Bordo (2008) 'Gold Standard' in The Concise Encyclopedia of Economics, Library of Economics and Liberty, available at http://goo.gl/OBJ8; MG Figueras and AC de Subirà (1997) Telematic Currency and Market Strategy, transl by Loti Perella Chapter 2, available at http://goo.gl/IPjAQ; NF Piffaretti (1998) 'A Theoretical Approach to Electronic Money FSES-302', available at http://goo.gl/UDlv1; R Mundell (1998) 'Uses and Abuses of Gresham's Law in the History of Money', available at, http://goo.gl/B63Le; RM Goode (1983) Payment Obligations in Commercial and Financial Transactions; RM Goode (1995) Commercial Law $2^{\text {nd }}$ ed; S Millard and V Saporta (2005a) 'Central Banks and Payment Systems: Past, Present and Future' Background Paper to the Bank of England Conference on the Future of Payments, 19-20 May 2005, available at http://goo.gl/uqdDC; S Millard and V Saporta (2005b) 'The Future of Payments' 19 Bank of England Financial Stability Review 59, available at http://goo.gl/tVDBh; SA Bell (1998) 'The Hierarchy of Money', The Jerome Levy Economics Institute WP No 231 1, available at http://goo.gl/mNvnx; WA McEachern (2006) Macroeconomics: A Contemporary Introduction; WT Newlyn and RP Bootle (1978) Theory of Money $3^{\text {rd }}$ ed.

On legal aspects relating to money, see: A Nussbaum (1937) 'Basic Monetary Conceptions in Law' 35 Michigan Law Review 865; A Nussbaum (1950) Money in Law: National and International; O Akindemowo (1998) 'The Fading Rustle, Clink and Jingle: Electronic Value and the Concept of Money' 21(2) University of New South Wales Law Journal 46; B Geva (1987) 'From Commodity to Currency in Ancient History: On Commerce, Tyranny, and the Modern Law of Money' 25 Osgoode Hall Law Journal 115-157 at 117; B Geva (1993) The Law of Electronic Funds Transfers at 1-5; B Geva (20002001) 'Legal Aspects Relating to Payment by E-Money: Review of Retail Payment System Fundamentals' 5 Yearbook of International Finance and Economic Law 255; B Geva (2001) Bank Collections and Payment Transactions: Comparative Study of Legal Aspects; B Geva and M Kianieff (2002) 'Reimagining E-Money: Its Conceptual Unity with other Retail Payment Systems', available at http://goo.gl/QfR4y; BW Fraser (1994) 'Central Bank Independence: What Does It Mean?' Talk presented at 20th SEANZA Central Banking Course, Karachi; C Proctor (2005) Mann on The Legal Aspect of Money $6^{\text {th }}$ 
These MFS (and non-MFS) systems use technologies to place purchasing power or 'wealth' in the prepaid SVP. Like a cash note or a coin, these new forms may not only act as the payment instrument but possibly also embody the value as money within that instrument, ${ }^{4}$ an artifact that may challenge the common law views of money and payments.

ed; C Proctor (ed) (2009) Goode on Payment Obligations in Commercial and Financial Transactions; CG Van der Merwe (1987) Sakereg at 26-27; Committee on Payment and Settlement Systems (CPSS) (2003a) 'A Glossary of Terms used in Payments and Settlement Systems', available at http://goo.gl/qL7xN; Committee on Payment and Settlement Systems (CPSS) (2003c) 'The Role of Central Bank Money in Payment Systems' at 102, available at http://goo.gl/nX5Au; D Kreltszheim (2003) 'The Legal Nature of "Electronic Money": Part 1' 14 Journal of Banking and Finance Law and Practice 161; DM Fox (1996) 'Bona Fide Purchase and the Currency of Money' 55 Cambridge LJ 547-565; DM Fox (2005) 'Property in Intangible Money' Society of Legal Scholars Strathclyde Conference 2005; DM Fox (2008) Property Rights in Money; DM Fox (2009) 'Defective Payments of Incorporeal Money in South African and English Law' 4 Tydskrif vir die SuidAfrikaanse Reg 638; DM Fox (2010a) 'Identification of Money at Common Law' 69 Cambridge Law Journal 28-30; E Akindemowo (2010) 'How to Devise U.S. SVP Policy? Prepare to Replace the Deposit Concept', Thomas Jefferson School of Law Research Paper No 1600888; F Gianviti (2005) 'Current Legal Aspects of Monetary Sovereignty' 4 Current Developments in Monetary and Financial Law, available at http://goo.gl/wG7Xz;; FA Mann (1982) The Legal Aspect of Money: With Special Reference to Comparative Private and Public International Law $4^{\text {th }}$ ed; FA Mann (1992) The Legal Aspect of Money $5^{\text {th }}$ ed; FK von Savigny (1851) Das Obligationenrecht ['Law of Contracts'] Vol 1 as cited by FA Mann (1982) The Legal Aspect of Money: With Special Reference to Comparative Private and Public International Law $4^{\text {th }}$ ed; FR Malan (1977) 'Share Certificates, Money and Negotiability,' 94(3) South African Law Journal 245-256; FR Malan and JT Pretorius (2006) 'Credit Transfers in South African Law (Part 1)' 69(4) Tydkrif vir Hedendaagse Romeins-Hollandse Reg 594-612; FR Malan and JT Pretorius (2007) 'Credit Transfers in South African Law' 1 Tydkrif vir Hedendaagse RomeinsHollandse Reg 1; FR Malan, JT Pretorius and SF du Toit (2009) Malan on Bills of Exchange, Cheques and Promissory Notes $5^{\text {th }}$ ed; G Hartmann (1868) Uber Den Rechtlichen Begriff Des Geldes Und Die Rechtliche Natur Von Geldschulden; IL van Jaarsveld (2011) Aspects of Money Laundering in South African Law, LLD thesis, University of South Africa; JC Burger (1990) 'Die Regsaard van Suid-Afrikaanse Geld' 2(3) SA Mercantile Law Journal 225-255; JC Sonnekus (2008a) 'Eensydige Terugskryf Van Kliënt se Krediet deur Bank Onregmatig' 2 Tydskrif vir die Suid-Afrikaanse Reg 348-354; JE du Plessis (2011) 'The Cause of Action in Nissan South Africa (Pty) Ltd v Marnitz NO (Stand 186 Aeroport (Pty) Ltd Intervening) 2005 (1) SA 441 (SCA)' in Mostert H and De Waal MJ (eds) Essays in Honour of CG van der Merwe; JG Hulsmann (2004) 'Legal Tender Laws and Fractional-Reserve Banking' 18(3) Journal of Libertarian Studies 33-55; JJ Chung (2009) 'Money as Simulacrum: The Legal Nature and Reality of Money' 5 Hastings Business Law Journal 109; JT Pretorius (2004) 'The Bona Fide Purchaser of a Krugerrand' 16(3) SA Mercantile Law Journal 466-476; L van Hove (2003) 'Making Electronic Money Legal Tender: Pros \& Cons', Paper prepared for Economics of the Future: Celebrating 100 Years of Cambridge Economics, University of Cambridge, September 17-19,2003, available at http://goo.gl/mXc; MM Kianieff (2008) Consumer Retail Online Electronic Payments: Potential Liberation Technology Or Source Of Despair? PhD Thesis, York University, available at http://goo.gl/nqKBH; MM Loubser (1978) The Theft of Money in South African Law; MM Loubser and D Swart (1999) 'Electronic Money in South African Law' 10 Stellenbosch Law Review 354; PJ Eder (1935) 'Legal Theories of Money' 20 Cornell Law Quarterly 52; R Vakhitov and L Vakhitov (2002-2003) 'The Concept of Money' 1 Review of Central and East European Law 103-118; RM Goode (1995) Commercial Law $2^{\text {nd }}$ ed; SF Du Toit (2009) 'Die Dematerialisasie Van Geld: In Die Skadu Van Die Sakereg’ Tydskrif vir die Suid-Afrikaanse Reg 1; WG Schulze (2001) 'Depositum, Deposit and Deposit-taking Institutions: Birds of a Feather? Not Quite' 13(1) SA Mercantile Law Journal 78-95; WG Schulze (2004b) 'E Money and Electronic Fund Transfers: A Shortlist of Some of the Unresolved Issues' 16(1) SA Mercantile Law Journal 50-66; WG Schulze (2007) 'Electronic Fund Transfers and the Bank's Right to Reverse a Credit Transfer: One Small Step for Banking Law, One Huge Leap for Banks: Case Comment' 19(3) SA Mercantile Law Journal 379-387.

Laws covered in this chapter include the: Banks Act 94 of 1990 (hereafter Act 94 of 1990); Consumer Protection Act 68 of 2008 (hereafter CPA or Act 68 of 2008); Currency and Banking Act 31 of 1920 (hereafter Act 31 of 1920); South African Reserve Bank Act 90 of 1989 (hereafter Act 90 of 1989); Directive 2000/46/EC on the Taking up, Pursuit of and Prudential Supervision of the Business of Electronic Money Institutions (EMD1); Directive 2007/64/EC on Payment Services in the Internal Market (PSD); Directive 2009/110/EC On The Taking Up, Pursuit and Prudential Supervision of the Business of Electronic Money Institutions (EMD2).

Cases covered in this chapter include: Banco de Portugal v Waterlow and Sons Ltd [1932] AC 452 (hereafter Banco); Foley v Hill (1848) 2 HLC, (hereafter Foley); Louw v Coetzee 2003 (3) SA 329 (SCA) 334H-I (hereafter Louw); Miller v Race (1758) 1 Burr. 452 (hereafter Miller); Moss v Hancock (1899) 2 QB 111 (hereafter Moss); Nissan South Africa (Pty) Ltd v Marnitz NO (Stand 186 Aeroport (Pty) Ltd Intervening) 2005 (1) SA 441 (SCA) (hereafter Nissan).

${ }^{4}$ The value, for example, could be a gold coin with legal tender status where the value that can be obtained when presenting the coin is the real value of the components of the gold, rather than the face value of the gold coin. The gold coin as an embodiment of the true value, and its use as a payment instrument is one and the same thing. 
While lawyers generally have an innate focus on payment as a consequence of the existence of money, ${ }^{5}$ the emergence of what could conceivably be termed dematerialised incorporeal 'forms' of money places the innate concept of money in focus. Indeed the instrument itself - that is, the 'form' ${ }^{9}$ - may become irrelevant in any determination of whether what is 'stored' is indeed 'money'. Specifically the crisp question in respect of MFS-based SOVs becomes whether they are storing filigreed money per se or if they simply represent a claim to state-issued fiat money.

If it is found, using the standard metrics to determine whether something (legally and economically) amounts to money, that it is not money, this finding may have implications for laws and regulations sounding in 'money', for example, the Anti-Money Laundering (hereafter AML) laws, rights related to 'money' and value, and generally those related to financial regulation. ${ }^{\text {? }}$

As the eminent legal scholar Arthur Nussbaum proffered:

'Money is a fundamental concept of the law. There are perhaps few other juridical notions of greater importance. $^{8}$

It then becomes necessary to redefine the import, role and place of money and its evolutionary successors in context with the legal, historical, anthropological, sociological, and economic views that may shape the understanding of money. ${ }^{9}$

More, succinctly, from the legal perspective of money, another eminent legal scholar FA Mann ${ }^{10}$ correctly reasoned that:

'[L]awyers cannot but accept what economic theory has elaborated.'

As a result then of the legal system's ostensible appropriation of economic criteria to define money, ${ }^{11}$ a necessary and comprehensive analysis of money from the perspective of economic theories of money is undertaken. ${ }^{12}$

\footnotetext{
${ }^{5}$ Goode (1995) op cit note 3 at 492.

${ }^{6}$ See ch 3, s3.2.4.2 on the form.

${ }^{7}$ See ch 8, s8.5 titled Anti-Money Laundering, Terrorist Financing and Customer Due Diligence Laws and Regulations and Chapters 9-12 on statutory approaches thereto in the European Union (EU), South Africa (SA), Kenya, and the United States (US).

${ }^{8}$ Nussbaum (1937) op cit note 3. As Chung observes, the legal significance of money was further underscored by Nussbaum's observation that " $[\mathrm{t}]$ he word "money" is perhaps more important and more often used in legal relations than any other. It appears everywhere - in constitutions, codes, statutes, judgments, administrative regulations, contracts, wills and other legal documents'. Nussbaum (1950) op cit note 3 at 19; and Chung (2009) op cit note 3 at 109.

${ }^{9}$ This is the essence of the discussion of money in this chapter and which, after a survey of common law and statutory contexts in following chapters will be re-evaluated in Chapter 13.

${ }^{10}$ Mann (1992) op cit note 3 at 24.

11 As was correctly said by Mann (1992) op cit note 3 at 24 in relation to money: '[L]awyers cannot but accept what economic theory has elaborated.'

${ }^{12}$ See ch 13 on a Re-evaluation of Money.
} 
While this study is primarily a legal one, the nature of the subject requires a necessary excursus into various other disciplines to explain money adequately from a legal perspective.

Without this rather lengthy excursus, it is submitted, this study would be wholly incomplete.

The author, it must be emphasised, is not an economist by training, but for the purposes of researching this thesis, has undertaken extensive analysis of the subject of money using available economic criteria and theories. The field of economics is not homogenous and appears to be as divided as law tends to be, involving as it does a number of disparate theories and associated nomenclature whose meanings vary depending on the context used.

While the economic theories that follow are founded in mathematical terms that relate to their macroeconomic import. Any mathematical and macro-economic theorems and the totality of their broader crossdoctrinal, macro-economic impact are of course beyond the scope of this study and are thus excluded. Instead an amalgam of the theoretical underpinnings of the economic theories are extracted and analysed as they may apply to the law, specifically to the legal basis for money.

Other components of the social sciences and humanities - historical, anthropological, sociological, and of course legal - relating to 'money' are included and any intersection or diversion between them is highlighted.

\section{What is Money?}

\subsection{1}

\section{The Nature of Money}

'Money ${ }^{13}$ has been thought of as a social, economic and anthropological contrivance or habit, a concept that has necessarily evolved to allow ease of mercantile utility, lower transaction costs, and generally to produce a 'neutral veil ${ }^{14}$ over transactions. ${ }^{15}$ While its origins are still mired in some controversy, ${ }^{16}$ the

\footnotetext{
${ }^{13}$ The English word 'money' is believed to be derived from Moneta, the temple of the Roman goddess Juno Moneta Regina where coins were manufactured. A Meadows and J Williams (2001) 'Moneta and the Monuments: Coinage and Politics in Republican Rome' 91 The Journal of Roman Studies at 27.

${ }^{14}$ Ingham (2004) op cit note 3.

${ }^{15}$ The celebrated economist Carl Menger maintained that money was a 'social' creation, a product of the 'invisible hand'. See Menger (1892) op cit note 3. Another economist, JM Keynes, notes that although money was originally a social institution, it subsequently became largely a government (state) institution; see Keynes (1971) op cit note 3 at 4. See also A Smith (1776) An Inquiry into the Nature and Causes of the Wealth of Nations Book IV Chapter II; Meltzer (2002) op cit note 3; and GA Selgin and LH White (1994) 'How Would the Invisible Hand Handle Money' 32 Journal of Economic Literature 1718-1749 at 1718, 1743-5. In general on the 'societary' theory of money's origins and acceptance as compared to the 'state' theory of money, see ch 3, s3.2.4.1 on Issuance and Production.

${ }^{16}$ See for example the writings of Mitchell-Innes (1913) op cit note 3; Hart (1986) op cit note 3; and Graeber (2011) op cit note 3. As discussed in ch 3, s3.4.2 on Barter and Commodities below, they all reject the conventional account of the evolution of money as starting from the barter of physical goods, and postulate instead that the origins of money are founded in abstract (virtual) debt relations. See similarly Ingham (2004) op cit note 3 for his view that money is conceivably 'virtual'.
} 
generally accepted view is that the concept and use of money emerged after a process of search and discovery for the cheapest and most efficient way to exchange goods ${ }^{17}$ so as to avoid the inconveniences of barter. It has a pivotal role in modern economies because society has elected to quote prices in terms of money. ${ }^{18}$ Money does indeed make the world go round. ${ }^{19}$

Seashells, gold and beads have in the past been used as money, but of course with modern economies it is rare that anyone, in a real commercial sense, would use seashells, solid gold coins or beads to pay for everyday goods and services. ${ }^{20}$ The physical shape of the means of payment is thus clearly accidental.

What then may act as money, and equally important, what may ultimately be accepted as money? The forms that, in an economic sense, could act broadly as money include coins, banknotes, scriptural money, ${ }^{21}$ credit money, wealth money ${ }^{22}$ and electronic (dematerialised, incorporeal) money. ${ }^{23}$

Hence, whether it is in the form of a tangible object like a coin or banknote or simply a scriptural computer entry that denotes value due to someone, the social agreement to recognise the value it represents - or is legally endowed with - may allow even computer entries that refer to money to have mercantile value and so be accepted in exchange for goods and services or for the settling of debts. ${ }^{24}$ This feature essentially endows any type of entity that may equate to money with a general acceptability as a type of standardised payment mechanism. ${ }^{25}$

Not all money is equal though. Cohen, ${ }^{26}$ Miller, Michalski, and Stevens ${ }^{27}$ as well as Bell ${ }^{28}$ refer to a 'hierarchy of money', based not on its conformity to ubiquitous definitions of money as described above, but on two attributes: its liquidity and its effectiveness in performing money's different functions. ${ }^{29}$ Those

\footnotetext{
${ }_{17}^{17}$ Capie, Tsomocos and Wood (2003) op cit note 2.

${ }^{18}$ This is what would be termed the Unit of Account (hereafter UOA), the standard measure of money. RE Hall (1982) 'Monetary Trends in the United States and the United Kingdom: A Review from the Perspective of New Developments in Monetary Economics' 20 Journal of Economic Literature at 1553; quoted specifically in terms of the high-powered money issued by the Government.

${ }^{19}$ See the observation by the economist and Nobel Laureate, George Stigler, that a world without transaction costs would seem a very strange place. There would be no firms - and therefore no banks, insurance companies or other financial institutions, and there would be no money. G Stigler (1972) 'The Law and Economics of Public Policy: A Plea to the Scholars' 1(1) The Journal of Legal Studies 1-12.

${ }^{20}$ See later ch 3, s3.4 tilted Evolution of Money.

${ }^{21}$ See ch 3, s3.7.2 titled Scriptural Money.

${ }^{22}$ See ch 3, s3.7.2.2 on money as a Store of Wealth.

${ }^{23}$ Fox (2008) op cit note 3 at $10-16$ on the types of assets that may amount to money.

${ }^{24}$ See ch 3, s3.7.2 on Scriptural 'Money' for a discussion of scriptural entries. For a legal exposition of the use of money to settle debts, see also Mann (1982) op cit note 3 at 3. For a further historical exposition, see Davies (1994) op cit note 3 at 36. Fundamentally money has an auxiliary abstract basis to assist in the exchange of real goods, but does not have an intrinsic nor real value like coinage.

${ }^{25}$ Meltzer (2002) op cit note 3; and C Skinner (2007) The Future of Banking at 3 and 11; and Davies (1994) op cit note 3 at 646.

${ }^{26}$ Cohen (2004) op cit note 3.

${ }^{27}$ Miller, Michalski and Stevens (2002) op cit note 3.

${ }^{28}$ See Bell op cit note 3 at 3, who indicates that a money's hierarchy is dependent on the level of its acceptance, something Menger called a particular money's (higher) 'saleableness' or marketability. See also Menger (1892) op cit note 3 at 243.

${ }^{29}$ Its liquidity is the ease with which it is redeemable into the dominant currency. For an explanation of money versus currency, see ch 3, s3.6 titled Money and Currency: General View. See also Miller, Michalski and Stevens (2002) op cit note 3 at 12-13 who give the example of frequent flyer miles (airmiles) which they consider as a genuine form of money. However, its utility and hierarchical position in the money strata is ameliorated because it does not act as a (generalised)
} 
tokens or forms acting as money that provide the highest degree of conformity to money's basic functions will be at the apex of this hierarchy. ${ }^{30}$

Any analysis of 'money' is complex. As Wray ${ }^{31}$ aptly described the challenge:

'[T]rying to "uncover" the origins of money is impossible or at least misguided unless it is placed within the context of a theoretical framework.'

'Money' thus may have various interpretations depending on whether there is a historical, ${ }^{32}$ anthropological,${ }^{33}$ sociological, ${ }^{34}$ economic,${ }^{35}$ or a legal ${ }^{36}$ doctrinal context to the enquiry.

Further, the analysis may depend on whether it is done from the perspective of users of money, use or function of money, issuers of money, producers of money, any potential form, and the denomination of a money. In a broad sense, these may relate to a micro or macro analysis of money.

In a few cases, distinct disciplines and features may coalesce to provide for a similar basis for money, but for the most part each manifestation must satisfy definitional qualities before the relevant discipline will call something 'money'. The use of 'de-materialised' or 'de-physicalised ${ }^{37}$ (incorporeal) electronic systems further complicates each doctrinal analysis and adds a dialectical component to any analysis.

The definitions of money below, as will be seen from the following selected examples, are manifest and diverse, and follow the doctrinal silos that engage in their ontological specificity. ${ }^{38}$ There does not appear to be any unified social science on this topic. ${ }^{39}$

UOA since no prices are posted in these units and because they are limited as a SOV as they expire at some point. Further, as a means of payment they are limited, as they can only be used within the frequent flyer scheme. They are also illiquid as they cannot be redeemed back into any (fiat) currency.

${ }^{30}$ The newer forms of money and payments use technologies that allow purchasing power or 'wealth' to be placed in prepaid SOV. On a similar theme, this hierarchy is what feeds the perennial spat in economic theory between the Orthodox and Claim Schools as regards the nature of money. See also Cohen who refers to a stratified hierarchy of money due to what he terms 'de-territorialisation' of money such that there is a pyramid that consists of a 'top currency', which is most widely accepted beyond its borders; 'patrician currency', which is used for cross-border transactions, but not on such a wide scale, 'elite currency', which is used internationally but has a limited international influence, 'plebeian currency', which enjoys a very limited international use, 'permeated currency', whose domestic competitiveness has been compromised through currency substitution, quasi-currency, which has been superseded not only as a SOV but also as a UOA and MOE, and 'pseudocurrency', which exists in name only. See Cohen (2004) op cit note 3 at 14-16.

${ }^{31}$ Wray (2006) op cit note 3.

${ }^{32}$ See ch 3, s3.2.3.1 on Historical views of money.

${ }^{33}$ See ch 3, s3.2.3.2 on Anthropological views of money.

${ }^{34}$ Sociology and anthropology both have similar investigations of 'money'. See ch 3, s3.2.3.3 on Sociological views of money.

${ }^{35}$ See ch 3, s3.2.3.4 on Economic views of money.

${ }^{36}$ See ch 3, s2.2.3 on Legal views of money.

${ }^{37}$ The expression 'de-physicalisation' was ostensibly first used in A Weinrib (1988) 'Information and Property' University of Toronto Law Journal 117 in the context of intellectual property rights; see also MJ Horowitz (1992) The Transformation of American Law 1870-1960 at 145-156 on the issues surrounding the legal analysis of non-physical, legal interests.

${ }^{38}$ These are, however, by no means homogenous. Legal, economists, sociologists and anthropologists all differ, even within their own disciplines.

${ }^{39}$ As observed by Smithin (2000) op cit note 3 at 7, in relation to sociologists and economists debating theories of money, neither the Orthodox economics nor the Orthodox sociology of the present day have, he says, got to grips with subject of money. He believes the cause is that the academic disciplines split to follow their different paths after the Methodenstreit method dispute - at the end of the nineteenth century. The sociologists, he believes, ceded a discussion of money to economists on the grounds that money is primarily an economic subject. But concludes Smithin, any unified social science worthy of the name must at some point seriously confront what has always been, and still is, one of the key social institutions 
Historians may investigate the evolutionary basis and development of money.

From a historian's view, Niall Ferguson says:

'Today's financial world is the result of four millennia of economic evolution ${ }^{40} \ldots$ Money is not metal. It is trust inscribed ${ }^{41}$

\subsubsection{2}

\section{Anthropological}

Anthropologists may analyse, on a comparative basis, the cultures of profiled communities and their development so as to determine what is used and accepted as money.

From an economic anthropologist's view, David Graeber says:

'What we call "money" isn't a "thing" at all: it's a way of comparing things mathematically, as proportions. $^{42}$

\subsubsection{3}

\section{Sociological}

Sociologists may attempt to interpret social actions or memes to arrive at a casual explanation of their course and effects, which in relation to money may mean the collective decision to accept something as a money.

Geoffrey Ingham takes the sociologist's view of money as:

'... [A] measure of abstract value and as a means of storing and transporting this abstract value for means of final payment or settlement of debt. ${ }^{43}$

in everyday life. It may be submitted here too then, that the legal profession also ceded questions of money to other professions in the social sciences.

${ }^{40}$ Ferguson (2008) op cit note 3 at 341, and further that: '[Money is] the crystallised relationship between debtor and creditor.'

${ }^{41}$ Ibid at 30.

42 Graeber (2011) op cit note 3 at 52 .

${ }^{43}$ Ingham (2004) op cit note 3 at 70. 
Economists, in aggregate, may look at money for example in terms of purchasing power and macroeconomic theories, of which there may be 'micro-analytical' components to their analysis.

From the economist Milton Friedman's view:

'Money is whatever is generally accepted in exchange for goods and services - accepted not as an object to be consumed but as an object that represents a temporary abode of purchasing power to be used for buying still other goods and services. ${ }^{44}$

Money is seen also as a primary component, or fulcrum, of the financial system servicing the wider economy that usually defines money in broad terms and primarily reflects its utilitarian or functional role in economies. $^{45}$

The mainstay of the economic 'definition' of money may caucus around that offered by what may be termed the 'Orthodox School' ${ }^{46}$ view of money, an economic theory of money, a largely asocial, functional approach that is based primarily on the ideas of Aristotle (384-322 BC) who in Politics $I,{ }^{47}$ said that in respect of money - a substance he believed had a telos (purpose) - that it is a unit that supplies a measure on the basis of which just exchange can take place. ${ }^{48}$

The appellation 'Orthodox' is one of many which represent a view by some economists' of money as a functional, quantitative measure related to values of exchange to a physical or tangible commodity that gives the money its value or, in its modern incarnation, a symbol in the form of a coin or note that represents that commodity, ${ }^{49}$ which is accepted by society and the state as being the bulwark or basis for that money's existence and value.

In broad terms the Orthodox $\mathrm{School}^{50}$ is a quantitative and largely asocial approach to money that says that money is solely based on a commodity - like gold - subject to the laws of competitive markets ${ }^{51}$ whose

\footnotetext{
${ }^{44}$ M Friedman (1992) Money Mischief: Episodes in Monetary History at 16.

${ }^{45}$ By comparison, general or 'economy-wide' macro-economic functions of money could include liquid assets. Housing a framework of the market allocates system (prices), a causative factor in the economy and a controller in the economy. See Davies (1994) op cit note 3 at 27.

${ }^{46}$ See ch 3, s3.9 on the Orthodox School below for a comprehensive treatise on the Orthodox School view of money. It is also known inter alia as the Commodity School, Monetarist School, and Classical School. See also Bell (1998) op cit note 3 for a general exposition of the Orthodox School; and Wray (2006) op cit note 3 on the derivation of the Orthodox School and its being mired in the Aristotelian-derived focus on a telos, or purpose.

${ }^{47}$ Aristotle $(350 \mathrm{BCb})$ op cit note 3 .

${ }^{48}$ The famed economist Joseph Schumpeter considered Aristotle's treatment of money in Politics to be 'the basis of the bulk of all analytical work in the field of money', which prevailed substantially until the end of the nineteenth century and even beyond. ${ }^{48}$ See Schumpeter (1952) op cit note 3 at 62 . For a general overview of Aristotle's economic work and his views on money, see Younkins (2005) op cit note 3; and Meikle (1994) op cit note 3; and Geva (1987) op cit note 3 at 120.

${ }^{49}$ As Ingham (2002) op cit note 3 describes at 126, the note became instead a symbol or representation of the 'real' value of the other commodities in the market, which Keynes says is 'only important for what it will procure' in Keynes (1924) op cit note 3 at 1 .

${ }^{50}$ See Bell (1998) op cit note 3 passim for a general overview of the economic Schools. They are also variously known as the Metallist School, Monetarist School, and Currency School.

${ }^{51}$ Hart (2000) op cit note 3 at 252.
} 
value is intrinsic to a metal or valuable object and free from social symbolism and hierarchical relations. ${ }^{52}$ In their view then, the objectivity of the market rather than subjective individual notions of money ${ }^{53}$ is paramount; that money developed by a process whereby the private sector sought to minimise the costs of making exchanges in the process of trading. ${ }^{54}$ As Goodhart ${ }^{55}$ notes:

'[O]rthodoxy tries to turn economic analysis into an 'arithmetic problem'... dropping successively social relations, economic history, and the politics of erstwhile 'political economy' from the pure, mathematical, but often jejune, core of economic analysis. We need to turn back that tide ....'

At a more granular level, the functional pivot in the Orthodox School is Aristotle's 'Medium of Exchange' (hereafter MOE), based as it is on commodities or objects. It is expressed as a standard unit, the 'Unit of Account' (hereafter UOA) ${ }^{56}$ in which prices and debts are measured. This may also hold what is now termed the SOV function which allows that money to maintain value for those who hold and pass it on to others in a transaction. ${ }^{57}$ Thus three of the four functions of money traditionally listed in $19^{\text {th }}$ century Orthodox School textbooks of economics can be traced back to Aristotle, namely, money as MOE, as UOA and SOV. ${ }^{58}$

The economic view of money, naturally, is more varied. ${ }^{59}$ There are various economic Schools which deemphasise the object-oriented focus of the Orthodox School and its shades of metallist basis. ${ }^{60}$ These antimetallist alternatives are variously known inter alia as the Chartalist School, Claim School, Banking School, Endogenous Money School, and Credit School. ${ }^{61}$ They describe money more qualitatively, as being more personalised and social, locating the origins of money primarily in credit and debt relations, a type of accounting or bookkeeping exercise. Money is described in terms of its intrinsic nature as a UOA with a derivative but equally critical role as a Means of Payment (hereafter MOP) for settling debts. In aggregate they will be termed the 'Claim School'. ${ }^{2}$

\footnotetext{
${ }^{52}$ Thus in macro-economic terms, the only money that should be available in a society is that which essentially is based on a one-to-one backing of money by a precious commodity. In other words, you cannot spend more than you actually have.

${ }^{53}$ As Hart notes in this regard, that attention is diverted away from social behaviour and toward individual utility calculation such that social power and economic classes are purged from the analysis, while the market is exalted. Hart (2000) op cit note 3.

${ }^{54}$ The story focuses on transactions-cost reducing innovations, except where government interferes, creating inefficiencies to be overcome. Hart (2000) op cit note 3.

${ }^{55}$ Goodhart (2005b) op cit note 3 at 760.

${ }^{56}$ See Robertson (1928/32) op cit note 3 at 2-3, and Davies (1994) op cit note 3 at 27.

${ }^{57}$ Other characteristics that are sometimes mentioned are durability, divisibility, transportability, and non-counterfeitability. See 'Money Characteristics' (2012) in AmosWEB Encyclonomic WEB*pedia, available at http://goo.gl/XfxgE. These four components are however considered generalised, and so are largely subsidiary to the primary components and will be assumed throughout, but not analysed in detail.

${ }^{58}$ The fourth - money as standard of deferred payments - was not a feature of the ancient world. Meikle (1994) op cit note 3 at 26 .

${ }^{59}$ See Bell (1998) op cit note 3 passim for a general overview of the economic Schools.

${ }^{60}$ As Keynes bluntly put it: 'In truth, the gold standard is already a barbarous relic.' Keynes (1924) op cit note 3 at 172.

${ }^{61}$ See Maclachlan (2003) op cit note 3 on a description of these Schools. See further ch 3, s3.10 on the Claim School and its variants.

${ }^{62}$ For a derivation of the term 'Claim School' - based on money as a debt relationship rather than on a MOE function - see J Schumpeter as quoted in Ellis (1934) at 3. See also Von Mises (1953) op cit note 3 at 467 and his view that Bendixen was one of the first users of the term 'claim'. See C Bendixen (1919) Wiihrungspolitik und Geldtheorie im Lichte des Weltkriegs $2^{\text {nd }}$ ed at 44. See further, ch 3, s3.8.2 titled History of the Analysis.
} 
This is also known as the 'Institutional Theory of Money' which sees money in similar 'Claim' terms, that is, as:

' $[\mathrm{N}] \mathrm{o}$ more than credit against an obligor, whose acceptance as a store of value and as a means of payment by the public is dependent on a comprehensive legal framework that ensures stable purchasing power, its availability even in time of banking stress and its functional capability to settle monetary obligations. It is no longer a chattel, but a transferable credit within an overall institutional framework. ${ }^{63}$

While they each have subsidiary Schools, ${ }^{64}$ for the sake of homologising the various Schools and their modern derivatives, the dominant commodity-based views of money and variants are in aggregate called the 'Orthodox School.' Those who do not rely on a tangible backing for a money, but rather describe it in terms of debt relationships, are described as the 'Claim School.'

The economist Joseph Schumpeter outlined the two major theories that have evolved, namely, the Commodity Theory and the Chartal (or Claim) theory:

'There are only two theories of money which deserve the name ... the commodity theory and the claim theory. From their very nature they are incompatible. ${ }^{65}$

This study settles on the appellations 'Orthodox' and 'Claim' for the two Schools' views on money as the appropriate descriptors that aggregate each of the competing - commodity-based versus credit-based economic Schools of thought.

\subsubsection{5}

\section{Legal Views of Money}

A legal view of money may concentrate on whether a creditor accepts value in final payment.

Accepted legal views of money have, to a large extent, appropriated an economic definition of money, ${ }^{66}$ in particular the functional, commodity-based Orthodox School approach which requires a tangible thing to serve as money. ${ }^{67}$ This requirement can be seen in the locus classicus, Moss ${ }^{68}$ where money was first defined in law as that which, inter alia:

\footnotetext{
${ }^{63}$ S de Vicuña (2010) 'An Institutional Theory of Money', in Giovanoli and Devos, International Monetary and Financial Law: The Global Crisis at par 25.01. See similarly, A Gribov (2008) The Institutional Theory of Money: The Essence and Legal Status of Money and Securities, available at http://goo.gl/qMHDc.

${ }^{64}$ For a high level differentiation between these Schools and their derivatives, see inter alia, Bell (1998) op cit note 3 at 2; Ingham (2002) op cit note 3 at 122-126; and Schmitz, SW (2005) 'Will Central Banking Survive Electronic Money?' prepared for the conference The Future of Payments, Bank of England, London 19-20 May.

${ }^{65}$ Schumpeter, as quoted in Ellis (1934) op cit note 3 at 3. For a discussion of Schumpeter's classifications, see Iwai (1997) op cit note 3. Schumpeter and others re-defined the foundations of monetary theory and replaced the traditional view of money as a 'veil', which facilitates exchanges, with the concept of money as capital, which instead acts as an essential premise for the starting of new production processes. For a tentative endorsement and mild criticism of aspects of the Claim School, see Von Mises (1953) op cit note 3 at 467; and Messori (2002) op cit note 3.

${ }^{66}$ See also Geva and Kianieff (2002) op cit note 3 at 6 who say that 'the adoption of the economic definition by Moss $v$. Hancock appears to us to be satisfactory'.

${ }^{67}$ For a historical exposition of how the common law came to appropriate the (Orthodox) economic School, see Mann
} 
'passes freely from hand to hand throughout the community in final discharge of debts and full payment for commodities, being accepted equally without reference to the character or credit of the person who offers it and without the intention of the person who receives it to consume it or apply it to any other use than in turn to tender it to others in discharge of debts or payment of commodities. ${ }^{69}$

This requirement for a physical thing for money is also seen in the classic scholarly legal definition of money by FA Mann, who in his magisterial work, The Legal Aspect of Money, refers to money as being:

'...all chattels which, issued by authority of law and denominated with reference to a unit of account, are intended to serve as a universal medium of exchange in the State of issue. ${ }^{70}$

This definition describes the concrete (or physical) form of money as 'all chattels ${ }^{71}$ (which) are meant to serve as universal MOE in the state of issue ${ }^{72}$ Coins and banknotes, inter alia, are chattels. ${ }^{73}$

While there are a variety of statutes that talk of 'money', statutory definitions of money (particularly in common law jurisdictions) are rare. ${ }^{74}$

While in the majority of cases, we see money today within the confines of the hegemony of state-issued and produced money in denominations of a UOA such as the Rand or Dollar, this has not always been the case. The history of money is dotted with examples of private monies, with emerging dematerialised forms providing new windows into the possible direction of new forms.

(1992) op cit note 3 at 1-10. See however Geva and Kianieff (2002) op cit note 3 at 5-6 who, whilst not agreeing with Mann's inclusion of a (tangible) chattel in the definition of money, approve generally of appropriating an economic definition of money by the law, but yet fail to analyse the implicit tangible - Orthodox School - economic components in the definition of money used in Moss op cit note 3. For a discussion and more detailed criticism thereof, see ch 13, s13.1.2 on the Parameters of the Enquiry. See also ch 3, s3.9 on the Orthodox School and the need for a tangible item.

${ }^{68}$ Moss op cit note 3.

${ }^{69}$ Consumption relates back to a barter system where a consumable like grain could be used to exchange values. Banknotes, by contrast, are not consumable, and there is usually a legal prohibition on their destruction.

${ }^{70}$ See Mann (1982) op cit note 3 at 8 . Mann was the eminent legal scholar on money. His book reached 5 editions under his penmanship since its publication in the 1930s. Alongside the other evolving and competing economic and legal views of money of that period, it has served as the preeminent text used by jurists worldwide as a reference point for legal investigations of money. Charles Proctor has since taken over authorship of Mann's work and altered some of Mann's fundamental conceptions of money in the process. Although controversial, Mann's original approach has been widely accepted and is still used as a reference work in scholarship and in case law involving money worldwide. See for example Camdex International Ltd v Bank of Zambia [1997] 6 Bank LR 43 (hereafter Camdex), discussed in ch 3, s3.12.2 on Legal Definitions and Theories Related to Money. For a criticism of Mann's view of money, particularly the 'chattel' component, see Geva and Kianieff (2002) op cit note 3 and which is described in more detail on ch 3, s3.12.3.2.2 on Money as Currency: Legal View; and SA Silard (1983) 'Reviewed Work(s): The Legal Aspect of Money: With Special Reference to Comparative Private and Public International Law by FA Mann’ 77(3) American Journal of International Law 676-679. The 2005 revision of Mann's book, authored by Proctor, however removes the 'chattel' component of Mann's original definition of money. See Proctor (2005) op cit note 3 at 35-36.

${ }^{71}$ The Oxford English Dictionary defines a 'chattel' as 'an item of property other than real estate'. See 'Chattel' (2012) in Oxford Dictionaries, available at http://goo.gl/ISQp6.

${ }_{72}$ Mann (1992) op cit note 3 at 8.

${ }^{73}$ Geva (1987) op cit note 3 at 117.

${ }^{74}$ See further ch 3, s3.11 on Interplay Between 'Money' Theories. 
Aristotle describes the nature of money as follows:

'[M]oney has become by convention a sort of representative of demand; and this is why it has the name 'money' (vó $\mu l \sigma \mu \alpha)$ - because it exists not by nature but by law $(v o ́ \mu o \xi))$ and it is in our power to change it and make it useless. ${ }^{.75}$

As Lagerspetz ${ }^{76}$ notes, the word vómo $\xi$ used by Aristotle is ambiguous. It could mean, he says, a 'custom', reflecting a theoretical problem in the classical social theory in that money has been seen either as a result of an act of will of the sovereign, or as a contract based on voluntary agreement between economic agents.

Thus it may either be the state or private structures that produce and issue these 'monies' which variously equate to a 'State' or a 'Societary ${ }^{, 77}$ theory of money issuance and production.

In the Societary Theory, ${ }^{78}$ money's continued use and acceptance is based upon the trust of, or a social agreement between, individuals who may accept any particular type of money as satisfying their need to settle a debt or obtain a good, ${ }^{79}$ not necessarily because of its form, but because they believe that what they receive as money has value to them and that other individuals will accept it in their turn in the future. ${ }^{80}$ As Lagerspetz notes, the institution of money, has often been seen to be based on some kind of contractual agreement. ${ }^{81}$ This social view of money is similar to the populist view of money as being 'money is what money does', ${ }^{82}$ an almost cynical moniker that ultimately implies that evolving forms of money are not easily classified or reconciled using traditional economic and legal analysis, and hints further at the possibility that there may be a future where it is not only the state that issues money. ${ }^{83}$

\footnotetext{
${ }^{75}$ Aristotle $(350 \mathrm{BCa})$ op cit note 3.

${ }^{76}$ Lagerspetz (1984) op cit note 3 at 1.

77 The Societary Theory is variously known as the 'Social Theory', 'Society Theory', and 'Contract Theory'. We will however settle in this study on the term 'Societary Theory' as the omnibus descriptor. See also the more expansive use of the term 'Society' by Hart (2000) op cit note 3 at 252 detailed below, who believes it to be the state, communities and nation.

${ }^{78}$ Adherents to the Societary Theory include Menger (1892) op cit note 3; Dodd (2005) op cit note 3; Mitchell-Innes (1913) op cit note 3; Hart (1986) op cit note 3; Graeber (2011) op cit note 3; Nussbaum (1950) op cit note 3 at 5-10; Von Hayek (1979) op cit note 3; Von Mises (1912) op cit note 3; and Fox (2008) op cit note 3 at 7, 17. For a critical discussion thereof, see Mann (1982) op cit note 3 at 20 and Lietaer (2001) op cit note 3.

${ }^{79}$ See also Ingham (2002) op cit note 3 at 124 who argues that it is not necessarily the form of money that is material in its general acceptance, but rather its features as a general bearer of abstract value; and Ferguson (2008) op cit note 3 at 30 who refers to a 'trust relationship'.

${ }^{80}$ See Simmel (1900) op cit note 3 at 162, and Lietaer (2001) op cit note 3 at 41 who views money simply as 'an agreement, within a community, to use something as a means of payment'; and Warmoth who says that:
}

'[T]he "something" needs to be countable. This definition describes the function of money in all times and places. Its value comes not from the fact that it is a thing, but from the fact that it is a social agreement to use some thing as a measure of value'.

A Warmoth (2002) 'The Economic Crisis of the Commons', available at http://goo.gl/J8wgs.

${ }^{81}$ The contract theory, Warmoth says, formed a natural part of the general 'contractarian' view on society in the works of such thinkers as John Locke who saw monetary institutions as being based on an explicit social contract. Ibid.

${ }^{82}$ For the use of this term, see Hermann (2007) op cit note 3 at 8 . See also the citations to this term in: A Walker (1878) Money; G Dalton (1965) 'Primitive Money' 67 American Anthropologist 44-65 (repr in G Dalton (ed)); JR Hicks (1967) Critical Essays in Monetary Theory, all cited in E Tymoigne (2006) 'An Inquiry into the Nature of Money: An Alternative to the Functional Approach' Working Paper No 481, available at http://goo.gl/OwpvP.

${ }^{83}$ Denominated as it is now primarily in its national currency. From a legal perspective, however, Mann discounts the 'Societary' theory of money, believing instead that money only obtains its value and acceptability from its proclamation by the state. See Mann (1982) op cit note 3 at 22-23. 
The State Theory of money posits that the state is the sole arbiter of money. ${ }^{84}$ Thus any new money may, depending on the applicable regime, also amount to legal tender, ${ }^{85}$ a state-authorised asset that may act as what is known as a Generally Accepted Means of Exchange (hereafter 'GAME). ${ }^{86}$ This may raise its profile and acceptability in the hierarchy, although legal tender is becoming less of a pivotal feature of any analysis and characterisation of money, as it refers to generally state-issued coins and banknotes that may be used in the settlement of debts in a particular jurisdiction, but which may be shunned generally by commercial actors as being of impractical use in facilitating transactions and in debt arrangements. Legal tender may thus merely be one of the qualities that can be used to determine whether something is 'money'.

Where the state issued money may have a higher rung on the hierarchy of money ${ }^{87}$-and related to who is responsible for the issuance and production of money - is on denomination, one of the key functions in quantifying value This is usually termed the UOA (or MOA), the abstract system of measurement. Knapp, Keynes and Ingham insist that these must be defined by a sovereign authority such as the state. ${ }^{88}$

As inter alia Hart and Dodd note however, this is yet another axis on which 'money' is diversifying such that the UOA may conceivably be measured in a new non-state form of minutes or bytes, or some other emerging currency like Facebook Credits. ${ }^{89}$

While the two concepts of money - State and Societary - appear mutually exclusive on both a legal and economic level, there is some confluence. Hart ${ }^{90}$ for example uses a differentiated concept of 'society' to include three distinct senses, at least within the sense of a sociological and anthropological context: as state, nation and community, each of which yields a distinctive conception of the interrelationship between money and social structure.

- When viewed as a creature of the state, money is conveyed as a tool of power which expresses 'vertical relations between unequals, rulers and ruled, like the top and bottom two sides of the coin, heads and tails'.

\footnotetext{
${ }^{84}$ Aristotle said 'that money exists by current convention and not by nature'. Aristotle (1962) Nicomachean Ethics (350 BC), Book V, translated by M Oswald at 126. For adherents to this theory, see Keynes (1971) op cit note 3, who asserted that 'all modern States have had the ability to decide what is money and what is not for at least 4,000 years'. See further, Knapp (1924) op cit note 3; Ingham (2006) op cit note 3; and Mann (1992) op cit note 3. On Weber and his 'State Theory of Money,' see Maclachlan (2003) op cit note 3. See also Burger (1990) op cit note 3 at 231 who points out that as a principle, the State Theory has been in operation since Roman law in the time of Diocletianus as ius cudendae monetae, and was also known in Roman-Dutch law.

${ }^{85}$ See for example, ch 3, s3.12.3.2.1 on Legal Tender and Fiats which covers state-based theories relating to acceptance of money.

${ }^{86}$ On the GAME, see ch 3, s3.5.3.3.1 titled Issuance by the Central Bank: Generally Accepted Means of Exchange (GAME).

${ }^{87}$ Bell (1998) op cit note 3 at 3; and Menger (1892) op cit note 3 at 243.

${ }^{88}$ As Smithin (2000) op cit note 3 at 7 observes, while some state-theories would not disagree with Societary theorists that money is a social relation, they are quite specific as to the nature of that relation: modern money, they posit, is pre-eminently state money, and the liabilities of state central banks (hereafter CBs) acquire the status of valuata - the value of one currency in terms of its exchange rate with another - money or base money because of the coercive power of the state, and in particular its ability to levy taxes on its citizens payable in its own currency.

${ }^{89}$ As Dodd (2005) op cit note 3 notes, the circulation of currency in an increasingly dematerialised form presents serious difficulties for monetary policy, whereas the circulation of monetary forms in other denominations raises formal (or legal) issues of monetary governance. For a critical discussion of the State Theory of money, see Nussbaum (1950) op cit note 3 at $5-10$.

${ }^{90}$ Hart (2000) op cit note 3 at 252.

${ }^{91}$ Ibid.
} 
- By contrast, when 'society' is taken to mean community, money's dependence on trust is underlined. This locates the source of monetary value within 'horizontal' relations between members of a community. ${ }^{92}$

- The association of money with nation combines these vertical and horizontal interpretations, i.e. 'the formality of the state with the informal substance of community., 93

These three notions, Hart suggests, are instruments of collective memory inspired by the Roman Arts, ${ }^{94}$ that is, a memory bank which tracks a diverse range of social exchanges that are mediated by increasingly specialised monetary forms. ${ }^{95}$ The community theory, says Hart, ${ }^{96}$ is a 'token of society', such that money is seen as a symbol of something intangible (ie, society) rather than a thing with objective value. ${ }^{97}$ This is contra of course to the Orthodox School which reinforces a notion that money and monetary relations are inherently impersonal.

This alternative emphasis on trust between people, leads to the idea that money is a type of 'personal credit' generated by social interaction. This, he says, creates the opportunity to provide for an alternative to all standard theories of money as an impersonal object.

Thus Hart sees emerging currencies such as electronic money (hereafter e-money) as SVPs ${ }^{98}$ increasingly manifesting as this 'personal credit, ${ }^{, 99}$ suggesting that these emerging forms of money will not necessarily require state involvement. Similarly, Hayek suggests that it is communities that will best accept their own (private) currencies. ${ }^{100}$

The state's role in the production of money is thus being eroded, although not altogether removed. That said, there is some confluence of a State and Societal role in money. ${ }^{101}$

Thus, says Zelizer:

\begin{abstract}
'All moneys are actually dual: they serve both general and local circuits ... Seen from the top, economic transactions connect with broad national symbolic meanings and institutions. Seen from the bottom, however, economic transactions are highly differentiated, personalised, and local, meaningful to particular relations. No contradiction therefore exists between uniformity and diversity: they are simply two different aspects of the same transaction. ${ }^{102}$
\end{abstract}

\footnotetext{
${ }^{92}$ Ibid.

${ }^{93}$ Ibid.

${ }^{94}$ Hart (2000) op cit note 3 at 234.

${ }^{95}$ Ibid at 318-319; and Dodd (2005) op cit note 3.

${ }^{96}$ Hart (2000) op cit note 3 at 235.

${ }^{97}$ As Dodd notes, all three senses imply a critique of the commodity-based Orthodox School by suggesting that 'money is a symbol of something intangible, an aspect of human agency, not just a thing'. Dodd (2005) op cit note 3.

${ }^{98}$ See ch 4, s4.8.4.4 titled Stored Value Products.

${ }^{99}$ Hart (2000) op cit note 3 at 318. See also ch 3, s3.11 titled Interplay Between 'Money' Theories; and 13, s13.4 on Evolution of Money.

${ }^{100}$ See Von Hayek (1976) op cit note 3 at 63; and similarly LD Solomon (1996) Rethinking Our Centralized Monetary System: The Case for a System of Local Currencies. On private currencies, see ch 4, s4.8.4.4.1.

${ }^{101}$ This to some extent mirrors the views of Mitchell-Innes and Zelizer discussed in ch 3, s3.11 titled Interplay Between 'Money' Theories in relation to the use of both the state and societary theories.

${ }^{102}$ Zelizer (2007) op cit note 3. Dodd suggests of Zelizer's view that a potential move towards an intersection of the State and Societary theories that there is no general circuit to which an equally generalised form of 'money' corresponds, but instead
} 
From the vantage point of hindsight, the continuum of the evolution of money from primitive tangible tokens to commodities exchanged by barter, to being primarily what it is now in the form of coins and paper notes acting as currency and incorporation in modern banking as being represented by electronic data, it is clear that money can take many forms.

Hart however, says that money is not one static 'thing' or idea. ${ }^{103}$ It is, as Simmel put it, not so much the form (thing), but the purest expression of the concept of economic value which trumps the diversity of monetary forms and denominations.

Hence is the word 'form' - or 'thing' as in one economic School, both of which implies as some level an object in the description of a money - still relevant in the light of new conceptions of value and indeed, application of newer (economic) theories to money?

Ingham argues that this is outdated, especially since monetary theory has been undermined by a fundamental category error between the specific form that is taken by what he terms 'money-stuff' and the more general quality of 'money-ness' which all monetary forms have in common. ${ }^{104}$ Thus, says Ingham, the material qualities of money should not enter into a (sociological) conception of money since once money has been defined as a generic promise to pay denominated in a quantitative measure of value - the UOA which Simmel conceptualised as the 'stable pole" 105 - the material qualities of actual forms of money are ostensibly irrelevant. As Dodd ${ }^{106}$ notes, for Simmel, this is money in its 'purest form" ${ }^{107}$ and embraces the diversity of money because it works on a generic level. It is also infinitely fungible: it can be exchanged with anything and with everything. ${ }^{108}$ In other words, says Ingham, all money is in principle 'virtual'.

But, cautions Dodd, when conceived in this way, 'money' can never empirically exist. Nevertheless, he says, emerging monetary forms can be classified as 'money' according to Simmel's definition although at the same time, none of them are equivalent to 'money.' This tautological conundrum notwithstanding, it may be asked then: what is 'money' so as to allow something to be equivalent to it?

The Claim School may yet provide an answer.

\footnotetext{
that a number of specialised circuits have emerged, each of which has acquired its own specific monetary forms that would circulate alongside State-issued currency. Dodd (2005) op cit note 3.

${ }^{103}$ Hart (2000) op cit note 3 at 233.

${ }^{104}$ Ingham (2004) op cit note 3 at 76 argues that this is 'a basic category error' that persists from Aristotle's time in the theory and use of metal coins.

${ }^{105}$ Simmel (2004) op cit note 3 at 119. '[M]oney as abstract value expresses nothing but the relativity of things that constitute value; and, at the same time ... money, as the stable pole, contrasts with the eternal movements, fluctuations and equations of the objects'. Simmel states that the anchor of money, as the 'stable pole', is a quantitative measure - the progenitor UOA that is free of any qualitative measure. This is similar to the Orthodox School's asocial view of money which sees money in intrinsic form, free of any personal interactions. Later conceptions of money such as in the Claim School use the UOA but introduce social, interpersonal relationships - a qualitative measure by some accounts - in a conception of money.

${ }^{106}$ Dodd (2005) op cit note 3.

${ }^{107}$ Simmel (2004) op cit note 3 at 128. 'For money represents pure interaction in its purest form; it makes comprehensible the most abstract concept.'

${ }^{108}$ Dodd (2005) op cit note 3.
} 
Out of the inter-doctrinal diversity that characterises the views of money described above, Dodd ${ }^{109} \operatorname{takes~a~}$ broader perspective:

'[T]here is no feasible definition of money which can embrace the diversity of monetary forms in circulation. It seems that the problem today is not that we cannot agree on a definition of money, but rather that no single definition of money will suffice. "Money", it would appear, is disintegrating. The terms of the present debate suggest that any attempt to build a coherent theoretical conception of money is bound to fail. ${ }^{110}$

I would agree.

Certain quintessential qualities however that may apply in order for something to be called 'money' permeate the literature, although they do not necessarily find ubiquitous inter-doctrinal or intra-doctrinal favour.

Common themes that characterise money include: firstly, it is seen as a SOV that is accepted by others because it embodies undiminished and consistent value; ${ }^{111}$ secondly, it is seen as a UOA, whereby the value of the transfer is homogenous and is accepted as such by all who take it as money and so allows society to compare the values of very dissimilar things in order to lower transaction costs; thirdly, that others will take it because it is accepted as an independent means or asset used to transfer value from one to another without reference to what means or asset is actually used to facilitate that exchange.

In the Orthodox School, this third quality - the 'means' - is seen as the Aristotelian-derived MOE, ${ }^{112}$ while the Claim School sees this 'means' in a chimerical relationship, whereby the UOA is the core attribute, while a Means of Payment (MOP) is seen as the primary function of the UOA. ${ }^{113}$

\footnotetext{
${ }^{109}$ Dodd, it should be noted, is a sociologist who subscribes to the Societary Theory. He has clashed in the literature with Ingham who subscribes mostly to a 'state-sanctioned' view of money. For an insight into their illuminating and sometimes personal foray, see Dodd (2005) op cit note 3; then in rebuttal, Ingham (2006) op cit note 3; Dodd (2007) op cit note 3. See also Dodd (2004) op cit note 3. For a discussion of the nature of and interplay between the state and social theories of money, see ch 3, ss3.2.4.1 on Issuance and Production; and 3.10.1 titled Overview on the Claim School and its offshoots, and 3.11 on how some anthropologists seek to contrive a nexus between the two Schools.

${ }^{110}$ Dodd (2005) op cit note 3 at 387. See also a similar conclusion by S Rashid (2001) 'Can There Be a Theory of Money?', available at http://goo.gl/eL7mC; Schulze (2004b) op cit note 3 at 50. See similarly Ganßmann (2009) op cit note 3, who says:
}

'Given the long history and evolution of what we call money, it may be wrong to push for one unified theory of money. Such a theory would have to maintain that whatever served as money has identical characteristics. It may be more adequate to think of the term "money" as a family name, with different kinds of money sharing, like family members, some characteristics while remaining distinct but related individuals; the implication is that the search for one unified general theory of money is futile.'

${ }^{111}$ In essence, acting as an asset that allows society to transfer purchasing power from one period to another.

112 This may relate to a corporeal commodity or 'chattel' that is either the object that is the MOE, or a temporal reference point for that exchange, or both. See ch 3, s3.9 on the Orthodox School. The MOE generally aims to lower transaction costs when compared say to barter, also known as the so-called double coincidence of need (or wants). See ch 3, s3.4.2 titled Barter and Commodities. In modern economies though money as an object, to wit, the commodity theory or use of money, is of less import especially since the abolition of the gold standard which acted as a reference point for determining the value of money. MD Bordo (1981) 'The Classical Gold Standard: Some Lessons for Today' Federal Reserve Bank of St Louis Review 63 describes the gold standard as a commitment by participating countries to fix the prices of their domestic currencies in 
Many of the inter-doctrinal views of money revolve around this broad Aristotelian-derived commoditybased economic view of money, while others adopt a more modern perspective that involves debt relationships, or 'claims'.

Further complicating the analysis of the two main economic theories analysed here - the Orthodox and Claim Theories - is that it appears that both have as their 'input' origins either the society (or the 'market) or the state, or a hybrid of both. For example, while Knapp and Keynes both rejected the metallism argument of the Orthodox School, in both alternative Schools, ${ }^{114}$ the state could be the source of the legitimacy and value of the money so created.

That said, the interplay of the state and private sector in money is an extremely complex area beyond the scope of this study and for which there is certainly no apparent homogeneity of thought amongst the economists, anthropologists and sociologists surveyed. Thus whether money is a product of the state or of society or something in-between is still as matter of some dialectical dispute, permeating even intradoctrinal beliefs.

Indeed, money creation is thought be a complex series of requisite steps that involve the treasury, ${ }^{115}$ the Central Bank (hereafter CB or CBs) and private banks each time the treasury taxes or spends. To that point, as noted by Wray ${ }^{116}$ :

\begin{abstract}
'The central bank and the treasury develop such procedures to ensure that government is able to spend, that taxpayer payments to treasury do not lead to bounced checks, and-most importantly-that undesired effects on banking system reserves do not occur. While the end result is exactly as described above (treasury spending leads to bank credits, taxes lead to debits, and budget deficits mean net credits to both demand deposits and bank reserves), it is more complicated.'
\end{abstract}

Although they may appear to be mutually exclusive, there is some intersection between the two suggested by an analysis of the evolution of money. ${ }^{117}$ Again, this depends to a great extent on which 'story' of the

\footnotetext{
terms of a specified amount of gold. Between 1880 and the late 1930s a gold standard was the most common monetary arrangement for a country, defining a national currency in terms of a fixed weight of gold. The US left the gold standard in 1971. See Davies (1994) op cit note 3. See also CM Meissner (s.d.) 'Gold Standard Entry' in Oxford Encyclopedia of Economic History, available at http://goo.gl/TC3D0.

${ }^{113}$ The MOP may relate to a series of debt relationships. See ch 3, s3.10 on the Claim School. See also Fox (2008) op cit note 3 at 8 , who says that the use of the MOP better captures the legal characterisation of something that in economic terms is simply an exchange function. Similarly, see Von Mises (1912) op cit note 3; and Proctor (2009) op cit note 3 at 2.

${ }^{114}$ In Knapp's case, he posited an abstract 'Chartal' or ticket as the basis for money; Knapp (1924) op cit note 3. See later, ch 3, s3.10 on the Claim School. Keynes posited a MOA created through 'bank (inside) money' to which the state gave legitimacy through enforcement of contracts based on this money. This may also to some extent be the same as that posited by the Keynesian offshoot, the 'Modern Money Theory' (MMT) School' developed by post-Keynesians who extend the Circuitism 'circulation' argument - see on Circuitism, ch 3, ss3.7.2.1 on Credit Money and 3.10.2.2 on 'Money' - in that taxation is used to establish a fiat money as currency, giving it value by creating demand for it in the form of a private tax obligation that can only be met using the government's currency. Money enters circulation through government spending, whilst the on-going tax obligation, in concert with private confidence and acceptance of the currency, allows a currency to maintain its value (a SOV). See further on Keynes' theories, ch 3, s3.10 on the Claim School.

${ }_{115}$ Usually termed the 'Department of Finance' in a country.

${ }^{116}$ Wray (2011) op cit note 3. Wray is an adherent of the MMT School.
} 
evolution is more credible, for example, if it is more credible that social relationships evolved into statebased relationships.

Interspersed in this fog of economic theory is yet another, far larger caveat: when the functions of money are stated, it is evidently taken for granted that we already know what money is. ${ }^{118}$ This is still unsettled however and discussion of the items which fulfill the functions of money versus the items which actually are money is needed, and this is an acknowledgment that money has taken on a wide variety of forms each specific to the characteristics of the exchanges and environment within which these forms are used.

However, adopting a normative approach to the analysis of what money 'is', the nomenclature derived from a swathe of functional economic and derivative legal definitions of money may play an important role in generating an understanding what may act as and be money. ${ }^{119}$

Scholarly attempts at elucidating the epistemic derivation of what 'is' of money actually means have been perennially overshadowed by the above-mentioned inter- and intra-doctrinal spats over the competing definitions of money, especially those between economists, lawyers, sociologists, and anthropologists who each inevitably bring their doctrinal biases to the fore. ${ }^{120}$ Their caustic approaches to one another are never more manifest than when they are confronted with the emergence of abstract and newer types of money schemes, for example, electronic forms of money and emerging virtual currencies. ${ }^{121}$ Similarly, there are both varying economic and legal views of the concept of a 'payment'. ${ }^{122}$

To date, the debate over money has focused primarily on the 'concrete' or tangible functions and forms of this money or value and, unfortunately, only to a lesser degree on the generic or abstract properties of money, the latter ostensibly allowing newer forms of money to emerge. ${ }^{123}$ While the concrete definition and its tangibility requirement obtains, this dogmatism may not strictly allow new 'forms' of what could ultimately be classified as money, such as electronic representations of money that simultaneously embody the value, to evolve. ${ }^{124}$

\footnotetext{
${ }^{117}$ See ch 3, s3.11 on the Interplay of 'Money' Theories which analyses a possible interplay between 'money' theories and their underpinnings.

${ }^{118}$ K Olivecronna (1957) The Problem of the Monetary Unit at 9.

${ }^{119}$ These describe in some detail the utility of money, how it comes to be used in an economy and how it is the object of legal obligations.

${ }^{120}$ For a description of what economists and lawyers view as money, see ch 2, s2.4 on Services Available from MFS above. For a neutral view, see that of Goodhart (2009) op cit note 3 at 824-826, who believes that money was invented as a social, and governmental, phenomenon. See further on this confluence, ch 3, s3.11 on Interplay of 'Money' Theories.

${ }^{121}$ See for example DD Friedman (1987) 'Economic Analysis of Law' in The New Palgrave: A Dictionary of Economic Theory and Doctrine, available at http://goo.gl/V4rpL. Friedman says that economic analysis of law involves three distinct but related enterprises. The first is the use of economics to predict the effects of legal rules. The second is the use of economics to determine what legal rules are economically efficient, in order to recommend what the legal rules ought to be. The third is the use of economics to predict what the legal rules will be. Economists tend to convert issues from disputes about equity, justice, fairness or the like into disputes about efficiency. This is because, he believes, economists do, and traditional legal scholars often do not, take account of the effects that legal rules have on market prices.

${ }^{122}$ See D Mavromati (2008) The Law of Payment Services in the EU: The EC Directive on Payment Services in the Internal Market at 142.

${ }^{123}$ See the debate between Ingham and Dodd in Dodd (2005) op cit note 3, then Ingham (2006) op cit note 3; and Dodd (2007) op cit note 3 .

${ }^{124}$ Forms as opposed to representations of money (an example of the latter being EFTs and SVPs that offer a claim to state issued money also known as the GAME.
} 
From the above sample of doctrinal theories of money, it would appear that a coherent view of what could act as money may be an unreachable nirvana, ${ }^{125}$ an artifact that reflects the fact that the fundamental nature of what could be termed 'money' has metamorphosed over the course of many generations. ${ }^{126}$ We may now be in that phase when it may be asked if the mobile phone, and its ability to store value in a prepaid mobile phone account, alongside its advertised use for the payment of goods and services in MFS, is the new 'seashell'?

Possibly then an investigation into a general reclassification of what can be accepted as money is necessary, more so since pervasive as it is, there does not appear to be any consensus on an empirical definition of money - the 'is' - that would suggest that there is an abstract concept that describes its intrinsic 'valuableness' ${ }^{127}$ or that describes what quality ${ }^{128}$ epitomises its core.

Such a reclassification may also allow what, generally, is currently described as a 'payment mechanism' acting to transfer value to satisfy an obligation, to converge with that value, such that the payment mechanism and the value may, like 'converged' cash notes and coins, and in and of themselves legally (and economically), be considered together as money. ${ }^{129}$

A general characterisation of MFS-based SVPs ${ }^{130}$ will also be attempted. The need is manifest. As Goode ${ }^{131}$ notes, there is often confusion in the terminology revolving around money and payment, but this is not merely of theoretical interest since the correct definitions and the analysis that follow may affect the outcomes of many (legal) disputes.

\footnotetext{
125 The 'Babylonian Madness' suggested by Keynes (1971) op cit note 3; and similarly see Dodd (2005) op cit note 3 and Nussbaum (1950) op cit note 3.

${ }^{126}$ Chung (2009) op cit note 3 at 110. It is further complicated by the way in which various legal systems approach infringement of 'rights' to money. The English legal system for example has a 'property' rights regime applicable to money. See the book devoted to this subject, Fox (2008) op cit note 3, and similarly for a direct English-South African comparison, see Fox (2009) op cit note 3. As Malan, Pretorius and Du Toit indicate, the English concepts used in relation to money such as 'proprietary interest' and 'superior title' are totally foreign concepts to South African law. Malan, Pretorius and Du Toit (2009) op cit note 3.

${ }^{127}$ A termed coined by Knapp who described 'valuableness' as being the quality conferred by authority, and value being actual purchasing. See Knapp (1924) op cit note 3.

${ }^{128}$ For a broader discussion on aspects of the quality of money, see Ingham (2002) op cit note 3 who says that as the Orthodox School views of money are at its core, a MOE fails to meet the description of the quality of money. See similarly Geva and Kianieff (2002) op cit note 3 at 6 who say that functional approaches that describe money as a MOE do not address the mechanism that converts balances to that MOE; and Mann (1992) op cit note 3 at 28 who sees quality as embodying the intrinsic values as opposed to the concrete and functional forms of money. For an example of a court looking at the intrinsic qualities of money, see the discussion in ch 3, s3.12 on the Legal View of money relating to the celebrated case of Banco op cit note 3 .

${ }^{129}$ See Akindemowo (1998) op cit note 3 who says that since money is now more abstract and less tangible. This sets the scene for the law to embrace electronic means of payment as money, rather than being considered, as with credit cards and (conditional payments instruments such as) Bills of Exchange as simply the means of transferring monetary value. Kreltszheim (2003) op cit note 3 at 173 says that these new forms of money may embody a value of some description, while Geva and Kianieff (2002) op cit note 3 at 13 agree to the extent that this new 'money' must confer final discharge so as to satisfy Moss op cit note 3.

${ }^{130}$ See ch 4, s4.8.4.4 titled Stored Value Products.

${ }^{131}$ Goode (1995) op cit note 3 at 489.
} 
The stage is set then to definine the boundaries of what historically and at a contemporary level may amount to money. This is summarised below ${ }^{132}$ after a survey of common law and the statutory roles of money.

We will continue though with an account of the evolution of money.

Money can be traced via a pedigree that transits mercantile, social, technical and legal evolution. ${ }^{133}$

While Keynes believes its origins are lost 'in the mists of time', ${ }^{134}$ it is thought to have developed from progenitor types such as barter, primitive stones, shells, iron and minerals to durable coinage, paper or electronic entries being managed by today's complex international banking systems. ${ }^{135}$ Adam Smith, the $18^{\text {th }}$ century Scottish scholar who was one of the first to systematically study the historical development of commerce in Europe and is considered the father of the discipline of modern economics, indicated in his seminal treatise The Wealth of Nations ${ }^{136}$ that money evolved as a social need driven by societies to solve the issue of what he saw as inefficiency of barter in facilitating humanity's natural tendency to trade and commerce. This self-interest was driven, he said, by an 'invisible hand ${ }^{137}$ that we now generally refer to as the 'markets.' The topology then in this version of the evolutionary process of 'money' offered by Smith and since followed in mainstream economic texts is that first there was barter, then money, then finally credit (money) offered by banks and others. This is driven by the 'market.'

A contra, revisionist argument ${ }^{138}$ as to money's evolution has been proffered by some economists and economic anthropologists who argue that the 'standard story' first offered by Smith is a "fairy tale" ${ }^{139}$ in that money did not spontaneously emerge, but instead was part of a calculated effort by state-societies to build, by mechanisms of 'debt', markets for their own benefit, and primarily to fund the war-machines they

\footnotetext{
${ }^{132}$ See ch 13 on a Re-evaluation of Money, which is assessed after an investigation in the following chapters of all 'forms' of money, of banking, payments and emerging payment mechanisms generally and at national levels, as well as the legal and regulatory environment they all could operate in.

${ }^{133}$ Davies (1994) op cit note 3 at 23.

${ }^{134}$ Keynes (1971) op cit note 3 at 13 .

${ }^{135}$ Akindemowo (1998) op cit note 3 at fn 6 groups money into four main evolutionary categories that follow the evolution of money. The 'objects-as-money' group consists, she explains, of the first generation payments of 'trade by barter', and the second generation payments of 'trade with valuable objects'. Here objects or commodities were used to swap goods deemed by the participants as equating in value. The 'currency-as-money' group consisting of the third generation (coins) and fourth generation (paper notes); the 'claims-as-money' group comprising the fifth (deposit accounts), sixth ('plastic money) and seventh generations (electronic payments (EPs) and Electronic Fund Transfers (EFTs); and the 'electronic-impulses-asmoney' group covering the eighth generation (smart cards) and ninth generation (digital coins).

${ }^{136}$ Smith (1776) op cit note 15. This body of theory later termed 'neoclassical economics' as a concise synonym for 'economic science' and a substitute for the earlier, broader term 'political economy' used by Smith.

${ }^{137}$ Ibid. On the 'Invisible Hand', see further Menger (1892) op cit note 3; and Selgin and White (1994) op cit note 3.

${ }^{138}$ See inter alia Mitchell-Innes (1913) op cit note 3; Mitchell-Innes (1914) op cit note 3; Hart (1986) op cit note 3; Hart (2005) op cit note 3; Pilkington (2011) op cit note 3; Graeber (2009) op cit note 3; Graeber (2011) op cit note 3; Wray (1998) op cit note 3 .

${ }^{139}$ Pilkington (2011) op cit note 3 .
} 
built around them. ${ }^{140}$ In that sense, money is not seen just as a 'plain vanilla' debt, but is seen more malevolently as an enslavement to debt, primarily debts owed by citizens to the state who issues 'money' so that these citizens are required to pay taxes to the state. They argue then that the evolutionary topology of money is the reverse of that posited by neoliberals; that credit and debt came first, then the emergence of coinage thousands of years later, and then barter systems. ${ }^{141}$

Despite and because of these doctrinal differences, the primary purpose for examining the history and pseudo-history of money is to shed light on the nature of modern 'money' and determining whether the historical precepts both legally and economically can be transposed to emerging systems and types such as those in MFS that deign to be, and may indeed amount to, money. ${ }^{142}$

\subsection{2}

\section{Barter and Commodities}

'Trade by barter' is seen as one of the most primitive forms of commerce, where objects or commodities are used to swap goods deemed by the participants to equate in relative value. ${ }^{143}$ 'Qualitative' satisfaction by participants is crucial in this system as there is no unit to quantify the value of the goods provided as an exact equivalence in the barter exchange. ${ }^{144}$ It was however an inefficient system because it required the double coincidence of needs (or wants) between the participants. ${ }^{145}$ With no standard unit of exchange, barter is the antithesis of what we know as a money system using a UOA. As cities grew and societies created norms, the subjective-qualitative barter began to be replaced by instruments that allowed the quantitative measure of Aristotle's MOE, that is, the exchange value of real goods. ${ }^{146}$ This manifested in the trading of valuable objects or commodities ${ }^{147}$ which had an intrinsic value that allowed non-perishable commodities in limited supply, such as precious metals, to act as a SOV ${ }^{148}$ and a primitive MOE. ${ }^{149}$ These objects could be used if people agreed on their value and accepted them for use in commerce when paying for goods and labour. ${ }^{150}$

\footnotetext{
${ }^{140}$ Graeber (2009) op cit note 3; Graeber (2011) op cit note 3. See also Ingham (2004) op cit note 3 at 99 who refers to a 'military-coinage-complex' used to fund wars.

${ }^{141}$ Goodhart (2009) op cit note 3 at 823 points out that the invention of money probably predated the development of formal markets such that money facilitated the rise of markets, rather than vice versa. He cites as evidence of this that many early money forms such as cattle are highly unsuitable for ordinary transactions,

${ }^{142}$ It may also be noted here, that while an assessment of each economic topology is ongoing and indeed beyond the scope of this study, salient points from each can however, it is submitted, be directly applied to the discussion below and in ch 13 in relation to whether a reassessment of the legal view of money is needed and if so, what this reassessment should entail. That is, that the economic and anthropological debate are linked to the extensive discussion below as to whether the Orthodox or Claim School economic views of what may be widely termed 'money' should be applied to a legal view of money. It may be said then at this stage of the study that the alternative motif proffered by the 'revisionists' - for want of a better term - in relation to essence of 'money' as being in essence a series of 'debt' relationships has merit, although their use of legal motifs to prove their point may, it appears, not be entirely legally sound. See for example Graeber (2009) op cit note 3 who says incorrectly, and clearly from the vantage point of a non-legal scholar in relation to physical (commodity) money like gold, that it 'is distinguished from credit money most of all by one spectacular feature: it can be stolen.'

${ }^{143}$ Described by Thornton as being used by society in its 'rudest state'. See Thornton (1802) op cit note 3 at 17.

${ }^{144}$ Geva (1993) op cit note 3 at $1-5$.

${ }^{145}$ McEachern (2006) op cit note 3 at 262.

146 The MOE is indicative of the functional approach to describing money in both an (Orthodox) and current legal sense. See also Younkins (2005) op cit note 3.

147 Thornton (1802) op cit note 3 at 17 and B Maestro (1993) Story of Money.

${ }^{148}$ These systems are the progenitors of the cash-based systems we use today.

${ }^{149}$ Davies (1994) op cit note 3 at 9 . These early modes of exchange ranged from the wampum (beads made from shells) of American Indians to cowries (brightly coloured shells) in India, to whales' teeth among the Fijians, to tobacco among early colonists in North America, to large stone disks on the Pacific island of Yap, to cigarettes and liquor in post-World War II Germany.

${ }^{150}$ Maestro (1993) op cit note 146 at 11.
} 
While any mercantile thing could be used in and of itself, the thing was not to be used as the MOE as that feature belonged to money only. ${ }^{151}$ These quantitatively equivalent exchanges have also been called 'money barters ${ }^{, 152}$ and demonstrate and allow the basic function of what came to be termed as 'money'. This enabled purchase to be separated from sale and thus permitted trade to take place without the need for the so-called double coincidence of wants that applies in barter. ${ }^{153}$ The use of an abstract reference to calculate comparisons amongst other goods valued in them was the progenitor of the 'standard unit of exchange,' or numeraire. ${ }^{154}$ Examples include the shekel, a specific volume of barley in ancient Babylon, while salt was used as a currency in pre-coinage societies in Europe. In the Neolithic Age, ${ }^{155}$ money units appear with some unit value and so 'barter' based on a standardised monetary-type (commodity-based) unit emerges. ${ }^{156}$

\subsection{3 \\ Coins}

As a result of the emergence of international trade and the need for states to pay their servants, ${ }^{157}$ species of coinage ${ }^{158}$ began to emerge as societies began to shape objects in semi-standardised forms. ${ }^{159}$ Historical consensus is that the first metallic coin monies date back to 2000-1800 BC and were made of bronze, were traded based on weight and were often molded into the shape of cattle. ${ }^{160}$ The use of coins enabled payment to be made by tale, or count, rather than weight, greatly facilitating commerce. ${ }^{161}$ In fact, the etymology of the word 'money' in many languages reflects the use of precious minerals in coinage, similar as it is to the word for silver or gold. In this way, the value of coin money began to be associated with the intrinsic value of its component commodity. ${ }^{162}$ This was the forerunner of the gold standard where currencies and their exchange to other currencies were fixed at a fulcrum price, namely, at the price of gold.

\footnotetext{
${ }^{151}$ Aristotle (1976) The Politics, transl by TA Sinclair at 41-48.

${ }^{152}$ Figueras and De Subirà (1997) op cit note 3.

${ }^{153}$ Thus, if a person has something to sell and wants to use the 'proceeds' of this to buy something else from someone else, the use of a general purchasing metric like money will obviate the need to find a person who has a similar coincidence of wants (of sale/purchase/barter). See Meltzer (2002) op cit note 3, available at http://goo.gl/1vpr3.

${ }^{154}$ See Shubik (2000) op cit note 3 at 9 . The numeraire is the money unit of measure within an abstract macroeconomic model in which there is no actual money or currency. A standard use is to define one unit of some kind of output of goods as the money unit of measure for wages. See definition of numeraire, defined as a basic standard by which values are measured, such as gold in the monetary system. See 'Numeraire' (2011) in Oxford Dictionaries, available at http://goo.gl/fJpci. The UOA is also known as the 'numeraire'. UOA could also mean 'money', 'coinage' or 'face value'. A numeraire is usually applied to a single good, which becomes the base good. All similar goods are then valued and priced against the base good. This comparison makes it possible to identify which goods are worth more than others.

${ }^{155}$ The Neolithic (or 'New' Stone Age) was a period in the development of human technology that is traditionally the last part of the Stone Age. It is from 8500 BC to 4500 BC. Miller, Michalski and Stevens (2002) op cit note 3 at 36.

${ }^{156}$ Figueras and de Subirà (1997) op cit note 3 at 1 , fn21.

157 Geva (1987) op cit note 3 at 134-135, says that original coin systems were issued to serve administrative rather than economic needs, specifically to pay mercenaries and for public works, followed by their use in international trade. This view comports somewhat with that of Graeber (2011) op cit note 3.

${ }^{158} \mathrm{~A}$ coin is defined as a device-marked piece of metal, issued by a governing authority and intended to be used as money; see 'Coin' (2006) in Random House Unabridged Dictionary.

${ }^{159}$ These monetary instruments recording transactions are the forerunners of the legal interpretation of money.

${ }^{160}$ See Davies (1994) op cit note 3 at 55, and see notations at Coin Gallery Online, Coin Community Forum (2005-2011) available at http://goo.gl/2BbPC. Most numismatic scholars credit the introduction of coinage to the Kingdom of Lydia in Asia Minor - now Turkey. See also Goodhart (2009) op cit note 3 at 827 who believes that one of the many early money forms was cattle, from which the word pecuniary derives from the later Latin word pecus for cattle.

${ }_{161}$ Meltzer (2002) op cit note 3.

${ }^{162}$ Usually gold, silver, copper, bronze or amalgams thereof. Modern economies tend to keep the intrinsic value of money to a minimum as it became routine for the public to melt the coin for profit.
} 
Initially anyone could mint their own coins, but this eventually this became the monopoly right of royalty and the state, which struck a seal into a standardised weight to indicate its official, monopoly status. ${ }^{163}$ Legal codes also began to enforce payment for injury in a standardised form, usually in precious metals. ${ }^{164}$

\subsection{4 \\ Paper-Type 'Money'}

The end of the Middle Ages coincided with an increase in global trade, and the amount of coinage in circulation could not sustain the emerging economies. The 'bankers' of that time - usually holders of gold in storage - then created a new form of monetary instrument, paper money ${ }^{165}$, to compensate for the shortage. ${ }^{166}$ Paper money was the archetypal token, where the purchasing power was greater than the token's intrinsic commodity value and was an acknowledgement of debt of a quantity of metallic money by the bank or other holder producing the note. ${ }^{167}$

Paper money originated in two forms: drafts, which were (goldsmith) receipts for value, usually gold, placed with the goldsmith on account, and goldsmith 'bills', which were issued with a promise to convert at a later date ${ }^{168}$ - the progenitor of a current commercial mainstay, the 'cheque' ${ }^{169}$ These drafts and cheques were followed by the formation of banks who issued standardised bills or notes that acted as money.

\subsubsection{Goldsmith Receipts}

Following King Charles' compulsory 'loan' from merchant money placed in the Tower of London in the mid- $17^{\text {th }}$ century, merchants began to leave their monies in the form of gold with goldsmiths. ${ }^{170}$ Gold and other precious metals soon became a viable alternative method of paying third parties ${ }^{171}$ whereby the goldsmith would hold gold 'deposits' on behalf of the merchant issuing a receipt useable as a payment instrument payable to a third party willing to accept it. The receipt was in favour of a payee ${ }^{172}$ or bearer ${ }^{173}$ and was an undertaking by the goldsmith to pay on demand when presented with the receipt. Since many of these receipts or notes passed around for long periods of time without being cashed in for the gold,

\footnotetext{
${ }^{163}$ Geva (1987) op cit note 3 at 136-138. See ch 3, s3.5 on Role of the State and Central Bank in Money.

${ }^{164}$ McEachern (2006) op cit note 3 at 264.

${ }^{165}$ The first recorded use of paper money was in China in the $2^{\text {nd }}$ Century BC, while the first circulating 'token' notes were issued in China in 810, also known as 'exchange notes', which were negotiable certificates dubbed 'flying money'. See the Metropolitan Museum of Art (2010) 'Heilbrunn Timeline of Art History', available at http://goo.gl/Ix27C.

${ }^{166}$ These drafts were also known in Mesopotamia when metallic money was introduced.

${ }^{167}$ A note is a promise to redeem later for some other object of value, usually specie. The issue of credit notes is often for a limited duration and at some discount to the promised amount later. See Shubik (2000) op cit note 3 at 9-19.

${ }^{168}$ See German Notes (s.d.) 'History of Paper Money', available at http://goo.gl/9ASjt. Drafts allowing a depositor to draw upon the goldsmith various amounts up to the amount of the deposit, and which were payable on demand and made out to a payee or bearer were the first incarnation of what are today known as 'cheques'. See Geva (1993) op cit note 3 at 1-7.

${ }_{169}$ See ch 3, s3.4.4.2 titled Drafts and Cheques.

170 Notes evolved from goldsmith receipts which were a substitute for carrying gold deposited with goldsmiths. These banknotes could be converted into metallic money when the holder so wished. Geva (1993) op cit note 3 at 1-7. See also Davies (1994) op cit note 3 at 304 who describes an initial resistance to banknotes by traders who thought of banknotes as money substitutes and not as a valuable type of money that stored value in and of themselves.

${ }^{171}$ These receipts, which were $17^{\text {th }}$ century precursors to modern banking systems and negotiable instruments like promissory notes, were known as 'running cash notes' and were made out in the name of the depositor. The receipts promised to pay the depositor on demand. To allow limited circulation, they also carried the words 'or bearer' after the name of the depositor. See Bank of England (s.d.) 'A Brief History of Banknotes', available at http://goo.gl/oLX3Q.

${ }^{172}$ Payee is the person who is the object of the payment. See more on payee in Malan, Pretorius and Du Toit (2009) op cit note 3 at 35 .

${ }^{173}$ The bearer is the person physically in possession of the receipt. M Fouché (2002) Legal Principles of Contracts and Negotiable Instruments $5^{\text {th }}$ ed at 271 .
} 
goldsmiths began issuing more notes as loans in excess of the underlying gold held in their keeping, and so earned interest on the money. ${ }^{174}$

\subsubsection{2}

\section{Drafts and Cheques}

Goldsmith receipts also spawned a new monetary instrument, the draft, which later came to be known as the cheque. ${ }^{175}$ This evolution coincided with the emergence in Europe of what became known as private banks ${ }^{176}$ that would hold cash or gold on behalf of customers. ${ }^{177}$ The draft was more a promise to pay someone else rather than that it possessed any actual recyclable value beyond this use. ${ }^{178}$ The holder of the draft was allowed to draw upon the goldsmith or bank various amounts up to the amount of the deposit, and was made out to a payee or bearer. ${ }^{179}$ This allowed the merchant or bearer of the draft to settle debts from a distance and avoided the danger of transporting metal. It also allowed the extension of a primitive form of credit. ${ }^{180}$ While the draft system proved to be a convenient payment system, it relied inter alia on the goldsmith's (and then the bank's) continued solvency, ${ }^{181}$ trust in the bank or goldsmith, knowledge of the goldsmith especially for people from faraway towns, ${ }^{182}$ the person paying ${ }^{183}$ having sufficient funds to satisfy the face value of the cheque, and of course the recipient ${ }^{184}$ accepting the draft or cheque instrument for (deferred) payment and as a substitute for cash-in-hand. ${ }^{185}$ ${ }^{174}$ Here again is another example of the commercial incentives behind the operation of a payment scheme such as interest,
lending, deposits, and which is the hallmark of modern banking systems where depositors have a choice in action (or claim)
for par redeemability of the deposits they have made with the banker, who is obliged to pay back the deposits on demand
subject to other arrangements such as a fixed deposit for a specified period, or the deposit being used as surety for a larger
loan from the bank.

${ }^{175} \mathrm{~A}$ cheque is a paper-based mechanism and is variously considered to be a written unconditional order signed by the drawer (payor), instructing his bank to pay to the payee's order (or to the bearer) on demand. Geva (1993) op cit note 3 at 1 30. Also spelt 'check,' or 'checque,' the word is derived from the counterfoil of a draft that was used to 'check' for forgeries and alterations. The cheque is now seen legally as a bill of exchange drawn on a bank and payable on demand, but not as money. See 'Check' (2011) Encyclopaedia Britannica Online Academic Edition, available at http://goo.gl/3AGJr; and Humphrey et al (1996) op cit note 3 at 21 . Section 1 of Act 34 of 1964 op cit note 3 defines a cheque as 'a bill drawn on a bank and payable on demand'. This payment instrument was originally known as a 'check' as a record of the transaction was 'checked' for fraud using a counterfoil. It became known as a 'cheque' possibly around 1828. See WJ Lawson (1855) The History of Banking: With a Comprehensive Account of the Origin, Rise and Progress of the Banks of England, Ireland and Scotland at 216. See also ch 4, ss4.8.4.2.5 on Electronic Cheques and 4.8.4.2.6 on Cheque Cards for more information on modern forms of cheques,

${ }^{176}$ The state had no shareholding or control over these 'banks.' The origin of the word 'bank' is in dispute. Ferguson (2008) op cit note 3 at 42-43 says that it is derived from the table (or 'banco' or 'banchieri) used by Renaissance money exchangers like the Medici family who counted, weighed and sorted money of various quantities and qualities in the streets. See JA Kregel (1998) The Past and Future of Banks at 15 cited in E Tymoigne and LR Wray (2005) 'Money: An Alternative Story', available at http://goo.gl/Mcv4Q. There are many statutory definitions of banks, although most statutes will define banks in terms of their functions.

${ }^{177}$ Large banks were founded in the 17th century in Amsterdam and Hamburg.

${ }^{178}$ Thus the draft, a trust instrument, does not substitute metallic money, but joins it.

${ }^{179}$ Deposit holders were able to specify exact amounts payable at a specific date to a specific person (the payee) who treated the note as a means of payment, subsequently presenting the note (cheque) to the goldsmith for payment in cash or gold. Geva (1993) op cit note 3 at 1-7.

${ }^{180}$ The so-called 'letter of credit'. This was the first type of indirect credit transfer. It is an order from a bank to a bank or other party abroad authorising payment of money (up to a specified limit) to a person named in the letter. A letter of credit, unlike a Bill of Exchange, is not negotiable and may be cashed only by the paying bank. The two main classes of letters of credit are commercial and traveller's. Commercial letters of credit are often used by exporters. See 'Letter of Credit' (2011) Encyclopaedia Britannica Online Academic Edition, available at http://goo.gl/oWhmG.

${ }_{181}^{181}$ Governments soon began creating prudential regimes to regulate banking operations.

${ }^{182}$ Modern banking systems of course allow cheques from one bank to be cleared by another bank for payment. See Geva (1993) op cit note 3 at $1-13$.

${ }^{183}$ Also known as the 'payor'. See Malan, Pretorius and Du Toit (2009) op cit note 3 at 35.

${ }^{184}$ Also known as the 'payee'. Ibid.

${ }^{185}$ As Humphrey et al (2006) op cit note 3 at 29 explain, with the expansion of domestic trade and the rise of population density in trading centres during the early 1800 s, paper checks increasingly substituted for coins and notes as currency in business transactions, representing the first stage in the evolution from currency to the use of non-cash payment instruments. 
Thus, payment cheques, unlike cash which was used when final payments were tendered, ${ }^{186}$ acting as a MOP were not final until the instrument was delivered by the payee to the payor's banker for payment, and the payor's banker checked and confirmed that the payor had sufficient funds. Another weakness was that the draft was also a limited-time device, with its buying power and negotiability disappearing once it had been honoured. What was required as a monetary instrument was something portable and durable. The idea of standard, paper-based money was born. ${ }^{187}$

\subsubsection{3}

\section{Banknotes}

Because of the possible refusal of a payee to accept a goldsmith's receipt or draft, or even because of the possible insolvency of the goldsmith, an alternative form of money used for payments for goods and services evolved. This resulted in the development of banknotes, whose issuance grew in major mercantile colonies. ${ }^{188}$ The first iteration of paper money in Europe was the banknote, first thought to be paper 'coins' issued in Protestant Leyden in the Netherlands during the Spanish siege of $1574,{ }^{189}$ while the first proper European banknotes were issued in 1656 by Stockholm's Banco, a predecessor of the Bank of Sweden. ${ }^{190}$

In the Americas, the Massachusetts Bay Colony in the 1690s was the first of the colonies to issue permanently circulating banknotes and these are thought be the first banknotes with sequential numbering and personalisation. ${ }^{191}$ As more notes began to replace metals, ${ }^{192}$ state issuers of money began to issue more notes than convertible precious metal deposits for ultimate redeemability. ${ }^{193}$ During times of crisis, however, holders of notes rushed to convert them into specie, which resulted in many states declaring compulsory use of the notes. ${ }^{194}$ This has obtained to this day. ${ }^{195}$

\subsubsection{4}

\section{Private Money Issuance}

While government-issued money eventually came to dominate the financial landscape after the global adoption of the (proto) concept of the omnipotent state-based $\mathrm{CB}$, this was preceded by a rich history of 'private money' issuance where banknotes were issued by private companies acting in effect as 'banks' and

\footnotetext{
${ }^{186}$ Even if cash is legal tender, a seller may however contractually refuse cash if it is inconvenient. Akindemowo (1998) op cit note 3. See also ch 3, s3.12.3.2.1 on Legal Tender and Fiats.

${ }^{187}$ General money could be privately issued paper notes, but this is in contradistinction to currency money, which is fiat money issued by a state for use in that state.

${ }^{188}$ Davies (1994) op cit note 3 at 304; Geva (1987) op cit note 3 at 141.

${ }^{189}$ During the siege, the residents resorted to making the notes out of leather.

${ }^{190}$ S Fritz (s.d.) 'Stockholm's Banco', available at http://goo.gl/USmVg.

${ }^{191}$ All bills were individually indented with a cut, so that no two cuts would be exactly alike. See Colonial Currency (1998) 'Introduction to Early Massachusetts Currency', available at http://goo.gl/xczqG. See also Geva (1993) op cit note 3 at 1-7.

192 This swap coincided with the establishment of the Bank of England in 1694 whose aim, inter alia, was to provide cheaper money than that provided by the goldsmiths. Davies (1994) op cit note 3 at 238.

${ }^{193}$ This is a practice that continues to this day and is known as fractional banking. See VZ Nuri (2002) 'Fractional Reserve Banking as Economic Parasitism: A Scientific, Mathematical, and Historical Exposé, Critique, and Manifesto' at 3, available at http://goo.gl/mYQhC. See also ch 3, s3.7.2.1 on Credit Money.

${ }_{194}$ Emergency paper money hand-written on playing cards was used in French Canada from 1685.

${ }^{195}$ For example, Shubik (2000) op cit note 3 at 1 refers to paper money as a virtual commodity that, with the dynamics of an economy that accepts it, permits it to serve as an imaginary gold so that it is seen to be valuable.
} 
issuers of money in the absence of a central banking structure. ${ }^{196}$ Sometimes the CB and private banks issued notes in parallel, which were accepted in society in equal measure.

One of the most striking examples of this competitive note landscape was during what has become known as the 'free banking' era, ${ }^{197}$ an oligopolistic period in North America and Europe from 1837 to $18666^{198}$ when private banks could issue notes and in some ways operate their own clearing and settlement systems in the absence of a centralised monetary authority. ${ }^{199}$ Examples include the Scottish free banking era from 1716 to 1844, the Suffolk Banking System that prevailed in New England, the USA, between 1825 and 1858, as well as the role of the New York Clearing House Association (hereafter NYCHA) in the 19th and early $20^{\text {th }}$ centuries. ${ }^{200}$ In all, it is estimated that stores, restaurants, churches and individuals had printed around 8,000 different money types by $1866 .{ }^{201}$ These deposit-taking institutions emerged and thrived because they could process private information at a lower cost than individuals. ${ }^{202}$

While private money in the sense of competitive banknotes in a state disappeared, it would seem that they may have re-emerged in the form of dematerialised or electronic types of money, as well as through the use of wealth to exchange value. These may be termed 'currencies'. ${ }^{203}$

This era of private note issuance was followed by the gradual removal of precious metals from the monetary system, which allowed governments to substitute for commodities by issuing their own banknotes, sometimes in competition with private banknote issuance. ${ }^{204}$ The economist Friedrich Von Hayek termed this an 'era of monetary nationalism, ${ }^{205}$ where governments expanded their involvement in

\footnotetext{
${ }^{196}$ On the proto bank concept, see ch 3, 3.5.3.4 titled Prototypical Bank: Store of Deposits; and Geva (1987) op cit note 3 at $147-155$ on the issuance of private money.

${ }^{197}$ The term 'free banking' originally referred to the period in the US between 1837 and the founding of the Federal Reserve Bank in 1913. During this period though, the banking system was not unregulated as the term misleadingly seems to suggest, but entry was possible without the need to require a legislative charter. See Holtzhausen and Monnet (2003) op cit note 3 at 23.

${ }^{198}$ While there were successes, the disparate, illiquidity, inelasticity (under issuance) and non-interchangeable nature of the UOA led to the National Banking Act that allowed 'nationally-chartered' banks to issue banknotes, and created a 'pyramid' structure of national banks consisting of country banks, reserve city banks, and central reserve city banks. See JMM Dykes (1995) 'Digital Cash and the Development of the Apolitical Currency Paper for MIT 6.805/STS085: Ethics and Law on the Electronic Frontier', available at http://goo.gl/OOVVH.

199 The European Central Bank (hereafter ECB) points out that the term 'free banking' is nowadays used for unregulated competitive banking, often associated with a system operating without a CB. See ECB (2004) op cit note 3.

${ }^{200}$ No monopoly emerged in the Scottish system and it was apparently very stable. See Millard and Saporta (2005) op cit note 3 at 59 .

${ }^{201}$ Closure of the scheme rendered the note worthless.

${ }^{202}$ See Janson (2001) op cit note 3 at 1 who also says that given this comparative advantage in managing private information, deposit-taking institutions could offer means of payment, both notes and deposits, as well as loans.

${ }^{203}$ See ch 3, s3.6 below on Money and Currency: General View.

${ }^{204}$ In 1661, the Bank of Stockholm created the first banknotes in Europe. See Banco de Portugal (s.d.) 'Money in the West of the Iberian Peninsula', available at http://goo.gl/C6q0a.

${ }^{205}$ Von Hayek (1937) op cit note 3.
} 
monetary affairs, inter alia, monopolising the issue of banknotes and substituting state-issued fiat monies for commodity based monies. ${ }^{206}$

As a result, the role of market institutions and particularly free banking proponents were ameliorated. The government money was given extra gravitas as it was backed by the edict or fiat of the state that declared the value of the notes as 'currency', that is, a 'fiat currency'. ${ }^{207}$

\subsection{2}

\section{Role of the State}

As noted earlier, ${ }^{208}$ the state may be the primary originator of policy and statute that decides on the fate of new forms of money. The issuance of fiat currency and the determination of the scope and autonomy of the $\mathrm{CB}^{209}$ of that country ${ }^{210}$ are two of the parcels of right to monetary sovereignty enjoyed by the state. A body of international law has been developed through customary law, doctrinal sources, judicial decisions and treaties that defines the contours of monetary sovereignty. ${ }^{211}$

As such, monetary systems in most countries with modern economies now consist of a number of key areas that define the perimeter of the country's monetary sovereignty.

There are essentially three exclusive rights for a given state to issue currency, that is, coins and banknotes that are legal tender within its territory; ${ }^{212}$ to regulate the use of that currency, or any other currency, within its territory; ${ }^{213}$ and to determine and change the value of that currency (also called Nominalism).

Nominalism is a principle of international law that allows each state to change the value of its currency and leads to a recognition abroad that a devaluation or revaluation operated by the lex monetae affects the value of obligations denominated in that currency. ${ }^{214}$

\footnotetext{
${ }^{206}$ Selgin and White (2002b) op cit note 3.

${ }^{207}$ As Akindemowo (1998) op cit note 3 notes, at a higher level and when stripping fiat currency of its 'mystique', the 'fiat' may be seen simply as circulating obligations (indirectly) linked to state debt obligations, where the national currency which in the Orthodox School money conceptualisation may be seen as the GAME - embodies undertakings made by the state that it has sufficient assets - possibly gold, or possibly currency reserves in another convertible currency - to maintain the face value of the currency. This embodies the principle of nominalism. As the fiat is 'incontrovertible' though, it cannot be redeemed and hence cannot be regarded as creating a direct debt owed by the state to the holder.

${ }^{208}$ See ch 3, s3.2.4.1 titled Issuance and Production of money.

${ }^{209}$ The terms 'Central Bank' and 'Reserve Bank' are used interchangeably, but essentially mean the same thing. Treasury, in contrast, usually refers to the political government finance ministries. In many countries, though, these institutions are not independent, but subject to the policy whims of the government of the day. Some CBs may ostensibly be nominally free of government interference in decision-making, for example the Bank of England. See BBC Report (1997) 'Brown sets Bank of England Free', available at http://goo.gl/beQZx.

${ }^{210}$ The currency between nation states may, however, be purposely identical. For example, a set of Euro notes and coins were officially introduced as a single pan-European currency throughout the EU on 1 January 2000. The same notes and coins thus became legal tender throughout the EU.

${ }^{211}$ Gianviti (2005) op cit note 3.

${ }^{212}$ See C Brokelind (2000) 'Discussion of Some Legal Issues Raised by the Introduction of the Euro' available at http://goo.gl/ctmYt at 9, who says that traditionally States are sovereign in ruling over a currency through their monetary law (lex monetae), often classified by lawyers within public law. However, the expression of this sovereignty also has consequences for the civil law of contracts, where the value of an obligation is determined by reference to national monetary law.

${ }^{213}$ The CB may regulate payments, impose exchange controls, prohibit the making or receipt of payments and transfers in foreign currency for domestic and international transactions, and so forth. It may limit the scope of legal tender, for example, by requiring that payments above a certain amount be made by cheques or transfers (to avoid tax evasion). See Gianviti (2005) op cit note 3 at 17.
} 
The right to issue currency internally by a state has economic implications that go far beyond the supply of coins and banknotes to a country's economy. For example, a devaluation of a strong currency may have a knock-on effect on other currencies and lead to an economic contagion, such as occurred in Russia in the early 1990s and Asia in the late 1990s when many regional currencies collapsed in a catastrophic domino effect in the region's economies. ${ }^{215}$ However, the state is not merely an arbitrator of monetary policy, it is also an active participant that directly benefits through its shareholding in the CB from the actual issuance of legal tender paper and scriptural money and the Bank's seigniorage ${ }^{216}$ or interest income from these notes. Many national CBs - whose shareholders mostly include the state ${ }^{217}$ - are responsible for the implementation of government policy, or for the execution of policy according to their mandate, or to some extent, for the creation of policy. Extending from the exclusive rights described above are some further rights which include control of private money markets, control of bond markets, control of government money markets and control of markets for bank loans. ${ }^{218}$ Many of these rights are seconded to the nominally independent $\mathrm{CB}$ of that state.

In the face of these challenges, new potential forms of money may have to navigate the leeways of prudential and state requirements and the vested interests of CBs in keeping their monopoly over the issuance of currency to find legal gravitas as a GAME or something similar. ${ }^{219}$

\section{Role of the Central Bank in Money}

3.5.3.1

\section{Overview}

To a great extent, governments around the world have given natural monopolies to the CBs over three core monetary policy imperatives, ${ }^{220}$ although this monopoly is fast being eroded by new forms of monetary instruments such as electronic representations of money ${ }^{221}$ and transfer of wealth. ${ }^{222}$ Overall though, many national or supra-national governments give their CBs general monopoly rights to many fiscal ecosystems, including interest rates and, importantly for this discussion, the creation of policy for money supply, legal tender issuance, banknotes, and the oversight of the integrity of national payment systems where these exist. These are clearly all important roles that assist stable economies.

\footnotetext{
${ }^{214}$ Ibid. The principle of nominalism was laid down by Aristotle in the Nicomachean Ethics, who said: 'Money has been introduced by convention as a kind of substitute for a need or demand, and this is why it is called "nomisma" because its value is not derived from nature but from law (nomos)'. See Mann (1992) op cit note 3 at 92.

${ }^{215}$ DK Nanto (1998) 'The 1997-98 Asian Financial Crisis: CRS Report for Congress', available at http://goo.gl/3F5XZ.

${ }^{216}$ See ch 3, s3.5.3.3.1 below on the potential loss of CB seigniorage revenue.

${ }^{217}$ There have however been siren calls to nationalise the SARB to 'allow a different approach to money creation'. See J Edozien (2008) 'Ending Economic Apartheid', South African New Economics Network, available at http://goo.gl/L9cQZ.

${ }^{218}$ See Gianviti (2005) op cit note 3 at 17.

${ }^{219}$ As indicated however in ch 2, s2.4.2, modern mercantile techniques using electronic means of payment as well as transfer of wealth may in fact be bypassing the need for new potential forms of money to be legally anointed as legal tender GAME so as to satisfy debts and obligations.

${ }^{220}$ See Mann (1992) op cit note 3 at 460-78 and Gianviti (2005) op cit note 3.

${ }^{221}$ See ch 4, s4.8.4.4.9 titled Nature of the Transaction and Settlement.

${ }^{222}$ See on transfer of wealth, see ch 3, s3.7.2.2 titled Money as a Store of Wealth.
} 
The monopoly ${ }^{223}$ thus usually entails issuance of money as legal tender or the GAME; ${ }^{224}$ preservation of monetary stability; financial stability and control of a National Payment System (hereafter NPS' or 'NPSs).

The preservation of monetary, financial and payment system stability entails the reduction of 'systemic risk' in the financial sector of a country, because one disruption within a bank could trigger or transmit further disruptions among participants or within the banking and payments sector. ${ }^{225}$

\subsubsection{2}

Rights

This suite of rights is usually a comprehensive and unassailable endogenous banking monopoly which results in the total regulation of the issuance and use of the national currency, ${ }^{226}$ the oversight and maintenance of payment and settlement systems, ${ }^{227}$ the supervision of banks, and in some countries, a monopoly on cheque clearing. ${ }^{228}$ The money issued by the CB is also called 'Outside Money' and usually includes all bank balances - or 'inside money ${ }^{, 29}$ - denominated in that currency.

While technology and novel monetary instruments may chip away at this monopoly by providing an alternate means to transfer wealth and settle debts inter partes, some have argued that the provision of money should be left as a government monopoly because it is a public good whose production is best left to the $\mathrm{CB}$, and by implication, the state. ${ }^{230}$ Notes and money, it is generally thought, ${ }^{231}$ represent a very homogeneous category good. Fundamental to this role as financial overseer, the CB will have oversight over payment mechanisms, ${ }^{232}$ and mediate a centralised interchange of payments in settlement of debt between banks. ${ }^{233}$ Hence banks to whom the CB has extended credit and who have in turn lent to other

\footnotetext{
${ }^{223}$ Some scholars, however, believe that monetary policy and the CB monopoly is trite and artificial, that money is a commodity and that therefore 'no institution is required to regulate the supply of money on a free market'. See Shostak (2000) op cit note 3 . The premise is based, however, more on the use of gold as the standard of determining a currency's UOA.

${ }^{224}$ See ch 3, s3.5.3.3 titled Issuance of Money on the 'GAME'.

${ }^{225}$ In that sense a CB , in its role as a proto Bank, could act as a 'lender of last resort' to assist domestic banks that have liquidity issues in repaying creditors and depositors. See further on the proto concept, ch 3, 3.5.3.4 titled Prototypical Bank: Store of Deposits. On systemic risk and supranational initiatives to contain it in respect of national payments systems, see ch 4, s4.8.1 titled Overview.

${ }^{226}$ Fama (1980) op cit note 3 passim.

227 This monopoly has been extended in the EU's PSD. An ECB opinion on the proposed PSD insists that 'all activities performed by CBs are exempt from the PSD', even for retail payment systems. European Central Bank (ECB) (2006) 'Opinion of the ECB on a Proposal for a Directive on Payment Services in the Internal Market (ECB/2006/21)' at 15, available at http://goo.gl/8EA5t.

${ }^{228}$ The Danish Central Bank has a monopoly over cheque clearing. See Holtzhausen and Monnet (2003) op cit note 3.

${ }^{229}$ See ch 3, s3.7.2.1 on 'Bank Money' and 'Credit Money'. These are often referred to as 'Inside Money'.

${ }^{230}$ Tobin argues that since there is an increased use of money (with a single UOA), the potential benefits from using this money rise, and from which flows, its character as a public good. Vaubel says that while a UOA might be a public good, this does not imply that money is one. See J Tobin (1980) 'The Overlapping Generations Model of Fiat Money: Discussion' in JH Karken and N Wallace (eds) Models of Monetary Economies and R Vaubel (1990) 'Currency Competition: Free Entry Versus Governmental Legal Monopoly' in K Groenveld, J Maks and J Muysken (eds) Economic Policy and the Market Process 23-386 cited in Holtzhausen and Monnet (2003) op cit note 3 at 12; see also SW Schmitz (2001) 'The Institutional Character of Electronic Money Schemes: Redeemability and the UOA' at 7, available at http://goo.gl/RDx01.

${ }^{231}$ Janson (2001) op cit note 3 at 7.

232 The Committee on Payment and Settlement Systems (CPSS) defines this oversight as: '(Promoting) the smooth functioning of payment systems and to protect the financial system from possible "domino effects" which may occur when one or more participants in the payment system incur credit or liquidity problems. Payment systems oversight aims at a given system (eg a funds transfer system) rather than individual participants'. See CPSS (2003a) op cit note 3. See Fraser (1994) op cit note 3 .

${ }^{233}$ Historically, this monopoly oversight and involvement evolved because of disparate mechanisms of payment that led to market inefficiencies and weaknesses in payment, and the need for an efficient mechanism of payments. For the role of CBs,
} 
banks will use the monies deposited by other member banks in its reserve as the 'settlement asset' of choice for settling the debts of its members. ${ }^{234}$ In that regard, the CB is a core contributor to NPS ${ }^{235}$ development and generally plays a variety of essential roles in the payment system: it is a provider of payment accounts and credit, an overseer in core payment arrangements, and an operator, provider and user of various payment services, ${ }^{236}$ and mediation of clearance ${ }^{237}$ and settlement. ${ }^{238}$

CBs in many cases may also have inordinate influence over national policy towards new forms of money and in some cases are allowed to create policy independently of the government of the day. ${ }^{239}$

An integral component of the monopoly rights afforded to CBs by fiat of the state is a monopoly to create and issue the currency of that country, that is, legal tender. ${ }^{240}$ Legal tender may also be the GAME. ${ }^{241}$ The $\mathrm{CB}$ as the prototypical bank has a unique position in monetary policy implementation since $\mathrm{CB}$ money is the GAME. The GAME, though, has two incidental functions, that of (uniform) UOA and as the medium of final settlement. $^{242}$

As described above, the CB is usually the only entity whose 'money' is regarded as legal tender. ${ }^{243}$ In terms of s15(1) of the Currency and Banking Act, ${ }^{244}$ and more recently s14 of the South African Reserve Bank

see F Ntuyenabo (2009) The Legal Foundation of the Independence of Central Banks: A Comparative Study LLM Thesis, University of South Africa, available at http://goo.gl/hCUs4.

${ }^{234}$ In supplying their money to the banking system, CBs typically make a distinction between lending overnight and intra-day lending. They typically charge the policy rate for credit extended overnight, but charge little or nothing for credit extended within the day. See Millard and Saporta (2005) op cit note 3 at 59.

${ }^{235}$ See on payment systems, ch 4, ss4.8.1 titled Overview and 4.8.2.3.1 on National Payment Systems.

${ }^{236}$ Committee on Payment and Settlement Systems (CPSS) (2005b) 'General Guidance for Payment System Development 2005', available at http://goo.gl/QU7ek.

${ }^{237}$ The exchange of information about payments entered into the system. J McAndrews (1997) 'Banking and Payment System Stability in an Electronic Money World' at 8, available at http://goo.gl/VGKOd.

${ }^{238}$ The final discharge of payment obligations. Ibid.

${ }^{239} \mathrm{CB}$ independence is not unconditional independence from government, but rather it manifests as the independence to pursue price stability (or inflation targeting). Its role in implementation of monetary policy involves inter alia the manipulation of relative price (ie opportunity costs) of the medium of final settlement; and the spread of rate of interest on the medium of final settlement and optimal alternative investment (ie money market). See SW Schmitz (2005) 'Will Central Banking Survive Electronic Money?' Prepared for the conference The Future of Payments Bank of England, London 19-20 May 2005 at 3.

${ }^{240}$ The Concise Oxford Dictionary defines legal tender as 'currency that cannot legally be refused in payment of debt (usually up to a limited amount for baser coins, etc.)'. See further on legal tender, ch 3, s3.12.3.2.1 titled Legal Tender and Fiats.

${ }^{241}$ This may be the legal tender of bank inside money representations thereof.

${ }^{242}$ The CB is able to manipulate the supply and relative price of the GAME at zero marginal cost. See Schmitz (2005) op cit note 3 at 1 .

${ }^{243}$ Menger (1892) op cit note 3 at 239-255. Similarly, by decree, governments could remove the appellation of legal tender from a currency. This has most often occurred in Zimbabwe as a result of hyper-inflation that has led to the obsolescence of banknotes and their replacement by novel means of government-issued tender such as 'bearer cheques' that replace banknotes of high nominal value.

${ }^{244}$ Act 31 of 1920 op cit note 3 . 
Act ${ }^{245}$ the South African Reserve Bank (hereafter SARB) has a monopoly on the right to manufacture, issue and destroy banknotes and coin in South Africa. ${ }^{246}$

With respect to their monopoly over the issuance of money, this primarily relates to fiat money, which is money issued by decree of a government and which cannot be converted into specie of equivalent value. ${ }^{247}$ The CB is given the right to control the amount of money issued into the commercial and consumer market by the commercial banks through continually adjusting the lending rate to the other banks in the payment hierarchy. ${ }^{248}$ Modern statutes establish an imposed equivalence - or fiat equivalence - between the privileged legal tender, as a MOE, and other MOEs. ${ }^{249}$

Although CBs are usually independent or semi-independent institutions created under decree or an act of government to manage the money supply and financial stability of a country, their main source of revenue is usually via 'seigniorage' revenue. ${ }^{250}$ This is the net revenue derived from the issuing of coins or banknotes and arises from the often substantial difference between the face value of a coin or banknote and the cost of producing and distributing it. ${ }^{251}$

Nowadays, even though a government monopoly in the provision of money is standard, there are still several levels where the $\mathrm{CB}$ may encounter some competition. First, CB money (public currencies) compete against each other internationally, with exchange values changing on a daily basis. Second, CB money may sometimes also compete at a national level with private systems, to wit, private SOVs where these private systems use CB money - for example, in purchasing the private money with CB money or redeeming it ex-system ${ }^{252}$ - there may be a strong incentive by a CB to control the private money issuers and their methods of issuance and settlement.

\footnotetext{
${ }^{245}$ Act 90 of 1989 op cit note 3 . It says that: 'The Bank shall have the sole right to issue or cause to be issued banknotes and coins in the Republic'.

${ }^{246}$ The first paper money was introduced into South Africa in 1782 when the Dutch Governor of the Cape, van Plettenberg, was obliged to introduce notes because of a shortage of money from the Netherlands. The first monies were the 'Rixdollar' and 'Stiver' denominations which were the currency of the Cape at that time. South African Reserve Bank (s.d.) 'History of South African Banknotes 1782 to 1920,' available at http://goo.gl/RwR9M. The SA Mint Company, a subsidiary of the Bank, mints all the coins on behalf of the Reserve Bank while the SA Bank Note Company, another subsidiary of the Bank, prints all banknotes on behalf of the Bank.

${ }^{247}$ Paper money that the CBs produce are fiat money because they can redeem one of these pieces of paper for another similar piece of paper (or issued coins) of equivalent value. Although the value of fiat money can be redeemed for fractional values issued by the state, modern economies do not allow redeemability against any underlying commodity value. The $\mathrm{CB}$ assures holders of currency that the circulating tokens endorsed and issued under its authority will continue to be valuable, and backs an incontrovertible currency with its fiat. See Akindemowo (1998) op cit note 3 at 5.

${ }^{248}$ The rate is known in South Africa as the 'repo rate.'

${ }^{249}$ See ch 3, s3.12.3.2.1 titled Legal Tender and Fiats.

${ }^{250}$ The term 'seigniorage' was used to refer to the share, fee or tax which the seignior, or sovereign, took to cover the expenses of coinage and for profit. See Bank for International Settlements (BIS) (1996) 'Implications for Central Banks of the Development of Electronic Money' 1-20 at 15, available at http://goo.gl/TxTnD and Bank of Canada (s.d.) 'Seigniorage Revenue', available at http://goo.gl/cEQhq.

${ }^{251}$ Or revenue from printing money ultimately remitted to their major or only shareholder, the government.

${ }^{252}$ The SOV component involves storing and transforming value, for example, through deposits, loans, securities, and savings. See s1.1a2 of Association of E-money Institutions in the Netherlands (2003) 'The Electronic Money Directive: Recapitulation and Outlook: Working Paper for the GTIAD-Meeting of November 27, 2003' at 4, available at http://goo.gl/QiG6N.
} 
The CB usually extends credit to commercial banks at a certain rate, ${ }^{253}$ who in turn may lend the money to their own customers for commercial reward, usually at a higher rate. ${ }^{254}$ This bank or credit 'inside' money is issued by banks and financial institutions via credit to its customers. ${ }^{255}$

It is termed 'inside money ${ }^{256}$ because it does not necessarily require the apparatus of the state to be granted. ${ }^{257}$

However, for final settlement purpose (at a payment systems level), all 'inside money' must be settled (and redeemed) using the CB GAME. Keynes ${ }^{258}$ and the Claim School believe in lending out the CB to multiple customers, the banks are themselves endogenously creating (inside or bank) money, although importantly, it is redeemable into the GAME. This is of course, 'fractional banking., 259

\subsubsection{4}

\section{Prototypical Bank: Store of Deposits}

The era of what Von Hayek called 'monetary nationalism, ${ }^{260}$ saw the establishment of CBs and the growth of national economies. This led to a change in the 'business of a bank' from its primary role as payment provider to that of managing deposits and of converting money titles such as loans, savings and securities. ${ }^{261}$ As the science of economics evolved, the need for national governments to encourage deposits as a method of inflation control became more pronounced, while banks became the primary method for depositing these funds. ${ }^{262}$ Controlling 'deposits' then became as important as controlling the payment systems and banking regulations as such evolved to reflect this. In many cases, 'deposit-taking' (and its role as a SOV) became the primary focus in the definition of 'the business of a bank.' With national economies at stake, the regulations tended to be very strict and conservative, allowing only a few players who were able to rise to the specified regulatory competencies required to take deposits and undertake payment activities. ${ }^{263}$

In most countries, it is mandatory for commercial banks to hold reserves at the $\mathrm{CB}$ - as the prototypical or proto national bank - in funds denominated in the GAME at the CB since the GAME is the only MOP that

\footnotetext{
${ }^{253}$ See for more on lending ch 3, s3.5.3.2 on Rights.

${ }^{254}$ The CB will not issue coins and banknotes per se, but will create book entries to reflect its lending to the banks.

${ }^{255}$ See Shubik (2000) op cit note 3 at 5.

${ }^{256}$ Versus 'Outside Money', discussed in ch 3, s3.7.2.1 below titled Credit Money. This contrasts with non-bank money, considered as 'Inside Money'.

${ }^{257}$ Ibid. For example in (primitive) societies where individuals knew the members of their small social unit.

${ }^{258}$ Keynes (1971) op cit note 3 at 3.

${ }^{259}$ See ch 3, s3.7.2.1 on Credit Money; and Wray (2006) op cit note 3 on endogenous money.

${ }^{260}$ Von Hayek (1937) op cit note 3.

${ }^{261}$ H Leinonen (2005) 'Liquidity, Risks and Speed in Payment and Settlement Systems: A Simulation Approach' at 31, available at http://goo.gl/cgCdj.

${ }^{262}$ The less money available in the market to spend, the better the inflationary outlook. CBs tend to increase interest rates to slow spending and credit provision. This however may stretch commercial banks' ability to settle with the CB.

${ }^{263}$ In the EU only credit institutions are allowed to conduct the business of a bank and take deposits and do payments. Similarly in South Africa, the Banks Act has provided strict guidelines for conducting the business of a bank.
} 
provides settlement. ${ }^{264}$ The CB may also act where needed as a 'lender of last resort.' Private currencies where the issuer settles with other currencies or other similar issuers in terms of their own liabilities ${ }^{265}$ or wealth ${ }^{266}$ may thus compete with the $\mathrm{CB}$ in this arena, so displacing the CB's mantle as sole controller of settlement. ${ }^{267}$ Even if the CB GAME maintained its mantle as the means of final settlement, private systems where the transfer of wealth allows private issuers to settle between themselves may reduce the $\mathrm{CB}$ role in the settlement process to the point where CB policy instruments lose their efficacy.

\subsubsection{5}

\section{Payment Systems}

Money has as we have seen two financial services components, that of payments ${ }^{268}$ and deposit-related businesses. These relate to the historical roles of money. In addition, and fundamental, to this role as financial overseer, the $\mathrm{CB}$ will have oversight over payment mechanisms, ${ }^{269}$ mediating a centralised interchange of payments in settlement of debt between banks, and by extension, others engaged in payment services. ${ }^{270}$

Thus national payment systems are at the core of the modern CB role, with the CB acting to supply (CB) money for settlement of payments. ${ }^{271}$

This hierarchy is said by many economists to be the most efficient method of transferring value (money) between banks. ${ }^{272}$ The role of the South African NPSs is discussed below. ${ }^{273}$

Money is often referred to interchangeably as 'currency' which, depending on its context, may mean many things, but which may not necessarily be the same. It may be private or via the state. Generically, currency may be defined as 'a system of money in general use in a particular country. ${ }^{274}$

\footnotetext{
${ }^{264}$ On the proto bank concept, see AG Haldane, S Millard and V Saporta (2007) The Future of Payment Systems at 20. There are also strict capital requirement rules for banks holding deposits under the 'Basle' rules. See ch 4, s4.2 on Nature of Banking: An Overview.

${ }^{265}$ That is, private (electronic) monies which are not redeemable in $\mathrm{CB}$ reserves.

${ }^{266}$ See ch 3, s3.7.2.2 on Money as a Store of Wealth.

${ }^{267}$ Schmitz (2005) op cit note 3 at 90, who indicates that these liabilities are denominated and redeemable in CB money such that the clearing house needs to hold reserves on the books of the $\mathrm{CB}$. All balances not netted out during the day continue to be settled in CB money so that the system remains ultimately anchored in CB money.

${ }^{268}$ The payment services component allows transportation of value along a payment system.

${ }^{269}$ The BIS sees this oversight as promoting the smooth functioning of payment systems and to protect the financial system from possible 'domino effects' which may occur when one or more participants in the payment system incur credit or liquidity problems. The oversight of payment systems is aimed at a given system (eg a funds transfer system) rather than at individual participants. See CPSS (2003a) op cit note 3; and Fraser (1994) op cit note 3.

${ }^{270}$ Historically, this monopoly oversight and involvement evolved because of disparate mechanisms of payment that led to market inefficiencies and weaknesses in payment, and the need for an efficient mechanism of payments.

${ }^{271}$ In 1998, the US Federal Reserve stepped in to preserve the financial markets when it filled a payment void left by the multibillion dollar failure of the Long-Term Capital Management hedge fund. See K Dowd (1999) 'Too Big to Fail?: LongTerm Capital Management and the Federal Reserve' Cato Briefing Paper No 52, available at http://goo.gl/q1n93.

${ }^{272}$ Banks towards the bottom of the 'pyramid' would have accounts with correspondent banks in the upper section of the pyramid, which in turn have accounts with other banks near the apex. At the base however is the CB, which acts as a settler of debts and an issuer of money.

${ }^{273}$ See ch 4, s4.8.2 on Hierarchies of Payments.

274 'Currency' (s.d.) Oxford Dictionaries, available at http://goo.gl/z3soH.
} 
As to its function, currency may be defined as 'something that is used as a MOE, of money'. ${ }^{275}$ Or, in a circular fashion, a currency could be considered as a kind of money in which payment finality occurs without the involvement of the issuer of the currency. ${ }^{276}$

It is argued that not all monies are necessarily currencies and not all currencies are money and not all currencies are legal tender. ${ }^{277}$ Money then, and state-issued fiat money in particular, must be distinguished from currency generally. Lietaer ${ }^{278}$ says that while money is a form of currency, currency is much broader $^{279}$ and tends to engage state control over money issuance, use and money supply. ${ }^{280}$

From this he sees the following incarnations of currency: legal tender currency, commercial private currencies like airtime and airmiles, ${ }^{281}$ complementary currencies ${ }^{282}$ and social purpose currencies. ${ }^{283}$

Currency can thus simply be the value accepted by parties to a transaction, be that a fiat currency or a private currency denominated in a standard measure as a UOA.

This may be airmiles, airtime minutes, Rands or Euros.

275 'Currency' (2006) Random House Unabridged Dictionary.

${ }^{276}$ JH Sommer (1998) 'Where is a Bank Account?' 57 Maryland Law Review 1, available at http://goo.gl/or29s.

${ }^{277}$ As Ingham (2004) op cit note 3 at 198 argues tangentially, for a 'money' to be 'complete' and to not be anthropologically characterised as of 'limited purpose' insofar as its legitimacy and insofar as its acceptance as legal tender is concerned, it must be backed by the state, or at the very least denominated in the UOA of the state in which it is used. Dodd (2005) op cit note 3 at 407, however, disputes this. He claims that there is no compelling reason to assume that forms of money not denominated in the official currency are bound to fail. The circulation of currency within an increasingly dematerialised medium, he says, presents serious difficulties for monetary policy, whereas the circulation of monetary forms in other denominations raises formal (or legal) issues of monetary governance. Ingham (2004) op cit note 3. For an extended doctrinal debate on the definition and scope of 'money', see Ingham (2007) op cit note 3, and for the counterview to Ingham, see Dodd (2007) op cit note 3. See also on e-currencies, JM Lacker (1996) 'SVCs: Costly Private Substitutes for Government Currency’ Federal Reserve Board of Richmond Economic Quarterly at 1, available at http://goo.gl/OFyQd; G Dwyer (1996) 'Wildcat Banking, Banking Panics and Free Banking in the United States' Federal Reserve Bank of Atlanta at 1, available at http://goo.gl/Rdiaf; KL Macintosh (1998) 'How to Encourage Global E-Commerce: The Case for Private Currencies on the Internet' 11 Harvard Journal of Law and Technology 733; TA Rohling and MW Tapley (1998) 'Optimal Regulation of Electronic Money: Lessons From the "Free Banking”' Era in Australia' 17(7) Economic Papers 729; RG King (1994) 'On the Economics of Private Money' Journal of Monetary Economics 127-155; Selgin and White (1994) op cit note 15.

${ }^{278}$ Lietaer (2002) op cit note 3 at 19.

${ }^{279}$ Kutyn says that currency is that which is used in trade as a MOE. See Kutyn (2005) op cit note3 at 2; and Mann (1992) op cit note 3 at 15 where he says that the chattel component of money is a result of the state's sovereign power over money. The currency thus includes the whole of monetary, credit, fiscal and budgetary policy as well control of inflation and interest rates.

${ }^{280}$ For another view that currency is broader than money (lato sensu), see Kutyn (2005) op cit note 3. For a view (strict sensu) of money encompassing as its subsidiary, currency, see S Mishkin (1989) The Economics of Money, Banking, and Financial Markets $2^{\text {nd }}$ ed at 22; Fox (2008) op cit note 3 at 16; and, overall, M Stathopoulos (1994) 'Modern Techniques for Financial Transactions and Their Effects on Currency: General and National Reports' in 14th International Congress of Comparative Law Athens at 4.

${ }^{281}$ Lietaer (2002) op cit note 3 at 19-21 describes commercial and private currencies where two types of commercial private 'virtual' currencies may be relevant: loyalty currencies, and so-called 'barter currencies'. See also ch 4, s4.8.4.4.4.1 titled Private Currencies. For a statutory perspective on these SVPs, see s35 of Act 68 of 2008 (CPA) op cit note 3 on loyalty

points as a MOE.
${ }_{282}$ Complementary currencies - possibly even virtual currencies like airmiles and Facebook credits - that are accepted in payment are different from legal tender and do not aim to replace but only to complement the conventional national currency. They are therefore designed to function in parallel with or as a complement to these conventional currencies. See Lietaer (2002) op cit note 3 at 19 .

${ }^{283}$ Currencies that aim at resolving a variety of social problems, such as elderly care currencies, unemployment currencies or environmental currencies; see Lietaer (2002) op cit note 3 at 20. See further on private currencies, ch 4, s4.8.4.4.1. 
The use and categorisation of money as a currency is in large measure derived from the various economic, legal and national perspectives of money, discussed in detail below. ${ }^{284}$

\section{Overview}

The preceding sections have shown that from its evolution from simple barter systems to banknotes, money can now essentially be represented in two basic forms. ${ }^{285}$

The first is the familiar token, usually those physical objects such as coins and paper that do not in and of themselves have any intrinsic value, but which are used in mercantile markets through direct physical exchange of tokens like cash coins or paper notes ${ }^{286}$ This circulating currency is what is used in a monetary payments system and is issued by CBs. ${ }^{287}$ The other modern form of what economists term money and which is typically used for transactions is an accounting system of exchange where there is simply a notation or scriptural representation ${ }^{288}$ of value that is able to account for and record values, usually through a mere entry in a system such as a ledger entry in a bank accounting system or even using a SVP. $^{289}$

Money's forms may have changed at different historical junctures from token to paper note to scriptural and emerging dematerialised (incorporeal) forms, but there is now a more pronounced gap between the value of money which, historically, was determined and backed by a commodity ${ }^{290}$ and its modern, more subsidiary and abstract ${ }^{291}$ value as a monetary instrument or 'wealth' money ${ }^{292}$ which does not require recourse to state-issued (fiat) instruments.

These advances are exemplified by the ostensible dematerialisation of money through the emergence and predominance of more electronic types of what could come to be termed 'money,' be they electronically stored scriptural ${ }^{293}$ entries representing 'money' in the books of the $\mathrm{CB}$ and its associated national banks, or

\footnotetext{
${ }^{284}$ See ch 3, s3.12.3.2 titled Money as Fiats, Legal Tender and Currency on, inter alia, legal tender and currency.

${ }^{285}$ Davies (1994) op cit note 3 at 119 and 292; and T Smedlinghoff (1996) Online Law at 105.

${ }^{286}$ Unless, of course, if its components increase in market value, like silver or gold. See Davies (1994) op cit note 3 at 292; and Mundell (1998) op cit note 3 at 26. Nowadays, though, the token has limited utility in a modern economy because of the need to carry increased amounts of money in inflationary times. Traditional token currency is thus only convenient for smallvalue transactions. See McCallum (1985) op cit note 3 at 4-5.

287 They are also difficult to exchange in large amounts and to transport or store securely. Commercial banks actively discourage the use of cash through exorbitant storage and security costs.

${ }^{288}$ Or monnaie scripturale, also known as 'bank money'. See Mann (1992) op cit note 3 at 5.

${ }^{289}$ See ch 4, s4.8.4.4 titled Stored Value Products.

${ }^{290}$ This is the Orthodox School view of money where money's intrinsic value is backed by a physical commodity such as gold or through a symbolic form. See ch 3, s3.9 on the Orthodox School.

${ }^{291}$ Figueras and de Subirà (1997) op cit note 3 at 7.

${ }^{292}$ See ch 3, s3.7.2.2 titled Money as a Store of Wealth.

${ }^{293}$ See ch 3, s3.7.2 below on Scriptural 'Money'.
} 
prepaid 'value' like electronic money ${ }^{294}$ and electronic forms of money placed in the systems of private payment systems. ${ }^{295}$

Technology has accelerated this change. ${ }^{296}$

\section{Scriptural Money}

\section{Credit Money}

As noted earlier ${ }^{297}$ and expanded upon below, one view of 'money' is that it is, in effect, a series of debts created through debits and credits whereby money units recorded merely as 'tokens' in bank accounting records to reflect token paper money or the equivalent in specie ${ }^{298}$ that has been deposited in that bank. ${ }^{299}$ This record is in the form of a written script ${ }^{300}$ - derived from the French term monnaie scriptural ${ }^{301}$ which represents the existence of the 'deposited' value and any subsequent movements of these value units, and is in effect a representation of financial claims ${ }^{302}$ on banks, other financial institutions, and those storing value generally. ${ }^{303}$ The holder of an account - if there is such a thing - may at some stage withdraw on demand the funds in cash or in specie and at par. ${ }^{304}$ The debts however may or may not circulate.

Seen one way, this is primarily a mechanism the commercial banks use to compensate for a shortage of notes in circulation or for those which they hold, and also to extend the mercantile utility of deposits held in their accounts. ${ }^{305}$ Seen from another perspective, money is created endogenously from the practice whereby a bank allocates multiple money credits to different accounts, but based on a single source trough of actual value received and then held by the bank. This process is called 'fractional banking, ${ }^{306}$ although the bank

\footnotetext{
${ }^{294}$ See ch 3, s3.7.3 titled Electronic Types of Money; and ch 4, s4.8.4.4 on Stored Value Products.

${ }^{295}$ Growth in money supply has led to metallic or even paper money gradually being replaced by credit money originating in banking activity. J Gouverneur (1983) Contemporary Capitalism and Marxist Economics at 186. This dematerialization of money has been labeled 'disruptive' by MH Sherif (2004) Protocols for Secure Electronic Commerce at 433.

${ }^{296}$ FX Browne and D Cronin (1995) 'Payment Technologies, Financial Innovation, and Laissez-Faire Banking' 15 Cato Journal at 1, available at http://goo.gl/LiAIh. See also Geva and Kianieff (2002) op cit note 3 at 6 who say that as money is part of an evolutionary process, the fact that legally money is only that legal tender issued by the state or its $\mathrm{CB}$, that this should not obscure the understanding of the concept of money as transcending any particular stage in its evolution.

${ }^{297}$ See ch 2, s2.2 titled The Rationale for MFS.

${ }^{298}$ A phrase used to describe the situation where assets are distributed in their existing form rather than being sold and distributed as cash. Definition from 'Alberta Justice Glossary of Terms', available at http://goo.gl/2Mvm9.

${ }^{299}$ Figueras and de Subirà (1997) op cit note 3 at ch 4.

${ }^{300}$ Modern banking uses electronic storage of money values to emulate bespoke writing.

${ }^{301}$ The term was coined in 1912 by Maurice Ansiaux, a Belgian economist, as noted by Lanskoy in S Lanskoy (2000) 'The Legal Nature of Electronic Money' No 73 Banque de France Bulletin Digest at $28 \mathrm{fn} 31$.

${ }_{302}$ This a personal right by the depositor to claim the money from the bank. The bank however becomes the owner of the money.

${ }^{303}$ The circulation represented by a movement of records between current accounts is seen as analogous to cash circulation, but since no tangible notes are transferred, it must be considered subsidiary to the circulation of paper money. A Crede (1995) 'Electronic Commerce and the Banking Industry: The Requirement and Opportunities for New Payment Systems Using the Internet' 1(3) Journal of Computer-Mediated Communication, available at http://goo.gl/NkdWC.

${ }^{304}$ Scriptural money, also known as bank, inside, credit or fiduciary money, is money recorded as money units in a bank account after money is deposited, or where money units are created using fractional banking. Thereafter, there will be only records of movements of money units. It is seen as the preeminent means of the bank credit, as much as $80 \%$ of the total money circulation.

${ }^{305}$ See C Goldfinger (2002) 'Intangible Economy and Electronic Money in the Future of Money' at 88, available at http://goo.gl/LX018. Fiduciary or fiat money managed by CBs coexists and interacts with scriptural monies managed by commercial banks.

${ }^{306}$ This also relates of course to the fact that banks lend more than what they receive in deposits, the quintessential feature of modern practices. Hence, bank deposits and banknotes based on fractional reserves can behave like commodities or MOEs as exchanges are often made with promises to pay the commodity in money.
} 
must have a 'fractional reserve' of value to compensate initial depositors, a ratio usually mandated by the $\mathrm{CB} .{ }^{307}$

Banks thus are said to 'create' money with what is variously termed their 'Inside Money,' 'Endogenous Money,' 'Bank Money, ${ }^{308}$ or 'Credit Money. ${ }^{309}$ All these conceptions are related to the 'Credit Theory of Money, ${ }^{310} \mathrm{CB}$ money was termed Outside Money. ${ }^{311}$

The process whereby essentially subservient bank money derived from borrowings from the CB and then re-lent 'fractionally' to others in multiples of the actual bank deposits held with the CB known as 'Inside Money' has also been termed 'Circuitism, ${ }^{312}$ described by Fisher in relation to the involvement of banks:

'We falsely picture the circulation of money when we think of it as consisting of a perpetual succession of transfers from person to person. But we form a truer picture if we think of banks as the home of money, and the circulation of money as a temporary excursion from that home. If this be true, the circulation of money is not very different from the circulation of checks. Each performs one, or at most, a few transactions outside of the bank, and then returns home to report its circuit., ${ }^{313}$

From this standpoint, debt generally - but bank debt in particular - may be seen as money in that it is accepted by others in payment of a debt, and that in fact and specifically, 'bank credit' amounts to money. This pool of value that is 'resold' in the form of loans and this essentially endogenously creates, through the use of credit, new money. Scriptural money is now the pre-eminent means of providing bank credit ${ }^{314}$ and for executing EFTs. ${ }^{315}$

\footnotetext{
${ }^{307}$ See ch 3, s3.5.3.2 titled Rights. When using scriptural money to extend credit, for example, banks must hold a prudent convertibility ratio between cash and the credit extended in their reserves. This is the so-called 'cash coefficient'. Figueras and de Subirà (1997) op cit note 3 passim.

${ }^{308}$ The term 'Bank Money' was suggested by Keynes. See Keynes (1971) op cit note 3 at 3. 'Bank Money' is thus all deposits held with that bank, private notes or liabilities issued by deposit-taking institutions payable on demand. Thus Bank Money or Credit Money as Inside Money is ultimately redeemable on demand on Outside Money, historically, gold. See generally Hulsmann (2004) op cit note 3; and Janson (2001) op cit note 3 at 3.

309 This is also known as 'fiduciary money', or 'Buchgeld'. For a brief discussion, see also Vakhitov and Vakhitov (20022003) op cit note 3 at 108 .

${ }^{310}$ Fractional Banking thus belongs inter alia to the 'Credit Theory of Money'. One of the first modern economists to provide a Credit Theory of Money was said to be Macleod: see Macleod (1889) op cit note 3; and later Schumpeter (1970) op cit note 3. For insightful analyses of the Credit Theory, see Moini (2001) op cit note 3; and Tymoigne and Wray (2005) op cit note 175; and also Maclachlan (2003) op cit note 3; and Wray (2001b) op cit note 3; Mitchell-Innes (1913) op cit note 3; MitchellInnes (1914) op cit note 3; and Fox (2008) op cit note 3 at 44. For a contrary, metallist view, see Shostak (2000) op cit note 3. ${ }^{311}$ See Fama (1980) op cit note 3.

312 This is a post-Keynesian School of economic theory generally called the 'Monetary Circuit Theory, but it is popularly known in the economic literature as 'Circuitism.' It posits that money is created endogenously by the banking sector, rather than exogenously by CB lending. As Hart (2005) op cit note 3 notes, the bulk of these 'circuitous' obligations are issued by banks, far outweighing 'money proper' in circulation. For a discussion thereof, see A Zazzaro (2002) 'How Heterodox is the Heterodoxy of the Monetary Circuit Theory? The Nature of Money and the Microeconomy of the Circuit', available at http://goo.gl/GH9kX.

313 I Fisher (1909) 'A Practical Method of Estimating the Velocity of Circulation of Money' at 604-605, as cited in MS Morgan (2006) 'Measuring Instruments in Economics and the Velocity of Money' Working Papers on the Nature of Evidence: How Well Do 'Facts' Travel? No 13/06 at $14 \mathrm{fn} 12$, available at http://goo.gl/YaEdH.

${ }^{314}$ See Figueras and de Subirà (1997) op cit note 3; and Kutyn (2005) op cit note 3 at 42, who controversially suggests that since these types of transactions result in the creation of new bank deposits to be used by the recipients as a MOE, they 'appear to violate government statute, in that they result in the bank creating a note (bank deposit) used or intended to be used as a MOE'. This apparent violation of legal tender laws, he suggests, 'is criminal'.

${ }^{315}$ Cash is a declining utility in many countries (except Africa and Asia), with circulation of scriptural money representing up to $80 \%$ of the total money in circulation. See inter alia Aite Group (2011) 'The Less-Cash Society: Forecasting Cash Usage in the United States', available at http://goo.gl/pVk2j. Credit money is not legal tender per se although, effectively, its redeemability into the CB's GAME - which is legal tender - means that the CB treats credit money as legal tender that can be used for the payment of goods and as a means of final settlement in a payment system.
} 
However, it is not the fractional banking way of creating money that makes it money; it is simply that the debits and credits entries - in banks and similar entities - that are used in payments and as a SOV that makes it money. ${ }^{316}$

\subsubsection{2}

Money as a Store of Wealth

In some cases money is equated to 'wealth', specifically where its SOV function is also described as a Store of Wealth (hereafter SOW). ${ }^{317}$ Money has been described intrinsically as 'wealth power' in relation to its purchasing power in general. ${ }^{318}$ Although there is no specific categorisation of 'wealth money', the SOW appellation may relate to the less transient nature of money when it acts as a MOE and payment, or may even relate to private money currencies or systems where the issuer settles with other money currencies or other similar issuers in terms of their own liabilities, ${ }^{319}$ such as mutual funds, ${ }^{320}$ share script, or ownership rights to goods and services. Functionally these systems all act outside the CB payment system to settle debts, and may thus compete with the CB in this arena, so displacing the CB as sole controller of settlement. ${ }^{321}$

Palley ${ }^{322}$ further uses the example of mutual funds which are not denominated in any UOA, but which are instead claims to real wealth. These are usually traded against one another as a MOP. He says that banks use this to settle transactions among themselves by transfer of bank assets while non-bank users (consumers/the market) could settle their debts by transfer of title to equities valued in real time. Non-bank financial intermediaries are already allowing customers to write checks and use debit cards against money market mutual funds, possibly reducing the existing 'money'-based system of settlement, but it does not eliminate it since some may insist on payment in CB money which will still possess a special place as legal tender for purposes of debt settlement. Further, he says, debtors holding both traditional bank deposit balances and e-mutual funds may also wish to settle their debts using deposit account balances rather than transferring e-mutual fund assets which they may believe to be under-valued owing to temporary market

\footnotetext{
${ }^{316}$ See Hulsmann (2004) op cit note 3 who says that issuers will firstly, promise to accept in payment of any debt owed to them, denominated in their declared money of account, the form of money that they have emitted and described by the same money of account. Secondly, money (with a known value, as opposed to mere tradable commodities) can exist as a credit for the holder only if there are other debts, denominated in the same money of account, awaiting cancellation. In other words, money (as opposed to mere tradable commodities) cannot be created without the creation of debt.

317 Jonker v Meester van die Hooggesregshof (88/85) 1986 ZASCA 64 (29 May 1986) (hereafter Jonker), available at http://goo.gl/NiFTO, a case regarding monies in a deceased estate, where 'money' was equated to value and 'wealth'. As a SOW is described by Sawyer as meaning that whatever serves as money will retain most of its value over the period of time for which it is held between its receipt and its disbursement, though it is envisaged that the time between receipt and disbursement is relatively short. A SOV, because it is possibly mostly transient in its storage, is thus comparable to the SOW as a longer-term proposition where individuals hold money as part of their asset portfolio for the holding of wealth, and intend to hold that money over a significant period of time. Sawyer (2003) op cit note 3 at 4.

${ }^{318}$ See Mann (1982) op cit note 3 at 26. See also Banco op cit note 3 which related a determination of whether illegally printed banknotes were mere paper or represented a loss of wealth. The court held that they were the latter. See the discussion above on this case in ch 3, s3.12.2 titled Legal Definitions and Theories Relating To Money.

${ }^{319}$ That is, private (electronic) monies which are not redeemable in CB reserves.

${ }^{320}$ Mutual funds, also known in South Africa as Unit Trusts, are a professionally-managed type collective investment schemes that pool money from many investors.

${ }^{321}$ These liabilities are denominated and redeemable in CB money such that the clearing house needs to hold reserves on the books of the CB. With netting and settlement in CB money, the system remains anchored in CB money. See Schmitz (2006) op cit note 3 at 90 .

${ }^{322}$ T Palley (2001-2002) 'The e-Money Revolution: Challenges and Implications for Monetary Policy' 24 Journal of Post Keynesian Economics 217-233, available at http://goo.gl/MeGW8.
} 
conditions. Too broad a concept of 'wealth' may have unwarranted ramifications, such as where a commodity like insider information in companies or other chartals such as those in Informal Value Transfer Systems (hereafter IVTS) ${ }^{323}$ can be used to launder money. ${ }^{324}$ Some laws then rather refer to 'property' as an omnibus term to capture wealth. ${ }^{325}$

Access to fiat money via Automatic Teller Machines (hereafter ATMs), the ability to do seamless electronic 'transfers' of value and pursue Internet banking and transfers via emerging MFS systems may give rise to the view that money has become 'electronic'. Electronic representations and access to stored money, however, does not necessarily equate to 'e-money' which may instead be the result of specific prudential regimes and policy directives such as the Electronic Money Directives (hereafter EMD) ${ }^{326}$ in the EU.

The first 'electronic' payments were introduced in 1919 when the US Federal Reserve initiated the movement of currency via the evolving telegraph system, ${ }^{327}$ although this was characterised more by the issuance of instructions to update written documents that recorded the requisite change in values than by the actual electronic movement of funds or value per se over the telegraph or its equivalent. Money, or rather representations thereof, became fully electronic with the emergence of computerised deposit, settlement and payment systems in the 1950s and 1960s and the evolution of the dispensing ATM in the early 1970s. ${ }^{328}$ Modern forms of money are now characterised by banking systems that include electronic forms of deposits and electronic payment systems ${ }^{329}$ allowing electronic movements of funds and payment of debts through electronic entries in the books of banking systems. ${ }^{330}$ Money may be seen to be dematerialised in these incarnations. ${ }^{331}$ Thus the law does not usually allocate the appellation of money to an $\mathrm{EFT}^{332}$ since it does not embody any rights, even though it may ultimately fulfil the criteria in $\operatorname{Moss}^{333}$ as a 'means of final discharge of a debt'. This does not mean however that there are no rights associated with

\footnotetext{
${ }^{323}$ On IVTS, see ch 2, s2.5.1 titled Overview.

${ }^{324}$ BAK Rider (1999) 'The Limits of the Law: An Analysis of the Interrelationship of the Criminal and Civil Law in the Control of Money Laundering'2 Journal of Money Laundering Control 209 at 212; and I van Jaarsveld (2004) 'Following the Money Across Cyber Highways: A Herculean Task or International Challenge? Some Thoughts on Money Laundering on the Internet' 16 SA Mercantile Law Journal at 687.

${ }^{325}$ See ch 8, s8.5 on Anti-Money Laundering, Terrorist Financing and Customer Due Diligence Laws and Regulations.

${ }^{326}$ See EMD1 op cit note 3; and EMD2 op cit note 3; and ch 9, s9.6.3.

${ }^{327}$ C Yang (2005) 'Electronic Money and Relevant Legal and Regulatory Issues', available at http://goo.gl/QOGAV.

${ }^{328}$ ATMs were mainly the purview of banks and their affiliates, with no private players in this progenitor e-money market. The concept of the modern ATM first began in 1968, a working prototype came about in 1969 and Docutel was issued a patent in 1973. The first working ATM was installed in a New York-based Chemical Bank. The first ATMs were offline machines, though, meaning money was not automatically withdrawn from an account. The bank accounts were not (at that time) connected by a computer network to the ATM. See CNN (1995) 'The ATM is 30 years old', available at http://goo.gl/scXce and M Bellis (s.d.) 'The ATM Machine of Luther George Simjian', available at http://goo.gl/aV5Go.

${ }^{329}$ The magnetic stripe on the card was later augmented or even totally substituted with a small embedded chip. See VA Lawack (1998) 'Electronic Innovations in the Payment Card Industry' 10 SA Mercantile Law Journal 233; and Schulze (2004b) op cit note 3 at 706. The resultant amalgam became known as a smart card. See W Faul (1989) 'Die "Smart" Kaart: Hoe Werk Dit?' 1 SA Mercantile Law Journal 381.

${ }^{330}$ These payments are based on a bank's intra-day loans from the local CBs and are considered legal tender.

${ }^{331}$ This dovetails in a sense with the Claim School view of money which allows dematerialised or incorporeal 'things' like even prepaid phone minutes stored on a MNO prepaid purse to be used as 'money,' rather than dogmatically insisting on a tangible item or a symbolic representation thereof, as is required in the competing Orthodox School of money. See ch 3, s3.8 below on Economic and Legal Views of Money.

${ }^{332}$ See ch 4, s4.8.4.2 on EFTs.

${ }^{333}$ Moss op cit note 3. See ch 3, s3.12.2 on Legal Definitions and Theories Relating to Money.
} 
an EFT. Rather, the associated instructions in an EFT by a payor to its bank or payment intermediary for it to pay to a payor (possibly from a deposit) a defined amount at a certain time and place, are seen in law as a compendium of interlocked circulating rights. ${ }^{334}$ In most jurisdictions they are not, for the moment, legally seen as money unless codified as such and are instead characterised as mere instructions to circulate those rights, with no value embodied in the instructions themselves. ${ }^{335}$

The move away from these institutionalised banking systems came with the emergence in the 1970s of plastic cards with magnetic stripes issued by service-based companies such as telephone operators that allowed consumers using legal tender GAME to purchase discrete values that were then stored on the card and which could be used by the holder to access the issuer's services. Various models were developed to this functionality, under the broad heading of SVPs, with its first commercial card-type iteration - the Stored Value Card (hereafter SVC). ${ }^{336}$

As a result, scriptural money that was electronically classified and stored on the computer mainframes of banks as a debit or credit on their books was deemed to have developed its own independent functionality in the private, non-bank world where the consumer, and not a licensed bank, had control over payments. ${ }^{337}$ These 'issuers' of electronic value - which may be called e-money under some circumstances - may be independent entities, the $\mathrm{CB}$, or licensed bodies in terms of national law. ${ }^{338}$

The impact of this evolving 'e-money' and its various incarnations - and their application to MFS - are discussed below in relation to new and emerging forms of payment. ${ }^{339}$

The evolution of sophisticated forms of money beyond just token value and nominalistic scriptural ${ }^{340}$ types may give rise to variations in the 'traditional' analysis of 'money' or 'money-type' variants and their use in transactions. The analytical choices that arise in these variations are anodyne; one has to look at the effect of either using the existing, dominant economic definitions of money as the basis for any analysis of money and payments, or the legal definitions or, where possible, a conflation of the legal and economic views at a common intersection using alternative (sometimes) heterodox methods or economic Schools.

\footnotetext{
${ }^{334}$ Geva (1993) op cit note 3 at 1-21. See ch 4, s4.8.4.2 on payments on EFTs and, in general, Schulze (2007) op cit note 3 at 379; and Malan and Pretorius (2006) op cit note 3.

335 These bank values/payments may however be seen as money in specific instances where there is the implied or express consent of the creditor. See Mann (1992) op cit note 3 at 8, and Akindemowo (1998) op cit note 3 at 3 and 5.

336 The early SVCs were mostly offline so that any value stored on the SVC when used to access goods and services was irrevocably deleted from the SVC. Usually additional credits could be added using only the issuer's system. On the distinction between 'offline' and 'online' in the context of SVCs and SVPs, see ch 4, s4.8.3.6 on Accessibility and Tracking of Payment Systems: Online and Offline.

${ }^{337}$ This evolution was characterised by a shift in competencies in money handling and payments, so that consumers and not just their banks began to have innate control over their own finances and payments, analogous to their decision to use cash when and where they chose to do so.

${ }^{338}$ For example, licensed in terms of the EMD op cit note 4.

${ }^{339}$ See ch 4, s4.8.4.4 on Electronic Money in relation to Stored Value Products and ch 6 passim on MFS commercial models.

${ }^{340}$ See ch 3, s3.7.2 on Scriptural 'Money'.
} 
As noted earlier, ${ }^{341}$ in broad terms, the choices are - at least in the legal system's use of economic theory between those that subscribe to the Orthodox School view or theory of money, and those that subscribe to the newer Claim School view of money and its variants. ${ }^{342}$

Economic analysis of money in the context of law is needed because of historical use of economic theories of money to frame the legal basis for money. ${ }^{343}$

It was also noted earlier ${ }^{344}$ that as the legal view of money is much narrower, conflicts may arise because economists freely incorporate into their view of money items that the law does not necessarily consider as money, for example, bills of exchange, credit cards, treasury bills, and cheques. ${ }^{345}$ Both lawyers and economists may consider bank - or credit, or fiduciary ${ }^{346}$ - money as money, although lawyers will only consider it as such if there is implied or expressed consent to do so by a creditor who finds it impractical to accept legal tender notes and coins. ${ }^{347}$

\section{History of the Analysis}

Noting that the potential challenges that the MFS, airtime-based SVA and its SOV pose to the concept of money and that 'there is no single definition of money that can suffice, ${ }^{348}$ the vexed question of the nature of money begins in antiquity, through the writings of the Greek and Roman philosophers, the putative modern economists and jurists, and continues into relatively modern times with similar divisions, although jurists have drawn inspiration from the economists, and in many cases, vice versa. Indeed, economists, just like legal scholars, differ on the fundamentals of their vocation, and as noted earlier, can be segmented by their own doctrinal strata into a veritable economic Tower of Babel. ${ }^{349}$

The conundrum that characterises any analysis relating to the essence of money was ably identified by the economist Menger:

\footnotetext{
${ }^{341}$ See ch 3, s3.2.3.4 describing broadly the Economic views of money.

${ }^{342}$ See Bell (1998) op cit note 3 passim for a general overview of the two heterodox economic Schools.

${ }^{343}$ See inter alia ch 3, s3.8.2 on History of the Analysis, and ch 3, s3.12.2 titled Legal Definitions and Theories Relating to Money. Cf however a contrary view by Van Jaarsveld regarding the usefulness of any economic analysis of money to any legal analysis of money where she proffers - I would suggest inaccurately - that 'economics offers limited help in clarifying the nature of money.' Van Jaarsveld (2011) op cit note 3 at 40.

${ }^{344}$ See ch 3, s3.2.3.5 titled Legal Views of Money.

${ }^{345}$ See Geva (1987) op cit note 3 at 115-116; and Mann (1992) op cit note 3 at 2-3. Both emphasise the gap between the economic and legal views of money.

${ }^{346}$ See ch 3, s3.7.2.1 on Credit Money.

${ }^{347}$ See Mann (1992) op cit note 3 at 2.

${ }^{348}$ Dodd (2005) op cit note 3 at 2.

349 The various macroeconomic Schools of thought encompass inter alia the Classical School, Say's Law, the Quantity Theory of Money and Monetarism, the New Classical Macroeconomics and the Rational Expectations School. Modern derivatives of each School include the Monetarists and Keynesian or New Monetary Economics (hereafter NME) Schools. The Keynesian School is named after the work of John Maynard Keynes, the English Nobel Laureate and economist, who through his seminal work, the General Theory of Employment, Interest and Money, is seen as one of the fathers of modern theoretical macroeconomics which maintains its relationship to the underlying microeconomic behaviours. Theories based on Keynes include The Circuit Theorists, the Eclectic Keynesians, the Extreme Keynesians, Modern Monetary Theory, the Real Business Cycle Theory and the Supply-side Economics Theory. For a description of some of these Schools, see Bell (1998) op cit note 3; and Wray (2006) op cit note 3.
} 


\begin{abstract}
'The great thinkers of antiquity, and following them a long series of the most eminent scholars of later times up to the present day, have been more concerned than with any other problem of our science with the explanation of the strange fact that a number of goods (gold and silver in the form of coin, as civilisation develops) are readily accepted by everyone in exchange for all other commodities, even by persons who have no direct requirements for them or whose requirements have already been fully met. ${ }^{350}$
\end{abstract}

The commodity-based monetary theories whereby the value of a money is based on its relationship to a commodity - such as gold and silver - began, according to Schumpeter, with Aristotle ${ }^{351}$ such that many still believe - or wish - that the paper money issued corresponded to an amount of gold kept by the CBs. ${ }^{352}$ This theory has held sway for centuries, even though the Claim-type theories of money developed with the emergence of laissez-faire economic and liberal thought in Europe. ${ }^{353}$ Indeed, Schumpeter observes that the Claim School theory of money - although not named as such - began, it is believed, as far back as Plato ${ }^{354}$ and his later adherents ${ }^{355}$ who believed that for something to serve as a general MOE, it need not be a commodity itself, but a token which society or a legal order have agreed to use as the representative value, ${ }^{356}$ encompassed in the state or societal theories respectively discussed earlier. ${ }^{357}$ Similar views to those of Plato were held by the Roman jurist Paulus. ${ }^{358}$

Broadly, as noted earlier, these two Schools translate into those who emphasise a quantitative, functional approach to money based on the Aristotelian view of a MOE function at its core versus those like Plato who delve into the qualitative, intrinsic nature of money, using as their tools (mostly) the UOA feature of money and its subsidiary MOP feature. ${ }^{359}$

To date, the legal analysis of money has been based on the Orthodox School's economic view of money. ${ }^{360}$ This historical nexus may have a bearing not only on how the common law but also on how regulators perceive and regulate new and evolving forms of money. Its appropriateness in the age of dematerialised, incorporeal value is explored later. ${ }^{361}$

\footnotetext{
${ }^{350} \mathrm{C}$ Menger (1871) 'Principles of Economics' at 315, available at http://goo.gl/iDjPz.

${ }^{351}$ Aristotle (350 BCa) op cit note 3.

352 See for example, M Olivella (1992) 'The Power of Money: Monetics Against Corruption', available at http://goo.gl/m3aSf.

${ }^{353}$ The a priori assumption in liberalism is in favour of freedom of political thought and laissez faire economics. Examples of early liberal philosophers include Thomas Hobbes and John Locke. Laissez faire economic views are the economic components of liberalism, represented inter alia by Keynes and Friedrich von Hayek. See 'Liberalism' (2007) Stanford Encyclopedia of Philosophy, available at http://goo.gl/Z3myh.

${ }^{354}$ Plato in Republic, II 371, as described in B Jowett (1892) The Dialogues of Plato at 52. For a description of Plato's theories in relation to the Credit Theory of Money, see Iwai (2007) op cit note 3.

${ }^{355}$ Such as the economists Nicholas Barbon, Pierre le Pesant sieur de Boisguillebert, James Stuart, and John Law. Knapp's theories revived Plato's theories. See ch 3, s3.10 on the Claim School.

${ }^{356}$ For a further description of the theories and a criticism of Shumpeter's classifications, see Iwai (1997) op cit note 3 passim.

${ }^{357}$ See ch 3, s3.2.4.1 titled Issuance and Production.

${ }^{358}$ Menger (1892) op cit note 3 passim.

359 As Ingham (2002) op cit note 3 at 125 notes, each theory gives different answers to the basic questions about those concerned with inter alia the functions of money and how it gets and maintains (or loses) its value. MOP is a subsidiary component of the Claim School which sees the UOA as the core of any money. Means of payment and MOE are often used interchangeably, although the former indicates that payment is final, while the latter indicates that payment is delayed on fulfillment of some event.

${ }^{360}$ See ch 3, s3.12 titled Legal Views of Money, epitomised by Moss op cit note 3; and Mann (1982) op cit note 3.

${ }^{361}$ See also ch 13 on a Reevaluation of Money.
} 


\section{Orthodox School}

As noted earlier, the 'Orthodox' School of economics is primarily derived from the works of Aristotle, who in Nicomachean ${ }^{362}$ delivered what is thought to be the first treatise on the development of the components of a market economy. In Politics $I^{363} \mathrm{He}$ created the concepts of value in use, or units, and of commensurability, that is, how ratios for a fair exchange of heterogeneous things - or commodities - could be set and answered, that is a MOE. ${ }^{364}$

Commodity-based money thus has at its core a 'utilitarian function' whereby money acts as a $\mathrm{MOE}^{365}$ based on an (exchange value to) a commodity, usually gold or some other precious metal. ${ }^{366}$

Schumpeter defined this School, which he called 'Theoretical Metallism', as:

' $\ldots$ the theory that it is logically essential for money to consist of, or to be "covered" by, some commodity so that the logical source of the exchange value or purchasing power of money is the exchange value or purchasing power of that commodity, considered independently of its monetary role,' ... [and which] ... 'prevailed substantially to the end of the nineteenth century and even beyond'. ${ }^{367}$

As alluded to above, the Orthodox School is also the mainstay of the legal view of money, implied in the legal definition of money offered in both Moss and to a great extent, Mann. ${ }^{368}$

Although they are a disparate group, at the micro-level analysis of money, Orthodox School economists will generally define money as anything that may be expressed as a standard unit in which prices and debts are measured and that is widely accepted in payment for goods as a MOE. ${ }^{369}$

\footnotetext{
${ }^{362}$ Aristotle (1962) op cit note 84.

${ }^{363}$ Aristotle $(350 \mathrm{BCb})$ op cit note 3 .

${ }^{364}$ For an extensive overview on Aristotle's contribution to money and the MOE function he created, see Meikle (1994) op cit note 3 at 26-44; and Geva (1987) op cit note 3 at 120.

${ }^{365}$ As Aristotle conceptualised it, when people associate for the exchange of goods each must be satisfied that both utilities and costs are equalised before exchange takes place. Aristotle saw mutuality as the basis for exchange and the equating of subjective utilities as the precondition of exchange. Exchange must be mutually satisfactory. Hence money translates subjective qualitative phenomena into objective quantitative phenomena, where the approximate extent of want satisfaction can be articulated indirectly through a 'unit' that supplies a measure on the basis of which just exchange can take place. This view of money, he taught, eliminates the need for a double coincidence of wants prevalent in barter economies and supplies an acceptable expression for the exchange ratio between various goods. See Younkins (2005) op cit note 3 passim. For a historical exposition of how the common law came to appropriate the (Orthodox) economic School, see Mann (1992) op cit note 3 at 1-10. It is submitted that this presages a looming contradiction between the various economic Schools and legal thought.

${ }^{366}$ Thus money, though it may serve other functions, originated and primarily functioned as a MOE, as part and parcel of the features that make up the Orthodox School view of money, and completed with its UOA and SOV functions.

${ }^{367}$ Schumpeter (1954) op cit note 3 at 288.

${ }^{368}$ See Mann (1992) op cit note 3 passim; and Moss op cit note 3.
} 
The standard measure or unit is usually referred to as a UOA and is the standard unit in which prices and debts are measured, and which is denominated by the state of issue. ${ }^{370}$ Without a UOA, any agent would have to know the bilateral exchange value of each commodity for every other commodity. ${ }^{371}$ It is trade over time that gives a UOA its fiduciary quality. ${ }^{372}$ Trite examples of a UOA are national currencies denominated in Rands, Shillings, Dollars and Euros. ${ }^{373}$

This concept may comprise more types of money than are legally defined. Thus, depending possibly on national prudential rules, the units may not only be characterised by the currency - or fiat - appellation given to the national currency by the national government which is responsible for its creation and continued use; and, if the economic and legal analysis allows it, the UOA could even be designated in other unit forms such as minutes available for use on a prepaid stored value cell phone account. The extent of the circulation may affect the value of the money and, correspondingly, its acceptance as money by a state or community. ${ }^{374}$

\subsubsection{2}

A Store of Value

The Orthodox School theorists identified the store (or standard) of value function of money or wealth as being a critical component of money. ${ }^{375}$ It means that money can be used by holders as a SOW. ${ }^{376}$ Functionally, it also allows the separation in time of the act of sale from the act of purchase and is, thus, a standard of deferred payment. ${ }^{377}$ The SOV attribute is seen as econo-centric ${ }^{378}$, but from it one can deduce

\footnotetext{
${ }^{369}$ See Robertson (1928/1932) op cit note 3. The economist Menger also saw money's essence in terms of its utility as a 'universally acceptable media of exchange' versus those like Schumpeter (and later Keynes) who saw the essence of money more in terms of its being a 'standard' (or unit) of value. See also Menger (1892) op cit note 3, and Shubik (2000) op cit note 3 at 5 , who believe that when the dynamics of the financial system as a whole are considered, further properties of a money are important, that it serves as a 'strategic decoupling' device in decision-making and that it should have the properties of divisibility, durability, fungibility, portability and cognisability. See also F van den Bogaerde and LJ Fourie (1986) Basic Macro Economics $2^{\text {nd }}$ ed at 107.

${ }^{370}$ The UOA - the 'numeraire - could also mean 'money', 'coinage' or 'face value'. A numeraire is usually applied to a single good, which becomes the base good. All similar goods are then valued and priced against the base good. This comparison makes it possible to identify which goods are worth more than others. See 'Numeraire' (2011) Investopedia, available at http://goo.gl/9vHGO.

${ }^{371}$ Capie, Tsomocos and Wood (2003) op cit note 2 at 12. This is how a UOA betters the qualitative barter-commodity system of exchange through providing certainty.

${ }^{372}$ M Aglietta (2002) 'Whence and Whither Money?' in Organization for Economic Co-operation and Development (OECD) 'The Future of Money' at 36, available at http://goo.gl/RTOse.

${ }^{373}$ The role of the UOA diverges in the Orthodox and Claim Schools, with the Claim School placing it paramount in its conceptualization of the function of money. A UOA is considered a nominal anchor which allows a seller to consider implicitly what his selling price may be worth in terms of other goods. See also Cesarano (1994) op cit note 3 at 42.

${ }^{374}$ Klein, generally, says that the existence of some rising costs of increasing (the nominal quantity of money) may place a limit on the rate at which a firm can profitably increase the supply of its money in circulation since more money in circulation could devalue the money. See B Klein (1974) 'The Competitive Supply of Money' 6 Journal of Money, Credit, and Banking at 436. See also similarly Schmitz (2001) op cit note 3 at 17.

${ }^{375}$ John Law is credited as being the first exemplar of this role in 1705. See J Law (1966) Money and Trade Considered at 78.

${ }^{376}$ See ch 3, s3.7.2.2 titled Money as a Store of Wealth.

${ }^{377}$ See University of London (s.d.) 'The Nature of Money' in Monetary Economics Lecture Notes at 13. It is also indicated that when a seller receives money (or any other item like shares) as a MOP in exchange for goods sold by them, the seller is allowed to hold on to the money until it is needed by them to be (further) exchanged for the goods and services they may later require. This added time dimension has been noted as indicting an inchoate or delayed payment, such that when using a MOE in the Orthodox School, there is no final MOP. For this inchoate nature, see Goodhart (1989) op cit note 3 at 24-27, 38-44;
} 
the following general characteristics: that money has a SOV that is recognised and accepted by, for example, merchants who will accept it as a means of (ultimate) payment, provided that the SOV translates into guaranteed payment. ${ }^{379}$

Keynes, a theorist of the Claim School, was somewhat contemptuous of its role:

\begin{abstract}
'Money, it is well known, serves two principal purposes ... it facilitates exchanges ... In the second place it is a store of wealth. So we are told, without a smile on the face. But in the world of the classical economy, what an insane use to which to put it! For it is a recognised characteristic of money as a store of wealth that it is barren ... Why should anyone outside a lunatic asylum wish to use money as a store of wealth? ${ }^{380}$
\end{abstract}

Nonetheless, despite his misgivings - apparently motivated by his uncertainty of the future - Keynes recognised that one of the reasons societies held money in a SOV was that it was a way of postponing transactions because of their distrust of the future:

'[O]ur desire to hold money as a store of wealth is a barometer of the degree of our distrust of our own calculations and conventions concerning the future. ${ }^{381}$

Therefore, society's distrust of the future caused people to hold money in a SOV, which in turn postponed spending in transactions. ${ }^{382}$ From his perspective then of the Orthodox (Classical) School view of economics, use of the SOV which 'postponed' transactions in turn created a MOE that was essentially inchoate. $^{383}$

The SOV role - at least when anchored in a commodity like precious metals - was also questioned by the economist Knut Wicksell:

'[T]he function of acting as a store of value is not essentially characteristic of money ... It is never this utility [of precious metals] which is contemplated by those who hoard money but the object in view is nearly always that of procuring something else for it at a future time. In other words, it is the exchange

Mann (1992) op cit note 3; Nussbaum (1950) op cit note 3; Sawyer (2003) op cit note 3 at 3; Papadopolous (2007) op cit note 3 passim; Newlyn and Bootle (1978) op cit note 3 passim; and Cesarano (1994) op cit note 3.

${ }^{378}$ See Mann (1992) op cit note 3 at 8; Keynes (1937) op cit note 3 at 141.

379 This guarantee function also relates to the traditional 'promise' by governments that they will maintain the value of the currency so that it stores that currency's value to the extent that it will not depreciate it considerably. These promises 'to pay the bearer' used to be printed on many national banknotes, but are now rare. While absent, promises are however still implicit in the issuance and general use of the note, in what may be termed a social contract between the state and its citizens.

${ }^{380}$ Keynes (1937) op cit note 3 at 141. Thus for Keynes the speculative motive for holding money is strictly related to the SOV function.

${ }^{381}$ Keynes (1964) op cit note 3 at 167.

${ }^{382}$ Keynes saw the Orthodox economists manifest their 'distrust' through higher interest rates: such that you were rewarded for postponing consumption. It is also the reason why people who distrust the financial system and the potential for devaluation of their national currencies and default of banks who engage in fractional banking will not spend: they will rather buy gold to store their wealth. In contra-distinction to these Orthodox (Classical) views, Keynes was a proponent of low interest rates to encourage credit and thus spending, seeing spending as a motivation for growth. This debate continues to this day, exemplified by the 'Keynes versus Hayek' debate over a solution for fixing the Great Recession.

${ }^{383}$ See a discussion of his theory in relation to the SOV and its impact on spending by Wray, LR (2010b) 'Keynes's Approach to Money: What can be Recovered?', available at http://goo.gl/7aeUT; and Economicae (s,d.) 'Keynesian Monetary Theory', available at http://goo.gl/iPW25. 
value which it is desired to preserve; it is the money as a future medium of exchange which is hoarded. ${ }^{384}$

In the context of the role of the SOV though, despite the misgivings of Keynes and other Claim School economists who posit a non-commodity basis for money, the SOV function is seen more in abstract terms, unhinged from a tangible commodity like gold. ${ }^{385}$

\subsubsection{3}

\section{Means (Media, Medium) of Exchange}

As noted earlier, Aristotle as one of the early economists coined the phrase 'Means of Exchange', $(\mathrm{MOE})^{386}$ based on reasoning that money makes exchange (between persons) easier by translating subjective qualitative phenomena like barter into objective quantitative phenomena based according to its value measured against a valuable commodity like gold and silver. This became known as money.

Monetary instruments in ancient Greece replaced barter to act as Aristotle's MOE, that is, the exchange value of real goods using valuable objects or commodities which had an intrinsic value to allow payment for debts and goods. Currencies and goods then were 'exchanged' based on their relation to a durable commodity (metal) - hence the term MOE. ${ }^{387}$ The MOE is seen as the concrete function of money. ${ }^{388}$

In this capacity, the MOE is seen as a general medium of exchange or as the $\mathrm{GAME}^{389}$ in the state of issue. The GAME is an object 'which is habitually, and without hesitation, taken by anybody in exchange for any commodity' ${ }^{390}$ While the form has to a great extent evolved the 'modern' pedigree of a MOE is derived from the time when coins were made using valuable metal. ${ }^{391}$

The MOE function is considered by the Orthodox School as the pivotal characteristic of money even over and above the UOA and SOV functions. ${ }^{392}$ Lately however, its role as a final MOP has been disputed in

\footnotetext{
${ }^{384}$ Wicksell (1906) op cit note 3.

${ }^{385}$ See further ch 3, s3.10 on the Claim School.

${ }^{386}$ See Aristotle (350 BCa) op cit note 3 for the use of this phraseology; Meikle (1994) op cit note 3 at 26-44; and Mann (1992) op cit note 3 at 1-30 for the use of 'MOE'. See also European Central Bank (ECB) (2004) 'Issues Paper for the ECB Conference on 10 November 2004: E-Payments Without Frontiers', available at http:/goo.gl/TQcLx.

${ }^{387}$ Similarly, Wicksell's definition of a MOE is 'an object which is taken in exchange, not on its own account ... not to be consumed by the receiver or to be employed in technical production, but to be exchanged for something else within a longer or shorter period of time'. See Wicksell (1906) op cit note 3. This definition is similar to the overall definition of money in Moss op cit note 3 which refers to the fact that the receiver must not have any 'intention ... to consume it'.

${ }^{388}$ This can be compared to money's intrinsic, abstract nature which Mann believes is based on its purchasing power insofar as wealth can be transferred. Mann (1982) op cit note 3 at 5 and 26. For a discussion on the evolution of the MOE, see RA Jones (1976) 'The Origin and Development of Media of Exchange' 84 The Journal of Political Economy 757; and GY Luo (1999) 'The Evolution of Money as a Means of Exchange' 23 Journal of Economic Dynamics and Control 415.

${ }^{389}$ On the GAME, see ch 3, s3.5.3.3 titled Issuance of Money.

${ }^{390}$ Wicksell (1906) op cit note 3 at 17.

${ }^{391}$ Metallists believed that money ought to take the form of 'commodities' like gold or silver coin, with notes fully backed by the metal. This, they believed, allowed the quantity of money in the system and hence prices to remain relatively stable, based as it was on a finite amount of metal to back available money.

392 Orthodox monetarists, however, while having identified the UOA and SOV, considered these two functions as subsidiary to, or as a necessary implication of, the MOE function, thus having no major place in the analysis. See Cesarano (1994) op cit note 3 at 42 .
} 
modern commercial use; it is seen as an inchoate MOP for which an extended time continuum may be at play rather than a final MOP characteristic generally accepted in modern commercial practice. ${ }^{393}$

As Schumpeter surmised:

' $\ldots$ whatever $\ldots$ its shortcomings, this theory [of Aristotle], though never unchallenged, prevailed substantially to the end of the nineteenth century and even beyond. It is the basis of the bulk of all analytic work in the field of money. ${ }^{394}$

The concept of money as a thing which functions primarily as a MOE and that is rooted in the ideology of metallism has survived tenaciously thus far, although the transition to a non-metallic world where, it appears innately dematerialised electronic impulses replace the metal backing, has begun. ${ }^{395}$ However, the continued focus on a MOE and thus the functional approach to analyse money is justified by the Orthodox School by the fact that the note or money has become a symbol or representation of the 'real' value of the other commodities money can purchase. ${ }^{396}$ It further claims its continued dominance from the acceptability of the MOE to the receiver. ${ }^{397}$ If the receiver is confident that he can then utilise the money as a MOE for some other purchase because it is stable, ${ }^{398}$ then the MOE potential of money is fulfilled. ${ }^{399}$

Taking a 'macro' view of money in terms of its modern national use, the MOE function and its acceptability is guaranteed by the state, and it is seen as a fiat money and legal tender. However, it is the emergence of paper money and the general trend towards the dematerialisation of money into scriptural and electronic forms generally which have altered and fundamentally challenged this metallist paradigm and provided a context for doubt arising as to its ability to act as a (final) MOP. It also means that there is now no tangible metal around which to pivot a MOE function, bringing the whole Orthodox School's theory into the sights of anti-metallists such as Keynes. ${ }^{400}$

\footnotetext{
${ }^{393}$ See Goodhart (1989) op cit note 3 at 24-27, 38-44; Mann (1992) op cit note 3; Nussbaum (1950) op cit note 3; Sawyer (2003) op cit note 3 at 3; Papadopoulos (2007) op cit note 3 passim; Newlyn and Bootle (1978) op cit note 3 passim; and Cesarano (1994) op cit note 3.

${ }^{394}$ Schumpeter (1954) op cit note 3 at 63. For a further discussion of this perennial influence, see Olivella (1992) op cit note 353.

${ }^{395}$ Authors such as Martin proposed expanding the definition of money to include in a definition of money an expansion of the components to include other liabilities which, while not legally spendable, are viewed, at least in part, by the owners as transactional balances. DA Martin (1972) 'The Medium is not the Money' 6(000002) Journal of Economic Issues 67 at 71.

${ }^{396}$ Although MOE was initially based on the exchange value of say a note or coin around its exchange value to a real commodity, the need for this exchange was removed in the late $19^{\text {th }}$ century and in the 1970 s, the latter when the exchange value of currencies based on a fixed value to the price of gold - the Gold Standard. See again Ingham (2002) op cit note 3 on the note or coin as a symbol or representation.

${ }^{397}$ See Moss op cit note 3 where it is referred to as 'being accepted equally'.

${ }^{398}$ That is, it retains a SOV.

${ }^{399}$ Capie, Tsomocos and Wood (2003) op cit note 2 argue that it is not essential, although probable, that the MOE also serves as UOA. Thus, they say, it would be possible for prices to be quoted in one thing - ounces of gold - while a national currency served as the MOE. The complicating factor however would be that all transactions required a calculation converting the price (quoted in gold) into the national currency before payment could be made. 'But each transaction would then need to be accompanied by a calculation converting the price (quoted in gold) into the national currency before payment could be made. There is thus a saving in having the MOE and UOA coincide. This can, however, be outweighed if the MOE is changing value sufficiently rapidly'. Thus, they believe, there is a saving in having the MOE and UOA coincide. Capie, Tsomocos and Wood (2003) op cit note 2 at 12.

${ }^{400}$ The MOE function is now not necessarily backed one-to-one by an actual metal commodity. Keynes says the role is ameliorated to simply being 'only important for what it will procure'; see Keynes (1924) op cit note 3 at 1.
} 
To this effect, even the representative fiat note itself has no utility except what is derived from its exchange value, that is, the utility of the (other) things which it can purchase. ${ }^{401}$ However, while its utility may be null outside its exchange value, its representation is seen to be that of wealth power, as described by Lord McMillan in Banco, in which he said that money is 'purchasing power in terms of commodities' ${ }^{402}$ The Orthodox School and the State Theory it encompasses, along with its use as the legal basis for money, is ripe for reconsideration in light of the exponential moves away from tangible money and even tangible representations of money.

As noted by Mitchell-Innes:

'The misunderstanding that has arisen on this subject is due to the difficulty of realising that the use of money does not necessarily imply the physical presence of a metallic currency, nor even the existence of a metallic standard of value. ${ }^{403}$

Thus, money's value may be independent of the medium used to represent it. ${ }^{404}$

The Claim School described below ${ }^{405}$ provides a cogent comparison to the Orthodox School and also a possible alternative in the age of de-materialised money.

\section{Claim School}

\subsection{1}

\section{Overview}

As indicated earlier, ${ }^{406}$ the need for a currency to be linked to a physical commodity - and hence founding its exchange functionality - began to be questioned by an increasing number of economists, starting with Smith who sought to discover the real or abstract (intrinsic) 'valuableness' of money other than that obtained via its metallic (or MOE) backing. In other words, he asked: what made anyone accept something as valuable and what would motivate them to accept this as payment for goods and services or in settlement of a debt. ${ }^{407}$

He found that money need not necessarily be tied to a commodity with intrinsic value, but instead may be a creation by fiat or through an institutional authority. Smith gave as an example a prince who, as the state, values (paper) money so that the money's value is independent of the medium used to represent it:

\footnotetext{
${ }^{401}$ Keynes indicates that a currency note has no utility in itself and is completely worthless except for the purchasing power which it has as money; see Ibid at 75. Akindemowo (1998) op cit note 3 at 3, concurs, indicating that nowadays (the note or coin) is accepted for goods, not for its own sake, but for its properties. Money, Keynes believed, is therefore endowed with the ability to provide indirect utility in the form of purchasing power. The substance of which it is made is irrelevant to the notion of money as a MOE.

${ }^{402}$ Banco op cit note 3 at 508.

${ }^{403}$ Mitchell-Innes (1913) op cit note 3.

${ }^{404}$ See Keynes (1937) op cit note 3 at 4.

${ }^{405}$ See ch 3, s3.10 on the Claim School

${ }^{406}$ See ch 3, s3.9 on the Orthodox School.

407 The exchange view of money is not altogether discarded in the Claim world: money can of course be traded as a commodity on foreign exchange markets, but it must first be constituted as money. Ingham (2006) op cit note 3 at 261. Similarly, Krugerrands have commodity value. See Pretorius (2004) op cit note 3 passim.
} 
'A prince who should enact that a certain proportion of his taxes should be paid in a paper money of any kind, might thereby give a certain value to this paper money, even though the time of its final discharge and redemption should depend altogether on the will of the prince'. ${ }^{408}$

Later, a group of European economists embraced Smith's views and led the neo-classical $19^{\text {th }}$ century charge away from the quantity-based, monetarist commodity theories of the Orthodox School. ${ }^{409}$

One of the first to provide a cogent, alternative theory as to the nature of money was the economist HD Macleod, who in $1889^{410}$ introduced the concept of money being based on 'credit' relationships and not on a tangible backing. ${ }^{411}$ While Macleod's non-metallic theories were seemingly initially ignored, they later began to attract adherents like Mitchell-Innes, ${ }^{412}$ and then later a leading proponent, the economist Georg Knapp who sought further to find the essential properties of money. Similarly, Joseph Schumpeter's ${ }^{413}$ 'Credit Theory of Money' was one of the foundational bases for the Claim School, embraced by Keynes ${ }^{414}$ as the basis for money as a credit-based accounting paradigm.

Just as with Smith, Knapp disagreed with the quantity theory of the Orthodox School about the necessity of limiting the quantity of money by tying it strictly to the quantity of precious metals or any commodity, generally, and indicated that the metallic contents of money are irrelevant to its validity. He formulated an

\footnotetext{
${ }^{408}$ Smith (1776) op cit note 15 at 369.

${ }^{409}$ For an overview of the Austrian School, see Von Mises Institute (s.d.) 'Overview Of The Austrian School of Economics' ,available at http://goo.gl/V2Kle.

${ }^{410}$ Macleod (1889) op cit note 3.

${ }^{411}$ Such a conception, says Messori, is not a radically new representation of the monetary system. The idea appears indeed to have originated in ancient times through the use of a 'tally' that kept track of debits or credits and which allowed trading to be based on how much each person owed. Mitchell-Innes (1913) op cit note 3 at 394 describes it as 'a stick of squared hazelwood, notched in a certain manner to indicate the amount of the purchase or debt. The name of the debtor and the date of the transaction were written on two opposite sides of the stick, which was then split down the middle in such a way that the notches were cut in half, and the name and date appeared on both pieces of the tally. One piece, called the 'stock' was issued to the seller or creditor, while the other, called the 'stub' or 'counter-stock,' was kept by the buyer or debtor. Both halves were thus a complete record of the credit and debt and the debtor was protected by his stub from the fraudulent imitation of or tampering with his tally'. There are other examples in antiquity. See also Fox (2008) op cit note 3 at 45 who describes the use of the deposit of grain in third millennium Babylon and later in Egypt as the basis for a transferable payment instrument or giro.

${ }^{412}$ Mitchell-Innes (1913) op cit note 3; and Mitchell-Innes (1914) op cit note 3.

${ }^{413}$ Schumpeter (1934) op cit note 3. His 'Credit Theory of Money' is compared to a 'Monetary Theory of Credit.' As Wray explains the difference, the first sees private 'credit money' as only a temporary substitute for 'real money', that is, state money possibly based on a metallic backing that is free of social relations. Ultimately, only the quantity of real money matters so far as economic activity is concerned, that is, real money that is the basis of deposit expansion should be controlled based on the quantity of metallic money. In contrast, the 'Credit Theory of Money', emphasises that credit normally expands to allow economic activity to grow. Wray (2006) op cit note 3 .

${ }^{414}$ ‘ $[$ T] oday all civilised money....is chartalist.' Keynes (1971) op cit note 3 at 4 . Not surprisingly, this has been termed the 'Civilised Money View' which finds adherents in the post-Keynesian School, the Modern Monetary Theory (MMT) which says that currency should be a public monopoly. See A Terzi (2102) 'Civilized Money View vs. Monetarist Keynesianism', available at http://goo.gl/lHmh6. See also Knapp (1924) op cit note 3 at 88 whose ideas on Chartals are thus regarded as a non-market based theory of money which is (also) not preoccupied with a MOE function. See also Bell (1998) op cit note 3, Maclachlan (2003) op cit note 3. Mann's definition of money is based on Knapp's State Theory of money. See also Ingham (2002) op cit note 3 at 127, who also points out that the analytical primacy given to money by the Orthodox School as a medium for the exchange of existing value diverts attention from its obvious role in the capitalist system.
} 
alternative view of money as being what he termed a 'Chartal', ${ }^{415}$ or ticket, which gained its value and validity by mere proclamation (and thus creation) usually by the state of issue. ${ }^{416}$

The 'Chartalist School', as Knapp's views became known, contends that money consists of a network of debit and credit relationships. ${ }^{417}$ In one view of this, the state is centre stage in this valuation of money, through declaring what 'thing' should answer as money in payment of the debts - primarily taxes - owed to it. If the state - the prince - decreed then that a particular Chartal or ticket should act as money, then that Chartal took on the mantle of legal money or legal tender.

Knapp however believed that legal tender laws were not sufficient to create Chartal money. Rather, he believed, it is the acceptability of the 'thing' by state pay offices that make it Chartal money. ${ }^{418} \mathrm{He}$ also made the distinction between state money and Keynes's Bank Money, the latter's banknotes, he argued, only became state money when the state decided to accept banknotes in public pay offices. ${ }^{419}$

Thus money is social in nature, consisting of complex social practices that include power and class relationships, socially constructed meaning, and abstract representations of social value. The credit approach locates the origin of money in credit and social debt relations. ${ }^{420}$ The analysis is thus inherently social - at the very least it requires a social relation between debtor and creditor. The UOA is emphasised as the numeraire in which credits and debts are measured. While the SOV function could also be important, for one stores wealth in the form of others' debts. On the other hand, the MOE function and the market are de-emphasised; indeed, one could imagine credits and debits without markets and without a MOE. There is thus an explicit and lasting social relation between creditor and debtor that could include hierarchy and power.

With their emphasis on money creation creating debts or claims - a Right - this School also became known as the 'Claim Theorists' from where the 'Claim School' is derived. ${ }^{421}$ Money then is simply a Right, enunciated as a type of (resurrected) bookkeeping exercise that records these debits and credits. ${ }^{422}$

\footnotetext{
${ }^{415}$ The term 'Chartal' was used by Knapp to describe bank money, a term derived from the Latin word charta and relates to a 'ticket', 'token' or 'Chartal' form. Thus any ticket or token that bears the stamp of the issuer can act in a broad sense, say the Chartalists, as money. See Knapp (1924) op cit note 3 at 88; and Bell (1998) op cit note 3 at 9.

${ }^{416}$ The value of the ticket would be (legally) established via legal tender laws. See LR Wray (2001a) 'Money and Inflation' in RPF Holt A New Guide to Post Keynesian Economics at 80.

${ }^{417}$ See Fox (2008) op cit note 3 at 44.

${ }^{418}$ For example, to pay taxes. Knapp argued that 'it is not the issue, but the acceptation ... which is decisive'. See Knapp (1924) op cit note 3.

${ }^{419}$ Keynes was an adherent to the School of thought that the state created the Chartal, not society. See Keynes (1937) op cit note 3; and further ch 3, ss3.10.2.1 on the UOA, and 3.10.2.2 on 'Money'.

${ }^{420}$ As Dodd (2005) op cit note 3 notes, those who adopt the credit approach identify the social nature of the money UOA and, indeed, the social processes that generate creditors and debtors. See also Mitchell-Innes (1913) op cit note 3 who offers that the origins of credit and debt relations are based on an elaborate system of tribal wergild designed to prevent blood feuds. In Anglo-Saxon and Germanic law, wergild was the price set upon a person's life on the basis of rank and paid as compensation by the family of a slayer to the kindred or lord of a slain person to free the culprit of further punishment or obligation and to prevent a blood feud.

${ }^{421}$ For a historical exposition of the derivation of the Claim School, see generally Bell (1998) op cit note 3 passim; Messori (2002) op cit note 3. See also similarly Ellis (1934) op cit note 3; and Schumpeter (1954) op cit note 3.

422 This 'book-keeping' conception of the monetary system, notes Messori, anticipates fundamental aspects of the current organisation of national payment systems and highlights both a bank's role in the creation of MOP as well as the essential role of credit in the cyclical (macro-economic) developments of the business cycle. M Messori (2002) op cit note 3.
} 
In aggregate then, the belief is that money is a debt relationship between actors of which the state may be, but does not necessarily have to be, one of the actors. ${ }^{423}$

In relation to an economic and legal view, Mitchell-Innes said that:

'.. while a debtor must be in a position to satisfy his creditor, the really important characteristic of a credit is not the right which it gives to "payment" of a debt, but the right that it confers on the holder to liberate himself from debt by its means - a right recognised by all societies'. ${ }^{424}$

Ingham describes it further as follows:

'[Money is] an abstract claim, or credit, measured by a money of account. Here money's nature is twofold: it measures and stores the abstract value of general purchasing power and transports it through space and time. Money has value not because it comprises a commodity with fixed intrinsic value (although an authority might declare it to have one, as in a gold standard), but because it is "the value of things without the things themselves".,425

A further abstraction from this Credit Theory of Money is that banks can use fractional banking practices to, in effect, create money via 'credit money'. ${ }^{426}$

The Chartalist and the Keynesian Schools have as a subsidiary the modern NME School. ${ }^{427}$ As Cesarano notes of this School:

'One of [the] main points is that currency and an accounting system are entirely different methods for exchanging wealth. Currency is a physical medium which can be characterised as money. An accounting system works through bookkeeping entries, debits and credits, which do not require any physical medium or the concept of money. ${ }^{428}$

Their central proposition then is the distinction between a tangible and a non-tangible MOP since, they say, the latter does not involve the notion of money. ${ }^{429}$

\footnotetext{
${ }^{423}$ For views on the debtor-creditor relationships that manifest with respect to money, see inter alia Hart (1986) op cit note 3 passim; Ferguson (2008) op cit note 3 at 341; and Graeber (2011) op cit note 3 passim. This inherently social nature of credit also appears to conceptualise the idea of a possible social and state nexus to infuse into The Credit Theory of Money. This potentially hybrid nature of the Claim School is explored further in ch 3, s3.11 titled Interplay Between 'Money' Theories.

${ }^{424}$ LR Wray (ed) (2004) Credit and State Theories of Money: The Contributions of A. Mitchell Innes (Chapters 2 and 3 written by AM Innes) at 394, available at http://goo.gl/zig59.

${ }^{425}$ Ingham (2006) op cit note 3 at 260-261. See also ch 3, s3.10.2.1 on the UOA.

${ }^{426}$ See ch 3, s3.7.2.1 on Credit Money.

${ }^{427}$ T Cowen and R Kroszner (1987) 'The Development of the New Monetary Economics' 95(3) The Journal of Political Economy at 567-590.

${ }^{428}$ Fama (1980) op cit note 3 at 39. The NME School's view of 'money' then appears to be most coincident with a view of the new electronic means of payment and SOV, as in and of itself being money.

${ }^{429}$ Cesarano (1994) op cit note 3 at 39-40.
} 
Adherents to the 'Claim School' are still not homogenous in their views. While all adherents commonly discard the Commodity (Orthodox) School theory of money and its metallic basis, many within the School and within its offshoots differ on the fundamental nature of money and in particular the role of a 'thing,' if any; the role of the UOA versus a MOP; as well as the role of the state versus society in the creation of money. Even then their scholarship appears to twist and turn according to the context and era.

For example, Knapp and Keynes believed that the state was responsible for the issuance of money, and that the bookkeeping debt-function of money sailed through this core. In Knapp's case, it was the state that gave the Chartal its validity, while in Keynes's case he believed that while the state may possibly create money through Chartals, since money can be considered credit (debt), it can be created by private entities through loans or other purchases. The state's role then may be to enforce the debt agreement and dictate the legal terms. $^{430}$

Although they are not a homogenous group, the essential characteristics of 'money' according to the Chartalist and Claim Schools and their subsidiary NME School can be distilled in the following sections on the UOA, 'Money', and the MOP. ${ }^{431}$

\subsubsection{1}

\section{Unit of Account (UOA)}

The School assigns a central role to the UOA function which precedes even its use as a 'MOP' for debts and SOV roles. Although the reasoning is largely macro-economic and highly technical in nature ${ }^{432}$ and beyond the scope of this work, the overarching reason that a UOA is chosen as the monetary pivot in the Chartalist School is that it shifts the focus away from the centralised roles of commodities - and indeed the state - in determining the value and character of money. Instead, the alternate focus on the UOA abstracts money beyond this determinable and quantitative tangibility. ${ }^{433}$

\section{As Fama notes:}

'The precise problem is not rendering a monetary system determinate, but rather giving content to a pure nominal UOA (a dollar) as a separate, well-defined economic good. ${ }^{434}$

\footnotetext{
${ }^{430} \mathrm{He}$ also follows Knapp's view of the role of the state: 'Knapp's chartalism ... the doctrine that money is peculiarly a creation of the state is fully realised' (1971:4). It is the state which enforces contracts and the nature of the things that stand as money and Keynes argued that this had been the case for four thousand years. See also Graeber (2011) op cit note 3 at 54. 431 The NME School is similar in conceptual thinking to the work of Black, Fama and Hall, also known as the BFH School of Economics (hereafter BFH) who also strongly encourage the relaxation of government controls on the banking industry, suggesting also that improved monetary performance could be induced by adoption of a new, non-monetary UOA. The two Schools do however disagree somewhat, with the BFH emphasising the accounting (as opposed to monetary) exchange and versus the floating exchange rate aspect of the various currencies in the NME group. See McCallum (1986) op cit note 3 at 23.

${ }^{432}$ A main macro-economic objective is to remove income and price fluctuations by building an alternative monetary system using a non-tangible MOE, the so-called 'Walrasian model' of general equilibrium so that money is viewed as the UOA in that model with no further distinctive characteristic. See Cesarano (1994) op cit note 3.

${ }^{433}$ Use of an accounting system to determine values of money acts to dematerialise money - the need for tangibility is removed.

${ }^{434}$ Fama (1980) op cit note 3 at 55.
} 
The UOA, then, could be a notional UOA denominated by the state or if prudentially possible, and/or market forces permitting, it could be an alternate UOA acting parallel to the national UOA, for example, local exchanges or MFS-based airtime minutes or other forms. ${ }^{435}$

Keynes embraced the Austrian School's laissez-faire approach that a money's value is independent of the medium used to represent it. ${ }^{436}$ To do this, he distinguished the way in which debts, prices or purchasing power are expressed from what is actually discharged or held. He thus refined the relative components of what commodity theorists know as 'money' to encompass instead what he terms the 'Money of Account' (MOA) approximating the UOA, and the 'money'. Thus the expressed form of money is the money as a UOA, or MOA, while the discharged or held component is the money as a MOE or money proper ('money). ${ }^{437}$

\subsubsection{2}

\section{'Money'}

With the UOA/MOA being pivotal to the Claim School, it follows then that something must be subsidiary to it in order to give it its form and gravitas. This, says Keynes, is 'money', ${ }^{438}$ or in Knapp's Chartalist nomenclature, a 'thing' which answers the description provided by the MOA. The 'money' then could be anything, even 'value' in prepaid airtime MFS SOV controlled by a MNO and which are denominated in the common national UOA, or even in (prepaid airtime) 'minutes'.

This abstraction allows other 'things' beyond what the state determines to be 'money' (and the GAME) to instead become, and be used as what Keynes calls 'money'.

In Keynes's world then, the MOA is the description or title (for example the Dollar), while the money is the 'thing' which answers to the description. ${ }^{439}$ Hence, the use of the term 'money' without a qualifier is describing it in terms of a 'UOA' feature, whereas 'money' without a qualifier is, for example, the Dollar or the Pound.

However, while there may be a common UOA, it has been noted that the use of a common numéraire or UOA does not logically compel the use of a common 'money' (or thing) in transactions. ${ }^{440}$ Other providers may provide a 'thing' acting as money that is denominated in the UOA but which is valued in values equated via an exchange rate mechanism that is referenced to numeraire or UOA prices. ${ }^{441}$

\footnotetext{
${ }^{435}$ On this possibility, see generally ch 13 passim,

${ }^{436}$ See Keynes (1937) op cit note 3 at 4.

${ }^{437} \mathrm{He}$ believed however that the emergence of a formal, defined MOA by the state rather than society was pivotal in an economy. As Mellor (2011) op cit note 3 observes, Keynes retention of the notion of the tangibility of money in the 'thing' that answers to the MOA leads to confusion in his account of 'money proper' since while 'money proper ... can only exist in relation to a money of account' - Keynes (1971) op cit note 3 at 3 - it is only 'money proper,' says Mellor, that can finally discharge a debt.

${ }^{438}$ Keynes (1971) op cit note 3 at 3; and Bell (1998) op cit note 3 passim. See the discussion on a 'thing' as the money in ch 13, s13.5.3.1 on the SOV.

${ }^{439}$ Keynes (1971) op cit note 3 at 3.

${ }^{440}$ Tobin (1980) op cit note 229.

${ }^{441}$ Tobin though finds it 'hard to imagine and illustrate historically, a UOA disembodied from a generally accepted means of payment'. See Tobin (1963) op cit note 3.
} 
For Keynes, with the state involved in the issuance of 'money,' via CBs, people could transact. It is the required MOP for taxes.

There are of course also 'obligations' - debt - of individuals, banks and companies that may compete with the state 'money,' highlighting the non-homogenous nature of the Claim School insofar as the focus is on the State providing the legitimacy for a 'money'. It may be said however that the ability in his mind for banks to endogenously create money through fractional banking provides some consonance to the belief that the State is not the only producer and issuer of money. Keynes's focus then appears to be on the legality and acceptability of the money, and not on the ability to produce and issue a money.

\subsubsection{Means of Payment}

Another subsidiary role of money is that of a MOP. ${ }^{442}$ Unlike the MOE in the Orthodox School, MOP in the Claim School is thought to signify a final payment by the payor which mostly, but not always, leaves the seller with no further claim on the buyer.

This is believed by adherents to the Claim School to be the critical appellation as it signifies the defining characteristic of money as final payment. ${ }^{443}$ The emphasis then is one where debts (or claims) are finally settled, ${ }^{444}$ rather than the (means of) exchange functionality of the Orthodox School which is perceived to be an inchoate - even intermediate $e^{445}$ - step to a final payment. ${ }^{446}$

The MOP thus sees the value (of money) a fiorti as a two-sided balance sheet, where the issuer 'owes' the holder, acting as creditor to the issuer, of the 'money ${ }^{447}$ (acting as a MOP). ${ }^{448}$

To understand this, we can use again the example of a coin provided to a merchant by a purchaser of a good. In this instance, the coin, as cash, acts simultaneously as both a MOP and a MOE in that the merchant exchanges his goods for the coin, and simultaneously accepts the coin as a 'final discharge of

\footnotetext{
${ }^{442}$ Using an accounting system that settles debts or claims that are created when 'money' per se is created. Mann (1992) op cit note 3 at 65 says that since money becomes capable of discharging all obligations, it is the subsidiary means of performance.

${ }^{443}$ For a detailed explanation of the functional difference between a MOE and a MOP and the inchoate nature of the MOE, Goodhart (1989) op cit note 3 at 24-27, 38-44; Mann (1992) op cit note 3; Nussbaum (1950) op cit note 3; Sawyer (2003) op cit note 3 at 3; Papadopoulos (2007) op cit note 3 passim; Newlyn and Bootle (1978) op cit note 3 passim; and Cesarano (1994) op cit note 3 .

${ }^{444}$ This is different to a use as the means of final settlement (or netting) in a (monetary) national payment system, where this would be a subsidiary function of the GAME.

${ }^{445}$ On the on the intermediate nature of a MOE, see Goodhart (1989) op cit note 3 at 24-27 and 38-44; Papadopoulos (2007) op cit note 3 passim; Newlyn and Bootle (1978) op cit note 3 passim; and generally Mann (1992) op cit note 3; Nussbaum (1950) op cit note 3; Sawyer (2003) op cit note 3 at 3; and Cesarano (1994) op cit note 3.

${ }^{446}$ Cesarano (1994) op cit note 3 . The need to 'exchange' values through a state-controlled system compared to the direct transfer of wealth and values under the claim system (ie means of final payment) is what gives it, inter alia, its inchoate nature, whereas with the UOA placed centre stage, its primary role is purely to finally settle debts - hence a MOP. For an exposition on the difference between MOP and MOE, see Goodhart (1989) op cit note 3 at 26; and for a discussion thereof, see Piffaretti (1998) op cit note 3. For a legal perspective on claims, see inter alia Fox (2005) op cit note 3, where he generally discusses on claims against bank money; also Sawyer (2003) op cit note 3 passim.

${ }^{447}$ Simmel (1900) op cit note at 3 as noted by Hermann (2007) op cit note 3.

${ }^{448}$ Minsky (1986) op cit note 3 at 226-228. See also Bell (1998) op cit note 3 at 19 and 21; and Goode (1983) op cit note 3, at ch 4 passim.
} 
(the) debts' ${ }^{449}$ However, the converse is not true with most other payment media; that which acts as a MOE may sometimes not simultaneously act as a MOP. For example, a merchant may accept a cheque to the value required as a MOE when handing over the goods so purchased. Hence, while there is a MOE, there is no 'final discharge' as yet for the purchase as the cheque still has to go through a process of clearance through the interbank system which means that the merchant will not receive immediate value that satisfies the debt and which he may consider as concluding, or providing finality to, the transaction. There is thus delayed MOP, assuming that the cheque clears and the value is transferred to the merchant. Even in EFT there is no direct payment per se using the GAME, as the payment still needs to be 'exchanged' through a NPS authority, ${ }^{450}$ which in practical terms may require netting the balances of the sending and receiving financial institutions through the CB payments system rather than a physical transfer of funds. ${ }^{451}$ Similarly, when using a credit card, although the merchant's account may be credited effectively immediately, it may still not be a final MOP since not only does the payor now have a debt outstanding to the credit card company, ${ }^{452}$ but the transaction and final 'payment' could still be disputed by the payor using the so-called charge-back card dispute resolution facility inherent in almost all credit cards ${ }^{453}$ available today. ${ }^{454}$

In this scenario, money evolves from being primarily a MOE that requires the involvement of the state to a means of payment provided by non-state, usually private entities. The 'thing', or 'money' in Keynes's terminology, is the demonstrable action or artifact that moves the UOA, or money, forward on its evolutionary continuum. In this scenario, with a common UOA, shares and even mobile prepaid minutes denominated in the common UOA is possible in terms of the UOA's role as Keynes's 'thing'. ${ }^{455}$

From the vantage point of hindsight, the continuum of the evolution of money from primitive tangible tokens, to commodities exchanged by barter, to being primarily what it is now in the form of coins and paper notes acting as currency ${ }^{456}$ and incorporation in modern banking as being represented by electronic data, it is clear that money can take many forms.

As described earlier ${ }^{457}$ and as Hart notes, ${ }^{458}$ most economic theories of money focus on one extreme to the exclusion of the other. On the one hand there is the quantitative Orthodox School where the existence, amount and value of money is based on a tangible object, traditionally a precious metal. It is primarily and

\footnotetext{
${ }^{449}$ Moss op cit note 3 .

${ }^{450}$ See ch 4, s4.8 titled Modern Payment Systems, Instruments and Regulations.

${ }^{451}$ Legally though there is no such thing as an EFT; instead it is termed a 'circulation of rights' between the sending and receiving institutions. See Geva (1987) op cit note 3; Malan and Pretorius (2006) op cit note 3.

${ }^{452}$ The payor has merely replaced a debt to the merchant with a debt to the credit card issuer.

${ }^{453}$ See ch 4, s4.8.4.2.7 titled Credit and Charge Cards.

${ }^{454}$ As a result of this, the bouquet of instruments that may be considered as money does not usually include credit cards, trade credit between firms, or any other line of credit such as unused overdraft facilities. Cheques, etc, are not money; they are merely a means of transferring money.

${ }^{455}$ This possibility of, and a new role for, dematerialised (incorporeal) money will be analysed in ch 13.

${ }^{456}$ Money is distinguishable from currency. For a discussion on currency, see ch 3, s3.6 on Money and Currency: General View.

${ }^{457}$ See ch 3, ss 3.9 on the Orthodox School and 3.10 on the Claim School.

${ }^{458}$ Hart (1986) op cit note 3 at 1.
} 
intrinsically asocial, based on market values and enforced through the gravitas of the state. There are also the more abstract, society-focused and qualitative Claim School type of money theories where qualitative factors, such as credit and trust in the person providing the value, are manifest.

The issue of the state involvement in money is the source of much of the didactical and robust discussion that permeates the scholarship amongst anthropologists, sociologists, historians, economists and to a lesser extent, lawyers. $^{459}$

Knapp and Keynes were proponents of the need for the state to be involved in money, ${ }^{460}$ while others believe that not just the state, but society also has a, if not the, pivotal role to play in creating the valuableness and acceptability of a money. ${ }^{461}$

Menger for example was doubtful that the origin of money was merely only via state or 'Chartal' proclamation: ${ }^{462}$ rather, anyone - or more pertinently, societies - had or could create money.

But while the State and Societary Theories may appear mutually exclusive, they may not necessarily be. Further, as noted earlier, ${ }^{463}$ nor is the state-money approach necessarily inconsistent with the credit money approach described in the previous section.

In relation then to a seeming disconnect between state money representing a credit/debt relation, MitchellInnes ${ }^{464}$ provides some degree of integration based on historical precepts in the use of money, suggesting that in relation to state debt, when the state spends, it becomes a debtor. ${ }^{465}$ As it issues state money, even state money is credit money - a special kind of credit says Wray - that is 'redeemed by taxation' and characterised by a 'promise to 'pay'.

\footnotetext{
${ }^{459}$ For a description of what economists and lawyers view as money, see ch 2, s2.4 above titled Services Available from MFS. For a neutral view, see that of Goodhart (2009) op cit note 3 at 824-826, who believes that money was invented as a social, and governmental, phenomenon, rather than as a mechanism for reducing transactions costs in private-sector markets, although money did reduce the transaction costs of government. In Goodhart (2005b) op cit note 3, he cites examples of a need to resolve social inter-relationships, for example the bride-price, restitution of personal injuries, settling feuds, rather than, or certainly as well as market relationships. But, he cautions, such a thesis has not yet lent itself to mathematical modelling to establish formal mathematical models of how private agents (with no government), transacting amongst themselves, might jointly adopt an equilibrium in which they all settle on a common monetary instrument. The net effect of this lacuna is that, he believes, economists have tended to ignore the historical reality leading to the doctrinal differences.

${ }^{460}$ For an interesting Claim School perspective that mediates between the Claim School and the need for the state to issue the money and in relation to finality of payment, see Ganßmann (2009) op cit note 3. He believes that CB payment obligations serve the state as functional equivalents of cash such that payments made with these notes are final. He compares this (superior) 'finality' of state-issued money to societal equivalents where in pair-wise transactions between borrowers and lenders defining the time and size of payment obligations persists as long as the payment obligation is not fulfilled. This, he says, means that the transaction - and thus money - is not a final MOP. It also introduces instability as it requires information about the creditworthiness of the borrower composed of knowledge about past performance, assets serving as collateral, and a belief in future payment capability. They are entered only if the lender believes that the borrower can service and repay the debt.

${ }^{461}$ That is, the 'Societary' or 'Social' or 'Societal' theory of money discussed in ch 3, s3.2.4.1 titled Issuance And Production. See further the views of Mitchell-Innes (1913) op cit note 3; Mitchell-Innes (1914) op cit note 3; Hart (1986) op cit note 3; Hart (2005) op cit note 3; Dodd (2005) op cit note 3; and Dodd (2007); Graeber (2009) op cit note 3; Graeber (2011) op cit note 3. For a discussion of the interplay between inter alia the state and social theories of money, see ch 3, s3.11 on Interplay Between 'Money' Theories.

${ }_{462}$ Menger (1892) op cit note 3 at 239-55.

${ }^{463}$ See ch 3, s3.2.3 titled Doctrinal Perspectives on Money: An Introduction on an initial analysis of the economic doctrines. ${ }^{464}$ Mitchell-Innes (1913) op cit note 3 at 168.

${ }^{465}$ See again Akindemowo (1998) op cit note 3 who notes that the 'fiat' may be seen simply as circulating obligations (indirectly) linked to state debt obligations but believes that since the fiat is 'incontrovertible', it cannot be redeemed and hence cannot be regarded as creating a direct debt owed by the state to the holder.
} 
In an acknowledgement that the state and society may often need to operate symbiotically, Hart ${ }^{466}$ provides an expansive and embracing view of society by using a differentiated concept of 'society' to include three distinct senses, at least within the a sociological and anthropological context: as a state, nation and community. Each, he says, yields a distinctive conception of the interrelationship between money and social structure.

The distinction though between State and Societary Theories and their respective intersections with the Orthodox and Claim-type theories may not be as dogmatically segmented as previously thought, although their theoretical basis and practical applications remain manifest. There may be some intersection between the two suggested through an analysis of the evolution of money. The economic anthropologist Graeber, for example, notes that during the last two centuries, state money has oscillated between being based on a commodity such as the gold standard or some equivalent fictional backing, versus being practically worthless when based on fiat or paper money. ${ }^{467}$ Thus, he suggests, most currencies are a hybrid:

\begin{abstract}
'Money has, for most of its history, been a strange hybrid entity that takes on aspects of both commodity (object) and credit (social relation) ... There are periods where credit is primary, and everyone adopts more or less Chartalist theories of money and others where cash tends to predominate and commodity theories of money instead come to the fore. We tend to forget that in, say, the Middle Ages, from France to China, Chartalism was just common sense: money was just a social convention; in practice, it was whatever the king was willing to accept in taxes. ${ }^{, 468}$
\end{abstract}

Keynes, Hart recounts, ${ }^{469}$ also tried to explain that modern money must be the managed outcome of the interplay between the state and markets in that it may be the product of social organisation both from the top down ('states) and from the bottom up ('markets). They both have in common though a commitment to founding the economy on impersonal money that keeps transactions secret.

Keynes ${ }^{470}$ however appears to acknowledge the utility and importance of non-state money by somewhat confusingly stating that:

\footnotetext{
'I propose to include as State money not only money which is itself compulsory legal tender but also money which the State or the central bank undertakes to accept in payments to itself or to exchange for compulsory legal-tender money'.
}

Similarly, this relates to the notion by Zelizer ${ }^{41}$ that moneys have a 'dual genesis,' serving both general and local circuits that may be top down (state) and bottom up (society). To this point, Hart ${ }^{472}$ points to the coin with its 'head' and 'tail' as an exemplar. The head contains a symbol of political authority, a token of

\footnotetext{
${ }^{466}$ Hart (2000) op cit note 3 at 252.

${ }^{467}$ Pilkington (2011) op cit note 3, in an interview with Graeber.

468 Ibid.

${ }^{469}$ Hart (1986) op cit note 3 at 638.

${ }^{470}$ Keynes (1971) op cit note 3 at 6

${ }^{471}$ Zelizer (2007) op cit note 3. See further ch 3, s3.2.4.1 titled Issuance and Production.

${ }^{472}$ Hart (1986) op cit note 3.
} 
society and thus Keynes's MOA. The tail indicates its worth, that is, its quantitative value in exchange for other commodities. Even Schumpeter alludes to this, since as Messori notes, ${ }^{473}$ he does not confine himself to state that all the means used for paying can be assimilated to the current form of money stricto sensu, that is, legal tender. ${ }^{474}$

And, says Messori, ${ }^{475}$ Schumpeter further improves the analytical framework because he does not fixate his analysis of bank behaviour in a 'pure credit' model. Instead he admits that the amount of legal tender acts as a restriction to bank creation of MOP by regulating the reciprocal links amongst the individual competing banks and between each bank and the central bank.

From this discussion, a priori it appears that the Claim School with its non-tangible credit focus and an ostensible allowance for the role of society - be that the state, a national or communities - in the production and issuance 'form', denomination and acceptability of money comports with the ability of new, emerging types of value such as that in MFS to not just rise to the appellation of money, but to in and of itself act as money.

The legal basis for this is explored below.

\section{PART B: $\quad$ Legal Perspectives Of Money}

\section{Overview}

It has been shown earlier ${ }^{476}$ that legal scholars do not have the same classification criteria as do economists for determining what may be considered as money, even though lawyers have generally adopted the economic view of money. ${ }^{477}$

Any nexus, then, between money's robust economic functions and its legal import ${ }^{478}$ is seen as arbitrary, almost ephemeral. ${ }^{479}$ Thus as Keynes expounded in his General Theory:

\footnotetext{
${ }^{473}$ Messori (2002) op cit note 3.

${ }^{474}$ Instead, says Messori, legal tender represents the ending rather than the initial ring in the chain of creation of purchasing power such that practically, monetary flows are governed by a "clearing system that cancels claims and debts and carries forward the differences - so that "money" payments come in only as a special case without any particularly fundamental importance.' Messori (2002) op cit note 3; and Schumpeter (1954) op cit note 3 at 717-720.

${ }^{475}$ Messori (2002) op cit note 3.

${ }^{476}$ See ch 3, s3.2.3.5 titled Legal Views of Money.

${ }^{477}$ Writing on MFS, economists seemingly applying the Orthodox School to MFS, say that MFS SVPs do not simply provide electronic access to existing bank accounts, but instead, deposits of money in a mobile phone-based accounts reflect holdings by the account 'owner of a commodity' that can easily be transferred from one individual to another such that as long as it is expected to retain its value, it can be used in equilibrium as a MOE, as well as to transfer purchasing power between individuals. See W Jack, T Suri and R Townsend (2010) 'Monetary Theory and Electronic Money: Reflections on the Kenyan Experience' 96(1) Economic Quarterly at 84, available from http://goo.gl/w5jvx.

${ }^{478}$ For example, monetary obligations or debt. Lawyers however generally concentrate on the obligations - through payments

that the use of money engenders. So while depositing money into a bank account may have a macro-economic effect, this may be distinct from the legal effect of that deposit. See Goode (1995) op cit note 3 at 492.
} 
'We can draw the line between "money" and "debts" at whatever point is most convenient' for handling a particular problem. ${ }^{480}$

Generally, the legal view of money is far narrower than the economic view of money, again in the context of possibly a micro-economic versus macro-economic analytical divide. Mann comments - again, possibly from an era-influenced view, that economic theory is unlikely to assist the lawyer to any appreciable extent as money in law does not have the broad-church approach of the economists, and instead narrows its scope to specific instances that relate to the settling of obligations and concomitant procedural rules to give effect thereto. ${ }^{481}$ This also includes a determination as to whether something is legal tender, and indeed whether this matters at all in commercial reality. ${ }^{482}$

While it appears that the functional, Orthodox School's (economic) view of money has generally and manifestly been accepted in law ${ }^{483}$ for determining whether debts have been validly settled, ${ }^{484}$ it will however be suggested below that in an age of money dematerialised in electronic form, and the use of 'wealth' as money, that the Claim School may be a more appropriate (economic) School for the law to appropriate.

As in the economic overview of money, a normative, legal meaning of the word 'money' is somewhat mercurial, like the meaning of so many legal terms. ${ }^{485}$ While there are a variety of statutes that talk of 'money', statutory definitions of money particularly in common law jurisdictions are rare. ${ }^{486}$

\footnotetext{
${ }^{479}$ Keynes (1937/1973) op cit note 3 at 167.

${ }^{480}$ Keynes (1971) op cit note 3 at 3 . Keynes however does maintain some nexus between money and debt: 'Money of account comes into existence along with debts which are contracts for deferred payment and price lists which are offers for sale and purchase'. Thus when individuals create forward contracts and so create a debt that the other is willing to hold, they are creating money. See also Bell (1998) op cit note 3 at 1.

${ }^{481}$ Mann (1982) op cit note 3 at 5 . While the narrow definition is favoured, there are some specific contextual exceptions of this approach to be found in the literature, for example, in the interpretation of the word 'money' in wills.

${ }^{482}$ See ch 3, s3.12.3.2.1 on Legal Tender and Fiats.

${ }^{483}$ See Mann (1992) op cit note 3 at 1-10 on how the common law came to appropriate the (Orthodox) economic School.

${ }^{484}$ These 'money' obligations could take the form of, for example, damages, value, payment, price, capital, tax and pecuniary legacy. See Mann (1992) op cit note 3 at 3-5 where he indicates that 'the meaning of the term money varies and consequently it is necessary in each individual context to examine its meaning. No hard and fast rule exists'. Thus, says Mann, while an economist may refer to a bank account as money insofar as it contributes to the overall money supply, it is not money in the legal sense - the bank account instead is a debt. Mann (1992) op cit note 3 at 5; and Akindemowo (1998) op cit note 3 at 3 . In casu, from the legal perspective, a debt and in the incumbent obligations thereto are ultimately settled by the transfer of (economic) money as payment and, consequential to this act, settlement of all outstanding rights.

${ }^{485}$ Nussbaum (1937) op cit note 3 at 868 .

${ }^{486}$ Money is not defined directly in South African law. See Malan, Pretorius and Du Toit (2009) op cit note 3 at 43 . The South African Exchange Control Regulations of 1961 issued in terms of the Currency and Exchanges Act 9 of 1933 indirectly define money to 'include foreign currency or any bill of exchange or other negotiable instrument'. This wide definition however is contrary to other bodies of law that specifically exclude negotiable instruments as being 'money'. See Malan, Pretorius and Du Toit (2009) op cit note 3 at 50. The SARB has been given the right to issue banknotes and coins under Act 90 of 1989 op cit note 3. The Canadian Personal Property Security Act [RSBC 1996] Chapter 359 defines money explicitly as 'a MOE that is (a) authorised by the Parliament of Canada, or (b) authorised or adopted by a foreign government as part of its currency.' Similarly, s16 of the Personal Property Securities Act 1999 (New Zealand) says “"money” means currency authorised as a MOE by the law of New Zealand or any other country'. All in all, then, it appears that it is the common law definition of money that prevails, although in Kazakhstan money is defined as 'a means of payment and savings
} 
Thus, it is the common law and the views of legal scholars such as Mann, ${ }^{487} \mathrm{Geva},{ }^{488}$ Nussbaum, ${ }^{489} \mathrm{Eder},{ }^{490}$ Goode, ${ }^{491}$ Proctor, ${ }^{492}$ Von Savigny, ${ }^{493}$ Hartman, ${ }^{494}$ Chung, ${ }^{495}$ and Fox $^{496}$ that offer the leading legal definitions and interpretations of the essence of money.

It must be noted however that an analysis of the legal (and economic) writings on money and the solutions they proffer, generally reflect the era in which they were constituted, especially in eras of either hyperinflation in Weimar Germany, the Great Depression and moves to abolish the Gold Standard. Nonetheless, some common themes in the legal definitions of money can be extracted, some which are functional and less about the essence or abstract nature of money.

For some of the period views of money, this is in part a consequence of the appropriation of the Orthodox School's view of money, which places money within a purposive scope. There are however some middle of the road, almost androgynous, legal views of money which, again, depend on the era of their constitution.

\subsubsection{Components and Scope of the Legal Definitions}

Issues and judgments from many hundreds of years ago appear to be harbingers of the current - and seemingly perennial - discussion on how to characterise new forms of dematerialised value as 'money' and the rights obtaining thereto.

Indeed, they are still often quoted and used insofar as explaining rights to tangible and intangible value, especially in relation to loss of money. As Fox outlines the genesis of the issue, since at least the $16^{\text {th }}$ century, victims of fraud have encountered what is termed the 'money has no earmark' rule of the common law as an obstacle to recovering their money. ${ }^{497}$ While it applied to metallic coins, the rule was for a while the only type of money in circulation and were practically indistinguishable from each other when the coins were placed together in a mixture. The lack of distinguishing physical features to allow an aggrieved owner of lost money to 'earmark' that money led to his inability to get his money back.

and serves as a measure of cost. Money exists in the form of banknotes (cash) or in the form of monetary obligations of a bank expressed as a notation in the bank accounts of clients' (see art 5, s2, 'Money', of the Law of the Republic of Kazakhstan 'On Payments and Money Transfers' Law of 29 June 1998 n 237, cited by Vakhitov and Vakhitov (2002-2003) op cit note 3.

${ }^{487}$ Charles Proctor who has taken over editorship of the late FA Mann's scholarship.

${ }^{488}$ Benjamin Geva is a contemporary legal scholar who has written extensively on money, banking, and payments law. Many of his works are cited in this chapter and in the bibliography.

${ }^{489}$ Nussbaum (1950) op cit note 3.

${ }^{490}$ Eder (1935) op cit note 3.

${ }^{491}$ Goode (1995) op cit note 3.

${ }^{492}$ Proctor (2005) op cit note 3.

${ }^{493}$ Von Savigny (1851) op cit note 3.

${ }^{494}$ Hartmann (1868) op cit note 3.

${ }^{495}$ Chung (2009) op cit note 3.

${ }^{496}$ Fox (2008) op cit note 3.

${ }^{497}$ Fox (2010a) op cit note 3 at 29. See also Malan (1977) op cit note 3 at 248, who says that the origin is closely linked to the development of the action of detinue, and its relationship to the action of debt. 
Thus once the claimant's money was mixed, he could not claim that value back because the lack of an 'earmark' meant that he could not prove his ownership of the specific coins. ${ }^{498}$ Money, once mixed, was then untraceable and became in a sense 'anonymous'. This 'no earmark' reasoning as a feature of money has obtained to this day, but has received continual criticism as will be discussed below. ${ }^{499}$

A judgment which helped to clarify this issue and also helped define the economic and legal import of money was crafted in 1759 by Lord Mansfield J in Miller, ${ }^{500}$

'It has been quaintly said that "the reason why money cannot be followed is because it has no earmark"; but this is not true. The true reason is upon account of the currency of it; it cannot be recovered after it has passed in currency. So, in case of money stolen, the true owner cannot recover it, after it has been paid away fairly and honestly upon a valuable and bona fide consideration; but before money has passed in currency, an action may be brought for the money itself.'

Thus, in the mind of Lord Mansfield J, the legal holder of the value had no more claim when his money became currency insofar as this feature allowed seamless trade, and not because it could not be identified though lack of an earmark. Thus, Lord Mansfield J believed, currency of money is a legal attribute not shared by other kinds of property trade even where there may be mala fides by a participant in a transaction. ${ }^{501}$ Money, in its role as currency is thus an exception to common law rules of property, usually embodied in the nemo dat quod non habet rule that a seller cannot transfer a better title than he himself has. ${ }^{502}$

The 'no earmark' rule of 1759 that posits a lacuna in an ability to identify and reclaim money at common law and which was dismissed by Lord Mansfield is still of importance however, especially when value is mixed with other value. Fox ${ }^{503}$ however, believes that the 'no earmark' rule should be retired. Indeed, the recent Canadian case of BMP Global Distribution Inc v Bank of Nova Scotia ${ }^{504}$ assisted in this quest where the court refused to accept the untraceability of funds simply because when the funds were mixed there was no longer an ostensible earmark to identify between the 'components' of the mixture. ${ }^{505}$

\footnotetext{
498 This, says Fox, harboured to the pre-modern monetary system that prevailed when Tudor and Stewart judges first pronounced it and before new forms bank money were developed by 17th and 18th century financiers. Fox (2010a) op cit note 3 at 28. On the application of this reasoning, see Isaac v Clark (1615) 2 Bulst 306, 314, 308, 310 as cited in Fox (2008) op cit note 3 at $243 \mathrm{fn} 23$.

${ }^{499}$ See ch 3, s3.12.3.2.2 titled Money as Currency: Legal View; and in particular Fox (2010a) op cit note 3 at 29-30.

${ }^{500}$ Miller op cit note 3.

${ }^{501}$ Mansfield said also of the interpretation of the term 'no earmark' and an expression attributed to CJ Holt that:
}

"Tis pity that reporters sometimes catch at quaint expressions that may happen to be dropped at the bar or bench, and mistake their meaning'.

\footnotetext{
${ }^{502}$ In essence then, the exception in Miller operates to ensure that rights of the bona fide holder for valuable consideration was paramount against the loser on the grounds of the course of business, the interests of trade, and especially that bank notes pass from hand to hand in all respects like coin. In a legal attribute sense, currency could be said to be a synonym for negotiability, in particular where someone takes a note for bona fide purchase for value.

${ }^{503}$ Fox (2010a) op cit note 3 at 30.

${ }^{504}$ BMP Global Distribution Inc v Bank of Nova Scotia (2009) SCC 15, a unanimous Supreme Court of Canada decision.

${ }^{505}$ The 'no earmark rule,' Fox correctly argues, has outlived its economic rationale and the Supreme Court of Canada was right to consign it to history, at least from Canadian perspective. The rule, he says, made sense in a pre-modern monetary system where the relative untraceability of coins and the recipient's immunity from proprietary claims gave money a greater degree of liquidity than ordinary chattels, but that the common law defence of bona fide purchase for value cited in Miller op cit note 3 now meets that need. Lord Mansfield CJ's trenchant opinion in that case, says Fox, has it appears finally been heeded. Fox (2010a) op cit note 3 at 30.
} 
With respect to legal definition of the cogent attributes that would make something money, a definition of money regarded as the locus classicus was provided by Darling J in Moss in 1899 as being:

' $\ldots$ that which passes freely from hand to hand throughout the community in final discharge of debts ... being accepted equally without reference to the character or credit of the person who offers it and without the intention of the person who receives it to consume it ...'

A putative extrapolation of the criteria in Moss is suggested by Geva and Kianieff, ${ }^{506}$ who say that 'the adoption of the economic definition by Moss v. Hancock appears to us to be satisfactory. ${ }^{507}$ They then paraphrase these economic criteria in Moss, such that for something to rise to be 'money', the direct and incidental features of money would need to be investigated. These include whether it passes freely from hand to hand; ${ }^{508}$ whether it circulates ${ }^{509}$ whether it confers final discharge in relation to payment of debts; ${ }^{510}$ whether there is no recourse against the offeror; ${ }^{511}$ and whether it is acceptable to a wide range of creditors (acceptors). ${ }^{512}$

Further, in regard to the requirement in Moss that money must be accepted 'without reference to the character or credit of the person who offers it', these ostensibly separate criteria can be conflated to one additional analytical feature, 'anonymity'. While this conflation and use of the appellation 'anonymity' could possibly provoke an uncomfortable association with the fading and increasingly irrelevant 'no earmark rule,' anonymity may the better descriptor as it demonstrates both the fact that the recipient should hold full title to the received value no matter who provided it, nor the circumstances of that provision. ${ }^{513}$ This characterisation is also similar to the currency motif used in Miller. Context of use is also important, as will be described later. ${ }^{514}$

\subsubsection{3}

Intersection of Legal Definitions with Economics

As mentioned previously, ${ }^{515}$ Mann $^{516}$ noted that lawyers readily appropriated an economic theory of money. Nussbaum too believed that the bond between the economic and legal views of money was covalent:

\footnotetext{
${ }^{506}$ Geva and Kianieff (2002) op cit note 3 at 6.

${ }^{507}$ Ibid. They however discount FA Mann's definition of money described earlier in ch 3, s3.2.3.5 titled Legal Views of Money. See the discussion thereof in ch 13, s13.1.2 titled Parameters of the Enquiry.

${ }^{508}$ Ibid.

${ }^{509}$ Ibid.

${ }^{510}$ Ibid at 6-7, 12.

${ }^{511}$ Ibid at 12 , in that 'no recourse against the payor is to be available to the payee.'

${ }^{512}$ Ibid at 7.

513 That is, the offeree's credit-relationship to the offeror. Anonymity used here may thus have two meanings: first, it could mean broadly, that the identity of the (previous) holder (of the value) is unknown; or second, it could mean specifically that there is no inkling of any potential adverse title fastening on the previous holder is irrelevant insofar as affecting the native, unencumbered ability of the value to act as a 'money'.

${ }^{514}$ See ch 13 titled Re-evaluation of Money.

${ }^{515}$ See ch 3, s3.1.1 titled Overview.

${ }^{516}$ Mann (1992) op cit note 3 at 24.
} 
"There is no merit in distinguishing between an "economic" and a "legal" notion of money since economics and law start from the same conception of money. ${ }^{517}$

However, distinct nuances and doctrinal differences between law and economics of course exist. Indeed, Mann famously criticised ${ }^{518}$ the money definition in Moss - which apparently used an economic definition of money espoused by FA Walker ${ }^{519}$ - as incorrectly appropriating an economic, functional approach to money rather than determining it to be that which is to settle debts. ${ }^{520}$

While pivotal and referenced even to this day, the criteria in Moss are however functional incidents of money, sans the qualitative notions that comprise its essence or intrinsic valuableness. ${ }^{521}$ As noted earlier, ${ }^{522}$ at the scholarly level, Mann offers an alternate legal definition of money as being:

'... all chattels which, issued by authority of law and denominated with reference to a UOA, are intended to serve as a universal medium of exchange in the State of issue. ${ }^{523}$

This approximates to the concept of a thing - the 'chattel' - whereby the state determines the value of money, in essence legal tender. The chattel then is nominalistic in nature, which means that whatever the face value of the chattel is as provided for by the state issuer, that this remains the value even if the currency is catastrophically devalued. Only a contract between those who are party to a debt can alter the intrinsic value of that debt, say by making allowance for the devaluation through other devices. ${ }^{524}$ This may place the risk of depreciation on the creditor and saddles the debtor with the risk of appreciation. ${ }^{525}$

While a further analysis of this follows below, it is important to note again at this juncture that Mann's definition - despite his trenchant criticism of Moss - itself also incorporates economic components into it, rather than being a pure, 'economic-free' legal definition of money which may, somehow, have at its core a classification of money as allowing the settling of debts and obligations, that is, as a MOP to 'final(ly) discharge...debts' ${ }^{526}$ Specifically and critically then, both Moss and Mann's definition of money appear to be predicated on a tangible (real) ${ }^{527}$ item being the focus of their enquiry, with Mann referring to a

\footnotetext{
${ }^{517}$ Nussbaum (1937) op cit note 3 at 875 fn 36.

${ }^{518}$ Mann (1992) op cit note 3 at 8.

${ }^{519}$ Walker (1879) op cit note 3 at 4

${ }^{520}$ The contemporary critic Hudson had also lambasted Walker's definition. Hudson (1895) op cit note 3 at 581 .

${ }^{521}$ As to the value of money, see Woodhead, Plant \& Co v Gunn (1894) 11 SC 4 at 7-8 (hereafter Woodhead) where the court found it difficult to find an equivalence of money to merchandise. See also the Banco case op cit note 3 - discussed further below - in relation to intrinsic value versus wealth in stolen bank notes.

${ }^{522}$ See ch 3, s3.2.1 titled Nature of Money.

${ }^{523}$ Mann (1982) op cit note 3. Although controversial, Mann's approach has been widely accepted. Harris says that these chattels are usually represented by either minted coins or CB notes, the latter constituting legal tender even though they are promissory notes ('I promise to pay ...). These tokens (of value) are protected by trespass rules, meaning that there is a prohibition on their theft. See JW Harris (2002) Property and Justice at 48.

${ }_{524}$ For a critique of Mann's approach to money, see Silard (1983) op cit note 70.

${ }^{525}$ For an example of the principle of nominalism applied in Zimbabwe during that country's hyper-inflation crisis, see JM Mafusire (2010) 'The Zim Dollar is the Zim Dollar Whatever its International Value: The Problem of Currency Nominalization', available at http://goo.gl/lbdP9. Currency nominalism is entrenched in South African law. See SA Eagle Insurance Co Ltd v Hartley 1990 (4) SA 833 (AD).

${ }^{526}$ Moss op cit note 3.

${ }^{527}$ See Ingham (2002) op cit note 3 at 126 on it being a symbol or representation of commodities.
} 
'chattel', and Moss implying something tangible to allow it to '[pass] from hand to hand' and 'without the intention of the person who receives it to consume it ... ${ }^{, 528}$

The thread of money as a chattel requiring a tangible thing thus still runs deep even in scholarly writings on money. ${ }^{529}$

Although Mann does not explicitly differentiate between the two economic Schools, both seem to feature in his analysis of money; on the one hand the use of the term 'chattel' appears to be based on the Orthodox views of money, while on the other hand, the definition also appears to refer to the theories of the economist Knapp who proffered a Chartal (or Claim) view of money whereby money gains its character and 'valuableness' from its issue by the state.

Despite however indicating that economics has no role to play in a legal determination of money, it seems that Mann has used the best of both economic worlds in his chimerical definition of money: the Chartal component of Knapp gives money legal validity as a product of the state, while the 'MOE' component gives it economic utility, ${ }^{530}$ wherefrom his use of the Orthodox economic term 'MOE', elicits again a concession from Mann that his use of this term must pander to economic views of money rather than offering a 'pure' legal view because:

'[I]t is impossible to describe money in concreto without reference to its cardinal function. ${ }^{531}$

The economic thread runs deeper still. Nussbaum, for example, writing in the 1930s on money wrote approvingly of the characterisation of money by Laughlin ${ }^{532}$ as having three functions that of a common denominator of value; a medium of exchange; and a standard of deferred payments. ${ }^{533}$

\footnotetext{
${ }^{528}$ Moss op cit note 3. It follows that the use of the term 'consume' could imply a tangible 'thing' as money, since only tangible things may, ostensibly, be consumed, especially in 1899 where electronic consumption of anything was not yet invented. This is also in contradistinction to the use of barter as an exchange of value, where a recipient of the barter commodity may freely consume what he has received if he wishes. It is however not inconceivable that, at a very abstract level, electronic impulses which are at the heart of all modern digital electronic components and circuits are infinitesimally created and extinguished as needed, that is, a cycle of consumption or of circulation in some form.

${ }^{529}$ The modern legal concept of money, says Geva, reflects the ancient history of metallic currency dating back to Aristotle who, he confirms, was the first to rationalise the concept of money: only money, rather than a 'thing' was intended to be a MOE alone. While there has been a continuous evolution of money from commodity to currency, coins and notes - except possibly rare and foreign varieties - are not considered chattels and are not considered suitable for direct consumption and resale, and are rather used in the primary role as a MOE. This underlies the opposition to usury. See Aristotle (1976) op cit note 151 at 41-48, as cited in B Geva (1987) op cit note 3 at 118, and Goode (1983) op cit note 3 at 4.

530 See indirectly Papadopoulos, who refers to money theories straddling both the Orthodox and Claim Schools. Papadopoulos (2007) op cit note 3.

${ }^{531}$ Mann (1992) op cit note 3 at 24 . However, it may be seen that when using the Claim School theory of money in particular in explaining the legal and economic import of new dematerialised forms of what may come to be termed money, that this is more coincident with legal theory than the Orthodox economic theory. See Ingham (2002) op cit note 3 at 126 on the concept and implications of dematerialised money. Mann's chimerical conception of money as a commodity was used in the case of Camdex op cit note 69 in deciding where foreign exchange of funds in settlement of debts was indeed more an exchange of commodities as was suggested by Mann, or whether in fact it was sui generis or was simply an incurring of mutual money obligations. The Appeals Court rejected Mann's commodity approach as used by the court a quo to monetary debts as per the facts of that case, deciding instead that the obligation was one of debt that could be set off and not where a commodity of forex need be provided. See also the commentary on this case in M Brindle, R Cox and R Coleman (2004) Law of Bank Payments at 36-38.

${ }^{532}$ J Laughlin (1919) The Principles of Money $2^{\text {nd }}$ ed cited in Nussbaum (1937) op cit note 3 at 867 . See however Newlyn and Bootle (1978) op cit note 3 at 2 who indicate that neither a UOA nor an ability to act as a standard of deferred payment is a necessary or sufficient condition for performance of money's function.
} 
Dismissing the other components of money, however, as merely 'piling up functions [that] would describe the efficacy, not define the essence of a thing', Nussbaum concluded that the MOE function must take centre stage in an evaluation of money insofar as being 'sufficient for an unambiguous characterisation of "money". ${ }^{534}$ Further, he believed, the bond between the economic and legal views of money was covalent:

"There is no merit in distinguishing between an "economic" and a "legal" notion of money since economics and law start from the same conception of money. ${ }^{535}$

Despite the Orthodox nomenclature however - possibly a sign of the flux (or evolution) of economic nomenclature and thought at the time of writing ${ }^{536}$ - Nussbaum was no die-hard metallist. He subscribed to the Societal Theory, ${ }^{537}$ whereby society would determine what should be considered as money, and what the value of that money is. ${ }^{538}$ Indeed, he believed that the metallist component would only really arise when society determines that the MOE should 'nominally' determine the value of a money - which could be, but preferably not pivot through, a metallic-based value - at a given time so as to allow its MOE. ${ }^{539}$

One of the first legal scholars to attempt to break the bond between an 'economic' and a 'legal' notion of money and the MOE pivot and to properly distinguish between the two, was Gustav Hartman, ${ }^{540}$ while Phandor Eder later crystallised the heterogeneity that distinguishes the two disciplines as identified by Hartman as one of, or a mixture of, the following economic theories of money that the law should take cognisance of money as a MOE; as a measure of value or more accurately phrased perhaps, as a common denominator of value; and as a medium of discharge or satisfaction of obligations, specifically as a medium of payment of debts. ${ }^{541}$

Further, he said, that while in practice these three functions are often interwoven:

'they are nevertheless, in law, separate and distinct and rules properly applicable in the solution of problems under one function are not necessarily valid for the other functions. ${ }^{542}$

This is where the Claim theory fundamentally deviates from the Orthodox-type view, and ultimately may allow the legal view of money to rather focus on money's qualitative, intrinsically abstract nature rather

\footnotetext{
${ }^{533}$ Nussbaum (1937) op cit note 3 at 867. These broadly could correspond to (1) a UOA, (2) MOE, and (3) a SOV. In essence, then, Nussbaum's definition of money is almost identical to Orthodox definitions of money, although qualified in his later writings.

${ }^{534}$ Nussbaum (1937) op cit note 3 at 869 .

${ }^{535}$ Ibid 8 at 875 , fn 36 .

${ }^{536}$ For a contextual overview of the political and economic factors that motivated each writer, see Maclachlan (2003) op cit note 3.

${ }^{537}$ See ch 3, s 3.2.4.1 titled Issuance and Production.

${ }^{538}$ This is similar to the economist Von Hayek who championed private money. Again Von Hayek's theories were a product of his era, the era of oil and economic crises in the early 1970s.

${ }^{539}$ Nussbaum described his theories as being a 'nominalistic' Societary Theory of money. See Nussbaum (1937) op cit note 3 at 888 . This position has sometimes been identified as monetary nominalism, as opposed to the monetary materialism of the commodity-exchange theorists' emphasis on the form and substance of money things. Ingham (2006) op cit note 3 at 261.

${ }^{540}$ Hartmann (1868) op cit note 3. This view was however described as 'confusing' by Nussbaum (1937) op cit note 3 at 36.

${ }^{541}$ Eder (1935) op cit note 3 at 55.

${ }^{542}$ Ibid.
} 
than merely on its quantitative functionality. ${ }^{543}$ The legal philosopher Von Savigny edged closer to this essence of money, and by doing so, moved somewhat closer to the Claim view:

'In the first place money appears in the function of a mere instrument for measuring the value of individual parts of wealth. As regards this function, money stands on the same basis as other instruments of measurement. But money also appears in a second or higher function, that is, it embraces the value itself that is measured by it and thus it measures all other items of wealth. Therefore money gives its owner a general power of wealth ... and ... appears as an independent bearer of such power. ${ }^{544}$

This 'theme' of understanding money's intrinsic value was further extended beyond the Orthodox School in the celebrated Banco case in 1932. ${ }^{545}$ Waterlow were contracted to Banco de Portugal to print and deliver 600,000 notes for 500 Escudos each, which they did. The printing plates were stolen, however, and unauthorised money printed and circulated. ${ }^{546}$ Banco de Portugal sued for damages based on the face value of the notes. Waterlow argued, however, that the damages should only be based on the cost of printing notes to replace the genuine notes. The majority held that Banco de Portugal when issuing new notes were parting with and putting into circulation a portion of their wealth 'as a purchasing power in terms of commodities, ${ }^{547}$ and not the cost of the printing of the notes and the paper itself.

This summation by Lord Macmillan leads to the conclusion that money's intrinsic and abstract quality is that it represents 'wealth'.

\subsubsection{Legal Classifications of Money}

\subsubsection{Overview}

As noted earlier, legal characteristics in relation to money signal a relatively narrower approach than the economic definitions of money, entrenched as they are in the precedent-bound nature of law where specific forms of money and payment system are favoured in the judicial process. The issuance of 'money' by banks, as well as the general issuance of money by the state, are seen to have measurable effects on the money supply of a country, unlike at the macroeconomic level. ${ }^{548}$ It appears that these broad-based

\footnotetext{
${ }^{543}$ For a discussion of the Claim School in relation to legal theories of money, see also Fox (2008) op cit note 3 at 44-48. Fox uses the alternative appellation 'Credit Theory' to describe this.

${ }^{544}$ Von Savigny (1851) as cited by Mann (1982) op cit note 3 at 26.

${ }^{545}$ Banco op cit note 3.

${ }^{546}$ Briefly, in 1925, the Banco de Portugal and Messrs. Waterlow were the victims of an elaborate fraud where Waterlow was induced, in the belief that they were acting with the approval of the Bank, to print and deliver an additional 580,000 notes, exact duplicates of the genuine notes printed under the contract. Waterlow printed 200,000 banknotes (almost 1\% of the country's GDP at the time) and large numbers were put into circulation by means of a bank formed by the conspirators for that purpose.

${ }^{547}$ Banco op cit note 3 at par 33 .

${ }^{548}$ A number of supply metrics are used to measure money. The narrowest measure is M0 (physical cash plus deposits); M1 (M0 plus deposits and instruments directly exchangeable for currency); M2 (M1 plus all money in savings accounts, money market accounts and low-value deposits); M3 (M2 plus foreign bank deposits and repurchase agreements). See D Caplinger (2006) 'Know Your Numbers: Money Supply', available at http://goo.gl/Im5Gl.
} 
economic metrics - which include deposits - have no direct bearing on a legal analysis of money which in strict law does not allow cheques, credit cards or bills of exchange to be considered as money per se. ${ }^{549}$

Instruments such as these are seen in law as mere means to transfer money. ${ }^{550} \mathrm{~A}$ bank deposit is likewise not seen as money, ${ }^{51}$ nor are EFTs, which are instead legally viewed as circulating legal rights. ${ }^{552}$ While they certainly do not offer any scholastic legal punditry nor do they expand the legal views of money, the Keynesian School and the accompanying Chartalist and NME Schools are, from the Claim School perspective, nominally more legalistic in their approach to money than the Orthodox School.

Keynes, as noted earlier, ${ }^{553}$ believed that debt that creates money, especially if a banker 're-lends' the money owed to one customer to one other or more customers as credit - that is 'bank (inside) money' creating money through fractional banking. In modern Credit theory, this is seen as banks endogenously creating money. ${ }^{554}$

However, the evolution of money and payment - and especially the ubiquitous use of electronic transactions - is altering both the economic and legal views of money and, correspondingly, its innate characteristics whereby an electronic representation of money may, like cash, be money in and of itself.

\subsubsection{Money as Fiats, Legal Tender and Currency}

\subsection{Legal Tender and Fiats}

Legal tender refers to the ubiquitous 'ordinary' money in circulation that is issued by the state, but may also mean currency that may be lawfully used for the payments of debts and which may not be deemed inadequate by a creditor to whom it is tendered in the proper amount. ${ }^{555}$ Legal tender can thus be defined as 'coins or banknotes that must be accepted if offered in payment of a debt., ${ }^{556}$

\footnotetext{
${ }^{549}$ Bills of exchange are in fact required to have a money component. See the definition of a 'bill' in Act 34 of 1964 at s2(1) where it is defined as 'an unconditional order in writing, addressed by one person to another, signed by the person giving it, requiring the person to whom it is addressed to pay on demand, or at a fixed or determinable future time, a sum certain in money to, or to the order of, a specified person, or to bearer'.

${ }^{550}$ See in this regard the legal observations of Geva (2001) op cit note 3 at 263 who says that bank drafts and certified cheques may provide for an absolute discharge of debts, but they do not circulate and thus are not money. A traveller's cheque may however, he says, be money as it nominally circulates. It will however have to fully satisfy the other criteria to be fully noted as a 'money'. Compare these legal observations of circulation to that of a pure economist's view of this 'circulation' requirement with that of Fisher (1909) op cit note 3 at 604-605.

${ }^{551}$ See ch 4, s4.4 on deposits.

${ }_{553}^{55}$ See ch 4, s4.8.4.2 on EFTs.

${ }_{553}$ Keynes (1971) op cit note 3 at 3.

${ }^{554}$ See Wray (2006) op cit note 3 for a discussion of endogenous money,

${ }^{555}$ Mundell (1998) op cit note 3 at 25; 'Legal Tender' (1996) Pocket Legal Dictionary $2^{\text {nd }}$ ed at 152, and Royal Mint (s.d.) 'Legal Tender Guidelines', available at http://goo.gl/J1U1p:
}

'Legal tender has a very narrow and technical meaning in the settlement of debts. It means that a debtor cannot successfully be sued for non-payment if he pays into court in legal tender. It does not mean that any ordinary transaction has to take place in legal tender or only within the amount denominated by the legislation. Both parties are free to agree to accept any form of payment whether legal tender or otherwise according to their wishes. In order to comply with the very strict rules governing an actual legal tender it is necessary, for example, actually to offer the exact amount due because no change can be demanded.'

556 'Legal Tender' (s.d.) Oxford Dictionaries, available from http://goo.gl/AKuSH. 
These usually relate to coins and banknotes issued by a CB as part of its natural monopoly in a defined jurisdiction as determined by the fiat of that state. ${ }^{557}$ Thus any currency that the state decrees (by fiat) must be accepted at face value for debt - whatever the commodity value of that currency or coin - and is considered legal tender. ${ }^{558}$ The fiat then is money issued by decree of a government and which cannot be converted into specie of equivalent value. ${ }^{559}$ No other money can be used as legal tender. Modern statutes, though, establish an imposed equivalence - or fiat equivalence - between the privileged legal tender, as a MOE, and other MOEs. ${ }^{560}$ Cheques, credit cards, debit cards and similar non-cash methods of payment are not generally defined as legal tender, but are merely means of transferring fiat money as legal tender. ${ }^{561}$

Legal tender laws which declare what shall be money and what the state shall accept as a modus of discharging of debts are reported to have been around for at least 2,500 years. ${ }^{562}$ Indeed, Aristotle said 'that money exists by current convention and not by nature ${ }^{563}$ which can be taken to mean that the state may declare what it requires to be money to be accepted as payment. ${ }^{564}$

The CB is usually the only entity whose 'money' is regarded as legal tender. ${ }^{565}$ The state, usually through the $\mathrm{CB}$, invariably has a monopoly over the issuance of money, ${ }^{566}$ although this primarily relates to fiat money.

In terms of s15(1) of the Currency and Banking Act, ${ }^{567}$ and more recently s14 of the South African Reserve Bank Act, ${ }^{568}$ the South African Reserve Bank ${ }^{569}$ has had the monopoly ${ }^{570}$ on the issue of notes ${ }^{571}$ and coins as legal tender. The South African Reserve Bank Act ${ }^{572}$ defines 'legal tender' as:

\footnotetext{
${ }^{557}$ For an extreme view on legal tender, see R Paul (2003) 'Bring Back Honest Money Speech to the US House of Representatives, July 25, 2003', available fromhttp://goo.gl/W8TVh.

${ }^{558}$ See Mundell (1998) op cit note 3 at 26, who says that that the attribute of legal tender would make one money 'good' relative to another money.

${ }^{559}$ The paper money that the CBs produce is fiat money because it can redeem one of these pieces of paper for another similar piece of paper (or issued coins) of equivalent value. Although the value of fiat money can be redeemed for fractional values issued by the state, modern economies do not allow redeemability against any underlying commodity value. The $\mathrm{CB}$ assures holders of currency that the circulating tokens endorsed and issued under its authority will continue to be valuable, and backs an incontrovertible currency with its fiat. See Akindemowo (1998) op cit note 3 at 5.

${ }^{560}$ Hulsmann (2004) op cit note 3.

${ }^{561}$ Schulze (2004b) op cit note 3 at 51 offers a shortlist of some of the unsolved issues; Mundell (1998) op cit note 3 at 25 believes that the endowment of coins or notes with the character of legal tender is an act of sovereignty, and hence of public law while the extent to which a creditor is under a duty to take 'legal tender' in payment is that of private law. Thus 'the sovereign determines that which constitutes legal tender but its enforcement in the courts is a matter of private law'. See Nussbaum (1950) op cit note 3 at 44-45.

${ }^{562}$ Hulsmann (2004) op cit note 3 at 45 . The compulsory acceptance of legal tender by the order of statute is a relatively recent phenomenon in England though: while the Bank of England's notes were around since 1694, but were only made legal tender in 1812. See Mundell (1998) op cit note 3 at 26. In Scotland and Northern Ireland, no banknotes are legal tender, and each bank which issues banknotes does so in the form of its own promissory notes. Notes are issued by the Bank of Ireland, the First Trust Bank, the Northern Bank and the Ulster Bank. See Kutyn (2005) op cit note 3 at 3, who wonders whether these Acts also prohibit the use of alternate forms of currency or payment systems.

${ }^{563}$ Aristotle (1962) op cit note 84.

${ }^{564}$ D Klinck (1991) 'Tracing a Trace: The Identity of Money in a Legal Doctrine' 83(1-2) Semiotica 1.

${ }^{565}$ Menger (1892) op cit note 3 at 239-255. Similarly, by decree, governments could remove the appellation of legal tender from a currency. This has most often occurred in Zimbabwe as a result of hyperinflation that has led to the obsolescence of banknotes and their replacement by novel means of government-issued tender such as 'bearer cheques' that replace banknotes of high nominal value.

${ }_{566}$ There are also pan-territorial CB issuers or regulators of money, for example, the ECB.

${ }_{567}^{56 t} 31$ of 1920 op cit note 3 .

${ }^{568}$ Act 90 of 1989 op cit note 3: 'The Bank shall have the sole right to issue or cause to be issued banknotes and coins in the Republic'.

${ }_{569}$ Ibid. Act 31 of 1920 op cit note 3 provided for the establishment of the Bank. This Act was promulgated in December 1920, and it opened for business on 30 June 1921. See East and Southern African Banking Group (s.d.) op cit note 3 at 3.
} 
'... a note of the Bank or of an outstanding note of another bank for which the Bank has assumed liability in terms of section 15(3)(c) of the Currency and Banking Act,' and 'an undefaced and unmutilated coin which is lawfully in circulation in the Republic and of current mass. ${ }^{573}$

A brief survey of legal tender laws shows that many countries make it absolutely illegal to refuse legal tender in settlement of a debt, while others provide some flexibility in what denominations and what type of payment may be accepted. ${ }^{574}$ In the United States of America, there is no federal statute that makes it peremptory for any private business, person or organisation to accept currency or coins as payment for goods and services. The US Coinage Act of 1965 says that:

'US coins and currency including Federal Reserve notes and circulating notes of Federal Reserve banks and national banks are legal tender for all debts, public charges, taxes, and dues. ${ }^{, 575}$

However, coins and notes provided by a debtor in settlement of a debt need not be accepted by a creditor beyond a certain amount, otherwise that form of payment could be seen as vexatious. ${ }^{576}$

The law of the EU does not have any explicit definition of legal tender in terms of any Regulation or Directive. ${ }^{577}$ In its absence, the general principle is that unless a valid agreement exists between parties on the acceptance of a certain MOP, legal tender constitutes a valid means of payment. ${ }^{578}$ Creditors of course may agree to forms of payment other than legal tender. The validity of such an agreement is to be assessed within the framework of general contract law.

Some countries have penalties for a refusal to accept legal tender. In Belgium, refusal to accept genuine and undamaged coins at their face value can be punished with a fine from $€ 25$ to $€ 75 .{ }^{579}$ Denmark, however, is more cash-centric and its laws accentuate this. ${ }^{580}$ The Danish Payment Card Act of 1984 (and 1992) at $§ 18$ states that:

'the payment creditor shall accept payment in cash within normal business hours in settlement of payment obligations which could be entered into and fulfilled by means of a payment card.'

\footnotetext{
${ }^{570}$ In terms of s14(1) Act 90 of 1989 op cit note 3: 'The Bank shall have the sole right to issue or cause to be issued banknotes and coins in the Republic'.

${ }^{571}$ The notes issued by the Bank were redeemable on demand in gold specie or gold certificates at the office of issue. The convertibility of notes into gold was abolished on 28 December 1932 owing to abnormal conditions during the Great Depression. See East and Southern African Banking Group (s.d.) op cit note 3 at 4.

${ }^{572}$ Section 17(1) of Act 90 of 1989 op cit note 3.

${ }^{573}$ Ibid.

${ }^{574}$ See overview by CPSS (2003c) op cit note 3 at 102.

${ }^{575}$ USC 5103 Section 31: Legal Tender. The US Dept of Treasury indicates that all US money is a valid and legal offer of payment for debts when tendered to a creditor.

${ }^{576}$ Savingsadvice.com (2004) 'Man Pays Traffic Ticket with 8,200 Pennies', available at http://goo.gl/UiDZL. See further ch 4, s4.4.4 titled Legal and Economic Effect of Deposits.

577 See CPSS (2003c) op cit note 3 at 102. See ch 9, s9.4.2 titled Directives on the differences between Regulations and Directives in the EU.

${ }^{578}$ Van Hove (2003) op cit note 3. In Belgium where there is no explicit statutory or case law definition of legal tender. Rather, local legal doctrine informs that legal tender is money that has the capacity to legally and therefore validly discharge pecuniary debts.

${ }^{579}$ CPSS (2003c) op cit note 3 at 102.

${ }^{580}$ See Van Hove (2003) op cit note 3 at 137-171.
} 
Dutch law says that money used to settle a claim should be in a 'passable or acceptable currency, ${ }^{581}$ while French law says of legal tender that it is the:

' $\ldots$ obligation of economic agents, in particular retailers, to accept banknotes and coins designated as legal tender according to their recognised value. ${ }^{582}$

In Germany, there is no explicit definition and parties are free to agree to accept other MOP ${ }^{583}$ Unless other means of payment were explicitly agreed upon, a refusal to accept legal tender could be seen as an unjustified delay in accepting payment. ${ }^{584}$ The only EU-wide restriction on the use of legal tender appears to be that no more than 50 coins $^{585}$ can be used for any one payment, ${ }^{586}$ except for issuing authorities and other designated persons or institutions. ${ }^{587}$

Even within its proper limited scope, the concept of legal tender has relatively little practical significance and because payment of debts in legal tender is unusual, a creditor has only limited rights to demand legal tender. ${ }^{58}$ Legal tender may be refused if no debt exists prior to the time of payment, for example, where the obligation to pay arises substantially contemporaneously with the offer of payment. ${ }^{589}$ Thus, private businesses can indicate which MOP they prefer, unless obligated by any other law to do otherwise. ${ }^{590}$

Indeed the CPSS acknowledges that while they have legal status, the legal tender status of banknotes (and coins) as GAME nowadays is of limited direct relevance in the majority of transactions as more electronic and scriptural non-cash transactions are replacing bespoke cash notes, and are the favoured mercantile MOE but, nonetheless, this creates the environment for solidifying the reputation of banknotes as being safe and unique assets that perhaps underpin other forms of money. ${ }^{591}$ Cheques, credit cards, debit cards and similar non-cash methods of payment are therefore not generally defined as legal tender, but are merely

\footnotetext{
${ }^{581}$ CPSS (2003c) op cit note 3 at 104.

${ }^{582}$ See Banque De France (2001) 'Recent Developments in the Banque de France's Scoring Method' No 93 Bulletin Digest, available at http://goo.gl/3rpzF.

${ }^{583}$ CPSS (2003c) op cit note 3 at 103.

${ }^{584}$ Ibid.

585 Ibid at 102.

${ }^{586}$ A maximum of 20 coins of the same denomination in Japan.

${ }^{587}$ The National Bank of Belgium and the local Post Offices are bound to accept all coins without any maximum amount. See CPSS (2003c) op cit note 3 at 102.

588 JS Rogers (2005) 'The New Old Law of Electronic Money' 58 Southern Methodist University Law Review 1253-1311, available at http://goo.gl/KetTp at 1276.

${ }^{589}$ Usually there is a practical consideration in the application of legal tender laws: although most currencies have legal tender status, they do not necessarily have to be used in transactions since a provider of goods or services is usually able to specify the commercial terms upon which payment will take place so that if a later means of payment is specified prior to the contract coming into being, then there is usually no obligation for legal tender to be accepted as payment. See Reserve Bank of Australia (s.d.) 'Legal Tender', available at http://goo.gl/xqr1h. As a result, vending machines or tollbooths do not have to accept the largest denomination of banknote or coin for a single bus fare or bar of chocolate and even shopkeepers can reject large banknotes. This latter concept is covered by the legal concept known as 'invitation to treat' which is an intimation by one party to another that it may be willing to do business in relation to a particular article on particular terms and that the other party, if interested, should make the first party an offer in relation thereto. See Sprecher Grier Halberstam LLP (s.d.) 'How to Contract Online', available at http://goo.gl/gYveu. See also the case of Nemser v New York City Transit Authority 530 N.Y.S. 2d 493 (N.Y. Sup. Ct. 1988) where several gadfly plaintiffs brought a declaratory judgment action challenging the policy of the New York City Transit Authority that dollar bills would not be accepted as payment for bus fare. The plaintiffs said that the policy violated the federal statute making dollar bills legal tender. The court however rejected their argument, concluding that the Transit Authority's policy was reasonable.

${ }^{590}$ For example, a bus line may prohibit payment of fares in pennies, cents or bills. In addition, movie theatres, convenience stores and gas stations may refuse to accept large denomination currency (usually notes above US\$20) as a matter of policy.

${ }^{591}$ CPSS (2003c) op cit note 3 at 104, fn 157.
} 
a variety of means to transfer fiat money as legal tender. ${ }^{592}$ There have however been initiatives to make electronic SOV legal tender. ${ }^{593}$

With creditors mostly allowed to specify how they wish to be paid, these instruments however become more of an obligatory tender when specified by the creditor and thus are de facto tender. Restrictions to this effect are of course dictated by government policy and vary by country. ${ }^{594}$ Although some laws indicate that legal tender must be accepted, refusal by a creditor to do so may create enforcement issues. By the same token, local legal tender laws may forbid other currencies from being used in that state which perpetuates the monopoly status of the local currency. ${ }^{595}$ Atkinson takes the contrary view and states that while a banknote is a title to money, it is not itself money according to any true discrimination, nor is it legal tender, because it cannot be forced upon a creditor. ${ }^{596}$

\subsubsection{2}

\section{Money as Currency: Legal View}

As noted earlier, ${ }^{597}$ while legal tender is currency, money is not necessarily currency nor is legal tender unless they are declared such by a fiat. ${ }^{598}$ Fiat currencies are those derived from fiats that create a national currency $^{599}$ and are usually produced under a system of monetary governance and can be seen as the

\footnotetext{
${ }^{592}$ Schulze (2004b) op cit note 3 at 51; Mundell (1998) op cit note 3 at 25 believes that the endowment of coins or notes with the character of legal tender is an act of sovereignty, and hence of public law while the extent to which a creditor is under a duty to take 'legal tender' in payment is that of private law. Thus 'the sovereign determines that which constitutes legal tender but its enforcement in the courts is a matter of private law'. See also Nussbaum (1950) op cit note 3 at 44-45.

${ }^{593}$ Japan, Singapore, Ireland and Thailand recently began constructive initiatives to an electronic payments society which is not necessarily a move to introducing an electronic currency, but as Akindemowo (2010) op cit note 3 at 54 points out, is an important step towards doing so. For example, see 'Central Bank (of Thailand) wants Cashless Society' (2009), available at http://goo.gl/dJca0, ‘To Fight Deflation, Abolish Cash: Could Japan Make Reality of “Science Fiction”?' (2009) The Times, available at http://goo.gl/UZXDv. See LS Kok (2002) 'Singapore Electronic Legal Tender (SELT): A Proposed Concept' in The Future of Money at 147. See also Info-communications Development Authority of Singapore (IDA) (2010) 'Specification for Contactless e-Purse Application (CEPAS)', available at http://goo.gl/QapJP, which is a significant milestone for Singapore's micro-payment landscape and a key component of making e-money and SVPs legal tender; and Japan, a mainstay of electronic payments and arguably the cradle of the genesis of mobile payments through its imode system in the 1990s has seen a huge growth in these virtual currencies. A prepaid card law has also introduced; see J Luyat (2009) 'A Tale of Regulation in the European Union and Japan' 18 Pacific Rim Law and Policy 525.

${ }^{594}$ For example, the UK Royal Mint specifies how many coins can be used as payment up to a maximum payment amount. The 5 pence coin for example can only be used as legal tender payment up to £5. See Royal Mint (s.d.) op cit note 555. In Mexico, metal coins are legal tender, limited to a maximum of 100 coins of each denomination in a single payment. However, Federal, State and Municipal offices are obligated to receive these coins without limitation as payment for any kind of taxes, services or rights.

${ }^{595}$ South African law has strict exchange control restrictions which expressly forbid the use of non-Rand currencies to be used within the borders of the Republic.

${ }^{596}$ E Atkinson (1894) 'Discussion of "The Value of Money" by FA Walker 9(1) Publications of the American Economic Association 47-56, cited in E Tymoigne (2007) 'An Inquiry into the Nature of Money: An Alternative to the Functional Approach', available at http://goo.gl/mDQQF.

${ }^{597}$ See ch 3, s3.6 titled Money and Currency.

${ }^{598}$ In relation to foreign currency, see the SA Exchange Control Regulations of 1961 op cit note 486 where 'foreign currency' is defined as:
}

'.. any currency which is not legal tender in the Republic, and includes any bill of exchange, letter of credit, money order, postal order, promissory note, traveller's cheque or any other instrument for the payment of currency payable in a currency unit which is not legal tender in the Republic.'

${ }^{599}$ Shubik (2000) op cit note 3 at 1 says fiat money is a creation of both the state and society with its value supported by expectations which are conditioned by the dynamics of trust in government, the socio-economic structure and by outside events such as wars, plagues or political unrest. Many modern currencies no longer have the 'promise' component on the notes, conspicuously too on South African banknotes. See also N Dodd (1994) The Sociology of Money: Economics, Reason and Contemporary Society at 75 who says that money possesses what he sees as contradictory qualities as both a medium which requires normative support throughout society in order to exist and as an economic instrument which symbolises and generates major asymmetries of wealth and power. 
official UOA within the country or countries of which it is legal tender. ${ }^{600}$ These are effectively trust notes whereby the holder accepts the state or CB promise that the circulating notes endorsed and issued under its authority will continue to be valuable. ${ }^{601}$ The fiat currency, though, is usually one where the UOA has been specified by a state as being the legal tender in the state of issue and which can legally be used and distributed in that state.

Dodd takes a similarly narrow view and describes currency as 'legal tender within a defined geopolitical space', which he says represents a reality that currencies may circulate beyond their state of issue, but which may somehow be given legitimacy when used in an extra-territorial environment that is not their country of issue. ${ }^{602}$ It may, however, not be the only currency in use in that country and need not be issued by the $\mathrm{CB}$ of that country to be currency; the Euro, for example, is issued by the European Central Bank and not by all the member states of the EU, yet it is the legal tender and currency of almost all member states who qualify for its use. The Bank for International Settlements (BIS), as noted earlier, acknowledges that the legal tender status of banknotes (and coins) is of limited direct relevance as the majority of transactions are electronic. ${ }^{603}$

Insofar as dissecting the obvious nexus between currency and money, Akindemowo says that the debt which constitutes an obligation to repay the money loaned is itself an abstraction, while currency is a manifestation of the value which it represents - a physical manifestation of value, value being a quality that all payments share. ${ }^{604}$ In the legal context, the concept of money as currency ${ }^{605}$ can also be seen in the chattel concept outlined by Mann and it is seen - at least in English law - to have a special place in the law of property described earlier ${ }^{606}$ in relation to Miller where it was shown that money in its role as currency is an exception to common law rules of property. The formulation by Lord Mansfield in Miller indicated that money is not recoverable once it is placed into circulation not because it is used as currency, meaning that it is used solely as a MOE and not as a chattel for direct use. It follows then that coins and banknotes which

\footnotetext{
${ }^{600}$ Dodd (2005) op cit note 3 at 393. On the use of solid gold Krugerrands as legal tender, see Pretorius (2004) op cit note 3 at 466.

${ }^{601}$ This promise embodies a social-contract (political) undertaking made by the government that it has sufficient assets to maintain the face value of the currency, that it will exchange in certain circumstances a worn out unit with a newer one of equivalent value, and that it will devalue (inflate) the currency at a certain targeted rate. Akindemowo (1998) op cit note 3 at 24. Shubik, however, sees the non-symmetry in size between individual users of the fiat currency and the state that issues it as more of a virtual asset than an enforceable contract. See Shubik (2000) op cit note 3 at 9 . The example of hyperinflation in Zimbabwe may illustrate this point, although to the extreme. Sometimes the governments backed up their promise by linking their currencies to a stable entity like gold in the form of the gold standard. This 'metallism' policy - the parallel circulation of metallic money and notes - found favour in the $19^{\text {th }}$ century as the gold standard. See Davies (1994) op cit note 3 at 354. Wray says that while economists often distinguish between a 'commodity money' like a gold coin and a 'fiat' paper money, he believes that the material from which the money thing issued by the state is produced does not matter as the state must announce the nominal value of the money thing it has issued which is the value at which the money thing is accepted in meeting obligations to the state. See Wray (2001b) op cit note 3. On a legal perspective of nominalism, see D Fox (2010b) 'The Case of Mixt Monies: Confirming Nominalism in the Common Law of Monetary Obligations', available at http://goo.gl/lcKOF.

${ }^{602}$ Dodd (2005) op cit note 3 at 394; and see Cohen (2004) op cit note 3 who believes that money is becoming increasingly 'de-territorialised,' and no longer the instrument of an exclusive national sovereignty. He says that currencies, if attractive enough, may be employed outside their country of origin for either of two purposes: for transactions either between nations or within foreign states. The former is conventionally referred to as international currency use or currency internationalisation; the latter is described as currency substitution and can be referred to as foreign-domestic use. Dodd (2005) op cit note 3 at 394 however believes that it is not money which is becoming de-territorialised, but rather currency. Governments have encouraged (and sometimes forced) the use of their banknotes by dissuading use of competing metallic currency.

${ }^{603}$ CPSS (2003c) op cit note 3.

${ }^{604}$ Akindemowo (2010) op cit note 3 at 54 .

${ }^{605}$ See ch 3, s3.6 titled Money and Currency: General View; and ch 3, s3.12.2.1 titled Overview on legal tender.

${ }^{606}$ See the discussion of Miller op cit note 3 in ch 3, s3.12.2 titled Legal Theories and Theories Relating to Money.
} 
have the function of money are not ordinary chattels since they are used as the MOE, and not as the object of exchange. ${ }^{607}$

Geva agrees that currency is the most predominant legal feature of money as a chattel, and in one early work defines money (as currency) as being:

'...the transferability of money from hand to hand, in payment of debts, free from claims to it on the part of all persons, including all owners and possessors. ${ }^{608}$

This definition echoes the definition of money in Moss, ${ }^{609}$ and to some extent the chattel requirement of Mann, as both Moss and Mann ${ }^{610}$ imply the need for a tangible thing to act as money.

However, in one of his later writings, ${ }^{611}$ Geva correctly criticises Mann's legal definition of money as:

' ... unjustifiably both expand[ing] the economic definition and restrict[ing] the legal one ... As for the legal definition, the chattel requirement is quite unfortunate. It may be a good description of what has been money from its inception to the present era. Nevertheless, it does not follow that this feature is inherent in the concept of money, particularly in an era in which we move into the electronic age ... (M)oney has not always been issued by the State, so that even more than the chattel feature, the State issue is not necessarily a feature inherent in the concept of money.'

There are also the obiter comments about money by Duff CJ in Re Alberta Statutes ${ }^{612}$ as highlighted by Mann, that:

'Any medium which by practice fulfills the function of money and which everybody will accept in payment of a debt is money in the ordinary sense of the word even though it is not legal tender. ${ }^{613}$

Mann relates this choice to the Societary Theory of money propounded by the Claim-type economists and jurists like Nussbaum, ${ }^{614}$ but dismisses it inter alia as being irreconcilable with the modern state control over money. ${ }^{615}$

But while all legal tender is money, not all money is legal tender. ${ }^{616}$ Legal tender is however legal currency. Loubser and Swart, concurring that there is tension between the restricted legal concept of money as legal tender and the economic and commercial aspects of money, argue that a legal definition of money should

\footnotetext{
${ }^{607}$ That is, coins and notes are not seen as commodities when used as currency. See Mann (1992) op cit note 3 at 24-25.

${ }^{608}$ Geva (1987) op cit note 3 at 117.

${ }^{609}$ See ch 3, s3.2.3.5 on legal definitions of money.

${ }^{610}$ Mann (1992) op cit note 3 at 8.

${ }^{611}$ Geva and Kianieff (2002) op cit note 3 at 5-6, who make their remarks in the context of 'electronic money'.

${ }^{612}$ Re Alberta Statutes (1938) S.C.R. 100 at 116.

${ }^{613}$ Mann (1992) op cit note 3 at 23.

${ }^{614}$ Nussbaum (1950) op cit note 3 at 5-10. This Societary Theory is roughly equivalent to the Claim and Keynesian theorists who allow any 'thing' to be used as money. See ch 3, s3.2.3 titled Doctrinal Perspectives on Money: An Introduction above.

${ }^{615}$ Mann (1992) op cit note 3 at 23.

${ }^{616}$ Nussbaum (1937) op cit note 3 at 903.
} 
be wide enough to include that which may economically function as money, and should not only include legal tender. ${ }^{617}$

\subsubsection{Legal Characterisation of Deposits and Payments}

Further interplay between the economic and legal perspectives is observed when analysing, for example, the impact of modern deposits and the utilisation of money for payments. The depositing of money has a macro-economic effect distinct from the legal effect of the deposit. ${ }^{618} \mathrm{~A}$ bank deposit is not regarded as legal GAME money per se, but as representative of the GAME. ${ }^{619}$

In relation to a transfer of money for payment, the law does not allocate the appellation 'money' to for example an EFT since it does not embody any rights, even though it may ultimately fulfill Moss's criteria as a means of final discharge of a debt. ${ }^{620}$ Rather, the associated instructions in an EFT by a payor to its bank or payment intermediary for it to pay to a payor (possibly from a deposit) a defined amount at a certain time and place, are seen in law as a compendium of interlocked circulating rights. ${ }^{621}$ They are not, for the moment, seen legally as money since ultimately they are characterised as mere instructions to circulate those rights, with no value embodied in the instructions themselves. ${ }^{62}$

Money is not defined specifically in South African law, ${ }^{623}$ although there are numerous references to 'money' in statute and in law. ${ }^{624}$ Where there is an obligation to pay money, it must ostensibly be in cash using notes and coins issued by the $\mathrm{SARB}^{625}$ and that are legal tender. ${ }^{626}$

Money can also be framed in terms of Roman law, which has categorisations of physical 'incorporeal' things ${ }^{627}$ or intangible incorporeal things. ${ }^{628}$ Money may be corporeal, for example in the use of coins and banknotes; ${ }^{629}$ or it may be incorporeal, such as a scriptural entry specifying the value of a bank account's balance. ${ }^{630}$

\footnotetext{
${ }^{617}$ Loubser and Swart (1999) op cit note 3 at 354.

${ }^{618}$ Foley op cit note 3 at 45 . The common law position appears to coincide with the Claim or Chartalist theory of money that refers to claims or debts owed by the issuer of money to the holder of that monetary instrument, where the creation of money is accepted for another's debt as with Minsky's conception of money as a two-sided balance sheet operation. See HP Minsky (1986) Stabilising an Unstable Economy; see also ch 4, s.4.4.4 titled The Legal and Economic Effects of Deposits.

${ }^{619}$ See ch 4, s 4.4 on deposits.

${ }^{620}$ Moss op cit note 3.

${ }^{621}$ See ch 4, s4.8.4.2 on EFTs; and in general Schulze (2007) op cit note 3; Malan and Pretorius (2006) op cit note 3.

${ }^{622}$ These bank values/payments may be seen as money in specific instances where there is the implied or express consent of the creditor. See Mann (1992) op cit note 3 at 8, and Akindemowo (1998) op cit note 3 at 3 and 5. See ch 4, s4.8 titled Payment Systems, and ch 7, s7.3 titled Payment Law

${ }^{623}$ Malan, Pretorius and Du Toit (2009) op cit note 3 at 43.

${ }^{624}$ The recent CPA op cit note 3, for example, makes numerous references to money and 'currency,' but does not define it.

${ }^{625}$ See F Du Bois (2007) Wille's Principles of South African Law $9^{\text {th }}$ ed at 820.

${ }^{626}$ Amounts paid in other coins are legal tender only up to ZAR50. See s17 of the Act 90 of 1989 op cit note 3.

${ }^{627}$ Res corporalis. Van der Merwe (1987) op cit note 3 at 26-27.

${ }^{628}$ Res incorporalis. Ibid.

${ }^{629}$ In that sense, money could also be said to be fungible (res fungibilis) in that something could replace it to provide the same value, for example different bank notes of the same denomination.

${ }^{630}$ Van der Merwe (1987) op cit note 3 at 24-26; and Van Jaarsveld (2011) op cit note 3 at 65-67 and the notes cited therein.
} 
As an observation, it seems that South African courts and legal scholars appear generally ad idem with English law and writers about the nature of money, but because of historical antecedents relating to their legal systems, differ fundamentally in the application of any rights attaching to money and in schemes available to reclaim money. ${ }^{631}$ This is especially so where 'money' is seen to be in mostly the dematerialised form of scriptural, electronic entries. ${ }^{632}$

The influence of English law on any 'money' discussion remains prevalent, however, in general and comparative terms. ${ }^{633}$

Thus, the scholarly literature caucuses around similar definitions of money and likewise around e-money as a species of SVP and whether it fits the same general criteria that it must be commonly accepted as a MOE, and not considered as goods, wares, or merchandise; should pass freely by mere delivery; should be selfcontained, require no collection, clearing, or settlement, and leave no record; that the transferee or payee should be able to take it free of the claims of prior owners or holders; and, further, that it should be given and accepted as final payment of a debt. ${ }^{634}$

While the MOE, then, appears to be the overriding reference point in any legal discussion of money's nature, the courts do not appear to have been constrained by it in relation to what can constitute money. So, for example, in outlining the scope of what could be called 'money' in relation to a tax case where the taxpayer's income was in dispute, the SCA said that:

\footnotetext{
${ }^{631}$ On the use of the MOE pivot characterising money, see inter alia Loubser and Swart (1999) op cit note 3 passim; Burger (1990) op cit note 3 at 231

${ }^{632}$ Visser in his magisterial book on Unjustified Enrichment (at 221-222) groups the following together under the heading of 'Transfers of Money Cheques': credit card payments, electronic transfers and documentary credits. This does not of course necessarily mean he believes these are all (legal) money - even though an economist would not blink at that - but rather that they represent a means to transfer fiat money. It highlights the easily penetrated Chinese firewall between the legal and economic views of money. See DP Visser (2008) Unjustified Enrichment.

${ }^{633}$ See Du Toit (2009) op cit note 3 at 5, who says that there is a need to compare English banking with South African banking law for the interpretation of similar laws and as indications of similar practices in England. The comparison is however less useful, he says, in respect of the law of obligations which for South African lawyers is bound rather by Roman law precepts. Du Toit (2009) op cit note 3.

${ }^{634}$ See WG Schulze (2004a) 'Countermanding an Electronic Funds Transfer: The Supreme Court Takes a Second Bite at the Cherry' 16(4) SA Mercantile Law Journal 667-684 at 674, fn 46; and Du Toit (2009) op cit note 3 at 6, fn 21, who both cite with approval the money criteria outlined in Bradley Crawford (1997) 'Is Electronic Money Really Money?' 12 Banking and Finance LR 399 at 402-403. Crawford lists the basic characteristics that new forms of money should have. Other characteristics include that it must be commonly accepted as a MOE, and not considered as goods, wares, or merchandise; it should pass freely by mere delivery; it should be self-contained, require no collection, clearing, or settlement, and leave no record; and the transferee or payee should be able to take it free of the claims of prior owners or holders. These relate broadly to the criteria of money that circulates, is accepted generally, can be redeemed on par and on demand. The issue of a common UOA is not addressed directly here though as a criterion for 'money'. Schulze queries whether an EFT satisfies all the characteristics identified by Crawford, but doubts that it is 'self-contained' and leaves no record, and ponders whether an EFT qualifies as legal tender. See also Schulze (2004b) op cit note 3 at 59-60. Du Toit (2009) op cit note 3 at 6also quotes with approval the newer definition of money by Proctor, who removed the 'chattel' requirement in FA Mann's book on money, such that the new definition of money in the $6^{\text {th }}$ edition of the books is that: '(a) it must be expressed by reference to a name and denominated by reference to a UOA which, in each case, is prescribed by the law of the state concerned; and (b) the currency and unit so prescribed must be intended to serve as the generally accepted measure of value and MOE within the State concerned'. Du Toit at 7 then indicates that while a deposit is not legal tender, it is money. For use of the MOE criteria in the local literature, see also Loubser and Swart (1999) op cit note 3 passim; and Burger (1990) op cit note 3 at 231.For an English perspective on criteria for money, see Fox (2008) op cit note 3 at 16-19 and 56-61 which inter alia relate to the criteria of acceptance in a community, circulation, reducibility, the face value not being discounted (the homogenous UOA criteria) and redeemability on demand and on par.
} 
'The first and basic proposition ... is that income, although expressed as an amount in the definition, need not be an actual amount of money but may be [e]very form of property earned by the taxpayer, whether corporeal or incorporeal, which has a money value ... including debts and rights of actio[n]. ${ }^{635}$

In addition, the Court said:

' $[\mathrm{I}] \mathrm{t}$ is hardly conceivable that the Legislature could not have been aware of, or would have turned a blind eye to, the handsome profits often reaped from commercial transactions in which money is not the medium of exchange. Consider, for example, the many instances of valuable property changing hands, not for money, but for shares in public or private companies; or share-cropping agreements, dividends in the form of bonus shares, or remuneration for services in the form of free or subsidised housing and the use of motor vehicles. These are only a few of the many possible illustrations that readily come to mind and which, as we know, have not been overlooked by the Legislature. ${ }^{636}$

Then, in relation to forged bank notes, an apparent expansion of what could be considered legal MOE, as being 'legal tender or legal means of exchange.',637

Despite this apparent (legal) expansion of the court's view of money to include additional economic forms of money, and for tax purposes it may be added, there still appears to be an adherence to the State Theory of money, ${ }^{638}$ namely that it is the state that is the only and prevailing entity which can declare something as a 'money. ${ }^{639}$ All other forms of this economic 'money' are, legally speaking then, mere representations of the GAME. They are not, however, the GAME if the state does not allow these forms to wear that mantle even if they exist parallel to the GAME. ${ }^{640}$

It also seems that the society theory of money is given passing attention ${ }^{641}$ and the primacy of the fiat as the GAME is absolute. Swart says that if something other than legal tender is offered as payment in discharge

${ }^{635}$ Commissioner for Inland Revenue v People's Stores (Walvis Bay) (Pty) Ltd 1990 (2) SA 353 (A) at 363I-364C; and with approval in Commissioner, SARS v Brummeria Renaissance (Pty) Ltd [2007] SCA 99 (RSA) at 16.

${ }^{636}$ See also Jonker op cit note 317 , a case regarding monies in a deceased estate, where 'money' was equated to value and 'wealth'.

${ }^{637} S v$ Van Der Westhuizen (256/2002) [2003] ZAFSHC 27 (30 October 2003) at 31. See also the CPA definition of 'consideration' as 'anything of value given and accepted in exchange for goods or services, including (a) money, property, a cheque or other negotiable instrument, a token, a ticket, electronic credit, credit, debit or electronic chip or similar object; (b) labour, barter or other goods or services; (c) loyalty credit or award, coupon or other right to assert a claim; or (d) any other thing, undertaking, promise, agreement or assurance, irrespective of its apparent or intrinsic value, or whether it is transferred directly or indirectly, or involves only the supplier and consumer or other parties in addition to the supplier and consumer'. See further, s35(1) of the CPA in relation to customer loyalty programmes which says that '[d]espite any provision in any law, agreement or notice to the contrary, for all purposes of this Act, loyalty credits or awards are a legal MOE when offered or tendered as consideration for any goods or services offered, or transaction contemplated, in terms of that loyalty programme'.

${ }^{638}$ See ch 3, s3.2.4.1 on the State Theory of Money; and Burger (1990) op cit note 3 at 231 on use of the State Theory in some manner in Roman law and Roman-Dutch law.

${ }^{639}$ See s14 of Act of 1989, where in relation to the issue of banknotes and coins, the ability of the SARB is constrained by the government of the day in that, at s14(2) '[t]he Bank shall not issue or cause to be issued any banknote of a denomination, in a form or of a material not approved by the Department of Finance'.

${ }^{640}$ See in this respect Du Toit (2009) op cit note 3 at 16-18, who in agrees with the decision in Tayeb v HSBC Bank plc [2005] 1 CLC 866 where it was noted that an agreement to be paid in 'cash' should have a wider meaning than notes and coins or other [my emphasis] any legal tender that encompasses any commercially recognised method of transferring funds. $\mathrm{Du}$ Toit at 16 opines that a definition of a legal transfer should be similarly extended. However this extension relates to legal methods of transferring fiat funds that represent the GAME, but not non-fiat value unsanctioned by the state.

${ }^{641}$ See, for example, the SARB views on private issuance of electronic money, where they specify that only banks may issue e-money, and then only fiat money. 
of a debt, the creditor can strictly speaking refuse to accept the payment and insist on payment in legal tender. ${ }^{642}$ It has however been accepted in South African law that payment of a debt in money can be provided for by some means other than legal tender as long as the parties have agreed. ${ }^{643}$ This other means may via an 'inside money' representation of the GAME or some other means such as a transfer of wealth.

Insofar as payment via a cheque may represent the GAME as legal tender, Trollip $\mathrm{J}$ in Esterhuyse $v$ Selection Cartage (Pty) Ltd said that:

\begin{abstract}
'In contract, where the debtor is obliged to pay in money to the creditor, the medium of payment must be that which the contract expressly or impliedly specifies, as determined by reference to its terms and such evidence of custom, usage and the surrounding circumstances as is admissible to aid in its interpretation. ${ }^{644}$
\end{abstract}

A cheque, though, is not money. ${ }^{645}$ The other views of money, such as that it relates to obligations, property rights ${ }^{646}$ and unjustified enrichment, are very much based upon and revolve around Roman law conceptions together with some English influence. ${ }^{647}$ In Roman law, money as notes and coins is considered as res corporalis and ownership in these notes and coins is said to be acquired by traditio and other methods of acquiring ownership in movables. ${ }^{648}$

Insofar as res corporalis generally, the owner has a real right of ownership to an object and usually may exercise one of the noted actions like a rei vindicatio to reclaim the object that is his property. It could rather be described as a way of obtaining 'property' defined in a broader sense and in the context of banking and payments law, and which may include anything that could form an asset in a person's estate. ${ }^{649}$ However, in the case of notes and coins, these innate property rights may be suspended. The main form of original property acquisition of money is via commixtio ${ }^{650}$ of the dispossessed's money with the recipient's

${ }^{642}$ D Swart (2000) 'Online Banking Law and Payment Systems' in R Buys (2001) Cyberlaw, available at http://goo.gl/5Z2Ms. See also ch 3, s3.12.3.2.1 on Legal Tender and Fiats.

${ }^{643}$ Ibid.

${ }^{644}$ Esterhuyse v Selection Cartage (Pty) Ltd 1965 (1) SA 360 (W) 361. See also Geva (2001) op cit note 3 at 263 who notes that cheques are not money, because they do not circulate and that they are not seen as a final payment.

${ }^{645}$ Ibid at 263.

${ }^{646}$ This is not to say that the rights are based on property rights as they would with rights in rem or personam. Ownership of the money in a bank account, for example, relates to a series of obligations by the bank to repay money, not that the bank necessarily has a real right to the money. See the discussion thereof by Sonnekus (2008a) op cit note 3 in relation to similar terms - ownership and property - used by Malan and Pretorius (2006) op cit note 3 at 594. For similar usage within the context of banking law, see Louw op cit note 3 at 334H-I. On the difference between personal and real rights such as ownership see, generally, PJ Badenhorst, JM Pienaar and H Mostert (2006) Silberberg \& Schoeman's Law of Property 91-95; AJ Van der Walt and GJ Pienaar (2010) Introduction to the Law of Property 23-26; H Mostert et al (eds) (2010) The Principles of the Law of Property in South Africa 25-26.

${ }^{647}$ On the interaction between Roman-Dutch and English law and its reception in South Africa, see R Zimmermann and D Visser (2006) Southern Cross: Civil Law and Common Law in South Africa; on unjustified enrichment, see generally Visser (2008) op cit note 632; and Sonnekus (2008a) op cit note 3. On the interrelationship between English and South African law on unjustified enrichment and property rights relating to money, see Fox (2009) op cit note 3 at 638.

${ }^{648}$ Malan (1977) op cit note 3 at 249; cf Ex Parte Estate Kelly 1942 OPD 265 at 269 (hereafter Kelly).

${ }^{649} \mathrm{Du}$ Plessis says that the protection accorded in s25 of the Constitution of the Republic of South Africa 1996 to all rights in property extends to property defined in this broader sense. The discussion of property should be seen in this context. Du Plessis (2011) op cit note 3. See also Louw op cit note 3 at $334 \mathrm{H}$, which deals with deposits by a customer and refers to 'property' of a bank and of 'becoming the owner' in relation to the claim of the client to the funds deposited. See a similar discussion in Sonnekus (2008a) op cit note 3 at 368.

${ }^{650}$ Commingling of fungibles that cannot be separately identified. In the case of a borrower, his obligation is to return not the exact money deposited, but an equivalent amount. For an overview of the relationships between the concepts of depositum, 'deposit' ('money-deposit) and mutuum, see Schulze (2001) op cit note 3 passim. 
money, such that there is no ability to separate the mixed pool. ${ }^{651}$ The (new) proprietor is owner of all the money. ${ }^{652}$

Further, as with English law, South African law provides an exception to this property-law rule insofar as a bona fide recipient of money may not be subject to non-money remedies for recovering his property, such as the rei vindicatio, which could apply to identifiable coins that act as commodities, such as a Krugerrand even if it could be identified. Again, this exception to the nemo rule is justified in terms of the 'currency' of money from Moss. Conversely, says Malan, money may be followed in the hands of a mala fide holder, provided that it can be related to a mixed fund. ${ }^{653}$ However, unlike English law, there is no general ability to recover money on the basis of 'tracing, ${ }^{654}$ a legal concept which has not been recognised in South African law. Tracing however has been strongly hinted at as a tool already used in some cases. ${ }^{655}$

In causa, someone who has had some dematerialised intangible item like money through an EFT stolen, could have recourse to one of the Roman-Dutch condictiones ${ }^{656}$ as a remedy, usually falling within the province of Unjustified Enrichment. ${ }^{657}$

The use and introduction of new, incorporeal and intangible means of payment challenge the common law view of money. ${ }^{658}$ In particular, the transfer of intangibles has less to do with real rights - with the bona

\footnotetext{
${ }^{651}$ There is then said to be a transition of property ownership, with no sharing of that ownership. Ownership of money may be acquired by delivery, also known as traditio. For a brief discussion, see Van Jaarsveld (2011) op cit note 3 at 67, and Fox (2008) op cit note 3 at 79-85.

${ }^{652}$ Burger (1990) op cit note 3 at 230-231. See also Woodhead op cit note 521 above, $R v$ Gordon 1914 CPD 123125 126, $S$ $v$ Gathercole 1964 (1) SA 21 (A) 24-25. The idea though of commixtio being the final arbitrator of ownership in the age of dematerialised money was questioned in Louw op cit note 3 where at [12] Lewis AJA said of commixtio:
}

'In my view, the inability of a bank to keep particular moneys of a customer held in trust separately identified from other funds is not of any consequence. As long as the records of a bank show that a particular amount is designated as being Due to a particular customer, there would appear to be ... no difficulty in finding that a bank holds money that is deposited or invested in trust for that customer.'

${ }^{653}$ Malan (1977) op cit note 3 at 249; and further Sonnekus (2008a) op cit note 3 at 366 . The rei vindicatio requires that the property must exist, must be clearly identifiable, and must not have been destroyed or consumed. For general application of this principle in relation to money, see SA Hyde (Pty) Ltd v Neumann 1970 (4) SA 55 (O); R v Manuel 1953 (4) SA 523 (AD); $R$ v Solomon 1953 (4) SA 518 (AD), where it was held that the question of ownership in specific coins no longer arises in cases where resort to that system is made, as there is ordinarily no obligation to hand over the notes or coins received. In SA Hyde it was held that money identifiable with or 'earmarked' as a particular fund is recoverable with a quasi-vindicatio.

${ }^{654}$ This assists in demonstrating the causal relationship between funds and the intermediaries who at one time held the funds. See Sonnekus (2008a) op cit note 3 at 378 and the reference therein to Lipkin Gorman v Karpnale Ltd [1991] AC 54 for an exposition of tracing in the content of unjustified enrichment.

${ }^{655}$ Du Plessis (2011) op cit note 3 passim; and Sonnekus (2008a) op cit note 3 at 366 . Sonnekus points out instances where 'tracing' has been the focus of South African judgments, for example, Blanche Sadahaw Dhelvi v Devamani Shunmoogun Padayachee case no 2001/19306 6 September 2005 (W) unreported following remarks by Schutz JA in First National Bank of Southern Africa Ltd v Perry (100/99) [2001] ZASCA 37; [2001] 3 All SA 331 (A) at 968E:

"What an applicant must do in such a case is to trace the money back to the stolen money, to identify it as a "fund" of stolen money in the defendant's hands.'

${ }^{656}$ On the condictiones and their application in reclaiming value, see ch 7, s7.3.6.8 titled Actions to Recover Value.

${ }^{657}$ The remedy of the person dispossessed against a mala fide possessor would then be either a rei vindicatio or via a condictio, depending on whether the possessor has acquired ownership of the notes and coins. The condictiones always presuppose a valid transfer of ownership, except in the case of the condictio firtiva. Malan (1977) op cit note 3 at 249, citing Kelly op cit note 648.

${ }^{658}$ South African courts have expanded the view of money with respect to theft, moving away from the need for a tangible 'thing' to be the object for the crime of theft to apply. In $S v$ Kotze 1965 (1) 118 (A) at 125 where Ogilvie-Thompson JA held in connection with the unauthorised issuance of a cheque, that the definition of a 'thing' had evolved in the South African law of theft to allow the theft of incorporeal things. He indicated that any conflict between the law of things and the criminal law definition of things can be avoided by regarding the theft of incorporeal as the theft of personal rights or an incorporeal sum of money, thereby widening the legal concept of money for the purposes of theft. The New Zealand Court of Appeal decision 
fide receiver exceptions noted - applicable usually to coins and notes, and more to do with personal rights than to any value.

The question of incorporeals in the law of property and their relationship to the law of obligations was neatly set out by Harms JA in the MV Snow Delta case, which may have an effect on consideration of money as a means of payment - seen in terms of obligations - and not as a MOE:

\begin{abstract}
'Rights in relation to the (contractual) performance (obligatio) of another have since time immemorial been classified as incorporeal. The obligation of the debtor is not property; it is the right (often referred to as the "action") of the creditor. Obligations can therefore not be attached because they do not form part of the patrimony of the creditor whereas rights can be attached and do form an asset in the estate of the creditor. Intangibles by their very nature cannot have a physical locality. They do not attach to the objects to which they relate. ${ }^{659}$
\end{abstract}

As Loubser notes, in the context of theft the courts have in effect accepted a wider concept of money where it has been recognised that theft of money can occur without actual corporeal coins and notes being stolen. ${ }^{660}$

Although property rights in corporeal notes and coins differ insofar as the rights obtaining to incorporeals relate more to the law of obligations and mandate, it has been held that it would be incongruous if the reason that someone could not reclaim his 'stolen' money in incorporeal form was because there was no handy legal remedy available from Roman-Dutch Law. ${ }^{661}$ An equivalent, however, to corporeal notions was founded based on the lack of a bilateral agreement to transfer value to the (unintended) recipient. ${ }^{662}$

Hence, intangible forms of value, such as demand deposits, are said to be personal rights rather than real rights of ownership. Indeed, someone who places value with a holder of value - such as the deposit in a bank account, or for that matter, if the analogy allows, through the issuer of a stored value system - is said 'merely' to have a personal right to claim that money. The holder becomes the owner. ${ }^{663}$

The recent South African CPA is possibly contra to this notion of the holder as the owner of money. In the case of prepaid SVPs, for example, it provides that the user of that value who purchased the value from the

in $R v$ Wilkinson (13 October 1998, CA 122/98) demonstrates that certain dishonest actions which constitute the offence of theft or obtaining by false pretense, if they result in payment being made to the accused by cash or cheque, are not offences if the mode of payment employed is a direct transfer of funds from one bank account to another. See also $S v$ Harper 1991 (1) SA 177 (A) which said that shares as incorporeals were also capable of being stolen; Nedbank Ltd v Pestana 2009 (2) SA 189 (SCA). See generally on theft of incorporeals, Loubser (1978) op cit note 3.

${ }^{659}$ MV Snow Delta: Serva Ship Limited v Discount Tonnage Limited 2000 (4) SA 746 (SCA) at par 9.

${ }^{660}$ Loubser (1978) op cit note 3 at 49-57.

${ }^{661}$ These were the facts in Nissan op cit note 3, a case which essentially involved a mistaken transfer of money to an incorrect bank account, which the court held would amount to theft if the unintended recipient was able to keep the money not due at all to him.

${ }^{662}$ Ibid pars 24 and 26. Indeed, it was Maple - the unintended recipient bank - that was enriched, and hence the claim of enrichment was held as against his bank which could not have paid out the money to Maple based on public policy grounds which would not allow enforcement of the banker-client contract couched in obligations and a mandate which would have facilitated the transfer to the incorrect bank account. See the discussion by Du Plessis (2011) op cit note 3 in this regard.

${ }^{663}$ Malan, Pretorius and Du Toit (2009) op cit note 3 at 5 say that the acquisition of ownership in movable $a$ non domino is generally not possible but negotiable instruments constitute an exception: it confers ownership of the bill on a holder in due course and invests in him the personal rights embodied in it. This protection, they say however, is seen as limitation of the rei vindicatio and not as the acquisition of ownership. 
issuer - or acquired it in some other way such as by a remittance or linked virtual electronic money-type currency - is the 'owner' in the broad sense - not the issuer holding that value. ${ }^{664}$

Putting aside the consideration that the CPA appears to alter common law views of ownership of money and that it may, in the light of $\operatorname{Louw}^{665}$ probably not pass muster in altering well-established principles of the ownership of money, the question, therefore is whether that SOV so held in a SVA of a SVP is 'money' so as to allow the new property regime in the legislation to obtain.

It is submitted, and will be shown later, that this provision may not pass muster if placed on review. Indeed, a similar attempt to alter common law precepts of the 'ownership' of incorporeals from the holder to the user of money failed.

\subsection{4 \\ Summary and Conclusions}

Money is the basis for economic prosperity, a social and anthropological contrivance that evolved to allow ease of mercantile utility, to lower transaction costs, and generally to cast a neutral veil over transactions. It thus has a pivotal role in modern economies because society has elected to quote prices in terms of money.

In common parlance, cash as coins and notes, as well as cheques, demand deposits, and bills of exchange payable to the bearer are all considered to be and to act as money. Modern economies though provide the state, usually through a CB, an absolute monopoly in deciding what could act as its legally sanctioned money, the GAME. Through appropriate (banking or similar, proportionately appropriated) licenses, legal fictions allow banks to provide a legal nexus to the GAME via 'inside money' - the creation, fractionally by banks of money - rather than the legally sound but commercially impractical 'legal tender.'

Despite apparent doctrinal differences, theories of money and their legal derivation ultimately coalesce together from the disparate disciplines of economics, anthropology and law to create universal, but mostly stratified, conceptions of money.

The legal system's appropriation of the 'Orthodox School' of money sees money as a UOA (like the Rand or Pound), a SOV that allows it to continue to be valuable to others in receipt of it, and a MOE that allows products and services to be acquired by and because of it.

The central MOE component has traditionally been based on a tangible backing such as gold or some other valuable item. This need for a tangible thing is implied, though, through the fiction that the incorporeal is a representation of corporeal tangible money, that is the GAME.

\footnotetext{
${ }^{664}$ CPA op cit note 3. See ch 12, s12.9.2.2.2 titled Legal Capacity below on the CPA and its treatment of SVPs; and in particular Section 32 of the CPA.

${ }^{665}$ See Louw op cit note 3. In this case the SCA reversed the court a quo's decision that trust beneficiaries were the true owners of money in a bank account. The SCA said at 13 that the decision in the court a quo, had it stood, would have changed well-established principles of the law relating to deposits made by a trustee in a bank, and would preclude money that would at common law be an asset of the bank from being treated as such. The ramifications of such a change to the common law understanding of traditional bank practices would be extensive and was thus rejected.
} 
The nexus - albeit obliquely - between the legal view of money and the Orthodox School was first outlined in Moss and Miller and then was classically framed by FA Mann in his definition of money as requiring what he termed a 'chattel' for it to be legally considered as money and generally the common law view of money in South African and in English law both reflect this definition, although there are outliers where the need for a different definition is implied, particularly in relation to legal questions around incorporeal payments where fundamentally no tangible thing is involved in the process.

These traditional economic definitions of money and by extension the legal definition are, it is submitted, not just historical footnotes in the face of new regulations around new forms or representations of money like those detailed in the EU's EMD1 ${ }^{666}$ and EMD2; ${ }^{667}$ they still play a critical role in contextualising the analytical framework that allows the scope and perimeter requirements of new forms of money to be evaluated.

Indeed, modern representations of what may popularly be termed money are placing the bespoke definitions of money, the legal fictions used and, concomitantly, payments, in the spotlight. Rules developed to explain money and payments from the time of Aristotle seem strained in the face of the challenges created by the dematerialisation of money, the emergence of electronic representations of money - like e-money, SVPS and those generally used in MFS - and, in some cases, the use of 'wealth' to act in final discharge of debts and obligations. Technology then - and payments technology, in particular is leading, it is submitted, to a reflection on monetary theory.

Debate though around whether to 'reclassify' money should not confuse specific forms of money such as metal, paper and electronic impulses with the generic properties of money as a measure and bearer of abstract value as, just like a cash banknote, the representations of money may even in and of themselves embody the value so as to earn the appellation money.

In causu, this complexity arises with modern payment mechanisms, where the instrument, such as a prepaid MFS SVP or a physical SVC, could be regarded not only as a payment instrument, but also as 'money.'

However the law does not yet regard them as money per se, since the doctrinal dogma from the law's use of the Orthodox School means that electronic transfers of value in the most part are regarded as a MOE and not as a UOA and a SOV, and certainly not as embodying any (end) value. Thus they currently can only be seen as payment instruments, but not (also) as money in and of themselves Instead then, as the means to money rather than the end, they are considered as 'near-money'.

In essence then, while the Orthodox MOE (and GAME) may at a stage have been an adequate description for money as we have known it in a pre-dematerialised, pre-electronic world, new intangible types of money require us, it is submitted, to delve rather into the core qualities of money, that is, into its abstract intrinsic value.

${ }^{667}$ EMD2 op cit note 3. 
The enquiry would investigate whether the mere payment instruction by the payee - usually via a payment intermediary - may perhaps also act as the actual value transfer to the payee such that the carrier of money (the payment system) becomes the money in and of itself. This possible convergence of the medium of payment and the value of payment makes it difficult to distinguish between them.

What may conceptually address the classification conundrum provided by new technologies in relation to money may yet be supplied by the competing 'Claim School' of money popularised by the Austrian School of Economics. It sees money in more abstract terms by generally divesting itself of the Orthodox School notion that money must be backed by something 'tangible,' or even by a representation of that tangibility.

Rather, it sees money as a UOA, SOV and a MOP, with the emphasis on the UOA. This is in contradistinction to the emphasis placed by the Orthodox School on the MOE. In all though, money is seen as a Claim - or Chartal, as the economist Knapp called it - in which the central theme is that something - a 'thing' - is declared or accepted as money as a result of debt relationships and a concomitant obligation.

This alternative thinking of the properties of money may, it is submitted, act as an arbiter to the doctrinal incompatibilities, and provide a more compatible nexus between the newer technologies, economic theory and the legal system. This ability to bridge the incompatibilities was discussed earlier.

Thus, the goal is for the new electronic forms of payment such as MFS SVP to in some way mimic cash as money, or even to be money, so that the abstract evolution of money and payment transaction integrates the value and function within the same instrument.

The difficulty in doing so under the current legal regime, based as it is on chattels and other tangible things as representations or symbols of money or the GAME, highlights the fact that legal precepts of money and payments are still largely enshrined in and measured against forms of these 'traditional' (Orthodox) monetary instruments.

It will also be shown below that use of the Claim theory of money, and its modern successor, the NMEs School, in enabling as it does the classification of new forms of dematerialised systems as indeed being money, are not inconsistent with bodies of law that have to this point been founded on what can be considered as money.

This analysis may also assist in efforts to provide a framework for working with intangible forms of money in circumstances for example where there is a need to recover money after it has been placed into the estate of a recipient or into a pool of funds such that commixtio takes place.

The Claim School may yet assist in any new determination since its guiding principle is less about form and more about the 'quality' of money in its role of settling claims or obligations. The form of this new 
'money' is not therefore material to any enquiry. Seen from this perspective, the 'quality' could be provided by MFS SVPs, for example, a possibility discussed later. ${ }^{668}$

While the State and Societary Theories may appear mutually exclusive, they may not necessarily be so. In relation to the credit theories then, Mitchell-Innes provides some degree of integration based on historical precepts in the use of money, while Hart provides an expansive and embracing view of society in acknowledgement that the state and society often need to work together.

The arguments posited inter alia then by relatively modern theorists such as Moini, ${ }^{669}$ Ganßmann, ${ }^{670}$ Hart, ${ }^{671}$ Graeber, ${ }^{672}$ Messori, ${ }^{673}$ Wray, ${ }^{674}$ Zelizer, ${ }^{675}$ Dodd, ${ }^{676}$ Goodhart and Ferguson ${ }^{677}$ that relate to economic focus not on commodity money, but rather a general shift towards 'virtual' values where wealth and credit effectively render legal tender and other forms of value an artifact, point to the need for a reevaluation of the legal perspective of money.

\footnotetext{
${ }^{668}$ See ch 13 titled Re-evaluation of Money.

${ }^{669}$ Moini (2001) op cit note 3.

${ }^{670}$ Ganßmann (2009) op cit note 3.

${ }^{671}$ Hart (2005) op cit note 3 passim

${ }^{672}$ Graeber (2011) op cit note 3 passim;

${ }^{673}$ Messori (2002) op cit note 3.

${ }^{674}$ Wray (2006) op cit note 3.

${ }^{675}$ Zelizer (2007) op cit note 3.

${ }^{676}$ Goodhart (2005b) op cit note 3.

${ }^{677}$ Ferguson (2008) op cit note 3 at 30 and 540.
} 


\section{CHAPTER 4}

\section{BANKING, PAYMENTS, MFS AND REGULATION}

\section{1}

Overview

As noted in the previous chapters, many of the services in Mobile Financial Services (hereafter MFS) are said to approximate to 'banking' services such as receipt of funds from users, the enabling of payments and remittance-type services. ${ }^{1}$ However, as time passes, a precise indication of the scope and role of banks becomes more uncertain as it has evolved continuously over time from the basic deposit to sophisticated financial services, and this makes it difficult to answer the seemingly simple question: 'What is a bank?' or as it is usually phrased, 'What is the business of banking?' The core activities of a 'bank' also become less clear.

This question infers a following question: 'Is it accurate to say that Mobile Financial Services Providers (hereafter MFSPs) or Mobile Network Operators (hereafter MNOs) are engaged in 'the business of banking'? This will be analysed below by examining the characteristics of a 'bank'.

The role, and types, of payments instruments will also be explored, both at the national and the private levels.

A

\section{Banking}

\section{Nature of Banking: An Overview}

The concept of a bank has evolved from the original 'bank' of the $17^{\text {th }}$ century when merchants turned to goldsmiths to provide - or 'deposit' - their valuables for safekeeping and for pecuniary advantage. Loans were also provided and allowed for payment to third parties based on orders given to the goldsmith by the depositor. $^{2}$

\footnotetext{
${ }^{1}$ On an overview of MFS, see ch 2, s2.1 titled Introduction, and ch 6 titled Mobile and Mobile Financial Services Commercial Models passim. See also the omnibus definition of 'mobile banking' by Porteous (2006a) who describes it as access by mobile devices to such banking services as account-based savings or transactions products, including m-payments. M-payments, by contrast, he says are financial transactions undertaken using mobile devices, such as the mobile phone. See D Porteous (2006a) 'The Enabling Environment for Mobile Banking in Africa', available at http://goo.gl/JDDRn. While these product innovations in retail payment systems have increased the role of non-banks in small value transactions, banks continue to dominate the wholesale payment system. A study by the Federal Reserve Bank of Kansas City in the United States showed that non-banks engage in a large number of payment activities, but are seldom involved in settlement activities. This is not surprising as, owing to concerns about systemic risk, settlement is usually done through the banking system and through the national and international payment systems. See SW Schmitz and GE Wood (2006) Institutional Change in the Payments System and Monetary Policy at 12-15; and RJ Sullivan and Z Wang (2007) 'Nonbanks in the Payments System: Innovation, Competition, and Risk - A Conference Summary' Q III Economic Review (Federal Reserve Bank of Kansas City) 83-106, available from http://goo.gl/vqBdE.

${ }^{2}$ See generally ch 3, s3.4 titled Evolution of Money.
} 
This safekeeping of valuables and payment methodology was known as the 'law merchant' (lex mercatoria) and was ultimately absorbed into the English common law from which English banking law emerged. ${ }^{3}$ What could be regarded as modern banking emerged from the activities of organisations that collected savings from the general public in Europe during the mid-1800s, when large limited liability commercial banks were established in many countries. ${ }^{4}$ The resulting increase in deposit-taking activity led to the gradual increase of account transfer-based payments at the expense of currency and coin. ${ }^{5}$ Other credit institutions such as savings banks, credit cooperatives as well as postal banks were established during this time and later around Europe and the United States of America (hereafter USA).

Modern incarnations of banks can be said to encompass a large range of financial institutions and activities that provide services beyond those of just deposit, payment and loan activities. ${ }^{6}$ The nature of their customer profile also varies, from small depositors to so-called private banks that cater to high net-worth individuals.

While the provision of credit alongside the handling of deposits, cash and cheques has traditionally been the purview of banks, technology and regulation have allowed banks to enter new and profitable, but sometimes extremely risky domains. As such, the modern bank provides traditional deposit, credit and payment facilities alongside the complex financial structures they create and participate in. ${ }^{7}$ These may include entities that focus on niche markets and generalist banks that offer anything from bespoke payment, deposit and lending services to real estate services, stock broking, derivative trading, life assurance, and even telecommunications and mobile products. ${ }^{8}$

The reality then is that shifting business models that may encompass variants such as merchant banks, clearing banks, cooperative banks, mutual banks and building societies, as well as policy imperatives may at a particular time and place give varied answers to the question of whether an entity is a bank, such that there may evolve and exist a lacuna between banking (common) law and banking practice. ${ }^{9}$ These variants beg the

\footnotetext{
${ }^{3}$ See also DB Humphrey et al (1996) 'The Evolution of Payments in Europe, Japan, and the United States: Lessons for Emerging Market Economies' at 21, available at http://goo.gl/LPSWs.

${ }^{4}$ For example, the English Bills of Exchange Act 1882. See ch 3, s3.4.4.2 titled Drafts and Cheques on the derivation of the word 'bank'. Dew notes that because of the negative perception of banks, as a consequence of the sub-prime banking collapse in 2007, some financial institutions appear to believe that the designation 'bank' has taken on a negative market value. See JK Dew (2009) 'Tying Bank Regulation to Banks' Risk-Return Trade-Offs Following the Financial Crisis: Holding Congress and its Regulatory Apparatus Accountable' Networks Financial Institute Working Paper No 2007-WP-17B at 5, available at http://goo.gl/FXQQr.

${ }^{5}$ Humphrey et al (1996) op cit note 3.

${ }^{6}$ The notion of an entity lending deposited funds to another party for profit is known as intermediation. Licensed banks exist primarily as intermediaries between depositors and borrowers. In that sense they manage assets and liabilities between customers. This channelling of funds between borrowers and savers is known as financial intermediation. In some contexts intermediation may also be taken to mean the taking of loans from one party and loaning the values out fractionally to others at a higher interest rate. This may rather be described as bank intermediation. The process of creating a new asset (a loan) from liabilities (deposits) with different characteristics is called asset transformation. Financial intermediation could also be a synonym for payment intermediation, where the bank acts as a means to allow one person to pay another. Usually, though, this is simply known as 'payment' rather than intermediation as the latter term has a lending and credit connotation. See S Heffernan (2003) Modern Banking in Theory and Practice at 15; R Apostolik, C Donohue and P Went (2009) Foundations of Banking Risk: An Overview of Banking, Banking Risks, and Risk-Based Banking Regulation at 5.

${ }^{7}$ In Re Roe's Legal Charge [1982] 2 Lloyd's Law Rep 370 (hereafter In Re Roe's), it was held that the proportion of banking transactions must be non-negligible in comparison to the lending transactions in order for the institution to be called a bank.

${ }^{8}$ See FNBConnect, a division of FNB Bank that offers fixed and mobile services to anyone, not only to bank customers.

${ }^{9}$ As Salmon J in Woods v Martins Bank [1959] 1 QB 55 at 56 said:
} 
question of whether an entity whose main venture is not banking can be classed as a 'bank' engaged in the 'business of banking'. 10

While common law definitions ${ }^{11}$ of banks may augment any statutory lacunae where there are attempts to define a bank, there is no consistent common law definition that provides an answer to the seemingly simple question: 'What is a Bank?' Further, as disembodied technological advances bring traditional banking services into the home, the local store or mobile handset, the traditional concept of a physical bank with local branches dealing with customers face-to-face to provide core retail banking services seems somewhat dated. $^{12}$

But whatever the new form of access and activities a 'bank' may allow and provide, it is important to get to the pith and marrow of the question of 'what is a bank' because of the implications of the appellation 'bank' at common law and statute. These implications relate to, for example, what have been termed the 'unique' relationship between a 'bank' and customer rather than any other entity that is not a bank, such as establishing a fiduciary duty of care. Further, a 'bank' enjoys some unique privileges, both legal and practical. ${ }^{13}$ In addition, at a prudential level, banking is also one of the most regulated and supervised of economic sectors with numerous regulations ${ }^{14}$ and an elaborate system of constant supervision. ${ }^{15}$

With this plethora of activities, the statutory definitions of the activities that would determine whether there is a 'business of banking' are at play. However, statutory definitions of a bank or the business of banking may not necessarily provide comprehensive answers to doubtful cases or new business models as to whether an institution is a 'bank'.

The enquiry becomes pertinent in determining whether those engaged in MFS are engaged in the 'business of banking.'

Common law views of banking, as they stand, would have to be sought to determine any statutory lacunae. Three general principles can be used in the determination of whether an entity is engaged in the business of

In an earlier taxation case, Bank of Chettinad v Commissioner of Income Tax, Colombo [1948] AC 378 at 383, it was said that: '... the words "banking" and "banker" may not bear different shades of meanings at different periods of history and their meaning may not be uniform today in countries of different habits of life'.

${ }^{10}$ See the discussion below on In Re Roe's op cit note 7 and United Dominions Trust Ltd v Kirkwood [1966] 2 QB 431 (hereafter $U D T$ ) where this was answered in the affirmative.

${ }^{11} \mathrm{~S}$ Wadsley and GA Penn (2000) Law Relating to Domestic Banking $2^{\text {nd }}$ ed at 91.

${ }^{12}$ Ibid at 89 .

${ }^{13}$ Ibid at 90.

${ }^{14}$ There are also strict capital requirement rules for banks' holding deposits. These rules, known as 'Basle I', 'Basle II' and 'Basle III', say that commercial banks should hold capital against risk-weighted assets and relates to the soundness or underlying strength of the banks. A bank's capital is essentially the cushion for potential losses. Tier 1 for example is the shareholders' core capital and it is available for absorbing actual or potential losses occurring from non-performing loans. Each national regulator however may have a slightly different way of calculating bank capital which is designed to meet the common requirements within that nation's individual legal framework. See generally 'The Basel II Accord', available at http://goo.gl/5wmGE.

${ }^{15}$ Generally, regulation of these financial institutions aims at efficient, flexible, fair, safe, sound and equitable distribution of economic power and the process of implementing monetary policy and the entities that are said to be engaging in the business of banking will fall under these strict prudential regimes. See FR Malan (1989) 'Legal Aspects of the Regulation of Financial Institutions' 18(4) Tydskrifvir die Suid-AfrikaanseReg at 553. See also ch 8, s8.3 titled Types of Regulation Foci. 
banking and which may, therefore, be classed as a bank. First of all, bank activities can change over time as they take on new business models, becoming multifunctional entities. ${ }^{16}$ Secondly, an entity engaged in the 'banking business' in one place is not necessarily considered a bank elsewhere ${ }^{17}$ and, thirdly, an entity's reputation may influence the determination. ${ }^{18}$

Common law views of banking and what is termed the 'business of banking' are based on judicial decisions, the evolution of business processes and the influence of related statutes. Banking as a construct of law, however, is a relatively recent evolution and has been more the domain of English law and has been incorporated into South African law over time. ${ }^{19}$ It is constantly evolving.

The sources of South African banking law are based on primary and secondary sources. ${ }^{20}$ One clear primary source that is part of the tapestry of laws and precedent that comprises a common law view of banking would be municipal banking legislation, while secondary law - such as banking law and precedents in other, similar jurisdictions - would be law used by South African jurists to assist in elucidating South African law where it may be unclear, underdeveloped or not developed at all on a certain point. ${ }^{21}$

While English banking law as a secondary source has influenced South African banking law, in many respects Roman law has remained pervasive and equally influential in both commercial and private law aspects. ${ }^{22}$ It has been noted that the essential Roman law character of South African banking law has been retained because of the critical private law components of banking, in particular the law of obligations and

\footnotetext{
${ }^{16}$ The relationships that are created beyond the traditional core activities of intermediation, such as investment advice and safe storage of value, can be described as sui generis.

${ }^{17}$ See, for example, the Australian case Commissioners of the State Savings Bank of Victoria v Permewan Wright and Co Ltd (1914) 19 CLR 457 (hereafter Permewan) where on the issue of the 'business of banking', Issacs J (at 470, 471) said that:
}

\footnotetext{
'The essential characteristics of the business of banking ... may be described as the collection of money by receiving deposits on loan, repayable when and as expressly or impliedly agreed upon, and the utilisation of the money so collected by lending it again in such sums as are required.'
}

As Tyree points out, this 'reservoir' definition does not require current accounts or payment facilities. Further, the purported 'bank' was not acting as a 'banker' since it neither allowed funds to be drawn upon by cheque nor did it collect cheques. See A Tyree (2008a) 'The Business of Banking', available at http://goo.gl/lD3ep.

${ }^{18}$ EP Ellinger, EZ Lomnicka and R Hooley (2006) Ellinger's Modern Banking Law at 69.

${ }^{19}$ WG Schulze (2002) 'The Sources of South African Banking Law: A Twenty-first Century Perspective (Part 1)' 14 SA Mercantile Law Journal 438 at 451. The first bank in South Africa was Bank van Leening and it was established in 1793. See FR Malan and W Faul (1991) 'Introduction to the Deposit-taking Institutions Act 94 of 1990' 7(3) Tydskrif vir die SuidAfrikaanse Reg 379, at 380.

${ }^{20}$ Schulze (2002) op cit note 19 at 442.

${ }^{21}$ Ibid note 20 at 443 . As Schulze correctly points out, because of the multifaceted nature of banking, banking law depends on the application of various fields of law and a large number of other pieces of legislation that apply indirectly to banking law.

${ }^{22}$ WG Schulze (2001) 'Depositum, Deposit and Deposit-taking Institutions: Birds of a Feather? Not Quite' 13 SA Mercantile Law Journal 78 at 81; see FR Malan and JT Pretorius (2001a) 'Contemporary Issues in South African Banking Law' 64 Tydskrif vir Hedendaagse Romeins-Hollandse Reg at 268; see also J de Jager (2010) 'Much Ado about Nothing? Legal Principles on Money, Banks and Their Clients after Joint Stock Company Varvarinskoye v ABSA Bank Ltd'22 SA Mercantile Law Journal 127-140. 
the law of things, including personal and real security which manifest particularly in the banker-client relationship. ${ }^{23}$ Further, 'deposits' have been subject to Roman law classifications. ${ }^{24}$

Beyond acknowledging the basic financial intermediation ${ }^{25}$ that banks commonly engage in (specifically the receipt of deposits), English law has not arrived at an exhaustive (common law) definition of banking, in particular one that assists in elucidating the ostensibly descriptive term, the 'business of banking, ${ }^{26}$

As has been noted, banking is not a technical or legal term but a loose popular term, comprising activities carried on by those who, likewise popularly, are called bankers ${ }^{27}$ and that 'to construct a definition which would embrace the whole of it is manifestly impossible'. ${ }^{28}$ However, it has also been noted that the peculiar status of bankers, their importance at the centre of the financial community, the expectation of the public that it can grant them implicit and utmost confidence has led, given the uncertainty of substantive tests, to various methods to identify or recognise banks and banking by way of formal and institutional means and tests. ${ }^{29}$ With the traditional, core 'business of banking, ${ }^{30}$ effusing into other commercial strata, the common law has thus adopted a practical approach to defining what this is, in part by listing what may be regarded as the core characteristics that seemingly constitute the 'business of banking'. ${ }^{31}$

Along with statutory guidelines, these may be considered as formal and institutional tests and are discussed below. Characteristics of Banking

Modern tests for the 'business of banking' are based on the institutional characteristics identified in the locus classicus United Dominions Trust Ltd v Kirkwood ${ }^{32}$ (hereafter UDT) where the nexus between deposit-money and payments was defined.

UDT were trying to prove that they were acting as a bank and as such had a common law right to claim back a loan given to Kirkwood. ${ }^{33}$ Kirkwood's defense was that UDT was an unregistered moneylender, and so the loan it had provided was not repayable because of that alleged illegality. This posed the question:

\footnotetext{
${ }^{23}$ Schulze (2002) op cit note 19 at 439.

${ }^{24}$ Schulze (2001) op cit note 22 at 80 ; see also ch 4, s4.4 titled Deposits.

${ }^{25}$ See ch 4, s4.4.2 titled History of the Deposit.

${ }^{26}$ Wadsley and Penn (2000) op cit note 11 at 92; A Guest (1991) Chalmers on Bills of Exchange at 10.

${ }^{27}$ Coyne JA in Re Bergethaler Waisenamt (No 2) [1949] 1 W.W.R. 323 at 334.

${ }^{28}$ RST Chorley (1974) Law of Banking $6^{\text {th }}$ ed at 23.

${ }^{29}$ Canadian Pioneer Management Ltd et al. v Labour Relations Board of Saskatchewan et al. [1980] 1 S.C.R. 433 at 462.

${ }^{30}$ Others indicate that core services that banks are said traditionally to provide are deposit collection, payment services and loan underwriting. See Apostolik, Donahue and Went (2009) op cit note 6 at 5.

${ }^{31}$ While statutory definitions may buttress the common law definitions, the common law definition has been criticised as being overly restrictive when it hones in on precise mechanisms; see Ellinger, Lomnicka and Hooley (2006) op cit note 18 at 73.

${ }^{32} U D T$ op cit note 10 .

${ }^{33}$ UDT sued the defendant endorser of a bill of exchange, but the defence was that UDT was an unregistered moneylender. UDT thus had to prove that it was acting within the ambit of the 'business of a bank'. UDT op cit note 10.
} 
Was UDT doing the 'business of banking', a determination which if answered in the affirmative would allow them to claim back the funds owed, this right being a feature of those rights that accrue to bank? $?^{34}$

Denning MR (at 446) in the majority, said of the criteria for determining the nature of 'business of banking':

'There are, therefore, two characteristics usually found in bankers today: (i) They accept money from, and collect cheques for, their customers and place them to their credit; (ii) They honour cheques or orders drawn on them by their customers when presented for payment and debit their customers accordingly. These two characteristics carry with them also a third, namely: (iii) They keep current accounts, or something of that nature, in their books in which the credits and debits are entered. ${ }^{35}$

In essence this nominalistic approach defines bank activity in terms of its functions, the enumeration of which in UDT is still held as the locus classicus in defining the 'business of banking, ${ }^{36}$ Specifically, the 'business of banking' is defined beyond 'mere' (direct) deposit-taking to include additionally the collection of cheques for customers and the honouring of cheques drawn on them by customers and the keeping of current accounts. ${ }^{37}$ Also required is something beyond these enumerated functional aspects: the institution's reputation as a banker. ${ }^{38}$ Holding oneself out as a banker - through actions or services - may provide the impetus for the acquisition of the reputation. ${ }^{39}$ Thus in UDT, it was held that UDT - although it had not succeeded in proving that its business, as distinct from its reputation - was effectively a banking business, had discharged the onus of proving that it was a banker because it had established, that for a long period of years it had been accepted as having the status of a banker by the banking community and government departments. $^{40}$

However, as noted above, banks nowadays engage in multifunctional, diversified activities, and even exclude potential clients who do not fall within their required class or value of assets ${ }^{41}$ from participating in their banking business. Similarly, banks are moving away from cheques to electronic Means of Payment

\footnotetext{
${ }^{34}$ To wit, the salient question was this: When is a moneylender not a money-lender? When is a moneylender a banker, as per Harman LJ (dissenting) in UDT op cit note 10 at 456.

${ }^{35}$ These three characteristics are much the same as those stated in M Megrah (1961) Paget's Law of Banking $6^{\text {th }}$ ed at 8, where it was said that:
}

'No one and nobody, corporate or otherwise, can be a "banker" who does not (i) take current accounts; (ii) pay cheques drawn on himself; (iii) collect cheques for his customers.'

${ }^{36}$ See In re Roe's op cit note 7 at 381, where the evidence showed that the plaintiffs were performing all the acts outlined in UDT and, as such, UDT was affirmed. See also Re Birkbeck Permanent Benefit Building Society [1912] 2 Ch. 183; and London and Harrogate Securities Ltd v Pitts [1976] 1 WLR 1063.

${ }^{37}$ See also Libyan Arab Foreign Bank v Bankers Trust Co [1989] QB 749 (hereafter Libyan Arab) where the court described a number of functions of a bank in relation to determining a 'bank customer'

${ }^{38} U D T$ op cit note 10 at 453.

${ }^{39}$ See In re Shields' Estate [1901] 1 Ir.R. 172 where Fitz-Gibbon LJ (hereafter Shields) wrote at 197:

'In all his dealings with the public, Shields held his firm out as "Bankers". He so described himself for the purpose of inducing custom and giving dignity to his operations. It may be conceded that people who are not bankers, cannot make themselves so by adopting the name ... But the name was assumed by Shields, and the Bank of Ireland accepted it as a truthful designation ... From beginning to end they treated him as a banker. That being so, it is only a question of fact, and one upon which the presumption is in the affirmative, whether there is reasonable evidence to warrant the conclusion that Shields was what he professed to be, and what the Bank of Ireland took him to be, namely a "Banker".'

\footnotetext{
${ }^{40}$ Harman LJ however dissented from this view on the grounds that reputation alone was not enough and that there had to be some performance behind it.

${ }^{41}$ These include specialised private banks where threshold deposit amounts are required before an account can be opened.
} 
(hereafter MOP), these core activities, it is submitted, may be outmoded and do not present, contextually, a useful modern metric for deciding what defines the essence of the 'business of banking'. ${ }^{42}$ Further, even though the presence (or absence) of some (common law) practical characteristics may point to the existence (or absence) of the business of banking the entity is engaging in, there may be other characteristics that override these practical core attributes, such as the reputation of the entity in the commercial world of doing the 'business of banking, ${ }^{43}$

Thus, the 'usual characteristics of a bank are not its sole characteristics ${ }^{44}$ Ultimately, the import is the extension of the potential characteristics that could be considered when determining whether an entity is engaging in the 'business of banking'. Further, it is also important to note (at 446) Denning's effective dismissal of previous cases that defined the business of banking:

'The march of time has taken us far beyond those cases of 50 years ago. Money is now paid and received by cheque to such an extent that no person can be considered a banker unless he handles cheques as freely as cash.'

Similarly, with the march of time, and in a modern payments and especially in the MFS context where cheques now play an increasingly diminished role in banking (and payments), there is a danger that modern payment schemes could be captured as equating to the business of banking. ${ }^{45}$

At the core though of the banking ecosystem is 'money', where it has been said that a banker is 'one that traffics in money'. ${ }^{46}$ This may mean 'bank money' and instruments treated as 'money'. ${ }^{47}$ This presages the first general characteristic which is that banks accept money on deposit for the purpose of reinvesting it for profit, that is, the bank acting as a financial intermediary between a depositor and a lender.

\footnotetext{
${ }^{42}$ See, for example, s2(1) of the Banking Act of Singapore (Cap 19) which defines 'banking business' as the 'business of receiving money on current or deposit account, paying and collecting cheques drawn by or paid in by customers, the making of advances to customers, and includes such other business as the authority may prescribe for the purposes of this Act'.

${ }^{43}$ See also in relation to the characteristics of the entity engaging in activities that may rise to the business of banking: '[A banker] ... must hold himself out as a banker and the public take him as such, assuming openly, avowedly and notoriously the character of a banker ...' Stafford v Henry [1850] 12 Ir. Eq. 400 and also Shields op cit note 39 at 199 where it was said that: 'If a man carries on other businesses besides that of banking, and if the banking is only subsidiary to the other businesses, he cannot be regarded as a banker'.

${ }^{44}$ Denning in $U D T$ op cit note 10 at 453.

${ }^{45}$ See in this regard the Australian case in relation to the scope of the business of banking in Permewan op cit note 17 where Issacs J provided a wide definition of banking:
}

'The essential characteristics of the business of banking ... may be described as the collection of money by receiving deposits on loan, repayable when and as expressly or impliedly agreed upon, and the utilisation of the money so collected by lending it again in such sums as are required.'

${ }^{46}$ Lord Denning in $U D T$ op cit note 10 at 445.

${ }^{47}$ Wadsley and Penn (2000) op cit note 11 at 92. 
In the early $19^{\text {th }}$ century, the bailment ${ }^{48}$ of fungibles, ${ }^{49}$ 'deposits' as they are now legally and commercially known, metamorphosed into the provision of funds to a bank that can be redeemed on request by the depositor. ${ }^{50}$ These funds may be used by the entity in its intermediation activities, where it usually lends the funds - as a scriptural entry in its books - fractionally to other bank clients for profit. ${ }^{51}$ This narrow view of a deposit though could possibly also be applied to non-banks, where entities controlling stores of value may take funds and convert them to stores of value that may or may not pay back some or all of the funds to the (putative) 'depositor'. ${ }^{52}$

The term 'deposit' - from the Latin term verb deponere ${ }^{53}$ - and the associated financial action of 'deposittaking' are not, however, always strictly associated with banking or redeemable deposits, since the provision of funds to a bank may be for some other purpose such as for the settlement of conventional trade debts unrelated to any deposit-taking arrangement or statutory regime on deposits. ${ }^{54}$ The latter broader view of deposit, then, may also encompass what may be seen as a deposit of money, for example, the deposit of money as a pledge that secures the rights embodied in a contract. ${ }^{55}$

It is the narrow view and its effect on banking and MFS will form the basis of the discussion below.

\subsection{2 \\ History of the Deposit}

The concept of a deposit along with the ability to earn interest on the deposit goes back to biblical times:

'Thou oughtest therefore to have put my money to the exchangers, and then at my coming I should have received mine own with usury. ${ }^{56}$

\footnotetext{
${ }^{48}$ Bailment is the delivery of money, possibly for a particular purpose. It exists free of the bank or deposit, but involves at least two persons and one object of property. See B Geva (2001) Bank Collections and Payment Transactions: Comparative Study of Legal Aspects at 76.

${ }^{49}$ A fungible is a commodity that is freely able to replace or be replaced by another identical item. See 'Fungible' (2011) Oxford Dictionaries, available at http://goo.gl/bQkaZ. A bailment of commingled goods is closer to deposits and refers to at least two items of property.

${ }^{50}$ This is usually considered as a debt relationship subject to a contract. See below.

${ }^{51}$ A deposit in this context could be seen as an unsecured advance of money to a bank to allow it to pursue its business of taking in and lending out money for profit. This would certainly apply to traditional banks where they would provide credit facilities to others based on fractional banking principles, where the book entry of the value of a deposit is lent out to multiple lenders. The base value of the bank value is, however, the single incoming deposit. See generally, R Bollen (2006) 'Time to modernise the concept of “deposit”?' 17(4) Journal of Banking and Finance Law and Practice 283-298.

${ }^{52}$ Grossman describes an early form of the deposit which was the closed deposit, similar to a deposit box used today. These were left in temples in ancient Greece. See RS Grossman (2010) Unsettled Account: The Evolution of Banking in the Industrialized World since 1800 at 31.

${ }^{53}$ See 'Deposit' (2011) Oxford Dictionaries, available at http://goo.gl/grsfy.

${ }^{54}$ See J Sommer (2007) 'Why Worry About Bank Deposits' Unpublished Manuscript; and JH Sommer (2005) 'Why Should a Legal Scholar Care About Bank Deposits?', available at http://goo.gl/C8ogR.

${ }^{55}$ The Oxford Dictionaries (2011) op cit note 53 describe a 'deposit' as (i) a sum of money placed or kept in a bank account, usually to gain interest; (ii) a sum payable as a first instalment on the purchase of something or as a pledge for a contract, the balance being payable later; and (iii) to store or entrust with someone for safekeeping.

${ }^{56}$ See Matthew 25:27 (King James Version), available at http://goo.gl/UjaNg.
} 
Roman law recognised a number of types of contracts, some of which are related to banking. There were the loans for consumption (mutuum) ${ }^{57}$, the commodatum (loans for use), the pledge (pignus) and depositum (loans for safekeeping). Deposits sounding in money as we know it today were called 'deposit irregular'. The lender of a mutuum or commodatum was entitled to terminate the loan at any moment by demand of payment or restitution, but was sometimes bound by a promise not to exercise this right before a given period. ${ }^{58}$ As Schulze points out, where money was the object of the depositum, a transaction would go beyond the scope and framework of the traditional contract of depositum and would more resemble the contract of mutuum. ${ }^{59}$

While the deposit of money that could be consumed by the borrower but which had to be paid back in equivalents were seen as depositum mutuum (loan for consumption), where specific coins were deposited and the same coins had to be paid back to the lender, this was called depositum commodatum (loan for use). ${ }^{60}$ The depositor would rely more on the solvency of the depositary than the honesty and trustworthiness of the depositary. The depositor did not want the corpus back, but the quantitas that has been deposited. Under those circumstances, the depositary would be allowed to use the money as an owner on the understanding he would give back the value he had been given. ${ }^{61}$

A number of South African cases have indicated that money deposited with a bank is a contract of mutuum. ${ }^{62}$ In $S v$ Kearney ${ }^{63}$ it was held that the bank becomes the owner of any money so deposited. ${ }^{64}$

\section{Nature of the Deposit}

From an economic point of view, the deposit is an entitlement to receive the credit standing to a customer's account. ${ }^{65}$ The legal view of a deposit was firmly formulated in the classic case of Foley $v$ Hill ${ }^{66}$ (hereafter Foley) where it was held that an entity taking deposits is said to be the debtor of the person making the deposit: ${ }^{67}$

\footnotetext{
${ }^{57}$ What is mine becomes yours (ex meotuum fit) when lent for such a purpose. See JIC Hare (1887) The Law of Contracts Repr 2003 at 73.

58 Ibid at 75 .

${ }^{59}$ Schulze (2001) op cit note 22 at 81-83. He points out that in the case of mutuum, the contract is made in the interest of the borrower. In the case of depositum (even where money was the object of the depositum), then the interests of the depositor (to be repaid in kind and on demand) are paramount.

${ }^{60}$ R Zimmermann (1996) The Law of Obligations: Roman Foundations of the Civilian Traditionat 215-218.

${ }^{61}$ Ibid at 218. Zimmermann argues that depositum irregulare provides the legal basis of the modern current account at banks. See also Schulze (2001) op cit note 22 at 80.

${ }^{62}$ Baylis' Trustee v Cape of Good Hope Bank (1886) 4 SC 442; Langford v Moore (1900) 17 SC 1 at 8; White v Brown (1883) 4 NLR 88 at 92.

${ }^{63} \mathrm{~S} v$ Kearney 1964 (2) SA 495 (A) at 503.

${ }^{64}$ See Schulze (2001) op cit note 22 at 89.

${ }^{65}$ Geva (2001) op cit note 48 at 61.

${ }^{66}$ Foley $v$ Hill [1848] 2 HL C 28 at 45 (hereafter Foley).

${ }^{67}$ As per Lord Cottenham LC. In Scotland the relationship was described by MacKay L in Royal Bank of Scotland v Skinner 1931 SLT 382 at $384, \mathrm{OH}$ as such:
}

'After some fluctuation of opinion, it is now well settled that the relationship of customer and banker is neither a relation of principal and agent nor a relation of a fiduciary nature, trust, or the like, but a simple relation - it may be one-sided, or it may be two-sided - of creditor-debtor. The banker is not, in the general case, the custodian of money. When money is paid in, despite the popular belief, it is simply consumed by the banker, who gives an obligation of equivalent amount.' 


\begin{abstract}
'Money, when paid into a bank ceases altogether to be the money of the principal; it is then the money of the banker, who is bound to return an equivalent by paying a similar sum to that deposited with him when he is asked for it. The money paid into a bank is money known by the principal to be placed there for the purpose of being under the control of the banker; it is then the banker's money; he is known to deal with it as his own; he makes what profit of it he can, which profit he retains to himself, paying back only the principal.'
\end{abstract}

From a legal point of view, then, the deposit is seen as a contract of bank debt owed to the account holder ${ }^{68}$ after consideration is paid to the bank by the putative depositor, whereby the bank must return a sum demanded by the depositor, or according to specified terms agreed upon. The relationship between the bank and client (acting as a depositor) is said to be one of debtor and creditor. In essence, however, repayment of some or all the amount deposited, whether by the direct request of the depositor or indirectly through some instrument or otherwise to draw value from the account, is required as part of the deposit process. ${ }^{69}$ The 'transaction motive' for the deposit of funds is, in a modern context, both for the depositor and the bank or institution taking the funds: each seeks to gain benefits from the placement of funds. ${ }^{70}$ It may also be noted here that the common law position of deposit as a debt appears to coincide with the Claim School view of money that refers to claims or debts owed by the issuer of money to the holder of that monetary instrument where the creation of money involves accepting another's debt as with Minsky's conception of money as a two-sided balance sheet operation. ${ }^{71}$ However, not all debts of a bank are deposits, as they may simply be conventional trade debts unrelated to deposits held. ${ }^{72}$ In addition, while bank deposits may be debts, they may not necessarily constitute fiduciary relationships. ${ }^{73}$

There is also credit risk attached to the deposit insofar as the deposit may not be paid back. Hence the solvency of the banker or holder of the funds is key to the relationship between the depositor and the deposit-taker. ${ }^{74}$ If a payor presents to a payee a payment order or instrument in final payment for goods or services and the banker is unable to transfer funds to the payee as a result of the insolvency, the payment is not final and the payee can claim payment from the payor. In a modern context, the deposit is usually monetary, that is using fiat money, and it may be set off against a depositor's debt to the bank, say in an overdraft. $^{75}$

\footnotetext{
${ }^{68}$ As Sommer points out, if a deposit is a debt, and a debt is a contract, a deposit must be a contract. See Sommer (2007) op cit note 54 at 3. See also on debt in relation to money, D Graeber (2009) Debt: The First 5,000 Years.

${ }^{69}$ Sommer notes that the movement of funds may alter the debt arrangement that forms the basis of the deposit, but as the deposit is a consensual arrangement based on consensual contract, the bank cannot touch the magnitude of the deposit without the customer's consent. This may, however, be altered by setting off any incoming flows into an account against any outgoing flows from that account; see Sommer (2007) op cit note 54 at 12.

${ }^{70}$ Geva (2001) op cit note 48 at 83-84.

${ }^{71}$ See HP Minsky (1986) Stabilizing an Unstable Economy. See also the Claim School view of money at ch 3, s3.10 titled Claim School.

${ }^{72}$ Sommer (2007) op cit note 54 at 11.

${ }^{73}$ Ibid, at 11 cites EL Symonds (1983) 'The Bank Customer Relationship' 100 Banking LJ at 220 and 235. The Federal Deposit Insurance Corporation (FDIC) and Federal Regulation D (Reg D) of the USA consider payment instruments as deposits. Sommer also describes what he calls a unique US invention, namely, the 'special deposit'. This derives from 1870 and refers to a contingent obligation unavailable to the deposit or beneficiary. Banks cannot set it off. Modern courts refer to this as 'deposit for a special purpose'. Ibid, at $6 \mathrm{fn} 22$

${ }^{74}$ A payer attempting to recover his money from an insolvent banker would be an unsecured creditor who competes with other creditors for repayment.

${ }^{75}$ A set-off case, which was a precursor to cases involving debts, was Anonymous 1 Mod. 215, 86 ER 837 (C.P. 1676) as discussed in Sommer (2007) op cit note 54 at 5 and in WJ Bergman, CA Johnson and RR Bliss (2003) 'Netting, Financial Contracts, and Banks: The Economic Implications', available at http://goo.gl/uvktt. The court found that upon bankruptcy, a
} 
It is evident that a deposit to a bank must be in 'money', which in the time of Foley was specie. In modern banking systems, this may be specie, a negotiable instrument like a valid cheque that represents specie money, or a scriptural representation of money, for example, a series of (electronic) transfers that represent money, and which are ultimately available to the bank to be used in an unfettered manner and mixed with funds from other sources for its own profit. ${ }^{76}$ It may also possibly be a species of a Stored Value Product (SVP) in a MFS system. ${ }^{77}$

\subsection{4}

\section{Legal and Economic Effect of Deposits}

Early case law on deposits is characterised by Foley where it was further held that:

'It may be admitted that bankers are debtors, but they are debtors with superadded obligations, as, for instance, to repay the money deposited by honouring the depositor's cheques ... ${ }^{, 78}$

The deposit is only one component of the account relationship, however. The other is a general need to honour all valid payment instructions, including repaying the entire deposited amount back to the account holder in specie or in another form, but usually at par. There are a number of legal effects that flow from this. First, since Foley, it is long accepted at common law that a deposit placed in a (bank) account means that the money becomes the property of the bank. ${ }^{79}$ Second, as indicated above, the account becomes an abstract representation of a debt (of repayment) wherein the bank now has a legal obligation to the depositor of the money for return of the money on demand, but with reasonable notice. ${ }^{80}$ The third legal effect is seen

solvent merchant owing, and simultaneously in debt to, a bankrupt merchant was not required to pay the gross amount owed, but had 'to pay only that which appears due to the bankrupt on the foot of the account', that is, the net amount. See further on set-off, JT Pretorius (2008) 'Combining Bank Accounts: The Validity of this Practice Explored' 16(11/12) Juta's Business Law 51-54 at 51.

${ }^{76}$ Geva (2001) op cit note 48 at 61.

${ }^{77}$ See ch 4, s4.8.4.4 titled Stored Value Products.

${ }^{78}$ Foley op cit note 66. See also N Joachimsonv Swiss Bank Corporation [1921] 3 KB 110 CA (hereafter Joachimson) where it was held in relation to repayment by a bank to the depositor that:

'Where money is standing to the credit of a customer on current account with a banker, in the absence of a special agreement a demand by the customer is a necessary ingredient in the cause of action against the banker for money lent.'

\footnotetext{
${ }^{79}$ Schulze points out that in the absence of legislation, the relationship between a bank and its client is regulated by the consensual and/or implied terms of their agreement and the relevant rules of contract; see Schulze (2002) op cit note 19 at 451. See also Louw v Coetzee 2003 (3) SA 329 (SCA) at 334H-I which held that when a customer deposits money with a bank, the bank becomes the owner of the money, and the bank in its turn becomes the customer's debtor. The bank does not hold the money as agent or trustee and only has a personal obligation to repay the amount, with interest, if so agreed. When a bank is liquidated the customer only has a concurrent claim against the bank. There is no indication in the Financial Institutions (Protection of Funds) Act 28 of 2001 that the common law position has been changed.

${ }^{80}$ Thus, the relationship between customer and banker (or holder of deposited funds) is seen as one of 'creditor' and 'debtor'. See note 67 above where the banker/customer relationship was described. See also London Joint Stock Bank Ltd v MacMillan and Arthur [1918] AC 7777 (HL) 789; Gilbey Distillers and Vintners (Pty) Ltd v ABSA Bank Case 12698/94 (unreported 4 Dec 1998 (C)); Joachimson op cit note 78; B Geva (2004) 'The Beneficiary's Bank and Beneficiary Described by Name and Number: Liability Chain and Liability Standard in Wire Transfers (Part 1)' 1 Tydskrif vir die Suid-Afrikaanse Reg 1-19; Geva (2001) op cit note 48 and B Geva (1990) 'Payment into a Bank Account' 3 Journal of International Banking Law at 108, which states that:
}

' ... payment by a third party into a customer's bank account is in effect a mode of discharging the payer's obligation to the customer by constituting the bank a debtor to the payee customer.' 
in terms of the use of the deposit, and the obligations that arise therefrom. ${ }^{81}$ However, a deposit is not a payment: a deposit of funds gives the depositary the right to use the depositor's money until it is called for by the depositor or another authorised person, while a payment occurs when a debtor transfers funds to a creditor to extinguish an existing debt. ${ }^{82}$ Porteous puts it succinctly with his observation that the danger of conflating the different universes of payments and deposits is that if the legal boundaries between the 'deposits' and 'payments' are vague or subject to a regulatory arbitrage or turf war, this may result either in legitimate payment developments being stifled through being incorrectly regarded as deposit-taking, or unregulated deposit-taking under the guise of being a payment service. ${ }^{83}$ Definitions, as much as policy, thus become critical in this determination.

Further interplay between the economic and legal perspectives is observed when analysing, for example, the impact of modern deposits and the utilisation of money for payments: depositing money has a macroeconomic effect that is distinct from the legal effect of the deposit. ${ }^{84} \mathrm{~A}$ bank deposit is not regarded as legal Generally Accepted Means of Exchange (hereafter GAME) money per se, but as representative of the GAME. Further, the bank deposit is not seen as embodying the GAME - and hence is not legal tender - per se. However, in practical terms, if it were not, large amounts of physical coins and notes would have to be carried around in specie and (even vexatiously) ${ }^{85}$ paid over to a creditor in settlement of a debt and the value in a bank deposit is ultimately redeemable to the $\mathrm{GAME}^{86}$, so a legal fiction is usually employed to characterise the incorporeal bank deposit as representing the GAME as money. ${ }^{87}$ However, as noted above, unlike economics, strict law does not consider a deposit to be money, although in some cases, where there is a creditor's implied or express consent ${ }^{88}$, or where the deposit is considered to be the subject of pecuniary benefit and termed 'money' in a will, it may well be considered money by the courts. ${ }^{89}$

\footnotetext{
${ }^{81}$ Where the customer has more than one account (one in debit and one in credit) and the banker has an exercisable right of set-off between the accounts, it is the net balance (if any) which the bank is liable to repay to the customer. See the submission from The Committee of Scottish Clearing Banks (s.d.) 'The Relationship between Banker and Customer', available at http://goo.gl/VSipP.

${ }^{82}$ E Akindemowo (2009) 'Contract, Deposit or E-value? Reconsidering Stored Value Products for a Modernized Payments Framework' 7(2) DePaul Business and Commercial Law Journal at 275, 297, 292, available at http://goo.gl/FP. A payment can only result from the manifested mutual intent of the parties. A promise to pay does not constitute payment. See ch 7 , s7.3.4 titled The Nature of Payment.

${ }^{83}$ Porteous (2006a) op cit note 1 at 30. See also ch 8, s8.4.2.3 titled Non-Bank Institutions and the implications of regulatory arbitrage.

${ }^{84}$ As noted above, the common law position appears to coincide with the Claim or Chartalist School of money that refers to claims or debts owed by the issuer to the holder.

${ }^{85}$ See Savingsadvice.com (2004) 'Man Pays Traffic Ticket with 8,200 Pennies', available at http://goo.gl/UiDZL and the discussion on legal tender in ch 3, s3.12.3.2.1 titled Legal Tender and Fiats; and ch 13, s13.8.2.3 titled Use as Legal Tender.

${ }^{86}$ FA Mann (1992) The Legal Aspect of Money $5^{\text {th }}$ ed at 78; on the macroeconomic effects of money, see ch 3, s3.5.3.3.1 titled Issuance by the Central Bank: Generally Accepted Means of Exchange (GAME).

${ }^{87}$ See the discussion on legal tender at ch 3, s3.12.3.2.1 titled Legal Tender and Fiats and and ch 13, s13.8.2.3 titled Use as Legal Tender.

${ }^{88}$ See Mann (1992) op cit note 86 at 7.

${ }^{89}$ Esterhuyse v Selection Cartage (Pty) Ltd 1965 (1) SA 360 (W) at 361; D Swart (2000) 'Online Banking Law and Payment Systems' in R Buys (2000) Cyberlaw at 281, available at http://goo.gl/5Z2Ms.
} 
Deposits have traditionally been a key determinant of whether banking supervisory restrictions apply to particular products offered by entities, such as payments and lending. ${ }^{90}$ The operation and conduct of banks in dealing with these deposits is subject to prudential supervision because of the systemic and contagion risks associated the use of depositor's funds. ${ }^{91}$ Deposit-taking is subject to a specialist and interventionist regulatory regime in many developed and developing countries ${ }^{92}$ and to operate what amounts to a deposittaking scheme without regulatory approval is usually a criminal offence. ${ }^{93}$

The prudential rules established by statute and regulation are designed to ensure that banks are solvent at all times by ensuring the prudent use of depositors' funds. ${ }^{94}$ Central banks (hereafter CBs) will also seek to assist banks and provide stability before that bank reaches crisis point, which is why there is usually mandatory monitoring and mandatory periodic reporting requirements for many banks. ${ }^{95}$ This ensuring of systemic soundness relates ultimately to consumer protection. ${ }^{96}$

Many jurisdictions have provided a statutory definition of deposit-taking. Banking activity and deposits in South Africa are regulated by the Banks Act. ${ }^{97}$ A detailed definition of a deposit is laid out in s1 of the Act. ${ }^{98}$ Even so, banks and the business of banking are terms not defined directly in the Banks Act, but rather by functional characteristics which include deposits. ${ }^{99}$

Deposits in a banking context usually imply intermediation, where the deposit-taking entity will lend out the value received at a higher rate of interest than it pays to the depositor. But as Tyree asks in relation to 'banking business': Is the carrying on of a business which accepts deposits included in this phrase even if it

\footnotetext{
${ }^{90}$ Akindemowo (2009) op cit note 82 at 345 . This is governed by contract and the common law duty of debt owed by the bank to the customer.

${ }^{91}$ Systemic risk is the risk of chain insolvency, or at least chain liquidity. See Sommer (2007) op cit note 54 at 36 . The bank is then said to have a liquidity crisis, and the mere rumour of a bank's inability to pay back depositors' funds may lead to a socalled 'run' on a bank. With the interconnected nature of global finance, where banks owe each other vast sums of money, this may in turn spread to other banks, affecting the entire financial system at a national, regional or international level. See also Systemically Important Payment Systems (SIPS) below in ch 4, s4.8.1 titled Overview.

${ }^{92}$ See Apostolik, Donohue and Went (2009) op cit note 6 at 55; Bollen (2006) op cit note 51 at 283.

${ }^{93}$ The approval for an institution to operate as a bank and to call itself a bank may be in the form of a banking license or, at the other extreme, a non-objection letter from the regulatory authority to the effect that although the scheme has the functional characteristics of a deposit, it does not amount to deposit-taking per se and that the scheme operator does not have to apply for an associated banking license. See the example of the eponymous MFS scheme in Kenya, m-pesa, where such a no-objection letter was provided by the Kenyan central bank, in ch 10, s10.2.3.3 titled Application to MFS.

${ }^{94}$ See ch 8.2 titled Philosophies Behind Regulation.

${ }^{95}$ See Apostolik, Donohue and Went (2009) op cit note 6 at 55.

${ }^{96}$ See ch 13, s13.8.3.4 titled Systemic Risks, on the systemic effects of new forms of money and payments.

${ }^{97}$ Banks Act 94 of 1990. See ch 12, s12.3.5 titled Banking Laws and Regulations in South Africa. The first legislation aimed at regulating banks was the Currency and Banking Act of 1920. This was followed by the Banking Act 38 of 1942 and the Banks Act 23 of 1965. For a history of banking legislation in SA, see A Itzikowitz (1992) 'The Deposit-taking Institutions Act 94 of 1990: Its History and Overview of its Main Provisions' 4 SA Mercantile Law Journal at 170. Courts up to that point relied on the Roman law instances of mutuum. See also Equitable Trust and Insurance Co SA Ltd v Registrar of Banks 1957 (2) SA 167 (T); and Schulze (2001) op cit note 22 at 79.

${ }^{98}$ See $\mathrm{s} 1$ of Act 94 of 1990 op cit note 97, the 'Definitions' clause. What is important in this 'deposit' definition are the sets of exclusions in subpar (b)(i).

${ }^{99}$ Malan and Faul (1991) op cit note 19 argue that the Act is more geared towards regulating deposits than it is banks. Banks are overseen inter alia by the Registrar of Banks in South Africa. See ch 12, s12.3.2.1 titled South African Reserve Bank (SARB).
} 
does not make any loans, or if a business provides loans but does not accept deposits, is it carrying on '(any) banking business'? ${ }^{100}$

Taking funds and lending are not necessarily siren indications of deposit-taking and intermediation leading to the 'business of banking', especially where it may relate to a closed, private club of participants. In the Australian case of Australian Independent Distributors Ltd $v$ Winter ${ }^{101}$ (hereafter AID $v$ Winter),for example, the court held that the society was not carrying on the business of banking when it lent to its members for the purpose of acquiring land or buildings. ${ }^{102}$ The court reasoned that the society was not carrying on the business of banking as it did not accept deposits from the public, but only from members. Ellinger, however, believes that this case was wrongly decided as it was as easy to join the society as it was to become a customer of a bank. ${ }^{103}$ The parallels to a closed-loop MFS system are manifest, however.

Similarly, there is the very curious case of Australian Prudential Regulation Authority v Siminton ${ }^{104}$ where an 'independent state declared' within Australia created what it termed its own bank, called Terra Nova Cache. ${ }^{105}$ It accepted deposits and indicated that a depositor became an 'owner' of the bank. Further, with the exception of one single short-term facility, Terra Nova Cache made no loans. ${ }^{106}$ Tyree believes that had Terra Nova not made that single loan, its defence of the closed, members-only substratum of banking would have been effective. ${ }^{107}$

There appears then to be some room for equivocation in the deposit concept that may require a rethink of its nature and role. The role of MFS in pursuing this rethinking is discussed in later sections.

It is trite that for any bank to operate, it needs customers. Indeed the essential elements of a banker's business or the 'business of banking' as it was termed in $U D T^{108}$ has been said to be the maintenance of

\footnotetext{
${ }^{100}$ Tyree (2008a) op cit note 17.

${ }_{101}^{1}$ Australian Independent Distributors Ltd v Winter(1964) 112 CLR 443 (hereafter AID v Winter).

${ }^{102}$ In fact, none of the society's money was used for making loans.

${ }^{103}$ Ellinger, Lomnicka and Hooley (2006) op cit note 18 at 70.

${ }^{104}$ Australian Prudential Regulation Authority v Siminton (No 6) [2007] FCA 1608.

${ }^{105}$ Briefly, Siminton established a 'country' called the 'Principality of Camside' by registering it as a business name. The Principality then made a 'Formal Declaration of War' against the Commonwealth of Australia which was ignored by the Commonwealth government. The 'country' became host to the Terra Nova Cache Bank. It was alleged by the Australian banking regulator, ARPA, that Siminton had contravened the Banking Act 1959 (Cth) by taking deposits and lending monies. For a discussion of this case, see V Hajenko (2008) 'Tell "Him He's Dreaming!" - The Constitution, Banking Business \& The Vibe' 77 Client Information Bulletin, June, available at http://goo.gl/8MfOj.

${ }^{106}$ On appeal in Siminton v Australian Prudential Regulation Authority [2008] FCAFC 88 it was held that a single loan was sufficient to establish that Terra Nova Cache had engaged in the business of banking.

${ }^{107}$ Tyree (2008a) op cit note 17. As Bollen (2006) op cit note 51 at 288 notes, in Australia, for historical reasons, only those institutions that both take deposits and make loans were required to be licensed as banks and the US courts have taken a similar approach.

${ }^{108}$ See also Wadsley and Penn (2000) op cit note 11 at 96.
} 
current accounts and the collection of cheques 'for customers' in relation to a bank's role as a payment facilitator. $^{109}$

There is however no statutory definition of a 'customer'. At common law it has been held that for someone to be a customer of an entity operating as a bank, a 'continuing relationship of some duration was required and sufficient to form the relationship ${ }^{, 110}$ and, therefore, 'if there is no account and no intention to open an account, then that person is not a customer. ${ }^{, 111}$ The customer relationship usually begins upon opening an account, ${ }^{112}$ although generally the bank may, with reasonable notice, terminate the relationship. ${ }^{113}$ Further, as has been noted above, banking law is not an autonomous branch of the law, but one which consists of and should be explained on the basis of the general law of obligations and the law of things. ${ }^{114}$ Thus the legal relationship between a bank and its customer is based on the contract between the customer and the bank, ${ }^{115}$ and that contract is dependent on the continued licensing of that bank in terms of applicable legislation and, as such, the contractual relationship cannot continue unchanged when the recognition of the bank by statutory authorities is withdrawn. ${ }^{116}$

Generally though, the relationship between a bank and its client should be explained in terms of these general principles, and in particular, the principles of contract and delict. ${ }^{117}$ However, the nature of the contract between banker and customer in relation to the customer's account is said to be complex and multifaceted, varying according to the particular banking function that is being analysed. ${ }^{118}$

\footnotetext{
${ }^{109}$ UDT op cit note 10.

${ }^{110}$ Mathews v Williams, Brown and Co (1894) 10 TLR 386 (N); Ladbroke v Todd (1914) 30 TLR 433 (K); Commissioners of Taxation v English, Scottish and Australian Bank [1920] AC 683; AIR 1920 PC 88 (L) (hereafter Taxation); Savory and Co v Lloyd's Bank Ltd (1932) 48 TLR 344 (M). A bank can itself be the customer of another bank. See Importers Co Ltd $v$ Westminster Bank [1927] 2 KB 297.

${ }_{111}^{11}$ Great Western Railway Co Ltd v London and County Banking Co Ltd [1901] AC 414.

${ }^{112}$ Taxation op cit note 110.

${ }^{113}$ See Joachimson op cit note 78 where it was said that:
}

'... the banker will not terminate the relation[ship] without giving the customer reasonable notice.'

This Reasonable Notification' was held in Prosperity Ltd v Lloyds Bank. Ltd [1923] 39 TLR 372 to be at least one month's notification. In Bredenkamp v Standard Bank of SA Ltd (599/09) [2010] ZASCA 75 (hereafter Bredenkamp), it was held in par 9 that

'[i]t was a term of the contract pursuant to which the banker/customer relationship was established that the bank was entitled to terminate any account or facility which may have been extended to the applicant for any reason on reasonable notice. Under and in terms of the contractual term the bank needed no reason to exercise the right of termination other that its own desire to terminate.'

On death, it is assumed that when the bank receives notification, the account is terminated. If an entity is dissolved, it is assumed when a company or partnership breaks up and the bank receives notification that the account is terminated. See Russian Commercial and Industrial Bank [1955] Ch. 148.

${ }^{114}$ See Schulze (2002) op cit note 19 passim; WG Schulze (2006) 'Delictual Liability of a Bank Towards Its Client: A New Prominence Given to the Element of Causation' Tydskrif vir die Suid-Afrikaanse Reg 834; Wadsley and Penn (2000) op cit note 11 at 103; Pretorius (2008) op cit note 75 at 51.

${ }_{115}$ Strydom v ABSA Bank Bpk 2001 (3) SA 185 (T) 192H-193B.

116 J Moorcroft (2010) Banking Law and Practice at 15.1, citing Registrar of Banks v Transafrica Credit and Savings Bank Ltd 1963 (2) SA 687 (C). The corollary, it is submitted, is not necessarily true: an entity without statutory recognition as a licensed bank, but which has customers, does not necessarily incur the same obligations to a customer that a licensed bank may have to its customers, nor do the protections which would normally fasten on the entity and its customers necessarily involve those which would obtain if the entity was indeed a licensed bank.

${ }^{117}$ For an example of a cause of action against a bank in terms of delict, see First National Bank of Southern Africa Ltd $v$ Duvenhage 2006 (5) SA 369 (SCA).

${ }^{118}$ RM Goode (1995) Commercial Law at 591. 
Incident to being a bank at common law is that certain obligations fasten on the bank, and correspondingly, on the customer. ${ }^{119}$ Indeed, it is said that there exists a special relationship between the customer and the bank, in which both owe one another duties of care. ${ }^{120}$ In particular, there is the common law duty of care that rests on a bank not to cause damage to its client through negligence. ${ }^{121}$ These reciprocal rights and duties of the parties are based to a great extent on custom and usage ${ }^{122}$ and, as such, there is continuous debate on the nature of the relationship with regard to whether the bank acts as a mandatory or agent on behalf of its client or as something else. ${ }^{123}$ In all, the relationship has been described as one that is 'conspicuously complex', ${ }^{124}$ and concomitantly the legal scholarship on this is divided. ${ }^{125}$

As far as the legal relationship between the customer and bank is concerned, it has been held that the relationship is governed by contract, and that there is only one contract that governs the general relations between the parties in terms of all the services a bank is bound to provide if asked by the customer, although separate contracts may be entered into for specific purposes like credit cards. ${ }^{126}$

While Foley clearly indicated that, in relation to the deposit of money, the bank-customer relationship is that of debtor and creditor, there are nevertheless many issues regarding the relationship which cannot be characterised or solved by the debtor-creditor theory alone. ${ }^{127}$ The situation is said to be a little more complex than just that nexus. Indeed, Foley also held that a bank has 'superadded obligations' to the

\footnotetext{
${ }^{119}$ The reason for knowing what is a 'bank' is to determine the nature of a specific relationship that may distinguish it from other relationships. There are a number of incidences that obtain once that 'banking' contractual relationship is identified, such as a special relationship of confidence and secrecy and as debtor/creditor, maintenance of an account (usually a current account), where mandates have been given. See ch 4, s4.5.2 titled Nature of the Relationship and Duties. However, not everyone who operates a repayment system is a banker. See GA Penn, AM Shea and A Arora (1987) The Law Relating to Domestic Banking: Banking Law (Vol 1) at 25-26. As Goodhart, CAE (1989) Money, Information and Uncertainty $2^{\text {nd }}$ ed at 40 notes wryly, there is a well-known maxim displayed in many English pubs which captures the essence of the banking relationship: 'We have an agreement with our bank: We do not cash cheques and they do not sell beer'.

${ }^{120}$ A bank may also be a customer of another bank, for example, where a bank provides clearing and settlement services for a bank that is not able to do so, or where a bank provides services to a foreign bank as a correspondent. Wadsley and Penn (2000) op cit note 11 at 97-98. See also Peterson and Another v ABSA Bank Limited [2011] ZAGPPHC 127, $24067 / 2010$ (27 July 2011) in which Makgoba $J$ said in par 46 in relation to the duty of care of a bank that ' $[w]$ hen considering the existence of a legal duty on the part of a bank (particularly a novel duty) evidence will ordinarily be necessary to appreciate fully considerations of policy and convenience'. In relation to the delictual liability of a bank due to negligence, see ch 7, s7.3.6.5.3 titled The Bank.

${ }^{121}$ See Schulze (2006) op cit note 114, and the discussion therein of Duvenhage op cit note 117 in relation to duties of care a bank may have to its customer and delictual liability that may follow. See ch 7, s7.3.6.5.3 titled The Bank on the allocation of fault with respect to banks.

${ }^{122}$ Moorcroft (2010) op cit note 116 at 15.1 .

${ }^{123}$ This may depend on the services being offered, which may include depositum, mutuum or agency, or deposit irregular. For an overview of some of these terms, see Schulze (2001) op cit note 22 at 78.

${ }^{124}$ As described by Moseneke AJ (as he then was) in Standard Bank of SA Ltd v ABSA Bank Ltd 1995 (2) SA 740 (T) 746 G$\mathrm{H}$.

${ }^{125}$ For a selection of South African cases that describe the practical incidents of the banker-customer relationship, see Indac Electronics (Pty) Ltd v Volkskas Bank Ltd 1992 (1) SA 783 (A); Kwamashu Bakery Ltd v Standard Bank of South Africa Limited 1995 (1) SA 377 (D); Columbus Joint Venture v Absa Bank Ltd 2002 (1) SA 90 (SCA); Bredenkamp op cit note 113; Commissioner South African Revenue Service v ABSA Bank Limited 2003 (2) SA 96 (W); Siman and Co (Pty) Ltd v Barclays National Bank Ltd 1984 (2) SA 888 (A); Nashua Mobile (Pty) Ltd v GC Pale CC t/a Invasive Plant Solutions (A3044/2010) [2010] ZAGPJHC 112 (18 November 2010); Lillicrap, Wassenaar and Partners v Pilkington Brothers (SA) (Pty) Ltd 1985 (1) SA 475 (A); Thoroughbred Breeders' Association v Price Waterhouse 2001 (4) SA 551 (SCA); Lloyd-Gray Lithographers (Pty) Ltd v Nedcor Bank Ltd t/a Nedbank 1998 (2) SA 667 (W); Holscher v ABSA Bank 1994 (2) SA 667 (T).

${ }^{126}$ Wadsley and Penn (2000) op cit note 11 at 104. Pretorius notes that a customer's underlying contractual relationship is with the bank, not the branch; see Pretorius (2008) op cit note 75 at 51.

${ }^{127}$ A Sese (2004) 'The Fiduciary Relationship between a Bank and Customers' 4 Shinshu Law Review 185-200 at 189, available from http://goo.gl/Mcnoq.
} 
customer, which in Joachimson, the court said revolved around a number of implied terms ${ }^{128}$ of the bankercustomer contract. ${ }^{129}$ Of the implied terms, the bank may be acting in the capacity of the customer's agent, or acting under mandate. ${ }^{130}$ It appears that the nature of these obligations depends on the context, ${ }^{131}$ and as such there is still some scholarly dispute as to the relationship, which may also be described as multifaceted. ${ }^{132}$

Ellinger, as well as Cowen and Gering, say the relationship may be sui generis, ${ }^{133}$ while Willis indicates that the contract of mutuum $^{134}$ is the clearest representation of the banker-client relationship. ${ }^{135}$ Malan and Pretorius say that the contract between the bank and client is mandatum, such that the bank must deliver services to the client based on that mandate. ${ }^{136}$ If there are loans or deposits at play, then a debtor-creditor relationship arises to facilitate the execution of the mandate between the parties. ${ }^{137}$ Further, Wadsley and Penn say that the bank is acting as an agent of the customer as a result of the implied terms that characterise

\footnotetext{
${ }^{128} N$ Joachimson op cit note 78 . The implied terms are, namely, to: receive money and collect bills and cheques; the bank borrows and undertakes to repay upon the demand of the customer; the promised repayment at the branch where account is held has been superseded by electronic banking; conform strictly with customer's mandate; pay and dishonour cheques; obey counter demands; secrecy; reasonable notice when changing terms or terminating the relationship; duty of care when dealing with the operation of accounts, and when dealing with cheques and with regards to advice and information. In Libyan Arab op cit note 37, Staughton J held that banks habitually provide standing order direct debits, banker's drafts, automatic cash tills and forex.

${ }^{129}$ These however reflect the implied terms of the time in which the judgement was written. As Ellinger, Lomnicka and Hooley (2006) op cit note 18 point out, courts may be reluctant to enforce these implied terms as they may not be well known to the customer. However it is now common practice for a customer to sign a bank mandate when opening an account and this will contain some express terms of the contract. See Joachimson op cit note 78 at 127 per Atkin LJ; Ellinger, Lomnicka and Hooley (2006) op cit note 18 at 124-5; and Wadsley and Penn (2000) op cit note 11 at 103-107.

${ }^{130}$ The duties also include monitoring debits and credits, the duty of a customer to read statements, and the obligation of a banker to act only on the basis of the customer's mandate. Akindemowo (2009) op cit note 82 at 345.

${ }^{131}$ The right to demand money however only exists where there is a current or savings account which provides for payment at call; see Ellinger, Lomnicka and Hooley (2006) op cit note 18 at 124.

${ }^{132}$ As Wadsley and Penn (2000) op cit note 11 at 103 point out, banking law is not an integral and distinctive body of law in itself, but applies to a range of branches of law, such as delict (tort), contract, trusts, and a technical manifestation in laws relating to negotiable instruments and cheques. For a further exposition on banking law, see also De Jager (2010) op cit note 22 passim; Schulze (2002) op cit note 19 passim; and S Heffernan (2005) Modern Banking at 1 and 41-45.

133 Sui generis means that the relationship does not fit into any recognised category. See Ellinger, Lomnicka and Hooley (2006) op cit note 18 at 124, and DV Cowen and L Gering (1985) The Law of Negotiable Instruments in South Africa at 36636. See also the comments by Stegmann J in GS George Consultants and Investments Ltd v Datasys Ltd 1988 (3) SA 726 (W) at 735B cited by Moorcroft (2010) op cit note 116 at 15.4, to the effect that the bank-client contact is part of the law merchant and one of sui generis, but which does not exclude the possibility that it is fundamentally one of mutuum with a number of superadded features, including secrecy.

${ }^{134} \mathrm{~N}$ Willis (1981) Banking in South African Law at 31.

${ }^{135}$ Schulze explains that when the bank lends money to the client in terms of an overdraft facility, the contract is one of mutuum. In terms of this contract of mutuum the bank acts as lender and the client as borrower. See Schulze (2006) op cit note 114 at 835. See also FR Malan (1978) 'Professional Responsibility and the Payment and Collection of Cheques' 11 De Jure at 326, which raises the possibility of the delictual liability of collecting banks.

${ }^{136}$ FR Malan, JT Pretorius and SF du Toit (2009) Malan on Bills of Exchange, Cheques and Promissory Notes $5^{\text {th }}$ ed at 279. See also Standard Bank of SA Ltd v Oneanate Investments (Pty) Ltd 1995 (4) SA 510 (C) (hereafter Oneanate) where Selikowitz J, with reference to South African and foreign legal authorities stated at 530G-H that:
}

\begin{abstract}
'The law treats the relationship between banker and customer as a contractual one. The reciprocal rights and duties included in the contract are to a great extent based upon custom and usage. Although historically the original objective of a depositor was to ensure the safekeeping of his money, over time jurists have considered characterizing and explaining the basic relationship as one of depositum, mutuum or agency. All of these approaches have on analysis proved to be inadequate. It is now accepted that the basic, albeit not sole, relationship between banker and customer of a current account is one of debtor and creditor.'
\end{abstract}

This case was cited with approval in Liebenberg v ABSA Bank Limited t/a Volkskas Bank [1998] 1 All SA 303 (C) at 308-309 and in ABSA Bank Bpk v Janse Van Rensburg 2002 (3) SA 701 (SCA) at 709A-B.

${ }^{137}$ The locus classicus is Foley op cit note 66 where it was held that 'bankers are debtors ... with superadded obligations'. The deposit may have the following key characteristics: it is a contract of bank debt owed to the account holder after consideration is paid to the bank by the putative depositor. 
the relationship, ${ }^{138}$ but there may be elements of mandate (mandatum) and agency, among other elements, depending on what services are being offered by the bank to a particular client. ${ }^{139}$

Where a bank is acting as an agent, its duties depend partly on what it has undertaken to do and otherwise may be implied from the circumstances. ${ }^{140}$ Further, whatever the pecuniary status of the account, the bank still acts as the accountholder's agent in relation to carrying out the client's instructions in making a payment. ${ }^{141}$ The parties may vary their agreement and enter into special arrangements with one another and third parties ${ }^{142}$ but the terms of the contract must however be interpreted to determine the rights and obligations that follow from it ${ }^{143}$ and within the precepts of the commercial and factual setting as well as any requirements imposed by law. ${ }^{144}$ This is especially so where the same set of facts between the client and bank may give rise to a number of varying contracts. ${ }^{145}$

Generally, though, the bank must act prudently in dealings that relate to its customer, a need which arises from aspects of the contract, be they the naturalia or some other tacit term. ${ }^{146}$ It is the duty of a financial institution to maintain its customer's accounts, which in some electronic money systems may be difficult to do when an access system is not used and value is stored instead on a device - like the Near Field Communication (hereafter NFC) phone - that is not always online and available, if at all. The duty of care thus becomes difficult if not impossible to fulfill. ${ }^{147}$

\footnotetext{
${ }^{138}$ These implied terms, they say, were enumerated in Joachimson op cit note 78, and which are based on the dictum in Foley op cit note 66 that a bank has a 'superadded obligation arising out of the custom of bankers to honour the customer's drafts'. See Wadsley and Penn (2000) op cit note 11 at 107.

${ }^{139}$ In addition, there may be contracts of deposit, depositum, deposit irregular, mutuum, and debtor and creditor.

${ }^{140}$ Wadsley and Penn (2000) op cit note 11 at 107.

${ }^{141}$ Moorcroft (2010) op cit note 116 at 15.6 citing Oneanate op cit note 136 at 531B. Where acting as an agent, the bank must not permit any conflicts between its own business interests as a commercial enterprise and its duties to the account holder. See Estate Ismail v Barclays Bank (DC and O) 1957 (4) SA 17 (T) at 26D-E.

${ }^{142}$ Oneanate op cit note 136 at $532 \mathrm{D}-\mathrm{E}$.

${ }^{143}$ Moorcroft (2010) op cit note 116 at 15.2 .

${ }^{144}$ Ibid, citing Harms JA in Berzack v Nedcor Bank Ltd 2001 (1) SA 410 (A) in pars 2 and 10 and Pratt $v$ First Rand Bank (416/07) [2008] ZASCA 92, both in connection with abiding by exchange control regulations.

${ }^{145}$ Schulze (2006) op cit note 114 at 835 gives the example of a client applying for a loan from the bank to finance the purchase of immovable property, and the bank undertakes to arrange for a bond to be registered over the immovable property to secure the loan. Here two types of contract come into being, the first being one of mutuum once the loan is approved and the money paid over to the creditor of the client and the second a contract of mandate where the bank undertakes to arrange for the loan and the bond to be registered.

${ }^{146}$ Moorcroft (2010) op cit note 116 at 15.3, citing Harms JA in Berzack v Nedcor Bank Ltd (2001) SA 410 (A) in par 10. See also David Trust v Aegis Insurance Company Ltd 2000 (3) SA 289 (A) in par 20-21 where Nienaber JA said in relation to the contract of mandate:
} 'It is one of the naturalia of each such contract, as it is of contracts of mandate in general, that the mandatory is obliged, first, to
perform his functions faithfully, honestly, and with care and diligence and, secondly, to account to his principals for his actions.'

Insofar as there is a need for good faith on the part of the parties to the bank and customer, the appellate division rejected the notion of utmost good faith, holding that there are no levels of good faith insofar as someone has acted either in good faith or in bad faith. See Mutual and Federal Insurance Co Ltd v Oudtshoorn Municipality 1985 (1) SA 419 (A). There is a standard of care required that is measured according to that which a reasonable person (diligens paterfamilias) would exercise in the same situation. See JT Pretorius (2002) 'New Bank Accounts and the Collecting Bank' 14(1) SA Mercantile Law Journal at 93.

${ }^{147}$ This duty presupposes that e-money is acting in an account-based paradigm. A Tyree (2000) 'The Legal Nature of Electronic Money', available at http://goo.gl/wcLhJ, citing as authority Lloyds Bank Ltd v Brooks [1950] 6 LDAB 161; Kepitigalla Rubber Estates Ltd v National Bank of India Ltd [1909] 2 KB 1010; see also Akindemowo (2009) op cit note 82 at 54; A Ramasastry (2005) 'Nonbank Issuers of Electronic Money: Prudential Regulation in Comparative Perspective' in Current Developments in Monetary and Financial Law at 663-707, generally, on the difficulties of 'off-line' account handling. 
The nature of the relationship though must constantly be re-evaluated in relation to expanded services offered as a result of advances in commerce and technology. ${ }^{148}$ The duties of care may extend to non-banks providing quasi-bank functions and to their agents and correspondents. ${ }^{149}$

\section{6}

\section{Summary and Analysis}

Monetary 'deposits' remain one of the most salient if not decisive indications in many jurisdictions in determining whether or not an entity is engaging in banking activity, or the 'business of banking'. There is no de minimus measure of what those deposits nominally need to be, such that even small amounts so deposited or paid into an account of sorts may trigger deposit analogies, even if that entity's main business based on aggregate transactions and profit - is not financial intermediation but rather, as in the case of MNOs for example, the provision of telecommunications services.

In terms of common law, the understanding of what is a 'bank', a 'banker', or the 'business of banking' usually depends on context and may be defined (and refined) by statute. These coexist in the sense that the common law and primary statutory definitions of banking in domestic law are 'complementary' for where the common law proclaims that a 'bank' is an entity engaged in the 'business of banking', a statute may provide the important detail by defining exactly what the 'business of banking' entails. ${ }^{150}$

However, whether an entity is a bank and, therefore, whether it owes its customer a duty of care, may not be entirely certain. The reason for this lack of clarity is that even those statues which refer obliquely if not explicitly to customers and banks, what constitutes a bank and the 'business of a bank' are couched in functional descriptions of the activities of an entity, for example, whether the entity takes in monies in a process that can amount to its being legally described as a deposit, and if the associated activity can be seen as the license-requiring activity of 'deposit-taking'.

Thus, given the multitude of prospective service providers involved in taking funds from the public, the bespoke legal and commercial categorisations whereby companies could be resolutely classified into silos that broadly represent their core financial business are becoming blurred.

This is especially pertinent to those service providers engaged in MFS who may take redeemable and nonredeemable funds and who may ultimately be classed as being involved in deposit-taking - and thus determined to be 'banks' and would require all manner of licensing and regulatory oversight.

\footnotetext{
${ }^{148}$ Oneanate op cit note 136 at 531B.

149 The incidentalia of this then relate to the special relationship that can be said to exist between banker and customer. It is not clear whether the incidents of this 'special relationship' are excluded in the express terms of a contract by an entity when it can be said that the entity is not a bank.

${ }^{150}$ See similarly in relation to the effect of e-money on the business of banking and the traditional core activities identified in UDT op cit note 10, WG Schulze (2004c) 'Smart Cards and e-Money: New Developments Bring New Problems' 16(4) SA Mercantile Law Journal at 712, who says with some latent urgency that the traditional definition of a bank as formulated in UDT op cit note 10 'needs to be revised, sooner rather than later'.
} 
Further, the 'usual characteristics of a bank are not its sole characteristics' ${ }^{151}$ Ultimately, the import of this is to extend the potential characteristics that could be considered when determining whether an entity is engaging in the 'business of banking'.

In the modern MFS context, there is a danger that modern payment schemes could be captured. However, a deposit is not a payment: a deposit of funds gives the depository the right to use the depositor's money until it is called for by the depositor or another authorised person, while a payment occurs when a debtor transfers funds to a creditor to extinguish an existing debt.

The introduction of these new entities and their focus on taking user funds not for intermediation purposes but primarily and narrowly for payments speaks to the broader issue of (re)defining the traditional concepts of the 'business of banking' and the 'deposit'.

The question that then (still) arises is: Does a MFS scheme amount to deposit-taking and, if so, is this form of deposit taking tantamount to the business of banking and does it therefore give rise to the normal incidences of the bank-customer relationship, even though the primary business of the entity is that of telecommunications provider?

It would appear, therefore, that in relation to Problem Statements 2 and $3,{ }^{152}$ the nature of MFS transforms the core aspect of 'deposit' into a mere and somewhat transient source for the primary use of making payments, and signifies that the 'business of banking' is becoming so stratified that the 'deposit' as we know it and its nexus with the core 'intermediary' role of bankers may no longer be the pivot around which the 'business of banking' coalesces.

Specifically it is the subjective policy assessment using 'time' as the metric of whether funds provided to an entity amounts to a deposit and the resultant inconsistency that triggers this review. ${ }^{153}$

Payment Systems And Instruments, And Their Regulation

\section{Evolution of Payments}

The preferred method of payment from biblical times has been cash. ${ }^{154}$ As trade expanded, the need for safer alternatives to transporting large amounts of cash increased. The draft or bill of exchange was developed by the merchants of the $14^{\text {th }}$ century. Merchants used these drafts to pay for goods in other countries. $^{155}$

\footnotetext{
${ }^{151}$ Denning $\mathrm{J}$ in $U D T$ op cit note 10 at 453.

${ }^{152}$ See ch 1 , s1.8 titled Overview.

${ }^{153}$ See ch 4, ss 4.9 titled Application to MFS and 4.10 titled Summary and Conclusions.

${ }^{154}$ See Matthew op cit note 56.

155 The draft could also be used through a series of money changers in the same, or another, city that would pay out the amounts to the payee for personal payments.
} 
During the late 1800s and early 1900s, postal savings institutions, commercial and savings banks, and credit cooperatives set up their own separate funds transfer system called ' giros ${ }^{156}$, followed by cooperative agreements between postal and bank 'giros'. This arrangement for the transfer of money was the genesis of what ultimately became known as payment systems, ${ }^{157}$ which may on a less formal basis, be considered as a set of arrangements recognised by society for the transfer of wealth.

In the late 1960s and early 1970s, the system of 'wages to banks' was established whereby employers paid wages directly into the bank accounts of their employees and this dramatically increased the use of bank and postal account transfers. This development has its roots in the banking structure and activities of European banks, and the earlier establishment of the giro system for the safe transfer of funds.

There is a hierarchy in electronic payments, broadly high value and lower value. The former is usually a national system, while the latter may be lower values and possibly even small, 'micro-payments'.

\footnotetext{
${ }^{156}$ The word is derived from the Greek word for 'circle'. Nowadays the Giro is seen as a method of payment associated with electronic funds transfer based on 'credit transfer', or 'push' transactions whereby the payer directs a payment intermediary or bank to transfer funds from the payer's account to the payee's account at the same or another bank. It also represents a General Interbank Recurring Order, also known as a 'wire transfer' in North America. For a discussion on the Giro and related terminology, see EP Ellinger (1986) 'The Giro System and Electronic Transfers of Funds' Lloyd's Maritime and Commercial Law Quarterly at 178.

${ }^{157}$ Ibid. See further on payment systems,Bank of Japan (2008) 'Outline of Payment and Settlement Systems, and Market Infrastructures', available at http://goo.gl/OPcqY; Bank for International Settlements (BIS) (1996) 'Implications for Central Banks of the Development of Electronic Money' 1-20, available at http://goo.gl/TxTnD; BIS (1997) 'Real-Time Gross Settlement Systems' Report prepared by the Committee on Payment and Settlement Systems of the Central Banks of the Group of Ten Countries, available at http://goo.gl/OUwkx; Committee on Payment and Settlement Systems (CPSS) and Bank for International Settlements (BIS) (2001) 'Core Principles for Systemically Important Payment Systems', CPSS Publications No 43, January, available at http://goo.gl/nxWH3, available at http://goo.gl/nxWH3; Committee on Payment and Settlement Systems (CPSS) (2003a) 'A Glossary of Terms used in Payments and Settlement Systems', available at http://goo.gl/ppxSi; European Central Bank (ECB) (2009a) 'Payment System' Glossary of Terms Related to Payment, Clearing and Settlement Systems, available at http://goo.gl/8E19w; M Fajfar (2004) 'Role and Security of Payment Systems in an Electronic Age' Remarks prepared for IMF Institute Seminar on Current Developments in Monetary and Financial Law at 9, available from http://goo.gl/BPHIs; B Geva (2007) 'Recent International Developments in the Law of Negotiable Instruments and Payment and Settlement Systems' at 685, available at http://goo.gl/MpW9G; B Geva (2008a) 'Payment Finality and Discharge in Funds Transfers'83(2) Chicago-Kent Law Review 633-675, available at http://goo.gl/jruIS;Institute of Technology Assessment of the Austrian Academy of Sciences (ITA) (2005) 'Institutional Change in the Payment Systems by Electronic Money Innovations: Implications for Monetary Policy' at 7, available at http://goo.gl/Znj3S; V Lawack-Davids (2008) 'Legal and Regulatory Framework Pertaining to National Payment System (NPS): Peeling the Layers of the Onion' 29(3) Obiter at 453; VA Lawack-Davids (2011) 'Mind the gap - increasing compliance - burden and regulatory misalignment' Obiter 32(2) 712730; WH Lawrence (2002) 'Understanding Negotiable Instruments and Payments Systems', available from http://goo.gl/dmI2j; P Lowe (2007) 'Non-Banks in the Payments System: A Central Bank Perspective' in Federal Reserve Bank of Kansas City Conference on Nonbanks in the Payments System: Innovation, Competition and Risk, available at http://goo.gl/Z24tW; FR Malan and JT Pretorius (2001c) 'The Reserve Bank, Banks, and Clearing Houses in South African Law: Part 1' 13 SA Mercantile Law Journal at 35; TT Mboweni (2006) 'A Historical Review and a Look at the Future Prospects of the National Payments System in South Africa' 10th Anniversary Function of the Payment Association of South Africa, available at http://goo.gl/TMLNl; S Millard and V Saporta (2005b) 'The Future of Payments' 19 Bank of England Financial Stability Review at 59, available at http://goo.gl/JnHMx; South African Reserve Bank (SARB) (2006) 'The National Payment System Framework and Strategy: Vision 2010', available at http://goo.gl/rej7c; S Millard and V Saporta (2005a) 'Central Banks and Payment Systems: Past, Present and Future' Background Paper to the Bank of England Conference on the Future of Payments, May 19 - 20 2005, available at http://goo.gl/uqdDC. See also, generally, C Visser (1989) 'Evolution of Electronic Payment Systems' 1(2) SA Mercantile Law Journal 189.
} 
Developed countries evolved keystone payment systems based on internationally accepted principles such as those established by the Model Law on International Credit Transfers adopted by the United Nations Commission on International Trade Law (hereafter UNCITRAL) in $1992,{ }^{158}$ and later by the Bank for International Settlements (hereafter BIS), the international organisation which serves as a bank for CBs ${ }^{159}$ via its Committee on Payment and Settlement Systems (hereafter CPSS) division. ${ }^{160}$

The CCPS has systemised a 'Payment System' as being either:

(a) a set of instruments, banking procedures and interbank funds transfer systems which facilitate the circulation of money in a country or currency area; or as a synonym for 'funds transfer system'. ${ }^{161}$

The latter 'funds transfer system' is the more current usage and encompasses the economy-wide payment system consisting of the entire web of payment instruments in an economy. ${ }^{162}$ In all, it consists of a number of individual payment systems, which are broadly categorised into two groups: wholesale, and together retail and small value interbank payment systems. ${ }^{163}$ This is distinguished from the Retail Funds Transfer Systems (hereafter RFTS) that handle large volume payments of relatively low value. ${ }^{164}$ A payment system may also be systemically important and known through what the BIS terms 'Systemically Important Payment Systems' (hereafter SIPS). ${ }^{165}$

The metric for risk profile will indicate something as SIPS when, if the system were insufficiently protected against risk, disruption within it could trigger or transmit further disruptions among participants or systemic

\footnotetext{
${ }^{158}$ United Nations Commission on International Trade Law (UNCITRAL) (1992) 'UNCITRAL Model Law on International Credit Transfers', available from http://goo.gl/xf9dg.

${ }^{159}$ Established in 1930, the BIS is the world's oldest international financial organisation. Its customers are central banks and international organisations, although the BIS does not accept deposits from, or provide financial services to, private individuals or corporate entities. It acts as a forum to promote discussion and policy analysis among central banks and within the international financial community. See Bank for International Settlements (BIS) (2011) 'About BIS' at http://goo.gl/fll2Q For a critical overview of its role in world financial market regulation, see C Felsenfeld and G Bilali (2004) 'The Role of the Bank for International Settlements in Shaping the World Financial System’ Fordham School of Law, Pub-Law Research Paper No. 44, available at http://goo.gl/FjlT1.

${ }^{160}$ Such was the need for a coordinated approach to strengthening the financial market infrastructure through promoting sound and efficient payment and settlement systems, that in 1990 the Governors of the central banks of the then Group of Ten (G10) industrialised countries established what is now known as the Committee on Payment and Settlement Systems (CPSS). The CPSS undertakes specific studies in the field of payment and settlement systems. There are a number of developed and developing country central banks who are members of the CPSS, including the South African Reserve Bank. The CPSS also serves as a forum for central banks to monitor and analyse developments in domestic payment, clearing and settlement systems as well as in cross-border and multi-currency settlement schemes. It is also a standard setting body for payment and securities settlement systems. Its 1995 detailed review of payment system developments in the G10 was the first in a series that have become known as 'Red Books'. See generally on the CPSS at http://goo.gl/MEfF7.

${ }^{161}$ CPSS (2003a) op cit note 157.

162 Geva (2001) op cit note 48 at 6 describes a 'Payment System' as being 'a complex set of arrangements involving such diverse institutions as currency, the banking system, clearing houses, the central bank, and government deposit insurance'. See also Section 1 of the South Africa National Payment System Act 78 of 1998 (NPSA) where 'payment system' is defined as 'a system that enables payments to be effected or facilitates the circulation of money and includes any instruments and procedures that relate to the system'.

${ }^{163}$ ITA (2005) op cit note 157 at 1.

${ }^{164}$ See ch 4, s4.8.2.4 titled Retail Funds Transfer Systems on EFTs.

165 BIS (2001) op cit note 157. Risks emanating from the settlement of payment-related activities increasingly became of particular concern to central banks, highlighting the credit and liquidity risks to which participants in the payment system were exposed.
} 
disruptions in the financial area. ${ }^{166} \mathrm{~A}$ banking crisis where liquidity was at issue could similarly cause a systemic breakdown. ${ }^{167}$

\subsection{2}

\section{Hierarchies of Payments}

\subsubsection{1}

\section{Overview}

While each nation has its own rules for payment systems, they are generally based on the international principles developed by the CPSS and UNCITRAL and which characterise a hierarchy of banking and payment systems in a country, with the control of the diverse systems involved in the systematic transfer of money and value falling under the auspices of the $\mathrm{CB}$ (hereafter $\mathrm{CB}$ ) at the apex of these systems. ${ }^{168}$ The CBs control and monitor the activities of the national banks within their jurisdictions, as well as ancillary networks that provide for the movement of funds in structured and associated payment networks like Visa and MasterCard and their affiliates. ${ }^{169}$

\subsubsection{Payment: The Process of Verification, Clearing, Settlement and Netting}

The modalities of a payment can be described by examining the authorisation and authentication process and then the clearing and settlement processes, in turn. ${ }^{170}$

At a generic level, a payment system must have three basic elements. ${ }^{171}$

Firstly, there must be a Store of Value (hereafter SOV) that can be accessed from which the payment value can be drawn.

Secondly, a system for exchanging payment instructions between institutions, a process usually known as clearing (arrangements), must be present. ${ }^{172}$ Clearing requires the creation, validation and transmission of a payment instruction, which can be broadly - as it may depend on the form of payment being utilised ${ }^{173}$ divided into verification and authentication of the identity of the parties involved, validation of the payment instrument, verification of the ability to pay, authorisation of the transfer of the funds by both the payor and the payor's financial institutions, communication of the information by the payor's financial institution to the payee's financial institution and the actual processing of the transaction.

\footnotetext{
${ }^{166}$ See further ch 8, s8.4.2.2 titled Payment Regulation.

${ }^{167}$ The 'Great Recession' as it was termed began in 2007. See P Krugman (2012) End This Depression Now! at 4.

168 Also known in this position as the proto Bank. See ch 3, s3.4.2 titled Barter and Commodities on a discussion of the hierarchies of money; and ch 3, s3.5.3.4 titled Prototypical Bank: Store of Deposits.

${ }^{169}$ See Millard and Saporta (2005b) op cit note 157 at 59.

${ }^{170}$ For general views of the payment, settlement and clearing process, see Geva (2001) op cit note 48 at 3; Malan and Pretorius (2001c) op cit note 157 at 35; Visser (1989) op cit note 157; Lawack-Davids (2008) op cit note 157.

${ }^{171}$ See Lowe (2007) op cit note 157.

${ }^{172}$ The exchange of information about payments entered into the system. J McAndrews (1997) 'Banking and Payment System Stability in an Electronic Money World' Working Paper No 97-9, available at http://goo.gl/SwPqq.

${ }^{173}$ The structure of such steps varies considerably with the type of payment instrument and in practice the steps may not be performed sequentially.
} 
Thirdly, the value must be moved from one account to another, a process known as settlement. ${ }^{174}$ The settlement may be achieved within the same payment environment - such as the same bank if the payor (sender) and payee (recipient) are clients of the same bank, or of the same closed walled garden (non-bank) system - in which case it is known in banking parlance as 'on-us payments'. ${ }^{175}$ The process whereby one bank settles its obligations against another bank in an exchange of obligations is called 'netting', with the net amount due being paid over - via the national payment system - to the bank to whom it is ultimately due. $^{176}$

Not too long ago, as Lowe ${ }^{177}$ notes, all these functions were almost always the exclusive preserve of banks; but with the advent of technology and private closed loop payment systems, non-banks are increasingly able to perform some or all three functions, especially where they utilise their own 'private currencies' which never need to 'touch' or involve a national payment system. MFS SVPs are obvious candidates. These technology providers may however simply be the technology facilitators, acting as System Operators (hereafter SOs) as they are sometimes known. ${ }^{178}$

\subsubsection{High Value Payment Systems}

\subsection{National Payment Systems}

As noted above, national payment systems are those national systems designed to facilitate payments via all national systems (usually) through the CB of a country. ${ }^{179}$ Known broadly as large-value funds transfer systems, ${ }^{180}$ these inter-bank funds transfer systems are at the apex of the hierarchy of payment in a country, being the arrangements through which funds transfers are made between banks for their own account or on behalf of their customers. It usually links a CB to national and even supra-national payment systems. ${ }^{181}$ The means by which monetary value is transferred is thus inextricably linked between these two systems and

\footnotetext{
${ }^{174}$ The Bank of Japan describes settlement as an economic transaction that involves the exchange of money or securities. Cash and deposit money are settlement assets that are exchanged in settlement. See Bank of Japan (2008) op cit note 157. An interbank settlement process may be seen as the completion of a transaction wherein the seller transfers securities or financial instruments to the buyer and the buyer transfers money to the seller. A settlement may be final or provisional. BIS (2003) op cit note 157 at 47

${ }^{175}$ As Lawack-Davids (2008) op cit note 157 explains at 464: 'on-us payments' refer to payment obligations that arise within the same bank and do not lead to inter-bank settlement. 'On-us' could also refer to intra-bank/entity cleaning arrangements. See also SARB (2006) op cit note 157, in par 3.4.2.11.

${ }^{176}$ In some cases there may be only one institution doing the clearing and settlement, in which case they may be known as a Clearing and Settlement Institution (CSI).

${ }^{177}$ Lowe (2007) op cit note 157 passim.

${ }^{178}$ System Operators in the context of this chapter are the issuers of the SOV. In South Africa, System Operators, who may be non-banks, have a different context of activity: they operate within the NPS and provide payment instructions electronically, including the delivery to and/or receipt of payment instructions, to two or more persons to allow such persons to make payments and/or to receive the proceeds of payment instructions. See on SOs ch 12, s12.3.7.4.6 titled Activities and Participants in the Third Layer.

${ }^{179}$ For an overview of the South African National Payment System (SANPS), see Lawack-Davids (2008) op cit note 157.

${ }^{180}$ The ECB (2009a) op cit note 157 defines a large-value payment and settlement system as a:
}

'... funds transfer system through which large-value and high priority funds transfers are made between participants in the system for their own account or on behalf of their customers.'

Although, as a rule, no minimum value is set for the payments they carry, the average size of payments passed through such systems is usually relatively large. Large-value funds transfer systems are sometimes known as wholesale funds transfer systems.

${ }^{181}$ See, for example, the EU Payment Services Directive 2007/64/EC (hereafter PSD) in ch 9, s9.6.2 titled Payment Services Directive; and the Single European Payment Area (SEPA) in ch 9, s9.8titled Payment Industry Self-Regulation: SEPA. 
mediated by the CB. The large value systems incarnations developed by the BIS are known as Real Time Gross Settlement (hereafter RTGS). ${ }^{182}$ RTGS is a funds transfer mechanism where the transfer of money takes place from one bank to another on a 'real time' and on a 'gross' basis at the (very exclusive) ${ }^{183}$ core of a national payment system. ${ }^{184}$ At this high(er) value, national level, many of the settlement activities described above ${ }^{185}$ are generally inter-bank settlements where the values are settled. This processing of funds transfers involves the transfer of information between the payor and payee banks, initiated by the transmission of a payment order or message requesting the transfer of funds to the payee. ${ }^{186}$ These payment messages may be credit transfers or debit transfers. ${ }^{187}$ The settlement is the actual transfer of funds between the payor's bank and the payee's bank whereby the obligation of the payor bank to the payee bank in respect of the transfer is discharged. ${ }^{188}$ The settlement is final in the sense that it is irrevocable and unconditional when it is recorded on the books of the CB. ${ }^{189}$

Large-value funds transfer systems are usually distinguished from lower-value retail funds transfer systems that handle a large volume of payments of relatively low value in such forms as cheques, Electronic Fund Transfers (hereafter EFTs), automated clearing house transactions and EFTs at the Point of Sale (hereafter POS). ${ }^{190}$ They typically process payments on behalf of bank customers, such as individuals, companies and public authorities. While they may process a large number of payment orders, the value of their individual orders are relatively small and usually not time-critical. As such their failure is not thought to be systemically important insofar as failure could trigger disruptions or transmit shocks across the financial system. ${ }^{191}$

\subsection{Participants in a Payment System}

Usually access to the core of a national payment system that has a SIPS profile is a very exclusive arrangement, with only certain, vetted banks that meet national criteria being allowed into this core, usually known as Clearing and Settlement Institutions(hereafter CSIs). These CSIs in turn may sponsor other banks who may not meet the criteria for membership. Non-banks are very seldom allowed, if ever, to settle in their own name, although there may be nominal provision for them to clear. ${ }^{192}$

\footnotetext{
${ }^{182}$ See Reserve Bank of India (s.d.) 'FAQ', available from http://goo.gl/trb4c.

${ }^{183}$ See the discussion in ch 12, 12.3.7.4 titled Participants in the NPS below on limited access to the South African National Payment System (NPS).

${ }^{184}$ In South Africa, the Real Time Gross Settlement System (RTGS) system employed by the SARB is called South African Multiple Option Settlement (SAMOS). See on SAMOS ch 12, s12.3.7.1 titled Overview.

${ }^{185}$ See description of settlement activities in ch 4, s4.8.2.3 titled High Value Payment Systems.

186 'Gross settlement' means the transaction is settled on a one to one basis without bunching with any other transaction. See International Financial Risk Institute (IFRI) (1997) 'Real-Time Gross Settlement Systems', available at http://goo.gl/3y5V0.

${ }^{187}$ Virtually all modern large-value funds transfer systems are credit transfer systems in which both payment messages and funds move from the bank of the payer (the sending bank) to the bank of the payee (the receiving bank). The payment messages are processed according to predefined rules and operating procedures.

${ }^{188}$ It is usually based on the transfer of balances on the books of a central bank- that is, the GAME.

189 The central institutional characteristics of payment systems concern the means of final settlement in the payment system and its relation to the generally accepted medium of exchange in the economy as well as to characteristics of the Clearing and Settlement Institution (CSI). See Humphrey et al (1996) op cit note 3.

${ }_{190}$ In South Africa, transactions higher than ZAR5mn are deemed to be wholesale or high-value.

${ }^{191}$ See European Central Bank (ECB) (2010b) 'Retail Payment Systems', available at http://goo.gl/QM7Xr. Retail payment systems traditionally cover only one country although the first pan-European automated clearing house was formed in 2003.

${ }^{192}$ See Lawack-Davids (2008) op cit note 157 at 465, who notes that the National Payment System Act now, following 'considerable political pressure to broaden access of this layer to non-banks,' allows for clearing additional system participants. However, as Hawkins concludes, this has not been given any practical consideration as yet. See P Hawkins
} 
Generally speaking, a payment system may consist of components that include a settlement asset, credit arrangements, as well as infrastructure and rules over which monetary value can be transferred. ${ }^{193}$ They need not however be on the scale of inter-bank settlement processes, ${ }^{194}$ as small value payment providers may simply be acting as cash-replacement services for micro-payments. In the large value hierarchy though, the CB usually acts as a settlement agent for disparate payment systems, and will oversee the operations of private systems they may view as systemically important to the overall health of a national payment system. ${ }^{195}$ Banks to whom the CB has extended credit and who have, in turn, lent to other banks will use the monies deposited by other member banks in its reserve for use as the 'settlement asset' of choice for settling the debts of its members. ${ }^{196}$ The $\mathrm{CB}$ in turn mediates clearance and settlement. With electronic representations of or even types of e-money possibly seen as a 'payment system' and possibly impacting on the large-scale settlement values, CBs have focused a wide lens on these emerging technologies and systems to (ostensibly) minimise their risk, or contagion, to all the payment systems they control. In South Africa, at a wholesale payments level involving banks, they are able to pass payments from one bank to another, that is, they are interoperable via BankservAfrica, which serves as an automated clearing house and for the provision of inter-bank electronic transaction switching and settlement services to the South African banking sector.

\subsubsection{Retail Funds Transfer Systems}

\subsubsection{1}

\section{Low Value Payments: Macro-payments}

The European Central Bank (hereafter ECB) defines a RFTS as one which typically handles a large volume of payments of relatively low value. These may include tangible and intangible payment instruments used in a retail setting, such as cheques, promissory notes, traveller's cheques, and EFTs ${ }^{197}$ such as those enabled by debit cards, ${ }^{198}$ credit cards, ${ }^{199}$ credit transfers and direct debits. ${ }^{200}$ In South Africa, credit transactions smaller than ZAR5million (hereafter $\mathrm{mn}$ ) are considered low-value transactions while debit transactions (other than cheques) smaller than ZAR500,000 are deemed to be low-value payment transactions. ${ }^{201}$

(2009) 'Competition in Banking: The Findings of an Inquiry into the SA Banking Sector and Lessons for Namibia', available at http://goo.gl/LFZII.

${ }^{193}$ Millard and Saporta (2005a) op cit note 157.

${ }^{194}$ The BIS defines this as the completion of a transaction wherein the seller transfers securities or financial instruments to the buyer and the buyer transfers money to the seller. A settlement may be final or provisional. CPSS (2003c) 'The Role of Central Bank Money in Payment Systems,' at 47, available at http://goo.gl/qVSck.

${ }^{195}$ Millard and Saporta (2005a) op cit note 157 passim

${ }^{196}$ In supplying their money to the banking system, central banks (CBs) typically make a distinction between lending overnight and intraday. They typically charge the policy rate for credit extended overnight, but charge little or nothing for credit extended within the same day. See Millard and Saporta (2005a) op cit note 157 at 59.

${ }^{197}$ See ch 4, s4.8.4.2 titled EFTs and Similar Schemes. There is no transfer, however, as nothing tangible or intangible is transferred. Electronic Funds Transfers (EFTs) are usually associated with bank transfers, although other electronic transfers of funds or value may not involve banks.

${ }^{198}$ See ch 4, s4.8.4.2.4 titled Debit Cards.

${ }^{199}$ Seech4, s4.8.4.2.7 titled Credit and Charge Cards.

${ }^{200}$ For a discussion on many of these payment methods, see ch 4, s4.8.3.2 titled Tangible Methods of Payments and ch 4, s4.8.3.3 titled Intangible Methods of Payments, and ch 4, s4.8.4.2 titled EFTs and Similar Forms.

${ }^{201}$ Cheques of up to ZAR5mn fall into the low-value category. 


\subsubsection{2}

\section{Low Value Payments: Micro-payments}

While the usual categorisation of payment values defined by a national prudential regulator is high value and low value and which then results in the requisite regulatory focus, it is submitted that a third category, micro-payments, be added to the broad canvas of payment values, lest its growing importance be quenched in the broad 'low value' appellation. There may also be other retail systems - like walled garden systems that do not 'touch' the national payment system, but which may be a payment mechanism nonetheless. These include MFS systems that use airtime as 'currency' and well as open and walled garden SVPs. ${ }^{202}$ Their individual functionality is described below.

Micro-payments are not necessarily the preserve of closed, walled garden systems, although given the current business models, their use of mostly e-money Stored Value Accounts (hereafter SVA) with mostly low-value balances and high transaction velocities and mostly non-bank SOs and unbanked participants may make it appear that way.

\subsection{3}

\section{Payment Methodologies and Characteristics}

\subsubsection{1}

\section{Introduction}

While the payment system may be the national road - or rail - on which payments travel, the vehicles on that road may be the payment instrument and a 'payment mechanism', which together may be seen as Methods (or Means) of Payment (hereafter MOP). ${ }^{203}$

When settling an obligation or making a payment sounding in money, the payment can be effected in various ways. In the modern era, there are a number of facilities, instruments or categories for effecting payment. ${ }^{204}$ The method used to execute or facilitate a payment may, for example, be a payment instrument defined by the CPSS as 'any instrument enabling the holder/user to transfer funds' ${ }^{205}$

\footnotetext{
${ }^{202}$ See ch 4, s4.8.4.4 titled Stored Value Products.

${ }^{203}$ A payment mechanism is not a term in common nor consistent use in the literature, but has been described by Geva (2008a) op cit note 157 as:
' $\ldots$ any machinery facilitating a non-cash payment in monetary value; while authorizing or conferring on the payee the right to claim the sum of payment from a third party, it enables the payor (i) to avoid the transportations of money and its physical delivery to the payee and (ii) where applicable, to obtain in the process a discharge of a debt owed by the payor to the payee.'

The ECB also refers to Means of Payment as being 'assets or claims on assets that are accepted by a payee as discharging a payment obligation on the part of a payer vis-à-vis the payee'. ECB (2009a) op cit note 157.

${ }^{204}$ For an overview of what it interestingly terms 'payment media used by non-banks', see the categories of payment identified by the CPSS. See Committee on Payment and Settlement Systems (CPSS) (2003b) 'Red Book: Payment Systems in the United Kingdom' at 403, available at http://goo.gl/ndC2B.

${ }^{205}$ ECB (2009a) op cit note 157 in 'Glossary'. 
Similarly, the European Central Bank (hereafter ECB) defines them generally as a tool or a set of procedures enabling the transfer of funds from a payor to a payee. ${ }^{206}$ The payor and the payee can be one and the same person. ${ }^{207}$

Again, the nomenclature around these payment mechanisms and 'funds transfers' is fuzzy: ${ }^{208}$ while it may have a national large value payment system connotation derived from the CPSS definition above, ${ }^{209}$ the term 'funds transfer' has also taken on the commercial (and legal) mantle as being an omnibus term for transfers of value that involve any electronic means of funds transfer. Within the scope of this broad 'electronic' funds transfer may be other (intangible) payment instruments and systems that facilitate the transfer of value, for example, credit cards, Electronic Fund Transfer at Point of Sale (hereafter EFTPOS), cheque cards, SVPs, electronic money and MFS systems. Generally, payment may be effected by tangible or intangible means described below. The payment type may be online or offline, it may be micro or macro in so far as the value of the payment, the transactions may or may not be tracked via an account system, the transactions may be prepaid or postpaid, they may have certain security needs, they may be open or closed use and may involve various value flows. These will all be discussed below. The focus of this section, however, is primarily on the electronic Means Of Payment (hereafter MOP).

\subsubsection{Tangible Methods of Payment}

Cash is the prototypical tangible payment method achieved simply by delivery of coins and bank notes from the payor to the payee. Cash has its obvious drawbacks, notably the risk of transporting large amounts of cash, readily obtaining cash, the difficulty in payments of wages and for goods using cash and the difficulty of safely and speedily transferring money across large distances. There are of course more modern equivalents designed to mitigate the use of cash and barter. Negotiable instruments such as cheques, promissory notes and traveller's cheques are usually tangible insofar as, at least in South Africa and many other jurisdictions, they must be in writing. ${ }^{210}$

\subsubsection{Intangible Methods of Payment}

As noted above, money, methods of payment and transfer of value are rapidly metamorphosing from tangible to more abstract and intangible means. Intangible payment methods that do not require tangible representations of the value include EFTs, ${ }^{211}$ debit cards, ${ }^{212}$ credit cards, ${ }^{213}$ credit transfers and direct

\footnotetext{
${ }^{206}$ Ibid.

${ }^{207}$ Ibid. This may capture the EFT, which Schulze believes is not an instrument of payment unlike a cheque, for example, since there is no physical instrument that embodies certain rights and that can be transferred from one person to another. He believes that an EFT should rather be described as a method of payment. See WG Schulze (2004a) 'Countermanding an Electronic Funds Transfer: The Supreme Court Takes a Second Bite at the Cherry' 16(4) SA Mercantile Law Journal at 668.

${ }^{208}$ For an overview of the evolution of electronic payment systems up to the point of ATMs, EFTPOS and smartcards, see Visser (1989) op cit note 157.

${ }^{209}$ See ch 4, 4.8.1 titled Overview.

${ }^{210}$ In some respects, however, cheques are metamorphosing into a product that emulates the paperless EFTs. In the United States, for example, remotely created electronic cheques are being used. Other examples include travellers' cheques and promissory notes. See on electronic cheques ch 4, s4.8.4.2.3 titled EFTPOS, and on cheque cards see ch 4, s4.8.4.2.4 titled Debit Cards.

${ }^{211}$ See ch 4, s4.8.4.2 titled EFTs and Similar Forms.

${ }^{212}$ See ch 4, s4.8.4.7 titled Debit Cards.

${ }^{213}$ See ch 4, s4.8.4.2.7 titled Credit and Charge Cards.
} 
debits, ${ }^{214}$ and SVPs such as e-money. ${ }^{215}$ As they are almost universally accepted in the domains in which they operate, they may fulfill money's traditional role as a Unit of Account (hereafter UOA), SOV and means of exchange or payment. The individual intangible types are discussed below. SVPs may represent a range of intangible MOP as a generic descriptor. ${ }^{216}$

\subsubsection{4}

\section{Pre-payment and Post-payment Forms}

A feature of modern economies is the explosion in the use of prefunded payment instruments where users simply pay in advance for any use of the funds stored on the instrument, or on a remote server if the device merely provides access to the stored value. By contrast, post-payment is a credit-type account where the user is sent a bill for usage which can be paid at the end of the billing period. Where there is some sort of account - either prefunded (prepayment) or post-paid, there is said to be a Stored Value Account (SVA) where the SOV is kept. ${ }^{217}$

Pre-payment may be for single use where the device, account or instrument cannot be reloaded or may be for continuous use where reloading of value is possible. Examples of prepaid systems include transport, telecommunications, parking and other similar uses, although in the case of most single use products, the value is usually a true prepayment in that it is not redeemable for any fiat money. These prepaid products may or may not attract regulatory attention if, for example, they allow payment in an open system for general goods and services, or where the prepayment is a surrogate or amounts to a deposit as may be defined in a statute, or where the value is redeemable. Further, although a prepaid card and a debit card share the same requirement for a positive balance for a transaction using them to be effected, a prepaid card is usually - but not always - associated with a non-prudentially supervised entity, while a debit card is usually associated with debits from a prudentially supervised entity holding the balance. In a MFS context, prepayment (or prefunding) is the predominant type of usage in most MNO systems in developing countries. ${ }^{218}$ The non-redeemable prepaid airtime purse is used for telecommunications and Value Added Services (hereafter VAS), and may have the same UOA as the national currency. Where there is a separate MFS purse, denominated in and redeemable for fiat money, this may amount to prudentially supervised e/m-money.

\footnotetext{
${ }^{214}$ For the ECB definition of RFTS, see European Central Bank (s.d.) 'Retail Funds Transfer System' in Payments and Markets Glossary, available at http://goo.gl/Kap9W.

${ }^{215}$ See ch 4, s4.8.4.4 on Stored Value Products. At the core of this new classification is the type of money used, followed by the core payment mechanism; then the channels and networks involved in the payment, followed by the form factor and authentication device used. The outermost layer contains seven generic payment methods. Special cases like money transmitters, loyalty schemes and collection/billing services are treated in a sixth, transcending layer, that also (partly) comprises value-added services (VAS). Institut für Bankinnovationan der Universität Regensburg (2006) 'Secure Payment Methods for E-Government' E-Government Manual, available at http://goo.gl/LoDdI.

${ }^{216}$ On the components of money, see ch 3 generally. On economic theories of money that have different conceptions of the requisite components, see ch 3, ss3.9 titled Orthodox School on this School's economic view of money, and 3.10 titled Claim School for a competing view. On the legal view of the necessary components of money, see ch 3, s3.12 titled Legal View. See also ch 13 passim which re-evaluates 'money' when taking into account emerging forms of value and payment such as those in SVPs and MFS.

${ }^{217}$ Prepaid and postpaid billing systems are often associated with MNO billing systems. See ch 5, s5.4 titled MNO Billing Systems. For stored value and component nomenclature usage and the interaction between them, see ch 4, s4.8.4.4.2 titled Stored Value Nomenclature for more on the SVP, SVA and SOV, see ch 2, s2.2 titled The Rationale for MFS and in particular, Exhibit A.

${ }^{218}$ See ch 5, s5.4 titled MNO Billing Systems.
} 


\subsubsection{Value of Payments}

While there are high value payments in national payment systems noted above, ${ }^{219}$ this study concentrates on the lower value macro- and micro-payments. Transaction values used in payments can be distinguished between micro and macro. Micro-payments can be anything up to ZAR20 or €10, but this is usually dependent on the economic realities of the country analysed. ${ }^{220}$ SVP transactions are usually, but not always, micro-transactions. Macro-payments are usually for high-value goods and services and usually involve credit cards, EFTs, cheques or traveller's cheques. They are usually, but not always, distinguished from micro-payments by the need to enter a secure Personal Identification Number (hereafter PIN) to verify the transaction.

\subsubsection{Accessibility and Tracking of Payment Systems: Online and Offline}

Not all payment products are created equal and vary in the type of features available to the user. At one level, there may or may not be persistent or any communication with the entity that issued the device or that controls the system. These are broadly known as 'online' and 'offline' payments. ${ }^{221}$

In an online payment, the payment request or instruction is immediately sent to the financial institution or institutional holder of the value, who may immediately authorise or reject the payment request. An offline payment system is one where the payment product is not in communication with the SO/issuer of the value. These are usually a type of prefunded SVP. ${ }^{22}$ Within these two communicability hemispheres, there are two accounting strata whether or not the system has a discrete account for that user such that the system is able to track the usage of the value. ${ }^{223}$ This scheme is ostensibly designed to provide ubiquity and affordability, but may ultimately result in skewed levels of protections, if any.

Systems may be classified at one level as being the functional equivalent of cash in that the value is stored locally on the device and the loss of the device results in the total loss of that value since the issuer does not - and usually cannot - mirror the value or keep track of its usage in an account. Examples include Stored

\footnotetext{
${ }^{219}$ See ch 4, s 4.8.2.4 titled Retail Funds Transfer Systems.

${ }^{220}$ The best analogy is what it would cost to purchase a good caffé latte. These are usually executed by Short Message Services (SMS) or Wireless Application Protocol (WAP), or Near Field Communications (NFC) where available. On SMS, see ch 5, s5.3.4 titled Short Message Service (SMS) and Shortcodes; on WAP, see ch 5, s5.5.3.1 titled Wireless Application Protocol (WAP); and on NFC, see ch 5, s5.5.6.5 titled Near Field Communication.

${ }^{221}$ See Committee on Payment and Settlement Systems (CPSS) (2004) 'Survey of developments in electronic money and internet and mobile payments' at 23, available at http://goo.gl/n01OR; B Geva and M Kianieff (2002) 'Reimagining EMoney: Its Conceptual Unity with other Retail Payment Systems' at 2-4, available at http://goo.gl/QfR4y. For the application of these 'online' and 'offline' appellations to SVPs, see ch 4, s4.8.4.4.3 titled Technical Aspects.

${ }^{222}$ With offline payments, the payment requests are checked for completeness and processed later or not at all.

${ }^{223}$ Systems may be classified as online accountable (where the system 'tracks' the account usage in real-time); online unaccountable (where the system does not 'track' the account usage, but does have access to system usage in a real-time manner); offline unaccountable (where the system does not 'track' the account usage, nor does it have access to system usage in a real-time manner); and offline accountable (where the system 'tracks' the account usage, but not in a real-time manner). These distinctions were proposed by the US Federal Reserve Board in Electronic Fund Transfers (Proposed Rules), 61 Fed. Reg. 19, 696 (May 2, 1996) in relation to SVCs and the then evolving e-money systems, and which are still used as differentiators in many scholarly and regulatory texts. See R Griffith and F Stephen (2000) 'Electronic Money and Monetary Policy', available at http://goo.gl/KzdKi at 48-49. See CPSS (2004) op cit note 221 at 23; Geva and Kianieff (2002) op cit note 221 at $1-3$.
} 
Value Cards (hereafter SVCs) used for payphones, transport and photocopying. ${ }^{224}$ At a legacy level of (regulatory) nomenclature, these are said to be 'offline unaccountable', in that there is no means of communication with a central server nor is there a central account where the usage (or accounting of) the device is tracked. ${ }^{225}$ There may be other products that are said to be 'online accountable' where constant communication between the device and a central server that keeps an identified account for that user and tracks his usage. In most of these cases, the device will not locally store any indication of the value available to the user. Instead, the device merely provides access to an account on a central server which tracks that user's usage and reflects the available value. ${ }^{226}$

In the MFS ecosystem, most products are access products in that they are 'online accountable' and can be tracked. $^{227}$

\subsubsection{Ubiquity of Use: Interoperability}

Payment systems may be 'open' use or 'closed' use. Closed use 'walled garden' systems usually indicate that the payment instrument will only operate with one service type or geographical location. It is usually issued by a single issuer. ${ }^{228}$ Open systems, on the other hand, are generally 'interoperable', meaning that they are generally redeemable and accepted by multiple merchants. ${ }^{229}$

Examples of these open systems include payment instruments such as prefunded debit cards issued by banks, card organisations such as Visa and MasterCard, ${ }^{230}$ Money Transfer Operators (hereafter MTOs), and to some extent some MNOs engaged in financial services.

4.8.3.8

Security and Reliability of Payments

Of concern to SOs, regulators and users alike is the security and reliability of a payment, as well as the security of the underlying funds. There are a number of transactions that take place in a payment system, be it from the user perspective, the issuer perspective, or the merchant and receiver perspective. All have

\footnotetext{
${ }^{224}$ See again ch 4, s4.8.4.4.3 titled Technical Aspects in relation to SVPs.

${ }^{225}$ Electronic Fund Transfers (Proposed Rules), 61 Fed. Reg. 19, 696 (May 2, 1996).

${ }^{226}$ As Geva and Kianieff (2002) op cit note 221 at 2point out, it is only an offline unaccountable system that is fully storedvalue and is not an access product. An offline accountable system is a hybrid system that combines features of both types of products.

${ }_{227}$ There may, however, be instances where because of MNO coverage issues, there may be instances where mobile phones with proximity features like Near Field Communication (NFC) which are innately accountable, trackable and online, may not be online and trackable when used in an underground subway system, for example, but which may be updated when coverage is subsequently available.

${ }^{228}$ Examples include SVP-like (non-Visa or MasterCard) store loyalty cards, transport cards, fixed-line phone cards, or parking payment cards. They are usually purchased directly from the issuer or his agent. Mostly these systems cater for microtransactions. Many fixed-line pay telephones use credit-card plastic cards with a chip embedded in the card containing a fixed purchased value bought from the operator, which is then depleted according to usage. If the user loses the card, the value is lost. See ch 4, s4.8.4.4 titled Stored Value Products on the use of SVPs in open and closed systems.

${ }^{229}$ They are usually not restricted to one merchant chain or geographic area.

${ }^{230}$ They usually have a magnetic stripe on the back or an embedded chip and they operate on and carry the logo of a branded card network like MasterCard, Visa, or American Express. There are no open network prefunded payment schemes currently operating in South Africa, although there are various store-specific prefunded payment schemes, such as gift cards. Consultative Group to Assist the Poor (CGAP) (2010c) 'Update on Regulation of Branchless Banking in South Africa January 2010', available at http://goo.gl/tBAc1. CGAP postulate that the primary reason is that banks, as the only institutions permitted to issue e-money or other stored-value instruments, are heavily invested in the existing payments systems and therefore have little incentive to invest in new systems.
} 
security requirements of varying levels. There are special concerns in MFS, because the mobile phone service is a very public payment instrument.

The security of electronic payment systems is realised predominantly by a combination of physical measures and encryption. ${ }^{231}$ Immediate security threats from a user perspective include unauthorised access to - or 'hacking' of - a system in order to make unauthorised transactions in the name of a user, and phishing or spoofing are used in identity theft to enable illegitimate accounts and payments. ${ }^{232}$

Payment fraud is a moving target. Even if it affects a minority of users, it generally undermines the general confidence in the payments system. ${ }^{233}$ Measures that can be taken to counteract the potential for harm include continuous, 'risk-based' measures that cover the entire organisation and which allow later auditing in order to detect adverse behaviour. ${ }^{234}$ At a broader level, but less so from a user's perspective, there is also the threat of money laundering (hereafter ML) and the financing of illegal activities, internal fraud, ${ }^{235}$ as well as extortion threats by hackers corrupting the data in electronic systems. ${ }^{236}$ At the physical level, many card-based payment systems use Europay, MasterCard and Visa (hereafter EMV) ${ }^{237}$ chip card technology developed through specifications agreed by EMV which adds a new layer of protection against fraud. ${ }^{238} \mathrm{~A}$ special token or fob using one-time access keys to augment the so-called two-factor secure authentication is often employed, but this has been compromised. ${ }^{239}$ Usually a PIN is required to complete a debit or credit${ }^{231}$ Physical security measures however depend on the current technology such that technological progress may seriously
threaten the existing systems. See JL Camenisch, J-M Piveteau and MA Stadler (1994) 'Security in Electronic Payment
Systems' in WR Bischofberger and HP Frei (eds) Computer Science Research at UBILAB at 148-153, available from http://goo.gl/d8qAe.

${ }^{232}$ Fajfar (2004) op cit note 157 at 9. See also ch 5, s5.7.4.1 titled Phishing and ch 7, s7.3.6.5.3.3 titled Security and Efficacy of Systems.

${ }^{233}$ A study conducted for the EC in 2007 showed that user trust in certain authentication methods for cashless payments could be improved and that maintaining or enhancing user confidence does not necessarily require new legislation but rather the commitment of the parties involved to achieve this goal. See European Commission (EC) (2008c) 'Report on Fraud Regarding Non Cash Means of Payments in the EU: The Implementation of the 2004-2007 EU Action Plan', available at http://goo.gl/nNWZH. The report showed that, including 2007, there were $€ 10 \mathrm{mn}$ fraudulent payment card transactions in SEPA (Single Euro Payments Area) per year, affecting 500,000 merchants, amounting to $€ 1$ bn in losses. An earlier study found that EU citizens had a reasonably high level of trust in electronic payments, although there still remain significant doubts about security, fraud and privacy threats. See Internal Market and Services Directorate General of the European Commission (2003) 'Study on the Security of Payment Products and Systems in the 15 Member States', available at http://goo.gl/zwxdg. Security concerns ranked (30\%), fraud (25\%) and lack of privacy (17\%) respectively.

${ }_{234}^{234}$ Fajfar (2004) op cit note 157 under 'Role' passim.

${ }^{235}$ See for example reports highlighting fraud syndicates using internal bank and MNO staff. Legalbrief (2010) 'Absa Employees in R1.38m Bank Fraud Case', available from http://goo.gl/LbJYr. For loss allocation criteria fastening on banks, see ch 7, s7.3.6.5.3 titled The Bank.

${ }_{236}$ The South African banking industry's financial losses resulting from credit card fraud decreased by $36 \%$, from ZAR409.3mn to ZAR263.8mn. See South African Banking Risk Information Centre (SABRIC) (2010) 'SABRIC Announces 2010 Banking Industry Card Fraud Figures', available from http://goo.gl/peT0n.

${ }^{237}$ Eurocard, MasterCard, Visa (or EMV) is the trade name for a technical consortium that was formed to devise a standard for producing chip-based cards.

${ }^{238}$ There is also the Payment Card Industry Data Security Standard (PCI DSS), a set of global and industry-wide requirements which are supported by all international payment card systems. PCI DSS was created by Visa and MasterCard in 2004. See PCI (Payment Card Industry) Security Standards Council home page, available at https://www.pcisecuritystandards.org, and Visa (2011) 'Payment Security', available at http://goo.gl/xPqch. Three of the best known options for the encryption and security of personal and card details are Secure Sockets Layer (SSL) which allows traffic to be scrambled (or encrypted); Secure Electronic Transaction (SET) which encrypts payment card transaction data and verifies that both parties in the transaction are genuine; and Public Key Software Infrastructure (PKI) which requires security keys to be provided in order to authenticate a transaction. The generation of the signature requires the knowledge of the signer's private key, while for the verification of the signature, only the knowledge of the corresponding public key is necessary. If the public key is publicly accessible, then everybody can verify the signature, while only the signer, who knows the private key, is able to sign. See home page of electronic-payments.co.uk (2011) 'Electronic Payments Security', available at http://goo.gl/ASmTM.

${ }_{239}$ In March 2011, global secure transaction behemoth, RSA, disclosed that they had been the victims of an 'APT' (Advanced Persistent Threat), a heuristic synonym for having been hacked. The RSA tokens, used by banks and their clients worldwide, operate by generating an authentication code that users enter in to their computer to gain access to their network or bank 
based transaction; ${ }^{240}$ or there may be a need to use a two factor authentication system such as sending a SMS - or One Time Password (hereafter OTP) - when a payment beneficiary is added to a user profile on a banking web site. ${ }^{241}$ This may also be the case in relation to a double opt-in requirement when subscribing to $\mathrm{VAS}^{242}$ Users though generally baulk at increased security measures, despite their being for their protection. $^{243}$ There may be a statutory indication of blameworthiness in relation to the security of a transaction and loss allocation. ${ }^{244}$

Payment reliability is also a concern and refers not only to the operational reliability of the system, but also to the payment of values to the correct recipients. Even sophisticated payment systems like those operated by such payment behemoths as BankservAfrica may experience downtime, and such system failures have negatively (albeit temporarily) affected PIN-based electronic transactions, including Automatic Teller Machine (ATM) transactions. ${ }^{245}$

\subsubsection{9}

\section{Payment Flows}

Depending on the system design or its innate characteristics, a payment instrument or facility may or may not enter a national payment system. ${ }^{246}$ Cash payments, for example, transfer value directly between payor and payee outside any banking or payment system, as do many prefunded electronic money instruments in

account. The RSA token system generates a new code every 30 to 60 seconds, and is normally combined with a separate password. See Help Net Security (2011) 'RSA hacked, SecurID users possibly affected', available at http://goo.gl/QRMBj.

${ }^{240}$ The EMV chip embedded in the card has significantly reduced counterfeit fraud, while the use of a PIN to identify the genuine cardholder prevents fraud after loss or theft of the card. In markets where the use of the chip and PIN is widespread, these types of fraud are at record low levels. The reader of the card will self-destruct if there are attempts to interfere with it. See Visa (2011) op cit note 242.

${ }^{241}$ See ch 5 titled Mobile Technology and MFS; A two factor authentication system means that instead of using only one type of authentication factor, such as things only a user knows - for example, login IDs, passwords, secret images, shared secrets, solicited personal information - a second factor, something the user has or something the user is, must be supplied in order to authenticate. This form of security is generally known as the 'something you have' + 'something you know' concept. In two factor authentication, the password still provides the something you know component. A SMS sent to a phone with a one-time password used to authenticate the user when logging in may be the 'something you have component'. See TopBits.Com (s.d.) 'Two Factor Authentication', available at http://goo.gl/3bls5. See however, ch 5, s5.7.4.1 titled Phishing, where transaction verification passwords sent by SMS to bank customers were intercepted by rogues.

${ }^{242}$ See ch 6, s6.5.4.2 titled WASP VAS on subscription services.

${ }^{243}$ See European Commission (2007e) 'Report on Fraud Regarding Non-cash Means of Payments in the EU: The Implementation of the 2004-2007 EU Action Plan' at 26, available at http://goo.gl/nNWZH. The report found that unlike card payments (where the PIN code is simultaneously trusted and easy to use), online payments require trade-offs to be made: onefactor authentication methods (such as static passwords) are considered to be more user friendly than two-factor authentication methods.

${ }^{244}$ In South Africa, the Electronic Communications and Transactions Act 25 of 2002 at s43 indicates that a supplier must utilise a payment system that is sufficiently secure with reference to accepted technological standards at the time of the transaction and the type of transaction concerned and that the supplier is liable for any damage suffered by a consumer due to a failure by the supplier to do so. 'Sufficiently secure' is not defined, however, in the Act. In the US though, the Uniform Commercial Code (UCC) §4A-201 defines 'security procedure' as a procedure established by agreement of a customer and a receiving bank for the purpose of (i) verifying that a payment order or communication amending or cancelling a payment order is that of the customer, or (ii) detecting error in the transmission or the content of the payment order or communication. A security procedure may require the use of algorithms or other codes, identifying words or numbers, encryption, callback procedures, or similar security devices. Comparison of a signature on a payment order or communication with an authorised specimen signature of the customer is not by itself a security procedure.

245 'Shoprite Lashes Out at Banks Over System Failures' (2009) Mail and Guardian, 6 Nov, available at http://goo.gl/aUYOF. The EU Payments Services Directive mandates quality of service criteria for all payments in the EU. Specific issues around the security and reliability of payments effected through mobile phones as they relate to MFS are discussed in ch 5, s5.7 titled Security Aspects of Mobile Technology and Application to MFS.

${ }^{246}$ The World Bank provides a conceptual model of the payment cycle to illustrate the major components of a typical noncash payment cycle. The seven steps are: (a) at payment entry; (b) inbound processing and transfer; (c) inbound clearing; (d) settlement (gross or net); (e) outbound clearing (f) outbound processing and transfer, and (g) at payment distribution. See the models discussed in S Setsuya and DB Humphrey (1995) 'Transforming Payment Systems: Meeting the Needs of Emerging Market Economies', available at http://goo.gl/cWLvP. 
closed-loop (unaccountable) systems offered and issued by mainly private commercial enterprises like MNOs offering prepaid airtime, prepaid railroads such as the Gautrain high speed railway system in South Africa. ${ }^{247}$ This is not true of all prefunded instruments however: postal money orders, travellers' cheques, and bank cashiers/guaranteed cheques usually enter a national payment system as a (prepaid) check instrument. ${ }^{248}$ Both payment system-centric and non-payment-centric methodologies may, depending on the type of facility being used, in turn be classified into what are termed 'credit-push' and 'debit-pull' systems. The use of this art may affect the regulatory domains applicable to them. ${ }^{249}$ 'Credit Push' is a transfer of funds where the payor initiates a transfer to move funds into the payee's/receiver's account such that there is 'finality' in the transaction. ${ }^{250}$ Sufficient funds must be available before the payment can be made. In almost all cases, the originator or the paying customer does not have to provide his or her banking information to the receiver of the funds. ${ }^{251}$

In the non-MFS sector, examples of low-value payment streams include e-money payments from prepaid systems, and EFT credit push like electronic account payments and stop orders, and Real Time Clearing (hereafter RTM). ${ }^{252}$ In the MFS sector, this may include the use of Premium Rated SMS (hereafter PSMS) payments via the MNO and associated billing system pushed to the WASP from the airtime-based SVA. ${ }^{253}$ This contrasts to 'debit-pull' transfers of funds where the receiver initiates a transfer of funds from the originator's account, effectively causing the collecting bank to 'pull' the funds through the payment system. Examples of low-value payment streams include debit orders, authenticated early debit orders, nonauthenticated early debit orders, debit, credit, cheque and garage cards, cash withdrawals at ATMs and selfservice devices, cheques and Mzansi Money Transfers from the low-cost Mzansi bank accounts. ${ }^{254} \mathrm{~A}$ disadvantage of the systems is that the payee may dispute the payment, and since the receiver had been given the originator's banking information, the receiver may have another opportunity to 'debit' the originator's bank for payment in error or unintentionally. ${ }^{255}$

\footnotetext{
${ }^{247}$ See ch 4, s4.8.3.6 titled the Accessibility and Tracking of Payment Systems: Online and Offline.

${ }^{248}$ Many non-cash transactions such as cheques, EFTs, open-loop debit cards, credit card, direct debit - will, however, require clearing and settlement to facilitate the transfer of value between payor and payee.

${ }^{249}$ See, for example, regulations and consumer protections in the US pertaining to credit and debit cards. Regulation Z 14 CFR pt. 226 (1998) (Reg Z) imposes a minimum liability of US $\$ 50$ for consumers for unauthorised transfers involving credit cards. The same concept applies in Regulation E 12 CFR pt. 205 (1996) (hereafter Reg E) in respect of debit card transactions. However, over time consumer liability eventually increases until it encompasses the entire amount in dispute.

${ }^{250}$ Another characterisation of the difference is that in a credit transfer, communication is in the same direction as the movement of funds, while in a debit transfer, communication is in the reverse direction. Geva and Kianieff (2002) op cit note 221 at 267. See the SARS definition of 'credit push' in relation to its e-filing system for paying taxes online:
}

'Credit push refers to payment transactions that are initiated on the eFiling site and presented to the banking product as bill presentation, i.e. a payment request. Only once the user has logged into the banking product and authorised the payment request is this transaction regarded as an effective payment. Credit push transactions are irrevocable once approved.'

South African Revenue Service (SARS) (2011) 'Make a Payment', available at http://goo.gl/pdrvx.

${ }^{251}$ See Venture 8 (2007) 'Frequently Asked Questions and Objections', available at http://goo.gl/Lns3p.

${ }^{252}$ Banking Association of South Africa (2008) 'Overview of the Payments Environment', available at http://goo.gl/JzDVq Mzanzi is a low-cost banking product offered in South Africa. See on Mzansi ch 12, s12.1 titled Overview.

${ }^{253}$ On WASPs and the sale of VAS to mobile users, see ch 5, s5.2.3 titled Types of Services Available to Users: Basic and VAS and generally ch 6, s6.5.4.2 titled WASP VAS below. On relationships in a WASP VAS transaction, see ch 6, s6.5.4.2.1 titled Relationships in the WASP and VAS Environment; and further on the legal effects in these transactions see ch 7 , s7.3.2.2.2 titled WASP VAS.

${ }^{254}$ Banking Association of South Africa (2008) op cit note 256. On Mzansi, see ch 12, s12.1 titled Overview. On the impact on Mzansi and its uptake amongst South Africans, see M Fisher-French (2012) 'Mzansi Accounts Reach Dead End' Mail and Guardian, available at http://goo.gl/jzUy1.

${ }^{255}$ See the SARS definition of 'debit pull' in relation to its e-filing system for paying taxes online: 
In the MFS sector, a putative debit-pull may include use of PSMS payments using technologies like the Online Billing System (hereafter OBS) ${ }^{256}$ that may be pulled or debited from the prepaid airtime purse

\section{Overview}

As noted above, money, methods of payment and transfer of value are rapidly evolving from tangible to more abstract and intangible means ${ }^{257}$ and include EFTs, debit cards, ${ }^{258}$ credit cards, ${ }^{259}$ credit transfers and direct debits, ${ }^{260}$ and SVPs $^{261}$ such as e-money.

There have been numerous attempts to define these new intangible systems and their components, especially insofar as any regulatory nexus is concerned and all within varying degrees of taxonomical hierarchies. ${ }^{262}$

Many systems use electronic means to transfer value, or more accurately, transfer instructions as to which accounts must be debited and credited. Despite the 'electronic transfer' component, however, they are not necessarily EFTs, but they may be.

The term 'EFT' is however usually reserved for fund transfers within the banking system. ${ }^{263}$ There are of course 'transfers' in non-bank systems such as closed loop (walled garden) payment systems where the value transferred is not even necessarily fiat-based. As such, and depending on the context and schemes in evolving payment technologies, the terminology and taxonomies can charitably be said to be inconsistent. Where they involve prefunded payment mechanisms - which may or may not involve banking institutions together they may be termed SVPs. ${ }^{264}$

\footnotetext{
'Authorised debit pull refers to payment transactions initiated on the eFiling site and authorised for each transaction. The transaction is assumed to be successful after user authorisation on eFiling. This payment mechanism involves the initiation of a payment instruction from SARS's bank to the client's bank. The debit push mechanism may reverse due to insufficient funds once the request is processed by the bank. Correct banking details are required to ensure the payment is successful.'
}

SARS (2011) op cit note 250.

${ }^{256}$ OBS is also known as Event Based Billing or EBB.

${ }^{257}$ From the traditional methods of barter, coins, notes, IOUs, traveller's cheques and drafts, for example. See ch 3, s3.4 titled Evolution of Money and ch 3, s3.7 titled Modern Forms of Money.

${ }^{258}$ See ch 4, s4.8.4.2.4 titled Debit Cards.

${ }^{259}$ See ch 4, s4.8.4.2.7 titled Credit and Charge Cards.

${ }^{260}$ See European Central Bank (ECB) (2011b) 'Retail Funds Transfer System', available at http://goo.gl/Kap9W.

${ }^{261}$ See ch 4, s4.8.4.4 titled Stored Value Products.

262 Bleyen and Van Hove, for example, have a classification framework that consists of multiple nested layers. See V-A Bleyen and L Van Hove (2009) 'Classifying Payment Instruments: A Matryoshka Approach', available at http://goo.gl/bz9Eu. At the core of this new classification is the type of money used, followed by the core payment mechanism, then the channels and networks involved in the payment, followed by the form factor and authentication device used. The outermost layer contains seven generic payment methods. Special cases like money transmitters, loyalty schemes and collection/billing services are treated in a sixth, transcending layer, that also (partly) comprises VAS. See also Institut für Bankinnovation an der Universität Regensburg (IBI Research)(2006) 'Secure Payment Methods for E-government' E-Government Manual, available at http://goo.gl/LoDdI. On the nomenclature and hierarchies used in this thesis relating to MFS and in particular on Stored Value, see ch 4, s4.8.4.4.2 titled Stored Value Nomenclature; as well as a graphical representation thereof in Exhibit A in ch 2, s2.2 titled The Rationale for MFS.

${ }^{263}$ Geva (2008a) op cit note 157 at 636.

${ }^{264}$ See ch 4, s4.8.4.4 titled Stored Value Products. 
Since the value and usage thereof may be mediated by a plethora of technical systems, a brief explanation of some of the most relevant of these is necessary to understand the accompanying legal, regulatory and prudential analysis of these systems.

\subsubsection{Electronic Fund Transfers (EFTs) and Similar Forms}

\subsection{Overview}

EFTs represent one of the most prevalent mechanisms of payment used worldwide. As noted above, while the term 'EFT' could be used in a colloquial sense to refer to any mechanism or process for the transmission of funds between two parties, or the making of non-cash payments, ${ }^{265}$ there are of course non-banking facilities for payments or remittances. This broad definition may be narrowed by statute. ${ }^{266}$ Generally though, the term EFT refers to the making of a non-cash payment though the banking or national payment system. $^{267}$

There may be two types of EFT systems operating at a national level: the RTGS ${ }^{268}$ and the RFTS, both in the banking system and in a national payment system, although the retail systems may not necessarily use a national payment system or the banking system per se, using instead private means of settlement. Examples of the latter include payments within an organisation or financial entity. Different regulations may apply depending on which system is used ${ }^{269}$ and when it is used in an MFS context. ${ }^{270}$

Examples of payment mechanisms that could be classed as EFTs insofar as the settlement leading to a payment to a creditor by a debtor requires an 'EFT' component, and which are discussed below, include EFTPOS,${ }^{271}$ debit cards, ${ }^{272}$ electronic cheques, ${ }^{273}$ credit cards, ${ }^{274}$ and remittances. ${ }^{275}$ An EFT may be a debit or credit transfer. ${ }^{276}$

\footnotetext{
${ }^{265}$ See, for example, the BIS definition of EFT: 'A standard mechanism for electronically transmitting funds between two parties.' See J Hawkins (s.d.) 'EFT' in Glossary BIS Papers No 7, available athttp://goo.gl/qs4ws. Federal Reserve Education (2011a) 'Electronic Funds Transfer (EFT)' Glossary, available at http://goo.gl/MBf1P: "Transfer of funds electronically rather than by check or cash. The Federal Reserve's Fedwire and automated clearinghouse services are EFT systems". See also: 'Transfer of funds between accounts by electronic means rather than conventional paper-based methods, such as check writing' in T Fitch (2006) 'EFT' in Barrons Dictionary of Banking Terms. They are also known as wire transfers. Office of the State Controller (2005) 'Electronic Funds Transfer 101', available at http://goo.gl/RnacC.

${ }^{266}$ See, for example, Article 4A on Fund Transfers in the US Uniform Commercial Code; the Federal Electronic Funds Transfer Act which covers wire transfers covered by the Federal Reserve (Fedwire), and wire transfers covered by the New York Clearing House Interbank Payments Systems (CHIPS). [Article 4A covers certain funds transfers, including ACH credit transactions not subject to the Electronic Funds Transfer Act.]

${ }^{267}$ Geva (2008a) op cit note 157 at 634 .

${ }^{268}$ See ch 4, s4.8.2.3.1 titled National Payment Systems.

${ }^{269}$ See, for example, the EU's PSD, and Reg E in the US which regulates EFTs and various clearing house and settlement rules in payment system organisations. See, for example, the National Automated Clearing House Association (NACHA), ACH Operating Rules, $\S \S 3.7-3.8$ (2007) that pertain to bulk electronic payments processed through the Automated Clearing House Network and for the National Automated Clearing House Association.

${ }^{270}$ In a MFS context, an EFT may in its most generic sense encompass the ability to transfer airtime from one user of an MNO to another user of that or some other MNO or bank using the MNO billing ecosystem, a type of EFT remittance. The source would be either the airtime SOV or a fiat-based SOV operated by the MNO.

${ }^{271}$ See ch 4, s4.8.4.2.3 titledEFTPOS

${ }^{272}$ See ch 4, s4.8.4.2.4 titled Debit Cards

${ }^{273}$ See ch 4, s4.8.4.2.5 titled Electronic Cheques

${ }^{274}$ See ch 4, s4.8.4.2.7 titled Credit And Charge Cards

${ }^{275}$ See ch 4, s4.8.4.3 titled Remittances

${ }^{276}$ See ch 4, s4.8.3.9 titled Payment Flows.
} 
As noted above, ${ }^{277}$ a debit transfer is usually via the request of the payee to 'pull' funds from the payor's institution or purse, while a credit transfer involves the payor 'pushing' the funds to the payee.

\subsection{EFTs Through Banks}

The payment mechanisms described below are generally types of mechanisms for funds transfer. Generally though, as noted, the term EFT refers to the making of non-cash payments through the banking or national payment system. ${ }^{278}$ There is no physical transfer though: the sender of the funds would send the value through his bank along a chain, whereby debts to the payor are extinguished or reduced pro tanto with respect to the payor's bank, while a new debt from the issuer to the payee is created in respect of the payee's bank. $^{279}$

In most cases, an EFT is said to be an absolute payment in that there is payment finality on transfer of the value from the issuer to the merchant. Indeed, much of the terminology used relates to banking systems, such as 'discharge', which in a banking sense is, according to Geva, 'the satisfaction of the liability or debt in payment of which the funds transfer is made'. Similarly, 'payment finality', he says, refers to 'the point of accountability, or the irrevocability of liability, of the bank in which the payment process is completed. In a debit transfer it is the payor bank. In a credit transfer it is the beneficiary's bank. Either way, however, it is the destination bank - the last bank in the communication chain'. 280

\subsection{EFTPOS}

EFTPOS is the general term used for the card-based systems used to process transactions through POS terminals at retail outlets. ${ }^{281}$ The payment may be for any number of transaction types allowed at that retail outlet, for example, third-party bill payments, payment for goods and services offered by that outlet or to use the POS as an ATM by withdrawing cash at the terminal. ${ }^{282}$ The consumer can use either a debit or credit card (or the consumer may choose a multifunctional card to charge or debit if it allows access to a choice of multiple stores of value or credit) that may be swiped at a terminal or which uses a chip reader with a PIN number if a 'chip ' $\mathrm{PIN}$ ' reader is available. There are online versions where the value paid is electronically transferred directly from the account of the payee to that of the merchant. ${ }^{283}$

\footnotetext{
277 Ibid.

${ }^{278}$ Geva (2008a) op cit note 157 at 634.

${ }^{279}$ Geva and Kianieff (2002) op cit note 221 at 23. This is the scenario contemplated in Libyan Arab op cit notes 37.

${ }^{280}$ See Geva (2008a) op cit note 157 at $633-675$.

${ }^{281}$ EFTPOS is also a brand name in Australia. Generally it is a network for processing credit cards, debit cards and charge card payments at the 'Point of Sale' and transacting at ATMs. The name and logo for EFTPOS in Australia were originally owned by the National Australia Bank and were trade marks from 1986 until 1991 and in April 2009 a company was set up to manage and promote EFTPOS - See website home page of EFTPOS Payments Australia, available at http://goo.gl/0HVNj. See generally B Geva (1989) 'The EFT Debit Card' 15 Canadian Business Law Journal at 406, and P Havenga et al (2007) General Principles of Commercial Law $6^{\text {th }}$ ed at 442 on the payments flows and types, including offline and online payments, and legal relationships in an EFTPOS transaction.

${ }^{282}$ This functionality is known as debit card cash-back in many other countries.

${ }^{283}$ Havenga et al (2007) op cit note 281 at 442 describes an EFTPOS as 'essentially a debit transfer'. While this may be so for debit cards and the attendant transaction flows, there may be other types of transactions using credit push allowed at that point of sale.
} 
Debit cards - also known as 'ATM Cards', 'EFT Debit Cards', ${ }^{284}$ and 'cash cards ${ }^{285}$ - represent one of the fastest growing components of the payments industry. ${ }^{286}$ They are usually associated with debits from bank accounts. The debit card may be one of the payment instruments used in an EFTPOS. ${ }^{287}$ Although they could also be considered prefunded cards, use of a debit card results in a direct debit to be made to the user's bank account where a positive balance must be held. If there are no funds available to match the required transaction amount, the transaction will fail. Any placement of funds in the bank account will effectively recharge that debit card for use up to the available balance in the bank account. They are also used within a systemic payment system, for example Visa or MasterCard, and linked to the user's bank account. ${ }^{288}$ Debit cards may also be used with online payment systems - over the Internet and via mobile - where allowed. ${ }^{289}$

\subsection{Electronic Cheques}

A cheque is an order to pay given by a customer to a bank with which the customer maintains an account. It has traditionally been a paper instrument, embodying an unconditional order in writing, signed by a drawer, instructing a drawee bank to make payment to, or to the order of, a designated payee or to the bearer. Geva describes a number of modern incarnations and disparate uses of the cheque in some jurisdictions though. ${ }^{290}$ The cheque, he says, may be provided simply as a source of information for initiating a one-time EFT as an 'electronic check'. ${ }^{291}$ In this instance it may be given to the payee with the authority to convert it to an electronic image such that a remotely created cheque is then drawn by the payee as an agent of the drawer, on the basis of information provided by the drawer to the payee. The electronic negotiation and presentment will be done via the transmission of an electronic image instead of the physical transfer of the paper cheque. $^{292}$

\footnotetext{
${ }^{284}$ For a general description of the technical and legal descriptors that underline what is called an 'EFT Debit Card,' see Geva (1989) op cit note 281 at 406.

${ }^{285}$ AS Rosenberg (2005) 'Better than Cash? Consumer Protection and the Global Debit Card Deluge' TJSL Public Law Research Paper No 05-04Available at http://goo.gl/4fmN3.

${ }^{286}$ These are sometimes also known as check or cheque cards.

${ }^{287}$ See on EFTPOS, ch 4, s4.8.4.2.3 titled EFTPOS.

${ }^{288}$ They are attractive to merchants and issuers alike as they attract less transaction charges as well as virtually no chargebacks opportunities characteristic of credit cards.

${ }^{289}$ In a MFS context, they may be linked to mobile based accounts in some hybrid MFS schemes such as those offered by Wizzit and MTN MobileMoney where the value is in the mobile purse, and is obtained either through a cash-in payment into the user's account at a bank or via an agent, or via an EFT into the purse, and can be cashed-out at a POS device or ATM using a branded magnetic stripe card linked to that account. See ch 6, s6.4 titled Licensed Bank-Led Model on bank-led MFS Models.

${ }^{290}$ Geva (2007) op cit note 157 at 688.

${ }^{291}$ The electronic cheque is usually a non-physical representation of a cheque, and although similar, must be distinguished from the recent incarnation, the cheque card described below. For a discussion on electronic cheques and the UCC regulation thereof in the US, see also JT Pretorius (2005) 'The Truncation of Cheques: Novel Developments in America' 13(1) Juta's Business Law 38-43 at 38.

${ }^{292} \mathrm{~A}$ check may be remotely created, and may also be negotiated to a collecting bank, whether by its customer the holder, or another collecting bank, by means of electronic transmission. A check may be presented for payment electronically. Geva points out, however, that the practice of electronic negotiation to non-banks has not yet developed to make provision for such electronic transmission. These 'Remotely Created Cheques' (RCCs) may serve as an EFT. The payee remotely creates preauthorised drafts, or remotely created checks under the authority of the accountholder but usually without the accountholder's signature. This may be done for payment to a creditor or to purchase an item via telephone or Internet. The absence of a signature is said to make RCCs vulnerable to fraud.
} 
A recent incarnation, at least in commercial nomenclature, is the 'cheque card'. This has been described as a 'plastic cheque book', ${ }^{293}$ a payment mechanism which allows a cardholder to pay for goods and services immediately with the funds being debited electronically from their cheque account simultaneously with the execution of the transaction. In one incarnation of its implementation, use of the cheque card requires the user to sign a receipt after purchasing goods from a merchant, but a PIN is not required. ${ }^{294}$

\subsection{Credit And Charge Cards}

Credit cards, and similarly charge cards, are a fixture of the modern economy. ${ }^{295}$ They are usually in the form of plastic cards with a chip ${ }^{296}$ or magnetic stripe at the back, usually embossed with the user's name and issued by a Payment Service Provider like Visa or MasterCard via a local agent, usually a licensed bank with or without a retail partner. They allow an extension of credit to the user, with partial payments allowed according to the credit agreement with the issuer. ${ }^{297}$ There are a number of extensive written contractual relationships in a credit card transaction that may include the cardholder, the third party retailer, and the issuing bank who will ultimately pay over the value spent by the cardholder to the retailer's account. ${ }^{298}$ This has led to describing credit card transactions as being 'tripartite credit cards'. 299

\subsubsection{Remittances}

Remittances are flows of private money from one individual to another, usually cross-border. ${ }^{300}$ There is not necessarily a payment due to the recipient: the remittance could simply be a gift.

\footnotetext{
${ }^{293}$ ABSA (2011) 'ABSA Bank Cheque Cards', available at http://goo.gl/85vsY. ABSA Bank indicates that its cheque card is not a debit card since the card can only be linked to ABSA cheque accounts, whilst debit cards can be linked and issued from an ABSA savings or cheque account. ${ }^{294}$ Ibid.

295 As Cornelius explains, the only difference between ordinary credit cards and charge cards concerns the contractual terms that regulate payment to the credit card issuer by the cardholder. The cardholder must settle in a single payment to the credit card issuer any debt incurred by using the card while the credit cardholder may only need to settle a proportion of the overall debt at the end of a billing cycle. See S Cornelius (2003) 'The Legal Nature of Payment by Credit Card' 15(2) SA Mercantile Law Journal at 153.

${ }^{296}$ These cards contain memory for data storage and often include a processor for making calculations. See JO Grabbe (1999) 'Smart Cards and Private Currencies', available at http://goo.gl/CCYJ5.

${ }^{297}$ Charge cards like those from American Express and Diners Club require that the credit extension be settled at the invoice date, usually 30-45 days from purchase. Both credit and charge cards may be used without the cardholder being present, usually in a mobile, print, Internet or telephonic scenario and may or may not require the cardholder's signature or PIN code. They are generally used within a systemic payment system and linked to a user's bank. They are attractive to merchants and issuers alike as they attract less transaction charges and virtually none of the charge-backs opportunities characteristic of credit cards.

${ }^{298}$ See Cornelius (2003) op cit note 295 at 153, and WG Schulze (2005) 'Credit Cards, Unauthorised Withdrawals and Fraudulent Credit-Card Users' 17(2) SA Mercantile Law Journal at 203.

${ }^{299}$ Cornelius (2003) op cit note 295 at 153; JC Stassen (1978) 'Betaling deur Middel van 'n Driepartykrediet kaart' De Jure 134 at 135; KM Landey (1983) 'Consumer-Cardholder Defenses in Tripartite Credit Card Arrangements: A Battleground for the Beleaguered Bank' 88 Commercial Law Journal 84. However, this is not entirely accurate as there may be multiple parties involved, especially if the retailer banks with a bank or uses a card machine not issued by or not affiliated with that of the issuer. In this case the issuer and the acquiring institutions are different and the tripartite appellation is inaccurate: rather, the appellation is more suited to defining the minimum number of parties required for the operation of a credit card scheme. Cornelius (2003) op cit note 295 at 153-154.

${ }^{300}$ The CPSS defines 'remittances' as 'cross-border person-to-person payments of relatively low value'. See Committee on Payment and Settlement Systems (CPSS) (2007) 'General Principles for International Remittance Services', available at http://goo.gl/mxsnF.
} 
There are domestic and international remittance flows. In essence, a user will use a remittance intermediary - a person, store or institution - commonly called a MTO to send value to a recipient, who in some cases may be the same person as the sender. ${ }^{301}$ The payment intermediary may have retail agents at either end of the process, all of whom take a cut of the total remittance cost - which is usually borne by the sender. ${ }^{302}$ The cost of a remittance from South Africa to most African countries by banks or MTOs is between ZAR200ZAR250 per ZAR1400 which equates to $15-20 \%$ of the total value sent. ${ }^{303}$ The cost of a bank-to-bank transfer in South Africa may range from free to a percentage of the value to be transferred. There is anecdotal evidence that the people who use domestic remittance services do so because they need to travel inland by bus or train and choose to cash-out the remittance at their journey's end to avoid the security risk of transporting cash on their person. ${ }^{304}$ The South African national supermarket chain Shoprite-Checkers offers this type of service in conjunction with Capitec Bank for ZAR9.99 per transfer. ${ }^{305}$

While there are international MTOs such as Western Union and Moneygram that have been in existence for decades, MNOs see remittances as a relatively easy and profitable means to add value within the MFS paradigm and as fertile ground for use in MFS.

MNOs may enable remittances through their systems using either airtime or fiat value as the remittance source of value, where the latter is available. Where the user has a separate fiat-based purse on that MNO's ecosystem, the value could be sent to another user on that MNO's system - or to another MNO's system or to another MTO or bank where there is interoperability - such that the value transferred can ultimately be cashed-out or fully redeemed at an ATM, participating bank, MTO or merchant, or a cash-out agent. ${ }^{306}$ Similarly, MNO airtime is being used as a method to transfer value across borders and domestically with the

\footnotetext{
${ }^{301}$ South African Reserve Bank (SARB) (2010b) Personal Communication. The storage for this particular purpose is temporary and the storage, as it is, is not considered as a deposit nor as savings.

302 Ongoing World Bank studies show that commercial banks remain the most expensive way to send remittances, at a global average total cost of $12.79 \%$ in Q3 2010, compared to the global average total cost of 8.89\%. MTOs maintained their status of being the cheapest at $7.08 \%$, while post offices saw a significant increase in the average cost at $8.83 \%$. Flows are grouped into 'corridors'. The South Asia, Europe and Central Asia corridors were 6.54\% and $7.57 \%$ respectively, and were the best performers when compared to the global average. East Asia and the Pacific, Sub-Saharan Africa, the Middle East and North African regions demonstrate higher average total costs for migrant remittances compared to the global average. The Sub Saharan Africa (SSA) region has the highest average cost of sending, at $11.57 \%$. The World Bank's Global Remittances Working Group (GRWG) supported by the G8 (Group of 8) has as its goal a multi-year platform aiming at facilitating the flow of remittances by providing guidance and policy options to the global community, and reducing the cost of remittances by five percentage points in five years, the so-called 5x5 objective. These areas are identified in the CPSS General Principles for International Remittances Services, the internationally agreed framework to guide actions to enhance the efficiency of international remittances which also includes fostering market transparency and consumer protection; improving the payment systems infrastructure; reforming the legal and regulatory framework; enhancing market structure and competition; and adopting governance and risk management best practices. See World Bank (2010) 'Remittance Prices Worldwide' No 2, November, available at http://goo.gl/m5poF; World Bank (2011b) 'Remittance Prices Worldwide: South Africa', available at http://goo.gl/s9rMz. See also Italian Ministry of Foreign Affairs (2009) 'Rome Road Map for Remittances', available at http://goo.gl/aZgWi.

${ }^{303}$ World Bank (2011b) op cit note 303.

${ }^{304}$ SARB (2010b) op cit note 302.

${ }^{305}$ A recipient takes his South African Identity (ID) book, the money transfer reference number and the PIN given to the sender to any Shoprite Money Market counter to collect the money. Collecting the money is free and the money can be collected within 5 minutes from any Shoprite store in South Africa. One person may send or receive a maximum of ZAR5,000 per day with a maximum of ZAR25,000 per month. See Shoprite (2011) 'Consumer Services: Money Market', available at http://goo.gl/jLNDJ.

${ }^{306}$ See Annexure 1 passim for examples of these transfers.
} 
value for transfer funded from the user's prepaid airtime SOV. ${ }^{307}$ Other values considered as 'money' may also be used for transfer. ${ }^{308}$

Remittances represent the largest flows of money to developing countries and are considered the largest source of external financing in many developing countries and, in some cases, more than twice the official aid received by developing countries and more than foreign direct investment flows. Officially recorded remittances worldwide including flows to high-income countries, reached US\$440bn in 2010 while remittances sent to developing countries reached US $\$ 325 \mathrm{bn} .{ }^{309}$ With increasing globalisation and increasingly large expatriate communities - usually in the form of migrant workers - they routinely send funds home as gifts to mark births and marriages, or to assist a parent. ${ }^{310}$ At the macro-level, governments and international development organisations value remittances because of their potential contribution to economic development and poverty alleviation.

There are also a number of informal, unofficial, non-recorded and virtually untraceable informal (alternative) remittance schemes - or Informal Value Transfer Systems (hereafter IVTS) ${ }^{311}$ as they are also known. These include fei-ch'ien (China), huikuan (Hong Kong), hundi (India), hawala (Middle East), ${ }^{312}$ padala (Philippines) and pheikwan (Thailand), and may have Anti-Money Laundering (hereafter AML) and Terrorist Financing (hereafter TF) implications. ${ }^{313}$

IVTS are defined as any 'system, mechanism, or network of people that receives money for the purpose of making the funds or an equivalent value payable to a third party in another geographic location, whether or not in the same form. ${ }^{314}$ IVTS are utilised by a variety of individuals, businesses and even governments to remit funds domestically and abroad. Their initial growth was primarily rooted in facilitating trade between distant regions at a time when conventional banking instruments were either absent or weak, but as the IMF notes, in cases where the user's intent is of an illegal or criminal nature, he will use IVTS irrespective of the level of financial sector development. ${ }^{315}$ Two types of IVTS exist: first, a traditional system with similar characteristics and operations like those used centuries ago; and second, a modern or contemporary system that frequently intersects with customers and accounts in formal financial institutions. The process may be very simple or quite complex, depending on the IVTS type.

\footnotetext{
${ }^{307}$ See ch 6, s6.5.4.3 titled Mobile Airtime Transfer.

${ }^{308}$ See S Singh (2008) 'The Social and Cultural Interpretation of Number: A Focus on Remittances as a Currency of Care' at 3-6, available from http://goo.gl/Mmjwf.

${ }^{309}$ Sub-Saharan Africa received US $\$ 21.9$ billion (bn) in 2010, up 5.5\% from 2009. Nigeria and Egypt were the largest African recipients, while India received the highest amount of remittances worldwide in 2010 - an estimated US\$53bn; see World Bank (2011a) 'Migration and Remittances Unit: Migration and Development Brief 16 - Outlook for Remittance Flows 2011-13', available at http://goo.gl/SZ17Q.

${ }^{310}$ See also Singh (2008) op cit note 309 at 6.

${ }^{311}$ N Passas (2006) 'Fighting Terror with Error: The Counter-productive Regulation of Informal Value Transfers', available at http://goo.gl/gTZPh.

${ }^{312}$ In some countries in these regions, the term 'hawala' is also used to refer to money transfers in the formal financial sector.

${ }^{313}$ See ch 8, s8.5 titled Anti-Money Laundering, Terrorist Financing and Customer Due Diligence Laws and Regulations on AML; and C Lengalenga (2005) 'Some Critical Issues on Informal Value Transfer Systems in Eastern and Southern Africa Anti-Money Laundering Group Member Countries' in International Monetary Fund Regulatory Frameworks for Hawala and other Remittance Systems at 80-86. They may also be affected by the definition of money.

${ }^{314}$ FinCEN (2003) 'FinCEN Advisory 33: Informal Value Transfer Systems', available at http://goo.gl/HYfks.

${ }^{315}$ International Monetary Fund (IMF) (2003) 'Informal Funds Transfer Systems: An Analysis of the Informal Hawala System’ IMF Occasional Paper No 222, available at http://goo.gl/z3Gth.
} 
The transfers generally take place outside of the conventional banking system through non-bank financial institutions or other business entities whose primary business activity may not be the transmission of money. These money transfers occur in the absence of, or are parallel to, the formal banking sector channels. Hundreds of billions of dollars are channeled annually through these IVTS. In a basic or traditional IVTS transaction (such as hawala), four participants are required: a sender of the funds, a recipient of the funds and IVTS operators in the respective countries of the sender and recipient. ${ }^{316}$ The IVTS operator charges a flat fee, a commission, or may alternatively, or in addition, profit from the exchange rate differential between the official and the black market prices of the currency in the recipient country.

MNO airtime transfers could also be considered as an IVTS where simple prepaid voucher access codes are sent via SMS or email to recipient countries, and the value cashed-out by an airtime agent, or used by the intended end-user. ${ }^{317}$

Similarly, 'private currencies ${ }^{318}$ such as those offered by social networks like Facebook as well as online gaming products 'bought' by rogues who employ malware on mobile phones to charge unsuspecting mobile phone users, ${ }^{319}$ could easily be laundered by selling these currencies in exchange for fiat value.

\subsubsection{Stored Value Products}

\subsection{Overview}

By far the largest growth area in payments worldwide and the largest contributor to the decline in the use of cash are prepaid or prefunded electronic payment products variously also known as Stored Value Products (hereafter SVPs).

Having emerged from the technological evolutions of the 1980s, the Internet boom of the 1990s, and the mobile boom from around 2000, some SVPs are now mature, some are still growing, and others are yet to emerge. They encompass a vast variety of products, applications, users, technology types ${ }^{320}$ and business models that may reflect a particular niche use. ${ }^{321}$ They may be obtained and funded by consumers, government, or businesses, and may be intended for one-time, short- or long-term use, such that some SVPs allow (their stored) value to be replenished (reloaded) after use, and others do not. Examples include store

\footnotetext{
316 The FinCEN (2003) op cit note 315 describes a transaction sequence where an individual (\#1) in Country A wants to send money to an individual (\#2) in Country B: Step One: Individual \#1 gives currency to an IVTS operator in Country A; Step Two: The IVTS operator in Country A provides Individual \#1 with a code or other identification mechanism; Step Three: The IVTS operator in Country A notifies his counterpart in Country B by phone, fax, or e-mail of the transaction amount to pay Individual \#2 and the code; Step Four: Individual \#1 contacts the intended recipient, Individual \#2, in Country B and provides the code to that person; Step Five: Individual \#2 goes to the IVTS operator in Country B, gives the appropriate code, and picks up the specified funds sent to him.

${ }_{317}$ See ch 6, s6.5.4.3 titled Mobile Airtime Transfer.

${ }^{318}$ See ch 4, s4.8.4.4.4.1 titled Private Currencies.

${ }^{319}$ See ch 5, s5.7.4.4 titled Malware and Viruses.

${ }^{320}$ See ch 4, ss4.8.4.4.2 titled Stored Value Nomenclature; and 4.8.4.4.4 titled Commercial Incarnations.

${ }^{321}$ In some jurisdictions, the type of use of the card may determine the regulation, if any, that will apply to the card. For the retail permutations of these cards in the US and their respective state and federal regulation, see P Keitel (2010) 'Conference Summary: Federal Regulation of the Prepaid Card Industry: Costs, Benefits, and Changing Industry Dynamics', available from http://goo.gl/EsJT1.
} 
gift cards, payroll cards for paying salaries, those used for social purposes, transport cards, or a SOV in MFS systems. ${ }^{322}$

SVPs appear in a multitude of forms, varieties and means to use the value stored, that is the Store Of Value (hereafter SOV). One method may be via the use of a physical card - variously termed a Stored Value Card (hereafter SVC) - where value is stored locally in a 'cash-like' manner and only on the SVC. ${ }^{323}$ This method may be termed 'offline. ${ }^{324}$ Alternatively, the SVP may be non-physical, where value, its usage and the rules on how it may be used are stored 'online' in an account - the Stored Value Account (hereafter SVA) - housed on a central server operated by what may be termed a System Operator (hereafter SO), such as an MNO. ${ }^{325}$ The 'online' access mechanism for communication with the SVA could be via a mobile phone, POS device, or via a computer.

In all, the value being 'stored', be it cash-like (locally-only) on a physical device or via a remote central server accessible by any of the 'access' devices, is what gives a SVP its character.

The SOV is usually determined by the SO as the 'currency' of the system, and may be denominated in the UOA of the fiat currency or the UOA of some other private currency ${ }^{326}$ like MNO airtime minutes.

They are usable for micro- or macro-payments, ${ }^{327}$ and may be acceptable in a limited (closed), or general (open) range of merchant acceptors or persons. ${ }^{328}$ Thereto, the system may be available from (closed) private, non-financial institutions and entities such as transport authorities, stores, malls, ${ }^{329}$ or by more generalised (open) issuers approximating to the closed and open systems respectively. The boundaries of what constitutes an open or closed system will depend on the particular usage scheme. ${ }^{330}$

There are thus a number of entities that may be involved in the scheme, ${ }^{331}$ to wit, the 'issuer' of the product (or value) who determines the UOA, the method of storage and access, and who may or may not also be the day-to-day operator of the system and holder of the (stored) value purchased if it is an online access system, ${ }^{332}$ agent, retailer or distributor responsible for selling the SVP to the user, and a bank or financial

\footnotetext{
${ }^{322}$ See ch 4, ss4.8.4.4.2 titled Stored Value Nomenclature and 4.8.4.4.4 titled Commercial Incarnations.

${ }^{323}$ See ch 4, 4.8.4.4.3 titled Technical Aspects.

${ }^{324}$ See ch 4, s4.8.4.4.3.1 titled Local 'Offline' Storage of Value on the 'offline' use of SVPs.

${ }^{325}$ See ch 4, 4.8.4.4.3 titled Technical Aspects.

${ }^{326}$ See ch 4, s4.8.4.4.4.1 titled Private Currency. A 'private' currency may sometimes also be referred to as a 'virtual' currency.

${ }^{327}$ See ch 4, s4.8.3.5 titled Value of Payments.

${ }^{328}$ See ch 4, s4.8.3.7 titled Ubiquity of Use: Interoperability. There may be geographic restrictions on the usage so that the product is, for example, useable only in certain towns.

${ }^{329}$ SVPs in the form of magnetic stripe SVCs may also be termed 'gift cards'. See ch 4, s4.8.4.4.4.4 titled Open and Closed SVPs.

${ }^{330}$ See ch 4, s4.8.3.7 titled Ubiquity of Use.

${ }^{331}$ See ch 4, s4.8.4.4.5 titled Underlying Financial Relationships. For a useful summary (albeit without any MFS components to it, and also US-centric) of the possible participants in a SVP ecosystem, see The Financial Crimes Enforcement Network (FinCEN) (2010) 'Amendment to the Bank Secrecy Act Regulations: Definitions and Other Regulations Relating to Prepaid Access 31 CFR Part 103', available at http://goo.gl/2k9Bh at 36-37; FinCEN (2010) 'Amendment to the Bank Secrecy Act Regulations: Definitions and Other Regulations Relating to Prepaid Access 31 CFR Part 103' at 4, available at http://goo.gl/2k9Bh.

${ }^{332}$ That is, the System Operator.
} 
institution that may house the funds collected from the public in a so-called 'pooled account'; and merchants who accept the SVP for payment. ${ }^{333}$

This array of SVP permutations alludes to the fact that the nomenclature on SVPs is fuzzy and inconsistent. One consequence of this heterogeneity and the varied maturity of SVP niches is that establishing a scope for regulation of a particular system or even generically for all SVP types can be difficult, ${ }^{334}$ posing challenges for regulators. ${ }^{335}$

The interplay between the varieties and the inconsistent stored value nomenclature that attempts to describe them will be discussed below.The comprehensive technical, commercial, legal, economic and prudential analysis that follows includes discussion of the creation and issuance of a SOV, the transaction flows, the settlement process, ${ }^{336}$ and the position of the SOV in relation to the 'deposit' concept. ${ }^{337}$ The application to MFS as a species of a SVP is also discussed. ${ }^{338}$ To put all the systems into context however, there is a need first to discuss the often-confusing and contradictory nomenclature 'soup' that surrounds SVPs. ${ }^{339}$

\subsection{Stored Value Nomenclature}

SVP is a useful and fairly accurate totem around which to hang all forms of emerging and commercialised consumer payment mechanisms touted as electronic replacements for cash.

However, constrained either by legacy nomenclature or incorrect conceptualisations of technology based on legacy commercial models that harp back to the 'irrational exuberance' of the early days of the commercial Internet in the 1990s, the nomenclature - and the relationships implied - surrounding new types of consumer-based electronic payment mechanisms is a lot more fuzzy. Indeed the nomenclature is still evolving, with regulators ${ }^{340}$ and scholars ${ }^{341}$ largely playing catch-up.

\footnotetext{
${ }^{333}$ See ch 4, s4.8.4.4.6 titled Pooled Master Accounts.

${ }^{334}$ Keitel (2010) op cit note 321 at 5.

${ }^{335}$ See for example the EU's first Electronic Money Directive (hereafter EMD1) - Directive 2000/46/EC of the European Parliament and of the Council of 18 September 2000 on the taking up, pursuit of and prudential supervision of the business of Electronic Money Institutions (hereafter ELMI or ELMIs) which had to be (effectively) discarded and then reworked to provide a more 'future proof' technology neutral framework following the discovery of inconsistencies in application to inter alia the airtime SVA offered by MNOs. See ch 9, s9.6.3.1 titled Background on the EMD1; and FinCEN (2010) op cit note 331 at 4.

${ }^{336}$ These stages of the life cycle of a SOV were devised by the Australian Bankers Association (ABA) (1997) 'A Commercial Lawyer's Take on the Electronic Purse: An Analysis of Commercial Law Issues Associated with Stored-Value Cards and Electronic Money (Task Force on Stored-Value Cards)' posted on Highbeam Business, 1 February, and originally published in Business Lawyer, available from http://goo.gl/n1b75. See also ch 3, s3.2.4.1 titled Issuance and Production.

${ }_{337}^{337}$ See ch 4, 4.8.4.4.7 titled Issuers and the Deposit Concept.

${ }^{338}$ See ch 4, s4.9 titled Application to MFS.

${ }^{339}$ See ch 4, ss4.8.4.4.2 titled Stored Value Nomenclature.

${ }^{340}$ See the proposed ruling made by the US Department of the Treasury's FinCEN indicating that they wish to rename 'stored value' as 'prepaid access' and define that term, in order to address regulatory gaps that they say have resulted from the proliferation of prepaid innovations since the original FRB rules were formulated, because if these gaps are not addressed, they believe there is increased risk for the use of prepaid access as a means to further ML. For the proposed rules and their rationale, see FinCEN (2010) op cit note 331. See also W Jack, T Suri and R Townsend (2010) 'Monetary Theory and Electronic Money: Reflections on the Kenyan Experience' 96(1) Economic Quarterly at 84, available from http://goo.gl/w5jvx. This effective parallel currency has triggered concerns amongst national governments and central bankers that these new paradigms may inter alia provide loopholes that may frustrate global efforts to combat ML and TF.

${ }^{341}$ This 'fuzziness' also permeates scholarly writings, where the method of usability - the functional aspects - appears to take centre stage, and which may mean that navigating a proper comparative study of this topic, a minefield of mis-directions.
} 
The landscape is thus littered with many totems, which now include the following that have entered the payments and banking lexicons: Stored Value Card (SVC), Store of Value (SOV), Stored Value Account (SVA), electronic money (e-money), mobile money (m-money); Cybercash, electronic wallets (e-wallets), electronic purses (e-purses), Digicash, Cyberbucks, gift cards, Electronic Gold (eGold), cloud-based accounts, networks-based accounts, account-based, online accountable systems, offline accountable systems and distributed accounting systems. The more recent incarnation is of course Mobile Financial Services (MFS).

Indeed, the genesis for this nomenclature 'soup' derives from early regulations related to prefunded stored value. Most of the literature has followed the lead from the BIS, CPSS and the US Federal Reserve Bank (hereafter US FRB or FRB) regulators in ascribing products and feature sets under available headings. Thus, the US FRB rule on Electronic Funds Transfers ${ }^{342}$ in 1996 introduced the concepts ${ }^{343}$ of stored value as either 'off-line accountable stored value systems', 'off-line unaccountable stored value systems' and 'online stored value systems'. ${ }^{344}$ The scope of the rules were linked to an 'account' as a possible EFT from an account based on the US Electronic Fund Transfer Act (hereafter US EFTA or EFTA) and its Federal Regulation E (hereafter Reg E), although they were also referred to as 'access products' presumably as a subset of stored value. ${ }^{345}$

Even though these definitions are limited to the commercial models, understanding and technology of that era, ${ }^{346}$ the initial use of this terminology has since led to a plethora of associated terminology in the literature designed to articulate commercial and technical variations, such that the original terminology is extended now by additional terms such as 'trackability', 'accountable' and 'unaccountable' and indeed as definitions of the original terminology $\mathrm{y}^{347}$ or, when necessary, they are discarded altogether. ${ }^{348}$

\footnotetext{
${ }^{342}$ See 61 Fed. Reg. 19,696, 19,699-19,703 (May 2, 1996) (codified at 12 C.F.R. pt. 205), available at http://goo.gl/F610d. See also Federal Deposit Insurance Corporation (FDIC) (1996) 'General Counsel's Opinion No. 8: Stored Value Cards', 61 Fed. Reg. 40,490 40,494 which outlines the US FDIC's legal opinion regarding the proper treatment of funds underlying SVCs for purposes of qualifying for federal deposit insurance. See also Task Force on Stored-Value Cards (1997) 'A Commercial Lawyer's Take on the Electronic Purse: An Analysis of Commercial Law Issues Associated with Stored-Value Cards and Electronic Money' 52 Business Lawyer 653.

${ }^{343}$ For the genesis of their consultations and thinking, see SI Lelieveldt (1997) 'How to Regulate Electronic Cash: An Overview of Regulatory Issues and Strategies' 46 American University Law Review at 1163, available at http://goo.gl/RHFTy. ${ }^{344}$ Offline accountable was said to relate to where a system 'tracks' the account usage, but not in a real-time manner. Offline unaccountable relates to a system that does not 'track' the account usage, nor does it have access to system usage in a realtime manner.

${ }^{345}$ Coverage of stored-value systems under the EFTA and Reg E depends on whether a stored-value transaction involves an EFT from a consumer's asset account. The Board made clear that a transaction involving such cards is covered by Reg E when the transaction accesses a consumer's account, such as when value was 'loaded' onto the card from the consumer's deposit account via an ATM.

${ }^{346}$ The distinction between locally stored value and access products, or hybrids of the two, is sometimes confused. See for example the plethora of overlapping and sometimes technologically contradictory definitions by regulatory bodies such as the US Treasury Department's FinCEN where its Task Force on money laundering referred to and tried to make sense of 'storedvalue products', which they said comprise stored-value cards, or 'electronic purses', and similar products that utilise computer networks, sometimes referred to as 'digital cash'; see FinCEN (2000) 'Electronic Cash, Electronic Banking, and Internet Gaming', available at http://goo.gl/6gkio.

${ }^{347}$ Akindemowo (2009) op cit note 82 at 309, and E Akindemowo (2010) 'How to Devise U.S. SVP Policy? Prepare to Replace the Deposit Concept' Thomas Jefferson School of Law Research Paper No 1600888 at 28. See also Geva (2008a) op cit note 157 at 702, who says the FRB's classification ought to apply to both access and store value systems, and disagrees with the original classification of the offline accountable and online accountable systems as stored value. According, then, to Geva's revised classification, card payment systems may well be classified as offline unaccountable, offline accountable or online accountable. Similarly, see Kreltszheim who believes that only an online accountable system where the system 'tracks' the account usage and in a real-time manner is worthy of legal characterisation as an 'account'. He bases this on its feature-set of fully-fledged accountability which he terms its 'cognitive' ability. D Kreltszheim (2003) 'The Legal Nature of "Electronic Money": Part 1' 14 Journal of Banking and Finance Law and Practice 161.
} 
In 1996, around the same time as the FRB rule-making on stored value, the CPSS also released its own set of definitions of SVPs, which comprised SVCs, or 'electronic purses', and similar products that utilise computer networks, sometimes referred to as 'digital cash' and a multitude of product names. The CPSS defined 'stored value' products as:

'... prepaid payment instruments in which a record of funds owned by or available to the consumer is stored on an electronic device in the consumer's possession, and the amount of stored "value" is increased or decreased, as appropriate, whenever the consumer uses the device to make a purchase or other transaction. ${ }^{349}$

Similarly, e-money products were defined by the BIS as 'stored value' or 'prepaid' products in which a record of the funds or 'value' available to a consumer is stored on an electronic device in the consumer's possession. ${ }^{350}$ The CPSS further distinguished between these SVPs and 'access' products, where instead of the value being stored locally, it is instead stored centrally. ${ }^{351}$

The resultant 'soup' of terms from these global bodies does not bring any clarity to the situation, but ultimately, though, it is submitted that they are all 'stored value': it is just the means of access to the value that fundamentally differs, be it simply offline (local) or online, or a combination of both.

At some stage all these terms were subsumed and conflated into the technology lexicon as 'e-money' as it became popularly known such that this became the appellation for legislation revolving around these new forms of stored value. ${ }^{352}$ Many of the terms though still dominate as perceived terms of art although in many instances, the terms 'stored value', 'e-money', or 'm-money' are used as generic descriptors of systems.

As such, in an increasingly technological age where mobile-, Internet- and card-based systems are converging, a more appropriate omnibus and technologically neutral term to describe this evolution may, it is submitted, simply be SVP or SVPs and this descriptor is used throughout this study.

To use a helpful taxonomic analogy ${ }^{353}$ the term SVP is used in this study to describe the 'family' of systems or devices that store value electronically. The next level down, the 'genus,' is where the actual useable value - the SOV (to wit, money) - is kept (stored) in some type of accessible online account-based or local-only

\footnotetext{
${ }^{348}$ FinCEN (2010) op cit note 331.

349 Committee on Payment and Settlement Systems (CPSS) (1996) 'Security of Electronic Money' at 3, available at http://goo.gl/DhrkY. The user simply uses an appropriate device or system to obtain access to the value and associated payment facilities through computer and telecommunications links.

${ }_{350}$ BIS (1996) op cit note 157.

${ }^{351}$ CPSS (1996) op cit note 339 at 3.

${ }^{352}$ In some cases entire sets of regulations were developed around the term 'e-money', for example the EMD1. See ch 9 , s9.6.3.1 titled Background on the EMD1.

${ }^{353}$ In binomial nomenclature, the hierarchy of biological classification has eight major taxonomic ranks. At the top is the family, which contains one or more genera, which in turn consist of many species. The full tree is in order of hierarchy: family; subfamilies; tribe; sub-tribes; genus; subgenus; section; subsection; series; subseries; species; subspecies; variety; sub-varieties; form; sub-forms. See 'Genus' (s.d.) in Wikipedia: the Free Encyclopedia, available at http://goo.gl/esvju.
} 
storage, the SVA and SVC respectively (to wit, a purse). 'Species' of the SVA may be 'e-money',354 or 'mobile money'. The SOV may either be in a UOA that is fiat-based or which uses a private UOA. ${ }^{355}$

As noted earlier, SVPs are prefunded, with the value available either through local storage on a device ('offline'), or through an access device like a mobile phone or computer ('online'). ${ }^{356}$ These are explored below.

\subsection{Local 'Offline' Storage of Value}

The moniker SVC is usually applied to 'offline' systems and devices that place and store value locally and electronically on a device like a credit-card sized plastic 'smartcard' with an embedded chip ${ }^{357}$ or with a magnetic stripe card. It may also be a contactless ('proximity') payment device that has a Radio Frequency Identity (hereafter RFID) ${ }^{358}$ radio chip embedded in it which communicates with a nearby reader at a POS, or the latest in proximity incarnation, Near Field Communications (NFC)-based devices or phones, ${ }^{359}$ and combinations thereof. ${ }^{360}$

Value is added to the SVC in exchange for fiat money and deducted from the SVC per usage. ${ }^{361}$ As the stored value may be stored simply as a record 'offline' 362 - that is, just on the SVC - then the loss of the

\footnotetext{
${ }^{354}$ The term e-money is used commercially as a generic moniker, but the use of the converged term SVP to describe the abovementioned multitude of prefunded products allows simpler analysis of the regulatory legal regimes and the technological art it purports to regulate to be accomplished uniformly across jurisdictions under comparison, even though regulatory regimes are usually cast in the terminology of the technological age in which they were written.

${ }^{355}$ For a graphical example of the interaction between the SVP, SVA, SOV (and UOA) in a MNO setting, see Exhibit A in ch 2, s2.1 titled Introduction. For examples of 'offline' (local) storage, see below at ch 4, s4.8.4.4.3.1 titled Local 'Offline' Storage of Value; and for 'online' ('cloud-based') storage, see ch 4, s4.8.4.4.3.2 titled 'Online' Storage of Value. See also somewhat similar categorisations of SVPs and e-money by IL van Jaarsveld (2011) 'Aspects of Money Laundering in South African Law,' LLD thesis, University of South Africa at 59, who describes e-money as having two main 'species,' based on bespoke 1996 categorisations of generic 'electronic purses' by Struber in G Struber (1996) 'The Electronic Purse: An Overview of Recent Developments and Policy Issues,' available at http://goo.gl/NOEzl. As to whether this SVA and the SOV within amounts to 'money', see ch 3 passim for an overview of the legal and economic components of 'money' and then ch 13 passim on a revaluation of money.

${ }^{356}$ See ch 4, s4.8.3.6 titled the Accessibility and Tracking of Payment Systems: Online and Offline.

${ }^{357} \mathrm{Such}$ as those used by the EMV specification, EMV (Europay, MasterCard and Visa) is a global standard for credit and debit payment cards based on chip card technology. As of the end of 2010 there were more than 1.24bn EMV compliant cards. See the EMVCo home page at http://www.emvco.com. These cards contain memory for data storage and often have a processor for performing encryption. See Grabbe (1999) op cit note 296.

${ }^{358}$ See ch 5, s5.5.6.4 titled Radio Frequency Identity.

${ }^{359}$ See ch 5, s5.5.6.5 titled Near Field Communication. NFC, which is built into mobile phones as an access mechanism for payments, may have an offline and online component to its usage depending on whether it is in a MNO coverage area and/or if allowed by the system operator. It is effectively 'offline' when there is no MNO coverage, such that the phone and any value stored locally on it in a secure, encrypted area of the phone's components becomes a type of SVC in that usage context. ${ }^{360}$ Communication with a POS terminal may be via the magnetic stripe, or the embedded chip.

${ }^{361}$ In this scenario, the cards have the value embedded in the magnetic stripe or chip, and the value is reduced per transaction. The balance is checked each time by only the terminal it is being used with every time the card is used at the POS and, once depleted, the card is discarded. As the value is used up in a transaction, the balance attached to or embedded in the card is reduced concomitantly. Like bank debit cards, they only have utility if they have sufficient funds for a transaction. If the card is lost, the value is lost. Some issuers will enforce a non-activity fee and/or an expiry date, and hence profit from non-use. See M Furletti (2004a) ‘Prepaid Card Markets and Regulation' at 3, available at http://goo.gl/3eGbi.
} 
card or similar devices means catastrophic loss of the value available, just like loss of cash in a wallet or purse. ${ }^{363}$ Hence, the use of such terms as 'purse', 'wallet' or 'digital cash' for the many SVC incarnations. ${ }^{364}$

\subsection{2 'Online' Storage of Value}

Depending on the technical construction and design of a system, the value being stored and the subsequent use of that value for payment or transfer may or may not be tracked by the SO. This is the 'online' iteration of SVPs, where the value is stored in a SVA, ${ }^{365}$ and tracked by a SO though the omnipresent technology 'cloud'.

In this access paradigm, the user needs to have some sort of remote access to that central server so as to access the available value in their SVA. Usage and replenishment is usually a simple process of debits and credits on the centralised SVA. ${ }^{366}$ To use the value, the customer usually pushes value to the merchant or to another user. Loss of the access device does not necessarily lead to catastrophic loss of the available value. $^{367}$

MFS systems largely employ the online SVA access mechanism for their users. ${ }^{368}$

\section{Commercial Aspects}

\subsection{Commercial Incarnations}

\subsection{Private Currencies}

Private currencies are those issued by commercial entities for use within their own commercial ecosystem or which may be exchanged (interoperable) with private currencies and offerings from other commercial entities. ${ }^{369}$ Those in a closed loop system include the MNO's airtime value, supermarkets, bookselling chain

\footnotetext{
${ }^{362}$ See ch 4, s4.8.3.6 titled Accessibility and Tracking of Payment Systems.

${ }^{363}$ Again, this relates to an 'offline unaccountable' manifestation.

${ }^{364}$ Many cards are sold in fixed amounts and used in an offline environment such as a transport SVC. A parking SVC, for example, could be loaded with value and used for payment at the parking POS device, with an amount required for payment of parking removed from the SVC upon each use. As a result, SVCs are most vulnerable to cloning or other types of hacking and loss of the value if lost. However, these offline systems seldom have an audit trail accessible to the consumer once lost. Owing to their potential for fraud, these systems are less prevalent than the online version where the account balance is stored centrally.

${ }^{365}$ See ch 4, s4.8.4.4.2 titled Stored Value Nomenclature; and Exhibit A in ch 2, s2.1 titled Introduction.

${ }^{366}$ The SVA is usually prefunded via cash, debit or credit cards, or electronically via some transfer facility like a remittance or EFT.

${ }^{367}$ This may of course depend on whether the user employs adequate safeguards, where available, such as having a PIN and keeping the PIN safe. See ch 7, ss7.3.6.5 titled Allocation of Risk, Loss and Liability, and 7.3.6.5.4 titled Bank Customers on the allocation of fault with respect to users; and ch 4, ss4.5.2 titled Nature of the Relationship and Duties on the relationship of the duties between a bank and its customers; and 4.8.3.8 titled Security and Reliability of Payments. See also Schulze (2006) op cit note 114, and the discussion therein of Duvenhage op cit note 117 in relation to duties of care a bank may have to its customer and delictual liability that may follow.

${ }^{368}$ See ch 4, s4.8.4.4.4.3 titled Mobile-type SVPs. Similarly, see ch 4, 4.8.4.4.4.3 titled Network-based SVPs.

${ }^{369}$ These may also be seen as 'complementary currencies' that are accepted in payment, which are different from legal tender and do not aim to replace but only to complement the conventional national currency. They are therefore designed to function in parallel with or as a complement to these conventional currencies. See BA Lietaer (2002) 'The Future of Payment Systems: Unisys Corporation' at 19, available at http://goo.gl/mlb1C. The use and categorisation of money as a currency is in large
} 
stores and Internet-based-businesses, for example those from emerging social media behemoths like Facebook who issue their own 'Facebook Credits'. 370

Indeed, the most common type of commercial private currencies today are the loyalty or reward currencies, such as 'frequent flyer miles' or 'airmiles ${ }^{371}$ from airlines or from chain stores. ${ }^{372}$

\subsection{Network-based Payment Products}

Other manifestations of SVP, which are not necessarily card-based, are the non-mobile but network-based (Internet-based) SOV that use a SVA. These systems are typically online, network-based SVAs operated by Payment Service Providers (hereafter PSPs) that allow consumers to access the value kept in their SVAs for use in activities such as banking, third party or other payments or transfers, a record of which is retained by the SO. ${ }^{373}$ PayPal, the Internet-based payment intermediary, is the most prominent and most successful exemplar of a network-based PSP. ${ }^{374}$ It has a central float that holds the value in its system. ${ }^{375}$

\subsection{Mobile-type SVPs}

As noted earlier and discussed in further detail elsewhere, in the MFS environment depending on commercial and regulatory imperatives, an MNO may simultaneously provide a SVA with a SOV to its users which uses two types of SVAs. ${ }^{376}$ The first is a closed, usually non-interoperable, SVA using a SOV in a UOA of the MNO's own 'airtime' currency. ${ }^{377}$ Additionally, if there is a regulatory opportunity, the

measure derived from the various economic, legal and national perspectives of money, discussed in detail below. See ch 3 , s3.12.3.2 titled Money as Fiats, Legal Tender and Currency.

${ }^{370}$ On a discussion of whether these amount to 'money', see ch 13 passim. See also ch 3, ss3.6 titled Money and Currency: General View; and similarly, 3.12.3.2.2 titled Money as Currency: Legal View.

${ }^{371}$ One figure quoted is that the global stock of unredeemed airmiles at one stage was worth about US\$700bn - more than all the US dollar bills in circulation. See S Wilson (2007) 'What To Do With Your Airmiles', available at http://goo.gl/ij6Ld.

372 One study says that out of roughly US\$48bn worth of perceived value in reward points and miles US businesses issue annually, at least one-third, representing US\$16bn in value, goes unredeemed by consumers. See K Hlavinka and J Sullivan (2011) 'The Billion Member March: The 2011 COLLOQUY Loyalty Census', available from http://goo.gl/xatFc.

373 They are usually proprietary, garden walled and network-based in the sense that they store value transferred to their central systems and allow this value to be sent to other users on their system. Although a number of PSPs came to the fore during the Internet boom of the 1990s, many of these early innovators, such as Digicash and Mondex, went insolvent. See T Clark (1998) 'DigiCash Files Chapter 11' CNET News 4 November, available at http://goo.gl/Zri97.

${ }^{374}$ It allows its users to simply create an account using their email address and allow others to send money to that account for payment of goods and services or for remittances. To pay another accountholder, one PayPal user will simply insert the email address of the recipient into the PayPal website, WAP site or mobile application: no device - other than any Internet-enabled computing device or mobile phone - is needed to access the PayPal system. PayPal has inter alia added mobile functionality to their offering where users simply send a SMS with the recipient details to the central PayPal server and the payment is effected. Users can also pay using WAP or add a PayPal software application to their compatible mobile phone. However, these are simply auxiliary access facilities: no devices or cards are needed to access the core PayPal functionality. Access to the value may simply be through software accessing the Internet or some other system in the online 'cloud', and with no other credentials required other than a user name and password.

${ }^{375} \mathrm{PayPal}$ was subject to some regulatory scrutiny in the US insofar as its system may have violated government consumer protection regulations, in particular, those allowing recourse for fraudulent transactions. See the discussion in ch 11, s11.2.5.8 [Note to Leon: This section no longer appears in latest version of Table of Contents.]on the PayPal case in which this was in dispute. Users can use a credit card or debit card, or an EFT from a bank to add value to the PayPal account and can also use a PayPal-issued ATM card to withdraw as cash the value in their accounts.

${ }^{376}$ On the types of services allowed, see ch 2, ss2.2 titled The Rationale for MFS and in particular, Exhibit A and 2.4 titled Services Available in MFS. On the methodology employed by MNOs to allow prefunding into a SVA for use in access to basic telecommunications services and VAS, see ch 5, s5.2.2 titled User Access to Mobile Networks. See also the models described in ch 6, ss6.4 titled Licensed Bank-Led Model, 6.5 titled MNO-Led Models, 6.4.3 titled Licensed Bank-MNO Model and 6.6 titled Hybrid MFS Models.

377 On a discussion of whether these amount to 'money', see ch 13 passim. 
MNO may provide a second SVA, in the forms of fiat money SOV where the value is redeemable back into fiat value and which may be used for general payments and remittances. ${ }^{378}$

\subsection{Open and Closed SVPs}

Many SVPs are designed to be used only in a closed loop (walled garden) system, while others have more or nominally more 'open' use. There may be some interoperability between some SVPs operated by different SOs.

Open system prepaid SVCs are those issued by third parties like banks, Visa and MasterCard, money transmitters and to some extent some MNOs involved in financial or similar services. ${ }^{379}$ Unlike closed system cards, they are mostly generally redeemable and accepted by multiple merchants. ${ }^{380}$ They usually have a magnetic stripe on the back or an embedded chip and they operate on and carry the logo of a branded card network like MasterCard, Visa or American Express. When value can be replenished on the SVC, ${ }^{381}$ the cards are generally known as General Purpose Reloadable (hereafter GPR) cards which can serve as substitutes for accounts for many unbanked individuals. ${ }^{382}$

Closed loop SVPs may contain fiat-based products or contain those based on private ('virtual) currencies. ${ }^{383}$ Fiat-based closed-loop SVPs may be store 'gift' cards which can only be used within a predefined group of stores, usually a large chain store or any of the shops within a particular mall. ${ }^{384}$ Others may be special purpose payment instruments such as for health care expenses and social welfare payments, ${ }^{385}$ while others may be are used to pay for mass transit fares or a combination of all. ${ }^{386}$

\footnotetext{
378 These fiat-based SVA are nominally interoperable: for example, the MNO may allow payments to third parties, but may not allow value transfer from its SVA to the SVA of a competing MNO.

${ }^{379}$ See VAS purchase by WASPs, ch 6, s6.5.4.2 titled WASP VAS. MNOs may, however, be prohibited by regulation from operating a fiat-based SVA for purchasing corporeal goods, and the value of what they may purchase and/or keep in their SVA may be stymied by the restrictions of the AML regulations. On the regulatory view in South Africa on WASP VAS, see ch 12, s 12.2.2 titled Wireless Application Service Providers VAS.

380 They are usually not restricted to one merchant chain or geographic area.

${ }^{381}$ While some cards can be replenished with value, others such as travel cards, insurance claim cards, and most gift cards, cannot.

${ }^{382}$ See ch 2, s2.2 titled The Rationale for MFS. Other scenarios where the value is provided is via social good. The prefunded, possibly reloadable, prepaid debit card is another of the burgeoning financial services products worldwide aimed primarily at the unbanked. For a more detailed discussion, see SLW Rhine and S Su (2005) 'SVCs as a Method of Electronic Payment for Unbanked Consumers Office of Regional and Community Affairs FRB of New York', available at http://goo.gl/Gr7Zz.

${ }^{383}$ See ch 4, s4.8.4.4.4.1 titled Private Currencies.

${ }^{384}$ It is thought that the national Blockbuster video store chain in the US launched the first stored value/prepaid product as a magnetic stripe SVC that replaced its paper gift certificates. It allowed them to offer the purchaser a more attractive product that, unlike its paper-based predecessor, could be issued in any denomination. The gift cards also allowed the balance to be monitored and offered security features against alteration or fraud. See M Buchanan (2009) 'The Vile History of Gift Cards and How They Came to Destroy Christmas', available at http://goo.gl/IusYw. Gift cards are usually purchased in various denominations as a gift for someone, replacing the traditional store paper-based voucher gift. These gift cards may have expiry dates for the funds and per-usage or per-month usage costs, which can rapidly drain their value if the consumer is not aware of these terms of use. The US and South Africa have sought to bring some consistency to prepaid cards, although in the US fragmented regulation according to the type of use and whether state or federal law applies have stymied consistent regulation. See s63 of the South African Consumer Protection Act 68 of 2008 (hereafter CPA) on SVPs discussed in ch 12, s12.10.2.2.2 titled Ownership of (MFS) SOV.

${ }^{385}$ Also known as Electronic Benefit Transfers (hereafter EBT) or simply Electronic Benefit Cards (hereafter EBCs), these are payments made via individual prepaid magnetic stripe cards preloaded with value. They may be used in social and government applications, for example, pension payouts can be made via individual prepaid magnetic stripe cards preloaded with welfare payments. For example in South Africa, which has a large proportion of unbanked persons, a pensioner is issued with a card that is loaded with the pension amount by the authority. The holder can then use the card as a debit or ATM card nationally. The US Department of Treasury likewise introduced a prepaid debit card called Direct Express for delivery of benefit payments to social security recipients without bank accounts. Finextra (2008) 'US Treasury to Introduce Pre-paid
} 


\subsection{Interoperability Between SVPs}

While many SVP systems are closed or normally open in some cases, there may however be some modicum of interoperability between these closed - fiat-based and virtual - systems. Indeed, business models in this sector have advanced to the extent that the initial 'private' currency can also be used to purchase other similar private currencies at an exchange rate determined by each SO. Thus it would be possible, ad infinitum, to purchase other virtual currencies, with or without an ability to 'cash-out' to a fiat currency where the currency in the chain allows it, and more specifically, where regulation allows it. ${ }^{387}$ However, while interoperability between fiat-based systems may be mandated, ${ }^{388}$ insofar as 'private' non-fiat systems, it appears that while there is some regulatory oversight of the initial purchase of the virtual currency using fiat monies, the resultant purchase chain of other virtual currencies using virtual currencies has very little oversight, especially within prudential and financial services frameworks. ${ }^{389}$ They are also easily laundered.

Another prominent closed-loop combination is of course in MFS, the focus of this study. Depending on commercial and regulatory imperatives, a fiat-based SVA used in MFS implementations may or may not have ubiquitous interoperable (open) use, for example, as a remittance to users on other MNOs, sending the value to a bank account or ATM machines, for bill payments, and for purchasing corporeal goods. ${ }^{390}$ Transfers of value - using so-called airtime donation or transfer remittance schemes - are available intraMNO, but usually not to and from other MNO's systems, unless the other MNO is part of the same company. $^{391}$

Welfare Card', available at http://goo.gl/07Thy. See ch 11, s11.1 titled Overview of MFS in the United States of America for a brief overview of their use in the US.

${ }^{386}$ The US Internal Revenue Service (hereafter IRS), however, devised a new rule effective from 2012 whereby under IRS Ruling 2006-57, employer-provided transportation fringe benefit systems that involve prepaid cards must be structured such that these prepaid cards function only as fare media for transit systems and cannot be used to purchase other goods or services. See IRS (2010) Internal Revenue Notice 2010-94 (December). As Keitel (2010) op cit note 321 at 12 points out, the IRS had to delay the rule, an example of inconsistencies that sometimes exist between requirements specified in a regulation and the ways in which the electronic payment system functions.

${ }^{387}$ The settlement and exchange rate mechanism between the various SOs in these private currency purchase chains are not analysed here. It is only the consumer-facing component and the exchange rate that is highlighted.

${ }^{388}$ See for example South African Reserve Bank (SARB) (2011d) 'NPSD: Position Paper on Interoperability' NPS 01/2011, available at http://goo.gl/gVB09 which encourages e-money interoperability between e-money issued by banks. See further on e-money in South Africa, ch 12, s12.4.4 titled Conclusion: E-Money.

${ }^{389}$ Consumer protection legislation, where it exists, may have some application, but there are no specific financial regulations that provide oversight, firstly, of the modus of the interchange between (virtual) currencies, the nominal 'exchange' rates that they care to use, their longevity as a currency and of their buying power at a particular purchasing power point, and the modalities of the arcane payment mechanism they care to use insofar as a determination of the consumer remedies should a dispute arise. See ch 12, s12.4.2.3 titled Interoperability. Interoperability between systems could be addressed by a new payment-specific law in South Africa. See inter alia, Recommendation 4 in ch 14, s14.9.3 titled Payment Providers on a proposed new regulatory regime encapsulated in a Payment Services Provider Law (hereafter PSPL).

390 For competitive reasons, a MNO may also not allow any interoperability in remittances between its networks and competitors. On the types of services allowed, see ch 2.2 titled The Rationale for MFS and in particular, Exhibit A. On application of these fiat-based SVAs, see the Bank-MNO MFS Model described in ch 6, ss6.4.3 titled Licensed Bank-MNO Model, and the model described in 6.5 titled MNO-Led Models.

${ }^{391}$ Ibid. For example, the ability of users of MNOs such as the pan-African MNOs MTN and Zain to transfer airtime value from a participating network in one country to another participating network in another country. 


\section{The Process of Issuance}

Depending on the system scheme, the fiat funds a user provides for later use in an SVP-based transaction may fasten to one or to a number of players in the scheme. Not all schemes are alike, such that the schemes generally determine the financial relationships. Concomitantly there may be a number of possible participants, to wit, the SO which is usually in an MFS sense an MNO; the SO's agent; the merchant; a licensed bank; and a Trust Company if so used for placing funds in a pooled account. ${ }^{392}$

When the SO or his/her agent receives fiat funds from a user, a SOV is ultimately issued for the beneficial use of that user and placed in their SVA. ${ }^{393}$ In the initial phase of this process, the SO will exchange the received fiat value for a SOV value, which may or may not be, at par and in the user's fiat UOA. ${ }^{394}$ The user may provide funds to the $\mathrm{SO}$ directly or to his agent if the $\mathrm{SO}$ is the issuer. The fiat funds received by the SO or his agent will usually land up in the bank account of the SO, who may have a depository relationship with a licensed bank. There may also be an intervening entity, for example a trust company subsidiary of the SO which may for safety and soundness reasons be used to store the (pooled) user funds, ${ }^{395}$ The SO - or even their trust company subsidiary - then is the ultimate beneficiary of the value placed with the bank. ${ }^{396}$

In all cases and at a high level, the prepayment usually manifests as the need for someone other than the user to effect the payment to a merchant: there is thus no need for the user - who has already prepaid his value and received a SOV for it - to participate in these settlement arrangements. ${ }^{397}$ Where the SO is a licensed bank, ${ }^{398}$ a typical bank-customer deposit relationship such as that envisaged by Foley ${ }^{399}$ and the concomitant incidences (of a deposit) may come into being, depending of course on the scheme agreed upon between the parties. ${ }^{400}$ Where, however, the bank devises a scheme that converts the fiat value to some alternative private UOA, such as points for a closed-loop bank loyalty scheme that is based on the scheme's particular fiat-exchange rate, the SOV in a SVA may usually be redeemed back into the fiat currency.

\footnotetext{
${ }^{392}$ See ch 4, s4.8.4.4.6 titled Pooled Master Accounts. For an example thereof in Kenya, see ch 10, s.10.2.3.3 titled Application to MFS.

${ }^{393}$ The SO usually is the issuer of the SOV. Or, there may be cases where the SOV is sold to the user by a retailer acting as the agent of the issuer. In another variation, the retailer purchases a SOV from the issuer for later sale to the user.

${ }^{394}$ When it comes time to pay the merchant, it is the SO that will pay the merchant from his underlying (fiat-based) depository funds if a fiat mechanism is at play. Similarly, when the user buys the SVP from the agent, the funds flow through the agent to the system operator, or the retailer may purchase SVPs from the issuer for later sale to the user.

${ }^{395}$ See ch 4, s4.8.4.4.6 titled Pooled Master Accounts.

${ }^{396}$ For issues surrounding who has better access to user funds in case of a SO insolvency, and the effect of common law precepts of banking on this discussion, see ch 4, s4.9 titled Application to MFS.

397 As Akindemowo points out, in all three cases there is a direct contractual relationship between the issuer and holder although there is a direct sale between the issuer and holder in the first case only. Akindemowo (2009) op cit note 82 at 275.

${ }^{398}$ Usually if the issuer is a licensed bank or credit institution as it is known in the EU, the SOV is in the same UOA as the prefunding UOA, and is redeemable back into the original unit, and redeemable on demand and at par.

${ }^{399}$ Foley op cit note 66.

${ }^{400}$ The SVP system is, then, just another payment mechanism offered by that bank and is, in a sense, additive. See ch 2, ss2.1-

2.4 on the use of the term 'additive' in an MFS context.
} 
Instead, the fiat value provided is seen as a prepayment for those new units for use in the closed scheme. The user thus does not have a deposit account with the bank.

Where a SO is not a bank and creates its own SOV on receipt of fiat funds and uses a bank to hold those funds, there is a variation on the above theme: the issuance is based on the scheme's particular fiatexchange rate to a SOV value from the fiat value, but the value in the SOV is usually not redeemable back into the fiat currency. Instead the fiat value provided is seen as a prepayment for those new units for use in the closed scheme. The user in this case will not necessarily have a deposit account with a 'bank'.

\subsection{Obligations of the Parties}

In SVA-based environments, a number of fundamental relationships come into being. Firstly, the issuer/controller of the account must warrant that the system and service provided are 'fit for purpose' insofar as the consumer has made known their requirements for participating in that system, and the SO has made known the general utility and capacities of their system. ${ }^{401}$

Since the obvious use of an e-money or other payment system is to use it for payments, there must be an implicit or explicit indication by the SO that the system is reasonably able to achieve that result. ${ }^{402}$ Since almost all SVP schemes operate on the basis that the account is in credit, ${ }^{403}$ it is trite that the user's obligations must include them having sufficient funds in their account when initiating a payment instruction to the issuer and must operate their SVA in a safe manner. ${ }^{404}$

\subsection{Pooled Master Accounts}

In many instances consumer funds used to prefund the value in a SVP e-money or MFS product are placed in what are variously called pooled, master or reservoir accounts with prudentially supervised banks where the SO, and/or a trust set up by that SO for reasons of safety and soundness, have accounts. The holder of the value however may be distinct from the $\mathrm{SO} .{ }^{405}$ Either way, one or both of these entities may be responsible for monitoring the value increments or decrements and the reasons therefore why a monitoring function is built into the scheme.

\footnotetext{
${ }^{401}$ One could expect all these issues to be provided in the system operators' T\&C. See again Schulze (2006) op cit note 114, and the discussion therein of Duvenhage op cit note 117 in relation to the duties of care a bank may have to its customer and the delictual liability that may follow.

${ }^{402}$ The corresponding obligations are inter alia that, for payment system use, the use will make payment for the correct amount and to the correct person.

${ }^{403}$ Some payment schemes like credit cards, however, can operate on the basis of post-payment of debt.

${ }^{404}$ See ch 7, ss7.3.6.5 titled Allocation of Risk, Loss and Liability and 7.3.6.5.4 titled Bank Customers on and the allocation of fault with respect to users. Further, ch 4, ss4.5.2 titled Nature of the Relationship and Duties (between a bank and its customers); and 4.8.3.8 titled Security and Reliability of Payments. See the user requirements under the EU's PSD op cit note 181, discussed in s9.6.2.5.2 titled Transactional Rules and Liability Allocation in the PSD. For a comparative approach, see ch 12, s12.11 titled Consumer Protection and Loss Allocation with Respect to Payment.

${ }^{405}$ See ch 7, s7.4 titled Trusts on the possible use of trust accounts in MFS and other pooled/master accounts. In particular, see ch 10, s10.2.3.3 titled Application to MFS which highlights the separate trust company established by MNO Safaricom for its MFS activities through its subsidiary, M-pesa. This could be a model for the emergence of MFS through new entrants in South Africa. See further also, ch 12, ss12.3.5.7.2 titled Application to MFS in South Africa; and 12.3.7.7 titled Conclusion: Payment Systems. See similarly ch 14, s14.9.4 titled Use of Trust Accounts, and in particular Recommendation 5 that recommends the use of trusts and trust accounts for prospective non-bank MFS providers in South Africa.
} 
The fiduciary relationship between the SVP user is invariably only with the SO - or its trust if that is what is used - insofar as they provide the user with an account number and technical access to the SOV in the SVA. ${ }^{406}$

This account number may not necessarily be a bank account number, but what may charitably be called a 'pseudo' (bank) account number. ${ }^{407}$ Even if, in some cases, there is a nexus established between a financial institution housing the funds and the SVP user insofar as the use of the SVP, the SVP user will usually still not have a direct say, or ability, in first redeeming any value directly from the master account or having ultimate ownership in a broad sense, or variation in the use of the master account. This direct nexus to the master account would be the exclusive domain of the SO or its trust. Ownership of the money rests with the trust. $^{408}$

\subsubsection{7}

\section{Issuers and the Deposit Concept}

In an SVP context, SOs take value from the public and convert it into a type of SOV stored in a SVA, the immediate connotation may be that that the value received and exchanged for the SOV could amount to a deposit such that the scheme would be subject to a prudential deposit regime at most, or in the absence of such a regime, the alternative common law precepts of deposit and banking. ${ }^{409}$

Deposit-taking of course is a salient if not definitive indication in many cases of someone engaging in the 'business of banking', but the fact that the value may be redeemable is, in and of itself, an indication that someone is a banker. ${ }^{410}$ The converse is true also: the fact that someone takes money but does not allow redemption does not mean they are not engaging in banking. This is pertinent to the quality of nonredeemable airtime SOVs. However, there are fundamental system design and policy considerations that give us pause when determining whether a deposit is at play. What is important is to determine the basis for the invocation, using the common law as a starting point, and technology as an arbitrator.

It is thus worth revisiting Foley ${ }^{411}$ where a money placed with a banker was 'the money of the banker' and the relation between banker and customer '[is] that of debtor and creditor'. Further, from Joachimson, in relation to the bank-customer contract underlying the bank deposit, that 'there is added ... obligation of the bank to honour the customer's [instruction] ... to any amount not exceeding the credit balance. ${ }^{412}$

\footnotetext{
${ }^{406}$ Users thus will not have an account with the licensed bank where the pooled, master account is held.

${ }^{407}$ Geva (2008a) op cit note 157 at 700-701 suggests that the account could be called a sub-account. This would suggest a direct nexus between the user and a personal right to the funds via tracing. It is submitted that the term pseudo account is more appropriate as it does not imply a direct nexus, rather an ephemeral and very detached point of attachment to the master bank account. See further, ch 4, s4.8.4.4.7 titled Issuers and the Deposit Concept.

${ }^{408}$ See ch 7, s7.4.6 titled Trust Bank Accounts and Ownership of Money and the notes therein on Saambou-Nasionale Bouvereniging v Friedman 1979 (3) SA 978 (A) (hereafter Saambou) in relation to ownership of trust monies. On the user's relationship to the funds if the entity accepting the funds is not considered a bank under national law, see ch 4 , s4.9 titled Application to MFS and its discussion of the m-pesa system in Kenya.

${ }^{409}$ There are of course variations of these SVPs, each with their own rules and idiosyncrasies, and where some may be subject to some regime other than the obvious banking and deposits regimes, for example, a telecommunications or consumer protection regime on funds attached to SVP.

${ }^{410}$ See ch 4, s4.4 titled Deposits, and Penn, Shea and Arora (1987) op cit note 119 at 25-26.

${ }^{411}$ Foley op cit note 66.

412 Joachimson op cit note 78 .
} 
As noted earlier, ${ }^{413}$ in the broad sense of SVPs, an 'obligation' arises when the customer provides the issuer with funds which are then stored in a SVA. ${ }^{414}$ In this configuration, it could be said that the issuer somehow owes the customer a debt. It is the nature of this debt that distinguishes some SVPs from others in terms of being analogous to, or indeed being, a deposit in the sense that the debt thus may be one of repayment of all or some of the prefunded value, or performance in lieu of the prefunded value, or a combination of both.

Thus where the stored value is placed on a product that is not linked to a 'trackable' account, the stored value is seen rather as a prepayment for goods and services and the prefunding value as non-redeemable.

Indeed, the transaction flows and the structural components of the commercial modalities employed point to this: the user may provide fiat value to an issuer, say, a prepaid SVP issuer, but this prepayment is deposited in an account belonging to a party other than the customer. During a transaction, a merchant will usually be paid by the card issuer who arranges a transfer of funds from the underlying account to the merchant's account. The underlying funds used for the payment do not belong to the customer. ${ }^{415}$ This iteration is contractual rather than prudential as there is no sense that funds are deposited with the issuer, nor is there any expectation of redeemability. This is especially prevalent with closed-loop walled garden type systems where the issuer and the merchant are one and the same. In this latter sense, the SOV is not considered 'money' per se in the sense that it is one and the same as the GAME backed by fiat, but instead it is viewed as more akin to a 'currency', albeit a currency developed, maintained and fulfilled by the closed-loop issuer of that currency. ${ }^{416}$

While the user has a discrete balance in their SVA, he may not necessarily have exclusive legal attachments to the value akin to that which would obtain with a deposit account with a bank. Invariably the SO will mix the fiat values obtained from each user on issuance into a giant pool or reservoir account which it holds under its own name - or possibly under the name of a trust subsidiary - with a licensed bank. ${ }^{417}$ Any beneficial values and rights allocated to the users will not derive from any direct legal attachments the user may have to the licensed bank, but from discrete value packets the SO decides to allocate to the users of the scheme in 'account' analogues. Thus the user will not have any beneficial direct access to the pooled funds in the (depositary) account; that is, directly to the pooled deposit account of the issuer as that account will not bear the user's name. The access to these pooled funds appears to be indirect and contractual, not

\footnotetext{
${ }^{413}$ See ch 4, s4.8.4.4.5.2 titled Obligations of the Parties.

${ }^{414}$ In the case of some NFC incarnations, it may be a hybrid of the two systems.

${ }^{415}$ The South African CPA, however, appears to alter this common law paradigm at $\mathrm{s} 63$ in relation to prepaid certificates, credits and vouchers, stating that:
}

'[A]ny consideration paid by a consumer to a supplier in exchange for a prepaid certificate, card, credit, voucher or similar device ... is the property of the bearer of that certificate, card, credit, voucher or similar device to the extent that the supplier has not redeemed it in exchange for goods or services, or future access to services'.

See the further discussion thereto in ch 12, s12.10.2.2.4 titled Liability for Loss of MFS SVP Value.

${ }^{416}$ See Akindemowo's comment that to conceptualise an e-money type of product that is stored on a prepaid card as a deposit is oxymoronic since these types of transactions are based on the prepayment being made and deposited in an account belonging to a party other than the cardholder. In a transaction, the merchant is reimbursed by the card issuer arranging a transfer of funds from the underlying account to the merchant's account. Crucially, the underlying funds that underwrite the stored value do not usually belong to the cardholder. See Akindemowo (2009) op cit note 82 at 337.

${ }^{417}$ See ch 4, s4.8.4.4.6 titled Pooled Master Accounts; ch 6, s6.5.5.2 titled Use of Trusts in MFS; and ch 7, s7.4.6 titled Ownership of Trust Money. 
depositary. Indeed, hundreds of thousands of users could have rights, not to the deposit account, but of indirect access via the account-type and access scheme devised and offered by the issuer.

Hence, even though he may be the beneficial owner of an account attached to it, the pooled fund is, from the user's perspective, only a pseudo deposit. ${ }^{418}$ There is not necessarily any obligatory right of repayment in this scheme as there would necessarily be in a demand prudentially supervised deposit account. The risk then to the user is that if the non-bank issuer of the SOV goes insolvent, the only recourse he has to claim back any value is as a concurrent creditor of that issuer during insolvency actions. ${ }^{419}$ Again, it would be the trust that owns the SOV. Hence unless the issuer is a bank, there is usually no prudential intervention - like deposit insurance ${ }^{420}$ - usually employed to prevent 'bank failures' that can save the user's funds from oblivion.

Geva and Kianieff believe that this description of the value given to the issuer by the user in a stored value e-money (SVP) environment may resemble the traditional situation of monetary value deposited in a bank account '...only to the extent that e-money constitutes "money", such that it ought to be regarded as deposited in an account with the issuer. ${ }^{421}$

Similarly, but argued for different reasons that are based primarily on the structural designs of some SVPs, ${ }^{422}$ Akindemowo believes that in prepaid e-money (SVP) conceptualisations where there is no direct debtor-creditor relationship between the user and the merchant and, more specifically, that the user has no access to the underlying (since deposited) funds received by the issuer from the user as a prepayment that will ultimately be used to pay the merchant are, in all, better served by the notion of the SOV being

\footnotetext{
${ }_{418}^{418}$ Akindemowo (2009) op cit note 82 at 331.

${ }^{419}$ The issue here is similar to the facts in the Saambou case op cit note 408. See also SJ Coetzee Inc v Louw 2002 (5) SA 602 (T).
}

${ }^{420}$ There is no deposit insurance scheme in South Africa as there is in the US through the Federal Deposit Insurance Corporation (hereafter FDIC). See ch 11, s11.2.2.2 titled Federal Overview on the FDIC. The SARB argue that the implementation of explicit deposit insurance schemes would be excessively costly, both directly and in terms of opportunity costs in so far as they believe it would be far too costly to cover the failure of just one of South Africa's largest banks, and that in reality without $100 \%$ depositor coverage, depositor insurance schemes are largely ineffective. In Nigeria there is limited insurance cover from the Nigeria Deposit Insurance Corporation: this done specifically by all the banks, who are responsible for the payment of the insurance premium after necessary determination by the NDIC. See Deloitte (2012) 'Deloitte on Africa: Banking regulatory environment and supervision in Africa', available at http://goo.gl/TdTKJ. There is however some implicit deposit insurance in South Africa provided and paid for by the state, but not the banks. For example, when Saambou Bank failed, the government stepped in to guarantee customer deposits. See A Ntingi (2011) 'Banks Not Keen On Deposit Insurance Plan', available at http://goo.gl/KqdCl.

${ }^{421}$ Further, Geva and Kianieff (2002) op cit note 221 at 14 say that it is only in connection with the single-purpose e-money products, and to a point, restricted or limited-use products, that e-money is to be regarded as an advance payment, or prepayment, for relevant goods or services. However, Geva and Kianieff's reference to 'money' as the arbiter of whether or not an e-money system requires a deposit regime akin to a bank-customer deposit amplifies the challenge in defining a scheme against its legal versus anthropological and sociological attributes. Money, as defined by Mann (1992) op cit note 86 and as implied by Geva and Kianieff (2002) op cit note 221, requires a chattel backing such that if there is no chattel (fiat) backing that would effectively render it a currency, such that the e-money scheme is not money and hence is not subject to a bankcustomer regime that usually and at common law sounds in chattel (fiat) money. Compare this with Akindemowo who cites a 'currency' attribute rather as the arbitrator as to whether a scheme should be subject to a 'currency' regime. Their views are, to some extent, parallel if one concurs that money is a broader concept than currency, something which appears still to be unsettled. Akindemowo (2009) op cit note 82 at 339. For a view of currency being broader than money (latosensu), see J Kutyn (2005) 'Nature of Money' at 2, available at http://goo.gl/5pbSB. For a view (strict sensu) of money encompassing as its subsidiary, currency, see S Mishkin (1989) The Economics of Money, Banking, and Financial Markets $2^{\text {nd }}$ ed at 22; D Fox (2008) 'Property Rights' in Money at 16 and, overall, M Stathopoulos (1995) Modern Techniques for Financial Transactions and Their Effects on Currency: General and National Reports at 4. See also ch 3, s3.6 titled Money and Currency.

${ }^{422}$ A distinction rooted more in the choice of nomenclature describing various incarnations of SVPs as access products versus non-trackable and possibly unaccountable stored value products. 
analogous to a currency rather than the usual analogy of the deposit. ${ }^{423}$ These prepaid e-money (SVP) systems then, she believes, mimic currency rather than deposit products, which demands a change from the usual analogy of deposit-taking. ${ }^{424}$ This stylised model of the nature of the issuer-user relationship is not necessarily applicable to many other e-money models, for example, where there is an open system of merchants payable.

Seen from these two perspectives, a (prepaid, non-redeemable) e-money SVP system is a narrower 'currency' on its own terms that does not amount to a deposit and which is mediated simply through contract, while a general-use (open) SVP system amounts to the broader 'money' that should be considered a deposit that could be mediated through the intervention of a prudential regime.

Despite these two similar constructs determining whether a deposit is at play in a SVP, derived as they are from common law precepts of a deposit, ultimately policy considerations creep in when attempting to (re)define the common law deposit regime. In the EU, for example, the EMD1 and its replacement, the second Electronic Money Directive ${ }^{425}$ (hereafter EMD2) both ${ }^{426}$ specifically excluded ELMIs from being part of any deposit-taking regime. According to Geva, ${ }^{427}$ the prefunded values would ordinarily have been conceptually identical to a deposit of money in licensed banks redeemable on demand.

As a result of this specific carve-out used in the EMD2, the issuance of electronic money is said not to constitute deposit-taking activity, but rather a circuitous activity that involves the sale of a fully redeemable monetary value represented by a claim on the ELMI issuer and, in essence, the ELMI is acting as a 'cash merchant ${ }^{428}$. In this case then, deposit-taking as it would apply to licensed banks, does not apply when the value received by an ELMI from a customer is immediately - and with the caveat of possible short delays from technology arbitrators accepted - converted into scriptural value in the form of e-money. However, any 'lingering' of that value in the intervening time in systems of the ELMI insofar as e-money has not yet been issued, would mean that the ELMI is engaging in deposit-taking. ${ }^{429}$

A similar conceptual 'workaround' regime regarding a deposit appears to have been employed in South Africa to explain why agents in a bank-led branchless banking scenario who take cash from the public are

\footnotetext{
${ }^{423}$ It is the issuer that will settle with the merchant.

424 Akindemowo (2009) op cit note 82 at 275.

${ }^{425}$ Directive 2009/110/EC On the Taking Up, Pursuit and Prudential Supervision of the Business of Electronic Money Institutions.

${ }^{426}$ See ch 9, s9.6.3.1 titled Background, on the EMD1 and EMD2.

${ }^{427}$ Geva and Kianieff (2002) op cit note 221 at 15 lament:
}

\begin{abstract}
' $\ldots$ that the $[\mathrm{EU}]$ adopted the position that "the issuance of electronic money does not constitute in itself ... a deposit taking activity", but rather the sale of a fully redeemable monetary value represented by a claim on the issuer. As applied to widely accepted e-money products, and particularly in light of the required convertibility under the Directive, the EU position appears to be unpersuasive. Moreover, one is rather hard pressed to see the difference between recognizing deposit-taking as a debtor creditor relationship while attempting to differentiate stored value on what would appear to be a variant of this concept. In other words, how is a claim against an issuer any different than a claim against any other debtor?'
\end{abstract}

${ }^{428}$ See ch 2, s2.5 titled Structure and Participants in MFS Schemes.

${ }^{429}$ According to Art 6(3) of the EMD2, the receipt of funds (or in other words, the issuance of electronic money) does not constitute a deposit or other repayable funds if the funds received are immediately exchanged for electronic money. Redeemability thus does not imply, in itself, that the funds received in exchange for electronic money should be regarded as deposits or other repayable funds, redeemability though being necessary for electronic money in order to ensure bearer confidence. 
themselves not seen to be deposit-taking: as long as the agents immediately convert the cash to 'e-money' on receipt of the cash making appropriate adjustments to their 'collateral' accounts with the licensed bank, so as to reduce their e-balance with the cash receipt. ${ }^{430}$ Ultimately it is up to the customer who receives an SMS of the conversion in(to) their SVA to check that the value increase matches their cash input.

In this sense, time is the simple arbiter of whether a deposit (given to an agent) is at play, not the physical handover of cash to the merchant.

Payments systems are also sensitive to the concept of deposit-taking, a nexus which has been central to payments regulation for centuries both as a characteristic feature of the 'business of banking' and an assessment tool in regulatory policy formation. ${ }^{431}$ The potential systemic risk of payment flows in a national payment system being compromised has led to the tight integration of the South African National Payments System (hereafter NPS) with the banking sector under the regulatory regime. ${ }^{432}$

Although they are systemically linked, a payment is not necessarily a deposit since a payment occurs when a debtor transfers funds to a creditor to extinguish a debt. That the debt may arise from a prepayment to buy a SOV that can be used in a general sense, or airtime that can only be used for payment in a limited sense should not confuse the issue: the payment made is still not a deposit. A deposit simply creates the right for the depositor to redeem his funds on demand and on par. In a SVP context, transfer of funds to the issuer is a payment that extinguishes the debt owed by the payor to the issuer for the provision of the service of the SOV. In a pure payment context, the provision of funds to someone who may mediate the payment in a payment mechanism is seen as an advance payment for a service to be delivered, or for providing funds as payment to a third party for service rendered.

Similarly, in terms of payment law, the EU's PSD ${ }^{433}$ indicates that as long as a provision of funds to a PSP is used for a legitimate payment in settlement of a debt that provision of funds will not amount to a deposit. In terms of South Africa's payment law, s7 of the National Payment Services Act ${ }^{434}$ (hereafter NPS Act) says that if payment is due, then any value received by an entity in respect of facilitating that payment will not amount to a deposit.

\subsection{Economic View}

As noted earlier, e-money and other species of SVPs usually results from a confused conflation with electronic forms (or representations) of money. ${ }^{435}$ At first glance, then, it appears to be an entity that simply replaces the cash in a wallet with some equally functional electronic representation of the GAME. ${ }^{436}$ The new 'e-money' may not necessarily be just the traditional electronic representation (or form) of GAME

\footnotetext{
${ }^{430}$ See ch 6, s6.4.2.3 titled Use of Agents.

${ }^{431}$ E Akindemowo (2010) op cit note 337 at 5.

${ }^{432}$ See ch 12, s12.3 titled The Prudential Landscape for Financial Products and Services in SA.

${ }^{433}$ PSD op cit note 181. See ch 9, ch 9, s9.6.2 titled Payment Services Directive.

${ }^{434}$ Act 78 of 1998. See further ch 12, s12.3.7.2 titled National Payment System Act.

${ }^{435}$ See ch 3, s3.7.3 titled Electronic Types of Money.

${ }^{436}$ Kreltszheim (2003) op cit note 337 at 162 says that a combination paper-electronic payment system will not obviate its overall classification as electronic, especially if the banks communicate electronically.
} 
money, which is merely an instruction to transfer GAME money from one entity to another. ${ }^{437}$ However, this new e-money - and m-money - may, in and of itself, also embody the value transferred. ${ }^{438}$ This may then qualify e-money as money in and of itself, possibly with its own UOA and an equivalent of, and parallel to, the fiat GAME. In that sense, e-money may fulfill common law views of money. ${ }^{439}$

Functionally, SVPs may be differentiated from the (traditional) electronic forms of money insofar as they act as an electronic SOV, generally within a prepaid scheme, with or without an auditable account ${ }^{440}$ providing access to the money on a network-based 'account' or a $\mathrm{SVP}^{441}$ which acts as a $\mathrm{MOP}^{442}$ and possibly which is also incorporated into a centralised payments system. ${ }^{443}$

This 'account' terminology appears to coincide - at least for now at an informal terminological level - with that of the Claim School view of money as an 'accounting-type,' two-sided system ${ }^{444}$ in the sense that by issuing e-money the issuer has a claim (or debit) against the holder of the value who has a credit against the issuer which is 'recorded' scripturally in an 'account.' Although the terminology (and effect) is the same, for the Claim School theory to apply generally to e-money there is, however, no specific requirement that a new form of money must have an accounting system per se for the Claim School theory to apply to emoney. ${ }^{445}$

\subsubsection{9}

\section{Nature of the Transaction and Settlement}

Two issues arise in discussion of the settlement of a transaction effected by a SVP. ${ }^{446}$ The first relates to who makes the payment to the merchant from underlying funds: is it the issuer on behalf of the user, so that the merchant has recourse to the user if there is a time, value, or general problem with the payment?

\footnotetext{
${ }^{437}$ Similarly, as Janson asks, are these new methods of payment in the form of private 'e-money' a mere restatement of deposits in a modern electronic form or a modern version of the historical private note? N Janson (2001) 'The Development of Electronic Money: Toward the Emergence of Free-Banking?', available at http://goo.gl/ocpDM.

${ }^{438}$ The Claim School view of money, it appears, could support this analysis. See ch 3, s3.10 titled Claim School.

${ }^{439}$ On a discussion of whether these amount to 'money', see ch 13, passim.

440 They may fall into one of the archetypes outlined above, namely online accountable, online unaccountable, offline accountable and offline unaccountable.

${ }^{441}$ See NF Piffaretti (1998) 'A Theoretical Approach to Electronic Money FSES-302' at 10, available at http://goo.gl/UDlv1, quoting the FDIC view of SVP:
}

'The use of the phrase "load value onto a card", "electronic value", or any similar terms used in this opinion, is not meant to imply that the information loaded on stored value cards is legal tender or anything similar to legal tender. Rather, such information is more in the nature of a right to be paid a sum of money.'

FDIC (1996) op cit note 332.

${ }^{442}$ Palley refers to e-money as a heterogeneous concept, and one component of this concept is what he terms 'e-tail' money, which may replace currency and demand deposits for traditional transaction purposes. The other component is what he terms 'e-settlement' money which may replace the use of demand deposits for purposes of discharge of private debts and may also replace the use of central bank reserves for purposes of settlement of clearing balances amongst banks. While Palley's distinctions may be descriptive, they nonetheless confuse the homogenous nature of e-money by ascribing to each of the Orthodox (commodity) and Claim schools these names. See T Palley (2001-2002) 'The e-Money Revolution: Challenges and Implications for Monetary Policy,' 24 Journal of Post Keynesian Economics 217-233, available at http://goo.gl/MeGW8.

${ }^{443}$ E-money - once the legal definitions have been clarified - appears to be mainly a means of payment. See Piffaretti (1998) op cit note 403 at 10. See also the EU's ch 9, s9.6.3.2 titled Second Electronic Money Directive; and similarly ch 12, s12.4 titled E-Money and Stored Value on SARB definitions of e-money, both of which describe e-money as a 'Means of Payment'. ${ }^{444}$ See Minsky (1986) op cit note 71.

${ }^{445}$ Although e-money may be an 'accounting' system, there is no requirement per se for it to be online accountable, although as many e-money systems do not have an online component, the value and 'accounting' (of the value used) simply resides on a prepaid SVC.

${ }^{446}$ See also ch 4, s4.8.2.2 titled Payment: The Process of Verification, Clearing, Settlement and Netting. 
Secondly, and concomitantly: is the payment absolute or conditional? Since there is a prepayment of value, funds underlying stored value remain in a user's account until the value is transferred to a merchant or other third party, such as a merchant or general payee, the key issue around which this type of analysis pivots is whether the payment is conditional, and what rights obtain to the user and an (unpaid) merchant if the issuer goes insolvent. ${ }^{447}$

Analogies may determine the nature of the settlement regime at play in various SVP schemes. This includes whether the payment mechanism is analogous to a credit card, an EFT, a cheque, traveller's cheques insofar as they may be issued by non-banks, bank cashier's (certified) cheques, sight deposits and bank notes. In an analogy to a typical three party-type credit card system, ${ }^{448}$ this involves at a minimum the bank, the merchant and the user. In an open system there will be others involved, to wit, the issuer and acquiring bank plus any payment system providers like Visa and MasterCard. In a closed loop system, the three party analogy possibly suffices insofar as there is usually only an issuer acting as a (pseudo) bank, plus the merchant and user. ${ }^{449}$

In relation then to when the settlement of the obligation the user has to the merchant is final, an analysis of the system employed determines the rights that obtain to the merchant. In Re Charge Card Services Ltd (hereafter Charge Card), a case which involved a payment made by a card, it was argued that a determination of whether a payment is conditional or absolute must depend upon the contract between the merchant and the issuer. ${ }^{450}$ A contract may however not expressly address this question, such that the true meaning of the contract between the issuer and the merchant will need to be inferred. ${ }^{451}$

While there is no general rule or presumption that any particular payment method is conditional, ${ }^{452}$ as per Charge Card, there are however general considerations - based primarily on the payment mechanism motif - that may be applied to determine whether payment is conditional or not. ${ }^{453}$ It has been held that payment by cheque and by letter of credit is generally conditional. ${ }^{454}$ In English law, payment by credit card is generally seen to be absolute as the payment obligation shifts to the issuer from the user and there is no

\footnotetext{
${ }^{447}$ The relationship between the user and the issuer could be one similar to the principle of debtor and creditor established in Foley op cit note 66.

${ }^{448}$ See ch 4, s4.8.4.2.7 titled Credit and Charge Cards.

${ }^{449}$ See a discussion of these analogies in RC Effros (2002) Electronic Payment Systems: Legal Aspects in Legal Issues in Electronic Banking at 192-195.

${ }^{450}$ Re Charge Card Services Ltd [1987] Ch. 150 at 164G-H and 168E-169D (hereafter Charge Card); M Brindle, R Cox and R Coleman (2004) Law of Bank Payments at 211.

${ }^{451}$ In the instant case, it was clear that both parties considered payment by means of the credit card to substitute for payment in cash and, hence, as an unconditional discharge of liability for payment of the price at $708 \mathrm{H}$, and see Cornelius (2003) op cit note 295 at 158 and, generally, that the transfer of obligation could either be via cession, subrogation, factoring, mandate, agency or delegation, but that it is most likely that it constitutes novation within a multilateral contract allowing for novation, whereby the issuer substitutes for the cardholder and assumes liability to the supplier, who, in turn, agrees to release the cardholder from liability and claim payment from the credit card issuer. Ibid, at 171. [Note to Leon: Does this 'ibid' refer to one of the references in note 450 above or to Cornelius (2003). Will need to clarify.] For an alternative view, see R Edwards (2009) 'Does Law Follow Money?' 21(1) Bond Law Review Article 3, 1-24, available at http://goo.gl/1o8w3.

${ }^{452}$ Charge Card op cit note 449 at 164G-H; A Tyree (2008b) 'Payment by Credit Card', available at http://goo.gl/GomPJ; Brindle, Cox and Coleman (2004) op cit note 449 at 211.

${ }^{453}$ See also A Beatty and C Hammond (1997) 'Smart Cards: An Australian Perspective' Butterworths Journal of International Banking and Financial Law at 312 as cited in Effros (2002) op cit note 447 at 207, who say that in light of Charge Card op cit note 449 , the payment via smart card is likely to be an absolute payment, but that this would have to be determined by the particular scheme.

${ }^{454}$ Tyree (2008b) op cit note 451 .
} 
redress to the user if the credit card company or bank goes insolvent. ${ }^{455}$ Charge Card, which dealt with credit cards, would be persuasive but not binding in South African law. ${ }^{456}$

The position in South African law at present is that the standard agreement is silent as to whether a cardholder becomes the owner of goods bought with a credit card. ${ }^{457}$ If the SVP payment is analogous to a cheque, then settlement is considered provisional subject to the clearing of the cheque. If the issuer goes insolvent between the time the transaction was made and the time when payment must be made, then the merchant would have a claim against the payee. However, it is unlikely that this analogy would be a useful one even in an age of the fiction of writing electronic cheques and electronic cheque numbers, ${ }^{458}$ and associated statutes, since the electronic value systems do not suppose any negotiability in any transfer of value.

Brindle and Cox argue, as per Charge Card, that the use of a card in payment of a purchase price is not conditional on the bank honouring its agreement with the supplier and, thus, that the supplier has no recourse against the cardholder for payment. The absolute nature of this payment thus militates against any analogy between a debit card and a cheque, the latter being conditional. ${ }^{459}$ Further, the fact that a debit card will - in the absence of any agreed or statutory overdraft facilities - only provide payment if the user has sufficient funds in his account to allow full debiting of the amount needed to pay a merchant provides an indication that any analogy between a cheque and the debit-card-like prepaid MFS purse is not viable. ${ }^{460}$

If the settlement is supposed to be analogous to the transfer of fiat bank notes, then it could be said that the obligation is discharged and thus absolute when value is transferred to the merchant. If however the cash is 'lost' while being sent - analogous to being lost in the post - then conceivably the payment obligation by the user is not settled, unless the merchant or payee has specified a method of payment, at which point the payment obligation may be said to be satisfied. In addition, and favoured by many studies, is the analogy with the traveller's cheque or cashier's cheque where the merchant has a claim against the issuer rather than the user. ${ }^{461}$ Similarly, if the settlement is analogous to an EFT, then it could be said that the payment using an SVP system is a transfer of funds, whereby the issuer's debt to the payor extinguishes while a new debt from the issuer to the payee is created. ${ }^{462}$ In most cases, an EFT is said to be an absolute payment in that there is payment finality on transfer of the value from the issuer to the merchant. ${ }^{463}$

\footnotetext{
${ }^{455}$ Brindle, Cox and Coleman (2004) op cit note 449 at 312.

${ }^{456}$ See Schulze (2002) op cit note 19 passim on the relevance of English banking decisions in South African law. See also the discussion in ch 7, s7.3.1 titled Overview on payment in South African common law needing to be a 'bilateral juristic act'.

${ }^{457}$ Schulze (2005) op cit note 298 at 204.

${ }^{458}$ See ch 4, s4.8.4.2.5 titled Electronic Cheques.

${ }^{459}$ Brindle, Cox and Coleman (2004) op cit note 449 at 229-230.

${ }^{460}$ Ibid at 213.

${ }^{461}$ See for example the ABA (1997) op cit note 383 at 58

462 Geva and Kianieff (2002) op cit note 221 at 23 . The obligations would be extinguished pro tanto, akin to the scenario contemplated in Libyan Arab op cit note 37.

${ }^{463}$ See ch 4, s4.8.4.2.2 titled EFTs Through Banks.
} 
In all cases and at a high level, the prepayment usually manifests as the need for someone other than the user to effect the payment to a merchant: there is no need for the user, who has already prepaid his value and received e-money value for it, to participate in these settlement arrangements. ${ }^{464}$

\section{Legal and Prudential Aspects}

\subsection{Prudential Views}

'[T]he development of pre-paid card can truely [sic] challenge the relationship between the central bank and the deposit-taking institutions. Indeed, it is the partial privatization of the money existing in the economy. ${ }^{465}$

From the above quote from Janson, and in the context of the intense regulatory scrutiny of e-money and SVPs thus far, it is possible that e-money and MNO airtime-based SVPs may challenge the unified concept of a deposit. ${ }^{466}$

The emergence of new SVPs, some seemingly disembodied from mainstream institutional banking and national payment systems, piqued the interest of prudential authorities who were apparently nervous about the potential of these SVP systems to 'bypass' CBs and the state in the issuance of money and in the control of payment systems. ${ }^{467}$

The idea of funds being taken by an entity immediately invokes deposit-taking terms that could trigger some prudential oversight or analogy with common law views of banks and deposits. ${ }^{468}$ An SVP may thus approximate to or even be a deposit, depending on the scheme and the policy imperatives at play.

As such, there have been concerns that, allowed to blossom uncontrollably, SVP systems where systems operators act as pseudo CBs may take fiat money and 'convert' the value into SVA but without any potential for redeemability, nor have any guarantees as to whether the value is secure. There may even be

\footnotetext{
${ }^{464}$ Akindemowo (2009) op cit note 82 at 282 points out that in all three cases there is a direct contractual relationship between the issuer and holder, keeping in mind that there is a direct sale between the issuer and holder in the first case only.

465 Janson (2001) op cit note 436 at 8.

${ }^{466}$ See, however, Van Jaarsveld who proffers that some types of e-money products may fall within the definition of deposittaking, depending on the agreement between the vendor issuing the card and the cardholder. See Van Jaarsveld (2011) op cit 355 at 59-60. It is argued here however that the determination is more complicated, such that an evaluation of whether value placed and stored in a SVP - whether called e-money or not - amounts to a deposit and should be predicated on a policybased analysis and determination of its primary use, that is, for funding transactions and not for use in risky intermediation activities by the issuer of the value or the holder of the SOV.

${ }^{467}$ The BIS, for example, published five reports on e-money between 1996 and 2001, the ECB (and its predecessor, the European Monetary Institute (EMI)), operating between 1994 and 1997) published two reports (1994 and 1998) and a security framework for e-money issuers (2002). The German government amended the German banking law in 1997 requiring emoney issuers to become banks - from M Krueger (2001/2005) 'Offshore e-Money Issuers and Monetary Policy', $a$ vailable at http://goo.gl/0Ib6s. For the effect of these new technologies on the CB and macroeconomic policies in general, see ch 13, s13.8.3 titled Economic Effects, on new forms of money.

${ }^{468}$ Any inapplicability of the deposit analogy to a large category of SVPs would mean that utilising bank-type deposit rules and principles for SVPs would be nugatory. Important in this consideration is the nature of the initial contract between the system operators and the user insofar as use of the funds handed over to the system operator or his agent, as well as the legal and prudential nature of the issuer.
} 
instances where a SOV is created out of thin air, with no fiat value input. ${ }^{469}$ Altogether, this raises concerns for CBs and governments around the world on the safety and soundness of these SVP systems, whether they amount to legal tender, ${ }^{470}$ and their potential systemic impact. ${ }^{471}$

Few prudential authorities have embraced e-money with fully-fledged and specific prudential regimes. Most have incorporated 'e-money' within their current regulatory regimes. In a rapidly evolving commercial and technical world, substance and form sometimes clash to frustrate regulatory ambitions. Some have gone so far though as to create specific 'e-money' prudential regimes to control the prefunding, use and redeemability of the prefunded value.

The EU for example, as noted earlier, ${ }^{472}$ passed the $\mathrm{EMD} 1^{473}$ in 2000 to create a specific regime for the issuance, use and redeemability of e-money, although because of inconsistent application primarily to MNOs, EMD1 was ultimately repealed and replaced by the EMD2 in 2009. ${ }^{474}$ The US though does not have a comparative e-money licensing regime, but instead provides protections for the functional use of any SOVs when they are used as payment instruments. ${ }^{475}$ South African monetary authorities have not embraced the e-money legislative framework prevalent in other jurisdictions like the EU. Instead, local efforts have been characterised by specific policy documents called Position Papers that, while not being law per se, have persuasive effect on potential e-money participants and the broader financial community. ${ }^{476}$

In all, as demonstrated by the EMD1 unraveling, the difficulty of devising a proper prudential framework is that many of the statues or regulations produced by regulators contain nomenclature ${ }^{477}$ that describes systems in use at the time the terms were introduced into the market. However, as also noted, with the rapid evolution of technology and the increased volume of scholarly literature on the matter, the nomenclature is already out of date when applied to the latest application thereof such as MFS. ${ }^{478}$ This illustrates the difficulty of determining clear legal (and commercial) frameworks, but this nomenclature is still used as a point of departure for legal analysis, policy imperatives and rule making.

A possible solution may be a more coherent framework that focuses, on a proportional risk basis, on the use generally of a SOV for transactional payments. ${ }^{479}$

\footnotetext{
${ }^{469}$ See ch 13, s13.8.3 titled Economic Effects on the potential systemic effects of new forms of money.

${ }^{470}$ See ch 4, s4.8.4.4.11 titled Stored Value and Legal Tender. See further ch 13, s13.8.2.3 titled Use as Legal Tender where this is discussed in terms of a re-evaluation of money.

${ }^{471}$ See the discussion on the economic effects of new forms of money in ch 13, s13.8.3 titled Economic Effects.

${ }^{472}$ See ch 4, s4.8.4.4.1 titled Overview.

${ }^{473}$ EMD1 op cit note 335.

${ }^{474}$ EMD2 op cit note 424. The EMD1 was replaced by the EMD2 because of faulty definitions that formed the basis of the EMD1 which had the inadvertent effect of causing commercial and legal uncertainty, particularly relating to whether the EMD1 was applicable to MNOs' airtime SOV. See ch 9, s9.6.3.1 titled Background for more on the two Directives.

${ }^{475}$ This strategy, it is noted later, creates a very fragmented regime since each protection differs, depending largely on the payment instrument used. See ch 11, s11.7 titled USA and MFS: Summary and Conclusion.

${ }^{476}$ Three Position Papers have been released, in 1999, 2006 and 2009. In essence, all three Position Papers allow only banks to issue e-money. See ch 12, s12.4 titled E-Money and Stored Value.

${ }^{477}$ See ch 4, s4.8.4.4.2 titled Stored Value Nomenclature.

${ }^{478}$ FinCEN (2010) op cit note 331.

${ }^{479}$ See ch 4, s4.10 titled Summary and Conclusions. See also inter alia, Recommendation 4 in ch 14, s14.9.3 titled Payment Providers on a proposed new regulatory regime encapsulated in a PSPL.
} 


\subsection{Stored Value and Legal Tender}

An immediate issue that arises with a SVA and the SOV therein created to allow payment for goods and services is whether the SOV is legal tender. ${ }^{480}$ Each jurisdiction will have its own legal tender laws. In that sense, while e-money may be denominated in the UOA of a particular jurisdiction, it is not necessarily legal tender. That can only be determined by statute and practice, although the distinction is sometimes blurred. ${ }^{481}$ It may have status similar to that of a cheque or a book entry in a bank account insofar as it represents a notional representation of the GAME. It is thus only in highly specialised cases, where there is a statutory indication of the legal tender status of e-money that the SOV becomes legal tender. As Geva notes, 'emoney' and 'legal tender' are not inherently incompatible. ${ }^{482}$

E Analysis

4.9 Application to MFS

Just as e-money has become associated with payments over the Internet, the MFS SVPs in MNO systems have come to be associated with a unique multi-use, prefunded ${ }^{483}$ but non-redeemable SOV controlled by the MNO that can be used for basic telecommunications-related services, ${ }^{484}$ but also for purchase of VAS digital goods and services from a restricted range of VAS merchants - Wireless Application Service Providers (hereafter WASPs) ${ }^{485}$ - contracted to the customer's MNO and for the transfer of stored value from one subscriber's SOV to another within the same MNO system. ${ }^{486}$ The development of MFS which allows a prefunded SVA with a SOV with a UOA that is fiat-based in a national currency and which could be used in an open environment where all manner of goods and services, as well as remittances, can be

\footnotetext{
${ }^{480}$ See ch 3, s3.12.3.2.1 titled Legal Tender and Fiats; and similarly in relation to potentially new forms of money, ch 13, s13.8.2.3 titled Use as Legal Tender. For a further discussion on e-money as legal tender, see L Van Hove (2003) 'Making Electronic Money Legal Tender: Pros and Cons', Paper prepared for Economics of the Future: Celebrating 100 Years of Cambridge Economics, University of Cambridge, September 17-19, 2003, available at http://goo.gl/mXcNT.

${ }^{481}$ See for example the EC Guidance Note to MNOs in par 14 on e-money, apparently describing e-money as legal tender [when it is not] insofar as e-money is an 'electronic surrogate' for notes and coins (Recital 3 of EMD1):
}

'Although it is clear that e-money may not have all the functionality of notes and coins, it's primary purpose is still to be used as legal tender in a payment transaction with a third party.'

European Commission (EC) (s.d.) 'Application of the e-Money Directive to Mobile Operators: Guidance Note from the Commission Services', available at http://goo.gl/9iF3U.

${ }^{482}$ Geva and Kianieff (2002) op cit note 221 at 10.

${ }^{483}$ On the methodology employed by MNOs to allow prefunding into a SVA for use in access to basic telecommunications services and VAS, see ch 5, s5.2.2 titled User Access to Mobile Networks.

${ }^{484}$ On the types of services - basic telecommunications and VAS - available to users, see ch 5, s5.2.3 titled Types of Services Available to Users: Basic and VAS.

${ }^{485}$ The MNOs may only be able to, or want to (for competitive reasons), sign up as participants in their system such that users will only be able to buy from certain merchants. On WASPs and the sale of VAS to mobile users, see ch 5, s5.2.3 titled Types of Services Available to Users: Basic and VAS and generally ch 6, s6.5.4.2 titled WASP VAS below. On relationships in a WASP VAS transaction, see ch 6, s6.5.4.2.1 titled Relationships in the WASP and VAS Environment; and further on the legal effects in these transactions see ch 7, s7.3.2.2.2 titled WASP VAS.

${ }^{486}$ See ch 6, s6.5.4.3 titled Mobile Airtime Transfer; and ch 6, s6.5.5.3.2 titled EFTs and Remittances, on fiat-based remittances in MFS. 
utilised. Both types of SVA are usually accessed via SMS, USSD or WAP. ${ }^{487}$ This fiat-based SVA is usually, but not always, subject to regulatory restrictions and licensing.

The discussion earlier on e-money as a species of SVP as a MFS SOV - to wit, 'mobile money' as it has been termed commercially - is in large part applicable to MFS using similar storage and access mediums. In large measure, the policy, prudential, technical, security, and economic issues that surround e-money and its closed or open, offline or online, redeemable or non-redeemable incarnations could apply broadly and specifically to implementations in MFS.

However, it appears, MFS has its own idiosyncrasies that affect prudential and statutory application, such as the equivocations that have arisen when trying to apply generic e-money regimes to airtime-based MFS SOV. For example in the EU, the EMD1 definition of e-money was broad enough to incorporate MNOs using airtime as a 'currency' to have incorporated them as ELMIs. ${ }^{488}$ The particular modalities of the MNO's billing system and commercial models however made this contestable.

In causa, it was successfully argued that MNOs do not act as payment gateways between VAS merchants (WASPs) and users, and that instead, at least for the airtime SVA, there was no debtor-creditor relationship between the merchant and the user. ${ }^{489}$ Instead, it was said, the user had a relationship (just) with the MNO, who in turn had a separate relationship with the merchant. The required direct nexus, it was said, was not there.

A political policy decision was then made to create a specific carve-out for airtime-based SVAs for the EMD1 such that MNOs were not seen to dealing in the licensable activity of e-money. ${ }^{490}$ A carve-out for different reason obtains in South Africa - where there is no e-money law per se $e^{491}$ - in that acceptance of funds from the public by the MNOs for prefunding the airtime-based SVA is not seen as a deposit, even if this SVA is used for VAS from WASPs that have nothing to do with any basic telecommunications activity per se. $^{492}$

Despite the respective circuitous routes that attempt to provide a practical way not to capture mobile behemoths in banking, payments statues and (in the EU), e-money statues, questions still remain on how to allocate the role of MNOs and MFSP that provide or wish to provide MFS using fiat-based SVA since the fiat-based SVA remains contentious as possibly being a deposit-taking activity which could trigger their categorisation as doing the 'business of banking' and as such needing a banking license. Common law conceptions of banking may also be triggered.

\footnotetext{
${ }^{487}$ See ch 5, ss5.3.4 titled Short Message Service (SMS) and Shortcodes, 5.3.5 titled Unstructured Supplementary Service Data (USSD), 5.5.3.1 titled Wireless Application Protocol (WAP).

${ }^{488}$ See ch 9, s9.6.3.1 titled Background on a discussion of the EMD1 and EMD2.

${ }^{489}$ See the discussion of the relationships in ch 6, s6.5.4.2 titled WASP Value Added Services.

${ }^{490}$ This carve-out was later codified in the EMD2 op cit note 335; and the PSD op cit note 181. See further ch 9, s9.6.2 titled Payment Services Directive.

${ }^{491}$ See the discussion in ch 12, s12.4 titled E-Money and Stored Value.

${ }^{492}$ See a discussion thereof in ch 12, s12.2.2 titled Wireless Application Service Providers VAS.
} 
The issue of course arises in that many of the services in MFS are said to approximate to 'banking'. For example, the receipt of funds from users, the enabling of payments, and the provision of remittance-type services. $^{493}$

The strong and direct inference then that could be made is that these entities and services are the same as or strongly emulate the structure and services of what may broadly be considered a 'traditional' bank. In causa, this close proximity in activities means that many MFS schemes have been described as 'mobile banking' or 'm-banking' provided by entities that supply 'branchless banking' services to the unbanked, underserved and the underbanked through the access medium of mobile phones and human agents who process cash. ${ }^{494}$

As noted earlier, ${ }^{495}$ while a 'banking' appellation may in some respects satisfy some of an entity's marketing and social responsibility imperatives, the caveat is calling oneself a 'bank' - or for that matter seemingly engaging in the business of banking - when that entity does not have a banking license or similar authorisation where it is legally required may bring that entity into the purview of criminal and civil liability and ultimate sanction.

However, liberal use of the term 'banking' does not necessarily imply that the institution offering bankinglike services constitutes a bank or carries out the 'business of a bank' under domestic regulation even though, in the context of MFS, MNOs may prima facie appear to encroach on the relationships that are generally the domain of licensed banks by, for example, accepting funds from the pubic for use in a SVA.

Rather, it must be noted again, commercial descriptors of MFS schemes, ${ }^{496}$ their activities are narrower than licensed banks. In most cases MNOs and MFSPs, although they accept funds from the public, are primarily engaged in the processing of payments, or facilitating remittances, rather than the riskier aspects of intermediation characteristic of licensed banks.

Whether the entity is engaged in the 'business of banking' may thus be a matter of degree insofar as the MNOs at the least are conscious and regular acceptors of funds on trust: the non-redeemable mobile airtimebased SVA that has virtually unlimited capacity for storage and spending, with only commercial imperatives applying to ensure the safety and soundness of the stored funds. Historically, then, these entities provide their own type of safety and soundness for advance payment for user access to services that include basic telecommunications and VAS.

The categorisation and application conundrum is best encapsulated by the interesting example of the eponymous m-pesa MFS system in Kenya operated by MNO Safaricom. ${ }^{497}$ It placed all user funds for use

\footnotetext{
${ }^{493}$ See ch 2, ss2.1-2.4. Even the provision of financial services by non-banks has been described as 'banking', although these are more payments than bespoke banking activities. M Jun (2009) 'Prepaid Cards: Second-Tier Bank Account Substitutes', available from http://goo.gl/CgwMd; K Jacob (2005) 'Retailers as Financial Services Providers: The Potential and Pitfalls of this Burgeoning Distribution Channel', available from http://goo.gl/38nFB.

${ }^{494}$ See ch 2, ss 2.1-2.4.

${ }^{495}$ See ch 2, s2.1 titled Introduction.

${ }^{496}$ See ch 6 passim on the permutations of MFS schemes.

${ }^{497}$ See thereto, ch 6, s6.5.5 titled Use of the Fiat SOV; and similarly ch 10, s10.2.3.3 titled Application to MFS.
} 
with a fiat-based SVA in a pooled account controlled by a subsidiary trust company. The funds were redeemable back into fiat value, but received no interest.

Instead any interest amassed in this pooled account was, said Safaricom, used to subsidise (user) costs for transactions and for downstream compliance. Nor did the entity lend any money through intermediation activities. The ostensible reason however was that a lacuna in Kenya's banking law ${ }^{498}$ meant that if an entity taking fiat value from the public did not give interest on that money to their customers, that then acceptance of those funds would not be considered a deposit and thus that entity would not be subject to the Kenyan banking law insofar as it may be partaking in, as is termed in the Kenyan law, 'banking business' ${ }^{499}$

Safaricom thus is an example of an entity that operated in a statutory vacuum insofar as it took fiat funds from the public, stored it in a fiat-based SVA, but did not need or utilise a banking license. As such, common law conceptions of the 'business of banking' may be applicable. Despite the safety and soundness activities implemented, whether or not the funds are deposits - which would trigger the 'banking business' and thus the appellation of 'bank' - has implications for the rights users have in the (pooled) value.

It is thus a tenuous exercise to determine (even the common law aspects of) 'banking', where nomenclature and law may clash.

Thus a precise indication of the scope and role of banks becomes more uncertain as time passes, continuously evolving over time from the basic deposit to sophisticated financial services, thus making it difficult to answer the seemingly simple question: 'What is a bank' or 'What is the business of banking?' The core activities of a 'bank' also become less clear.

The nature of the relationship may be uncertain. As noted earlier, ${ }^{500}$ it may be sui generis, or mutuum, or mandatum while a debtor-creditor relationship may characterise the provision of funds to the bank by the user. Indeed, as was said in Foley, ${ }^{501}$ a bank has 'superadded obligations' to the customer, which in Joachimson ${ }^{502}$ was said to revolve around a number of implied terms of the banker-customer contract.

In practise then and in the context of someone who may be or may not be a bank customer, the distinction between a bank customer and a non-customer may become sufficiently blurred that a bank may owe duties of care to non-customers which are similar if not identical to those owed to customers.

\footnotetext{
498 The Banking Act 1989 (cap 488), available at http://goo.gl/CVrXo. For a discussion thereof, see ch 10, s10.2.3.1 titled Banking Act.

499 Through the use of a Trust Account and Trust entity that did not pay out any interest received when the pool of user funds was deposited in a commercial bank, they were able to take funds and not require a banking license.

${ }^{500}$ See ch 4, s4.5.2 titled Nature of the Relationship and Duties.

${ }^{501}$ Foley op cit note 66.

${ }^{502}$ N Joachimson op cit note 78.
} 
This is especially so when an entity - such as a MNO - has simultaneously dual relationship with its customer: that of providing telecommunication services and an ability to spend on services from an airtime and fiat-based SVA. ${ }^{503}$

Further, what would happen if the SO - in this case Safaricom or the trust company - or the bank where the pooled master account funds are housed go insolvent? Does the fact that there is a pseudo banking activity possibly inherent in the SVP scheme mean that prudential (bank) deposit insurance, if provided, is now available to the user? Or does the user simply become a 'normal' creditor of the SVP SO?

This then relates to the nature of the relationship between the user and the $\mathrm{SO}$ - if the value received could somehow amount to a deposit, a putative bank-customer relationship may come into being such that the species of rights afforded to the customer fall into that of the bank-customer, not a plain vanilla creditor in insolvency actions.

Under current common law precepts, it is likely that Safaricom would be considered to be doing the 'business of banking'. While this has yet to be tested, it is submitted that in the case of fiat-based SOV, it would still be preferable to create an extra layer of safety between the user funds and their ultimate ability to be redeemed at par - if this redeemability is allowed by the scheme rules or mandated by regulations - using a trust account where trustees may safeguard consumer funds placed in a master account.

The non-redeemable airtime-based SOV have not, up to now, been subject to any of the safety and soundness criteria, ${ }^{504}$ with the value stored unsecured other than through the commercial vagaries of that MNO's Terms and Conditions (hereafter T\&Cs), and its commercial modelling that would allow the value purchased through an airtime voucher to retain, at a minimum, its face value..$^{505}$

Further, the fact that there is no intermediation and interest paid to the user is another siren indication that the primary business of an MNO or MFSP is transactional and that use of the MNO-based SOV, in particular, has taken on the mantle of a payment system.

As such it may be a case of disproportionate regulation to apply the full suite of banking regulation to a SOV which in effect is a transient SOV for funding payments.

\section{Summary and Conclusions}

MFS is trumpeted commercially as transformational banking. It is there to provide 'banking' services where banks have been unable or unwilling to provide banking services. The introduction of MFS and other nonbanks amplifies the fact that bespoke categorisations whereby companies could be resolutely classified into

\footnotetext{
503 The MNO thus provides faux banking services, invariably transaction and not savings and credit services, from a redeemable prepaid SVA to that same customer.

${ }^{504}$ See, however, the CPA op cit note 359 which refers to (mobile airtime) recharge vouchers that are subject to a minimum validity period even if not used for recharging an (airtime) account. See ch 12, s12.10 titled Consumer Protection Laws.

${ }^{505}$ It is important to note, however, that while the face value may remain the same over time until redeemed or used, the SO may effectively devalue the face value by increasing the pricing for services.
} 
silos that broadly represent their core financial business are being blurred. While the mere commercial appellation 'banking' does not necessarily trigger a legal association with bespoke banking, that is, the 'business of banking', it does however necessitate an enquiry into whether MFS as 'mobile banking' is analogous to traditional banking services such that the rights and obligations that fasten on banks similarly fasten on MFSPs.

MFS could be classed under the broad purview of SVPs, which may take redeemable fiat-based funds, or non-redeemable funds, as a 'private' currency and store value in an online SVA as a SOV. Both incarnations use the SVA primarily for payments. Very few are used as savings facilities. The MNO airtime-based SOV is seen as one of the most successful and enduring uses of these private currencies and has to a large extent been a closed, walled garden system where only the digital goods and other VAS are offered by the MNO or its partners. ${ }^{506}$

The introduction of these new entities and their focus on taking user funds not for intermediation purposes but primarily and narrowly for payments speaks to the broader issue of (re)defining the traditional concepts of the 'business of banking' and the 'deposit'. Specifically it is the subjective policy assessment using 'time' as the metric of whether funds provided to an entity amount to a deposit and the resultant inconsistency that brings this review. The concern is that if the legal boundaries between the 'deposits' and 'payments' are vague or subject to a regulatory arbitrage or turf war, this may result either in legitimate payment developments being stifled through being incorrectly regarded as deposit-taking, or unregulated deposittaking under the guise of being a payment service.

A SVP with a redeemable fiat-based SOV, though, may invoke some prudential investigation, particularly as to whether this is deposit-taking and as such whether the entity (the issuer) is engaging in the 'business of banking'. Like many other jurisdictions, the concept of 'bank' has not been defined directly in South African banking law. ${ }^{507}$ Rather there have evolved institutional and formal tests to determine whether the entity is engaged in the 'business of banking'. Statutes that refer to the 'business of banking' are helpful but not unequivocal determinants of whether there is a 'business of banking' motif at play. The symbiosis between the common law and statutory law is such that common law and primary statutory definitions of banking in municipal law may be seen as 'complementary' in that where the common law proclaims that an entity is engaged in the 'business of banking', a statute may provide the important detail in defining exactly what this 'business of banking' may be. The common law assistance was enunciated in $U D T^{508}$ where first a functional approach was used to classify banks as inter alia accepting money from, and collecting cheques for, customers to be used for payments. Second, there was the more subjective observation of the entity having, through its activities and proffering, the 'reputation as a banker'. In all, though, bankers may be those who 'traffic' in money. Acceptance of money - as a deposit - then is seen as a salient if not decisive indication of the business of banking. There is however no de minimis measure of what those deposits nominally need to be, such that even small amounts so deposited or paid into an account of sorts may trigger

\footnotetext{
506 There is a move towards integration - a type of interoperability - between the mobile airtime purse with other 'private currency' systems at some exchange rate.

${ }^{507}$ In South Africa the Banks Act, discussed in detail in ch 12, s12.3.5.2 titled Banks Act, does not define a bank per se, but rather the activities that constitute the 'Business of a Bank'.

${ }^{508}$ UDT op cit note 10.
} 
deposit analogies, even if that entity's main business based on aggregate transactions and profit is not financial intermediation but may be something else - such as MNOs providing telecommunications services.

Based on this de minimis inflection, the distinction between a bank customer and non-customer may become blurred such that an entity may owe a 'bank-like' duty of care to customers. This is especially so when an entity such as an MNO has simultaneously a dual relationship with its customer: that of providing telecommunication services and enabling the ability to spend on VAS from a non-redeemable prepaid airtime SOV; and providing faux banking - mostly transactional - services from a redeemable prepaid fiatbased SOV to that same customer, a true type of sui generis relationship. According to Foley, the relationship between the bank and the customer when the customer 'deposits' money with the bank is one of debtor and creditor.

Still, the 'money' accepted as part of a deposit may mean 'bank money' and instruments treated as 'money', but not necessarily either. In the midst though of the introduction of dematerialised forms of value, or 'private currencies', it becomes a fine judgment as to whether that value amounts to 'money' and thus whether there is even a deposit to speak of such that there is a prudential invocation. Indeed, the transaction flows and the structural components of the commercial modalities employed point to this: the user may provide fiat value to a SVP issuer, but this prepayment is deposited in an aggregate 'pooled' account belonging to a party other than the customer. During a transaction, a merchant will usually be paid by the SVP issuer who arranges a transfer of funds from the underlying account to the merchant's account. The underlying funds used for the payment though do not belong to the customer. This iteration, it is submitted, is contractual rather than prudential as there is no sense of deposit of funds with the issuer, nor is there any expectation of redeemability. This is especially prevalent with closed-loop walled garden type systems where the issuer and the merchant are one and the same. In this latter sense, the e-money is not considered 'money' per se in the sense of its being one and the same as the GAME backed by fiat, but instead may be seen as more akin to a 'currency', albeit a currency developed, maintained and fulfilled by the closed loop issuer of that currency.

The equivocation triggered by the MFS airtime SOV is reflected in the prudential views of SVPs. In the EU, redeemable fiat-based SVP schemes are housed as 'e-money' under the EMD and PSD regimes. On a controversial policy basis, however, they exclude the non-redeemable MFS SOV from being e-money. ${ }^{509}$

Further, in both the PSD and EMD regimes, the redeemable fiat-based prepaid SOV is not seen as a deposit if the funds used to fund the SOV are 'immediately' exchanged for e-money by the issuer or his agent. ${ }^{510}$ Time as a subjective metric - seemingly at a policy level - brings into the focus the SVP's use as a SOV and whether this amounts to deposit-taking. Thus, although an entity may 'accept money' from users for the source of funds for an SOV, these funds do not linger as they may do with a bank deposit as savings. Instead

\footnotetext{
${ }^{509}$ See Chapter 9 on the EU.

510 This regime though has been criticised as missing policy considerations with common law banking practices which may see these redeemable SOV as deposits. There is a similar policy regime in South Africa in relation to MFS agents and deposittaking. Time, then, is an arbiter of whether deposit-taking is at play. See further the discussion below in ch 9 on the EU and MFS, and ch 12 on South Africa.
} 
they are usually of a transient nature and of relatively modest value, prefunded enough for regular payments and then some.

Since SVPs are hardly used for savings and since the majority of the entities that operate these systems do not, or cannot, use the funds for intermediation, it may be asked then in relation to the 'business of banking' as to whether this should still include those who accept 'deposits', but who do not make any loans or for that matter, one that provides loans but does not accept 'deposits'. This was obliquely asked in AID v Winter ${ }^{511}$ where the court held that the society was not carrying on the 'business of banking' when it lent to its members for the purpose of acquiring land or buildings since the society did not accept deposits from the public, but only from its members. While criticised, the parallels to a MFS system are nonetheless manifest, for in many MFS models no interest may be paid nor loans made. Invariably any interest would be kept by the MNO (or MFSP) and used to subsidise transactions and downstream compliance costs. While the Australian decisions are persuasive, South Africa primarily follows the precedents of English banking law however.

Payments are of course also sensitive to the concept of deposit-taking, a nexus which has been central to payments regulation for centuries both as a characteristic feature of the 'business of banking' and lately as an assessment tool in regulatory policy formation. As a SOV primarily for payments, MNOs and MFSPs will engage in processing of payments from the 'pool' of user funds, be it in the open or closed variety. The open system may, depending on municipal regulation, be part of a NPS. The potential systemic risk of payment flows in a NPS being compromised has led to a tight integration under regulatory regimes with the banking sector.

However, while the use of funds as payments in an aggregate amount of new, emerging non-bank providers of MFS could have systemic implications, this is unlikely given the relatively low aggregate values involved in MFS thus far compared to non-MFS payments. Further, although they are systemically linked, a payment is not necessarily a deposit since a payment usually occurs when a debtor transfers funds to a creditor to extinguish a debt or to transfer value. That the debt may arise from a prepayment to buy a SOV in a SVA that can be used in a general sense, or airtime that can only be used for payment in a limited sense should not confuse the issue: the payment made is still not a deposit. A deposit simply creates the right for the depositor to redeem his funds on demand and on par. In an e-money/SVP context, transfer of funds to the issuer is a payment that extinguishes the debt owed by the payor to the issuer for the provision of the service of that e-money. This is distinguishable then from Foley. In a pure payment context, the provision of funds to someone who may mediate the payment in a payment mechanism is seen as an advance payment for a service to be delivered, or for providing funds as payment to a third party for service rendered.

Adding an extra layer of uncertainty which further shakes the 'deposit' and 'business of banking' concept and their nexus is whether what is stored is actually 'money,' since at the core though of the banking ecosystem is 'money', where it has been said that a banker is 'one that traffics in money'. ${ }^{512}$ This also

\footnotetext{
${ }^{511} A I D v$ Winter op cit note 101. See further the discussion in ch 4, s4.4.6 titled Rethinking the Deposit Concept.

${ }^{512}$ Lord Denning in $U D T$ op cit note 10 at 445. See further the discussion in ch 4, s4.3.2 titled Characteristics of Banking.
} 
depends of course on whether the SOV in a SVA prefunded by acceptance of fiat-based funds does indeed legally (and economically) amount to 'money'. This remains uncertain. ${ }^{513}$

The focus though on payments as the primary business case in MFS may mean that deposit-taking and intermediation are not indicators of the presence of the 'business of banking', especially where it relates to a closed, private club of participants. MFS SVPs may provide some direction to the question of whether the deposit is still a useful metric of the 'business of banking', specifically since it is not certain that an entity (non-bank) in the MFS financial ecosystem would necessarily be carrying on a business which accepts deposits, as included in this phrase, if it does not make any loans, or similarly if a business provides loans but does not accept deposits. A provider of MFS - at least in a fiat-money sense - will be taking funds from the public which will have to be redeemed, but will be using this for payments, not intermediation.

Further, the nature of MFS transforms the core aspect of 'deposit' into a mere and somewhat transient source value in a primary use for payments, another indication of the stratification of the 'business of banking' such that the bespoke 'deposit' concept and its nexus with the core 'intermediary' role of bankers may no longer be the pivot around which the 'business of banking' coalesces. Further, the somewhat arbitrary use of 'time' as a metric for determining whether a deposit exists, is another indication of the need for a review. Without this review, banking (and payment) legislation could be used - and inconsistently - to regulate SOVs (as deposits) whereas the SOVs are actually more related to a source of value for payments. The inconsistency may stifle innovation and introduce a heavy-handed, disproportionate regulation of MFS.

A solution possibly then may be a more coherent framework that focuses, on a proportional risk basis, on the use generally of a SOV for payments ${ }^{514}$ shifting from and reducing concomitant focus on the value received as being a 'deposit'. This nuanced shift then begins a possibly necessary disaggregation of the monolithic and venerated 'deposit' from its covalent link to the 'business of banking' such that it becomes the less totemic 'deposit concept'. This, it is submitted, would allow a more proportional regime to emerge that is differentiated from the riskier aspects of acceptance of user funds: their use for intermediation activities.

The need for and use of proportionality in MFS regulation - to whatever degree, if at all - is explored below in relation to the specific application of domestic banking, payments and SVP (e-money) rules, regulations and policies in the European Union, ${ }^{515}$ Kenya, ${ }^{516}$ USA $^{517}$ and South Africa. ${ }^{518}$

\footnotetext{
${ }^{513}$ See the discussion of the nature of money used in MFS-based SVPs in ch 13 titled Re-Evaluation of Money.

${ }^{514}$ See also inter alia, Recommendation 4 in ch 14, s14.9.3 on a proposed new regulatory regime encapsulated in a PSPL.

${ }^{515}$ See ch 9 on the EU and MFS.

${ }^{516}$ See ch 10 on Kenya and MFS.

${ }^{517}$ See ch 11 on the USA and MFS.

${ }^{518}$ See ch 12 on SA and MFS. See also inter alia, Recommendation 4 in ch 14, s14.9.3 titled Payment Providers on a proposed new regulatory regime encapsulated in a PSPL; Recommendation 5 on the use of trust accounts to ring-fence funds stored by non-banks providing transactional services in MFS; Recommendation 6 in ch 14, s14.9.5 titled Access to the National Payment System on proposed access to the South African NPS by PSPs; Recommendation 7 in ch 14, s14.9.6 titled Payments Law on the need for a new regulatory regime that codifies consumer and service provider rights in macro retail payments, preferably within the framework of a proposed PSPL; and Recommendation 8 in ch 14, s14.9.7 titled Payments Regulatory Agency on the need for a dedicated agency (authority) to regulate consumer payments. Recommendation 8 would be in the form of a proposed Payment Services Regulatory Authority (hereafter PSRA), modelled on the US Consumer Financial Protection Bureau (hereafter CFBP). See further on the CFPB, ch 11, s11.2.4.2.2 titled Consumer Protection Bureau.
} 


\section{CHAPTER 5}

\section{MOBILE TECHNOLOGY AND MOBILE FINANCIAL SERVICES}

\subsection{General Overview}

Mobile Network Operators (hereafter MNOs) are able to bill users for basic telecommunications services such as Internet access, SMS, and phone calls via their post-paid and prepaid Stores of Value (hereafter SOVs) available in Stored Value Accounts (hereafter SVA), as well as billing at micro-payment levels for a range of so-called Value Added Services (hereafter VAS). ${ }^{1}$

The technologies, user interfaces and billing systems in VAS and fiat-based Mobile Financial Services (hereafter MFS) are analogous, and are repurposed with relative ease to provide seamless MFS on the handset. The technologies outlined below include some of those described throughout this study. ${ }^{2}$

\subsection{Mobile Network Technologies}

\subsubsection{Technology Types}

With the attrition of maintenance-heavy and copper cable based fixed line networks, mobile networks have grown to replace them. ${ }^{3}$ The mobile networks have evolved into primarily digital ${ }^{4}$ mobile systems that have simultaneous voice and data capabilities.

The most prominent of these networks is the Global System for Mobile Communications (hereafter GSM) which was invented in the late 1980s in Europe. It has become the dominant mobile technology today with over 4 billion (hereafter bn) global users. ${ }^{5}$ GSM was one of the first digital mobile systems. It was, in effect, an upgrade of the first generation - or ' $1 \mathrm{G}$ ' - analogue and the largely insecure mobile networks

\footnotetext{
${ }^{1}$ VAS may relate to premium services for which there would be a surcharge above the cost of basic services, also known as Premium Rated Services (hereafter PRS). Examples of VAS would be the purchase of music and videos, entering competitions or traffic information. See ch 5, s5.2.3 titled Types of Services Available to Users: Basic and VAS, including PRS, and see further ch 6, s6.5.4.2 titled WASP Value Added Services.

${ }^{2}$ The complex nature of MFS and the various technical implementations that are critical components of the MFS ecosystem require a large focus on technology in this study. This chapter serves that purpose. It is recommended that, owing to the numerous acronyms used for technical terms, the reader utilises the 'Abbreviations' section placed towards the end of this study.

${ }^{3}$ Fixed-line, always-on broadband penetration is also comparatively low, creating a huge opportunity for mobile to become the most preferred vehicle for the supply of digital services to South Africans. WASPs are quickly filling this service void. The mobile industry itself is huge: by June 2011, the four licensed mobile networks in South Africa - 8ta, Cell C, Vodacom and MTN - had some 50 million (hereafter $\mathrm{mn}$ ) users between them versus less than $4 \mathrm{mn}$ users with access to traditional dialup telephone lines. See CellularOnline (2011c) 'South African Mobile', available at http://goo.gl/154Ay.

${ }^{4}$ Broadly speaking, a digital system is a data technology that allows the performance of complex operations. Analogue systems use a continuous range of values to represent information. The ultimate distinction is that digital technologies are more modern and for the same effort provide more facilities than analogue systems. See 'Digital' (2011) Oxford Dictionaries at http://goo.gl/ckFyU.

${ }^{5}$ See the latest GSM global user statistics at the GSM World home page at http://www.gsmworld.org.
} 
introduced in the 1970s. ${ }^{6}$ The first incarnation of GSM is now known as ' $2 \mathrm{G}$ ' and it provides basic services such as voice calls, Person to Person (hereafter P2P) SMS messaging and Multimedia Messaging Services (hereafter MMS), ${ }^{7}$ low-speed Circuit Switched Data (hereafter CSD) facilities ${ }^{8}$ and a more rudimentary form of information access via the mobile phone keypad called for Unstructured Supplementary Service Data (hereafter USSD). ${ }^{9}$ The always-on, untimed data facilities in the late 1990 s and use a data transmission technique called General Packet Radio Service (hereafter GPRS). ${ }^{10}$

The technical evolution from GSM, which provides substantially faster speeds of data access is commercially known as ' $3 \mathrm{G}$ ', and later even faster versions are known as ' $3 \mathrm{G}+$ ' or 'HSPA' (hereafter High Speed Packet Access), and Long Term Evolution (hereafter LTE). ${ }^{11}$ These networks are very fast, allowing effortless video and music streaming. The 3G-type of network, however, is more prevalent in developed countries as these networks require an entirely new and costly mobile network infrastructure and compatible mobile handsets. ${ }^{12}$ GPRS, Enhanced Data Rates for GSM Evolution (hereafter EDGE), USSD, SMS, 3G CSD are known as (hereafter data) 'bearers' in that they facilitate the transfer of voice and data over mobile networks. ${ }^{13}$ There are of course competing digital mobile phone technologies other than GSM and 3G/HSPA, notably the MNOs in China, the United States and parts of Africa and Asia that use competing Code Division Multiple Access-based (hereafter CDMA) ${ }^{14}$ networks technology. The 3G/HSPA technology is, however, the most prevalently used high-speed mobile data access worldwide. ${ }^{15}$

For the purposes of MFS though, and as a result of specific designs, the basic 2G, 2.5G, and 2.5G+ networks are manifestly capable of powering most forms of secure MFS.

\footnotetext{
${ }^{6}$ The underlying transmission system in GSM is called SS7, for 'Signaling System 7', a robust mobile version of the fixedline Integrated Services Digital Network (hereafter ISDN) technology. SS7 sits in the GSM 'signaling channel', which essentially is the portion of the frequency used to tell the GSM network, for example, to which base station the GSM terminal is connected. For the import of this definition on the applicability of the South African Electronic Communications and Transactions Act 25 of 2002, see ch 12, s12.9.2.2.3 titled Formation of Contracts by Users Contracting with Electronic Agents.

${ }^{7}$ MMS is used mainly to send P2P images and small videos.

${ }^{8}$ CSD data access is billed per minute compared to always-on systems like GPRS, EDGE and 3G or 4G which charge according to how much data is transferred.

${ }^{9}$ See ch 5, s5.3.5 titled USSD.

${ }^{10}$ See ch 5, s5.3.2 titled GPRS and EDGE. As an example, all the competing mobile technologies have always-on facilities. They may also incorporate so-called 'proximity' payment technologies like Near Field Communications (hereafter NFC) and Radio Frequency Identity (hereafter RFID). See ch 5, s5.5.6.5 titled NFC.

${ }^{11}$ The newest high-speed mobile data technologies, like LTE, are sometimes called ' $4 \mathrm{G}$ ' technologies, which stands for 'fourth generation'.

${ }^{12}$ Although limited to mainly high density urban areas, $3 \mathrm{G}$ mobile access technology is becoming more prevalent as $3 \mathrm{G}$ coverage expands across South Africa.

${ }^{13}$ In telecommunications nomenclature, a bearer is a generic technical appellation of a data transfer mechanism that is inherent in the telecommunication technology used. Thus SMS is a bearer in mobile networks, while TCP/IP would be the bearer technology to transport (hereafter Internet) data packets over the Internet. Together, GPRS, USSD, SMS, IVR, WAP and $3 \mathrm{G}$ are 'bearers.' The billing of users may be of either a prepaid or post-paid nature or a combination of the two. The technical term 'bearer' should not be confused with the banking-related term 'bearer' which is related to negotiable instruments, discussed briefly in ch 4, s4.8.4.2.5 titled Electronic Cheques. The contemporary Internet as it is known and used was preceded by 'ARPAnet', a communications system developed in the 1960s by the US military to assist the military in the event of nuclear war. See M Hauben (hereafter s.d.) 'History of ARPANET', available at http://goo.gl/DCsVD.

${ }^{14}$ Code Division Multiple Access (hereafter CDMA) is a high-speed digital mobile phone standard invented by Qualcomm and forms the technology basis for high-speed mobile data networks worldwide.

${ }^{15}$ There are variations of third generation technologies in China (hereafter SCDMA), in Japan through iMode and in the use of CDMA 1x EVDO. A fixed-mobile broadband technology like WiMax is used mainly to interconnect broadband and mobile base stations. It may also be used in some consumer connections.
} 
Users can access many basic mobile payment access facilities using text-based SMS messages, the sessionbased and text-based component of GSM called USSD, through mini-Internet facilities such as the Wireless Application Protocol (hereafter WAP) ${ }^{16}$ that uses a combination of mainly picture-based icons and text for navigating through mobile phone links.

Because of their use in MFS, all these technologies form the template for the (technical) discussion in this chapter and others that follow, as the principles insofar as MFS usage and systems are applicable to these other mobile technologies.

\section{2 .2}

\section{User Access to Mobile Networks}

GSM and 3G phones use what is known as the Subscriber Identity Module (hereafter SIM), or SIM card ${ }^{17}$ technology which allows and mediates access to MNO services. ${ }^{18}$ SIM cards are generally cheap plastic cards with a special SIM access chip embedded into them and they are for sale at retail outlets. ${ }^{19}$ Usually, access to MNO services is as simple as inserting the SIM card into a compatible phone. ${ }^{20}$ In some cases, statute law may require that the user provide verifiable forms of identity to the merchant before the SIM card is activated for use after sale. ${ }^{21}$

To use the MNO's services, the activated user must either have a 'post-paid' account with the MNO where credit is given, or the user must first purchase what is colloquially known as prepaid 'airtime' vouchers at retail locations. These are sold in various denominations determined by the MNO. ${ }^{22}$ The economics of the

\footnotetext{
${ }^{16}$ See ch 5, s5.5.3.1 titled WAP.

${ }^{17}$ A SIM card is a 'smart card' with an electronic chip that has an internal digital processor and storage capacity, and it contains specific digital imprints or keys that determine a user's access rights to the relevant $\mathrm{MNO}$, and sometimes also to a range of services like MFS. These may include digital keys for data encryption that is done on the SIM in what is known as a S@T data session using a specific encryption program embedded in the SIM. The SIM may also contain small applications called 'apps' or 'applets' - that are preprogrammed by the MNO at the factory or updated wirelessly once the SIM is inserted into a phone. These apps may be secure banking applications or some other VAS that will appear on the handset screen with its own menus and functionality when that SIM, together with that app, is placed in the mobile handset. See ch 5, s5.5.3.2 titled S@T Mobile Phone Navigation Menus for MFS. For a similar legal definition of the SIM card in South African law, see the definition of a SIM card in the Regulation of Interception of Communications and Provision of Communication-Related Information Amendment Act 48 of 2008, also known colloquially in South Africa simply as 'RICA'. If the phone number allocated to a user is unused for any length of time, usually 4-6 months, that phone number may be 'recycled' by an MNO and allocated to a new owner. In a prepaid environment, the original owner may then lose any airtime credit in the airtime SVA. The new owner of that number may however be billed for some VAS by WASPs. See again ch 5, s5.2.3 on the types of services generally available to mobile users and for PRS, and see further ch 6, s6.5.4.2 titled WASP VAS. See further on the registering a SIM card under RICA rules, ch 12, s12.8.4.2.

${ }^{18}$ In the $3 \mathrm{G}$ environment, the SIM card is known as the Universal SIM (hereafter USIM), and uses what is known as the Third Generation Partnership Project (hereafter 3GPP) set of mobile data standards. CDMA networks do not use a SIM card, but instead an Electronic Serial Number (hereafter ESN) embedded within the phone. Thus, the user cannot use another phone for MNO access when the phone with their ESN is inoperable, unlike GSM and 3G which involves a simple SIM swap between phones.

${ }_{19}$ This contract would amount to a so-called 'shrink-wrap' agreement common in the over-the-counter sale of software products. The purchaser would somehow be made aware that opening the packaging and using the product within that wrapping would amount to constructive acceptance of the terms embodied in the contract included in the package.

${ }^{20}$ A SIM card has what is known as an International Mobile Subscriber Identity (hereafter IMSI) number programmed into it that provides a unique identifier to the MNO when inserted into a compatible phone. Based on the IMSI, the MNO will allocate a specific phone number to the handset. Similarly, the handset in a GSM environment has a unique serial number called an IMEI (hereafter International Mobile Equipment Identity) number. Both the IMSI and IMEI numbers are transmitted to the MNO when the user accesses the MNO's network.

${ }^{21}$ It may be a criminal offence not to report a lost or stolen SIM card to the authorities. See ch 8, s8.5 on Anti-Money Laundering, and Customer Due Diligence and, in particular, ss47-55 of the RICA. See ch 12, s12.7.3 on RICA.

${ }^{22}$ Users may also get access to the network via a reverse charge, where a post-paid subscriber accepts a reverse charge call from a prepaid subscriber who does not have sufficient airtime balance to make that call. For an example of this type of service, see the MNO Vodacom website at www.vodacom.co.za.
} 
creation and distribution of prepaid vouchers are such that the face value of the voucher may sometimes be more than the value being provided by the MNO for the code that must be entered.

This reflects the wholesale and retail chain of the creation and distribution chain such that the distributors and retailers of these vouchers will purchase the vouchers in bulk at a large discount compared to the face value of the airtime voucher and may arbitrage that discount when selling the voucher, so that the actual cost to the user at the retail level ends up being less than the face value. The MNO will provide a facility through the user's mobile handset or via some other means to input the once-off use codes on these vouchers into the MNO's prepaid system, after which the user may be credited with the value on the voucher in their SVA. The important point here is that even though the user may have paid less than the face value for the airtime voucher, the MNO is obliged to provide value in the airtime SOV that is equal to the face value of the voucher. ${ }^{23}$

\subsection{3}

\section{Types of Services Available to Users: Basic and VAS}

The operating licenses of most MNOs worldwide are issued by a National Regulatory Authority (hereafter NRA) in terms of a telecommunications or technology convergence law regime; this regime determines the minimum services or range of services they must provide to their users, the frequencies they can use, reporting and quality control measures, as well as the minimum radio coverage area of their network. ${ }^{24}$

Mandatory 'Basic Services', at least within the world of GSM technology, would include making and receiving voice calls at an acceptable level of quality and reliability, sending and receiving text messages, providing data services, the numbering range to be used, ${ }^{25}$ any universal service obligations, ${ }^{26}$ and where there is a license for just transmitting data, the type of data technology to be used and the area of radio coverage. These services will usually be charged at what are called 'Standard Rates' insofar as they may be consumer-facing and wholesale rates for (basic) services lodged with and approved by the NRA.

Over and above these Basic Services, the MNO may provide a range of other services, which may or may not be classified as VAS so as to distinguish these services from the Basic Services. There are a plethora of VAS, which may include, for example, Caller Line Identity (hereafter CLI) which is charged separately; Interactive Voice Response (hereafter IVR) systems that provide content services, location-based tracking services, as well as content services such as provision of ringtones for mobile phones, music and entrance to competitions. MFS would also be a type of VAS.

\footnotetext{
${ }^{23}$ The MNO may even provide more value to the user's mobile airtime SVA (as a bonus) than the face value of that voucher when the user inputs the code, as recognition for that user's loyalty or for some other promotional reason.

${ }^{24}$ For an overview of the telecommunications and converged license regimes, see ch 8, s8.6 titled Telecommunication Laws And Regulations.

${ }^{25}$ The use of the leading numerical prefix identifies the network to a user, for example, the 082 or 083 prefix.

${ }^{26}$ The policy in a number of developing nations is that all residents should have access to basic communication services at affordable prices. An NRA may promote this by placing requirements in a MNO's license to roll out services in underserviced areas. In South Africa, this also entails licensees contributing to what is known as the Universal Service Fund which assist in providing services to under-serviced areas. See Independent Communications Authority of South Africa (ICASA) (2010) 'Discussion Document: Universal Service and Access Obligations', available at http://goo.gl/f0Q91.
} 
The services may be provided by third party providers called Wireless Application Service Providers (hereafter WASPs). ${ }^{27}$ Most of these VAS supplied by the MNO and/or WASPs to consumers will have different charges to the standard service rates lodged by the MNOs with the NRAs (at so-called Premium Rates) and the services that use premium rates are called Premium Rated Services (hereafter PRS). These Premium Rates are usually far higher than the Standard Rates. Separate billing systems may be used by the MNO for charging users for the use of VAS. ${ }^{28}$,

Access to the Basic Services and VAS of the MNO is mediated by the types of technology provided by the MNO to the user for use on the network. There are a variety of these technical access methods, but for the purpose of access to, and the use of, MFS and related services as provided by the MNO and other third party providers of services that use the MNO's facilities, the following access methods are highlighted as they are the most prevalent in both the developed and developing world. ${ }^{29}$

GPRS is a technology used to upgrade GSM networks that use time-based billing to access data. GPRS instead allows subscribers to stay constantly connected to any online data on the Internet and to be billed per data unit (in megabytes or gigabytes ${ }^{30}$ ) rather than to be billed in units of time. ${ }^{29} \mathrm{EDGE}^{31}$ is a bolt-on ${ }^{32}$ enhancement for $2.5 \mathrm{G}$ GSM/GPRS networks that makes it easier for existing GSM networks to upgrade to it. EDGE is a superset to GPRS and can function on any network on which GPRS is deployed. It is substantially faster than GPRS, but is much slower than 3G.The majority of phones - especially in developing countries - used for MFS are those that use EDGE.

\section{Interactive Voice Response (IVR)}

IVR is a method of accessing specific menus and information using the tone-generating keypad of mobile and fixed-line phones. In most incarnations, users are prompted by a recorded voice to input specific

\footnotetext{
${ }^{27}$ See ch 5, s5.3.4 titled SMS and Shortcodes.

${ }^{28}$ See ch 6, s6.5.4.2 titled WASPs and the use of Premium Rated SMS (hereafter PSMS) and Premium Rated Unstructured Supplementary Service Data (hereafter PUSSD) systems with WASPs. Usually the P-prefix to any technology indicates that the service is 'Premium Rated'

${ }^{29}$ For a general overview of MFS and the technology it could use, see GT Krugel (2007) 'Mobile Banking Technology Options: An Overview of the Different Mobile Banking Technology Options, and their Impact onn the Mobile Banking Market' FinMark Trust, available at http://goo.gl/8eHv7.

${ }^{30}$ GPRS and the other data facilities outlined above are charged for, by the MNO, in data units like megabytes or gigabytes of use.

${ }^{31}$ This is known also as Enhanced GPRS (hereafter EGPRS).

32 'Bolt-on means that the MNO system can be upgraded via a software upgrade rather than by installing entirely new hardware to provide the intended result.
} 
numbers on the keypad that then allows access to data or services. ${ }^{33}$ These IVR calls may cost more than (basic) conventional voice calls, and are usually associated with customer care calls and for access to certain VAS. $^{34}$

\subsection{4}

\section{Short Message Service (SMS) and Shortcodes}

Short Message Service (hereafter SMS) - also known as text messaging - was originally designed in the 1980s to act as a data bearer for system engineers developing and maintaining the initial version of the GSM system and was less the consumer-facing P2P messaging facility that it has now become. An SMS sent by a user from their mobile handset is known as a MO-SMS, or simply MO, for Mobile Originating. ${ }^{35}$ An SMS received by the user on their handset - from another person or from an automated machine - is known as MT-SMS, or simply MT, for Mobile Terminating. A user sending a MO-SMS will send it to the MNO's SMS 'post office', technically termed a Short Message Service Centre (hereafter SMSC), and the SMSC then routes the MO-SMS (and other types of SMSs) to the intended recipient. ${ }^{36}$ The MNO's SMSC is linked to that MNO's billing system, and will only send forward that MO-SMS to the intended recipient - which could be a person or SMS-receiving machine or device - if the billing system flags the MO as having sufficient credit or the permission to do so.

SMS has evolved further to allow so-called Person to Machine (hereafter P2M) messages, where in a VAS environment, SMSs may be sent by a mobile user from their mobile phone - as an MO-SMS - to electronic systems run by third party vendors of VAS digital goods and services such as mobile jokes, love poems and phone ringtones. ${ }^{37}$ These technical and content vendors are called WASPs, while the content-only vendors are called Information Providers (hereafter IPs). ${ }^{38}$

The MO-SMS sent by the user may act as a payment to the WASP or IP. The number to which the user will send the P2M SMSs as payment is known as a 'shortcode' - usually 5 digits long and common to all MNOs in a country - and are classed as Premium Rated SMSs (or PSMS), insofar as they usually cost more than a standard MO P2P SMS. Launched in South Africa in 2002-2003, the shortcode system is currently the only common payment gateway for mobile services across all four licensed MNOs in South

\footnotetext{
${ }^{33}$ The latest incarnations of IVR are those using interactive video whereby users with $3 \mathrm{G}$-type mobile phones can interact with a live operator via the phone's built-in camera.

${ }^{34}$ Using IVR as the access and payment medium, users typically went through a website or advert showing a range of ringtones, noted a code associated with that ringtone, and then called an IVR number billed at standard mobile rates. They then typed in the code of the particular ringtone they wanted as well as their mobile phone number. A few minutes later the ringtone would be delivered direct to their phone via a special binary SMS.

${ }^{35}$ The MO-SMS must be differentiated from SMSs sent from websites that send SMSs using the phone number specified by a user. The website is said to spoof - recreate or emulate - that mobile phone number so that the recipient (hereafter justifiably) believes that the MO came from a specific mobile phone number and mobile handset. In some jurisdictions, spoofing of phone numbers is illegal.

${ }^{36}$ The SMSC number is usually embedded in the SIM card by the MNO's suppliers at factory level, making the process of sending and receiving SMSs transparent to the user.

${ }^{37}$ For use of SMS as a payment instrument, see ch 6, s6.5.4.2 titled WASP VAS.

${ }^{38}$ Ibid.
} 
Africa. These shortcodes are leased from the $\mathrm{MNOs}^{39}$ by WASPs, who may in turn sub-lease them to the third parties like IPs. ${ }^{40}$ PSMSs range in price from less than ZAR1 up to ZAR30 per SMS.

This P2M MO-SMS payment methodology - using mainly PSMS - has become the progenitor and archetype for the development of novel and widely available payment systems that are easy, relatively secure, localised, personalised and portable and that may rival cash in its ubiquity and as a dominant, pervasive payment system, especially in a MFS context. ${ }^{41}$

Similar shortcode and WASP-type schemes using PSMS and permutations thereof for payment for VAS operated by third parties are operated worldwide by most MNOs.

\subsubsection{Unstructured Supplementary Service Data (USSD)}

USSD is a novel standard within the GSM and $3 \mathrm{G}$ specifications for transmitting information over mobile networks. ${ }^{42}$ A USSD is session-based and therefore when a USSD session is activated, using a series of star or hash ${ }^{43}$ commands, the mobile user may input the access commands on the mobile handset for a particular service, and this session will last for less than 3 minutes before the (data) session is automatically cancelled. When activated using these star and hash commands on the mobile handset, ${ }^{44}$ the user is presented with a numbered menu and can use the mobile keypad to respond to and to input any data required. USSD has a mostly utilitarian function: it is often used as a method of adding codes from airtime vouchers in the refilling of mobile airtime-based SOVs, and to query the available airtime balance in prepaid GSM services. The simplicity of the input has resulted in it being one of the most predominant MFS and VAS access techniques, since the input mechanism shares keystroke and functional similarities with methods of recharging prepaid airtime SOVs. It also has varied application in information services in both prepaid and post-paid environments.

With USSD, unlike the SMS, no data sent or received during the USSD session is stored on the mobile handset, which makes it ideal for the transmission and receipt of passwords in MFS sessions. ${ }^{45}$ However, the major weakness of USSD is that it is not 'doubly' encrypted (like an SMS sent and received using SIM Application Toolkit (hereafter S@T) mobile data encryption techniques), ${ }^{46}$ but uses instead the innate and

\footnotetext{
${ }^{39}$ The shortcode values are not controlled by ICASA, the NRA in South Africa. However, ICASA can, pursuant to s68(1)( a) of the Electronic Communications Act 36 of 2005 (hereafter ECA), regulate numbering plans to control the use of these numbers. See ch 12, s12.8.3.1 on ICASA.

${ }^{40}$ See ch 6, s6.5.4.2 titled WASP VAS. The WASP, IP and MNO will all share in the revenue from the PSMS.

${ }^{41}$ Ibid.

${ }^{42}$ USSD uses SS7 for transmission. For the import of this use of specific technology for the South African Electronic Commerce and Transactions Act (hereafter ECTA), see ch 12, s12.9.2.2.3 Formation of Contracts by Users Contracting with Electronic Agents.

${ }^{43}$ These relate to combinations of the use of the * [star] and \# [hash] keys respectively on the mobile handset. The hash key is also known as the 'pound key'.

${ }^{44}$ For example, to access Standard Bank's mobile banking facility via a mobile phone, the user would type *120*2345\# on the mobile handset and the bank menu for payments, transfers, and balance enquiries will appear after the user successfully enters their specific bank security PIN code.

${ }^{45}$ Functions triggered when sending USSD star and hash keys are MNO-dependent and on what kind of services the operator has made available. For aspects of handset and MNO security, see ch 5, s5.7 on Security Aspects of Mobile Technology and Application to MFS below.

${ }^{46}$ See S@T in ch 5, s5.5.3.2 titled S@T Mobile Phone Navigation Menus for MFS.
} 
possibly unsecure data encryption of the GSM network. ${ }^{47}$ The impact of this data insecurity on issues of a consumer's liability for unauthorised access to their financial data and banking facilities is discussed below.

A MNO usually has two methods of charging for access to its network and for the use of basic and VAS prepaid and post-paid. Prepaid is by far the most prevalent means of access around the world across all mobile technologies. In South Africa, the average is $80 \%$ prepaid, whilst in Africa at large it is over $90 \%{ }^{48}$ Users will only be able to access services offered by the MNO if they are creditworthy, which in a prepaid context means that they must have sufficient value in their prepaid SVA. In a post-paid environment they must not be delinquent in their monthly payment to the MNO. Both prepaid and post-paid users may access a range of basic services and VAS using their airtime-based SVAs - or fiat-based SVA if offered by that $\mathrm{MNO}^{49}$ - and may be billed according to the service and transaction type. The most predominant billing mechanisms are the à la carte or once-off mechanisms, and the periodic billing mechanisms. ${ }^{50}$

\section{4 .2}

\section{Prepaid Consumer Billing Systems}

Advances in technology have allowed MNOs to allow users to prepay their use of any facilities on the MNO's network. This gross value - or airtime in MNO parlance - is usually bought at a retail outlet, on the Internet, via $\mathrm{WAP}^{51}$ or via a bank Automatic Teller Machine (hereafter ATM) linked directly to the MNO billing system.

The most predominant method of obtaining airtime value is to buy a scratch card or voucher at a certain face value and which possesses a unique access code that the user then enters via a USSD menu or via IVR. Once entered, the value is stored as a SOV in a SVA maintained by the MNO. Each airtime voucher will have a unique one-time use code which the user must enter into the MNO's airtime recharge system using either the user's handset or some other available means like an ATM machine linked to the MNO recharge system. The user is then credited with the value on the voucher, and that value is stored on the MNO's airtime SOV system. ${ }^{52}$ Thus, the user has credit in their airtime SVA and may then use that value for any manner of basic services or for any other VAS offered by the MNO, WASP or IP, which may include certain MFS. In the absence of any credit in that SVA, the user will be unable to make calls or undertake

\footnotetext{
${ }^{47}$ As is indicated in ch 5, s5.7.1 titled Security of the Mobile Network below, however, the innate system encryption has been compromised a number of times.

${ }^{48}$ CellularOnline (2011d) 'Statistics of Cellular in South Africa', available at http://goo.gl/7B3Af.

${ }^{49}$ See ch 6, s6.6 titled Hybrid MFS Models on the use of fiat money for MFS.

${ }^{50}$ See ch 5, s5.4.1 titled MNO transaction billing mechanisms.

${ }^{51}$ See ch 5, s5.5.3.1 titled WAP.

${ }^{52}$ Similarly, the value storage once entered into the MNO's recharge system is not necessarily infinite and may have an expiry date. Statute law, however, may override these conditions, for example, the Consumer Protection Act 68 of 2008 (hereafter CPA). See ch 8, s8.8 for an introduction to the CPA, and further, ch 12, ss12.9 titled E-Commerce Laws and 12.10 titled Consumer Protection Laws and the implementation and application of the CPA.
} 
any specific VAS, although the extent of these usage restrictions will vary with each MNO. ${ }^{53}$ The airtime voucher is regarded as advance payment for future services and is not at all redeemable or refundable. ${ }^{54}$

\subsection{3}

\section{Post-paid Consumer Billing Systems}

If the user is given credit, the account is said to be post-paid and all usage by the accountholder is invoiced at the end of a billing cycle, usually the end of a calendar month. ${ }^{55}$ Commonly, the account is provided via a fixed-time contract of 6,12 or 24 months and the contract may or may not include a free phone when the contract is initiated or renewed at the end of the contract cycle. Pricing for many basic telecommunication services may be a lot cheaper on contract than on prepaid, although the MNO or service provider offering the contract may be taking a credit risk with that user. In a post-paid environment, the user is invoiced for the basic services and VAS they used in the previous month.

\subsubsection{Mobile Network Transaction Billing Mechanisms}

\subsubsection{A la Carte Billing}

A la carte billing is once-off billing for Basic Services and VAS such that there is only one, non-recurring debit to the user's prepaid or post-paid account for a service.$^{56}$ It is usually, but not always, associated with the acquisition and use of Premium Rated VAS. When a user sends in a Premium Rated ${ }^{57}$ MO-SMS, similar in effect to the use of a debit or credit card, the MO-SMS will first route through the MNO's SMSC, which then interrogates the MNO's prepaid or post-paid records to determine whether enough funds are available in the subscriber's prepaid SVA or whether their post-paid account is creditworthy. If there are funds, the account is irrevocably debited with the value associated with the requested service and the indication thereof is communicated to the MFS provider or a merchant. ${ }^{58}$

\subsubsection{Periodic Billing}

Periodic billing differs from the à la carte billing insofar as there are multiple abilities to debit the user's account by the MNO, WASP or IP and also multiple methods by which this is done. Periodic billing mostly associated with WASP-type subscription VAS which may automatically charge users via a mixture of periodic and per-content billing - will debit the user's account without necessarily having a trigger MO

\footnotetext{
${ }^{53}$ A user may still be able to send a SMS known as a 'Call Me' to persons whom they want to call them back, or may request a reverse charge call in which the receiver pays for the call.

${ }^{54}$ The longevity of the voucher is not necessarily infinite and may have an expiry date. Statute law may override these conditions, for example, the CPA which defines for how long the voucher is valid.

See ch 8, s8.8 on AML, CTF and CDD Laws and Regulations consumer protection and ch 12, s12.9 on e-commerce Laws and the CPA.

${ }^{55}$ There are also hybrid prepaid/post-paid products whereby the user will prepay a month in advance to obtain cheaper postpaid rates.

${ }^{56}$ Once-off means that there is a single transaction with a single debit and only a specific additional MO request from the user will result in a debit.

${ }^{57}$ PRS mean that the cost of access and use is more than a standard P2PSMS.

${ }^{58}$ The MNO's billing system immediately deducts the amount from the subscriber's SVA and forwards the SMS with the specific service request to the merchant. The merchant will only send the content/service if they have been given the green light by the MNO's billing system that there are sufficient funds. See ch 6, s6.5.4.2 on WASP VAS and on similar schemes in WASP transactions.
} 
from that user to initiate the billing (hereafter debiting) process. This is because this type of billing system does not first check the SMSC, and then progress to the billing system as is done in the à la carte system, but usually uses a separate billing system, commercially called $\mathrm{OBS}^{59}$ or $\mathrm{EBB}^{60}$. In this scheme, a 'trusted' third party - usually a WASP ${ }^{61}$ - linked to the MNO can directly access the user's account via an automated request to the OBS system and so debit any amount simply through that request.

This unbridled access to user funds in the SVA has, of course, the potential for abuse and fraud as the OBS mechanism can rapidly drain all the credit in an account. As a result, some MNOs have developed 'double opt-in' mechanisms that may involve an MO so as to create an audit trail.

\section{Mobile Phone Technologies}

\subsection{1}

\section{Overview}

As the mobile infrastructure within which they operate has evolved since their modern digital genesis in the late 1980s, mobile handsets have become substantially more sophisticated. The newest $2.5 \mathrm{G}, 3 \mathrm{G}$ and fourth generation (hereafter $4 \mathrm{G}$ ) mobile networks have substantially increased the speed of data access and are able to provide the location of the user. The mobile handsets have also become far cheaper, smaller and analogues of computing devices, otherwise known as smartphones, such that the distinction between a phone and computing devices is increasingly blurred. They now resemble fully fledged computing devices, and the form factor or size of the mobile unit is also no longer a major arbitrator, especially if mobile tablet devices like the Apple iPad and its built-in 3G/4G access are used.

Generally, this is a result of the evolution of the handset's relatively sophisticated Operating Systems (hereafter OS), their data access and security mechanisms such as WAP, ${ }^{62} \mathrm{~S} @ \mathrm{~T},{ }^{63}$ Bluetooth,${ }^{64} \mathrm{RFID}{ }^{65}$ and $\mathrm{NFC}^{66}$ that mediate the mechanisms to communicate directly with one another and via MNOs, their enhanced security mechanisms, as well as the augmentation of their functionality through the addition of additional applications or 'apps'. That said, however, it is still the relatively basic and bland $2.5 \mathrm{G}$ and $2.5 \mathrm{G}+$ phones that dominate MFS activity today, primarily in developing nations.

\subsection{2}

\section{Mobile Phone Operating Systems}

A key feature of mobile handsets is their ability to operate ubiquitously across mobile networks without any modification. The majority of mobile phones are thus relatively simple access devices with simple if not bland user interfaces. In the past few years, however, the demand for increased functionality has given

\footnotetext{
${ }^{59}$ Online Billing System (hereafter OBS).

${ }^{60}$ Event Based Billing (hereafter EBB).

${ }^{61}$ See ch 6, s6.5.4.2 below titled WASP VAS.

${ }^{62}$ See ch 5, s5.5.1 Overview titled Wireless Application Protocol (WAP).

${ }^{63}$ See ch 5, s5.5.3.2 titled SIM Application Toolkit, (S@T).

${ }^{64}$ See ch 5, s5.5.6.3 titled Bluetooth.

${ }^{65}$ See ch 5, s5.5.6.4 titled Radio Frequency Identity (RFID).

${ }^{66}$ See ch 5, s5.5.6.5 titled Near Field Communication (NFC).
} 
rise to more sophisticated handsets that use specialised interfaces or 'Operating Systems' that can utilise sophisticated applications. ${ }^{67}$ The venerated Apple iPhone along with the newer Apple iPad Tablet computing device are examples of this rapid evolution, along with Operating Systems (hereafter OSs) championed by Apple (Apple OS), Nokia (Symbian), ${ }^{68}$ Google (Android OS), Microsoft (Windows Mobile), and Blackberry (Blackberry OS). In all, the OS may make the user's experience of accessing MFS far easier than using the 2.5G-type phones that employ USSD and SMS for access and commands. The Java application platform ${ }^{69}$ is the only system that is cross-platform and cross-OS, because Java-based applications will operate on most OSs, so long as there is a facility - called a Java engine or emulator - that is loaded onto the phone. Java may also be used on non-smartphones, and is commonly loaded on SIMs via $\mathrm{S} @ \mathrm{~T} .{ }^{70}$ These applications can operate on earlier models of phones, commonly called feature phones.

\subsection{3}

\section{Data Access Mechanisms}

\subsubsection{1}

\section{Wireless Application Protocol (WAP)}

Wireless Application Protocol, or WAP, is a type of mini-Internet experience designed for small mobile phone screens. It is used to allow the transmission of simple web pages in $2 \mathrm{G}$ networks and may contain links and icons formatted especially to be usable and visible on the small screen of the mobile phone.

\subsubsection{2}

\section{S@T Mobile Phone Navigation Menus for MFS}

The SIM Application Toolkit, or S@T, is a SIM-card dependent technology that allows digital security keys or signatures ${ }^{71}$ to be used on the handset for MFS transactions, as well as for placement of specific, tailored menu items like banking applications on the screens of compatible handsets. S@T as a simple, common facility available across a range of entry-level and expensive mobile phones is one of the most extensively and globally used mobile interfaces in MFS, other than USSD. ${ }^{72}$

When a SIM card with an application placed on that SIM card through S@T methods by the MNO - for example, in conjunction with a specific bank - a menu item relating to that bank will appear on the handset screen. If updates for functionality or security need to be made to the application on the SIM, a series of what are known as 'Over the Air', or OTA, digital SMSs are sent wirelessly over the MNO's network to the phone which together will update the application on the SIM. ${ }^{73}$

\footnotetext{
${ }^{67}$ Most of these OSs are proprietary in that an application designed for one OS will usually only work on that OS and no other.

${ }^{68}$ Nokia's Symbian mobile phone Operating System, once the world's most popular, is now in decline. See R Richmond (hereafter 2011) 'Security to Ward off Crime on Phones' New York Times 23 February, available at http://goo.gl/HMcCZ.

${ }^{69} \mathrm{Java}$ is a programming language and computing platform first released by Sun Microsystems in 1995. It is the underlying technology that powers state-of-the-art programs including utilities, games and business applications. See Java (2011) 'FAQ: Mobile Java', available at http://goo.gl/Lo SFO.

${ }^{70}$ See S@T in ch 5, s5.5.3.2 titled S@T Mobile Phone Navigation Menus for MFS.

${ }^{71}$ These are symmetric digital keys sent via SMS for the digital signing of data messages and for session authentication.

${ }^{72}$ As with USSD, S@T is especially prevalent in developing nations where entry-level phones are mostly used.

${ }^{73}$ See on OTA, Annex 1: Exhibit A.
} 
Where SMS is being used as the communication medium in a MFS transaction, any data sent between the handset and the server mediating the transaction may be secured by special encryption applications using S@T. ${ }^{74}$ Here small software applications are loaded onto the SIM card by a MNO or bank before being shipped to the user, or are transferred to the phone and then to its SIM card over the mobile network using OTA. Using sets of predefined encryption keys acting as digital signatures and mediated by S@T software on the SIM and at the mobile operator, the data is encrypted and thus the integrity of the transmission over the mobile network is facilitated end-to-end, that is, entirely from the mobile handset to the mobile operator and then on to a third party provider. ${ }^{75}$ For example, user authentication PINs used in S@T-based MFStype banking applications would be encrypted from the handset by the S@T-based banking application on the SIM card, then sent to the mobile operator, and on to the S@T server at the bank where it would be decrypted for use, and vice versa.

In a typical example of a MFS transaction, a content bank or supplier requiring a transaction to be digitally signed by the user will deliver to the user's mobile handset a special digital SMS containing a process for signing a contract to an application in the SIM card. ${ }^{76}$ Using special encryption keys embedded in the application that must match that which is sent by the bank, the client accepts the contract by using their PIN code to digitally 'sign' the contract. A special encryption algorithm in the SIM matching that of the bank then encrypts the PIN and sends it back via binary SMS to the bank for verification. This methodology creates an audit trail for legitimate transactions, and prevents repudiation of that transaction by either party. ${ }^{77}$

\subsection{4}

\section{Mobile Phone Applications}

Although there is a large influx of so-called smartphones that can allow a mobile handset to act as if it were a TV, radio or payment hub, as noted above, the majority of mobile phones in the world are relatively 'basic' $2.5 \mathrm{G} / 2.5 \mathrm{G}+$ designs that allow simple SMS, IVR and USSD commands. ${ }^{78}$ Newer, 'smartphones' that have enhanced functionality and which resemble computers in functionality have however an extraordinary ability to store and execute applications or 'apps' that provide specific functionality, for example, a secure payment application. The applications may be phone OS-specific or may be generic types that can run on any type of mobile phone - and this is not necessarily limited to the smartphone - and

\footnotetext{
${ }^{74}$ See, generally, CellularOnline (2011b) 'SIM Toolkit', available at http://goo.gl/rHTL3; and T Johannessen (2009) 'The SIM Card as a Secure Basis for ID', available at http://goo.gl/7cB Sf.

${ }^{75}$ While the handset is generally considered insecure, the SIM card is thought to provide an additional level of security by communicating with the handset through specified secure commands so that the combination can be considered relatively secure.

${ }^{76}$ Commonly called the 'client-side'.

77 These S@T-generated signatures are also necessary to authenticate the user to prevent repudiation by an authenticated user to the effect that they are not responsible for a particular transaction and to prevent session hacking. Where possible, a payment application may even be stored on the SIM card, and would be available on any phone capable of reading the SIM card and executing the application thereon.

${ }^{78}$ This is a legacy of, for example, the GSMA's 2005 'Emerging Market Initiative' to introduce a basic mobile handset whose cost is sub-US\$40, and at a level of affordability inclusive of those at the Bottom of the Pyramid (hereafter BOP). See JC Tanner (2005) 'GSMA Kicks Off Emerging Market Push with Sub-\$40 Handset', available at http:/goo.gl/FtDnb; and JC Aker and IM Mbiti (2010) 'Mobile Phones and Economic Development in Africa' 24(3) Journal of Economic Perspectives 207-232. On the BOP, see ch2, s2.1.
} 
that can ably execute almost ubiquitous 'Java' applications on Java-capable phones. ${ }^{79}$ The security and privacy guarantees of the applications, which are developed by third parties and placed on specific OS Application Stores for sale, are not settled however.

\subsection{5}

\section{Mobile Phone User Interfaces Best Suited to MFS}

While the explosion of new types of phones and operating systems has solved many technological issues in mobile phones, there is an equally critical need to find effective User Interfaces (hereafter UI) for the simpler devices which would be at the usage core of basic MFS. MNOs in their effort to place as many handsets in the hands of new customers as possible, invariably sell at subsidised cost the cheapest of handsets, with basic $2 \mathrm{G} / 2.5 \mathrm{G}+$ functionality like phone calls, SMS, MMS and USSD, with some that can accommodate WAP over GPRS/EDGE. Most potential users of MFS, though, have very little technical literacy beyond the procedures used for making basic phone calls and using the mobile phone to input a code from a prepaid airtime voucher using USSD or IVR to place credit in their airtime SVA. Navigating through a swathe of hierarchical menus even in truncated WAP sessions and having to select the correct menu items for multiple purposes are new and possibly complex concepts for neophytes. ${ }^{80}$ It has been shown that users who obtain new low-cost handsets that have WAP menu buttons will immediately start using the WAP menus for the novelty and may inadvertently start subscribing to PRS subscription services that drain their prepaid SVA, without the new user being or becoming aware of the reason. ${ }^{81}$

Some research has been done that investigates the best mobile handset interfaces for low-technical literacy users, and recommends inter alia the use of voice feedback, ${ }^{82}$ speech interfaces, ${ }^{83}$ fewer menus and dedicated buttons, ${ }^{84}$ which make sense for low-technical literacy and novice users. ${ }^{85}$ Research based on the user interfaces (hereafter UIs) used in MFS in South Africa, India, Kenya and the Philippines show that non-text designs are preferred over text-based designs and that while task-completion rates are better for the rich multimedia UI, speed is faster and less assistance is required on spoken-dialogue systems. ${ }^{86}$

\footnotetext{
${ }^{79}$ See, for example, Obopay Mobile Application which is based on the Java 2 Platform and boasts a simple, intuitive interface. See Obopay Mobile Payment Service at Obopay's home page at http://goo.gl/OR8Qe.

${ }^{80}$ See S Lehrman (2007) 'Dialing In: Mobile Phones Target the World's Non-reading Poor' 296(5) Scientific American 30-31.

${ }^{81}$ L Perlman (2010) 'Mobile Money and Payments Issues: [Aspects of Legal \& Regulatory Issues in Mobile Financial Services in the Developing World]' Mobile Money II Conference, Friday, November 5, 2010, Columbia University, The Columbia Institute for Tele-Information (CITI) at Columbia Business School, available at http://goo.gl/PxViy.

${ }^{82}$ T Parikh et al (2006) 'Mobile Phones and Paper Documents: Evaluating a New Approach for Capturing Microfinance Data in Rural India' ACM Conference on Computer-Human Interaction (CHI), Montreal, Canada, available at http://goo.gl/m635Z.

${ }^{83}$ AL Ratan (2008) 'Using Technology to Deliver Financial Services to Low-income Households: A Preliminary Study of Equity Bank and M-PE SA Customers in Kenya' Microsoft Research Technical Report, available at http://goo.gl/oY5wg; I Medhi, I, A Ratan and K Toyama (2009) 'Mobile-Banking Adoption and Usage by Low-Literate, Low-Income Users in the Developing World' Microsoft Research, available at http://goo.gl/YgOLt.

${ }^{84}$ S Lehrman (2007) op cit note 80.

${ }^{85}$ Issues that have been reported include customers confusing the purpose of buttons on phones, problems in fine motor control because of the small size and physical closeness of the buttons leading to customers pressing incorrect keys. See Parikh et al (2006) op cit note 82.

${ }^{86}$ Medhi, Ratan and Toyama (2009) op cit note 83. Recommendations for an ideal MFS UI include providing graphical cues; providing voice-annotation support wherever possible; provide local language support, both in text and audio, to minimise hierarchical structures; avoid requiring non-numeric text input; avoid menus that require scrolling; minimise soft-key mappings and integrate human mediators into the overall system.
} 


\section{Overview}

Special chips built into mobile handsets enable users to communicate directly with one another at short ranges and with third party devices (like POS devices), and so do not necessarily need to be connected to an $\mathrm{MNO}^{87}$ These short-range 'proximity' or 'contactless' communications can cover a range of a few centimetres to a few metres. ${ }^{88}$

Some examples include WiFi, Bluetooth, RFID and NFC which are further described below. ${ }^{89}$ Functionally, they allow users to transmit or swap data that can be used generally and specifically in an MFS environment, for example, tapping the phone against a reader at a transit turnstile to allow the purchase of an electronic access ticket or by sending value from one enabled handset to another in an inter partes transaction equivalent to cash, where the proximity chip is linked to a MNO, to a fiat-based SVA or to an 'offline' unconnected SOV on the handset itself. ${ }^{90}$

\subsubsection{2}

\section{Wireless Fidelity (WiFi)}

Wireless Fidelity (hereafter WiFi) is a Wireless Local Area Network that enables computers like Personal Digital Assistants (hereafter PDAs), laptops and personal computers to send and receive data both indoors and outdoors and anywhere within the range of a wireless base station, commonly known as a 'Hotspot'. ${ }^{91}$ Some MFS systems use WiFi to operate and to link together component pieces.

\subsubsection{Bluetooth}

Bluetooth is a proximity standard launched in May 1998 that uses a short-range radio link to exchange information. This enables effortless wireless connectivity between mobile phones, mobile PCs, handheld computers and other peripherals. ${ }^{92}$ The most common use today is for communicating via headsets, although in the MFS setting, Bluetooth is used for communicating with barcode scanners, mobile credit card slip printers and POS devices.

\footnotetext{
${ }^{87}$ In the case of NFC, below, there may be instances where a MNO connection may be needed to check available balances for use in a transaction.

${ }^{88}$ There are usually specific types of enabling chips and software which are built into the device, which can make them far more expensive than basic handsets.

${ }^{89}$ Some systems, like NFC and RFID, allow cheaper NFC chip-enabled stickers to be placed on the device instead of embedding a more expensive NFC chip inside. The sticker version of NFC does not have the same level of functionality however as the embedded version.

${ }^{90}$ On the differences between 'online' and 'offline' and their effect, see ch 4, s4.8.4.4.3.2

${ }^{91}$ See CellularOnline (1996-2006b) 'What is WiFi?', available at http://goo.gl/berL4.

${ }^{92}$ See CellularOnline (1996-2006a) 'What is Bluetooth? [Goodbye Infrared!]', available at http://goo.gl/TjH0O.
} 
Radio Frequency Identity (hereafter RFID) is a 'contactless' or 'proximity' system that has a small radiobased chip embedded in it that allows a card or device to communicate with a nearby reader without the need to insert the card or device into the reader. RFID is used worldwide in a number of applications. It is used in the London Underground's Oyster ${ }^{93}$ micro-payment system and the similar Octopus ${ }^{94}$ system in Hong Kong. ${ }^{95}$ Many security door systems also use this for access control as do some bank-issued debit and credit cards with embedded RFID chips that allow the user to simply 'wave' the card against a RFIDbased POS reader to effect payment. The chips embedded in these RFID cards have, on average, a (unidirectional) proximity range of about $10 \mathrm{~cm}$ to allow them to be read by the RFID reader. ${ }^{96}$ The only way to secure the chip from being read by people operating their own scanners is to shield the chip from unwanted radio signals.

\subsubsection{5}

\section{Near Field Communication}

Near Field Communication (hereafter NFC) is another, more modern 'Contactless Payments' system. It differs from RFID in that it is bidirectional and allows communication between devices (as does Bluetooth). ${ }^{97}$ Unlike the plethora of RFID standards, NFC is being touted as a universal mobile phone payment standard using special standardised NFC chips designed by Sony and Philips that are embedded in NFC-capable mobile phones. ${ }^{98}$ The handset integrates the NFC chip and antenna and possibly a smart card, although stick-on NFC tags are used in current, cheaper incarnations of NFC. ${ }^{99}$ NFC will also allow payments via special merchant NFC-enabled POS devices, while inter partes payments can also be made between two NFC-enabled phones that are in proximity to one another. MNOs and banks are in discussions to embed account numbers like credit and debit cards in special areas of the SIM card. The MNO will then 'rent' space on the SIM to financial providers and banks possibly in exchange for a revenue share from any micro or macro transaction utilising the account details embedded in the SIM. ${ }^{100}$ The MNO thus acts in a manner analogous to a payment switch, or even as an acquirer of the payment/transaction or issuer of the device, system or card used as a payment instrument.

\footnotetext{
${ }^{93}$ For example, Transport for London's Oyster contactless RFID rechargeable SVC used to pay for the tube, bus and some train fares in London. The card, thought of as a single-purpose card, is however also accepted by other commuter companies serving the London area. They have recently upgraded the system to use NFC

${ }^{94}$ Octopus is a contactless RFID-based rechargeable SVC used for payment of mass transit and small-value goods at POS in Hong Kong. See Octopus website (in English) at http://goo.gl/4uqKO.

${ }^{95}$ The Oyster card may have been inspired by Hong Kong's transport system, which uses the similar Octopus card. There is no authentication mechanism. East Japan Railway's contactless payment card launched in January 2006 allows riders to download train tickets and recharge their Suica e-cash SVA over the air to their mobile phones and permits them to pass through transit gates or make purchases at more than 10,000 merchant locations in Tokyo. See East Japan Rail Company (s.d.) 'Suica \& N'EX: What Is It?', available at http://goo.gl/EnftW.

${ }^{96}$ RFID uses one of the Industrial Scientific Medical (hereafter ISM) licence free frequencies at $13.56 \mathrm{MHz}$ which can thus be used by anyone.

${ }^{97}$ See C Mulliner (2009) 'Vulnerability Analysis and Attacks on NFC-enabled Mobile Phones' 1st International Workshop on Sensor Security, available at http://goo.gl/w1 gkO.

${ }^{98}$ Many new models of mobile phones have NFC chips as standard. See Sarah Clark (2010a) 'All new Nokia Smartphones to come with NFC from 2011' Near Field Communications World website, $17^{\text {th }}$ June, available at http://goo.gl/mfGOb.

${ }^{99}$ The tag data is processed by either OS functionality or third party application.

100 See Sarah Clark (2010b) 'Dutch Banks and Mobile Operators to Launch National NFC Service' Near Field Communications World September 9th, 2010, available at http://goo.gl/n2yJk; and Total Telecom (2010) 'US Telcos to Unveil Details of Mobile Payment JV', available at http://goo.gl/6soMh.
} 
Based on the MNO's license conditions, ${ }^{101}$ users of the MNO's prepaid and post-paid billing systems are usually able to undertake a range of basic telecommunications-related services and be billed accordingly. ${ }^{102}$ The MNO's billing systems may also support access to a range of VAS for which users will pay a premium over and above the basic services. ${ }^{103}$ It is in this realm that MNOs have embarked on a range of putative MFS, where they act as the SOV and billing processors - and in many cases an active profit participant with third party providers of VAS, commonly called WASPs. ${ }^{104}$

These emerging WASP transactions are geared more towards micro-payments than macro-payments, ${ }^{105}$ that is, relating to the relative value of the transaction. Micro-payments may be classified as any transaction up to ZAR20 or $€ 10$, but this is usually dependent on the economic realities of the country analysed. ${ }^{106}$ They are usually executed by SMS or WAP, or NFC where available. Macro-payments are usually for higher-value goods and services - and for fiat-based remittances and payments - and are usually, but not always, distinguished from micro-payments by the need to input a secure PIN to verify the transaction. Besides one or two micro-payment examples such as Oyster in London and Octopus in Hong Kong that use contactless rechargeable RFID SVCs from transport-based micro-payments, there is very little to rival this ubiquity and pervasiveness in micro-payments, giving MNOs a currently effective and unrivalled global 'monopoly' over micro-payments.

These micro-payments are however limited at present to the purchase of predominantly digital goods and services and intra-MNO airtime SOV transfers, ${ }^{107}$ where subscribers belonging to the same MNO can transfer airtime value up to a certain amount between one another. ${ }^{108}$

The trend is towards the metamorphosis of m-payments into motifs that bear functional similarities to card payments, EFTs, banking and e-money and include the use of the MFS systems to transfer (MNO) airtime $^{109}$ or of value from fiat-based accounts operated by the MNO alone or in conjunction with a bank partner. ${ }^{110}$ These will largely evolve as macro-payments, although both macro- and micro-payments have found specific dominant payment niches. ${ }^{111}$

\footnotetext{
${ }^{101}$ See ch 12, s12.8 titled Telecommunications-related Laws and Regulations, and the licensing regimes employed.

102 These include basic telephone calls, sending and receiving SMSs, USSD and WAP data sessions via 2G+ and 3G/4G systems.

${ }^{103}$ See ch 6, s6.5.4.2 on WASP services.

${ }^{104}$ For a broader exposition of WASP services and their relationship to MFS, see ch 6, 6.5.4.2 on WASP services.

${ }^{105}$ See also ch 4, s4.8.3.5 titled Value of Payments.

${ }^{106}$ The best analogy is to ask what it would cost for a good Café Latte.

${ }^{107}$ See ch 6, s6.5.4.3 below titled Mobile Airtime Transfer, and Vodafone (2007) 'The Transformational Potential of MTransactions' at 30, available at http://goo.gl/mJGNt.

${ }^{108}$ For further examples of these services see Vodacom's page on Airtime Transfer at http://goo.gl/1JA81.

${ }^{109}$ See ch 6, s6.5.4.3 titled Mobile Airtime Transfer.

${ }^{110}$ See ch 6, s6.3.1 on an overview of MFS Schemes.

${ }^{111}$ Micro- and macro-payments to a large extent also share the same policy lacunae that surround electronic money, primarily around the interlinked legal and economic impacts.
} 
A serious and perennial challenge to any technology is its vulnerability to unlawful eavesdropping and access, also known as 'hacking'. Entire industries have sprung up to secure financial and telecommunications technologies from being compromised. In a mobile environment, four main areas of security and possible compromise are at risk: the radio link over the mobile network; the data sent over the mobile network; access to security keys or PINs on the handset; and internal fraud. ${ }^{112}$

On the mobile network transmission level, the ubiquitous GSM standard encompasses a myriad of encryption techniques some dating back to the genesis of GSM in the 1980s. GSM security algorithms are used to provide authentication and radio link privacy to users on a GSM network, ${ }^{113}$ but a key encryption technique called the A5/1 algorithm ${ }^{114}$ was compromised. ${ }^{115}$ Although the GSM industry association, the GSMA, released a more powerful replacement 128-bit encryption technique called A5/3, the compromised A5/1 is still in use with many legacy $2 \mathrm{G}$ and $2.5 \mathrm{G} /+$ phones and GSM networks. While it requires some relatively complex equipment and software to listen in on calls and extra data sent and received in real time, a device has been publicly shown that uses off-the-shelf material to intercept some types of mobile calls and record everything that is said. ${ }^{116}$ The $3 \mathrm{G}$ system however uses more complex encryption, although $3 \mathrm{G}$ use is not yet as generally widespread in MFS due to $3 \mathrm{G} /+$ handset and network roll-out costs. ${ }^{117}$

\section{7 .2}

User Aspects of the Mobile Handset

Generally, out-of-the box access to basic handset functionality has limited security measures so as to ease the user's first experience of the handset. Some users may input PINs for their SIMs, but most are only vaguely aware of the threats and available safeguards; and of those who are aware of the basic security measures, the perceived inconvenience of having to continually input PINs may not, in some users' minds, be regarded as sufficient and certain enough to justify this 'inconvenience'. ${ }^{118}$

\footnotetext{
${ }^{112}$ Another factor may be internal fraud by staff members of the MNO or its Service Providers. Some cases that have arisen include the interception of SMSs - called One Time Passwords (hereafter OTPs) or Random Verification Number (hereafter RVN) - used for verification of banking transactions. See ch 5, s5.7.4.1 on so-called 'Phishing' by fraud syndicates sometimes with assistance from internal MNO and bank staff - intent on intercepting these crucial security SMSs. The SMS containing the OTP could be sent by a bank to its customer directly through an MNO, or via an intermediary such as a WASP who in turn connects to an MNO. See ch 6, s6.5.4.2 on WASP VAS.

${ }^{113}$ GSM uses three different security algorithms called A3, A5, and A8. The GSMA says that A3 and A8 are generally implemented together (known as A3/A8). An A3/A8 algorithm is implemented in the SIM and in GSM Network Authentication Centers. It is used to authenticate the customer and generate a key for encrypting voice and data traffic. Development of A3 and A8 algorithms is considered a matter for individual GSM network operators, although examples of implementations are available. An A5 encryption algorithm scrambles the user's voice and data traffic between the handset and the base station to provide privacy. An A5 algorithm is implemented in both the handset and the MNO's Base Station Subsystem (hereafter BSS). For a complete description, see Global System for Mobile Communications Association (2011) 'GSM Security Algorithms' GSM World, available at http://goo.gl/kQU3a.

${ }_{115}^{114} \mathrm{~A} 5 / 1$ uses what is known as a 64-bit binary code for data encryption.

${ }^{115}$ See KJ O’Brien (2009) 'Mobile Phone Encryption Code is Divulged' New York Times, available at http://goo.gl/CGYPy.

116 J Robertson (2010) 'Hacker Builds \$1,500 Cell-phone Tapping Device', available at http://goo.gl/EWJW.

${ }^{117}$ See ch 5, s5.2 above on Mobile Network Technologies.

${ }_{118}$ R Clarke (2008) 'A Risk Assessment Framework for Mobile Payments' Proceedings of the 21st Bled eCommerce Conference, June 2008 63-77, available at http://goo.gl/dP3Ns.
} 
GSM/3G networks only provide protection on the radio frequency links for the user traffic. These are the links that connect the user's mobile phone to the MNO via a set of MNO radio base stations. If that link is compromised, as it has been, an additional level of security is to encrypt the data sent over the radio network from being hacked. However in many markets, the relatively low value of transactions and the relative ability to communicate loss or theft of the handset to the MNO is said to vitiate the need for more robust security mechanisms like using OTA ${ }^{119}$ upgrades of phones, S@T, encryption keys, and SIM swaps. ${ }^{120}$ When using USSD, the encryption is based entirely on the encryption technique employed by the MNO. Some MFS use a combination of USSD and SMS/S@T, for example, to protect the PIN code which may somehow be stored: as USSD is session based and does not store any data, USSD is used to initiate communication with the MFS server and input account numbers and PINs, while SMS is then used to execute specific transactions in a secure, or even insecure, manner. Users of Bluetooth technology may also be vulnerable, although its vulnerability to hacking - commonly called 'Bluejacking' ${ }^{121}$ - is not caustic to MFS transactions unless the mobile phone is used to communicate with an MFS-type Bluetooth device like a credit card reader or biometric identifier. ${ }^{122}$ A relatively obscure but entirely possible threat to the handset comes from 'cloning' - making an exact duplicate of - the SIM card components and access keys, so as to intercept any secure data sent to the handset in an MFS environment. ${ }^{123}$

\subsubsection{Phishing}

An increasingly and serious means of unlawful access to financial accounts is the use of so-called 'Phishing' techniques where a user is conned into revealing the access details of his banking account and access password details through the use of sophisticated web pages or emails that resemble or mimic a regular login page of a bank or financial institution website and which usually contain 'urgent attention' or similar content that entices and tricks the recipient into divulging their bank user name and password as well as their mobile phone number as provided to the bank. ${ }^{124}$

\footnotetext{
${ }^{119}$ See ch 5, s5.5.3.2 titled S@T Mobile Phone Navigation Menus for MFS on S@T over the air remote upgrades of secure applications on SIM cards.

${ }^{120} \mathrm{~A}$ 'SIM swap' means that the user must obtain from the MNO a new SIM card with updated and possibly more details. For the effect of a 'SIM swap' by fraudsters, see ch 5, s5.7.4.1 on 'Phishing'.

${ }^{121}$ See CellularOnline's home page at http://goo.gl/ImIYb.

122 See V Jain and RC Joshi (s.d.) 'Integrating Bluetooth, Biometrics and Smartcards for Personal Identification and Verification', available at http://goo.gl/oiK9N; and D Kearns (2008) 'Privaris Releases Bluetooth-supported Portable Biometric Authentication Device: Privaris PlusID 75 Supports Bluetooth for Short Distance Wireless Control' Security Identity Management Alert [Newsletter], January 23, NetworkWorld, available at http://goo.gl/1euHB.

${ }^{123}$ This threat is described in ch5, s5.7.4.2 titled Mobile Number Spoofing.

${ }^{124}$ The mobile phone number is employed by banks to send to their customers registered mobile phone notification of a login into a customer's banking account, notification of a credit or debit card transaction, or notification of the addition of a new payment beneficiary attached to the customer's account, or payment to any beneficiary. See also AJ van der Merwe and R Seker (2004) 'Mobile Phishing' 33 South African Computer Journal at 111-112 who, in an early paper on the subject, describe types of mobile hacking possible in the era of its writing.
} 
The 'Phishing' scourge ${ }^{125}$ has primarily been using emails that can be read and accessed on non-mobile screens, but may have impact insofar as it allows fraudsters using accomplices at MNOs, their agents, and/or banks and/or using fraudulent ID documents that allow them to ultimately intercept SMSs containing OTPs for verification of banking transactions sent to handsets for beneficiary addition verification, so allowing them to rapidly transfer money to other accounts under their control. ${ }^{126}$ The 'Phishing' scourge is however rapidly spreading to vulnerable mobile phones: so-called malware enabling 'Phishing' on mobile phones is becoming more prevalent. ${ }^{127}$ Mobile Number Spoofing

The handset and SIM are also vulnerable. Although not yet shown to be a common occurrence, special software written by hackers allows certain versions of internal operating software - or firmware - to be

\footnotetext{
${ }^{125}$ According to South Africa's banking risk assessor, the South African Banking Risk Information Centre (SABRIC), South Africa is the third most victimised country after the United States and the United Kingdom subject to phishing attacks. See SABRIC (2010) 'Phishing Scams Rising in South Africa', July, available at http://goo.gl/3X6aN.

${ }^{126}$ In a somewhat intriguing 'world-first' case of internal MNO fraud that enabled the OTP verification-by-SMS component of a 'Phishing' attack, a rogue technician employed by MNO Vodacom South Africa created a diversion, active for a very short period of time, that sent all SMSs containing the OTP/RNV destined for a real owner's mobile phone to a temporary SIM card under the control of his accomplices. This diversion was for a short time and effectively cut off the real owner's access to Vodacom and allowed the accomplices effectively to be the real owner. All the real owner would have noticed was that they were no longer connected to Vodacom for a short period, not an uncommon occurrence for most mobile phone users. During this time, the fraudsters logged into the online banking account of the victim using their victim's user name and password, details of which they had somehow obtained possibly through 'Phishing'. They had of course also obtained the victim's mobile phone number, which would be needed to receive the SMS containing the security OTP - that would confirm the addition of a new payment beneficiary. Armed with the crucial security SMS diverted to their own phones as well as the username and password, this was used by the accomplices to complete the creation of a new payment beneficiary payable to their own fraudulent banking account. They then transferred money to this account. Some 1,500 clients of First National, Standard, ABSA, Nedbank and Capitec banks were affected. The syndicate was located, caught and charged under s49(1) of the Regulation of Interception of Communications and Provision of Communication-related Information Act 70 of 2002 . They were found guilty of defrauding 10 Vodacom customers out of about R380,000. For details of the modus operandi and subsequent case, see R Muller (2009) 'This Is How SMS Banking Fraudsters Did It' MyBroadband, available at http://goo.gl/DDbEI; and O Molatlhwa (2012) 'Banks Clients Lost R180m in Fraud Scam' SowetanLive, available athttp://goo.gl/M9U9C. This 'world-first' case is of course a more sophisticated version of the 'SIM swap' technique in which fraudsters who have access to a victim's mobile phone number and banking user name and password, and armed with false identification documents, will try to obtain a new SIM card via a retail outlet that issues a new and replacement SIM card on behalf of a MNO, claiming to have lost 'their' phone with its SIM card. For another example of the impact of the interception of the OTP, see Nashua Mobile (Pty) Ltd v GC Pale CC t/a Invasive Plant Solutions (A3044/2010) [2010] ZAGPJHC 112 (18 November 2010) (hereafter 'Nashua') where the plaintiff instituted a delictual action against the defendant - the retail outlet owned by Nashua Mobile - for losses suffered in an unauthorised EFT when the OTP was intercepted after an unauthorised 'SIM swap' at the defendant's premises and after a suspected phishing attack on the plaintiff in which their user name and password were somehow captured. See the discussion in ch 7, s7.3.6.5.4 on responsibilities of bank customers. For a discussion of the legal implications of SIM swaps, see C van der Bijl (2009) 'SIM-Card Swapping, Mobile Phone Banking Fraud and RICA 70 of 2002' 21(2) SA Mercantile Law Journal 159-173. On a syndicate involving MNO service providers and bank staff in cahoots to harvest bank user names and passwords and intercept SMS OTPs, see Legalbrief (2010) 'Absa Employees in R1.38m Bank Fraud Case', available from http://goo.gl/LbJYr.On methods of protecting the security of electronic banking, see S Powell (2009) 'Critical Measures to Protect Against Rocketing EFT Fraud Risk' Without Prejudice December 48-50, who says that within companies, password abuse is prevalent amongst staff members in finance teams and that this should be made a dismissible offence. See also S Powell (2011) 'EFT Fraud and Password Abuse' Without Prejudice November 43-44. For a case involving a successful 'phishing' attack on an attorney, see Roestof v Cliffe Dekker Hofmeyr Inc (34306/2010) [2011] ZAGPPHC 219 (2012). In this instance, an attorney fell victim to a sophisticated 'phishing' attack involving phony ABSA Internet banking web pages, receipt of phony verification SMSs containing OTPs that purported to come from ABSA, and even a phony legal client. The court found the victim was negligent in his online banking activities. For a further discussion of this case, see ch 7, s7.3.6.5.3 titled The Bank and s7.3.6.5.4 titled Bank Customers.

${ }^{127}$ See ch 5, s5.7.4.4 titled Malware and Viruses.
} 
reprogrammed in order to 'clone' or 'spoof' the real owner's mobile number and so receive their SMSs or to access their data (this occurred, for example, with the now-discontinued Nokia 1100 mobile phone). ${ }^{128}$

Another form of spoofing may also result in inadvertent calls to premium rated IVR numbers. In this scheme, the fraudster will use a sophisticated device that perverts the SS7 system that is at the core of GSM networks so as to generate a specific number that appears on the handset when called. They call the user's handset momentarily, which the user sees as a missed call on their Caller ID on the handset, and out of human curiosity, the user may call back that number, incurring at a minimum, a premium rated charge.

\subsubsection{Man in the Middle Attacks}

While it has huge potential as a payment instrument, numerous potential security flaws have been identified in NFC proximity systems. ${ }^{129}$ For example, many current handsets and services use passive NFC tags instead of NFC chips built into the handset. There is no authentication mechanism like a PIN, for example, as there is with 'Chip ' $n$ PIN'-based credit cards. ${ }^{130}$ Further, NFC chips and tags can be read if the NFC card or tag is within range of a malevolent NFC reader. ${ }^{131}$

This third party application or device operated by the so-called 'man-in-the-middle' can then intercept and take control of NFC functionality to steal user access credentials or inject malicious content into an enabled NFC device for arbitrary or malevolent use, so compromising the security and reliability of NFC systems. ${ }^{132}$ The man in the middle can of course also be a human and seek the exposure of PINs by sleight of hand or by pretending to be representatives of an MFSP. ${ }^{133}$

\footnotetext{
${ }^{128}$ The hacking technique consists of modifying the Nokia phone's internal factory-installed operating software - the firmware - and such information as the IMEI and the IM SI, whereby a phone registers itself with an operator. The hacker then clones a SIM card. See J Kirk (2009) 'Investigators Prove Nokia 1100 Online Banking Hack', available at http://goo.gl/RwvJm. To avoid cloning of - albeit only - smartphones, South African bank Nedbank launched security 'certificates' for smartphones. The bank associates registered devices with specific accounts to avoiding the risk of cloned SIMs. The application uses a common PIN requiring an additional password for features like business banking. The PIN must be re-entered every time the application is opened, even if it is only closed briefly to answer a call, reducing the risk of a phone being stolen with an authenticated session open. See ITWeb (2012) 'Nedbank Chooses Entersekt for its Mobile Security Software', available at http://goo.gl/eUe1w.

${ }^{129}$ See Mulliner (2009) op cit note 96.

${ }^{130}$ However, even seemingly impenetrable PIN pads that self-destruct when they are tampered with are now penetrable. See Security News (2011) 'PIN Pads Hacked at Michaels Stores Nationwide', available at http://goo.gl/CDXYe.

${ }^{131}$ This (NFC) range is typically around $10 \mathrm{~cm}$ for the readers currently deployed by Transport for London (TfL) NFC devices. The only security against their being accidentally overcharged or having private details read or associated with a particular Oyster Card by people operating their own MIFARE scanners, is to shield the Oyster Card from unwanted radio signals. These private details include information about the last 10 trips that a user has made, which is data stored directly on the card, and which will be available to third party retailers who come on board the potential 'electronic SOV' aspects of the scheme. The MIFARE system uses one of the ISM license-free frequencies at $13.56 \mathrm{MHz}$, so it is not illegal for other people to have or to use their own NFC reader equipment. See TfL website at http://www.tfl.gov.uk/.

${ }^{132}$ See Mulliner (2009) op cit note 96.

${ }^{133}$ In one reported instance in January 2010, an agent lost around US\$400 in a scam that appears to have arisen when his phone address book was altered to make it look like a SMS confirming a transaction was made from the official $\mathrm{m}$-pesa phone number. Two persons had approached the m-pesa agent, presenting Safaricom credentials. They claimed to be doing an audit and asked to see the agent's accounts. They then left. Some 20 minutes later, another man approached the agent and requested cash. He appeared to start an m-pesa transaction on a mobile device in which he supposedly was requesting a (legitimate) withdrawal from m-pesa based on that agent's account as the cash-out 'ATM'. Shortly afterwards, the agent received a SMS that purported to be a legitimate m-pesa transaction authorisation, and which contained the agent's current credit balance with m-pesa. The agent verified the man's name on his national identity card, and paid out the cash. The agent noticed later though that the withdrawal had not been recorded on his (the agent's) m-pesa account, since his paying out the cash would have triggered a credit on his account. M-pesa later confirmed that the transaction had been fraudulent. What appears to have happened is that a contact from the agent's phone address book was remotely inserted into the phone address book, as a socalled 'vCard' payload in an SMS message. The ability to do so is a feature of many phones: Nokia mobile phones, for
} 
It is possible, although currently not a general problem, to send malevolent software, or malware and also called spyware, and viruses directly to smartphones. ${ }^{134}$ Malware is malicious software that may take control of the handset surreptitiously and capture user names, passwords or PINs and other access credentials. The malware could be embedded in applications that users download to their phones, or though malicious links within WAP sites. ${ }^{135}$

Some malware handset applications have been known to automatically dial or send to Premium Rated numbers, an effective method for the ringleaders to monetise their activities. ${ }^{136}$

Generally, mobile-based malware is OS-specific, ${ }^{137}$ but applications on the popular and usable crossplatform Java ${ }^{138}$ system that runs on most low to high-end phones may pose the biggest vulnerability. ${ }^{139}$

\subsubsection{5}

\section{Security Safeguards}

The number of reported breaches of MFS based on technological intrusions is growing with an ever increasing culture of manufacturing malware from freely available hacker software 'kits'.

example, will open the vCard automatically. For a detailed account of this intrusion, see Telco 2.0 (2010) 'Security Breach at M-PE SA: Telco 2.0 Crash Investigation', available at http://goo.gl/ym8Br. For a general overview of MFS security issues, see A Fanon and I Ateya (2008) 'Security Issues in M-Banking', available at http://goo.gl/3yEmy; and Clarke (2008) op cit note 117 .

${ }^{134} \mathrm{~A}$ smartphone is a more sophisticated mobile handset that provides additional functionality beyond basic voice, SMS, MMS, USSD and possibly WAP. Usually it uses an OS that allows applications to be easily added to the handset, as well as having sophisticated multimedia functionality.

${ }^{135}$ Most attacks originate from Eastern Europe. Initially limited to Nokia's Symbian mobile OS, the scourge has rapidly spread to the Android Orthodox School.

${ }^{136}$ Malware is 'monetised' - that is, revenue generating - by enabling mobile pickpocketing through use of Premium Rates call and SMS fraud. The user is unaware that his phone is sending an SMS or making a call to premium-rated numbers such as those for buying virtual currency codes, eg, for access time to popular online games which can be automatically bought and sent to the infected phone. The malware however surreptitiously captures the currency codes sent to the phone, and forwards it to the ringleader who is then able to sell these codes for fiat value on the black market. A malware named Gemini appeared in third-party mobile phone applications like games which allowed hackers to manipulate SMSs, steal contact lists, place calls, visit websites and quietly download files. See Richmond (2011) op cit note 68.

${ }^{137}$ See, however, Zeus and its variant Zitmo, which intercepts OTPs sent to mobile phones by banks providing ostensibly secure additional 'two factor' security measure in web-based access to their banking websites. A user whose PC is infected and who tries to access a bank website triggers the Zeus malware, which reportedly asks the user to download an authentication or security component onto their mobile device in order to complete the login process. According to investigations done on the malware, it then generates a fraudulent transaction on behalf of the user and authenticates it by intercepting the OTPSMS verification message on the phone and forwarding it to the malware on the PC. The mobile Zeus variant then deletes the OTP message from the user's mobile device so the user will not see it and enters the code on the PC to complete the transaction. It runs on Nokia Symbian, RIM Blackberry, Android and Microsoft Windows Mobile OS devices. See P Roberts (2011) 'Threat Post: Zeus Banking Trojan Comes to Android Phones', available at http://goo.gl/lUeiQ.

${ }^{138}$ For a discussion on Java, see ch 5, s5.5.2 titled Mobile Phone Operating Systems, and ch 5, s5.5.3.2 titled S@T Mobile Phone Navigation Menus for MFS.

${ }^{139}$ For an example of 'Phishing', where a transaction verification SMS was intercepted by fraudsters, see Nashua op cit note 125. For a discussion on this case, see ch 5, s5.7.4.1 on 'Phishing'; and ch 7, s7.3.6.5.6.2 on agents. With regard to whether banks, for example, have a legal duty to notify customers about specific computer viruses and other security threats, see A Ramasastry (2005) 'Do Banks Have a Legal Duty to Notify Customers About Specific Computer Viruses? A Miami Suit Raises the Question' Findlaw, available at http://goo.gl/MMuqA. She believes that banks should not be responsible for protecting customers' personal computers where 'Phishing' may occur. It has however become common practise by many South African and other banks to offer their clients free 'security software' so as to mitigate the risk of 'phishing'. See ch 7, s7.3.6.5.3 on the bank's responsibilities with regards to matters of security and allocation of risk - under the general rubric of a bank's common law 'duties of care' - when 'phishing' and other attacks on bank customers occur. 
Most of the reported breaches though appear to be via the user as shown above. A number of safeguards ${ }^{140}$ against the unauthorised use of a handset in the MFS context can be provided to users, but some may require technical literacy training or even an understanding of some anthropological uses of money in community. Measures may vary in efficacy, but ultimately rely on awareness and understanding of risks and how to prevent and avoid them.

Clarke details, in the MFS context, some measures which he believes may reduce the scope for use of the device by unauthorised people, but warns that these do not reliably prevent it because of the sophistication of many schemes and techniques that are intended to subvert the preventative measures. ${ }^{141}$

The 'Logical Safeguards' suggested by Clarke include:

- The prevention of the user 'login' to the device itself for basic telecommunications or the facility unless users authenticate themselves;

- The auto-locking of the device after a period of inactivity, typically 10-15 minutes, forcing authentication to be performed again in order to unlock the device;

- The prevention of the performance of any access to the MFS component of the handset even on a logged-in device, until knowledge of a specific 'secret' is demonstrated. This would have to be done for each access so as to protect against transactions being conducted by another party who gains possession of a device, if only temporarily, that has been effectively left unlocked by its authorised user and in a usable state for an unauthorised user;

- Possibly stronger forms of authentication using biometric applications are available, whereby the device demands periodically that the authorised user's thumb be placed on a reader built into or connected to the device, with the device rendered inoperable if the thumbprint does not match sufficiently closely to a pre-recorded reference measure. ${ }^{142}$

To this may be added a design parameter that allows the input of a dummy 'duress' PIN that when entered during the confirmation stages of an MFS transaction will tag the transaction as being undertaken by someone under duress and so alert the MFS provider and police, but ingeniously, will allow the transaction to continue as if the non-duress PIN was being used.

Ultimately no transaction will be legally effected, but for the person under duress, it may allow them some protection and time to placate the malfeasant by showing them that the transaction is progressing as they have ordered.

\footnotetext{
${ }^{140}$ A safeguard is a measure intended to counter a threat or reduce any vulnerabilities.

${ }^{141}$ Clarke (2008) op cit note 117.

${ }^{142}$ This, however, is impractical for typical MFS in the field.
} 
The availability and the ease of use of affordable mobile phones around the world provide the perfect brew for their use as a platform from which to offer financial services. Indeed, a mobile phone appears to have become an economic necessity for rich and poor alike. The mobile phone, then, is a platform for conjoining multi-faceted markets consisting inter alia of the MNOs, users, service providers, retailers and agents who may mediate the sale of airtime and other services.

Specifically the use of so-called Premium Rated Services ${ }^{143}$ (hereafter PRS) where users transact via the airtime-based MNO SVA provides a useful foundation for MNOs and other Payment Service Providers (hereafter PSPs) to provide similar MFS-type services using fiat-based SOVs.

For the MNO, the experience emanates from the critical use of 'deposit' management, ${ }^{144}$ customer care services, interface management and the use of agents who ordinarily sell airtime but who certainly could be repurposed to also 'sell' and 'buy' the value in fiat-based and redeemable electronic SOVs in exchange for cash, that is, cash-in/cash-out services.

MFS then is a logical extension of the mobile phone's use and the user experience of telecommunications services.

Emboldening their use in all the commercial variations of MFS, ${ }^{145}$ the user interfaces to access new 'branchless banking' forms of MFS which are much the same as that used for loading (prepaid) mobile airtime value vouchers and for current payments use in micro-payment environments.

Hence the experience MNOs have in developing and maintaining the prepaid airtime SVAs used to pay for basic telecommunications, PRS PSMS services and incorporeal digital goods like ringtones, means they are well placed to transition relatively easily from using the SOV solely for basic telecommunications and PRS to using it as a general payment instrument in the provision of more robust general MFS services that include corporeal goods and services.

The ability to transfer MNO-based airtime balances to other users as a form of remittance is another harbinger of the potential of MFS to emerge as a preferred mechanism for payments in the general economy.

However, the relatively low level of technical literacy required to operate the mobile phone for basic services and for recharging - using for example the basic USSD, S@T and SMS phone commands described above - belies the need for caution when using these services in the general economy.

\footnotetext{
${ }^{143}$ As described in ch 6, s6.5.4.2.1 titled Relationships in the WASP Environment; and ch 6, s6.5.4.2.3 titled Interoperability: Clearing, Payment and Settlement.

${ }^{144}$ Even though the deposit is a non-fiat airtime SOV.

${ }^{145}$ As described in detail in ch 6, ss 6.4.4 and 6.6.3 titled Use of Agents, and 6.5.5 titled Use of the Fiat SVA.
} 
That said, there are of course not only unscrupulous criminal elements waiting to take advantage of the financial and technical illiteracy prevalent in the developing world, but the users themselves may be their own worst enemies in failing to secure their phones against intrusion and mistaken use.

Internal fraud at MNOs and MFSPs may risk user funds, while omnipresent digital security threats where so-called 'malware' may be placed on the phone that drains mobile phone's airtime-based SVA without the user's knowledge adds further to the need for caution and triggers a necessary discussion on available legal protections for users. ${ }^{146}$

This is especially so in a prefunded SVA environment where the 'paper trail' characteristic of post-paid systems may not be present.

\footnotetext{
${ }^{146}$ On available consumer protections see, inter alia, ch 8, ss8.6 titled Telecommunications Laws and Regulations, 8.7 titled E-Commerce Laws and Regulations, and 8.8 titled Consumer Protection-type Laws, and the relevant and corresponding sections in the country specific chapters in ch $9,10,11$, and 12 . See also the common law condictiones described in ch 7 , s7.3.6.8.
} 


\section{CHAPTER 6}

\section{MOBILE AND MOBILE FINANCIAL SERVICES COMMERCIAL MODELS}

\section{1}

\section{Overview}

Mobile Financial Services (hereafter MFS) are provided in a number of potential commercial incarnations, but this thesis looks at those that are in commercial use and which have been the subject of some regulatory scrutiny. These include those from Mobile Network Operators (hereafter MNOs), licensed banks, bankMNO hybrids, and from independent Mobile Financial Service Providers (hereafter MFSPs). ${ }^{1}$ Incidences such as the type of transactions available, contractual relationships, dispute resolution and the use of agents are discussed. Examples across South Africa (hereafter SA), Kenya, the European Union (hereafter EU) and the United States of America (hereafter USA) are shown.

When a prepaid mobile user purchases a SIM card and mobile prepaid airtime, the retailer may act as a (retail) agent of the MNO as well as an external Service Provider (hereafter SP) contracted to the MNO to distribute the Subscriber Identity Module (hereafter SIM) card required for user access to the MNOs facilities through the retail channel and to sign up and maintain a customer. ${ }^{2}$

The sale of prepaid mobile airtime by an MNO to a subscriber is usually governed by a contractual provision accepted on purchase by the purchaser of either the initial SIM chip pack and/or the prepaid recharge voucher which usually specifies that the MNO and/or the seller of the prepaid airtime as an agent of the MNO is not obliged to, or will not, pay back any amount on demand to the subscriber. ${ }^{3}$ In a post-paid

\footnotetext{
${ }^{1}$ For examples of MFS commercial permutations, see Exhibit A: Permutations Of MFS Provision And Actors.

${ }^{2}$ See ch 5, s5.2.2 titled User Access to Mobile Networks. There is thus an ongoing contractual relationship between the user and the MNO insofar as the technical provision of services. Where the SP acts as the MNO's agent in, inter alia, debt collection for contract payment as well as customer care and technical assistance such as for the provision of new phones and replacement SIM cards, an additional legal relationship comes into being. In a chain of agents possibly stretching from the MNO, SPs may thus be primary agents of the MNO; while retail stores may act as agents for the SP agent of the MNO. For the interplay between the MNO and the SP acting as an agent of the MNO in distributing SIM cards that provide user access to a MNO's services, and the effect of providing a replacement 'SIM Swap' card to a fraudster rather than the true SP client in a case of 'Phishing', see Nashua Mobile (Pty) Ltd v GC Pale CC t/a Invasive Plant Solutions (A3044/2010) (2010) ZAGPJHC 112 (18 November 2010) (hereafter Nashua'). For a discussion on this case, see ch 5, s5.7.4.1 on 'Phishing'; and ch 7, s7.3.6.5.6.2 on agents. On the use of agents in MFS, see ch 2, s2.5.2; and ch 6, ss6.4.4.3, 6.5.5.4 and 6.6.3. For a different vantage point on the interplay and putative (and often controversial) legal relationships involved in provision of VAS, see ch 6, s6.5.4.2.1 titled Relationships in the WASP and VAS Environment. Note the distinction in terminology between a Service Provider and a Wireless Application Service Provider (WASP): the former acts primarily as distributor of SIM cards, as a billing agent and marketer for MNOs with respect to mobile user's access to and use of basic voice and general data services. The latter acts either as a Value Added Services (hereafter VAS) mobile content provider - such as supplying ringtones or music for mobile phones - or also acts as billing agent ('aggregator') for third party Information Providers (IPs) who may supply similar VAS content to mobile users. See below, thereto, Exhibit B: VAS Relationships in ch 6, s6.5.4.2.1; and similarly Exhibit C: Money Flows in ch 6, s6.5.4.2.3.

${ }^{3}$ For the use of mobile airtime as a means of accessing MNO services, see ch 5, titled User Access to Mobile Networks. This contract would amount to a so-called 'shrink-wrap' agreement common in over-the-counter sales of software products where the purchaser would be made aware that opening the packaging will amount to constructive acceptance of the terms of the contract.
} 
environment, the user may be contracted to the MNO for provision of service, but to an external SP for any billing procedures. The MNO may be contracted to a SP to handle the billing with the subscriber, while the SP may be contracted to the retailer to provide annuity income.

As noted in earlier chapters, mobile phones because of their almost ubiquitous worldwide use and their ability to access information and digital services from locations where a MNO has coverage, have enabled access to a range of services beyond 'basic' mobile services, to wit, MFS. ${ }^{4}$ There are a number of MFS configurations ${ }^{5}$ highlighted in this study, falling under the broad headings of Bank-Led, ${ }^{6}$ MNO-led, ${ }^{7}$ and Independent MFSP. ${ }^{8}$ Examples highlighted include the Licensed Bank Branchless Banking Model ${ }^{9}$ the MNO-only model $;{ }^{10}$ the Bank-MNO Model $;{ }^{11}$ and the Independent MFSP model. ${ }^{12}$ Exhibit A details some practical examples representative of the MFS ecosystems worldwide, showing the entities involved in the MFS scheme; who provides the service to the customer; the nature of the SOV; and who has ultimate control of the SVA for contractual or prudential reasons.

\begin{tabular}{|l|c|c|c|c|c|c|}
\hline Scheme & Provider & Type & SOV Type & SVA Control & Example & Jurisdiction \\
\hline Bank & Bank & Sole & Fiat & Bank & Standard Bank $^{13}$ & SA \\
\hline Bank-MNO & MNO & Hybrid & Fiat & Bank & Vodacom M-Pesa $^{14}$ & SA \\
\hline Bank-MFSP & MFSP & Hybrid & Fiat & Bank & Wizzit $^{15}$ & SA \\
\hline MNO & MNO & Sole & Fiat & MNO & Safaricom M-Pesa & Kenya \\
\hline MNO & WASP & Hybrid & Private & MNO & Vodacom/MTN $^{18}$ & SA \\
\hline MNO & MNO & Sole & Private & MNO & Vodacom/MTN $^{16}$ & SA \\
\hline MFSP & MFSP & Sole & Fiat & MFSP & Paypal Europe & EU \\
\hline MFSP & MFSP & Sole & Fiat & MFSP & Obopay & USA \\
\hline
\end{tabular}

Exhibit A: $\quad$ Permutations of MFS Provision and Actors.

For banks, the use of the mobile phone along with an agent network may provide a viable 'additive' 'branchless banking' extension to their existing but limited 'bricks ' $n$ mortar' offerings. ${ }^{20}$ For MNOs, there

\footnotetext{
${ }_{5}^{4}$ See ch 5, s5.2.3 on types of basic mobile services.

${ }^{5}$ See for example ch 2 , ss 2.3 and 2.5 .

${ }^{6}$ See ch 6 , s6.4 on the bank-led MFS model.

${ }^{7}$ See ch 6, s6.5 on the MNO-led MFS model.

${ }^{8}$ See ch 6 , s6.6 on independent MFS models.

${ }^{9}$ See ch 6, s6.4.2 titled the Licensed Bank Branchless Banking Model.

${ }^{10}$ See ch 6, s6.5 on the MNO-led MFS model.

${ }^{11}$ See the licensed bank-MNO MFS model described in ch 6, s6.4.3.

${ }^{12}$ See the independent MFSP model described in ch 6, s6.6. An example of an independent MFSP is Obopay. See further www.obopay.com.

${ }^{13}$ See ch 6, s6.4.2 titled the Licensed-Bank Branchless Banking Model.

${ }^{14}$ See the licensed bank-MNO MFS model described in ch 6, s6.4.3.

${ }^{15}$ See ch 6, s6.4.4 titled Licensed-Bank-MFSP Model. See further on Wizzit in the context of other South African MFSPs, ch 12 , s12.2.7.

${ }^{16}$ See ch 10, s10.1 that introduces MFS in Kenya.

${ }^{17}$ Wireless Application Services Providers (hereafter WASPs). See ch 6, s6.5.4.2 on WASP services.

${ }^{18}$ See ch 6, s6.5.4 titled Use of the Airtime-Based Prepaid SVA In Transactions.

${ }^{19}$ See the Independent MFSP model described in ch 6, s6.6.
} 
is an empowered customer base: technical literacy of their users in basic mobile phone commands for adding value - 'recharging' - their airtime-based SVA ${ }^{21}$ containing a private SOV denominated in a Unit of Account (hereafter UOA) in say mobile airtime minutes, as well as the use of the SVA for accessing Value Added Services (hereafter VAS), ${ }^{22}$ sets the stage for the more expansive transformational MFS milieu that includes provision of a broader range of financial services and payment facilities.

Additionally, as noted earlier, where allowed by regulation or where available, MNOs may also create a separate prepaid SVA with a SOV that is fiat-based, redeemable on par and on demand into fiat money, and which may be used to purchase corporeal and incorporeal goods and services. Cash-in/cash-out facilities would be provided by the MNO's retail agents contracted to the MNO and/or a bank, ${ }^{23}$ but which may be the same actors as the MNO's retail agents who sell basic mobile airtime vouchers and SIM cards. ${ }^{24}$ In some jurisdictions, regulatory rules and/or commercial imperatives may necessitate collaboration between the MNO and a local licensed bank in a hybrid type of MFS model.

In the Independent MFSP model, the MFSP's services can be used on any mobile phone or MNO, where an MNO simply provides agnostic data transfer (bearer) access to the MFSP's services through the mobile phone. $^{25}$

\subsubsection{Bank Services versus MNO Mobile Financial Services}

As noted earlier, ${ }^{26}$ traditional categorisations whereby companies could be resolutely classified into silos that broadly represented their core financial business ${ }^{27}$ are becoming blurred. It may be noted that the nimbleness of MNOs to transform into entities that provide transactional equivalents of bank services is such that 'branchless banking ${ }^{28}$ in Africa is currently dominated by MNO-based models, using retail agents for their so-called cash-in/cash-out activities. ${ }^{29}$ This, says Mas, reflects low levels of banking penetration and the poor state of fixed communications infrastructures. ${ }^{30}$

In almost all the MFS schemes, any transactional ability by the user is invariably predicated on the user prefunding a (prepaid) SVA provided by the MNO or MFSP, be that the airtime-based or a fiat-based

\footnotetext{
${ }^{20}$ See ch 2, s2.1 on an introduction to the 'transformational' and 'additive' motifs in MFS.

${ }^{21}$ Ibid on the types of SVAs available and Exhibit A therein. As noted earlier, the hierarchy of value storage is that there is a Stored Value Product (hereafter SVP) offered to users which may contain different types of SVA, each with its own type of SOV denominated a UOA of the fiat of the national currency such as the Rand; or some other private UOA, such as airtime minutes respectively. The basic MNO SVA contains a SOV denominated in a mobile airtime-based UOA.

${ }^{22}$ See ch 5, s5.2.3 on the types of basic mobile services available. On some VAS offerings, see ch 6, 6.5.4.2.

${ }^{23}$ On the use of agents in MFS, see ch 2, s2.5.2; and ch 6, ss6.4.4.3, 6.5.5.4 and 6.6.3.

${ }^{24}$ See ch 5, s5.2.2 titled User Access to Mobile Networks that discusses SIM cards and prepaid mobile airtime values.

${ }^{25}$ The MNO would in some cases provide similar agnostic bearer services for a bank's 'additive' offerings. On aspects of data bearer facilities offered by MNOs, see ch 5, s5.2.1 titled Technology Types.

${ }^{26}$ See ch 4, s4.8.6 titled Conclusions and Summary.

${ }^{27}$ For example, commercial banking, insurance, securities trading and investment banking. See FR Malan (1989) 'Legal Aspects of the Regulation of Financial Institutions' 18(4) Tydskrif vir die Suid-Afrikaanse Reg at 554.

${ }^{28}$ See ch 2, s2.3 for an overview of 'branchless banking' in the context of MFS.

${ }^{29}$ See I Mas (2009a) 'The Economics of Branchless Banking' 4(2) Innovations at 59, available at http://goo.gl/qSXr0; and ch 2, s2.2 titled The Rationale for MFS.

${ }^{30}$ Ibid.
} 
SOV. ${ }^{31}$ No credit is thus given to the user, ameliorating to some extent the potential systemic risk associated with fractional banking. Both banks and MNOs will take cash from customers, which in a traditional bank setting would be called a deposit, and which in a MFS setting would be called 'cash-in'. ${ }^{32}$ The nomenclature, however, disguises their ultimate functions: both accept funds from customers who, in a fiat-setting, would ordinarily expect the funds to be paid back on demand and on par.

\subsection{1}

\section{Overview}

For the purpose of Financial Inclusion (hereafter FI) and an omnipresent commercial need to grow their traditional customer base, banks have been eager providers of electronic banking and payment services that ultimately serve to either replace the need for bank branches or to provide branch-like services in underserved areas.

Crisp issues in this model revolve around the policy of conversion of fiat-money into an electronic money (hereafter e-money) SOV, the status of bank agents in branchless banking, dispute resolution and the effect of Anti-Money Laundering (hereafter AML) and Know Your Customer (hereafter KYC), telecommunications, e-commerce and consumer protection laws.

\subsubsection{1}

\section{Overview}

As noted above, banks have begun to provide branchless banking where allowed by regulation, ${ }^{33}$ either doing it on their own, or partnering with specific service providers who are able to extend the bank's reach in areas not traditionally served and in preference to establishing traditional 'bricks 'n mortar'-type branches. In many cases, however, in order to promote and achieve the goals of FI, they have embraced the so-called additive model insofar as they target new but mostly existing bank customers to transact via their mobile phones instead of having to open 'bricks ' $n$ mortar' branches to reach underserved areas. The additive access to fiat-based redeemable accounts - a SVA or 'purse' - in MFS parlance, which house a

\footnotetext{
${ }^{31}$ The MNO involved in MFS will usually not risk customer funds or potential regulatory opprobrium by embarking on somewhat risky enterprises such as intermediation of customer funds. Indeed, the models employed in MFS services show a distinct firewall between 'risky' services - as seen from the perspective of the provider - and less risky services. See ch 4 , s4.4.1 titled Overview, on fractional banking in relation to use of deposits.

32 Some banks, however, do allow the retail agents to take cash 'deposits', although these deposits are almost always immediately converted - via sets of communications between the retail agent and the bank via the phone - into electronic money ('e-money) so as not to appear to the regulator as a 'deposit'. See ch6, s6.4.2.3.

${ }^{33}$ See ch 10, s10.2.4 on the use of MFS agents in Kenya, and ch 12, s12.7.3 on the South African Reserve Bank's Exemption 17 in relation to lower KYC criteria for low-value transactional accounts.
} 
fiat-based SOV. Ubiquitous mobile coverage powers the additive platforms ${ }^{34}$ but requires only basic technical literacy ${ }^{35}$ to use the simple Short Message Service- (hereafter SMS-), Interactive Voice Response(hereafter IVR-) ${ }^{36}$ and Unstructured Supplementary Service Data- (hereafter USSD-) based ${ }^{37}$ commands and SIM Application Toolkit (hereafter S@T) menus ${ }^{38}$ required to augment financial literacy. Where needed, agents would extend the branchless banking addition to the existing presence of fixed bank branches in many towns.

In a prototypical bank-led model, Standard Bank South Africa (hereafter SBSA) and their Community Banking Division provide their customers with a fully operational bank account and a transactional account that uses the mobile banking platform of the MNO MTN. ${ }^{39}$

\subsubsection{Contractual Relationships}

In this bank-led model, users have a direct contractual relationship with a prudentially supervised bank or financial institution even though their daily or periodic interaction may only be through the bank's agent acting on behalf of the bank, or through a device or mobile phone linked to that bank or institution. ${ }^{40}$

\subsubsection{Use of Agents}

When agents in the bank-led model are employees or contractors of the banks offering the service, they may be considered as true agents in the legal sense. The banks may extend the agent paradigm to allow retailers to open up accounts on the bank's behalf but not to take deposits or engage in any activities that amount to banking activity. These persons may instead be termed retail agents. ${ }^{41}$ While commercial nomenclature may refer to them as 'correspondents', 'agents' or 'retail partners', they are in effect acting as agents of the bank. In addition to opening accounts, they may also provide bank teller-like functions such as cash-in/cash-out facilities. In some cases they may be called 'outlets', 42 'retail partners', or 'cash merchants ${ }^{43}$ insofar as their role is primarily to receive cash from a user - whose electronic SVA is then credited with the cash amount - or to dispense cash. In both cases, the user may be charged a nominal transaction fee. SBSA for example employ a group of what they term 'Community Bankers' in underserved $\operatorname{areas}^{44}$ where there are no bank branches, to open accounts. The initiative, called Community Banking

\footnotetext{
${ }^{34}$ See ch 2, s2.3 on the scope of MFS.

${ }^{35}$ Prepaid users are innately familiar with using SMS and USSD for basic airtime recharging or SMS communications. See also O Morawczynski (2007) 'Innovations in Mobile Banking: The Case of M-pesa' First National Consultative Forum on Microfinance November 12-14, 2007 in Khartoum, Sudan, available at http://goo.gl/NaDX1.

${ }^{36}$ See ch 5, s5.3.3 titled Interactive Voice Response (IVR).

${ }^{37}$ See ch 5, s5.3.5 titled Unstructured Supplementary Service Data (USSD).

${ }^{38}$ See ch 5, s5.5.3.2 titled S@T Mobile Phone Navigation Menus for MFS.

${ }^{39}$ See further, ch 6, s6.4.2.3 titled Use of Agents; and ch 12, s12.2.5 on the MFS activities of Standard Bank in South Africa.

${ }^{40}$ For an introduction to the agent model as it is used in the 'branchless banking' paradigm, see ch 2, s2.5.2 titled Use of Agents.

${ }^{41}$ See K Jacob (2005) 'Retailers as Financial Services Providers: The Potential and Pitfalls of This Burgeoning Distribution Channel', available from http://goo.gl/38nFB.

${ }^{42}$ See ch 6, s6.4.3 on the Licensed Bank-MNO Model; and similarly, ch 12, s12.2 on MFS implementations in South Africa.

${ }^{43}$ See Nashua op cit note 2.

${ }^{44}$ The first deployment of Standard Bank's Community Banking project was in Bekkersdal in April 2007. Its aim was to determine client usage behaviour and the pricing of a transactional product. See Paths to Learning (2008) 'Community Banking: A Microfinance Unit of the Standard Bank Group South Africa', available athttp://goo.gl/m43LY.
} 
Mobile Money, ${ }^{45}$ has a number of components to the scheme, namely, Community Bankers, sales partners and retail partners. The Community Bankers are full-time bank employees and have a role similar to the local branch manager. However, they contract out the functionality of opening accounts and transactions to what they term 'sales ${ }^{46}$ and 'retail partners, ${ }^{47}$ - the agents - who in turn open accounts for clients and provide after-sales service. ${ }^{48}$

Despite retail partners (agents) taking cash and then possibly falling within the scope of the deposit-taking prudential regime, the South African Reserve Bank (hereafter SARB) does not interpret the cash-in functions as deposit-taking if the retail agent immediately passes the credit to the banking system and the (cash) value is immediately reflected on the system of the relevant bank. ${ }^{49}$ Therefore, upon the agent's receipt of cash from the customer, it must be converted immediately into scriptural 'e-money' value for it not to be considered a deposit by the SARB.$^{50}$ The result is technically a bank-led model that is marginally 'branchless', in that the bank's infrastructure and personnel are used for all cash transactions except where services are rendered through post offices.

With regard to the use of 'intermediaries', these are usually technical providers - such as WASPs - who a bank or MFSP would utilise for the distribution of, for example, data message SMSs containing important security information, say for notification to customers of any login into their transaction systems, the addition of and payment of beneficiaries. ${ }^{51}$ They are thus, in a technical sense, not agents per se, but they could be deemed so under certain circumstances, ${ }^{52}$ for example, where automated agents provide technical facilities for processing transactions. ${ }^{53}$

\footnotetext{
45 See Standard Bank (2011) 'Community Banking', available at http://goo.gl/VcpKo. In addition to the low-cost transactional banking solution, there is also a lending model for informal businesses that currently do not qualify for credit from the bank, and a wholesale lending model built around partnerships with microfinance institutions which then on-lend to their membership or client base.

${ }^{46}$ The sales partners open accounts for clients and provide after-sales service and, as the Bank describes it, operate in the same way as insurance sales agents. There will be 10 sales agents working for every team of 2 community bankers. They are recruited from the community and are remunerated on a commission basis. See Paths to Learning (2008) op cit note 70.

${ }^{47} \mathrm{Up}$ to 10 retailers are contracted to SBSA in each community. They have community retail devices installed on their premises. They are selected to ensure there is a wide geographical spread throughout the community, and include informal general stores called 'spaza' shops, hairdressers, butchers and shebeens (bar-type speakeasies).

${ }^{48}$ Clients are able to pay the retail partner for goods purchased, hand over cash to the retailer who will make a transfer to the client's mobile account, receive cash from the retailer, in turn depositing money in the retailer's account, make balance inquiries and buy airtime.

${ }^{49}$ Standard Bank (2009-2010) Personal Communication to author. In respect of whether the retail partner is taking deposits, time is of the essence in this determination: a day's delay by the agent passing the bank a credit could mean the agent is deposit-taking. There is a similar time-based criteria - 'without delay' as it is termed - in the EU Electronic Money Directive (hereafter EMD) regime where unless the incoming is immediately noted in the servers of an Electronic Money Institution (ELMI), there could be deposit-taking at play. See further on the EU EMD and ELMIs, ch 9, s9.6.3.

${ }^{50}$ This scheme may touch on technical aspects of depositum versus depositum irregulare. For an analogous situation where the differences between these two concepts are explained in detail, see WG Schulze (2001) 'Depositum, Deposit and Deposittaking Institutions: Birds of a Feather? Not Quite' 13(1) SA Mercantile Law Journal at 79, and the discussion therein of the fascinating case of Randfontein Transitional Local Council v ABSA Bank Ltd 2000 (2) SA 1040 (W) at 1048, where the two concepts intermingle according to the role of each party in the deposit and safekeeping of cash. See on the SARB, ch 12 , s12.3.2.1.

${ }^{51}$ See ch 7, s7.3.6.5.6.3 titled Intermediaries that discusses the role of intermediaries in allocation of risk.

${ }^{52}$ The Electronic Communications and Transactions Act 25 of 2002 defines an 'intermediary' as 'a person who, on behalf of another person, whether as agent or not, sends, receives or stores a particular data message or provides other services with respect to that data message'. The context, it is submitted, of the intermediary as used in the ECTA is that of a technical intermediary who facilitates the actual transmission of a data message, not of an agent. See ch 12, s12.9 on the ECTA.

${ }^{53}$ See ch 7, s7.2.6.3.2 titled Automated Agents.
} 


\subsubsection{4}

\section{Types of Transactions}

As the licensed bank provides the service, many of the transaction types associated with bespoke banking will be available. These may include access to current accounts, savings accounts, a loan, or some combination thereof even though in some instances the bank customer will deal only with an agent of the bank. There may however be truncated sets of services, based on the regulatory risk profile of the customer and the types of Customer Due Diligence (hereafter CDD) that are possible. For example, the SARB mandates certain account and transaction value maxima in cases where the customer does not have identification or a confirmed address available as this is a common challenge in developing countries. In that case, the customer will have transaction facilities available in proportion to the extent of the confirmations they can provide in terms of applicable law. ${ }^{54}$

\subsubsection{Dispute Resolution}

Where a consumer has a dispute with a licensed bank offering MFS, much the same facilities and criteria that obtain for branch-based banking would arise.

In South Africa, at least, while consumer protection and electronic commerce laws may have some bearing on resolving an issue, there is the possibility that banks and other licensed financial institutions which are members of Banking Association of South Africa (hereafter BASA) may be subject to an industry ombudsman such as the Ombudsman for Banking Services in South Africa (hereafter OBSSA). ${ }^{55}$

\section{A2 Licensed Bank-MNO Model}

\subsubsection{Licensed Bank-MNO Model}

\subsubsection{Overview}

While in some jurisdictions MNOs may dominate the transformational MFS landscape and may simply choose to provide fiat-based MFS activities alone without a banking partner, in other jurisdictions regulatory rules and/or commercial imperatives may necessitate that the MNO collaborate with a local licensed bank in a type of hybrid MFS model. As an exemplar of this hybrid, pan-African operator Vodacom South Africa in 2010 teamed up in a joint venture (hereafter JV) with licensed bank Nedbank as the prudentially licensed and supervised entity to offer the South African version of M-pesa, ${ }^{56}$ the

\footnotetext{
${ }^{54}$ See ch 8, s8.5 on AML and CDD issues generally, and ch 12, s12.6 titled Conclusion: Banking and Payments on their application in South Africa.

${ }^{55}$ See ch 12 , s12.3.2.10 on the OBSSA.

${ }^{56}$ See Annex 1: Exhibit B on the method for registering for the M-pesa MFS service in South Africa.
} 
eponymous MFS scheme developed and use successfully in Kenya. ${ }^{57}$ Users here have two SVAs to choose from for transacting: the fiat-based SVA and the airtime SVA, ether of which may be used according to the type of service available and the billing and SOV-source mechanism allowed in the scheme's rules. While the bank is prudentially responsible for the fiat-based SVA, the MNO usually retains complete control over the mobile airtime-based SVA.

Crisp issues in this model revolve around the policy of and rules around conversion of fiat-money to an emoney-type SOV (or as an airtime-based SOV as the case may be), the status of bank agents in branchless banking, dispute resolution and the effect of AML/KYC, telecommunications, e-commerce and consumer protection laws.

\subsubsection{Contractual Relationships}

To operate the SA version of M-pesa, Vodacom SA formed a new division called Vodacom Payment Services Pty Ltd (hereafter VPSPL) to operate M-pesa. VPSPL styles itself as a corporate agent of the licensed bank Nedbank, with the funds are housed in what is termed a 'collateral account' with Nedbank as the licensed bank partner. ${ }^{58}$ There are also appointed 'outlets' acting as agents. ${ }^{59}$

\subsubsection{Use of Agents}

VPSPL allows what it terms an 'outlet' to open up accounts for new users of M-pesa and to provide some cash-in/cash out services. ${ }^{60}$ There are over 4,000 outlets that include chain stores, informal general stores called 'spaza' shops, and community containers. VPSPL says that the outlets are independent, simply authorised by VPSL to provide services, and which are not in partnership with VSPL. ${ }^{61}$

\subsubsection{Types of Transactions}

Users can transact from the M-pesa menu on their cell phone. Services include buying Vodacom mobile airtime, withdrawing cash at ATMs, and fiat-based Person- To-Person (P2P) remittances to other M-pesa users and some non-M-pesa users. There are transaction and SVA-value limits according to the degree of KYC the M-pesa user has undertaken. ${ }^{62}$

\footnotetext{
${ }^{57}$ See ch 10 passim on the activities of M-pesa run by Kenyan MNO Safaricom; and Exhibit A in ch 2, s2.1 on the tylised configuration of the SVAs offered by Safaricom. See also MNO Globe Telecom's G-Cash service in the Philippines, who have partnered inter alia with local banks. G-Cash operated stored value m-wallets, which users can load via agents. They can use an SMS sent from their cell phones to effect loan repayments, deposits, withdrawals, or transfers from a savings account with a participating bank to add value their mobile SVAs. See G-Cash (2011a) 'How It Works', available at http://goo.gl/TYBR9.

${ }^{58}$ The M-pesa Terms and Conditions (hereafter T\&Cs) define e-money as 'electronic money created and issued by Us (acting as the agent of Nedbank) in the system, which will equate to the deposits'. See Vodacom (2011a) 'M-PESA Terms \& Conditions', available at http://goo.gl/gMotV. On pooled accounts, see ch 4, s4.8. The contractual relationships linking to these pooled accounts may differ according to the jurisdiction and/or the commercial arrangements.

${ }^{59}$ See ch 6, s6.4.3.3 on these relationships.

${ }^{60}$ In the MNO contract with M-pesa users, the T\&Cs refer to the 'outlet' providing services.

${ }^{61}$ Vodacom (2011a) op cit note 58.

${ }^{62}$ It costs ZAR2.45 to send value to another registered -pesa customer.
} 


\subsubsection{5}

Dispute Resolution

Users can query transactions and complaint to VSPSL via their call centre, but if there is no resolution to an issue to the satisfaction of the M-pesa user, VPSPL indicates that since it's banking partner Nedbank and holder of the principal banking license, is a member of the BASA, that users should thus use the services of the OBSSA. ${ }^{63}$

Licensed Bank-MFSP Model

6.4.4

Licensed Bank-MFSP Model

\subsubsection{1}

\section{Overview}

There are a number of hybrid models in the MFS domain that do not necessarily involve just a bank or MNO, but which may involve joint ventures between banks and MNOs where licensed banks can partner with technology service providers and MNOs in the development of e-money-based branchless banking. ${ }^{64}$

There may also be instances where a bank or MNO may partner with just a MFSP. An early example in South Africa is Wizzit which was launched in 2004 and provides what amounts to a fully functional interoperable bank account.

Wizzit has positioned itself as a virtual bank and has no branches of its own. It operates under the banking license of the South African Bank of Athens, ${ }^{65}$ as well as provisions of Exemption 17 of the Financial Intelligence Centre Act (hereafter FICA) that relax identification criteria for some prospective users. ${ }^{66}$

\subsubsection{Contractual Relationships}

Wizzit binds its users to its corporate entity and to the South African Bank of Athens.

\subsubsection{3}

\section{Use of Agents}

Wizzit is a prototypical branchless banking business which means that its services are designed to let customers conduct transactions without the need to visit a bank branch.

\footnotetext{
${ }^{63}$ See ch 12, s12.3.2.10 on the OBSSA.

${ }^{64}$ The expanded partnership necessitated by regulation invariably means an increase in operational costs and a possible period of delay to market.

${ }^{65}$ Wizzit's marketing material describes Wizzit as a 'division of the South African Bank of Athens'. The bank, however, does not hold any shares in Wizzit. It is also known as an 'Alliance Partner'. Wizzit does not have to provide any capital reserves to the SARB since its does not intermediate user funds, with the user 'float' ring-fenced at the Bank of Athens. Any loans are funded out of capital. Wizzit (2011) Personal Communication. See also the official website of the Bank of Athens at http://goo.gl/HQayp.

${ }^{66}$ Financial Intelligence Centre Act 38 of 2001. See Wizzit (s.d.) 'Terms \& Conditions', available at http://goo.gl/YcAYJ. On Exemption 17, see ch 12, s12.7.1 on Anti-Money Laundering, Terrorist Financing and Customer Due Diligence Laws and Regulations.
} 
Users open up accounts via so-called 'Wizzkids' ${ }^{67}$ and some retail stores, ABSA bank branches and branches of The South African Post Office act as banking agents to allow Wizzit's customers to deposit funds.

Wizzit's Wizzkids may open up accounts and act as bank agents. It also provides services through local retailers such as Dunns.

\subsubsection{4}

\section{Types of Transactions}

It provides basic banking and transaction services for the unbanked and underbanked in South Africa ${ }^{68}$ and offers an account that allows customers to access all banking and payments functionality ${ }^{69}$ using simple USSD and SMS commands on their cell phones to make P2P payments, to transfer money, to purchase prepaid electricity, and to buy prepaid mobile airtime. They are given a linked Maestro debit card.

\subsubsection{Dispute Resolution}

Wizzit indicates that since the Bank of Athens, it's banking partner and holder of the principal banking license is a member of BASA, that users should use the services of the of the OBSSA. ${ }^{70}$

MNO-Led Models

6.5

$$
\text { MNO-Led Models }
$$

\subsection{1}

Overview

As noted above, depending on the types of commercial models and associated regulations, an MNO may have at least two simultaneously available SVAs for use by customers.

The first is the non-redeemable prepaid mobile airtime-based SVA which may be used for purchase of basic telecommunications services like calls and SMSs as well as for digital VAS goods and services ${ }^{71}$ offered within a walled-garden ${ }^{72}$ through WASPs and Information Providers (hereafter IPs). ${ }^{73}$

The second is a fiat-based SVA which extends an MNO's existing prepaid and post-paid billing systems for VAS for use for a number of additional transactional touch points (depending on the regulatory

\footnotetext{
${ }^{67}$ Wizzkids are typically unemployed university graduates from low-income communities. They receive annuity income based on the transaction level of account holders. See Annex 1: Exhibit $\mathrm{H}$ on Wizzkids.

${ }^{68}$ See further on Wizzit, ch 12, s12.2.7.

${ }^{69}$ These include debit orders and salary deposits, remittances, pay accounts, the purchase of airtime and balances. Payments can be made to any bank account or be received from any account.

${ }^{70}$ See ch 12, s12.3.2.10 on the OBSSA.

${ }^{71}$ See ch 6 , s6.5.4.2 on WASP VAS.

${ }^{72}$ See ch 4, s4.8.3.7 titled Ubiquity of Use: Interoperability.

${ }^{73}$. See ch 6, s6.5.4.2 on WASPs and IPs in relation to provision of VAS using the airtime-based SOV. This SVA type is discussed in relation to South African MNOs, which all allow the airtime-based SVA to be used for purchasing VAS WASPservices
} 
environment) such as corporeal goods, and to do fiat-based remittances. This SVA is redeemable, at some point, back into fiat money at par and on demand. This SVA type is discussed in relation to the eponymous and hugely successful M-pesa system in Kenya.

When the user purchases a mobile airtime voucher using fiat money, the fiat value is converted into a SOV determined by the MNO and is stored in the airtime-based SVA.

The SVA may reflect the airtime-based SOV balances therein in the UOA of national currency, or it may be in some other unique UOA, such as minutes or megabytes - or whatever UOA the MNO or its system operators choose.

That unit balance is what is seen as a SOV for transactional spending use within the closed-loop, walled garden $^{74}$ of the MNO, albeit using a closed system of third party suppliers who may be given direct or indirect access to the SOV in the airtime-based SVA where the MNO acts as the treasury using its own airtime currency to mediate the sale of content and other services.

In this sense, the airtime SOV acts as a limited, and not general, Means of Payment (hereafter MOP) available to this chosen set of suppliers. Users are able to use the value in the network-based airtime SVA to purchase of digital-only goods and services, as well as to transfer ${ }^{75}$ the (airtime) value into the prepaid account of another user on the MNO's network.

Where the airtime-based SVA is used for purchasing digital goods and services, the SMS bearer ${ }^{76}$ channel plays the rather unique dual role of being (both) the payment instrument ${ }^{77}$ as well as being the delivery medium for the purchased goods, the latter being mostly digital goods and other interactive services. ${ }^{78}$

Crisp issues in this model revolve around whether the funds used for transactions amount to a deposit, whether the entity is acting within the scope of what could be classed as the 'business of banking', the policy of and the rules around the conversion of fiat-money to an e-money SOV (or as an airtime-based SOV), the status of bank agents in aspects of what could amount to branchless banking, dispute resolution and the effect of AML/KYC, telecommunications, e-commerce and consumer protection laws.

\footnotetext{
${ }^{74}$ See ch 4, s4.8.3.7 titled Ubiquity of Use: Interoperability.

${ }^{75}$ Also known as 'top up'.

${ }^{76}$ See ch 5, s5.2.1 on technology types on mobile network technologies and bearers.

${ }^{77}$ See ch 4, s4.8.4 titled Forms of Payment.

${ }^{78}$ See ch 6, s6.5.4.2 below on WASP VAS.
} 
MNOs mostly use retail agents as their customer-facing facility for selling airtime, SIM cards, and other services the MNO may offer. In a pure telecommunication sense, these retail customer-facing agents may be termed SPs, discussed earlier. ${ }^{79}$

\subsubsection{Use of the Airtime-Based Prepaid SVA in Transactions}

\subsubsection{1}

\section{Types Of Transactions}

In the MNO-led model, available transactions for the user to undertake are dependent on the type of SOV being used. For the user, SOV selection in the course of a transaction may be automatic - for example, using SMS shortcodes to pay for WASP-type services through use of SMS, USSD and Wireless Application Protocol (hereafter WAP), usually from the non-redeemable airtime-based SOV. Use of the fiat-based SOV may be dependent on selection via a specific icon on a WAP menu, USSD, and SMS commands that relate specifically to that $\mathrm{SOV} .{ }^{80}$ If the service uses a $\mathrm{S} @ \mathrm{~T}^{81}$ or $\mathrm{USSD}^{82}$ facility, there is a simple text-based menu on the phone which can specify a payment recipient or any payment feature. Similarly, a WAP menu on a phone may provide the same type of functionality, albeit using a richer media with clickable hyperlinks for executing a payment. Again, depending on the SOV being employed - and allowed by the MNO and/or a telecommunications or prudential regulator - transactions may include mobile remittances (hereafter m-remittances), ${ }^{83}$ payments for say taxes and rent and loans, mobile airtime purchases, purchase of digital goods like ringtones from $\mathrm{WASPs}^{84}$ that can be used on the handset itself, and corporeal goods and services such as foodstuffs.

\subsubsection{2 \\ WASP Value Added Services}

Premium Rated Services (hereafter PRS) are primarily for content and are similar to VAS provided by third parties known as WASPS. WASPs may be considered as the first incarnation of MFS as a 'mobile payment' (hereafter m-payment), albeit in a limited 'walled-garden ${ }^{, 85}$ setting. The sale value is deducted from the mobile airtime-based SVA in real-time, while those with postpaid accounts are billed at month's end on conventional invoices. Use of WASP services is mostly at the more expensive rates than the normal Premium Rates (hereafter PR). ${ }^{86}$

\footnotetext{
${ }^{79}$ See ch 6, s6.2 on Relationships Generally in the Mobile Ecosystem explains the chain of agents that may exist in a general telecommunications context.

${ }^{80}$ The MNO may or may not operate a closed or open transacting system. This relates to whether there is a degree of interoperability between MNO systems, or whether an MNO allows interoperability with (non-MNO) systems such as those mediated by Visa and MasterCard or a NPS. Within a closed walled-garden system, only the services that the MNO allows for transacting are available.

${ }^{81}$ See ch 5, s5.5.3.2 on S@T.

${ }^{82}$ See ch 5, s5.3.4 on USSD.

${ }^{83}$ The ability to send/transfer value or money from one system participant to another using just the recipient's phone number as the 'account' identifier. See ch 11, Part II, B. State Rules, ss11.4.1 and 11.4.3 below.

${ }^{84}$ Usually at Premium Rates. See ch 5, s5.2.3 titled Types of Services Available to Users: Basic and VAS on Premium Rates.

${ }^{85}$ See ch 4, s4.8.3.7 on Ubiquity of Use: Interoperability.

${ }^{86}$ See ch 5, s5.2.3 titled Types of Services Available to Users: Basic and VAS on Premium Rates.
} 
Examples $^{87}$ of WASP services in South Africa include the sale via the handset of VAS mobile games, competitions, location services, tracking services, news alerts, financial information and alerts, and entrance to competitions via SMS. ${ }^{88}$ WASPs may market content directly to the public, or simply act as a technical solution provider or aggregator for content providers, or IPs. Where a MNO is engaged in these customer-facing activities, they are also considered to be a WASP. ${ }^{89}$

\subsection{Relationships in the WASP And VAS Environment}

Commercial models employed in the WASP environment include the following:

- The MNO buys digital content from an IP, and resells it as a VAS to its subscribers under its own brand;

- The MNO buys digital content from an IP, resells it as a VAS to its subscribers co-branded with a third party like the IP;

- WASPs advertise (and provide) digital content and other VAS direct to consumers using the MNOs billing and delivery infrastructure, but without using the MNO's brand; and

- WASPs provide technical services only as so-called aggregators to third parties IPs who advertise and provide that content and other VAS to consumers. These IPs rely primarily on the billing and delivery facilities of the WASP through the use of the WASP's direct billing mechanisms and technical relationship with individual MNOs.

A schematic of the relationships and flows in the WASP Model is shown in Exhibit A below.

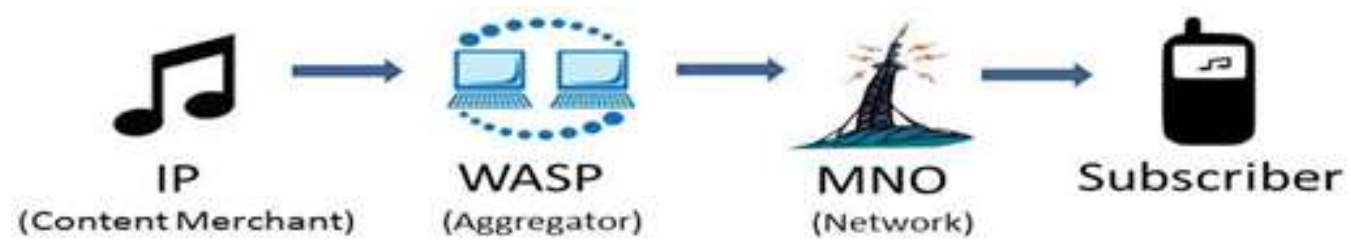

Exhibit B: $\quad$ VAS Relationships

Exhibit B shows the some of the relationships and flows in the WASP VAS model. Each of these commercial models creates its own sets of contractual relationships, not all of which are certain, and some of which may even be ephemeral. For example, in a WASP transaction, it is trite that there are set individual contractual relationships between the MNO and the WASP, between the MNO and its subscriber, between the WASP and the IP, but not usually between the MNO and IP. A relationship

\footnotetext{
${ }^{87}$ See Annex 1: Exhibit G for an example of a South African WASP service advertisement. See Exhibit I for the range of $\mathrm{T} \& \mathrm{C}$ provided to the user.

${ }^{88}$ This ease and ubiquity of use is a far cry from the early days of the MFS industry when in 1999 the first 'Over the Air' (hereafter OTA) downloads of tinny-sounding ringtones to Nokia cellphones went live. Using IVR as the access and payment medium, users typically went through a website or advert showing a range of ringtones, noted a code associated with that ringtone, and then called an IVR number billed at standard mobile rates. The service bouquet currently includes availability of more sophisticated tunes, music, video, games and images.

${ }^{89}$ The average monthly spend on a WASP transaction on the South African MNOs in 2011 was sub-ZAR30 for prepaid and sub-ZAR70 for post-paid users. Author's personal communications with South African MNOs.
} 
between the WASP and/or the IP with the consumer may be ephemeral in the sense that it may exist only for the provision of a once-off service or content item as the case may be. The unsettled issues relate to the nuances in the relationships between these parties, usually on the basis of the ability to bill for services, of who shall be liable for the correct provision of content and services, as well as for the correct billing for these services.

This issue of billing is often framed in terms of who has the direct 'debtor-creditor' relationship with the consumer. ${ }^{90}$ In relation to prepaid services, there is usually no direct payment or transfer of funds from the customer's account to the third party. At a billing level for example and where an IP (or WASP) is involved, when an instruction by a WASP or IP to the MNO is sent to the MNO for the MNO to debit the user's prepaid SVA on behalf of the WASP or IP for a certain retail value, the MNO will attempt to do this. If there are sufficient funds in the consumer's SVA and the access rules for that SVA allow any debiting of that SVA for content services, then after a successful debiting of the SVA, the MNO will pay portions of the retail price over to the WASP - the so-called out-payment. If the IP is involved in the transaction, for example as the content provider, then the WASP will in turn pay the IP a portion of the out-payment value received from the MNO. When there is, for example, a dispute as to whether the instruction to the MNO for the debiting of the SVA was indeed authorised by the consumer, the consumer could raise a dispute and conceivably claim a refund from one of the parties in the transaction. This may be from the WASP, IP or MNO as the case may be depending on the contractual relationships at work or as decided upon through convention or circumstance. ${ }^{91}$

Besides the billing aspects, the contractual relations similarly may also relate to who is responsible for the Quality of Service (hereafter QOS) aspects of a VAS transaction, in causa, who is responsible for the nonprovision, or quality, of the actual VAS provided to the consumer as the case may be. Again, in many instances, this liability is unsettled and may be based on specific contractual provisions as to who is liable for this aspect of the VAS transaction, or from a directive from a state or self-regulatory body.

\footnotetext{
${ }^{90}$ The modalities of these relationships are, as yet, unsettled. One issue for example relates - in connection with the MNO's prepaid airtime SOV used to pay for WASP VAS transactions - to whether there is a direct 'debtor-creditor' relationship at play between the MNO and the consumer. See ch 4, s4.9 titled Conclusion; and in particular in ch 9, s9.6.3.2.3 titled New Definition of e-Money for an in-depth discussion of a seminal instance that occurred in the EU where this seemingly trivial distinction led to the unraveling of the first EMD in the EU, Directive 2000/46/EC on the Taking up, Pursuit of and Prudential Supervision of the Business of Electronic Money Institutions. The circumstances are included here for convenience and to put the 'relationship' issues into context. In causa, the issues related to whether MNOs were subject to, and thus needed to be licensed as electronic money issuers in terms of, the EMD1. Ordinarily, this determination would have turned on whether the MNOs were acting purely as (mere) billing agents on behalf of WASPs and IPs providing VAS, or rather whether there was a direct 'debtor-creditor' relationship between the MNO and the consumer in relation to these transactions. If the former was the case, then the MNOs required licenses. However, in what appears to have been a decision based less on law and more on political considerations, the European Commission (hereafter EC) decided that the MNOs were not acting as 'mere' billing agents for WASPs and IPs providing VAS, but rather that there existed a direct billing - 'debtor-creditor' - relationship between the MNO and the consumer where the MNO supplied the VAS to consumers. In non-EU jurisdictions where such licensing implications are not at issue MNOs, because of liability issues relating to the actual content, usually wish to avoid becoming involved in any way whatsoever in the WASP/IP VAS transaction. They thus frame their activity in any WASP VAS transaction as their being the 'mere' billing agents for the WASP VAS activities, who simply debit the consumer SOV and pay over the transaction value to the WASP.

${ }^{91}$ Invariably in cases of dispute and/or where instructed by a self-regulatory body, for example, the WASP or IP will provide the refunds directly to the user using an EFT or via a so-called 'micro-recharge' of the SOV through external means, although in some cases it will be the MNO that provides a full refund of the retail price to affected consumers by a direct crediting ('recharging) of the consumer's SOV. In that instance the MNO would not provide any out-payments to the WASP that relate to disputed transactions. See ch 12, s12.8.3.2 on the Wireless Application Service Providers' Association (hereafter WASPA) which discusses the role of the WASPA in dispute resolution in the WASP industry.
} 
Central to the current WASP payment model is what is known as the shortcode, a series of usually 5-digit numbers common to mobile networks in a particular country. ${ }^{92}$ Launched in South Africa in 2002-2003, the shortcode system is currently the only common micro-payment gateway for mobile services across all four licensed MNOs in South Africa. These shortcodes are leased from the MNOs ${ }^{93}$ by WASPs who may in turn sub-lease them to the third parties, the IPs. Similar shortcode and WASP-type schemes are operated worldwide by MNOs.

Billing for these PRS offered by WASPs may be via once-off (à la carte) ${ }^{94}$ or periodic (subscription services). ${ }^{95}$ Similarly, a USSD ${ }^{96}$ session may be premium rated, usually charged in higher-value per-minute or similar increments. Consumers obtain content or access a service simply by sending an SMS with a 'keyword' or a number to the common shortcode from their handsets. By sending the SMSs to a premium rated shortcode number or to access a USSD session menu or by clicking on a WAP link, the user may be billed by the WASP. ${ }^{97}$ This type of more expensive PRS SMS in this instance is known as a Premium Rated SMS (hereafter PSMS) ${ }^{98}$ and the more expensive USSD sessions as Premium Rated USSD (hereafter PUSSD). ${ }^{99}$ This mechanism allows payment of and access to a variety of WASP-type services by both prepaid and post-paid customers, either on a once-off or subscription basis. With Mobile Operating PSMS (hereafter MO-PSMS) billing, the consumer unequivocally indicates that they wish to use/purchase a service or content by sending an SMS (or some other means) to the merchant via the MNO bearer facilities. With Mobile Terminating PSMS (hereafter MT-PSMS) billing, ${ }^{100}$ the consumer unequivocally indicates that they wish to use/purchase a service or content by sending an SMS (or by some other means) to the digital merchant via the MNO. ${ }^{101}$ Once the subscriber's phone is switched on and is able to receive and store any incoming messages, the subscriber will be billed for the service or content. ${ }^{102}$

\footnotetext{
${ }_{92}^{92}$ Long number network prefixes are not required.

${ }^{93}$ The shortcode values are not controlled by Independent Communications Authority of South Africa (hereafter ICASA), the National Regulatory Authority in South Africa. However, ICASA can, pursuant to s68(1)(a) of Act 36 of 2005 op cit note 39, make numbering plan regulations that control the use of these numbers. See ch 12, s12.8.3.1 on ICASA.

${ }^{94}$ See ch 5, s5.4.4.1 titled à la carte Billing.

${ }^{95}$ See ch 5, s5.4.4.2 titled Periodic Billing.

${ }^{96}$ See ch 5, s5.3.5 titled USSD.

${ }^{97}$ See ch 5, s5.3.4 titled SMS. A PSMS means that the SMS sent is not free or part of an SMS bundle. The technical flow enabling this consumer request and subsequent billing of the subscriber prepaid SOV starts with an MO requesting the service/content that is sent to the MNO. If the SMS is premium rated or requires some payment before processing, the MNO immediately checks the balance of the subscriber to check whether there are sufficient funds for the transaction. If these are present, then the MNO's billing system immediately deducts the amount from the subscriber's SOV and forwards the SMS with the specific service request to the WASP who may then communicate this to the IP, who may be the entity providing the content or service. The WASP/IP then checks what content/service the consumer has requested and, depending on the content system, the WASP/IP will use the MNO's technical bearer infrastructure to send the content or a content link back to the subscriber for their consumption thereof. The transaction usually ends there unless there is a defect in the delivery or the type of content actually delivered following which the contractual liabilities and responsibilities for defective service as indicated in the MNO subscriber agreement usually come into play.

${ }^{98}$ Premium Rated SMS. See ch 5, s5.3.4 titled SMS.

${ }^{99}$ Premium Rated USSD. See ch 5, s5.3.5 titled USSD.

${ }^{100}$ Also known as Reverse Charge Billing.

101 The technical flow enabling this consumer request is similar to that described above up to the point where the WASP/IP checks what content/service the consumer has requested, and may send the content to the subscriber. However, at this point, the determination by the merchant as to whether to send the content is now not necessarily dependent on the MNO's explicit confirmation of available funds in the prepaid SOV before sending, as the Mobile Terminating (MT) system will only debit the prepaid balance when the message is actually delivered to the handset and confirmation thereof is sent by the handset to the MNO. This, again, is not conventional business practice, as there is no guarantee of ultimate payment by the consumer for that delivered content and the merchant may have incurred some costs in sending of the content, even though it has not been
} 
The more common billing mechanism in use today in WASP transactions is the periodic billing-based subscription service which automatically charges users via a mixture of periodic and per-content billing. Values are debited from the consumer's airtime-based SVA on say a per-event, daily, weekly, or monthly basis. ${ }^{103}$ This periodic billing is usually triggered by an initial interaction by a subscriber with a WASP merchant, but, as described above, ${ }^{104}$ in many cases, billing may be initiated without the presence of a triggering Mobile Originating (hereafter MO), a process known as auto-subscription. As a precautionary measure against this and potential fraud, many MNOs and regulatory bodies now require that merchants offering subscription services include what is known as a 'double opt-in' system for payment confirmation ${ }^{105}$ whereby the merchant must send a message to the consumer after receiving the consumer's first MO or similar request, ${ }^{106}$ and then request that the consumer in turn actively reply ${ }^{107}$ to the merchant's SMS to unambiguously confirm their willingness to pay for a service. ${ }^{108}$ The consumer at this point can elect not to continue simply by not replying to the confirmatory SMS. The only charges they may have incurred then in total may be the cost of an initial MO to the merchant if this was the initial billing trigger. $^{109}$

The double opt-in procedure is, however, seen as resulting from a business decision for MNOs (and some merchants) ${ }^{110}$ as it is merely a comfort factor: in the main, there is no technical requirement for a double opt-in since consumers can be quite easily billed without the second, confirmatory double opt-in SMS being received. ${ }^{111}$ These subscription services and their periodic billing permutations have been very contentious wherever they have been introduced, and have been the cause of a number of lawsuits around the world as well as regulatory backlashes. ${ }^{12}$

delivered. This is unlike PSMS MO billing, when the funds are immediately deducted by the MNO on receipt of the PSMS sent by the subscriber, and before the payment confirmation is sent to the aggregator/merchant.

${ }^{102}$ In some mobile VAS billing schemes, MT is a type of reverse charging, the subscriber may also be billed when possible for the cost of the SMS bearing the content, and not just for the content itself so received.

${ }^{103}$ See ch 5, s5.4.4.2 titled Periodic Billing.

104 Ibid.

105 This means that the merchants cannot automatically accept the initial SMS as the only indication that the consumer is willing to pay for the service.

${ }^{106}$ Among other subscription service/Online Billing Systems (OBS) acquisition models is the web-based form: the potential subscriber, instead of sending an initial MO SMS request to start the subscription service, types their mobile number into the web form. The merchant then sends the subscriber an SMS message with subscription information which the subscriber must reply to in the affirmative to start the subscription process. No reply from the subscriber will be taken to be a negative reply. This obviates spam subscriptions, where someone may nefariously enter an innocent user's number into the web form without that subscriber's consent.

${ }^{107}$ Usually merchants in this scheme cannot negatively induct a consumer into the periodic payment scheme if a reply is not received. So, for example, terms like "If you do no reply to this SMS you will be automatically subscribed to this service" are not allowed.

${ }^{108}$ Usually the merchant's confirmatory SMS has some critical payment information included.

${ }^{109}$ Some merchants provide toll-free (zero-rated) SMSs for the initial subscription service sending request, and trumpet this as a marketing ploy to entice subscribers to opt into their subscription service.

${ }^{110}$ From a legal perspective, the consumer 'double opt in' serves as an unequivocal agreement to pay. Without it, the consumer could easily argue that they were being duped into participating in a service.

${ }^{111}$ Unlike the pull-based MO system which is a more explicit method of recording the consumer's desire to be billed (onceoff) for a service as first it must be transmitted through the MNO's Short Message Service Centre (SMSC), the push subscription model does not go through the MNO's SMSC. Instead, the billing system of the merchant is directly connected to the MNO's billing system, where the merchant has direct access to the subscriber's funds at any time. It is only ex post that the subscriber may find out that they have been periodically billed, if they discover this at all.

${ }_{112}$ See the class action against WASP Mblox and the service provider Jamster, who were fined UK£40,000 for illegal billing of mobile subscribers. See M Grenville (2005) 'Crazy Frog Fined and Ordered to Pay Refunds: 160 Characters', available at http://goo.gl/n9g01. 
In WASP-type transactions using the non-redeemable airtime-based SOV, a subscriber purchasing digital goods and services from a merchant using a premium rated mechanism like PSMS need not necessarily be on the same network as the merchant, such that a modicum of interoperability is possible. The subscriber simply sends a SMS to a common shortcode ${ }^{113}$ used by the merchant, and the content or service is delivered to him. The fact that the user has a positive balance available for the transaction is a form of clearing in that the MNO allows the transaction to continue following the MNO's debiting of the subscriber's airtimebased SOV, and the merchant responds by making the digital goods and services instantly available to the subscriber. Settlement arrangements - the actual transfer of fiat-based funds - once the user's airtime-based SVA is debited are those between the WASP and the MNOs to whom it is contracted (usually all the MNOs in the country participate in the common shortcode scheme) and hence the WASP is paid directly by the MNO to whom the subscriber belongs. Payment (settlement) by the MNO usually takes place some 6090 days after the transaction. It is also important to note that the purchase action is (usually) irrevocable, and as such the debiting of the subscriber's account by the MNO with the airtime value is simultaneous upon the request to purchase the content/service. ${ }^{114}$

The payment splits in a model WASP transaction are shown in Exhibit C below. The WASP (and its IP) will usually get a percentage of the retail value of payment for a PRS. This split - out-payment - may be in the range of $30 \%-60 \%$ of the retail value paid by the consumer, and is dependent on factors such as whether the user has a prepaid or postpaid account with the MNO, the retail cost of the digital purchase, and the volumes the WASP is able to generate for the MNO. There are a few instances though in an MNObased settlement process where the purchase of content/services by a subscriber does not automatically give rise to an irrevocable transfer to the WASP/IP merchant. As a consequence, the payment liability of the MNO may not necessarily equate to settlement liability. ${ }^{115}$

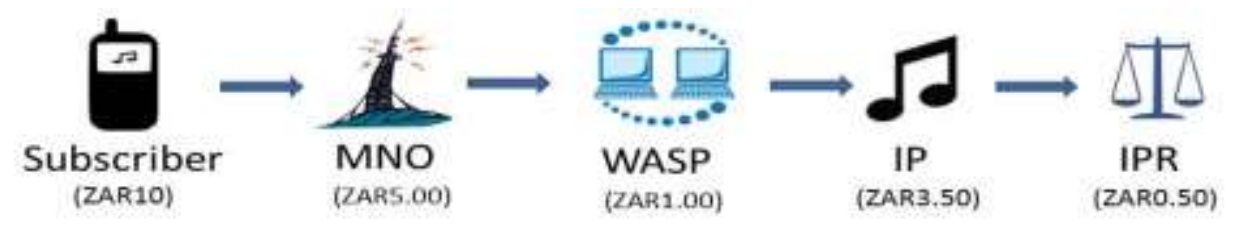

Exhibit C: $\quad$ Money Flows in VAS Transactions

Exhibit $\mathrm{C}$ shows the money flows and out-payments in the WASP Model from the sale of a ringtone for ZAR10 by a PSMS to a subscriber. The MNO may in certain cases retain most of the payment, in this example ZAR (50\%).

\footnotetext{
${ }^{113}$ The common shortcode is interoperable between all the MNOs in terms of an agreement between them. See above ch 5, s5.3.4 on SMS and shortcodes; and ch 6, s6.5.3 titled Types of Transactions.

${ }^{114}$ This is especially so with regard to PSMS, where the MNO first checks for sufficient credit and then debits the e-purse before sending through the service request to the merchant. What is important to note in this scenario, however, is that unlike an e-money transaction where there must first be a valid claim by the merchant and a subsequent request for redemption of value, the subscriber's account is first and irrevocably debited with the e-value by the MNO without a later request for evalue redemption by the WASP.This irrevocable debiting by the MNO takes place before and irrespective of the merchant's subsequent attempt at a much later date to invoice the MNO for the due amount, or at redemption.

${ }^{115}$ This is discussed further in ch 13, s13.1.2 in relation to a re-evaluation of money.
} 
Where the WASP and the IP are the same, the two values payable may be conflated, such that the WASP may keep the total out-payment of ZAR5. If the WASP is a mere technical enabler for an IP, the outpayment is split, with the IP usually taking most of the available value, in this case ZAR3.50.

Of a ZAR5 out-payment, the WASP/IP may have to pay Intellectual Property Rights (hereafter IPR) costs to a collection society, agent or to an artist, in this case at cost of ZAR0.50.

\subsection{Dispute Resolution}

Insofar as the airtime-based SVA is used for transacting by WASPs, the organisation in South Africa that directly regulates the WASP industry on a self-regulatory basis and in relation to trust in VAS purchases is the Wireless Application Service Provider's Association (WASPA). ${ }^{116}$

It was formed in 2004 as a voluntary self-regulatory body intended to represent and self-regulate mobilebased VAS providers. Membership of WASPA has been made compulsory by South African MNOs Vodacom, MTN, 8ta and CellC. ${ }^{117}$ WASPA's Code of Conduct and Advertising Rules were developed and implemented in 2005. It has developed a complaints handling process to enforce these rules independently of the WASPA Management Committee.

Complaints are handled by an independent secretariat that processes complaints using a mandated civil procedure scheme, while independent Information and Communications Technology (hereafter ICT) lawyers and an appeals panel of three ICT lawyers adjudicate the complaints lodged with the secretariat.

An emergency panel of three WASPA adjudicators may sit to shut down services pending a formal adjudication where there is evidence of immediate and ongoing consumer harm.

\footnotetext{
${ }^{116}$ See the Wireless Application Service Provider's Association website at www.waspa.org.za; and ch 12, s12.8.3.2 on WASPA. In relation to trust in m-commerce in South Africa, in general, see J Joubert (2006) How Do Trust and Risk Factors Influence the Adoption and Usage of M-commerce by Consumers in South Africa? presented to the Department of Information Systems, LLM Thesis, University of Cape Town. See also J Joubert and J-P Van Belle (2009) 'The Importance of Trust and Risk in M-Commerce: A South African Perspective' Pacific Asia Conference on Information Systems (PACIS) 2009 Proceedings, available at http://goo.gl/ckkvQ, and L Perlman (2007) 'WASPA: Laying the Foundations for Mobile Money' in A Goldstuck (ed) The Hitchhiker's Guide to Going Mobile: The South African Handbook of Cellular and Wireless.

${ }^{117}$ WASPA is also a prominent member of the International Audiotext Regulators Association (see the Association's home page at http://www.iarn.org).
} 
A specialised form of value transfer using the prepaid airtime SOV as the source of value is the mobile airtime transfer. ${ }^{118}$ This is especially useful in most developing nations where the number of prepaid users is usually more than $80 \%$ of the total mobile subscriber base. Here subscribers of an MNO can transfer small amounts of value of their airtime balance to a subscriber on the same MNO within a country or to a subscriber on another MNO within that country or, where possible, to subscribers across borders on the same MNO family or other MNOs. ${ }^{119}$ The recipient will usually receive the (airtime) value in the same UOA as was sent. These airtime transfers are also known as 'm-remittances.' 120

In some cases, these m-remittances and mobile payments ('m-payments') are commercially conflated as 'Mobile Money Transfer', or MMT. ${ }^{121}$ In the case of MFS, there is a monetary or value consideration paid from the need to settle an obligation. In the latter case there is a value or funds transfer where no obligation is due. $^{122}$

In the MNO-led model, a system participant can transfer value to another participant using just their mobile phone number. In most cases, the sender pays all the charges associated with the transfer, so the recipient receives the gross proceeds. The recipient can keep the value on his account or phone, or use it to pay bills or send similar value to another participant. The airtime transfer system has been primarily designed for what has been described as the "ethnic market' ${ }^{123}$ and allows foreign workers and expatriates to recharge the prepaid mobile phone of their relatives in the same or other countries by SMS, WAP or USSD or other simple means of technical access. ${ }^{124}$ While these airtime transfers are ostensibly designed to top up the airtime value of the airtime-based SVA, they are also being controversially used as value transfers for onward sale as airtime in the recipient country and for payment for goods and services in many cases. ${ }^{125}$

\footnotetext{
118 See Annex 1: Exhibits D and E on the use of the mobile phone for airtime transfer.

119 The value transferred may be denominated in minutes, a national currency, or some other UOA at an exchange rate determined by the systems operators.

${ }^{120}$ See ch 4, s4.8.4.3 titled Remittances.

${ }^{121}$ See for example 'MMT conferences' at http://www.mobile-money-transfer.com.

${ }^{122}$ See similarly s7 of the South African National Payment System Act 78 of 1998, which says that money can only be received by a party and will not be considered as a deposit if money (for a payment) is due. If it is not due, then it could be considered as a deposit with the licensing implications thereto. See further, h 12, s12.3.7.6.2 titled Application to MFS in South Africa.

${ }^{123}$ See TransferTo at http://corporate.transfer-to.com, a global prepaid airtime remittance system.

${ }^{124}$ See for example the MNO, MTN South Africa's Me2U airtime transfer system, where the mechanism for sending airtime is as simple as the sending user typing in on their mobile phone the keystrokes: $* 141 * 6328 *($ recipient's cellphone number)*(South African Rand amount)\# which will execute an instant transfer of the value to the recipient via the MNO's billing system. See MTN Me2U airtime transfer system at http://goo.gl/I5mBu.

${ }^{125}$ In a survey of 17 countries by Research ICT Africa above, $7.4 \%$ to $53.9 \%$ of respondents indicated that they had transferred airtime to someone else's mobile phone. The majority, the survey report said, were as a favour to family and friends but there was also significant usage of airtime to pay for goods and services in a few countries. In Ghana, Nigeria, Tanzania and Zambia, $4.2 \%$ to $14 \%$ respondents indicated that the transfer was to pay for goods and services. The survey report also indicated that the most prevalent transfers were those received from family or friends or airtime received as part of a financial transaction with someone else. A Comninos et al. (2008) 'M-banking the Unbanked' Vol 1 Research ICT Africa, Policy Paper 4, at 6, available at http://goo.gl/UdXks.
} 
Unlike fiat-based money flows, there is no similar requirement to report the transportation of prepaid access products across borders. ${ }^{126}$ Besides the implications in terms of the foreign exchange (forex) rules, ${ }^{127}$ this method of transfer may have AML implications as even small amounts can be eventually aggregated into a large-scale money laundering operation, a process known as 'smurfing' ${ }^{128}$ The airtime is laundered by being cashed out through the retail sale of the airtime by vendors but it is never captured by any authority as having been sent and, generally, the value sent is not traceable insofar as identifying the ultimate beneficiary.

In other methods of value transfer using Informal Value Transfer Systems (hereafter IVTS), ${ }^{129}$ users wanting to send money to a relative in a village may call or SMS a vendor operating a small phone kiosk in that village and read or send the airtime value code to the vendor. ${ }^{130}$ The vendor resells the airtime to third parties, and will pay the relative the value of the airtime sent minus a small commission. ${ }^{131}$ In a few cases where there is interoperability between transfer systems, ${ }^{132}$ there is an ability to send the value to another user on another MNO or, again, where there is redeemability at par, to a bank account or bank Automatic Teller Machine (ATM)using a system's cardless withdrawal features. ${ }^{133}$ In more basic cases of airtime transfer, users will buy airtime value denominated in usable minutes or SMSs or megabytes, or in an international currency, a regional currency, or some network devised currency and send the code via some means to a recipient, usually via SMS. ${ }^{134}$

In a more formal setting, some South African banks allow their clients to transfer airtime to a non-South African MNO when that airtime is on their systems. First National Bank (hereafter FNB), for example, allows cross-border international prepaid top up airtime purchases for numbers in Namibia to users of MNO Mobile Telecommunications Company (hereafter MTC) and to users in Lesotho on MNO Vodacom

\footnotetext{
${ }^{126}$ See however a proposed rule that the US Financial Crimes Enforcement Network (FinCEN) impose the full panoply of BSA requirements on the entity identified as a 'provider of prepaid access', which is defined as 'the person with principal oversight and control over one or more prepaid programs'. This may provide some oversight over prepaid value transfers that may include MNO airtime transfers where offered. See Financial Crimes Enforcement Network (FinCEN) (2010) 'Financial Crimes Enforcement Network; Amendment to the Bank Secrecy Act Regulations - Definitions and Other Regulations Relating to Prepaid Access' 75(123) Federal Register June 28, 36589-36608, available at http://goo.gl/Qh0Hm.

${ }^{127}$ See ch 12, s12.3.7.5 on foreign exchange controls, in South Africa.

${ }^{128}$ See ch 8, s8.5 below on AML. For the types and impact of 'smurfing', see Financial Action Task Force (FATF) (2005)

'Money Laundering \& Terrorist Financing Typologies 2004-2005', available at http://goo.gl/5sITY.

${ }^{129}$ On IVTS, see ch 2, s2.5.1 titled Overview; and also ch 4, s4.8.4.3 titled Remittances.

${ }^{130}$ CGAP estimate that in the case of Uganda, the cost of the user sending money to a person who ultimately receives the cash from an airtime reseller may be as high as $25 \%$, which compares, they say, to the cost of money transfer fees from Money Transfer Organisations (hereafter MTOs) like Western Union. M Pickens (2008) 'Airtime as Remittance: Good Deal for the Poor?' CGAP Blog, available at http://goo.gl/2zN5X.

${ }^{131}$ During civil unrest in Kenya in 2008, the Kenyan diaspora bought Kenyan MNO airtime on websites and sent the airtime access numbers to relatives in Kenya too scared to venture out to work. See IRIN News (2008) 'Kenya: Diaspora Clicks in to Keep Kenya Talking', available at http://goo.gl/cMzrh. For other example, see S Corbett (2008) 'Can the Cellphone Help End Global Poverty?' New York Times Magazine (April 3), available at http://goo.gl/US99k; and Pickens (2008) op cit note 112 passim.

${ }^{132}$ See ch 4, s4.8.4.7 above on Interoperability Between Systems.

${ }_{133}$ ABSA bank in South Africa has devised such a system, where an access code to draw cash from an ATM is sent to a recipient's mobile phone.

${ }^{134}$ See S Nagarajan (2009) 'Impact of Global Financial Crisis on Remittances Flows to Africa' African Development Bank, available at http://goo.gl/uX89K. In Columbia, a study that showed that three quarters of the people that own a mobile phone use informal re-sale of calls. The sale of recharge vouchers or digital versions thereof was higher than the number of prepaid users in Columbia. The economic ease of this resale supports conclusions that this is far more prevalent than is reported. It is thought that informal channels like airtime transfer contribute to the vast underreporting of remittances in Africa and Latin America by Central Banks (CBs). See LF Gamboa and LH Gutierrez (2008) 'Use of Informal Mobile Telephony in Low Income Households in Colombia’ Documentos de Trabajo, Facultad de Economía, Universidad del Rosario, No 45, available at http://goo.gl/uDDH3.
} 
Lesotho. The recharge may be direct so that the purchase in South Africa almost instantly fills the airtimebased SVA of the cross-border mobile recipient. ${ }^{135}$

B2

\section{Fiat-Based SOV}

\section{Use of the Fiat-Based SVA}

\subsubsection{Overview}

As noted earlier, besides the airtime-based SVAs, MNOs may if there is an opportunity through domestic law, also provide redeemable fiat-based SVA to their users, a transformational evolution whereby the MNO may be performing the functions of, and effectively replacing the need for, banks in customer-facing fiatbased transactions like funds transfers, savings and payments. The models are fairly simple, based in part on the successful model of the prepaid mobile airtime-based SVA.

M-Pesa in Kenya operated by MNO Safaricom ${ }^{136}$ indeed presents as interesting case where the lack of a distinct prohibition in Kenyan banking and payments law ${ }^{137}$ gave Safaricom the opportunity to accept and store fiat-based user value in a fiat-based SVA as part of a dual-use SVP offering to its subscribers. ${ }^{138}$ Accepting and storing fiat-based SOV in an SVA is usually a licensed activity in a number of jurisdictions. Depending on the regulatory environment, this SVA housing the SOV may be prudentially supervised, possibly under e-money laws and regulations. ${ }^{139}$ In South Africa, only licensed banks may accept and store fiat-based funds for use as e-money. ${ }^{140}$ In the EU, ability is limited to licensed banks - also called credit providers - and specialised licenses provided to so-called Electronic Money Issuers (hereafter ELMIs) and to Payment Service Providers (hereafter PSPs). ${ }^{141}$

Value is usually added to the SVA through a number of methods. ${ }^{142}$ In developing nations, this is primarily through a cash-in/cash out 'branchless banking' agent network. ${ }^{143}$ There may however be methods where value is inserted into the SVA via a linked bank deposit, or via a MTO like Western Union, or where a remittance is simply paid directly into the user's account. These fiat-based SVAs are usually independent of the user's mobile phone number so as to protect users in cases where their telecommunications (airtime) account is suspended because of inactivity or if they are not registered under a telecommunications-based

\footnotetext{
${ }^{135}$ See Balancing Act (2008) 'Bank to Offer Cross-Border Prepaid Airtime in Namibia' 43 News Update, available at http://goo.gl/dXsiB; and Staff Reporter (2009) 'FNB Unveils Cross-border Airtime Top-up Service' Lesotho Times 30 April, available at http://goo.gl/RzYeb.

${ }_{136}$ Described in full in ch 10 passim

${ }^{137}$ This lacuna in the law was fortuitous as it allowed the flourishing of a system that not only provided a social good, but also served as a model for MFS systems worldwide.

${ }^{138}$ For an explanation of this dual-SVA SVP, see the stylised graphic shown in Exhibit A in ch 2, s2.1.

${ }^{139}$ See ch 4, s4.8.4.4.10 titled Prudential Views.

${ }^{140}$ See ch 12, 12.4.2 titled E-Money in South Africa.

${ }^{141}$ See ch 9, ss9.6.2 on the Payment Services Directive; and 9.6.3 titled E-Money, Stored Value Laws and Regulations.

${ }^{142}$ See also for methods of placing value onto prepaid airtime SOVs ch 5, s5.4.2 titled Prepaid Consumer Billing Systems.

${ }^{143}$ See ch 2 , ss $2.1-2.3$.
} 
KYC statue. ${ }^{144}$ The SOV is invariably classed as an electronic representation of the Generally Accepted Means of Exchange (hereafter GAME), and not a private currency of the MNO or any similar issuer as it may be where a non-redeemable airtime SOV is used. ${ }^{145}$

Safaricom markets M-pesa as being primarily for transactional purposes and not necessarily as a savings facility. ${ }^{146}$ In many cases, these may be micro-transactions, while with remittances these will usually be macro-transactions. ${ }^{147}$

Values placed into the SVAs are usually comparatively small and median revolving balances are usually quite low, ${ }^{148}$ reflecting the transient nature of the funds placed in the SVA and their primarily use for payments and funds transfers rather than savings. Invariably interest from any value in the SVA is not paid to the user. ${ }^{149}$

Transactions include payments for certain types of goods and services, as well as Electronic Fund Transfers (hereafter EFTs) or m-remittances to and from participants in the MNO system, or where there is interoperability, to recipients in other payment systems or other MNOs, nationally or internationally.

\subsubsection{Use of Trust Accounts}

In many cases, either due to a regulatory requirement or suggestion, and/or for prudent risk and reputation management, the MNO will form a specific MFS subsidiary that contracts with a commercial bank. In the case of M-pesa in Kenya, this was a specific trust company which acts as trustee of the user funds that are housed in a bank account.

All funds from an MNOs fiat-based MFS activities will be pooled in this master trust account. ${ }^{150}$

Any interest accruing to the trust company is ostensibly then used as a cross-subsidy mechanism for funding the development and maintenance of the transactional systems and for lowering transaction costs. $^{151}$

\footnotetext{
${ }^{144}$ For example, the need to register mobile SIM cards under the rules of the Regulation of Interception of Communications and Provision of Communication-Related Information Act 70 of 2002 (hereafter RICA) in South Africa. See further on this ch 8, s8.5 on AML/TF/KYC/CDD and on RICA specifically, see ch 12, s12.7 on AML, CDD and CTF.

${ }^{145}$ See ch 4 , s4.8.4.4.8 on the economic view of SVPs.

${ }^{146}$ See on usage statistics O Morawczynski and M Pickens (2009) 'Poor People Using Mobile Financial Services: Observations on Customer Usage and Impact from M-pesa' CGAP Brief, available from http://goo.gl/UuQDD.. The new Mkesho product offering from Safaricom provided in conjunction with a licensed bank has a savings component.

${ }^{147}$ See ch 4, s4.8.3.5 titled Value of Payments.

${ }^{148}$ In Kenya, for example, M-pesa users accumulate 'small money' into a lump sum, which are deposits ranging from Ksh 100 ( US\$1.30) to Ksh 1,000 ( US\$13.00) or approximately one week’s wages. Morawczynski and Pickens (2009) op cit note 204.

${ }_{149}$ The amounts stored in the SOV are relatively small in comparison to savings accounts, and usually do not, or cannot, attract interest See ch 10, s10.2.3 on bank regulations in Kenya, where earning interest on value amounts to a deposit under Kenyan banking law See further ch 6, s6.5.5.2 on the use of interest by trust companies and trust accounts set up by the MNOs.

${ }^{150}$ See ch 10, s10.2.3.3 titled Application to MFS on the use of trust companies and trust accounts in relation to MFS by MNO Safaricom; and also ch 4, s 4.8.4.4.6 titled Pooled Master Accounts. While all the MNO's fiat-based redeemable MFS funds will be pooled in this master trust account, the commercial bank will not have any relationship with the customer or retail agent.
} 
The availability of fiat money for payments allows a plethora of payment possibilities far beyond the relatively modest scope of the MNO's walled-garden system. In many cases and depending on the degree of interoperability and ubiquity allowed by the MNO and/or regulator, users simply send an SMS to a predetermined account number or mobile phone number equivalent to effect loan repayments, pay utility bills or pay for any goods and services. The MNO may for competitive reasons directly sign up specified merchants into its system on an exclusive basis to receive payment, or it may simply allow a generic connection for its users to link to a NPS where there could be any number of merchants participating.

Where the MNO combines its phone offering with a linked debit or gift card, payments can generally be made at specific participating merchants and ATMs using compatible Point of Sale (hereafter POS) devices. ${ }^{152}$ Constraining the use of payments for incorporeal goods is very difficult, as users can simply transfer value to a recipient masked as a personal remittance without any indication that it is being sent for the purposes of payment for goods.

\subsubsection{2 $\quad$ EFTs and Remittances}

A subset of m-payments is that of sending P2P remittances - or EFTs in traditional banking parlance - in the form of fiat money using a mobile phone. These P2P transfer services are touted as the solution to delivering banking services to the unbanked ${ }^{153}$ and follow a global initiative by the Global System for Mobile Communications Association (hereafter GSMA) in February 2007 to enable the world's 200 million (hereafter $\mathrm{mn}$ ) international migrant workers to easily and securely send (fiat-based) payment remittances to their dependents, who likewise do not have bank accounts. ${ }^{154}$ World Bank data show officially recorded remittance flows to developing countries reached US $\$ 316$ billion (hereafter bn) in $2009^{155}$ and are expected to increase by $6.2 \%$ in 2010 and by $7.1 \%$ in $2011 .{ }^{156}$ Developing countries received more than twice as

\footnotetext{
${ }^{151}$ Ibid. The fiat funds provided for use as an airtime-based SOV is seen as a prepayment - - or advance payment - for services and as such will be stored in the MNO's conventional (non-trust) bank account. This SOV is invariably not redeemable back into fiat value. In both instances, the commercial bank where funds are stored will not have any direct relationship with the customer or retail agent.

${ }^{152}$ There may also be links to other MOP, such as to a bank account, an Internet-based payment intermediary behemoth like PayPal, or credit or debit cards. See ch 4, s4.8.4 titled Forms of Payment.

${ }^{153}$ See for the differences between the unbanked, underbanked and underserved ch 2, s2.2 titled The Rationale for MFS.

${ }^{154}$ Spearheaded by a special group of 19 MNOs in over 100 countries, the GSMA indicated at the launch of the initiative in 2007 that this proposal could double the number of recipients of international remittances to more than 1.5 billion (bn), while helping to quadruple the size of the international remittances market to more than US\$1 trillion (hereafter tn) by 2012. See Global System for Mobile Communications Association (GSMA) (2007) 'Global Money Transfer Pilot Uses Mobile to Benefit Migrant Workers and the Unbanked', available at http://goo.gl/Azkgk. G-cash, M-pesa, and Wizzit are examples of successful remittance services bolted onto m-payment facilities offered by MNOs in developing nations.

${ }^{155}$ This was down $6 \%$ from US\$336bn in 2008 due in part, the World Bank says, to the downturn in the global economy in 2007-2009.

156 See World Bank Development Prospects Group: Migration and Remittances, available at http://remittanceprices.worldbank.org; and see World Bank Development Prospects Group: Migration and Remittances, available at http://remittanceprices.worldbank.org; and International Finance Corporation (IFC) (2010) 'An Analysis of Trends in the Average Total Cost of Migrant Remittance Services', available at http://goo.gl/kAVoS.
} 
much inward-bound remittance as government development assistance grants ${ }^{157}$ while in sub-Saharan Africa, inbound remittances values were over three times larger than this assistance. ${ }^{158}$ The true size of remittances using non-recorded channels that include unrecorded flows is thought to be even larger, although as money transfers are now under more scrutiny because of AML/KYC initiatives, the remittance industry has experienced a large shift in remittances from informal to formal channels. ${ }^{159}$

\subsubsection{Use of Agents and Correspondents}

In the context of a fiat-based MFS scheme, MNOs will usually appoint their existing and trusted airtime vendors as the MFS cash-in/cash-out agents, although this may sometimes be a difficult commercial proposition for MNOs because of the current comparative profitability to an agent of their MFS versus their pure airtime sales, the latter usually having better margins for the agent. ${ }^{160}$ For the MNO, building a MFS business runs the potential risk of sullying its telecommunications brand and its reputation if its agents act in discourse to the brand's value. It may also incur a financial risk if agents and their liquidity are not controlled correctly. The MNOs, however, usually attempt to exclude liability for fraud or negligence on the part of these retail agents through the terms and conditions of their contract with the customer.

In a model where just the MNO is involved in the MFS transaction, the agent will be provided with an MFS account with the MNO - and not with the commercial bank - for accepting and paying out cash funds, the so-called cash-in/cash-out model of 'branchless banking'. EFTs are of course also available. The agent usually begins his activities by depositing his own funds into the pool of funds in the MNO-MFS's master account ${ }^{161}$ held at the commercial bank. Once this is accepted and converted by the MNO into e-money, the agent now has his own store of e-money, or mobile money as it is commercially known. During the course of commercial operations, the balance of the agent's account may increase or decrease, depending on the ebbs and flows of his operations.

In the operational flow of the operation, where the agent takes cash funds from a customer, he will, in the customer's presence notify the MNO of this receipt of cash funds via a WAP, USSD, IVR, SMS/S@T message or session. Once an acknowledgement is received by the agent from the MNO-MFS, a conversion of the customer's fiat funds to an electronic SOV, that is, e-money (or m-money as the case may be), will have been done. When the agent receives cash (cash-in) from the customer, his balance with the MNOMFS will decrease; as it will increase with each cash-out. As a safety precaution, there may also be sets of SMS-based notifications to the user (and to the agent) from the MNO to verify the agent, the value and the

\footnotetext{
${ }^{157}$ According to the OECD, official development assistance is estimated to have been US\$26bn in 2009. Organisation for Economic Co-operation and Development, Development Co-operation Directorate (OECD DCD)(2010) 'Development Aid Rose in 2009 and Most Donors will Meet 2010 Aid Targets', available at http://goo.gl/JDSxK.

${ }_{158}$ Comninos et al (2008) op cit note 125.

${ }^{159}$ D Ratha et al (2007) 'Remittance Trends 2007' Migration and Development Brief 3, available at http://goo.gl/JVCZ0; UK Remittance Working Group (2007) 'UK Remittance Market Best Practices for the Remittance Industry in the UK' DFID, available at http://goo.gl/BJMKu.

${ }^{160}$ This margin differential was cited by Standard Bank and MTN as to why their MTN mobile money initiative in South Africa did not gain enough traction and had to be scaled back (author's notes from presentation by David Parrott of MTN at the GSMA Mobile Money Summit 2010: Unleash the Power of Mobile Money in Rio de Janeiro, May 2010).

${ }^{161}$ This may be in the form of a trust account.
} 
new balances to assure each party that the conversion has been done. ${ }^{162}$ Further, some types of agents may not have a directly financial nexus with the MNO-MFS: some models call for the use of so-called 'superagents' who may handle the cash liquidity issues for a series of agents in a region.

In a legal sense, the agents are retail agents, rather than pure agents, as they may not necessarily be allowed to take cash deposits (or even pay out cash) for their own account. They are effectively 'human ATMs', or as they have also be described, as 'borrowed tellers', ${ }^{163}$ and 'cash merchants'. ${ }^{164}$

The risk to the MNO-MFS and indeed to all the participants in the MNO-MFS ecosystem of an unbridled agent network - the core super-agent and extended retail agent network - being unable to provide, for example, appropriate cash-out ability to customers or engaging in blatant fraud or money laundering are paramount.

Pickens ${ }^{165}$ describes, inter alia, the following aspects as being key elements in the handling of an agent network by an MNO engaged in MFS:

- Selection of agents flush with cash;

- Agents needing up-front capital from low or no interest loan sources, the capital secured by commissions;

- Easy exchange of cash/e-float;

- Balancing of cash flows from airtime and cash-out transactions;

- Maintaining system reliability with daily troubleshooting; and

- The risk of robbery and the possible need for insurance and the means to recognise counterfeit bills.

The ability of the agent to consistently apply KYC/CDD where required by regulation is also a necessity.

\subsubsection{Interoperability: Clearing, Payment and Settlement}

When compared to the airtime-based SOV, the situation with interoperability, clearing and settlement especially is vastly different in regard to the use of fiat-based, redeemable SOV. The initial and ongoing crop of MNO-branded MFS systems allow payments and remittances mostly only with those who have specifically signed up with that MNO's system. Even though a user may obtain all manner of goods and services where allowed by its legal and regulatory environment, merchants and users from other systems are usually unable to send and receive value between these systems. Thus, in order for a merchant to receive value from any user, the merchant must have an account with each of the MFSPs in a particular country. It is the equivalent of having different credit card machines for each bank in each country so as to

\footnotetext{
${ }^{162}$ However, see ch 5, s5.7.4.3 on attacks on M-pesa in Kenya using so-called 'Man in the Middle' attacks.

${ }^{163}$ See TR Lyman, G Ivatury and S Strachen (2006) 'Use of Agents in Branchless Banking for the Poor: Rewards, Risks, and Regulation' 38 CGAP Focus Note, passim, available at http://goo.gl/sXHMU.

${ }^{164}$ See C Alexandre, I Mas and D Radcliffe (2011) 'Regulating New Banking Models that can Bring Financial Services to All' Challenge Magazine March/April at 5, available from http://goo.gl/9uY0k.

${ }^{165}$ M Pickens (2010) 'Building Viable Agent Networks: Brazil and Kenya' CGAP, available at http://goo.gl/pKuos.
} 
ensure ubiquitous payment. Similarly a user on one system cannot usually send value - airtime or fiat value - to a user on another system. ${ }^{166}$ Interoperability can be mandated by the payments regulator or the central bank if it has the power to do so and sees a need to do so. This speaks then to the issue of access of the players to a national payment system (hereafter NPS) for purposes of clearing and settlement. Clearly central banks have historically been averse to allowing non-banks, as they may be defined, into the core of a NPS, following rules set by the Bank for International Settlements/Committee on Payment and Settlement Systems (hereafter BIS/CPSS) on Systematically Important Payment Systems (hereafter SIPS). ${ }^{167}$

However, while the BIS/CPSS defines payment systems that may be core and have systemic issues in relation to clearing and settlement rights and abilities in a NPS, this does not mean however that a wholesale exclusion from any NPS is warranted. While the dual role of clearing and settlement is done at the core by banks that have proven sufficient and ongoing capital to do so, clearing is possible with nonbanks within the system. This is usually a policy decision.

The irony is that interoperability is technically and financially possible, ${ }^{168}$ but through private clearing and settlement hubs outside a country. ${ }^{169}$ Hence, although interoperability (and clearing) between MFS systems using fiat values is possible through licensed banks and other (private) hubs, allowing these systems into a NPS in their own right for clearing purposes using proportionate capital requirements and with robust safety and soundness rules would not only be seen as a social good to enhance FI, but makes profound business, economic, legal, and regulatory sense. The safety and soundness may be augmented through the use of separate, dedicated trust companies and trust accounts in licensed banks to store user funds.

\subsubsection{6}

\section{Contractual Arrangements}

In M-pesa Kenya as an example, there are a number of complex contractual relationships in existence across the entire M-pesa ecosystem. these include the agent agreement; a declaration of trust in favour of all m-pesa account holders of Safaricom limited; a management agreement; commercial bank agreement; a customer terms and conditions agreement; and an agent network manager agreement. ${ }^{170}$ Again, depending

\footnotetext{
${ }^{166}$ Clearly while there are 'islands of excellence', the concomitant lack of interoperability is an issue as regards cost and economic efficiency and may have anti-competitive impacts as far as first-mover advantage is consolidated over time to exclude and so impede the growth of competitors and any incentive for the first-mover to interoperate.

${ }^{167}$ On a national payment system, see ch 4, s4.8.2.3.1. On the NPS in South Africa, see ch 12, s12.3 passim. While each nation has its own rules for payment systems, they are generally based on international principles developed by the BIS/CPSS and United Nations Commission on International Trade Law (UNCITRAL) that characterise a hierarchy of banking and payment systems in a country, with the control of the diverse systems involved in the systematic transfer of money and value being the Central Bank (CB) at the apex of these systems, controlling and monitoring the activities of the national banks within their jurisdictions, as well as ancillary networks that provide for the movement of funds. See further ch 4 , s4.8 titled Modern Payment Systems, Instruments and Regulations; and on SIPS, see Bank for International Settlements (BIS) (2001) 'Core Principles for Systemically Important Payment Systems', available at http://goo.gl/nxWH3; and S Millard and V Saporta (2005b) 'The Future of Payments' 19 Bank of England Financial Stability Review at 59, available at http://goo.gl/JnHMx.

${ }^{168}$ If the CB allows international transparent fund transfers.

${ }^{169}$ See, for example, the international hubs provided by Belgacom International Carrier Service at www.bics.com.

${ }^{170}$ World Economic Forum (2011) The Mobile Financial Services Development Report 2011 at 39. See further ch 10 , s10.6 on Consumer Protection.
} 
on the regulatory regime, users would obtain these services directly from an MNO without any direct contractual relationship with a prudentially licensed and supervised financial institution. ${ }^{171}$

Their contractual relationship would be with the MNO who in turn may have contractual relationships with the cash-in/cash-out agents who accept and pay out cash on the MNO's behalf.

\subsubsection{7}

\section{Dispute Resolution}

The Central Bank of Kenya's 2010 Agent Guidelines provide direct consumer protection provisions, although these relate more to formalities in the transaction process than any dispute resolution facilities. ${ }^{172}$ There are also internal dispute resolution mechanisms utilised by Safaricom. ${ }^{173}$

In South Africa, a new licensing regime for enabling non-banks to provide MFS could also include explicit consumer protections and an Authority that mediates on payment disputes. ${ }^{174}$

\section{Independent MFSP Models}

\section{Independent MFSP Models}

\subsection{1}

\section{Overview}

The Independent MFSP model is a type of hybrid model where the MFSP entity has no relationship with a MNO or bank, but uses any MNO simply as a technical bearer ${ }^{175}$ or data carrier ${ }^{176}$ that facilitates access to the MFSP system to be loaded on to compatible mobile phones. MFSPs, such as Paypal, may also have a dual SVA, with a non-redeemable SOV with a UOA of the MFSP's choosing and which may be combined with a fiat-based redeemable SOV where the payments are interoperable with other MFSPs, MNOs, MTOs, or banks. ${ }^{177}$

The cash-in/cash-out facilities may be via agents or MTOs or similar organisations. A licensed bank's only role here would be as the prudential store of the pool of funds received by the MNO or its subsidiary. ${ }^{178}$

\footnotetext{
${ }^{171}$ See TR Lyman, M Pickens and D Porteous (2008) 'Regulating Transformational Branchless Banking: Mobile Phones and Other Technology to Increase Access to Finance', available at http://goo.gl/YboX0.

${ }_{172}$ Central Bank of Kenya (2010) 'CBK/PG/15: Guidelines on Agent Banking', available at http://goo.gl/cs41.

${ }^{173}$ See further ch 10, s10.6 on Consumer Protection.

${ }^{174}$ See ch 14, s14.1 titled Study Summary And General Conclusions

${ }^{175}$ See ch 5, 5.2.1 titled Technology Types.

${ }^{176}$ In this context, the MNO as a bearer is simply a facilitator of (data) access to MFS and does not contribute to nor participate in any MFS transactions

${ }_{177}$ A number of network-based Payment Service Providers (PSPs) such as PayPal are evolving their systems to include a mobile component, including providing applications that can be added to compatible mobile phones. See ch 4, s4.8.4.4.4.2 titled Network-based Payment Products.

${ }^{178}$ See ch 7, s7.4 on use of trust accounts for housing pooled funds with licensed banks.
} 
The crisp issues in this model revolve around whether the funds used for transactions amount to a deposit, whether the entity is acting as a bank, the policy of conversion of fiat-money to an e-money-type SOV, the status of bank agents in branchless banking, dispute resolution and the effect of AML/KYC, telecommunications, e-commerce and consumer protection laws.

6.6.2 Types of Transactions

Transactions available include bill payments, purchase of private (virtual) currencies, as well as P2P remittances.

6.6.3 Use of Agents

As the primary commercial example of an independent MFSP, Paypal does not use agents per se. Rather users may place value in their Paypal SVA via EFT, MTOs and via other Paypal users. However, other MFSPs like Celpay operating in Tanzania, Zambia, Uganda and Zimbabwe may use 'branchless banking' agents.

\subsection{4}

\section{Dispute Resolution}

If users have a complaint they may escalate it to the European Consumer Centre (hereafter ECC-Net); the UK Financial Ombudsman Service (hereafter FOS); and Commission de Surveillance du Secteur Financier (hereafter CSSF). ${ }^{179}$

Broadly, there are three types of MFS schemes and associated commercial models being pursued worldwide: first, the bank-led model; second, the MNO-led model; and third, hybrid models using independent MFSPs. Many of these schemes and models are termed 'branchless banking' ${ }^{180}$ In almost all the models provided by non-bank actors, the introduction of a human agent is a common factor. ${ }^{181}$ Where a non-bank offers much the same services as a licensed bank but sans intermediation (credit) facilities, this offering is termed 'transformational.' Where a licensed bank adds a mobile access component to its existing offerings and account holders, this is termed 'additive'.

All models have their own commercial strengths and weaknesses and their own sets of legal and regulatory challenges. The common issues revolve around the status of bank agents in 'branchless banking'; dispute

\footnotetext{
${ }^{179}$ The CSSF is the authority responsible for the prudential supervision of companies in the financial sector in Luxembourg where Paypal Europe is registered. See http://www.cssf.lu.

${ }^{180}$ See for an overview of 'branchless banking' ch 2, s2.3 titled The Scope of MFS.

${ }^{181}$ On the use of agents in MFS, see ch 2, s2.5.2; and ch 6, ss6.4.4.3, 6.5.5.4 and 6.6.3.
} 
resolution; and the effect of $\mathrm{AML} / \mathrm{KYC} / \mathrm{CDD}$, telecommunications, e-commerce and consumer protection laws. $^{182}$

The bank-only model ${ }^{183}$ employs mostly a relatively simple additive access to fiat-based redeemable accounts - a SVA or wallet in MFS parlance - with or without the use of agents for cash-in/cash out facilities. The bank operates its MFS services through its domestic banking license, and as such any fiatbased values accepted from the public will amount to a deposit and are subject to domestic banking law. Beyond the common issues, the crisp issue in this model revolves around the policy of conversion of fiatmoney into an 'e-money' SOV.

In some cases, a bank may be the lead in a JV with an MNO where the MNO provides MFS facilities utilising the (banking) license of the bank. This link-up may be required by law when fiat-based funds are accepted and stored as part of the MFS scheme. An example of this is the JV between Vodacom South Africa with its variant of the M-pesa MFS offering in Kenya, which it operates in conjunction with Nedbank. In other cases, the bank may also be the lead in a licensed bank-MFSP model where an independent MFSP, like a MNO, utilises the banking licensed of its bank partner. An example of this is Wizzit in South Africa.

The MNO-led model ${ }^{184}$ has the MNO as the core. At a minimum this model may provide a non-redeemable airtime-based SVA as the transaction locus, allowing users to use their airtime-based SOVs to purchase digital goods and services via WASPs. This may be seen as the (micro-payment) progenitor of ubiquitous macro-payment MFS. Indeed where regulations allow, MNOs may also provide a (transformational) redeemable fiat-based SOV as well as use agents for cash-in/cash out facilities. An example of this type of MFS variant is the M-pesa MFS system in Kenya, which through a loophole in the Kenyan banking law, allowed MNO Safaricom to accept and store user funds for its M-pesa activities without a banking license: no licensed bank is involved in their MFS activities, except to act as the store for the pooled funds on behalf of the or its MFS subsidiary, a trust company formed specifically for purposes of safety and soundness so as to create a distinct financial firewall that cordons off Safaricom's MFS services from its core telecommunications business activities.

In all, the crisp issues in this model revolve around whether the funds used for transactions in the MNO SOVs amount to a deposit; whether the entity is acting within the scope of what could be classed as the 'business of banking'; elucidating the policy of and the rules around the conversion of fiat-money to an 'emoney' SOV; ${ }^{185}$ the status of bank agents in 'branchless banking'; and the modalities of dispute resolution. $^{186}$

\footnotetext{
${ }^{182}$ See the detailed discussion on these issues in ch 8 on Additional Oversight Related to MFS.

${ }^{183}$ See ch 6, s6.4 on the bank-led MFS model..

${ }^{184}$ See ch 6, s6.5 on the MNO-led MFS model

185 Additionally, whether the MNO's airtime-based SOV legally amounts to ‘money’ per se is discussed in ch 13 titled Reevaluation of Money.

${ }^{186}$ See the discussions passim in ch 8 on the effect of AML/KYC/CDD, telecommunications, electronic commerce (ecommerce) and consumer protection laws.
} 
In the independent MFSP model, ${ }^{187}$ the MFSP entity has no relationship with a MNO but uses any MNO simply as a technology bearer, allowing an MFS software application that allows access to its system to be added on to compatible phones. No licensed bank may be involved, except to act as the store of the pooled funds on behalf of the MFSP. The MFSP may have its own SOV, which may be redeemable at par, while cash-in/cash out facilities may be via bank branches or MTOs or similar organisations, usually by special arrangement. Again, beyond the common issues, the crisp issues in this model revolve around the nature of the funds used for transactions, insofar as whether they amount to a deposit; whether the entity is acting as a bank; and the policy of conversion of fiat-money to an 'e-money' SOV.

In a comparative sense, many of the MFS models signify the genesis of the blurring of traditional categorisations that resolutely classified companies into silos that represented their core businesses, be that purely financial or telecommunications, or more succinctly, bank or bank-bank entities. This equivocation then, it is submitted, gives us pause before fastening any ostensibly coincident regulatory and legal dogma on the entities engaged in MFS. This equivocation though is amplified by the insistence of the commercial MFS, industry bodies and their marketing partners in describing basic MFS functionality as 'mobile banking', whereas it is rather and in essence mostly transactional payments-based. ${ }^{188}$ Further, non-bank entities participating in emerging MFS models, divine financial potential risks and other, less certain, issues - besides the conundrum in determining the status of the airtime and fiat-based values in SOVs - which relate inter alia to interoperability ${ }^{189}$ between systems and the methodology for doing so, and similarly whether they should be allowed into a secure NPS. ${ }^{190}$

While interoperability between MFS systems using fiat values is possible through existing licensed banks and other private clearing and settlement hubs, allowing these systems into the NPS in their own right for clearing purposes on a proportionate risk basis insofar as lower capital requirements with safety and soundness rules would not only be seen as a social good that enhances FI, but, it is submitted, makes profound business, economic, legal, and regulatory sense. ${ }^{191}$

\footnotetext{
${ }^{187}$ See ch 6, s6.6 on independent MFS models.

${ }^{188}$ Indeed, as discussed in other chapters, despite the widespread and somewhat loose commercial use of the appellation 'mobile banking' or 'shadow banking' to describe all MFS models, it is submitted that the term should properly fasten only on banks undertaking 'additive' MFS schemes where users simply access their (bank) accounts via their mobile phones. This would serve to distinguish clearly between those entities - licensed banks or their equivalents - which domestic regulation indicates are engaged in the 'business of banking' and deposit-taking, versus entities that take funds from the public but where the funds are primarily used as a pool for use in payments and other transactions and not as a source for the intermediation of funds.

${ }^{189}$ See ch 6, s6.5.1 titled Overview, and further ch 8, s8.5 on AML, TF and CDD Laws and Regulations.

${ }^{190}$ See ch 4, ss4.8.1 titled Overview on SIPs; and 4.8.2.3.1 titled National Payment Systems.

191 This safety and soundness, it will be suggested later, may be augmented through the use of separate, dedicated trust companies and trust accounts in licensed banks to store user funds, augmented and mediated through statutory agencies and laws dealing with retail payments. Further, it will be shown later, consumer protection for payments through MFS may be encouraged, mediated and overseen by a dedicated agency or other agencies that will each (or together) deal on a regulatory or co-regulatory basis only with consumer macro- or micro-payments respectively, the rules thereto, as well as dispute resolution. This may be within the framework of a dedicated retail payments law, discussed in ch 14 on Research Summaries, Conclusions and Recommendations.
} 


\section{CHAPTER 7}

\section{LEGAL NATURE AND CHARACTERISTICS OF MOBILE FINANCIAL SERVICES}

The relationships embedded within Mobile Financial Services (hereafter MFS) schemes are invariably based on contracts between the participants. ${ }^{1}$ The multifaceted nature of MFS schemes means that these relationships may involve inter alia banking, payment and telecommunications contracts. The contracts may be ephemeral, especially when applied to prepaid mobile contracts, or they may involve long-term commitments between the user and the MFS provider in the form of a Mobile Network Operator (hereafter MNO) or its service provider agent. ${ }^{2}$

Even where the primary entity in the MFS transaction is a MNO, it is crucial to determine whether an entity is acting as a bank in as far as there are incidences that flow from the bank-customer relationship that do not necessarily apply when such a relationship is in existence. ${ }^{3}$ The common law rules around the relationship between a bank and a customer which arise from contract may be invoked. ${ }^{4}$

This chapter will explore the functional transactional, payment aspects of MFS that arise from methods of extinguishing obligations formed under the contract, ${ }^{5}$ and the nature of the payment will also be explored.

The essence of contracts and payments and their component parts as they relate to MFS - in particular the effect of and allocation of risk to insalubrious conduct and circumstances in MFS transactions that may give rise to a loss - are discussed below. The potential use of legal trusts to house MFS pooled funds to mitigate scheme risk is also explored.

\footnotetext{
${ }^{1}$ While contracts are obligatory agreements, they are distinguishable from their consequences, namely, obligations. The conclusion that a contract has come into force is a juristic abstraction. See S van der Merwe, L van Huyssteen and M Reinecke (1993) Contract: General Principles at 7.

${ }^{2}$ See ch 6, s6.2 on Relationships Generally in the Mobile Ecosystem; ch 6, s6.3 titled Relationships and Types of Models in the MFS Ecosystem; ch 7, s7.2.6.3 titled Agents; and ch 7, s7.3.6.5.6 titled Third Parties, and their liability generally and in relation to MFS. For an interplay of the relationships between the mobile phone owner, a bank, an MNO and the MNO's Service Provider agent in a type of MFS setting, see the discussion in ch 5, s5.7.4.1 on Phishing as it relates to the case of Nashua Mobile (Pty) Ltd v GC Pale CC t/a Invasive Plant Solutions (A3044/2010) [2010] ZAGPJHC 112 (18 November 2010) (hereafter Nashua), where the nature of these relationships was explored to determine whether there was an ability by a plaintiff to sue in delict or contract for damages incurred on the basis of a telecommunications service provision contract, as a result of a fraudulent EFT transfer. See further on the interplay between delict and contract in ch 7, s7.2.5.2 titled Breach of Contract Versus Delict; and generally C van der Bijl (2007) 'The Cloning of Credit Cards: The Dolly of the Electronic Era' 31 Stellenbosch Law Review 331-346; and C van der Bijl (2009) 'SIM-Card Swapping, Mobile Phone Banking Fraud and RICA 70 of 2002' 21(2) SA Mercantile Law Journal 159-173.

${ }^{3}$ If the relationship is one of banker and customer, it would mean that certain incidences peculiar to banks would obtain. See ch $4, \mathrm{~s} 4.5$ on the banker-customer relationship for details of these incidences.

${ }^{4}$ P Havenga, M Havenga and R Kelbrick (2007) General Principles of Commercial Law $6^{\text {th }}$ ed at 371; J Wadsley and G Penn (2000) The Law Related to Domestic Banking $2^{\text {nd }}$ ed at 104. The contractual relationship between a bank and a customer that underlies the operation of a current account is that of creditor and debtor, with the bank acting as intermediary in the transactions.

${ }^{5}$ The basis of a contract is either consensus where there is an actual meeting of the minds of the contracting parties, or the reasonable belief by one of the contractants that there is consensus. See Van der Merwe, Van Huyssteen and Reinecke (1993) op cit note 1 at 19; A van Rensburg, JG Lotz, and TAR van Rijn (2004) 'Contract' in WA Joubert (ed) The Law of South Africa $2^{\text {nd }}$ ed Vol 5 Part 1 at 248 and 215 respectively; C Visser et al (2004) Gibson: South African Mercantile and Company Law $8^{\text {th }}$ ed at 34-39.
} 


\section{Contracts}

\section{Nature of a Contract}

A contract is generally a conscious agreement made with the intention of creating an obligation or obligations between parties. ${ }^{6}$ Not all agreements are contracts, however, as they must be recognised in law to have binding effect on the parties. ${ }^{7}$ For an agreement to be binding in law it must comply with a number of essential elements and if one of these elements is absent the agreement is void and it may be said that no contract came into being. ${ }^{8}$ The agreement may be apparent or actual. It is actual when there is said to be a true meeting of the minds of the parties, and apparent when there is an objective appearance of agreement. ${ }^{9}$

The freedom of the parties to determine the contents of a contract - known as pacta sunt servanda ${ }^{10}-$ is a general principle of contract law recognised by almost all legal systems. ${ }^{11}$

The contract may be a multilateral - mostly bilateral - legal act since two or more persons are usually required. ${ }^{12}$ It may however be unilateral, where only one party assumes a duty to perform. ${ }^{13}$ Where it is a bilateral juristic act, ${ }^{14}$ liability ex contractu is generally based on the agreement of the parties. ${ }^{15} \mathrm{~A}$ creditor's right derived from the contract is called a personal right, or claim, because the subject matter of the right is a performance by another person. ${ }^{16}$ The debtor must conduct himself in the manner agreed, while the creditor has a corresponding performance right that the debtor shall conduct himself in a particular way. ${ }^{17}$ Unlike English law, a contract in South Africa does not require consideration for a

\footnotetext{
${ }^{6}$ Van Rensburg, Lotz and van Rijn (2004) op cit note 5 at 215.

${ }^{7}$ Visser et al (2004) op cit note 5 at 10; F du Bois (2007) Wille's Principles of South African Law $9^{\text {th }}$ ed at 736.

${ }^{8}$ Visser et al (2004) op cit note 5 at 9 . In the case of a minor, however, a contract he enters into without the consent of his guardian may be ratified subsequently. Again, see Visser et al (2004) op cit note 5, at 10, and on legal capacity, see ch 7, s7.2.2.5 below.

${ }^{9} \mathrm{Du}$ Bois (2007) op cit note 7 at 737.

${ }^{10}$ See ch 7, s7.2.4 titled Terms of the Contract.

${ }^{11}$ In private international law, party autonomy means the freedom of the parties to choose the law applicable to the contract. It also involves the choice to determine the forum which is to have jurisdiction to hear any potential or actual dispute between them. Within the European Union, the Council Regulation on Jurisdiction and Recognition and Enforcement of Judgments in Civil and Commercial Matters gives wide room for party autonomy in Art 15(1). See also Van der Merwe, Van Huyssteen and Reinecke (1993) op cit note 5 at 10 . However, this freedom may be qualified by a court for reasons of public policy. For a more detailed discussion, see ch 7, s7.2.4.5 titled Good Faith And Unfair Terms.

${ }_{12}$ As Glover notes, the Romans classified their contracts in an assortment of ways as found in Gaius Institutes 389 and Justinian Institutes 3132 . They were divided into four categories in terms of the manner in which the various contracts were concluded: contracts re, contracts verbis, contracts litteris and contracts consensu. These contracts were then classified in terms of whether they were bilateral or unilateral, and then procedurally by whether they were contracts strictiiuris or contracts bonae fidei. See GB Glover (2004) 'Metus in the Roman Law of Obligations' (10) Fundamina at 31, and the extensive overview of aspects of Roman contracts detailed therein.

${ }^{13} \mathrm{~A}$ donation is an example of a unilateral contract. In English law, the doctrine of privity in contract law provides that a contract cannot confer rights or impose obligations arising under it on any person or agent except upon the parties to the contract. See RM Goode (1995) Commercial Law $2^{\text {nd }}$ ed, at 106.

${ }^{14}$ For example, a sale.

${ }^{15}$ Van der Merwe, Van Huyssteen and Reinecke (1993) op cit note 5 at 45 . An obligation may not be created voluntarily by a unilateral act as was possible in Roman law by pollicitatio.

${ }^{16}$ This is distinguished from other types of rights such as real rights, personality rights, and immaterial property rights. See Van der Merwe, Van Huyssteen and Reinecke (1993) op cit note 5 at 2.

17 A personal right is also known as a claim as it entitles the holder to claim that another person shall act in a particular
} 
contract to be valid. $^{18}$

In essence then, the essentials of a contract ${ }^{19}$ require that: the parties must have the intention to bind themselves; ${ }^{20}$ the parties must have the capacity to contract; ${ }^{21}$ the parties must communicate this intention; the agreement must not be vague; the parties must be of the same mind as to the subject matter; the agreement must be lawful ${ }^{22}$ and performance must be possible. ${ }^{23}$ Thus, in the context of applicability to possibly insalubrious circumstances that could arise in an MFS transaction, selected critical aspects of contract formation are discussed below. ${ }^{24}$

\subsubsection{Requirements for Valid Contracts}

\subsubsection{Overview}

As noted above, ${ }^{25}$ contracting parties at common law must fulfill a number of criteria for a contract to be valid. These criteria take on an added dimension when seen in the context of financial inclusion, financial literacy and technical literacy where consensus, for example, may be vitiated by mistake and fraud, and misrepresentation. The validity of the MFS transaction may also be affected by the lack of legal capacity of the contractants, especially those - such as minors - who may not have the requisite contractual capacity.

\subsubsection{2}

\section{Consensus}

The basis of the contract is either consensus - an actual meeting of the minds - or the reasonable belief by one of the contractants that there is consensus. This relates to the will theory, also known as the intention or consensual theory. ${ }^{26}$ The parties are then said to be ad idem about the obligations they wish to create. ${ }^{27}$ South African law, like German law, uses an abstract system ${ }^{28}$ for the acquisition of property such that the way in which MFS-based remittances are considered. See ch 7, s7.3 titled Payments in General, and the discussion that follows.

${ }^{19}$ For a brief discussion of the essentials of a contract, see Visser et al (2004) op cit note 5 at 10.

${ }^{20}$ See ch 7, s7.2.2.2 titled Consensus.

${ }^{21}$ See ch 7, s7.2.2.5 titled Legal Capacity.

${ }^{22}$ See ch 7, s7.2.2.7 titled Lawfulness.

${ }^{23}$ See ch 7, s7.2.2.6 titled Possibility of Performance.

${ }^{24}$ For further exposition on the basis of contract, and on the time and place of formation of the contract, see Du Bois (2007) op cit note 7 at 823; Van der Merwe, Van Huyssteen and Reinecke (1993) op cit note 5 at 49; Efroiken v Simon 1921 CPD 367; Finestone v Hamburg 1907 TS 629 at 632; Reid Bros (South Africa) v Fischer Bearings Co Ltd 1943 AS 232 241; Kergeulen Sealing \& Whaling Co Ltd v CIR 1939 AD 487; Levin v Drieprok Properties (Pty) Ltd 1975 SA (2) 397 (A) 407; Brandt v Spies 1960 (4) SA 14 (E); Shell SA (Pty) Ltd v Corbitt 1986 (4) SA 523 at 525-6.

${ }^{25}$ See ch 7, s7.2.1 titled Nature of a Contract.

${ }^{26}$ Roman jurists required a causa obligationas, that is, a special reason for the creation of an obligation. Some agreements, however, were legally binding although they were not accompanied by a special causae obligationum - instead, they were consensual contracts (contractus ex consensus) which were binding simply because the parties to the agreement concurred on the essential parts of their pact, which were generally consensual. Van der Merwe, Van Huyssteen and Reinecke (1993) op cit note 5 at 11.

${ }^{27}$ Ibid at 14 .

${ }^{28}$ The abstract theory was confirmed in South African law in Air-Kel (Edms) Bpk h/a Merkel Motors $v$ Bodenstein en 'n Ander 1980 (3) SA 917 (A) at 922E-F; see also Legator McKenna v Shea \& others [2008] ZASCA 144; 2010 (1) SA 35 (SCA) at para 2 where Brand JA said:
} 
ownership will pass if a real agreement (saaklikeooreenkoms) exists and other conditions like delivery are met, but importantly, irrespective of the legal status of the underlying obligatory agreement. ${ }^{29}$ There are a number of theories that aggregate the consensus: the will theory, the declaration theory ${ }^{30}$ and the reliance theory. ${ }^{31}$

The will theory is the favoured approach, and it says that a contractant is legally bound to his contract because there is an actual meeting of minds in relation to coinciding intentions, such that without any conscious consensus between the parties, there is no contract. ${ }^{32}$ Associated with the 'will' or intention of the parties, the parties may also be bound by issues like legal certainty, good faith, the protection of reasonable expectations and the creation of undue risks. ${ }^{33}$ Should actual consensus be prevented by some other factor such as material mistake, ${ }^{34}$ the parties will not be contractually bound as the contract will not have come into existence. ${ }^{35}$ Consensus only exists if the parties who agree are aware of their agreement. ${ }^{36}$ Coinciding intentions alone do not constitute consensus. The consensus between the parties must relate to both parties agreeing on the terms of the contract, and they must not have made a mistake or been forced into the contract by forms of duress, undue influence or as a result of a misrepresentation. ${ }^{37}$

A contract or the application thereof may be void or voidable because of mistake as there is an absence of consensus, that is, dissensus. ${ }^{38}$ At common law, someone will be bound unless he can show that the agreement was vitiated by mistake, and even this exception operates very narrowly. ${ }^{39}$ The mistake may

'In accordance with the abstract theory the requirements for the passing of ownership are twofold, namely delivery ... coupled with a so-called real agreement or "saaklikeooreenkoms." The essential elements of the real agreement are an intention on the part of the transferor to transfer ownership and the intention of the transferee to become the owner of the property .... Broadly stated, the principles applicable to agreements in general also apply to real agreements. Although the abstract theory does not require a valid underlying contract, eg sale, ownership will not pass as a defect in the real agreement.'

${ }^{29}$ See JC Sonnekus (2008b) Unjustified Enrichment in South African Law at 22, in which he cites as authority Commissioner of Customs and Excise v Randles Brothers and Hudson Ltd 1941 AD 369; Bank Windhoek Bpk v Rajie 1994 (1) SA 115 (A) 141C-E; Krapohl v Oranje Kooperasie Bpk 1990 (3) SA 848 (A) 864E-H; Kriel v Terblanche NO 2002 (6) SA 132 (NC) 144C-D. For a brief exposition of the abstract theory, see H Mostert et al (2010) Property Law in South Africa at 190-191. For a discussion on the link between the real agreement and payment, see ch 7, s7.3 passim on payments.

${ }^{30}$ Van der Merwe, Van Huyssteen and Reinecke (1993) op cit note 5 at 28. The 'declaration theory' relating to consensus says that the contractants are bound to their contract not on the basis of their subjective, coinciding intentions but on the basis of their objective, coinciding declarations of will. The declaration theory is less favoured in South African law than the will theory. The declaration theory found favour in South African Railways \& Harbours v National Bank of South Africa Ltd 1924 AD 704 at 715-716.

${ }^{31}$ Van der Merwe, Van Huyssteen and Reinecke (1993) op cit note 5 at 13.

${ }^{32}$ Ibid at 14-15. An expression of will made without any intention of being legally bound by its eventual acceptance cannot be classed as an offer leading to the creation of a contract. Mondorp Eiendomsagentskap (EDMS) BPK v Kemp en de Beer 1979 (4) SA 74 (A).

${ }^{33}$ Van der Merwe, Van Huyssteen and Reinecke (1993) op cit note 5 at 13.

${ }^{34}$ See ch 7, s7.2.2.3.1 below on mistake.

${ }^{35}$ A formal cause or reason for the obligations is not a requirement for their creation in terms of will theory. Conradie op cit note 18 as cited by Van der Merwe, Van Huyssteen and Reinecke (1993) op cit note 5 at14.

${ }^{36}$ Van der Merwe, Van Huyssteen and Reinecke (1993) op cit note 5 at 14.

${ }^{37}$ D Hutchison (ed) (2009) The Law of Contract in South Africa at 113-114.

38 Van der Merwe, Van Huyssteen and Reinecke (1993) op cit note 5 at 16.

${ }^{39}$ The mistake must be reasonable (iustus error). For example, a mistake must influence a party's decision to conclude a contract in order to be relevant to the question of possible dissensus. Khan v Naidoo 1989 (3) SA 724 (N) (hereafter Khan'; D 
relate to a fact, legal rule, or principle where that facet or rule is material and where the mistake (whether of fact or law) is also reasonable. ${ }^{40} \mathrm{~A}$ mistake that excludes consensus may be material or essential to the agreement if it affects the obligations decided upon, particularly as to the contents of an obligation such as the performance in terms of the agreement or the persons between whom the obligation is created to perform will not be material if it does not affect the mistaken party's decision to agree, which would be a question of fact. $^{41}$

There may be material mistakes that relate to the terms of the contract, ${ }^{42}$ for example, error in corpora (mistake relating to the object of performance), error in persona (mistake relating to the persons between whom the obligation exists), and error in negotio (mistake relating to the nature of the juristic act concerned). A mistake about a quality or attribute of the object of performance - error in qualitate - is generally not regarded as material. ${ }^{43} \mathrm{~A}$ party to an agreement who raises mistake to escape contractual liability must prove that not only is the mistake material (as would be expected in terms of the will theory) but also that it is reasonable, together with iustus error. However proof that the mistake is material will not by itself excuse the mistaken party. ${ }^{44}$ The mistake may be unilateral, mutual or common. ${ }^{45}$ In cases of unilateral mistake, it may be that only one party has the incorrect perception, although the other party may be aware of the other's mistake. A mistake is reasonable if accompanied by objective circumstances that make it excusable in the eyes of the law. This may be when the mistake was induced by an unacceptable misrepresentation by the contract-assertor or someone for whose acts he may be liable. This misrepresentation may be via commission ${ }^{46}$ or omission. ${ }^{47}$ 'Mutual mistake' would be evident where each party has the wrong impression of the other's intention and neither is aware of the other's mistake. ${ }^{48} \mathrm{~A}$ 'common mistake' is when both parties are under the same incorrect perception of fact external to the minds of the parties, ${ }^{49}$ although this does not necessarily lead to complete dissensus as the parties are in complete agreement although their consensus is based on an incorrect assumption or supposition. ${ }^{50}$

Hutchison (ed) (2009) op cit note 37 at 83). Otherwise the maxim caveat subscriptor - let the signer beware - may apply to hold a party to the contract. Van der Merwe, Van Huyssteen and Reinecke (1993) op cit note 5 at 39; T Leng (2006) 'Legal Effects of Input Errors in e-Contracting' 22(2) Computer Law \& Security Report 157-164 at 157.

${ }^{40}$ Havenga, Havenga and Kelbrick (2007) op cit note 4 at 63.

${ }^{41}$ Khan op cit $\mathrm{n} 39$.

${ }^{42}$ For a discussion on defective payments and their effect, see ch 7, s7.3.6 below.

${ }^{43}$ Trollip v Jordaan 1961 (1) SA 238 (A) (hereafter Trollip); Allen v Sixteen Stirling Investment (Pty) Ltd 19744 SA (D). Provisions of the South African Consumer Protection Act 68 of 2008 (hereafter CPA) relating to quality may, however, alter this. For an introduction to the CPA, see ch 8, s8.7 titled E-Commerce Laws and Regulations, and further, ch 12, ss12.9 titled E-Commerce Laws; and 12.10 titled Consumer Protection Laws.

${ }^{44}$ Van der Merwe, Van Huyssteen and Reinecke (1993) op cit note 5 at 33.

${ }^{45}$ Ibid.

${ }^{46}$ Misleading the contract-denier by a statement or other positive act.

${ }^{47}$ Failure to correct or remove an incorrect impression existing in the mind of the contract-denier.

${ }^{48}$ See, for example, Diamond v Kernick 1947 (3) SA 69 (A) where each party was mistaken as to the other's intention, although neither realised that his promise was misunderstood by the other. In the circumstances, the plaintiff failed to prove that the minds of the parties ever met, or, to use another phrase, failed to prove a true consensus ad idem. See also Double Option Trading 197 (Pty) Ltd v Grimbeek and Another (13703/07) [2009] ZAWCHC 204 (13 August 2009).

${ }^{49}$ See, for example, Dickinson Motors (Pty) Ltd v Oberholzer 1952 (1) SA 443 (A) where the plaintiff claimed with the condictio indebiti repayment of an amount paid in error to the defendant. The substance of the plaintiff's case was that he had paid the amount in error because both he and the defendant thought that the car which was to be delivered to him in return for the payment was a Plymouth motor car A, and had no idea that it was Plymouth motor car B, which belonged to someone else.

${ }^{50}$ Van der Merwe, Van Huyssteen and Reinecke (1993) op cit note 5 at 19. 
The law approaches situations where a contract has been formed or performed under duress or undue influence in imputing an actual agreement, but which may be voided if one of the contractants who indicates that his will was defective. ${ }^{51}$ A contract may thus be voided by the existence of duress or undue influence over a contractant. ${ }^{52}$ There is duress where the decision by a prospective contractant to conclude a contract may be as a result of him being forced - under some duress or metus - to agree to the terms of the contract such that his true will is not present, ${ }^{53}$ and may take the form of emotional ${ }^{54}$ or physical threats of force ${ }^{55}$ or actual physical force ${ }^{56}$ that effectively compels the person to agree ${ }^{57}$ There may of course be circumstances where someone is under duress, but their consent is still a valid expression of their intent. ${ }^{58}$ Undue influence may relate to someone who takes advantage of a contractant to force them into a contract or transaction they would not ordinarily have pursued. A contractant must prove that the other contractant obtained an influence over him such that this influence weakened his powers of resistance and made his will pliable; and that the other contractant used this influence in an unconscionable manner to persuade him to agree to a transaction which was to his detriment and which he would have not concluded if he had enjoyed normal freedom of will. ${ }^{59}$ Besides duress, there may be impropriety, unconscionability, the boni mores and abuse of the situation, all of which relate to the conduct of one of the parties. ${ }^{60}$

\subsection{Fraud and Misrepresentation}

Misrepresentation and fraud are additional grounds for rescission of a contract insofar as there may be an absence of consensus. Misrepresentation occurs when one of the contractants provides a false statement of fact which induces the other party to enter the contract. The misrepresentation usually results in error in motive, insofar as a contractant believes that particular elements of the contract are or will be available. ${ }^{61}$ There are classes of misrepresentation, for example, no-fault (innocent and thus no wrongfulness), or types of fault (intentional, with wrongfulness). ${ }^{62}$ An example of no-fault would be an innocent misrepresentation. The party misled thus labours under a mistake, and if this mistake is material, there is said to be no

\footnotetext{
${ }^{51}$ Ibid op cit note 5 at 71 .

${ }^{52}$ See ch 7, s7.3.6 titled Defective Payments and their Effect.

${ }^{53}$ As Glover points out, rather than use the traditional Latin term metus, South African law has adopted the English (or Norman-French) word 'duress' to describe the situation where an agreement or transaction is induced by threats which invoke fear in the mind of the victim. See Glover (2004) op cit note 12 and the references cited therein.

${ }_{55}^{54}$ See Savvides v Savvides 1986 (2) SA 235 (T) where the threat of a partner abandoning the marriage was seen as a threat.

${ }^{55}$ Known as vis compulsive.

${ }^{56}$ Known as vis absoluta. The physical compulsion may come about where the person is forced to agree, but under circumstances where they are not in control of their own actions, for example, where someone holds their hand and forces them to sign a document or enter their PIN number into an ATM.

${ }^{57}$ Where there is threat to goods, for example, there may be a claim for unjustified enrichment, such that the condictio indebiti obtains as performance made sine causa. Van der Merwe, Van Huyssteen and Reinecke (1993) op cit note 5 at 90 ; and see ch 7, s7.3.6.8.3 below on the redemptive action of condictio indebiti.

${ }^{58}$ Known as coacta voluntas voluntas est. ['A coerced will is nevertheless a will']; Van der Merwe, Van Huyssteen and Reinecke (1993) op cit note 5 at 85.

${ }^{59}$ Van der Merwe, Van Huyssteen and Reinecke (1993) op cit note 5 at 93; Preller v Jordaan 1956 (1) SA 483 (A); Patel v Grobbelaar 1974 (1) SA 532 (A) 534A-B.

${ }^{60}$ Van der Merwe, Van Huyssteen and Reinecke (1993) op cit note 5 at 96 . Other considerations included the circumstances generally surrounding the process of transacting the contract as well as the inequality of bargaining power between the contractants, or the contract which is greatly inequitable.

${ }^{61}$ Ibid

${ }^{62}$ Ibid at 73-75.
} 
consensus such that generally no contract arises. ${ }^{63}$ South African law tends to gravitate towards distinguishing between fraudulent, negligent and innocent (no-fault) misrepresentation. ${ }^{64}$ The effect of any actionable misrepresentation may be to make the contract voidable, allowing the innocent party the right to rescind the contract as well as claim damages in delict. However, while the contract may be voided, it may still have some effect on the affected party insofar as the surrounding circumstances may yet fasten and allocate some risk to him. ${ }^{65}$

\subsubsection{4}

\section{Application to MFS}

Common law aspects of contract formation are to be seen in the light of the Electronic Communications and Transactions Act (hereafter ECTA) and the Consumer Protection Act (hereafter CPA), both of which have some relevance to MFS. ${ }^{66}$ In relation to the time and place of formation of a contract, MFS contracts are affected by both common law and the ECTA, such that where the parties have not specified in their contract what scheme applies to the time and place of formation of the contract, the provisions of the ECTA are applied. ${ }^{67}$ Unless the parties to an electronic transaction decide otherwise within their contract, the deeming provisions relating to the time and place of formation of the contract in the ECTA automatically apply the common law reception theory to the formation of contracts formed by electronic means. ${ }^{68}$ The application of this theory in statute takes precedence over any other common law view of contract formation via electronic means, although the application thereof is subject to common law interpretation. ${ }^{69}$ The more recent CPA governs contracts generally, and defers in many parts to the ECTA. There is, however, the ability for telecommunications law to have ultimate authority over some contracts that relate specifically to telecommunications-linked activities via exception criteria allowed for in the CPA. ${ }^{70}$

Mistake, fraud and duress are of particular concern as MFS and general online financial services grow around the world. At the very least, mobile phones have a conspicuous presence in public and are often sought after items for rogues and thieves as they are valuable and easily sold. Users are often victims of violent attacks to dispossess them of their phones and possessions. Similarly, users of Automatic Teller Machine (hereafter ATM) cards are often forced at gunpoint to withdraw cash or hand over their Personal Identification Number (hereafter PIN) codes to hijackers and robbers. In the latter case, financial institutions may reimburse users to a certain limit if the duress was proven to be the cause of loss to the user. While it is innovative, convenient and ubiquitous, the mobile phone with its live banking-like

\footnotetext{
${ }^{63}$ Ibid.

${ }^{64}$ Ibid.

${ }^{65}$ See ch 7, s7.3.6.5 titled Allocation of Risk, Loss and Liability; and ch 12, s12.11 titled Consumer Protection and Loss Allocation with Respect to Payments for a comparison of the risk and loss allocation for consumers in South Africa with that of the EU and USA.

${ }^{66}$ Act 25 of 2002 and Act 68 of 2008 respectively. See in relation to South Africa, ch 12, ss12.9 titled E-Commerce Laws, and 12.10 on consumer protection laws.

${ }^{67}$ See ch 12, s12.9 titled E-Commerce Laws and Regulations. The ECTA, as an enabling technology-agnostic piece of legislation that recognises contracts - using what it terms 'data messages' made electronically - aims to variously govern the formation of contracts done via electronic means such as via mobile Wireless Application Protocol (hereafter WAP) or Internet web sites. See s5.5.3.1 on WAP.

${ }^{68}$ See s22(2) of the ECTA: 'An agreement concluded between parties by means of data messages is concluded at the time when, and at the place where, the acceptance of the offer was received by the offeror.'

${ }^{69}$ Havenga et al (2007) op cit note 4 at 61.

${ }^{70}$ The interaction between the ECTA and the CPA is discussed in ch 12, s12.10.2.2.6 titled Interplay of the CPA and the ECTA.
} 
payments and remittance facility ${ }^{71}$ offers a tempting target for rogues - a perfect storm that involves not only the loss of a mobile phone but also the possible loss of any stored funds. Users targeted by rogues may be forced at gunpoint (and therefore under duress) to divulge their PINs or to execute a transaction such as transferring funds to the criminal's account, or to perform cash outs at $\mathrm{ATMs}^{72}$ or agents. ${ }^{73}$ Further, the duress may not be an immediate apprehension of physical harm: it may be a visceral emotional reaction to some imminent harm to the person's pecuniary interests. A user may, for example, receive a false message indicating that their account has been hacked or suspended, and that they need to access their account with their full details to remedy the issue, except that the message is false and contains a so-called 'Phishing' $\operatorname{link}^{74}$ that automatically redirects the user to a false web or Wireless Application Protocol-based (hereafter WAP-based) login page. In all the somewhat dark but demonstrably necessary scenarios detailed above, users may suffer losses, though daily transaction limits in most MFS schemes may mitigate the overall risk. ${ }^{75}$ Fraud, while it may be a component of the misrepresentation, may also exist where the affected innocent party was not involved in the contract or performance thereof, despite evidence that may link him to the contract. Thus identity theft or theft of identifying credentials like a PIN number for a financial transaction would vitiate any contract and performance therein as there was wholesale absence of consensus in that the innocent party was not a party to the contract and performance. ${ }^{76}$

In relation to the ability to transfer funds from a fiat-based or airtime store of value using the mobile phone, the deliberately simpler design of the transfer process can also result in mistake as to the recipient. Unlike Electronic Fund Transfers (hereafter EFTs) which require a number of routing and account details such as an International Bank Account Number (hereafter IBAN), bank branch, or Society for Worldwide Interbank Financial Telecommunication (hereafter SWIFT) number or a combination thereof to effect the transfer to the correct recipient, phone-based transfers usually only require the phone number of the recipient to execute the transfer instruction. Very often the transfer is instantaneous and can be cashed out at an ATM or an agent if available. For example, new ATM card-less withdrawal facilities introduced by South African banks, further raise the possibility of loss via duress or mistake. Here, users in a MFS scheme can remit funds to any phone number - which may or may not be authenticated via a national SIM card registration scheme like that implemented by the Regulation of Interception of Communications Act (hereafter RICA) $^{77}$ - which does not necessarily have to be part of the MFS scheme. The sender simply inputs the cellphone number of the receiver of the value, along with the sender's PIN, and the value to be sent. The MFS system then sends a Short Message Service (hereafter SMS) text message to the receiving number with a one-time access code linked to the receiver's cellphone number. The recipient then inputs

\footnotetext{
${ }^{71}$ See ch 6, s6.5.4.3 titled Mobile Airtime Transfer schemes and ch 6, s6.5.5.3.2 titled EFTs and Remittances on fiat-based MFS transfer schemes.

${ }^{72}$ If the account is, for example, linked to a plastic access card.

${ }^{73}$ See inter alia on the use of agents in the various MFS models, ch 2, s2.5.2 titled Use of Agents; ch 6, ss6.4.4.3 titled Use of Agents; 6.5.3 titled Use of Agents; 6.5.5.4 titled Use of Agents and Correspondents; and 6.6.3 titled Use of Agents.

${ }^{74}$ See ch 5, s5.7.4.1 on Phishing.

${ }^{75}$ See further ch 7, ss7.3.6.2 titled Mistaken Payment Scenarios; and 7.3.6.3 titled Unauthorised Payment Scenarios.

${ }^{76}$ For a brief survey of the potential risks in the technologies underpinning financial and general transactions, see ch 5, s5.7.4 titled Common Security Threats; ch 4, s4.8.3.8 titled Security and Reliability of Payments; ch 7, s7.3.6.5.3.3 titled Security and Efficacy of Systems; and MA Mthembu (2010) 'Electronic Funds Transfer: Exploring the Difficulties of Security' (5)4 Journal of International Commercial Law and Technology 201.

${ }^{77}$ Regulation of Interception of Communications and Provision of Communication-related Information Act 70 of 2002 (hereafter RICA). See generally ch 8, s8.5 titled Anti-Money Laundering, Terrorist Financing and Customer Due Diligence Laws and Regulations for AML and CTF schemes; ch 8, s8.6 titled Telecommunications Laws and Regulations; and ch 12, s12.8 titled Telecommunications Regulations.
} 
that access code along with their cellphone number on-screen at any participating ATM machine anywhere in the country and withdraws all the value that was sent as cash. The buffer of Day+1 or Day+x is generally not available in the case of mistake or duress, unless the system operator provides it. In fact, the speed of the transfer via MFS compared to EFTs is seen as a selling point rather than a security risk.

While there may be daily and/or transaction limits for these transfers mandated by Anti-Money Laundering (hereafter AML) and Counter Terrorist Financing (hereafter CTF) regulations or business safety considerations, generally there is very little leeway in the case of mistake, fraud or duress. That the recipient is unjustifiably enriched by this mistake, duress or fraud could be subject to an action or condictio $^{78}$ to recover to the loss. These have been employed in relation to mistaken or fraudulent payments via EFTs, but as case law, suggests, the de minimus nature of the smaller - micro-payment - amounts involved in MFS would militate against anyone taking the trouble to embark on an expensive legal battle to reclaim the value, especially with no specific and effective statutory backing or assistance for the recovery of mistaken and fraudulent payments.

In relation to transactions for Value Added Services (hereafter VAS) using Premium Rate Services (hereafter PRS) and billed via Premium Rated SMSs (hereafter PSMS), as offered by Wireless Application Service Providers (hereafter WASPs), there is a similar conundrum. Mistake and misrepresentation are unfortunately not the exception in many jurisdictions where these facilities are made available to the general public. ${ }^{79}$ Depending on the marketing and the method of discovery of a PRS by a consumer, the design of the marketing may be such that the user is unaware of the implications of simply browsing a particular service or interacting with it via a single SMS. When, for example, a user receives a SMS-type message with a WAP link embedded in the message and then clicks on that link, it may automatically activate a chargeable facility such as a (WASP-type) VAS subscription service, which ultimately could drain all the stored value in the user's Store of Value (hereafter SOV). This scenario usually occurs in relation to the use of the airtime-based SOV in a Stored Value Account (hereafter SVA). The user may also interact with a provider via a single SMS after viewing an advertisement on TV where the fact that the facility does not undertake an à la carte billing procedure, but rather a more expensive subscription billing, is hidden from view by clever design - usually unreadable fonts - that are intended to mask the true costs.

Unlike charges placed on (bank) credit or debit cards where there may be a record, the dominance of prepaid accounts in the developing world does not allow the user to know the extent of the billing. In most cases, the SVA is, in the eye of the user, mysteriously drained and the de minimus principle usually ensures they do not undertake any extensive enquiry as to why the value has disappeared. This is especially for those prepaid users who do not have an accounting record in the form of a post-paid bill in order to perform a reconciliation of their charges. This type of loss is further manifest in the experiences of financially and technically illiterate prepaid phone users.

\footnotetext{
${ }^{78}$ See ch 7, s7.3.6.8 titled Actions to Recover Value, highlighting use of the condictiones.

${ }^{79}$ See ch5, s5.2.3 on VAS; and ch 6, s6.5.4.2 on WASP VAS.
} 
In these cases, both fraud and misrepresentation could be present; the former if the user was 'autosubscribed ${ }^{80}$ because they simply landed on a WAP page when they clicked on the data link in the SMStype message. As noted above, a unilateral mistake induced by the seller's innocent misrepresentation does not necessarily void the contract. ${ }^{81}$ However, a mistake that excludes consensus - that is, dissensus - may be material or essential to the agreement if it affects the obligations decided upon, in particular, on the contents of an obligation such as the performance in terms of the agreement or the persons between whom the obligation to perform was created or will not be material if it does not affect the mistaken party's decision to agree, which would be a question of fact. ${ }^{82}$ This relates to material mistake in relation to the terms of the contract. For example, error in corpora (mistake relating to the object of performance) and error in negotio (mistake relating to the nature of the juristic act concerned) would be relevant here as the user who believes he is simply buying one item à la carte (once-off) and did not want to (or would have not agreed to had he been made aware) that he was undertaking a more expensive, and continuous billing via a subscription service, would possibly rise to the level of error in corpora and certainly to error in negotio.

A mistake about a quality or attribute of the object of performance - error in qualitate - is generally not regarded as material but may have some ground if the provider engages in a 'switch ' $n$ bait' tactic whereby the nominally 'quality' material is provided upfront but the provider then switches to inferior quality or infrequent delivery so as to maximise profits by, for example, avoiding to have to pay royalties.

\subsubsection{5}

\section{Legal Capacity}

\subsubsection{1}

\section{Overview}

The law of persons has at its core the basic tenet that every legal subject or legal person - persona iuris can have legal rights and duties. ${ }^{83}$ However, this does not necessarily mean that they can always acquire rights and incur duties since the ability to exercise these rights will depend on their status at a point in time.

Status depends on factors such as age, insolvency, mental dis(ability), domicile, legitimacy and criminal conviction. ${ }^{84}$ Status in turn determines a person's legal capacity, that is, their ability to participate as a legal subject in valid juristic acts. ${ }^{85}$ Where someone lacks a capacity to contract, the general principle is that no valid and enforceable obligations will arise, but this does not mean that the person, in a legal sense, has no will (intention) or cannot give expression to that will, but means that the law does not attach any validity to the expression of that will. ${ }^{86}$ The resultant exclusions may, under the circumstances, give rise to one of the

\footnotetext{
${ }^{80}$ Ibid, which deals with the nature of 'auto-subscription' and its effect on the user's SVA.

${ }^{81}$ Trollip op cit note 43.

${ }^{82}$ Khan op cit note 39 as cited in Van der Merwe, Van Huyssteen and Reinecke (1993) op cit note 5 at $17 \mathrm{fn} 26$.

${ }^{83}$ Van Rensburg, Lotz and Van Rijn (2004) op cit note 5; DSP Cronje, JA Olivier and AH Barnard (1986) The South African Law of Persons and Family Law 2nd ed at 40; J Heaton and JT Pretorius (2007) 'Minors as the Payees of Cheques' 124 South African Law Journal 112-127; and PQR Boberg (1975) 'Emancipation and the Attainment of Majority' (92) South African Law Journal 183.

${ }^{84}$ Du Bois (2007) op cit note 7 at 147. Other examples of the types of persons with no or limited contractual capacity include prodigals, intoxicated persons, and persons under the influence of drugs. See Van Rensburg, Lotz and Van Rijn (2004) op cit note 5 at $248-249$.

${ }^{85}$ Du Bois (2007) op cit note 7 at 146; Cronje, Olivier and Barnard (1996) op cit note 83 at 40.

${ }^{86}$ Du Bois (2007) op cit note 7 at 145-147 passim; Cronje, Olivier and Barnard (1996) op cit note 83 at 40-41.
} 
following descriptions of that contract: valid, ${ }^{87}$ void, ${ }^{88}$ voidable, ${ }^{89}$ ratifiable $^{90}$ or unenforceable on one side ${ }^{91}$ or on both sides. ${ }^{92}$ In many cases, because MFS transactions can be done by minors, for example, who often surreptitiously use a parent's mobile phone, the implications thereof for contract formation are discussed below.

\subsection{Majors and Minors}

In South African law, someone who has reached the age of 18 years is said to be of majority and thus has capacity, except of course in circumstances of some or all of the exclusions outlined above. ${ }^{93} \mathrm{~A}$ minor is any natural person who has not yet reached the age of majority. The Children's Act ${ }^{94}$ lowered the traditional age of majority from 21 to 18 years and thus the law recognises three major age bands: birth to 7 years, 7 to 18 years, and 18 years and older. ${ }^{95}$ While minors have capacity to contract, their capacity to contract is limited in respect of contracts that impose obligations on them. ${ }^{96}$ A minor under 7 - an infans - is said to be unable to conclude a contract in terms of which he acquires rights without incurring any concomitant obligations ${ }^{97}$ and applies even in respect of a unilateral contract that confers only rights on the infans and does not impose any duties on him or her. ${ }^{98}$ A guardian with capacity to act may however act on behalf of the minor ${ }^{99}$ but as a general rule, the guardian does not incur personal liability to a third party. ${ }^{100}$ An infans' lack of capacity to act does not mean however that he or she cannot have rights and duties: as such, once the guardian of an infans has acted on his or her behalf, it is upon the infans that rights are conferred and duties imposed, and not on the guardian. ${ }^{101}$ Minors between the ages of 7 and 18 have the capacity to contract, but their capacity is limited in respect of all contracts that impose obligations on them such that they have contractual liability only if assisted by their guardian. ${ }^{102}$ Hence, as Heaton and Pretorius

\footnotetext{
${ }^{87}$ See Van Rensburg, Lotz and Van Rijn (2004) op cit note 5 at 249, describing the unassisted contract of a minor above the age of seven in terms of which only the other party is bound to perform (via a unilateral contract).

${ }^{88}$ See Van Rensburg, Lotz and Van Rijn (2004) op cit note 5 at 249, describing the effects of an ante nuptial contract entered into by a minor without his guardian's consent.

${ }^{89}$ Ibid, describing a contract entered into by a minor with his guardian's consent but which was prejudicial to the minor.

${ }^{90}$ Ibid, describing a contract entered into by a minor above the age of seven, concluded without his guardian's consent.

${ }^{91}$ Ibid, describing a contract involving a minor in which he is required to perform.

${ }^{92}$ Ibid, describing a contract between two minors above the age of seven where both are required to perform.

${ }^{93}$ For example, mental incapacity.

${ }^{94}$ Act 38 of 2005.

${ }^{95}$ Havenga, Havenga and Kelbrick (2007) op cit note 4 at 72. The Romans only conferred full legal status at 25 years old. See Boberg (1975) op cit note 83 at 183.

${ }^{96}$ Heaton and Pretorius (2007) op cit note 83 at 121.

${ }^{97}$ Thus, a minor under 7 years of age may not even accept an offer of a donation. Havenga, Havenga and Kelbrick (2007) op cit note 4 at 73 .

${ }^{98}$ Heaton and Pretorius (2007) op cit note 83 at 118.

${ }^{99}$ Havenga, Havenga and Kelbrick (2007) op cit note 4 at 73. If a contract concluded on behalf of the minor is deemed to be to the minor's detriment, the minor may, within one year of reaching majority, apply to the High Court for the cancellation of the contract and restitution of everything that has been performed in terms thereof. See also Heaton and Pretorius (2007) op cit note 83 at 118 .

${ }^{100}$ It also makes no difference whether the guardian assisted the minor or acted on his behalf. Cronje, Olivier and Barnard (1986) op cit note 83 at 97 and the sources cited therein at fn 19.

${ }^{101}$ Heaton and Pretorius (2007) op cit note 83 at 119. The High Court may step in if the guardian refuses to assist. See Cronje, Olivier and Barnard (1986) op cit note 83 at 94. Further, Heaton and Pretorius (2007) op cit note 83 at 119 indicate that in the case where an infans is the payee of a cheque, or if the cheque is a bearer bill, the guardian of the infans has to accept delivery of the cheque on behalf of the infans, but ownership of any rights that arise as a result of the guardian's acceptance on behalf of the infans, vest in the infans.

${ }^{102}$ Cronje, Olivier and Barnard (1986) op cit note 83 at 95; Heaton and Pretorius (2007) op cit note 83 at 120 and the sources cited therein. Thus a minor may independently enter into a contract that improves his position without imposing duties on him.
} 
explain ${ }^{103}$ in respect of contracts that confer only rights on a minor, the minor has capacity to contract independently of his guardian and thus the minor may independently accept a donation or enter into an agreement with a third party whereby the minor's debt to that person is extinguished. ${ }^{104}$ The minor cannot however validly enter into an agreement regarding a debt someone owes the minor unless the minor has his guardian's consent. ${ }^{105}$ Even if the minor has his or her guardian's consent, the consent merely supplements the minor's limited capacity to contract in order to render the transaction valid but does not convert that minor into someone with full capacity to contract. ${ }^{106} \mathrm{~A}$ minor is not liable ex contractu whenever a contract is in a 'vague and general way to his advantage, ${ }^{, 107}$ but the minor may be held liable ex lege by a condictio for the amount by which the transaction enriches him at the moment the action is instituted. ${ }^{108}$

A minor may also seek the remedy of restitutio in integrum ${ }^{109}$ where he entered into a contract with or without the assistance of his guardian. ${ }^{110}$ The purpose is to restore the status quo ante, and also any loss suffered. ${ }^{111}$ Restitutio is not only a cause of action, but may also be raised as a defence when the minor is sued for performance in terms of a contract by which he was prejudiced. ${ }^{112}$ The minor may possibly escape liability provided that the contract was prejudicial to him at the moment it was made. ${ }^{113}$ This remedy is also available where the minor initially contracted without the necessary consent but where his guardian subsequently ratified the contract. ${ }^{114}$ There may be situations where a minor's guardian generally authorises him to enter into juristic acts independently where the minor is employed ${ }^{115}$ or runs a business as an economically independent person. The minor is thus said to be emancipated, and has acquired full capacity to contract, but subject to the exception relating to immovable property. ${ }^{116}$ Whether he is so emancipated is a question of fact in light of all circumstances. ${ }^{117}$ The emancipation may be express or tacit. ${ }^{118}$ However,

\footnotetext{
${ }^{103}$ Heaton and Pretorius (2007) op cit note 83 passim. While their discussion relates to cheques and the Bills of Exchange Act 34 of 1964 and in particular to s5(3) relating to 'a person not having capacity to act' in relation to cheques for purposes of s5(3) of that Act. The discussion about legal capacity may apply generally to minors in other circumstances, such as MFS.

${ }^{104}$ Accordingly, if a minor receives a cheque or some other bill as a donation to him, the minor has full capacity to contract in respect of that transaction and can validly accept the donation, for example, a birthday gift.

${ }^{105}$ As Heaton and Pretorius explain in relation to a minor receiving a cheque, if that minor takes possession of the cheque received from a third party in order to extinguish a debt owed by the third party to the minor, the minor cannot validly accept the payment without his guardian's consent since the object of (the delivery of) the cheque is to extinguish the debt that is owed to the minor and not purely to confer rights on the minor. But the debtor is not released from his or her duty to pay the minor if the minor accepts the debtor's cheque without his guardian's consent. The minor can, however, acquire possession and thus also ownership of that cheque, provided that he or she is sufficiently mature to form the necessary animus possidendi. See Heaton and Pretorius (2007) op cit note 83 at 120-121.

${ }_{106}$ Heaton and Pretorius (2007) op cit note 83 at 122.

${ }^{107}$ Edelstein v Edelstein NO 1952 (3) SA 1 (A).

${ }^{108}$ Ibid. This will have an effect on the claim value: ex lege at a point maybe less than ex contractu.

${ }^{109}$ Restitutio in integrum is a Roman remedy used to allow restoration to the original condition where there is prejudice to one of the contracting parties, such that each party must return to the other whatever he has received in terms of the contract. A minor seeking restitution must prove that all the requirements of the remedy were met. See JAC Thomas (1976) Textbook of Roman Law at 113; Cronje, Olivier and Barnard (1986) op cit note 83 at 98; Breytenbach v Frankel 1913 AD 390; GB Glover (2003) The Doctrine of Duress in the Law of Contract and Unjustified Enrichment in South Africa, PhD Thesis, Rhodes University, at 20.

${ }^{110}$ In Roman law, the disadvantage was thought to be through the minor's lack of expertise (in consulta facilitas).

${ }^{111}$ Cronje, Olivier and Barnard (1986) op cit note 83 at 99.

112 Ibid at 100. Van der Byl \& Co v Solomon (1877) 7 Buch 25; Skead v Colonial Banking \& Trust Co. Ltd 1924 TPD 497 (hereafter Skead).

${ }^{113}$ Cronje, Olivier and Barnard (1986) op cit note 83 at 98; Wood v Davies 1934 CPD 250. Prejudice arising at some other stage is irrelevant, even if it arose as a result of some fortuitous event. Skead op cit note 112.

${ }^{114}$ Cronje, Olivier and Barnard (1986) op cit note 83 at 98.

${ }_{116}^{115}$ For example, as a child model.

${ }^{116}$ Heaton and Pretorius (2007) op cit note 83 at 123. In respect of other onerous contracts the emancipated minor still does not have the capacity to contract independently.

${ }^{117}$ See PQR Boberg (1975) op cit note 83 at 732-3; Heaton and Pretorius (2007) op cit note 83 at 122; Cronje, Olivier and Barnard (1986) op cit note 83 at 98.

${ }^{118}$ Boberg (1975) op cit note 83 at 183.
} 
the effect of emancipation on the minor's capacity to contract has not been authoritatively decided insofar as whether the emancipation relates only to transactions in connection with the minor's employment or business, or whether the minor can act beyond the scope of such employment or business. ${ }^{119}$

The common law position on minors contracting and on emancipated minors is codified with some exceptions in the CPA, discussed below. ${ }^{120}$

\subsection{Application to MFS}

Mobile phones are often given to or acquired by what may be termed minors who may go on to use the device for any manner of unsecured or secured MFS, incurring obligations in the process. The legal status of these transactions is a point of contention.

With the majority of mobile customers in developing countries being prepaid users, there is often no ability to determine who is using a service or their legal status. This means that there is an innate inability beyond using biometrically-linked technology - to verify a user's age when age verification is required in an MFS-based transaction as it would be required when using the same type of (age-restricted) service in a 'bricks ' $\mathrm{n}$ mortar' environment where a minor would invariably be unable to participate in a restricted service or would only be allowed to participate if consent was given by their guardian. The majority of the methods of age verification in the online world, while being implemented slowly either through telecommunications or financial regulators, ${ }^{121}$ are currently passive as opposed to active methods of age verification. In an active method - for example in a session on a mobile phone using a WAP mobile page or in a Unstructured Supplementary Services Data (USSD) session - before continuing, a user may have to (actively) click on a link or check a conformation box that says 'I am over 18' and agree to the terms. In the passive method, the user will be presented with a statement that says, for example: 'By continuing you acknowledge that you are over 18'. In both cases, however, this approach relies on the honour of the person using that service to tell the truth about whether they are or are not of an age to have the capacity to perform contacts. ${ }^{122}$ There is, however, little or no independent verification of the status alleged. The active and passive methods are being used in WASP-type services and may apply to those accessing adult services. Where there is a need to access any service - adult or non-adult - by paying for it via PSMS or a subscription service, then issues of contractual capacity may come into play. This is especially so with a subscription service where a user enters into a contract with the WASP for continuous billing from the airtime purse, that is, daily, weekly, or general periodic billing. ${ }^{123}$ The subscription service contract is usually acceded to passively. The issue becomes somewhat more complicated where a minor

\footnotetext{
${ }^{119}$ The leading case on emancipation is Dickens v Daley 1956 (2) SA 11 (N) where an emancipated minor was held liable on a cheque he had drawn in respect of payment in terms of a contract of lease that had nothing to do with his employment as a clerk.

${ }^{120}$ See ch 12, s12.10.2.2.1 titled Agreements by Persons Lacking Legal Capacity on the CPA and legal capacity.

${ }^{121}$ On AML laws see ch 8, s8.5, as well as a discussion thereof in ch 12, s12.7.

${ }^{122}$ For a discussion on WAP, see ch 5, s5.5.3.1; and on Unstructured Supplementary Service Data (USSD), see ch 5, s5.3.5. Vodacom South Africa has a USSD system in place that allows parents to block their children from using their phones to access adult services. See also Vodacom South Africa (2007) 'A Parent's Guide to Cellphones,' available at http://goo.gl/WQdxY.

${ }^{123}$ It is a matter of some dispute as to who exactly the user enters into a contract with in a WASP transaction. For a detailed discussion on this issue, and for more on parties to a contract in WASP-type transactions see ch 7, s7.3.2.2.2 on WASP VAS.
} 
surreptitiously uses his parent's cell phone for WASP-type transactions and in circumstances where there is no need for a PIN to execute a VAS transaction. The minor then incurs charges on behalf of the parent.

AML and ostensible national security concerns are changing the ability to stay anonymous even in the prepaid environment. ${ }^{124}$ Many telecommunications regulators have issued directives mandating users of prepaid telecommunication services to register their SIM cards by providing the MNO with proof of identity and residential address before they can use the prepaid services. ${ }^{125}$ The above type of bolt-on identification provisions and 'work-arounds' are usually not sufficient in MFS transactions involving banks and MFS providers where Know Your Customer/ Customer Due Diligence (hereafter KYC/CDD) criteria are instantly available to discern capacity ${ }^{126}$ through age as these methods will determine the age of the proposed user. ${ }^{127}$ For the purposes of capacity though, it does not matter who the contract is with: the issue is whether the person is of an age to enter into an ongoing contract.

\subsubsection{Possibility of Performance}

\subsection{Overview}

A contract may be void if performance is objectively impossible (impossibilium nulla obligatio). ${ }^{128}$ If the impossibility relates to the circumstances of a particular party (that is relatively or subjectively), there is no objective impossibility, and the party not able to perform may be liable for breach of contract. ${ }^{129}$

\subsection{Application to MFS}

In a technical universe, there are a multitude of possible technical issues that could objectively prohibit performance.

This could include the inability to pay or receive, or generally perform because of external MNO coverage issues, the inability to communicate because of the lack of prepaid airtime, the illiquidity of a cash-in/cash out agent or correspondent to provide digital or cash liquidity to the user; the lack of a WASP product to provide to a subscriber, or the MFS instrument - the phone - being stolen or damaged.

\footnotetext{
${ }^{124}$ While RICA calls for the registration of SIM cards, this identification scheme it is submitted, will not necessarily be able to prevent the minor from using an (unlocked or unsecured) mobile phone with a SIM registered under RICA by the parent.

${ }^{125}$ In the case of existing users who acquired access SIMs before the regulations went into force, these users usually have to provide the proof before a cutoff date otherwise their service and prepaid balance will be cut and forfeited to the MNO. See ch 8, s8.5 on AML and CFT issues.

${ }^{126}$ Capacity insofar as mental capacity is clearly another issue of concern in MFS.

${ }^{127}$ See ch 8, s8.5 on AML and CFT issues.

${ }^{128}$ Van Rensburg, Lotz and Van Rijn (2004) op cit note 5 at 249-250.

${ }^{129}$ Van der Merwe, Van Huyssteen and Reinecke (1993) op cit note 5 at 135.
} 


\subsubsection{1}

\section{Overview}

Legality is a requirement for a contract to come into force. Agreements are illegal if they conflict with statutory law or common law. ${ }^{130}$ An illegal agreement will thus not create any obligations. ${ }^{131}$ In some circumstances though an illegal agreement will constitute a contract, but one which is not enforceable by law ${ }^{132}$ such that no obligations are created and any performance rendered may be reclaimed. ${ }^{133}$ An agreement is not illegal, however, simply because it does not comply with statutory formalities which may be prescribed for its conclusion. ${ }^{134}$ This proviso may also relate to unethical transactions, which although they may be prima facie legal, may yet not necessarily be honoured because of public policy insofar as they may be found to be contra bones mores, that is, against the public interest or public policy. ${ }^{135}$ However what may be unethical may not necessarily be illegal. Whether something is contra bones mores is usually determined by legal precedents where the court will look at 'the tendency of the proposed transaction, not the actual result. 136

\subsection{Application to MFS}

It is trite law that lawfulness is a criterion for any (MFS) transaction. In this regard the focus of a transaction may invalidate it. This is especially so where a service is offered that may be contra bones mores, or simply illegal. For example, in WASP transactions, the provision of adult services to users has been a controversial issue, primarily because sexually explicit material classified as ' $\mathrm{X} 18^{, 137}$ can only, according to the South African Film and Publications Act, ${ }^{138}$ be sold in a licensed adult store. ${ }^{139}$

However, the relatively effortless access to information afforded by the nature of the Internet and access via WAP and mobile phones generally allows these materials to be viewed from anywhere that has mobile network access. Owing to potential criminal sanctions, WASPs will presumably and generally not violate the 'X18' provisions of the Act intentionally, although some non-South African WASPs have allowed

\footnotetext{
${ }^{130}$ Examples of illegality are where the conclusion of an agreement or the performance agreed upon or the purpose for which the agreement is concluded is contrary to the law. Van der Merwe, Van Huyssteen and Reinecke (1993) op cit note 5 at 139.

${ }^{131}$ Van Rensburg, Lotz and Van Rijn (2004) op cit note 5 at 252; the term is ex turpicausa non oritur action.

${ }^{132}$ Van der Merwe, Van Huyssteen and Reinecke (1993) op cit note 5 at 139.

${ }^{133}$ Ibid at 147.

${ }^{134}$ Ibid at 141 .

${ }^{135}$ Public interest, public policy, and boni mores are only relevant insofar as they provide the basis upon which a decision of illegality is made in law. It has been noted that the distinction between them is not clear. Van der Merwe, Van Huyssteen and Reinecke (1993) op cit note 5 at 139-140. For circumstances and reasoning behind public policy, see Magna Alloys and Research SA (Pty) Ltd v Ellis 1984 (4) SA 874 (A) at 891G (hereafter Magna). Public policy is 'an expression of vague import', as per Innes CJ in Law Union and Rock Insurance Co Ltd v Carmichael's Executor 1917 AD 593 at 598.

${ }^{136}$ Van Rensburg, Lotz and van Rijn (2004) op cit note 5 at 252, citing the judgment in Mufamadi v Dorbyl Finance (Pty) Ltd 1996 (1) SA 799 (A) at 803-804.

${ }^{137}$ Schedule 7 of the Films and Publications Act classifies a film as 'X18' if it 'contains a scene or scenes, simulated or real, judged within context, of explicit sexual conduct which, in the case of sexual intercourse, includes an explicit visual presentation of genitals'. See Films and Publications Act 65 of 1996, available at http://goo.gl/ic1f1. See s1(j) of the Films and Publications Amendment Act 3 of 2009, available from http://goo.gl/x61Pw. Some MNOs have their own internal rules that prohibit the sale of items that are more explicit than images of topless women.

${ }^{138}$ Act 65 of 1996.

${ }^{139}$ Ibid s24.
} 
access to the material from servers usually located outside the borders of South Africa that may be viewed within South Africa on computing devices and mobile phones. Usually (full) access to these X18 visual materials may only be provided to the user once payment has been received. However, it is this act of using a South African-based payment method - either using a credit or debit card or a PRS billing mechanism that brings either the user or the provider within the purview of South African law and possible criminal sanction. Similarly, gambling and betting within South Africa is a controlled activity at both the national and provincial levels. Section 77(1) of the current National Gambling $\mathrm{Act}^{140}$ - as well as similar provincial laws on gambling - states that 'no person shall gamble at any place other than the licensed premises'.

Provision of online gambling aimed at South Africans but where the gambling servers and ownership lie outside South Africa is a fiercely contested issue and, likewise, the advertising of online gambling within South Africa has been the subject of court action and extensive regulation. ${ }^{141}$

While there have been proposals to develop regulations ${ }^{142}$ in terms of the National Gambling Amendment $\mathrm{Act}^{143}$ to allow online gambling - or 'Interactive Gambling Software' as it is defined ${ }^{144}$ - it remains illegal. ${ }^{145}$ There are similar rules in other jurisdictions where online gambling is not permitted. ${ }^{146}$

Use of a mobile phone to enter what may be called 'lotteries, ${ }^{147}$ under the Lotteries Act has also been a contentious issue, as the National Lotteries Board (NLB) has taken action against WASPs and other service providers using PSMS to pay for competitions in terms of the Lotteries Act. The Regulations issued in terms of the CPA have specified that a maximum of ZAR1.50 may be charged for entering competitions, although there are a number of possible loopholes. ${ }^{148}$

Further, airtime and fiat-based MFS-type remittances using mobile phones have the potential to violate

\footnotetext{
140 Act 7 of 2004.

141 CasinoScamReport.com (2010) 'South Africa's High Court Rules all Online Gambling Illegal', available at http://goo.gl/AEd.Y. See also Gamingzion (2010) 'South Africa ISPs Battle Online Gambling Board', available at http://goo.gl/WMovV.

${ }^{142}$ See Notice 211 of 2009 National Gambling Act 7 of 2004: Interactive Gambling Regulations: For Written Comments in Government Gazette, no 31956 (hereafter Notice 211 of 2009).

${ }_{143}$ National Gambling Amendment Act 1 of 2008, available from http://goo.g1/17sDf.

${ }^{144}$ Section $1(\mathrm{~h})$ of the Act 1 of 2008 op cit note 143 defines 'interactive gambling software' as 'computer software designed for use in connection with interactive games, but does not include software designed for use solely in connection with a gambling', available from http://goo.gl/I7sDf.

${ }_{145}$ The interactive games may only be accessed via the Internet through the interactive provider's website, by means of electronic communication devices, such as a computer and mobile phone or any other device that the Board may determine; see Notice 211 (2009) op cit note 142. However online sports betting is allowed for licensed bookmakers. Further, the Exchange Control Department of the South African Reserve Bank (hereafter SARB) issued a regulatory Circular which says that in terms of sB.16(F) of the Exchange Control Rulings, residents may not use their credit and/or debit cards in the Republic to facilitate payments for gambling and lottery purchases. South African Reserve Bank Exchange Control Circular No. 11/2010, available at http://goo.gl/4icso. Likewise, credit card companies may not accept debits in respect of these activities. See Exchange Control Regulations promulgated in 1961 in terms of the Currency and Exchanges Act 9 of 1933. The Exchange Control Rulings are issued by the Exchange Control Department of the SARB.

${ }^{146}$ See the US Department of the Treasury and the Federal Reserve Board joint final rule to implement the Unlawful Internet Gambling Enforcement Act of 2006, 31 U.S.C. 5361(b). The Act prohibits gambling businesses from knowingly accepting payments in connection with unlawful Internet gambling, including payments made through credit cards, EFTs and checks. 12 CFR Part 233 Federal Reserve System Regulation GG, and Department of the Treasury 31 CFR Part 132.

${ }^{147}$ Section 1(xi) of Act 57 of 1997 defines a lottery as one which 'includes any game, scheme, arrangement, system, plan, promotional competition or device for distributing prizes by lot or chance and any game, scheme, Arrangement, System, Plan, competition or device which the Minister may by notice in the Gazette declare to be a lottery'.

${ }^{148}$ For an introduction to the CPA, see ch 8, s8.7 titled E-Commerce Laws and Regulations; and further on the CPA, see ch 12, ss12.9 on E-Commerce Laws and 12.10 on Consumer Protection Laws.
} 
AML legislation because in many cases they are underreported or unreported. ${ }^{149}$ The mobile phone's facility as a conduit for unlawful conduct is thus manifest.

\subsection{3}

\section{Formalities in Contracts}

\subsubsection{1}

\section{Overview}

Generally, the validity of a contract is not dependent on compliance with any formalities ${ }^{150}$ and may even be achieved without any words having to be spoken, for example, a contemporaneous transaction like inserting coins in a vending machine or paying a transport fare to a driver. Contractants may however insist that terms be reduced to writing for the contract to be effective, or where the law requires it to be in writing. ${ }^{151}$ That the writing takes an electronic form - in a data message that is accessible for later reference ${ }^{152}$ - does not preclude its legality. ${ }^{153}$

\subsubsection{2}

\section{Application to MFS}

As noted above ${ }^{154}$ and discussed further below, ${ }^{155}$ information transmitted in MFS transactions could be classified as 'data messages' in terms of $\mathrm{s} 1$ of the ECTA ${ }^{156}$ since the ECTA provides legal recognition to contracts formed through data messages. Hence, generally, none of these transactions or services may be excluded when done via a MFS-based activity except where the ECTA or some other applicable Act like the CPA specifies certain formalities - such as Terms \& Conditions (hereafter T\&C) - unless a law specifically excludes them. ${ }^{157}$ Further effects of the application of the ECTA are detailed below. ${ }^{158}$

\subsection{4}

\section{Terms of the Contract}

\subsubsection{1}

\section{Overview}

The scope of any contract is set out in the 'terms' which specify the nature of the performance due. A term will thus usually impose one or more obligations to act in a specific manner, or may qualify the contractual obligations. ${ }^{159}$ The principle of pacta sunt servanda introduced earlier ${ }^{160}$ generally allows the parties to a contract to set out the terms of the contract as they wish, subject to public policy and general legality. ${ }^{161}$

\footnotetext{
${ }^{149}$ See ch 6, s6.5.4 titled Use of Airtime-Based Prepaid SVA in Transactions; and also ch 8, s8.5 on AML and CTF issues.

${ }^{150}$ Van Rensburg. Lotz and van Rijn (2004) op cit note 5 at 259.

${ }^{151}$ Ibid. For example, notarial execution and registration.

${ }^{152}$ Section 12 of the ECTA.

${ }^{153}$ See $\mathrm{s} 22$ of the ECTA.

${ }^{154}$ On formation of contracts in MFS, see ch 7, s7.2.2.4 titled Application to MFS.

${ }^{155}$ See the discussion in ch 12, s12.9 titled E-Commerce Laws on the ECTA.

156 Ibid.

${ }^{157}$ Section 4(4) read with Schedule 2 of the ECTA lists the items not capable of being reduced to electronic form for validity. See further ch 12, s12.9 titled E-Commerce Laws below on exclusions in the ECTA.

${ }^{158}$ On the ECTA, see ch 12, s12.9 titled E-Commerce Laws.

${ }^{159}$ Havenga, Havenga and Kelbrick (2007) op cit note 4 at101; Du Bois (2007) op cit note 7 at 795; Van der Merwe, Van Huyssteen and Reinecke (1993) op cit note 5 at 10.

${ }^{160}$ See ch 7, s7.2.1 titled Nature of a Contract.

${ }^{161}$ Wells $v$ South African Alumenite Company 1927 AD 69; Magna op cit note 135; K Hopkins (2003) 'The Influence of the Bill of Rights on the Enforcement of Contracts' 19(25) De Rebus at 22. See further the discussion in ch 7, s7.2.4.5 titled
} 
There are also express, tacit and implied terms in a contract. These may be material or non-material to the possibility of determining, in the absence of a specific cancellation clause, ${ }^{162}$ whether there has been a breach of contract such that the contract may be rescinded and damages sought. ${ }^{163}$ Express terms placed within the contract articulate the intent of the parties. ${ }^{164}$ Tacit terms are those which have not been expressed in words, but which may be based on the parties' true intention (ex consensus) or their intention as imputed by the law (ex lege). ${ }^{165}$

A tacit term might deal, for example, with the desired need and degree of care required of a party executing a financial transaction to safeguard an ATM PIN number. This term will also relate to the consequences of the parties not doing so in respect of risk and liability where this is not expressly stated in a contract. ${ }^{166}$ Although the courts are reluctant to import a tacit term into a contract, ${ }^{167}$ they will do so where there is a necessary implication and where the parties intended to contract on the basis of such a term. ${ }^{168}$

Implied terms are also terms that have not been expressed (nor excluded by the parties), but which can be incorporated into the contract by the operation of the law or via trade usage. ${ }^{169}$ The tacit term will however only be imported into the contract so as to give efficacy to the contract when viewed from a business perspective. ${ }^{170}$

Contractual terms may further be classed according to the essentialia, naturalia and incidentalia so as to provide guidelines from the common law for classifying various types of contracts.

\subsubsection{Essentialia}

The essentialia relate to identifying a contract as belonging to a particular type of contract such as a contract of sale, a contract of lease, or a contract for service. ${ }^{171}$ The parties through their words may expressly outline the parameters or the contract. ${ }^{172}$ Even if an agreement lacks the essentialia of one

Good Faith and Unfair Terms.

${ }_{162}$ Or lex commissoria. See Du Bois (2007) op cit note 7 at 797.

${ }^{163}$ Ibid at 797. See also ch 7, s7.2.5 titled Breach of Contract.

164 Articulation may be done either in written or oral format. Havenga, Havenga and Kelbrick (2007) op cit note 4 at 101.

${ }^{165}$ Havenga, Havenga and Kelbrick (2007) op cit note 4 at 102. A tacit term may be inferred by a court from the expressed terms and surrounding circumstances including custom.

${ }^{166}$ See C Visser (1985) 'Banking in the Computer Age: The Allocation of Some of the Risks Arising from the Introduction of Automated Teller Machines' 102 South African Law Journal 646 at 653. See also Banking Council policy on PINs, and ch 7, s7.3.6.5 titled Allocation of Risk, Loss and Liability, as well as ch 12, s12.11 titled Consumer Protection and Loss Allocation with respect to Payments, which compares risk and loss allocation for consumers in South Africa with that of the EU, Kenya and USA.

${ }^{167}$ Alfred McAlpine \& Son (Pty) Ltd v Transvaal Provincial Administration 1974 (3) SA 506 (A) (hereafter McAlpine).

${ }^{168}$ Ibid. Tacit terms are not the same as terms implied by law. See Van den Berg v Tenner 1975 (2) SA 268 (A) at 277E.

${ }^{169}$ Havenga, Havenga and Kelbrick (2007) op cit note 4 at 102. These are also deemed the naturalia of the contract.

${ }^{170}$ DP Visser (2008) Unjustified Enrichment at 653 and the authorities cited therein at fn 54. See also WG Schulze's belief in relation to a bank-client agreement which does not expressly provide for the bank's right to reverse an EFT transfer and therefore that the transfer is conditional, that this bank-client agreement contains a naturale to that effect (that the EFT is conditional), especially where the bank discovers fraud on the part of the originator after the latter had given the payment order to the bank. WG Schulze (2008) 'Electronic Fund Transfers and the Bank's Right to Reverse a Credit Transfer: One Big Step (Backwards) for Banking Law, One Huge Leap (Forward) for Potential Fraud: Pestana v Nedbank (Act One, Scene Two)' 20(2) SA Mercantile Law Journal 290 at 297.

${ }^{171}$ Van der Merwe, Van Huyssteen and Reinecke (1993) op cit note 5 at 200. Van Rensburg, Lotz and Van Rijn (2004) op cit note 5 at 273-274. Even if the parties call it by another name, it will still be a specific type of contract if those essentialia are present.

${ }_{172}$ Visser et al (2004) op cit note 5 at 10. 
contract type, it may still contain elements of another, or may even be a contract sui generis. ${ }^{173}$

\subsubsection{3}

\section{Naturalia}

While the parties may determine the terms amongst themselves there are terms - the naturalia - that are attached by the law (ex lege) to every contract of a particular class. They are thus terms implied into the contract that determine the rights and duties of contracting parties and the effects and consequences of their contracts. ${ }^{174}$ The implied terms may be implied ex lege or implied from the facts (via tacit terms). ${ }^{175}$ While express terms may be proven by direct evidence, implied terms may be proven by circumstantial evidence. ${ }^{176}$

A tacit term derives from the common intention of the parties as derived from the express terms, the circumstances surrounding the conclusion of the contract and the subsequent conduct of the parties. ${ }^{177}$ Naturalia may however be excluded by agreement between the parties as, ultimately, they depend on the will of the parties. ${ }^{178}$

\subsubsection{4}

\section{Incidentalia}

Once the parties have agreed on the essentialia of a contract, such contract may be said to have been concluded. However, there may be additional matters not necessarily catered for in the agreement, and the naturalia too may not necessarily fulfill this function. ${ }^{179}$ The incidentalia may fulfill this need to supplement the original agreement, for example, in stipulating the time, place and manner of performance; in imposing additional duties of performance such as warranties of quality, preparatory duties or a duty to care for or ensure the subject matter of the contract. ${ }^{180}$ These may also relate to the relative risks involved in any performance due by any of the parties.

\subsubsection{Good Faith and Unfair Terms}

As noted above, pacta sunt servanda has been regarded as the epitome of the common law position with regard to overseeing the enforcement of contracts. This is also supported by the Constitution. ${ }^{181}$ This principle is qualified by the concept of legality, of which public policy and good faith are the major arbiters. ${ }^{182}$ It has been a cornerstone of the common law that contracts which are contrary to public policy

\footnotetext{
${ }^{173}$ Van der Merwe, Van Huyssteen and Reinecke (1993) op cit note 5 at 200.

${ }^{174}$ Ibid.

175 Although parties entering into a contract may give expression to their common intention by some form of conduct such as expressing it in words in the essentialia, there may be other implied terms deduced from the express terms and from the surrounding circumstances. Tacit terms are not the same as terms implied by law. See McAlpine op cit note 167.

${ }^{176}$ Van der Merwe, Van Huyssteen and Reinecke (1993) op cit note 5 at 197.

${ }^{177}$ Van Rensburg, Lotz and Van Rijn (2004) op cit note 5 at 277.

178 Although many of these were determined in Roman law, existing naturalia or new naturalia may yet evolve. Van der Merwe, Van Huyssteen and Reinecke (1993) op cit note 5 at 201.

${ }^{179}$ Ibid.

${ }^{180}$ CG van der Merwe and JE du Plessis (2004) Introduction to the Law of South Africa at 256.

${ }^{181} \mathrm{Du}$ Bois (2007) op cit note 7 at 737. Barkhuizen v Napier 2007 (5) SA 323 (CC) (hereafter Barkhuizen); Brisley v Drotsky (432/2000) [2002] ZASCA 35 (28 March 2002) at pars 90 and 94.

182 Good faith is an ethical component of contractual negotiations and is contextualised by aspects of fairness and decency.
} 
will not be enforced by the courts. ${ }^{183}$

The Bill of Rights in the Constitution of the Republic of South Africa, $1996^{184}$ has set the parameters against which this public policy is measured. In Barkhuizen $v$ Napier, ${ }^{185}$ the Constitutional Court (hereafter $\mathrm{CC}$ ) in dealing with a potentially unfair term in an insurance contract, outlined the principles of contract that would be against public policy. ${ }^{186}$ The $\mathrm{CC}$ held that despite the principle of pacta sunt servanda, public policy required that a party to a contract cannot impose a term on another party if its application would operate unfairly, and subsequently could not enforce a term in a manner that is unfair. ${ }^{187}$ The CC also relied $^{188}$ on the reasoning in Afrox Healthcare Ltd $v$ Strydom ${ }^{189}$ - which related to a clause in a hospital admissions form that excluded hospital employees from liability - that sketched the unequal nature of South African society and emphasised that the relative situation of contracting parties was a relevant consideration in determining whether a contractual term was contrary to public policy. ${ }^{190}$ That is, in addition to objectively determining the reasonableness of a particular contractual provision, there should be a further enquiry that involves investigating the circumstances of the case. This investigation may include consideration of the relative situation of the contracting parties and an acknowledgment that the unequal bargaining power of parties to a contract is an applicable factor in the consideration of public policy. ${ }^{191}$ This, said the $\mathrm{CC}$, is recognition of the potential injustice that may be caused by inequality of bargaining power. This modus, said the Court:

'... leaves space for the doctrine of pacta sunt servanda to operate, but at the same time allows courts to decline to enforce contractual terms that are in conflict with the constitutional values even though the parties may have consented to them. ${ }^{192}$

Hence, in terms of Barkhuizen, any disputed contractual clauses will be tested against public policy. ${ }^{193}$

In relation to banking, specifically, in a case where a bank acts as an agent, the court in SDR Investment Holdings CO (Pty) Ltd and Others v Nedcor Bank Ltd and Another ${ }^{194}$ indicated that banks owed their principal a fiduciary duty to act, inter alia, in good faith and in the principal's best interests.

Du Bois (2007) op cit note 7 at 737; as Lotz points out, consumer protection provisions in statutes have been introduced in respect of contracts of sale to place retractions on a seller's power to impose unreasonable incidentalia on buyers, but have left the essentialia and naturalia of the contract largely unchanged, eg, the Alienation of Land Act 69 of 1981; J Lotz (1997) 'Purchase and Sale' in R Zimmermann and D Visser (eds) Southern Cross: Civil Law and Common Law in South Africa at 361.

${ }^{183}$ Basson v Chilwan 1993 (3) SA 742 (A); Ex Parte: Minister of Justice In Re: Nedbank Ltd v Abstein Distributors (Pty) Ltd and Others (240/93) [1995] ZASCA 40; [1995] 2 All SA 420 (A) (30 March 1995); Du Bois (2007) op cit note 7 at 737.

${ }^{184}$ Section 34.

${ }^{185}$ Barkhuizen op cit note 181.

${ }^{186} \mathrm{Ibid}$ at 333CD, the court indicated that public policy was now deeply rooted in the Constitution, and represented the legal convictions of the community and embodied those values held closely by society.

${ }^{187}$ The court noted that if it is found that the objective terms of a contract are not inconsistent with public policy on their face, the further question will then arise as to whether the terms are contrary to public policy in the light of the relative situation of the contracting parties. See Barkhuizen op cit note 181

${ }^{188}$ Barkhuizen op cit note 181 at par 59.

${ }^{189}$ Afrox Healthcare Ltd v Strydom (172/2001) [2002] ZASCA 73 (hereafter Afrox).

190 The CC at 59 referred with approval to the Supreme Court of Appeal (hereafter SCA) reasoning in Afrox that unequal bargaining power is a factor which, together with other factors, plays a role in the consideration of public policy.

${ }^{191}$ Barkhuizen op cit note 181 at par 59.

${ }^{192}$ Ibid at par 30

${ }^{193}$ Ibid at 186 .

${ }^{194}$ SDR Investment Holdings CO (Pty) Ltd and Others v Nedcor Bank Ltd and Another 2007 (4) SA 190 (C). 
While untested, it is submitted that the somewhat new and relatively untested CPA may alter the landscape insofar as interpretation of good faith and unfair contract terms by codifying this principle in part, and introducing statutory rules of what is termed in Part G of the CPA as the 'Right to fair, just and reasonable terms and conditions'. The CPA in essence limits the incidentalia of any contract. Examples of these terms are outlined in a list of specific terms included in the 'Grey List' of the CPA Regulations, ${ }^{195}$ such that their use in a contract would give rise to a presumption, unless the supplier can show otherwise, of being unfair, unjust and unreasonable. A court may decide which terms are invalid beyond the Grey List in the Regulations. ${ }^{196}$ There is also a so-called 'Black List' of prohibited contractual terms specified in $\mathrm{s} 51$ of the CPA, whereby use of any of these prohibited terms in a contract will automatically be considered unlawful and invalid. ${ }^{197}$ It is worth noting here for the purposes of MFS that the supplier of goods or services cannot exempt himself from liability for any loss directly or indirectly attributable to the gross negligence of the supplier or any person acting for or controlled by the supplier. ${ }^{198}$ However while this indicates what a supplier cannot do, it does not provide any distinct direction as to what the supplier must do.

Similar considerations must be taken into account when dealing with Exemption Clauses, discussed below.

\subsubsection{Exemption Clauses}

Contracts may contain exemption clauses that limit a party's ability to obtain redress where that exemption is allowed by law. Usually the limited party is the user, not the provider. The general rule regarding the validity of exemption clauses is that the onus to establish the validity of an exemption clause is on the party wishing to rely on it. ${ }^{199}$ While it may proffer wide scope, an exemption clause will be enforceable if it is clear, unambiguous and not against public policy. ${ }^{200}$

In Sasfin (Pty) Ltd v Beukes, Smalberger AJ cautioned that:

'The power to declare contracts contrary to public policy should, however, be exercised sparingly and
only in the clearest of cases, lest uncertainty as to the validity of contracts result from an arbitrary and
indiscriminate use of the power. One must be careful not to conclude that a contract is contrary to
public policy merely because its terms (or some of them) offend one's individual sense of propriety and

\footnotetext{
${ }^{195}$ See s44 of the CPA Regulations, Government Gazette, No. 34180, 1 April 2011.

${ }^{196}$ A court will consider terms that are unfair, unreasonable or unjust which inter alia require a consumer to waive any rights, assume any obligation, or waive any liability of the supplier, on terms that are unfair, unreasonable or unjust, or impose any such terms as a condition of entering into a transaction. See s48 of the CPA on 'Unfair, unreasonable or unjust contract terms'.

${ }^{197}$ See 551 of the CPA outlines these 'Prohibited transactions, agreements, terms or conditions'. They are discussed below in ch 12, s12.10 titled Consumer Protection Laws in South Africa.

${ }^{198}$ Section $51(1)(\mathrm{c})$ of the CPA.

199 F Marx and A Govindjee (2007) 'Revisiting the Interpretation of Exemption Clauses: Drifters Adventure Tours CC v Hircock 2007 (2) SA 83 (SCA)' Obiter at 624; and Drifters Adventure Tours CC v Hircock 2007 (2) SA 83 (SCA) at 339F (hereafter Drifters). See also Hayne \& Co v Kaffrarian Steam Mill Co Ltd (1914) AD 363 371; Minister of Education v Stuttaford \& Co (Rhodesia) (Pty) Ltd 1980 (4) SA 517 (Z); First National Bank of SA Ltd v Rosenblum 2001 (4) SA 189 (SCA); Chubb Fire Security (Pty) Ltd v Greaves 1993 (4) SA 358 (W); Johannesburg Country Club v Stott 2004 (5) SA 511 (SCA). Many of these cases assess the proper meaning of words and phrases such as 'any', 'any damage', 'any loss', 'however caused', 'from whatever cause arising' and 'for whatever reason'. It is true that such words and phrases cannot be read in isolation and must be interpreted specifically within the context in which they operate.

${ }^{200}$ Afrox op cit note 189.
} 
fairness. ${ }^{201}$

Further, as expressed by Scott JA in Durban's Water Wonderland (Pty) Ltd v Botha: ${ }^{202}$

'If the language of the disclaimer or exemption clause is clear such that it exempts the proferens ${ }^{203}$ from liability in express and unambiguous terms, effect must be given to that meaning. If there is ambiguity the language must be construed against the proferens. [See Government of the Republic of South Africa v Fibre Spinners \& Weavers (Pty) Ltd 19782 SA 794 (A) 804C]. But the alternative meaning on which reliance is placed to demonstrate the ambiguity must be one to which the language is fairly susceptible; it must not be "fanciful" or "remote".

Further, in Drifter ${ }^{204}$ where the issue was whether a clause in a contract excluded a contractant's adequate and fair opportunity to seek judicial redress, the court held that the measures employed in a contract must be consistent with the notions of fairness and justice which inform public policy. Exemption clauses in contracts, the court said, ${ }^{205}$ may amount to a limitation of the constitutional right of persons as contained in Section 34 of the South African Constitution. ${ }^{206}$

The effect of the statutory changes as a result of the CPA (described above) may thus be seen in the same light as exemption clauses.

\subsubsection{Application to MFS}

Despite the principle of pacta sunt servanda or contractual supremacy that permeates our common law, the uneven bargaining and contractual power between users of MFS and the Mobile Financial Services Providers (hereafter MFSPs) and WASPs may, in the absence of any specific law governing payments and the modalities around payment, skew the ability of users to enforce any rights that may accrue to them, or to present unfair contractual terms being imposed on them. Hence an analogy between MFS activities and those of other industries, and especially banking and how the courts approach any inequality is appropriate here. Contracts, like many others, may contain exemption clauses that limit a party's ability to obtain redress where that exemption is allowed by law. Usually that party is the user, not the provider. The harm to the consumer is manifest and immediate in many cases.

While untested, it is submitted that the CPA may alter the landscape insofar as interpretation of good faith and unfair contract terms is concerned by codifying this principle in part, by introducing statutory 'Grey List' rules of the 'Right to fair, just and reasonable terms and conditions' as well as the 'Black List' of prohibited terms. ${ }^{207}$ It is worth noting here for the purposes of MFS that the supplier of goods or services

\footnotetext{
${ }^{201}$ Sasfin (Pty) Ltd v Beukes 1989 (1) SA 1 (A) at 9B (hereafter Sasfin).

${ }^{202}$ Durban's Water Wonderland (Pty) Ltd v Botha 1999 (1) SA 982 (SCA) at 989G-J.

203 'A party which proposes or adduces a contract or a condition in a contract'. See 'Proferens' (2012) Oxford Dictionaries, available at http://goo.gl/UHPTl.

${ }^{204}$ Drifters op cit note $199339 \mathrm{~F}$.

${ }^{205}$ Ibid at 339F.

${ }^{206}$ Again, the Grey List in the CPA Regulations op cit note 195 may alter the common law view.

${ }^{207}$ See ch 12, s12.10 titled Consumer Protection Laws, for more on the CPA.
} 
cannot exempt himself from liability for any loss directly or indirectly attributable to the gross negligence of the supplier or any person acting for or controlled by the supplier. ${ }^{208}$ However, as noted above, while this section indicates what a supplier cannot do, it does not provide any distinct direction as to what the supplier must do, and in the context of MFS and payments generally, does not give the user any distinct rights in solving issues of misdirected or fraudulent payment. This is still left to an Ombuds-scheme - such as the one recognised in terms of the CPA, or an ADR agent not so recognised or needed to be recognised in terms of the CPA by the National Consumer Commission (hereafter NCC) to be effective $e^{209}$ - or the courts if necessary to decide on the parameters of these rights.

\subsubsection{Breach Of Contract}

\subsubsection{Overview}

Breach of contract may be classed as malperformance of the contractual obligation. ${ }^{210}$ Breach is seen as wrongful in that the contractant has not complied with his contractual duties, be it in the form of a specific duty to perform, or in the form of a more general duty. ${ }^{211}$ The breach may be positive $\mathrm{e}^{212}$ or negative ${ }^{213}$ and may be of five other forms: mora debitoris (delay by the debtor); mora creditoris (delay by the creditor); repudiation; prevention of performance; and positive malperformance. ${ }^{214}$

Remedies for breach of contract become available to the contractant by operation of the law (ex lege). These remedies are a claim for specific performance of the contract, cancellation of the contract, and a claim for damages.

Breach then is a primary reason for rescission of a (voidable) contract. Rescission then is a unilateral act of the aggrieved contractant based on the breach of a material term of the contract, the effect of which extinguishes the obligation or obligations concerned. ${ }^{215}$ The presence of a ground for rescission does not necessarily lead to the invalidity of the contract. As long as the agreement satisfies the requirement set out by law, the contract is not void. ${ }^{216}$

An act which constitutes a ground for rescission renders a contract voidable at the behest of the aggrieved contractant. ${ }^{217}$ This may result in restitution and damages. The restitution should restore the aggrieved party

\footnotetext{
${ }^{208}$ Section 51(1)(c) of the CPA.

${ }^{209}$ See ch 12, s12.10 titled Consumer Protection Laws, and in particular s82 of the CPA on Industry Codes.

${ }^{210}$ See Visser (2008) op cit note 170 at 108 and the case law discussion therein, and 106-113 generally on treatment of Rescission of Contract under English and South African Law. English law recognises mistake, misrepresentation, duress or undue influence as grounds for rescission of a contract. South African law similarly recognises these English principles, but is mostly based on Roman-Dutch law, although the latter leans towards perfect restitution. The courts have however indicated that this restitution must be based on pragmatism.

${ }^{211}$ Van der Merwe, Van Huyssteen and Reinecke (1993) op cit note 5 at 237.

212 This may be where there is performance, but it is the wrong type of performance.

${ }^{213}$ This may be where there is no performance.

${ }^{214}$ Van der Merwe, Van Huyssteen and Reinecke (1993) op cit note 5 at 240. However, these do not represent a numerus clauses, and other breaches may develop.

${ }^{215}$ Ibid.

${ }^{216}$ Van der Merwe, Van Huyssteen and Reinecke (1993) op cit note 5 at 99; Trollip op cit note 43; Broodryk v Smuts 1942 TPD 47.

${ }^{217}$ Van der Merwe, Van Huyssteen and Reinecke (1993) op cit note 5 at 100.
} 
to his full financial position, also known as restitutio in integrum. ${ }^{218}$ The right to rescind exists irrespective of the presence or absence of fault, especially where there has been misrepresentation. ${ }^{219}$ The fact that a sum of money forms part of the restitution does not render it an award of damages. ${ }^{220}$ Rescission puts an end to the obligations and justifies restitution. ${ }^{221}$

\subsubsection{Breach of Contract Versus Delict}

The same set of facts can conceivably give rise simultaneously to a claim for damages in delict and in contract, ${ }^{222}$ but while breach of contract may be malperformance of a contractual obligation to exercise care or act without negligence, the breach of such obligation does not per se constitute a delict. ${ }^{223}$ It would only amount to a delict where the conduct independently constitutes a delict irrespective of the contractual obligation. ${ }^{224}$ Liability for breach of contract then is distinct from liability in delict with different types of proof and remedies. ${ }^{225}$

One of the remedies available to someone claiming patrimonial loss as a result of a delict is the Actio Legis Aquilla or Aquilian action. ${ }^{226}$ While fault is generally not a requirement for the recovery of damages for breach of contract, ${ }^{227}$ in delict it is a plaintiff who must prove fault. In the case of a breach of contract, the onus would fall on the defendant to show that he was not negligent. ${ }^{228}$ The distinction becomes relevant also in allocation of fault in respect of any damages. ${ }^{229}$

In terms of section 1 of the Apportionment of Damages Act $^{230}$, a plaintiff's claim in delict must be reduced in accordance with his own degree of fault. In Thoroughbred Breeders' Association v Price Waterhouse, ${ }^{231}$ it was held that the Act only applies to delictual claims. ${ }^{232}$ In terms of section 2 of the Act, persons who are delictually liable to the plaintiff for the same damage, are considered to be joint wrongdoers, and may be

\footnotetext{
${ }^{218}$ This remedy may also apply to a minor who has been disadvantaged whilst contracting without his guardian's consent; see ch 7, s7.2.2.5 titled Legal Capacity.

${ }^{219}$ Viljoen v Hillier 1904 TS 312. Van der Merwe, Van Huyssteen and Reinecke (1993) op cit note 5 at 103.

${ }^{220}$ Davidson v Bonafede 1981 (2) SA 501 (C) 511. Van der Merwe, Van Huyssteen and Reinecke (1993) op cit note 5 at 101.

${ }^{221}$ Van der Merwe, Van Huyssteen and Reinecke (1993) op cit note 5 at 102.

${ }^{222}$ J Neethling, JM Potgieter, and PJ Visser (1989) Law of Delict at 6.

${ }^{223} \mathrm{Du}$ Bois (2007) op cit note 7 at 859 . Negligent conduct giving rise to damages is, however, not actionable per se: it is only actionable if the law recognises it as wrongful. Wrongfulness depends on the existence of a legal duty not to act negligently and the imposition of such a legal duty is a matter for judicial determination involving criteria of public or legal policy consistent with constitutional norms. Trustees, Two Oceans Aquarium Trust v Kantey and Templer (Pty) Ltd 2006 (3) SA 138 (SCA) at par 10

${ }^{224}$ Lillicrap, Wassenaar and Partners v Pilkington Brothers (SA) (Pty) Ltd 1985 (1) SA 475 (A), (hereafter, 'Lillicrap); Holtzhausen v ABSA Bank 2005 (2) All SA 560 (SCA) (hereafter Holzthausen); Nashua op cit note 2; Lillicrap decided that a claim in delict is not competent where the negligence relied upon arises from a breach of a contractual term, while in Holtzhausen, the plaintiff's case was that the defendant had infringed a right which the plaintiff had independently of the contract. See further ch 7, s7.3.6.5.6.2 titled Agents on the distinction between a claim in delict or contract.

${ }^{225}$ Neethling, Potgieter, and Visser (1989) op cit note 222 at 6.

${ }^{226}$ The Aquilian action, along with the actio injuriarum are the cornerstones of delictual liability. The Aquilian action is a general remedy for wrongs to interests of substance, and requires that the defendant was at fault, and had intention (dolus) or negligence (culpa). There must be patrimonial - pecuniary or financial - loss that must be compensated. PQR Boberg (1984) The Law of Delict: Volume One: Aquilian Liability at 18.

${ }^{227}$ Administrator of Natal $v$ Edouard 1990 (3) SA 581 (AD) at 597.

${ }^{228}$ Van der Merwe, Van Huyssteen and Reinecke (1993) op cit note 5 at 237-238

${ }^{229}$ See ch 7, s7.3.6.5 on Allocation of Risk, Loss and Liability; and for a comparison of risk and loss allocation for consumers in South Africa with that in the EU and USA, see ch 12, s12.11 titled Consumer Protection and Loss Allocation with Respect to Payments.

${ }^{230}$ Act 34 of 1956.

${ }^{231}$ Thoroughbred Breeders' Association v Price Waterhouse 2001 (4) SA 551 (SCA).

232 Ibid.
} 
sued in the same action by the plaintiff. ${ }^{233}$

\subsubsection{3}

\section{Application to MFS}

The issue of rescission of a contract, if there was indeed ever a valid contract through consensus, often arises in WASP-type MFS services where users frequently complain of 'switch 'n bait' tactics whereby the initial content offering is somehow superseded after a short period by something else unrelated to their initial interest. In the WASP environment, this often occurs when the WASP or Information Provider (hereafter IP) runs out of appropriate content and then provides - often without notification to the subscriber of the switch - a full suite of non-desired content. In many cases the subscriber will seek to halt further billing if it is an Online Billing System-type (hereafter OBS-type) transaction, and will claim a refund for amounts debited during the period of non-delivery of the advertised and desired content. PSP PayPal's mobile incarnation, PayPal Mobile, has like its Web-based version, a 'Buyer Protection Policy'234 whereby a buyer who feels that certain goods and services paid for on PayPal's subsidiary, eBay, ${ }^{235}$ using PayPal as a payment 'intermediary,' do not match the original offer, can lodge a dispute with PayPal and request a refund of the full amount paid through PayPal.

\subsubsection{Parties to a Contract}

\subsubsection{Overview}

A contract may simply be bilateral in that two persons contract to one another and impose obligations on one another; or it may be multilateral such that there are other participants in the contract, and where possibly the proper execution of the contract is dependent on the actions of others, or where third parties act on behalf of others, say as mandatories or agents. Although mandate and agency are clearly not the same thing, these terms are often used interchangeably. ${ }^{236}$ These are all explored below.

\subsubsection{2}

\section{Mandatories}

Mandate (or mandatum) is a Roman-Dutch contract in which one person, the mandatory, undertakes to perform some lawful tasks for another, the mandator. ${ }^{237}$ Where the mandate involves or is linked with a power or authority to represent ${ }^{238}$ the mandatory, the mandatory is classed as an agent. ${ }^{239}$ The mandate

\footnotetext{
${ }^{233}$ See also in relation to a collecting bank, M Kelly (2001) 'Apportionment of Damages between a Negligent Collecting Bank and a Thief of Cheques: Does the Apportionment of Damages Act Apply?' 13(3) SA Mercantile Law Journal 509-530. ${ }^{234}$ See Paypal Purchase Protection from PayPal, available from http://goo.gl/Hktp4.

${ }^{235}$ See eBay at www.ebay.com.

${ }^{236}$ See, for example, E Ellinger, E Lomnicka and A Hooley (2009) Ellinger's Modern Banking Law $4^{\text {th }}$ ed at 180 who say: 'In the various types of money transfer operations ... the guiding legal principles are derived from the law of agency. The payor gives a mandate to the transferring bank.' The latter issues a specified order to the recipient bank. See Schulze (2008) op cit note 170 on agency and mandate referring to Wadsley and Penn (2000) op cit note 4.

${ }^{237}$ Du Bois (2007) op cit note 7 at 985 . As Kerr notes at 17, there may be multilateral and composite contracts where some contracts combine within their ambit characteristics of more than one class of contracts; A Kerr (2006) The Law of Agency $4^{\text {th }}$ ed. See also, for example, The Firs Investment Ltd v Levy Bros Estates (Pty) Ltd 1984 (2) SA 881 (A) (hereafter The Firs) where a contract of employment also contained a contract of agency.

238 'Representation' is termed the phenomenon whereby one person concludes a juristic act on behalf of another with the intention to create, alter or extinguish legal relationships for another and not for himself. Whether he intends to conclude a
} 
given by the mandator to the mandatory must be legal. This includes a mandate which is in principle legal but which has an illegal aim, for example, to defraud any other party. ${ }^{240}$

\subsubsection{3}

\section{Agents}

\subsubsection{1}

\section{Overview}

The law of agency is one of a combination of the Roman-Dutch law of contract of mandate and the modern English principles of commercial agency. ${ }^{241}$

Agency is used in a wide variety of contexts, but generally refers to the performance of a juristic act on behalf of or in the name of one person (the principal) by another (the agent) who is authorised by the principal to act, in a manner that creates, alters or discharges legal relations between the principal and the third party. ${ }^{242}$ The essence of the modern view of agency is that there must be a third party in existence or contemplation and that the agent is simply and solely the representative of his principal to make transactions for him and with the third party. ${ }^{243}$ The contract where the principal and the agent create rights and obligations inter se has been classed as a part of the contract of mandatum. ${ }^{244}$ As such, agency is sometimes an omnibus term for defining an agent as a person performing for and on behalf of another person such that he places the latter in a legal relationship with third persons, ${ }^{245}$ and then also as a relationship of mandate in which the agent is bound as a mandatory to carry out some task for the principal. ${ }^{246}$ The agent may act in a representative capacity ${ }^{247}$ to affect the principal's legal relationships as a result of the authority of the agent to do so. ${ }^{248}$ This authorisation to act is a distinct unilateral juristic

juristic act for himself or for another is a question of fact. BP Wanda (2003) 'Agency and Representation' in WA Joubert (ed) The Law of South Africa $2^{\text {nd }}$ ed 1 at pars 176 and 183.

${ }^{239}$ Totalisator Agency Board, OFS v Livanos 1987 (3) SA 283 (W) at 290J-292E (hereafter Totalisator); The Firs op cit note 237.

${ }^{240}$ See Schulze (2008) op cit note 170 at 294 in relation to Pestana $v$ Nedbank Ltd 2008 (3) SA 466 (W) (hereafter Pestanal) which dealt with an EFT by a bank under mandate from an account holder in relation to a s99 notice sent by the South African Revenue Service (hereafter SARS) to the Head Office of the accountholder's bank (in terms of s170 of the Companies Act 61 of 1973) regarding the confiscation of funds in that account for a tax lien. See also Standard Bank of South Africa v Oneanate Investments (In Liquidation) 1998 (1) SA 811 (SCA) at 823B for the position of a bank in relation to the discovery of the deposit of a fraudulent cheque into an account insofar as its ability to 'look behind the true state of affairs'.

${ }^{241}$ Faure v Louw (1880) (1) SC 17 (hereafter Faure) as cited in Visser et al (2004) op cit note 5 at 455. 'Mandate' was defined by Roman-Dutch jurists as a contract whereby one person gives a mandate for some lawful act, transaction or affairs to another to accomplish for him and accepts the commission gratuitously. If any remuneration was agreed to be given for services to be rendered, the contract became one of location conduction operaru (a letting and hiring of services).

${ }_{242} \mathrm{Du}$ Bois (2007) op cit note 7 at 984; Kerr (2006) op cit note 237 at 3; Totalisator op cit note 239 at 290J-292E.

${ }^{243}$ The transactions that are made as ipso jure the transactions of the principal insofar as they inure to his benefit or render him liable without any benefit of liability attaching to the agent.

${ }^{244}$ Wanda (2003) op cit note 238 at 167.

${ }^{245}$ See a brief discussion on the Roman-Dutch sources of law in relation to agency by scholars Voet and Grotius in Visser $e t$ al (2004) op cit note 5 at 455 .

${ }^{246}$ Wanda (2003) op cit note 238 at 175.

${ }^{247}$ See Kerr (2006) op cit note 237 at 48 who indicates that if a contract is entered into gratuitously, it is probably more one of mandate than employment. This may have a bearing on how the action of agents engaged in MFS may be considered insofar as vicarious liability for their principals is concerned.

${ }^{248}$ See Kerr (2006) op cit note 237 at 4, who introduces the concept of the 'empowered agent' or 'un-empowered agent' to distinguish between the former as being an agent who can enter into or terminate contracts on behalf of a principal, and the latter whose service contributes to bringing about an opportunity for the principal to enter into, vary, or terminate a contract or contractual obligation, but who does not himself do so on the principal's behalf, being rather a 'broker' (makelaars in Roman-Dutch times) on behalf of the principal. 
act. $^{249}$

The current tendency is to reserve the terms 'agent' to denote a representative who is bound by contract with the principal to carry out a mandate and who is also authorised to create, alter or discharge legal relations for the principal. ${ }^{250}$ This agent can acquire, enforce or extinguish rights via contract against third persons, or incur, perform or discharge obligations in favour of third persons. ${ }^{251}$ Agents may also appoint agents, or 'sub-agents' or 'substitutes' as they have been variously termed. ${ }^{252}$ The sub-agent acts for and on behalf of the principal but may do so in terms of a contractual obligation which binds him to the agent, not the principal. Alternatively, the sub-agent may exercise power on behalf of the principal, but not on behalf the agent and must accept instructions from the principal in regard to the exercise of power. ${ }^{253}$ The (empowered) sub-agent may be a fiduciary of the principal. ${ }^{254}$

An agent may also be a special or general agent. ${ }^{255}$ A special agent may be one employed by his principle to do a single specified transaction, while a general agent is employed to perform a number or acts or transactions, to wit, to act generally for his principal. He may be employed to act for his principal either in all transactions of a particular nature or in all matters concerning a particular business, ${ }^{256}$ or in all transactions or acts which the principal himself could perform. ${ }^{257}$ An agent may also be appointed expressly via contract or implicitly via the operation of law, or via the conduct of the parties, or by ratification. $^{258}$

\subsubsection{2}

Automated Agents

In matters of modern commerce - including, and notably, MFS - there are effectively two types of agents: human and electronic. Agents exist in a number of 'information' forms. ${ }^{259}$ Information models dictate what is known to each agent such that there may be complete information in which each agent has complete knowledge of both the state of the world and the preference of the other agents; or it may be a model of incomplete information, in which agents have only a partial knowledge of either the states of the world or the preferences of other agents (for example, bargaining games with asymmetric information), or they may

\footnotetext{
${ }^{249} \mathrm{Du}$ Bois (2007) op cit note 7 at 984. See also JM Silke (1981) The Law of Agency in South Africa $3^{\text {rd }}$ ed at 2, who categorises representation as being either conventional representatives or juristic representatives. The former may be part of an agreement (conventus) such as with an agent, servant or messenger whereas the juristic representative is one whose role comes about as a result of contract or legal necessity such as natural guardians representing minors.

${ }^{250}$ Whittal v Alexandria Municipality 1966 (4) SA 297 (E) cited in Du Bois (2007) op cit note 7 at 984

${ }^{251}$ Visser et al (2004) op cit note 5 at 455 . See also Silke (1981) op cit note 249 at 1.

${ }^{252}$ Kerr (2006) op cit note 237 at 185 . Kerr says that the appointment of another by an agent where the agent empowers another to do what he is himself empowered to do, or where the agent requires another to do what he himself is obliged to do is 'delegation'. He says that the word 'substitute' is appropriate when the other to whom a power or duty is delegated is brought into a contractual relationship with the principle. In one case, this can be deduced, he says, by asking to whom is the person appointed responsible in the performance of his duties. See the distinction between substitutes and agents in The South African Encyclopedia of Forms and Precedents vol 1 at 396, 440 and 494 as cited in Kerr (2006) op cit note 237 at 186.

${ }^{253}$ Kerr (2006) op cit note 237 at 188.

${ }^{254}$ Ibid at 189. Kerr refers to English law to support this contention.

${ }^{255} \mathrm{Du}$ Bois (2007) op cit note 7 at 987; Faure op cit note 241.

${ }^{256}$ Ibid; and Visser et al (2004) op cit note 5 at 244-245.

${ }^{257}$ Ibid. This latter agent is an agent cum libera, or with a full mandate or universal agent.

${ }^{258}$ Visser et al (2004) op cit note 5 at 244-245.

${ }^{259} \mathrm{R}$ Lin and S Kraus (2010) 'Can automated agents proficiently negotiate with humans?' 53(1) Communications of the ACM January 2010 at 80-81. In essence then, an Automated Agent could act as an agent in the legal sense, as well as being a technical 'intermediary'. See ch 6, s6.4.4.3 titled Use of Agents, and any necessary distinctions between them.
} 
be ignorant of the preferences of the opponents and the states of the world. ${ }^{260}$ Invariably though, in an automated agent environment the parameters are set such that there are only a limited number of 'options' available to the automated agent with which to interact with the human. These may be a set of transaction types and levels available according to the profile of the human. Correspondingly, the human may only have a number of choices available at any one time, but must use cognitive reasoning to determine which option is appropriate for him. This is a limited bilateral set of interactions that do not however rise to the level of a negotiation in which a form of cognitive understanding of the options is available to the automated agent. Lin and Kraus however sketch environments where there is the real possibility of bilateral bargaining in an automated agent model in which that agent is matched against people. ${ }^{261}$

While there is a large body of law and precedent relating to human agents, there is yet to be any significant testing of the variations that may arise in the treatment of agents insofar as they may be automated.

\subsubsection{Application to MFS}

\subsection{Overview}

In the case of the airtime purse usage for WASP-type services, there may be multiple relationships or single relationships at play. In the fiat-based MFS, there may be these same types of transactional relationships which may be augmented by the introduction of agents who handle cash-in/cash out arrangements. Contractual relationships always exist throughout a MFS transaction value chain. A key to understanding the nature of the transaction in a typical MFS transaction are the legal relationships that are formed and the contractual obligations that ipso facto are created. Each of these models will be investigated below.

\subsection{MFS-based Agents}

As described above, ${ }^{262}$ both MNOs and banks use agents, 'cash merchants, ${ }^{263}$ or 'correspondents' to extend their reach via the 'branchless banking' paradigm. ${ }^{264}$ In effect, they act as the face of the MNO and banks, and incur rights and responsibilities to the public on behalf of these entities. Specifically, the (cashin/cash out) agent when taking cash from the public for conversion into a putative electronic money (hereafter e-money) may be considered to be undertaking deposit-taking if he does not immediately convert the cash taken into e-money. ${ }^{265}$ Usually, the consequence of using a human agent is that a number of rights and corresponding obligations arise between the principal and the agent and also between the principal and

\footnotetext{
${ }^{260}$ Ibid.

${ }^{261}$ Ibid.

${ }^{262}$ See ch 6 passim on the use of agents in MFS models.

${ }^{263}$ Ibid; and specifically ch 2, s2.5.2 titled Use of Agents, on cash merchants.

${ }^{264}$ For an introduction to MFS, see ch 2, s2.1; and also ch 2, s2.3 titled The Scope of MFS. The agent may take cash funds from the public, ultimately converting that cash into e-money. As noted before, these agents may undertake other activities beyond MFS services, but in the MFS context they may be able to offer services such as disbursements of loans or microloans, effect bill payments and transfers, take deposits and loan payments, allow inquiries on account balances or recent movements of funds and open savings.

${ }^{265}$ In that respect, time is an arbiter of whether deposit-taking is at work. See the discussion in ch 4, s4.4 on deposits; ch 12 , ss12.3.7 titled Payment Systems and Governing Frameworks, and 12.12 titled South Africa: General Summary and Conclusions
} 
the third person. If however the agent discharges his duties properly, no rights or obligations arise between him and the third person beyond what is contemplated in the ephemeral cash-in transaction, but they do arise if he acts improperly. However, the public's recourse to hold the agent liable for any improper deeds or actions or where loss is contemplated may be excluded by contract between the principal and the customer. In a legal sense, the agents are retail agents, rather than pure agents as they may not necessarily be allowed to take cash deposits (or even pay out cash) for their own account. They are effectively then 'human ATMs' or as they have also been described, 'borrowed tellers ${ }^{266}$ or 'cash merchants'.

\subsubsection{3}

WASP-type Transactions

The airtime-based SOV available the airtime SVA, and the novel shortcode payment mechanism for PRS VAS through PSMS, ${ }^{267}$ was created to enable seamless flow of transactions between the parties to a transaction. ${ }^{268}$ The relationships embedded in the transaction are not clear however. As noted earlier, on one hand, the issuer of the electronic airtime value - the MNO - may be seen simply to act agnostically ${ }^{269}$ as a pure bearer or mere conduit when transferring value from the purchaser's account to that of the WASP merchant. ${ }^{270}$ The subscriber is the debtor, the WASP or IP the creditor, with the MNO sealing a trilateral relationship ${ }^{271}$ as a payment intermediary between the subscriber and the WASP merchant. ${ }^{272}$ At the other end, there could be a debtor-creditor relationship between the subscriber and the MNO and then another between the MNO and the merchant. The pivotal metric in this determination then is whether there is a direct legal/contractual relationship between the consumer and the merchant.

What is germane is to determine whether there is a causal relationship between debiting the subscriber's account of the mobile-value (hereafter m-value), and the subsequent methodology that ultimately transfers some or all of the m-value to the third party WASP merchant. The causal relationship may be one where the purchase by a subscriber of a WASP's content/service and the subsequent value transfer from the consumer to the merchant is effectively linear. Here the MNO is placed in the middle of the transaction as the mere payment conduit, such that it is clear that any debtor-creditor relationship created by the transaction is merely between the subscriber and the WASP in this situation. ${ }^{273}$ In the alternative, there may be a situation where it is deduced that there is no such direct relationship between the consumer and the WASP, as the purchase and m-value transfer from the consumer to the merchant is non-linear, which could be characterised instead as a two-step process whereby the subscriber first effectively 'buys' the content/service from the MNO, with the MNO at some later time paying the merchant some or all of the

\footnotetext{
${ }^{266}$ G Ivatury, TR Lyman and S Staschen (2006) 'Use of Agents in Branchless Banking for the Poor: Rewards, Risks, and Regulation' 38 CGAP Focus Note at 1, available at http://goo.gl/sXHMU.

${ }^{267}$ See ch 5, s 5.3.4 on Short Message Service (SMS) and Shortcodes.

${ }^{268}$ See ch 6, s6.5.4.2 passim on WASP VAS.

${ }^{269}$ In the sense that it does not mediate in any sense, shape or form the type of content/service offered. An e-money issuer that for example refuses, for moral reasons only, to complete a transaction that involves say adult services may be said to have descended into the commercial arena, militating against its role as a pure payment provider.

${ }^{270}$ See ch 5, s5.2 passim on Mobile Network Technologies. On the issue of whether a debtor-creditor relationship between the MNO and the consumer is in existence in respect of VAS, see ch 4, s4.9; ch 6, s6.5.4.1; and ch 9, s 9.6.3.1.

${ }^{271}$ European Commission (EC) (2006a) 'Application of the E-money Directive to Mobile Operators: Summary of Replies to the Consultation Paper of DG Internal Market' at 6, available from http://goo.gl/q0Hcz.

${ }^{272}$ Correspondingly, there may not be a 'mere conduit' relationship and hence no trilateral relationship because the 'intermediary' may be shown to have acted in excess of its deigned, benign role as an e-value payment conduit.

${ }^{273}$ For the business models employed in WASP-type transactions and the relationships therein, see ch 6, s6.5.4.2 titled WASP Value Added Services, on the WASP industry.
} 
retail purchase price as an 'out-payment' ${ }^{274}$ In this scenario, there is no trilateral relationship as the MNO is acting as a reseller of WASP goods and services on behalf of that WASP. Put another way, the argument pivots around who has the obligation to pay the WASP. The obligation may rest with the subscriber where there is a direct debtor-creditor relationship between the subscriber and the WASP, or the obligation to pay the WASP may rest with the MNO because of an effective putative reseller agreement between the MNO and the WASP.

Both arguments have merit, and so require separate analysis and testing. Germane to this analysis are the intertwined contractual and legal points of attachment between MNO, merchant and subscriber in both post-paid and prepaid markets. There is, firstly, a contractual relationship between the Subscriber and the Prepaid Airtime Seller; secondly, a contractual relationship exists between the subscriber and the postpaid service provider; thirdly, a contractual relationship exists between the subscriber and the MNO for either prepaid or post-paid billing; fourthly, a contractual relationship exists between the MNO and the merchant $^{275}$ and, lastly, a contractual relationship exists between the subscriber and the WASP or IP content merchant.

One view is that a direct debtor-creditor relationship is present. This is a relationship where there is an obligation on the part of the purchaser towards the WASP, who, it is argued, enters into a valid agreement to pay the merchant when the purchaser initiates or participates in an m-commerce transaction. The merchant accepts the purchaser's payment via the MNO as the means of payment in fulfillment of the obligation created by the transaction. If so, then it is assumed that there is a direct debtor-creditor relationship between the purchaser and the merchant. An opposing school of thought is that the causal relationships between the MNO and the merchant, who has accepted the prepaid balance as a means of payment, is more of an analogue for a pure reseller relationship. Here, the subscriber purchases the content/service through their contractual relationship with the MNO, which acts less as an issuer of a type of e-money than as a reseller of this content/service. In this view, the subscriber does not have a direct debtor-creditor relationship (with the WASP). Instead, the direct debtor-creditor relationship the consumer has with respect to the payment due for purchase of content/service is only with the MNO, while the MNO in turn has a simultaneous direct debtor-creditor relationship with the merchant. The WASP accepts as a means of payment, payments directly from the MNO and not from the subscriber such that when the consumer purchases a service, the MNO acquires ownership of the content service for what has been euphemistically called a 'legal moment ${ }^{276}$ and then sells the content to the subscriber. ${ }^{277}$ Adoption of this view as being the de facto description of the payment relationships in a number of scenarios can be

\footnotetext{
${ }^{274}$ A putative redemption of the e-value due to the merchant on settlement. On payment and settlement, see ch 6, s6.5.4.2.3 titled Interoperability: Clearing, Payment and Settlement.

${ }^{275}$ In a content purchase domain, the MNO will usually pay the merchant 45-60 days after the content purchase by the subscriber, assuming the merchant has correctly invoiced on time and the reconciliations between the merchant's Content Management System (hereafter CMS) and between the billing system of the MNO do not have any major variance in allowing for settlement of due amounts. What is key here is that the payment default risk falls entirely on the MNO in the post-paid environment as the subscriber may still default on the due payment date. The merchant will still get paid even if the MNO does not receive the due amount from the subscriber (via the Service Provider, if present).

${ }^{276}$ See European Commission (EC) (2004) 'Application of the E-Money Directive to Mobile Operators: Consultation Paper of DG Internal Market', 1-18, available at http://goo.gl/U9rcD.

${ }^{277}$ Complaints of poor service/non-performance are usually addressed to the MNO or its designated agent in this regard, for example, a self-regulatory body like Wireless Application Service Provider's Association (hereafter WASPA); see ch 6, s6.5.4.2.4 titled Dispute Resolution.
} 
employed to test this 'reseller' supposition.

When the subscriber purchases the content/service, the purchase action is (usually) irrevocable, and as such the debiting of the subscriber's account by the MNO with the airtime value is simultaneous upon the request to purchase the content/service. This is especially so with regard to PSMS, where the MNO first checks for sufficient credit and then debits the SVA before sending through the service request to the merchant. What is important to note in this scenario, however, is that unlike an e-money transaction where there must first be a valid claim by the merchant and a subsequent request for redemption of value, the subscriber's account is first and irrevocably debited with the SOV by the MNO without even a later request for e-value redemption by the WASP. ${ }^{278}$ The merchant of course can obtain some or all of this retail purchase value via a settlement transfer at some future date. ${ }^{279}$ Thus, the debit of the subscriber's purse persists whether or not the merchant ever presents an invoice for payment/settlement redemption to the MNO. ${ }^{280}$

This, it can be argued, is the signal indication that the purchase relationship is not trilateral as such, but is instead a reseller-type of arrangement characterised by a primary contractual relationship between the subscriber and the MNO, and then between the MNO and the merchant. The MNO, it can again be argued, is the supplier to the subscriber at the retail level, while the business (of supply and subsequent settlement) with the merchant WASP is subject to wholesale agreements that - in the payment sense only - relate to revenue sharing agreements.

\subsection{7 \\ Conclusion}

At the core of an MFS transaction are incidents relating to contractual formation, consensus among the parties, legal capacity, possibility of performance, formalities if there are any to be followed, the terms of the contract, grounds for rescission of a contract, and the parties to a contract. The common law may govern these incidents, although many of these contractual rules are slowly being augmented or even replaced by relevant or general statute.

MFS provides a number of general concerns, since much of the contracting is done at a distance, and the nature of the medium makes verification of intent in contract making dependent on terms decided on, usually by the stronger party, although in South Africa, the CPA may alter this paradigm. It is also not certain who the parties are to the contract, or who may be in breach, as many of these systems are anonymous and may not necessarily have any ability to uniquely identify the actual user of the system rather than the contracting party. They may be the same person, but not always. Since many phones and MFS systems do not have age verification or other persistent identification mechanisms in place, minors too may be involved in a contract or performance by simply using the phone as a payment and transaction

\footnotetext{
${ }^{278}$ This irrevocable debiting by the MNO takes place before and irrespective of the merchant's subsequent attempt, at a much later date, to invoice the MNO for the due amount, or at redemption.

${ }^{279}$ Usually, however, the MNO takes a substantial percentage of the retail value as well as a bearer/service charge for the transaction.

${ }^{280}$ This is analogous to the situation in the post-paid world where the MNO pays the merchant even if there is no subsequent payment (at a future date) to it by the subscriber.
} 
instrument without the actual owner's consent and knowledge, although an emancipated minor may complicate the issue. Does the use of that instrument by an unauthorised person, who does not have consent, vitiate any transaction done, or is the contractant still held liable? In the case of WASP-based services, there is no distinction though as to the type of user: if the instrument is used, the owner is liable for that transaction, and it is up to that owner to provide proof of unauthorised use. That the user may be a close relative - and even a minor - usually counts against the transaction being voided.

Similarly, in a fiat-based MFS transaction where banking rules may be prevalent, Banking Codes of Conduct may also vitiate the excuse that a minor or similar unauthorised person - again, especially if the person concerned is a close relative of the phone's owner - used the instrument if the instrument was not kept secure and the PIN or other secure access mechanism somehow became known to that close, but unauthorised, person. Allocation of risk principles would also apply. ${ }^{281}$

Fraud or violence would similarly vitiate a transaction, but in the absence of any specific legislation, this could only be decided by contract and then by courts - or an ombuds-scheme or arbitration if available - if a dispute arose. In most cases though, and especially where micro-amounts are involved, the de minimus philosophy alongside the legal and time costs involved in pursuing any matter would lead to the stronger party - usually the service provider or MNO - maintaining the status quo.

There is more reason to vitiate a contract if, in any of these circumstances, the contract - or transaction performed according to that contract - was contra bones mores or plainly illegal. In a WASP environment, lotteries, betting, gambling and adult content are some aspects that could cause this. Similarly, in a fiatbased environment, AML and CTF considerations would come to the fore if a MFS transaction was done to circumvent AML or CTF restrictions, or for some other restriction on the cross-border movement of funds. $^{282}$

The parties to a MFS-type contract and subsequent transaction may also vary according to the business model employed. For example, whether a WASP-type transaction involves a direct relationship between the merchant and the subscriber or not has been a matter of much controversy, especially in the European Union (hereafter EU). In essence, the determination revolves around who has an obligation to pay the merchant when the subscriber purchases the goods and services of the merchant, and in relation to this, who has the obligation to remedy defective service pertaining to the VAS purchase.

On the one hand, the use of the MNO's airtime SOV may be an indication that the MNO is simply an agnostic financial conduit between the merchant and the subscriber, which would indicate that the relationship between the subscriber and the merchant is one where the subscriber is the debtor to the creditor merchant and that there is an obligation placed on the subscriber debtor to pay the merchant directly. On the other hand, the MNO may interrupt this ostensible direct debtor-creditor relationship by

\footnotetext{
${ }^{281}$ See ch 7, s7.3.6.5 titled Allocation of Risk, Loss and Liability; and also ch 12, s12.10 titled Consumer Protection Laws, which compares risk and loss allocation for consumers in South Africa with that of the EU, Kenya and USA.

${ }^{282}$ AML/CTF considerations could also apply to airtime value transfers if the airtime was seen as 'money'. See ch 8 , s8.5 for a comprehensive discussion thereof, and in relation to South Africa, see ch 12, s12.7.
} 
acting not merely as a conduit, but as a purported 'reseller' of the merchant's services to the subscriber. The MNO is thus the 'new' creditor to the subscriber debtor. In this latter model, the MNO acts like a typical 'bricks ' $\mathrm{n}$ mortar' store, where it 'purchases' the goods from the merchant for 'resale' to the subscriber. After purchase, though, the subscriber is directed by the MNO to the merchant for any issues around defective services. Refunds though may still be provided for by the store owner (the MNO).

Similarly, when applied to fiat-based MFS Stored Value Products (hereafter SVPs), the MNO or MFSP may employ an agent - or correspondent, as the case may be - to act in a cash-in/cash out capacity on behalf of his principal. In that case, contract will determine the nexus between the parties, taking into account domestic law on the abilities and role of agents in this value chain.

Insofar as the MNO-customer relationship in an MFS setting where fiat money or airtime-based SVA may be utilised, may be analogous to traditional banking relationships. Consequently, similar sets of relationship criteria may fasten on the MNO that provides services analogous to those of a bank even if what the MNO provides does not necessarily amount to the 'business of banking' in accordance with domestic law, but using common law precepts when domestic law does not provide an unequivocal determination. ${ }^{283}$

As such, and similarly, the relationships therein may be multifaceted, ${ }^{284}$ reflecting the varying types of services that MNOs as telecommunications providers and MFSPs may offer their clients within the sphere of private law. Ultimately though, banking law mostly depends on the application of general legal principles - both English and Roman-Dutch - to domestic law when adjudicating a particular set of facts. ${ }^{285}$

Even so, the role of the agent or correspondent - automated or human - will still be decided in terms of common law agency precepts. ${ }^{286}$

\footnotetext{
${ }^{283}$ As Wadsley and Penn (2000) op cit note 4 point out at 103, banking law is not an integral and distinctive body of law in and of itself, but applies to a range of branches of law, such as delict (tort), contract, trusts, and a technical manifestation in laws relating to negotiable instruments and cheques.

${ }^{284}$ For a further exposition on banking law, see also J de Jager (2010) 'Much Ado about Nothing? Legal Principles on Money, Banks and Their Clients after Joint Stock Company Varvarinskoye v ABSA Bank Ltd' (22) SA Mercantile Law Journal 127-140 at 127; and Joint Stock Co Varvarinskoye v ABSA Bank Ltd and Others 2008 (4) SA 287 (SCA) (hereafter ('Varvarinskoye).

${ }^{285}$ See discussion in ch 4, s4.3 titled The Common Law and Banking below and generally De Jager (2010) op cit note 284 at 127.

${ }^{286}$ See further, WG Schulze (2002) 'The Sources of South African Banking Law: A Twenty-first Century Perspective (Part I)' (14) SA Mercantile Law Journal 438; CAE Goodhart (1989) Money, Information And Uncertainty (2 ${ }^{\text {nd }}$ ed) at 40; SA Heffernan (2005) Modern Banking at 1 and 41-45.
} 
In general, in South African law, a payment is seen as a performance whereby obligations formed under a valid contract are extinguished. ${ }^{287}$ In Harrismith Board of Executors v Odendaal, Innes CJ opined that:

'Payment is the delivery of what is owed by a person competent to deliver to a person competent to receive. And when made it operates to discharge the obligation of the debtor. ${ }^{288}$

The term 'payment' however is used inconsistently in South African law insofar as it is used as a synonym for 'performance' in the law of obligations, and as such these two terms are often used interchangeably. ${ }^{289}$ The payment too may involve a transfer that may involve money. ${ }^{290}$

It has been held numerous times in South African law that payment is a 'bilateral act' that requires, in the absence of contrary agreement, the cooperation of debtor and creditor, and payment must be performed in fulfillment of a valid contract. ${ }^{291}$ Similarly, it has also been held that payment is a bilateral juristic act ${ }^{292}$ requiring the meeting of two minds such that it can be said to be a real agreement ${ }^{293}$ by these minds as to the manner in which payment is to be effected. ${ }^{294}$ Where the parties are not ad idem or where there is no debt-extinguishing agreement, it is said that no payment has been made. ${ }^{295}$

\footnotetext{
${ }^{287}$ The basis of a contract is either consensus that is an actual meeting of the minds of the contracting parties or the reasonable belief by one the contractants that there is consensus. Van der Merwe, van Huyssteen and Reinecke op cit note 5 at 14-19. See also V Lawack-Davids (2000) ‘Aspects of Internet Payment Instruments', Unpublished LLD Thesis, University of South Africa, at 10.

${ }^{288}$ Harrismith Board of Executors v Odendaal 1923 AD 530 at 539.

289 Vereins-Und Westbank AG v Veren Investments and Others (433/2000) [2002] ZASCA 36 (hereafter Vereins). Visser (2008) op cit note 170 at 223 defines transfer as 'a deliberate transfer of money, property, or services from one person or entity to another'. This is not the same as the transfer in an EFT which is not a transfer of physical property, but rather a series of assignments of value that have the effect of a transfer of value from one to another.

${ }^{290}$ In regard to function, Visser describes performance as a 'deliberate transfer of money, property or service which discharges a duty or fulfills an obligation' but distinguishes a transfer as not necessarily being one where it is done in fulfillment of a debt. Visser (2008) op cit note 170 at 223.

${ }^{291}$ Volkskas Bank Bpk v Bankorp Bpk (h/a Trust Bank en 'n Ander) 1991 (3) SA 605 (A) (hereafter Volkskas); Nissan South Africa (Pty) Ltd v Marnitz NO And Others (Stand 186 Aeroport (Pty) Ltd Intervening) 2005 (1) SA 441 (SCA) (hereafter Nissan) at par 24; Burg Trailers SA (Pty) Ltd and Another v ABSA Bank Ltd and Others 2004 (1) SA 284 (SCA) at 289B (hereafter Burg Trailers). Vereins op cit note 289 at par 38. JC De Wet and AH van Wyk (1992) Kontraktereg en Handelsreg $5^{\text {th }}$ ed at 263 .

${ }^{292}$ From the German word 'Rechtsgeschäft' where 'juristic act' means an action intended and capable of having a legal effect. See TE Holland (1896) The Elements of Jurisprudence repr 2006 at 96. See Rand Townships Registrar 1945 AD 277 at 287, where 'juristic act' was used to denote an 'act giving rise to jural relations'. Wanda (2003) op cit note 238 at 176 points out that the expression 'juristic act' is not in common use in SA legal literature written in English, nor does it appear to be a term of art in English law. It is, however, used in civilian legal traditions.

${ }^{293}$ Volkskas op cit note 291; Vereins op cit note 289; see also Van der Merwe, Van Huyssteen and Reinecke (1993) op cit note 5 at 252 .

294 As noted by Christie, the Romans used the word solutio to cover not only the payment of money, but the delivery of a thing. RH Christie (2001) The law of contract in South Africa $4^{\text {th }}$ ed at 467.

${ }^{295}$ Visser (2008) op cit note 170 at 225 . In Vereins op cit note 289, the court at 12, indicated that for effective payment to occur the payee must in the absence of contrary agreement acquire 'the unfettered or unrestricted right to the immediate use of the funds in question'; otherwise the payment is inchoate. The court noted that there is no authority in this respect, but cited therein A/S Awilco v Fulvia Spa Di Navigazione (The Chikuma) [1981] 1 All ER 652 (HL) 656d-657g, [1981] 1 WLR
} 
The discharge of monetary obligations can be effected by means of payment which in a legal sense means a gift or loan of money or other act offered and accepted in performance of a money or other value obligation. ${ }^{296}$ While the general rule is that the means of payment must be determined by agreement between the payer and payee, unilateral conduct on the part of the debtor in purporting to effect payment, if subsequently accepted by the creditor or his agent, is effective to discharge the debt. ${ }^{297}$ Payment (or performance) must be made in its entirety. ${ }^{298}$

\section{Participants in a Payment}

\subsubsection{Overview}

The requirement that payment must be a bilateral juristic act involving two parties acting in consensus is set against the broad canvas of obligations, where a debtor-creditor relationship is usually at play. While in the abstract this may be the case, there are a number of practical situations where this is not necessarily so. For example, there may be specific instances where a unilateral act by one party, who may not even be a debtor in the obligation sense, but who may be a benevolent donor to a putative 'creditor,' in causa the beneficial recipient of value. Thus, there could be a transfer of value that is unilateral insofar as the transfer benefits another. There may even be classes of unilateral acts of payment, such as placing funds in an account that is in the name of another, or placing funds in an account for another without any debt obligation being present or being the cause for the payment. ${ }^{299}$

The issue of unilateral payment also arises in connection with the opening of bank accounts: it has been said that it is well established in our law that, apart from statute, a solitary act by someone in opening a separate bank account in the name of another and depositing money in it does not confer any special title on the person named. ${ }^{300}$

\footnotetext{
314 at 320, per Lord Bridge (hereafter Awilco).

${ }^{296}$ Vereins op cit note 289 at par 38; Saambou-Nasionale Bouvereniging v Friedman 1979 (3) SA 978 (A) at 993A-C; Volkskas op cit note 291 at 612C-E; Pfeiffer v First National Bank of SA Ltd 1998 (3) SA 1018 (A) at 1025I-J.

${ }^{297}$ Thus should the debtor unilaterally pay a stranger to a contract, and the creditor later ratifies and approves the action, this constitutes a valid payment. It is considered valid from the moment of payment and not from the moment of ratification and approval, said Cameron JA in Vereins op cit note 289 at 12. Further, even if the creditor does not have unfettered access to the funds, the payment is still made once the creditor is made aware of the disposition of the funds to him by the debtor. Vereins at par 13. See the dissenting view by Nienaber in Vereins at par 38 where he states that it requires an animus solvendi of the debtor corresponding to that of the creditor as to a manner, recognised by law, whereby the debtor relinquishes and the creditor acquires access to and control over the funds to be transferred. Hence, even if the creditor has access to the funds deposited by the debtor, without that intention by the creditor for that money to act as payment, no payment has been made.

${ }^{298}$ Kei Brick \& Tile Co (Pty) Ltd v AM Construction 1996 (1) SA 150 (E). Paterson Exhibitions CC v Knights Advertising and Marketing CC 1991 (3) SA 523 (A) at 529C-D; see further ch 7, s7.3.4 titled Nature of Payment.

${ }^{299}$ For example, a donation, or a gift. See ch 6, s6.5.4.3 titled Mobile Airtime Transfers.

${ }^{300}$ Ex parte Kelly 1942 OPD 265 (hereafter Kelly), per Van den Heever J, and applied in Dantex Investment Holdings (Pty) Ltd v National Explosives (Pty) Ltd (in liquidation) 1990 (1) SA 736 (A) (hereafter Dantex) and De Freitas v Society of Advocates of Natal and another 2001 (3) SA 750 (SCA) (hereafter De Freitas). Dantex related to the collection of cheques on behalf of another in a named account, while De Freitas related to the deposit of trust funds into an account. See similarly also Vereins op cit note 289 where the court indicated that this principle would obtain because the person opening the account cannot by a unilateral act deprive him- or herself of title to the money and would be more evident when a bank opens a separate account in another's name, not with another bank, but with itself. The mere fact that a bank earmarks funds in an account specially designated for another does not constitute an effective payment to it. Similar principles were applied in
} 
This suggests that if no debt forms the basis of the action of provision of funds for another, then the classification of this action in our law has too broad an application. As Du Plessis points out, there is a resultant inconsistency of the 'bilateral' requirement whereby for every act of performance, there must be some definite acknowledgment of this act by the person at whom the act or performance is ostensibly aimed. ${ }^{301}$ In a commercial context, the two distinct 'acts' of the real agreement and the actual value transfer are usually conflated into one seamless 'act' of payment where there is creditor-relationship at play. However, it may not properly explain situations where there no debtor-creditor relationship, which may then be described rather as a unilateral act of payment. ${ }^{302}$

In regard to form and having regard to the interchangeability of performance and payment, Du Plessis believes that the courts and authors, by basing the requirement for a payment to be a bilateral juristic act, have mistakenly interpreted the Roman-Dutch sources. ${ }^{303}$ The finer detail though of what this 'act' is in regard to a general legal principle or requirement is not entirely clear. It may refer to the act of transferring value to the recipient, such that the recipient is aware, bilaterally so to speak of the value transfer and is able or willing to accept it. Alternatively, it may also refer to a separate underlying real agreement that is designed to extinguish a debt under specific conditions. ${ }^{304}$ Insofar as payment can be said to have only taken place when it is a 'bilateral act', but without a context to show why the payment actually occurred, it appears that the bilateral act requirement may then be too generic a construct of law that, insofar as a modern payment context, it is not sufficiently able to be contextualised to explain all manner of modern

Varvarinskoye op cit note 284 in which the named account holder warehousing monies in an ABSA bank account was held not to have rights to the monies therein; and see also the case commentary in De Jager (2010) op cit note 285.

${ }^{301}$ Translation by Visser (2008) op cit note 170 at 227 of JE du Plessis (2002) 'Die Regsaard van Prestasie' 65(1) Tydskrif vir die Hedendaagse Romeins-Hollandse Reg 61. Cf D Fox (2009) 'Defective Payments of Incorporeal Money in South African and English Law' (4) Tydskrif vir die Suid-Afrikaanse Reg 638 at 645-647, who notes that English law recognises two different aspects involved in a payer's act of passing money to a recipient in discharge of a money obligation. The first involves the effectiveness of the transaction as a payment discharging the payer's debt obligation. The second he says is the effectiveness of the transactions to pass the payer's property in money by a valid derivative transfer. Each corresponds to the different legal functions performed by the money in the transaction. In essence then, while English law recognises payment as a bilateral act, it differentiates the transfer of property in the money as abstract from the underlying obligatory agreement to which the money is paid. In that respect - and similar to the argument advanced by Du Plessis - English law looks at whether the payer has formed an effective intention to transfer ownership in the money to the recipient, it does not generally enquire into the recipient's state of mind because English law, he says, does not depend on the existence of a bilateral real agreement between the payer and the recipient, and the transfer of value is treated as unilateral. This is especially so where there is a transfer to a bank account of incorporeal money since the beneficiary does not have to know of the transfer to his account, and as such does not need to have animus possidendi.

${ }^{302} \mathrm{Du}$ Plessis, as cited in translation by Visser (2008) op cit note 170 at 226-228, thus argues for a less restrictive approach to the nature of performance (as payment) insofar as the real agreement required for the meeting of the minds should instead be based on the German theory 'Theorie der realen Leistungsbewirkung' ('Theory of actually bringing about a performance'). This would not require any bilateral agreement and instead would analyse the debtor's behaviour insofar as determining whether the performance in a real or actual sense with respect to any specific obligation. Visser concurs, saying that the intention of the transferor must be considered in devising whether the performance was actually achieved, although he disagrees with Du Plessis who, Visser says, does not believe that there need be a necessary intention by the debtor to make the transfer. See Du Plessis (2002) op cit note 301 at 70. Indeed, it may or may not be required to give notice of the acceptance of an offer to conclude a debt-extinguishing agreement. RH Christie and GB Bradfield (2011) Christie's The Law of Contract in South Africa $\left(6^{\text {th }}\right.$ ed) at 71-2.

${ }^{303}$ De Wet and van Wyk (1992) op cit note 291 at 263, as cited and analysed by Du Plessis (2002) op cit note 301 passim and whose analysis shows that incorporation of the 'bilateral' requirement in our law may have arisen as a result of a misinterpretation of De Groot by JC de Wet with respect to de Groot's statement that ' $[\mathrm{O}] \mathrm{m}$ betalling behoorlik te laat geskied word die wil van beide vereis'. [For payment to be done properly, the will of both is required - my translation]. Du Plessis (2002) op cit note 301 believes that this interpretation is wrongly premised on the belief that De Groot refers to a debt. Rather, says Du Plessis, the statement refers to the capacity of persons to perform.

${ }^{304}$ See also Goode (1995) op cit note 13 at 500 who says that it may be necessary to distinguish payment in its strict legal sense from some intermediate step which the parties may label 'payment'. This would indicate that anything where there was this intervening step would not amount to a means of payment, and, in the eyes of the Claim School view of money, would not amount to money. See ch 3, s13.10 on the Claim School view of money. 
commercial payment operations. $^{305}$

Du Plessis sensibly calls for a less restricted approach to performance, proposing that South African law adopt in some measure the German legal approach whereby the analysis of whether someone has performed is based not on the objective pronouncement by the intended recipient (which may be a debtor) and, correspondingly, based also on the purpose for which the payor performed, but rather on whether the debtor (or payor) has performed (something) in a real or actual sense. Du Plessis' overarching perspective then, which focuses on the contextual reasons for the payment rather than the steps involved in the act itself, would thus explain situations where there are unilateral payments of say a benevolent donation to a recipient, or in a modern context, the unilateral payment by EFT or e-money where the recipient may not necessarily be aware of or able to have sight of the payment but is nonetheless the actual and beneficial recipient of the value sent. In Du Plessis' view, then, the recipient would play no real part in determining whether there was a payment (performance) made. ${ }^{306}$ That the payor executed the act of the EFT that benefitted the ultimate recipient would be sufficient indication of performance, ${ }^{307}$ while as Visser suggests, ${ }^{308}$ his intent would assume the purpose for the payment. ${ }^{309}$

\section{Application to MFS}

\subsection{General Overview}

The need in South African law for a payment to be a 'bilateral juristic act' buttresses against evolving commercial realities for which the current conception of payment does not appear to be adequately equipped.

For example, the issue of MFS airtime and fiat-based remittances where there is a unilateral payment where no debt-relationship - as is implicitly implied by the common law view of payment - per se between the sender (payor) and the recipient (payee). The recipient would not necessarily expect or know about the value transfer to his 'account'; it would (commercially at least) amount to a payment for which value can be given, but because of theoretical legal dogma, it would not amount to a payment. Any rights and obligations then obtaining to the uninformed but intended recipient could thus conceivably be lost, clearly an unintended consequence of the dogma. Further, the WASP environment produces some interesting

\footnotetext{
${ }^{305}$ See the example given in Du Plessis (2002) op cit note 301 that the payment as performance will not necessarily explain EFTs in which the recipient of a benefit (of the EFT) may not necessarily be aware at the time of transfer that this beneficial transfer has taken place.

${ }^{306}$ This would go some way to explaining how a payment can be said to have been made when a third independent party that for example is not a bank or a financial intermediary that is mandated to transfer value on behalf of the debtor to a creditor - decides to pay to the creditor the full debt of the debtor without the debtor's knowledge, the so-called three-way payment. Payment in this instance can indeed be said to have been made, despite the need for the legal requirement for it to be a bilateral act.

${ }^{307}$ See also Visser (2008) op cit note 170 at 226.

${ }^{308}$ Ibid.

${ }^{309}$ Visser sees the payor's intent as being an exposition of what he terms a 'deliberate transfer' as opposed to say a transfer where the actual recipient may, by way of mistake or some other reason, not be the intended recipient. The intent may also show how much the payor wanted to pay, if somehow the actual value transferred fell short of what was required to extinguish a debt. See Visser (2008) op cit note 170 at 228, and also B Geva (2008a) 'Payment Finality and Discharge in Funds Transfers' at 634, available at http://goo.gl/jruIS. Geva makes a distinction between the relationship of what is termed the final payment in relation to the mechanics of the payment and the discharge of an obligation made by, for example, an EFT as the mechanism of a payment.
} 
permutations of payment where the ultimate recipient of the value paid may be split amongst parties, that is, payment can also be multilateral.

\subsection{WASP VAS}

A further example of how the bilateral dogma affects the commercial reality is that of the WASP transaction, where the nexus in the payment chain is largely a matter of confusion, and which may vary according to contract and commercial circumstances. In a nutshell, the payment (ultimate settlement) nexus may be characterised as being between the user and the IP only, between the user and the WASP only, between the user and the MNO only, or at the extreme, the user and the WASP and the IP. In a world shaped by the bilateral legal dogma, there is no bilateral relationship at work here. ${ }^{310}$ It is, in this case, possibly even multilateral. Further, noting the settlement criteria at work in the WASP commercial world, ${ }^{311}$ what is paid to the WASP or IP is not what the user pays: what the WASP or IP usually pays back to the user is the full value sent by the user. This is different to the 'three-party' credit card payment process $^{312}$ in that, unlike the credit card company or bank involved in mediating the payment, the MNO and the WASP descend into the arena of the payment by providing a suite of billing, technical and other facilities to facilitate the transaction and the payment.

Another way of evolving the debate around the relationships in the MFS WASP transaction is to dissect the payment flows in these transactions. It is trite that in the WASP payments world, especially as it relates to billing and getting payment from prepaid customers who are notorious for 'churning', there are largely ephemeral legal attachments at play. As indicated above, ${ }^{313}$ there is usually no direct link between customers and merchants since the legal or contractual relationships of WASP merchants are exclusively with MNOs. In other words, users of a WASP service are not usually contractually bound per se to pay the WASP beyond the period in which they have agreed to utilise their services in, for example, a periodicbilling content subscription service. If the subscriber runs out of funds, the WASP has the right to terminate their content subscription but has no real legal basis for claiming future revenues that would have accrued to the merchant had the 'contract' between the merchant WASP and the subscriber continued. ${ }^{314}$ Further, and this is a crucial indication, the subscriber's relationship with the merchant is usually instantly terminated once the subscriber 'ports' or moves its services or subscription from its existing MNO acting as 'donor' and the one executing on the billing with the merchant to another competing 'recipient' MNO who may also have a billing relationship with the same merchant, but under its own particular contract with that merchant. The fact that the (telecommunications) relationship is terminated when a number is ported is probably a warning that indicates there is no enduring payment relationship between the subscriber and the WASP, not just that it is simply the result of the termination of the subscriber's billing relationship with the 'donor' MNO. ${ }^{315}$

\footnotetext{
${ }^{310}$ On settlement in the WASP Industry, see ch 6, s6.5.4.2.3 titled Interoperability: Clearing, Payment and Settlement. ${ }^{311}$ Ibid.

312 On credit card payments, see ch 4, s4.8.4.2.7 titled Credit and Charge Cards.

${ }^{313}$ On WASP-type transactions and the relationships therein, see ch 6, s6.5.4.2 titled WASP Value Added Services.

${ }^{314}$ The right of the merchant WASP to terminate or suspend services to the consumer if there is a lack of funds in the prepaid purse to pay for the services may be placed in the Terms of Conditions of the service by the merchant.

315 On the CPA and its effect on the validity of 'credits' used for MNO airtime and other similar SVP systems, see ch 12 ,
} 


\subsubsection{3}

\section{MFS Value Transfer Remittances}

The issue of participants and the payment being a 'bilateral act' accepted in South African law is particularly strained when it comes to dealing with MFS-based remittances outside the context of the debtor-creditor relationship as the sender does not owe the recipient of the remittance anything by virtue of debt. The payment may be a gift, an anonymous donation or some other non-debt based reason. In that sense, the dogmatic adherence to the tenets of payment being a bilateral act seems passé in the modern context of electronic means of doing business. Further, the implication of having to contort a modern value transfer technique within the precincts of a 'payment' needing to be a bilateral juristic act may also impact on any potential remedies available to the sender and receiver. In this sense, the common law definition adopted by our courts may, it is suggested, be tautological: where the transfer is not a bilateral juristic act, the dogma dictates therefore that it is not a payment and as such any remedies based on unjustified enrichment flowing from a payment cannot be used by the wronged party. ${ }^{316}$

\subsection{3}

\section{Form of the Payment}

\subsubsection{1}

\section{Overview}

While it has been held that the general rule is that the payment must be made in cash, ${ }^{317}$ modern payments make use of substitute forms of payments and such that the payment may be effected by any number of means. ${ }^{318}$ Hence besides cash, payment may involve traditional means like monetary value (such as currency) or a modern and more abstract representation of money or value such as an e-money, stored value or a scriptural representation of money or value. ${ }^{319}$

These payments may be achieved using a "payment system, ${ }^{320}$ in use in a particular jurisdiction, which normally may be the systemic systems in place, but which may include nominally private systems - like MNO airtime, or closed-loop/non-interoperable purse systems - that transfer value. The payment may be executed via a transfer of money or the performance of some other act tendered and accepted in discharge of a money obligation but usually the parties to a contract use the term to denote some intermediate step such as conditional payment or transfer of funds. ${ }^{321}$

\footnotetext{
s12.10 titled Consumer Protection Laws.

${ }^{316}$ See ch 7, s7.3.6.7 titled Unjustified Enrichment.

317 Schneider \& London v Chapman 1917 TPD at 504. Du Bois (2007) op cit note 7 at 820; 'cash' may mean notes of the SARB or gold coins, although other 'legal tender' coins can only be used to pay debts of up to ZAR50. See s17 of the South African Reserve Bank Act 90 of 1989; and ch 3, s3.12.3.2 on legal tender.

318 See ch 4, s4.8.4 titled Forms of Payment.

319 Usually the monetary obligations may be discharged by the appropriate sum of money, that is bank notes or coins recognised as legal tender. See Van der Merwe, Van Huyssteen and Reinecke (1993) op cit note 5 at 514 and $B$ \& $H$ Engineering v First National Bank of Southern Africa Ltd 1993 (2) SA 41 (T). Section 17(2)b of the South African Reserve Bank Act 90 of 1989 restricts the debtor's capacity to pay a debt by means of coins. A creditor may also refuse to accept payment in foreign currency unless the parties have agreed to payment in that currency.

${ }^{320}$ See ch 4, s4.8 titled Modern Payment Systems, Instruments and Regulations.

${ }^{321}$ Goode (1983) Payment Obligations in Commercial and Financial Transactions at 11.
} 
In the case of MFS using fiat money purses, the stored value could be seen as an analogue to or representation of 'money' where there is a prudential regime that creates equivalence between the value placed in a SVP and which is redeemable on par and on demand, using fiat money, and cash. The money however is not necessarily legal tender. ${ }^{322}$ Effectively the scriptural nature of the value storage and the subsequent payment of this stored value in some sense appear to emulate the law around EFTs in that a series of book entries mediates the process of a 'funds transfer', rather than there being a physical transfer of anything as may be implied by the term EFT.

The airtime-based SOV however does not appear to amount to 'money', instead approximating to a form of currency and possibly, as a payment mechanism for that purpose. While there is a strong argument for transfer of value in e-money or stored value ${ }^{323}$ to be considered the same 'form of payment', the fundamental difference between these and EFTs of course is that there is not necessarily a licensed bank or financial institution involved in the transfer of value to make a payment to which general principles may be applied, especially where private currencies like airtime transfer and other closed-loop walled garden systems are concerned. In the case of an airtime-based SVP, the form of the payment is not certain to be 'money' such that a contract that is based on payment of 'money' may not necessarily be fulfilled where the payment is somehow made to a recipient in airtime value as the debtor's method of extinguishing a debt that is due to his creditor, even if there is economic value in the amounts sent to the creditor. In practice however - and especially in the WASP industry - the airtime SOV is seen as a type of convertible currency since the out-payment ${ }^{324}$ from the MNO to the WASP is in fiat money. ${ }^{325}$

Whatever the source of funding and its legal import, many of the electronic, abstract systems used for payment are covered by the law of contract with payment by an EFT usually governed by the law of mandate, ${ }^{326}$ agency and the law of contract. ${ }^{327}$

\subsection{4}

\section{The Nature of Payment}

\subsubsection{1}

Overview

Payment (or performance) ${ }^{328}$ must be made in its entirety, such that the debtor is not entitled to make delivery or payment in installments unless such payment is provided for in the contract or can be implied from the circumstances. ${ }^{329}$

\footnotetext{
322 See ch 3, s3.12.3.2 titled Currency and Legal Tender.

${ }^{323}$ See ch 4, s4.8.4.4 on SVPs.

${ }^{324}$ On payment and settlement in the WASP industry, see ch 6, s6.5.4.2.3 titled Interoperability: Clearing, Payment and Settlement.

${ }^{325}$ See ch 6, s6.5.4.3 titled Mobile Airtime Transfer, on the use of the mobile airtime SOV in transactions.

${ }^{326}$ Schulze (2008) op cit note 170 at 290-297.

${ }^{327}$ WG Schulze (2004a) 'Countermanding an Electronic Funds Transfer: The Supreme Court Takes a Second Bite at the Cherry' (16)(4) SA Mercantile Law Journal passim; FR Malan and JT Pretorius (2007) 'Credit Transfers in South African Law Part 1' 69(4) Tydskrif vir die Hedendaagse Romeins-Hollandse Reg at 594.

${ }^{328}$ See ch 7, s7.3 on Payments in General.

${ }^{329}$ Du Bois (2007) op cit note 7 at 820 and the authorities cited; BK Tooling (Edms) Bpk v Scope Precision Engineering
} 
As noted above, ${ }^{330}$ payment has been held not to be a unilateral act by the debtor that can be imposed on him by the creditor. The creditor too must also accept unambiguously any tender (of payment) made by the debtor as a compromise in part fulfillment of a debt. ${ }^{331}$

There is a distinction in this respect between offers made animo solvendi where payment is offered with the intention to fulfil an obligation or an offer animo contrahendi where an amount is proffered by the debtor on condition that the creditor, by accepting it, should forego his claim for the balance. In the latter case the offer may be made for the purpose of entering into a new contract with the creditor. ${ }^{332}$

\subsubsection{2}

\section{Application to MFS}

There are instances in an MNO-based settlement process where the purchase of content/services by a subscriber does not automatically give rise to an irrevocable transfer (payment) of the requisite e-value from the MNO (acting as an issuer) to the third party (merchant). Rather, it is tentative, and is merely an indication by the MNO that it may pay the amount ostensibly due, subject to criteria that include a valid invoice being presented to it sometime after the transaction has occurred. ${ }^{333}$ As a consequence, the payment liability of the MNO may not necessarily equate to settlement liability. ${ }^{334}$

Thus, the entire transaction that gives rise to transfer of e-value based on a transaction initiated by a subscriber ${ }^{335}$ can be entirely or partially repudiated on the basis of various contractual touch-points determined by the MNO as a result of their contractual and economic power. ${ }^{336}$ A WASP transaction is thus irrevocable such that payment of the amounts the WASP believes are due to it may be delayed,

(Edms) Bpk, 1979 (1) SA 391 (A).

${ }^{330}$ See ch 7, s7.3 on Payments in General.

${ }^{331}$ See Mantra Consulting (Pty) Limited v Valor IT CC and Others (09/35874) [2010] ZAGPJHC 36 (7 April 2010). A compromise is a settlement of a disputed liability by agreement; it is a rearrangement of the parties' rights and obligations arising from such disputed liability. In Be Bop a Lula Manufacturing \& Printing CC v Kingtex Marketing (Pty) Ltd 2008 (3) SA 327 (SCA) at par 10, Malan AJA (as he then was) stated: 'The essential issue is whether an agreement of compromise was concluded: one is concerned simply with the principles of offer and acceptance'. This relates to the subjective intent of the parties. See also Harris v Pieters 1920 AD 644 (hereafter Harris) where De Villiers JA said at 654-5 in relation to compromise tenders: 'A debtor, in offering a sum in full settlement, may intent to tender the amount unconditionally, only adding the words 'in full settlement' by way of emphasising his contention that the amount tendered covers the whole of his liability. In that case the offer is made animo solvendi. Or he may intend to offer the amount on condition that the creditor, by accepting it, should forego his claim for the balance. In the latter case the offer is made for the purpose of entering into a new contract with the creditor, animo contrahendi'.

See also Vereins op cit note 289 at par 38 in relation to the will of the creditor in accepting payment.

${ }^{332}$ Harris op cit $\mathrm{n} 331$.

${ }^{333}$ Thus, if there is a dispute between the reconciliation of the WASP's CMS and the billing system of the MNO, the variance of between 2\%-5\% may almost always be given in favour of the MNO owing to its contractual and market might. This may be because of technical errors in the MNO billing system, typically 2-5\% where their real time payment system may give erroneous indications that the subscriber's account was indeed debited (and thus that settlement is due). These errors may only emerge during the month-end reconciliations the MNOs send to the merchant.

${ }^{334}$ See ch 4, s4.8.4.4.9 titled Nature of Transactions and Settlement, on settlement in SVP-based transactions.

335 The completion of the transaction is determined by the successful debiting of the subscriber's prepaid purse by the MNO at the retail value of the transaction.

${ }^{336}$ It is entirely possible that the MNO may at a later date repudiate any (WASP) transaction - even without an 'affected' consumer complaining, or even being nefariously affected at all - based on external influence, for example, a notice of sanction to the MNO from a self-regulatory body like WASPA acting on a general complaint lodged against the WASP merchant. This means that the merchant may suffer a loss - which is typically a book entry loss - but practically the cost of bearers used for delivery of the content like a ringtone, a transaction charge levied by the MNO to the WASP as well as the royalties due and possibly already paid to a contents rights holder. It may even have to refund the subscriber, with the MNO keeping the full payment or a portion thereof after the 'outpayment' to the WASP. On payment and settlement in the WASP Industry, see ch 6, s6.5.4.2.3 titled Interoperability: Clearing, Payment and Settlement. 
repudiated, or varied according to circumstance. ${ }^{337}$ The (final) payment quantum then may amount to settlement. ${ }^{338}$

If the equivocations in the amounts due are settled, then at some stage afterwards there is usually transfer of fiat-based funds from the MNO to the merchant, whereby there is a conversion of the e-value due to the merchant into a scriptural value via bank transfer at a determined contractual date. In all, this reseller model and the implications for irrevocability outlined above can be contrasted to that of a 'pure' intermediary environment, where non-payment to the merchant by the issuer of a valid claim usually means that the merchant has some legal recourse against the issuer to enforce the payment. ${ }^{339}$

If the WASP is not guaranteed payment because the payment obligation from the MNO to the merchant is revocable, then this would indicate that a means of exchange rather than a means of payment may be at play in the type of value provided.

\subsubsection{Time and Finality of Payment}

\subsubsection{Overview}

The time of payment may refer to performance of a contractual obligation to pay. That is, when value is provided to the creditor, but not necessarily when the creditor has unfettered and unrestricted use of the funds. ${ }^{340}$ This latter incidence may also be referred to as the 'finality of payment'. Geva indicates that finality of payment has acquired diverse meanings. ${ }^{341}$

It may denote the irreversibility of the payment process; it may signify the potential loss of the right to recover a mistaken payment; or it may signify the accountability to a payee/beneficiary by a bank instructed to pay that beneficiary. ${ }^{342}$

While the time and finality may depend on the payment type being utilised, general principles may be extracted even from this diversity.

Thus far, English law has not provided a fully consistent scheme for determining finality of payment, ${ }^{343}$

\footnotetext{
${ }^{337}$ This may be further indication that the relationships are not that of a debtor-creditor type but instead may be a form of resale agreements.

${ }^{338}$ In the usual course of business, settlement and payment may be the same thing, so that there is an irrevocable, direct transfer of virtually all the e-value (of the retail purchase price) to the merchant. Usually, however, payment and settlement amount to the same thing.

${ }^{339}$ This is not the case in the 'reseller' payment and settlement environment, where the merchant supplies the content/service effectively on risk (practically small, but still relevant) as it is supplied, unlike in the pure e-money environment, prior to any real and unequivocal payment.

${ }^{340}$ Awilco op cit note 295 per Lord Bridge. See also Vereins op cit note 289 at par 11.

${ }^{341}$ See Geva (2008a) op cit note 309 at 634 who says that this accountability is either the legal result or synonym of 'final payment' and not an ensuing stage.

${ }^{342}$ In a mobile VAS sense, these principles may be applied too with some modification of the actors.

${ }^{343}$ Geva (2008a) op cit note 309 at 644. See also ch 4, s4.8.4.4.9 titled Nature of the Transaction and settlement, on settlement in SVP-based transactions.
} 
and neither has, it is submitted, South African law, where there is diverse opinion on how to determine the time of payment, and correspondingly determine the 'finality of that payment' insofar as the payment may be deemed irrevocable. ${ }^{344}$ The meaning of 'time of payment' depends to a great extent on how this term has been defined in the contract, and whether this time has been fixed by the contract or not, either expressly or impliedly by the circumstances. If the time for the performance has been fixed, it must be carried out by the time agreed upon or the debtor is in default or mora debitoris. ${ }^{345}$ Where the time for performance has not been fixed, the performance may be demanded immediately or within a reasonable time. ${ }^{346}$

Cash is the prototypical payment mechanism and as such simple delivery of the specie may denote both the time of payment and indeed the finality of payment were the creditor to accept what is offered in specie. Where a cheque is paid over the counter, payment takes place when the money is handed over to the holder. ${ }^{347}$ Where there is intermediation in the process of payment through clearing houses, the time of payment becomes less clear and can be resolved only with reference to the - unfortunately opaque clearing house rules embodying the agreement between payor and payee. ${ }^{348}$ The clearing house rules determine in large measure the time when a cheque is paid as a customer instructing his bank to collect payment will be bound by any clearing house rule when it is notorious, certain, reasonable and legal. ${ }^{349}$

However, Malan and Pretorius ${ }^{350}$ indicate that this does not mean that a customer derives any rights from the inter-bank clearing rules since it is a contract between banks in which they specifically disavow the creation of any rights in favour of the customer. The rules are also relatively secret and will only permeate into the public domain during court proceedings ${ }^{351}$ although there have been a few cases where the customer's reliance on the clearing rules was upheld. ${ }^{352}$ Cheque law may shed some faint light on the matter insofar as the event of handing over the cheque to a creditor may, through this act, signify the time of payment in some cases where that is accepted by the creditor. ${ }^{353}$ Taking into account the inter-bank clearing mechanisms of cheques, this act by the debtor however may not necessarily represent the time the payment is executed such that it allows the beneficiary unfettered access to the funds as if cash had been deposited into his account. ${ }^{354}$ Normally payment by cheque constitutes immediate payment subject to the

\footnotetext{
${ }^{344}$ For a discussion of the inconsistencies in application of payment principles to payment by cheque and debit and credit transfers; see WG Schulze (2004b) 'E-Money and Electronic Fund Transfers: A Shortlist of Some of the Unresolved Issues' (16) SA Mercantile Law Journal at 50.

${ }^{344}$ Awilco op cit note 295; see also Vereins op cit note 289 at par 11.

${ }^{345}$ Du Bois (2007) op cit note 7 at 824 .

${ }^{346}$ There may be ambiguity in contract of the computation of the last day of the performance, especially when the last day of performance is expressed in terms of a calendar. This may arise in the use of the words 'of', 'from', 'after', or 'from or after' a fixed date or event. Further, see Du Bois (2007) op cit note 7 at 825.

347 Malan and Pretorius (2007) op cit note 327; Chambers v Miller (1862) 13 CB (NS) 125 (143 ER 50); Balmoral Supermarket Ltd v Bank of New Zealand 19742 Lloyd's LR 164.

${ }_{348}$ Malan and Pretorius (2007) op cit note 327.

${ }^{349}$ Ibid.

${ }^{350}$ CJ Nagel and JT Pretorius (2005) 'Cheques: Honour, Dishonour and Re-honour' 68 Tydskrif vir die Hedendagse RomeinsHollandse Reg 527.

${ }^{351}$ Burg Trailers op cit note 291 in par 10 as discussed by CJ Nagel and JT Pretorius (2004) 'Countermanding Payment of a Cheque' 67 Tydskrif vir die Hedendagse Romeins-Hollandse Reg 641 at 648-650 and Standard Bank of South Africa Ltd v Peens \& others 20051 SA 315 (SCA) at 321E-G para 18 discussed by Nagel and Pretorius (2005) op cit note 350.

${ }^{352}$ See Riedell v Commercial Bank of Australia Ltd 1931 VLR 382 at 385-6 and cf National Slag v Canadian Imperial Bank of Commerce et al (1982) 140 DLR (3d) 473.

${ }^{353}$ Geva (2008a) op cit note 309 at 661.

${ }^{354}$ Ibid. As Geva puts it, this represents a distinction between payment by cheque and payment of the cheque. This allows the debtor to pay on time without being concerned with the time of payment.
} 
cheque being honoured on presentation. ${ }^{355}$ Two South African cases are important here. In respect of a cheque drawn on one and collected by another branch of the same bank, Goldstone AJ (as he then was) in Rosen $v$ Barclays National Bank $L t d,{ }^{356}$ said that a cheque is paid the moment it is passed for payment by the official concerned and not at the expiry of the time allowed for by the clearing house rules to dishonour the cheque. ${ }^{357}$ Rosen, which has often been criticised, ${ }^{358}$ is distinguished from Volkskas, ${ }^{359}$ which concerned a cheque drawn on one bank but collected by another bank and the rights of the drawer to countermand payment of a cheque.

The court stated that payment was a bilateral act which required the co-operation of both parties such that even though there was a modernisation of the mechanisms for payment of cheques, the legal principles governing it had remained the same ${ }^{360}$ and that the drawer still had a right to countermand payment of a cheque provided that required procedures were followed. ${ }^{361}$ But as Malan and Pretorius indicate further, the judgment does not indicate when payment takes place, but merely when it does not occur, and as such the moment of payment is as uncertain as it was before the judgment. ${ }^{362}$ In other cases the time of payment may be when there is acceptance by the beneficiary's bank of the cheque and the beneficiary's account is credited. In these cases it may signify final discharge of the debt. ${ }^{363}$

In relation to debit and credit transfers, ${ }^{364}$ it is said that finality of payment occurs at the destination bank: in a debit transfer the finality takes place at the payor's bank, while in a credit transfer it is at the payee's bank. ${ }^{365}$ This does not of course suit time-sensitive payments, and may constitute mora debitoris if the funds only become available after a due date owing to its transit in a payment system or national payment system. ${ }^{366}$

In relation to a credit transfer, a distinction between time of (the act by the debtor) and finality of (unfettered use of all the funds by the beneficiary) payment may not necessarily exist. Geva notes that no discharge of the debt, conditional or otherwise, is accorded to the debtor in the course of carrying out a credit-based funds transfer until 'finality of payment' takes place. ${ }^{367}$ Time of payment and the finality of payment in a credit transfer, he says, are the same thing such that a debtor only discharges the debt obligation when that payment becomes final. ${ }^{368}$ There may or may not be a similar intermediation at play in the funds transfer: where the same financial institution is involved, there simply may be a change of

\footnotetext{
${ }^{355}$ The creditor presenting the cheque to the bank would result usually only in a credit entry, such that payment will not have occurred if there was a subsequent countermanding. See Du Bois (2007) op cit note 7 at 821.

${ }^{356}$ Rosen v Barclays National Bank Ltd 1984 (3) SA 974 (W), hereafter ('Rosen).

${ }^{357}$ Ibid at $978 \mathrm{G}-\mathrm{I}$.

${ }^{358}$ See for example AN Oelofse (1991) 'Onlangse Ontwikkelings in die Tjekreg' (3) SA Mercantile Law Journal at 376; Malan and Pretorius (2007) op cit note 327.

${ }^{359}$ Volkskas op cit note 291.

${ }^{360}$ Ibid at 611-612.

${ }^{361}$ Ibid at 612B-C.

${ }^{362}$ Malan and Pretorius (2007) op cit note 327. They also point out that, in relation to Rosen, Volkskas creates the complex situation where it may be necessary to distinguish between cases where the drawee and collecting banks are branches of the same bank and cases where they are different legal entities

${ }^{363}$ Geva (2008a) op cit note 309 at 645.

${ }^{364}$ See ch 4, s4.8.3.9 titled Payment Flows.

${ }^{365}$ Geva (2008a) op cit note 309 at 637.

${ }^{366} \mathrm{Du}$ Bois (2007) op cit note 7 at 823-825.

${ }^{367}$ Geva (2008a) op cit note 309 at 661 .

${ }^{368}$ Ibid.
} 
position of the debtor and creditor, but not the bank as it relates to clearing and settlement arrangements in a national payment system such that there is an almost instantaneous availability of funds where the debtor transfers value to the creditor when they share the same institution. The situation is of course different when clearing and settlement intermediation is required because the debtor and creditor are at different institutions. Similar to the cheque clearing bureaus used by banks as noted above, these payment systems ${ }^{369}$ are usually clouded in secrecy and their machinations are not visible to non-bank actors and as such may be a drawback to time-sensitive payments. ${ }^{370}$ Schulze ${ }^{371}$ however notes that in Royal Products Ltd $v$ Midland Bank Ltd, ${ }^{372}$ the Court held that the relationships between banks involved in a funds-transfer transaction are governed by the rules of agency and submits that the agency relationship would also hold true for the relationships between South African banks involved in a funds-transfer transaction. The relationships, he says, would be governed by the provisions of any inter-bank agreement and that these provisions, as well as the naturale of their relationship, would be governed by the common-law principles of representation. The effect of time in relation to a credit transfer can be seen for example in relation to Internet-based payments of tax where the SARS Reference Guide Provisional $\operatorname{Tax}^{373}$ says that 'where payments are done electronically, provision must be made for your bank's cut-off times and for a clearance period that could take between two and five days'. SARS is of the view that payment will only have been made once the relevant amount is reflected in the SARS bank account. ${ }^{374}$

\subsubsection{2}

\section{Application to MFS}

While there is a continuing debate as to the time of payment in the common law, the picture in respect of the time of payment in electronic payments seems to be somewhat clearer via statute. For example, s23 of the ECTA governs the time and place of communications, dispatch and receipt of data messages. Although Schedule 2 of the ECTA lists exclusions to its application, only the execution of a bill of exchange as defined in the Bills of Exchange Act, ${ }^{375}$ general banking services are defined. Instructions to send EFTs, which could be construed as being the sending and receiving of data messages, are not one of these exclusions and thus it is submitted the ECTA would have bearing on EFTs and specifically the time of sending and receipt.

Specifically, s23(a) says that a data message used in the conclusion or performance of an agreement:

'must be regarded as having been sent by the originator when it enters an information system outside the control of the originator or, if the originator and addressee are in the same information

\footnotetext{
${ }^{369}$ For a brief discussion on these systems, see C Visser (1989) 'Evolution of Electronic Payment Systems' 1(2) SA Mercantile Law Journal 189.

${ }^{370}$ Geva (2008a) op cit note 309 at 635 notes that final payment denotes the accountability of a bank to the payee and typically marks the (absolute) discharge of the debt paid by the funds transfer. Thus, he says, finality is achieved as a result of and at the end of a banking process in which the non-bank actors usually have no control.

${ }^{371}$ Schulze (2008) op cit note 170 at 294.

${ }^{372}$ Royal Products Ltd v Midland Bank Ltd [1981] Com LR 93.

${ }^{373}$ South African Revenue Service (SARS) (2010) Reference Guide: Provisional Tax 10 July 2010 at 7.

${ }^{374}$ Ibid at par 6(1) of the Fourth Schedule and interest (s89bis). An employer will be liable for a penalty of $10 \%$ if this is not done. See Edward Nathan Sonnenbergs (2010) 'Electronic Funds Transfers to SARS?' 126 Integritax Newsletter, posted on MoneyWebTax, 20 April, available at http://goo.gl/zr116.

${ }^{375}$ Act 34 of 1964 op cit note 103.
} 
system, when it is capable of being retrieved by the addressee.'

This relates to where the sender and receiver are in the same information system. Hence, if the payor and payee are with the same bank (and possibly in the same country), this would mean that the time it was sent by the sender would equate to the time of the payment. The situation where the parties are not in the same information system is covered in $\mathrm{s} 23(\mathrm{~b})$, which says that the data message:

'must be regarded as having been received by the addressee when the complete data message enters an information system designated or used for that purpose by the addressee and is capable of being retrieved and processed by the addressee.'

'Information system' is defined in the Act as 'a system for generating, sending, receiving, storing, displaying or otherwise processing data messages and includes the Internet'. This generally could include the entire end-to-end electronic scheme - even the mechanics of the inter-bank system to which the consumer is not entirely privy but is usually bound by - that results in an EFT, insofar as the communication by a customer using a mobile or Internet link to a bank or other financial institution's payment gateway (probably, but not always, via the Internet in the case of a walled-garden MFS) would be 'an information system outside the control of the originator'.

The rules in the ECTA then, it is submitted, would apply to a customer's use of these systems. As a result, banking convention would need to take cognisance of the rules in the ECTA in relation to the time of sending the payment (instruction). ${ }^{376}$

Furthermore, as Schulze points out, electronic transfers, and specifically the electronic clearing process, are conceptually no different from the clearing of paper-payment transactions (for example, cheque clearing). ${ }^{377}$

Correspondingly, it is submitted that in relation to the time of payment, payment via MFS should present similar equalities even if the mechanism is not necessarily one that is part of a national payment system in which a licensed bank would probably participate. ${ }^{378}$

\footnotetext{
${ }^{376}$ Curiously, even since the ECTA came into force in 2002, there is no mention of the ECTA in relation to these services in recent cases concerning EFTs; the courts seemingly prefer to conveniently use only existing banking law and precedents to frame their answers to matters at hand. Banking law may have its own analytical ecosystem, but like weather patterns elsewhere, cannot be unaffected by changes in patterns elsewhere. See similarly a general discussion in Mthembu (2010) op cit note 76.

377 Schulze (2008) op cit note 170 at 293.

${ }^{378}$ There is less certainty when other means of payment are utilised, such as by debit or credit transfers using card mechanisms, EFT or via cheque.
} 
Defective payments could be characterised as to existing in circumstances where the payment was made as a result of a mistake ${ }^{379}$ or through some other unauthorised circumstances, such as fraud, ${ }^{380}$

There may also be instances where one party does not comply with what is expected either through contract or in delict. The affected party will want to remedy the situation so he is placed in the same position as before, if possible.

As noted above, ${ }^{381}$ the general principle in banking is that a bank and client owe reciprocal duties of care to one another. ${ }^{382}$ Less certain however is whether these principles extend to non-banks - and their intermediaries and agents - involved in MFS. The effect on MFS, if any, is discussed below ${ }^{383}$

\subsubsection{Mistaken Payment Scenarios}

There may be instances where a payment is mistakenly made to the wrong recipient or to the intended recipient for a wrong amount, or where payment was not intended to be made at all but proceeded nonetheless.

A mistake by one party in a transaction may not entirely be their fault: a party to a transaction or contract may have, for example, failed to provide sufficient means to prevent the mistake, or may have even induced the mistake by their actions. ${ }^{384}$

Money could be paid under mistake of law or paid under mistake of fact. Insofar as an ability to recover this (mistaken) payment, the following burden fastens on the claimant: he must prove first that there is no relationship of indebtedness or other legal ground to support it, and second that there is some specific, positive reason why it ought to be paid back. ${ }^{385}$

\footnotetext{
${ }^{379}$ See ch 7, s7.2.2.3.1 on Mistake in general.

${ }^{380}$ See ch 7, s7.2.2.3.3 on Fraud and Misrepresentation.

${ }^{381}$ See ch 4, s4.5.2 on Nature of the Relationship and Duties in banking.

382 Wadsley and Penn (2000) op cit note 4 at 173. See also Barclays Bank v Quincecare [1992] 4 ER 363 at 375-376; and N Joachimson v Swiss Bank Corporation [1921] 3 KB 110 (hereafter Joachimson) where aspects of what a bank provides to customers is expounded. Although a bank's liability to a customer is primarily contractual and based on common law, a complex, multifaceted mixture of duties in other fields of law follows, in respect of delict, trusts, restitution, and contract. See Wadsley and Penn (2000) op cit note 4 at 104.

${ }^{383}$ See also ch 7, s7.2.2.3 on Absence of Consensus in relation to mistake and absence of consensus.

${ }^{384}$ Ibid.

${ }^{385}$ The positive reason may be an excusable factor. H Scott and D Visser (2010) 'The Impact of Legal Culture on the Law of Unjustified Enrichment: The Role of Reasons' in E Bant and M Harding (eds) Exploring Private Law at 155. This potential ability to recover value falls generally under the purview of the law of unjustified enrichment. See ch 7, s7.3.6.7 on Unjustified Enrichment, where specific actions (condictiones) are ostensibly available to recover value under specific circumstances that fit within the confines of the requirements of each condictio. An action to recover value provided under mistakes of law and fact could be the condictio indebiti, but the burden fastens on the claimant. See ch 7, s7.3.6.8.3 on Condictio Indebiti. The burden of proof is high: specific reasons provided must be reasonable and excusable. See Willis Faber Enthoven v Receiver of Revenue 1992 (4) SA 202 (A) 223-7; and H Scott (2007) 'The Requirement of Excusable Mistake in the Context of the Condictio Indebiti: Scottish and South African Law Compared' 124(4) South African Law Journal 827 at 849-850.
} 
Practically, the Payment Association of South Africa in relation to mistake says that the paying customer is responsible for ensuring the correct beneficiary account number is provided to the paying bank, such that neither the paying nor the receiving bank can be held liable if they acted on information supplied by the paying/initiating customer. ${ }^{386}$

\subsubsection{3}

\section{Unauthorised Payment Scenarios}

Unauthorised payment scenarios are manifold: ${ }^{387}$ for example, a payment made on behalf of an accountholder by an unauthorised person by using a stolen cheque ; a stolen or cloned credit card, debit card, or cheque; the unauthorised use of an account holder's PIN number, ATM card, mobile banking, telephone-type IVR banking, or Internet banking login and password details; or where there is an authorised payment generally but someone manages to change the details of the amount and/or beneficiary to be paid; ${ }^{388}$ or the payor may have been compelled in some way to pay, through duress via a threat to his person or something or someone else he considers valuable. ${ }^{389}$

The parties possibly responsible for the defective payment may include either - or a combination of - the payor and payee banks, any technical or similar intermediaries, ${ }^{390}$ any agents, ${ }^{391}$ the payor or payee, or of course, a fraudster. ${ }^{392}$

\subsubsection{4}

\section{Effect of Defective Payments}

In all the above scenarios, a payment was made that was contrary to the intent and wishes of the accountholder. That is, he did not fundamentally intend to make that payment at all, to that recipient, or to make a payment for the amount actually paid. ${ }^{393}$ The recipient may therefore be seen to be unjustifiably enriched ${ }^{394}$ by the payment, and as such the payor may require recourse to reclaim the value, if at all

\footnotetext{
${ }^{386}$ Payment Association of South Africa (PASA) (s.d.) 'Consumer Information: Guidelines EFT Credit', available at http://goo.gl/dlC1t. PASA also indicated that if the paying client makes an error and some other person besides the intended beneficiary receives the funds the paying customer has the right to the return of these funds through 'unjust enrichment', and the banks will assist him where possible to affect such recovery. See ch 7, s7.3.6.7 titled Unjustified Enrichment.

${ }^{387}$ See also ch 7, s7.2.2.3 titled Absence of Consensus; and generally on security risks, Mthembu (2010) op cit note 76.

${ }^{388}$ See ch 5, s5.7.4.1 titled Phishing in relation to an unauthorised transfer of funds by fraud syndicates from an Internet banking system using the ubiquitous, so-called 'Phishing' techniques, and its footnotes which describe how fraudsters use emails to fool users into divulging their account usernames and passwords and mobile phone numbers; and similarly ch 5, s5.7.1 titled Security of the Mobile Network on the related 'SIM-swap' fraud techniques that allows the One Time Password (OTP) PIN - or Random Verification Number (RVN) detailed in ch 5, s5.7.1 - sent via SMS to the genuine payee's mobile phone allowing for authentication of a new beneficiary on an Internet banking web site. For a legal overview of 'SIM swaps' and their implications, see Van der Bijl (2009) op cit note 2; and Nashua op cit note 2.

${ }^{389}$ See ch 7, s7.2.2.3.2 titled Duress and Undue Influence.

390 These may be, for example, a technical intermediary like an MNO or WASP responsible for sending out an OTP.

${ }^{391}$ The agent may be the MNO's agent - a retail service provider - or the bank's agent, or a combination of both depending on the regulatory rules applicable. In an MNO context, or a MNO's Service Provider as an agent who provides a new SIM card to a fraudster allowing the fraudster to intercept the SMS containing the OTP authentication data using the fraudulently obtained replacement SMS card provided by an unsuspecting MNO retail agent based on a false identity document provided to the MNO's agent. For details of inter alia 'SIM swaps' and internal MNO and internal bank fraud, see ch 5, s5.7.1 titled Security of the Mobile Network; and on 'Phishing', see ch 5, s5.7.4.1 and its footnotes.

${ }^{392}$ Negligence in allowing the fraudster access to account details and access criteria may make one of the parties liable in delict, contract, or statute, depending on the circumstances.

${ }^{393}$ There are of course other permutations of why a plaintiff in an enrichment action may claim an enrichment action, but these examples will be limited to the schemes in this paragraph.

${ }^{394}$ Lotz describes the term enrichment as the situation where one person's estate is increased at the expense of another
} 
possible. $^{395}$

\subsection{General Principles}

As noted above, ${ }^{396}$ the legal system has devised numerous methods for determining how to provide recourse - if it can at all - in the case of mistake and unauthorised transactions by allocating various levels of 'risk' to each party's actions and apportioning any remedy according to that risk assessment. ${ }^{397}$ This assessment, if vicarious liability is stipulated and enforced, may be guided either by private rules that form part of the contract, and which may present itself as a determination by a (private) industry Ombudsman, ${ }^{398}$ common law rules, or statute where available that together determine the overall rights and responsibilities of each party. ${ }^{399}$

Liability resulting in a loss to a party may be a result of breach of contract or through delict, for example though negligence ${ }^{400}$ by one or more of the parties.

The process of determining who should or could have mitigated the resultant risk usually starts with the general view that a reasonable person will take reasonable measures to prevent the occurrence of any foreseeable harm. ${ }^{401}$ Another view is that the most efficient way to allocate losses would be to place

without legal cause. See JG Lotz (2005) 'Enrichment' in The Law of South Africa (9) at 107.

${ }^{395}$ See below ch 7, s7.3.6.7 titled Unjustified Enrichment; and further on the Roman actions that are available and could possibly be used to recover value, see ch 7, s7.3.6.8 titled Actions to Recover Value.

${ }^{396}$ See ch 7, s7.2.5.2 titled Breach of Contract Versus Delict.

${ }^{397}$ Boberg (1984) op cit note 226 at 269-279.

${ }^{398}$ See, for example in South Africa, the self-regulatory Ombudsman for Banking Services of South Africa (OBSSA) described in ch 12, s12.3.2.10 titled Ombudsman for Banking Services of South Africa, who enforces adherence by banks to the voluntary Code of Banking Practice (COBP) which sets out minimum standards that the bank must adhere to as well as reasonable care criteria it expects of bank clients. Banking Association of South Africa (2012) 'Code of Banking Practice', available at http://goo.gl/56DMx. For a discussion of the rights and responsibilities of banks and consumers detailed in the COBP, see ch 7, ss7.3.6.5.3 titled The Bank and 7.3.6.5.4 titled Bank Customers. See similarly, the self-regulatory ombudsman for micropayments where a mobile airtime-based SOV is used, see on WASPA ch 6, s6.5.4.2.4 titled Dispute Resolution; ch 12, s12.8.3.2 on WASPA.

${ }^{399}$ Ibid. In South Africa in the absence of any general statute with loss allocation rules relating to payments, this allocation is generally done via contract, guided in part where applicable by broad rules outlined in statute, for example the National Credit Act 34 of 2005 (hereafter NCA). Usually the stronger power prevails in matters of dispute and the user may be liable for the entire loss. In the US and EU, however, there are general rules around allocation, with maxima set for potential loss. In the EU's Payment Services Directive (PSD) - Directive 2007/64/EC - matters of gross negligence in relation to loss are also considered in any determination of allocation of loss. For a discussion on the PSD, see ch 9, s9.6.2 on the Payment Services Directive; and for a comparative discussion of loss allocation rules in South Africa, see ch 12, s12.11 titled Consumer Protection And Loss Allocation with Respect to Payments.

${ }^{400}$ Negligence forms part of the law of delict and, in turn, this is part of the law of obligations. A delict is a civil wrong which can be redressed by civil proceedings. Du Bois (2007) op cit note 7 at 1091. A delict may derive from an unlawful act that can be ascribed to someone that causes harm to another. See also JR Migley and JC van der Walt (2005) 'Delict' in The Law of South Africa 8 part $12^{\text {nd }}$ ed. While each case where there is a determination of a loss must be approached on the facts, the point of departure must however assume prima facie, that a plaintiff's loss is represented by the amount stolen from him. The onus is on the defendant to rebut this prima facie view. See Holscher v ABSA Bank en ' $n$ Ander 1994 (2) SA 667 (T).

${ }_{401}$ A reasonable person will take reasonable measures to prevent the occurrence of foreseeable harm, determined by balancing the reasonably foreseeable risk against the social value or utility of the interests served by the (defendant's) conduct. See Du Bois (2007) op cit note 7 at 1100. This 'reasonableness' is generally the standard measured against what the diligens paterfamilias would have done in the same circumstances. Boberg (1984) op cit note 226 at 269-279. See also Sonnekus (2008b) op cit note 29 at 20 who says that a plaintiff's own conduct may be a factor in assessing any restitution if this is at issue. Thus, he says, reasonableness is the overall qualification to assessing the ultimate damage and the restitution, if any, that could follow from any event, insofar as the plaintiff's 'laxity' is a factor that, in accordance with societal considerations, would label an order for restitution (for unjustified restitution) as 'inequitable', this despite the transfer of 
liability for (clearly avoidable) losses on the party responsible for the loss, and divide liability for the other losses between the customer and the financial institution. ${ }^{402}$ Nonetheless, in assessing whether there were attempts at mitigating the risk, a determination will be done through balancing the reasonable foreseeability of the risk against the social value or utility of the interests served by a defendant's conduct. ${ }^{403}$

Liability for an act or omission that caused the risk can be said to be based on three broad elements. First, the risk of doing (or omitting to do) something which the law deems inappropriate; second, the risk that such acts or omissions will cause damage or loss; and third, that the risk that those suffering such loss will be legally entitled to bring a claim. ${ }^{404}$ The costs and burden of possible precautionary measures - and the resultant cost of an action to claim back a loss ${ }^{405}$ - must be balanced against the risk as must the objective evaluation of whether or not the conduct complied with normal and generally accepted practice. ${ }^{406}$ The overriding standard in every instance is that of the reasonable person in the particular situations, which may be prescribed also by statute. ${ }^{407}$

A breach of a statutory duty may be indicative of negligence. ${ }^{408}$ The parties may agree to supplement and supplant such natural incidents by means of incidental provisions such as stipulating the time, place and

value - to the detriment of the plaintiff - being objectively unjustifiable. Sonnnekus cites in respect of this criterion of 'reasonableness' AS Hartkamp (2005) Asser's Handleiding tot de Beoefening van het Nederlands Burgerlijk Recht, Verbintenissenrecht Deel III De Verbintienis uit die Wet s \$\$319 and 350. See similarly, Sonnekus op cit note 29 at 376 for a discussion of Pestanal op cit note 240; and Nedbank Ltd v Pestana 2009 (2) SA 189 (SCA), where he concurs with the judgment $a$ quo and then twice on appeal that a mistake by a bank - here Nedbank - in a credit transfer to an account should not be reversed, despite even the SCA's suspicion that an associated transfer Nedbank was trying to reverse 'was tainted with fraud'. See also JC Sonnekus (2008a) 'Eensydige Terugskryf van Kliënt se Kredietdeur Bank Onregmatig' 2 Tydskrif vir die Suid-Afrikaanse Reg at 348.

${ }^{402}$ See E Rubin (1991) 'Efficiency, Equity and the Proposed Revision of Articles 3 and 4' 42 Albany Law Review 551 at $553-$ 554 , and 564. Generally, then, the law of delict or tort system operates to shift the burden of losses from innocent plaintiffs to the negligent defendant. Policy considerations may however apply the loss-spreading principle which is to assign liability for a loss to the party that can achieve risk neutrality at the lowest cost. This is usually the one with the greatest economic power (like a bank) and is in a position to spread the loss most effectively. See RD Cooter and EL Rubin (1987) 'A Theory of Loss Allocation for Consumer Payments' 66(1) Texas Law Review at 71.

${ }^{403}$ Van der Merwe, Van Huysteen and Reinecke (1993) op cit note 5 at 308. Risks can be classified as either objective or subjective. Objective risk is concerned with predicting future events on the basis of records of what has happened in the past. Subjective risks are risks which are perceived by individuals and may or may not correlate strongly with objective risk assessment. See also TS Kaye (2008) 'Risk and Predictability in English Common Law: Risk and the Law' in G Woodman and D Klippel (eds) Risk and Predictability in English Common Law: Risk and the Law at 103, available at http://goo.gl/jSz48.

${ }_{404}^{405}$ Kaye (2008) op cit note 403 at 107.

${ }^{405}$ As Budnitz explains, albeit in a US context but with possible general application, if there is unauthorised use or bank error, the consumer may have no feasible means of getting the bank to investigate the consumer's complaint. Furthermore, the consumer likely cannot afford to hire an attorney in order to sue the financial institution in the absence of an error resolution procedure. ME Budnitz (2008b) 'Technology as the Driver of Payment System Rules: Will Consumers be Provided Seatbelts and Air Bags?' 83(2) Chicago-Kent Law Review, at 919, available at http://goo.gl/dj0vi. Therefore, a bank can simply refuse to investigate a consumer's complaint unless the consumer takes the complaint to an ombudsman like the OBSSA.

${ }^{406}$ See the decision in Caparo Industries plc $v$ Dickman and Others House Of Lords [1990] 2 AC 605 in which the House of Lords upheld the earlier Privy Council case of Yuen Kun-Yeuv Attorney-General of Hong Kong 38 to the effect that the test of whether a duty exists or not actually involves three stages, namely, reasonable foreseeability, proximity and 'fairness, justice and reasonableness'.

${ }^{407}$ Van der Merwe, Van Huysteen and Reinecke (1993) op cit note 5 at 308; J Moorcroft (2010) Banking Law and Practice at 15.21. See, for example, the SIM card identification provisions in RICA op cit note 77 and the references therein. Section 72B of the Bills of Exchange Act op cit note 103 places a duty on certain clients to 'exercise reasonable care in the custody of cheque forms and in reconciliation' of bank statements. It applies generally to companies, close corporations, co-operatives, estate agents, practicing attorneys, Eskom, national government, provincial government and municipalities. Any duties must also be read in relation to any obligations in the Financial Advisory and Intermediaries Services Act 37 of 2002; and the Financial Intelligence Centre Act 38 of 2001 (hereafter FICA).

${ }^{408}$ For delictual liability fastening on banks, see Moorcroft (2010) op cit note 407 at 15.21. A bank's duties may give rise to a defence based on estoppel to contractual or delictual liability. As negligence may be at play, its measure may be based also on a predictive approach versus an ex post facto positivistic emphasis on certainty. See the discussion in terms of English common law in Kaye (2008) op cit note 403 at 107-9. 
manner of performance or imposing additional duties of performance in contract, such as warranties of quality, preparatory duties, or a duty to care for or ensure the subject matter of the contract. ${ }^{409}$ These may also relate to the relative risks involved in any performance due by any parties and there may be an umbrella agreement in place that defines the relative risks and the obligations in place. ${ }^{410}$ In Columbus Joint Venture v ABSA Bank $L t d,{ }^{411}$ Malan J in considering contributory negligence by a plaintiff indicated that a customer's duty to his own bank is a limited one and his duty to a collecting bank cannot exceed his duty to his own bank. ${ }^{412}$

\subsubsection{2}

\section{Payment Scenarios}

In many of the emerging cases, there may not be directly applicable case law or legislation regulating this issue and it must therefore be decided based on the relevant factors which are applicable. ${ }^{413}$.

In a payment scenario, and in the absence of guiding principle in a statute, the form in which payment is made or the payment instrument used will, based on the express or implied terms of the contract, allocate the appropriate risk and responsibility for any loss.

Generally where there are mistaken and unauthorised payments, there may be a need for a determination of all attendant risks surrounding the events that gave rise to the loss and the results thereof will usually inform the degree of allocation of loss. While mistake by one party and any ensuing loss can usually be traced back to a party, there may be instances where a loss is not attributable necessarily to the actions of one party in a contract, for example, where a third party commits fraud or theft against one of the parties. This does not however necessarily exonerate an affected party: there may be a reason to analyse whether a party - or parties, if there is dual or multiple contribution - could have mitigated the risk that led to the loss.

This allocation of risk may be part of the duty of fulfilling the express or implied terms of a contract and a lack of mitigation (of the risk so experienced) may constitute negligence on behalf of one or more parties. $^{414}$

\footnotetext{
${ }^{409}$ Van der Merwe, Van Huysteen and Reinecke (1993) op cit note 5 at 256. See also ch 7, s7.2.4 titled Terms of the Contract.

${ }^{410}$ See ch 12, s12.3.2.10 on the OBSSA, which enforces the COBP.

${ }^{411}$ Columbus Joint Venture v ABSA Bank Ltd 2002 (1) SA 90 (SCA) (hereafter Columbus)

${ }^{412}$ Moorcroft (2010) op cit note 407 at 18.15. As noted by Brink, Cohen and Le Roux, whether apportionment can take place where one wrongdoer acts negligently and the other intentionally - as joint wrongdoers in terms of s2 of the Act - has been the subject of much debate, although the court in Lloyd-Gray Lithographers (Pty) Ltd v Nedcor Bank Ltd t/a Nedbank 1998 (2) SA 667 (W) answered this question in the affirmative. Brink, Cohen, Le Roux (s.d.) 'Collecting Banker's Duty of Care', available at http://goo.gl/h5pgU.

${ }^{413}$ OBSSA (2008) 'Card Cloning', Bulletin 13, available at http://goo.gl/m7rrBat 4, on card cloning but which may have more general applicability in terms of application of allocation of loss principles. In making a decision on the basis of for example, card cloning, OBSSA will look at the contract between the bank and the card holder, the Code of Banking Practice and any applicable case law which can provide guidance, and any possible negligence on the part of the card holder. For liability allocation and obligations of the parties in the EU via the PSD, see ch 9, s9.6.2.5.2 titled Liability Allocation and Obligations of the Parties. This Directive inter alia codifies the maxima a consumer could be liable for in case of fraud and mistake in specific circumstances. For similar protections in the US, see for example ch 11, s11.2.4.1 on the provisions of the Electronic Fund Transfer Act 15 USC 1693-1693 which limits a consumer's liability for any unauthorised EFTs involving his account, as well as providing a detailed dispute resolution process for resolving claims of errors by the financial institution in charging a consumer's account for a funds transfer and for losses for unauthorised transfers.

${ }^{414}$ For particular responsibilities fastening on the various parties, see ch 7, ss7.3.6.5.3 titled Banks; 7.3.6.5.4 titled Bank
} 
Laws and case law relating to problems with credit card, ${ }^{415}$ EFTs, ${ }^{416}$ and cheque ${ }^{417}$ usage may also be relevant in any determination insofar as providing some guiding principles. This may include a determination of whether a contract imposing duties of care on one party was fair, ${ }^{418}$ or whether any agents or technical intermediaries contributed to a loss. ${ }^{419}$

\subsection{The Bank}

\subsection{Nature of a Bank's Activities}

In the light of the banker-customer relations discussed above, ${ }^{420}$ a bank's duties of care ${ }^{421}$ may arise not only in contract, but also in delict, ${ }^{422}$ such that a bank may owe duties of care in delict concurrently with a duty in contract. ${ }^{423} \mathrm{~A}$ bank though may incur liability in delict in respect of both its clients and third parties. $^{424}$

The bank's duty of care may, for example and as described below, extend to identity verification of its customers, adequate supervision of its agents, the provision of industry-standard security for its internal and consumer-facing systems and proper functioning thereof. ${ }^{425}$

There is however tension between what a plaintiff may claim in terms of contract or in terms of delict. In

Customers; 7 7.3.6.5.5 titled Non-Banks; and 7.3.6.5.6 titled Third Parties. See also generally Cooter and Rubin op cit note 402 passim.

${ }^{415}$ See ch 4, s4.8.4.2.7 titled Credit and Charge Cards. Credit cards are subject to the NCA op cit note 399. The NCA makes provision for unauthorised card use. While individual contracts and terms of a credit card contract are also regulated by selfregulation, s94 of the NCA says that a credit provider must not impose a liability on a consumer for any use of a credit facility after the time that the consumer has reported the loss or theft of the associated card, personal identification code or number or similar device, unless the consumer's signature appears on the voucher, sales slip, or similar record evidencing that particular use of the credit facility; or if the credit provider has other evidence sufficient to establish that the consumer authorised or was responsible for that particular use of the credit facility, whereafter the issuer will bear the loss. For application to disputes over a cash withdrawal from a credit card, see Diners Club SA (Pty) Ltd v Singh and Another 2004 (3) SA 630 (D) (hereafter Diners Club). For a discussion of this case, see WG Schulze (2004d) 'Unauthorised Cash Withdrawals with a Credit Card, and Unfair Contract Terms' 12(3) Juta's Business Law 143-146; and WG Schulze (2005) 'Of Credit Cards, Unauthorised Withdrawals and Fraudulent Credit-Card Users' 17(2) SA Mercantile Law Journal 202-213; Van der Bijl (2007) op cit note 2; and generally on payment by credit cards, S Cornelius (2003) 'The Legal Nature of Payment by Credit Card' 15(2) SA Mercantile Law Journal 153-171; and A Tyree (2008b) 'Payment by Credit Card', available at http://goo.gl/GomPJ.

${ }^{416}$ On EFTs, see ch 4, s4.8.4.2

${ }^{417}$ On cheques, see ch 4, s4.3.2 titled Characteristics of Banking. Cheques are subject to the Bills Of Exchange Act op cit note 103. See generally on cheques, Malan, Pretorius, and Du Toit (2009) op cit note 18; and on cheque fraud, JT Pretorius and C Vlvan der Bijl (2006) 'A New Mode of Forgery: The Rise of Cloned and Washed Cheques' 18(2) SA Mercantile Law Journal 196-203. See also Indac Electronics (Pty) Ltd v Volkskas Bank Ltd 1992 (1) SA 783 (A), (hereafter Indac)

${ }^{418}$ See Sasfin op cit note 201; Diners Club op cit note 415; and ch 7, s7.3.6.5.3.3 titled Security and Efficacy of Systems. See on the CPA ch 12, s12.10 titled Consumer Protection Laws.

${ }^{419}$ See Nashua op cit note 2; and a brief discussion of the case in ch 5, s5.7.4.1 on Phishing.

${ }^{420}$ See ch 4, s4.5 titled The Banker-Customer Relationship.

${ }^{421}$ The common law for example has developed so as to impose a duty of care on a collecting bank. See Indac op cit note 417; and Columbus op cit note 411.

${ }_{422}$ Wadsley And Penn (2000) op cit note 4 at 173.

${ }^{423}$ Ibid.

${ }^{424}$ Moorcroft (2010) op cit note 407 at 18.1; Wadsley and Penn (2000) op cit note 4, at 17. This may relate for example to a bank giving references about their customers to others and investment advice.

${ }^{425}$ Where a banker's negligent conduct and a thief's intentional conduct both cause the (true) owner (of a cheque) to suffer patrimonial loss, it is uncertain whether they may be treated as joint wrongdoers. The court in Lloyd-Gray op cit note 412 answered this question in the affirmative. For a discussion on who bears the risk in relation to forged cheques, see Pretorius and Van der Bijl (2006) op cit 417, who argue that the risk of a forged cheque lies with the drawee bank. 
Liebenberg v ABSA Bank Limited t/a Volkskas Bank, Traverso J opined that a claim based on delict will not be available to someone when a contractual remedy is still available to the plaintiff in that:

'... a party cannot by simply not calling his claim a contractual claim turn it into a delictual claim' such that 'there is no need to extend the Bank's duty to a delictual duty exists parallel to the contractual duty' as this 'would subvert the basic principles of banking law'. ${ }^{426}$

In Kruger v Coetzee, ${ }^{427}$ it was held that since bankers must render a professional service, the standard of care to which they will be held is that of the bonus argentarius, the reasonable banker. ${ }^{428}$ Conformity with general practice in the profession is merely prima facie proof of the absence of negligence, but this is not conclusive. ${ }^{429}$ The infinite variety of circumstances that may arise makes it undesirable if not impossible to formulate and advance concrete standards of conduct for all conceivable situations. ${ }^{430}$ The court should however not refrain from forming its own opinion as to whether a bank's practice complies with the standard of care expected of bankers. ${ }^{431}$ In this regard, negligence could be said to be present if a reasonable banker would have foreseen that his conduct might reasonably cause another to sustain a patrimonial loss, such that the banker would have taken reasonable steps to guard against such a loss, but that the defendant banker failed to take such steps.

While delict is an option in these instances, plaintiffs may not sue in both delict and contract, unless the two claims are framed in the alternative. The onus of establishing negligence on a balance of probabilities lies with the party alleging negligence. ${ }^{432}$ The proof required would have to show the standard of care of what would be required of a bank in those circumstances. ${ }^{433}$

In Duvenhage, the court looked at the elements of delict and decided that the loss, and its causal

\footnotetext{
${ }^{426}$ Liebenberg v ABSA Bank Ltd 1998 (1) All SA 303 (C) at 311. See also the discussion below in ch 7, 7.2.5.2 titled Breach of Contract Versus Delict on the issues in Nashua op cit note 2.

${ }^{427}$ Kruger $v$ Coetzee 1966 (2) SA 428 (A) at 430 E-F.

${ }^{428}$ Ibid. See also Indac op cit note 417, and similarly the discussion in FR Malan and JT Pretorius (1994a) 'Liability of the Collecting Bank: More Clarity?' 6(2) SA Mercantile Law Journal at 218 where the decision in KwaMashu Bakery Ltd v Standard Bank of South Africa Ltd 1995 (1) SA 377 (D) (hereafter KwaMashu) which approves of a duty of care on a collecting bank in relation to the true owner of a cheque) not to act negligently when dealing with the cheque. This does not mean that a collecting bank will automatically be liable in each instance, as its liability is based in delict. Accordingly the requirements for delictual liability must first be met, that is causation, conduct and lawfulness. Liability though will fasten on the facts of each case. See further in relation to each of these components of delict, WG Schulze (2006) 'Delictual Liability of a Bank Towards its Client: A New Prominence Given to the Element Of Causation: Court Judgment' 22(4) Tydskrif vir die Suid-Afrikaanse Reg at 836 and the discussion therein of First National Bank of Southern Africa Ltd v Duvenhage 2006 (5) SA 369 (SCA) (hereafter Duvenhage) where the court suggested that litigants in delictual claims should consider the element (or requirement in the case of a contractual claim) of causation at the outset of considering the claim in that causation should be the starting point in considering to institute (or defend) an action based on delict (or contract). Schulze however says that the potential prominence given just to causation over the other elements of a delict should be viewed with caution as all elements of a delict, including that of causation, should be present before one could claim successfully on delict..

${ }^{429}$ Colman v Dunbar 1933 AD 141 at 157-158. See Moorcroft (2010) op cit note 407 at 18.7; and FR Malan and JT Pretorius (1994c) 'Questions of Negligence and the Collecting Bank: A Brief History of the Bonitas Trilogy' 6(1) SA Mercantile Law Journal at 117.

${ }^{430}$ Ibid.

${ }^{431}$ African Life Assurance Co Ltd v NBS Bank Ltd 2001 (1) SA 432 (W) 447E-448B; see also Moorcroft (2010) op cit note 407 at 18.8. See also ch 4, s4.5.2 titled Nature of the Relationship and Duties passim on evidential considerations in determining the extent a bank's duty of care.

${ }^{432}$ Moorcroft (2010) op cit note 407 at 18.1 and 18.2.

${ }^{433}$ Moorcroft (2010) op cit note 407 at 18.2; see also Fedgen Insurance Ltd v Bankorp Ltd 1994 (2) SA 339 (W) in relation to a teller not noticing altered payee details on a cheque, where Van Zyl J remarked that if there is something in the course of a transaction that should arouse suspicion, it may be reasonably expected of the banker to institute an inquiry and take such steps as may be required to mitigate loss.
} 
connection, should be the initial measure of the existence of the delict insofar as determining whether the loss for which damages are claimed is causally connected to the allegedly unlawful conduct. In that determination, 'one must make a hypothetical enquiry as to what probably would have happened but for the wrongful conduct of the defendant'. ${ }^{434}$

In Indac, ${ }^{435}$ the Supreme Court of Appeal (hereafter SCA) held that in respect of cheques, a collecting banker owes the owner of a cheque a duty of care not to collect its proceeds negligently on behalf of one not entitled to payment. ${ }^{436}$ This duty, the court said, was developed and accepted as encompassing an obligation to take reasonable care when receiving and processing an application to open a new banking account through which cheques belonging to another are subsequently collected for payment. ${ }^{437}$ Further, in regard to the identity of a new client, the SCA in Energy ${ }^{438}$ did not lay down general guidelines in this regard, but agreed with the trial court's statement that when opening a new account 'the very least that is required of a bank is to properly consider all the documentation that is placed before it and to apply their minds thereto'.

\subsection{Identity Verification}

Banks are required in terms of common law ${ }^{439}$ and statute ${ }^{440}$ to identify and verify prospective clients who want to open (bank) accounts. ${ }^{441}$ Regulations under the South African Bank Act ${ }^{442}$ require banks to appoint compliance officers with senior executive status in the bank and to maintain an independent and adequately resourced compliance function. This is required in the enforcement of AML/KYC/CDD rules and regulations. $^{443}$

Ramasastry ${ }^{444}$ believes, however, that banks should not be responsible for protecting customers' personal computers from identity-theft scenarios that involve 'Phishing' attacks on bank customers. ${ }^{445}$ The net effect

\footnotetext{
${ }^{434}$ Duvenhage op cit note 428 at par 17.

${ }^{435}$ Indac op cit note 417.

${ }^{436}$ See similarly Kwamashu op cit note 428.

${ }^{437}$ For a survey of the decisions and law that relate to the possible delictual liability of banks, see Malan and Pretorius (1994a) op cit note 428 at 218; and JT Pretorius (2002) 'New Accounts and the Collecting Bank' 14(1) SA Mercantile Law Journal at 93.

${ }^{438}$ Energy Measurements (Pty) Ltd v First National Bank of South Africa Ltd 2001 (3) SA 132 (W) (hereafter Energy Measurements).

439 See KwaMashu op cit note 428; Powell v ABSA Bank Ltd (t/a Volkskas Bank) 19982 SA 807 (SEC); Energy Measurements op cit note 438.

${ }^{440}$ See ch 8, s8.5 on AML regimes.

${ }^{441}$ Section 3.23 of COBP says that a bank will generally only act a customer's written instructions, once the bank is satisfied that the customer's identity has been established by means of the customer's PIN, identity document, signature or other unique means of personal, identification. The bank will accept other forms of authority in exceptional circumstances only or where the nature of the process so dictates, for example internet, telephone or ATM banking. See the COBP as described in ch 12, s12.3.2.10 titled Ombudsman for Banking Services of South Africa. For a discussion of the rights and responsibilities of banks and consumers detailed in the COBP, see ch 7, ss7.3.6.5.3 titled The Bank and 7.3.6.5.4 on Bank Customers. ${ }^{442}$ Act 94 of 1990.

${ }^{443}$ Particularly in relation to FICA. See ch 8, s8.5 on AML regimes. See also the discussion in L de Koker (2002) 'Money Laundering in South Africa', available at http://goo.gl/yvqnN.

${ }^{444}$ A Ramasastry (2005) 'Do Banks Have a Legal Duty to Notify Customers About Specific Computer Viruses? A Miami Suit Raises the Question' Findlaw, available at http://goo.gl/MMuqA.

${ }^{445}$ It has however become common practice by many banks around the world to offer their clients free 'security software' so as to mitigate against the risk of 'Phishing' and general malevolent software - malware - that could compromise online banking. See further ch 5, ss5.7.4.4 titled Malware and Viruses, and 5.7 titled Security Aspects of Mobile Technology and Application to MFS, explaining the use of OTPs.
} 
proffered though is that banks should not be responsible for incidences of these attacks. ${ }^{446}$

In respect of differentiating between opening accounts for new ('stranger) and existing accounts, the SCA in Columbus Joint Venture v ABSA Bank Ltd quoted with approval Malan J (as he then was) in the court $a$ quo: ${ }^{447}$

\begin{abstract}
'Where a stranger requests that an account be opened for him the circumstances are quite different from those when an existing client applies. An existing client asking for further facilities or another account is known to the bank and his personal particulars are, if not known to the official, ascertainable. Where a stranger approaches the bank, the need for objective evidence of his trustworthiness and creditworthiness is apparent. His own ipse dixit is not sufficient. ${ }^{448}$
\end{abstract}

In Bredenkamp and Others $v$ Standard Bank of South Africa Ltd and Another ${ }^{449}$ the court held that banks are put on enquiry in respect of existing and future customers. They are required to be aware of the possibility of a bank account being used with impunity to commit fraud or to launder monies. While this enquiry differs depending on the knowledge the bank has in respect of the customer, banks in their dealings with customers must be alert to the possibility of fraudulent conduct on their part. ${ }^{450}$ Failure on the part of a bank to meet the standards of control may result in a bank being liable for losses and even criminal sanction. ${ }^{451}$ A bank though is not obliged to contract with a client. ${ }^{452}$

\title{
7.3.6.5.3.3 Security and Efficacy of Systems ${ }^{453}$
}

Banks and payment providers must also use industry standard security systems that relate to internal controls ${ }^{454}$ and processes, ${ }^{455}$ as these are customer-facing. ${ }^{456}$ This would also presumably include being

\footnotetext{
${ }^{446}$ German banks cumulatively also disclaim responsibility for any risks exposed to customers 'beyond the banks' control'. See Bundesverband Deutscher Banken (2007) 'Online Banking Security', available at http://goo.gl/bKK5G at 5. This, it is submitted, is untenable as a blanket vindication for banks and other financial institutions in the light of the potential highlighted by incidents of internal fraud that assists 'Phishing' syndicates. For a representative report on these internal bank syndicates and their modus operandi, see Legalbrief (2010) 'ABSA Employees in R1.38m Bank Fraud Case', available from http://goo.gl/LbJYr.

${ }^{447}$ Columbus op cit note 411 at $510 \mathrm{~F}-\mathrm{G}$.

${ }^{448}$ Ibid at 97G. See also the discussion in JT Pretorius (2000) 'More Guidelines on the Negligence of the Collecting Bank' 12(3) SA Mercantile Law Journal at 359.

${ }_{449}$ Bredenkamp and Others $v$ Standard Bank of South Africa Ltd and Another (09/7907) [2009] ZAGPJHC at 51, (hereafter Bredenkamp).

${ }^{450}$ Commissioner South African Revenue Service \& Another v ABSA Bank Limited \& Another 2003 (2) SA 96 (W) (hereafter SARS).

${ }_{451}$ Bredenkamp op cit note 449 at par 52.

452 Moorcroft (2010) op cit note 407 at 18.11, citing Siman \& Co (Pty) Ltd v Barclays National Bank Ltd 1984 (2) SA 888 (A) at 910B. The Bill of Rights though may have application here if some form of discrimination could be shown.

${ }^{453}$ See ch 4, s4.8.3.8 titled Security and Reliability of Payments; and ch 5, s5.7.4 titled Common Security Threats.

${ }^{454}$ See S Powell (2009) 'Critical Measures to Protect Against Rocketing EFT Fraud Risk' Without Prejudice December 4850 , who outlines the possibility of bank employee fraud.

${ }^{455}$ While not law per se, the SARB's persuasive Position Papers outline what is required of those engaging in payments. In particular, designated clearing system participants involved in the NPS must be able to comply with all security and payment industry standards that are applicable. While this refers to the NPS, the need for security criteria using industry standard presumably extends to those employed in any consumer-facing systems. See SARB (2000) 'NPS 01/2000: Position Paper on Risk Reduction Measures for Payment Clearing Houses in the NPS', available at http://goo.gl/GtKXz; and SARB (2008) 'Position Paper Number 02/2008: Interbank Settlement Network Security Architecture', available at http://goo.gl/xZeGA. See also ch 12, s12.3.1 titled Overview on the role of SARB Position Papers.

${ }^{456}$ At a statutory level, the ECTA also has a peremptory requirement on 'payment systems' in relation to 'transactions' insofar as $s 43(5)$ says that '[t]he supplier must utilise a payment system that is sufficiently secure with reference to accepted technological standards at the time of the transaction and the type of transaction concerned'; while s43(6) fastens liability on
} 
aware of ${ }^{457}$ preventing, ${ }^{458}$ and preempting ${ }^{459}$ any security threats or any other factors that would affect the efficacy of their systems.

The security employed by credit card company Diners Club was challenged in the case of Diners Club SA (Pty) Ltd $v$ Singh and Another ${ }^{460}$ where Singh alleged that the security system for ATM access and, in particular, access to customer PINs was able to be compromised, an allegation ultimately rejected by the Court.

While the court found that Singh was 'dishonest,' the case however highlighted the inability - based on confidentiality and issues - of potentially affected customers to gain access to information on internal bank processes to assist in formulating an action for loss. ${ }^{461}$

There have however been reported instances of sophisticated and determined syndicates involving MNO service providers and bank staff in cahoots to harvest bank user names and passwords and intercept One Time Password (hereafter OTP) SMSs. ${ }^{462}$

\subsection{Bank Customers}

As discussed above, ${ }^{463}$ in financial services generally and banking specifically, a client generally has some broad duties to his banker or financial service provider. This however depends on the nature of the relationship, and the duties are generally limited. ${ }^{464}$ At common law, the duty of the customer includes

the supplier insofar as he will be 'liable for any damage suffered by a consumer due to a failure by the supplier to comply with subsection (5).' A 'transaction' is widely defined in the ECTA to be 'a transaction of either a commercial or noncommercial nature, and includes the provision of information and e-government services.' While 'payment system' is not defined in the ECTA but is defined in the National Payment System Act 78 of 1998 (hereafter NPSA) as amended as 'a system that enables payments to be effected or facilitates the circulation of money and includes any instruments and procedures that relate to the system', the expansive 'transactions' definition in the ECTA could, it is submitted, include any consumer-facing electronic payment (system) and general banking and payment facilities offered by banks, or non-banks providing MFS, or merchants selling goods and services. At a self-regulatory level, the COBP invokes a responsibility of a bank to 'provide reliable banking and payment systems services and take reasonable care to make these services safe and secure'. See COBP (2012) op cit note 398; and the OBSSA described in ch 12, s12.3.2.10 on the OBSSA. For a discussion thereof, see Van der Bijl (2007) op cit note 2 passim.

${ }^{457}$ This would include notices from and interaction with industry bodies that deal with security issues. South Africa's banking risk assessor is the South African Banking Risk Information Centre (SABRIC) which coordinates and disseminates relevant information. In the US, there is the Financial Services - Information Sharing and Analysis Center, the industry forum for collaboration on critical security threats facing the financial services sector, launched in 1999, in response to 1998's Presidential Directive 63 later updated by 2003's Homeland Security Presidential Directive 7 that mandated that the public and private sectors share information about physical and cyber security threats and vulnerabilities to help protect the US's critical infrastructure. See www.fsisac.com.

${ }^{458}$ The OBSSA advice to member banks in relation to card cloning reasons that where a payments system is open to abuse, the bank is expected to take reasonable measures to ensure that it is safe in terms of the COBP's 'reasonable care' criteria. OBSSA (2008) op cit note 413 at 6 ; and COBP (2012) op cit note 398.

${ }^{459}$ This would presumably also mean that the bank has the responsibility to ensure that the facilities it puts into place for customers to transact must be reasonably protected from being tampered with. In cases where banks provide secure SIM cards to customers with their own SIM Application Toolkit/ Wireless Internet Gateway (hereafter S@T/WIG) menu systems on the SIM cards, and/or provide wireless 'Over The Air' (OTA) updates to these SIMs in mobile phones, a customer would have a reasonable expectation of these SIMs being secure from physical and OTA tampering. See ch 5, s5.5.3.2 on S@T mobile phone navigation menus for MFS on MFS/WIG and OTA updates.

${ }^{460}$ Diners $C l u b$ op cit note 415.

${ }^{461}$ On secrecy in the interbank process, see Malan and Pretorius (2007) op cit note 327; and Nagel and Pretorius (2005) op cit note 350 .

${ }_{462}$ See Legalbrief (2010) op cit note 446.

${ }^{463}$ See ch 4, Section 4.5.2 titled Nature of the Relationship and Duties

${ }^{464}$ Inter alia, the client must warn the bank of known or suspected forgeries or fraud and (in relation to cheques) must draw his cheques with reasonable care to prevent forgery or alterations. He generally has no duty to supervise his own employees, 
exercising care and skill in transmitting instructions to avoid misleading the bank or facilitating fraud ${ }^{465}$ and to notify the bank of known unauthorised payments. ${ }^{466}$

The COBP has a number of 'reasonable care' duties ${ }^{467}$ which it fastens on bank customers. These include expecting clients to inform their bank of any unauthorised transactions on their accounts; of the loss of items such as cheque books and credit cards; when they know or suspect that someone is aware of their secure access code like a PIN; ${ }^{468}$ and where they are aware of unauthorised access to their account or to pivotal account access details like their PIN.

Generally, they are also meant to take safety precautions when using cheque books, debit and credit cards, Internet banking and payments, cell phones for banking, telephone banking using IVR systems and ATMs. It is also recommended that their access PINs and their associated account details should never be stored together, and they should not willingly divulge their PINS to third parties. ${ }^{469}$

All the risk-mitigation criteria require a level of common sense, which is usually acquired by a degree of financial and technical literacy. The evidence in South Africa is that while financial and technical literacy is increasing ${ }^{470}$ there are still huge vulnerabilities especially in rural areas where there may be insufficient levels of general, technical and financial literacy.

'Phishing ${ }^{471}$ emails however are so realistic that even financially and technologically literate persons may have difficulty in distinguishing scam emails from those sent by their bank, especially if the wording and design of the 'phishing' scam emails suggest that they themselves are being sent to avoid scams. ${ }^{472}$

Indeed, the court in Roestof $v$ Cliffe Dekker Hofmeyr Inc ${ }^{473}$ relating to 'Phishing', found it sufficient that a

exercise care in running his own business, detect fraud, or check his own bank statements. Moorcroft (2010) op cit note 407 at 15.21 .

${ }^{465}$ London Joint Stock Bank v Macmillan and Arthur [1918] AC 777 HL.

${ }^{466}$ Greenwoods v Martins Bank [1933] AC 51 HL.

${ }^{467}$ See COBP (2012) op cit note 398 at 17, which under a section 'What We Expect From You', says that 'there are certain principles that you as our client should adhere to in our relationship.' Specific security examples in the COBP are outlined in s5.13: 'Reasonable Care'.

${ }^{468}$ See for example the M-pesa rules T\&C from MNO Vodacom, available at http://goo.gl/nyfyn.

${ }^{469}$ Moorcroft (2010) op cit note 407 at 15.21; see also ABSA Bank CBP at http://goo.gl/Pwgxj. Some bank T\&C insist that only transactions requested from the mobile phone number registered with the bank and associated with a particular account 'will be deemed legitimate and acted upon.' FNB (2010) 'Cellphone Banking Terms and Conditions', available at http://goo.gl/S2jM5 at s1.7 and similarly African Bank (s.d.) 'African Bank General Terms and Conditions', available at http://goo.gl/Dk893 at sD7. As Van der Bijl correctly asserts, this security motif is possibly tautological in that identity theft via 'Phishing' interception and OTP SMSs will in some sense 'legitimise' the fraudulent activity to the detriment of the account holder. Van der Bijl (2009) op cit note 2 at 166. Harsh or inconsistent as this may appear, as Schulze points out, banks are simply not prepared to negotiate on most of the important terms in their agreements with their clients such that clients are usually left with what he terms a Hobson's choice: 'take it or leave it'. See WG Schulze (2004d) op cit note 415 at 146. In Diners Club op cit note 415 at 659A, where the court indicated in relation to a credit card agreement, that although it might be said that a liability clause was one-sided and favoured Diners Club, the company was still entitled to protect itself by placing the risk of a wrongful user on its customer. Provisions of the CPA relating to unfair contractual terms may however alter the nature of what terms may be considered to be acceptable in bank-customer service contracts. See for more on the CPA ch 12, s12.10 titled Consumer Protection Laws.

${ }^{470}$ See generally ch 2, ss2.1 titled Introduction and 2.3 titled The Scope of MFS in outlining the rationale for and scope of MFS.

${ }^{471}$ See ch 5, s5.7.3.1 on 'Phishing'.

${ }^{472}$ In relation to 'cloning' or illegal duplication of credit and debit cards, see OBSSA (2008) op cit note 413; and for the legal implications thereof, see Van der Bijl (2007) op cit note 2; and Diners Club op cit note 415.

${ }^{473}$ Roestof v Cliffe Dekker Hofmeyr Inc (34306/2010) [2011] ZAGPPHC 219 (2012) ('hereafter 'Roestof). 
bank just provide due and ubiquitous warnings to its customers. ${ }^{474}$ This, the court reasoned, would obviate any responsibility of the bank for any loss incurred by a financially-versed customer whose identity and bank access credentials were stolen through their own actions. ${ }^{475}$

\subsubsection{5}

\section{Non-Banks}

While there is copious case law relating to risk allocation for banks, as well as the responsibility banks have to their customers, more vexing is the question as to whether the same relationship and loss-allocation principles ${ }^{476}$ can be fastened onto non-banks who may be providing similar services to licensed banks, albeit providing more transaction-focused services and no intermediation. ${ }^{477}$

It is submitted that similar but not exact principles could obtain to non-banks, albeit couched in terms of breach of contract and delict.

A non-bank and its customer will thus owe each other reasonable 'duties of care', simply because this is what is expected in any pecuniary relationship. Information asymmetries ${ }^{478}$ that favour the more powerful non-bank entity however, it may be suggested, would mean that the non-bank has some additional responsibilities ${ }^{479}$ compared to the customer.

However, the extent and implications of this is - until the perimeter activities of a non-bank involved say in MFS are codified - unknown. Some general principles though can be extracted from Commissioner, South African Revenue Service and Another v ABSA Bank Ltd and Another, ${ }^{480}$ which said that it is not possible without evidence to determine how great a burden of recognition of the legal duties contended for will place upon banks. ${ }^{481}$

\footnotetext{
${ }^{474}$ The court indicated that notices in ABSA bank's banking web pages warning of 'Phishing' scams as well as regular email warnings to that effect fastened then a responsibility on the affected customer to be aware of the potential of these scams occurring and for that customer not to divulge any banking login details in emails supposedly with the banks' 'getup' or purported links to the banking web site.

${ }^{475}$ In a somewhat scathing judgment, Du Plessis J at par 94 said that the failure of the 'Phishing' victim, an attorney, to read the ubiquitous 'Phishing' warnings he had seen on the bank's web site amounted to his own negligence that directly led to his loss. Further, said the Judge at par 22, the fact that the fraudster used an easy-to-obtain "@gmail” email address for communications with the victim rather than an email address corresponding to a supposed large company that usually has its own domain name, should also have alerted the victim to a potential fraud. It may be said here as an aside that if an attorney used to dealing inter alia with FICA documents, companies and large amounts was fooled, this case emphasises just how sophisticated these scams have become, placing the layman in peril of fraud. The large increase reported by the South African Banking Risk Information Centre (SABRIC) on 'Phishing' scams bears out this concern. See SABRIC (2010) 'Phishing Scams Rising in South Africa', July, available at http://goo.gl/3X6aN. This rise, it is submitted, also indicates that more normative rules with loss-allocation criteria that deal with permutations of 'Phishing' and similar scams are required in law to protect both the financial institution and the consumer.

${ }^{476}$ For example, responsibilities relating to identify verification and standards of care. See ch 4, s4.5.2 titled Nature of the Relationship and Duties on the incidents of the bank-customer relationship.

${ }^{477}$ See ch 6, ss6.5 on MNO-Led MFS models; and 6.6 on hybrid MFS models.

${ }^{478}$ See Lin and Kraus (2010) op cit note 259.

${ }^{479}$ In common bank terms, 'superadded obligations,' as per Foley v Hill (1848) 2 HLC 28. See also ch 4, s4.4.4 titled Legal and Economic Effects of Deposits.

${ }^{480}$ SARS op cit note 450 at par 123.

${ }^{481}$ This case related to potential customer-monitoring duties that could be imposed on a bank. Further, as noted by Malan and Pretorius in relation to contributory negligence potentially fastening on a bank, questions of negligence, contributory negligence, and causation may finally prove crucial to the determination of the delictual liability. These questions are complex. In all then, the 'unknown effect' issue remains generic even to non-banks. See Malan and Pretorius (1994c) op cit note 429.
} 


\subsection{Overview}

The ever-expanding universe of payments encapsulated by the popularity of MFS has of necessity involved the inclusion of a number of third parties in the process chain. There may be technical intermediaries and agents acting for or on behalf of an MNO or bank. A claim for damages against these third parties by someone claiming a loss due to their actions could potentially lie in contract or delict.

\subsection{Agents}

While in a transformative MFS sense there are cash-in/cash out 'agents, ${ }^{482}$ at an MNO telecommunications-service level, the MNO may have a retail-facing agent - usually called a Service Provider ${ }^{483}$ but which may also be a retail agent contracted to that Service Provider or MNO - who is responsible for the customer-facing service component, which could include providing new or replacement SIM cards via a 'SIM swap' process, to the customer. At a financial level, the agent could be a bank agent or an 'outlet' accepting and dispensing cash from and to customers. The agent could also be an automated agent. $^{484}$

The facts in Nashua ${ }^{485}$ detail how losses were suffered by the plaintiff when unauthorised EFTs were effected out of the plaintiff's Internet bank account by a person - unknown to the plaintiff and unauthorised by it to do so - who managed to obtain from the defendant, a SIM card through a 'SIM swap' process that allowed the fraudsters to intercept a verification OTP SMS sent to the plaintiff's mobile phone, which combined with the obtaining of the plaintiff's user name and password, led to an unauthorised EFT. ${ }^{486}$ The action in delict was against Nashua as an agent of MNO Vodacom, who distribute the SIM cards provided to it by Vodacom to its Nashua mobile phone subscription contract holders. The court, following Lillicrap ${ }^{487}$ held however that since Nashua did not owe the plaintiff any independent duty of care if the plaintiff did not have a mobile phone contractual relationship with the plaintiff, ${ }^{488}$ the plaintiff could not sue in delict.

It is submitted that the court missed an opportunity to properly define the boundaries of the liability for

\footnotetext{
${ }^{482}$ See inter alia on the use of agents in the various MFS models, ch 2, s2.5.2 titled Use of Agents ; ch 6, ss6.5.3 on Use of Agents; 6.5.5.4 titled Use of Agents and Correspondents; and 6.6.3 titled Use of Agents.

${ }_{483}$ See ch 6, s6.2 on Relationships Generally in the Mobile Ecosystem; and ch 6, s6.3 titled Relationships and Types of Models in the MFS Ecosystem.

${ }^{484}$ For the distinction between agents and intermediaries in an MFS context, see ch 6, ss6.4.4.4 titled Use of Agents; and 6.5.5.4 titled Use of Agents and Correspondents.

See ch 7, s7.2.6.3.2 titled Automated Agents.

${ }^{485}$ Nashua op cit note 2.

${ }^{486}$ It was not clear how the fraudster obtained the critical user name and password of the plaintiff to enter the bank account, but the court said phishing was suspected in that the ability to successfully use an OTP was predicated on also having access to that user's username and password for the account. As such, Nashua op cit note 2 in allowing the SIM swap was too far removed from the fraudulent access. See ch 5, s5.7.4.1 on so-called 'Phishing' scams.

${ }^{487}$ Lillicrap op cit note 224 .

${ }^{488}$ Nashua op cit note 2 at par 27.
} 
technology hacking, instead couching its decision in terms of a legal distinction between liability based on delict and contract. ${ }^{489}$

\subsection{Intermediaries}

At a technical level, ${ }^{490}$ banks provide OTPs via SMS to customers. The SMS containing the OTP could be sent by a bank to its customer directly via the bank's direct large-volume SMS connection to a MNO acting as a technical 'intermediary, ${ }^{, 41}$ or rather by the bank to the MNO via a WASP. A WASP ${ }^{492}$ also acts as a technical 'intermediary' who in turn connects to an MNO. ${ }^{493}$

As noted above, from a contractual perspective, the bank must carry out the customer's mandate with the reasonable care and skill required. The standard of skill and care is what is reasonably expected of persons of similar standing and competence.

While Gkoutzinis ${ }^{494}$ believes that this duty extends to the bank merely selecting reliable intermediaries to carry out part of the service in appropriate circumstances, Howard and Masefield believe that this duty also fully extends to intermediaries. ${ }^{495}$

Munir ${ }^{496}$ says however that:

'Like the customer, the bank is simply a user of the telecommunications service and the technical aspects of the system may be beyond the bank's control ... Fairness requires the apportionment of liabilities among all parties involved ... depending on the relative degree of fault.'

\footnotetext{
${ }^{489}$ It is submitted that the facts of this case, beyond the evidence of the expert witness who fastened blame on the victims, did not provide any absolute certainty as to whether the victim was the cause of the evident compromising of the critical user name and password which allowed two of the three necessary components to authenticate a new payment beneficially. In that respect, notice should be taken of the existence of very sophisticated malware that allows capturing of user names and passwords without the victim even knowing of the malware's existence, let alone its origin and modus in capturing critical access data. The point here then is that it is not obvious - beyond a balance of probabilities - that there was direct negligence, by, and which may fasten on, the victim: they could simply have been unsuspecting victims, like many others, of global attempts to seed malware on phones and computers for nefarious purposes such as garnering user access data like user names and passwords for web sites, even those with a direct and secure "https" link - the "s" means secure - rather than a nonsecure "http" link. Further, the final step in the fraud in this case - that of the background interception of SMSs on phones, in this case the OTP SMS sent by the bank when a payment beneficiary was added - is also part of the modus of some malware. See further ch 5, ss5.7.4.4 titled Malware and Viruses and 5.7 titled Security Aspects of Mobile Technology and Application to MFS, explaining the use of OTPs. See also KwaMashu op cit note 428 in relation to liability for loss fastening on the facts of each case.

${ }^{490}$ There are clearly multiple layers of technical assistance provided to bank and MNOs - this section though focusses for brevity on the technical facilitators used by banks.

${ }^{491}$ The ECTA defines an 'intermediary' as 'a person who, on behalf of another person, whether as agent or not, sends, receives or stores a particular data message or provides other services with respect to that data message.' The context, it is submitted, of the intermediary as used in the ECTA is that of a technical intermediary who facilitates the actual transmission of a data message.

${ }^{492}$ See ch 6, s6.5.4.2 on WASP VAS.

${ }^{493}$ See ch 5, s5.7 titled Security Aspects of Mobile Technology and Application to MFS, explaining the use of OTPs.

${ }^{494}$ AA Gkoutzinis (2006) Internet Banking and the Law in Europe at 34.

${ }^{495}$ M Howard and R Masefield (eds) (2006) Butterworths Banking Law Guide at 572.

${ }^{496}$ AB Munir (2004) Internet Banking: Law and Practice at 232-5/233, as cited by Van der Bijl (2009) op cit note 2 at 171. Recital 47 of the recent EU PSD op cit note 399 indicates that for the proper functioning of credit transfers and other payment services, the 'Payment Service Provider' and its intermediaries such as processors should have contracts that ensure legal certainty such that their mutual rights and obligations are agreed upon, and which should include issues related to their respective liabilities. See ch 9, s 9.6.2.5.2.4 titled Liability Allocation between PSP and its Technical Providers. Munir's suggestion then, resonates with Recital 47.
} 
Van der Bijl, citing Munir, ${ }^{497}$ suggests that in the case of an 'intermediary ${ }^{498}$ somehow being drawn into the circumstances of a loss, resolving which of the parties should bear the risk of unauthorised transactions could depend on whether the unauthorised transaction occurred within or outside a specific party's control, the degree of fault displayed by the parties, or whether an offence has been committed in terms of legislation by a specific party. ${ }^{499}$

\subsubsection{6}

\section{Application to MFS}

The concept of allocation of loss by placing liability for (possibly avoidable) losses on the party responsible for the loss is usually predicated on both parties having access to equivalent information. It is submitted though that in a MFS and commercial context it may prove difficult to achieve informational symmetries given the small screen sizes of handsets. An informational asymmetry may mean that one party is well positioned to take precautions against a loss, but another party actually has superior information that is necessary to determine the expected value of taking these precautions. In such a case, according to Gillette and Walt, it would be desirable to have a legal rule that induces the party with superior information to convey it to the uninformed party or to develop precautionary measures that can be utilised by the less informed party.

Indeed, this asymmetry appears to be recognised by the Ombudsman for Banking Services in South Africa (hereafter OBSSA), albeit in relation to ATM cards duplicated and used by fraudsters but which may be of general application:

'The bank cannot make a bare allegation that the customer must have been negligent in some way. The bank must produce substantial evidence or argument that the card holder was negligent and is therefore responsible for the losses incurred. It is impossible to specify what would constitute substantial evidence or

\footnotetext{
${ }^{497}$ Van der Bijl (2009) op cit note 2 at 171

${ }^{498}$ Van der Bijl Ibid appears to conflate the use of the term 'intermediary' in the ECTA to extend to someone doing a 'SIM swap.' It may be suggested, however, that correct use of terminology in the case of the person who provides the (replacement) SIM is rather that of an 'agent,' be they an agent of the MNO; or a retail agent of the primary agent to the MNO, the Service Provider. As per the similar use in Recital 47 of the PSD, op cit note 399, the term 'intermediary' is geared rather towards technical processes for distributing a data message SMS as a technical intermediary. Nonetheless, if a 'SIM swap' - or the virtual equivalent where internal fraud within the MNO amounts to the same as a physical SIM swap resulting in the diversion of an SMS containing a transaction-verification OTP to the fraudsters that leads to a loss, is (somehow) outside the bank's control but within the control of the MNO, she believes that it would be difficult to fasten liability solely on the bank but would rather fasten liability on the MNO acting as a 'service provider'. Provisions in RICA op cit note 77 - specifically ss40(1)(a), 40(2) and 40(3) which provide that an MNO or his agent obtain identification documents of the SIM card's owner when issuing physical SIM cards - may possibly make the MNO or its agent liable in terms of RICA if this was not done according to the full requirements of the Act. Even so, this may have limited application in the case of virtual' SIM swaps' due to internal MNO fraud which results in the diversion of SMSs to fraudsters - and then a loss. Specifically, this is because Chapter XI of the ECTA op cit note 66 dealing with 'Limitation of Liability of Service Providers' provides for a limitation of liability of 'service providers' who inter alia 'send data 'in an automatic, technical manner without selection of the data' [s73(1)(c), but who must send that data 'in a manner that makes it ordinarily inaccessible to anyone other than anticipated recipients' [s73(2)(b)]. Clearly internal fraud that provides the fraudsters' access to an (OTP) SMS intended for a genuine banking customer would bring the limitation into question, although the MNO would have to be proven to be negligent in allowing the circumstances for the internal fraud, say by lax internal supervision. With the sophistication of these syndicates and reports indicating their apparent growing deep penetration into banks and MNOs, as with many internal company processes, it would be difficult - but not impossible, one may assume - to prove that the MNO internal supervision was entirely negligent.

${ }^{499}$ Ibid. Van der Bijl sensibly also suggests that statutory intervention is possibly the best solution to regulate this position, by providing for apportionment or distribution of liability in such cases to the extent that the acts or omissions of the various parties contribute to a loss.
} 
argument as each case would be evaluated on its own merits ... The bank is undeniably in the best position to gather evidence in this regard or to take steps to limit its risk and exposure. Except in the most obvious and rare of cases it would be absolutely impossible for a bank customer to prove a negative assertion - that he was not negligent when his PIN and card was compromised and then cloned ... Any decision made will be based on a balance of probabilities. ${ }^{500}$

Hence banks and MNOs, as experts in payments, banking and MFS, will usually have superior information relative to any given customer about the schemes used to defraud individual customers. Customers of banks and MFS, on the other hand, are in a superior position to take certain precautions that will protect their accounts against theft or fraud. ${ }^{501}$

ABSA Bank, however, provides multiple media methods for the T\&C of a transaction or contract to be accessed, including an IVR system that will read out the T\&C. Some suggest however that a financial institution may be able to shoulder more of the loss as it is able to spread the loss across its customer base. $^{502}$

Further, in the MFS environment, the role of financial literacy along with technological literacy has been identified as being an important issue in securing transactions and mitigating risk. Growth in services and users has led to increased incidents of fraud and mistake in not just MFS transactions, although most of the growth has come from consumers in developing countries. ${ }^{503}$

While MFSPs have filled a critical need for consumers, such services raise important issues of consumer disclosure, safety and education. The crux of the issue is what is seen as an asymmetric relationship between user and MFS provider, where there may be an imbalance of power, information and resources between consumers and their financial service providers, placing consumers at a disadvantage. ${ }^{504}$

Increased consumer protection in the form of set rights and responsibilities between the parties may redress the imbalance, with readily available information relating to $\mathrm{T} \& \mathrm{C}$ and pricing, by prohibiting any financial institution or its agents from engaging in unfair or deceptive practices, and by providing timely and accessible mechanisms to lodge complaints and obtain redress if necessary. ${ }^{505}$

A corresponding obligation then by the MFSP (or financial institution) would be to inform consumers of any general breaches of security on their system, attempts to unlawfully access a particular person's account, and to put in place general risk-management procedures such as specific dummy 'duress PINs' where the input of that specific PIN when inputted is a silent alarm-type that indicates that the user is under duress such that the system then merely simulates a transaction process to completion, but which does not

\footnotetext{
${ }^{500}$ OBSSA (2008) op cit note 413 at 6.

${ }^{501}$ See CP Gillette and SD Walt (2008) 'Uniformity and Diversity in Payment Systems' 83 Chicago-Kent Law Review 499 at 532.

${ }^{502}$ See Rubin (1991) op cit note 402 at 564.

${ }^{503}$ See SL Rutledge (2010) 'Consumer Protection and Financial Literacy: Lessons from Nine Country Studies the World Bank' at 5, available from http://bit.ly/bYhcII.

${ }^{504}$ Ibid.

${ }^{505}$ Ibid.
} 
properly execute it.

As Schulze points out in relation to payment cards and e-money, issuers thereof:

'...unilaterally determine the rules and procedures in terms of which cards and e-money are to be used including who bears the risk in the case of loss arising from the use of such products. Suffice it to say that the card or purse holder bears the largest part of the risk of loss resulting from the use of the card or electronic purse. $^{506}$

In essence then, a specific set of harmonised statutory rules (such as those outlined by the EU specifically in regard to retail electronic payments) may codify existing soft payment rules, but now in a more symmetrical and fairer manner so as to provide a degree of protection to all parties in electronic payments be it between the payor and the recipient or between the payor and the recipient and their respective financial institutions. ${ }^{507}$

This thinking forms the basis of a recommendation in this thesis for a Payment Services Provider Law (hereafter PSPL) which will license PSPs and also incorporate normative rules for retail payment services. $^{508}$

\subsubsection{Unjustified Enrichment}

When an unauthorised or mistaken payment is made, the value by which the recipient may be said to have been unjustifiably 'enriched by transfer" ${ }^{509}$ of that value may be recovered through the application of one of a set of condictiones or Roman actions ${ }^{510}$ that are invoked where there is 'failure of the purpose of the transfer'. 511

These actions fall within the province of the law of unjustified enrichment, and are seen as a form of corrective justice. $^{512}$ Restitutionary actions are said to be needed because of the abstract system of transfer

\footnotetext{
${ }^{506}$ WG Schulze (2004c) 'Smart Cards and e-Money: New Developments Bring New Problems' 16(4) SA Mercantile Law Journal at 714 .

${ }^{507}$ For a similar understanding, see CJ Nagel and JT Pretorius (2010) 'Taxpayers Beware the SARS Cheque Refund' 73 Journal of Contemporary Roman-Dutch Law at 482, available at http://goo.gl/K74SB, who argue that although there has been a huge increase in the number and value of electronic transactions, there is no legislation in place that regulates these payments and the risks involved where these payments go wrong are borne by the customers of banks and that they believe that there is an urgent need for the banking industry to regulate these payments. It is submitted though that a Payment Services Provider Law (hereafter PSPL) would be a better implementation insofar as consumer protection is concerned.

${ }^{508}$ See ch 14, s14.1 titled Thesis Summary and General Conclusions.

${ }^{509}$ See Visser (2008) op cit note 170 at 222 . This is similar to the English law notion of 'enrichment by subtraction'.

${ }^{510}$ See ch 7, s7.3.6.8 titled Actions to Recover Value, which deals with the condictiones.

${ }^{511}$ See Visser (2008) op cit note 170 at 222. Further at 223, he refers to transfer as:
}

'[A] deliberate transfer of money, property or services from one person to another' as opposed to performance which could be
described as "'a deliberate transfer of money, property or services (which could include refraining from something) which discharges a duty or obligation".'

English law recognises a tracing order to persons who have been defrauded. Moorcroft (2010) op cit note 407 at $27-2$. This has not been applied to a great extent nor specifically in South Africa however which does not recognise 'tracing' per se.

${ }^{512}$ Du Bois (2007) op cit note 7 at 1043. 
of ownership used in our law. ${ }^{513}$

A vast swathe of the current legal thought and reported judgments in South Africa on unjustified enrichment revolves around mistaken or unauthorised payments where there is a 'banking' component to the payment. ${ }^{514}$

This is symptomatic of the systemic policy of central banks and governments to effectively limit the ability to effect and settle payments to institutions that have licenses to provide banking services, or who use banks as their intermediaries or mandatories for payment.

This may for example involve a payment via cheque, ATM card, or a debit or credit transfer of value, or even e-money where applicable.

Thus many cases of unjustified enrichment touch at some point on the bank-customer relationship from both the payor and recipient perspectives insofar as the bank or banks facilitating the payment may have made a mistake in payment, and/or may have been unjustifiably enriched when it became known that the recipient was not authorised to keep or withdraw the value received into their account.

The payment however usually follows the same legal structure where, generally speaking, the financial institution is seen to act as a mere neutral mandatory for the parties involved in effecting a payment, and does not usually, except under specific or unusual policy considerations, ${ }^{515}$ descend into the arena of determining the quality of the debtor-creditor relationship and the underlying transaction insofar as whether or not it gives the recipient the right to receive the value. ${ }^{516}$

\footnotetext{
${ }^{513}$ Van der Merwe, Van Huyssteen and Reinecke (1993) op cit note 5 at 148. See also ch 7, s7.2.2.2 titled Consensus. On application of Roman-Dutch remedies to reclaim physical goods, which may include physical bank notes, see the discussion of the rei vindicatio in ch 3, s3.13 titled Money in South African Law, and ch 13, s13.8.2.2 titled Specific Legal Effects.

${ }^{514}$ See for example: Nissan op cit note 291; Nedbank Ltd v Pestana op cit n401; Commissioner for Inland Revenue $v$ First National Industrial Bank Ltd 1990 (3) at 646-7 (hereafter Industrial); First National Bank of Southern Africa Ltd v Perry NO And Others 2001 (3) SA 960 (SCA) at 969F/G (hereafter Perry); SARS op cit note 450 at 129E-131; Commissioner of Customs and Excise v Bank of Lisbon International Ltd and Another 1994 (1) SA 205 (N) (hereafter Lisbon); Take and Save Trading CC and Others $v$ Standard Bank of SA Ltd 2004 (4) SA 1 (SCA).

${ }^{514}$ In that sense a cause is also absent. See Perry op cit note 513 at $969 \mathrm{~F} / \mathrm{G}$.

${ }^{515}$ See Nissan op cit note 291 at 16 where Streicher AJ noted with approval comments by Thirion J in Lisbon op cit note 513 in relation to receipt of money by an unauthorised recipient, that 'our law would be deficient if it did not provide a remedy for recovery of stolen money direct from the bank which received that money to the credit of the thief's account, for as long as the amount stands to the credit of the thief'. See also the judgment in Pestana op cit note 401, where it was stated at par 16.1 that '[o]nce the debit and credit occurred as they did, they constituted a completed juristic act independent of any underlying justa causa'. This judgment has been heavily criticised. See for example Schulze (2008) op cit note 170; and WG Schulze (2009) 'A Final Curtain Call, but Perhaps not the Last Word on the Reversal of Credit Transfers: Nedbank Ltd $v$ Pestana' 21(3) SA Mercantile Law Journal at 403. It has also been praised: see JC Sonnekus (2008b) op cit note 29.

${ }^{516}$ In the case of probable theft or misappropriation of funds brought to the attention of the financial institution, the bank may adopt what was termed a 'stakeholder' approach whilst there is a determination of the true state of affairs in the transaction. However, it reverses a transfer to a beneficiary unilaterally 'at its peril'. See Nissan op cit note 291. As Streicher AJ indicated in Nissan, courts often grant interim interdicts against persons in respect of allegedly stolen money paid into a bank account of the alleged thief and against the bank concerned, pending an action to determine whether the money had been stolen. See Lockie Bros Ltd v Pezaro 1918 WLD 60; and Perry op cit note 513 at par 18. See also Varvarinskoye op cit note 284 where ABSA bank was held to be aware of the true owner of warehoused funds based on documents that had been presented to it at the time of the opening of an account at that bank.
} 


\subsection{Overview}

South African law recognises a number of actions to reclaim funds which the owner did not intend to pass to the recipient. While there are references to the need for an enrichment action, ${ }^{517}$ there is no general enrichment action in South African law $^{518}$ and some commentators have queried the need for one lest it 'introduces uncertainty and the possibility of runaway liability'. ${ }^{519}$ Hence, while some notable exceptions extend the boundaries of Roman-Dutch law as being 'a living system adaptable to modern conditions, ${ }^{520}$ most enrichment actions fall within traditional Roman condictiones and a few other related actions. ${ }^{521}$ They are the condictio sine causa specialis, condictio causa data causa non secuta, the condictio indebiti, the condictio ob turpem vel iniustam causam; and, to a very limited extent, the actio pauliana. ${ }^{522}$

Although they each have specific requirements usually pertaining to peculiar sets of facts, ${ }^{523}$ and could thus be considered to be constrained to their own probable spheres of influence, they are said to cover the typical enrichment actions that occur commercially today. ${ }^{524}$ The courts have however repeatedly recognised liability for enrichment where none of the old actions would necessarily apply. ${ }^{525} \mathrm{Just}$ as in English law the actions make it incumbent on the claimant to prove enrichment via a subjective process. ${ }^{526}$

There are three elements common to all enrichment actions. ${ }^{527}$ First, the enrichment of the defendant and the corresponding impoverishment of the plaintiff; second, a causal link between the defendant's enrichment and the plaintiff's impoverishment; and third, the absence of a cause that justifies the retention of the enrichment by the defendant.

\footnotetext{
${ }^{517}$ McCarthy Retail v Shortdistance Carriers CC 2001 (3) SA 482 (SCA) and then Perry op cit note 513. In McCarthy, the court indicated that enrichment actions were subsidiary to existing remedies.

${ }^{518}$ Du Bois (2007) op cit note 7 at 1045. See also Lotz (2005) op cit note 394 at 109, who notes that the appeals court in Nortje en ' $n$ Ander v Pool NO 1966 (3) SA (A) indicated that there is no general enrichment action, and that there should be an incremental development of the parameters needed for such an action before there is a recognition of a general enrichment action.

${ }_{519}$ Du Bois (2007) op cit note 7 at 1045 fn 16. See however the provisions of the CPA where liabilities for enrichment where others have ostensibly suffered are catered for. These may give rise to punitive damages that far exceed the purported enrichment.

${ }^{520}$ Streicher AJ in Nissan op cit note 291, quoting with approval at 24 the sentiments in Sv Graham 1975 (3) SA 569 (A) at 573E of extending Roman-Dutch law when necessary. See also Stratford CJ in Jajbhay v Cassim 1939 AD 537 who said at 542: 'Now the Roman Dutch law, which we must apply, is a living system capable of growth and development to allow adaptation to the increasing complexities and activities of modern life. The instruments of that development are our courts of law.'

${ }^{521}$ Visser (2008) op cit note 170 at 4. See also FR Malan (1992) 'Price $v$ Neal Revisited' 25(3) Acta Juridica at 131 where he says that SA's 'law of enrichment is concerned with actions and condictiones and not expressly with enrichment as a general source of liability.'

${ }^{522}$ While the functional properties of a payment may differ, the remedies available in the event of mistaken or unauthorised payment must in a sense fit into this limited range of actions for enrichment.

${ }_{523}$ Sonnekus (2008b) op cit note 29 at 19.

${ }^{524}$ Visser (2008) op cit note 170 at 5.

${ }^{525}$ Lotz (2005) op cit note 394 at 109.

${ }^{526}$ D Johnston and R Zimmerman (2002) Unjustified Enrichment at 4. By contrast, the German law approach is objective: a payment or non-pecuniary performance made without legal ground is recoverable, subject to defences.

${ }_{527} \mathrm{Du}$ Bois (2007) op cit note 7 at 1046. The condictiones always presuppose a valid transfer of ownership, except in the case of the condictio firtiva. FR Malan (1977) 'Share Certificates, Money and Negotiability,' 94(3) South African Law Journal at 249, citing Kelly op cit note 300 at 270.
} 
But, as Sonnekus ${ }^{528}$ suggests, since Kudu Granite Operations (Pty) Ltd v Caterna Ltd, ${ }^{529}$ common law condictiones need no longer be used as the only point of departure for a claim, such that the mere proof of the generic requirements common to all claims in enrichment will suffice. However, Sonnekus cautions that the corrective nature of the law of enrichment is such that it is not necessarily subject to what he terms the 'derogatory' effects of reasonableness and equity lest they cause damage to legal certainty. ${ }^{530}$

In respect of the modern payments ecosystem, the condictio sine causa specialis and the condictio indebiti are used. They are both based on the factual absence of a cause for the transfer of property to another.

\subsection{Condictio Sine Causa Specialis}

In the case of the condictio sine causa specialis, there is simply no cause for the payment. ${ }^{531}$ It is seen as the appropriate action in most cases of mistaken transfers by banks. ${ }^{532}$ For example, in Nissan in 2006, a case where there was a mistaken EFT into an unintended recipient's account, the condictiones were discussed but not expressly stated. Instead the SCA characterised the matter as being one where 'our law would be deficient if it did not provide a remedy for recovery of stolen money direct from the bank which received that money to the credit of the thief's account, for as long as the amount stands to the credit of the thief ${ }^{533}{ }^{\text {Visser }}{ }^{534}$ however suggests that since the SCA was quoting an analogous case of Perry which concerned the deposit of fraudulently obtained cheques - where the condictio sine causa specialis was held to be the remedy in an enrichment action - that the SCA was mistakenly using this condictio in relation to this type of enrichment.

\subsection{Condictio Indebiti}

In the case of the condictio indebiti there is a (reasonable) mistaken belief that there is a cause for the payment. ${ }^{535}$ In Frame $v$ Palmer, the requisites for a claim under the condictio indebiti were set out as follows:

(a) plaintiff must prove that the property or amount he is reclaiming was transferred or paid by him or his agent to the defendant;

(b) he must prove that such transfer or payment was made indebiti in the widest sense (i.e. that there was no legal or natural obligation or any reasonable cause for the payment or transfer);

(c) he must prove that it was transferred or paid by mistake. ${ }^{536}$

\footnotetext{
${ }^{528}$ Sonnekus (2008b) op cit note 29 at 19.

${ }^{529}$ Kudu Granite Operations (Pty) Ltd v Caterna Ltd 2003 (5) SA 193 (SCA) at 200F; and then Mndi v Malgas 2006 (2) SA 182 (E) concerning a large interest rate loan.

${ }^{530}$ Sonnekus (2008b) op cit note 29 at 19.

${ }^{531}$ In Govender v The Standard Bank of South Africa Ltd 1984 (4) SA 392 (C) Rose-Innes J at 404B said: 'The fact of the payment of money is itself prima facie proof of enrichment, but not conclusive proof. In assessing whether [a] defendant has been enriched by the payment, account must be taken of any performance which was juridically connected with the receipt of the money.'

${ }^{532}$ Visser (2008) op cit note 170 at 339.

${ }^{533}$ Streicher AJ in Nissan op cit note 291 at par 16.

${ }^{534}$ Visser (2008) op cit note 170 at 373.

${ }^{535}$ Perry op cit note 513 at $969 \mathrm{~F}-\mathrm{G}$.

${ }^{536}$ Frame v Palmer 1950 (3) SA 340 (C) at 346D-F.
} 
The value must have been transferred in the erroneous belief that it was due, and the fact that the undue transfer was made in error must be positively proven for the condictio to obtain. ${ }^{537}$ The condictio indebiti however is also available to reclaim an undue transfer made where the payor is made to pay under some sort of compulsion or threat, even in the absence of mistake. ${ }^{538}$

\subsection{Condictio Ob Turpem Vel Iniustam Causam}

The condictio ob turpem vel iniustam causam is applicable where there is a cause, but where that cause is unlawful and so the law cannot recognise it as a valid means of conferring title. ${ }^{539}$ There must be a measure of malevolence by the recipient such that property must have been transferred to him under an illegal agreement, where the recipient had knowledge of the illegality at the time of the transfer and was enriched by the transfer. ${ }^{540}$ In Perry ${ }^{541}$ it was held this condictio was applicable where a thief deposits stolen funds into his account, such that he has no claim against the bank for repayment of the funds.

\subsection{Condictio Causa Data Causa Non Secuta}

This is a claim for return of a transfer which was made in the knowledge that it was not owed but with a view to eliciting a counter-performance, but the quid pro quo does not materialise. ${ }^{542}$ Thus in circumstances where a contractual modus has been specified in a contract, but subsequently not fulfilled, anything transferred in the meantime will be reclaimable using this condictio. ${ }^{543}$

\subsection{Actio Pauliana}

The actio pauliana is an action available to a debtor whose assets are diminished by the fraud of another. The recipient must receive the assets from the debtor and it must not be his own property. ${ }^{544}$ For the action to succeed, it must be shown that the innocent party's assets have been irrevocably diminished, and a party may reclaim those assets as a result of his personal right to claim from the bank in which the money was deposited. $^{545}$ The actio pauliana was initially only available in circumstances where the debtor was insolvent and he disposed of his assets merely to defraud his creditors but it has been used variously in our

\footnotetext{
${ }_{537}^{538}$ Visser (2008) op cit note 170 at 274.

${ }^{538}$ Visser (2008) op cit note 170 at 384 . This condictio will be valid only if a valid contract had not resulted in spite of the compulsion and also that the claimant had protested at the time of the payment as proof of it being made involuntarily. See Miller v Bellville Municipality 1973 (1) SA 914 (C), Port Elizabeth Municipality v Uitenhage Municipality 1971 (1) SA 724 (A) and Industrial op cit note 514 at 646-647.

${ }^{539}$ In that sense a cause is also absent. See Perry op cit note 513 at 969 F/G.

${ }^{540}$ As to whether the condictio may apply in circumstances where the recipient subsequently discovers the illegality of the transaction by which he (innocently) acquired the value, the SCA in Perry op cit note 513 at par 24 cited the Digest 12.5.6 to the effect that 'Sabinus always said that the early jurists were right in holding that the condictio would go for anything in someone's hands on an unlawful basis (ex iniusta causa).'

${ }^{541}$ Perry op cit note 513 at par 32.

${ }^{542}$ Visser (2008) op cit note 170 at 5.

${ }^{543}$ R Zimmermann, D Visser, and K Reid (2006) Mixed Legal Systems in Comparative Analysis: Property and Obligations in Scotland and South Africa at 425.

${ }^{544}$ Moorcroft (2010) op cit note 407 at 27-1; in a cheque and specie context, where the fraud occurs outside a contractual context or when it is of a fundamental nature, Moorcroft (2010) op cit note 407 points out that consent is vitiated and delivery does not result in passing of ownership.

${ }^{545}$ Moorcroft (2010) op cit note 407 at 27-2.
} 
courts, and is seen as being inconsistent and even to have been incorrectly applied by extension to its original role for rescission of an alienation by a debtor in fraudem creditorum, for example where it was applied in the matter of Commissioner of Customs and Excise v Bank of Lisbon International Ltd. ${ }^{546}$

\subsubsection{9}

\section{Application to MFS}

Without minimising their role generally, but as noted above, Roman-Dutch condictiones are adequate for macro-payments and there is a capacity for those who have been unjustifiably impoverished to take the matter further than exhausting any protections, if any, offered in terms of conditions of their provider and any Ombudsman like WASPA or the Banking Ombudsman. Further, they apply primarily to EFTs where there is nominally a two-level type of confirmatory mechanism that a user must undertake to execute an EFT, that is, the IBAN and the bank routing number.

Comparatively in an MFS payment environment, only the recipient's phone number is required, which means 'finger trouble' could easily cause value to be sent to the wrong recipient. Further, as noted below, the mobile device provides the perfect storm of opportunity for rouges: the phone and the user are visible, the instrument for access to the value is also visible and easily available, and the mechanisms of access are relatively simple. Only a PIN, if any, separates the savvy and daring rogue from his enrichment. What then is the dispossessed to do when dispossessed? He could - if the contractual provisions allow - contact the MFSP and attempt to stop any value from being finally withdrawn as a 'cash out', or passed along a value chain in the MFSP system or to another competing but interoperable system in a series of remittances, but what if someone along the chain is a bona fide holder for value?

Ultimately the dispossessed will stay dispossessed because there is no statutory assistance, even with the supposed armoury of the South African ECTA and the new CPA. However, neither of these laws specifically addresses mala fide payments and value transfers in any appreciable degree. ${ }^{547}$

That then leaves the condictiones, but given the strict confines of the condictiones described above, it would possibly require further legal resources by the user to argue an expansion of their scope, if at all possible, beyond the context in which the condictio could theoretically be brought. It is unlikely - and the lack of reported cases bears this out - that anyone would engage counsel to fight for a de minimus action invoking the condictio, because first, it is a de minimus and secondly, the condictiones are, it is submitted, too constrained to be of any general use.

\footnotetext{
${ }^{546}$ Lisbon op cit note 513. See criticism of the judgment in Lisbon in FR Malan and JT Pretorius (1994b) 'Money, Bank Accounts and Tracing' 10(2) South African Law Journal at 387; as well as in Nedcor Bank Ltd v ABSA Bank and another 1995 (4) SA 727 (W) 729F-730C as cited by Moorcroft (2010) op cit note 407 at 27-3; and in SARS op cit note 450 at pars 72 and 73 as cited in Moorcroft (2010) op cit note 407 at 27-3.

${ }^{547}$ Frequently consumers resort to reporting their case to the media to fight a case where they do not find assistance from the financial institution. In the case of airtime-based WASP transactions, they usually complain to WASPA for recourse, and often get their value returned. This however does not stop the rogues generally as it may only be certain users - those who actually bother to complain - that are refunded. The CPA however provides for a general class action that could in effect refund the entire swathe of persons dispossessed by the rogue's actions.
} 
As was stated obiter in Perry:

'... too much time is spent in enrichment cases in identifying the correct condictio or actio. Counsel, the Courts and academics frequently err' and that 'a general enrichment action desirable, as eliminating confusion in identification of appropriate condictio, and fixing attention on requirement of enrichment rather than on definition and application of old actions. ${ }^{548}$

It is submitted that the first part of these dictum have extreme merit in being a cogent rationale for a general law that may harmonise payment law.

However, the first part does not necessarily lead to the second part of the dictum, that a general law of enrichment is necessary. A general law relating to the modalities that define the rights and obligations of parties in a payment transaction would, it is submitted, give general comfort in MFS-based and general payment transactions, providing in the public interest, a codification of the rights and obligations of parties.

The payment law would not necessarily solve the issue of the circumstances in reclaiming the funds, but would give some measure of stability in an area where the fortunes of the luckless loser of funds are left to the vagaries of spending 'too much time ... in enrichment cases in identifying the correct condictio or actio'.

Rather than a general enrichment action - the discussion of which is beyond the scope of this work protections would, it is submitted, be best contrived and executed by a specific statutory intervention in a narrow law that deals specifically with retail payments at both the macro and micro levels.

This would allow MFS systems to be operated with a degree of confidence so as to obviate any systemic risk concerns, ${ }^{549}$ provide for consumer confidence, and also then regularise the disparate and contradictory sets of consumer protections, e-commerce laws and regulations, and outdated common law condictiones that currently apply.

\footnotetext{
${ }_{548}^{54}$ Schutz J in Perry op cit note 513 at $970-972$.

${ }^{549}$ These concerns may be vitiated too through use of Trusts to store user funds. See ch 7, s7.4 titled Trusts.
} 


\subsection{1}

\section{Introduction}

In jurisdictions where an MNO or some MFSP has been given fiat-based redeemable funds from the public for use in a SOV, and where allowed or directed by legislation or the local prudential regulator, the funds have been pooled in what could be called a 'master bank account' the bank account of a separate entity usually either a separate corporate company or a business trust - that is given responsibility for the safekeeping of user funds.

These 'trust' tools are part of the raft of safeguarding measures aimed at ensuring liquidity as part of safety and soundness regimes, aimed at ensuring that customers can ultimately redeem the value placed with the MFSP or MNO, that cash out the value provided. ${ }^{550}$

It will be submitted that in relation to provision of fiat-based MFS services in South Africa, that the establishment of trusts to house the 'pool' of funds would be desirable.

\subsection{2}

\section{Overview of Trusts}

South African trust law is a mixture of English, Roman-Dutch ${ }^{551}$ and distinctively South African rules. ${ }^{552}$

A trust has been defined as:

'... a legal institution in which a person, the trustee, subject to public supervision, holds or administers property separately from his or her own, for the benefit of another person or persons or for the furtherance of a charitable or other purpose. ${ }^{553}$

A trustee is any person holding or administering property. They may be a trustee by virtue of their office and have fiduciary duties. However, ordinary agents who administer funds for their principals are not regarded as holding an office. ${ }^{554}$ In some cases, trust and trustee are used in this wide sense, whereby a trust

\footnotetext{
${ }^{550}$ M Tarazi and P Breloff (2010) 'Nonbank E-Money Issuers: Regulatory Approaches to Protecting Customer Funds' CGAP Focus Note 63, available from http://goo.gl/OSection 4AL.

${ }^{551}$ In respect of Roman-Dutch law, they derive from the rules of the fideicommissum, fiducia, stipulation alteri, tutorship, curatorship, and common-law administratorship. See E Cameron (2002) Honore's South African Law of Trusts (5 $5^{\text {th }}$ ed) at 23.

${ }^{552}$ See Cameron (2002) op cit note 551 at 23. For an overview of the development of South African trust law, see MJ de Waal (2000) 'The Core Elements of the Trust: Aspects of the English, Scottish and South African Trusts Compared' 117(3) South African Law Journal at 548. As De Waal notes, while the notion of a trust was introduced into South African practice by British settlers and officials during the first half of the nineteenth century, South African law evolved a 'trust law' that was different to English law insofar as the English law of trusts with its dichotomy of legal and equitable ownership was not received into South African law. For the fissure between South African and English law, see Braun v Blann and Botha 1984 (2) SA 850 (A) (hereafter Braun); and L Olivier (1998) 'Pitfalls in Creating an Investment Trust' 115 South African Law Journal 519-527.

${ }_{553}$ Cameron (2002) op cit note 551 at 1.

${ }^{554}$ Conze v Masterbond Participation Trust Managers 1996 (3) SA 786 (C) 794D-795G (hereafter Conze). In the wide sense they are trustees and may be guilty of offences such as the theft of trust funds. Cameron (2002) op cit note 551 at 4.
} 
is said to be any legal arrangement by which one person is to administer property for another for some impersonal object. ${ }^{555}$

Two types of trusts are considered, that is in a wide and narrow sense. The trust in the narrow sense is seen as a species of the genus trust in the wide sense. ${ }^{556}$ The wide sense exists when someone is bound to hold or administer property on behalf of another or for some impersonal object and not for his own benefit. ${ }^{557}$ These may include curators of mental patients, and agents who hold money for goods for their principals. ${ }^{558}$ In a strict or narrow sense a trust is formed when the founder of a trust hands over to another person, usually called the trustee, control of property to be administered or disposed of by the trustee or administrators for the benefit of another, usually called the beneficiary, or for some impersonal object. ${ }^{559}$ The narrow trust is thus also known as the 'ownership' trust. ${ }^{560}$ Thus the essential difference between the wide and narrow sense is that in the latter the trustee generally becomes the owner of the property he is entrusted with, but does not do so for his own personal benefit. ${ }^{561}$ Further, the trustee or administrator in the narrow sense does not act in a private capacity, but holds an office which is not necessarily the situation with trusts in a wide sense. ${ }^{562}$

While trusts are available and used in most jurisdictions worldwide, ${ }^{563}$ trusts in South Africa emanate from Germanic and English law, although there are elements of Roman-Dutch law, particularly in relation to the founder giving a gift or bequest - also known as a bewind- to an individual or juristic person but vests the control of the assets in a trustee or administrator, corresponding to the 'administrateur' in Roman-Dutch law. ${ }^{564}$

In South Africa, the Trust Property Control Act 57 of 1988 (hereafter TPCA) regulates trusts. It defines a trust as:

'... the arrangement through which the ownership in property of one person is by virtue of a trust instrument made over or bequeathed-

\footnotetext{
${ }^{555}$ In Beningfield v Baxter (1886), L.R, 12 H.L. 167.

${ }_{556}^{557}$ Cameron (2002) op cit note 551 at 4-5.

${ }^{557}$ This person has at a minimum a duty to keep the property administered separately from personal property and to avoid a conflict of interest with the beneficiary of the trust object; Cameron (2002) op cit note 551 at 3. ${ }_{558}^{558}$ Ibid.

${ }^{559}$ Deedat v The Master 1995 (2) SA 377 (A) 383E-G (hereafter Deedat). At common law one of the essential requirements for the existence of a valid trust is 'a definite or identifiable subject-matter'. Cameron (2002) op cit note 551 at 4 . Havenga, Havenga and Kelbrick (2007) op cit note 4 at 435. The founder must have either transferred the control of the trust property by a legally valid mode of transfer or must have bound himself to hand over the control of a property. The trust property may be movable or immovable. Control of a trust property must be handed over via transferring ownership of the property.

560 The founder may also bind himself through the conclusion of a contract to transfer certain property. In this sense, a trust creates fiduciary obligation.

${ }_{561}^{56}$ Havenga, Havenga and Kelbrick (2007) op cit note 4 at 455.

${ }^{562}$ Thorne and Molenaar NNO v Receiver of Revenue, Cape Town 1976 (2) SA 50 (C), 38 SATC 1 where it was held that if the trustee of an insolvent estate were to be subject to tax, it could only be as a representative taxpayer and not in his personal capacity. It was held that although the trustee of an insolvent estate fell within the statutory definition of 'trustee', he did not fall within the definition of 'representative taxpayer'.

${ }^{563}$ See, for example, the Hague Convention of the Law Applicable to Trusts and on their Recognition was signed on 1 July 1985 , but came into force on 1 January 1992

${ }^{564}$ Cameron (2002) op cit note 551 at 6.
} 
(a) to another person, the trustee, in whole or in part, to be administered or disposed of according to the provisions of the trust instrument for the benefit of the person or class of persons designated in the trust instrument or for the achievement of the object stated in the trust instrument; or

(b) to the beneficiaries designated in the trust instrument, which property is placed under the control of another person, the trustee, to be administered or disposed of according to the provisions of the trust instrument for the benefit of the person or class of persons designated in the trust instrument or for the achievement of the object stated in the trust instrument, but does not include the case where the property of another is to be administered by any person as executor, tutor or curator in terms of the provisions of the Administration of Estates Act, 1965 (Act 66 of 1965).'

Trust as defined in the Act relates to trusts in the strict or narrow sense. ${ }^{565}$

\title{
7.4.3
}

\section{Creation of a Trust}

For creation of a trust, the following is said to be required: ${ }^{566}$

\begin{abstract}
'A founder must intend to create a trust; The founders' intention must be expressed in such a manner as to create a binding obligation; the trust property must be defined with reasonable clarity; The trust object, which may be personal or impersonal, must be defined with reasonable certainty; The trust object must be lawful.'
\end{abstract}

Inter alia, this may come about via written agreement, a will or a court order. ${ }^{567}$ A trust will however generally not fail for want of a trustee. ${ }^{568}$ The TPCA requires that trusts must be registered with the Master of the High Court. ${ }^{569}$

\subsection{4}

\section{Types of Trusts}

Trusts are extremely flexible, with rules adopted to suit specific needs in an almost infinite variety of objects. ${ }^{570}$ As such they have been adopted to function within a business environment. ${ }^{571}$ Concomitantly, there are a number of trust types, such as an inter vivos trust, ${ }^{572}$ charitable trusts, trusts for unformed

\footnotetext{
565 Conze op cit note 554 at 2-3.

${ }^{566}$ Havenga, Havenga and Kelbrick (2007) op cit note 4 at 457.

567 Ibid at $458-459$

${ }^{568}$ Ibid at 462 .

${ }^{569}$ Section 4(1). This provision does not apply to oral trusts. See De Waal op cit note 552 at 566 and Deedat op cit note 559 at 384 .

${ }^{570}$ Cameron (2002) op cit note 551 at 14 .

571 Olivier (1998) op cit note 552 at 519.

572 A trust inter vivos is a trust set up by a living founder, and may be considered as a contract for the benefit of a third person (stipulation alteri), which in essence is a contract between the founder (the stipulans) and the trustee (the promittens) for the benefit of a beneficiary (the third party) such that the right of the trust beneficiary in an inter vivos trust is merely personal in nature. See Commissioner for Inland Revenue v Estate Crewe \& another 1943 AD 656; Commissioner for Inland Revenue $v$ Smollan's Estate 1955 (3) SA 266 (A); Crookes NO and another v Watson \& others 1956 (1) SA 277 (A).' (hereafter Crookes). See also Cameron (2002) op cit note 551 at 35. This type of trust is not construed as a fideicommisssum. HR Hahlo (1961) 'The Trust in South African Law' (78) South African Law Journal 195 at 202. The contract can be revoked or varied in the normal sense of contract law if the parties agree, which differs from what Cameron (2002) op cit note 551 at 35 says are the public law aspects of trusts that relate to the administration of trusts and the supervisory jurisdiction of the court and
} 
companies, a discretionary trust ${ }^{573}$ or business trusts. However, as Cameron notes, the legal problems arising from the use of trusts are largely the same no matter the type of trust such that it is a matter of separation of management and ownership from the beneficial enjoyment of trust property. ${ }^{574}$

South African trust law is evolving insofar as a trust is not necessarily a legal persona ${ }^{575}$ but may be evolving as legal persona in its own right. ${ }^{576}$ Creation and understanding of the method in which a trust is formed is critical because of the 'immense' legal consequences which may result from the nature of the transaction where money or other property is received or disposed and which may, resultantly, invoke the provisions of trust legislation like the Trust Property Control Act. ${ }^{577}$ In particular, this may apply to instances where there may be an equivocation as to whether a trust, whether it is a 'mere' donation, or a pseudo-trust structure like a partnership has in fact been created. ${ }^{578}$ Their relevant points of comparison depend on context and purpose. ${ }^{579}$ For example, there are particular issues with certain forms of business trust such as an investment trust. ${ }^{580}$ Olivier notes that these investment trusts contain two unusual features, first the identities of the beneficiaries are not certain at the inception of the trust, and they have to pay for the right to become beneficiaries. ${ }^{581}$ Whether this amounts to a trust was answered in the affirmative in Pretorius $v$ Commissioner for Inland Revenue ${ }^{582}$ where a trust initially founded with nominal capital was augmented from the beneficiaries in the form of contractual undertakings to contribute. ${ }^{583}$

\footnotetext{
the Master.

573 A discretionary trust is a trust where the beneficiaries or their entitlements to the trust fund are not fixed, but are determined by the criteria set out in the trust instrument which are executed at the discretion of the trustees such that the trustees select the income or capital beneficiaries. Cameron (2002) op cit note 551 at 125-127.

${ }^{574}$ Cameron (2002) op cit note 551 at 16-17. As noted by Cameron, this separation of property is a feature of common law usufruct, although in trust law, the trustee is neither a present nor prospective beneficiary.

${ }^{575}$ For an overview of and the pitfalls of contracting with business trusts, see JS McLennan (2006) 'Contracting with Business Trusts' 18 SA Mercantile Law Journal 329 at 333.

${ }^{576}$ See IB Murray (1962) 'Is a Trust or an Estate a Legal Persona?' 79 South African Law Journal 37; and Hahlo (1961) op cit note 572 at 195 . As Sher says, the law recognises trusts insofar as investments and immovable property may be registered in the name of a trust, a trust can receive benefits under a will, trust creditors must proceed against a trustee in his official capacity and not against his private estate, the trust estate may be sequestrated and litigation may be conducted in the name of a trust. H Sher (1996) 'Trusts in South Africa' Trusts \& Trustees 2(7) 11 at 12.

${ }_{577}$ Cameron (2002) op cit note 551 at 33.

${ }^{578}$ Ibid. For an overview of the structures of in particular investment trusts and whether they could be classed as deposits, partnerships, unit trusts, or in fact some other structure designed to avoid tax, see Olivier (1998) op cit note 552 at 519 . See also Conze op cit note 554 where the court indicated that a trust is only one where it is a trust in a strict sense, that is, one where the creator or founder of the trust handed over or is bound to hand over to another the control of property which, or the proceeds of which, is to be administered or disposed of by the other (trustee or administrator) for the benefit of some person other than the trustee as beneficiary, or for some impersonal object.

579 Cameron (2002) op cit note 551 at 34.

${ }^{580}$ An investment trust should be distinguished from the investment of trust monies (by trustees of a trust). See RC Williams (2001) 'The Investment of Trust Moneys' 13(2) SA Mercantile Law Journal at 311, who refers to Sackville West v Nourse \& Another 1925 AS 516 as authority for the view that trustees who have not been given wide powers of investment must confine their investment activities to what are known as 'trust investments' which are commonly safe investments earning fixed rates of interest. See also Olivier (1998) op cit note 552 passim.

${ }_{581}^{581}$ Olivier (1998) op cit note 552 passim.

${ }_{582}^{582}$ Pretorius v Commissioner for Inland Revenue 1984 (2) SA 619 (T) (hereafter Pretorius).

${ }^{583}$ Le Roux J at 627E-G said that there is:
}

'... no objection to a multiplicity of donors (who are also beneficiaries) undertaking to pay an ascertainable sum of money to trustees in order to obtain some benefit for themselves. The fact that the pro rata payments are also a condition which must be fulfilled before a beneficiary can become entitled to the benefit, does not appear to detract from the validity of the stipulation.' 
As Olivier notes, Pretorius did not deal with the situation where the beneficiaries are entitled to the repayment of their capital contributions ${ }^{584}$ but she argues that despite this factual distinction, the Pretorius case can serve as authority for the proposition that a valid trust is created where the trust beneficiaries are contractually obliged to make a contribution in return for the right to become a trust beneficiary, whether this right entitles them to claim either an asset acquired by the trust or repayment of their capital contributions. ${ }^{585}$ The issue then is whether the (redeemable) capital contributions may amount not to a contribution to a trust, but instead to a deposit that would place the funds (and the scheme controlling it) under the ambit of banking law. ${ }^{586}$

\subsubsection{Administration of a Trust}

It is a common feature of trusts in England, Scotland and South Africa that a number of duties fasten on a trustee in the administration of a trust, both at common law $^{587}$ and at statute. ${ }^{588} \mathrm{~A}$ trustee has a duty to give effect to the trust deed; must take possession of the trust property; must preserve trust property; must collect debts due to the trust; must invest trust funds; must properly supervise the trust and must keep proper accounts. ${ }^{589}$ A person shall act as trustee only if authorised thereto in writing by the Master, ${ }^{590}$ and may be required to furnish security. ${ }^{591} \mathrm{~A}$ trust must thus be operated in an efficient manner that does not put trust assets at unnecessary risk and dilute value to beneficiaries. ${ }^{52}$ As such the trustee must keep documentation for 5 years after the termination of the trust that serves as proof of the investment, safe custody, control, administration, alienation, or distribution of the trust property. ${ }^{593}$ To this end they may need to hold meetings if there is more than one trustee. ${ }^{594}$ Trustees must act jointly in their dealings with outsiders if they are to bind the trust estate ${ }^{595}$ which means that an outsider may thus assume that contractual powers have to be exercised by all trustees acting together unless the trust instrument

\footnotetext{
${ }^{584}$ In Pretorius op cit note 582, the beneficiaries were entitled to assets acquired by the trust with the capital contributions made by them.

585 Olivier (1998) op cit note 552 at 521.

586 Olivier (1998) op cit note 552 at 525-526. Olivier also raises the possibility that the repayable funds mean that the 'beneficiaries' are in fact creditors. In respect of banking law, the depositor has a personal right against the deposit-taking institution for repayment of the funds. See, however, in relation to trusts generally in English law, Parkinson who speaks of the language of trusts as being that of property rights, not personal rights. P Parkinson (2002) 'Reconceptualising the Express Trust' 61(3) Cambridge Law Journal 657. See however Cameron (2002) op cit note 551 at 23 who says that, while there is no clear authority on this matter, in South African (trust) law, a beneficiary unless possessed of a personal right to the transfer of the ownership of or a real right in specific property (ius personam ad rem acquirendam), has no greater right than the ordinary unsecured creditor to follow the trust property into the hands of an alienee to whom the trustee has improperly parted with it, such that the trustee is 'merely' bound by delictual and contractual obligations reinforced by statute such as the TPCA and the ordinary incidents of such obligations apply. Cameron (2002) op cit note 551 at 576-577 concludes on this matter that while there is no clear authority on this matter, it must be decided on principle: while in South African trust law a trust beneficiary's right is normally in personam against the trustee only, when the beneficiary has a personal right to acquire the ownership of or a real right in specific property and the trustee is bound to hand over to the beneficiary the capital of the trust in specie, then any third party who at the time of acquiring the trust property has notice of the beneficiary's right is bound by it. In English law, the beneficiary has stronger claim, however, insofar as he has in his firmament what may be termed a form of ownership or property right, the 'equitable ownership' of or an 'equitable interest' in the trust property.

${ }^{587}$ For a general overview of the duties of a trustee, see De Waal (2000) op cit note 552 at 558; and Cameron (2000) op cit note 551 .

588 Via the TPCA.

${ }^{589}$ De Waal (2000) op cit note 552 at 558-559.

${ }^{590}$ TPCA s6(1) of the TPCA.

${ }^{591}$ Sections 6(2) and 6(3) of the TPCA.

${ }_{592}$ Cameron (2002) op cit note 551 at 320-322.

${ }^{593}$ Section 17 of the TPCA.

${ }^{594}$ Cameron (2002) op cit note 551 at 321.

${ }^{595}$ Ibid at 324. Hoosen v Deedat 1999 (4) SA 425 (SCA). Trustees may also be sued for delict even though they may not have participated or authorised it. For the differences between liability in delict and contract with regards to trusts, see further Cameron (2002) op cit note 551 at 325.
} 
specifically authorises action by a lesser number of trustees in which case the person may rely on estoppel. ${ }^{596}$ The trustee's private assets and the trust's assets must be kept separate, especially when this relates to money where there may be commixio of the two 'estates. ${ }^{, 597}$ There is nothing however that prevents a trustee from being a beneficiary of the trust. ${ }^{598}$ In Braun $v$ Blann and Botha $N N O,{ }^{599}$ the court held that the trust is a sui generis institution ${ }^{600}$ and the trust agreement was likened to a contract. ${ }^{601}$ In relation to an inter vivos trust, it has been held in Crewe $^{602}$ and in Crookes ${ }^{603}$ that trust arrangements were akin to the stipulation alteri which is essentially a third party beneficiary contract. Here, the trust deed itself is the embodiment of the contract pursuant to a 'donation' of the trust corpus to the trustee. ${ }^{604}$ In the analogous case of Gross v Pentz ${ }^{605}$ where there was a testamentary trust, the court held that although contingent beneficiaries have no vested rights to the future income or capital of the trust, they do have vested interests in the proper administration of the trust. In this case, the (future) beneficiaries could invoke the TPCA to ensure proper administration of the trust.

A financial officer or trustee must also abide by a number of laws applicable to investment management and investment funds which includes the Financial Institutions (Protection of Funds) Act 28 of $2001 ;^{606}$ the Collective Investment Schemes Control Act 45 of 2002; Financial Advisory and Intermediary Services Act 37 of 2002; Inspection of Financial Institutions Act 80 of 1998 and the Pension Funds Act 24 of 1956. This investment management falls under the supervision of the Financial Services Board (hereafter FSB), the independent statutory oversight body ${ }^{607}$ governed by the Financial Services Board Act. ${ }^{608}$

The trustee must open a separate bank account and deposit in trust moneys not yet invested. ${ }^{609}$ Banks usually permit accounts to be opened in the name of a trust or in the name of trustees for the duration of a trust. The Act requires trustees to register and identify trust property separately by inter alia making any

\footnotetext{
${ }^{596}$ Cameron (2002) op cit note 551 at 324.

${ }^{597}$ De Waal (2000) op cit note 552 at 562-563. As De Waal points out, the recognition of separate estates may, at a theoretical level, come close to bestowing, but does not ultimately bestow juristic personality on the trust. This may arise inter alia from the ability to sequestrate and tax a trust.

${ }_{598}$ Cameron (2002) op cit note 551 at 11 ; TPCA s12.

${ }^{599}$ Braun op cit note 552.

${ }^{600}$ This was confirmed by s12 of the TPCA which declares that: 'Trust property shall not form part of the personal estate of the trustee except insofar as he and the trust beneficiary is entitled to the trust properly.'

${ }^{601}$ For an application thereof, see Hofer $v$ Kevitt 1998 1 SA 382 (SCA) where the beneficiaries of a trust were unsuccessful in preventing the variation of the terms of the trust, though their shares were being negatively affected. The court held that their rights were inchoate because they were not parties to the signature and acceptance of the trust deed. For a brief discussion of this case, see JA Schoenblum (2009) Multistate and Multinational Estate Planning Toolkit Media Group at 18-61.

${ }^{602}$ Crewe op cit note 572.

${ }^{603}$ Crookes op cit note 572 at $291 \mathrm{~B}-\mathrm{C}$.

${ }^{604}$ Schoenblum (2009) op cit note 601 at $18-60$.

${ }^{605}$ Gross and Others v Pentz 1996 (4) SA 617 (SCA).

${ }^{606}$ The Act provides for and consolidates the laws related to the investment, safe custody and administration of funds and trust property by financial institutions; enabling the registrar to protect such funds and trust property; and improving the enforcement powers of the registrar. Inspectors may also be appointed to ensure that the banks comply with the regulations relating to trust property under this Act.

${ }^{607}$ See ch 12, s12.3.2.4 on the Financial Service Board and its jurisdiction.

${ }^{608}$ Financial Services Board Act 97 of 1990 . The FSB is under the general authority of the Minister of Finance who appoints the members of the Board and selects the senior officers, after consultation with the Board. It regulates and supervises the non-bank part of the financial services industry. See also International Monetary Fund (IMF) (2010b) 'South Africa: Detailed Assessment of Implementation on IOSCO Principles - Securities Markets', available at http://goo.gl/ULSng.

${ }^{609}$ Section 10 of Act 57 of 1998; Cameron (2002) op cit note 551 at 306.
} 
account or investment at a financial institution identifiable as a trust account or trust investment. ${ }^{610}$ The trustee must keep trust assets separate from private assets, and further the trustee is not empowered to borrow trust money. ${ }^{611}$

The Trust Act 1998 also requires that they must clearly indicate in their accounts what property belongs to whom, and to register trust property in such a manner that it is clear that it is trust property ${ }^{612}$ and that any bank account identifies it as such. ${ }^{613}$ There are also obligations in terms of the Financial Institutions (Investment of Funds) Act. ${ }^{614}$ The trustee has a general duty to preserve trust property, ${ }^{615}$ but may be required to sell and reinvest the proceeds if so allowed. ${ }^{616}$ There must however be a balance between security of capital and capital growth. ${ }^{617}$

\subsection{7}

\section{Trust Beneficiaries}

A person may be a trust beneficiary, including unborn children and natural or legal persons. When there is an ownership trust, the trustee has bare but not beneficial ownership. ${ }^{618}$ That said, the beneficiary has a personal right against the trustee to claim the income or capital due to the beneficiary in terms of the trust. ${ }^{619}$ The trustee must pay the income and deliver or transfer the capital in a trust account to one entitled to receive it, except when this is subject to an express or implied provision. ${ }^{620}$ The trustee must not favour one beneficiary or group of beneficiaries over another, but must treat all impartially, ${ }^{621}$ which will be less of a concern if there is a 'pooled' account within a single trust. ${ }^{622}$ This applies to current and future trust beneficiaries. ${ }^{623}$ The trustee may advance capital to a beneficiary where there is an express provision that allows them to do so, or where ordered to do so by a court, but this must balance income and capital beneficiaries. ${ }^{624}$

In cases where the pooled funds are placed in a single master account that is under the name of the MFSP or MNO as the issuer of the SOV, MFS users invariably only have a fiduciary relationship with the MNO or MFSP insofar as they provide the user with an account number and access to the SOV. Users thus will not have an account with the licensed bank where the pooled master account is held. This account number

\footnotetext{
${ }^{610}$ Act 57 of $1998 \mathrm{~s} 11(1)(\mathrm{c})$; Cameron (2002) op cit note 551 at 306. Where there are pending legalities, the trustee must retain a reserve until the contingent liabilities are no longer a factor. See Alexander NO v Perdicologou 1996 (3) SA 454 (R) at 459 .

${ }^{611}$ The Heirs Hiddingh v De Villiers, Denyssen and Others (1887) 5 SC 298; Cameron (2002) op cit note 551 at 294.

${ }^{612}$ Act 57 of 1998 s11(1)(b); Cameron (2002) op cit note 551 at 294.

${ }^{613}$ s11(1)(d); Cameron (2002) op cit note 551 at 294.

${ }^{614}$ Financial Institutions (Investment of Funds) Act 39 of 1984. Cameron (2002) op cit note 551 at 294; Tijmstra v BluntMacKenzie NO and Others 2002 (1) SA 459 (T).

${ }^{615}$ Cameron (2002) op cit note 551 at 296.

${ }^{616}$ Ibid.

${ }^{617}$ Cameron (2002) op cit note 551 at 297-306.

${ }^{618}$ Havenga, Havenga and Kelbrick (2007) op cit note 4 at 472.

${ }^{619}$ Ibid.

${ }^{620}$ Cameron (2002) op cit note 551 at 314; Fakroodeen v Fakroodeen 1971 (3) SA 395 (D).

${ }^{621}$ Ibid at 409.

${ }^{622}$ Ibid at 316. Parker Wood v Swinbourn 1916 NPD 474.

${ }^{623}$ Cameron (2002) op cit note 551 at 316-317.

${ }^{624}$ Ibid at 318; and Ex parte Hulton 1954 (1) SA 460 (C).
} 
is not a bank account number, rather a pseudo bank account number. The effect is thus that either the MNO/MFSP has a proprietary right to the funds in the bank account as a (pooled) deposit, or a specific Business Trust set up as a safeguarding measure that ring-fences the pooled funds from non-Trust beneficiaries and thus effectively prevents the MNO from using the pooled funds as a source of working capital to fund its non-MFS activities, or a possible credit component of its MFS activities where allowed. This is not a perfect system: the funds in the Trust may certainly be protected from creditors in cases where the MNO/MFSP is financially exposed, insolvent or delinquent in some way but the Trust is still able to sue in its own capacity as events arise.

As a non-bank issuer, there is not necessarily any deposit insurance-type scheme that is available at either a commercial insurance or 'prudentially-guaranteed' level. There is even the risk that the licensed bank holding the pooled Trust Account funds may go insolvent. Where large values are at risk, the use of more than one bank to hold the monies is usually prudentially and commercially sound behaviour.

As Tarazi notes, the safety and soundness schemes related to ensuring liquidity and the veracity of customer funds in fiat-based MFS schemes vary from country to country, some of which involve trusts where this facility exists. In Afghanistan, all e-money issuers must maintain liquid assets to at least $100 \%$ of e-float and must be held in a trust account at a banking organisation. ${ }^{625}$

In Kenya, MNO Safaricom provided for a safety regime for its M-pesa customers with a 'Declaration of Trust' by Safaricom in favour of all M-pesa accountholders. ${ }^{626}$ The M-pesa trust deed was executed by the M-pesa Holding Company in 2007 and the sole trustee of this trust is M-pesa Holding Co, a company registered in Kenya and the Trust funds are held in numerous bank accounts, such as with the Commercial Bank of Africa (CBA). ${ }^{627}$

Interest on the bank account is to the credit only of the Trust Company, not M-pesa clients as Trust beneficiaries.

In some models, the e-money balances are not liabilities of the MNO. This is the case for instance with Mpesa in Kenya. The float is held in a Trust account, with a commercial bank (prudentially regulated) and is therefore not a liability of Safaricom.

\footnotetext{
${ }^{625}$ See Islamic Republic of Afghanistan, Da Afghanistan Bank Article (s.d.) 'Article Two: Money Service Providers Regulation', available from http://goo.gl/bLUaG.

${ }^{626}$ For a copy of 'Declaration of Trust' by Safaricom in favour of all M-pesa account holders, see http://goo.gl/Azju8.

${ }^{627}$ Safaricom Kenya, personal communication.
} 


\section{Contracts}

7.5.1.1

Terms

Contractual relationships always exist throughout a MFS transaction value chain. A key to understanding the nature of the transaction in a typical MFS transaction are the legal relationships that are formed and the contractual obligations that ipso facto are created. Since there is no (retail) payments statute in South Africa, common law considerations thus fundamentally apply insofar as they can, to aspects of MFS contracts $^{628}$ and payment facilities. The issue of lawfulness is also manifest.

The nature of MFS lends itself to issues of equivocation in matters of identification of the parties, the remote nature of the transaction, legality of a transaction, allocation of risk in a transaction, mistake and in applying any traditional remedies if at all possible and practical. The nature of the medium makes verification of intent in contract-making dependent on terms decided on usually by the stronger party, despite the principle of pacta sunt servanda or contractual supremacy permeating our common law. Uneven bargaining and contractual power between users of MFS and the MFSPs and WASPs for example may, in the absence of any specific law governing payments and the modalities around payment, skew the ability of users to enforce any rights that may accrue to them or to prevent unfair contractual terms being imposed on them. While it is relatively new and thus mostly untested, it is submitted however, that the CPA may alter the legal landscape with regard to good faith and unfair contract terms with its 'Black List' and 'Grey List' of contractual terms. Although these indicate what a service provider cannot do, they do not provide any distinct direction as to what he must do. In the context of MFS and payments generally, this then does not give the user any distinct rights in solving issues of misdirected or fraudulent payment, which is still left to an Ombuds-scheme or an ADR agent - or the courts if necessary - to decide on the parameters of these rights. ${ }^{629}$ A statutory intervention may be required to codify rights and obligations of the parties.

\subsubsection{Parties}

Parties to a transaction and allocation of rights and responsibilities to various parties are not often clear in MFS, creating a barrier for the ultimate enforcement of any rights where these rights are obvious and available. For example, there are usually no direct links between customers and merchants in a WASP-type VAS transaction since the legal or contractual relationship that WASP merchants have are exclusively with MNOs. It is also not always certain who the parties to the contract may be, or who may be in breach, as many of these systems are anonymous, and could be permeated by fraudulent means of identification.

\footnotetext{
${ }^{628}$ See ch 7, ss7.2.2.2 titled Consensus; 7.2.2.5 titled Legal Capacity, titled 7.2.2.7 titled Lawfulness; and 7.2.2.6 titled Possibility of Performance.

${ }^{629}$ See on allocation of risk, ch 12, s12.11 titled Consumer Protection and Loss Allocation with Respect to Payments.
} 
The issue of capacity is also manifest. Mobile phones are often given to or acquired by minors who may go on to use the device in any manner of unsecured or secured MFS, potentially incurring obligations even though ordinarily they may not have the capacity to do so. The legal status of these transactions is thus a point of contention because there is often no ability to determine who is the actual - and not necessarily registered - user of a service, as well as their legal status. Mandatory registration of users of SIM cards, while useful, are often not sufficient in MFS transactions involving banks and MFS providers where somewhat tighter KYC/CDD criteria ${ }^{630}$ may be available to determine the age of the ostensible user. Does the use of that instrument then by an unauthorised person vitiate any transaction, or is the actual user liable? Guidance may be obtained through common law rules on the abstract system of property relating to the need for consensus. ${ }^{631}$ Default system rules via statute may be preferable though.

In fiat-based MFS transactions, the use of agents adds a layer of complexity. In a legal sense, these agents are 'retail agents' - sometimes called correspondents or outlets - rather than pure agents. ${ }^{632}$ Unravelling who is responsible for any user loss and the public's ability to hold an agent liable for any improper deeds or actions or where loss is contemplated may be complicated by their status and the current ability to exclude by contract the liability of the principal for the agent's conduct.

\subsubsection{Effect of Mistake, Fraud, and Duress}

Mobile phones have a conspicuous presence and are often the perfect opportunity for rogues. As such, fraud and duress are of particular concern as MFS and general online financial services grow around the world. ${ }^{633}$ The deliberately simple design of the MFS-based value transfers can also result in mistake as to the recipient. In all though, while there may be daily and/or transactions limits for these transfers mandated by AML regulations or business safety considerations, generally there is little leeway or protections for users in cases of mistake, fraud and duress. That the recipient is unjustifiably enriched could be subject to an action or condictio to recover the loss, employed in relation to mistaken or fraudulent larger-value EFTs. The difficulty in auctioning any remedy provided by the common law is discussed below. ${ }^{634}$

\subsection{2}

\section{Payments}

Payments are at the heart of the MFS system, with very little savings built up by users. The major focus of these systems is on payments which then brings to the fore issues of the fundamental nature of a payment, parties to a payment, time of payment, remedies available to the parties to a payment in matters of dispute, fraud and mistake such that a party may be said to be unjustifiably enriched. There is also the issue of payments using airtime-based MFS SVP, which may or may not be 'money' ${ }^{635}$ and the import of this on any potential remedies. ${ }^{636}$

\footnotetext{
${ }^{630}$ See ch 8, s8.5 below on AML and CTF issues.

${ }^{631}$ See ch 7, s7.2.2.2 titled Consensus

${ }^{632}$ See ch 6, s6.3.1 on MFS Schemes.

${ }^{633}$ See generally ch 7, s7.2.2 titled Requirements for Valid Contracts.

${ }^{634} \mathrm{See}$ ch 7, s7.3.2 titled Participants in a Payment.

${ }^{635} \mathrm{See}$ the discussion thereof in ch 3 passim and ch 13 passim.

${ }^{636}$ See ch 7, s7.3.6 titled Defective Payments and their Effect passim.
} 
7.5.2.1 Nature of a Payment

South African law considers payment as a 'bilateral juristic act' that requires the cooperation of the payor and payee, but this conception may be blocking the need for this notion of payment to become better equipped to deal with evolving commercial realities.

A good example of this commercial reality is the issue of MFS airtime and fiat-based remittances which involve a unilateral payment and no debt-relationship per se - as is implicitly implied by the common law view of payment - between the sender (payor) and the recipient (payee). In the light of this, dogmatic adherence to the tenet that payment is a bilateral act seems passé and is too limited to function in the context of modern electronic means of doing business.

Thus, the recipient would not necessarily expect or know about the value transfer to his 'account,' which would (commercially at least) amount to a payment for which value can be given, but because of theoretical legal dogma, it does not amount to a payment.

Thus the implication of having to contort a modern value transfer technique within the precincts of a 'payment' needing to be a bilateral juristic act may also impact on any potential remedies available to the sender and receiver. In this sense, the common law definition adopted by our courts may, it is suggested, be tautological: where the transfer is clearly not a bilateral juristic act, the dogma dictates therefore that it is not a payment and as such any remedies based on unjustified enrichment flowing from a payment cannot be used by the wronged party.

The WASP environment produces some interesting permutations of payment where the ultimate recipient of the value paid may be split amongst parties, that is, payment can also be multilateral. The contractual nexus in the transaction also confuses the issue: the transaction and payment may be between the user and the WASP and his IP, between the user and the IP only, the user and the WASP only or the user and the MNO only or at the extreme, between the user and the WASP and the IP. In the world shaped by the bilateral dogma then, there is no bilateral relationship at work here.

Whatever the source of funding and its legal import, many of the electronic, abstract systems used for payments are covered by the law of contract with payment by an EFT usually governed by the law of mandate, agency and the law of contract.

While there is a continuing debate in the common law as to the time of payment, the time of payment in electronic payments seems to be somewhat clearer thanks to statute law, for example, s23 of the ECTA. The rules in the ECTA then, it is submitted, would apply to a customer's use of these systems.

As a result, banking conventions, it is submitted, should take cognisance of the rules in the ECTA in relation to the time of sending the payment (instruction). 
MFS and the visible and accessible nature of phones accentuate user vulnerabilities. With respect to riskallocation in payments as discussed as regards financial services generally and banking specifically, a client generally has some broad duties to his banker or financial service provider. This however depends on the nature of the relationship, and the duties are generally limited.

The concept of allocation of loss by placing liability for (possibly avoidable) losses on the party responsible for the loss is usually predicated on both parties having access to equivalent information. In the MFS context and commercial context generally, it is submitted that it may prove difficult to achieve informational symmetries owing to small mobile handset screen sizes.

The crux of the issue is the asymmetric relationship between user and MFS provider, where there may be an imbalance of power, information and resources between consumers and their financial service providers that places consumers at a disadvantage.

\subsubsection{Efficacy of Common Law Remedies}

Further, the condictiones as remedies in the case of mistake, fraudulent or similarly unintended payments are, it is submitted, incapable of providing clear, available, accessible, and affordable remedies to the dispossessed.

Their intricate, narrow purview, alongside the de minimus nature of the smaller (micro-payment) amounts usually involved in MFS, practically militates against an aggrieved user taking the trouble to embark on an expensive legal battle to reclaim the micro value. There is also no specific and effective statutory backing or assistance for recovery of mistaken and fraudulent payments. This indicates the need, it is submitted, for more statutory protections in the (retail) payments market and a dedicated payments regulator. ${ }^{637}$

\subsubsection{Trusts}

From the perspective of ensuring safety and soundness, competition and the 'transformational' aspects of banking and payments, the use of Trust Accounts whereby funds collected would be placed therein and administered by a trust company would be beneficial.

These pooled funds would be placed in a single master account where the specific trust is set up as a safeguarding measure to ring-fence the pooled funds from non-trust beneficiaries and this effectively prevents the MNO from using the pooled funds as a source of working capital to fund its non-MFS

${ }^{637}$ Ibid. See also on further, ch 8, s8.7 titled E-Commerce Laws and Regulations for an introduction to the CPA; also ch 12, ss12.9 titled E-Commerce Laws; and 12.10 titled Consumer Protection Laws. 
activities for any intermediation purposes, or as a possible credit component of its MFS activities where allowed.

\section{6}

\section{Conclusion}

While MFSPs have filled a critical need for consumers, such services raise important issues of consumer disclosure, safety and education.

The preceding discussion on the ephemeral and often opaque nature of contracts and contractants, a seemingly misplaced focus in respect of the nature of a payment in light of inter alia new business models, attendant risks in MFS and payments generally, the narrow confines of potential remedies available and the expense to consumers in their application demonstrates the need for increased consumer protection and a reassessment of the nature of a payment transaction.

This may take the form of fastening set rights and responsibilities on the parties which, if realised, may redress the imbalance caused by information asymmetries, with readily available information relating to $\mathrm{T} \& \mathrm{C}$ and pricing, by prohibiting any financial institution or its agents from engaging in unfair or deceptive practices, and by providing timely and accessible mechanisms to lodge complaints and obtain redress if necessary.

It is submitted then that a specific law relating to the modalities that define the rights and obligations of parties in a payment transaction is necessary to give general comfort in MFS-based transactions specifically and for general payment transactions. Such a law would provide a codification of the rights and obligations of parties that serves the public interest.

This payment law would not necessarily solve the issue of the circumstances in reclaiming the funds, but would give some measure of stability in an area where the fortunes of the luckless loser of funds is left to the vagaries of spending 'too much time ... in enrichment cases in identifying the correct condictio or actio' as was noted above.

It would be desirable to have a legal rule that induces the party with superior information to convey it to the uninformed party or to develop precautionary measures that can be utilised by the less informed party. ${ }^{638}$

In essence then, a specific set of harmonised statutory rules such as those employed in the scope of electronic payments and regulations in the $\mathrm{EU}^{639}$ may codify existing payment rules, but in a more symmetrical manner so as to provide some measure of protection to all parties in an electronic payment, be it between the payor and the recipient, and between the payor and the recipient and their respective financial institutions.

\footnotetext{
${ }^{638}$ See ch 12, s12.10.2.2.1 titled Comparative Applications to MFS in Other Jurisdictions.

${ }^{639}$ See the discussion in ch 9, s9.6.2 on the Payment Services Directive.
} 


\section{CHAPTER 8}

\section{ADDITIONAL OVERSIGHT RELATED TO MOBILE FINANCIAL SERVICES}

\section{1}

\section{Overview}

Mobile Financial Services (hereafter MFS) and their operating entities are often subject to a panoply of regulations of direct or indirect application, but of application nonetheless.

Conceivably, MFS could have hundreds of laws applicable to them, ${ }^{1}$ but the scope of this study and the evolving nature of MFS business models will require only the most MFS-related laws to be outlined and analysed.

This chapter examines the regulatory underpinning and philosophies of rule-making generally and introduces each of the specific sections, while later chapters will examine each of these in more detail at the country-specific level.

Besides the general banking, payment, and e-money laws that have applicability to MFS, the regulatory domains identified as having specific applicability to MFS relate to security-type laws, e-commerce laws, consumer protection laws, and telecommunications laws.

The security-related laws and regulations examined include those that deal with Counter Terrorist Financing (hereafter CTF), Customer Due Diligence (hereafter CDD), Know Your Customer (hereafter KYC), and Anti-Money Laundering (hereafter AML), all of which are slowly infusing into domestic laws worldwide.

Consumer protection laws are likewise being strengthened, especially since finance and banking, in particular, are often characterised by asymmetric information flows between banks and their customers and by their systemic effects. ${ }^{2}$

At a technical level, laws pertaining to electronic commerce (e-commerce) and telecommunications will also have an effect on the operational aspects of MFS.

\footnotetext{
${ }^{1}$ See, for example, the Firstrand Group's submission to the South African Competition Commission which outlined the statutes, regulatory instruments, codes and rules under which South African banks operate. Over 250 statutes and codes were listed, although many relate to the intermediation activities that banks generally undertake. The restricted nature of MFS business models would certainly truncate the applicable laws and codes under which they would operate. See Firstrand Group (s.d.) 'Annex 11: Regulatory Framework: Submission to the Competition Commission', available at http://goo.gl/KeKKK. See further in relation to South Africa, V Lawack-Davids (2011) 'Mind The Gap - Increasing Compliance - Burden And Regulatory Misalignment' Obiter 712-720, who notes the 149 Acts which impact the business sector in general and the additional 53 Acts which impact the financial sector specifically. See further, ch 12, s12.3.1 titled Overview.

${ }^{2}$ D Hardy (2006) 'Regulatory Capture in Banking' IMF Working Paper at 3, available at http://goo.gl/tRrVU.
} 
The regulatory philosophies underpinning these laws are discussed below insofar as they may provide a basis for a reassessment of existing banking and payment-related laws and regulations in some of the jurisdictions under discussion to create a more flexible and risk-proportional regulation approach. ${ }^{3}$

Banking is one of the most regulated and supervised economic sectors, with daily inspections of banking balance sheets. ${ }^{4}$ The sinew of the global financial system is such that most of, if not all, the financial institutions are connected in some way or another, and are at a minimum buffeted by systemic events in other countries or other sectors of the financial world. ${ }^{5}$

Therefore, elaborate sets of interconnected regulations are imposed on many components of the financial system.

\footnotetext{
${ }^{3}$ See ch 6 passim for the various MFS models used as the totem for the discussions in this chapter. For general discussions on regulating Mobile Financial Services Providers (MFSP) and similar non-banks, see inter alia A Stervinou (2011) 'The Role of Non-banks in Retail Payments' Regional Payment Systems Workshop - LAC Port of Spain, Trinidad \& Tobago, 08 February 2011, available at http://goo.gl/5x3CZ; Alliance for Financial Inclusion (AFI) (2010b) 'Consumer Protection: Leveling the Playing Field in Financial Inclusion', available from http://goo.gl/bGeUp; C Alexandre, I Mas and D Radcliffe (2011) 'Regulating New Banking Models that Can Bring Financial Services to All' 54(3) Challenge Magazine 116-134, available at http://goo.gl/TtoCN; CM Paridon (2008) 'New Changes and Challenges: Non-banks in the Payments System', available at http://goo.gl/XV9RQ; Consultative Group to Assist the Poor (CGAP) (2010a) 'Financial Access 2010: The State of Financial Inclusion Through the Crisis', available at http://goo.gl/iRSD; D Lascles (2000) 'Europe's New Banks: The "Non-bank" Phenomenon', available at http://goo.gl/QTynJ; D Porteous (2004) 'The Regulator's Dilemma: Opening Space for Innovation and Development in the Financial System' Workshop on Tiered Banking Regulation, Pretoria, 22 November, available at http://goo.gl/9mjG5; D Porteous (2006a) 'The Enabling Environment for Mobile Banking in Africa', available at http://goo.gl/JDDRn; D Porteous (2006b) 'The Regulator's Dilemma', available via www.finmarktrust.org.za; D Reichwein and S Rosati (2007) 'Nonbanks in the Payments System: European and US Perspectives', available at http://goo.gl/HPOi6; GB Gorton and A Metrick (2010) 'Regulating the Shadow Banking System', available at http://goo.gl/026f; J Isern and L de Koker (2009) 'AML/CFT: Strengthening Financial Inclusion and Integrity' No 56 CGAP Focus Note August, available at http://goo.gl/wxyx6; J Simon (2005) 'Payment Systems Are Different: Shouldn't Their Regulation Be Too?' Paper presented to Federal Reserve Bank of New York Conference Antitrust Activity in Card-Based Payment Systems: Causes and Consequences September 15-16, 2005 at 2, available at http://goo.gl/qOJag; L Bångens and B Söderberg (2008) 'Mobile Banking: Financial Services for the Unbanked?' Spider, available at http://goo.gl/rmbSJ; O Morawczynski and M Pickens (2009) 'Poor People Using Mobile Financial Services: Observations on Customer Usage and Impact from M-PESA' CGAP Brief, available from http://goo.gl/UuQDD; P Hawkins (2006) 'Financial Access and Financial Stability' Bank for International Settlements (BIS), available at http://goo.gl/HZEjW; P Klopper (2007) 'Non-banks in the Dutch Retail Payments System: A Central Bank Perspective', Nonbanks in the Payments System: Innovation, Competition, and Risk: An International Payments Policy Conference sponsored by the Federal Reserve Bank of Kansas City May 2-4, 2007, presented at Session 6 on 4 May, 1-14, available at http://goo.gl/XyHhe; P Lowe (2007) 'Non-Banks in the Payments System: A Central Bank Perspective' Federal Reserve Bank of Kansas City Conference on Nonbanks in the Payments System: Innovation, Competition and Risk Santa Fe, 2-4 May 2007, available at http://goo.gl/Z24tW; PH Rubin (s.d) 'Law and Economics', available at http://goo.gl/0Skeq.; RA Bollen (2009) 'Recent Developments with Banking Services in Developing Countries' Journal of International Banking Law and Regulation at 509, available at http://goo.gl/Q1JIx; RA Bollen (2010) 'Best Practice in the Regulation of Payment Services' Journal of International Banking Law and Regulation at 370, available at http://goo.gl/X0acO; RH Coase (1960) 'The Problem of Social Cost' 3 Journal of Law and Economics 1-44, available at http://goo.gl//ggerk; RJ Sullivan and Z Wang (2007) 'Nonbanks in the Payments System: Innovation, Competition, and Risk - A Conference Summary', available at http://goo.gl/OLB2A; S Chakravorti (2007) 'Nonbanks and Risk in Retail Payments' Payments and Monetary and Financial Stability Conference, Bank of England/ European Central Bank November 2007, available at http://goo.gl/1ZOR1; T Lyman (2009) 'Framing the Policy and Regulatory Issues' Windsor II Leadership Seminar on Regulating Transformational Branchless Banking March 9-11, 2009, Windsor, United Kingdom, CGAP, Alliance for Financial Inclusion and Department for International Development, available at http://goo.gl/vBjGr; TR Lyman, M Pickens and D Porteous (2008) 'Regulating Transformational Branchless Banking: Mobile Phones and Other Technology to Increase Access to Finance', available at http://goo.gl/YboX0.

${ }^{4}$ This may be achieved using internationally recognised banking principles such as those put forward by the BIS. See generally www.bis.org.

${ }^{5}$ Hardy (2006) op cit note 2 at 3.
} 
The financial sector's 'crash' in 2007-8 set off a pandemic of associated crises around the world and highlighted the weaknesses, and the gaps, in the regulation of this sector. The inadequacies of the contemporary model of financial regulation were exposed at national and global levels. ${ }^{6}$

Regulation here may refer to governmental actions to grant or place conditions upon the rights of firms to provide goods and services in particular areas of economic enterprise with the purpose of preventing decisions by private agents that would take insufficient account of the "public interest'.

Available regulatory tools and models that provide answers to these regulatory challenges range from general principles to detailed rules. ${ }^{8}$ Two theories of regulation of industry are widely held: positive theories of regulation and normative theories of regulation. ${ }^{9}$ Positive theories of regulation examine why regulation occurs, ${ }^{10}$ while normative theories of regulation are based on a theory of market failure. ${ }^{11}$ Famed economist Stiglitz notes that regulation begins with a simple question: Why is regulation needed and followed, and why do markets by themselves not suffice?; and then, if there is to be government intervention, why does it take the form of regulations? ${ }^{12}$ Some would see the need for regulation ${ }^{13}$ as a response to market failure, others as the need to provide the groundwork for growth and consistency in ${ }^{6}$ See E Avgouleas (2008) 'Financial Regulation, Behavioural Finance, and the Global Credit Crisis: In Search of a New
Regulatory Model', available at http://goo.gl/7r7Pt; Gorton and Metrick (2010) op cit note 3; S Agarwal et al (2009) 'The
Age of Reason: Financial Decisions over the Life-Cycle with Implications for Regulation', available at http://goo.gl/P7shu;
SJ Friedman (1984) 'A New Paradigm for Financial Regulation: Getting from Here to There' Pace Law Faculty Publications,
Paper 118, available at http://goo.gl/WJkWP.
7 S Breyer and PW MacAvoy (1987) 'Regulation and Deregulation' in J Eatwell, M Milgate and P Newman (eds) The New
Palgrave: A Dictionary of Economics. As Lee notes, government's duty to safeguard the public interest can be traced to 1690
when John Locke said that governments are able impartially to distinguish between outcomes that are in the public interest
and those that are not and, furthermore, are possessed of sufficient information and wisdom to determine the optimal form
and level of regulation. See J Locke (1690) The Second Treatise Concerning Civil Government, available at
http://goo.gl/uu0z; and also B-C Lee (2002) 'Regulation in the New Economy' University of Wollongong Department of
Economics Working Paper Series 2002 at 1, available at http://goo.gl/WJSkL, and see also B-C Lee and O Longe-
Akindemowo (1998) 'Regulatory Issues in Electronic Money: A Legal-Economics Analysis', available at http://goo.gl/EwuNO.

${ }^{8}$ As AFI (2010b) op cit note 3 indicates a principles-based approach has a lighter touch and is a more market sensitive approach as it builds on the regulated industry's greater knowledge of the market and encourages thoughtful solutions rather than 'box-ticking'. However, it is more difficult for firms to know if they are in compliance and requires flexible supervision, which calls for greater capacity on the part of the supervisor and more maturity on the part of the industry. Further, they say, users may be confused with a principles-based approach, as each institution creates a unique system to comply with the principles. A rules-based approach has the advantages of being clear and uniform in application.

${ }_{9}^{9}$ RW Hahn (2006) 'Theories of Regulation and Deregulation: A Critical Appraisal' American Economics Association Annual Meeting, available at http://goo.gl/smnWm; Public Utility Research Center (2011) 'Theories of Regulation', available at http://goo.gl/slr9b; JE Stiglitz (2009) 'Government Failure vs Market Failure: Principles of Regulation', available at http://goo.gl/TsVr9 p2; see J den Herto (1999) 'General Theories of Regulation', available at http://goo.gl/8QjYD.

${ }^{10}$ The positive theories attempt economic explanations of regulation and derive the consequences of regulation. They are said to include theories of market power, interest group theories that describe stakeholders' interests in regulation, and theories of government opportunism that describe why restrictions on government discretion may be necessary for the sector to provide efficient services for customers. In general, the conclusions of these theories are that regulation occurs because the government is interested in overcoming information asymmetries with the operator and in aligning the operator's interest with the government's interest; customers desire protection from market power when competition is non-existent or ineffective; operators desire protection from rivals; or operators desire protection from government opportunism. Public Utility Research Center (2011) op cit note 9; Den Herto (1999) op cit note 9.

${ }^{11}$ They are called normative because there is usually an implicit assumption that efficient regulation would also be desirable. These theories are said to generally conclude that regulators should encourage competition where feasible, minimise the costs of information asymmetries by obtaining information and providing operators with incentives to improve their performance, provide for price structures that improve economic efficiency, and establish regulatory processes that provide for regulation under the law and independence, transparency, predictability, legitimacy, and credibility for the regulatory system. Public Utility Research Center (2011) op cit note 9; Hahn (2006) op cit note 9.

${ }^{12}$ Stiglitz (2009) op cit note 9. Similarly, the questions could be phrased as 'how to fix it?' and the form that the solution or 'fix' will take.

${ }^{13}$ Regulation can be taken to mean the employment of legal instruments for the implementation of social-economic policy objectives. See Den Herto (1999) op cit note 9. 
rule-making and policy. The argument is not yet settled, and puts into relief what has been called the 'regulator's dilemma, ${ }^{14}$ which exists where a balancing act is required whereby the regulator enables innovation whilst still having to mitigate any risks. ${ }^{15}$

These dilemmas arise because financial regulators are charged primarily with maintaining system stability as the price of systemic disruption is so high and the interdependencies great. Network externalities and the need for competition efficiency - which may be from market failure ${ }^{16}$ - may greatly influence policy. ${ }^{17}$

The regulatory rationale could be placed under the heading of public interest ${ }^{18}$ which allows the public or some subclass of the public to interact with financial institutions with a degree of safety by increasing consumer awareness and information. ${ }^{19}$

Regulation is an instrument of social policy ${ }^{20}$ intended to influence and control market and business behaviour, which may amount to strata of regulations, usually forms of self-regulation, co-regulation or pure statutory regulation. ${ }^{21}$ The latter especially is informed by public policy goals, which may in turn be influenced by national, regional or international trends. The need for consumer protection is especially

\footnotetext{
${ }^{14}$ Porteous (2006a) op cit note 3.

${ }^{15}$ Alexandre, Mas and Radcliffe (2011) op cit note 3 at 8 . The risk includes balancing the dual objectives of identification and traceability to allow financial integrity.

16 'Market failures' are departures from the economists' notion of a perfectly efficient market where first, consumers and producers take decisions that reflect all possible, relevant information; secondly, prices reflect all costs, including costs to third parties; and thirdly, firms cannot profitably charge prices in excess of 'marginal' cost, ie where their 'market power' is absent. See Financial Services Authority (FSA) (2006) 'A Guide to Market Failure Analysis and High Level Cost Benefit Analysis' available at http://goo.gl/kFzus.

${ }^{17}$ Economists and economic theory greatly affect this debate, to which Keynes caustically remarked that 'Practical men, who believe themselves to be quite exempt from any intellectual influences, are usually the slaves of some defunct economists'. See JM Keynes (1964) The General Theory at 383.Economists then especially see the debate of the varying functions of government regulation versus market regulation framed, inter alia, by Arthur Pigou who believed that government is assumed to be a neutral arbiter in providing regulation in response to the demand of the public for the correction of inefficient, fragile or inequitable market practices. This contrasts with the economist Ronald Coase who believed that efficient outcomes could be generated without government intervention when property rights are clearly defined. Coase (1960) op cit note 1. He is said to have invented the field of 'Law and Economics,' also known as the 'Economic Analysis of Law' which is said to differ from other forms of legal analysis in looking at efficiency and incentives. A component thereof is the 'Positive Theory' of legal efficiency which believes that the common law is efficient, while the Normative Theory says that that the law should be efficient. Most economists accept both. Coase believed thereto that markets are more efficient than courts, but when possible, the legal system will force a transaction into the market. When this is impossible however, the legal system attempts to 'mimic a market' and guess at what the parties would have desired if markets had been feasible. See further L Zingales (2004) 'The Costs and Benefits of Financial Market Regulation' ECGI Law Working Paper No 21/2004, available at http://goo.gl/mgAIf.

${ }^{18}$ FR Malan (1989) 'Legal Aspects of the Regulation of Financial Institutions' 18(4) Tydskrif vir die Suid-Afrikaanse Reg at 555.

${ }^{19}$ The 'public interest' approach says that the notion of externalities serves to define the proper role of government, and emphasises the government's role in correcting market imperfections that result from externalities. In this view, regulatory agencies may or may not be well informed, but they are well intentioned. See SE Woodward (1998) 'Regulatory Capture at the U.S. Securities and Exchange Commission' Sand Hill Econometrics Working Paper, available at http://goo.gl/um9Hh. See also Winn who notes that political scientists and economists distinguish between 'economic regulation' aimed at supporting competition in markets and 'social regulation' aimed at protecting health and safety. Winn notes further that consumer protection laws are now treated as a form of economic regulation in the US insofar as government intervention is appropriate only when it is clear that competition is not doing an adequate job of meeting consumer needs. By comparison, Winn notes further that European Union (EU) lawmakers appear to be skeptical that mere economic regulation provides enough support for online consumer markets in Europe. JK Winn and M Webber (2006) 'The Impact of EU Unfair Contract Terms Law on U.S. Business-to-Consumer Internet Merchants' 62 The Business Lawyer, available at http://goo.gl/zqFRJ.

${ }^{20}$ Rubin says that legal rules, especially those in the commercial area, are instruments of social policy rather than an autonomous body of doctrine reflecting general and apolitical principles of law. See R Rubin (1991) 'Efficiency, Equity and the Proposed Revision of Articles 3 and 4' 42 Albany Law Review 551 at 553-4, 560.

${ }^{21}$ Bollen (2010) op cit note 3. Since network industries like payments can provide socially important or utility services to the public and the economy, they may need to address broad public policy agendas over and above supporting effective competition, such as financial stability and consumer protection. See Australian Payments Clearing Association (APCA) (2009) 'Competition and Coordination in the Australian Card Payments System', available at http://goo.gl/fNzRI.
} 
considered to be a public policy response to a market failure. ${ }^{22}$ Regulators must however balance the need to protect consumers whilst avoiding over-regulation, ${ }^{23}$ or for that matter, effectively impractical regulation that may have the opposite of what is intended. ${ }^{24}$

Generally, though, regulators will not act in a vacuum, but will undertake consultation with industry and impact analysts beforehand, usually as Regulatory Impact Assessments (RIA) which check on the cost, practical implementation effects, and generally any benefits or hazards of any proposed regulations. ${ }^{25}$

Regulators however may be caught in the vice of what Stigler termed 'Regulatory Capture', ${ }^{26}$ variously defined as the possibility that the regulated institutions may have inordinate influence ${ }^{27}$ on their own regulator such that the 'captured' regulator acts primarily in the interests of those that it should regulate independently, rather than in accordance with their putative mandate to promote the common good, that is, the 'public interest' option identified by Breyer and MacAvoy. Often, regulation may be necessary where contractual remedies may be seen to be insufficient to produce equitable results possibly due to the substantial inequality of one contracting partner. ${ }^{28}$ Many of the newest products and services are processed through private networks subject only to private rulemaking from which consumers are excluded. ${ }^{29}$

The resultant call for public law to step in may be explained in behavioural science where it is thought that if economic agents are subject to behavioural biases, then there is scope for some 'paternalism' in the form of the choice of default rules, usually determined by normative rules and regulations. If these defaults can

\footnotetext{
${ }^{22}$ MA Eisner, J Worsham and EJ Ringquist (2000) Contemporary Regulatory Policy; and AFI (2010b) op cit note 3.

${ }^{23}$ Over-regulation may occur when the cost of ensuring equality of information for both provider and consumer reduces the availability of products and services in the market and/or drives prices higher. AFI (2010) op cit note 3.

${ }^{24}$ See Rubin who 'analyses market failure generated by the structure of the legal system' where he says consumers will never be able to enforce their rights against a bank because it is too expensive to do so. Consumers must initiate any legal action, but invariably the action - especially for smallish amounts - cannot be economically pursued. The only thing, he says, that is economically more inefficient than failing to bring an action is when the consumer has an unjustified loss and initiates an action to recover that loss at large expense to himself and possibly costing more to pursue to recover that loss than the initial monetary loss. This, he believes, is effectively a market failure. See Rubin (1991) op cit note 20 at 569.

${ }^{25}$ See generally on the impact of financial regulation, Zingales (2004) op cit note 17. In relation to South Africa, LawackDavids (2011) op cit note 1 details the need for regulatory impact assessments, and cites examples in the United Kingdom (UK) through inter alia, the Regulatory Impact Unit (RIU) in the Cabinet Office, the Department for Business, Innovation and Skills policies, and the Better Regulation Task Force; in the US via the Office for Information and Regulatory Affairs; and in Australia via its Office of Regulation Review. Indeed, the UK's Department for Business, Innovation and Skills' overall regulatory policy is framed by them as being 'Less regulation, better regulation and regulation as a last resort.' See United Kingdom, Department for Business, Innovation and Skills (2010) 'Reducing Regulation Made Simple,' available at http://goo.gl/ABzyj. For a general view of regulatory exigencies in South Africa, see South Africa Foundation (2003) 'Designing a Regulatory Impact Assessment for South Africa' available at http://goo.gl/5RzpZ. The Foundation concluded that some ten principles of success are needed to guide the design of a regulatory reform regime for South Africa. These are Integration with independence; Public private partnership; Appropriate authority; Public accountability; High-level political support; Reform embedded in legislation; Clear guidelines; Coordination; Appropriate cost; and Sufficient information. The EU, especially because of its vast constituency and membership, undertakes vast series of consultations, often extending the time frames for the implementation of new rules.

${ }^{26}$ The 'Regulatory Capture' theory was developed by Stigler, outlined in GJ Stigler (1971) 'The Economic Theory of Regulation' 2 Bell Journal of Economics at 3-21, available at http://goo.gl/CY63C. See also Malan (1989) op cit note 19 at 555 and Hardy (2006) op cit note 2.

${ }^{27}$ The influence may be at political and staffing levels. See Hardy (2006) op cit note 2 at 4 . The desire for strict regulation does not stem from the advantage incumbents might gain from restricted competition, but from the risk shifting and moral hazard phenomena that are endemic in financial systems. See Hardy (2006) op cit note 2 at 3.

${ }^{28}$ There may also be a presumption in regulatory theory that commercial law - both private and state rules - should do for parties what they would otherwise have done for themselves. See CP Gillette and SD Walt (2008) 'Uniformity and Diversity in Payment Systems' 83 Chicago-Kent Law Review 499 at 502.

${ }^{29}$ This may occur in instances of error resolution, where there may be mistake by one party in a payment, or fraud visited upon a party. For a consumer perspective on the impact of private rules versus public rules, see ME Budnitz (2008b) 'Technology as the Driver of Payment System Rules: Will Consumers be Provided Seatbelts and Air Bags?' 83(2) ChicagoKent Law Review, available at http://goo.gl/dj0vi; and see also Rubin (1991) op cit note 20 at 553-554.
} 
be easily changed, this new form of paternalism is thought to have no cost, but possibly to have substantial benefits to the actors and society. ${ }^{30}$

There have been and are two broad approaches to the issue of regulation and concomitant consumer protection, in causa, the institutional and functional approaches which may also reflect variation in legal frameworks.

The functional approach places the focus on the service received by the consumer regardless of the type of institution providing that service. This broad protection may be the remit of specific consumer protection agencies, competition authorities, or ministries of trade and industry. The issue however, is that while this 'catch-all' appears to provide recourse insofar as all institutional types ${ }^{31}$ are concerned, the reality is that these entities may ultimately lack the necessary institutional capacity and specialised knowledge to pronounce on, for example, complicated aspects of financial consumer protection. Thus, multiple regulators may have (ineffective) remit over the same entity for different reasons, and may result in consumer ambivalence, corporate intransigence and posturing, and thus the effective maintenance of the status quo. General consumer protection agencies are often overwhelmed when obliged to address financial sector complaints in addition to other economy-wide consumer protection issues. ${ }^{32}$

In contrast, the institutional approach focuses not on the service per se, but on the institutions providing any financial service. It supposedly leaves the regulation in the hands of specialised bodies, for example, the central bank (CB), which may implement consumer protection provisions in relation to regulated financial institutions. However, this approach may distort market dynamics by fragmenting responsibilities amongst too many regulators to the extent that some entities like nonbanks are not captured. Implementation may also be challenging insofar as multiple regulators with varying levels of capacity may be required.

There is often, however, no one-size-fits-all solution to the design of a legal framework for financial consumer protection, and for coherence and maintenance of the financial system generally. It should reflect the structure of the financial system and the nature of each economy's overall legal framework. This may take the form of specific, single, dedicated agencies to deal with consumer protection issues relating to specific or general aspects of retail financial services.

Regardless of whether a functional, institutional, or single agency approach is used, the effectiveness can be enhanced by gold-plating the enabling law to define their roles clearly and, in particular, that an agency responsible for financial consumer protection should be given an express mandate on consumer protection

\footnotetext{
${ }^{30} \mathrm{~T}$ Thaler and C Sunstein (2003) 'Libertarian Paternalism' 93(2) The American Economic Review 175-179; cited in Zingales (2004) op cit note 17.

${ }^{31}$ For example banks and nonbanks providing the service.

${ }^{32}$ SL Rutledge (2010) 'Consumer Protection and Financial Literacy: Lessons from Nine Country Studies' The World Bank at 18, available from http://goo.gl/Mg20F.
} 
issues rather than it being implied ${ }^{33}$ and that the single, mandated entity receives and deals with consumer customer complaints and inquiries. ${ }^{34}$

The nature of banking is changing and the lines between traditional bank participants and nonbank participants are becoming blurred. Transactional banking services are now a key element in the relationship between many banks and their customers, ${ }^{35}$ but these services may also be offered by nonbanks. In many quarters, while this is seen as a socio-economic good that promotes efficiency and economic growth, the recent global financial crisis has spurred renewed interest in assessing the appropriate regulatory reforms to mitigate, if not prevent, future banking crises. More generally, effort is being devoted to identifying the bank regulatory regime that works best to promote a well-functioning banking system. ${ }^{36}$ Indeed, one of the principal functions of financial regulators is to guard public confidence in money, and this confidence depends crucially on the ability of economic agents to transmit money and financial instruments smoothly and securely through payment and settlement systems. The ensuing regulation of banks and financial institutions seeks to ensure that banks are operated prudently, that systemic risk is reduced, and that there are support mechanisms to assist institutions before they reach a crisis. ${ }^{37}$

The importance of banks for economic growth coupled with their fragility has led governments to establish official 'helping hand ${ }^{38}$ agencies to regulate and supervise banks. ${ }^{39}$ Indeed, financial regulators now have more tools at their disposal than in other sectors, and as a result, the financial sector is more regulated than

\footnotetext{
${ }^{33}$ Rutledge (2010) op cit note 32 at 19 and OP Ardic, J Ibrahim and N Mylenko (2011) 'Consumer Protection Laws and Regulations in Deposit and Loan Services: A Cross-Country Analysis with a New Data Set' World Bank Policy Research Working Paper No 5536 at 11, available at http://goo.gl/eD9aa.

${ }^{34}$ CGAP (2010a) op cit note 3 .

${ }^{35}$ See generally on the regulatory scope relating to non-banks and the interaction with consumer protection, Lowe (2007) op cit note 3; and MS Barr, S Mullainathan and E Shafir (2008) 'Behaviorally Informed Financial Services Regulation' Report, New America Foundation, available at http://goo.gl/ZihEc; L Brix and K McKee (2010) 'Consumer Protection Regulation in Low-access Environments: Opportunities to Promote Responsible Finance' CGAP Focus Note 60, available at http://goo.gl/r36Pc; M Ebers (2004) 'Information and Advising Requirements in the Financial Services Sector: Principles and Peculiarities in EC Law' 8(2) Electronic Journal of Comparative Law, available at http://goo.gl/U6kln; Zingales (2004) op cit note 17; Lyman, Pickens and Porteous (2008) op cit note 3.

${ }^{36}$ JR Barth et al (2010) 'Do Bank Regulation, Supervision and Monitoring Enhance or Impede Bank Efficiency?', 21 March, Social Science Research Network, available at http://goo.gl/2ncNx.

${ }^{37}$ R Apostolik, C Donohue and P Went (2009) Foundations of Banking Risk: An Overview of Banking, Banking Risks, and Risk-Based Banking Regulation at 55.

${ }^{38}$ As Levine and Caprio note, the basic intuition underlying most approaches to bank supervision and regulation is based upon a 'helping hand' vision whereby numerous market failures such as information asymmetries, enforcement impediments and transaction costs make it impossible to rely on the 'invisible hand' of the market. More specifically, market failures imply that private agents alone cannot effectively monitor banks, and so do not achieve sufficient stability and efficient intermediation A powerful supervisory agency should then directly supervise and regulate banks to promote bank stability and efficiency. R Levine and G Caprio (2003) 'Bank Regulation and Supervision: Lessons from a New Database' in JAM Garza (ed) Macroeconomic Stability, Financial Markets, and Economic Development, available at http://goo.gl/B1lnm.

${ }^{39}$ Ibid.
} 
other sectors. ${ }^{40}$ There may however sometimes be more outside pressure to use these tools, ${ }^{41}$ and possibly other times when there is pressure not to use them. ${ }^{42}$

Sociology may explain the precision of the core legal doctrine behind, as well as the importance of operational integrity for, financial institutions. ${ }^{43}$ Payments (with money) for example are seen as a social phenomena whereby people accept bills in payment only because they know others will take them as payment; that the modalities of a payment will be backed by an understanding that the payment will be processed (consistently) and delivered as requested; that an issuer of money or a payment instrument will back the value of the money stated by that instrument; or at a deposit-taking level, that there is a (legal) compact whereby banks will (usually) repay monies deposited with them at par.

This confidence may manifest as a heuristic or principle-based structure that underlies the confidence and is what drives the epistemological genesis of financial regulation that may take the form of regulation, supervision and oversight. ${ }^{44}$ The infusion of so-called 'nonbank ${ }^{, 45}$ players into the banking and payments sector complicates the picture somewhat.

However, much of current economic theory and activity is based on the principles that were developed through the first industrial revolution and associated silos that developed to organise and regulate banking and payments through the prism of a bank-only model. ${ }^{46}$ However, as Adams points out, the focus is on electronic infrastructures and technologies which are now dictating the rate and specifics of the transformation. ${ }^{47}$ Information - which could include information on the storage of value and the transit of payment - in its wider form via information-based services has become the main sellable commodity in today's hyper-linked information economy, such that the traditional silos are being tweaked and even discarded to allow for the tentative entry of new (nonbank) players into the traditional banking and payments domains.

\footnotetext{
${ }^{40}$ Malan (1989) op cit note 18 at 553; Reichwein and Rosati (2007) op cit note 3.

${ }^{41}$ Porteus (2006a) op cit note 3 passim.

${ }^{42}$ This relates to 'Regulatory Capture'. See further ch 8, s8.2 titled Philosophies Behind Regulation above; and J Kay (2009) 'The Slow Drip of Faster Payments' Financial Times 16 June, available at http://goo.gl/82sO7. A more cynical view of the role of government in supervision is the 'grabbing hand' view which assumes that politicians act in their own self-interest and by using powerful supervisory agencies to induce banks to lend to favoured borrowers on advantageous terms, they may not necessarily act to ameliorate information, enforcement, and transactions costs.

${ }^{43}$ G Simmel (2004) The Philosophy of Money $3^{\text {rd }}$ enl ed at 167; VA Zelizer (1989) 'The Social Meaning of Money: "Special Monies"' 95(2) The American Journal of Sociology 342-377, available at http://goo.gl/4BDpL; J Sommer (2008) 'Commentary: Where is the Economic Analysis of Payment Law?' 83 Chicago-Kent Law Review 7511; and SL Harris (2008) 'Introduction to Rethinking Payments Law' 83 Chicago-Kent Law Review 477, 492; N Dodd (1994)The Sociology of Money: Economics, Reason and Contemporary Society at 59-82.

${ }^{44}$ An extreme example is the hyper-inflation in Zimbabwe where the populace and the government lost confidence in their currency, their central bank and financial institutions.

${ }^{45}$ See Lascles (2000) op cit note 3

${ }^{46} \mathrm{C}$ Adams (2010) 'The Rise of Complementary Currencies and Corporafinance: E-commerce Driven Competition in the Financial Sector', available at http://goo.gl/Leh2n.

${ }^{47}$ Ibid.
} 


\subsubsection{1}

\section{Overview}

Ongoing changes in the structure and nature of banking, as well as banking crises across the globe, have focused the attention of policy makers on the appropriate structure, scope and degree of independence of banking and payment supervision.

Depending on the market, there are strata of management in the banking and payments sectors that could be described as prudential regulation, prudential supervision, oversight and Market Conduct Supervision. ${ }^{48}$ In many cases all these functions could be the remit of a single central authority, the central bank, while in other cases they could be the work of different agencies especially those relating to market conduct which may be the remit of a competition body or some other specialised agency. ${ }^{49}$ The main driving forces behind this tendency are the changing, more blurred, structure of the financial system, and continuing concerns with conflicts of interest. As such, the arguments for and against separate or integrated supervisory bodies are by no means settled. ${ }^{50}$

Central banks have traditionally influenced payment and settlement systems primarily by being banks which provide a variety of payment and settlement services to other banks. ${ }^{51}$ Their role however has relatively recently expanded in varying degrees into the domain of regulation, supervision and oversight. Many of these are based on rules and guidelines for banking and payment systems developed by international bodies like the BIS, IMF and CPSS. ${ }^{52}$

\footnotetext{
${ }^{48}$ For overviews on the differences and effect of these various roles, see United States General Accounting Office (1999) 'Electronic Banking: Enhancing Federal Oversight of Internet Banking Activities', available at http://goo.gl/8YYRp; Klopper (2007) op cit note 3; CAE Goodhart (2000) 'The Organizational Structure of Banking Supervision' FSI Occasional Papers No 1, November at 1, available at http://goo.gl/rUL0C; JR Barth et al (2010) op cit note 36, and Levine and Caprio (2003) op cit note 38 .

${ }^{49}$ In South Africa, the South African Reserve Bank (SARB) is the ultimate authority for banking and payments supervision and regulation. See further for regulatory bodies operating in the financial sector in South Africa ch 12, s12.3.2 titled Financial-Related Regulatory and Advisory bodies in South Africa. The Financial Services Board has as its remit financial products like insurance and investment. A similar scheme operates in Australia. In the UK in 1997, the then newly elected Labour Government provided responsibility for prudential supervision of commercial banks from the UK's Central Bank the Bank of England (BOE) - to a new body known as the Financial Services Authority (FSA). The FSA combined the prudential and the conduct of business supervision for most financial institutions such as banks, finance houses, mutual savings institutions, insurance companies, etc., and financial markets. In 2010, though, the newly elected minority Conservative government announced plans to strip the FSA of its powers and return much of these powers to the BOE. See Goodhart (2000) op cit note 48.

${ }^{50}$ Committee on Payment and Settlement Systems (CPSS) (2005a) 'Central Bank Oversight of Payment and Settlement Systems’, available at http://goo.gl/cW8rr; Barth et al (2010) op cit note -36. As Goodhart (2000) op cit note 48 concludes, as the dividing lines between differing kinds of financial institutions become increasingly fuzzy, continuing banking supervision by (just) the Central Bank (CB ) may cause inefficient overlap between supervisory bodies and a potential creep of the Central Bank safety net and other responsibilities into ever-widening areas. Continued CB supervisory authority may enhance concerns about the potential conflicts of interest, and raise issues about the limits of delegated powers to a nonelected body while separation of supervision from the (CB) raises questions as to whether systemic stability might suffer.

${ }^{51}$ CPSS (2005a) op cit note 50.

${ }^{52}$ The BIS then established the Committee on Payment and Settlement Systems (CPSS) of the CBs of the Group of Ten countries which developed core principles for Systemically Important Payment Systems (SIPS), an international consensus on such principles. On SIPS and the CPSS, see ch 4, s4.8.1 titled Overview. See generally, Bank for International Settlements (BIS) (2001) 'Core Principles for Systemically Important Payment Systems', available at http://goo.gl/PScYW. See also Feasibility (2006) 'The National Payment System and Competition in the Banking Sector: Report prepared for the Competition Commission: Executive Summary and Synopsis', available at http://goo.gl/iTymu. Many of these rules and
} 
Bank and payment regulation and supervision are seen to be fundamentally different from oversight. Prudential (bank and payment) regulation is often different in character and different in purpose, which is to protect the depositor and is heuristic in nature. ${ }^{53}$

Regulation is said to achieve these purposes by using licensing and supervision, regulations and the monitoring of activities. ${ }^{54}$ Financial regulators generally address issues such as consumer protection, the stability of and the financial integrity of national payment systems and banking systems by means of AML, KYC, and CTF measures. ${ }^{55}$ The role of supervision in developing countries based on international principles such as Basle have been criticised as being ill-suited to developing countries. ${ }^{56}$ By contrast, payments may be characterised by oversight, which has a different purpose insofar as it may focus on the integrity and the continuity and safety of the payments system and is seen to be more principle-based than bank supervision ${ }^{57}$ which allows some scope for developments of the future insofar as it allows maintenance of adequate oversight of new players and maintains a level playing field between banks and nonbanks. $^{58}$

It is only relatively recently that this oversight has become a function that is more formal and systematic namely a function whereby the objectives of safety and efficiency are promoted by monitoring existing and planned systems, assessing them against these objectives and, where necessary, inducing change. ${ }^{59}$ This oversight role has developed partly as a response to the expanding role of the private sector into providing payment and settlement systems and where there is, therefore, a perceived risk that these private players might not take sufficient account of the negative externalities that may cause systemic risk. As such, central banks have sought to pursue public policy objectives of safety and efficiency by guiding and influencing system operators through oversight. ${ }^{60}$ For all its newness, this development in the nature of the oversight function has been rapid and it is now generally recognised as a core responsibility of central banks. ${ }^{61}$ Central banks have traditionally influenced payment and settlement systems primarily by being banks which provide a variety of payment and settlement services to other banks. As such, central banks

guidelines are however geared towards large-value deposits and fund transfers than to small(er) value systems like Stored Value Products (SVPs). See ch 4, s4.8.4.4 on SVPs.

${ }_{53}^{53}$ Klopper (2007) op cit note 3.

${ }_{54}$ Apostolik, Donahue and Went (2009) op cit note 37 at 55.

${ }_{56}^{55}$ Bångens and Söderberg (2008) op cit note 3.

${ }^{56}$ See Ward, for example, who says that for supervision to be effective, supervisors must have the skills, incentives and legal powers to change banks' behaviour, and it is difficult and costly to design a regime in which supervisors have desirable incentives. Further, he argues, the supervisory approach is based on qualitative standards and general principles. This delegates a great deal of discretion to bureaucrats, which he says is legally and politically difficult in many countries. He argues instead to retain an emphasis on quantitative rules, and to improve the process of interpreting, enforcing and revising them. See J Ward (2002) 'The Supervisory Approach: A Critique', available at http://goo.gl/pgVaW.

${ }^{57}$ Klopper (2007) op cit note 3. Examples of oversight regimes include the design and operation of a payment system; how payment systems interconnect; the nature of payment system operators and payment system infrastructure providers; business continuity arrangements; availability of data and information from or relating to payment systems; rules of a payment system; the governance structure of a payment system, and/or market practices and behaviours. This may manifest as engagement on specific projects from time to time and by the collection of information and data which assist in identifying issues that need to be addressed or might benefit from the Central Bank's involvement. See Reserve Bank of New Zealand (s.d.) 'Statement of Principles: Payment System Oversight', available at http://goo.gl/IOx40.

${ }^{58}$ Klopper (2007) op cit note 3.

${ }^{59}$ However, although recent, this development in the nature of oversight has been rapid and the function has now come to be generally recognised as a core responsibility of central banks.

${ }^{60}$ CPSS (2005a) op cit note 50 at 1.

${ }^{61}$ Central banks and supervisors have been known to use their powers of prudential supervision to influence the banks' behaviour with regard to payments: 'moral suasion'. See Klopper (2007) op cit note 3; and CPSS (2005a) op cit note 50. 
provide a safe settlement asset and in most cases they operate systems which allow for the transfer of that settlement asset. ${ }^{62}$

In relation to supervision, the key issues noted by Barth et al for a banking supervision structure are whether there should be one or multiple supervisory authorities, and whether the CB should be involved in bank supervision. ${ }^{63}$ The issue pertaining to the scope of supervision is whether bank supervisory authorities should supervise other financial service industries, including in particular securities and insurance. There is also the issue regarding the independence of supervisory authorities relating to the degree to which bank supervisors should be subject to political and economic policy pressure and influence from political masters and/or appointees. Even so, should there be a single bank supervisory authority or would a system of multiple supervisory authorities be preferable, and should the CB be involved in bank supervision? These issues have received a good deal of attention from policy makers in a number of countries in the recent past, but systematic research on the issues is relatively thin.

A regulatory environment for banking, payments and associated activities may vary significantly in the different jurisdictions particularly insofar as which agencies - if any - are responsible and under which mandate (legislative or other). However, the nexus - possibly through organic infusion in regional blocks like the European Union (hereafter EU) or Southern African Development Community (hereafter SADEC) or through supra-national bodies like the Bank for International Settlements (hereafter BIS) and the World Bank - between the main objectives are generally very similar and relate to avoiding excessive fragility, ensuring efficient intermediation between savers and borrowers, flexibility, fairness, safety and soundness, equitable distribution of economic power and the implementation of monetary policy. ${ }^{64}$ Practically, these may entail a wide range of bank regulations and supervisory practices, such as capital regulation, entry regulation, activities restrictions, supervisory power and independence, external governance and private sector monitoring. ${ }^{65}$

Concomitantly, there may be - and usually is - a need to entrust a public authority like a CB with the role of oversight of payment systems that ultimately ensure the safety ${ }^{66}$ and efficiency of the banking sector and payment systems. ${ }^{67}$ Ancillary to this would be the need to ensure that the banking and payment sectors are not misused by criminal elements ${ }^{68}$ and to ensure a modicum of competition.

\footnotetext{
${ }^{62}$ CPSS (2005a) op cit note 50 .

${ }^{63}$ Barth et al (2010) op cit note 36; Levine and Caprio (2003) op cit note 38.

${ }^{64}$ Barth et al (2010) op cit note 36 .

${ }^{65}$ Ibid.

${ }^{66}$ In a payments context, safety means that 'the funds will be transferred from the sender to the receiver with finality when expected and that the system or payment arrangement is sufficiently robust to neither create nor transmit financial shocks'. See Reichwein and Rosati (2007) op cit note 3.

${ }^{67}$ Efficiency means that 'the speed of the transfer and the allocation of its end-to-end costs are acceptable to the sender and the receiver of the transaction and, where applicable, to their customers'. Reichwein and Rosati (2007) op cit note 3.

${ }^{68}$ See ch 8, s8.5 titled Anti-Money Laundering, Terrorist Financing and Customer Due Diligence Laws and Regulations.
} 
Payment systems are seen to be different from other markets and may require different regulation. Among other things, the differences identified are that they are two-sided markets, ${ }^{69}$ that they exhibit network effects $^{70}$ and that normal competitive forces do not always operate. ${ }^{71}$ These, Barth et al believe, usually mean that market forces, left to their own devices, may not deliver outcomes that are socially optimal. ${ }^{72}$ As a result, there is a case for regulation in the payments sector which includes two broad models: generic antitrust (competition) regulation ${ }^{73}$ and payments system specific regulation. ${ }^{74}$

Generally, however, payments require the maintenance of public confidence in the payment instruments and systems used to transfer funds via a sound and transparent regulatory environment that ensures legal certainty for all parties and, in particular, consumer protection for individual customers in relation to the proper execution of the transaction and maintenance of the confidence in any payment instruments used. ${ }^{75}$

Risks emanating from the settlement of payment-related activities increasingly became of particular concern to central banks, highlighting the credit and liquidity risks to which participants in the payment system were exposed. A payment system may be classed as SIPS. ${ }^{76}$

It is submitted, however, that the scope of micro-payments is far from a SIPS-level event, simply because of the micro amounts and the value of the purposes. This does not imply that there is no need for vigilance of these systems, but rather proportional regulation, where required.

The need for systemic reliability underlies the dilemma of how to maintain financial integrity in financial systems without prejudicing local needs and priorities, but whilst promoting financial inclusion through innovative and more transaction-focused systems like MFS.

\footnotetext{
${ }^{69}$ Two-sided markets which mean that there is a need for joint supply and joint demand which requires cooperation among potential competitors within a payment system. Simon (2005) op cit note 3 .

${ }^{70}$ Network goods insofar as size may increase efficiency.

${ }^{71}$ In payment systems the bargaining power between the various parties can be quite unequal which could lead to little competitive discipline on payment systems and result in higher interchange fees. However, competition among payment providers may require third parties to provide services. This may be true of national payment systems, but it is submitted, it is not necessarily the case with micro-payment systems where percentage differences in cost are more manifest when viewed from a retail pricing perspective. For discussion of these perceived differences, see Simon (2005) op cit note 3 at 2; and Chakravorti (2007) op cit note 3.

${ }^{72}$ The market for payment services is such that unfettered competition between payment systems can lead to distorted price signals to consumers and socially inefficient outcomes whereas in most other markets competition tends to lower, not increase, prices and competition generally delivers efficient price signals.

${ }^{73}$ In South Africa, the former indeed resulted in an extensive Competition Commission investigation into the banking and payments sector, recommending that it was too restricted and should be opened up to nonbanks. For more on this report, see ch 12, s12.5 titled Competition Commission Enquiry into Banking and Payments in South Africa. The latter is manifested in the South African National Payments System Act 78 of 1998 (NPSA). In Australia, a more liberal regime was instituted in both the clearing and settlement domains. Simon (2005) op cit note 3; Lowe (2007) op cit note 3.

${ }^{74}$ Simon (2005) op cit note 3 .

${ }^{75}$ There may also be some examination and reporting criteria embedded in the oversight regime.

${ }^{76}$ See ch 4, s4.8.1 titled Overview, for more on modern payment systems.
} 


\subsection{Overview}

Not too long ago, in developed countries and in many developing countries, the majority of financial transactions were mediated by banks, building societies and mutual societies licensed by a prudential regulator. Money was deposited and kept in these institutions and any payment transactions were usually done through many of these institutions and national payment systems, such that only banks were allowed into the core of the payments process: the high-value settlement accounts at the CB. In many countries this 'exclusivity' paradigm led to legislative restrictions on the type of institutions that could issue cheques and other payment instruments. ${ }^{77}$

Regulatory and technological changes though are driving greater nonbank participation along with a move to electronic payments. ${ }^{78}$ There is recognition that as technology has evolved, it is not only licensed banks that now handle and keep consumer funds. These may be classed as nonbank institutions or nonbank payment service providers, ${ }^{79}$ private currencies in SVPs or institutions, ${ }^{80}$ and possibly even in a shadow banking system. ${ }^{81}$

In a study by the European Central Bank (hereafter ECB) and the Federal Reserve Bank of Kansas City, a non-bank in the payments system was classed as 'an enterprise that is not a bank and which provides, primarily by way of electronic means, payment services to its customers. ${ }^{82}$ Examples from the study ${ }^{83}$ designated a nonbank payment system provider's customers as either end-users of retail payment services,

\footnotetext{
${ }^{77}$ Lowe (2007) op cit note 3 passim.

${ }^{78}$ Paridon (2008) op cit note 3; Chakravorti (2007) op cit note 3; and Simon (2005) op cit note 3, and Lowe (2007) op cit note 3 .

${ }^{79}$ For an extensive overview of non-banks and their roles, see Reichwein and Rosati (2007) op cit note 3.

${ }^{80}$ See Adams (2010) op cit note 46 who refers to corporate monies such as electronic payment systems, nonbanks and new forms of money which he terms 'corporafinance' that are supported by the capabilities of electronic commerce infrastructures to provide competition in the financial sector.

${ }^{81}$ See Gorton and Metrick (2010) op cit note 3. They argue that what they term the 'shadow' banking system played a major role in the financial crisis, yet still remains largely unregulated. The three main institutions of shadow banking they identify are: Money-Market Mutual Funds (MMMFs) to capture retail deposits from traditional banks, securitisation to move assets of traditional banks off their balance sheets, and repurchase agreements ('repo') that facilitated the use of securitised bonds in financial transactions as a form of money.

${ }^{82}$ Reichwein and Rosati (2007) op cit note 3. The study demonstrated that in the European context, nonbanks included all entities that are not authorised as credit institutions, for example, licensed Electronic Money Institutions (ELMIs) are considered to be nonbanks while in the U.S. context, nonbanks include all entities that do not accept demand deposits. A nonbank payment service provider may be either bank-controlled or nonbank-controlled. See also examples in Stervinou, (2011) op cit note 3; Paridon (2008) op cit note 3; Sullivan and Wang (2007) op cit note 3. For a very early study that looks at the implications for the banking sector, consumer choice and competition, see Lascles (2000) op cit note 3. A nonbank was loosely defined then to include savings cooperatives like those offered by post offices and large industrial companies offering savings products to their employees. In Europe the definition is blurred because of the existence of ELMIs and banks that do stock-brokering. Germany banking, for example, includes stock broking and investing

${ }^{83}$ For a very early study that looks at the implications for the banking sector, consumer choice and competition, see Lascles (2000) op cit note 3 .
} 
in which case the nonbank is providing front-end services; ${ }^{84}$ banks or other nonbank payment service providers, in which case the nonbank is providing back-end services ${ }^{85}$ or both types of customers. ${ }^{86}$

The presence of nonbanks in payment processing is thus often due to outsourcing by banks, for example, through: data processing, file transmission, network services like gateway provision and switching services, authorisation services, risk and fraud management services. ${ }^{87}$ While many large retailers have partnered with banks to provide payment and in some cases also banking-type services at their Points of Sale (POS), only recently have nonbanks come out of the technical back-office closet and begun to provide bulk frontend retail payment systems themselves. ${ }^{88}$

Nonbanks could provide many of the omnibus services shown above. For example, bar the settlement process of a fiat-based payment, ${ }^{89}$ Mobile Network Operators (MNOs) providing MFS could fit into or straddle any of these paradigms. Further, many of Stored Value Accounts (SVA) described earlier ${ }^{90}$ that house Stores of Value (SOV) from funds taken from users and which allow transactions to be done from the SVA value, may essentially mimic banking structures, although seminal differences being broadly that the funds paid over are not necessarily redeemable at par if at all redeemable and that they are not necessarily subject to any prudential regulation, supervision or oversight; that their position across many technological spheres may lead to regulatory arbitrage or failure insofar as there may not be any definitive regulator, or any institution that has oversight over these new systems; and that they are usually low-value payments with concomitant lower risk and regulatory profiles than entities involved in high-value funds transfers and 'deposits'.

\subsection{Possible Risks}

While traditional banks provide an omnibus gate-keeping function with respect to payment systems that are mediated by regulations and oversight, some of the identifiable operation risks of nonbanks in this space include the need for more complex infrastructure using a mix of players in complex interactions; use of open access technology that is not necessarily always under the direct control of banks and regulators; the

\footnotetext{
${ }^{84}$ Examples cited of front-end services include money-transfer services provided to households and acquiring services provided to merchants, MNOs and large retailers. See Reichwein and Rosati (2007) op cit note 3 at 5; Stervinou (2011) op cit note 3, and Sullivan and Wang (2007) op cit note 3.

${ }^{85}$ Examples cited of back-end services include back-office technical service providers such as data processors, data processing, network managers, security vendors' authentication and authorisation, and hosting of payments-enabled websites. Reichwein and Rosati (2007) op cit note 3 at 5; Stervinou (2011) op cit note 3 and Sullivan and Wang (2007) op cit note 3.

${ }^{86}$ An example cited of a firm with both types of customers is a company that is leasing Point of Sale (POS) devices to merchants and at the same time performing processing and routing services on the data captured on those devices for the banks issuing the associated payment cards. Such a firm would be considered to be providing front-end services to the merchants and back-end services to the issuing banks. Reichwein and Rosati (2007) op cit note 3 at 5.

${ }^{87}$ Stervinou (2011) op cit note 3; Reichwein and Rosati (2007) op cit note 3.

${ }^{88}$ In South Africa, for example, Capitec Bank partnered with Shoprite-Checkers to do payments and Money Transfer Services (MTS); and Pick n Pay Go Banking with Nedbank. See www.gobanking.co.za.

${ }^{89}$ Settlement in a BIS context would still be done by a bank with appropriate rights given by the national authority, usually a $\mathrm{CB}$ bank. However, where there is a closed loop system or where non-fiat-based values are at play, the MNO could act internally as its own settlement provider. Conceptually there is nothing stopping - bar regulation - the MFS providers from settling outside the national settlement domain: it is regularly done with mobile minute settlement by companies such as Mach and Belgacom, who not coincidentally are entering the MFS space in a settlement and switching capacity, particularly in remittances.

${ }^{90}$ See generally as an introduction to the SVP, SVAs and SOV concepts and their hierarchy, ch 2, 2.1, and in particular Exhibit A which shows a MNO operating an SVP with two types of prefunded SVAs.
} 
use of open networks, off-the-shelf/open source applications; dissemination of sensitive data in multiple places; and the potential new vulnerabilities and channels for fraud. Online fraudsters can use a variety of nonbank payment services to launder the proceeds of crime, since the concatenation of different Stored Value Card (hereafter SVC) services may ultimately quench the traceability and revocability of stolen and laundered funds. ${ }^{91}$ While they are manifest, the combination of KYC/AML/CDD rules and Subscriber Identity Module (hereafter SIM) card registration regulations if applied correctly and proportionately may to some extent ameliorate these risks. ${ }^{92}$

\title{
8.4.2.3.3 Regulatory Domains
}

Regulatory oversight of nonbanks differs by country and by degree. Systemic and Money Laundering (hereafter ML) risks that unbridled deposit-taking without a banking license, or payments that fall outside the scope of a national payment system may be real (perceived) or possibly even unduly elevated. But as has been noted by Lowe - from a Central Bank perspective - where nonbanks do bring (potential) financial risks, these risks need to be managed, not avoided altogether by preventing access (to payment systems):

\begin{abstract}
'The world of today is a lot different. Value does not need to be stored in bank accounts. Messaging and processing systems do not need to be run by banks. And in some countries, non-bank providers of payment services are able to have accounts at the central bank. [T]his new world opens up a whole range of possibilities. From my perspective, the central issue seems to be how you can best take advantage of these possibilities, without adding unnecessarily to the risk in the system. ${ }^{93}$
\end{abstract}

Similar sentiments indeed led to the genesis of m-pesa in Kenya as a flourishing nonbank provider of services and it has risen to become the bell-wether of nonbank entities providing deposit-like payment facilities, a feat that has been studied and, worldwide, attempts have been made to emulate its success. ${ }^{94}$

Reform, if at all needed, of this exclusivity arrangement may lead to a number of possible new paradigms for entities handling consumer funds. Three main issues may be identified:

- What roles do nonbanks play in the payment chain?

- What are the risks of their presence? and

- Is the current supervision of nonbanks appropriate? ${ }^{95}$

\footnotetext{
${ }^{91}$ Stervinou (2011) op cit note 3; R Anderson (2007) 'Closing the Phishing Hole: Fraud, Risk and Nonbanks', available at http://goo.gl/LHD8t. As Anderson notes further, many nonbank payment systems use contracts that attempt to make them judge and jury in disputes with customers - risking a 'race to the bottom' that would undermine consumer protection, and moral hazard which exacerbates operational risks. On potential technical risks in MFS, particularly the security aspects of mobile handsets and general security threats in the online environment, see ch 5, s5.7 titled Security Aspects of Mobile Technology and Application to MFS.

${ }_{92}$ On the financial-related safeguards, see below, ch 8, s8.5 titled AML, CDD, CTF and KYC laws and regulations. On telecommunications-related safeguards, see ch 8, s8.6 titled Telecommunications Laws and Regulations relating to mobile phones.

${ }^{93}$ Lowe (2007) op cit note 3 at 64. In Australia, where nonbanks are able to hold a store of value for the purpose of offering transaction services to consumers, reflecting a functional approach to regulation. If the SOV has the general characteristics of a bank deposit in that it is redeemable on demand, and if the payment product can be used for purchases in a wide variety of situations, then it is subject to prudential regulation by the regulator, the Australian Prudential Regulation Authority (APRA). Lowe (2007) op cit note 3 at 65.

${ }^{94}$ See ch 10, s10.2.3.3 titled Application to MFS on how the Central Bank of Kenya (CBK) allowed m-pesa to evolve; and ch 2, s2.6 titled Current and Future Schemes.
} 
Some of the other public policy issues that may need to be addressed include whether the entry of nonbanks may potentially increase competition and so improve social welfare, and whether systemic risk is of concern with retail payments. ${ }^{96}$

Some of these new nonbank institutions may be those who issue and run SVP such as SVCs and e-money stored in SVCs, all products which may have the effect of emulating 'deposits' - except that in some cases the value may not be redeemable - as well as an ability to use the value for doing a payment or for transferring value. ${ }^{97}$ Each may have a different regulatory regime attached to them that reflects the degree of risk their activities hold to the financial system (if any), or, for example, to law enforcement. This may take the form inter alia of e-money or AML laws or regulations, or rules on outsourcing of services by banks to nonbank technical providers. The former may require a type of license allowing the entity to take funds without any payment necessarily being due to anyone, or specific exemption from being considered as a deposit-taking institution based on the limited scope of their business activities, for example, a closed loop system where value received by the system operator is not generally able to be used by users outside a walled garden.

In some cases the distinction that invokes 'deposit-taking' may be arbitrary, based rather on political ${ }^{98}$ and business continuity and stability considerations than on traditional banking (common) law precepts of 'banking business' and concomitant views of what 'deposits' are. It may, however, be the case that there is a seismic shift in the way deposits and banking business are linked, such that a narrowly-defined deposit does not necessarily automatically trigger the formidable regulatory spectre relating to involvement in the 'business of banking'.

Any risks, if demonstrably present, thus need to be considered, it is submitted, on the basis of proportional risk rather than to take a sledgehammer approach where the service is not necessarily one which fits into a traditional comfort zone, that is the traditional concept of deposit-taking - if shown to be so - invoking systemic risk implications and similar regulations to that employed by the traditional purveyors of deposittaking: licensed banks. Similar considerations attach to activities in the payment services domain and any AML legislation being invoked and fastened on these activities.

\subsection{Examples of Consumer-based Financial Regulation}

Because there may not be a one-size-fits-all solution to the design of a legal framework for both financial consumer protection and for coherence and maintenance of the financial system, generally, some jurisdictions have taken specific approaches to financial consumer protection by creating single, dedicated

\footnotetext{
${ }^{95}$ Stervinou (2011) op cit note 3.

${ }^{96}$ Chakravorti (2007) op cit note 3.

${ }^{97}$ For example, a remittance using Money Transfer Organisations (MTOs).

${ }^{98}$ See the discussion of the political considerations that gave rise to an exemption in the EMD1 to the MNO's prepaid SOV in ch 9, s9.6.3 titled E-money, Stored Value Laws and Regulations on the Directives.
} 
agencies to deal with consumer protection issues relating to specific or general aspects of retail financial services. ${ }^{99}$

This may be, for example, a focus just on credit provision, like the National Credit Regulator of South Africa (hereafter NCRSA) responsible for retail credit issues, ${ }^{100}$ or the Financial Consumer Agency of Canada (hereafter FCAC) ${ }^{101}$ established in 2001 by the federal government to strengthen oversight of consumer issues and expand consumer education in the financial sector. In July 2010, its remit was extended to the oversight of payment card network operators and their commercial practices. This includes most SVPs.

In the US there is the neophyte Consumer Financial Protection Bureau (CFPB), the federally-mandated agency responsible for financial services and products which was created in the wake of the excesses of the 'Great Recession'. 102

\section{Anti-Money Laundering, Terrorist Financing and Customer Due Diligence Laws and Regulations}

It has been suggested that MFS provides the ideal ecosystem for ML, that is, the processing of the proceeds of criminal activities to disguise their illegal origin. ${ }^{\mathbf{1 0 3}}$ Activities to prevent and counter ML, called AML, often coalesce around associated terms such as KYC, CDD, Terrorist Financing (hereafter TF) and Counter Terrorist Financing (hereafter CFT). CDD and KYC rules generally compel institutions to take measures on a risk sensitive basis to verify the identity of their customers and where applicable their beneficial owners. $^{104}$

\footnotetext{
${ }^{99}$ See a brief discussion in CGAP (2010a) op cit note 3 at 23-25; Rudtlege (2010) op cit note 32 passim; and Ardic, Ibrahim and Mylenko (2011) op cit note 33 passim.

${ }^{100}$ See ch 12, s12.3.2.7 titled The National Credit Regulator.

101 The FCAC was established in 2001 by the federal government to strengthen oversight of consumer issues and expand consumer education in the financial sector. In July 2010, its remit was extended to the oversight of payment card network operators and their commercial practices. This includes most SVPs. See generally the FCAC web site at http://goo.gl/IkD4d.

${ }^{102}$ See ch 11, s1 1.2.4.2.2 below on the CFPB. It will be able to autonomously write rules for consumer protections governing all financial institutions - including banks and nonbanks - offering consumer financial services or products, although it has some exclusions that may not offer robust protections for SVPs.

${ }^{103}$ See Financial Action Task Force (FATF) (s.d) 'What is Money Laundering?', F.A.Q., available at http://goo.gl/wo405. For concerns and overviews of how and whether MFS and similar non-bank entities may be used for ML, see inter alia African Development Bank (2007) 'Bank Group Strategy for the Prevention of Money Laundering and Terrorist Financing in Africa', available From http://goo.gl/bBt6H; PL Chatain et al (2008) 'Integrity in Mobile Phone Financial Services: Measures for Mitigating Risks from Money Laundering and Terrorist Financing' World Bank Working Paper No 146, available at http://goo.gl/c6UCV; L de Koker (2009) 'The Money Laundering Risk Posed by Low-risk Financial Products in South Africa: Findings and Guidelines' 12(4) Journal of Money Laundering Control 323-339; see also L de Koker (2010) 'Will RICA's Customer Identification Data meet Anti-Money Laundering Requirements and Facilitate the Development of Transformational Mobile Banking in South Africa? An Exploratory Note' Finmark Trust, available at http://goo.gl/dtboP; United States Department of State, Bureau of International Narcotics \& Law Enforcement (2008) 'International Narcotics Control Strategy Report: Mobile Payments - A Growing Threat', available athttp://goo.gl/XZ5R; P Leyva (2008) 'MPayment: A Threat to Anti-Money Laundering' The Vermont Bar Journal, available at http://goo.gl/MAzH0; and J Forbes (2007) 'The Convergence of Telecom and Financial Services and its Effects on AML/CFT Wire Remittance Operations', available at http://goo.gl/m4Wdm; M Solin and A Zerzan (2010) 'Mobile Money: Methodology for Assessing Money Laundering and Terrorist Financing Risks', available at http://goo.gl/F6vw5; Anderson (2007) op cit note 91; D Rees (2010) 'Money Laundering and Terrorism Financing Risks Posed by Alternative Remittance in Australia' Australian Institute of Criminology, available at http://goo.gl/Fip0H; Isern and De Koker (2009) op cit note 3.

${ }^{104}$ European Commission (EC) (2009) 'The EU Compendium Paper on AML Supervisory Practices' 2 EU AML Info-Letter December, available at http://goo.gl/UzhWB; and 3L3 Anti Money Laundering Task Force (2009) 'Compendium Paper on
} 
The attacks in the US on 11 September 2001 - where the perpetrators were thought to have used a web of ML schemes to finance their activities - spurred the US to push for even more vigorous CDD, KYC, CTF and AML rules. The domino effect of these actions, especially in an interconnected financial world, led governments around the world to tighten their own AML laws and regulations. ${ }^{105}$ The tracing of people is now on par with the tracing of funds.

Almost all of these AML-type regimes are based in some way on the so-called ' $40+9$ ' Recommendations of the Financial Action Task Force (FATF), ${ }^{106}$ an inter-governmental body whose purpose is the development and promotion of policies at national and international level to combat money laundering and terrorist financing. ${ }^{107}$ The $40+9$ Recommendations, together with their interpretive notes, provide the international standards for combating ML and TF globally. Governments around the world are slowly implementing these $40+9$ in some measure in their own domestic laws. The FAFT recommendations ostensibly use a proportional, risk-based approach such that resources should be focused on persons and activities posing a higher risk of ML and TF and less on those lower risk, lower value schemes. ${ }^{108}$ The potential of Informal Value Transfer Systems ${ }^{109}$ - also known as 'alternative remittance systems' by the FATF - for use in ML was identified by the FATF in 1996 as one method in a list of ML techniques most frequently employed in the Asian region. ${ }^{110}$ In particular, while MFS uniquely offers an ability to provide services to unbanked and underbanked populations, and is able to provide a platform for convenience, speed, availability, and low cost, state agencies have begun to fear that the relative anonymity of prepaid mobile phones in markets where there is a majority prepaid subscriber base, poses distinctive risks in comparison with traditional ways to channel financial services. ${ }^{111}$ The risk is thus seen as being much greater. ${ }^{112}$ The World Bank ${ }^{113}$ has

the Supervisory Implementation Practices across EU Member States of the Third Money Laundering Directive [2005/60/EC]', available at http://goo.gl/2nwqA.

${ }^{105}$ See JB Taylor (2007) Global Financial Warriors: The Untold Story of International Finance in the Post-9/11 World at 12. See also www.knowyourcountry.com; and Anderson (2007) op cit note 91. The underlying problem noted by Anderson is that banking regulations are largely driven by law enforcement concerns, strategies and tactics rather than pure economic criteria such that bank customers must participate in what he calls an 'identity circus' where even private bankers feel driven to write to customers of thirty years' standing asking them for utility bills as proof of address.

${ }^{106}$ See FAFT-GAFI (2011) 'What is the FATF?', available at http://goo.gl/PDdiP.

107 The FATF global standards are contained in the FATF Forty Recommendations on AML and its Nine Special Recommendations on CTF, collectively, the FATF Recommendations. The Task Force, formed in 1989, is essentially a policy-making body which monitors members' progress in implementing necessary measures as well as reviewing money laundering and terrorist financing techniques and counter-measures. It also promotes the adoption and implementation of appropriate measures globally. Initially developed in 1990, the 40 Recommendations provide a complete set of countermeasures against money laundering covering the criminal justice system and law enforcement, the financial system and its regulation, and international co-operation. The additional 9 Special Recommendations are on how to detect and prevent TF.

${ }_{108}^{108}$ See generally FAFT at http://goo.gl/JmboN.

${ }^{109}$ See ch 4, s4.8.4.3 on remittances.

${ }^{110}$ FATF (1996) 'FATF-VII Report on Money Laundering Typologies,' at 9-10, available at http://goo.gl/hoz02. As Vlcek notes, the term 'Terrorist Financing' first appeared in these FATF reports on methods and techniques in the 1999 Report with a discussion of the extension of anti-money laundering laws to combat terrorist financing by the USA See W Vlcek (2006a) 'Development v. Terrorism: Migrant Remittances or Terrorist Financing', Challenge Working Paper, Work Package 2 Securitization Beyond Borders: Exceptionalism inside the EU and Impact on Policing Beyond Borders, September, available at http://goo.gl/wYD4o.

${ }_{111}$ Chatain et al (2008) op cit note 103 passim.

${ }^{112}$ De Koker (2010) op cit note 103.

${ }^{113}$ Chatain et al (2008) op cit note 103 at 13. 
identified some of these perceived MFS-based risks as the unknown identity of the user; ${ }^{114}$ false identification; $;{ }^{115}$ smurfing; ${ }^{116}$ fast transaction speed; $;{ }^{117}$ and pooling and delegation. ${ }^{118}$

These principles and the objective to regulate money transfer and how individuals may choose to handle their own finances, have been questioned by some as being 'rules by the financially stable citizens that regulate those who may be at the Bottom of the Pyramid, and possibly even a subtle method to discourage immigration to the developing world ${ }^{119}$ insofar as rules around ML may make it increasingly expensive for migrants to send their earnings to any family in their home country, and this has resulted in a tension between the desire of migrant labour to send money home and fears of insecurity against the financing of terrorism. ${ }^{120}$ As Anderson notes, these FATF rules impose unnecessary burdens, particularly on the poor, while not doing enough to facilitate the rapid recovery of stolen assets and the future regulation of nonbank payment services should take this into account. Further, the FATF rules assume traceability is the key to AML, ${ }^{121}$ but some studies show that (expeditious) revocability may be more important - where possible. ${ }^{122}$ While in many cases fraudulent payments within the banking system can be traced and recovered depending on the regime at play, by contrast, stolen funds used to buy transferable (nonbank) financial assets such as eGold and other SVPs, recovery becomes much harder if not impossible. ${ }^{123}$ Use of airtime as a currency is one of the methods of this transfer of funds into a black hole of recovery and traceability as it is a fast-consumed good. ${ }^{124}$

Proportionately, some AML regimes may be seen as overkill in context of de minimus transactions, where the incremental cost of AML procedures designated even for low-value accounts and small transactions may be disproportionate to both the risks they purport to address and the value of these services to poor people. ${ }^{125}$ This may have unintended consequences in forcing some users back to the use of untraceable (and possibly more expensive) informal money transfer systems. ${ }^{126}$ With these scenarios in mind,

\footnotetext{
${ }^{114}$ MFS may not necessarily need any or the same level of customer authentication for opening accounts or transacting as with traditional banks. There may be exceptions to any KYC requirement where amounts in a purse or where there is a transaction level below a set threshold.

${ }^{115}$ See ch 12, s12.8.4.2 titled Application to MFS in South Africa.

on how South African mobile users are generally able to obtain false documents and unregistered mobile SIM cards, thus easily evading SIM-card registration laws.

${ }^{116}$ Smurfing in a financial transaction context means the deliberate splitting of a large financial transaction into multiple smaller transactions such that each smaller transaction falls below a minimum threshold required for reporting to the authorities.

${ }_{117}$ This risk is based on the speed, geographical independence, and fast settlement of transactions, even across jurisdictions.

${ }_{118}^{11}$ Pooling occurs when mobile phones are shared amongst many individuals, say in a village.

119 Vlcek (2006a) op cit note 110; and for a similar critique, N Passas (2006) 'Fighting Terror with Error: The Counterproductive Regulation of Informal Value Transfers', available at http://goo.gl/gTZPh.

${ }^{120}$ Vlcek (2006) op cit note 110 .

${ }^{121}$ See for example FATF Recommendation \#38, that states: 'There should be authority to take expeditious action in response to requests by foreign countries to identify, freeze, seize and confiscate property laundered, proceeds from money laundering or predicate offences, instrumentalities used in or intended for use in the commission of these offences, or property of corresponding value.'

${ }_{122}$ Anderson (2007) op cit note 91.

${ }^{123}$ Ibid.

${ }^{124}$ Anderson suggests that anonymous, low-value payment mechanisms can be tolerated so long as (stolen) funds can be quickly traced and recovered. The implied converse of this supposition - that they cannot be tolerated if they cannot be recovered - seems however to be somewhat of an overkill in response. Anderson (2007) op cit note 91.

${ }^{125}$ Alexandre, Mas and Radcliffe (2011) op cit note 3 at p8. See for example Anderson (2007) op cit note 91 who suggests that regulators should 'think seriously about the revocability of electronic payments' so as to 'make nonbanks less attractive as vehicles for financial flight'.

${ }^{126}$ Thus, as Alexandre, Mas and Radcliffe (2011) op cit note 3 at 8-9 suggest, applying reduced KYC procedures for low value accounts and small deposits which pose lower AML risks would not only be more access-friendly, but may also increase the effectiveness of AML and monetary policy as more transactions would be done electronically and tracked. This
} 
governments are challenged to make an innovation-friendly climate while simultaneously ensuring that business development remains sustainable. Criminal use of the technology challenges business viability in the long run via the risk of massive investment flight and public distrust of new players entering the market. As such, institutions conducting banking or investment business - 'accountable institutions' in global AML nomenclature - are required under respective regulatory codes to have in place adequate policies, procedures and practices to deter and prevent money laundering and the financing of terrorism. The security issues around money relate to KYC and CDD insofar as initially identifying a new customer and checking the activities of that customer on an ongoing basis. ${ }^{127}$ The accountable institutions are also required to report any transactions that they believe may be related to ML or TF. 'Suspicious' transactions are not easy to spot, but may, it is suggested, ${ }^{128}$ be seen through the prism of profiling each customer and looking for activities that may be outside of the expected range of transaction activity. ${ }^{129}$

If AML schemes are to work ubiquitously, measures must be taken to equip the institutions and their agents in their AML activities. As agents have a legal nexus to (accountable) MNOs and banks, for example, they would also be required to implement AML/KYC procedures correctly so as to ensure that they fulfill their agency obligations. Where an agent is processing a transaction, some systems may not only flag the transactions as suspicious, but may also provide guidance to the system operator and/or agent as to what actions to take. The agents themselves will need to be 'KYCd' by their principles.

Two 'Special Recommendations' with a direct impact upon remittances were devised by the FATF. The Special Recommendation VII ${ }^{130}$ relates to 'wire transfers' and urges that the remitter should be identified, as well as that data collection is not only for local retention, but also for its dissemination to receiving institutions and officials along 'the payment chain'. ${ }^{131}$

proportional risk approach should, they believe, allow immediate account opening with minimal barriers for poor people, with a progressive tightening of $\mathrm{KYC}$ as their usage of financial services grows.

${ }^{127} \mathrm{CDD}$ and KYC principles are outlined in FATF Recommendation 5 which says that service providers that transfer money or value should take CDD measures by identifying the customer and verifying the customer's identity using reliable, independent source documents, data or information. There should also be ongoing due diligence on the business relationship, and transactions undertaken should be scrutinised throughout the course of that relationship to ensure that they are being conducted consistently such that transactions should fit within the institution's knowledge of the customer's business and risk profile. See FATF (2003) 'The 40 Recommendations', available at http://goo.gl/c8e1o.

${ }^{128}$ See C Bold (2010) 'Tackling Fraud, Money Laundering and Terrorism Financing in Mobile Banking' CGAP Blog January 13 , available at http://goo.gl/ZgcCB and the examples that follow below.

${ }_{129} \mathrm{Ibid}$; Bold gives the example of a customer who declares that he is unemployed when he opens an account, but who then starts to deposit large amounts of money into his account might be deemed worthy of further investigation. However, the very low limits on accounts in some countries prevent these large transactions that might be considered 'suspicious'. A customer's employment status or sources of income are useful indicators that may be used to categorise customers under different profile types in order to build a model of the range of transactions they should expect to see. Income data can also be useful if the mobile financial services provider wants to offer more complex products, such as credit.

${ }^{130}$ Specifically, FAFT Recommendation VII says that: 'Countries should take measures to require financial institutions, including money remitters, to include accurate and meaningful originator information (name, address and account number) on funds transfers and related messages that are sent, and the information should remain with the transfer or related message through the payment chain; and countries should take measures to ensure that financial institutions, including money remitters, conduct enhanced scrutiny of and monitor for suspicious activity funds transfers which do not contain complete originator information (name, address and account number).' See FATF (2001) 'FATF Special Recommendation VII: Wire Transfers,' at 3, available at http://goo.gl/RvL5b

${ }^{131}$ As Vleck points out an unintended consequence of this may be where the individual remitting money home is an asylum seeker in the EU; they may have justifiable reasons for not wanting government officials in the receiving jurisdiction to know where they are while they continue to provide financial support for family members left behind. For a detailed discussion of the impact of these recommendations, see Vleck (2006a) op cit note 110. 
South Africa has adopted the FAFT 40+9 principles on ML and these are implemented through a number of specific AML laws discussed above. ${ }^{132}$ Besides common law application to illegal transactions in contract, the relatively newer concept of AML also overlaps with other common law offences like fraud, forgery and uttering as well as statutory offences such as corruption. ${ }^{133}$

In the EU, many of the Special Recommendations of the FATF are incorporated into Community legislation for the Single Market, for example, the EC wire transfer regulation ${ }^{134}$ and the Payment Services Directive (hereafter PSD). ${ }^{135}$ US AML Laws usually coalesce around Federal Money Services Business (MSB) statutes and regulations ${ }^{136}$ and to a limited extent by similar state laws. Nonbank issuers of e-money and providers of certain types of electronic payments were initially grouped as financial institutions, ${ }^{137}$ and then later as Money Services Businesses (hereafter MSBs) ${ }^{138}$ under a package of AML statutes which comprise the Banking Secrecy Act; ${ }^{139}$ Federal Crime of Money Laundering; ${ }^{140}$ Federal Crime of Operating an Unlicensed or Unregistered Money Transmitting Business; ${ }^{141}$ and Regulations and Financial Recordkeeping and Reporting of Currency and Foreign Transactions. ${ }^{142}$ In Kenya, the Proceeds of Crime and Anti-Money Laundering Act ${ }^{143}$ provides mechanisms for detecting and seizing the proceeds of ML. ${ }^{144}$

\footnotetext{
${ }^{132}$ The Prevention of Organised Crime Act 121 of 1998 (POCA); the Financial Intelligence Centre Act 38 of 2001 (FICA) and the Protection of Constitutional Democracy against Terrorist and Related Activities Act 33 of 2004 (POCDATARA). POCA and POCDATARA criminalise money laundering and terrorist financing while FICA requires financial service providers and certain professionals to maintain specific AML/CFT controls. For overviews of AML issues in South Africa, see further ch 12, s12.7.1 titled Introduction; and generally Isern and De Koker (2009) op cit note 3 at 323-339; and De Koker (2010) op cit note 103.

${ }^{133}$ See further ch 12, s12.7.1 for a discussion of $S v$ Dustigar (Case No CC6/2000 (Durban and Coast Local Division) unreported) and $S$ v Caswell (Case No 27/87/98 (Regional Court, Cape Town) unreported) as cited in L de Koker (2002) 'Money laundering in South Africa', ISS, available at http://goo.gl/4TXD5.

${ }^{134}$ Regulation (EC) No 1781/2006 of The European Parliament and of The Council of 15 November 2006 on information on the payer accompanying transfers of funds.

${ }_{135}$ Payment Services Directive 2007/64/EC (PSD). See further ch 9, s9.6.2 on the Payment Services Directive (PSD).

${ }^{136}$ See FinCen MSBs at http://goo.gl/mlwbD.

${ }^{137}$ One of the first groupings of the range of nonbank entities was with the passage of the Annunzio-Wylie Anti-Money Laundering Act of 1992 when the definition of 'financial institution' for Bank Secrecy Act reporting purposes was expanded to include nonbanks. In 1997, the US Department of Treasury, via its FinCEN, coupled these disparate industries together, as entities that sold payment instruments or transferred funds for consumers, but did not accept deposits or make loans.

${ }^{138}$ The Bank Secrecy Act, Titles I and II of Pub. Law 91-508, as amended, codified at 12 USC 1829, 12 USC 1951-1959, and 31 USC 5311-5330]. See T Bolt and A Ramasastry (2000a) 'Memorandum: UMSBA - Matters Relevant to Consideration for Final Approval', available at http://goo.gl/i6Cg5 where it is explained that MSBs were, under the UMSA and under initial federal guidelines, grouped together conceptually because they provide an interrelated group of services to the 'unbanked' population and because their services were vulnerable to money laundering.

${ }^{139}$ Title 31 United States Code - Money and Finance, Chapter 53 - Monetary Transactions.

${ }^{140}$ Title 18 US Code, Crimes and Criminal Procedure.

141 Ibid.

${ }^{142}$ Title 31 Code of Federal Regulations - Money and Finance: Treasury Part 103

${ }^{143}$ Act 9 of 2009 defines the 'proceeds of crime' as:
}

\begin{abstract}
'any property or economic advantage derived or realized, directly or indirectly, as a result of or in connection with an offence irrespective of the identity of the offender committed after the passing of the Proceeds of Crime and Money Laundering (Prevention) Act and includes, on a proportional basis, property into which any property derived or realized directly from the offence was later successively converted, transformed or intermingled, as well as income, capital or other economic gains derived or realized from such property at any time since the offence.'
\end{abstract}

Section 1.4: definition, available http://goo.gl/hzqAb.

${ }^{144}$ Section 45(1) of the Act mandates new KYC requirements in that a reporting institution must take reasonable measures to satisfy itself as to the true identity of any applicant seeking to enter into a business relationship with it or to carry out a transaction or series of transactions with it, by requiring the applicant to produce an official record reasonably capable of establishing the true identity of the applicant. This may include a birth certificate; a national identity card; a driver's license; a passport; or any other official means of identification as may be prescribed. 
The general convergence of purpose of where MNOs provided a full range of services from voice, data and multimedia applications accessible from a mobile handset and a full range of end-user devices has meant that countries around the world are updating their licensing and regulatory frameworks to address the increasing reality of this convergence. ${ }^{145}$

At the very least, MNOs and Service Providers (SPs) are usually subject to a host of telecommunicationsrelated laws and regulations by their National Regulatory Authorities (hereafter NRAs) which may impact their ability to provide MFS-related services. ${ }^{146}$ License holders usually have to account to their telecommunications regulatory authority and also possibly abide by any additional self-regulatory rules.

Invariably, the concern of many NRAs is that the outlay by MNOs on non-core activities like MFS, at least in terms of their service license, may impact on their ability to provide core telecommunications facilities for which there may be strict Quality of Service (QOS) agreements in place such that these MFS activities by MNOs may fall into some telecommunications licensing regime beyond just the provision of telecommunications-only services. This may include the provisions of WASP-like services through 'content licenses' and the provision of shortcode ranges and the regulation of pricing for these shortcodes and possibly of the content and pricing of these services. Some revised NRA licensing approaches favour a generic license - often called a unified or converged license - for all providers of telecommunication services, regardless of what technology they deploy or services they ultimately offer through their telecommunications facilities. ${ }^{147}$ This is related in some measure to the concept of 'net neutrality' or 'technology neutrality' where licensees can transfer any type of data across their network without differentiating between the service and data types. ${ }^{148}$

Other NRA approaches - such as that adopted in South Africa - favour the 'class license' approach, where there is segmentation in the licensing types, requiring various individual licenses for those engaged in, for example, network infrastructure-only or services-only or content-only. Ostensibly designed to present vertical monopolies where one entity controls everything in the ultimate service provision, it may stifle innovation in requiring consent or general authorisations by requiring operators to apply for, or notify, or register their services with their NRA. ${ }^{149}$

\footnotetext{
${ }^{145}$ International Telecommunication Union (2004) 'Trends in Telecommunication Reform 2004/05: Licensing in an Era of Convergence: Summary' at 1-2, available at http://goo.gl/aU3MP.

${ }^{146}$ See for example the NRA in Kenya - the Communications Commission of Kenya (CCK) - which implemented a content licensing regime that in effect captured MFS services. See ch 10, s10.4 titled Telecommunications-related Laws and Regulations.

${ }^{147}$ Under a converged license framework there are two major principles: technological neutrality and services neutrality. For a discussion of converged licenses, see A Narayan (2007) 'Overview of Regulatory Challenges in the Converged Telecommunication/ICT Environment', available at http://goo.gl/32OlY. In 2005, the Tanzania Communications Regulatory Authority introduced the Converged Licensing Framework. See ICT Regulation Toolkit (s.d.) 'Tanzania - The Converged Licensing Framework', available at http://goo.gl/S1oJq.

${ }_{148}$ A Blowers (2010) 'Net Neutrality: Ofcom Briefing for Analysts 21st July 2010', available at http://goo.gl/t8j8d.

${ }^{149}$ In some cases, previously licensed services may be subject to no licensing requirements at all.
} 
NRAs' tasks are usually made very challenging by first, a lack of qualified personnel and second, continued threats of or actual legal action against them by dissenting licensees, or those wanting licenses. As a result their licensing and rule-making procedures may often take years and be very rigid and normative, and sadly largely inchoate. In the MFS sense, though, this may actually favour the deployment of MFS in some cases, as the NRAs defer to the prudential regulators, especially where fiat-based, redeemable purses and services are involved. NRA and the prudential regulators do however cooperate in many cases over MFS, at one extreme if only to simply ink a Memorandum of Understanding (MOU) that gives the prudential regulator autonomy over most MFS, but at the other extreme to determine sharing of regulatory responsibilities, especially where there may be a possibility of regulatory arbitrage because of competing prudential and telecommunications licensing regimes. An example may be where the MNO must obtain a class license for MFS 'content' alongside the prudential license, as well as responsibilities in the handling of customer care issues. ${ }^{150}$ Competition and anti-trust issues also arise. ${ }^{151}$ Global bodies like the World Economic Forum (hereafter WEF) ${ }^{152}$ and the Global System for Mobile Communications Association (hereafter GSMA) ${ }^{153}$ have made strides in physically getting the NRAs and prudential regulators together to discuss these dueling regulatory issues. ${ }^{154}$

At a regulatory level, MNOs in South Africa are directly licensed through the provisions of the Electronic Communications Act (ECA). ${ }^{155}$ This Act recognised individual and class licenses, depending on the services provided. This is designed, at best, to recognise that, for example, the boundaries between telecommunication and broadcasting technologies are increasingly blurred. WASPA ${ }^{156}$ is the selfregulatory body for WASP services and has devised a new civil procedure for regulating Value Added Services (hereafter VAS) based on its Code of Conduct.

In the EU, a new set of rules for making telecommunication services more affordable, more competitive, more accessible and more diverse in its application based on the emergence of new technologies like $3 \mathrm{G}$ have been devised. The EU has enacted seven directives and related documents in connection with Information and Communications Technology (hereafter ICT) regulation, beginning in 2002 in order to have a flexible regulatory framework capable of responding to new technologies, convergence, and an increasingly competitive market. ${ }^{157}$

\footnotetext{
${ }^{150}$ See for example the telecommunications licensing regime in Kenya in ch 10, s10.4.

${ }^{151}$ European Commission (EC) (2002) 'Commission Directive 2002/77/EC of 16 September 2002 on Competition in the Markets for Electronic Communications Networks and Services', OJ L 249, 17 September 2002, 21-26, available at http://goo.gl/DxCGJ.

${ }^{152}$ See www.weforum.org.

${ }^{153}$ See www.gsmworld.com.

${ }^{154} \mathrm{See}$, for example, this meeting between regulators in the financial and telecommunications world. Citibank (2010) 'Citi Global Transaction Services and the GSMA Host Mobile Money Policy Forum in Africa', available at http://goo.gl/Dsr6v.

${ }^{155}$ Electronic Communications Act 36 of 2005. See ch 12, s12.8.2 titled Laws and Regulations.

${ }^{156}$ Wireless Application Service Providers Association (WASPA). See ch 6, s6.5.4.2 titled WASP Value Added Services; and ch 12, s12.8.3.2 on WASPA. See also www.waspa.org.za.

${ }^{157}$ ICT Regulation Toolkit EU Regulatory Framework, available at http://goo.gl/SOpRt. An agreement on EU Telecoms Reform was reached by the European Parliament and Council of Ministers on 4 November 2009. The new rules will now need to be transposed into national laws of the 27 Member States by May 2011. This will include the establishment of the European Body of Telecoms Regulators. See European Commission Information Society (EC) (s.d.) 'The Telecoms Reform', available at http://goo.gl/C6nin.
} 
In Kenya, the Kenya Communications (Amendment) $\mathrm{Act}^{158}$ was passed to expand the opportunities presented by converged technologies; in so doing it also expanded the regulatory scope and jurisdiction of the Communications Commission of Kenya (hereafter CCK), the regulatory authority for the communications sector. ${ }^{159}$ The CCK issues licenses in terms of the Kenya Communications Act, ${ }^{160}$ the Kenya Communications (Amendment) Act of 2009, ${ }^{161}$ and the Kenya Communications Regulations. ${ }^{162}$

In the US, the Federal Communications Commission (hereafter FCC) is the federal authority tasked with the oversight and regulation of the telecommunications sector at a state and federal level. ${ }^{163}$ Use of a mobile device for payments and money transfer may, tangentially, bring this usage into the realm of telecommunications regulation relating to MNO billing systems. Insofar as telecommunications devices may be used to purchase basic and 'enhanced' telecommunications services and be billed there for, the FCC put in place its Truth-in-Billing rules ${ }^{164}$ in 1999 to prevent a malevolent form of unauthorised billing.

\subsection{E-Commerce Laws and Regulations}

Like the other jurisdictions, the enforceability of electronic transactions had been the subject of extensive legislative efforts, derived mostly from the United Nations Commission on International Trade Law (hereafter UNCITRAL) Model Law on Electronic Commerce of $1996 .{ }^{165}$

In the midst of the dot.com revolution of the 1990s, a number of jurisdictions passed laws and regulations to provide structure for new electronic forms of contracting. The overall idea was to provide what was generally termed 'functional equivalence' of electronic contracting and services to bespoke offline contracting, as well as providing rules around newer forms of contracting. This speaks to the issue of 'technology neutrality', where the equivalence is designed to not favour one technology over another, for example, mobile systems versus Internet systems. ${ }^{166}$

\footnotetext{
${ }^{158}$ Kenya Communications (Amendment) Act 1 of 2009, available at http://goo.gl/sC687.

${ }^{159}$ See ch 10, s10.4 titled Telecommunications-related Laws and Regulations on the Communications Commission of Kenya (CCK).

${ }^{160}$ Kenya Communications Act 2 of 1998.

${ }^{161}$ For a broader perspective on how the Act possibly impacts on media freedoms and the ability to disseminate information, see R Wanjiku (2009) 'Kenya Communications Amendment Act (2009): Progressive or Retrogressive?', available at http://goo.gl/vAP05.

${ }_{162}$ Communications Commission of Kenya (2011b) 'Sector Regulations', available at http://goo.gl/yNHiQ.

${ }^{163}$ See www.fcc.gov.

${ }^{164}$ See ch 11 , s11.4.2 on the FCC rules.

165 United Nations General Assembly Resolution 51/162: Model Law on Electronic Commerce adopted by the United Nations Commission on International Trade Law (UNCITRAL), available at http://goo.gl/fODz5. The Model Law was intended to facilitate the use of modern means of communications and storage of information. It is based on the establishment of a functional equivalent in electronic media for paper-based concepts such as 'writing', 'signature' and 'original'. By providing standards by which the legal value of electronic messages can be assessed, the Model Law should play a significant role in enhancing the use of paperless communication. The Model Law also contains rules for electronic commerce in specific areas.

${ }^{166}$ But see C Reed (2010) 'Online and Offline Equivalence: Aspiration and Achievement' 18(3) International Journal of Law and Information Technology 248-273, available at http://goo.gl/EsgXM.
} 
As Reed points out, this may manifest as an attempt at formal equivalence, by seeking new wording for the rule which seems equally applicable to both, but this creates a risk that the offline effects of the rule might be altered unintentionally. ${ }^{167}$

Terms like 'Browsewrap' and 'Clickwrap' have emerged to describe the presentation of terms on a Web or Wireless Application Protocol (hereafter WAP) site with the statement that some further action - such as continuing use of a site, downloading software or a simple click on an appropriate link - would be construed by the owner of that site or facility as acceptance of the terms, but without the need for an express assent by the user. ${ }^{168}$ This of course has implications for consensus in contract where one party may not be fully aware of the Terms and Conditions (hereafter T\&C) because it is well hidden, say within a series of WAP-based menus on a mobile phone. To date however there have not been any specific laws or directives in any of the major jurisdictions that provide specific context or application to MFS despite gradual acceptance that their existing e-commerce laws have worrying lacunae in direct application to mobile. $^{169}$

However, what has been evident are the regulations and services passed by various CBs and NRAs around the world that touch on MFS. Similar legislative initiatives have been at the point of unequivocally proving a party's assent to a contract via the use of an electronic signature, or even an Advanced Electronic Signature where the latter is provided by a state-accredited issuing authority under strict guidelines for robust evidential purposes.

The issue however is how to provide for consistency between these 'e-specific' pieces of legislation and regulations so as to prevent regulatory failure and regulatory arbitrage. It appears that some regulators, when they deem it necessary, will adopt a risk-based approach to deciding whether there should be a deviation from the desired neutrality and functional equivalence.

South Africa's Electronic Communications and Transactions Act ${ }^{170}$ (hereafter ECTA) was passed to regulate and govern e-commerce in South Africa. It is an enabling piece of legislation, and ostensibly applies to any form of electronic communication such as e-mail and Web, and promotes functional equivalents between paper-based methods and their digital equivalents. It regulates, for example, the time and place of the formation of contracts via electronic means, the use of agents and digital signatures, and provides for policing and cybercrime. ${ }^{171}$

\footnotetext{
${ }^{167}$ Ibid. The functional equivalence may be attempted irrespective of whether there is also formal equivalence of wording. Reed suggests that there may be instances where the only way to achieve equivalence is via a fundamental reform of offline law such that there is equivalence in application of the rules, as well as in the outcomes.

168 Any Terms and Conditions (T\&C) applicable to the transaction may or may not be displayed in a way that is readily visible to the user. This could be a mere reference to the existence of the T\&C elsewhere on the site or facility or an express indication of only portions of the T\&C at the point of assent. See ch 5, s5.5.3.1 on WAP.

${ }^{169}$ See this issue addressed by the United Kingdom Department of Trade and Industry (2002) 'A Guide for Business to the Electronic Commerce (EC Directive) Regulations 2002 (SI 2002/2013)', available at http://goo.gl/gVLIL. See also P Lefebvre (2003) 'M-Payment Deployment: Paving the Way for an Efficient Mobile Commerce Market' Conference Proceedings Mobile Payment Forum, Dublin, March 262003.

${ }^{170}$ Electronic Communications and Transactions Act 25 of 2002 (ECTA).

${ }^{171}$ See ch 12, s12.10 titled E-Commerce Laws in South Africa and on the ECTA's application.
} 
In the EU, the E-Commerce Directive (hereafter ECD) ${ }^{172}$ was passed in 2000 to provide rules for doing business over electronic bearers. It mandates which information is to be provided on a website or similar electronic medium, information that a consumer must have about the steps to take to conclude a contract online, information to provide in online advertising, limits on the potential liability of Internet Service Providers (ISPS) for unlawful material which they carry unwittingly, and the national law that will apply to online services, codes of conduct, out-of-court dispute settlements, court actions and cooperation between EU member states. ${ }^{173}$

In Kenya, the Kenya Communications (Amendment) $\mathrm{Act}^{174}$ was passed to expand the opportunities presented by converged technologies, and incorporates aspects of electronic commerce regulation. ${ }^{175}$

In the US, the Uniform Computer Information Transactions Act ${ }^{176}$ (UCITA) is an update to the Uniform Commercial Code and a model law adopted by all states as a guide to contract law and business practice and the development, sale, licensing, support and maintenance of computer software and for many other contracts involving information. The Uniform Electronic Transactions Act (UETA) was adopted by the National Conference of Commissioners on Uniform State Laws (NCCUSL) in 1999 and regulates 'electronic records and electronic signatures relating to transactions' that are not subject to the Uniform Commercial Code (UCC) ${ }^{177}$ and guarantees that electronic transactions are just as enforceable as their paper counterparts ${ }^{178}$ and that any signature requirement can be met by an electronic signature. ${ }^{179}$

The Electronic Signatures in Global and National Commerce Act ('ESIGN') ${ }^{180}$ is a federal law that facilitates the use of electronic records and signatures in interstate and foreign commerce by ensuring the validity and legal effect of contracts entered into electronically. ${ }^{181}$ The Controlling the Assault of NonSolicited Pornography and Marketing Act (CAN-SPAM) Act ${ }^{182}$ regulates rules for commercial email, and establishes requirements for commercial messages. ${ }^{183}$

\footnotetext{
${ }^{172}$ Directive 2000/31/EC.

${ }^{173}$ See further ch 9, s9.12 titled E-commerce and Associated Laws.

${ }^{174}$ See Act 1 of 2009 op cit note 158.

${ }^{175}$ See ch 10, s10.5 titled Electronic Commerce on Kenyan e-commerce laws and regulations.

${ }^{176}$ Uniform Computer Information Transactions Act (UCITA) - see http://goo.gl/E2yWd.

${ }^{177}$ They do however affect sales transactions under Arts 2 and 2A of the UCC (Uniform Commercial Code).

${ }^{178}$ Uniform Electronic Transactions Act (UETA) ss7 and 9.

${ }^{179}$ UETA does not apply to wills, codicils, or testamentary trusts; the UCC, other than ss1-107 (rights after a breach) and ss1-206 (statute of frauds), and Arts 2 and 2A (sales); transactions governed by UCITA; or transactions states identify as not being covered.

18015 USC ch 96. The Act went into effect in October 2000. Although UETA spells outs rules for digital signatures, the federal Electronic Signatures in Global and National Commerce Act (ESIGN) lays out the basis for interstate commerce.

181 Federal Trade Commission (FTC) Electronic Signatures in Global and National Commerce Act, available at http://goo.gl/N3rN3

${ }_{182} 15$ USC 7701. See http://goo.gl/8TjgU.

${ }^{183}$ See ch 11, s11.5 titled US Electronic Commerce Laws and Regulations.
} 
Many jurisdictions are placing an increased focus on consumer protection. The main focus is on the relationship and interaction between a retail customer and a business entity, be it a financial institution or a simple bricks and mortar business. ${ }^{184}$

This is the so-called Business to Consumer (hereafter B2C) relationship, although in some countries there is legislation which has a threshold value criteria for deciding whether a small business doing business with a larger business - ordinarily Business to Business (hereafter B2B) - qualifies as a 'consumer' for the purposes of utilising the consumer protection laws. ${ }^{185}$ This distinction amplifies the general principle in consumer protection and regulation: proportional regulation which entails determining a balance between detailed interventionist rules and high-level principles. Regulatory models generally try to fall in a spectrum between the general principles and detailed rules. ${ }^{186}$

One of these principles is the freedom of the parties to determine the contents of a contract. ${ }^{187}$ It is a general principle of contract law recognised by almost all legal systems, and many jurisdictions have seen the need to add protections to dealings between consumers and businesses, and even between a business and other businesses.

This applies especially when one party has an overarching economic advantage over another, be it in terms that can be set within an agreement, or the actual implication thereof.

The overarching goal is to prevent a significant imbalance in the party's rights and obligations arising under the contract; to protect the legitimate interests of the party who would be disadvantaged where that disadvantage would cause a financial determinant, or otherwise, to a party.

As indicated above, ${ }^{188}$ regulation may be needed where contractual remedies are insufficient to produce equitable results that may result from the substantial inequality of one contracting partner such that the state must step in to remedy the situation.

Many of the newest products and services are processed through private networks subject only to private rulemaking from which consumers are excluded such that if economic agents are subject to behavioural

\footnotetext{
${ }^{184}$ Rutledge (2010) op cit note 32.

${ }^{185}$ Ibid at 12, at fn 18. The World Bank notes that there is evidence that suggests that sole proprietorships - which may be microcredit borrowers - suffer the same kind of consumer protection issues as do retail consumers.

${ }^{186}$ A principles-based approach usually employs a light touch self-regulatory approach building on the regulated industry's greater knowledge of the market. However, the broad nature of a principle may make it difficult for entities to know if they are in compliance and requires flexible supervision. The rules-based approach is usually designed to be clear and uniform in application and usually needs relatively less high- level supervisory capacity to ensure compliance. The rules may affect the ability to innovate as entities instead spend their time and money on compliance and try means to circumvent the rules. See AFI (2010b) op cit note 3 at 6.

${ }^{187}$ See ch 7, s7.2.4 titled Terms of the Contract.

${ }^{188}$ See for more on regulatory intervention ch 8, s8.2 titled Philosophies behind Regulation.
} 
biases, then there may be scope for some 'paternalism' in the form of the choice of default rules, usually determined by normative rules and regulations and provide substantial benefits to the actors and society.

Generally the less sophisticated the market participants, the more the potential for consumer harm, although in some jurisdictions the general principle of the state having regard for the welfare of its economic participants is the overriding factor. ${ }^{189}$

These reflect different assumptions about the role of government in regulating markets, and about what legal reforms, if any, may be needed to achieve regulatory objectives. ${ }^{190}$ The consumer protection laws that arise generally reflect that jurisdiction assumptions, based on ex post planning, or ex ante experiences, or usually a combination of both, that there is bound to be, or has been, an element of market failure insofar as consumers have been abused by economic heavyweights.

Until recently, US law adopted a relatively laissez-faire attitude to financial transactions especially, but predatory lending practices and a massive economic meltdown has signaled a shift in regulatory oversight.

The EU however has consistently embraced the concept of consumer protection since the beginning of the common market. These differences are highlighted in their definitions of the 'consumer': in the EU, generally, this can be a natural person or a business, ${ }^{191}$ while in the US it has generally been the purview of only natural persons who undertake an endeavour for goods or services for personal, family or for household use. ${ }^{192}$

In South Africa, the omnibus Consumer Protection Act (CPA) ${ }^{193}$ was assented to in 2009 and was implemented in most part by the $1^{\text {st }}$ April 2011. It was designed to prevent exploitation or harm to consumers through a number of mechanisms that include an omnibus National Consumer Commission (NCC) to mediate consumer complaints. ${ }^{194}$

The CPA aims to establish effective mechanisms for enforcement of these consumer rights; prohibits certain conduct and places certain obligations on suppliers of goods or services. ${ }^{195}$ Consumers will in

\footnotetext{
${ }^{189}$ The World Bank notes that distinguishing between unsophisticated retail and highly sophisticated corporate customers is important when designing successful consumer protection since transactions among well-informed financial and corporate institutions, it believes, are not subject to many of the problems that can potentially harm retail consumers. Rutledge (2010) op cit note 32 at 12 .

${ }_{190}$ Winn and Webber (2006) op cit note 19 at 183.

${ }^{191}$ See the Council Regulation on Jurisdiction and Recognition and Enforcement of Judgments in Civil and Commercial Matters (hereinafter, Brussels I Regulation and BIR) which defines 'consumer' as the person who concludes a contract 'for a purpose which can be regarded as being outside his trade or profession'. The vague nature of this definition was clarified by the European Court of Justice (ECJ) in Bertrand v Ott Bertrand v Ott [1978] ECR 1431. See further, ch 9, s9.13.

${ }^{192}$ See Title 15 USC $\$ 1602$ (h) of the TILA which defines 'consumer' as one in which the party to whom the credit is offered or extended is a natural person, and the money, property, or services which are the subject of the transaction are primarily for personal, family, or household purposes. Regulation Z §226.2(a)(11) which implements the TILA defines 'consumers' as:
}

' $[\mathrm{A}]$ cardholder or a natural person to whom consumer credit is offered or extended. However, for purposes of security interest is or will be retained or acquired, if that person's ownership interest in the dwelling is or will be subject to the security interest.'

${ }^{193}$ Consumer Protection Act 68 of 2008.

${ }^{194}$ The NCC is an enforcement and investigative body for consumer protection issues.

${ }^{195}$ See South Africa, Department of Trade and Industry (2009) 'President Motlanthe Approved Consumer Protection Bill', 30 April 2009, available at http://goo.gl/vjKRo. 
certain instances be allowed to cancel contracts if they are not satisfied with the terms of contract as well as if their contracts will be renewed. ${ }^{196}$

While the CPA appears in the most part to follow the mixed EU approach, ${ }^{197}$ the Australian Consumer Protection Law, a generic law, is designed to apply consistently to conduct across all sectors and is aimed primarily at natural persons. ${ }^{198}$ The CPA also includes provisions designed to prevent unfair contract terms, as well as promoting plain language provisions in contracts.

While expanding access to financial services and entry-level banking or transactional products is seen as an important public policy goal that may spur the economy, both financial institutions and financial consumers need to be responsible in their use of financial services. ${ }^{199}$

The recent financial crisis highlights the need to make customer protection, financial access and financial stability mutually reinforcing. ${ }^{200}$ As Lyman notes, consumer protection issues in transformational branchless banking are not unique but the nature of branchless banking amplifies the issues of consumer protection, ${ }^{201}$ especially since there is usually a large power imbalance between low-income users of financial services and the providers thereof, and since consumers of financial services are unlikely to have the resources to go through the court process to resolve a dispute with a financial institution. ${ }^{202}$

While there is not necessarily a 'one-size-fits-all' legal framework or solution to address issues of consumer protection in financial services, many economies have basic legal and regulatory frameworks for financial consumer protection and have formed specialised agencies to oversee financial institutions and financial schemes. These protections however do not necessarily extend to specific laws on evolving (or even existing) payment mechanisms and the potential specific issues ${ }^{203}$ such as product failure, ${ }^{204}$ product mismatch,${ }^{205}$ transactional failure, ${ }^{206}$ remedies, ${ }^{207}$ privacy ${ }^{208}$ and security. ${ }^{209}$

\footnotetext{
${ }^{196}$ Section 55 excludes goods bought at auction from the right of return and implied warranty benefits. Common law rights are still available however in these cases.

${ }^{197}$ For example, in relation to the definition of consumer. There is a threshold below which a small business could be classed as a 'consumer'. See ch 12, 12.10 .

${ }^{198}$ Section 2 of the Trade Practices Amendment (Australian Consumer Law) Act (No 2) 2010, defines a consumer as someone who acquired goods and services for personal, domestic or household use or consumption or up to Aus $\$ 40,000$; see http://parlinfo.aph.gov.au.

${ }^{199}$ Rutledge (2010) op cit note 32.

${ }^{200}$ Lyman (2009) op cit note 3.

${ }^{201}$ Ibid.

${ }^{202}$ CGAP (2010a) op cit note 3 . An effective way of dispute resolution is necessary.

${ }^{203}$ See Bollen (2010) op cit note 3 for an enumeration of these issues.

${ }^{204}$ This is the risk that the service will not perform as promised insofar as it does not have all the features or qualities that it was purported to have, either because the qualities of the service were oversold or because the provider is unable to deliver the service as promised. See Bollen (2010) op cit note 3.

${ }^{205}$ Here consumers do not get what they thought they were getting, possibly because of inadequate disclosure of the products features and terms of use, or a misunderstanding of the product's features and terms of use. The issue is particularly acute in developing nations where MFS requires technical and financial literacy along with basic numeracy and literacy.

${ }^{206}$ Bollen describes this as the risk that the service will function properly but that some transactions may not execute as the user or the system operator intended, for example, the wrong amount, the wrong payee, the wrong time of payment; or that an unauthorised payment transaction was made via the user's account. See Bollen (2010) op cit note 3.

${ }^{207}$ The remedies may be provided for in the T\&C, but in the absence of guiding principles or obligatory statutory rules which the user usually has no say in developing or rejecting/modifying in part, these may be irrelevant to the user, especially if legal fees must be incurred to enforce their rights.

${ }^{208}$ Unless within a separate statutory privacy regime. South Africa is considering privacy legislation. The Data Protection Directive - Directive 95/46/EC - which regulates the processing of personal data within the EU. The United States has a
} 
General consumer protection provisions are enough to suffice. ${ }^{210}$

What is usually mandated then, at a minimum and for general application, are disclosure requirements, mostly in standardised forms and in limited measure, ${ }^{211}$ although very few have requirements to disclose information on dispute resolution which in new and rapidly expanding innovative payment technologies is of paramount importance. ${ }^{212}$ It is usually left up to third party, self-regulatory bodies and self-regulatory codes and the use of ombudsmen to fill in the oversight function where regulations do not exist for MNOs. $^{213}$

In the EU, Member States have over time developed a number of Directives that relate to varying spheres of economic activity, from food products, to telecommunications, to payments as set out in Articles 153 and 95 of the Treaty establishing the European Community. From the mid-1970s, the EU has endeavoured to harmonise these national measures in order to guarantee European citizens the same high level of protection throughout the single market. ${ }^{214}$ Generally, there is the Unfair Commercial Practices Directive ${ }^{215}$ which contains general prohibitions on unfair business-to-consumer commercial practices as well as the Unfair Contract Terms Directive. ${ }^{216}$ National consumer laws in a particular country may provide consumers with additional rights that supplement rights provided by EU laws: ${ }^{217}$ the ECD, ${ }^{218}$ the Distance Selling Directive, ${ }^{219}$ and the Directive on Distance Marketing of Consumer Financial Services. ${ }^{220}$ In the area of retail financial services, EU legislation has established minimum consumer protection rules concerning retail financial services, allowing the Member States to create stricter rules, for example, in the Payment Services Directive.

The US has no omnibus consumer protection law, but various sectors and states have introduced consumer protection laws. There are thus a variety of laws at both the federal or state levels to regulate consumer affairs. Among them are the federal Fair Debt Collection Practices Act, Truth in Lending Act and Financial

sectoral approach to data protection legislation, which relies on a combination of legislation, regulation, and self-regulation, rather than governmental regulation alone.

${ }^{209}$ Unless within a separate statutory security regime. There is a modest reference in the ECTA - op cit note 170 - for the need to implement 'payment standards'.

${ }^{210}$ CGAP notes in its 2010 survey of Financial Access, that 123 economies (87\% of those surveyed) had at least some fair treatment provisions within the existing legal and regulatory framework, including restrictions on deceptive advertisement, abusive collections, unfair or high-pressure selling practices, and breach of client confidentiality. There was also some form of disclosure requirement regarding financial products and services in 115 economies (81\%), although the availability of third-party dispute resolution mechanisms, such as an ombudsman or a mediation centre were only present in $60 \%$ of the economies surveyed. Only two-thirds of the financial regulators who said that they are responsible for at least some aspect of financial consumer protection have a designated unit or team to work on financial consumer protection. CGAP (2010a) op cit note 3.

${ }^{211}$ CGAP reports that a standardised disclosure format for general financial products may include a one-page 'Key Facts' document summarising terms and conditions in a clear and transparent manner. It says that $41 \%$ of economies reporting to its survey have such a requirement. CGAP (2010a) op cit note 3 at 27.

212 Ibid.

213 Ibid.

${ }^{214}$ See generally an overview of the EU Consumer Protection laws at http://goo.gl/iUgRq.

${ }^{215}$ The Unfair Commercial Practices Directive 2005/29/EC. See Winn and Webber (2006) op cit note 19.

${ }^{216}$ Unfair Contract Terms Directive 93/13/EEC on Unfair Terms in Consumer Contracts, available at http://goo.gl/9h81G.

${ }^{217}$ See for example Citizens Information available at http://goo.gl/oVPtU.

218 Directive 2000/31/EC of the European Parliament and the Council of 8 June 2000 on Certain Legal Aspects of Information Society Services.

${ }^{219}$ Directive97/7/EC.

${ }^{220}$ Directive 2002/65/EC of the European Parliament and the Council of 23 September 2002 concerning The Distance Marketing of Consumer Financial Services. 
Services Modernization Act of $1999 .{ }^{221}$ There are a number of federal consumer protection laws such as the Consumer Product Safety Act, ${ }^{222}$ National Do Not Call Registry; ${ }^{223}$ the Communications Act of $1934^{224}$ and the Fair Credit Reporting Act.

The infusion of telecommunications-based nonbank providers of MFS into various strata - or silos traditionally occupied by banks and payment, suggests a challenge to regulators worldwide and to common law banking and payment law precepts and may invoke cross-sector regulation and induce a 'regulators' dilemma' in balancing the social and economic goals of Financial Inclusion (FI) with systemic financial integrity principles.

At a more heuristic level, the disaggregated value chain of 'shadow banking' or 'secondary - or second-tier - banking services' in MFS suggests that multiple regulators may have concurrent regulatory oversight over the same entity, creating the specter of regulatory arbitrage and coordination failure.

In a specific MFS context, this may manifest as involving not just financial regulators as the usual suspects, but also (and possibly inadvertently) to also include, inter alia, consumer protection, AML concerns, and telecommunications regulations and regulators who may have simultaneous oversight over the individual components that make up MFS. The simultaneous oversight may be exacerbated through posturing by each agency to 'protect its turf,' leading to this arbitrage specter. There have been and are two broad approaches to solving this: the functional and institutional approaches. ${ }^{225}$

The functional approach places the focus on the service received by the consumer regardless of the type of institution providing that service. The reality though is that these entities may ultimately lack the necessary institutional capacity to pronounce on complicated aspects of financial consumer protection which results in consumer ambivalence, corporate intransigence and posturing, and maintains the status quo. By contrast, the institutional approach focuses not on the service per se, but on institutions providing any financial service and leaves the regulation in the hands of specialised bodies. In all, though, this may distort market dynamics by fragmenting responsibilities amongst too many regulators to the extent that some entities like nonbanks are not captured.

Further, through the converged, chimerical nature of the MFS service offering and the nature of the bank, MNO, or MFSP entities providing the services, tests even the functional versus institutional approach that creates the regulatory strategy conundrum, or 'regulators' dilemma.'

\footnotetext{
${ }^{221}$ Pub. Law 106-102, 113 Stat. 1338, enacted November 12, 1999. The Act allowed commercial banks, investment banks, securities firms and insurance companies to consolidate.

${ }^{222}$ This provides the Consumer Product Safety Commission the power to develop safety standards and pursue recalls for defective products.

${ }^{223}$ The registry allows US consumers to limit the telemarketing calls they receive.

${ }^{224}$ This Act created the Federal Communications Commission (FCC) to regulate all radio and interstate cable, fixed line and cell phone, and satellite communications.

${ }^{225}$ See ch 8, s8.3 titled Types of Regulatory Foci.
} 
The dilemma is more a policy question of how to prudently boost financial access, than a narrow regulatory concern of how to adequately protect consumers against unscrupulous actors. The regulatory conundrum further extends to the fact that while new nonbank entrants may result in greater efficiency and greater FI, they could possibly also disrupt established systems and possibly even impact on systemic stability. On the other hand, overburdening regulation may, and probably does, have inadvertent secondary effects: those already within the financial system enjoy the benefits of greater financial integration at the expense of the resulting unbanked or uninsured.

While there may be statutory solutions to these systemic and risk issues, there may also be tension with the common law at a micro-level, for example in determining the allocation of loss in transactions or in determining the legality of transactions and their participants. In relation to payments then, to distil the cascading issues and for legal certainty, the law should try to answer certain basic questions such as who bears the risk of authorised payments; what must be done about claims of error; when are payments completed so that they discharge the underlying obligation; and can payments be reversed, and if so, when and how can they be reversed? There appears though not to be a one-size-fits-all solution to the design of a legal framework for both financial consumer protection, and for coherence and maintenance of the financial system generally. It may also reflect variations in legal frameworks. It should however reflect the structure of the financial system and the nature of each economy's overall legal framework.

It is submitted that many of these issues and risks can be addressed by, inter alia, licensing, mandatory disclosures available to consumers, determination ex ante of conduct rules that outline the obligations and rights of the parties; and methods of dispute resolution that may result from inter alia mistake or fraud. The implementation approach may be graduated to reflect the relative risks, such that a proportionality regime for regulation - or supervision - could be introduced.

This may be a purposive approach to licensing broad schemes with or without some necessary exclusions, or one where each type of scheme or payment has its own set of discrete rules. Regardless though of whether a functional, institutional, or single agency approach is used, the effectiveness can be enhanced by gold-plating the enabling law to clearly define their roles, and in particular that an agency responsible for financial consumer protection should be formed and first, given an express mandate on consumer protection issues rather than it being implied, and that second this single, mandated entity receives and deals with consumer complaints and inquiries. ${ }^{226}$

Although a chimera between the two approaches may be preferable, if MFSPs are to be specifically captured then the institutional approach - alongside an enabling licensing framework - appears to edge out the functional approach.

\footnotetext{
${ }^{226}$ Indeed, some jurisdictions have taken specific approaches to financial consumer protection by creating single, dedicated agencies such as the National Credit Regulator of South Africa, the Financial Consumer Agency of Canada (FCAC), or the federally mandated Consumer Financial Protection Bureau (CFPB) in the US. See ch 11, s11.2.4.2.2 on the CFPB.
} 


\title{
CHAPTER 9
}

\section{THE EUROPEAN UNION AND MOBILE FINANCIAL SERVICES}

\author{
Overview of MFS in the European Union
}

The European Union (hereafter EU) has a sophisticated financial, technical and commercial infrastructure in the spheres of payments, banks and general electronic commerce (hereafter e-commerce) and is developing an equally sophisticated set of legislative instruments and rules for the purposes of consolidated legislation known as 'Directives'. ${ }^{1}$ The Directives are issued by the European Commission (hereafter EC),

\footnotetext{
${ }^{1}$ See ch 9, s9.4.2 titled Directives and Regulations. For various overviews of the EU's financial and banking laws (Directives) and regulations, including payment services and electronic money, see inter alia: D Reichwein and S Rosati (2007) 'Nonbanks in the Payments System: European and US Perspectives', available at http://goo.gl/HPOi6; European Central Bank (ECB) (2010a) 'The Payment System: Payments, Securities and Derivatives, and the Role of the Eurosystem' edited by T Kokkola, available at http://goo.gl/INfJ3; M Forster (2010) 'The New EU Financial Regulatory Framework', available at http://goo.gl/ejRCZ; European Central Bank (2003) 'Oversight Standards for Euro Retail Payment Systems', available at http://goo.gl/spzs1; D Singh (2007) Banking Regulation of UK and US Financial Markets; MC Malaguti (2009) 'The Payment Services Directive: Pitfalls between the Acquis Communautaire and National Implementation' European Credit Research Institute (ECRI) Research Report No 9, available at http://goo.gl/5vR1g; The de Larosière Group (2009) 'Report on Financial Supervision in the EU', available at http://goo.gl/CroZY; OO Cherednychenko (2010) 'Full Harmonisation of Retail Financial Services Contract Law in Europe: A Success or a Failure?', available at http://goo.gl/BXRwL; S Grundmann and J Hollering (2008) 'EC Financial Services and Contract Law: Developments 20052007' 4 European Review of Contract Law 45, available at http://goo.gl/e5PAx; RA Bollen (2007a) 18(27) 'The History and Operation of International Payment System' 18(27) Journal of Banking and Finance Law and Practice, Social Science Research Network, available at http://goo.gl/J62Gv; R Bollen (2008c) 'A Review of Recent Developments in European Payment System Regulation (Including the Proposed Payment Services Directive)' 19 Journal of Banking and Finance Law and Practice 47; RA Bollen (2008a) 'Harmonisation of International Payment Services Law - Part 1 (the UNCITRAL Model Law)' 44 Journal of International Banking Law and Regulation, available at http://goo.gl/HiBvA; RA Bollen (2008b) 'Harmonisation of International Payment Services Law - Part 2 (US Article 4a)' 105 Journal of International Banking Law and Regulation, available at http://goo.gl/dGKtK; RA Bollen (2010) 'Best Practice in the Regulation of Payment Services' Journal of International Banking Law and Regulation, Social Science Research Network, at 370, available at http://goo.gl/X0acO; Financial Services Authority (FSA) (2011a) 'E-money Directive', available at http://goo.gl/naM8j; B Geva (2009b) 'Payment Transactions Under the EU Payment Services Directive: A US Comparative Perspective' 24(3) Pennsylvania State International Law Review 713-755, available at http://goo.gl/Wj2BB; B Geva (2009a) 'The EU Payment Services Directive: An Outsider's View' 28 Yearbook of European Law at 177-215; B Geva (2010) 'The Harmonisation of Payment Services Law in Europe and Uniform and Federal Funds Transfer Legislation in the USA: Which is a Better Model for Reform?' Annual Banking Law Update at 22; R Steennot (2008) 'Legal Aspects of Credit Transfers and Electronic Payments: A Belgian Perspective' Financial Law Institute Working Paper No 2008-12, available at http://goo.gl/STVJ8; A Gkoutzinis (2003) 'Online Financial Services in the European Internal Market and the Implementation of the E-Commerce Directive in the UK', available at http://goo.gl/85YAU; R Steennot (2010) 'Allocating Liability in Case of Fraudulent use of Electronic Payment Instruments and the Belgian Mobile Payment Instrument Pingping' Financial Law Institute WP 2010-12 at 1, available from http://goo.gl/pDx5X; Organisation for Economic Co-operation and Development (OECD) (2002) 'The Future Of Money', available at http://goo.gl/5dhqr; Committee on Payment and Settlement Systems (CPSS) (2004) 'Survey of Developments in Electronic Money and Internet and Mobile Payments', CPSS Publications No 62, available at http://goo.gl/n01OR; JJ Luyatt (2009) 'A Tale of Regulation in the European Union and Japan: Does Characterizing the Business of Stored-Value Cards as a Financial Activity Impact its Development?' 18(3) Pacific Rim Law \& Policy Journal at 525; Y Mansour (2007) 'The E-Money Directive and MNOs: Why it All Went Wrong', available at http://goo.gl/ILah2; B Flismark (2010) 'The Payment Services Directive: A Crucial Step Toward Payment Harmonisation Across the EU', available at http://goo.gl/OdcE4; European Banking Association (EBA) (2008) 'Banks Preparing for PSD: A Guide for Bankers on the Payment Services Directive' Version 1.1 November, available at http://goo.gl/mWW5e; JA Usher and A Guadamuz (2008) 'Electronic Money: The European Regulatory Approach (October 17, 2008)' in L Edwards (ed) The New Legal Framework for E-Commerce in Europe 173-201, available at http://goo.gl/2cKGH; P Arestis, K McCauley and MC Sawyer (1999) 'From Common Market to EMU: A Historical Perspective of European Economic and Monetary Integration' The Jerome Levy Economics Institute Working Paper No 263, available at http://goo.gl/djvpr; GM Duhl (2009) 'International Developments in Consumer Financial Services Law 2007-2008' 64 Business Lawyer (William Mitchell Legal Studies Research Paper No 2009-07), available at http://goo.gl/FqG84; M Huertas (2009) 'The Transposition of the Payment Services Directive ('PSD')
} 
which is the administrative body of the EU. They apply across all member states and so provide legal certainty and enhanced consumer protection. ${ }^{2}$ This includes the Financial Services Action Plan, established in 1999 to create an integrated European market to complement the introduction of the Euro. ${ }^{3}$

Cashless systems are on the ascent in the EU. The most commonly used cashless payment instruments are payment cards, credit transfers, direct debits and cheques. ${ }^{4}$ Although there are pockets of intra-EU Mobile Financial Services (hereafter MFS) systems where users can pay for (real) goods and services - by, for example, sending a Short Message Service (hereafter SMS) to the recipient system, machine or person's mobile phone number, as well as sending intra-country or intra-EU funds - the sophisticated banking infrastructures and the ubiquity of branches, Point of Sale (hereafter POS) and Automatic Teller Machines (hereafter ATMs) in the European Economic Area (hereafter EEA) somewhat quenches the demand for fiat-based transformational type MFS in the European Economic Community (EEC). ${ }^{5}$ Indeed, the latest evolution in the EU's MFS use contactless Near Field Communications (hereafter NFC) systems that appear to be a more concerted focus of EU-wide service providers. They thus generally do not utilise the more 'rudimentary' transformational aspects found in developing nations who use mainly SMS and Unstructured Supply Service Data-based (hereafter USSD) 'transformation' MFS systems. ${ }^{6}$

The major growth area in the EU however are those MFS-like services where remittances - money transfers - are sent by expatriate workers in the EU to recipient users of MFS systems in developing countries, where the cash out procedures applicable there would then apply. ${ }^{7}$ While the destinations may be mobile phone users, the values are sent primarily from non-mobile sources in the EU, such as Money Transfer Organisation (hereafter MTO) stores like those of remittance providers Western Union and

into UK Domestic Law: Providing a Solution to Overcoming the New Regulatory Challenges that Financial Institutions Will Face', available at http://goo.gl/Fa5Z1; VA Lawack-Davids and FE Marx (2010) 'Consumer Protection Measures for Erroneous or Unauthorised Internet Payments: Some Lessons from the European Union?' 31(2) Obiter 446-458 at 446; B Geva (2008b) 'TARGET2 Transfer of Funds and Harmonisation of EU Payment Law' 41(2) Uniform Commercial Code Law Journal at 113-145; Her Majesty's Treasury (HMT) (2009) 'Consultation on the Revision of the E-money Directive and Implementation of the EU Regulation on Cross-border Payments in Euro', available at http://goo.gl/5KdtH; European Commission (EC) (2007b) 'New Legal Framework (NLF) for Payments', available at http://goo.gl/HYNEG; B Schimk (2006) 'Payment Institutions: Potential Implications of the New Category of Payment Service Providers for the Austrian Financial Market', available at http://goo.gl/VedWG; European Commission (EC) (2011d) 'Financial Services: Additional Legislative Proposal to Complete the Framework for Financial Supervision in Europe', available at http://goo.gl/LqWxC; E Fahey (2011) Does The Emperor Have Financial Crisis Clothes? Reflections on the Legal Basis of the European Banking Authority' 74(4) Modern Law Review, available at http://goo.gl/Ge1C4; European Banking Industry (EBI) (2009) 'Guidance for the Implementation of the Payment Services Directive', available at http://goo.gl/rdbtc.

${ }^{2}$ Much of the EU legislative framework was developed before the explosion in online systems and there are constant efforts to harmonise governing consumer and investor protection laws and regulations.

${ }^{3}$ EC (2001) COM (1999) 232, 11.05.1999. As the EC noted later:

\footnotetext{
'New technology is already having a profound impact on the financial services industry. It is revolutionizing the operation of, and access to, wholesale markets; it is transforming cross border service provision; and acting as a catalyst for the creation of new financial services and new business models, often triggering new alliances involving telecommunications, information technology, retail, and financial services providers.'
}

See European Commission (EC) (2001) 'COM/2001/0066 Communication from the Commission to the Council and the European Parliament: E-commerce and Financial Services’, Brussels, 07.02.2001, COM (2001) 66 Final, available at http://goo.gl/ITTTw.

${ }^{4}$ ECB (2010a) op cit note 1 at 30, shows graphically the use of various payment instruments in the EU.

${ }^{5}$ On the difference between the EU and the EEC with regard to their respective memberships, see ch 9, s9.2 titled Overview of the European Union and the European Economic Area

${ }^{6}$ For a discussion on the role of the Internet in the development of banking and financial systems in Europe, see Gkoutzinis (2003) op cit note 1; EC (2001) op cit note 3. See ch 5, s5.5.6.5 on Near Field Communication.

${ }^{7}$ See for example 'Homesend', a private global remittance hub built to allow the transfer of any type of funds, such as airtime and cash, and from various fund sources, such as eWallets, bank accounts, credit cards and cash. See www.bics.com. 
Moneygram, and from payment companies (and MTOs) operating web, and sometimes Wireless Application Protocol (hereafter WAP), sites in the EU. Sources of the funds may be from credit and debits cards, prepaid cards, cash and cheque. ${ }^{8}$

Some companies will provide 'switching', clearing and settlement hubs that enable interoperability between global MFS providers, ${ }^{9}$ while others provide technical security and Anti-Money Laundering (hereafter AML) backend functions for remittance or general payments transactions originating, transiting, or ending in the EU where there is an MFS component.

The destination of the remitted funds also has a bearing on the legal regime used, ${ }^{10}$ if there is one at all. ${ }^{11}$ While most of these remittances flow out of Europe, MFS may serve a large underbanked and unbanked population within Europe. This is especially prevalent in Eastern Europe. ${ }^{12}$

As with this and many other jurisdictions, specific telecommunications, e-commerce, consumer protection, and AML laws have an effect on the provision of all types of MFS. Indeed, many of the financial services qualify as what is termed an 'Information Society Service' (hereafter ISS) ${ }^{13}$ defined in the Electronic Commerce Directive (hereafter ECD) as:

'[A]ny service normally provided for remuneration, at a distance, by means of electronic equipment for the processing (including digital compression) and storage of data, and at the individual request of a recipient of a service.'

With a plethora of EC Directives that could affect MFS - such as distance marketing, telecommunications, AML, banking and payments - how these Directives interact with one another and existing financial services legislation is of central significance to the development of a clear and coherent policy for crossborder trade in financial services. ${ }^{14}$ Those involved in financial services need to comply with other relevant

\footnotetext{
${ }^{8}$ This compares to the sources of funds in the developing countries which are primarily cash in the absence of an infrastructure to support debit, credit, prepaid debit cards and cheques.

${ }^{9}$ Again, see www.bics.com. See also generally, ch 4, s4.8.2.2. titled Payment: The Process of Verification, Clearing, Settlement and Netting.

${ }^{10}$ One of the derogations from the Payment Services Directive (hereafter PSD) is Art 73 of the PSD on the so-called leg-out transactions when the destination or source of the funds used for transfer or payment are outside the EC.

${ }^{11}$ See, for example, the lack of EU-wide laws on ad hoc-type airtime-based remittances described in ch 6, s6.5.4.3 titled Mobile Airtime Transfer.

${ }^{12}$ According to a study of 14 European countries carried out in 2008, almost half (47\%) of the adult population in Eastern Europe does not have a bank account, and 5-6\% have limited access to banking services, compared with $10 \%$ of unbanked people and $10 \%$ of underbanked people in the old EU countries. The results vary however according to the countries studied: $60 \%$ of the population is without a current account in Latvia, 50\% in Poland, around $40 \%$ in Slovakia but only $10 \%$ in Slovenia. See European Financial Marketing Association (EFMA) (2008) 'High Level of Unbanked People in Eastern Europe', available at http://goo.gl/weaWa.

${ }^{13}$ The term 'Information Society Service' (ISS) is used in the Electronic Commerce Directive (ECD). A service in turn is defined in the Technical Standards Directives $98 / 34 / \mathrm{EC}$ and $98 / 84 / \mathrm{EC}$. 'Service' is: 'any service normally provided for remuneration, at a distance, by electronic means and at the individual request of a recipient of services', and 'at a distance' means that the service 'is provided without the parties being simultaneously present', while 'by electronic means' refers to when 'the service is sent initially and received at its destination by means of electronic equipment for the processing (including digital compression) and storage of data, and entirely transmitted, conveyed and received by wire, by radio, by optical means or by other electromagnetic means'. 'At the individual request of a recipient of services' means that the service is 'provided through the transmission of data on individual request'. For the text of the consolidated Technical Standards Directives, see http://goo.gl/DdDUN.

${ }^{14}$ See EC (2001) op cit note 3.
} 
national legislation to the extent that these do not conflict with the newest set of specific legislation, such as the legislation relating to payment services in the EU. ${ }^{15}$

The latest legislative instruments and policies in the EU appear to cover most types of existing additive and transformational MFS. The governing law in the EU on payments is the Payment Services Directive (hereafter PSD), ${ }^{16}$ and it covers existing banks and issuers of e-money alongside new, autonomous entities called 'Payment Institutions' (hereafter PI or PIs) that are enabled to provide payment services in the EU. ${ }^{17}$

\section{2 \\ Overview of the European Union and the European Economic Area}

The $\mathrm{EU}^{18}$ was established ${ }^{19}$ to end the frequent and bloody wars between neighbours and it has since evolved into an integrated, borderless economic ${ }^{20}$ and political union with common laws, a common central bank - the European Central Bank ${ }^{21}$ (hereafter ECB) - common standards and governing bodies, a parliament, and ultimately a common currency, the Euro. ${ }^{22}$ There are now 27 member nations that make up the EU. Most of the laws issued by the EU and which govern economic relations within and between the member states are in the form of directives and regulations. ${ }^{23}$

9.3

Institutions of the European Union

There are five major institutions of the EU: the European Parliament, ${ }^{24}$ the Council of the EU, ${ }^{25}$ the EC, the Court of Justice and the Court of Auditors. The EU's decision-making process in general and the codecision procedure in particular involve three main institutions: the European Parliament (hereafter EP), which represents the EU's citizens and is directly elected by them; the Council of the European Union, which represents the individual member states; and the European Commission (hereafter EC), which seeks

\footnotetext{
${ }^{15}$ Financial Services Authority (FSA) (2010a) 'The FSA's role under the Payment Services Regulations: Our Approach' at 53, available at http://goo.gl/6ulKi.

${ }^{16}$ Directive 2007/64/EC on Payment Services in the Internal Market.

17 The Payment Services Directive (PSD), however, does not necessarily cover Premium Rated Services (PRS) as a component of MFS. Incorporation of PRS in the first Electronic Money Directive (EMD) was considered a failure and led to a revamping of the Directive. See the discussion on the EMD below in ch 9, s9.6.3 titled E-Money, Stored Value Laws and Regulations.

${ }^{18}$ The EU consists of the European Community, formerly known as the European Economic Community. See C Turner (2002) European Law: Key Facts at 1-16.

${ }^{19}$ In 1950, the European Coal and Steel Community united European countries economically and politically. In 1957, the Treaty of Rome created the European Economic Community (EEC) or 'Common Market'. The six founders were Belgium, France, Germany, Italy, Luxembourg and the Netherlands. See European Commission (EC) (2011e) 'History of the EU', available at http://goo.gl/4vBN.

${ }^{20}$ The member states in 1987 adopted the Single European Act which creates a unified, free-trade market in Western Europe.

${ }^{21}$ The European Central Bank (ECB) was formed in 1998; its forerunner was the European Monetary Institute formed by the Maastricht Treaty. See Organisation for Economic Co-operation and Development (OECD) (2003) 'Glossary of Terms: EMI', available at http://goo.gl/efR3k.

${ }^{22}$ The European Monetary System was established in 1978 to regulate currency exchange rates and aid monetary stability among members.

${ }^{23}$ European Commission (EC) (2005b) 'How the European Union Works: Your Guide to the EU Institutions', available at http://goo.gl/6fohY.

${ }^{24}$ The European Parliament consists of 785 members that are directly elected by European citizens every five years.

${ }^{25}$ The European Council, previously known as the Council of Ministers, is the principal legislative and decision-making body in the EU. The Council consists of EU representatives based on the country's population.
} 
to uphold the interests of the Union as a whole. ${ }^{26}$ There is also the European Economic Area (hereafter EEA) which comprises the EU Member States plus Iceland, Liechtenstein and Norway.

\subsection{1}

\section{Overview}

There are three sources of European law: primary, secondary and tertiary. Many affecting MFS will be from secondary and tertiary sources.

Primary laws are the Conventions or Treaties, which may be procedural or substantive in nature. ${ }^{27}$ An important example is the EC Treaty. Secondary sources consist of EU legislation, which may take the form of Regulations, Directives, Decisions and Recommendations, and Opinions. Tertiary Sources derive from the case law of the European Court of Justice (hereafter ECJ) and general principles decided inter alia from public international law, and national laws of member states. ${ }^{28}$

Two of the 'fundamental freedoms' considered central to the effective functioning of the EU Internal Market and which are core to the provision of services are the freedom of establishment ${ }^{29}$ and the freedom to provide cross-border services ${ }^{30}$ which together enable an economic operator - whether a person or a company - to carry on an economic activity in a stable and continuous way in one or more Member States. The consolidated Service Directive aims to create a legal framework for ensuring harmonised rules relating to services provided and to their establishment in Member States. ${ }^{31}$

The EC, based in Brussels, is the executive arm of the $\mathrm{EU}^{32}$ and is the primary originator ${ }^{33}$ of $\mathrm{EU}$ directives and regulations, which are the common laws that need to be implemented by member states. ${ }^{34}$

\footnotetext{
${ }^{26}$ European Union (EU) (s.d.) 'EU Institutions and Other Bodies', available at http://goo.gl/2AbjS; see Turner (2002) op cit note 18 at $1-16$.

${ }^{27}$ Some main treaties include the Treaty of Lisbon (2007) on the Constitution; The Treaty on EU (1993) or Maastricht; the Treaty of Rome (1957) which established the European Economic Community (EEC). See European Union (2011c) 'EU Treaties', available at http://goo.gl/ftToi.

${ }^{28}$ The various forms of secondary legislation are described in Art 249. They are all subordinate to the Treaties and so cannot repeal or amend any primary instruments.

${ }^{29}$ Set out in Art 49 of the Treaty of the EC. See European Commission (EC) (2008a) 'Consolidated Version of the Treaty on the Functioning of the European Union', available at http://goo.gl/RMvkp.

${ }^{30}$ Set out in Art 56 the Treaty of the EC. See EC (2008a) op cit note 29.

${ }^{31}$ Member States have to modify national laws that restrict freedom of establishment or the freedom to provide services and may only maintain such restrictions in specific circumstances where these are justified by overriding reasons of general interest and which are proportionate.

${ }^{32}$ The term 'Commission' is used to refer to the team of men and women - one from each EU country - appointed to run the institution and take its decisions; it also refers to the institution itself and to its staff. The day-to-day running of the Commission is done by its administrative officials, experts, translators, interpreters and secretarial staff.

${ }^{33}$ The Commission, however, remains politically accountable to the European Parliament.

${ }^{34}$ It has four main roles: to propose legislation to Parliament and the Council; to manage and implement EU policies and the budget; to enforce European law (jointly with the Court of Justice); and to represent the EU on the international stage, for example, by negotiating agreements between the EU and other countries. At an executive level, the EC consists of 27 persons — one from each EU country. EC (2005b) op cit note 23 passim.
} 
Of all the legislative instruments, ${ }^{35}$ Directives and Regulations are the most pertinent to any discussion of MFS. ${ }^{36}$ They aim to 'harmonise' the laws across the EU and are issued in terms of the EC Treaty at Art $288 .^{37}$ A Directive or Regulation may be said to be one of 'maximum (or 'full') harmonisation' whereby Member States may not adopt stricter rules than those provided for in a Directive or Regulation, for example, even in order to achieve a higher level of consumer protection than that catered for by the Directive. $^{38}$

This should be seen in the context of a general move in EU consumer law away from a 'minimum' harmonisation principle of laws and regulations towards 'full' harmonisation.

\section{Regulations}

Art 288 of the Consolidated Treaty allows the EC to issue Regulations as an efficient way of harmonising laws across the EU. 'A regulation shall have general application. It shall be binding in its entirety and directly applicable in all Member States.' A regulation may thus automatically apply throughout the EC and may be self-executing. ${ }^{39}$ Regulations are directly applicable as written.

\subsection{4}

\section{Directives}

Unlike Regulations, Directives issued in terms of Art $288^{40}$ of the EC Treaty are used to bring national laws into line with each other and are particularly common in matters that affect the operation of the single market. Directives may concern one or more EU countries or all of them and lay down certain end results that must be achieved in every Member State.

After the EC, Council, and Parliament have approved a Directive, the national authorities have to adapt their laws to meet these goals by an agreed deadline, but are free to decide how to implement the Directives. $^{41}$

\footnotetext{
${ }^{35}$ See J Shaw (2000) Law of the EU 3rd ed at 243-245.

${ }^{36} \mathrm{~A}$ decision $\mathrm{n}$ is binding in its entirety, but a decision which specifies those to whom it is addressed will be binding only on them. Recommendations and opinions have no binding force.

37 'To exercise the Union's competences, the institutions shall adopt regulations, directives, decisions, recommendations and opinions'. See EC (2010) '2010/C 83/01: Consolidated Versions of the Treaty on EU and the Treaty on the Functioning of the European Union', available at http://goo.gl/Y3UhG. See also EC (2005b) op cit note 23; and Turner (2002) op cit note 18 at $26-28$.

${ }^{38}$ See for example, European Court of Justice (ECJ) (2009) 'Press Release No 31/09', available at http://goo.gl/cKmx7. As Cherednychenko (2010) op cit note 1 at 2 points out, there is a general move away from 'minimum' harmonisation towards 'full' harmonisation in EU consumer law as announced by the EC in 2002. See also Duhl (2009) op cit note 1; and LawackDavids and Marx (2010) op cit note 1.

${ }^{39}$ EC (2005) op cit note 23.

40 'A directive shall be binding, as to the result to be achieved, upon each Member State to which it is addressed, but shall leave to the national authorities the choice of form and methods.' See EC: Art 288 of The Lisbon Treaty, available at http://goo.gl/sRtbV.

${ }^{41}$ Turner (2002) op cit note 18 at 29.
} 
A Directive is not effective until it is transposed by the Member State. ${ }^{42}$ Where a divergence occurs between a national law and a Directive, the national law must be interpreted to give effect to the Directive.

PART I. Money, Banking Payments Laws And Guidelines

Regulatory coverage of banking and payments in the EU is usually a combination of a number of Regulations and Directives that may be institutional, specific or general in nature, say in regard to either the type of entity or the type of payment instrument. ${ }^{43}$ To give effect to these rules and to allow for the smooth functioning of the EU, its member economies, banking and payment systems, consumer protection in financial services, and the EU currency, and the Euro, a number of bodies have been developed to implement the rules and to develop policies around payments and banking in furtherance of the EU's collegial goal of monetary and economic union. ${ }^{44}$

\subsection{2}

\section{Regulatory Bodies and Entities}

At the apex of the financial system in the EU is the European Central Bank ${ }^{45}$ and what is known as the European System of Central Banks (hereafter ESCB), both of which were established in 1998 in terms of the EC Treaty ${ }^{46}$ and which are responsible inter alia for oversight in the fields of banking, payment and settlement systems. ${ }^{47}$ The ESCB comprises the ECB and the National Central Banks (hereafter NCBs) of all EU Member States ${ }^{48}$ whether or not they have adopted the Euro as their national currency. ${ }^{49}$ There is also the Eurosystem which is comprised of the ECB and the NCBs of the countries that have adopted the Euro. ${ }^{50}$ Almost as critical is the Committee of European Banking Supervisors (hereafter CEBS) ${ }^{51}$ one of the main financial regulatory bodies in the EU that gives advice to the EC on policy and regulatory issues related to banking supervision, while the 'College of Supervisors' consists of all the Supervisors of the

\footnotetext{
${ }^{42}$ The flexibility in transposition can be problematic, however, as variations in national implementation may confuse the harmonisation objective of a Directive even though the general principles of the Directive are seen in the national legislation.

${ }^{43}$ Reichwein and Rosati (2007) op cit note 1 passim; Bollen (2007) op cit note 1; Geva (2009) op cit note 1 passim; Luyatt (2009) op cit note 1.

${ }^{44}$ For an overview, see Arestis, McCauley and Sawyer (1999) op cit note 1.

${ }^{45}$ In relation to the authority of the ECB, see A Arda (2004) 'Consulting the European Central Bank: Legal Aspects of the Community and National Authorities' Obligation to Consult the ECB Pursuant to Article 105(4) EC' 1 European Banking and Financial Law Journal 111-152, available at http://goo.gl/HY6ZF.

${ }^{46}$ See A282(1) of the EC Treaty. See EC (2010) op cit note 37; and European Central Bank (ECB) (2003) Oversight Standards for Euro Retail Payment Systems, available at http://goo.gl/wEJIh.

${ }^{47}$ For a brief overview of the roles and responsibilities of existing and newer regulatory entities formed in the wake of the Great Recession, see Financial Services Authority (FSA) (2011b) 'European Supervisory Authorities', available at http://goo.gl/DL6q8; and EC (2011c) op cit note 27.

${ }_{48}$ Art 13, Art 127(1) and Art 282 of the EC Treaty.

${ }^{49}$ Reichwein and Rosati (2007) op cit note 1 passim.

${ }^{50}$ A282(1) of the EC Treaty. See EC (2010) op cit note 37.

${ }^{51}$ See Committee of European Banking Supervisors (CEBS) at http://www.c-ebs.org.
} 
Member States involved in the supervision of any of the relevant activities of cross-border insurance groups, banking groups or financial conglomerates. ${ }^{52}$

One of the oldest Councils in the EU is the EU Economic and Financial Affairs Council - Ecofin ${ }^{53}$ Council - which is one of the oldest configurations of the Council and is composed of the Economics and Finance Ministers of the Member States, as well as the Budget Ministers when budgetary issues are discussed. A number of new European Supervisory Authorities (hereafter ESAs) for the supervision of financial services under the framework of the European System of Financial Supervisors (hereafter ESFS) have recently been created: the European Banking Authority (hereafter EBA); ${ }^{54}$ the European Insurance and Occupational Pensions Authority (hereafter EIOPA); the European Securities and Markets Authority (hereafter ESMA); and the European Systemic Risk Board (hereafter ESRB). ${ }^{55}$ The EBA replaces the CEBS. ${ }^{56}$

A separate oversight approach for non-banks has not been properly defined, although their activities can, in part, be subsumed under the oversight for payment instruments or they can be treated as third-party services, although there is a clear statutory competence for the oversight of all payment systems and instruments covering banks and non-banks irrespective of their status. ${ }^{57}$ Some of this is subsumed in the PSD, particularly those aspects relating to MTOs, agents and outsourcing partners, and authorised PIs. ${ }^{58}$ The EC has also established some non-judicial bodies to assist in disputes. ${ }^{59}$

\subsection{3}

\section{Regulatory, Licensing and General Oversight Regimes}

The approach that has evolved in the EU with regard to banking, payments and associated services and instruments covers affected banks and non-bank entities via an institution-based, ${ }^{60}$ functional, ${ }^{61}$ and specific-instrument ${ }^{62}$ approach, although the new PSD takes both a functional and institutional approach and harmonises a number of national laws. ${ }^{63}$ As a result, the provisions of the PSD may be applicable to banks and non-banks alike.

\footnotetext{
${ }^{52}$ See Committee of European Banking Supervisors (CEBS) (2009) 'CEBS and CEIOPS Publish Today Ten Principles for the Functioning of Supervisory Colleges', available at http://goo.gl/yQnbo. See also European Commission (2008b) 'Memorandum of Understanding on Cooperation between the Financial Supervisory Authorities, Central Banks and Finance Ministries of the EU on Cross-Border Financial Stability 2008', available at http://goo.gl/cjwmY.

${ }^{53}$ It meets once a month. See Council of the EU at http://goo.gl/H7Wbo.

${ }^{54}$ For analysis of the EBA's genesis, see Fahey (2011) op cit note 1.

${ }^{55}$ The new authorities build on the existing powers of the current financial services committees with a number of additional technical powers. See European Parliament (2009) 'Commission Proposal for a Regulation on Community Macro-prudential Oversight of the Financial System and Establishing a European Systemic Risk Board (23 September 2009)', available at http://goo.gl/CdPji; see also European Union (2011a) 'ESFS Frequently Asked Questions', available at http://goo.gl/BdzfB ${ }^{56}$ On the EBA, see Fahey (2011) op cit note 1

57 A Stervinou (2011) 'The Role of Non-banks in Retail Payments' Regional Payment Systems Workshop: LAC Port of Spain, Trinidad and Tobago, 08 February 2011, available at http://goo.gl/5x3CZ passim.

${ }^{58}$ See for example Art 17 of the PSD.

${ }^{59}$ Council Resolution of 25 May 2000 on a Community-wide Network of National Bodies for the Extra-Judicial Settlement of Consumer Disputes OJ C 155 of 06.06.2000, available at http://goo.gl/Rs69V. See s9.13 on Consumer Protection below.

${ }^{60}$ Such as licensing for e-money issuers classed as non-banks.

${ }^{61}$ For example, technical systems used for clearing payments or assisting banks in various technical and logistical outsourcing capacities

${ }^{62}$ For example, legislation implementing the international convention on cheques. Reichwein and Rosati (2007) op cit note 1.

${ }^{63}$ For a list of pre-PSD licensing and exemption criteria for various institutions and instruments, see European Commission (2003b) 'Comparative Tables of National Rules', available at http://goo.gl/ULYH4.
} 
In the sphere of payments, there are a number of bolt-on provisions to several of these rules, many of which relate to consumer protection. For example there are those relating to cross-border payments in the $\mathrm{EC} ;{ }^{64}$ the Payment Systems Market Expert Group ${ }^{65}$ settlement finality in payment and securities systems; ${ }^{66}$ information on the payer accompanying transfers of funds; ${ }^{67}$ the Directive $1997 / 5 / \mathrm{EC}$ on cross-border credit transfers; and a Regulation on equality of fees for domestic and cross-border transfers in Euros. ${ }^{68}$ Depending on the institution (entity), a license may be required. For example banks - or 'credit institutions' as they are known in the EU - fall under their own licensing regime. ${ }^{69}$ E-money issuers (as non-banks) also have their own licensing regime, ${ }^{70}$ while non-banks providing certain types of payment services as 'Payment Institutions' defined in the PSD also require a license. ${ }^{71}$ Each of these possible licensing regimes for banks and non-banks are discussed below.

\subsection{4}

\section{Banking Laws and Regulations in the EU}

\subsubsection{1}

\section{Overview}

There is no definition of a bank per se in EU law. Rather, Directive 2006/48/EC ${ }^{72}$ lays down the rules on the taking-up and pursuit of the business of 'credit institutions' as they are termed and on the prudential supervision of such institutions. ${ }^{73}$

The authorities will be able to take decisions directly applicable to financial institutions but only at the end of a long procedure for the consistent application of Community law, in order to ensure the effectiveness of that procedure, and only in cases where there is EU legislation that is directly applicable. ${ }^{74}$

\footnotetext{
${ }^{64}$ Regulation (EC) No 924/2009.

${ }^{65}$ Decision 2009/72/EC.

${ }^{66}$ Directive 98/26/EC.

${ }^{67}$ Regulation (EC) No 1781/2006.

${ }^{68}$ Regulation $2560 / 2001$ of the EC.

${ }^{69}$ Directive 2000/28/EC - Credit Institutions.

${ }^{70}$ Directive 2000/46/EC - Electronic Money Institutions.

${ }^{71}$ For a list of current payment laws in the EU, see European Commission (EC) (2011a) 'EC Payments Legislation', available at http://goo.gl/2dhGd.

${ }^{72}$ A recasting of the original Directive 2000/12/EC of the European Parliament and of the Council of $20^{\text {th }}$ March 2000 relating to the 'taking up and pursuit of the business of credit institutions'. See http://goo.gl/wj6PD for the text of the Act and the Explanatory Memorandum.

${ }^{73}$ See also the related Directive on the reorganisation and winding up of credit institutions; Directive 2006/49/EC on the capital adequacy of investment firms and credit institutions (recast); and Directive 2009/111/EC amending Directives 2006/48/EC, 2006/49/EC and 2007/64/EC as regards banks affiliated to central institutions, certain own funds items, large exposures, supervisory arrangements and crisis management.

${ }^{74}$ For a broad discussion on the new EU financial regulatory framework, see Forster (2010) op cit note 1 passim.
} 
Art 4(1) of the Directive ${ }^{75}$ defines a 'credit institution' as:

(a) an undertaking whose business is to receive deposits or other repayable funds from the public and to grant credits for its own account; or

(b) an electronic money institution within the meaning of Directive 2000/46/EC. ${ }^{76}$

While there is copious use of the terms 'deposit' and 'repayable funds', there is no explicit definition of these terms in any EC laws. ${ }^{77}$ This is left to the case law.

Article 23 of this Directive refers to the activities that a credit institution may undertake and which are included in Annex 1 of the Directive. ${ }^{78}$ The Directive applies to all activities carried out by credit institutions, including payments and settlement activities risk. ${ }^{79}$ Further, nonbank providers of payment services which belong to a banking group fall within the scope of supervision of the credit institution on a consolidated basis. ${ }^{80}$

While it is left to member states to transpose the directive into their law, generally the Directive sets out requirements for access to the taking up and pursuit of the business of credit institutions:

- $\quad$ Existence of separate own funds; ${ }^{81}$

- $\quad$ Existence of initial capital of at least $€ 5$ million (hereafter $\mathrm{mn}$ );

- $\quad$ Presence of at least two persons who effectively direct the business of the credit institution (and who are of sufficiently good repute and have sufficient experience to perform such duties); and

- Notification to the competent authorities of the identities of the shareholders or members, whether direct or indirect, natural or legal persons, that have qualifying holdings, and of the amounts of those holdings.

Member States can adopt additional conditions, of which the Commission must be informed. Supervision may be carried out by the home Member State with limited exception such as supervisions of liquidity. ${ }^{82}$

\footnotetext{
${ }^{75}$ On taking up and pursuit of the business of credit institutions.

${ }^{76}$ A 'financial institution' is defined as an undertaking other than a credit institution, the principal activity of which is to acquire holdings or to carry on one or more of the activities listed in points 2 to 12 of Annex I; op cit note 72 for the text of the Act and the Explanatory Memorandum.

${ }_{77}^{77}$ Malaguti (2009) op cit note 1 at 8.

${ }^{78}$ These are inter alia, and unremarkably, acceptance of deposits and other repayable funds; lending, including, inter alia: consumer credit, mortgage credit, factoring, with or without recourse, financing of commercial transactions (including forfeiting); financial leasing; money transmission services; and issuing and administering means of payment (eg credit cards, travellers' cheques and bankers' drafts. These are in part very similar to the list of activities available to payment providers.

${ }^{79}$ Its settlement business activities are explicitly considered in the framework of operational risk management and are subject to coverage in the form of capital requirements. Reichwein and Rosati (2007) op cit note 1.

${ }^{80}$ Reichwein and Rosati (2007) op cit note 1.

${ }^{81}$ The Directive puts forward a definition of own funds comprising two elements: original own funds and additional own funds; op cit note 72 for the text of the Act and the Explanatory Memorandum.
} 
The general principle outlined in the Directive 2006/48/EC are enshrined in the United Kingdom's (hereafter UK's) regulatory regime regarding banks and other institutions engaged in what amounts to the business of a 'credit institution'. ${ }^{83}$ The UK Banking Act 2009 defines a UK credit institution which has permission under Part 4 of the Financial Services and Markets Act 2000 to carry on the regulated activity of accepting deposits (within the meaning of s22 of that Act).

There is now a more restricted view of the business of banking, regulating more the demand side of banking - that is, deposits - rather than the supply side, which is the lending side of banking. ${ }^{84}$ Despite banks being engaged in both activities, the UK Financial Services Authority (FSA) protects the perimeter of the business by regulating those who engage in unauthorised deposit-taking. The FSA has made a distinction between deposits and payments for services. ${ }^{85}$ The FSA has indicated that deposits do not include 'advancements in normal commercial transactions for goods and services. ${ }^{86}$

There is also currently a tripartite regime in place for regulating banks, although ultimately this falls on the Financial Services Authority. ${ }^{87}$ There are distinct roles for HM Treasury (the Treasury), the Bank of England (the Bank) and the Financial Services Authority (the FSA) (together, the Authorities) and distinct responsibilities for overall financial stability issues, which are set out in a memorandum of understanding between the Authorities. The UK Treasury provides the public money for financial activities, sets up the regulatory structures, and decides whether or not to nationalise banks.

The Bank of England Act of 1998 established the arrangements for the Bank's current monetary policy responsibilities. It also acts as a lender of last resort to failing banks. ${ }^{88}$ Under the 1998 Banking Act, the banking supervision function that had previously been undertaken by the Bank of England was transferred to the FSA. The Financial Services and Markets Act 2000 set out the framework within which the FSA operates, as the single regulator for the financial services industry. The FSA supervises and licenses the individual banks and looks after the interests of consumers. ${ }^{89}$ There is some political pressure to disband or reform the FSA.

\footnotetext{
${ }^{82}$ Art 5 allows credit institutions to perform a range of services in other member states. These include inter alia acceptance of deposits and other repayable funds; lending; financial leasing, money transmission services, and issuing and administering means of payment.

${ }^{83}$ See generally on transposition of some financial laws into UK domestic law, Huertas (2009) op cit note 1.

${ }^{84}$ Singh (2007) op cit note 1 at 54.

${ }^{85}$ See, for example, the decision of SCF Finance Co Ltd v Masri (No 3) [1987] 2 WLR 81 CA, cited in Singh (2007) op cit note 1 , that distinguished between margin payments and deposit-taking business and in which Slade LJ ruled that the former was for the provision of services and were not deposits.

${ }^{86}$ Financial Services Authority (FSA) 'FSA 2001/53 Threshold Conditions (Amendment) Instrument 2001, Auth 2.6.2G, ' available at http://goo.gl/Jt7Xw.

${ }^{87}$ See National Archives (s.d.) 'Explanatory notes for UK Banking Act 2009,' available at http://goo.gl/1ca0H.

${ }^{88}$ Ibid.

${ }^{89}$ Explanatory notes for UK Banking Act 2009 op cit note 87.
} 
The ECB maintains a vigilant overview of payment systems as a Systemically Important Payment Systems (hereafter SIPS) and is armoured with two Directives for risk-management of any systemic risk in retail payment systems with the Directive on settlement finality in payment and securities systems, ${ }^{90}$ and on bilateral financial collateral arrangements. ${ }^{91}$ The Eurosystem has oversight competence on all payment systems and their infrastructures, which includes retail payment systems.

The Eurosystem has adopted various minimum standards for its oversight policy on payment systems which payment system service providers are expected to meet ${ }^{92}$ and comply with a harmonised set of oversight standards ${ }^{93}$ to prevent market disruptions. ${ }^{94}$ Infrastructure used by payment systems that are designated as systemically important or critical are also subject to oversight. ${ }^{95}$ In many countries the National Central Bank (hereafter NCB) will oversee the national payments infrastructure provider serving the NPS via a set of national regulations, as well as setting information and reporting requirements, and examination. ${ }^{96}$ In other cases oversight is based on moral suasion. ${ }^{97}$

Enforcement - usually via a NCB where a target entity is legally based - can be effected by legal instruments available to a $\mathrm{NCB}^{98}$ as well as informal tools such as moral suasion. ${ }^{99}$

Oversight of payment instruments is done in some cases on a national basis such as in France, Greece, and Italy while national legislation also gives NCBs some supervisory tasks over institutions providing payment services. $^{100}$

\footnotetext{
${ }^{90}$ Directive 1998/26/EC.

${ }^{91}$ Directive 2002/47/EC.

${ }^{92}$ Examples of these standards are the 1998 report on electronic money and the G10 standards entitled Core Principles for Systemically Important Payment Systems (Core Principles) adopted by the Governing Council of the ECB in January 2001. See ECB (2003) op cit note 46.

${ }^{93}$ ECB (2010a) op cit note 1.

${ }^{94}$ Where the disruption to a retail payment system threatens the stability of financial markets, the Eurosystem requires the identified systems to comply with the entire set of BIS Core Principles. Where it is non-systemic but disruptive, it must observe a sub-set of the Core Principles or 'Retail Standards'. Others must comply with the relevant oversight standards determined by NCBs.

${ }_{95}$ An example is SWIFT, the Society for Worldwide Interbank Financial Telecommunication. This interbank communication network is neither a payment nor a settlement system and, as such, is not regulated by central banks (hereafter CBs) or bank supervisors. Nevertheless, a large and growing number of SIPS have become dependent on SWIFT, which has thus acquired a systemic character. The NCB of the G10 agreed that SWIFT should be subject to cooperative oversight by central banks. The oversight of SWIFT in its current form dates from 1998. See SWIFT (2011) 'Oversight of SWIFT,' available at http://goo.gl/AV2yv.

${ }^{96}$ Reichwein and Rosati (2007) op cit note 1 passim.

${ }_{97}^{97}$ ECB (2010a) op cit note 1; Reichwein and Rosati (2007) op cit note 1 passim.

98 Ibid.

${ }^{99}$ Ibid.

${ }^{100}$ For example, the competence of the Bank of Greece includes also licensing, regulation, and supervision of money remittance undertakings. Reichwein and Rosati (2007) op cit note 1.
} 
The Directive on Payment Services (hereafter PSD) ${ }^{101}$ provides the legal foundation for the creation of an EU-wide single market for payments and opens up payment markets to new entrants to foster greater efficiency and cost-reduction in the cost of doing payments. ${ }^{102}$

Before the PSD, each Member State had its own rules on payment. The PSD, which became law on 1 November 2009 and which had to be transposed in Member States by 2010, has resulted in the modification and repeal of a number of payment Directives and Recommendations. ${ }^{103}$ The PSD aims to establish a modern and comprehensive set of rules applicable to all payment services in the EU and EEC ${ }^{104}$ countries. ${ }^{105}$ It does so by providing the legal framework for the operation of a single market in payment services using a harmonised ${ }^{106}$ authorisation regime that provides a single EU-wide license for qualified entities. ${ }^{107}$ These newly qualifying entities could be neither deposit-takers nor e-money issuers, but part of the new regime of autonomous entities known as PIs that provide payment services drawn from another new concept called a 'Payment Account' (hereafter PA).

The PSD, together with the new, second E-Money Directive ${ }^{108}$ (hereafter EMD2), according to the EC, creates a proportionate regulatory regime for new entrants in the payments market, including mobile operators, thereby allowing them to enter the market and develop innovative services. Being able to issue electronic money and provide payment services under a single license, it says, will significantly reduce the usual administrative burden. ${ }^{109}$

\footnotetext{
${ }^{101}$ Directive 2007/64/EC. The PSD was proposed in December 2005 via IP/05/1514.

102 The EC says that the removal of these barriers could save the EU economy $€ 28$ billion (hereafter bn) per year overall. European Commission (EC) (2007c) 'Payment Services Directive: Commission Encourages Swift and Coherent Implementation at National Level', available at http://goo.gl/10A6l.

${ }^{103}$ In particular, it repealed Regulation (EC) No 2560/2001 on cross-border payments in euro; Recommendation 97/489/EC on transactions by electronic payment instruments; and Directive 97/5/EC on cross-border credit transfers. For a current list of payment-related legislation in force in the EU, see EC Legislation, available at http://goo.gl/2dhGd.

104 That is, those in the European Union, Iceland, Norway and Liechtenstein.

105 The PSD is in most respects an example of 'full harmonisation', insofar as Member States cannot maintain or introduce provisions other than those laid down in the PSD. There are some provisions that member states can implement themselves, such as Art 30(2), Art 33, Art 34(2), Art 45(6), Art 47(3), Art 48(3), Art 51(2), Art 52(3), Art 53(2), Art 61(3) and Arts 72 and 88 . The PSD however allows payment service providers to grant more favourable terms to payment service users. See EC (2007c) op cit note 102.

106 The Preamble to the PSD at (6) says that the PSD uses the principle of 'subsidiarity'. This is defined in Art 5 of the Treaty of Lisbon as being closely bound up with the principles of proportionality and necessity, which require that any action by the Union should not go beyond what is necessary to achieve the objectives of the Treaty. See Europa (2011a) 'Subsidiarity', in Glossary available at http://goo.gl/J1bJf.

${ }^{107}$ It also provides a legal platform for the self-regulatory Single Euro Payments Area (SEPA), an initiative of the European Payments Council. The most important difference between the PSD and SEPA is that the PSD applies to the 30 EU/EEA countries plus Switzerland, and SEPA applies to Euro payments in the 16-member Eurozone. Without the PSD, however, SEPA would have no legal basis.

${ }^{108}$ The EMD2's official title is 'Directive 2009/110/EC of the European Parliament and of the Council of 16 September 2009 on the taking up, pursuit and prudential supervision of the business of electronic money institutions amending Directives 2005/60/EC and 2006/48/EC and repealing Directive 2000/46/EC', available athttp://goo.gl/zHgbm.

${ }^{109}$ European Commission (EC) (2011c) 'FAQ on the PSD: Question 385', available at http://goo.gl/d5cAw.
} 
Much of the PSD concerns the front-end providers of payment services and in particular the activities that these PIs will be allowed to do. ${ }^{110}$ In this regard, the PSD adds a number of consumer protection initiatives, covering many types of electronic and non-cash payments, ranging from credit transfers, direct debits, card payments (including credit card payments) and money remittance to mobile and online payments. It does not however cover cash and cheque payments.

Many payment instruments and activities such as credit or debit transfers are traditionally regulated separately, the PSD attempts to find common rules such that provision of payment services is seen as an autonomous activity requiring a license under certain conditions and for certain providers. ${ }^{111}$

Although it is aimed at 'payment services', it specifically excludes from its ambit payments executed via paper-based payment instruments such as cheques, drafts, vouchers, travellers' cheques and postal money orders ${ }^{112}$ such that it effectively 'only' regulates credit or debit transfers initiated by a payer and executed electronically. ${ }^{113}$ The PSD also does not, in respect of access to payment systems, apply to systems set up and operated by a single Payment Service Provider (hereafter PSP or PSPs).

This ostensible lack of homogeneity and systemic objectivity in the inclusion of certain services within the scope of the PSD is confirmed in Recital 6 of the PSD, which says in reference to the need for a payment services law in the EU that: '[I]t is not appropriate for that legal framework to be fully comprehensive.'

The PSD applies to payment services provided within the EC, ${ }^{114}$ and payments in any European currency (not only the Euro) are covered as long as the PSPs for both the payer and the payee are located in one of the 30 countries.

\footnotetext{
${ }^{110}$ There are however some provisions around outsourcing services to the Payment Institutions (PIs), in particular, the use of agents.

${ }_{111}^{111}$ Malaguti (2009) op cit note 1 at 5-6.

${ }^{112}$ Recital 19 justifies this exclusion:
}

'This Directive should apply neither to payment transactions made in cash since a single payments market for cash already exists nor to payment transactions based on paper cheques since, by their nature, they cannot be processed as efficiently as other means of payment. Good practice in this area should, however, be based on the principles set out in this Directive.'

${ }^{113}$ Art 3 of the PS; see also Malaguti (2009) op cit note 1 at 7.

${ }^{114}$ Title I deals with subject matter, scope and definitions; Title II deals with aspects of payment service providers; Title III deals with transparency of conditions and information requirements for payment services; Title IV deals with rights and obligations in relation to the provision and use of payment services; Title V deals with implementing measures and payments committee; Title VI deals with the harmonisation and review of the Directive. With the exception of Art 73, which deals with value date and the availability of funds, Titles III and IV apply only where both the payer's PSP and the payee's PSP are, or the sole PSP in the payment transaction is, located in the Community. 
The PSD applies to 'Payment Services', which are defined as any business activities listed in the Annexes of the PSD. ${ }^{115}$ Any entity that provides these Payment Services requires authorisation to do so, and include the following:

'(a) Services enabling cash to be placed on a Payment Account and all of the operations required for operating a payment account;

(b) Services enabling cash withdrawals from a Payment Account and all of the operations required for operating a payment account;

(c) The execution of the following types of payment transaction -

(i) direct debits, including one-off direct debits;

(ii) payment transactions through a payment card or a similar device;

(iii) credit transfers, including standing orders;

(d) The execution of the following types of payment transaction where the funds are covered by a credit line for the payment user-

(i) direct debits, including one-off direct debits;

(ii) payment transactions executed through a payment card or a similar device;

(iii) credit transfers, including standing orders;

(e) Issuing payment instruments or acquiring payment transactions;

(f) Money remittance;

(g) The execution of payment transactions where the consent of the payer to execute the payment transaction is given by means of any telecommunication, digital or IT device and the payment is made to the telecommunication, IT system or network operator acting only as an intermediary between the payment user and the supplier of the goods or services. ${ }^{116}$

The 'payment transactions' referred to in the Annex are defined in Art 4(5) as:

'[A]n act, initiated by the payer or by the payee, of placing, transferring or withdrawing funds, irrespective of any underlying obligations between the payer ${ }^{117}$ and the payee'

and it includes deposits and withdrawals. ${ }^{118}$

\footnotetext{
${ }^{115} \operatorname{Art} 4(3)$.

${ }^{116}$ This provision was inserted as a result of the controversy that arose with the categorisation of (Wireless Application Services Provider) WASP-type Value Added Services (VAS) activities of MNOs who allow the sale of digital goods by third party providers and the payment thereof from the MNO prepaid airtime purse as EMI in terms of the old EMD 2000/46/EC. Annex 1 at (g) to the PSD now specifically excludes MNOs who pursue such activities. This section then recognises that the sale of such digital goods, where the MNO credits the account of the service provider and debits the prepaid account holder balance, does not amount to a payment service activity. On WASPs and VAS, see ch 6, s6.5.4.2 titled WASP Value Added Services.

${ }^{117}$ Art 4(7) defines a 'payer' as a natural or legal person who holds a Payment Account and allows a payment order from that payment account, or, where there is no payment account, a natural or legal person who gives a payment order.

${ }_{118}$ Art 4(8) defines a 'payee' as a natural or legal person who is the intended recipient of funds which have been the subject of a payment transaction.
} 
A 'payment instrument' is defined as:

'[A]ny personalised device(s) and/or set of procedures agreed between the payment service user and the payment service provider and used by the payment service user in order to initiate a payment order. ${ }^{119}$

To be able to do these payment services and transactions, only certain types of entities will be authorised under the PSD. These are what Art 1(1) calls 'Payment Service Providers' (PSPs) and they are defined as: ${ }^{120}$

'(a) credit institutions within the meaning of Art. 4(1)(a) of Directive 2006/48/EC; ${ }^{121}$

(b) electronic money institutions within the meaning of Art. 1(3)(a) of Directive 2000/46/EC;

(c) post office giro institutions which are entitled under national law to provide payment services;

(d) payment institutions within the meaning of this Directive;

(e) the European Central Bank and national central banks when not acting in their capacity as monetary authority or other public authorities;

(f) Member States or their regional or local authorities when not acting in their capacity as public authorities.'

All the above entities, with the exception of the entities in section (d), automatically become PSPs due to their general operating characteristics.

The 'Payment Institution' (PI) referred to in section (d) above is defined in Art 4(4) as:

'[A] legal person that has been granted authorisation in accordance with Art $10^{122}$ to provide and execute payment services throughout the Community.'

The PI then is essentially a new type of regulated autonomous entity that can compete with the other institutions - including banks - to provide payment services in the EU. ${ }^{123}$ Certain money transmitters, companies providing bill payment services, ATM operators and Mobile Network Operators (hereafter

\footnotetext{
${ }^{119}$ Art 4(23). This definition is meant to cover physical devices (such as cards or mobile phones) and/or sets of procedures (such as PIN codes, TAN codes, digipass, login/password, etc.) which a payment service user can use to give instructions to his payment service provider in order to execute a payment transaction. If the payment transaction is initiated by paper, the paper slip itself is not considered as a payment instrument.

${ }^{120}$ A 'Payment Service Provider' means bodies referred to in Art 1(1), and legal and natural persons benefiting from the waiver under Art 26. Art 26 provides the ability to wave compliance with the PSD for entities where the average of the preceding 12 months' total amount of payment transactions executed by the person concerned, including any agent for which it assumes full responsibility, does not exceed $€ 3$ million (hereafter $\mathrm{mn}$ ) per month.

${ }^{121}$ (1) 'credit institution' means: '(a) an undertaking whose business is to receive deposits or other repayable funds from the public and to grant credits for its own account; or (b) an electronic money institution within the meaning of Directive 2000/46/EC (1).' This includes a branch thereof within the meaning of point 3 of Art 4 of that Directive, where such a branch is located within the EU and its head office is located outside the EU in accordance with Art 38 of that Directive.

${ }^{122}$ This section deals with the granting of authorisation for those who intend to provide payment services. Excluded from this are those referred to in Art 1(1)(a) to (c), (e) and (f) and other than legal or natural persons benefiting from a waiver under Art 26.

${ }^{123}$ Certain MTOs, companies providing bill payment services, ATM operators and mobile phone operators may all constitute payment institutions However, with the exception of Art 73, Titles III and IV shall apply only where both the payer's PSP and the payee's PSP are, or the sole PSP in the payment transaction is, located in the Community.
} 
MNOs) may all constitute payment institutions. ${ }^{124}$ Importantly, a PI cannot be excluded from a payment scheme because they are not a bank. Thus, this new entity means the PSD opens the payments market in the EU to entities other than banks. Further, a PI regulated in one country can also provide payment services without being approved by the second country's regulator, the so-called EU 'passport'. In particular, payment institutions may issue debit and credit cards, offer acquiring services and loans, although they may not use customer money to fund these loans. ${ }^{125}$

The PIs are able to compete with banks and electronic money (hereafter e-money) institutions to provide payment services and may be money remitters, retailers, and even mobile phone operators. The scope of business for these PIs is more limited than banks (credit institutions) and thus they face less stringent rules with regard to their supervision, application and authorisation procedures and capital requirements. ${ }^{126}$ Authorised PIs are able to provide services on a cross-border or branch basis, using passport rights acquired under the PSD. It also provides the legal foundation for the launch of cross-border direct debit schemes. PIs are allowed to provide limited credit, but only where it is closely linked to payment services. ${ }^{127}$ The PSD also implements definitive consumer protection rules on liability for unauthorised payments and the effect of delayed payment transactions. The PSD however accelerates payment settlement times, ensuring that all Euro-based or domestic electronic payments are completed in a maximum of one day after the payment order is given. ${ }^{128}$

PIs are also required to fulfill a variety of qualitative and quantitative requirements. Qualitative requirements include, but are not limited to, sound administrative, risk management and accounting procedures, proper internal control mechanisms, directors and managers that are of good repute and possess appropriate knowledge and experience, as well as shareholders that are suitably taking into account the need to ensure the sound and prudent management of a payment institution. Quantitative capital requirements to ensure financial stability include (non-onerous) initial and ongoing capital requirements appropriate to the low level of risk of payment institutions. ${ }^{129}$

There is also a category available - at least in the UK - as a 'Small Payment Institution' (hereafter SPI) which means that the entity does not have to gain authorisation as a Payment Institution. In the UK, to

\footnotetext{
${ }^{124}$ Credit institutions, for example, banks and e-money issuers, are already authorised to carry out payment services as a result of their existing authorisation and do not therefore need to seek further authorisation or registration. They are however required to comply with the conduct of business requirements.

${ }^{125}$ Under the PSD, any credit provided by a PI has to be provided from the PI's own funds or monies that it has raised in capital markets, not from the funds received or held for the purpose of executing a payment transaction. National supervisory authorities must also be satisfied that the own funds of the payment institution are appropriate to the overall amount of credit provided. See European Commission (2007d) 'Payment Services Directive: Frequently Asked Questions \#23', available at http://goo.gl/rSVr; and U Elsenhuber and B Schimk (2006) 'Payment Institutions: Potential Implications of the New Category of Payment Service Providers for the Austrian Financial Market', available at http://goo.gl/VedWG.

${ }^{126}$ EC (2007c) op cit note 102.

${ }^{127}$ See PSD Preamble (13). The major restriction though is that credit can only be sourced from a payment institution's own funds, or funds from the capital markets, but not the funds held on behalf of clients for payment services.

${ }^{128}$ All payment orders initiated by the payer and denominated in Euro currency or the currency of a Member State outside the Euro area, including credit transfers and money remittances, are subject to a maximum one-day execution time. See Recital 43 of the PSD.

${ }^{129}$ EC (2007d) op cit note 125.
} 
qualify, Regulation 13 of the UK Payment Services Regulations of $2009^{130}$ sets out that to qualify, the entity's average amount of payment transactions - including its agents in the UK - in the preceding 12 months must not exceed $€ 3 \mathrm{~m}$ (or an equivalent amount) per month; that none of the individuals responsible for the management or operation of the business has been convicted of offences relating to money laundering or terrorist financing, the Act, the PSD Regulations or financial crimes; its head office, registered office or place of residence, as applicable, is in the UK; and that the entity complies with the registration requirements of the Money Laundering Regulations 2007 where they apply. A waiver from the prudential requirements and registration rather than obtaining authorisation will usually be given if they meet those conditions. An entity registering as a small PI though cannot acquire passport rights to provide services in other EU states under the regulations, although it may become an agent of a PSP. ${ }^{131}$

The PSD envisages the payment transaction to be executed from funds a consumer - or payments service user $^{132}$ in PSD nomenclature - places in what is termed a 'payment account'. This PA in turn is defined as:

'an account held in the name of one or more PSUs which is used for the execution of payment transactions. ${ }^{133}$

This low-cost ${ }^{134}$ innovation attempts to detach payment services from banking and other 'traditional' financial activities connected with the opening of an account even in respect of remittances and allowing the provision of services without the opening of an account. ${ }^{135}$ The underlying purpose of the PA will determine if it is a PA that falls within the scope of the PSD. ${ }^{136}$ Where, then, these accounts are objectively used for payment services, the value placed (or received) in them is not however considered a deposit by the PSD. ${ }^{137}$ Art 16(2) specifically says that funds received by PIs from PSUs with a view to the provision of payment services shall not constitute a deposit or other repayable funds within the meaning of Art 5 of Directive 2006/48/EC, or e-money within the meaning of Art 1(3) of Directive 2000/46/EC. ${ }^{138}$ The payer's PSP may not however keep the funds in the PA for long: the PSP must ensure that after receipt of the funds

\footnotetext{
${ }^{130}$ Financial Services Authority (FSA) (2009b) 'Statutory Instruments 2009 No. 209: Financial Services and Markets: The Payment Services Regulations 2009', available at http://goo.gl/WzEBE. The 2EMD and the PSD were considered so closely interlinked that, for consistency, the UK government decided to implement the 2EMD through regulations.

${ }^{131}$ See Financial Services Authority (FSA) (2011c) 'Financial Services Authority Handbook: PERG 15.4 Small Payment Institutions, Agents and Exempt Bodies', available at http://goo.gl/FkL4Q.

${ }^{132}$ Art 4(10) defines a 'payment service user' as a natural or legal person making use of a payment service in the capacity of either payer or payee, or both.

${ }^{133}$ Art 4(14). According to Art 71, where a consumer places cash on a Payment Account with that PSP in the currency of that payment account, the PSP shall ensure that the amount is made available and value dated immediately after the point of time of the receipt of the funds.

${ }^{134}$ Recital 28 of the PSD says that Member States should be allowed to set rules requiring that monthly paper-based statements of payment accounts are always to be given free of charge.

${ }^{135}$ Malaguti (2009) op cit note 1 at 5.

${ }^{136}$ This may include the functional aspects of the account insofar as it does or does not allow payment services; or, generally, the purpose the PSP has objectively designed the account. This may also relate to what Art 4(12) calls the 'framework contract' defined as a payment service contract which governs the future execution of individual and successive payment transactions and which may contain the obligation and conditions for setting up a payment account.

${ }^{137}$ Art 2 says that when payment institutions engage in the provision of one or more of the payment services listed in the Annex, they may hold only Payment Accounts to be used exclusively for payment transactions.

${ }^{138}$ While the clarification is welcome, the nomenclature used is not: it directly and negatively links payment accounts to the new concept of repayable funds, implying that a Payment Account is a short-term holder of funds for payment purposes only and that they are not repayable. This may of course have some limited validity in respect of a payer's view of the funds transfer in a debit or credit transaction, but from a payee's 'payment account' perspective the incoming funds must be repayable. It also does not take into account the fact that the Payment Account may be the same thing as a (repayable) emoney or current account.
} 
from the payer, that the amount of the payment transaction placed in the Payment Account by the payer is credited to the PSP account of the payee by the end of the next business day at the latest. ${ }^{139}$ It is notable that remittance providers who are PSPs do not need to keep a PA due to the virtually instant payment nature of the business model. Malaguti believes similarly that a 'payment transaction' simply amounts to a money transmission, since it is 'irrespective of any underlying obligations. ${ }^{140}$

Even so far as its scope in terms of electronic payments, the PSD is (purposely) not comprehensive since many electronic transaction types are excluded from the scope. ${ }^{141}$ For example, it is geared towards the regulation of consumer contracts and debit and credit payments but does not deal with B2B payments or the underlying mechanism and law relating to the Business to Business (hereafter B2B) payment, unlike Art 4A of the Uniform Commercial Code (hereafter UCC) in the USA which is limited to credit transfers ${ }^{142}$ and only includes B2B transactions. The PSD thus deals with the private law aspects of consumer ${ }^{143}$ transactions, specifically only the contractual obligations and responsibilities between the PSU and his $\mathrm{PSP}^{144}$ and so replaces general national law in the member states with regard to who may participate in the payment space and under which circumstances, as well as the rights and obligations. ${ }^{145}$

Further, the EC does not see the Directive as applying to monetary value stored on specific pre-paid instruments, designed it says, to address precise needs that can be used only in a limited way. ${ }^{146}$ Such instruments could include store cards, petrol cards, membership cards, public transport cards, meal vouchers or vouchers for services, ${ }^{147}$ which are sometimes subject to a specific tax or labour legal framework designed to promote the use of such instruments to meet the objectives laid down in social legislation.

\footnotetext{
${ }^{139}$ Art 69(1) of the PSD. Until 1 January 2012, a payer and his payment service provider may agree on a period no longer than three business days. These periods may be extended by a further business day for paper-initiated payment transactions.

${ }^{140} \mathrm{Art}$ 4(5) of the PSD. Malaguti concludes that the EC's need to link the payment transaction to an 'account' is an attempt to reflect the fact that fiduciary money, being scriptural in essence, needs an account in order 'to exist'. Malaguti (2009) op cit note 1 at 6.

${ }^{141}$ See the Preamble to the PSD at (6). These include services based on instruments that can be used to acquire goods or services only in the premises used by the issuer or under a commercial agreement with the issuer either within a limited network of service providers or for a limited range of goods or service; services provided by technical service providers, which support the provision of payment services; and some services offered by mobile operators where the payment is made from the prepaid airtime purse of the mobile subscriber.

${ }^{142}$ Geva (2009b) op cit note 1 at 722 .

${ }^{143}$ Defined in Art 4(11) as: '... a natural person who, in payment service contracts covered by this Directive, is acting for purposes other than his trade, business or profession.'

${ }_{144}$ Preamble to PSD at 47.

${ }^{145}$ The regulations distinguish between payment transactions between payment service providers and payment services provided to clients insofar as the object of the regulations is the payment service provided to specific clients and not the dealings among payment service providers to deliver the end payment arising from that service even though a payment transaction may involve a chain of payment service providers. The FSA also points out that the Directive does not cover inter-bank settlement, such as payment transactions carried on within a payment or securities settlement system between payment service providers and settlement agents, central counterparties, clearing houses, central banks or other participants in the system. Financial Services Authority (FSA) (2009a) 'Financial Services Authority (FSA) 2009/19: Perimeter Guidance (Payment Services Scope) Instrument 2009', 15 Annex 3(h), available at http://goo.gl/f9GqW.

${ }^{146}$ It defines 'limited' as being characterised by situations where the electronic money holder can only purchase goods or services in the premises of the electronic money issuer, or within a limited network of service providers under direct commercial agreement with a professional issuer, or because they can be used only to acquire a limited range of goods or services. An instrument should be considered to be used within such a limited network if it can be used only for the purchase of goods and services in a specific store or chain of stores, or, only for a limited range of goods or services, regardless of the geographical location of the point of sale.

${ }^{14}$ Such as vouchers for childcare, or vouchers for social or services schemes which subsidise the employment of staff to carry out household tasks such as cleaning, ironing or gardening.
} 
An example of the PSD attempting to collate heterogeneous payment types into a homogenous framework, but having to provide carve-outs is that of money transfer services, or remittances via MTOs. If anything, these MTOs are examples of an autonomous payment service where there are ad hoc payments done without there being necessarily a contractual reason other than the sender wanting to send value to the recipient, say as a gift.

The PSD defines a 'money remittance' as:

'[A] payment service where funds are received from a payer, without any payment accounts being created in the name of the payer or the payee, for the sole purpose of transferring a corresponding account to a payee or to another payment service provider acting on behalf of the payee, and/or where such funds are received on behalf of and made available to the payee. ${ }^{148}$

This is further clarified by Recital 7 of the PSD, which in respect of a money remittance, says:

\begin{abstract}
'Money remittance is a simple payment service that is usually based on cash provided by a payer to a payment service provider, which remits the corresponding amount, for example via [a] communication network, to a payee or to another payment service provider acting on behalf of the payee. In some Member States supermarkets, merchants and other retailers provide to the public a corresponding service enabling the payment of utility and other regular household bills. Those bill-paying services should be treated as money remittance as defined in this Directive, unless the competent authorities consider the activity to fall under another payment service listed in the Annex.'
\end{abstract}

However, Recital 7 extends the traditional definition of an ad hoc simple value transfer to include billpaying at supermarkets, saying that ' $[\mathrm{t}]$ hose bill-paying services should be treated as money remittance as defined in this Directive ...'

While money transfers were included in Directive 2006/48/EC as a service that credit or other financial institutions could provide, the PSD brings them into the domain of regulation as autonomous entities providing a 'payment service' subject to authorisation. However, unlike other PSPs captured in the PSD who require a PA or equivalent to operate, the PSD does not include MTOs in the blanket need for a PA. Recitals 7 and 15 of the PSD allude to some of the reasons: first, many MTOs are entities whose core focus is not on financial services, for example, merchants, supermarkets and retailers for whom payment accounts would be an unnecessary burden and would have cost implications; however, there is concern that by not providing a flexible payment service regime to effectively exclude MTOs, there will be serious AML implications ${ }^{149}$ for the EC and it may possibly drive MTOs underground. ${ }^{150}$

\footnotetext{
148 Art 4(13) of the PSD.

${ }^{149}$ See Recital 15 which says in respect of AML concerns: 'Given the desirability of registering the identity and whereabouts of all persons providing remittance services and of according them all a measure of acceptance, irrespective of whether they are able to meet the full range of conditions for authorisation as payment institutions, so that none are forced into the black
} 
Art 3 of the PSD excludes from the scope of the PSD and of definition 3 in Art 4 a number of entities and services. ${ }^{151}$ Notable in the exclusions are those relating to services provided by technical service providers which support the provision of payment services. Further, certain Stored Value Products (hereafter SVPs) appear to be excluded insofar as they are:

'[S]ervices based on instruments that can be used to acquire goods or services only in the premises used by the issuer or under a commercial agreement with the issuer either within a limited network of service providers or for a limited range of goods or services.'

Further, Art 53 allows parties to exclude from the scope of the PSD low value individual payment transactions not exceeding $€ 30$ or which have either a spending limit of $€ 150$ or store funds which do not exceed $€ 150$ at any time. PSDs may also agree with their PSUs other specific derogations. ${ }^{152}$ For national

economy and bring all persons providing remittance service within the ambit of certain minimum legal and regulatory requirements, it is appropriate and in line with the rationale of Special Recommendation VI of the Financial Action Task Force on Money Laundering to provide a mechanism whereby payment service providers unable to meet all those conditions may nevertheless be treated as payment institutions.'

${ }^{150}$ As Malaguti also points out, the overriding AML and public policy concerns probably include MTOs in the PSD regime despite Recital 6 and Art 3(a) effectively excluding paper-based instruments from the scope of the PSD. MTOs of course often accept cash and cheques for the cash-in component, and provide a cash out facility for the recipient at their premises. Malaguti (2009) op cit note 1 at 9.

${ }^{151}$ The following are excluded (the abbreviation PSU below refers to 'Payment Services User'):

'(a) payment transactions made exclusively in cash directly from the payer to the payee, without any intermediary intervention; (b) payment transactions from the payer to the payee through a commercial agent authorised to negotiate or conclude the sale or purchase of goods or services on behalf of the payer or the payee; (c) professional physical transport of banknotes and coins, including their collection, processing and delivery; (d) payment transactions consisting of the non-professional cash collection and delivery within the framework of a non-profit or charitable activity; (e) services where cash is provided by the payee to the payer as part of a payment transaction following an explicit request by the PSU just before the execution of the payment transaction through a payment for the purchase of goods or services; (f) money exchange business, that is to say, cash-to-cash operations, where the funds are not held on a payment account; (g) payment transactions based on any of the following documents drawn on the PSP with a view to placing funds at the disposal of the payee: (i) paper cheques in accordance with the Geneva Convention of 19 March 1931 providing a uniform law for cheques; (ii) paper cheques similar to those referred to in point (i) and governed by the laws of Member States which are not party to the Geneva Convention of 19 March 1931 providing a uniform law for cheques; (iii) paper-based drafts in accordance with the Geneva Convention of 7 June 1930 providing a uniform law for bills of exchange and promissory notes; (iv) paper-based drafts similar to those referred to in point (iii) and governed by the laws of Member States which are not party to the Geneva Convention of 7 June 1930 providing a uniform law for bills of exchange and promissory notes; (v) paper-based vouchers; (vi) paper-based traveller's cheques; or (vii) paper-based postal money orders as defined by the Universal Postal Union; (h) payment transactions carried out within a payment or securities settlement system between settlement agents, central counterparties, clearing houses and/or central banks and other participants of the system, and payment service providers, without prejudice to Art. 28; (i) payment transactions related to securities asset servicing, including dividends, income or other distributions, or redemption or sale, carried out by persons referred to in point (h) or by investment firms, credit institutions, collective investment undertakings or asset management companies providing investment services and any other entities allowed to have the custody of financial instruments; (j) services provided by technical service providers, which support the provision of payment services, without them entering at any time into possession of the funds to be transferred, including processing and storage of data, trust and privacy protection services, data and entity authentication, information technology (IT) and communication network provision, provision and maintenance of terminals and devices used for payment services; (k) services based on instruments that can be used to acquire goods or services only in the premises used by the issuer or under a commercial agreement with the issuer either within a limited network of service providers or for a limited range of goods or services; (l) payment transactions executed by means of any telecommunication, digital or IT device, where the goods or services purchased are delivered to and are to be used through a telecommunication, digital or IT device, provided that the telecommunication, digital or IT operator does not act only as an intermediary between the PSU and the supplier of the goods and services; (m) payment transactions carried out between payment service providers, their agents or branches for their own account; (n) payment transactions between a parent undertaking and its subsidiary or between subsidiaries of the same parent undertaking, without any intermediary intervention by a PSP other than an undertaking belonging to the same group; or (o) services by providers to withdraw cash by means of automated teller machines acting on behalf of one or more card issuers, which are not a party to the framework contract with the customer withdrawing money from a payment account, on condition that these providers do not conduct other payment services as listed in the Annex.'

${ }^{152}$ For example, Art 53 - subject to the specific targeting provisions in that Art - allows the PSP and/or the PSU to exclude provisions fastening on obligations of the PSU in relation to PIs for loss or misappropriation if the PI does not allow it to be blocked or prevent its further use; that if the payment instrument is used anonymously or the PSP is not in a position for other 
payment transactions, Member States or their competent authorities may reduce or double the amounts referred to in Art 53 and may increase them for prepaid payment instruments up to $€ 500$.

In relation to MFS, there is a somewhat oblique reference to the potential participation of MNOs and Mobile Financial Service Providers (hereafter MFSPs) in Art 3(1) which refers to:

'...payment transactions executed by means of any telecommunication, digital or IT device, where the goods or services purchased are delivered to and are to be used through a telecommunication, digital or IT device, provided that the telecommunication, digital or IT operator does not act only as an intermediary between the PSU and the supplier of the goods and services.'

This provision should be read with the definition of 'Payment Services' in Art 4(3) and the Annex to the PSD which together include in the scope of the PSD the:

'... execution of payment transactions where the consent of the payer to execute the payment transaction is given by means of any telecommunication, digital or IT device and the payment is made to the telecommunication, IT system or network operator acting only as an intermediary between the payment user and the supplier of the goods or services. ${ }^{153}$

The test then to determine whether certain MNO activities are excluded from the scope of the respective Directives is whether the goods or services are delivered to the handset and add value. ${ }^{154}$

At a transactional level, the PSD favours mostly the PSU such that the payer's PSP is made to assume liability for correct payment execution including, in particular, the full amount of the payment transaction and execution time, and full responsibility for any failure by other parties in the payment chain up to the account of the payee. ${ }^{155}$

reasons which are intrinsic to the payment instrument to prove that a payment transaction was authorised; that the PSP is not required to notify the PSU of the refusal of a payment order if the non-execution is apparent from the context; that the payer may not revoke the payment order after transmitting the payment order or giving his consent to execute the payment transaction to the payee.

${ }^{153}$ As indicated above, this provision was inserted as a result of the controversy that arose from the use of the MNO airtime purse for WASP-type activities such that at (g) of Annex 1 to the PSD now specifically excludes MNOs who pursue such activities.

${ }^{154}$ On the applicability of PSD and EMD2 to MFS, see ch 9, s9.9 titled Application to MFS

${ }^{155}$ Preamble to PSD at 46. 
For a payment transaction to be valid there should be valid authorisation, the terms of which are set out in Arts 54-63 of the PSD. ${ }^{156}$ Article 54 specifies that a payment transaction will be considered to be authorised only if the payer has given consent to execute the payment transaction, which may be given by the payer prior to or, if agreed between the payer and his PSP, after the execution of the payment transaction. ${ }^{157}$ In the absence of such consent, a payment transaction is not unauthorised. ${ }^{158}$ The payment may however be blocked if, for example, agreed spending limits are reached by the payer. ${ }^{159}$ These must however be unblocked if the reasons for the blocking no longer obtain. ${ }^{160}$ Authorisation is generally not irrevocable nor given for an indefinite duration. ${ }^{161}$ It is only in connection with low value transactions that irrevocability by the payer appears to be allowed according to PSD, but subject to what would appear to be an ex ante agreement to this effect with the PSP. ${ }^{162}$ Article 54 allows for consent that may be withdrawn by the payer at any time, but no later than the point in time of irrevocability. There may be instances however where payments may be irrevocable, but these are usually after an ex ante agreement between the PSU and his PSP.

However where the payment transaction is initiated by or through the payee, the payer may not revoke the payment order after transmitting the payment order or giving his consent to execute the payment transaction to the payee. ${ }^{163}$ In the case of a direct debit, the payer may revoke the payment order at the latest by the end of the business day preceding the day agreed for debiting the funds. Consent to execute a series of payment transactions may also be withdrawn with the effect that any future payment transaction is to be considered as unauthorised. Generally though, even after the above time limits, the payment order may be revoked if agreed between the user of the payment service - also known as a PSU - and his PSP. ${ }^{164}$

Article 75 deals broadly with non-execution or defective execution such that where a payment order is initiated by the payer, his PSP shall ${ }^{165}$ be liable to the payer for correct execution of the payment transaction, unless he can prove to the payer and, where relevant, to the payee's PSP that the payee's PSP received the amount of the payment transaction. If not, the payee's PSP will be liable to the payee for the correct execution of the payment transaction as well as for any fees or interest. Similarly, where a payment order is initiated by or through the payee, his PSP shall be liable to the payee for correct transmission of the payment order to the PSP of the payer. ${ }^{166}$ In addition, payment service providers shall be liable to their

\footnotetext{
${ }^{156} \mathrm{Ch} 2$ of the PSD.

${ }^{157}$ Art 54(1).

${ }^{158}$ Art 54(2).

${ }^{159}$ Art 55(3).

${ }^{160}$ Art 55(4)

${ }^{161}$ Geva (2009b) op cit note 1 at 726.

162 See for example Art 53 where in the case of low value payment instruments and e-money where 'payment service providers may agree with their payment service users that at (d), by way of derogation from Art. 66, the payer may not revoke the payment order after transmitting the payment order or giving his consent to execute the payment transaction to the payee. A low value payment instrument is one which solely concerns individual payment transactions not exceeding $€ 30$ or which either have a spending limit of $€ 150$ or store funds which do not exceed $€ 150$ at any time.'

${ }^{163}$ Art 66(2).

${ }^{164}$ Art 66(5).

${ }^{165}$ And without prejudice to Arts 58, 74(2) and (3), and 78.

${ }^{166}$ Where the payee's PSP is liable under this section, he shall immediately re-transmit the payment order in question to the PSP of the payer.
} 
respective PSUs for any charges for which they are responsible, and for any interest to which the PSU is subject as a consequence of non-execution or defective execution of the payment transaction. ${ }^{167}$

For low value payment instruments and electronic money, there are specific information requirements. ${ }^{168}$

\section{Liability Allocation and Obligations of the Parties}

\subsection{Overview}

The PSD is the first EU law that has binding rules on the allocation of liability in case of fraudulent use of an electronic payment instrument. ${ }^{169}$ It fastens certain obligations on the PSU and PSP insofar as risk management and allocation of loss in cases of the fraudulent use of the instrument resulting from the loss or theft or cloning of the payment instrument or misappropriation by the PSU of the access Personal Identification Number (hereafter PIN) $\operatorname{codes}^{170}$ regardless of whether or not there is negligence by the PSU at play.

There is also a distinction made between loss allocation between a payment instrument that can be blocked by the PSU from further use and an 'offline' version that cannot be blocked. ${ }^{171}$ Art 53.3 , for example, says that the basic rules on liability in instances of the fraudulent use of electronic payment instruments also apply to electronic money instruments. ${ }^{172}$

Since the PSD is a maximum harmonisation ${ }^{173}$ Directive, there is very little leeway for increasing the liability of the parties when transposing the PSD into national law. ${ }^{174}$ Similarly, PSPs cannot impose more burdensome rules on PSUs than are allowed in the PSD.

\footnotetext{
$167 \operatorname{Art} 75(3)$.

168 Arts 34 and 53 specifically deal with derogation related to payment instruments which according to the framework contract, solely concern individual payment transactions not exceeding $€ 30$ or which either have a spending limit of $€ 150$ or store funds which do not exceed $€ 150$ at any time payment service providers may agree with their payment service users. In the case of Art 34, there is derogation from information requirements for e-money and these low-value payment instruments. In the case of Art 53, the payment user and PSP are released from certain obligations relating to use of and liability for unauthorised transactions, specifically those relating to Arts 56(1)(b) and 57(1)(c) and (d); Arts 59, 60, 61(10, (2), (4) and (5); Art 65(1); Art 66; Arts 56(1)(b) and 57(1)(c) and (d) as well as Art 61(4) and (5); Arts 59, 60 and 61(1) and (2); Arts 65(1) and 66, the payer may not revoke the payment order after transmitting the payment order or giving his consent to execute the payment transaction to the payee; Arts 69 and 70.

${ }^{169}$ Before the PSD there was the non-binding Recommendation 97/489/EC of 30 July 1997 concerning transactions carried out by electronic payment instruments and in particular the relationship between the holder and the issuer. However, it appears that Belgium was the only member state to formally transpose the Recommendation into legislation. Steennot (2010) op cit note 1 at 1 .

${ }^{170}$ See Art 61.2 of the PSD.

${ }^{171}$ See ch 9, s9.6.2.5.4 titled Effect of Fraud by the PSU below.

${ }^{172}$ Art 53(3) further says that the exception is where the payer's PSP does not have the ability to freeze the Payment Account or block the payment instrument. Member States may limit that derogation to payment accounts or payment instruments of a certain value.

${ }^{173}$ See ch 9, s9.4.2 titled Directives and Regulations on the significance of maximum harmonisation.

${ }^{174}$ They may however make it easier for PSUs. See ch 9, s9.6.2.5.6 titled Burden of Proof for Unauthorised Payments below on reducing the burden of proof for PSUs.
} 


\subsection{Obligations of the PSU}

Art 56 of the PSD specifies that the PSU must use the payment instrument in accordance with the terms governing the issue and use of the payment instrument and notify the PSP, or the entity specified by the latter, without undue delay on becoming aware of the loss, theft or misappropriation of the payment instrument or of its unauthorised use. The PSU must, as soon as he receives a payment instrument, take all reasonable steps to keep its personalised security features safe. ${ }^{175}$

\subsection{Obligations of the PSP}

Article 57 of the PSD indicates that the PSP issuing a payment instrument must ensure that the personalised security features of the payment instrument are not accessible to parties other than the PSU entitled to use the payment instrument; must refrain from sending an unsolicited payment instrument, except where a payment instrument already given to the PSU is to be replaced; and must ensure that appropriate means are available at all times to enable the PSU to make a notification of loss or request unblocking. On request, the PSP must provide the PSU user with the means to prove, for 18 months after notification, that he made such notification, and prevent all use of the payment instrument once notification of loss/theft is received.

Article 60 deals with cases of unauthorised payment transactions. Here, the PSU's PSP must immediately refund the PSU the amount of the unauthorised payment transaction. Any damages that may result from the misappropriation will be determined in accordance with the law applicable to the contract concluded between the PSU and the PSP. The extent of the protective clauses in Art 60 are, however, tempered by the time when the loss and subsequent transaction(s) took place and whether there was any gross negligence or fraud on the part of the PSU.

\subsection{Liability Allocation between the PSP and its Technical Providers}

While the PSD concerns only contractual obligations and responsibilities between the PSU and his PSP, Recital 47 indicates that for the proper functioning of credit transfers and other payment services, the PSP and its intermediaries such as processors should have contracts that ensure legal certainty such that their mutual rights and obligations are agreed upon, and which should include issues related to their respective liabilities. ${ }^{176}$

\subsection{Loss from Lost or Stolen Instruments}

\footnotetext{
175 The PSP bears the risk however of sending a payment instrument to the payer or of sending any personalised security features of it. Art 57(2).

${ }^{176}$ Recital 47 indicates that a non-responsible PSP should be compensated for losses incurred or sums paid under the provisions of the PSD relating to liability. Further rights and details of content of recourse and how to handle claims towards the PSP or intermediary attributable to a defective payment transaction should be left to be defined by contractual arrangements. Art 77 says that where the liability of a PSP for non-execution is attributable to another PSP or to an intermediary, that PSP or intermediary must compensate the first PSP for any losses. Further financial compensation may be determined in accordance with agreements between PSPs and/or intermediaries and the law applicable to the agreement concluded between them.
} 


\subsection{1 Loss for Transactions Pre-notification of Loss/Theft}

Article 61 says that by way of derogation from the PSP's liability for unauthorised transactions outlined in Art 60, the PSU bears the losses relating to any unauthorised payment transactions up to a maximum of $€ 150$ resulting from the use of a lost or stolen payment instrument, or, if the payer has failed to keep the personalised security features safe from the misappropriation of a payment instrument. ${ }^{177}$

\subsection{2 Loss for Transactions Post-notification of Loss/Theft}

Unless the PSU has acted fraudulently, he will not bear any financial consequences resulting from use of the lost, stolen or misappropriated payment instrument after timely notification to the PSP. ${ }^{178}$ It is up to the PSP however to ensure that there are means for the PSU to rapidly notify them of the loss/theft, ${ }^{179}$ and must be able to provide the PSU with a means to prove that he has made such notification. ${ }^{180}$ If however the PSP did not provide the PSU any appropriate means for the notification at all times of a lost, stolen or misappropriated payment instrument as required under Art 57(1)(c), the PSU will not be liable for losses from use of that payment instrument, except where the PSU acted fraudulently. ${ }^{181}$ However, it matters not that the loss/misappropriation was due to gross negligence ${ }^{182}$ of the PSU: all that matters is that there was timely notification to the PSP.

\subsection{3 Loss for Transactions of 'Offline' Payment Instruments}

The above scenarios of loss allocation presume that the PSP will somehow be locked by the PSU remotely or blocked from being used at a POS or some other transaction interface that authenticates the instrument. However, in cases where the payment instrument is merely an 'offline' version - such as a magnetic stripe or smartcard used at a 'dumb' offline terminal like a soft drink vending machine or parking garage that is not authenticated in real time and thus cannot be blocked, the loss is borne purely by the PSU. ${ }^{183}$ The loss of the instrument is the equivalent to the loss of cash.

\subsection{Loss from Cloned/Forged Payment Instruments}

The PSD, however, does not have any explicit rules on liability in cases where the PI is used fraudulently without physical presentation and electronic identification of the instrument at point of use or where the PI has effectively been cloned or forged. However, Recital 32 of the PSD says in this respect that the PSP

\footnotetext{
${ }^{177}$ See ch 9, s9.6.2.5.3 titled the Effect of Gross Negligence by the PSU.

${ }_{178}$ Art 61(4) of the PSD.

${ }^{179}$ Art 57 of the PSD. Art 61.5 contains a specific sanction in case the PSP does not fulfill its obligation to provide appropriate means to notify loss or theft.

${ }^{180}$ Art 57 of the PSD.

${ }^{181}$ Art 61(5).

${ }^{182}$ See ch 9, s9.6.2.5.3 titled Gross Negligence by the PSU.

${ }^{183}$ See ch 9, s9.6.2.5.4 titled Effect of Fraud by the PSU below.
} 
should be responsible for the technical security of its own products ${ }^{184}$ such that where a PI is somehow cloned or forged, the PSP is said to be the one that must bear the loss for use. This may be so with cardbased payment instruments where say the magnetic strip is easily copied and the instrument cloned, but in an MFS sense, however, the cloning could be done without the PSU ever having provided the phone - as a payment instrument - to someone to be able to copy it, for example, the use of the Nokia 1100 as a cloning device. $^{185}$

\subsection{Effect of Gross Negligence by the PSU}

In terms of Art 61.2, the PSU will bear all the losses relating to any unauthorised payment transactions if he incurred them by failing to fulfil one or more of his obligations under Art 56 with intent or gross negligence. Art 61.2 applies to all unauthorised transactions made as a result of this gross negligence and does not distinguish between loss, theft and misappropriation. ${ }^{186}$ In all such cases, the $€ 150$ maximum liability will not apply and the PSU will be liable for all amounts. ${ }^{187}$ However, gross negligence is not defined in the Directive and it is left to national law and, ultimately, the discretion of judges to decide. Steennot cites, however, some potential examples of gross negligence: Recording the access PIN such that the PIN is easily discovered; leaving the payment instrument in an environment where it can be used by unauthorised persons or stolen; last notification to the PSP once the PSU is aware of the loss/theft or unauthorised use of the PI. ${ }^{188}$

These are not however unequivocal examples of gross negligence as sophisticated hacking may still have taken place. ${ }^{189}$ The PSD makes some provision for this in assessing the burden of proof required to prove or disprove a transaction's authenticity. ${ }^{190}$

\subsection{Effect of Fraud by the PSU}

The maxim fraus omnia corrumpit is of trite application when there is fraud perpetrated by the legal owner of the payment instrument, either in the use of the payment instrument for purchasing goods and services, or in the use of counterfeit notes or stolen funds for use during the payment transaction or adding value to the Payment Account or e-money purse. ${ }^{191}$ In such cases, the $€ 150$ maximum liability will not apply and the PSU will be liable for all amounts. ${ }^{192}$ Criminal sanctions may follow under national law.

\footnotetext{
184 This is justified in civil law codes based on the so-called Sphären theory which says that he who is best capable or avoiding loss, must bear the risk of any loss. See Steennot (2010) op cit note 1 at 2 citing E Ulmer (1938) Das Recht der Wertpapiere.

${ }^{185}$ See ch 5, s5.7.4.2 titled Mobile Number Spoofing.

${ }^{186}$ In the case of (proven) misappropriation of the PIN code, for example, gross negligence will increase the PSU's potential liability. See ch 9, s9.6.2.5.5 titled Effect of Misappropriation of the PI or its Security Features.

${ }^{187}$ Art 61(2).

${ }^{188}$ Steennot (2010) op cit note 1 at 7.

${ }^{189}$ See ch 9, ss9.6.2.5.2.6 titled Loss from Cloned/ Forged Payment Instruments and 9.6.2.5.6 titled Burden of Proof for Unauthorised Payments.

${ }^{190}$ Ch 9, s9.6.2.5.5 on Burden of Proof for Unauthorised Payments.

${ }^{191}$ Steennot (2010) op cit note 1 at 6 .

${ }^{192}$ Art 61(2).
} 


\subsection{Effect of Misappropriation of the PI or its Security Features}

There may be instances where the PSU made it possible for details of the PI and its personalised access features to come into the hands of an unauthorised person. The details of a card number for example may be copied, or the PIN placed in an obvious place that effectively makes it accessible to the fraudster. This may be considered misappropriation by the PSU. Bearing in mind that under Art 59 the PSU can only be held liable if the PSP can prove that the transaction was authenticated (by say a PIN), where the PSU notifies the PSP only after the unauthorised use has been detected, the liability to the PSU is set at a maximum of $€ 150$. It is trite that - according to Art 61(4) - the PSU will not bear any financial consequences resulting from use of the lost, stolen or misappropriated payment instrument after notification in accordance with Art 56(1)(b). However if gross negligence is proven as outlined in terms of Art 59 relating to evidence on authentication and execution of payment transactions in that it resulted from the misappropriation, Art 61(2) says that there is no ceiling on the PSU's potential liability. It is similarly so in instances of fraud.

\subsection{Burden of Proof for Unauthorised Payments}

Article 59 of the PSD outlines the evidence required for proving or disproving the authentication and execution of payment transactions. Art 59(1) requires that Member States must implement rules that in cases where a PSU denies having authorised an executed payment transaction or claims that the payment transaction was not correctly executed, that the PSP must prove that the payment transaction was authenticated via its personalised security features like a PIN, ${ }^{193}$ accurately recorded, entered in the accounts and not affected by a technical breakdown or some other deficiency. As to the quality of that proof, Art 59(2) says that where a PSU denies having authorised an executed payment transaction, the use of a payment instrument recorded by the PSP is itself not necessarily sufficient to prove either that the payment transaction was authorised by the PSU, or that the PSU acted fraudulently or failed with intent or gross negligence to fulfill one or more of his obligations. Thus, even if a PIN was recorded as being entered and which then allowed the PI to be used in a transaction, this does not in and of itself mean that the PSU entered the PIN: there are well known instances where PIN capture by fraudsters has been successfully achieved, for example, by hidden cameras at ATMs and POS devices, or by hacking the seemingly impenetrable PIN input pad on a POS device. ${ }^{194}$

Similarly, in the sense of mobile financial services, 'Man in the Middle Attacks' on NFC-based transactions may capture streams of user data, including PINs. ${ }^{195}$ However, where the payment instrument - such as a Stored Value Account (hereafter SVA) containing a Store of Value (hereafter SOV) on a mobile phone using NFC for payment, say at a vending machine or transit hub - is mostly or totally offline and cannot be blocked by the PSP, the loss fastens totally on the PSU.

\footnotetext{
${ }^{193}$ Art 4(19) defines authentication as a 'procedure which allows the PSP to verify the use of a specific payment instrument, including its personalised security features.'

${ }^{194}$ See security aspects of MFS generally.

${ }^{195}$ See ch 5, s5.7.4.3 titled Man in Middle Attacks.
} 
The varying types of hacking possibilities may make the burden of proof stratified according to the payment instrument, which may however be too burdensome on unsophisticated users who are thrust into the technological limelight by the need to use payment instruments that they are unfamiliar with, or at least somewhat naïve as to the impenetrability of the payment instrument even when it is ostensibly under their control.

\subsection{Possible Reduction of PSU Liability}

The possibility of sophisticated hacking where the PSU is unaware that the security of his PI has been completely compromised until it is too late is recognised by Recital 33 which, when read with Art 59, effectively gives the PSU some benefit of the doubt when the evidence is equivocal by disallowing any contractual T\&C that would increase the burden of proof on the consumer or to reduce the burden of proof on the issuer.

This recognises many situations where it may be impossible to determine whether the PI was lost or stolen. ${ }^{196}$ Further, Art 62(3) allows member states when transposing the Directive into national law to reduce the PSU's liability in cases where he has neither acted fraudulently nor with intent failed to fulfil his obligations under Art 56 of the PSU. ${ }^{197}$

In doing so, the member state takes into account, in particular, the nature of the personalised security features of the payment instrument and the circumstances under which it was lost, stolen or misappropriated.

At the height of the Internet/Dotcom boom of the 1990s, the EU formulated and passed in 2000 what was then a very progressive Directive on the issuance and use of electronic money. The (first) Electronic Money Directive (hereafter EMD1) ${ }^{198}$ was adopted in response to the emergence of new prepaid electronic payment SVPs and was intended to create a clear legal framework designed to strengthen the internal market while ensuring an adequate level of prudential supervision.

In the EMD1, e-money was defined as:

‘ $[\mathrm{M}]$ onetary value as represented by a claim on the issuer which is:

\footnotetext{
${ }^{196}$ Steennot suggests that in these instances the PSP should be wholly liable as he is the party that is best placed to introduce technical solutions that further limit the risks of fraudulent use of the PI. See Steennot (2010) op cit note 1 at 9.

${ }^{197}$ Inter alia, to use the payment instrument in accordance with the T\&C, and to notify the PSP timeously on becoming aware of loss, theft or misappropriation of the payment instrument or of its unauthorised use, as well as securing the personalised security features.

${ }^{198}$ Directive 2000/46/EC of the European Parliament and of the Council of 18 September 2000 on the taking up, pursuit of and prudential supervision of the business of electronic money institutions.
} 
(i) stored on an electronic device;

(ii) issued on receipt of funds of an amount not less in value than the monetary value issued;

(iii) accepted as means of payment by undertakings other than the issuer ...'

This definition gave rise to a host of problems, specifically with regards to its applicability to the prepaid purses of MNOs who were ostensibly captured by the definition such that MNOs would have to register as e-money issuers. They objected vociferously, as was shown by the Guidance Note of the EC to MNOs in 2005 on the applicability of EMD1 to MNOs. ${ }^{199}$

In 2006, the EC reported on the success of EMD1 in the EU. ${ }^{200}$ It found that while the EMD1 encouraged the participation of nonbanks in the provision of e-money, only a small number of licenses to issue emoney had been granted and as such a true single market for e-money services in the EU had not developed as anticipated. The reasons were manifest: strict regulations that stifled the business case for e-money issuers, but pivotally, due to uncertainties arising from the application of the Directive within Member States $^{201}$ may have hindered innovation by creating a barrier for issuers to passport their e-money services into another Member State. ${ }^{202}$ Further, the definition of e-money in EMD1 was not technologically neutral and as such was inconsistent with prevailing business models, particularly when applied to prepaid purses operated by MNOs and used to purchase digital goods and services.

The result, the Commission found, was to create confusion and possibly bias by seemingly excluding certain businesses whose models may have approximated to e-money, in particular MNO prepaid purses.

It was noted also that MNOs specifically had not participated in the e-money arena as it may have affected the use of MNO prepaid airtime balances by their prepaid subscribers. ${ }^{203}$ The major issue touching on the redeemability of e-money balances on demand for par value was that the MNOs were unable to segment their customers' prepaid funds for basic mobile services - such as making phone calls - versus funds that could be used for e-money purposes such as payment for third party (digital) goods and services. This issue had been outlined in a Guidance Note by the EC to MNOs in 2005. ${ }^{204}$ The Commission considered that the redeemability provision was one of the reasons for the observed lack of MNO issuance of e-money and for MNO products remaining outside the EMD.

The Commission further noted that there was a lack of clarity surrounding how funds not redeemed should be treated. It was also felt that the Electronic Money Lending Institutions (hereafter EMLIs) were subject to

\footnotetext{
${ }^{199}$ European Commission (EC) (2005a) 'Application of the E-Money Directive to Mobile Operators: Guidance Note from the Commission Services', available at http://goo.gl/9iF3U.

200 European Commission (EC) (2006c) 'Evaluation of the E-Money Directive (2000/46/EC)', available at http://goo.gl/xBarE.

${ }^{201}$ The EMD1 was a minimum harmonising Directive, and Member States differed in their application of certain provisions within the Directive. The definition of e-money was also inconsistent between member states.

${ }^{202}$ The Commission indicated that this was as a result of the inconsistencies in the regulatory regimes between Member States.

${ }^{203}$ HMT (2009) op cit note 1 at 27.

${ }^{204}$ EC (2005a) op cit note 199.
} 
a disproportionate amount of regulation compared to broadly comparable institutions like banks; for example, EMLIs under EMD1 could not pay interest on balances, could not provide credit under any circumstances, and could not engage in any other business activity other than e-money issuance. In all, conditions and prudential requirements for granting and maintaining authorisation as EMLIs were not proportionate to the operational and financial risks faced by such bodies. ${ }^{205}$

The goal then was to reform the EMD1 to allow for a prudential regime that was proportional to the risk in being an EMLI, but structured so as to recognise the other (non-e-money) commercial activities carried out by the EMLI. This would balance the less cumbersome features of the prudential regime applying to EMLIs against those they applied (more stringently) to credit institutions such as banks, notably for the safeguarding of the funds of an e-money holder. ${ }^{206}$

Another major reason for a revision was the emergence of the PSD, and the similarity in many respects with the EMD1 insofar as the issuers of e-money could be considered PIs in the PSD. ${ }^{207}$ Indeed, for the most part, the SVP component of e-money was less about savings and more about using the SVP for payment transactions. It was felt then that the rules to which EMLIs were subject needed to be reviewed so as to ensure a level playing field for all PSPs: The goal then was to create a level playing field between authorised non-bank e-money issuers and authorised PIs (non-bank PSPs authorised under the PSD regime), while also creating an overall harmonised framework for the payments market in Europe.

In its assessment of the situation relating to the EMD1, the EC said of the EMD1:

'The E-Money market has ... evolved in ways which were not foreseen at the time of the Directive's adoption, 208

and that:

'[A]lthough a recent piece of legislative work, was arguably conceived at a time when it was difficult to foresee the potential for widespread and innovative uses of electronic purses'.,209

As a result, the Commission adopted a proposal in 2008 to repeal the EMD1 and to introduce a new Directive that had at its core the prudential regulation of e-money issuers, but with the objective of enabling innovation within the market to create tangible benefits for consumers, businesses and the EU.

The revised Electronic Money Directive was passed in 2009. ${ }^{210}$

\footnotetext{
${ }^{205}$ EMD2 Preamble at 13.

${ }^{206}$ Preamble to EMD2 at 14.

${ }^{207}$ And financial institution according to Directive 2006/48/EC as amended.

${ }^{208}$ EC (2006b) 'Commission Staff Working Document on the Review of the E-Money Directive (2000/46/EC)', available at http://goo.gl/1GuIG.

${ }^{209}$ European Commission (EC) (s.d.) 'Application of the e-Money Directive to Mobile Operators: Guidance Note from the Commission Services', available at http://goo.gl/9iF3U.

${ }^{210}$ EMD2 op cit note 108 .
} 
For the sake of convenience and comparison to the first Electronic Money Directive (EMD1), the revised (and second) Electronic Money Directive is hereafter referred to as the EMD2. ${ }^{211}$

\subsubsection{Second Electronic Money Directive}

\subsection{Overview}

The broad strokes of the provisions and principles of the EMD1 still obtain. Specifically, in relation to deposits, the Commission indicates that in view of its specific character as 'an electronic surrogate for coins and banknotes, which is to be used for making payments, usually of limited amount and not as means of saving', the issuance of e-money does not constitute a deposit-taking activity. ${ }^{212}$

There were some major changes. First, the definition of 'e-money' was changed to consider current and future uses of e-money. Second, the prohibition on an EMLI's ability to conduct other types of business that in effect could cross-subsidise their e-money business was removed. Third, onerous prudential requirements that stifled competition were relaxed; and fourth, there was a major alignment of the EMD2 with the PSD so as to homologise the activities of EMLIs now also acting as PSPs. ${ }^{213}$

\subsection{Scope}

As noted above, ${ }^{214}$ Art 1 of EMD2 refers to categories of electronic money issuer to which the Directive applies:

Further, an 'electronic money institution' is defined as:

'[A] legal person that has been granted authorisation under Title II to issue electronic money.'

An electronic money issuer' is then defined as being one of the entities referred to in Art 1(1). ${ }^{215}$

\footnotetext{
${ }^{211}$ Title I of EMD2 deals with scope and definitions. Title II deals with Requirements for the taking up, pursuit and prudential supervision of the business of electronic money institutions; Title III deals with issuance and redeemability of electronic money; while Title IV deals with final provisions and implementing measures. Art 21 of EMD2 repeals Directive 2000/46/EC with effect from 30 April 2011. The transitional provisions outlined in Art 18 of EMD2 mean inter alia that EMI that have taken up, before 30 April 2011, activities in accordance with national law transposing Art 8 of Directive 2000/46/EC, to continue those activities within the Member State concerned in accordance with Directive 2000/46/EC until 30 April 2012, without being required to seek authorisation under Art 3 of EMD2 or to comply with the other provisions laid down or referred to in Title II of EMD2. During that period, however, any EMI that has been neither authorised nor waived ${ }^{211}$ is prohibited from issuing electronic money.

${ }^{212}$ EMD2 Preamble at 13. Pursuant to Directive 2006/48/EC of the European Parliament and of the Council of 14 June 2006 relating to the taking up and pursuit of the business of credit institutions. The Commission recommends that credit institutions should, alternatively, be able to carry out that activity through a subsidiary under the prudential supervisory regime of the EMD2, rather than under Directive 2006/48/EC. See EMD2 Preamble at 25.

${ }^{213}$ This includes a new naming regime in line with the classifications and nomenclature used in the PSD.

${ }^{214}$ See ch 9, s9.6.2.2 on the PSD.

${ }^{215}$ The definition further indicates that they will be institutions benefiting from the waiver under Art 1(3) and legal persons benefiting from a waiver under Art 9.
} 
In relation to the definition of 'credit institutions' and 'financial institutions', it was felt that the definition in Directive 2006/48/EC on Credit Institutions should be amended to reflect the fact that although EMLIs could be classed as credit institutions, they neither gave credit to third parties from funds received from users, nor could their receipt of funds be classed as a deposit. ${ }^{216}$ Hence, in the EMD2, EMLIs are not classified as credit institutions ${ }^{217}$ as they were in EMD1, and are instead called 'financial institutions' as per the changes that the EMD2 makes to the Credit Institutions Directive 2006/48/EC. ${ }^{218}$ Insofar as the EMD2's relationship with the PSD is concerned, in recognition of the tight integration between the EMD2 and the PSD, many of the provisions in the PSD such as authorisation, ${ }^{219}$ accounting and statutory audit, ${ }^{220}$ outsourcing ${ }^{221}$ liability, record-keeping, competent authorities, supervision, professional secrecy, right to apply to the courts, exchange of information and 'passporting' are incorporated by reference, mutatis mutandis, into the EMD2. ${ }^{222}$

The nomenclature also changes, such that reference to 'payment institution' in the PSD should be read as a reference to Electronic Money Institution; a reference to 'payment service' needs to be read as a reference to the activity of payment services and the issuing of electronic money; while a reference to "payment service user' needs to be read as a reference to PSU and e-money holder. ${ }^{223}$ Further, operation of payment systems can be done by e-money institutions or any other payment institution. ${ }^{224}$

The EMD2 also limits its application only to PSPs that issue e-money, and not to a broad range of providers who may issue closed loop/limited-use payment instruments such as in transport or for photocopying. ${ }^{225}$ The new definition of e-money in EMD2 also limits this scope of application.

\subsection{New Definition of e-Money}

Consonant with the policy and nomenclature changes detailed above, the EMD2 uses a new definition of emoney.

\footnotetext{
${ }^{216}$ Preamble to EMD2 at 25 . However, credit institutions are still allowed to issue electronic money and to carry on such activity.

${ }^{217}$ Accordingly, Art 20 of EMD2 amended Art 4(1) of Directive 2006/48/EC defining a 'credit institution' as meaning 'an undertaking the business of which is to receive deposits or other repayable funds from the public and to grant credits for its own account'.

${ }^{218}$ Similarly, the EMD2 redefined a 'financial institution' in Directive 2006/48/EC to be 'an undertaking other than a credit institution, the principal activity of which is to acquire holdings or to pursue one or more of the activities listed in points 2 to 12 and 15 of Annex I.' The additional effect of this is that the provisions of the Banking Consolidation Directive that currently apply to ELMIs will no longer apply to ELMIs under the EMD2 regime.

${ }^{219}$ Art 5 and 10 of PSD.

${ }^{220}$ Art 15 of PSD.

${ }^{221}$ Art 17(7) of PSD

${ }^{222}$ Financial Services Authority (FSA) (2011a) 'E-money Directive', at 3.

${ }^{223}$ See EMD2 Preamble at (9). A reference to 'this Directive' needs to be read as a reference to both Directive 2007/64/EC and this Directive; a reference to Title II of Directive 2007/64/EC needs to be read as a reference to Title II of Directive 2007/64/EC and Title II of this Directive; a reference to Art 6 of Directive 2007/64/EC needs to be read as a reference to Art 4 of this Directive; a reference to Art 7(1) of Directive 2007/64/EC needs to be read as a reference to Art 5(1) of this Directive; a reference to Art 7(2) of Directive 2007/64/EC needs to be read as a reference to Art 5(6) of this Directive; a reference to Art 8 of Directive 2007/64/EC needs to be read as a reference to Art 5(2) to (5) of this Directive; a reference to Art 9 of Directive 2007/64/EC needs to be read as a reference to Art 7 of this Directive; a reference to Art 16(1) of Directive 2007/64/EC needs to be read as a reference to Art 6(1)(c) to (e) of this Directive; and a reference to Art 26 of Directive 2007/64/EC needs to be read as a reference to Art 9 of this Directive.

${ }^{224}$ EMD2 Preamble 12.

${ }^{225}$ Preamble to EMD at (5).
} 
E-money is now defined as:

'[E]lectronically, including magnetically, stored monetary value as represented by a claim on the issuer which is issued on receipt of funds for the purpose of making payment transactions as defined in point 5 of Art. 4 of Directive 2007/64/EC, and which is accepted by a natural or legal person other than the electronic money issuer. ${ }^{226}$

The definition was 'future-proofed' by crafting it widely and in technology neutral terms such that it is not of concern where the e-money is held, be it on an electronic device in the holder's possession such that it could be classed as a SVP, or whether it is held on a remote server that the holder accesses through an access device such as a mobile phone, or combinations of the two such as is the case with NFC. ${ }^{227}$ The fact that it is electronic and accepted as payment by third parties other than the issuer ultimately suffices. Further, if there was any equivocation, as there was in EMD1, to the applicability of the EMD2 to certain providers, Recital 6 of the EMD2 in almost the same terminology as the PSD explicitly ring fences the applicability: it says that where the good or service can be used only through a digital device, such as a mobile phone or a computer, and provided that the telecommunication, digital or information technology operator does not act only as an intermediary between the PSU and the supplier of the goods and services, then e-money is not at play. Specifically, it says, this would arise where a mobile phone or other digital network subscriber pays the MNO directly and there is neither a direct payment relationship nor a direct debtor-creditor relationship between the MNO's subscriber and any third-party supplier of goods or services delivered as part of the transaction. This, not surprisingly, was the same argument accepted by the Commission in the exemption of the MNOs' prepaid purses being designated e-money and thus being subject to the EMD1.

Applying, then, these PSD interpretations of 'not act only as an intermediary' mutandis mutatis to the EMS2's criteria, of 'the operator adds intrinsic value to it' ${ }^{228}$ the operator will not be classed as an EMLI/FI if the purchase of digital goods and services (via use of a prepaid purse) is a result of any 'value added' intermediation by the MNO with regard to, for example, how and when the subscriber obtained the digital goods and services which were purchased from a third party using the MNO's prepaid purse.

This carve-out is still the subject of debate, though, ${ }^{229}$ since it, like the PSD carve-out, causes a somewhat contrived and artificial differentiation between digital goods sold electronically (and used electronically), and physical goods sold electronically. ${ }^{230}$ The former scheme is exempt from the EMD2 as being e-money,

\footnotetext{
${ }^{226}$ Art 2(2) of EMD2.

${ }^{227}$ See generally the concerns about future business models for e-money issuers in the Preamble at 9 to the EMD.

${ }^{228}$ EMD2 Preamble at (6).

${ }^{229}$ See the comments from HMT who indicate that the EMD2 and PSD were not entirely clear in regard to their applicability to mobile payments. It is important that there is an objective test against which business models could be assessed. See Financial Services Authority (FSA) (2010b) 'Minutes of the First Meeting of the 2EMD Stakeholder Liaison Group held on 22 April 2010', available at http://goo.gl/0g9Qj.

${ }^{230}$ South African MNOs have the opposite view: they see themselves as intermediaries between the user and the WASP, taking a commission for facilitating any WASP transaction.
} 
while the latter payment scheme is not. ${ }^{231}$ Further, simply by adding access, search and distribution functionality to the transaction, miraculously the entire application of the EMD2 is removed. This also shifts the application of the definition to one based on relationships rather than on who is responsible for the user's funds. A similar criticism can be levelled at the almost identical carve-out in the PSD based on 'access, search and distribution facilities'.

\subsubsection{4 'Deposits'}

The receipt of funds by an EMLI does not constitute a deposit or other repayable funds if the funds received are immediately - 'without delay' - exchanged for electronic money. ${ }^{232}$ EMLIs cannot take deposits or other repayable funds from the public within the meaning of Art 5 of Directive 2006/48/EC. . $^{233}$ Such funds shall not constitute either a deposit or other repayable funds received from the public within the meaning of Art 5 of Directive 2006/48/EC. ${ }^{234}$ An e-money issuer must issue e-money at par value on the receipt of user funds.

As with the EMD1, all e-money must be redeemable at par at any time and without any minimum thresholds for redemption. ${ }^{235}$ This, says the Commission, is to preserve the confidence of the e-money holder. While it is desirable that redemption should be free, EMLIs can charge a proportionate cost-based fee for this facility. ${ }^{236}$ Redeemability however does not mean that the funds received in exchange for emoney should be regarded as deposits or other repayable funds for the purpose of Directive 2006/48/EC. The EMD2 does not place a time limit on redemption. Redemption should, in general, be granted free of charge. $^{237}$

The distinction between e-money stored with an EMLI or a credit institution, and a deposit held with a credit institution is also important. The recitals to the Commission's proposal further clarify that, in view of

\footnotetext{
${ }^{231}$ This was the view of the UK Department of Treasury in its consultation document in January 2009 entitled: 'Consultation on the Revision of the E-money Directive and Implementation of the EU Regulation on Cross-border Payments in Euro' asking for responses to the proposed revisions to the EMD, 'Q2: Do you agree that the exemption for digital payments could be further refined, with the aim of achieving technological neutrality between digital and material goods, and if so, how?' and 'Do you agree that the proposed new definition of e-money, and the exemptions for limited networks and digital payments where the operator is not acting only as an intermediary, are positive developments?' The FSA's initial view (until this was effectively overturned by the EC Guidance Note of 2006) was that MNOs did act as a payment intermediary and as such an EMI, using the prepaid funds in an MNO prepaid purse to pay WASPs. See HMT (2009) op cit note 1.

${ }^{232}$ Art 6(2) of EMD2.

${ }^{233} \operatorname{Art} 6(3)$ of EMD2.

${ }^{234}$ Art 6(3) of EMD2. Curiously, EMD2 does not specify, as EMD1 did, that the receipt of funds from the public in exchange for electronic money, which results in a credit balance left on account with the issuing institution, will constitute the receipt of deposits or other repayable funds.

${ }^{235}$ Art 11 of EMD2; see also Art 3(4) of EMD2 relating to the use of agents for the distribution and redemption of e-money.

${ }^{236}$ According to the Preamble to the EMD2 at 18, redemption can be facilitated without prejudice to national legislation on tax or social matters or any obligations on the electronic money issuer under other relevant Community or national legislation, such as anti-money laundering and anti-terrorist financing rules, or any action targeting the freezing of funds or any specific measure linked to the prevention and investigation of crimes.

${ }^{237}$ EMD2 permits the imposition of a redemption fee as long as it is clearly and prominently stated in the contract and only in one of the following situations: (i) where redemption is requested before termination of the contract; (ii) where the contract provides for a termination date, the electronic money holder terminates the contract before that date; or (iii) where redemption is requested more than one year after the date of termination of the contract. Any fee for redemption must be 'proportionate and commensurate' with the actual costs incurred by the electronic money issuer. It might not be easy to assess what would constitute a 'proportionate and commensurate' fee.
} 
the specific character of e-money as an electronic surrogate for notes and coins, e-money is only likely to be used for making payments of limited amounts, and not as a means of saving.

For this reason, the prudential regime for EMLIs must be proportionate to the operational and financial risks they face in the course of their business, rather than tied to the Capital Requirements Directive (hereafter CRD) on capital requirements for credit institutions. ${ }^{238}$ Like the EMD1 though, EMLIs are still not allowed to grant credit from the funds received for the purpose of issuing e-money nor are they allowed to grant interest or any other benefit, unless those benefits are not related to the length of time during which the e-money holder holds the e-money. ${ }^{239}$

\section{Use of Agents and Other Outsourcing Partners}

Although EMLIs are allowed ${ }^{240}$ to distribute e-money by selling or reselling e-money products to the public, providing a means of distributing e-money to customers, or of redeeming e-money on the request of customers or of topping up customers' e-money products, through natural or legal persons on their behalf, the EMD2, like the EMD1, prohibits them from issuing e-money through agents. ${ }^{241}$

However, in recognition of their role as PSPs under the PSD, the EMD2 allows EMLIs to provide payment services as defined in the $\mathrm{PSD}^{242}$ through agents and branches, where the conditions in Art 17 of the PSD relating to the use of agents, branches or entities to which their activities are outsourced. The agents must, however, be registered with the financial authority. ${ }^{243}$

The criteria around agent outsourcing include listing the agent's contact and management details with the competent authority in its Member State, as well as describing the internal control mechanisms to be used by agents in order to comply with the obligations in relation to money laundering and terrorist financing under the AML Directives. ${ }^{244}$ The authority may however refuse to register any agent if the listing details are incorrect or suspect or if there is a possibility of illegality at play. ${ }^{245}$ The specific enforcement powers

\footnotetext{
${ }^{238}$ The CRD (Directives 2006/48/EC and 2006/49/EC) came into force on 1 January 2007 and introduced a supervisory framework in the EU designed to ensure the financial soundness of credit institutions such as banks, building societies and certain investment firms and reflects the Basel II rules on capital measurement and capital standards. The Directives are available at http://goo.gl/gcEKY.

${ }^{239}$ Art 12 of EMD2; see also EMD2 Preamble 13.

${ }^{240}$ In terms of Art 3(4) of EMD2.

${ }^{241}$ Art 3(5) of EMD2.

${ }^{242}$ Listed in the Annex to Directive 2007/64/EC.

${ }^{243}$ See Financial Services Authority (FSA) (2011e) 'Minutes of the Meeting of the 2EMD Stakeholder Liaison Group', available at http://goo.gl/EbYks.

${ }^{244}$ Directive 2005/60/EC on the prevention of the use of the financial system for the purpose of money laundering and terrorist financing. See ch 9, s9.10 titled Anti-Money Laundering, Terrorist Financing and Customer Due Diligence Laws and Regulations.

${ }^{245}$ However, Art 17(6) says that if the competent authorities of the host Member State have reasonable grounds to suspect that, in connection with the intended engagement of the agent or establishment of the branch, money laundering or terrorist financing within the meaning of Directive 2005/60/EC is taking place, has taken place or has been attempted, or that the engagement of such agent or establishment of such branch could increase the risk of money laundering or terrorist financing, they must inform the competent authorities of the home Member State, which may refuse to register the agent or branch, or may withdraw the registration, if already made, of the agent or branch.
} 
of the supervisory authorities over agents however will depend on how the Member States implement the PSD in their national legislation. ${ }^{246}$

Art 3(j) in the negative scope of application of the PSD excludes from the PSD services provided by technical service providers, which support the provision of payment services, without them entering at any time into possession of the funds to be transferred, including processing and storage of data, trust and privacy protection services, data and entity authentication, IT and communication network provision, provision and maintenance of terminals and devices used for payment services.

Although they are separate initiatives, the PSD has some similarities to the self-regulatory initiative amongst payment providers in the EU's Single Euro Payments Area (hereafter SEPA). ${ }^{247}$

SEPA began as a voluntary initiative of the European banking industry to allow consumers, companies and other economic actors to make and receive payments in Euro, whether within or across national borders, with the same basic conditions, rights and obligations, regardless of their location. ${ }^{248}$

The goal of SEPA is thus to create an integrated, competitive and innovative retail payment market for all non-cash Euro payments, with such payments eventually being conducted entirely electronically.

The industry created a consortium, the European Payments Council, to develop the commercial and technical frameworks for payment instruments and generally to define how SEPA would work in practice.

\footnotetext{
${ }^{246}$ Reichwein and Rosati (2007) op cit note 1.

${ }^{247}$ For a quantitative overview of the workings and impact of the Single Euro Payments Area (SEPA), see W Bolt and H Schmiedel (2009) 'SEPA, Efficiency, and Payment Card Competition' December 30, ECB Working Paper No 1140, available at http://goo.gl/B2GuZ; and European Central Bank (ECB) (2009b) 'SEPA Brochure 2009' at 1, available at http://goo.gl/yt463.

${ }^{248}$ See ECB (2009b) op cit note 247.
} 


\subsubsection{Overview}

The 'payment institution' created in the PSD allows entities to compete with banks to provide payment services in the EU. ${ }^{249}$ This would allow MNOs and MFSPs - as payment institutions - to participate as PSPs if they meet the authorisation conditions for a PSP. This would allow PSPs to access many payment systems, although not necessarily core, systemic NPSs. They may also provide credit, although they may not use customer SVA SOV to fund these loans. ${ }^{250}$

The need for an MNO or MFSP to gain authorisation however is not necessary when applied to their bespoke business models.

In both the EMD2 and PSD instances, and with somewhat obtuse phraseology, there are provisions ultimately designed to ensure that MNOs who intermediate the sale of ringtones and other items from prepaid airtime purses and where those ringtones or similar goods can only be consumed on the mobile handset, are not captured either as a PSP or as an EMLI (or PI as it is known in the PSD).

\subsubsection{Applicability to MFS Models}

\subsection{MNO as SVP Provider}

In apparent recognition of the legal and regulatory equivocation that the EMD1 engendered as a result of MNO Wireless Application Service Provider-type (hereafter WASP) services first being captured by some authorities, but ultimately being exempted after a long period of consultation with MNOs and EMLIs, the EMD2 says that where the MNO provides its closed loop system to the user for the purchase of digital goods, under the EMD2 regime it would not be classed as an EMLI requiring a license if the conditions for e-money are met, if the value 'is accepted by a natural or legal person other than the electronic money issuer. $^{251}$

\footnotetext{
${ }^{249}$ Certain money transmitters, companies providing bill payment services, ATM operators and mobile phone operators may all constitute payment institutions. However, with the exception of Art 73, Titles III and IV shall apply only where both the payer's PSP and the payee's PSP are, or the sole PSP in the payment transaction is, located in the Community.

${ }^{250}$ Under the PSD, any credit provided by a payment institution has to be provided from the payment institution's own funds or monies that it has raised in capital markets, not from the funds received or held for the purpose of execution of a payment transaction. National supervisory authorities must also be satisfied that the own funds of the payment institution are appropriate to the overall amount of credit provided. See EC (2007d) op cit note 125; and Elsenhuber and Schimk (2006) op cit note 125. For an explanation of the distinction and hierarchical relationships between a SVP offered by an issuer, such as an MNO housing one or more SVAs and each with a specific SOV, see ch 2, s2.1 and Exhibit A.

${ }^{251}$ Art 2(2) of the EMD2.
} 
The rationale then is that since the SOV in an MNO's closed loop system is not accepted by others, it does not amount to e-money, and so as to avoid any equivocation in the EMD2 e-money definition, the preamble to EMD2 attempts to lay any equivocation to rest by further refining e-money to (only) be :

' $[\mathrm{M}]$ onetary value that is used to purchase digital goods or services, where, by virtue of the nature of the good or service, the operator adds intrinsic value to it. ${ }^{252}$

Thus where there is 'intrinsic value' - which again may be provision of access to a service - then the MNO is not bound. The SVP thus is excluded from the EMD2 insofar as digital goods and services are concerned.

This view is very similar to the exclusion clause in the PSD that has a direct bearing on which MNO activity, if any, is captured under the PSD as being a 'Payment Service. ${ }^{253}$ The exclusion is phrased positively at Art 3(1) which describes a 'Payment Service' as:

'[P]ayment transactions executed by means of any telecommunication, digital or IT device, where the goods or services purchased are delivered to and are to be used through a telecommunication, digital or IT device, provided that the telecommunication, digital or IT operator does not act only as an intermediary between the PSU and the supplier of the goods and services. ${ }^{254}$

There are thus two requirements that would trigger the exemption of an MNO or MFSP from the provisions of the PSD and EMD2: First, the goods or services purchased via the handset used as a payment instrument must be delivered through a telecommunications, digital or IT device. Thus if a digital good or service like a ringtone, subscription service or some other purchase like a competition entry is published on the handset, this would trigger the exemption. ${ }^{255}$ Secondly, according to Preamble 6 of the PSD, the telecommunication, digital or IT operator must add value to the process of that digital purchase for the exemption to be fully operable. ${ }^{256}$ Where, then, the MNO acts as an intermediary between the PSU and the supplier of the goods and services, the second criteria for the exemption is not met and the MNO would be captured. The exclusion is justified in terms of Recital 6 where it is said that where digital goods or services are produced

\footnotetext{
${ }^{252}$ EMD2 Preamble at (6).

${ }^{253}$ Many provisions of the Payment Services Directive (PSD) apply mutatis mutandis to the EMD2. In the UK, under both the current and the new electronic money regimes, electronic money issuers must comply with the applicable conduct of business requirements in the Payment Services Regulations 2009. See Financial Services Authority (FSA) (2009b) op cit note 130. See generally also Financial Services Authority (FSA) (2011f) 'The FSA's role under the Electronic Money Regulations 2011: Our approach,' available at http://goo.gl/7USnQ.

${ }^{254}$ Art 3(1) of the PSD.

${ }^{255}$ As Steennot (2010) op cit note 1 at 11 points out, this use of the phone for the purchase of soft drinks or food would negate this part of the exclusion.

256 'Adding value', according to the FSA's interpretation of the PSD Art 3(1) exclusion relating to MNOs, would be, for example, where the mobile-based transaction resulted from a search for the item say through a WAP portal, and ultimately the ringtone found and bought as a result of that search was then delivered to and used on the handset. The MNO would not be captured in this instance as a payment service as the transaction came about from the added 'value' of the search provided by the MNO. The MNO then, in PSD terminology, 'does not act only as an intermediary'. It is trite also that the MNO would not be captured if a subscriber uses his mobile device merely as an authentication tool to execute payment from his bank account by simply providing instructions to his bank via SMS or via WAP, and where the MNO in this instance has not transmitted any identifiable or actionable payment information per se. In other words, the MNO is acting purely as a bearer. A mobile prepaid recharge would also not fall under this arrangement as a payment service. Analysis from interpretation of the contents of a Personal Communication received from the FSA by email by the researcher on 15 July 2010; see also Financial Services Authority (FSA) (2009a) 'op cit note 145 at 16-17.
} 
either by a third party or by the MNO, the MNO would be excluded if he adds intrinsic value to them in the form of access, distribution or search facilities and where they can be used only through a mobile phone, the PSD's legal framework should not apply as the activity of the operator goes beyond a mere payment transaction. ${ }^{257}$ However, Recital 6 indicates that the PSD should apply where the MNO acts only as an intermediary who simply arranges for payment to be made to a third-party supplier.

The EMLI/FI, when acting as a PSP has manifestly the same criteria as to what entities are subject to the PSD as any of the PSD's provisions apply mutatis mutandis to the EMD2. ${ }^{258}$ The test then in both cases that is, the EMD2 and PSD exclusions of certain MNO activity from the scope of the respective directives is whether the goods or services are delivered to the handset and whether they add value.

The limit to the exemption of these specific-purpose instruments is where the instrument develops into a general-purpose instrument. ${ }^{259}$

\subsection{MNO-Only}

Looking at the PSD and its contrived definition of a PSP - using the somewhat arbitrary criteria given by the EC and the PSD Recital 6 and the negative scope in Art 3(1) - it appears that the MNO using its airtimebased (and also possibly any) fiat-based SVA does not qualify as a PSP for two salient reasons: First, the MNO if it provides simple access to services, distribution and possibly even adds some other value like a search function to any of the services it may offer its users, this would exempt it. Second, where the SVA is based on funds placed in a pooled bank account under the name of the MNO (or even a Trust Company) account, this is averse to the definition of a 'Payment Account' in Art 4(14) of the PSD which defines it as 'an account held in the name of one or more payment service users'. Hence, since the pooled account has only one name, the account is not a PA.

Despite these obvious legal equivocations from this assessment, practically however it is probable that the EC may yet have a basis for requiring a MNO using pooled accounts and who provide customer-facing

\footnotetext{
${ }^{257}$ The 'access' criteria, it is submitted, appear to be an extremely wide derogation - indeed, a catch-all one at that especially when 'access' according to Recital 6 is used as a trigger for the exclusion. That is because the entire raison d'être of an MNO is access to facilities. There is no access to any third party goods and services without access provided by the MNO. It is trite also that the MNO would not be captured if a subscriber uses his mobile device merely as an authentication tool to execute payment from his bank account by simply providing instructions to his bank via SMS or via WAP, and where the MNO in this instance has not transmitted any identifiable or actionable payment information per se. In other words, the MNO is acting purely as a bearer. Where the MNO would be captured as a payment service under Annex 1, par 7 of the PSD, however, is where customer consent to execute payment is provided by means of the mobile device provided by the MNO and the MNO receives payment for transmission to a supplier of goods and services, acting only as intermediary between the PSU and supplier. In practice then, for example, where an SMS is delivered after a transaction to the handset which acts as a ticket/PIN or other means of access to goods or services and where that payment process has not added value to the actual handset per se - such as being able to use on the handset the goods or services bought, like a downloaded ringtone - and where in this instance the MNO acted 'only as an intermediary and did not only add value (such as a search function to discover the product ultimately bought)', receiving payment from the PSU to pay for the goods or service. In this instance, the MNO would be captured as it provided a payment execution service to its subscribers. See Financial Services Authority (FSA) (2009a) op cit note 145 at 16-17.

${ }^{258}$ COB provisions of PSD apply to EMLIs' payment services. See D Peachy (2010) 'Key Changes in the Second Electronic Money Directive E-Money Stakeholder Liaison Group Meeting 22 April 2010', available at http://goo.gl/G7aW3.

${ }^{259}$ As an example, it specifically mentions instruments which can be used for purchases in stores of listed merchants and which should not be exempted from the scope of EMD2 as it says such instruments are typically designed for a network of service providers which is continuously growing.
} 
services to obtain authorisation as a PSP. ${ }^{260}$ Whatever the relationship in regard to payments, though, the user will also simultaneously have a relationship with the MNO insofar as its technical provision of telecommunications services, and which would be subject to the EU's telecommunications regimes. ${ }^{261}$ If however the MNO is found to be a PSP (as a PI), then it will be subject to the authorisation requirements of the PSD, as well as being subject to Art 9 of the PSD's safeguarding requirements such that they would have to either segregate user funds or adequately insure them. The MNO/MFSP may however act as an agent of a PSP. ${ }^{262}$

\subsubsection{3 \\ Bank-Only}

In the MFS model where a bank has its own 'additive' MFS facilities, but where the bank has a cooperation agreement with an MNO or WASP to provide some technical services like a link to the MNO's Short Message Service Centre (hereafter SMSC) for bulk-sending of SMS transaction alerts, then the MNO is not captured - unlike the bank as a PSP - by the PSD ${ }^{263}$ Where however the bank uses non-MNOs as agents, then again these gents would also be subject to Art 17 of the PSD and would need to be authorised. Again, where the MNO is involved in technical services provision, that relationship will be subject to the EU's telecommunications regime. ${ }^{264}$

\subsection{Hybrid MNO-Bank}

Where the MNO and a bank as a PSP have a joint venture for cooperation in provision of MFS services, such that the MNO provides technical services as well as agent services, then the derogation allowed for in Art 3(j) is trumped by Art 17 of the PSD with regard to the general authorisation allowing a PSP to outsource operational functions, since the MNO is now no longer just a mere technical service provider. ${ }^{265}$ This would also invoke Art 18 in regard to connected liabilities.

The exact legal liabilities however would be determined by the legal structure agreed upon between the bank and the MNO with regard to both technical outsourcing and use as an agent. Indeed, in this instance the bank is the PSP as part of its general authorisation as a credit institution and the MNO (and its agents) are mere agents of the bank. While the PSP has an agency relationship with the MNO (or its own agents), again, there will be a user relationship that will be subject to the EU's telecommunications regimes. ${ }^{266}$

\footnotetext{
${ }^{260}$ See also Malaguti (2009) op cit note 1 at 17 who believes that there is a policy and possibly legal justification for proclaiming the MNO as the PSP since, she believes, that it qualifies as such by interposing itself between the customers and the bank and enters into possession of the customers' money to execute payment transactions and provides concrete transactional functions like managing the pooled account, operating reconciliation in a way that is not under the control of the bank and of which the bank has no trace.

${ }^{261}$ See ch 9, s9.11 titled Telecommunications Laws and Regulations below.

${ }^{262}$ See ch 9, s9.9.1.2.5 below on Use of Agents.

${ }^{263}$ The exclusion is determined by Art 3(j) which excludes services provided by technical service providers who do not have access to any funds.

${ }^{264}$ See ch 9, s9.11 below titled Telecommunications Laws and Regulations.

${ }^{265}$ An alternative view may be that when the customer has a bank account, the MNO is not a PI, because all transactions occur through the bank. Of course, it could be argued that the customer has a direct relationship with the MNO and that s/he is its client. Still, the MNO acts as an agent of the bank and it is through this role that it presents itself to the client, who will have two different contractual relationships with the MNO according to the services entailed (either payment or voice mail).

${ }^{266}$ See ch 9, s9.11 below titled Telecommunications Laws and Regulations.
} 


\subsubsection{5}

\section{Use of Agents}

As indicated above, the PSD makes provision for the roles and responsibilities of agents in various scenarios. This may be on an 'agency' or 'outsourcing' basis as provided for in Art 17 of the PSD but which, in the absence of precise demarcations, may amount to the same thing. ${ }^{267}$ In this respect, the business models cited above point to how agents may fit into relationships with MFSPs, MNOs and banks in the EU and whether or how the PSD may regulate these relationships. The agents though in an EU context will probably be one in an 'additive' context, rather than a 'transformational' context where there is no bank - or credit institution in EU parlance - to speak of. Unless of course there is a wholesale registering by MNOs as PIs so as to become PSPs, what is most likely - in the face of the overwhelming number of existing bank accounts in the EU compared to the more transformational nature found in developing nations - is that an MNO or MFSP will act as agents of a bank as a PSP, rather than there being a number of agents of the MNO/MFSP.

Thus, as an agent of the bank or any PSP, the MNO as a non-PSP providing payment services on behalf of the PSP would need, in terms of Art 17 of the PSD, to be authorised to provide any of these outsourcing functions or to provide services as agents of the PSP. ${ }^{268}$ These (outsourcing) agents - which could also possibly extend past the MNO to its own agents who are now agents of a bank as a PSP ${ }^{269}$ - would then also be subject to the connected liabilities specified in Art 18 of the PSD. ${ }^{270}$ The MNO will also have contractual arrangements with agents that provide the cash-in/cash out facilities as well as merchants who participate in the MNO scheme. In this scenario, it may be asked who the PSP, agent and outsourcing provider (individually) are?

\subsubsection{6}

\section{Use of Trust Accounts}

Trust accounts in MFS are features of transformational MFS in developing nations in scenarios where a user has no bank account per se, and instead provides its funds to an MNO who then places the user's funds amongst a pool of funds in the MNO or a trust company's name. If, in an EU and PSD context, the MNO is found to be a PSP (as a PI), then it will be subject to the authorisation requirements of the PSD, as well as be subject to Art 9 of the PSD's safeguarding requirements such that it would have to either segregate user funds or adequately insure them. ${ }^{271}$

\footnotetext{
${ }^{267}$ Art 17(7) of the PSD refers to 'outsourcing of important operational functions' of payment services.

${ }^{268}$ The Payment Institution has the responsibility to apply for registration on an agent's behalf, at least in the UK. See Financial Services Authority (FSA) (2009b) op cit note 130. See also Art 17(1) of the PSD on the use of Agents and Outsourcing.

${ }^{269}$ Agents so authorised in terms of Art 17(1) of the PSD after application by the PSP. It is likely then that the PSP - and not the MNO - (can and) must apply for the authorisation for the use of agents by the MNO where these ultimately directly involve payment services offered by that PSP.

${ }^{270}$ Art 18 of the PSD in respect of liability says that where payment institutions rely on third parties for the performance of operational functions, those payment institutions take reasonable steps to ensure that the requirements of the PSD are complied with and that payment institutions remain fully liable for any acts of their employees, or any agent, branch or entity to which activities are outsourced.

${ }^{271}$ The safeguarding provisions are intended to prevent customer losses in the event of an insolvency of an authorised Payment Institution. Art 9 says that the funds shall not be commingled at any time with the funds of any natural or legal person other than payment service users on whose behalf the funds are held and, where they are still held by the payment
} 
In addition to the safeguarding provisions, the UK FSA also requires a PI to adhere to capital requirements which include 'own funds' in an amount of initial capital specified by the FSA, or an amount of the entity's own funds requirement calculated by the FSA subject to any adjustment directed by the FSA, whichever is greater. ${ }^{272}$ The value of these capital requirements are related on a proportional risk basis to the types of authorised activities of the PI.

\title{
Part II. Additional Statutory Oversight Related to MFS
}

\author{
Anti-Money Laundering, Terrorist Financing, Customer Due Diligence Laws and \\ Regulations
}

9.10 .1

Overview

As with other jurisdictions, the EU has passed the first of a number of AML Directives in 1991. The first AML Directive in $2001^{273}$ introduced the first customer identification obligations. In terms of the Directives, Member States had to ensure that credit and financial institutions ${ }^{274}$ required customer identification by means of supporting evidence when entering into business relations, particularly when opening an account or savings account, or when offering safe custody facilities. Where there was doubt that the customer was acting on its own behalf, reasonable measures had to be taken to obtain information that verified the customer's real identity. ${ }^{275}$

The second Money Laundering Directive in $2001^{276}$ enlarged the scope of the institutions and persons to which the rules are applicable, but did not give further details on identification or verification procedures. It introduced the term 'non-face to face customers' and required those institutions and persons subject to the Directive to take necessary, specific and adequate measures to compensate for the greater risk of Money

\footnotetext{
institution and not yet delivered to the payee or transferred to another payment service provider by the end of the business day following the day when the funds have been received, they shall be deposited in a separate account in a credit institution or invested in secure, liquid low-risk assets as defined by the competent authorities of the home Member State; and they shall be insulated in accordance with national law in the interest of the payment service users against the claims of other creditors of the payment institution, in particular, in the event of insolvency. Or the funds shall be covered by an insurance policy or some other comparable guarantee from an insurance company or a credit institution, which does not belong to the same group as the payment institution itself, for an amount equivalent to that which would have been segregated in the absence of the insurance policy or other comparable guarantee, payable in the event that the payment institution is unable to meet its financial obligations.

${ }^{272}$ The FSA for example specifies a range of $€ 20,000$ to $€ 125,000$ in capital for a Payment Institution. See FSA (2010a) op cit note 15 at 18 .

${ }^{273}$ Directive 91/308/EEC, available at http://goo.gl/Om9LD.

274 'Credit Institution' means a credit institution as defined in the first subpar of Art 1(1) of Directive 2000/12/EC of the European Parliament and of the Council of $20^{\text {th }}$ March 2000 relating to the taking up and pursuit of the business of credit institutions.

${ }^{275}$ European Commission (2009) 'The EU Compendium Paper on AML supervisory practices' 2 EU AML Info-Letter December, available at http://goo.gl/UzhWB; and 3L3 Anti Money Laundering Task Force (2009) 'Compendium Paper on the Supervisory Implementation Practices across EU Member States of the Third Money Laundering Directive [2005/60/EC] $15^{\text {th }}$ October 2009', available at http://goo.gl/2nwqA.

${ }^{276}$ Directive 2001/97/EC, available at http://goo.gl/bszk5.
} 
Laundering (ML). The Third Money Laundering Directive ${ }^{277}$ (hereafter TMLD) repealed previous Directives ${ }^{278}$, and introduced specific and detailed provisions relating to customer identification and the verification of identity. ${ }^{279}$ There are also on information on the payer accompanying transfers of funds. ${ }^{280}$ This latest version also incorporates the Recommendations of the Financial Action Task Force (hereafter FATF ${ }^{281}$ for combating money laundering and the financing of terrorism. ${ }^{282}$ Inter alia, institutions are expected to know their customers and use this knowledge to prevent and detect suspicious transactions that could amount to ML and/or Terrorist Financing (hereafter TF). ${ }^{283}$ Member States had to transpose TMLD and its implementing measures into national law by December $2007 .^{284}$

The interplay between the FATF and financial regulation can be seen in the numerous references to the TMLD in the EC wire transfer regulation, ${ }^{285}$ specifically on provision of information on the payer accompanying transfers of funds to further facilitate the traceability of money transfers. The Regulation lays down rules for payment service providers to send information on the payer throughout the payment chain for the purpose of the prevention, investigation and detection of money laundering and terrorist financing. The PSD also requires that applicants for authorisation must provide a description of the internal control mechanisms that they will establish in order to comply with the AML rules. ${ }^{286}$ This also applies to the use of agents by PIs. ${ }^{287}$

\subsubsection{Application to MFS}

While its potential for cost reduction and financial inclusion has been noted, the use of MFS has also been seen as providing an increased risk factor for ML and fraud. The EU Payments Regulation with its incorporation of the FATF Recommendations on wire transfers, effectively projected financial surveillance

\footnotetext{
${ }^{277}$ Directive 2005/60/EC,s available at http://goo.gl/gck7X. Directive 2006/70/EC outlined implementation measures, available at http://goo.gl/hSxAj.

${ }^{278}$ It repealed Directive 91/308/EEC and Directive 2001/97/EC.

${ }^{279}$ See Art 6-9 of Directive 2005/60/EC.

${ }^{280}$ Regulation (EC) No 1781/2006 of the European Parliament and of the Council of 15 November 2006 on information on the payer accompanying transfers of funds. This Regulation aims to transpose into Community legislation Special Recommendation VII on 'wire transfers' (SR VII) of the FATF. It lays down rules aimed at establishing the traceability of transfers of funds and is applicable to all PSPs involved in the payment chain. It does not apply to transfers of funds which flow from a commercial transaction carried out using a credit or debit card or any other similar payment instrument, provided that a unique identifier allowing the transaction to be traced back to the payer accompanies all transfers of funds and that the beneficiary has entered into agreement with the PSP enabling the payment of the provision of goods and services.

${ }^{281}$ See Reichwein and Rosati (2007) op cit note 1.

282 'Since the FATF Recommendations were substantially revised and expanded in 2003, this Directive should be in line with that new international standard' ( $O J$ L 309, 25 November 2005, at 15).

${ }^{283}$ Art 8 Directive 2005/60/EC.

${ }^{284}$ Some member states had partially implemented it, or not at all, by the deadline and some were referred to the ECJ for their failure to do so. See updated detail on implementation of the AML Directives and Regulations, see EC (2011i) 'Transposition of the 3rd Anti-Money Laundering Directive: State of Play', available at http://goo.gl/MLJU2 .

285 Regulation (EC) No 1781/2006 of the European Parliament and of the Council on information on the payer accompanying transfers of funds was adopted in December 2006 to transpose Special Recommendation VII (SRVII) of the FATF into EU law.

${ }^{286}$ See FSA (2010a) op cit note 15 at 21.

${ }^{287}$ See the PSD Art 17 on Agents.
} 
into the official/formal money transfer business sector. ${ }^{288}$ There are also provisions in the PSD where agents of PSPs will have to abide by the AML Directives. ${ }^{289}$

Even though MNOs may be the predominant facilitators of remittances, in the UK for example, there are several Money Service Businesses (hereafter MSBs) that may engage in Money Transfer. ${ }^{290}$ Their regulation however is fragmented: as Vlcek notes, responsibilities are split between Her Majesty's Revenue and Customs (hereafter HMRC) and the FSA, where the FSA is responsible only for those firms that also provide a service that is already regulated by the FSA which means that most small and medium-sized MSBs are regulated by HMRC. ${ }^{291}$ While all MSBs are covered by the Money Laundering Regulations, those regulated by HMRC are further subject to HMRC notices and guidance on Money Laundering, ${ }^{292}$ whereas those regulated by the FSA follow the Joint Money Laundering Steering Group (hereafter JMLSG) Guidance Notes. ${ }^{293}$ The potential impact on remittances and the ability to provide them relatively cheaply compared to banks though is such that UK banks with international wire transfer facilities were reportedly so concerned about whether those MSBs were engaging in ML that they closed their accounts. ${ }^{294}$

Notably though, the Regulation on information on the payer accompanying transfers of funds does not apply to transfers of funds carried out via a mobile phone or any other digital device linked to Information Technology (hereafter IT), when the payments are post-paid and insofar as the PSP must comply with the obligations in the TMLD. ${ }^{295}$ As Vlcek ${ }^{296}$ notes, the AML and Counter Terrorism (hereafter CT) provisions in all these regulations provide for increased data collection, but do not automatically fully 'prevent' terrorists and other criminals from having access to payment systems for moving their funds. ${ }^{297}$

Instead, these regulations only serve to establish an audit trail that may be followed once a suspected terrorist or terrorist organisation has been identified. Regulation (EC) No 1781/2006 on the payer

\footnotetext{
${ }^{288}$ W Vlcek (2006b) 'Development vs. Terrorism: Money Transfers and EU Financial Regulations in the UK' 10(2) The British Journal of Politics \& International Relations 286-302 at 288.

${ }^{289}$ See the Preamble to the PSD at 11, 13, 29 and 58; as well as Arts 5(f) and 26 on Conditions for Authorisation; Art 17(6) on PSP agents; and Art 24 on Exchange of Information.

${ }^{290}$ The UK Money Transmitters Association (UKMTA) had indicated that there were 1,400 registered money transfer firms operating with 10,000 registered premises in 2006. See these statistics cited in W Vlcek (2006a) 'Development v. Terrorism - Migrant Remittances or Terrorist Financing,' available at http://goo.gl/wYD4o.

${ }_{291}$ These include Money Service Businesses, High Value Dealers, Trust or Company Service Providers, and Accountancy Service Providers. For a detailed discussion, see Vlcek (2006b) op cit note 288 at 293.

${ }^{292}$ For the latest version of these notices and guidance, see Her Majesty's Revenue and Customs (HMRC) (2011) 'Detailed Guidance,' available at http://goo.gl/eloGY.

${ }^{293}$ The Joint Money Laundering Steering Group (JMLSG) is made up of the leading UK Trade Associations in the Financial Services Industry. Its aim is to promulgate good practice in countering money laundering and to give practical assistance in interpreting the UK Money Laundering Regulations. This is primarily achieved by the publication of industry guidance. JMLSG has been producing Money Laundering Guidance for the financial sector since 1990. Its latest Guidance was published in 2009. See further on the JMLSG at http://www.jmlsg.org.uk.

${ }^{294}$ Vlcek (2006a) op cit note 288.

295 See European Commission (EC) (2011f) 'Information on the Payer Accompanying Transfers of Funds', available at http://goo.gl/NQihO, in relation to summarising Regulation (EC) No 1781/2006 of the European Parliament and of the Council dated 15 November 2006 on information on the payer accompanying transfers of funds.

${ }^{296}$ Vlcek (2008b) op cit note 288 at 288-289.

${ }^{297}$ See this problem identified in the opening paragraph of the Third Money Laundering Directive (TMLD): 'All those measures [in the Directive] do not, however, fully prevent terrorists and other criminals from having access to payment systems for moving their funds'.
} 
accompanying transfers of funds has the effect of extending aspects of financial surveillance into the official/formal money transfer business sector. ${ }^{298}$

The EU has designed a new set of rules to make telecommunication services more affordable, more competitive, more accessible and more diverse in their application, based on the emergence of new technologies like Third Generation Mobile Networks (hereafter 3G).

\subsection{Telecommunications Laws and Regulations}

\subsubsection{Laws and Regulations}

To keep up with technological progress and market requirements, ${ }^{299}$ the EU since 2002 has adopted a new regulatory framework ${ }^{300}$ on electronic communications, the main aim of which is to strengthen competition by making market entry easier and by stimulating investment in the sector previously reserved for oligopolies. Regulation of the ICT sector in the EU is subject to a set of Directives and other legal instruments that together comprise the regulatory framework.

The new framework consists of seven Directives and related documents in connection with ICT regulation and is bracketed by the 'Framework Directive' ${ }^{301}$ which forms part of the Telecommunications Package designed to recast the existing regulatory framework for telecommunications so as to allow for a flexible regulatory framework capable of responding to new technologies, convergence, and an increasingly competitive market. ${ }^{302}$ There is also the Access Directive; ${ }^{303}$ the Authorisation Directive; ${ }^{304}$ the Universal Services Directive; ${ }^{305}$ the Privacy and Electronic Communications Directive; ${ }^{306}$ the Radio Spectrum Decision; ${ }^{307}$ and the Commission Competition Directive. ${ }^{308}$

\footnotetext{
${ }^{298}$ Vlcek (2008b) op cit note 288 at 288-290.

${ }^{299}$ In 1993, the European Community and its Member States gave a commitment, in accordance with the Treaty on European Union, to liberalise the telecommunications services anticipating the agreement on the opening up of markets worldwide under the General Agreement on Trade in Services (GATS). The necessary legislative measures of the Community consisted essentially of a number of directives intended to create a single market for telecommunications services in Europe. See European Union (s.d.) 'Summaries of EU Legislation: Fifth Report on the Implementation of the Telecommunications Regulatory Package', available at http://goo.gl/rZHp6.

300 Directive 2002/21/EC of the European Parliament and of the Council of 7 March 2002 on a common regulatory framework for electronic communications networks and services. Directive is available at http://goo.gl/myZJJ.

${ }^{301}$ Directive 2002/21/EC of the European Parliament and of the Council of 7 March 2002 on a common regulatory framework for electronic communications networks and services.

${ }^{302}$ Information for Development Program (infoDev) and the International Telecommunication Union (ITU) (2012) 'The EU Regulatory Framework' (Module 3: Authorisation of Telecommunication/ ICT Service, s 2.5.1) in ICT Regulation Toolkit available at http://goo.gl/SOpRt. An agreement on EU Telecoms Reform was reached by the European Parliament and Council of Ministers on 4 November 2009. The new rules had to be transposed into national laws of the 27 Member States by May 2011 and included the establishment of the European Body of Telecoms Regulators. See European Commission (EC) (2011g) 'Information Society: The Telecoms Reform', available at http://goo.gl/5jSUN.

${ }^{303}$ Directive 2002/19/EC of the European Parliament and of the Council of 7 March 2002 on access to, and interconnection of, electronic communications networks and associated facilities.

${ }^{304}$ Directive 2002/20/EC of the European Parliament and of the Council of 7 March 2002 on the authorisation of electronic communications networks and service.

${ }^{305}$ Directive 2002/22/EC of the European Parliament and of the Council of 7 March 2002 on universal service and users' rights relating to electronic communications networks and services.

${ }^{306}$ Directive 2002/58/EC of the European Parliament and of the Council of 12 July 2002 concerning the processing of personal data and the protection of privacy in the electronic communications sector.

${ }^{307}$ Radio Spectrum Decision 676/2002/EC.
} 
Recital 10 of the Directive on a common regulatory framework for electronic communications networks and services ${ }^{309}$ says that:

\begin{abstract}
"The definition of "information society service" in Art. 1 of Directive 98/34/EC ... spans a wide range of economic activities which take place on-line. Most of these activities are not covered by the scope of this Directive because they do not consist wholly or mainly in the conveyance of signals on electronic communications networks. Voice telephony and electronic mail conveyance services are covered by this Directive. The same undertaking, for example an Internet service provider, can offer both an electronic communications service, such as access to the Internet, and services not covered under this Directive, such as the provision of web-based content.'
\end{abstract}

This would cover a range of MNO services, including MFS-type services.

In the UK, for example, the National Regulatory Authority (NRA) is the Office of Communications (hereafter Ofcom) which styles itself as the independent regulator and competition authority for the UK communications industries. ${ }^{310}$ Ofcom acts under the provisions of the UK's Communications Act of 2003. In respect of value added and Premium Rated Services (hereafter PRS), the co-regulatory body is PhonePayPlus. ${ }^{311}$

The electronic communications Directives were developed in response to a dynamic and increasingly unpredictable market in which a growing number of competitors are participating.

\title{
9.11.2 Application to MFS
}

PRS clearly qualify as 'telecommunications services', as there is no specific legislation as yet at EU level relating to PRS. Jurisdiction would be applicable from National Regulatory Authorities (hereafter NRAs) and/or associated co-regulatory or self-regulatory bodies. ${ }^{312}$

As far as fiat-based MFS services, certainly the bearer component of the MFS would be subject to the Directive although it is not certain which would have overriding jurisdiction: financial or telecommunications-based Directives. As with other jurisdictions, unless it is explicitly stated, there will probably be concurrent jurisdiction, setting the stage for elements of regulatory arbitrage.

\footnotetext{
${ }^{308}$ Commission Directive 2002/77/EC of 16 September 2002 on competition in the markets for electronic communication networks and services.

${ }^{309}$ Directive 2002/21/EC.

${ }^{310}$ Ofcom regulates the TV and radio sectors, fixed line telecoms and mobiles, plus the airwaves over which wireless devices operate. See details of Ofcom at http://www.ofcom.org.uk.

${ }^{311}$ PhonePayPlus (previously known as ICSTIS) regulates phone-paid services in the UK. It has a Code of Conduct that is enforced by a Code Compliance Panel. See the official site at www.phonepayplus.org.uk.

${ }^{312}$ For example, Comreg in Ireland, and PhonePayPlus in the UK. For an overview of PRS regulators in the EU, see the International Audiotext Regulators Network (IARN), at www.iarn.com.
} 
The Electronic Commerce Directive ${ }^{313}$ (hereafter ECD) was passed in 2000 to provide rules for doing business over electronic bearers and for an essential, coherent and appropriate legislative framework to develop e-commerce within the EU. ${ }^{314}$ It is a horizontal framework Directive that applies to all ISS, that is, those provided at a distance and by electronic means, ${ }^{315}$ although it only applies to service providers established within a Member State.

Similar to the South African Electronic Communications and Transactions Act, it mandates which information is to be provided on a website or similar electronic medium, information that a consumer must have about the steps to take to conclude a contract online, information to provide in online advertising, limits on the potential liability of ISPs for unlawful material which they carry unwittingly, and the national law that will apply to online services, codes of conduct, out-of-court dispute settlements, court actions and cooperation between Member States. ${ }^{316}$ It also establishes harmonised rules on issues such as the transparency and information requirements for online service providers, commercial communications and electronic contracts and sets down limited liability conditions for intermediary service providers. It covers all ISS, ${ }^{317}$ which means that it covers both B2B and B2C ISS irrespective of whether or not the services are provided free of charge to the recipient. ${ }^{318}$ Examples of online sectors and activities covered include shopping, newspapers, databases, financial services, professional services, entertainment services, direct marketing, advertising and Internet intermediary services such as hosting and search engines. ${ }^{319}$ It also provides for what is known as 'the country-of origin principle' in certain fields. The principle says that a

\footnotetext{
${ }^{313}$ Directive 2000/31/EC.

314 The Directive was adopted in 2000 and transposed by most EU Member States in 2002.

315 Offline activities are not within the Directive's scope even if connected with an 'on-line service'. Thus where financial services are provided in part offline and part online, different legal regimes will be applied to each part. So, when a service is promoted online but provided offline, only the online promotion is covered by the E-commerce Directive.

${ }^{316}$ In the UK, the ECD was implemented by the Electronic Commerce (EC Directive) Regulations 2002. Online selling and advertising is subject to the laws of the UK if the trader is established here. Online services provided from other Member States may not be restricted. There are exceptions, particularly for contracts with consumers and the freedom of parties to choose the applicable law The UK Regulations do not apply to non-commercial interactions, or the offline elements of online transactions, eg the goods or services themselves where these are not provided online or the delivery of goods or services are not provided online; the offline elements (eg the conclusion of a hardcopy contract) of any transaction that commences online (eg in response to an advertisement on a website) are therefore not within their scope. See Department for Business Innovation and Skills (s.d.) 'FAQ', available at http://bit.ly/ddPuDl. The Electronic Commerce (Financial Services and Markets) Regulations 2002 modified the powers of the Financial Services Authority (FSA) to give effect to the E-commerce Directive. Within their scope of application, the 'Financial Services Regulations' constitute lex specialis and take precedence over the overall Regulations. See A Gkoutzinis (2003) op cit note 1.

${ }^{317}$ A list of non-Information Society services is provided in Annex 5 of the ECD. Among those services which are not seen as being provided by 'electronic means' are voice telephony services and services provided via telephony or fax. However, where voice services are part of an IVR system, they are probably ISS. See the Report on the EC-commissioned study on pan-European market Premium Rate Services (hereafter PRS). It concluded that PRS constitute ISS when they (1) include storage and processing at both ends such as downloading ring tones to a mobile telephone; and (2) include storage and processing only at the platform provider level such as services delivered from IVR platforms (at 30). See the 2005 study on pan-European market for premium rate services in Cullen International SA and WIK Consult GmbH (2005) 'Final Report For Study On Pan-European Market For Premium Rate Services', available at http://goo.gl/mTKnf.

${ }^{318}$ For example, funded by advertising or sponsorship revenue.

${ }^{319}$ See Cullen International SA and WIK Consult GmbH (2005) op cit note 317.
} 
business need only comply with its domestic laws when selling abroad. In turn, the Member State in which the ISS is received cannot generally restrict incoming services. ${ }^{320}$

The ECD does not necessarily trump the existing level of protections from general interest objectives that are set down in existing Community law, including those relating to the level of consumer protection and complements sector-specific financial services legislation, such that the information requirements in the ECD will supplement financial services legislation, such as the PSD. ${ }^{321}$ Similarly, there are some derogations ${ }^{322}$ in the ECD which fall into general and specific case-by-case categories. ${ }^{323}$

Of similar import is the Distance Selling Directive ${ }^{324}$ that gives a broadly similar set of rights to EU consumers whenever they enter into a distance contract, as well as the Distance Marketing of Consumer Financial Services Directive ${ }^{325}$ which aims to provide retail customers ${ }^{326}$ who deal with a financial services $^{327}$ firm or buy a product through distance channels such as post, fax, Internet and telephone with a high level of protection within a defined legal framework. Its main aims are to ensure that these consumers are given minimum standard information about the firm that they propose to deal with and the product or service being offered; and that they have the right to cancel a range (but not all types) of contracts once entered into.

\subsection{2}

\section{Application to MFS}

The ECD appears to be manifestly applicable to a broad range of MFS, with providers and users alike having to navigate the ECD alongside other applicable provisions such as the PSD. Pertinently, the general derogations in the ECD reflect different legal solutions provided by other general instruments and include certain provisions that are specific to existing Community financial services legislation. These are listed in the Annex to the ECD and in respect of financial transactions, include 'the emission of electronic money by institutions'; the freedom of the parties to choose the law applicable to their contract; contractual obligations concerning consumer contacts; $;{ }^{328}$ formal validity of contracts creating or transferring rights in

\footnotetext{
${ }^{320}$ European Commission (EC) (2003a) 'Communication from the Commission to the Council, the European Parliament and the European Central Bank: Application to Financial Services of Article 3(4) to (6) of the Electronic Commerce Directive' Brussels, 14.05.2003, COM(2003) 259 final, available at http://goo.gl/NwUDD

${ }^{321}$ Where, however, an EU law does not prescribe information requirements, the provisions of the ECD may apply. The effect of this derogation is to allow Member States other than the State in which a service provider is established to apply rules which restrict the freedom to provide information society services, subject to compatibility of such measures with Art 49 of the EC Treaty. See EC (2001) op cit note 3.

${ }^{322}$ These are listed in the ECD's Annex.

${ }^{323}$ The second category of derogation permits a Member State, on a case by case basis and subject to community procedure, to apply restrictions to an information society service from another Member State to protect general interest objectives, in particular, to protect consumers and investors.

${ }_{324}$ Distance Selling Directive 97/7/EC.

325 Directive 2002/65/EC of the European Parliament and of the Council of 23 September 2002 concerning the distance marketing of consumer financial services and amending Council Directive 90/619/EEC and Directives 97/7/EC and 98/27/EC. The Directive is available at http://goo.gl/QNw2U.

${ }^{326}$ Individuals acting outside their trade, profession or business.

${ }^{327}$ Art 2 of the Direct Marketing Directive defines a financial service as 'any service of a banking, credit, insurance, personal pension, investment or payment nature'. A 'means of distance communication' is defined as 'any means which, without the simultaneous physical presence of the supplier and the consumer, may be used for the distance marketing of a service between those parties'.

${ }^{328}$ The parties are thus free to choose the law applicable, but in the absence of choice, the law of the state to which the contract has the closest connection will govern the contract. EC (2001) op cit note 3. Where there is a conflict of laws
} 
real estate where such contracts are subject to mandatory formal requirements of the law of the Member State where the real estate is situated; and the permissibility of unsolicited commercial communications by electronic mail.

As an example of the interaction between the ECD, Direct Marketing Directive and financial services, the UK FSA specifies that inter alia the provider of a financial promotion must include a description of the main features of the product or service; the total price to be paid by the consumer under the contract, including all related fees, charges and expenses or, if this cannot be given, the basis for the calculation of the price; any risks associated with the specific features of the contract; and the name and address or contact point of the person with whom the consumer would enter into a contract. ${ }^{329}$ The logistics of providing these details on a small mobile screen remains an unsolved issue. ${ }^{330}$

\section{Consumer Protection-Type Laws}

\subsection{1}

\section{Overview}

One of the mainstays of EU law-making is to improve services throughout the EU by ensuring consistent treatment of consumers across national boundaries. Unlike South Africa and Australia which have developed an omnibus consumer protection law, there is no one Consumer Protection law, although the EU has over time developed a vast number of sector-specific laws with consumer protection components that relate to varying spheres of economic activity from food products to telecommunications to payments as set out in Arts 95 and 153 of the Treaty establishing the European Community.

From the mid-1970s it has endeavoured to harmonise these national measures in order to guarantee European citizens the same high level of protection throughout the single market. ${ }^{331}$ As such, it implemented a broad swathe of consumer protection rules in the form of Directives, Regulations and Recommendations aimed at protecting the economic and legal interests of consumers. ${ }^{332}$ Many of these are

because the service is provided in a different county, the provisions of the Rome Convention on the Law Applicable to Contractual Obligations may apply. As Gkoutzinis (2003) op cit note 1 points out, a contract concluded between a bank and its customer will be governed by the law chosen by the parties through an express provision although in the absence of an express choice, a real choice of law may be implied, provided that the chosen law is demonstrated with reasonable certainty by the terms of the contract or the circumstances of the case.

${ }^{329}$ See Financial Services Authority (FSA) (2005) 'Handbook Release 041 April 2005: Ecommerce Directive', available at http://goo.gl/dM56v.

${ }^{330}$ Also required is information about the firm and its products or services; requirements relating to the placing and receipt of orders, although these do not apply to contracts concluded exclusively by exchange of e-mail or by equivalent individual communications. See Financial Services Authority (FSA) (2011b) 'Financial Services Authority (FSA) Handbook: BCOBS Banking Conduct of Business Sourcebook', available at http://goo.gl/PJETH.

${ }^{331}$ See, for example, Council Resolution of 25 May 2000 on a Community-wide network of national bodies for the extrajudicial settlement of consumer disputes OJ C 155 of 6 June 2000; Decision No 1926/2006/EC (programme of Community action in the field of consumer policy for the years 2007-2013) as of 31 December 2006; Decision No 1926/2006/EC of the European Parliament and of the Council of 18 December 2006 establishing a programme of Community action in the field of consumer policy (2007-2013). See generally, EU consumer law overviews at http://goo.gl/Nrnhr.

${ }^{332}$ For a view of the EU's broad consumer protection philosophies and efforts, see European Commission (EC) (2011h) 'Protection of Consumers' Economic and Legal Interests', available at http://goo.gl/Oz1Ny. See the Council Regulation on Jurisdiction and Recognition and Enforcement of Judgments in Civil and Commercial Matters (hereinafter, Brussels I Regulation and BIR) which defines 'consumer' as the person who concludes a contract 'for a purpose which can be regarded as being outside his trade or profession'. The vague nature of this definition was clarified by the ECJ in Bertrand v Ott [1978] 
consumer-facing in that the consumer can avail themselves of the rules, while others are out of sight, providing stability in the operation of wholesale financial markets. A number of mechanisms for redress have also been developed, many of which use Alternative Dispute Resolution (hereafter ADR) processes.

At a national level, consumer protection even for the same Directive or Regulation may be spread across multiple agencies under whose entities jurisdiction falls. ${ }^{333}$ Generally, there is the Unfair Commercial Practices Directive ${ }^{334}$ which contains general prohibitions on unfair B2C commercial practices; national consumer laws in a particular country may provide consumers with additional rights that supplement the rights provided for in the EU laws, ${ }^{335}$ such as the ECD, ${ }^{336}$ the Distance Selling Directive, ${ }^{337}$ the Unfair Contract Terms Directive, ${ }^{338}$ and the Directive on Distance Marketing of Consumer Financial Services. ${ }^{339}$

The ECD for example defines a consumer as:

'[A]ny natural person who is acting for purposes which are outside his or her trade, business or profession.'

Thus a legal person cannot be regarded as a 'consumer' within the meaning of the Directive. ${ }^{340}$

ECR 1431, which held that there was a need for a restrictive interpretation of the concept of consumer. See BA Terradas (2003) 'Restrictions on Jurisdiction Clauses in Consumer Contracts within the European Union' Oxford University Comparative Law Forum 1, available at http://goo.gl/zL3Cp.

${ }^{333}$ See, for example, with respect to the UK's implementation of the PSD where in addition to the Financial Services Authority (FSA), the Office of Fair Trading (OFT) deals with competition issues concerning access to payment systems, while the Financial Ombudsman Service (FOS) will provide a dispute resolution service.

${ }^{334}$ Directive 2005/29/EC, the Unfair Commercial Practices Directive. It defines these 'unfair commercial practices' as practices that are 'contrary to the requirements of professional diligence' (Art 5(2)(a) of the Unfair Contract Terms Directive). Terms not individually negotiated will be deemed unfair if they create a significant imbalance, to the consumer's detriment, between the rights and obligations of the contracting parties. If a contract term is drafted in advance and the consumer has no influence over the substance of the term, then it is always considered not to be individually negotiated, and hence subject to review based on substantive fairness.

${ }^{335}$ See, for example, a compendium of consumer rights information at Citizens Information Board (Ireland) (2011) 'Consumer Rights', available at http://goo.gl/DGSJP.

${ }^{336}$ Directive 2000/31/EC of the European Parliament and the Council of 8 June 2000 on certain legal aspects of information society services.

${ }^{337}$ Directive97/7/EC of the European Parliament and of the Council of 20 May 1997 on The Protection Of Consumers in Respect of Distance Contracts. The Directive is available at http://goo.gl/rL0fZ. It applies to any consumer distance contract made under the law of an EU-Member State as well as the EEA and provides a number of fundamental legal rights for consumers in order to ensure a high level of consumer protection throughout the EU. Some types of contracts are excluded from all the provisions of the directive. The exemptions include contracts for financial services and contracts concluded through an auction. As an example, Art 8 of the Directive provides that member states have to ensure that appropriate measures exist to allow a consumer to request cancellation of a payment where fraudulent use has been made of his payment card in connection with distance contracts and in the event of such fraudulent use, that such consumer be re-credited with the sum paid or have it returned.

${ }^{338}$ Directive 93/13/EEC on Unfair Terms in Consumer Contracts, available at http://goo.gl/9h81G. It introduces a notion of 'good faith' in order to prevent significant imbalances in the rights and obligations of consumers on the one hand and sellers and suppliers on the other hand. This general requirement is supplemented by a list of examples of terms that may be regarded as unfair. Terms that are found unfair under the Directive are not binding for consumers. The Directive also requires contract terms to be drafted in plain and intelligible language and states that ambiguities will be interpreted in favour of consumers.

${ }_{339}$ Contracts for financial services are covered by the Distance Marketing of Financial Services Directive 2002/65/EC. See European Commission (EC) (2007a) 'Commission Communication on the Implementation of the Distance Selling Directive', available at http://goo.gl/wkZSP.

${ }^{340}$ For a discussion from an EC perspective on the interaction between the ECD and financial services, see EC (2003a) op cit note 320 . 
The ECJ has ruled that both insurance ${ }^{341}$ and banking are particularly sensitive sectors from the point of view of consumer protection. ${ }^{342}$

In the area of retail financial services, EU legislation has established minimum consumer protection rules concerning retail financial services, allowing the Member States to create more strict rules. Retail financial services include current accounts, payments, personal or mortgage loans, savings, pensions, investments or insurance products, when they are provided to individual customers, including retail investors.

The $\mathrm{PSD}^{343}$ adds to consumer certainty for example on payments in the EU by establishing a modern and harmonised legal framework for payment services by replacing existing national rules in the 27 Member States by a set of provisions applying throughout the single market. A high level of consumer protection is provided for via strict information requirements and the definition of the rights and obligations of the users and providers of payment services. ${ }^{344}$ It does not apply however to payments via cash or cheque. The ECD complements the PSD with a range of informational requirements that must be presented to a user for an electronic contract and transaction to be valid. In order to maintain consumer confidence in payment instruments, the Eurosystem has also formulated policies such as the E-Money Systems Security Objectives which are used by several NCBs to perform their statutory tasks in relation to oversight of e-money schemes. $^{345}$

The EC has also established some non-judicial bodies to assist in disputes. ${ }^{346}$ The Network for the ExtraJudicial Settlement of Consumer Disputes (hereafter EEJ-Net) was established in 2001 to assist consumers to settle cross-border disputes with companies that provide defective goods or services, by guiding them towards ADR mechanisms. The network currently comprises 17 national contact points, one for each Member State plus one for Norway and another for Iceland. ${ }^{347}$ There is also the Financial Dispute Resolution Network (hereafter FIN-NET), a financial dispute resolution network of national out-of-court complaint schemes in the EEA countries launched by the EC in $2001 .^{348}$ It is responsible for handling disputes between consumers and financial services providers like banks, insurance companies, investment firms and others.

If a consumer in one country has a dispute with a financial services provider from another country, FINNET members will put the consumer in touch with the relevant out-of-court complaint scheme and provide the necessary information about it.

\footnotetext{
${ }^{341}$ Case 205/84 Commission v Germany [1986] ECR 3755.

${ }^{342}$ Case C-222/95 Parodi [1997] ECR I-389.

${ }^{343}$ Directive 2007/64/EC of the European Parliament and of the Council of 13 November 2007 on payment services in the internal market, amending Directives 97/7/EC, 2002/65/EC, 2005/60/EC and 2006/48/EC and repealing Directive 97/5/EC. 344 See European Commission (EC) (2007b) 'New Legal Framework (NLF) for Payments', available at http://goo.gl/HYNEG.

${ }^{345}$ Reichwein and Rosati (2007) op cit note 1.

${ }^{346}$ Council Resolution of 25 May 2000 on a Community-wide network of national bodies for the extra-judicial settlement of consumer disputes (OJ C 155 of 06.06.2000), available at http://goo.gl/Rs69V.

${ }^{347}$ See European Commission (EC) (2011b) 'EEJ-Net', available at http://goo.gl/Rs69V.

${ }^{348}$ It currently has 50 members from 22 EEA countries.
} 
In the sphere of MFS though, the PSD appears to be the most preeminent and relevant consumer protection law applicable.

\subsection{The EU And MFS: Conclusion}

To enhance the use of cashless payment facilities in the EU and to promote consumer protection, the EU has implemented a range of progressive laws and regulations that allow for the genesis of new forms of payments and payment service providers that include clear licensing regimes, and designated roles for bodies engaged in the supervision and oversight of financial entities, especially those 'non-bank' entities engaged in financial services and payments. Their ability to access payment networks - albeit not those considered systemically important in member states - is also to be welcomed and provides a framework for similar implementations worldwide, including, it is submitted, in South Africa.

The new EU regulations have either an institutional or an instrument focus, and may be supervised using hard and soft law by NCBs or similarly designated regulators in member states of the EU. While there are Regulations and Directives in relation to systemically important institutions and payment systems, there are two EU Directives that have the most applicability to the business models of MFS: the two EU EMDs and the PSD, a consumer payments law relating to and offering consumer protection measures for many noncash payment types.

It becomes clear, however, from the analysis above - and from the contrived nature of the exclusions relating to the EMD2 and PSD in relation to a user's funds not being a deposit and for certain types of MNO business models and uses of the airtime or fiat-based SVA as not being subject to either the PSD or EMD2 - that the EMD2 and PSD are geared towards the more 'additive' models of MFS where the MNO is not necessarily the primary facilitator of MFS services, instead being more of a partner (or agent in the PSD scheme thereof). When applied to more transformational MFS services - in particular using both the airtime and fiat-based SVA - it is doubtful that the exclusions and contrived notions of how to exclude or include certain business models stand up to the scrutiny of legal certainty. Indeed, exclusions of applicability based on static business models - and a determined focus on particular payment instruments are never a good idea, as these evolve too quickly for any legal system to keep up with their newest forms. The politically-motivated derogation from the EMD1 to its applicability to MNO's airtime-based SVA is a siren indication of the effect of incorrect definitions and the fast-moving evolution which may upset even the most carefully crafted legal rules. Slight variations - and the introduction of newer payment instruments like those presented by transformational SVAs - may upset this harmony. It also then means that macropayments are given prominence in the EU's consumer protection initiatives rather than also including the growing micro-payments industry, which includes massive growth in airtime-based remittances.

Thus, for example, in the hybrid and pooled model, the PSD's contrived definitions skew the focus of who actually has effective day-to-day possession of the user funds and who profits from that. Indeed then, the MNO benefits from the arrangement as it collects the transaction fees, but does not effectively assume the 
risks and rules mandated under the PSD. This may however be modified by agreement between the bank and the MNO to allocate risk as seen in Recital 47 which recognises that while the PSD concerns only contractual obligations and responsibilities between the PSU and his PSP, for the proper functioning of credit transfers and other payment services, the PSP and its intermediaries such as processors - the MNO in this case - should have contracts that ensure legal certainty such that their mutual rights and obligations are agreed upon, and which should include issues related to their respective liabilities. This exclusion may have a knock-on effect, particularly on AML regimes since those providing these services insofar as they do not qualify as PSPs do not necessarily have to abide by any AML rules and regulations as a sine qua non for being a PSP. It is then left to AML laws to fill in this AML gap, leading to possible regulatory arbitrage. Similarly, the sector-focus on consumer protection - and the exclusion of more transformational aspects of MFS business models in the PSD and EMD2 - means that it is left to more omnibus protection measures that could be based on telecommunications law and e-commerce-type laws. The non-specificity though also creates the environment for regulatory arbitrage, ultimately negating and undermining the EU's fulsome drive towards consumer protection across all sectors.

In all, though, the introduction of the PSD that allows MFSPs and other non-banks to provide payment services either as primary providers or as payment intermediaries to users is to be welcomed. The issue then is not that they should be subject to the same capital requirements as banks, but that there should be consistent rules across the board that adhere to the principles of proportional regulation and strata of compliance for the values involved rather than a wholesale exclusion of consumer protection rules as there is in the EMD2 and PSD based on the institutions and their novel payment instruments. The primary focus therefore should be on how to protect user funds and their use, not necessarily the institution and the instruments involved. This of course is easier said than done, but co-regulatory bodies like PhonePayPlus in the UK - similar to the self-regulatory Wireless Application Service Providers 'Association in South Africa - that have evolved micro-payment-value-based, and have enforced de minimis-aware Codes of Conduct in regard to WASP-type MFS telegraph how stratified, value-based regulations may evolve without derogating from the overall goal of protection of user funds and providing legal certainty for payment services for SVPs in MFS.

Scaling up to create an omnibus payments law with specific goals and principles that licenses transactionfocused payment providers in South Africa alongside a specific agency for enforcement - either on a statutory or co-regulatory basis based on value - is, it is submitted, desirable in the context of the transformational nature of banking in the South African market. ${ }^{349}$

\footnotetext{
${ }^{349}$ See inter alia, Recommendation 4 in ch 14, s14.9.3 on a proposed new regulatory regime encapsulated in a PSPL. Indeed, the distinction and stratified licensing regimes in the EU that feature 'credit-institutions' of which banks are core, indicates that a regulatory approach to a stratified regime that acknowledges and nurtures the operational and systemic differences between entities that do intermediation (credit provision) versus entities that only do transactions (payment services provision), is eminently achievable. It then becomes just a policy issue.
} 


\section{CHAPTER 10}

\section{KENYA AND MOBILE FINANCIAL SERVICES}

Kenya is lauded globally as the bellwether of successful Mobile Financial Services (hereafter MFS) and, likewise, Kenya's regulators for allowing the development of the transformative M-pesa MFS product offered by Mobile Network Operator (hereafter MNO) Safaricom in 2006 in the face of regulatory uncertainty and a regulatory void. ${ }^{1}$ Through the genesis of M-pesa, originally designed as a simple mobilebased repayment mechanism for Micro-Finance Institutions (hereafter MFIs) in Kenya and financed by the government of the United Kingdom, Kenya has become one of the leaders in MFS worldwide. ${ }^{2}$ It is said that M-pesa has managed to overcome the 'last mile problem, ${ }^{3}$ (for users) by creating a network that connects over $70 \%$ of Kenyan households to the financial system. ${ }^{4}$ This success is manifested in its acceptance within the space of four years by 14 million $(\mathrm{mn})$ users or $57 \%$ of the adult population (as of mid-2011). ${ }^{5}$ Some US $\$ 8.5$ billion (bn) has been sent through M-pesa from its launch in 2007 to mid-2011, and this means that money that previously moved informally can now be tracked by the Central Bank of

\footnotetext{
${ }^{1}$ Kenya has a population of around 40 million $(\mathrm{mn})$, of which $22 \mathrm{mn}$ are over the age of 16 , and $78 \%$ of the population lives in the rural areas. The adult literacy rate is $86.5 \%$, and $38 \%$ of the population have deposit accounts at banks. The GDP per capita is US\$1,600 and Internet penetration is $10 \%$. See G Nyaoma (2010) 'Mobile Payments Regulatory Framework Perspectives in Kenya', available at http://goo.gl/lDPDl; H Bester (2010) 'M-PESA: From Kenya to South Africa ...', available at http://goo.gl/plrqM; World Economic Forum (WEF) (2011) The Mobile Financial Services Development Report 2011 at 102.

${ }^{2}$ For a general view of M-pesa and other MFS systems in Kenya and their regulatory ecosystem, see inter alia Nyaoma (2010) op cit note 1; M Ndung'u (2009) 'CBK Presentation to the Board of Directors of Domestic Regulators', available at http://goo.gl/KMbKe; Consultative Group to Assist the Poor (CGAP) (2007) 'Notes on Regulating Branchless Banking in Kenya', available at http://goo.gl/1VxlM; Consultative Group to Assist the Poor (CGAP) (2010b) 'Update on Regulation of Branchless Banking in Kenya January 2010. Available at http://goo.gl/eIZcd; Rural Finance (2008) 'Knowledge Management' 9 Newsletter March, available at http://goo.gl/Yidcq; S McGregor (2010) 'Safaricom of Kenya MoneyTransfer Users Rise to 61\% in July from Year Ago', available at http://goo.gl/DFrW9; I Mas (2010b) 'M-kheso in Kenya: A New Step for M-pesa and Mobile Banking', available at http://goo.gl/q1KI8; W Jack \& T Suri (2009) 'Mobile Money: The Economics of M-pesa', available at http://goo.gl/HnS6y; I Mas and D Radcliffe (2010) 'Mobile Payments go Viral: MPESA in Kenya: Yes Africa Can: Success Stories from a Dynamic Continent, World Bank, August 2010', available at http://goo.gl/mwhxz; Alliance for Financial Inclusion (AFI) (2010a) 'Case Study: Enabling Mobile Money Transfer: The Central Bank of Kenya's Treatment of M-PESA' at 4, available at http://goo.gl/zJXi4; M Pickens (2007) 'When is Mobile Banking not Banking?', available at http://goo.gl/qfomV; A Fanon and I Ateya (2008) 'Security Issues in M-Banking', available at http:/goo.gl/3yEmy; I Mas and A Ng'weno (2010) 'Three Keys to M-PESA's Success: Branding, Channel Management and Pricing', available at http://goo.gl/2AF1V; A Heyer and I Mas (2009) 'Seeking Fertile Grounds for Mobile Money', available at http://goo.gl/anWnt; Safaricom (2011) 'M-KHESO Frequently Asked Questions', available at http://goo.gl/tXHrR; S Nduati (2006) 'Expanding Financial Services to the Poor: The Role of ICT/Regulatory Challenges', available at http://goo.gl/4dgBW; AT Liu and MK Mithika (2009) 'Mobile Banking: The Key to Building Credit History for the Poor', available at http:/goo.gl/OE4Ra; T Suri and W Jack (2008) 'The Performance and Impact of M-PESA: Preliminary Evidence from a Household Survey', available from http://goo.gl/TGjwY; AllAfrica.com (2010) 'CBK Licenses Another Cash Transfer Service Firm', available at http://goo.gl/yVD8U; D Radcliffe (2010) 'Expanding Customers' Financial Options through Mobile Payment Systems: The Case of Kenya', available at http://goo.gl/6D6YD; J Kendall et al (2011) 'An Emerging Platform: From Money Transfer System to Mobile Money Ecosystem', available at http://goo.gl/khQDt; M Pickens and C McKay (2010) 'Branchless Banking 2010: Who's Served? At What Price? What's Next?', available at http://goo.gl/6LL61.

3 'Last mile' is a term used in telecommunications nomenclature to emphasise the provision of services direct to users' homes.

${ }^{4}$ Kendall (2011) op cit note 2.

${ }^{5}$ See also ch 2, s2.7 titled Current and Future MFS Schemes, where further statistics on M-pesa are presented.
} 
Kenya (hereafter CBK). ${ }^{6}$ The value of these transactions represents more than $15 \%$ of Kenya's Gross Domestic Product (GDP), and the system mediates more transactions annually than the global remittance provider Western Union does globally. ${ }^{7}$

Generally speaking, MFS has created jobs for multitudes of Kenyans, created troves of branchless banking throughout Kenya, enabled Financial Inclusion (hereafter FI) and extended the level of commercial interaction possible amongst the previously underbanked and unbanked. The M-pesa agent network is large and complex, but has been hugely pivotal to the huge success of M-pesa in its interaction with customers. ${ }^{8}$ Subscribers now have the option of paying bills and premiums to a network of nearly 100 utility companies, as well as insurance brokers, farmers, Non-Governmental Organisations (hereafter NGOs), group salary payments, school fees, satellite TV companies, and Micro-Finance Institutions (hereafter MFIs) as well as using remittance services to and from Europe. ${ }^{9}$ Because of their associated savings in terms of time and cost, urban users of MFS usually persuade their rural recipients to register with the service. ${ }^{10}$ Besides the convenience, users also appear to be attracted to cost savings when compared to similar services offered by banks. On average, branchless banking has been found to be some $19 \%$ cheaper than banks. ${ }^{11}$ The lower the transaction value, the cheaper branchless banking is in comparison with banks. ${ }^{12}$ Reported barriers to usage for urban users are failed transactions and not receiving help from the MNO Safaricom, while for rural users, barriers to usage include cash float shortages at agents. The surprising success of M-pesa even led to a rearguard, but ultimately unsuccessful, campaign by licensed banks to convince the government of Kenya to close down M-pesa on spurious grounds, but which has subsequently led to robust 'co-opetition' between the licensed banks and other MFS providers in Kenya, including M-pesa. A number of additional MFS systems from competing providers - both MNO and nonMNO entities - have since started operations in Kenya in competition with M-pesa. ${ }^{13}$

Kenya has a modern communications system using the Global System for Mobile Communications (GSM) and Third Generation Mobile Network (3G) technology, with around 55\% mobile coverage of its population. ${ }^{14}$ Bank account penetration is $21 \%$ with limited use of Automatic Teller Machines (ATMs) and Point of Sale (hereafter POS) technology.

\footnotetext{
${ }^{6}$ J Mwihia and J Straziuso (2011) 'Kenyans Sending Drought Aid Money by Mobile Phone' USA Today, available at http://goo.gl/ebIpM.

${ }^{7}$ Kendall (2011) op cit note 2. See Annex 1, Exhibit J for an example of the popular use of M-pesa in Kenya.

${ }^{8}$ As noted earlier in ch 6, s6.5.5.6, there are a number of complex contractual relationships in existence across the entire Mpesa ecosystem. These include the Agent Agreement; a Declaration of trust in favour of all M-pesa account holders of Safaricom limited; a Management Agreement; Commercial Bank Agreement; a Customer Terms and Conditions agreement; and an Agent Network Manager Agreement. World Economic Forum (2011) The Mobile Financial Services Development Report 2011 at 39. See further ch 10, s10.6 on Consumer Protection.

${ }^{9}$ Heyer and Mas (2009) op cit note 2 at 2.

${ }^{10}$ O Morawczynski and M Pickens (2009) 'Poor People Using Mobile Financial Services: Observations on Customer Usage and Impact from M-pesa' CGAP Brief, available from http://goo.gl/JIrO2.

${ }^{11}$ Kenyans felt they had saved up to US $\$ 3$ per transfer that they otherwise would have spent on bus fare to travel to the country to physically hand over the money to their relatives. Mwihia and Straziuso (2011) op cit note 6.

${ }^{12}$ CGAP found that with a transaction value of US\$23, branchless banking is on average $38 \%$ cheaper than commercial banking. It is also some 54\% cheaper than informal money transfers. Pickens and McKay (2010) op cit note 2.

13 AllAfrica.com (2010) op cit note 2; Equity Bank (2010) 'Orange Money is Launched in Kenya', available at http://goo.gl/OEDBI. Other MFS systems now operating in Kenya include MobilePay (Tangaza), Zain's Zap and Essar Telecom's yu cash.

${ }^{14}$ Nyaoma (2010) op cit note 1.
} 
The Kenyan legal system is based on statutory law, Kenyan and English common law, tribal law, and Islamic law. Most of Kenya's substantive laws are statutory in nature, although the laws of delict (torts), contracts and agency largely follow England's common law and many statutes are merely codifications of the older common law rules. Kenyan courts follow or apply (but not always) the rules of common law, the doctrines of equity, the English statutes of general application and examine the rules in the context of the local circumstances. ${ }^{15}$ There is judicial review available in the High Court and the country accepts compulsory International Court of Justice (hereafter ICJ) jurisdiction with reservations. ${ }^{16}$ It has a Banking Act, but no national payment systems legislation. ${ }^{17}$ There is no consumer protection legislation per se, although there are elements of e-commerce consumer protection in its telecommunications legislation. It also has a Financial Action Task Force-based (hereafter FATF) Anti-Money Laundering (hereafter AML) law.

\section{Prudential and Financial Services}

10.2.1

\section{Overview}

Banking businesses and the conditions under which they operate are governed by the Banking Act and the Central Bank of Kenya Act. Other legislation includes the Bills of Exchange Act, the Companies Act, the Building Society Act and the Cheques Act. ${ }^{18}$ Kenya has some 169 players in the formal banking sector, of which 43 are commercial banks, 123 foreign exchange (hereafter forex) bureaus, two mortgage finance companies, and one MFI. ${ }^{19}$

Following the banking crises, the Central Bank of Kenya (hereafter CBK) mandated that banks had to increase their minimum core capital to Kshs 1 bn by $2010 .^{20}$ There are a number of companies providing MFS services in Kenya. The eponymous system is M-pesa ${ }^{21}$ which was developed for the largest MNO in Kenya, Safaricom. ${ }^{22}$

\footnotetext{
${ }^{15}$ FK Gitonga (2010) 'Kenya', available at http://goo.gl/fvWSy.

${ }^{16}$ United States, Central Intelligence Agency (CIA) (2011a) 'The World Factbook: Africa: Kenya', available at http://goo.gl/KYPIq.

${ }^{17}$ See ch 4, s4.8.6 titled Summary and Conclusions, above. It must be noted that by the completion of all legal research into this thesis, Kenya was set to implement new payment systems legislation. This legislation has however not been included in this thesis.

${ }^{18}$ CBK (2003) 'Payment System in Kenya' at 1, available at http://goo.gl/REmgt. Laws relating to the use of cheques are based on English law, primarily the Cheques Act of 1957 and the Bills of Exchange Act 1882.

${ }^{19}$ Ndung'u (2009) op cit note 2 . In 2007, an estimated $19 \%$ of the adult population had access to formal financial services through banks, with $8 \%$ served by MFIs and SACCOs. See CGAP (2010b) op cit note 2.

${ }^{20}$ Ndung'u (2009) op cit note 2.

21 'Pesa' is the Swahili word for money.

${ }^{22}$ Safaricom is part of the Vodafone group. M-pesa's development was financed by the UK's Department For International Development (DFID).
} 


\subsection{2}

\section{Regulatory Bodies}

The primary regulator of banking, payments and financial services in Kenya is the CBK, which operates under the Central Bank Act (cap 481) $1966 .{ }^{23}$ Section 4 of the Act says that the CBK's core mandate is to formulate and implement monetary policy directed at achieving and maintaining stability in the general level of prices by fostering the liquidity, solvency and proper functioning of a stable market-based financial system, and will support the economic policy of the Government, including its objectives for growth and employment. $^{24}$

The Banking Supervision Department (hereafter BSD) and National Payment System Division (hereafter NPSD) of the CBK oversee banking and payments respectively. The BSD implements the Banks Act, in relation to Commercial Banks, Non-Bank Financial Institutions, Mortgage Finance Companies, Building Societies, Foreign Exchange Bureaus, Deposit-Taking Microfinance Institutions and Credit Reference Bureaus. $^{25}$

In addition to licensing institutions under the Banks Act, the BSD's two divisions have the broad mandate of policy and surveillance. ${ }^{26}$ Together they deal with the development of legal and regulatory frameworks to foster stability, efficiency and access to financial services.

The Department conducts on site evaluation of the financial condition of institutions and their compliance with the statutory and prudential requirements of institutions licensed under the Banking Act, Microfinance Act and Foreign Exchange Bureaus licensed under the Central Bank of Kenya Act. ${ }^{27}$

Kenya is one of the five members of the East African Community (hereafter EAC) trade bloc. ${ }^{28}$ The EAC has launched initiatives to harmonise the supervisory and regulatory regimes and has signed Memorandums of Understanding (hereafter MOUs) to facilitate information sharing and consolidated supervision. ${ }^{29}$

\footnotetext{
${ }^{23}$ The CBK was established in 1966 under the Central Bank Act (cap 481) 1966. Central Bank of Kenya (CBK) (2011) 'Central Bank of Kenya: Background Information', available at http://goo.gl/FnLsy.

${ }^{24}$ CBK (2009a) 'CBK Mandate', available at http://goo.gl/FnLsy.

${ }^{25}$ CBK (2009c) 'Oversight of Payment System in Kenya: Policy Framework', available at http://goo.gl/OIu0D.

${ }^{26}$ CBK (2009a) op cit note 23.

${ }^{27}$ Ibid.

${ }^{28}$ East African Community (EAC) (2011) 'EAC Quick Facts', available at http://goo.gl/13zpm.

${ }^{29}$ Ndung'u (2009) op cit note 2.
} 


\section{Banking Laws and Regulations in Kenya}

10.2.3.1

\section{Banking Act}

In Kenya, banks are regulated by the Banking Act, ${ }^{30}$ while MFIs are regulated under the Microfinance Act. $^{31}$ The Kenyan Banking Act was passed in 1989 and replaced the Banking Act of 1969. ${ }^{32}$ The Act is very similar to many acts around the world in that it requires that only an entity that has a valid license from the CBK may do 'banking business'. 33

A 'bank' means a company which carries on, or proposes to carry on, banking business in Kenya and includes the Co-operative Bank of Kenya Limited but does not include the Central Bank. ${ }^{34}$

\subsection{Business of Banking}

Section 2(1) defines a 'banking business' as:

'(a) the accepting from members of the public of money on deposit repayable on demand or at the expiry of a fixed period or after notice;

(b) the accepting from members of the public of money on current account ${ }^{35}$ and payment on and acceptance of cheques; and

(c) the employing of money held on deposit or on current account, or any part of the money, by lending ..'

Further, a 'financial business' is defined as: ${ }^{36}$

'(a) the accepting from members of the public of money on deposit repayable on demand or at the expiry of a fixed period or after notice; and

(b) the employing of money held on deposit or any part of the money, by lending, investment or in any other manner for the account and at the risk of the person so employing the money ...'

\footnotetext{
${ }^{30}$ The Banking Act 1989 (cap 488), available at http://goo.gl/CVrXo.

${ }^{31}$ The Microfinance Act 19 of 2006, available at http://goo.gl/LkyX0.

${ }^{32}$ Prior to the Banking Act of 1969 , banking in Kenya was regulated under a piece of legislation from the colonial era, namely, the Banking Ordinance. The 1969 Act allowed the Minister of Finance to license banks and non-bank financial institutions. It also gave the CBK the responsibility of inspecting all financial institutions. The Banking (Amendment) Act, 1985 changed the licensing regime, such that the CBK did so with the Minister's approval. A series of bank failures in Kenya led to the Deposit Protection Fund (DPF) in 1986. For a comparative and historical perspective on banking in East Africa, see A Mauri (2007) 'The Currency Board and the Rise of Banking in East Africa', available at http://goo.gl/IT24r.

${ }^{33}$ Part II of the Banking Act deals with the Licensing of Institutions.; Part III deals with Prohibited Business; Part IV deals with Reserves And Dividends.

${ }^{34}$ Banking Act s2 - Interpretation.

35 'Current Account' means an account maintained by a bank for, and in the name of, or in a name designated by, a customer of the bank into which money is paid by or for the benefit of such customer and on which cheques and other bills of exchange may be drawn by, and transfers and other banking transactions made on the instructions of, the customer. Banking Act s2 Interpretation.

${ }^{36}$ Ibid.
} 
A 'financial institution' in turn is defined in s2 as:

'A company, other than a bank, which carries on, or proposes to carry on, financial business and includes any other company which the Minister may, by notice in the Gazette, declare to be a financial institution for the purposes of the Act.'

Section 3 restricts the carrying on of banking business ${ }^{37}$ in that no one shall:

(a) transact any banking business or financial business or the business of a mortgage finance company unless it is an institution which holds a valid licence;

(b) unless it is a bank and has obtained the consent of the Central Bank, use the word "bank" or any of its derivatives or any other word indicating the transaction of banking business, or the equivalent of the foregoing in any other language, in the name, description or title under which it transacts business in Kenya or make any representation whatsoever that it transacts banking business;

(c) unless it is a financial institution or mortgage finance company and has obtained the consent of the Central Bank, use the word "finance" or any of its derivatives or any other word indicating the transaction of financial business or the business of a mortgage finance company, or the equivalent of the foregoing in any other language, in the name, description or title under which it transacts business in Kenya or make any representation whatsoever that it transacts financial business.'

Nonbanks may provide local currency payment services if the activity does not fall under the definition of banking business in the Banking Act. ${ }^{38}$

\subsubsection{2}

Deposits

Section 16(1) prohibits any person other than an institution which holds a valid license, from inviting or accepting deposits in the course of carrying on a deposit-taking business.

Section 16(2) defines a 'deposit' as:

'[A] sum of money paid on terms under which it will be repaid, with or without interest or a premium, and either on demand or at a time or in circumstances agreed by or on behalf of the person making the payment and the person receiving it; and which are not referable to the provision of property or services or the giving of security. ${ }^{39}$

\footnotetext{
${ }^{37}$ Banking Act s3.

${ }^{38}$ CGAP (2007) op cit note 2 at 7.

${ }^{39}$ Section 16(3) says that for the purposes of s16(2) money is paid on terms which are referrable to the provision of property or services or to the giving of security if, and only if, it is paid by way of advance or part payment under a contract for the sale, hire or other provisions of property or services, and is repayable only in the event that the property is, or services are not, in fact sold, hired or otherwise provided; if it is paid by way of security for the performance of a contract or by way of security in respect of loss which may result from the non-performance of a contract; or it is paid by way of security for the delivery up or return of any property whether in a particular state of repair or otherwise. In terms of s16(4), a 'Deposit' does not include a sum paid by the Central Bank or by an institution or the persons mentioned in s54; or a sum which is paid by a person to an associate of that person.
} 
A business is a deposit-taking business if: ${ }^{40}$

'(a) in the course of the business money received by way of deposit is lent to others; or

(b) any other activity of the business is financed, wholly or to any material extent, out of the capital of or the interest on money received by way of deposit. ${ }^{41}$

However, an entity will not be a deposit-taking business if the person carrying on the business does not hold himself out as accepting deposits on a day-to-day basis, and any deposits which are accepted are accepted only on particular occasions, whether or not involving the issue of debentures or other securities. ${ }^{42}$

\subsubsection{2}

\section{The Microfinance Act}

The Microfinance $\mathrm{Act}^{43}$ and the Microfinance Regulations ${ }^{44}$ issued in terms of the Act set out the legal, regulatory and supervisory framework for the microfinance industry in Kenya. The Microfinance Act became operational with effect from $2^{\text {nd }}$ May 2008 and was enacted to develop additional financial markets and to enhance access to financial services and products by the majority of the Kenyans.

The principal object of the Microfinance Act is to regulate the establishment, business and operations of microfinance institutions in Kenya through licensing and supervision. The Act enables Deposit-Taking Microfinance Institutions licensed by the Central Bank of Kenya to mobilise savings from the general public, thus promoting competition, efficiency and access.

The Central Bank may license any institution in Kenya, either as a nationwide microfinance institution, which may carry out its deposit-taking business operations countrywide, or as a community microfinance institution which may carry out its deposit-taking business operations within defined and agreed areas. ${ }^{45} \mathrm{~A}$ deposit-taking MFI must obtain the CBK's approval before opening or closing any 'place of business', which is defined in the Microfinance Act as including 'agencies'.

Non-depositary MFIs, according to the Microfinance Act, are governed by the Ministry of Finance who may prescribe regulations. ${ }^{46}$ However, as these MFIs are not subject to any restrictions under the Microfinance Act, the common law of agency governs their use of agents.

\footnotetext{
${ }^{40}$ Section 16(5) of the Banking Act.

${ }^{41}$ To determine whether deposits are accepted only on particular occasions, the CBK looks at the frequency of those occasions and to any characteristics distinguishing them from each other; s16(8) Banking Act.

${ }^{42}$ See s16(6) of the Banking Act.

${ }^{43}$ Microfinance Act op cit note 30.

${ }^{44}$ The Microfinance (Categorization of Deposit-Taking Microfinance Institutions) Regulations, 2008. Regulations for nondeposit taking microfinance institutions are not yet in place. The former Regulations are available at http://goo.gl/usFVB. ${ }^{45}$ Ibid.

${ }^{46}$ Rural Finance (2008) op cit note 2.
} 


\section{Application to MFS}

M-pesa was first piloted in 2006 primarily as a mobile-based means of payment for repayment of MFI loans, but it has since metamorphosed into a gargantuan system with over $12 \mathrm{mn}$ users that have access to a range of MFS including bill payments and remittances. ${ }^{47}$

At the time of the M-pesa launch, there were 1.5 bank branches per 100,000 people and one ATM per 100,000 people. A recent national financial access survey carried out in Kenya in 2009 revealed that $66 \%$ of women have no access to formal financial services and $33 \%$ of them are completely excluded from accessing any financial services. ${ }^{48}$ Further, banking services are seen as being relatively expensive in Kenya, with minimum balances equaling $44 \%$ of the GDP per capita, versus the 62-country average of $8 \%$. Annual fees are $2 \%$ of GDP per capita versus the $0.38 \%$ country average. ${ }^{49}$

In the M-pesa environment, users must first present their national ID at an authorised M-pesa agent to be able to transact. They are then assigned an individual account that is linked to their phone number and is accessible through a SIM Application Toolkit (hereafter S@T) on their mobile phone. MFS customers can place value in their stored value purses by exchanging cash for e-money via a network of retail stores or informal stores - often called 'spaza' shops - operated from shacks, collectively known as 'agents'. They can add value to their M-pesa account by providing cash to an M-pesa agent, buy Safaricom airtime, or by receiving a payment or remittance from another M-pesa user. As users deposit this money, it is transformed into stored value electronic money (hereafter e-money) stored on the M-pesa system. They receive secure, encrypted SMSs in real time to indicate that their account has been credited or debited when transacting. They can use the account for general transacting, including bill payments, Person to Person (hereafter P2P) remittances to and from other or non-M-pesa users, and can withdraw funds at any time from any M-pesa agent or M-pesa-point, a series of national ATMs linked to the M-pesa system. ${ }^{50}$

The stores and agents earn commission from the MNO each time they exchange these two forms of liquidity on behalf of customers. ${ }^{51}$ Since M-pesa balances cannot get interest on their accounts, the account is only transactional. Agents wishing to become part of the M-pesa system must first deposit a sum of money, a 'float', in the M-pesa pooled bank account. ${ }^{52}$ This deposit is the guarantee that when a user places money in the M-pesa system by depositing cash with the agent, the agent's e-money float is used to guarantee all customer deposits and withdrawals. Hence, when a user deposits money in cash, the agent's float is decreased, and the user's account increased with the e-money value as the agent has received the equivalent amount in cash from the user. Then when the agent pays the user in cash, his e-money account is

\footnotetext{
${ }^{47}$ McGregor (2010) op cit note 2. For updated M-pesa statistics, see Safaricom's statistics web page at http://goo.gl/ZJbPs.

${ }^{48}$ RO Odinga (2009) 'Investing in Women: African Women's Economic Summit 2009', available at http://goo.gl/g8peb.

${ }^{49}$ Rural Finance (2008) op cit note 2.

${ }^{50}$ Mas (2010b) op cit note 2. See also Jack and Suri (2009) op cit note 2, who describe three agent groups. In the first, one member of the agent group (the 'head office') deals directly with M-pesa, while subsidiary agents are owned by the head office, manage cash and e-float balances through transactions with the head office. There is also the aggregator model, as well as the 'super-agent' that performs the functions of the aggregator in the second model.

${ }^{51}$ Mas and Radcliffe (2010) op cit note 2.

${ }^{52}$ Ibid.
} 
increased by the same value plus any transaction fees if applicable. Safaricom when it developed the Mpesa system structured it in such a way that it did not amount to a banking business as defined in the Banking Act and so avoided the restriction present in s3 of the Act.

The key provisions that enabled this loophole were the definitions of 'banking business' and 'deposit'. In essence, an entity would be engaging in the 'banking business' where it accepted deposits repayable on demand or at the expiry of a fixed period or after notice, or where it accepted money on current account and payment on and acceptance of cheques. Crucially, the definition requires that to be captured, the entity must employ any money held on deposit or on current account, or any part of the money, by lending. An entity would similarly be a 'financial business' if it 'accepted from members of the public money on deposit repayable on demand or at the expiry of a fixed period or after notice; and also if it employed the money held on deposit or any part of the money, by lending, investment or in any other manner for the account and at the risk of the person so employing the money'. Further, it would be deposit-taking if 'in the course of its activities, it lent out money received by way of deposit, or where it financed, wholly or to any material extent, the business out of the capital of or the interest on money received by way of deposit, ${ }^{53}$

Although M-pesa accepted repayable funds from the public, Safaricom structured the product in such a way that it effectively fell outside the definitions of 'banking business', 'financial business' and 'deposit'. This in essence was the conclusion of the CBK's in-house counsel who, after investigating the scheme as presented to it, concluded ${ }^{54}$ the M-pesa was not engaging in the banking business by virtue of the criteria below.

In relation to the definition of 'banking business', it was required that the entity must meet the following criteria to be captured: it must accept from members of the public money on current account ${ }^{55}$ and payment on and acceptance of cheques; and employ the money held on deposit or on current account, or any part of the money, by lending. Thus, the use of the word 'and' meant that if the entity (taking deposits) lent any of the funds, it would be captured. However, since M-pesa was structured only to be in the transaction business, and not to be in the lending business, it was not captured as a 'banking business'.

In relation to its then being a 'financial business', that '(a) accepted from members of the public money on deposit repayable on demand or at the expiry of a fixed period or after notice; and also (b) employed this money held on deposit or any part of the money, by lending, investment or in any other manner for the account and at the risk of the person so employing the money', M-pesa also escaped this definition. This, the CBK concluded, is because the methodology whereby an agent first deposited a float of cash upfront in an M-pesa account, held by a commercial bank mitigated any (solvency) risk that section (b) requires.

\footnotetext{
${ }^{53}$ To determine whether deposits are accepted only on particular occasions, the CBK looks at the frequency of those occasions and to any characteristics distinguishing them from each other; see s16(8) of the Banking Act.

${ }^{54}$ AFI (2008) op cit note 2. See also Pickens (2007) op cit note 2; and Fanon and Ateya (2008) op cit note 2.

${ }^{55}$ Banking Act s2 - Interpretation 'Current Account' op cit note 34.
} 
Another exclusion was in the definition of a deposit-taking business which captured an entity as being such if (a) the money received by way of deposit in that business is lent to others via 'intermediation, ${ }^{, 56}$, or (b) if any other activity of the business is financed, wholly or to any material extent, out of the capital of or the interest on money received by way of deposit. ${ }^{57}$ Hence, if (a), customer funds received are not on-lent to others, and (b), any interest received from those user deposits or the capital itself is somehow used to finance the business. As Safaricom placed the (deposited) funds in a pooled trust account at a commercial bank that could not be accessed by Safaricom to fund its business via the capital and/or the interest, in all, the CBK's legal counsel concluded that Safaricom was not engaging in a 'banking business' through its Mpesa activities. ${ }^{58}$

Safaricom had engaged the CBK from the pilot stage of the system, and in February 2007 received a letter of 'no objection' to the commercial launch of the service from the then Acting Governor. ${ }^{59}$ The letter indicated that its activities should not amount to 'banking activities' as defined in the Banking Act, ${ }^{60}$ specifically that M-pesa is not permitted to operate bank accounts; ${ }^{61}$ that appropriate measures had to be put in place to safeguard the integrity of the system in order to protect customers against fraud, loss of money and loss of privacy and quality of service; that the system had to provide adequate measures to guard against money laundering; that proper records should be kept and availed to regulatory authorities in formats as may be required from time to time; and that Safaricom would observe all existing laws governing its relationship with its agents and customers. ${ }^{62}$ In all, these related to operational risk, AML/Know Your Customer (hereafter KYC), systemic risk, consumer protection, agency risks and insolvency.

Since clearly the funds paid in were in specie, they had to be placed - at the insistence of the $\mathrm{CBK}^{63}$ - in a special trust company, the not-for-profit M-pesa Trust Company Limited. The money was placed (in trust) for the users of the system's clients in a pooled account with initially just the Commercial Bank of Africa. Any interest from the pooled account accrues to the Trust Company rather than to Safaricom and its users. Any claims from any fault by the Trust Company or by Safaricom are covered by Safaricom, ${ }^{64}$ while Mpesa (and its agents) earn revenue on fees for withdrawals, deposits and transfers. ${ }^{65}$ As such, M-pesa is not

\footnotetext{
${ }^{56}$ Intermediation is a term used by the CBK to describe this process. See, for example, Nyaoma (2010) op cit note 1.

${ }^{57}$ To determine whether deposits are accepted only on particular occasions, the CBK looks at the frequency of those occasions and to any characteristics distinguishing them from each other; see s16(8) of the Banking Act.

${ }^{58}$ To determine whether deposits are accepted only on particular occasions, the CBK looks at the frequency of those occasions and to any characteristics distinguishing them from each other; see s16(8) of the Banking Act

${ }^{59}$ AFI (2010a) op cit note 2 at 4; see also Pickens (2007) op cit note 2, and Fanon and Ateya (2008) op cit note 2.

${ }^{60}$ The CBK reportedly insisted that Safaricom have a full audit trail and that all customer funds be deposited in a regulated financial institution, and reviewed the security features of the technology platform. Mas and $\mathrm{Ng}^{\prime}$ weno (2010) op cit note 2.

${ }^{61}$ Safaricom (2011a) op cit note 2.

${ }^{62}$ See criteria by CBK in Nyaoma (2010) op cit note 1.

${ }^{63}$ CGAP (2007) op cit note 2 at 5.

${ }^{64}$ Mas and Ng'weno (2010) op cit note 2.

${ }^{65}$ It did, however, recently open up the opportunity to earn interest using a conventional bank account in an agreement with Equity Bank. Their m-kheso scheme is a full savings account issued by Equity Bank, but marketed as an 'M-pesa Equity account'. Safaricom describes it as allowing customers to withdraw cash from their Equity Bank account to their M-pesa accounts and to also deposit through their M-pesa accounts to their M-kheso bank account. Other features of the account include micro-credit facilities (emergency credit availed through M-pesa), micro-insurance facilities as well as a personal accident cover. Inter-account transfers are not allowed. All transfers in and out of the account are through the M-pesa system or another Equity account. Access to the account will only be within Kenya, and the customer must be a M-pesa subscriber. M-kheso accounts pay interest, but they do not have a limit on account balances and are linked to limited emergency credit
} 
designed as a savings mechanism earning interest because legally it cannot be used as such without contravening the Banking Act. Furthermore, since M-pesa is not regulated as a bank, and there is no payment system act in Kenya, it was run effectively as a payments system, allowing a user balance to be used for payments and money transfer.

The CBK's decision to allow, enable ${ }^{66}$ and support M-pesa precipitated furious lobbying by the licensed banks to the Kenyan Ministry of Finance on the basis that M-pesa was an 'unlicensed bank' and should be shut down. ${ }^{67}$ The CBK, however, did an audit of M-pesa in January 2009 and declared it safe ${ }^{68}$ the audit revealed that the average balance on M-pesa accounts was around US\$3. ${ }^{69}$

\section{Overview}

In terms of the Banking Act, banks are not allowed to open or change the location of a branch of that bank without the approval of the $\mathrm{CBK} .^{70} \mathrm{~A}$ 'branch' means any premises, other than its head office, at which an institution transacts business inside or outside. ${ }^{71}$

There are also no regulations explicitly governing the outsourcing of functions by banks. ${ }^{72}$ Nonbank institutions do not face such restrictions on the use of agents or super-agents if so used. ${ }^{73}$

In April 2010, the Central Bank of Kenya issued new agent banking regulations that allowed banks to engage a wide range of retail outlets for transaction handling (cash-in and cash out) and product promotion (receiving account applications, though applications must be approved by a bank staff member). ${ }^{74}$ This paved the way for banks to begin utilising the M-pesa platform and associated network of M-pesa outlets as a channel.

\subsubsection{Application to MFS}

M-pesa's 'status' as a nonbank allowed it to create an agent network that approximated the functional characteristic of a bank branch insofar as cash was taken in and given out. As of August 2011, it had 23,000

and insurance facilities. Unlike its regular Equity account holders who can only transact at the bank's 140 branches, Equity's m-kheso customers will be able to transact at any of the 17,000 retail outlets that accept M-pesa.

${ }^{66}$ The CBK says that an enabling approach requires purposeful and continued engagement to understand and facilitate innovations that can improve financial inclusion. See Nyaoma (2010) op cit note 1.

${ }^{67}$ Daily Nation (2008) 'Michuki: Probe cash transfer', available at http://goo.gl/bhRMj.

${ }^{68}$ Mas and Ng'weno (2010) op cit note 2.

${ }^{69}$ Mas and Radcliffe (2010) op cit note 2.

${ }^{70}$ Section 8(1) of Banking Act.

${ }^{71}$ Banking Act s2 - Interpretation. This may affect the functioning of agents.

${ }^{72}$ CGAP (2007) op cit note 2 at 7.

${ }^{73}$ Ibid.

${ }^{74}$ Central Bank of Kenya (2010) 'CBK/PG/15: Guidelines on Agent Banking', available at http://goo.gl/cs41. The guidelines define an agent as 'an entity that has been contracted by an institution and approved by the Central Bank to provide the services of the institution on behalf of the institution in the manner specified in this Guideline'. It also defines an 'outlet' as being 'an agent's place of business directly responsible to the Head Office, used for carrying out a commercial activity of the agent but does not include a mobile unit'. 
agents ${ }^{75}$ to facilitate customer registration and so-called cash-in/ cash out facilities. ${ }^{76}$ By contrast, outsourcing by banks to agents is only approved by the CBK on a case-by-case basis. ${ }^{77}$

The new CBK guidelines on agents have altered the landscape for banks as the guidelines permit banks to have agents that are not their physical branches as required by s8(1) of the Banking Act. ${ }^{78}$ While they have provisions that relate inter alia to $\mathrm{AML} / \mathrm{KYC}$ and consumer protection, these guidelines are applicable only to 'institutions' as defined in the Banking Act, that is, a bank or financial institution or a mortgage finance company. ${ }^{79}$

M-pesa agents, all of whom are not registered by the CBK, cannot be m-kheso agents, as this requires CBK approval. However, the use of m-kheso (interest-bearing) accounts alongside M-pesa accounts provides an interesting legal workaround insofar as customers cannot use M-pesa agents to deposit funds directly into $\mathrm{m}$-kheso accounts, even though the interface is the same as that for M-pesa. It is the user that must deposit the funds into his m-kheso account.

The legal workaround works thus: the customer with dual M-pesa and m-kheso accounts will deposit funds into his M-pesa account via an M-pesa agent, and once confirmation via SMS is received by the customer that the deposited funds are available, the customer will use the M-pesa interface to transfer funds to the mkheso account. ${ }^{80}$

\section{Payment Systems and Governance}

\subsubsection{1}

\section{Overview}

Kenya has a large wholesale and retail value payment system. Value is transferred via the Real Time Gross Settlement System (hereafter RTGS), Kenya Electronic Payment and Settlement System (hereafter KEPSS) (launched in July 2005), the Government domestic debt Central Securities Depository, and other Securities Settlement Systems. ${ }^{81}$

There is also the Nairobi Automated Clearing House for retail-based payments. ${ }^{82}$

\footnotetext{
${ }^{75}$ Safaricom (2011) op cit note 2. Cash agents get incentives for registering customers and a share of commission on remittances so as to compensate them for being bypassed for the purchase of airtime voucher recharges by subscribers.

${ }^{76}$ Safaricom list the following as the duties of an agent: register M-pesa customers; deposit cash into registered customers Mpesa accounts; process cash withdrawals for registered M-pesa customers; process cash withdrawals for non-registered Mpesa customers; Customer Education Compliance with Safaricom AML \& KYC Policy; compliance with Safaricom business practices; branding of their outlets as per provided guideline.

${ }^{77}$ CGAP (2007) op cit note 2 at 7.

${ }^{78}$ CBK (2010) op cit note 73 .

${ }^{79}$ Section 2 of the Banking Act 1989 as amended.

${ }^{80}$ Banks that could not have the same type of loose affiliation of banking agents such as those used in MFS are now able to do so within the parameters of the CBK 'Agent Guidelines' issued in 2010 in terms of the Banking Act.

${ }^{81}$ Central Bank of Kenya (CBK) (2009d) 'Presentation to the Board of Directors of Domestic Regulators July 2009', available at http://goo.gl/6cK6D.

${ }^{82}$ CBK (2009c) op cit note 24 at 14.
} 
At a regulatory level, there is no national payments law. ${ }^{83}$ Instead the NPSD of the CBK derives its powers from the general functions and mandate of the CBK Act. ${ }^{84}$ The CBK considers oversight of payment systems as one of its core functions. ${ }^{85}$

The NPSD's oversight role involves periodic examinations relating to system integrity and the technical and risk management infrastructure (including back-up facilities) of payment systems. ${ }^{86}$ This covers both large value (wholesale) and retail value payment systems including the bank's own internal systems. ${ }^{87}$

The NPS division of the Banking and NPS Department deals with the integrity, effectiveness, efficiency, and security of the payment system. It subscribes to the Bank for International Settlements (hereafter BIS) Core Principles for Systemically Important Payment Systems (hereafter CPSIPS) ${ }^{88}$ and deals with System Registration; System Assessment; Regulations and Incentives; Policy Dialogue; Monitoring; Analysis and Surveys, and Contact with Market Players. ${ }^{89}$

\subsubsection{2}

\section{Application to MFS}

There is however no National Payment System law in Kenya: the NPS gains its powers through the CBK Act. It is thought that a draft NPS Bill is under consideration by the Ministry of Finance.

There are also no specific laws and regulations or policies dealing directly with e-money, although these are in development by the CBK. As there is no payment system law in Kenya, Safaricom, the MNO in Kenya that developed M-pesa, obtained implicit consent from the NPSD of the CBK to launch M-pesa in 2007 in the form of the 'no objection letter' to its proposed activities from the NPSD of the CBK. ${ }^{90}$ Although M-pesa involves accepting repayable funds from the public, Safaricom structured the product in such a way that it falls outside the definition of 'banking business', insofar as no interest was payable lest it fall under the definition of deposit in terms of the Banking Act. Reports indicate that the letter referred to the CBK's broad authority to regulate the payment system under the CBK Act and states that Safaricom's M-pesa activities would be subject to the proposed 'National Payment Systems Act' once it becomes law. ${ }^{91}$

\footnotetext{
${ }^{83}$ While the CBK has published a framework and strategy document on the payment system, a draft National Payment System Bill is mooted. In the absence of any payment laws, the Payment Systems Division has the authority to ask for information from nonbank payment service providers, but it does not have the power to inspect them. See CGAP (2007) op cit note 2 passim.

${ }^{84} \mathrm{CBK}(2009 \mathrm{c})$ op cit note 24 at 14.

${ }^{85}$ CBK (2009c) op cit note 24 at 4.

${ }^{86}$ This involves requisitioning selected information from system participants or through regular off-site data reporting by participants and system operators and on site inspections or online monitoring of real time payment and settlement flows and of risk levels across the payment systems. CBK (2009c) op cit note 24 at 12.

${ }^{87}$ The Kenyan Payment System consists of Electronic Payment Systems, ATM networks (maintained by large banks), KenSwitch (maintained by some small and medium banks), PESA point (maintained by private provider linked to one commercial bank), Remittances (commercial banks licensed to send/receive domestic/foreign remittances), the Post Office Savings Bank (receives foreign remittances), Western Union (uses agents) sends and receives. See Nduati (2006) op cit note 2.

${ }^{88}$ CBK (2009c) op cit note 24 at 16.

${ }^{89}$ Ibid at 13.

${ }^{90}$ Mas and Ng'weno (2010) op cit note 2.

${ }^{91}$ Ibid. The letter reportedly also states that Safaricom should establish a full audit trail for all transactions and abide by the draft AML Bill. At the time of completion of research for this study, this bill was set for deliberation in the Kenyan parliament. It has not been included in the final version of this study.
} 
Hence M-pesa, devised originally for repayment of MFI loans via cell phone, was structured as an (unregulated) payment or transaction platform subject to the funds held by Safaricom being placed in a special vehicle, the M-pesa Trust Company Limited. To ameliorate any AML and systemic risk issues, there are also caps on the maximum M-pesa account balance at around US\$750, while the maximum transaction size allowed is around US\$530. As mentioned above, according to the January 2009 CBK audit of M-pesa, the average balance on M-pesa accounts was around US $\$ 3 .^{92}$

\section{Anti-Money Laundering, Terrorist Financing and Customer Due Diligence Laws and Regulations}

\section{Overview}

The omnibus AML law in Kenya is the Proceeds of Crime and Anti-Money Laundering Act ${ }^{93}$ which provides mechanisms for detecting and seizing the proceeds of money laundering. ${ }^{94}$

Section 45(1) of the Act mandates new KYC requirements in that a reporting institution must take reasonable measures to satisfy itself as to the true identity of any applicant seeking to enter into a business relationship with it or to carry out a transaction or series of transactions with it, by requiring the applicant to produce an official record reasonably capable of establishing the true identity of the applicant. This may include a birth certificate; a national identity card; a driver's license; a passport; or any other official means of identification as may be prescribed. The Registration of Persons Act, (cap 107), requires Kenyan citizens of 18 years old and above to register with the National Registration Bureau and to be issued with a national identity card. ${ }^{95}$

As noted earlier, the CBK issued agent guidelines in April 2010 under s33(4) of the Banking Act that outlined new criteria for adherence to the AML/KYC law and which specify agent and customer due diligence, KYC and Counter-Terrorist Funding (hereafter CTF) policies and procedures. Section 5.5 relates to Agent Due Diligence (hereafter ADD) procedures. Institutions hiring agents must have clear and well documented ADD policies and procedures which at a minimum must contain methods of identifying potential agents, initial due diligence and regular due diligence checks to be performed at specified intervals and a list of early warning signals and corrective actions to ensure proactive agent management.

\footnotetext{
${ }^{92}$ Mas and Radcliffe (2010) op cit note 2.

${ }^{93}$ Act 9 of 2009.

${ }^{94}$ It defines 'proceeds of crime' as 'any property or economic advantage derived or realised, directly or indirectly, as a result of or in connection with an offence irrespective of the identity of the offender committed after the passing of the Proceeds of Crime and Money Laundering (Prevention) Act and includes, on a proportional basis, property into which any property derived or realised directly from the offence was later successively converted, transformed or intermingled, as well as income, capital or other economic gains derived or realised from such property at any time since the offence. Section 1.4: definition, available at http://goo.gl/hzqAb.

${ }^{95}$ See National Registration Bureau at http://www.identity.go.ke. Under the Act, the National Registration Bureau has been mandated to identify, register and issue identity cards to all citizens of Kenya who have attained the age of eighteen (18) years and above.
} 
Once an agent is approved by the institution, every applicant seeking to engage in agent banking business shall, on a once off basis submit its AML/CFT policies and procedures to the CBK. ${ }^{96}$ Every contract between an institution and an agent will also have to include any AML/CFT requirements. ${ }^{97}$ Institutions must also CDD to ensure that requirements of AML/CFT are not compromised, which include KYC requirements; transactional limits per day, month and year limits commensurate with customer's profile; maximum balance limits on debit and credit, minimum technological security requirements; and two-factor authentication per customer using national IDs, PINs, passwords, ATM cards, secret codes or secret messages while performing any transaction requiring identification. ${ }^{98}$

Appropriate agent-monitoring procedures ${ }^{99}$ and AML/CTF training ${ }^{100}$ must also be put in place. Agents must, within twenty-four hours, report to the institution all suspicious activities that come to the agent's knowledge, ${ }^{101}$ and not exceed any mandated transactional limits. ${ }^{102}$

\subsection{2 \\ Application to MFS}

As the CBK guidelines refer to 'Institutions' as defined in the Banking Act, the guidelines do not apply to MFS players. ${ }^{103}$ Instead, the AML/CTF law applies directly to the MFS players and it is up to the MFSP to ensure that their agents apply the AML/CTF law. ${ }^{104}$

An agent will capture the name, national ID or passport number, ID type, and date of birth of the prospective user. The agent then enters this information into a database, although the national ID number is not verified against the National Registration Bureau database unless a need arises, for example, when there is fraud, or where the user wants to do a high value transaction. ${ }^{105}$ Safaricom keeps this information for ten years.

The omnibus telecommunications laws in Kenya are the Kenya Communications Act, ${ }^{106}$ the Kenya Communications (Amendment) Act 1 of 2009, ${ }^{107}$ as well as the Kenya Communications Regulations. ${ }^{108}$

\footnotetext{
${ }^{96}$ CBK (2010) op cit note 73 at s2.3.1(viii).

${ }^{97}$ Ibid at s4.5.1(vi).

${ }^{98}$ Ibid at s5.4 and s8.1.2(i).

${ }^{99}$ Ibid at s5.5.7.

${ }^{100} \mathrm{Ibid}$ at s8.1.1.

${ }^{101}$ Ibid at s8.1.2(ii).

102 Ibid at s8.1.1.2(iii).

${ }^{103}$ Section 2 of the Banking Act.

${ }^{104}$ Central Bank of Kenya Personal Communication October 2010. See also Nyaoma (2010) op cit note 1.

${ }^{105}$ Liu and Mithika (2009) op cit note 2.

106 The Kenya Communications Act 2 of 1998, Kenya Gazette Supplement No 64, November 9, 1998 at 219-220, available at http://goo.gl/98dpL. For a critical analysis of the Act, see R Wanjiku (2009) 'Kenya Communications Amendment Act (2009): Progressive or Retrogressive?', available at http://goo.gl/vAP05.
} 


\subsection{2}

\section{Regulators}

The telecommunications regulator is the Communications Commission of Kenya (hereafter CCK), alongside the National Communications Secretariat which is housed in the Ministry of Information Communication (hereafter MoIC). ${ }^{109}$ The CCK issues regulations in terms of the Communications Act, ${ }^{110}$ guided by the provisions of the relevant statutes, and its regulatory mandate spans the telecommunications, broadcasting, information technology (hereafter IT), (hereafter e-commerce) and postal/courier industries, including managing the country's frequency spectrum. ${ }^{111}$ Commercial telecommunications licensees are authorised to set up telecommunications systems and/or to provide telecommunications services to third parties in accordance with the license terms and conditions. The Commission has in place a Unified Licensing Framework (hereafter ULF) which is technology and service neutral. The ULF market is structured into three main licenses: (i) Network Facilities Provider, (ii) Application Service Provider and (iii) Content Service Provider. An entity may be issued with multiple commercial licenses, provided that it maintains separate accounts for each license.

In respect of content, licensees under this category provide 'contents services material, information services and data processing services'. ${ }^{112}$

\subsection{3}

\section{Application to MFS}

Anyone providing MFS services must obtain a license from the CCK and the telecommunications regulations require that a MNO offer only the telecommunication services listed in its license. MFS ostensibly falls under the definition of "content ${ }^{113}$ and must thus be listed in the license agreement. This listing of services in the MNO license is the most that the CCK requires from MNOs engaging in MFS. The primary regulator with respect to a MNO's MFS activities is however still the CBK. When the CCK receives an application for a Content Service Provider license that involves MFS, they inform CBK as a courtesy. ${ }^{114}$ However, where the CCK regulations may impact on MFS is on the data-protection aspects of the MNO activities. Section 31 of the Kenya Communications Act, 1998, for example, makes it an offence for a licensed operator to intercept or disclose a message sent through the operator's system or to disclose the contents of any statement or account specifying the telecommunications services provided. Further, s93

\footnotetext{
${ }^{107}$ Kenya Communications (Amendment) Act 1 of 2009, available http://goo.gl/UH891. The Kenya Communications Act 2 of 1998 is now known as the Kenya Information and Communications Act 2 of 1998.

${ }^{108}$ For an overview of the Regulations and Legislation, see the relevant CBK web pages at http://goo.gl/Zu2L3 \& http://goo.gl/yNHiQ.

${ }^{109}$ See Kenyan Ministry of Information and Communication at http://goo.gl/3x2TU.

${ }^{110}$ The CCK exercises the powers conferred on it by ss27, 38, 46K and 66 of Act 2 of 1998.

${ }^{111}$ Communications Commission of Kenya (CCK) (2011c) 'What We Do', available at http://goo.gl/13owV.

${ }^{112}$ Communications Commission of Kenya (CCK) (2011a) 'Market Structure - Telecommunications: Unified Licensing Framework', available at http://goo.gl/bKORK.

${ }^{113}$ See an example of a general CCK Content Service Provider License, where 'Content Services' is defined as information of any kind normally provided at a fee and is delivered over electronic communications networks and services. They include broadcasting content, financial information services and other information society services, available at http://goo.gl/OE4Ra.

${ }^{114}$ Liu and Mithika (2009) op cit note 2 at 11.
} 
of this $\mathrm{Act}^{115}$ restricts disclosure by the CCK of information about an individual or business during their lifetime without their consent, except where there are criminal and civil proceedings.

As one of M-pesa's key facilities is bill payment, this may impact on its ability to share information about payment defaulters to credit bureaus envisaged under the Banking (Credit Reference Bureau) Regulations $2008 .^{116}$

The Kenya Communications (Amendment) Act 1 of $2009^{117}$ provides an e-commerce-like set of laws, although it is not under a dedicated and named 'e-commerce' law. ${ }^{118}$

The Amendment Act for example introduces inter alia the concepts of 'electronic record', ${ }^{119}$ 'advanced electronic signature', 'certificate', ${ }^{120}$ 'computer', ${ }^{121}$ 'electronic form', ${ }^{122}$ 'electronic signature', ${ }^{123}$ and 'signature-creation device', ${ }^{124}$ which could be applied to MFS. Part VIA of the Act applies to 'Electronic Transactions' and specifically excludes the creation or execution of a will, negotiable instruments and documents of title. ${ }^{125}$ It has a plethora of provisions that provide for the functional equivalence of electronic messages in respect of their written, paper equivalents. In essence, then, the Act recognises electronic signatures as legally binding, and gives the Minister of Information the power to approve the manner and format of affixing an electronic signature as well as the control of the processes for ensuring adequate integrity, security and confidentiality of electronic records or payments. ${ }^{126}$ This includes the legal

\footnotetext{
${ }^{115}$ Act 2 of 1998 op cit note 105.

${ }^{116}$ The Regulations paved the way for the licensing and surveillance of Credit Reference Bureaus (CRB) by the CBK. These Bureaus will collate credit information from institutions licensed under the Banking Act. See Central Bank of Kenya (2009b) 'Credit Information Sharing to Enhance Financial Sector Development', available at http://goo.gl/DFVQU.

${ }^{117}$ Act 1 of 2009 op cit note 106.

118 See E-Government (2009) 'Kenya: Kenyan Legislators Underscore the Role of e-Transactions Law', available at http://goo.gl/FhtUz.

${ }^{119}$ An 'electronic record' is defined as a record generated in digital form by an information system which can be transmitted within an information system or from one information system to another, and stored in an information system or other medium. See Sixth Schedule of the Act 1 of 2009 op cit note 106.

${ }^{120}$ A 'certificate' is defined as a record which is issued by a certification service provider for the purpose of supporting a digital signature which purports to confirm the identity or other significant characteristics of the person who holds a particular key pair; identifies the certification service provider issuing it; names or identifies the person to whom it is issued; contains the public key of the person to whom it is issued; and is signed by a responsible officer of the certification service provider issuing it.

121 'Computer' is defined as any electronic, magnetic, optical or other high-speed data processing device or system which performs logical, arithmetic and memory functions by manipulations of electronic, magnetic or optical impulses, and includes all input, output, processing, storage, software and communication facilities which are connected or related as a system or network.

122 'Electronic form' with reference to information is defined as any information generated, sent, received or stored in magnetic, optical, computer memory, microfilm or similar device.

${ }^{123}$ An 'electronic signature' is defined as data in electronic form affixed to or logically associated with other electronic data which may be used to identify the signatory in relation to the data message and to indicate the signatory's approval of the information contained in the data message.

${ }^{124}$ A 'signature-creation device' is defined as configured software or hardware used to implement the signature-creation data.

${ }^{125}$ See s83B(1) Application.

${ }^{126}$ The payment system, however, remains the purview of the CBK, although it appears that the two bodies will have to work in concert.
} 
recognition of electronic records, ${ }^{127}$ the attribution of electronic records, ${ }^{128}$ the formation and validity of contracts, ${ }^{129}$ recognition of parties of electronic messages, ${ }^{130}$ acknowledgement of receipt ${ }^{131}$ and legal recognition of electronic signatures. ${ }^{132}$

\section{6 \\ Consumer Protection}

\subsubsection{Overview}

There is no specific consumer protection law in Kenya. Instead, MFS issues are directly and indirectly dealt with by a number of financial laws that address consumer protection issues.

The CBK's 2010 'Agent Guidelines ${ }^{133}$ however provide direct consumer protection provisions, although these relate more to formalities in the transaction process than any dispute resolution facilities. For example, s9.2 of the 'Agent Guidelines' specifies that, at a minimum, the following requirements must be complied with:

ii) Institutions shall establish mechanisms that will enable their customers or users to appropriately identify their agents and the services provided through such agents.

ii) Agents shall issue receipts for all transactions undertaken through them. Institutions shall provide their agents with equipment that generates receipts or acknowledgements for transactions carried out through agents. In this regard, electronic receipts or acknowledgements are permissible.

iii) Where an agent acts as a receiver and deliverer of documents, an acknowledgement shall be provided for all documents received or delivered by the agent to or from the customer.

iv) A channel for communication of customer complaints to the institution shall be provided. Institutions shall provide dedicated customer care telephone lines for lodging complaints by their customers. The customers can also use this telephone line to verify with the institution, the authenticity and identity of the agent, its physical location and the validity of its agent banking business.

v) Institutions shall establish a complaints redressal [sic] mechanism and shall ensure proper communication of this mechanism to their customers.

vi) All customer complaints shall be addressed within a reasonable time and in any case not later than thirty days from the date of reporting or lodging the complaint with the institution. Institutions shall keep record of all customer complaints and how such complaints are redressed.

vii) An agent shall have signs that are clearly visible to the public indicating that it is a provider of services of the institution with which it has an agency contract. The agent shall not however represent to the public that it is an institution.

\footnotetext{
${ }^{127}$ Section $83 \mathrm{G}$.

${ }^{128}$ Section 83L.

${ }^{129}$ Section 83J.

${ }^{130}$ Section 83K.

${ }^{131}$ Section 83M.

${ }^{132}$ Section 83P.

${ }^{133}$ CBK (2010) op cit note 73 at s9.
} 
viii) In the provision of agent banking services, institutions shall use secure systems that ensure customer information confidentiality.

ix) The customer should be made aware of the fact that he is not supposed to carelessly store his PIN and other critical information or share such information with other parties including agents.

$\mathrm{x})$ An institution may establish contact centres to facilitate easy communication between a customer and the institution.'

\subsection{2}

\section{Application to MFS}

While the Banking Act allows the CBK to, for example, restrict increases in bank charges, it is not certain that MFS services like M-pesa would be subject to these restrictions as there is no licensed bank structure per se to regulate. The $\mathrm{CBK}$ however indicates that it requires any provider to have procedures and capacities to handle and resolve complaints timeously, and must provide reports to the Regulator. ${ }^{134}$

The Kenya Information and Communications (Dispute Resolution) Regulations, $2010^{135}$ set out the scope of and the guidelines for any disputes ${ }^{136}$ between a license holder and a consumer. A 'consumer' is defined as any person who uses communication services or a product offered by a licensee, and does not distinguish between telecommunications and MFS services. Section 3 allows the CCK to resolve disputes between a consumer and a service provider; a service provider and another service provider; or any other persons as may be prescribed under the Act. This may ostensibly bring an MFS service like M-pesa under the jurisdiction of the CCK if there is any dispute as to charges, billing and general loss of value in the prepaid stored value purse.. 137

A particular issue around prepaid billing is raised by the Kenya Information and Communications (Tariff) Regulations, $2010^{138}$ which state inter alia that a licensee shall provide accurate billing information on tariffs to enable customers to verify whether they are billed correctly. ${ }^{139}$

Since prepaid is usually a paperless system at worst, and a web or Wireless Application Protocol-based (hereafter WAP) interface for transaction-logging at worst, any MFSP would have to provide an accessible billing system via web or WAP, or if possible, a printout via an agent or an MNO office.

\footnotetext{
${ }^{134}$ Nyaoma (2010) op cit note 1.

${ }^{135}$ Available at http://goo.gl/uZwHw.

${ }^{136}$ Section 2 of the Kenya Information and Communications (Dispute Resolution) Regulations defines 'dispute' as any matter that is in contention between a licensee and another, a consumer and a licensee, where one or both parties is aggrieved by the conduct of the other and the parties have failed to reach an amicable resolution after due effort has been made.

${ }^{137}$ For registered users, any value sent to another M-pesa user remains in their account as long as their Safaricom SIM is active. If their Safaricom subscription expires, M-pesa will contact them to request that they withdraw their money. For unregistered users, if they do not cash their M-Pesa funds in seven days, the money is automatically returned to the senders account. See Safaricom (s.d.) 'General M-PESA FAQs', available at http://goo.gl/azEfw.

${ }^{138}$ Kenya Information and Communications (Tariff) Regulations, 2010, available at http://goo.gl/uZwHw.

${ }^{139}$ Ibid note 136 at $\mathrm{s} 4(2)$..
} 
The success of M-pesa in Kenya is rightfully held up as the bellwether of transformational innovation and regulatory latitude by a progressive prudential regulator.

Its ability to rapidly evolve and grow - albeit even in a regulatory vacuum characterised by the lack of a national payments law - demonstrates the success of, and need for, nonbank participation in the primary provision of payment services. Besides a rapid enabling of financial inclusion, there were also immediate and manifest downstream benefits with some 28,000 agent outlets that opened, competition in financial services was enhanced, while a web of interconnected business users were now able to be paid through Mpesa where they previously had difficulty getting paid

Further, while M-pesa was not originally conceived as a savings service, the usage suggests that the users turn to it as a safe store of value. The m-kheso MFS hybrid system that complements M-pesa's pure payments regime points to a second generation of usage and users. ${ }^{140}$

Some notable regulatory arbitrage concerns are evident though: the involvement of the CCK in licensing MNOs that engage in MFS as 'content providers' creates unnecessary regulatory confusion and shows a lack of regulatory coordination, although it appears the two bodies will have to work in concert when further regulating MFS in Kenya.

The rather modest legal contribution of the Kenya exposition to this discourse on MFS indicates inter alia just how critical contextualised legal drafting is in relation to banking and payments law: one seemingly innocuous lacuna in the definition of a deposit provided a (well exploited) loophole which in the end had demonstrable public-policy benefits, but in another time or context may have caused adverse effects on the Kenyan economy or on the sub-region.

That said, the (legal) contribution of Kenya is thus more of a policy and regulatory one: the siren message is that the introduction of MFS into Kenya alongside the establishment of safety and soundness provisions to safeguard user funds - such as regular reporting by MNOs and MFSPs on their financial health to the CBK and placement of funds in Trust Accounts at commercial banks - demonstrates that adequate planning, a progressive regulator, alongside technical innovation ensures that there is no systemic impact on the financial health of a country or perceivable consumer harm.

This success of the 'Trust Account' model employed in Kenya to provide a proportional regulation context for MFS is, it is submitted, demonstrably applicable to potential deployment of MFS in South Africa by non-bank actors under a proportional licensing regime.

\footnotetext{
${ }^{140}$ M-kheso was launched in May 2010. It allows M-pesa users to move money between their M-pesa Store of Value (SOV) to an interest-bearing Equity Bank account, and account holders can also access loan and insurance facilities. By August 2010, 455,000 customers had opened accounts, and 718,000 by April 2011. Activity on these accounts is reportedly low. Radcliffe (2010) op cit note 2 at 4.
} 


\section{CHAPTER 11}

\section{UNITED STATES OF AMERICA AND MOBILE FINANCIAL SERVICES}

\subsection{Overview of MFS in the United States of America}

The United States of America (hereafter US) is one of the largest and most sophisticated economies in the world, but it has strata of economic activities that, in some respects, mirror mixed economies like South Africa in its financial, technological, banking and payment systems. ${ }^{1}$ Despite a sophisticated banking system, there exists a growing parallel banking system in the form of Stored Value Products (hereafter

\footnotetext{
${ }^{1}$ For an overview of MFS, financial inclusion and aspects of SVP and bank regulation in the US: see JS Cheney (2008) 'An Examination of Mobile Banking and Mobile Payments: Building Adoption as Experience Goods?', available at http://goo.gl/DWiH7; PL Keitel (2008) 'The Laws, Regulations, Guidelines, and Industry Practices that Protect Consumers Who Use Gift Cards', available at http://goo.gl/Mj6jy; PL Keitel (2010) 'Electronic Payments and the Consumer-Protection Landscape', available at http://goo.gl/jGRzc; PL Keitel (2011) 'Conference Summary: Federal Regulation of the Prepaid Card Industry: Costs, Benefits, and Changing Industry Dynamics' Federal Regulation of the Prepaid Card Industry: Costs, Benefits and Changing Industry Dynamics' April 8-9, 2010, a conference sponsored by the Payment Cards Center, available at http://goo.gl/EsJT1; Federal Reserve System (FRS) (2011b) 'The 2010 Federal Reserve System Payments Study: Noncash Payments Trends in the United States: 2006-2009', available at http://goo.gl/HCRMH; The Federal Deposit Insurance Corporation (FDIC) (2009c) 'FDIC National Survey of Unbanked and Underbanked Households: Executive Summary' at 36, available at http://goo.gl/DRqn1; Center for Financial Services Innovation (CFSI) (2008) 'The CFSI Underbanked Consumer Study: Underbanked Consumer Overview and Market Segments Fact Sheet', available at http://goo.gl/bV2LZ; ME Budnitz (2007) '2005-2006 Developments in Payment Systems Law', 3 Journal of Consumer and Commercial Law 116, available at http://goo.gl/Lhp8o; ME Budnitz (2008a) 'Developments in Payments Law 2008' 12Journal of Consumer \& Commercial Law 2; SLW Rhine and S Su (2005) 'Stored Value Cards as a Method of Electronic Payment for Unbanked Consumers', available at http://goo.gl/h6d0H; L Haralson (2006) 'FRB of St. Louis, Stored-Value Cards: Opportunities, Risks', available athttp://goo.gl/FFwZA; LH Teslik (2008) 'The US Financial Regulatory System', available at http://goo.gl/RNGl7; Committee on Capital Markets Regulation (2009) 'Committee on Capital Markets Regulation Releases Recommendations for Reorganizing U.S. Regulatory Structure', available at http://goo.gl/ZPtGE; US Senate Committee on Banking, Housing, and Urban Affairs (2010) 'Brief Summary of the Dodd-Frank Wall Street Reform and Consumer Protection Act', available at http://goo.gl/XrSh; MJ Furletti (2004b) 'The Debate Over the National Bank Act and the Preemption of State Efforts to Regulate Credit Cards' 77 Temple Law Review, available at http://goo.gl//fquk; CF Zarnowski and M McDermott (1986) 'The Non-bank Bank Impasse', available at http://goo.g1/2Tt85; Office of the Comptroller of the Currency (OCC) (2008a) 'Activities Permissible for a National Bank', available at http://goo.gl/hFT2Z; Office of the Comptroller of the Currency (OCC) (2008b) 'A Guide to the National Banking System', available at http://goo.gl/4RV1X. For commentary on the US banking system: see MN Rothbard (1999) 'A History of Money and Banking in the United States: The Colonial Era to World War II', available at http://goo.gl/peUBs. For a regulatory overview of banks: see Office of the Comptroller of the Currency (OCC) (2011) 'National Banks, Thrifts, Credit Unions: Who Regulates Them?', available at http://goo.gl/pXBKo, and RJ Sullivan (2006) 'The Supervisory Framework Surrounding Non-bank Participation in the US Retail Payments System: An Overview' FRS Bank of Kansas City, Payments System Research Working Paper 04-03, available at http://goo.gl/paJwC. For a comparative overview with the EU, see: E Akindemowo (2009) 'Contract, Deposit or E-Value? Reconsidering Stored Value Products for a Modernized Payments Framework' 7(2) DePaul Business and Commercial Law Journal at 275, available at http://goo.gl/FP297; E Akindemowo (2010) 'How to Devise U.S. SVP Policy? Prepare to Replace the Deposit Concept', Thomas Jefferson School of Law Research Paper No 1600888; B Geva (2008b) 'TARGET2 Transfer of Funds and Harmonization of EU Payment Law', 41(2) Uniform Commercial Code Law Journal 113145; B Geva (2009b) 'The EU Payment Services Directive: An Outsider's View' 28 Yearbook of European Law at 177-215; B Geva (2009b) 'Payment Transactions Under the EU Payment Services Directive: A US Comparative Perspective' 27(3) Pennsylvania State International Law Review 713-755, available at http://goo.gl/Wj2BB; B Geva (2010) 'The Harmonization of Payment Services Law in Europe and Uniform and Federal Funds Transfer Legislation in the USA: Which is a Better Model for Reform?' Annual Banking Law Update at 22; T Bolt and A Ramasastry (2000b) 'Questions and Answers about the Uniform Money Services Business Act', available at http://goo.gl/xloec; A Ramasastry (2000a) 'Memorandum to the Cyberpayments Working Group of the Uniform Money Services Business Act Drafting Committee', available at http://goo.gl/E1buF; A Ramasastry (2005) 'Non-bank Issuers of Electronic Money: Prudential Regulation in Comparative Perspective' in Current Developments in Monetary and Financial Law International Monetary Fund, available via http://goo.gl/Yzq0O; A Ramasastry (2008) 'Confusion and Convergence in Consumer Payments: Is Coherence in Error Resolution Appropriate?' 83 Chicago-Kent Law Review, No 2, at 813; D Reichwein and S Rosati (2007) 'Non-banks in the Payments System: European and US Perspectives', available at http:/goo.gl/HPOi6; The Federal Deposit Insurance Corporation (FDIC) (2009a) 'Banks' Efforts to Serve the Unbanked and Underbanked Report 2009', available at http://goo.gl/rVF5A.
} 
SVPs) that are attractive to those who either do not or cannot be part of the formal banking system. There are nearly 80 million (hereafter $\mathrm{mn}$ ) consumers in the US without a traditional bank account or with limited access to credit and who receive almost US\$1 trillion (hereafter tn) annually from employers, governments, insurance companies and other sources. ${ }^{2}$

An estimated $7.7 \%$ of US households, approximately $9 \mathrm{mn}$ people, are unbanked in that they do not have a checking or a savings account. ${ }^{3}$ An estimated $17.9 \%$ of US households, roughly $21 \mathrm{mn}$, are underbanked in that, while they have a checking or savings account, they rely on alternative financial services. ${ }^{4}$ Specifically, underbanked households have used non-bank money orders, non-bank check-cashing services, payday loans, rent-to-own agreements or pawn shops at least once or twice a year or have refunded anticipation loans at least once in the past five years. The proportion of US households that are unbanked varies considerably among different racial and ethnic groups, with certain racial and ethnic minorities more likely to be unbanked than the population as a whole. The underbanked and unbanked groups together spend around US\$13 billion (hereafter bn) annually. ${ }^{5}$

A 2010 study on payment methods in the US by the United States Central Bank, the Federal Reserve, found that although prepaid card-based payments remain far fewer in number than payments made using credit or debit cards, SVP (prepaid) transactions increased 21.5\% per year from 2006 to 2009 and that the value of prepaid transactions increased $22.4 \%$ per year over the same period. ${ }^{6}$ Some $2 \mathrm{bn}$ transactions were made using Electronic Benefits Transfer (EBT) cards, while some US $\$ 1.3$ bn was spent by consumers using prepaid General Purpose Reloadable cards (hereafter GPR cards). ${ }^{7}$ This is the fastest growing payment segment in the US and tracks a decline in the usage of paper cheques, ${ }^{8}$ although the everlasting hegemony of the cash cheque as a payment, especially for those living and working illegally in the US, ${ }^{9}$ adds to the unbanked statistic.

SVPs can offer the opportunity to encourage inclusion in mainstream financial services as long as they are less expensive than the financial products or services they are displacing (for example, check cashers) and as long as they are quick, convenient, safe, and thoughtfully designed. ${ }^{10}$ There is a push by the US government to use SVPs in many social grant programmes. While it may contribute to the overall growth

\footnotetext{
${ }^{2}$ Keitel (2011) op cit note 1 at 23; FDIC (2009c) op cit note 1 at 3-6.

${ }^{3}$ FDIC (2009c) op cit note 1 at 3-6. Minorities in the US that are more likely to be unbanked include African Americans (an estimated 21.7\% of African American households are unbanked), Hispanics (19.3\%) and Native American Indians/Alaskans (15.6\%). Racial groups that are less likely to be unbanked are Asians (3.5\%) and Caucasians (3.3\%).

${ }^{4}$ FDIC $(2009 \mathrm{c})$ op cit note 1 at $3-4$. Certain racial and ethnic minorities are more likely to be underbanked than the population as a whole. Minorities that are more likely to be underbanked include African Americans (an estimated 31.6\%), Native American Indians/Alaskans (28.9\%) and Hispanics (24.0\%). Asians and Caucasians are less likely to be underbanked ( $7.2 \%$ and $14.9 \%$, respectively). For more insight into underbanked populations in the US, see CFSI (2008) op cit note 1 , and Rhine and $\mathrm{Su}(2005)$ op cit note 1.

${ }^{5}$ Keitel (2011) op cit note 1 at 23. For details on the unbanked and underbanked in the US, see FDIC (2009c) op cit note 1. This survey distinguishes unbanked individuals from underbanked individuals at 46.

${ }^{6}$ See FRS (2011) op cit note 1 at 17-18.

7 The Federal Reserve study looked at prepaid debit card payments, payroll cards, single-use and the General Purpose Reloadable (GPR) prepaid SVCs, which are usable at multiple merchants and branded by payment networks such as Visa or MasterCard. See on the various types of SVCs available, ch 4, s4.8.4.4.4 titled Use in Open and Closed Systems.

${ }^{8}$ The United States Treasury Department's initiatives to displace paper checks are expected to save billions of dollars. See Financial Management Service (2011) 'US Treasury to "Retire" Paper Check for New Recipients of Social Security and Other Federal Benefits, Saving Taxpayers \$1bn,' available at http://goo.gl/9HQfz

${ }^{9}$ Many of these may be deterred from entering the formal financial sector by the need for photographic identification or biometric verification, or to call upon employers for verification. See Keitel (2011) op cit note 1 at 23.

${ }^{10}$ Keitel (2011) op cit note 1 at 22-23.
} 
of electronic payment and increase financial inclusion amongst the unbanked and underbanked in the US, Mobile Financial Services (hereafter MFS) are still in their infancy in the US, and it is the additive banking model that dominates the banking and payments space. There are, however, initiatives to grow MFS using Near Field Communication-based (hereafter NFC) systems, with many Mobile Network Operators (hereafter MNOs) and banks joining forces to develop interoperable MFS systems based on this technology.

At the regulatory level, MFS development may be buffeted by the varying and sometimes inconsistent regulatory roles of various US government agencies, each with their own remit, and further complicated by the fact that the US has a dual banking system at the state and federal levels and that MFS and SVP are subject to these varying state and federal laws. For the time being, the state-level Money Service Business (hereafter MSB) laws appear to provide the most direct regulation and oversight of evolving MFS-type business models.

\section{PART I: $\quad$ Money, Banking And Payments Laws And Guidelines}

\section{The Prudential Landscape for Financial Products and Services}

\subsection{1}

\section{Overview}

For decades, the US has been seen as the incubator of new technologies and of progressive banking and payment systems. A dual banking system - state and federal - exists in the US and this is reflected in the complex regulatory structure. ${ }^{11}$ A whole gamut of payment products are available: cheques, e-cheques, credit transfers, Electronic Benefits Transfers (hereafter EBTs), Electronic Fund Transfers (hereafter EFTs), Personal Identification Number-debit (hereafter PIN), money remittance, e-money and a range of pre-funded or SVPs. Many of these products are provided by non-banks who are seen to dominate a large number of payments activities for a large number of payment types in the retail and wholesale banking and payments space.

The prudential regimes in the US are comparatively progressive compared to, for example, the European Union (hereafter EU) insofar as licensing regimes for SVPs like e-money and for those providing payment services appear not to exist. ${ }^{12}$ This almost laissez faire attitude appears to be evolving though, prodded by the almost systemic meltdown of the US financial system that led to the start of the 'Great Recession' in $2008,{ }^{13}$ with attendant non-bank and bank failures, and that sends the salient message that even non-banks may have a catastrophic systemic effect on a country's financial system. As a result, and alongside a watchful eye on Anti-Money Laundering (hereafter AML) and Terrorist Financing (hereafter TF) due to

\footnotetext{
${ }^{11}$ For a complete structural overview of the US banking system, see OCC (2008b) op cit note 1 and for commentary on the US banking system, see Rothbard (1999) op cit note 1.

${ }^{12}$ For an overview, see European Central Bank (ECB) (2007) 'Nonbanks in the Payments System: European and U.S. Perspectives' Payments System Research Working Paper No PSR WP 07-01 at 62, available athttp://goo.gl/HPOi6.

${ }^{13}$ For a discussion, see AR Mian and A Sufi (2010) 'The Great Recession: Lessons from Microeconomic Data', available at http://goo.gl/C9aoS.
} 
ongoing security threats, a swathe of new laws and regulations ${ }^{14}$ designed to avoid a repetition of the crises and harm to consumers were introduced, but with careful oversight of the expansion of financial inclusion amongst the banked and unbanked in the US.

There has great debate amongst scholars ${ }^{15}$ on whether there is an existing body of US statutory or common law that would apply to e-money, SVPs and payment systems. ${ }^{16}$ The still progressive nature of the regulatory landscape for prefunded SVP and related MFS systems is, as will be shown below, ${ }^{17}$ becoming more complex due in part to the lack of a homogenised, federal/state prudential and legal landscape similar to the EU's e-money and Payment Services Directive (hereafter PSD), with omnipresent competitive agendas resulting from the powers vested in the states to devise their own laws via their state legislatures. Indeed the states comprising the Union have a range of payment, money-type and telecommunications laws, but their efficacy and the states' right to create similar new laws has sometimes been stunted by perennial clashes with the federal government over who has ultimate authority over matters of 'commerce'and whether federal law preempts (or trumps) state law. ${ }^{18}$

It is instructive then to scan the existing laws and the private law of payment systems, banking and currency and their application to traditional money, EFT and other payment products and then apply the same laws, if possible to new and emerging money and payment products using a SOV (hereafter SOV) in a Stored Value Accounts (hereafter SVA) offered by MNOs.

\subsubsection{Regulatory Bodies}

\subsubsection{General Overview}

Responsibility for oversight of retail payments and banking involves a large number of federal - and state authorities. Not all are financial authorities though: they include bodies that regulate and have oversight over competition policy, consumer protection, prudential supervision, privacy and data security, and law enforcement relating to AML and Counter-Terrorist Financing (hereafter CTF). ${ }^{19}$ Banks, thrifts and some non-bank institutions that have a financial focus are under the supervisory authority of federal and state

\footnotetext{
${ }^{14}$ See ch 11, s11.2.4.2 on the Dodd-Frank Wall Street Reform and Consumer Protection Act which covers the new Bureau of Consumer Financial Protection.

${ }^{15}$ See inter alia JS Rogers (2005) 'The New Old Law of Electronic Money' at 1, available at http://goo.gl/KetTp; M Kohlbach (2004) 'Making Sense of Electronic Money' (1) The Journal of Information, Law and Technology (JILT), available at http://goo.gl/R1mxj; S Nativ (2007) 'The Demand for Research-Based Policy Alternatives: The Case of Electronic Money in the US and the EU', available at http://goo.gl/2JvSB; Sullivan (2006) op cit note 1; Akindemowo (2009) op cit note 1; Akindemowo (2010) op cit note 1; Geva (2008) op cit note 1; Geva (2009a) op cit note 1; B Geva (2009b) op cit note 1; Geva (2010) op cit note 1; Bolt and Ramasastry (2000b) op cit note 1; Ramasastry (2000) op cit note 1; Ramasastry (2005) op cit note 1; Reichwein and Rosati (2007) op cit note 1.

${ }^{16}$ Kohlbach (2004) op cit note 15, comparing the EU e-money regime to that of the US, says that ' $[\mathrm{t}]$ he US approach ... is refreshingly simple ... because it is an approach not to regulate at all, such that "there are presently no special restrictions pertaining to the issuing of e-money".,16

${ }^{17}$ See ch 11, s11.2.5 on E-Money and SVPs.

${ }^{18}$ The rift originates over powers granted to the US Congress and the states in the US Constitution, and is centred around the so-called Commerce Clause in the US Constitution at Art I, s8, clause 1. Where these rights begin and end has been the subject of lengthy scholarly debate. For a discussion thereto, see RG Natelson (2006) 'The Legal Meaning of "Commerce" in the Commerce Clause' 80(3) St. John's Law Review, available at http://goo.gl/VvcUG.

${ }^{19}$ Reichwein and Rosati (2007) op cit note 1 passim.
} 
agencies, with enforcement including regular examination as well as ongoing monitoring of the financial health and operation of the institution. ${ }^{20}$ There is also a large body of private, self-regulation.

\subsubsection{Federal Overview}

A range of federal bodies have oversight over the US financial system. At the apex is the US central bank, the Federal Reserve System (hereafter FRS), ${ }^{21}$ an independent entity within the government. ${ }^{22}$ Also known as the 'Federal Reserve', or simply 'The Fed', it has both public purposes and private aspects ${ }^{23}$ such as interest rates and payment regulation. ${ }^{24}$

The Office of the Comptroller of the Currency (hereafter OCC) is the federal agency within the Department of the Treasury established under the National Currency Act as the regulator of national banks, with the sole authority to examine, supervise, and regulate national banks, unless otherwise provided by federal law. The OCC defines the permissible activities for a national bank mandated under the National Bank $\mathrm{Act}^{25}$ to trade, including those that are part of, or incidental to, the business of banking, or are otherwise authorised for a national bank.

The Office of Thrift Supervision (hereafter OTS) ${ }^{26}$ regulates all federal and many state-chartered thrift institutions, including savings banks and savings and loan associations. ${ }^{27}$ The Federal Deposit Insurance Corporation (hereafter FDIC) is the primary federal regulator of banks that are chartered by the states that do not join the FRS. ${ }^{28}$ Its most prominent role is to insure deposits, allowing banking customers to claim up to US\$250,000 from the FDIC if their bank fails.

The Federal Trade Commission (hereafter FTC) is tasked with preventing unfair methods of competition in commerce. ${ }^{29}$ It is the only federal agency with both consumer protection and competition jurisdiction.

\footnotetext{
${ }^{20} \mathrm{ECB}$ (2007) op cit note 12 at 30.

${ }^{21}$ See Board of Governors of the Federal Reserve System (2005) 'The Federal Reserve System: Purposes \& Functions' $9^{\text {th }}$ ed, available at http://goo.gl/nHIUh

${ }^{22}$ It is considered an independent central bank because its decisions do not have to be ratified by the executive or legislative branches, although it is subject to oversight by Congress.

${ }^{23}$ Its responsibilities include: monetary policy; supervision and regulation of banking institutions; maintaining the stability of the financial system and containing systemic risks. See Committee on Capital Markets Regulation (2009) op cit note 1.

${ }^{24}$ Board of Governors of the Federal Reserve System (2011) 'Federal Reserve Policy on Payment System Risk', available at http:goo.gl/Thcrt; and Reichwein and Rosati (2007) op cit note 1. It lacks explicit legal authority, though, to oversee Systemically Important Payments Systems (hereafter SIPS) in surprising contrast to South Africa, Kenya, the Eurosystem and many others. ECB (2007) op cit note 12.

${ }^{25}$ See ch 11, s11.2.3.1 titled Banking Legislation: Overview.

${ }^{26}$ For a complete overview of the OTC's role, see DA Attaway (2007) 'Cracking the Door to State Recovery from Federal Thrifts', 3(1) Seventh Circuit Review 275, available at http://goo.gl/J5kwx.

${ }^{27}$ There is also the National Credit Union Administration, or NCUA, which is responsible for chartering and supervising US credit unions, non-profit savings and loans companies. See Teslik (2008) op cit note 1.

${ }^{28}$ Banks can be chartered by the states or by the federal government. Banks chartered by states also have the choice of whether or not to join the Federal Reserve System.

${ }^{29}$ See generally, Federal Trade Commission (FTC) (2012) 'About the Federal Trade Commission', available at http://goo.gl/BFsII, and ch 11, s11.6 titled Consumer Protection.
} 
The new Consumer Financial Protection Bureau (hereafter CFPB), discussed in detail below, ${ }^{30}$ is a federal consumer protection agency for financial services and products. While it has been given an arsenal to create rules for banks and non-banks, the CFPB's ability to operate and be adequately funded has been constantly handicapped by political skirmishes between Democrat and Republican lawmakers and as such its efficacy is untested.

The FDIC is an independent agency of the federal government created in 1933 in response to the thousands of bank failures that occurred in the 1920s and early 1930s. It insures consumer deposits in banks and thrift institutions for at least US $\$ 250,000 .^{31}$

\subsubsection{State Overview}

Every bank or thrift, or a variety of financial, institutions in the US operating in any state under license from that state will invariably be subject to what could be termed a banking or financial supervisor for that state acting to enforce that state's particular banking and financial services laws. New York State's Banking Law, for example, requires Banking Board approval for any action to be taken that causes any company to become a bank holding company. ${ }^{32}$ If a company is failing and threatens to damage consumers, the supervisor may, as ordered by an appropriate court of jurisdiction, place the business into receivership to allow distribution of assets to creditors and customers.

\subsubsection{Conference of State Bank Supervisors}

The Conference of State Bank Supervisors (hereafter CSBS) advocates for the interests of state banking to the respective state legislative and regulatory agencies so as to advance and protect the US dual banking system and to prevent any federal regulatory pre-emption of state laws. ${ }^{33}$ Acting as the single voice to congress for state banks, the CSBS also enhances cooperation between state and federal regulators to improve oversight.

\subsubsection{5}

The Money Transmitters Regulatory Association

The Money Transmitters Regulatory Association ${ }^{34}$ (hereafter MTRA) is a national non-profit organisation of state regulators formed in 1989 to foster effective and efficient regulation of money transmitters and other MSBs. It drafted model legislative guidelines and made them available to states developing or

\footnotetext{
${ }^{30} \mathrm{Ch}$ 11, s11.2.4.2.2 on the Consumer Financial Protection Bureau.

${ }^{31}$ See www.fdic.gov.

${ }^{32}$ See s142 of Art III-A of the New York State Banking Law. See http://goo.gl/uun7e which defines a 'bank' at $\S 2$ as follows: 'Definitions. 1. Bank. The term, "bank", when used in this ch[apter], unless a different meaning appears from the context, means any corporation, other than a trust company, organized under or subject to the provisions of article three of this ch[apter].'

${ }^{33}$ See Conference of State Bank Supervisors (CSBS) (2012) 'What is CSBS?', available at http://goo.gl/LjWxm.

${ }^{34}$ See www.mtraweb.org.
} 
modernising their money transmission legislation. Some transfers may also fall under relevant portions protecting fund transfers under UCC 4A, although this will only apply to the inter-MNO transfers if done through an ACH system ${ }^{35}$

\section{Banking Law and Regulations}

\subsubsection{Banking Legislation: Overview}

The US has a dual banking system that allows a bank to seek either a state or national charter ${ }^{36}$ insofar as they may take the form of nationally chartered, state-chartered, thrifts, as well as Savings and Loan Credit Unions. ${ }^{37}$ For banks seeking a national presence, the National Bank Act (NBA) ${ }^{38}$ authorises national banks to exercise several enumerated powers as well as 'all such incidental powers as shall be necessary to carry on the business of banking, ${ }^{39} \mathrm{~A}$ national bank will be regulated primarily by the OCC, which issues national bank licenses and which may define the 'incidental powers' of national banks and to authorise activities beyond those enumerated in the statute. ${ }^{40}$

State-only banks have a charter approved by the banking regulatory authority of the state in which it is located under that state's banking laws and can be primarily regulated by that authority as well as the Federal Reserve, or by that authority and the FDIC. ${ }^{41}$

Non-banks, though, may be snared by the banking and payment regulators if, for example, they are affiliated with banks or, if not affiliated with a bank, are in an outsourcing relationship with a bank, ${ }^{42}$ while entities providing SVPs may be subject to state MSB laws. ${ }^{43}$

\footnotetext{
${ }^{35}$ According to Rogers (2005) op cit note 15 at 17, a transfer of funds from that account to e-notes would constitute a 'funds transfer' governed by UCC Art 4A.

${ }^{36}$ Of the over 8,000 domestic banks and thrifts in the US, $73 \%$ of them are state chartered, while $70 \%$ of the bank and thrift assets in the US are in federally chartered institutions. See RH Neiman (2010) 'Managing Pre-emption and Oversight in a Modernized Dual Banking System’ Bureau of National Affairs Banking Report, available at http://goo.gl/ob5xZ.

${ }^{37}$ For banks, credit unions, and savings and loan associations, the advantages of a state charter include greater access to legislators and regulators as well as the possibility of lower annual assessments. Institutions generally choose a national charter if their operation is interstate. Besides the State-chartered banks, or thrifts, Mann describes three additional types of entities that do not strictly fall under the definition of a bank, but which may act as a bank: a non-bank bank, a CEBA creditcard bank, and a Utah industrial loan company under the Utah Code Ann. §7-8-21. See RJ Mann (2008) 'A Requiem for Sam's Bank' 74 Chicago-Kent Law Review 101 at at 102-103, available at http://goo.gl/ZzOIX.

${ }^{38}$ National Banking Act of 1864 (ch. 106, 13 Stat. 99). The US Congress intended to make the National Bank Act (hereafter NBA) the only law applicable to national banks. As Furletti (2004) op cit note 1 at 3-4 points out, states are not powerless in relation to nationally chartered banks as the NBA calls for the application of the laws of the state in which a national bank is chartered. The NBA also allows the Office of the Comptroller of the Currency (hereafter OCC) to pre-empt state banking laws, particularly those relating to consumer protection.

3912 USC \$24 Seventh. See also Barnett Bank of Marion County, N.A. v Nelson, 517 US 25, 32 (1996) where the Supreme Court has interpreted 'grants of both enumerated and incidental "powers" to national banks as grants of authority not normally limited by, but rather ordinarily pre-empting, contrary state law.'

${ }^{40}$ National banks may only operate once their charter has been approved by the OCC, and are exempt from state regulation unless Congress or the Office of Thrift Supervision (hereafter OTS) (and the OCC) explicitly authorise the state regulation. See 12 CFR $\$ 560.2(\mathrm{c})$. State regulations and common law actions are valid only if they 'incidentally affect the lending operations of Federal [S\&Ls]'. The other type of national financial institutions are the 'thrifts' that originally provided home loans. They are supervised by the OTS. Federal thrifts are not the same as national banks, which are authorised and regulated by the OCC. See G Liberman and A Lavine (2006) 'Banks vs. Thrifts vs. Credit Unions: Which Financial Institution Will Work Best for You?' MarketWatch, available at http://goo.gl/YJHID.

${ }^{41}$ See Board of Governors of the Federal Reserve System (2005) op cit note 21.

${ }^{42}$ The Bank Service Company Act of 1962 gave authority to bank supervisory agencies to examine non-bank service companies to whom banks outsource specified financial services. Payments are among those services specified. If a non-bank payments processor is affiliated with a bank, then federal laws authorising bank supervision provide federal agencies with the authority to examine the activities of the non-bank processor. If a non-bank payment processor is not affiliated with a bank,
} 
A.

Federal

11.2.3.2

Federal Overview

The OCC summarises that the business of banking is an evolving concept and the permissible activities of national banks similarly evolve over time. ${ }^{44}$ New technologies are contemplated in this evolution. ${ }^{45}$ The most natural indication that an entity is acting as a bank - and therefore implicating the application of state and federal banking laws - is whether or not it is engaged in receiving deposits, or maintaining accounts as a debtor of its customers. ${ }^{46}$

Federal and state laws either expand or narrow these basic attributes such that to avoid banking regulation, a non-bank entity must attempt to avoid being perceived as taking demand deposits or otherwise maintaining deposit accounts for consumers. ${ }^{47}$ The provisions of the Bank Holding Act of $1956,{ }^{48}$ for example, define a bank as any organisation that both accepts demand deposits and makes commercial loans. ${ }^{49}$ The fundamental indicia that suggest a non-bank entity is acting as a bank is whether a non-bank issuer is in the business of receiving deposits or otherwise maintaining accounts as a debtor of its customers.

The statutory definition of 'deposit' maybe found in s3(1) of the Federal Deposit Insurance Act (hereafter FDIA $)^{50}$. This section includes several paragraphs. At par 3(1)(1), the term 'deposit' is defined in part as:

'[T]he unpaid balance of money or its equivalent received or held by a bank or savings association in the usual course of business and for which it has given or is obligated to give credit, either conditionally or unconditionally, to a commercial, checking, savings, time, or thrift account, or which is evidenced by its certificate of deposit, thrift certificate, investment certificate, certificate of indebtedness, or other similar name. ${ }^{51}$

then it may or may not be subject to federal supervision depending on whether it has an outsourcing relationship with a bank. See Reichwein and Rosati (2007) op cit note 1 at 30; and also Sullivan (2006) op cit note 1.

${ }^{43}$ Federal and various state authorities are engaged in a battle over the pre-emption power of the National Banks Act. See Furletti (2004) op cit note 1 passim for more information on this battle.

${ }^{44}$ A non-exhaustive list of 'business of banking' activities allowed by the OCC include branching, payment services, electronic bill payments and dispensing prepaid alternate media from ATMs. Any activity described is permissible for a national bank and is also permissible for an operating subsidiary of a national bank, and vice versa. See OCC (2008a) op cit note 1 .

${ }^{45}$ For example, national banks may acquire membership interests in LLCs that operate an 'open' SVC system. This is permissible because the creation, sale, and redemption of a SOV in exchange for currency are all part of the business of banking. See OCC (2008a) op cit note 1 generally, and specifically Office of the Comptroller of the Currency (OCC) (1996) 'Interpretive Letter' No 220, available at http://goo.gl/PILgh.

${ }^{46}$ At common law this usually means the receipt and possession of money or its equivalent, payable upon the demand of the depositor or pursuant to agreement. See JP Morgan (2005) 'Legal Implications of SVCs', available at http://goo.gl/U2zex. In banking terms, the issuance of prepaid, or other forms of, SVC is considered a non-bank financial activity. Federal and state banking laws generally are not applicable to non-bank prepaid services or similar SVCs unless the card issuer appears to be holding a demand or depository account for a third party.

${ }^{47}$ Ibid.

4812 USC $\$ 1841$. The Act establishes guidelines for the financial industry.

${ }^{49}$ Zarnowski and McDermott (1986) op cit note 1.

${ }^{50} 12$ USC 1813(1)

${ }^{51} 12$ USC 1813(1)(1). At 12 USC 1813(a), a bank is described as any national bank and state bank, and any federal branch and insured branch, and includes any former savings association. 
Further, at par 3(1)(3):

'[M]oney received or held by a bank or savings association, or the credit given for money or its equivalent received or held by a bank or savings association, in the usual course of business for a special or specific purpose, regardless of the legal relationship thereby established ..., funds deposited by a debtor to meet maturing obligations, .....52

The FDIC may, in consultation with the other federal banking agencies, define 'deposit' through regulation. ${ }^{53}$ It has done so insofar as the underlying pooled funds in a payroll Stored Value Card (hereafter SVC) may be a deposit. ${ }^{54}$

\subsubsection{3}

\section{Application to MFS}

Technological evolution has involved a number of non-bank companies in the payment space, sometimes as payment processors affiliated with banks either as subsidiaries of the bank or as separate entities in a bank holding company, or separate independent payment or SVP companies like PayPal. ${ }^{55}$ Depending on their affiliation, some non-bank providers are subject to supervision via the Bank Service Company Act of 1963 (hereafter BSCA) ${ }^{56}$ whereby financial institutions are required to notify their primary federal regulator in writing of any relationships or contracts they enter into with third parties for provision of certain services to the financial institution. ${ }^{57}$ The authority to supervise any non-bank payments processor depends on bank affiliation such that it is only when a non-bank payments processor is affiliated with a bank that federal agencies will be able to examine the activities of the non-bank processor. Thus, if a nonbank payment processor is not affiliated with any bank, then it may or may not be subject to federal supervision depending on whether it has an outsourcing relationship with any bank. ${ }^{58}$

Practically, bank supervisors can regulate and supervise some non-bank companies - called Technology Service Providers (hereafter TSPs) - that provide technology services to banks. ${ }^{59}$ These are selected via a risk-based process, based on factors such as the risk in services provided, ${ }^{60}$ the number of clients or the number of transactions processed by the TSP, the number of clients and the TSP's internal controls. ${ }^{61}$

\footnotetext{
${ }^{52} 12$ USC 1813(1)(3).

${ }^{53} 12$ USC 1813(1)(5).

${ }_{55}^{54}$ See ch 11, s11.2.5.4 on The Federal Deposit Insurance Corporation (FDIC) and Deposits.

${ }^{55}$ Reichwein and Rosati (2007) op cit note 1.

56 USC $\$ 1867$.

57 These services include cheque and deposit sorting and posting, as well as other 'similar functions performed for a depository institution' Ibid at 4 .

58 See CM Paridon (2008) 'New Changes and Challenges: Non-banks in the Payments System', available at http://goo.gl/XV9RQ; and Reichwein and Rosati (2007) op cit note 1. As Paridon notes further, whenever a federally regulated depository institution, or its functionally regulated subsidiary or affiliate 'causes to be performed for itself ... any [permissible bank service company] services', this performance will be subject to regulation and examination 'to the same extent as if such services were being performed by the bank itself ...' such that any company that provides services to a bank will be subject to regulation and examination by the bank's federal regulator. See 12 USC $§ 1867(\mathrm{c})$.

${ }^{59}$ Reichwein and Rosati (2007) op cit note 1 believe that the main purpose is to protect the depositors of banks that outsource to the Technology Service Providers (hereafter TSPs), and not protection of the payments system.

${ }^{60}$ Those providing clearing and settlement or wholesale payment services are examples of high-risk services, while Automated Clearing House (hereafter ACH), ATM and POS transaction processing and credit card processing are medium risk services. Mostly, TSPs offer Information Technology (hereafter IT) services for accounting and information systems. See Federal Deposit Insurance Corporation (FDIC) (2011) 'FFIEC Information Technology Examination Handbook', available at http://goo.gl/JQoC5.

${ }^{61}$ FDIC (2011) Ibid.
} 
However, as noted by Reichwein and Rosati (2007), ${ }^{62}$ this examination is limited in reach: many non-bank payments system providers can ultimately avoid full federal regulatory supervision due to the narrow definition of outsourcing in the BSCA, which specifies that there must be an outsourcing relationship present before the BSCA applies.

This means that entities - like money transmitters and PayPal - who originate payments and who then send the payment instruction information to a bank for processing will ultimately avoid the provisions of the BSCA. $^{63}$ There is also no comprehensive data source with a list of companies that provide payment services to financial institutions. ${ }^{64}$ If a Mobile Financial Services Provider (hereafter MFSP) funds transfer is such that the value for the money transfer is held by the MNO and recognised as money in a FDICinsured bank, then the purse would be considered a deposit by the FDIC subject to pass-though insurance.

The time the value sits in the MNO account however may impact on whether it indeed can be characterised as a deposit for the purposes of the FDIC insofar as the value is transiently held in the purse, and/or some value is also used for MNO-type purchases, third party purchases, or even general mercantile purchases.

The prepaid purse would not be a deposit for FDIC purposes, as the FDIC definition of deposit only relates to Stored Value (hereafter SV) where the value is placed by the issuer of the payment instrument in a 'pooled' FDIC-insured (bank) account from which funds for a subscriber would be drawn. As such, the MNO under these circumstances of payment would not require an OCC or Over The Counter (hereafter OTC) license. While they may avoid deferral regulation relating to depository institutions, they may however be subject to other federal provisions such as those from the Financial Crimes Enforcement Network (hereafter FinCEN) of the US Department of Treasury, and electronic payments, particularly those relating to the Electronic Fund Transfer Act (hereafter EFTA) and Federal Regulation E (hereafter Reg E), both described below. ${ }^{65}$

In relation to the use of agents, there is no restriction per se on their use under the BSCA. Whether or not there is an outsourcing relationship to the financial institution, the same criteria apply.

B

State

\subsubsection{State Overview}

All the states may license national or state-wide banks, and place their products under the state laws dealing with banking. Most states have laws that address the 'business of banking', which usually encompass taking deposits and making loans and which require state licenses for the operation of state-wide banks. ${ }^{66}$

\footnotetext{
${ }^{62}$ Reichwein and Rosati (2007) op cit note 1 at 30-32.

${ }^{63}$ Ibid. Payroll processors may purchase some payment services from a bank, or Internet payments processors may purchase transaction processing services from a financial institution, or cheque cashing services may purchase services from a bank to process cheques. They all avoid supervision under these circumstances. See Reichwein and Rosati (2007) op cit note 1.

${ }^{64} \mathrm{Ibid}$. Even if these TSPs are examined and found to have weaknesses in their organisation, the supervisory agencies have limited enforcement power although they can prohibit financial institutions from doing business with them.

${ }^{65}$ See ch 11, s11.2.4.1 on the Electronic Fund Transfer Act (EFTA).

${ }^{66}$ According to Morgan (2005) op cit note 46, state laws tend to focus on the debtor-creditor relationship created by taking a demand deposit. California law, for example, says a depositor is one who transfers money to a bank to the credit of the
} 
The prudential frameworks that oversee banks and non-traditional financial services vary from state to state, but most are characterised as consumer protection statutes that establish certain safety and soundness standards. Entities providing SVPs may be subject to state MSB laws, discussed below.

\title{
11.2.3.5 Application to MFS
}

The states also license some institutions who offer services to 'unbanked' consumers. Where there is equivocation as to whether an entity involved in financial services actually takes deposits, and thus is not in the business of a bank, state money service laws may apply. ${ }^{67}$ Older statutes written specifically for licensing requirements for sellers of checks ${ }^{68}$ have been expansively interpreted by state regulators to include new payment instruments and (electronic) money transmission ${ }^{69}$ with several States taking the position that the transfer of money over the Internet or the use of an electronic payment instrument is the equivalent of money transmission or the sale of physical payment instruments. ${ }^{70}$ Indeed many still categorise new payment instruments as 'money transmitters'.71

The EFTA ${ }^{72}$ was first enacted in 1978. The EFTA is implemented by the Federal Reserve Board's Reg E. The EFTA mandates uniform protections for individual consumers for debit cards, Automated Clearing House (hereafter $\mathrm{ACH}$ ) Transfers, and consumer EFTs, ${ }^{73}$ as well as a recent addition, prepaid payroll

\footnotetext{
depositor and subject to the depositor's check, thereby creating a debtor-creditor relationship. Any entity that solicits or receives deposits is engaging in the business of banking.

${ }^{67}$ Some states implement the Uniform Money Services Act (2002) (hereafter UMSA) as a model law for MSBs. See Ramasastry (2005) op cit note 1 for a brief discussion of the key provisions of the UMSA.

${ }^{68}$ Travellers' checks and money orders are considered the original 'money transmitters'. See B Peterson (2006) 'Money Service Businesses: Meet Your Regulator(s)', available at http://goo.gl/Sr3aA for an overview.

${ }^{69}$ In Georgia, for example, bonds must be posted while in Alaska, all MSBs are required to obtain a license. See Alaska Division of Corporations, Business, and Professional Licensing Information (s.d.) 'Money Service Businesses (MSBs)', available at http://goo.gl/NH9Hf.

${ }^{70}$ As Ramasastry (2005) op cit note 1 points out, some states have included Stored Value (hereafter SV) within their existing money transmission law. She sites Connecticut's definition of SVPs as a form of 'electronic payment instrument'. West Virginia defines 'currency transmission' or 'money transmission' as including 'the transmission of funds through the issuance and sale of stored-value cards which are intended for general acceptance and use in commercial or consumer transactions'. See W. Va. Code 32A-2-1(6) (West 1999).

${ }^{71}$ In 2008, Florida altered its money transmission laws to encompass MSBs, and renamed the law as the 'Money Service Business Code' to reflect this. See ch 69V-560-2008 of Florida's Money Services Business law, available at http://goo.gl/iKoY2.

7215 USC 1693-1693. It was strengthened by the omnibus financial consumer protection law known as 'Dodd-Frank'. See ch 11, s11.2.4.2 on the Dodd-Frank Wall Street Reform and Consumer Protection Act above.

${ }^{73}$ An EFT is defined by the EFTA as:
}

\begin{abstract}
'any transfer of funds, other than a transaction originated by check, draft, or similar paper instrument, which is initiated through an electronic terminal, telephonic instrument, or computer or magnetic tape so as to order, instruct, or authorise a financial institution to debit or credit an account. Such term includes, but is not limited to, point-of-sale transfers, automated teller machine transactions, direct deposits or withdrawals of funds, and transfers initiated by telephone.'
\end{abstract}

See EFTA 15 USC §1693(a)(6) - Definitions. Reg E at §205.3(b) has a similar definition of an EFT, although it excludes inter alia any transfer of funds other than those processed via an $\mathrm{ACH}$ by a financial institution on behalf of a consumer by 
cards. ${ }^{74}$ These consumer rights cannot be abrogated by contract. ${ }^{75}$ The Act contains a catch-all provision allowing the Federal Reserve Board (hereafter FRB) to issue regulations that are '... in the judgment of the Board are necessary or proper to effectuate the purposes [of the EFTA] ${ }^{,},{ }^{76}$ which effectively allows the FRB to also regulate entities other than entities that do not necessarily fit the EFTA and Reg E's definition of an 'account'. 77

That is, it will regulate account-holding "financial institutions ${ }^{, 78}$ such as non-traditional financial institutions or persons other than financial institutions providing EFTs, including Internet-initiated transactions. $^{79}$

The types of transfers covered by the EFTA/Reg E include transfers initiated through an Automatic Teller Machine (hereafter ATM), Point of Sale (hereafter POS) terminal, ACH, telephone bill payment plan, or remote banking program. ${ }^{80}$

Reg E also applies to entities that issue access devices and enter into agreements with consumers to provide EFT services. EFTs can go through an ACH system, governed by the National Automated Clearing House Association (hereafter NACHA) rules.

While Reg E does not apply to reloadable SVCs, flexible spending account cards or travel cards, the inclusion of payroll SVCs in 2006 under the definition of account ${ }^{81}$ was a compromise decision that followed the FRB's continued reluctance to implement a previous proposal to regulate prepaid SVCs as an incarnation of e-money, ostensibly to allow these products to develop and fill a niche that serviced the unbanked. $^{82}$

means of a service that transfers funds held at either Federal Reserve Boards or other depository institutions and which is not designed primarily to transfer funds on behalf of a consumer.

${ }^{74} 12$ CFR pt 205 (2007).

${ }^{75}$ Office of the Comptroller of the Currency (OCC) (1998b) 'The Report of the Consumer Electronic Payments Task Force', available at http://goo.gl/EtLkt.

${ }^{76} 15$ USC $1693 b(C)$.

7715 USC §1693(b)(d)(1) Regulations: Applicability to service providers other than certain financial institutions. Reg E defines an 'account' primarily as a demand deposit (checking), savings, or other consumer asset account (other than an occasional or incidental credit balance in a credit plan) held directly or indirectly by a financial institution and established primarily for personal, family, or household purposes, and includes a 'payroll card account'. A payroll (or wages) account, is an account to which wages, salary, or other compensation, are deposited. Also see definition of an account in EFTA 15 USC $\S 1693(\mathrm{a})(2)$.

${ }^{78}$ A financial institution is defined as a 'bank, savings association, credit union, or any other person that directly or indirectly holds an account belonging to a consumer, or that issues an access device and agrees with a consumer to provide electronic fund transfer services'. See 12 CFR Part 205 \$205.2. Also see the EFTA definition of a financial institution at 15 USC $\S 1693(a)(8)$ as: 'a State or National bank, a State or Federal savings and loan association, a mutual savings bank, a State or Federal credit union, or any other person who, directly or indirectly, holds an account belonging to a consumer.'

${ }^{79}$ RJ Mann (2004) 'Making Sense of Payments Policy in the Information Age' 93 Georgetown Law Journal 633, available at http://goo.gl/E8dKR; here it is underlined and ME Budnitz (1997) 'Stored Value Cards and the Consumer: The Need for Regulation' 46 American University Law Review 1027, available at http://goo.gl/5Nxe6.

${ }^{80} 15$ USC 1601-1667 (f) (2000)

${ }^{81}$ See FRS 12 CFR Part 205 Reg E; Docket \#R-1247. EFTs where payroll card accounts specifically are included in the definition of 'account' for purposes of Reg E. See Federal Reserve Board (FRB) (2006) 'Electronic Funds Transfers', available at http://goo.gl/9zG36.

${ }^{82}$ K Neely and E Fonte (2010) 'The Future of Plastic', available at http://goo.gl/zmlxL; RG Ballen and TA Fox (2008) 'The Role Of Private Sector Payment Rules And A Proposed Approach For Evaluating Future Changes To Payments Law' 83(2) Chicago-Kent Law Review 937 at 948; S Ritchie (2005) 'Will Regulators Burst the Prepaid Bubble?' 9 North Carolina Banking Institute Journal 201-222 at 220, available at http://goo.gl/RnXN0 notes that this limited view over prepaid cards is consistent with its prior attempt at regulating them in 1996. See the brief discussion thereof in ch 11, s11.2.5.3 on Regulation E and Regulation Z. 
Any transaction within the parameters of the EFTA/Reg E regime will generally protect consumers from losses caused by any unauthorised transactions. ${ }^{83}$

Reg E itself limits a consumer's liability for any unauthorised EFTs involving his account to no more than US $\$ 50$ if he notifies the financial institution within two business days after learning of the loss or theft of an access device. ${ }^{84}$

The EFTA/Reg E regime also provides a detailed dispute resolution process for resolving claims of errors by the financial institution in charging a consumer's account for a funds transfer and for losses for unauthorised transfers. ${ }^{85}$

The scale of the protection is limited however to whether the EFT is strictly covered by the EFTA/Reg E, and even if it is, the protection is dependent on inter alia, timely reporting of the fraud or loss by the consumer and use of an accepted card or other means of access. ${ }^{86}$

The law is however clear that debit cards from issuers and EFTs generally are covered. ${ }^{87}$

Enforcement is spread through multiple agencies. ${ }^{88}$

\footnotetext{
${ }^{83}$ See Mann (2004) op cit note 79 at 13-14. The EFTA and Reg E require issuers to make various initial disclosures of terms and conditions of the EFT service, including the consumer's liability for unauthorised transfers; charges for services; the consumer's right to receive documentation such as statements of activity; the right to stop payment of preauthorised transfers; information disclosure; and error resolution procedures.

${ }^{84}$ If the consumer fails to notify the financial institution within two business days after learning of the loss or theft of the access device, the consumer's liability shall not exceed the lesser of US\$500 or the sum of US\$50 or the amount of unauthorised transfers that occur within the two business days, whichever is less; and the amount of unauthorised transfers that occur after the close of two business days and before notice to the institution, provided the institution establishes that these transfers would not have occurred had the consumer notified the institution within that two-day period. A consumer must report an unauthorised EFT that appears on a periodic statement within 60 days of the financial institution's transmittal of the statement to avoid liability for subsequent transfers. See Sec. 205.6 Liability of Consumer for Unauthorised Transfers. The total liability for a consumer is US\$50 for credit cards. See 12 CFR 226.12(b)(1).

${ }^{85}$ Mann (2004) op cit note 79 at 13-14. If the unauthorised transfer is done using an access card method such as a Personal Identification Number (hereafter PIN) code, the consumer can be held liable for certain amounts. See 15 USC §1693g(a)(1)(2) where the statute specifies that under those circumstances, the loss to the consumer is capped at the lesser of the amount taken or US\$50 per unauthorised transaction. Further, the statute allows the consumer to be held liable for up to US\$500 if the consumer does not report the loss or theft of an access device within two business days of discovery. If the consumer does not report an unauthorised fund transfer that appears on a statement provided to the consumer within 60 days (or longer for extenuating circumstances), and the financial institution establishes that the loss would not have occurred if the report had been timely, then the consumer's potential loss is not limited by the statute.

${ }^{86} 15$ USC $\$ 1693 \mathrm{~g}(\mathrm{a})$.

${ }^{87}$ Banks, in this case, or anyone captured by the definition of deposit.

${ }^{88}$ Reichwein and Rosati (2007) op cit note 1. Generally, enforcement may include examination of covered institutions for compliance as well as consumer disputes. Curiously, although Reg E emanates from the FRS, there is no single federal agency that enforces it. Rather, it is currently enforced by various agencies in their respective jurisdictions. For example, federal financial institution supervisory agencies will enforce Reg E for banks, thrifts and credit unions, while the SEC enforces it for the brokers and dealers in its jurisdiction. Retailers and other payment participants not covered by other agencies face enforcement by the FTC. The newly formed CFPB may, however, undertake many of these disparate enforcements. See ch 11, s11.2.4.2.2 on the Consumer Financial Protection Bureau (CFPB).
} 


\subsection{Overview}

The Dodd-Frank Wall Street Reform and Consumer Protection Act ${ }^{89}$ (colloquially and hereinafter referred to as 'Dodd-Frank') is a wide-ranging set of financial reforms that make the largest change in financial regulation in decades. It was developed in direct response to the Great Recession in the US and elsewhere, where inter alia reckless lending practices and a general lack of oversight and regulation of financial institutions led to financial meltdowns. A number of new agencies are created, with power granted over a particular aspect of financial regulation, or power transferred from an existing agency. With consumer financial protection measures spread across agencies with specific institutional responsibilities, Dodd-Frank creates a super-agency, the CFPB described below.

\subsection{Consumer Financial Protection Bureau}

The relatively new CFPB - also known as the Bureau for Consumer Financial Protection (BCFP) consolidated consumer protection powers from a variety of agencies as well as being empowered with sweeping rulemaking and enforcement authority. In contrast to previous law, the CFPB largely supersedes the FTC's enforcement authority over federal consumer financial statutes, and importantly, gives the CFPB rulemaking authority that enables it to write rules autonomously for consumer protections governing all financial institutions - including banks and non-banks - offering consumer financial services or products. ${ }^{90}$ This rulemaking authority will cover most federal consumer-related financial laws that are currently handled by a variety of different federal agencies. ${ }^{91}$ While the CFPB is expected to issue new rules possibly consolidating the protections - and exclusions - the variables in Reg E and Federal Regulation Z (hereafter $\operatorname{Reg} \mathrm{Z}$ ) are likely to remain in force until that time. ${ }^{92}$

Of a selection of its broad powers, and notably, in recognition of the CFPB's specific remit, s1061(b)(5) deprives the Federal Reserve, the OCC, the FDIC, and the FTC of general authority to make and prescribe rules, issue guidelines, conduct studies, or issue guidelines related to consumer protection for financial

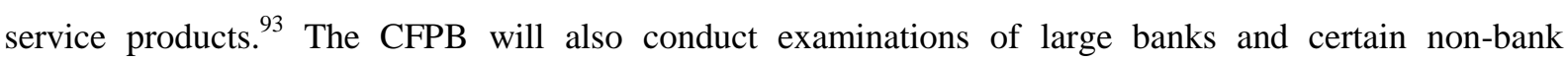
providers of financial services and products to enable it to highlight potential consumer issues, issue new rules, and enforce them with minimal complication. ${ }^{94}$ While the CFPB will examine all depository institutions over US\$10bn and their service providers, Dodd-Frank at $\$ 1024$ also mandates the CFPB to examine certain other non-deposit taking institutions. It will also have authority over 'Covered Persons'

\footnotetext{
${ }^{89}$ Pub. Law 111-203, H.R. 4173.

${ }^{90}$ US Senate Committee on Banking, Housing, and Urban Affairs (2010) op cit note 1.

${ }^{91}$ This includes the OCC, the former OTS, the FDIC, the FRS, the National Credit Union Administration (hereafter NCUA), the Department of Housing and Urban Development, and the FTC.

92 E Cohen-Cole (2010) 'Consumer Protection and Regulatory Changes in the Dodd-Frank Bill' NERA Economic Consulting, available at http://goo.gl/2EIP0. The CFPB to write rules to curtail deceptive, unfair, or abusive practices related to consumer financial products; and for the imposition civil fines and criminal actions by the Department of Justice.

${ }^{93}$ Section 1073 though mandates the FRS to prescribe rules to govern money remittance transfers and certain acts of remittance transfer providers. These include notices and disclosures; error resolution; liability for agents and delegates; and ACH expansion. Section 1028(a) allows the CFPB to restrict mandatory pre-dispute arbitration clauses between financial service companies and consumers.

${ }^{94}$ Cohen-Cole (2010) op cit note 92.
} 
whose conduct poses a risk to consumers and it will determine who these persons are based on complaints or surveillance. ${ }^{95}$

It also has powerful rulemaking authority to write new rules to curtail deceptive, unfair, or abusive practices related to consumer financial products. ${ }^{96}$ This does not of necessity, though, require the reexamination of inherited rules. However it must conduct cost/benefit analysis for its new rules, consider the impact on Deposit Institutions that have capital of under US\$10bn, the impact on consumers in rural areas, must conduct consumer testing for all model form disclosures, must study mandatory arbitration clauses and can issue regulations based on its findings. The new Financial Stability Oversight Council can stay or overrule regulations if they pose a danger to the financial system.

\subsubsection{Additional Consumer Protection Legislation}

The Truth in Lending Act (hereafter TILA) ${ }^{97}$ implemented by Reg Z of the FRB, ${ }^{98}$ grants consumers a broad right to withhold payment even for authorised transactions if the seller fails to perform as agreed, and the Act is designed to protect consumers in credit by requiring that key terms of the lending arrangement and all costs be made clear. TILA's general rulemaking authority was transferred to the CFPB.The Expedited Funds Availability Act (hereafter EFAA) ${ }^{99}$ and the Check Clearing for the 21st Century Act (Check $21 \mathrm{Act})^{100}$ were enacted to standardise hold periods on deposits made to commercial banks and to regulate institutions' use of deposit holds. The Check 21 Act allows a recipient of the original paper check to create a digital version of the original check, called a 'substitute check'. Regulation CC (hereafter Reg $\mathrm{CC}$ ) was issued by the FRB to implement the EFAA ${ }^{101}$ Users of credit cards are protected by the Consumer Credit Protection Act, an umbrella consumer protection law that provides for loss allocation rules for credit cardholders. ${ }^{102}$

\footnotetext{
${ }^{95}$ Keitel (2010) op cit note 1.A Financial Stability Oversight Council was formed through Dodd-Frank, and is charged with identifying and responding to emerging risks throughout the financial system by promoting market discipline. It may also regulate non-bank financial companies if it believes there would be negative effects on the financial system if the company failed or its activities would pose a risk to the financial stability of the US.

${ }^{96}$ The CFPB could also impact consumer protection litigation, restricting as it does mandatory pre-dispute arbitration clauses between financial service companies and consumers, s1028(a) of Dodd-Frank. However this may be affected by a recent Supreme Court decision in AT\&T Mobility LLC v Concepcion, Slip Opinion \#09-893, available at http://goo.gl/894Qg.

${ }^{97}$ Truth in Lending Act of 1968 Pub. Law No. 90-321 (hereafter TILA).

${ }^{98} \mathrm{Reg} \mathrm{Z}$ is codified at 12 CFR Part 226. It mandates standardised disclosures about credit terms and costs. The TILA also gives consumers the right to cancel certain credit transactions.

9912 USC 4001-4010.

10012 USC 5001-5018.

10112 CFR Part 229. Reg CC sets down the requirements that depository institutions make funds deposited into transaction accounts available according to specified schedules. The checks covered in Reg CC should not be confused with e-checks, which are electronic debits to a checking account that is initiated on the Internet, at the POS, or over the phone. See Federal Financial Institutions Examination Council (s.d.) 'Consumer Affairs Laws and Regulations: Regulation CC', available at http://goo.gl/X1pIv.

${ }_{102}$ Consumer Credit Protection Act 15 USC $\$ 1601$. The Act includes the Equal Credit Opportunity Act, the Fair Credit Billing Act, the Fair Credit Reporting Act, and the Truth in Lending Act. In terms of the Act, limits on a consumer's liability are established such that a cardholder shall be liable for the unauthorised use of a credit card only if: the card is an accepted credit card; the liability is not in excess of US\$50; the card issuer gives adequate notice to the cardholder of the potential liability; the card issuer has provided the cardholder with a description of a means by which the card issuer may be notified of loss or theft of the card, which description may be provided on the face or reverse side of the statement or on a separate notice accompanying such statement; the unauthorised use occurs before the card issuer has been notified that an unauthorised use of the credit card has occurred or may occur as the result of loss, theft, or otherwise; and the card issuer has provided a method whereby the user of such card can be identified as the person authorised to use it. The Fair Credit Billing Act (FCBA) 15 USC $\$ 1666$ was enacted in 1974 as an amendment to the Consumer Credit Protection Act, and defines and establishes a procedure for resolving billing errors in consumer credit transactions.
} 
The more recent Credit Card Accountability, Responsibility and Disclosure Act (Card Act) passed in 2009 curtailed many practices regularly used by credit card providers and mandated new disclosure rules. ${ }^{103}$ It also applies to gift cards and GPR cards. ${ }^{104}$ The creation of the CFPB consolidates enforcement of the Card Act in a single agency.

\subsubsection{Application to MFS}

For the general purposes of MFS, a provision in Dodd-Frank affects some potential additive MFS models in that banks with over US\$10bn in assets are restricted in the (debit card swipe) fees they may charge in that they must be 'reasonable and proportional to the actual cost' of processing the transaction, for fees for fraud prevention on debit transactions and debit transaction network fees. It also includes provisions which allow retailers to refuse to use cards for small purchases and offer incentives for using cash or another type of card. ${ }^{105}$ There are however statutory exemptions for small issuers under US $\$ 10 \mathrm{bn}$ in assets from the new debit fee rules, as well as for government-administered payment programs and reloadable SVPs. ${ }^{106}$

In relation to Person to Person (hereafter P2P) transfers, s1073 of Dodd-Frank mandates rules for P2P money transfers by amending the EFTA by adding a new s919, entitled 'Remittance Transfers' alongside laws that mostly fall under omnibus provisions relating to AML. ${ }^{107}$

The CFPB has subsequently issued proposed rules in terms of s919 that amend Reg E to protect consumers who send money electronically to foreign countries, a transaction which it terms 'remittance transfers' ${ }^{108}$

\footnotetext{
${ }^{103}$ Credit Card Accountability Responsibility and Disclosure Act of 2009, Pub. Law No. 111-24, 123 Stat. 1734 (codified in scattered sections of 15 USC). The Act is available at http://goo.gl/Sw7aj. See also Cohen-Cole (2010) op cit note 92 passim. ${ }^{104}$ It applies to gift certificates, store gift cards and GPR cards. Not every type of gift card is covered by the law though: paper gift certificates, GPR cards not marketed as gift cards such as Visa or MasterCard prepaid cards, and telephone cards are exempt from the restrictions as are loyalty, award or promotional gift cards. The card itself must include certain disclosures regarding expiry dates, fees and contact information. The card or the underlying funds must be good for at least five years from issuance, similar in the South African Consumer Protection Act 68 of 2008 (hereafter CPA) which is 3 years. The issuer cannot impose any inactivity, dormancy or service fee unless there has been a one-year period. The new regulation conflicts with many existing state unclaimed property laws; see L McFadden (2010) 'How the CARD Act impacts gift cards' Bankrate, available at http://goo.gl/YFko; and Neely and Fonte (2010) op cit note 82.

${ }^{105}$ Section 1075 of Dodd-Frank amends the EFTA to prohibit card issuers from establishing anti-competitive payment card network restrictions, including inhibiting the ability of any person to provide a discount or in-kind incentive for the use of cash, cheque or another payment card; or inhibiting the ability of any person to set minimum or maximum dollar amounts for the use of card.

${ }^{106}$ Section 1075 extends through the EFTA amendment, the exemption in respect of fees to a plastic card, payment code, or device that is linked to funds, monetary value, or assets which are purchased or loaded on a prepaid basis; or not issued or approved for use to access or debit any account held by or for the benefit of the cardholder (other than a subaccount or other method of recording or tracking funds purchased or loaded on the SVC on a prepaid basis); or redeemable at multiple, unaffiliated merchants or service providers, or ATMs; or used to transfer or debit funds, monetary value, or other assets; or reloadable and not marketed or labelled as a gift card or gift certificate. See further below in ch 11, s11.2.5.5 titled Application to MFS for the scope and effect of laws and regulations on mobile-related SVPs.

${ }^{107}$ Specifically regulating the businesses of money transmission insofar as they fall within parameters set by statute and require registration and reporting. Licensing is within the ambit of state money transmitter and MSB-type laws and regulations.

${ }_{108}$ The new rules relate to banks, thrifts, credit unions, and money transmitters. CFR Part 1005 [BCFP 2012 Final Remittance Rule (Amendment to Regulation E)], available at http://goo.gl/kC8qM. They take effect in January 2013 and require companies to give to a consumer certain disclosures before the consumer pays for a remittance transfer. The disclosure must list the exchange rate, fees, and the amount of money to be delivered. Consumers get around 30 minutes to cancel. For certain errors, consumers can get a refund or transfer without charge the money that did not arrive as promised and companies that provide remittance transfers are responsible for mistakes made by certain people who work for them. It includes EFTs. Exemptions to some disclosure rules are allowed if, for example, a sender initiates the transaction electronically and the information is displayed electronically in a manner that the sender can keep.
} 
The new rules apply to values of more than US $\$ 15$, made by a consumer in the US, and sent to a person or company in a foreign country, and apply whether or not the transfers are EFTs within the meaning of the EFTA as well as whether or not the consumer maintains an account with the money transmitter. ${ }^{109}$

The plain language of s919 suggests that new domestic P2P remittance rules can also be expected, although where there is intra-MNO transfer of value (rather than monetary value), it is not certain where this type of scheme would fall for the purposes of the CFPB rules, laws and regulations as there does not appear to be a statutory framework to provision them.

Dodd-Frank though also holds a remittance transfer provider liable for any violation by any agent, authorised delegate, or person affiliated with such provider, when such agent, authorised delegate, or affiliate acts for that remittance transfer provider. ${ }^{110}$

\subsubsection{5}

\section{Overview}

Implementation of the states' payments and money laws are largely through the Uniform Commercial Codes and 'Model Acts' like the Uniform Money Services Act described below that are proposed laws on topics where reform not uniformity is the dominant aim and which allow state legislatures to make alterations. $^{111}$

\subsubsection{Uniform Commercial Code}

\subsection{Overview}

The Uniform Commercial Codes (hereafter UCC) are seen as the bellwether and core of the state's own creation and implementation of commercial law. ${ }^{112}$ Only acts of Congress are equivalent to the UCC insofar as homogenous rules applying to each state, although there is an increasing number of federal laws

\footnotetext{
${ }^{109}$ Remittance transfers within the Dodd-Frank Act that do not meet the definition of electronic funds transfers under EFTA $\$ 903$ are not subject to EFTA s905- 9136, while those remittance transfers that are within the definition of electronic funds transfers in s903 will be subject to all EFTA provisions except s908, regarding error resolution, which is governed by the new EFTA's s919(d). Remittance transfers that are currently subject to the EFTA and Reg E will continue to be subject to existing rules as well as the new remittance transfer requirements of s919. The section though provides an exception in information disclosure for a remittance transfer provider in regard to the amount of currency to be received if the provider is an FDICinsured depository institution and if a remittance transfer is conducted through a demand deposit, savings deposit, or other asset account that the sender holds with such remittance transfer provider. See further, SR Koppel (2010) 'The Dodd-Frank Act: Remittance Transfers', available at http://goo.gl/snzHa.

${ }^{110}$ Section 919(f)(1).

111 There are also 'Restatements', devised by the ALI and to codify or restate areas still governed by common law. AH Boss (2007) 'The Future of the Uniform Commercial Code Process in an Increasingly International World' 68 Ohio State Law Journal 349 passim, available at http://goo.gl/et5T0.

${ }_{112}$ Devised in the 1950s, the UCC and its revisions are overseen by the non-governmental National Conference of Commissioners on Uniform State Laws and the American Law Institute (ALI). Their output as sets of 'Uniform Codes' is, however, not law anywhere in the US per se, but rather legislative proposals addressed to state legislatures. Boss (2007) op cit note 111.
} 
and regulations that pre-empt state consumer laws. ${ }^{113}$ In the payments and 'money' areas, Arts 3, 4 and 4A are the leading Codes. While almost all states have adopted the UCC, either verbatim or with changes that are necessary to integrate into a particular state's laws, the UCC has been criticised as being the product of 'private rule making' that poses high barriers to effective consumer participation. ${ }^{114}$ The UCC also allows contracting out of its provisions. ${ }^{115}$

\subsection{Uniform Commercial Code Articles 3, 4, and 4A}

The Uniform Commercial Code 3 deals with checks, where the consumer's potential loss ranges from no loss to the loss of all. A consumer is not responsible for an unauthorised check unless that check is one of a series, in which case comparative negligence may apply. UCC 4 deals with interbank collection of checks, and the rights and obligations of banks and their customers with respect and relationship between a bank, its depositing customer and its check drawer customer insofar as the liability of a bank for action or nonaction with respect to an item ${ }^{116}$ handled by it. ${ }^{117}$ UCC 4 says that consumers will not be responsible for the first in a series of forged or unauthorised checks, but their later culpability in mitigating losses depends on whether they reasonably could have discovered and reported the problem to allow a bank to stop further losses. ${ }^{118}$ Unlike Federal Payment laws associated with checks, the UCC 4 rule may be contractually varied between bank and customer. ${ }^{119}$ UCC $4 \mathrm{~A}$ governs wholesale 'funds transfers' made through the banking system, allocating risks of losses between the parties. If a consumer sends money through the banking system and uses a wire service system, the transaction is covered by Art 4A.

\subsubsection{Money Service Businesses Laws}

\subsection{Overview}

The states are the primary front line regulators of non-traditional financial entities that offer a diverse range of services like cheque cashing, money transmission and foreign exchange to the unbanked. The state laws governing these services may be product descriptors, for example 'Money Transmitter' or 'Check Cashing'

\footnotetext{
${ }^{113}$ Federal agencies are snatching enforcement authority from the hands of state agencies, says Budnitz (2008) op cit note 1 at 9. See also for example Watters $v$ Wachovia Bank, N.A., 127 S. Ct. 1559, 1564-65 (2007), where the US Supreme Court upheld the OCC's power to pre-empt state law, stating that the National Bank Act pre-empted state supervision over national bank subsidiaries.

${ }^{114}$ Criticisms include that the process has been dominated by interest groups such that the results have not been in the broader public interest. For an overview of these criticisms, see G Hillebrand (2001) 'What's Wrong with the Uniform Law Process?' 52 Hastings Law Journal 631, 632, 640-41; and RK Rasmussen (2002) 'The Uneasy Case Against the Uniform Commercial Code' 62(4) Louisiana Law Review, available at http://goo.gl/yRGi1.

${ }^{115}$ The UCC allows contracting out of its provisions in circumstances where at least one of the parties believes that the UCC default rule does not adequately protect their interests. See SH Jenkins (2007) 'Contracting Out of the UCC (Introduction)' 40 Loyola of Los Angeles Law Review, available at http://goo.gl/i5KW6; and S Heller (2007) 'An Endangered Species: The Increasing Irrelevance of Article 4 of the UCC in an Electronics-Based Payments System' 40 Loyola of Los Angeles Law Review 513.

${ }^{116}$ Section 4-104(a)(9) defines an item as 'an instrument or a promise or order to pay money handled by a bank for collection or payment. The term does not include a payment order governed by Art 4A or a credit or debit card slip.'

${ }^{117}$ The rules on bank collection set forth in UCC Art 4 have been supplemented by the FRB's regulations, such as those in the Expedited Funds Availability Act (hereafter EFAA).

${ }^{118}$ See UCC $\$ 4-406(\mathrm{e})$, and discussions of the consumer protection clauses by Hillebrand in G Hillebrand (2008) 'Before the Grand Rethinking: Five Things to do Today with Payments Law and Ten Principles to Guide New Payments Products and New Payments Law' 83(2) Chicago-Kent Law Review, at 769.

${ }^{119}$ UCC 4's necessity in an era of EFTS has been questioned by Heller (2007) op cit note 115, while others see a legal necessity for its use, whilst banks use electronic cheque imaging systems and so-called telephone-cheques. Indeed Arts 3 and 4 were amended to cater for so-called remotely created cheques.
} 
laws. They can vary greatly from state to state in terms of their scope and licensing regimes, but on the whole are primarily consumer protection-focussed. ${ }^{120}$ With the emergence of products such as gift cards, wireless transfers, and other prefunded SVPs that do not necessarily have a regulatory home under these laws, many states are modernising their payment laws to take into account these new payment products. It is an inexact science, though: the new technologies have simply been bolted onto 'check' or 'money transmitter' statutes, the rationale for the latter being that these products are simply vectors in aiding the overall act of 'money transmission'. While there is the bolt-on approach, some states regard these products as being of a generic appellation MSBs regulated under new 'Money Service Business' laws (hereafter MSB laws). These MSB laws may be renamed and updated check or money transmitter laws, or may be de novo pieces of legislation. Their regulatory schemes require those who comport within the ambit of a states' MSB legislation to obtain a licence from a state regulatory body, ${ }^{121}$ meet certain net worth requirements and post a bond. ${ }^{122}$ Failure to register (as an MSB or equivalent) can be both a state and federal offence. ${ }^{123}$

MSB-type statutes are viewed as inconsistently structured or interpreted, with the states varying the extent to which they regulate both payment instrument sellers and money transmission. ${ }^{124}$ Some states regulate money transmission, others the sale of payment instruments and still others a combination of the two activities. Only some states have created frameworks that link all MSBs together within a statute, with uniform enforcement and penalty provisions for all MSBs whilst at the same recognising the differences inherent in the various activities concerned and so retaining separate licensing and record keeping provisions for each type of money service activity. ${ }^{125}$

\subsection{Uniform Money Services Act}

Uniformity is somewhat available through utilising the provisions of the Uniform Money Services Act (hereafter UMSA), a model law first approved by the National Conference of Commissioners on Uniform State Laws (hereafter NCCUSL) in 2000. ${ }^{126}$

The UMSA was developed to assist states in juxtaposing new payments instruments and systems with their existing money services state consumer protection laws. ${ }^{127}$

\footnotetext{
${ }^{120}$ T Bolt and A Ramasastry (2004) 'Memorandum (to the) Drafting Committee and Observers on Revisions to Uniform Money Services Act', available at http://goo.gl/i6Cg5

${ }^{121}$ This is usually the regulatory agency that supervises banks in a state. See Morgan (2005) op cit note 46.

${ }^{122}$ Ibid.

${ }^{123}$ There have been some prosecutions under state and federal AML statutes via state MSB Acts. See United States Department of Justice (2008) 'Digital Currency Business E-Gold Pleads Guilty to Money Laundering and Illegal Money Transmitting Charges', available at http://goo.gl/379zC

${ }^{124}$ Peterson (2006) op cit note 68.

${ }^{125}$ See, for example, Florida's MSB op cit note 71. It imposes additional regulatory requirements on MSBs, inter alia, requiring compliance with federal AML regulations and a requirement to suspicious file currency transport and transaction reports with the Financial Crimes Enforcement Network (hereafter FinCEN).

${ }^{126}$ See UMSA (2002) as amended, available at http://goo.gl/E8vJI.

127 The UMSA states its goals and objectives inter alia to be a state safety and soundness law that creates licensing provisions for various types of MSBs. The UMSA creates a framework that connects all types of MSBs and sets forth clearly the relationship between a licensee and its sales outlets. See Prefatory Note of the Uniform Money Services Act (UMSA) (2004) as amended, available at http://goo.gl/wDFHa.
} 
The Act takes the approach that newer electronic payment mechanisms may pose the same safety and soundness concerns as non-electronic payment mechanisms. It thus incorporates some Internet payment mechanisms into the statute's licensing framework, but does not include new or different licensing regimes for such payment mechanisms. ${ }^{128}$

Many of the provisions within the UMSA are modelled on the EU's Electronic Money Directives (hereafter EMDs). ${ }^{129}$

It has two separate licensing regimes, one for money transmitters and another for check casher and currency exchangers.

However it somewhat confusingly groups money transmitters, payment instrument sellers, and certain types of Internet payment services all under the banner of 'money transmitters' ${ }^{130}$

Based on the UMSA structure and definitions, disparate state MSB-type or updated check/money transmission statutes have a few common definitional themes.

These include definitions of money transmission, ${ }^{131}$ payment instruments, ${ }^{132}$ MSBs, checks, SVPs, ${ }^{133}$ and monetary instruments. It defines 'money' as a Means of Exchange (hereafter MOE) that is authorised or adopted by the United States or a foreign government. ${ }^{134}$

The term includes a monetary Unit of Account (hereafter UOA) established by an intergovernmental organisation or by agreement between two or more governments. ${ }^{135}$ Some loopholes relating to money transmission still appear to remain, with disparate approaches to regulation. ${ }^{136}$

\footnotetext{
${ }^{128}$ It also has some AML provisions that reflect the state's desire towards definitional conformity and a rational framework for licensing based on federal AML statues, specifically the AML provisions on MSBs in the PATRIOT (Uniting and Strengthening America by Providing Appropriate Tools Required to Intercept and Obstruct Terrorism Act) Act. See USA Patriot Act, Pub. Law \#107-56, 115 Stat. 272 (2001) (codified as amended in scattered sections of 18 USC, 28 USC, 31 USC, 47 USC, 50 U.S.C.), available at http://goo.gl/zmmq6.

${ }^{129}$ See the UMSA (2004) op cit note 127. Prefatory notes to the UMSA on 'money',

${ }^{130}$ The definition of 'money transmission' under s102 of the UMSA is the 'selling or issuing payment instruments, stored value, or receiving money or monetary value for transmission. The term does not include the provision solely of delivery, online or telecommunications services, or network access.' It excludes from the ambit of the Act 'instruments redeemable by the issuer in goods or services', that is, closed systems. This is utilised in a number of definitions in subsequent state MSB Acts. The Act expands the definition of 'money' to reflect the fact that certain payment service providers employ a form of value that is not directly redeemable in money, but nevertheless serves as a Means of Exchange (hereafter MOE) and places the customer at risk of the provider's insolvency while the medium is outstanding.

131 'Money transmission' typically includes the transmission of money and the sale or issuance of payment instruments. See Morgan (2005) op cit note 46.

132 'Payment instruments' are defined broadly to include 'a check, draft, money order, traveller's check, or other instrument for the transmission or payment of money or monetary value, whether or not negotiable. The term does not include a credit card voucher, letter of credit, or instrument that is redeemable by the issuer in goods or services.'

${ }^{133}$ In UMSA (2004) - (21) op cit note 127: 'stored value' means 'monetary value that is evidenced by an electronic record.'

${ }^{134}$ UMSA (2004) op cit note 127: Definitions (12).

${ }^{135}$ Correspondingly, 'monetary value' is defined as a 'medium of exchange, whether or not redeemable in money.' The accompanying notes to the UMSA indicate that MOE refers to value that is exchanged and accepted by a community that is larger than the two ('bilateral') parties to an exchange. While it recognises that bilateral Units of Account (hereafter UOA) would not constitute 'monetary value' for purposes of the Act, there may come a point where certain types of (monetary) value metamorphoses into a species that has become widely accepted to acquire products that are beyond the initial scope of their issuance, so as to constitute a means of exchange. Other factors it takes into account in determining this evolution to 'widely accepted' include just how widely circulating such value is, whether the value is redeemable, and whether the value can be used to purchase or acquire a wide range of products and services. The line is very blurred though. Texas, for example, requires the issuer of shopping mall gift certificates that can be redeemed at multiple issuers to become licensed.
} 
The payments industry in the US has evolved a number of self-regulation initiatives that set standards inter alia for the control and mitigation of payments risk.

\subsubsection{National Automated Clearing House Association}

There are a range of private rules that may capture mobile payments. Some have been incorporated by reference into the FRB rules. For example, there are rules on payments created and overseen by the NACHA, a non-profit association ${ }^{137}$ that oversees and establishes standards, rules, risk mitigation, and procedures that enable participating depository financial institutions to exchange payments across the ACH network, a nationwide EFT system. ${ }^{138}$ All merchants and financial institutions using ACH for electronic transfers contractually agree to comply with the NACHA Operating Rules. ${ }^{139}$

\subsubsection{Credit Card Networks}

The credit card networks based in the US developed a Payment Card Industry (hereafter PCI) data security standard. ${ }^{140}$ The Payment Card Industry Data Security Standard (hereafter PCI DSS) is a set of requirements designed to ensure that all companies - such as any merchant that has a merchant ID - that process, store, or transmit credit card information maintain a secure environment.

\footnotetext{
The UMSA analysis predicts that in determining whether or not a value has de facto become a MOE, a major factor in this determination will be just how wide the use and the circulation of a certain type of value may be.

${ }^{136}$ See Peterson (2006) op cit note 68, who points out that some UMSA implementations prohibit receiving money from customers for money transmission purposes without a license, although they are silent about the actual transmission of money itself. Others prohibit both the receiving of money for transmission and the actual transmission of money without license. Others prohibit money transmission but make no explicit mention of electronic transmission.

137 The National Automated Clearing House Association (hereafter NACHA) represents more than 11,000 financial institutions through direct membership and 19 regional payments associations that link diverse payments systems.

${ }^{138}$ The ACH provides for the interbank clearing of electronic debits. It is supported both by the FRS and by private or bankowned companies. See M Crowe, S Schuh, and J Stavins (2006) 'Consumer Behavior and Payment Choice: A Conference Summary' at 7, available at http://goo.gl/TyEux ; and B Mantel and T McHugh (2002) 'Changing E-Payment Payment Networks in the U.S.: The Strategic, Competitive \& Innovative Implications' 2-10 cited in Mann RJ 'Regulating Internet Payment Intermediaries' 86 Texas Law Review 681-683, who also speaks of telecommunication and MNOs advancing the concept of micro-payments.

${ }^{139}$ Budnitz describes the evolution of these rules as '[ $t$ ]he partial privatization of payment law'. See Budnitz (2007) op cit note 1 at 119 . Although consumers are not a party to these agreements, contractual service contracts between consumers and their banks may require the consumer to comply with NACHA rules and, by corollary, afford the consumer rights if the bank and/or merchant do not abide by ACH rules. See Security First Network Bank v C.A.P.S. Inc. 2002 WL 485352, (ND Ill 2002) at 6, where the court found that the agreement between the customer and the bank incorporated the NACHA rules and allowed the customer to reap the benefits of that agreement. This carte blanche approach was not followed in Volden $v$ Innovative Financial Systems, Inc., 440 F.3d 947 (8 Cir. 2006).

${ }^{140}$ The Council's five founding global payment brands - American Express, Discover Financial Services, JCB International, MasterCard Worldwide, and Visa Inc. See PCI Security Standards Council at http://goo.gl/ObEaV.
} 
While there have not been any new implementing statutes to authorise the use of payments over the Internet, ${ }^{141}$ private rules have been developed. The NACHA imposed pecific requirements relating to authorisation of the payments and verification of a consumer's identity. For debit and credit cards, the card associations created unique rules relating to charge-backs and authorisations that differ from bricks and mortar transactions. ${ }^{142}$

This higher order of complexity where the MNO is acting as a payment intermediary in a closed (and nominally) MSB-exempt system presages a larger conceptual conundrum, when consumers use products in mixed environments ${ }^{143}$ or where new hybrid payment products appear. While Mann correctly indicates that the legal rules for consumer protection depend on how the consumer pays for the transaction, equally important in this new mixed payment universe is what the consumers purchase. Bespoke money transmitter laws and regulations appear to comprehensively capture this type of value transfer, requiring licenses for those engaged in money transfer. This applies even to intermediaries that piggyback on mobile phone systems without necessarily being integrated into the mobile purse. ${ }^{144}$ Many states require an MSB to be licensed and to have an insurance bond to cover any loss if money does not reach its destination or any payment instrument issued fails. ${ }^{145}$

\subsubsection{E-Money and SVPs}

\subsubsection{Overview}

While federal and state laws and regulations make copious reference to 'electronic money' and its varied nomenclature, unlike the EU, there is no framework per se in federal law that provides guidance as to what could qualify as electronic money.

Despite the lack of a specific e-money law, issuance of any form of money is regulated by the OCC, which has a broad mandate for 'the issue and regulation of a national currency secured by United States bonds and, under the general supervision of the Board of Governors of the Federal Reserve System, of all Federal Reserve notes. ${ }^{, 146}$ Insofar as a form of 'money' may or may not be legal tender, 31 U.S.C $\S 5103$ says that:

\footnotetext{
${ }^{141}$ Ballen and Fox (2008) op cit note 82 at 945.

${ }^{142}$ These are the so-called 'Card Not Present' rules. See, inter alia, Visa's chargeback rules which govern disputed charges. See Visa (2007) 'Rules for VISA Merchants: Card Acceptance and Chargeback Management Guidelines' at 63, available at http://goo.gl/xiKmx. See also MasterCard Worldwide (2011) 'MasterCard Rules' 7 December, available at http://goo.gl/Ee6Cn.

${ }^{143}$ For example, the consumer may with the same magnetic stripe or chip card, use the card either as a debit, ATM or credit card at a POS terminal and, where possible, in an online environment. This choice mediates which payment rules and degrees of protection they are afforded for that transaction, although as pointed out by Mann (2004) op cit note 79, their choice may not be their own as the POS device may provide them with only one choice, even if the consumer's intent is different.

${ }^{144}$ For an overview of the regulatory requirements in the US for mobile money transmitters, see C Daniel (2008) 'Mobile Payments: A Push Towards a Cashless Society or a Fad?', available athttp://goo.gl/C3BqX. For a list of State Money Transmitter Licenses required to operate, see Obopay website at http://goo.gl/jvH2O.

${ }^{145}$ See, for example, the notes from the Maryland Office of Consumer Protection on Money Transmitters available at http://goo.gl/I570M.

${ }^{146} 12$ USC ch 1 Sec 1.
} 
'United States coins and currency (including Federal reserve notes and circulating notes of Federal reserve banks and national banks are legal tender for all debts, public charges, taxes, and dues.'

Clearly notes and coins whilst being legal tender are not the predominant form of 'money' in general use in the US. ${ }^{147}$ There must thus be a way of extending a financial institution's ability to issue 'legal tender' in electronic (e-money) form which does not cross the restriction above. ${ }^{148}$ In this scenario, legal tender may be used in a context where a debtor who wants to satisfy an obligation by delivery of legal tender would be entitled to do so, but this does not mean that a seller is obligated to take a certain payment device, nor does it mean that a debt has been incurred so as to necessitate payment in legal tender. ${ }^{149}$ The lack of a nexus between legal tender and how to satisfy a payment obligation means that the form (in e-money) is not germane, such that the seller of goods and services or a recipient of payment is in a position to accept whatever form of 'money' they prefer. ${ }^{150}$

The above scenario accepted, the most cogent and relevant set of rules that approximate to e-money are those that revolve around the treatment of prefunded SV and money within the AML, Reg E, Reg Z, and FTC schemes indirectly and the UMSA at a state level directly. ${ }^{151}$ The nomenclature however is somewhat muddled, giving rise to some possible regulatory arbitrage. For example, although prepaid cards and SVCs are now generally - commercially - conflated under the appellation 'prepaid', ${ }^{152}$ use of product descriptors by the Federal Communications Commission (hereafter FCC), UMSA, state MSB statutes, the FTC, FRB, FDIC, and various AML statues somehow all distinguish between the two as being different types of products. Insofar as the services may involve telecommunications, the term 'prepaid' is applied to describing the prefunding, ${ }^{153}$ while $\mathrm{SV}$ on the other hand is said to relate to more general spending abilities with the funds, which may also tangentially be spent on telecommunications products. ${ }^{154}$ Or 'prepaid' is said to be associated with products for which the prefunded value is recorded on a remote server which must be accessed for payment authorisation, while SV is associated with products for which a prefunded

\footnotetext{
${ }^{147}$ See also Rogers (2005) op cit note 15 at 37 His discussion on e-money automatically conflates e-money as a currency with its use as a means of payment - ('[t]he simplest form of payment system is currency' at 3 ) - and thus automatically subsumes the entire US payments law into the analysis. He says that courts confronting questions that might be posed by systems of e-money, or lawyers participating in the design and implementation of such systems, should look at the case law developed in the early 19th century concerning circulating bank notes, not just as a source of potential analogies, but because this may already apply to such systems as a matter of ordinary principles of stare decisis.

148 Ibid. Rogers suggests that this could be accommodated by a legal rather than prudential framework. Rogers (2005) op cit note 15 passim.

${ }^{149}$ This would mean that a contemporaneous sale (and thus debt) where, for example, someone boarding a bus with legal tender coins has not yet incurred a debt for the bus ride. It means then that the bus driver need not necessarily accept the combination of legal tender coins or notes presented by the rider, insisting instead on a specific combination of payments. For example, see Nemser v New York City Transit Authority 530 N.Y.S. $2 d 493$ (N.Y. Sup. Ct. 1988) where this circumstance arose. The court held that insistence on coins for a bus ride rather than dollar notes was acceptable practice.

${ }^{150}$ The distinction between precedent and contemporaneous debts was raised by Rogers to illustrate what would happen when an e-money issuer or payment provider went insolvent. He cites diverging $19^{\text {th }}$ century case law, but notes with approval those cases that held that a transfer of a banknote operated as a discharge of the underlying debt, whether the debt was contemporaneous or precedent, and whether the bank- note was transferred before or after the bank failed. See Rogers (2005) op cit note 15 at 48

${ }^{151}$ As Budnitz (2008a) op cit note 1 at 4 correctly observes, although no federal law directly regulates SVCs except payroll cards, the Federal Trade Commission Act 15 U.S.C. $\$ \S 41-58$, as amended prohibits unfair and deceptive practices, regardless of the type of payment device involved.

${ }^{152}$ See for example how the New York Federal Reserve uses the terms interchangeably.

${ }^{153}$ See FCC and FTC rules on some prefunded telecommunication services which refer to them as 'prepaid' telephone cards. Most of the prepaid telephone card programs are really debit systems where the value does not reside on the card but in an account maintained by the issuer.

${ }^{154}$ Federal Reserve Board (2004) 'A Summary of the Roundtable Discussion on Stored-Value Cards and Other Prepaid Products', available at http://goo.gl/c79E2.
} 
value is recorded on the payment instrument. ${ }^{155}$ These (artificial) product-based descriptors, it is submitted, become more arcane when applied to prepaid mobile phone purses which may possibly be used for general purchases and thus could, under this chimerical nomenclature regime, be classed as prepaid SVPs. ${ }^{156}$ These product-based artificial distinctions have meant that there is a sense that 'stored value' and prepaid value require separate regulatory regimes. This muddled set of interpretations turns on essentially the same result - prefunded value, stored electronically. ${ }^{157}$ This distinction and the continuing drafting emphasis on SVCs, is however a feature of the UMSA and various state money services acts. ${ }^{158}$ Some commentaries continue this unsound product-based distinction to establish regulatory insight. ${ }^{159}$

A.

\section{Federal}

\subsubsection{2}

The Office of the Comptroller of the Currency (OCC)

Insofar as a broad need to regulate any new form of money that may rise to the level and equivalence of legal tender coins and notes, banks that had requested the right to issue e-money in the 1990s could do so after authorisation by the federal OCC and FDIC. ${ }^{160}$ The OCC authorised national banks to engage in what it termed "electronic SV systems ${ }^{161}$ insofar as this activity was under an extension of their rights in terms of the NBA to do the 'business of banking. ${ }^{162}$ The states may have their own laws. ${ }^{163}$ Such systems, the OCC indicated, included payment cards that enabled 'individual cardholders to store pre-paid value outside of a conventional consumer demand deposit bank account relationship. ${ }^{164}$ This extension also allowed national banks to acquire membership interests in companies that operated an 'open' SVP system because, the OCC said, the creation, sale, and redemption of electronic SV in exchange for dollars is part of the 'business of banking, ${ }^{165}$

\subsubsection{Regulation $E$ and Regulation $Z$}

The federal oversight regime of this type of stored value, and non-traditional mechanisms is not uniform. At a more non-traditional level, the FRB in its first attempt to understand and regulate this prefunding

\footnotetext{
${ }^{155}$ Some may act as cash insofar as they have a magnetic stripe or chip which records the embedded value. Loss of the card would be equivalent to losing cash. Other systems, though, use the SVP merely for access.

${ }^{156}$ SM O'Connor (1998) 'The De Minimis Exemption of Stored Value Cards From Regulation E: An Invitation to Fraud?' 5 Richmond Journal of Law and Technology 6.

${ }^{157}$ For discussion of the prepaid and SV iterations, see ch 4, s4.8.4.4.2 titled Stored Value Nomenclature.

${ }^{158}$ UMSA (2002) op cit note 126.

${ }^{159}$ See, for example, Ritchie (2005) op cit note 82, and Rhine and Su (2005) op cit note 1, who describe the same product suite, but divide them under either SVC or prepaid.

${ }^{160}$ Ramasastry (2005) op cit note 1 passim.

${ }^{161} 12$ CFR $\$ 7.5002(a)(3)$.

${ }^{162}$ See an OCC commentary in relation to bank issues of e-money in the form of an SVC, at OCC (1996) op cit note 45.

${ }^{163}$ State prudential regulators may determine that a particular scheme has indeed become a 'money' because its MOE has become widely accepted beyond just a closed system. If so, it may need a license to operate in a state, as well as conforming to federal AML rules under the Bank Secrecy Act. At the state level such a scheme would not get an 'e-money' license per se, but rather an MSB or money transmitter license as per the state definitions and rules of 'money' or 'monetary value'. See Bank Secrecy Act Pub. Law 91-508 1970 [31 USC 5312].

${ }^{164}$ Office of the Comptroller of the Currency (OCC) (2003) 'Conditional Approval' \#568, available at http://goo.gl/OHKzB. In an earlier OCC Guidance document, it defined (electronic) SVPs as 'retail payment products in which value is recorded on a personal electronic device or on a magnetic strip or computer chip in exchange for a predetermined balance of funds.' See Office of the Comptroller of the Currency (OCC) (1998a) 'Guidance on Electronic Financial Services and Consumer Compliance', available at http://goo.gl/BRLEN.

${ }^{165}$ See OCC (2008a) op cit note 1 generally, and specifically OCC (1996) op cit note 45 and Office of the Comptroller of the Currency (OCC) (1999) 'Interpretive Letter’ \#855, available at http://goo.gl/hjPS9.
} 
product, considered as representing the majority set of products on the market. ${ }^{166}$ In tackling their import, the FRB released a swathe of proposals in $1996^{167}$ around 'e-money' that would have regulated prepaid and SVCs as being incarnations of 'e-money'. The proposal was to classify them as 'accounts' in terms of the Reg E nomenclature so that the full range of EFTA and Reg E consumer protections that apply to consumer EFTs and debit card-based accounts would then also apply to all SVCs. Opposition to the extension of Reg E to prepaid cards was (and still is) predicated on the cost of implementation of any compliance, especially if many of the cards are geared towards micro-payments. ${ }^{168}$ As noted above, ${ }^{169}$ the FRB in 2006 through the definition of 'account', cherry-picked the payroll cards' incarnation of SVC as worthy of Reg E protection, rather than all generic-type SVCs.

\subsubsection{The Federal Deposit Insurance Corporation (FDIC) and Deposits}

Insofar as a SV may be considered 'money' for the purpose of a being a 'deposit' (of money), the FDIC in 2008 provided a somewhat more expansive view of SVCs than the FRB, classifying them as 'deposits' eligible for deposit insurance when the funds underlying SVPs have been placed at an insured depository institution. ${ }^{170}$ However, not all SVPs will be insured: the FDIC made it clear that the rule did not apply to 'gift cards' offered by retailers in closed systems that have scope beyond a closed system or that are quasiopen, prepaid airtime cards, as significantly, the FDIC's definitions of 'accounts' and 'deposits' were not applicable to other laws and regulations. ${ }^{171}$ There is no definition of 'account' in the FDIC definition.

\subsubsection{Application to MFS}

At the federal level, use of the fiat- and airtime-based SOV for purchasing products other than digital goods and outside the MNO walled garden could possibly bring the MNO into the realm of a number of federal payment statutes. The MNO would then, in those circumstances, act as a payment intermediary in respect of the subscriber rather than as a provider of goods and services as it would be closed in a quasi-open or closed service.

\footnotetext{
${ }^{166}$ It gave examples of prepaid cards and included gift cards, payroll cards, flexible spending account cards, Electronic Benefits Transfers (EBTs), remittance payment cards and transportation cards. It also recognised that most prepaid cards serve a single purpose, but there may be cases in which multiple prepaid functions are combined on one card. Some are nonreloadable.

${ }^{167}$ See generally on the FRS proposals, Office of the Federal Register (1996) 'CFR Parts Affected During May' (Proposed Rules) 61(86) Federal Register, available at http://goo.gl/MCm01.

${ }^{168}$ The transactions may be considered micro even if the card itself is, in its fully (pre-)funded state, a predominantly macrobased amount.

${ }^{169}$ See ch 11, s11.2.4.1. on the Electronic Fund Transfer Act.

${ }^{170}$ Federal Deposit Insurance Corporation (FDIC) (2008) 'General Counsel's Opinion No. 8: Stored Value Cards and Other Nontraditional Access Mechanisms', available at http://goo.gl/IXoI5. In applying the insurance limit to a pooled custodial account, the FDIC recognises the holders of the SVCs - or other access mechanisms - as the owners of the deposits if the FDIC's standard requirements for 'pass-through' insurance coverage have been satisfied. Otherwise, the card distributor or other named accountholder will be recognised as the owner.

${ }^{171}$ Reg E, 71 Fed. Reg. at 51,447, where the FRB says that '( $t$ )he definition of "account" as amended by the final rule does not affect the treatment of payroll card accounts under other laws. This final rule is intended only to address coverage issues under Reg E.' This means that they are not also "accounts" for purposes of coverage under other laws, such as for customer identification procedures under the Bank Secrecy Act, for reserve requirements under the Board's Regulation D, for Truth in Savings Act purposes, and possibly for other purposes under state laws. A recent ruling extended the definition of deposits to prepaid cards issued via insured institutions. See DG Weiss (2005) 'Letter to the FDIC', available at http://goo.gl/hvkny; and Association for Financial Professionals (2005) 'Comment', available at http://goo.gl/nTHMj. For a further commentary on this issue, see J Albers (2007) 'Stored Value Cards: Should We Know the Holder?' 11 North Carolina Banking Institute Journal 363 at 388-390, available at http://goo.gl/56gBb.
} 
The most instructive, but not deductive case governing these circumstances revolved around the Internet payment intermediary - and extrapolating to MFSPs - that was sued in 2002 as it was alleged that the MFSP had violated the EFTA provisions dealing with information about dispute resolution procedures and investigating complaints of unauthorised or incorrect transfers. PayPal disputed that it was subject to the EFTA. Although the case was settled, it highlighted gaps in the regulatory coverage for payment intermediaries - of which an MFSP could be one. ${ }^{172}$ The rules that could apply then are the emerging CFPB rules made under Dodd-Frank, existing and payment rules and protections based on the mechanisms and instruments used to fund a mobile SVA. Therein are a number of statutes and corresponding regulations from the FRB that establish the rights of consumers when initiating and receiving payments through a payment system with respect to unauthorised or erroneous payments. ${ }^{173}$ It is where there are variations that the applicability of these law and regulations are pronounced.

As to their applicability then, there are number of permutations. Insofar as the funding mechanism, it would have to be determined inter alia whether the prepaid balance value is designated/denominated as the same monetary value as currency buying power, rather than, by extension to the designated value system. The protections would also only be relevant if the prefunding takes place via a noted non-cash instrument or system. It is not clear what the protections are for the SOV in the SVA under these circumstances and whether the opening of the SVA to non-walled garden uses changes the protection dynamic afforded by federal law. If the account is open and prefunded by cash, there would be some protection if the MNO operating as a MFSP chooses to allocate the usable funds into a FDIC insured bank account. If it is open, funded by cash or other means, but the MNO chooses not to place the funds in any bank account but rather to draw off the pool of funds as a scriptural billing system customer data record (the so-called CDR), then it is unlikely to have any FDIC insurance. ${ }^{174}$ The FDIC in any event only classes the funds that underlie payroll SVPs as worthy of insurance. In terms of payment law then, while there are a number of consumer payment regimes which could apply, although it is not clear whether the type of funding of a mobile Stored Value Account (hereafter SVA) amounts to capture with the regulatory frameworks.

Insofar as a payment - be it for a purchase or remittance - from the SVA is concerned, it is also not clear whether an MNO using an intermediary-type, open payment system using the purse as a source of funds

\footnotetext{
${ }^{172}$ Ramasastry argues that, at a minimum, Reg E and the EFTA should be extended to clearly include payment intermediaries as a means to reduce ambiguities and even gaps in regulatory coverage by broadening the expansion to include a broader range of SVC and prepaid cards. Ramasastry (2008) op cit note 1 at 818-820. Hillebrand (2001) op cit note 118 similarly argues that the FRB's inclusion of payroll cards in Reg E could provide a model for how to amend Reg E to cover smallvalue SVCs, such that there is a de minimus exception that exempts only those cards that are not reloadable and that cannot hold more than a set amount, say US $\$ 250$.

${ }^{173}$ Ballen and Fox (2008) op cit note 82 at 939. They point out that Reg E and Reg G purposely do not specify how a financial institution may re-allocate the risk from fraud or error back into other linked participants in a transaction. These issues, and how to allocate any losses accruing to any non-consumer participant, are instead left instead to private rules created by members of payment associations like Visa and MasterCard. The allocation depends also on whether the transaction was done online or via a telemarketer.

${ }^{174}$ The likelihood of this happening however is limited: firstly, at a prepaid level the MNO usually gives 1:1 redemptive-like value to the subscriber who expects parity with other payment instruments in that there is no premium for the use and convenience of a mobile transaction. In doing so, the MNO must take into account the (profit) share it must give the third party service provider, alongside the retail and wholesale values involved in sale along the distribution chain of that repaid voucher. A MNO giving a subscriber say 25 units of spending power (denominated possibly in dollar specie), while the MNO only gets say 15 units after distribution costs are removed, will not survive. The funds therefore would have to be backed 1:1 in a banking institution for it to equate to real-world specie. This commercial reality could possibly then bring it into the realm of FDIC protection if the MNO pools its funds in a FDIC-insured bank. Secondly, policy considerations would most likely mean that the MNO would, for the purposes of reputation, place the funds in a FDIC-insured institution.
} 
would be subject to Reg E/EFTA. ${ }^{175}$ Specifically, the transfer of value will be considered an EFT under the EFTA/Reg E regime once the value leaves the MNO system and enters the ACH system. ${ }^{176}$ It matters not that the prefunding of the value for the transfer was done via a SVC-type system/prepaid purse that in and of itself was not necessarily subject to Reg E or Reg Z if say the prefunding was done via cash. Further protections under Reg E or Reg $Z^{177}$ may however apply if the prepaid account is prefunded from a credit or debit card or from electronic cheque conversion. ${ }^{178}$ Thus where a mobile phone is used for purchases, the protection available depends on whether the phone is used to pass a charge through to a credit card, bank account, or the mobile phone bill itself. Charge-back protections, for example, are provided by statute only if the charge is passed through to a credit card bill. As Mann points out, it is odd to have such an important protection turn on something like how the purse was funded. Outdated provisions of the EFTA and the applicable regulations thus appear to leave consumers exposed to losses from fraud and error in the new transactions from which federal law would protect them if the transactions had been completed directly with conventional payment systems. ${ }^{179}$ The CFPB though is mandated to introduce new rules if necessary.

B.

State

\subsubsection{6}

\section{SVPs and MSB Statutes}

Unlike Reg E, FDIC, Reg Z, AML, OCC/OTC schemes, at a state level a prefunded SVA's function as a SOV and means of payment functionality is not necessarily treated under two sets of regimes. Instead 46 states group the new products under existing money transmitter or EU EMD-type ${ }^{180}$ MSB statutes, ${ }^{181}$ some using the UMSA as a 'model law' guide. ${ }^{182}$

Implementations relating to prefunded SVCs, money transmission, and prepaid cards have not been uniform though, creating a patchwork of compliance obligations for MSBs. ${ }^{183}$ Moreover, there have been jurisdictional conflicts with federal agencies in relation to gift-card type SVCs that are issued by banks or that are issued by private merchants but underwritten by banks. ${ }^{184}$ Insofar as the UMSA can be used as a

\footnotetext{
${ }^{175}$ As Rogers (2005) op cit note 15 at 21 suggests the principal substantive consequences would be that the initial disclosure requirements, error resolution procedures, and limits on liability for unauthorised transfers of the Reg E regime would apply. However, the individual transaction documentation provisions, which require paper receipts for ATM and debit card POS transactions, should not apply. The Reg E transaction documentation requirements, 12 CFR §205.9, apply only to an EFT that is initiated through an 'electronic terminal', defined as 'an electronic device, other than a telephone operated by a consumer, through which a consumer may initiate an EFT. The term includes, but is not limited to, POS terminals, ATMs, and cash dispensing machines.' See 12 CFR \$205.2(h). The FRS has indicated in an Official Staff Interpretation that the exclusion of transactions initiated by a 'telephone operated by a consumer' will also cover a transfer by a means analogous in function to a telephone, such as by home banking equipment or a facsimile machine. See 12 CFR Supp. I to Part 205, $\S 205.2(\mathrm{~h})$.

${ }^{176}$ See ch 11, s1 1.2.4.9 on the National Automated Clearing House Association and the Automated Clearing House.

${ }^{177}$ Credit card use would mean Reg Z applies. Debit card use means that Reg E applies.

178 Non-banks or merchants that offer electronic cheque conversion are not subject to federal regulation as depository institutions, but are required to provide consumers with notice that their cheques may be converted to electronic payments and thus must obtain consumer consent before initiating such transactions. The FTC currently enforces this provision in relation to non-banks.

${ }_{179}^{179}$ Mann (2004) op cit note 79 at 690.

${ }^{180}$ Many are based on the UMSA, codified in 2000 and amended in 2004.

${ }_{181}$ A MSB statute is usually in the form of a money transmitter or sale of cheques statute.

182 KS Ellis (2004) 'Gift Cards/SVCs Overview AFSA SGR Card Subcommittee Legislative Report', available at http://goo.gl/p6JBi.

${ }_{183}$ Morgan (2005) op cit note 46 passim.

${ }^{184}$ See SPGCC, LLC v. Ayotte, \#06-2326 (1 $1^{\text {st }}$ Cir. May 30, 2007) 2007 WL 154584. Here, the state of New Hampshire passed a statute restricting the sale of 'gift certificates', including SVCs issued by national banks and national thrifts that carry
} 
progenitor model law for the purposes of determining whether a purse is e-money and as such needs to be regulated, the siren definitions that telegraph a purse being subject to a state MSB-type regime is whether its use rises to a 'stored value' record that is 'monetary value' that is a 'means of exchange'. Monetary value in turn is defined as a 'medium of exchange, whether or not redeemable in money.' Money is defined as a 'medium of exchange that is authorised or adopted by the United States or a foreign government. The term includes a monetary unit of account established by an intergovernmental organization or by agreement between two or more governments.'

The registration requirements of SV then do not appear to be predicated on whether or not it is 'money', rather on whether it is a 'means of exchange' and has a 'unit of account' issued by a government only. The prefatory notes to the amended UMSA version indicate that the term 'medium of exchange' (although not specifically defined in the Definition clause) refers to value that is exchanged and accepted by a community that is larger than the two parties implicated in the exchange. While the UMSA notes acknowledge that it is trite that bilateral units of account would not constitute 'a means of exchange' for purposes of the Act, there may come a point where certain types of (monetary) value morph into a species that has become widely accepted to acquire products that are beyond the initial scope of their issuance, so as to constitute a medium of exchange. Other factors to take into account in a determination of this evolution is how widely circulating such value is, ${ }^{185}$ whether the value is redeemable, and whether the value can be used to purchase or acquire a wide range of products and services. ${ }^{186}$

With respect to an SVP falling within this definition as a means of exchange, it may not be considered as money for the purposes of the UMSA if the SVP does not have a unit of account issued by a 'government'. This then would appear to limit the definition of money to only specie-type money and not money where the 'means of exchange' is not bilateral, but widely and generally accepted, and where in fact the unit of account is non-governmental, for example, designated in minutes, bytes or points. However, while a purse may not be considered as money under the Act, it may be 'monetary value' for purposes of capture by the Act with regard to rules regulating money transmission, as the definition of money transmitter only requires transmission of 'monetary value', not money. In yet another twist, even if a purse falls within the definition of 'monetary value', the UMSA specifically excludes from its ambit those entities engaged in 'provision solely of delivery, online or telecommunications services, or network access'. While the clause was probably in line with general 'mere conduit' exceptions (to ISPs) for liability, common in e-commerce regulations, the inadvertent import of this may be that MNOs that somehow fall within this definition because most of their business is 'solely' telecommunications-type transmission will be excluded from registration. However it is likely that policy imperatives relating to the need for business and regulatory continuity would quickly shut this loophole if it ever became an issue. The degree to which the SOV in a MNO 's prepaid SVA may be considered as money does not necessarily turn on how the purse is funded, but rather on how the purse is used. Insofar as the treatment of 'money' by the states, Morgan notes that

expiry dates or are subject to administrative fees. The USSC said later, however, that the OCC and OTS are entitled to regulate the terms and conditions of gift cards sold by national banks and national thrifts and that their regulations pre-empt the New Hampshire laws.

${ }^{185}$ The UMSA analysis predicts that in determining whether or not a value has de facto become a 'medium of exchange', a major factor in this determination will be just how wide the use and the circulation of a certain type of value may be.

${ }^{186}$ The line is very blurred though. Texas, for example, requires the issuer of shopping mall gift certificates that can be redeemed at multiple issuers to become licensed. 
generally, of the 46 states that have MSB-type statutes, 23 have an express 'goods and services' exception that will exclude payment instruments that are 'redeemable by the issuer in goods and services' from their Acts. ${ }^{187}$ This relates specifically to closed (bilateral) systems, where the value stored by the issuer is redeemable only for the issuers' own goods and services. ${ }^{188}$ It is still not clear though as to what constitutes a truly closed or 'quasi-closed' SVC system and whether quasi-closed systems should be subject to MSB laws and regulations. ${ }^{189}$

In relation to remittances, the UMSA has two separate licensing regimes: one is for plenary 'money transmitters', which consists of bespoke money transmitters, payment instrument sellers; and the second for certain types of Internet payment services. ${ }^{190}$

\section{Application to MFS}

\subsubsection{Application to MFS}

A prepaid wallet's function as a store of value and means of payment functionality is not necessarily treated under two sets of regimes at state level. Instead, the 46 states group the new products under existing money transmitter or MSB statutes, some of which used the UMSA as a guide. ${ }^{191}$

Most state laws codified generally under money transmitter laws specify the regulatory ambit relating to stored value. Insofar as a prepaid or post-paid purse could be used for buying goods and services within the 'mall' constraints of the MNO purchasing prowess, the purse would largely fall under the categorisation of being bilateral as purchasing only the MNO's own goods and services. State laws that define money largely

\footnotetext{
187 Ballen and Fox (2008) op cit note 82 at 943 remark that these state money transmitter laws typically regulate the insolvency of the licensed entity as opposed to payment law type issues. Taken together with the lack of federal oversight on these accounts, Ritchie (2005) op cit note 82 at 220-221 notes that by only including payroll cards within the ambit of Reg E, altogether there may be less consumer protection such that consumers using prepaid cards will be left in the hands of the lessregulated merchants.

${ }^{188}$ Morgan (2005) op cit note 46 passim points out that while the other 23 states do not have an express exception (for closed systems), they generally do not consider there to be any 'transmission' of money or a 'sale' of a cheque within the meaning of the law if the payment instrument is used in a completely closed system. This means that gift certificates, merchant credits and closed prepaid systems generally are not regulated by state MSB laws.

${ }^{189}$ Morgan (2005) op cit note 46. The Texas Finance Code conflates 'money' and 'monetary value' in the same definition as 'currency or a claim that can be converted into currency through a financial institution, electronic payments network, or other formal or informal payment system.' Then 'currency' is defined as 'the coin and paper money of the US or another country that is designated as legal tender and circulates and is customarily used and accepted as a medium of exchange in the country of issuance.' Texas Finance Code $\$ 151.301$, available at http://goo.gl/qvRMY. The Florida MSBs Act does not have a definition of money, nor of the means of exchange and instead uses the term 'monetary value' as a 'medium of exchange, whether or not redeemable in currency.' See Title XXXIII s560.103, available at http://goo.gl/KOSP. In the case of Texas then, a SOV would fit into the Act's definition of money, as a 'claim' without it specifically having to test the mercantile usage borders for it to be a 'means of exchange'. However, Florida's Act would capture the SV purse only if it exceeded the mercantile border to become a 'means of exchange', even though it (as minutes or something non-specie) was not 'redeemable in money'. Insofar as 'stored value', it is defined as 'funds or monetary value represented in digital electronic format, whether or not specially encrypted, and stored or capable of storage on electronic media in such a way as to be retrievable and transferred electronically.' Insofar as the stored value is 'monetary value', for the purposes of the Act, it would only be captured as a stored value subject to the Act if it was a general means of exchange beyond just a bilateral exchange.

${ }^{190}$ The UMSA defines 'money transmission' as 'the selling or issuing payment instruments, stored value, or receiving money or monetary value for transmission. The term does not include the provision solely of delivery, online or telecommunications services, or network access.' It defines 'monetary value' is defined as 'a medium of exchange, whether or not redeemable in money' while 'money' is defined as 'a medium of exchange that is authorised or adopted by the US or a foreign government. The term includes a monetary unit of account established by an intergovernmental organization or by agreement between two or more governments.'

${ }^{191}$ Ellis (2004) op cit note 182.
} 
exempt bilateral SV under their 'goods and services' exemption found in many statutes. Some clarity is meant to be derived from the UMSA, the model safety and soundness law, which defines money as 'a medium of exchange, whether or not redeemable in money. ${ }^{192}$ The UMSA prefatory notes indicate that the term 'medium of exchange' connotes that the value that is being exchanged be accepted by a community, larger than the two parties to the exchange, although it points out that there are borderline SV cases like university payment cards that are accepted by a few local stores. However, university payment cards accepted by most local merchants would more likely be 'monetary value'. Texas requires the issuer of mall gift certificates that can be redeemed at multiple issuers to become licensed. ${ }^{193}$ However this definition alone and the accompanying prefatory notes to the UMSA do not give absolute guidance on whether a particular 'quasi-closed' or mixed system like that usable for the purchase of digital goods via a MNO purse would be subject to a particular state's licensing laws as being a 'media of exchange'. ${ }^{194}$

In fact, the UMSA drafters anticipate this equivocation, predicting that: 'it is possible ... that a certain type of monetary value of SV might not constitute a medium of exchange when first introduced, but might evolve into a more commonly accepted form of payment and would become a medium of exchange. ${ }^{195}$

The definition would strongly suggest that there must be widespread acceptance of the value, and not 'widespread geographically' as a MNO's coverage would easily satisfy this requirement. Rather the emphasis should be on widespread acceptance as a medium of exchange. Thus bilateral, closed systems would not necessarily fall under these regimes. ${ }^{196}$ Even with the UMSA, the approach to this encapsulation amongst the states is not uniform, leaving room for regulatory discretion. ${ }^{197}$ Insofar as their treatment of payment instruments, of the 46 states that have MSB statutes, 23 have an express 'goods and services' exception that will exclude payment instruments that are 'redeemable by the issuer in goods and services' from their Acts. ${ }^{198}$ This relates specifically to closed systems, where the value stored by the issuer is redeemable only for the issuers' own goods and services. ${ }^{199}$ Their application however is still subject to some dispute, with jurisdictional conflicts between the state MSB laws and federal agencies in relation to gift-card type SVCs that are issued by banks or that are issued by private merchants but underwritten by banks. $^{200}$

\footnotetext{
192 This expanded definition, the notes say, reflects the fact that certain PSPs employ a form of value that is not directly redeemable in money, but nevertheless serves as a medium of exchange and places the customer at risk of the provider's insolvency while the medium is outstanding.

${ }^{193}$ JK Winn (2006) Consumer Protection in the Age of the "Information Economy" at 327.

${ }^{194}$ Morgan (2005) op cit note 46.

${ }^{195}$ See UMSA (2004) Prefatory Notes on 'monetary value' op cit note 125.

${ }^{196}$ Rogers (2005) op cit note 15 passim.

${ }^{197}$ See, for example, the Texas Money Services Act which defines 'money' or 'monetary value' as a 'currency or a claim that can be converted into currency through a financial institution, electronic payments network, or other formal or informal payment system.' See The Texas Money Services Act (Act of May 26, 2005, 79th Leg., R.S., H.B. 2218, §1), codified as Finance Code, Title 3, Subtitle E, ch 151, available at http://goo.gl/CTOJD.

198 The Texas Money Services Act regulates persons that engage in MSBs in Texas, specifically the businesses of money transmission and currency exchange. The term 'payment instrument' that, if applicable, would trigger the MSB licensing regime excludes those that are 'redeemed by the issuer in goods or services'. See 'Texas Finance Code - s151.301. Definitions', available at http://goo.gl/gllOO.

${ }_{199}$ Morgan (2005) op cit note 46comments that while the other 23 states do not have an express exception (for closed systems), they generally do not consider there to be any 'transmission' of money or a 'sale' of a cheque within the meaning of the law if the payment instrument is used in a completely closed system. This means that gift certificates, merchant credits and closed prepaid systems generally are not regulated by state MSB laws.

${ }^{200}$ For example, SPGCC, LLC v Ayotte op cit note 184.
} 
An analysis of MSB laws generally shows that if the goods and services are primarily digital goods that can only be telecommunications-based, or more specifically, can only be primarily utilised with the payment instrument itself, then the goods and services exemption would probably apply. This is not absolute of course: using a PSMS via the phone to enter a competition offered by a third party would mean that the goods and services, although digital and paid for via the phone and its associated prepaid purse, are not necessarily that which would be classified as primarily usable within the closed system.

If a prepaid or post-paid purse is used for buying goods and services other than those of the issuer, purchase of goods and services outside the MNO's quasi-open 'mall' may implicitly bring the MNO into the state regulatory fold. Purchase of the MNO's own goods and services as well as other services beyond the walls of the digital mall will mean that this is no longer bilateral, and hence the MNO will not be able to avail itself of the 'goods and services' exception in many state laws. The purse could thus be considered a true means of exchange, albeit in MNO-type currency and not specie per se, as anticipated by the UMSA drafters. ${ }^{201}$ This brings the purse into the realm of amounting to SV (or putative 'e-money') subject to state licensing as 'money transmitters' - unless prepaid MNO purses are specifically exempted from this - and possibly even subject to additional consumer protection clauses like dormancy and expiry terms and conditions for SV gift cards. ${ }^{202}$ They could also be classed as payment intermediaries subject to UCC $4 \mathrm{~A}^{203}$

As with federal laws, the capture of a MNO purse being used to fund purchases of goods and services within existing states that have money service business-type laws, it is to what extent the purse is being used for purchases outside that payment ecosystem that would fall into the exempt category under MSB/MT laws. ${ }^{204}$

Look at the formatting here In relation to remittances, since money or monetary value is not restricted to specie, but instead is widely defined - for example, a 'medium of exchange' - any designation would be captured by these two statutes and that the MNO would have to register as a money transmitter in these two states.

Since most MNOs operate in many US states, just the presence of these two statutes would mean that their entire business model, were they to embark on such a commercial scheme of value transfer, would need to be modelled on abiding by money transmitter/MSB statutes.

\footnotetext{
${ }^{201}$ See UMSA Prefatory Notes on 'monetary value' op cit note 125.

202 If they were classed as a SVC, it would be protected by the provisions relating to Expiration; Dormancy and Service Fees; Refunds or Replacement for SVC; Disclosures about Expiration and Fees; Escheat; Reporting and Recordkeeping Requirements.

${ }^{203}$ Rogers (2005) op cit note 15 at 23 believes that it is unlikely that the UCC 4A regime, which establishes a loss allocation regime based on the concept of a 'commercially reasonable security procedure' would apply if the MNO system is not linked to a deposit account per se, since it applies mainly to transfers on a bank-to-bank, wholesale basis rather than for personal, family, or household use.

${ }^{204}$ Again, the most instructive case on payment intermediaries comes from PayPal who, in another dispute in 2006, reached a settlement agreement with 28 United States Attorneys General following a lawsuit on differences between PayPal's own dispute resolution programmes and chargeback rights granted by federal and state consumer laws. PayPal agreed to present consumers with a clear choice regarding the form of payment, but did not admit liability. See Assurance of Voluntary Compliance or Discontinuance in re PayPal Inc., available at http://goo.gl/nVvxe.
} 
It matters not that a prepaid purse is not (initially) captured within a state's MSB as SV per se. The picture changes in some states however when any value is transferred through an electronic system. It also matters not that the transfer is initiated at the instruction of the person who may in the end be the same person who receives that value, even within the same MNO, for example a person with two subscriber 'accounts'. Thus bespoke money transmitter laws and regulations appear to comprehensively capture this type of value transfer, requiring licenses for those engaged in money transfer.

This applies even to intermediaries that piggyback on mobile phone systems without necessarily being integrated into the mobile purse. ${ }^{205}$ Many states require MSB to be licensed and have an insurance bond to cover any loss if money does not reach its destination or any payment instrument issued fails.

\section{PART II Additional Statutory Oversight Related to MFS}

\section{Anti-Money Laundering, Terrorist Financing and Customer Due Diligence Laws and Regulations}

A

Federal

\subsection{1}

\section{Overview}

Incarnations like prepaid cards and SVC may be impacted by federal AML schemes such as Title III of the omnibus anti-terrorism PATRIOT Act ${ }^{206}$ which refers to the 'International Money Laundering Abatement and Anti-Terrorist Financing Act of $2001^{, 207}$ and also expands the provisions of the $\mathrm{UCC}^{208}$ and guarantees that electronic transactions are just as enforceable as their paper counterparts ${ }^{209}$ by providing that 'a contract may not be denied legal effect or enforceability solely because an electronic record was used in its formation.'

Some of the other issues covered under the Act are security procedures, record retention, the admissibility of electronic records, the time and place of sending and receiving electronic records, and errors in and changes to electronic records. It also allows any law that requires a physical record to be satisfied by an electronic record, and that any signature requirement can be met by an electronic signature. ${ }^{210}$ For the purposes of reporting transactions under AML statutes, two definitions come into focus:

\footnotetext{
${ }^{205}$ For an overview of the regulatory requirements in the US for mobile money transmitters, see Daniel (2008) op cit note 144.

${ }^{206}$ USA Patriot Act op cit note 128.

${ }^{207}$ International Money Laundering Abatement and Financial Anti-Terrorism Act of 2001, Pub. Law 107-56, 115 Stat. 272 , 296-342 (2001) (codified in scattered sections of 31 USCA).

${ }^{208}$ But they do affect sales transactions under Arts 2 and $2 A$ of the UCC.

${ }^{209}$ Uniform Electronic Transactions Act (1999), ss7 and 9.

${ }^{210}$ UETA does not apply to wills, codicils, or testamentary trusts; the UCC, other than ss1-107 (rights after a breach) and 1206 (statute of frauds), and Arts 2 and 2A (sales); transactions governed by UCITA; or transactions that states identify as not being covered.
} 
Under the Bank Secrecy Act (hereafter BSA), ${ }^{211}$ a 'Financial Institution' means:

\begin{abstract}
'(A) an insured bank, [and further] ... (R) a licensed sender of money or any other person who engages as a business in the transmission of funds, including any person who engages as a business in an informal money transfer system or any network of people who engage as a business in facilitating the transfer of money domestically or internationally outside of the conventional financial institutions system; (S) a telegraph company; ... (Z) any other business designated by the Secretary whose cash transactions have a high degree of usefulness in criminal, tax, or regulatory matters.'
\end{abstract}

B

State

11.3.2

Overview

An entity need not be registered at a state-level as a MSB to be captured under federal AML regimes. Even so, it is not clear whether the value received by the sending MNO would be captured, since it is only the accepting MNO (if in an inter-MNO system) party that can claim a putative exemption for only receiving currency and not the (equivalent) 'value of the currency or funds. ${ }^{212}$ However, policy considerations would mean that this scenario is probably moot, since the Secretary could (and probably would) simply issue new regulations if the Secretary felt that mobile payments (hereafter m-payments) were causing a leak in AML efficacy - even if specie is not used. The ability to do so is mandated in the BSA ${ }^{213}$ as well as the enabling Regulations which include '[a]ny other person engaged as a business in the transfer of funds', ${ }^{214}$ which can be determined by 'facts and circumstances'. 215

\title{
11.3.3
}

\section{Application to MFS}

The ability of MFS to be used in AML and TF has been raised a number of times in the US. ${ }^{216}$ It has also been suggested that new legislation is needed to regulate m-payment service providers that could include requirements that service providers monitor accounts, enhance suspicious activity reporting, require maximum transaction limits, require the registration of prepay cell phones with m-payment, and development of new, m-payment specific software to detect suspicious activity.

At a federal level, it is not clear whether (R) in the BSA above with its reference to 'funds' and 'money' means value in the form of airtime or even airmiles as falling within the statute, nor is it clear whether 'telegraph' is a catch-all phrase that can seamlessly be applied to MNOs. However, there is further clarification provided $31 \mathrm{CFR} \S 103.12$ which are the regulations issued pursuant to the BSA’s $\S 5312$ (Z) in

\footnotetext{
${ }^{211}$ Bank Secrecy Act (hereafter BSA) - Sec. 5312. Definitions and application, available at http://goo.gl/cz8a6.

21231 CFR $\$ 103.11$ (uu)(5)(i)(A).

${ }^{213}$ BSA -- 31 USC 5312 - Sec. 5312(a)(2)(Z) - Definition of Financial Institution.

${ }^{214} 31$ CFR $\$ 103.11$ (uu)(5)(i)(B).

21531 CFR $\$ 103.11$ (uu)(5)(ii). They could also be captured by the BSA 31 USC 5312(a)(2)(R) in that they would be engaged in the business in transmission of funds.

${ }^{216}$ P Leyva (2008) M-Payment: A Threat to AML' The Vermont Bar Journal, available at http://goo.gl/MAzH0; and J Forbes (2007) 'The Convergence of Telecom and Financial Services and its Effects on AML/CFT Wire Remittance Operations', available at http://goo.gl/m4Wdm; M Solin and A Zerzan (2010) 'Mobile Money: Methodology for Assessing Money Laundering and Terrorist Financing Risks', available at http://goo.g1/F6vw5.
} 
relation to designation of other businesses by the Secretary that may be captured by the BSA. ${ }^{217}$ These enabling Regulations at 31 CFR $§ 103.11(\mathrm{uu})^{218}$ define a money transmitter as someone who 'engages as a business in accepting currency, or funds denominated in currency, and transmits the currency or funds or the value of the currency or funds, by any means through a financial agency or institution. ${ }^{219}$ It appears then that an MNO that sends 'the value of the currency or funds' in the form of an equivalent amount of say, MNO airtime minutes paid for that monetary value may be captured by the definition as requiring reporting to the Financial Crimes Enforcement Network (FinCEN), but then only if it is transmitted through a financial agency or institution or an (undefined) electronic funds transfer system. The definition of financial agency or institution is 'a bank (except bank credit card systems) .... A money services business as defined in paragraph (uu); A telegraph company; ... Card club.' Although a telegraph company has a bespoke meaning that would equate it to Western Union-type money transmitter companies that used 'telegraph' wires to transmit transfer instructions, the lack of a definition does not make it clear whether an MNO is captured in this definition. ${ }^{220}$

Unlike the transfer of abstract 'value' equivalent of currency as captured by definition of a money transmitter, ${ }^{221}$ an MNO transferring monetary value from an account with monetary value (and not minutes) in terms of this section would be captured by this section for the purposes of the federal AML regime as a money transmitter, ${ }^{222}$ even though the MNO is not registered at a state-level as an MSB. Where the funds held by the MNO in a pooled account in an FDIC-insured financial institution before transfer, then a bank pooling funds for an MNO-based wallet pooling system would also have to do a periodic due diligence of the MNO to check whether the MNO or any other similar entity it is powering/enabling via this funds pool is engaged in money transmission business as defined by federal statute. ${ }^{223}$ If it fails to do so, then it may itself be held liable for that downstream entity's activities. ${ }^{224}$ Similarly, MFS providers like Obopay $^{225}$ or PayPal that act as financial intermediaries between subscribers using a mobile phone for transfer may also be captured by the AML regime. The MNO itself may not however necessarily be a significant participant in this type of money transfer, other than acting as a mere data conduit to, and enabler of access to, the server of the intermediary. There would not necessarily be any funds movement to

\footnotetext{
21731 CFR §103.11. Determination by the Secretary. Part 103 relates to Financial Recordkeeping and Reporting of Currency and Foreign Transactions.

21831 CFR $\$ 103.11$ - Meaning of terms.

21931 CFR $\$ 103.20(\mathrm{uu})(5)(\mathrm{A})$. The definition also says that 'the acceptance and transmission of funds as an integral part of the execution and settlement of a transaction other than the funds transmission itself ... will not cause a person to be a money transmitter.'

${ }^{220}$ This equivocation makes the definition of financial institution circular, as it is dependent on the MSB definition which in turn refers to a 'financial institution'.

${ }^{221}$ See 31 CFR $\$ 103.11(\mathrm{uu})(5)(i)(\mathrm{A})$ - 'transmits the currency or funds, or the value of the currency or funds, by any means an electronic funds transfer network'.

22231 CFR $\$ 103.11$ (uu)(5)

22331 CFR $\$ 103.20$ (uu)(5)(A).

${ }^{224}$ For the effect of AML laws on banks dealing with an entity that is or could be engaged in MSB-type activities, see R Rasske (2004) 'AML Requirements Upon Identifying an MSB' Bankers Online, available at http://goo.gl/Qphz8. There are, however, attempts in Congress for MSBs to self-certify instead of needing a bank to enable them to do so.

${ }^{225}$ See Obopay Press Release (2008) 'CITI and Obopay Launch Person-To-Person Mobile Payment Pilot Service for Citibank Customers', available at http:/goo.gl/GX5yx. Account activities are capped at US\$1000/day, are regulated under the EFTA/Reg E, although funding of the account can be used with credit cards, which may invoke Reg Z. Obopay describes itself as a 'payment service provider', acting as an agent only with respect to the custody of funds. An Obopay user 'account' is not a bank deposit account and is not FDIC-insured.
} 
and from a (pooled) account operated by the MNO, even though its subscribers would be using a money transfer system over its network. ${ }^{226}$

Further, a MNO or payment intermediary accepting or selling funds could be captured in respect of being a 'seller or redeemer of traveller's checks, money orders, or stored value' if they sell or redeem such checks or money orders or SV in an amount greater than US\$1,000 in currency or monetary or other instruments with any person on any day in one or more transactions.

It is important to note though that a bank doing mobile based money transfers using a third party enabler, either a licensed MNO or a payment service provider, which for the purposes of statute would both be captured in an AML scheme, the banks themselves are not part of the definition of money transmitter. ${ }^{227}$

It follows then that only the third party or MNO working with that bank would need to register separately as an MSB at state level for operating (and reporting) purposes, and as an MSB as defined at a federal level for AML reporting purposes. ${ }^{228}$

At a federal level, anyone doing money transfer would necessary be classified as a MSB under federal AML laws even if the transfer was (pre)funded from a system not captured under the definition of a SVC. However, it appears that this is not being done. ${ }^{229}$

Although the BSA does not require, and neither do FinCEN or the Federal Banking Agencies expect, banking institutions to serve as the de facto regulator of the money services business industry, ${ }^{230}$ sensing an increased threat to MSBs and regulatory burdens for banks if they have to police MSBs in accordance with state and federal AML statues. ${ }^{231}$

\footnotetext{
${ }^{226}$ See 31 CFR $\$ 103.20$ (uu) where a MNO would probably not be captured since 'the funds transmission itself ... will not cause a person to be a money transmitter.'

${ }^{229}$ See the US Bureau of International Narcotics and Law Enforcement Affairs report on MFS, which soberly characterises the situation with respect to mobile payments (hereafter m-payments) as one where the US has few safeguards against abuse of MFS. MFSPs in the US are classified as MSBs and must register. However, most do not do so and there is little enforcement. The compromised ability to monitor, the report says, is exacerbated by security features that hinder efforts to detect suspect transactions as well as so-called low-value, high frequency transfers - or 'digital smurfing' - that represent a ML threat. The use of 'smurfing' allows money launderers to bypass regulated banks and their financial reporting requirements by transferring low-value 'dirty money' funds in large iterations to be exchanged for digital value in the form of SVCs or mobile payment credits. United States, Department of State, Bureau of International Narcotics and Law Enforcement Affairs (2008) 'International Narcotics Control Strategy Report: Mobile Payments: A Growing Threat', available at http://goo.gl/XZ5R.

230 Federal Deposit Insurance Corporation (FDIC) (2005) 'FIL-24-2005: Statement on MSBs', available at http://goo.gl/2lML4. The note advises banking organisations that open or maintain accounts for MSBs to apply the requirements of the Bank Secrecy Act on a risk-assessed basis only.

${ }^{231}$ See Albers (2007) op cit note 171 at 388-390 who uses the context-specific approach in respect of prepaid cards effect on ML statutes that open-loop SVCs - regardless of the precise business model used - pose significant risk to AML and TF purpose of the regulation.
} 


\section{Overview}

The FCC is the federal authority tasked with oversight and regulation of the telecommunications sector at a state and federal level. ${ }^{232}$ The Communications Act of 1934 gave the FCC the power to regulate the radio frequencies used by mobile services. The need to regulate frequencies allows the FCC to have jurisdiction over states. $^{233}$

In 1993, the FCC was granted exclusive authority to regulate what were termed 'rates charged' and the 'entry' of wireless carriers. States were permitted to continue regulating 'other terms and conditions' of wireless services. Use of a mobile device for payments and money transfer may, tangentially, bring this usage into the realm of telecommunications regulation relating to MNO billing systems.

\subsection{2}

Truth-in-Billing Rules

Insofar as a telecommunications devices may be used to purchase basic and 'enhanced' telecommunications services and be billed for these services, the FCC put in place its Truth-in-Billing (hereafter TIB) rules $^{234}$ in 1999 to prevent a malevolent form of unauthorised billing which the FCC and the telecommunications industry call 'cramming'. Cramming is defined as 'the practice of placing unauthorised, misleading, or deceptive charges on your telephone bill or a service provider does not clearly or accurately describe all of the relevant charges to customers when marketing a service. ${ }^{235}$ The aptly named TIB rules require all telephone companies to use clear, non-misleading, plain language to describe the services for which a customer is being billed on the account. The carrier sending the bill must identify the service provider associated with each charge. The FCC in 2005 extended the TIB Rule to wireless carriers in a $2005 \operatorname{order}^{236}$ and also declared state laws requiring or prohibiting use of line items on bills for wireless services pre-empted by s332(c)(3)(A) of the Communications Act of 1934, as amended. ${ }^{237}$ The

\footnotetext{
${ }^{232}$ See www.fcc.gov.

${ }^{233}$ Other components of its regulatory ambit however have been the focus of challenges to its regulatory ambit by some states who challenged the ability of federal pre-emption over state-made rules.

${ }^{234}$ Truth-in-Billing and Billing Format, First Report and Order and Further Notice of Proposed Rulemaking, CC Docket \#98170, 14 FCC Rcd 7492 (1999), available at http://goo.gl/QL8zn.

${ }^{235}$ The FCC Rule extends the scope to situations where customers may have authorised the service, but may have not understand or were misled about how much it would really cost. See Federal Communications Commission (FCC) (s.d.) 'Unauthorised, Misleading, or Deceptive Charges Placed on Your Telephone Bill: "Cramming"' FCC Consumer Facts, available at http://goo.gl/e85hF.

${ }^{236}$ In the Matter of Truth-In-Billing and Billing Format, Second Report and Order, Declaratory Ruling, and Second Further Notice of Proposed Rulemaking, 20 F.C.C.R at 6449 (2005), available at http://goo.gl/6ODkq. This pre-emption right was later overturned by the USSC.

23747 USC \$332(c)(3)(A) -- Mobile services. In 1996, Congress amended the Communications Act of 1933 [Communications Act of 1933, 47 USC] with the passage of the Telecommunications Act of 1996. Congress gave the federal government exclusive authority as to the 'rates charged' and the 'entry' of wireless carriers. While this in some respect cordoned off wireless carriers from state regulation, it allowed states to continue regulating 'other terms and conditions' of
} 
FCC felt that different state laws regulating line items would result in a variety of conflicting rules. ${ }^{238}$ It does not though prohibit a State from regulating the other terms and conditions of commercial mobile services. $^{239}$

\section{State Rules}

\subsection{3}

\section{Overview}

The jurisdiction of the FCC over state consumer protection statutes relating to telecommunications have been the subject of a number of court cases. Essentially the dispute has been over the interpretation of provisions within the Communications $\mathrm{Act}^{240}$ that allow the FCC general jurisdiction over 'rates' for basic telecommunications services ${ }^{241}$ versus the state's right to regulate so-called line items - discrete charges identified separately on an end user's bill, or terms and conditions of usage. ${ }^{242}$ An FCC rule on these items was ultimately overturned by the USC. With respect to 'information services' and descriptions of these services within wireless bills, the Indiana Court of Appeals affirmed in Micronet, Inc. v. Indiana Utility Regulatory Commission that the FCC rules cannot pre-empt the Indiana state laws for its action against a service provider that violated Indiana's Consumer Protection law for a purported deregulated 'information service'. ${ }^{243}$ Attempts to prevent cramming therefore, may be under both state and federal jurisdiction.

C

\section{Private Rules}

\subsection{4}

\section{Self-regulatory}

The CTIA-The Wireless Association is a non-profit membership organisation founded in 1984, representing all sectors of wireless communications. It represents service providers, manufacturers, wireless data and Internet companies. The CTIA has a number of voluntary Industry Guidelines signed by all of the country's major MNOs. ${ }^{244}$ In 2004, several MNOs signed an 'Assurance of Voluntary Compliance' with 33 state attorneys general that detailed nationwide consumer protection standards for

wireless services. For a brief discussion of this interplay, see S Cooper (2008) 'NARUSCA v FCC: Federalism, Line Item Billing, and the Future of Wireless Consumer Protection' 9(2) Engage: The Journal of the Federalist Society's Practice Groups, available at http://goo.gl/Hw5vg.

${ }^{238}$ Cooper (2008) op cit note 237. It is not clear though whether the TIB Rules apply to prepaid customers of fixed and/or wireless telecommunication services.

${ }^{239}$ Section 332(c)(3)(A) - Mobile Services. In relation to content subscription services, TIB requires that the bill must clearly and conspicuously identify any service provider which has a continuing relationship with the subscriber resulting in periodic charges, unless the service is subsequently cancelled. It is not clear however whether the TIB regulations relate to prepaid accounts. Protections relating to refunds are left to state law. See Federal Communications Commission (FCC) (2007) 'Sec. 64.2401 Truth-in-Billing Requirements' (Subpart Y Truth-in-Billing Requirements for Common Carriers, 47 U.S.C. 154, 254(k); secs. 403(b)(2)(B),(c), Pub. Law 104-104, 110 Stat. 56), available at http://goo.gl/esGx6.

24047 USC $\$ 332(\mathrm{c})(3)(\mathrm{A})$-- Mobile services.

${ }^{241}$ The so-called POTS, or Plain Old Telephone Services.

${ }^{242}$ See FCC Second Report and Order, 20 F.C.C.R. op cit note 238 at 6462.

${ }^{243}$ Micronet, Inc. v Indiana Utility Regulatory Commission Indiana Court of Appeals \#93A02- 0603-EX-237. May 10, 2007. See also allBusiness (2007) 'Federal Law Doesn't Bar Telephone 'Cramming' Suit, Rules Indiana Court of Appeals', available at http://goo.gl/J0RZD.

${ }^{244}$ See various guidelines available at CTIA Media page under 'Voluntary Industry Guidelines', available at http://goo.gl/0tih6. 
MNOs. ${ }^{245}$ The lack of a regulatory framework for MNOs and general wireless services has given rise to an entire species of class action lawsuits though in the US, with many revolving around mobile content subscription. ${ }^{246}$ In relation to purchase of digital services using shortcodes, under the Communications Act of 1934 as amended, text messaging and short code provisioning are 'information services' and not telecommunications services. $^{247}$

\subsubsection{Application to MFS}

If there are no protections available under Reg E or Reg Z, then some telecommunication-related laws may apply, for example, state anti-cramming statues. There are however some statutory protections that apply in California for unauthorised charges on a phone bill, including a cell phone bill, but only for unauthorised charges and not for disputes about the delivery or quality of goods or services. ${ }^{248}$

But as Budnitz points out, while there are state consumer laws over certain consumer protection aspects, if at some level the protection would then be subject to the Consumer Clause of the US Constitution and other federal acts means that the entity offering the product is subject only to federal law. In those circumstances there may be lacunae in regulation where there is no federal law to explicitly cover that product. ${ }^{249}$

Insofar as there is no explicit payment/prudential regime, one would thus think then of state laws around Terms and Conditions (hereafter T\&C) in prepaid wireless cards. The FCC's Truth-In-Billing may apply here, although it is not clear how a prepaid customer who does not receive a bill would be captured by the statute FTC.

And although no federal law directly regulates SVCs except payroll cards, the Federal Trade Commission Act (hereafter FTCA) prohibits unfair and deceptive practices, regardless of the type of payment device involved. $^{250}$

\footnotetext{
${ }^{245}$ See Cooper (2008) op cit note 237.

${ }^{246}$ See Classaction Connect, a website dedicated to reporting and encouraging class action lawsuits. It has a specific section on class actions relating to mobile issues at http://goo.gl/SIOGU. The first in a series against subscription services was that against Jamster. Consumers who responded were automatically subscribed to a service to receive additional ringtones each week for which they were charged US\$1.99 up to US\$5.99. In a specific cramming case, see Tracie McFerren $v$ AT\&T Mobility LLC, Case \#08-CV-151322 relating to MNO AT\&T's billing of third party mobile content to its subscribers. The case was settled. See 'Thirdpartycontentrefund.com' home page available at http://www.thirdpartycontentrefund.com/.

${ }^{247}$ See comments by MNO T-Mobile to the FCC: T-Mobile (2008) 'Petition for Declaratory Ruling that Text Messages and Short Codes are Title II Services or are Title I Services Subject to Section 202. WT Docket \#08-7' at 2, available at http://goo.gl/VS0pj.

${ }^{248}$ See California Public Utility Code $\$ 2890($ a) (West 2007) which says that a 'telephone bill may only contain charges for products or services, the purchase of which the subscriber has authorised.' See also California Public Utility Commission (2006) Revised Gen. Order 168, Market Rules to Empower Telecommunications Consumers and to Prevent Fraud Pts. 3C, E-G, available at http://goo.gl/ftW34. See also Hillebrand (2008) op cit note 118 at 778

${ }^{249}$ See Budnitz (2008a) op cit note 1 at 1 , who cites examples where states regulate gift cards, but issuers may avoid laws by partnering with entities - such as national banks in the case of the underlying funds in gift cards - that are regulated by federal law. See Hillebrand (2008) op cit note 118 at 778 on the regulatory gap mobile phone payments may expose.

${ }^{250}$ The FTC took action against the seller of prepaid telephone cards to immigrants, saying that the seller failed to provide consumers with the correct usable number of minutes.
} 
The Electronic Signatures in Global and National Commerce Act (hereafter ESIGN), ${ }^{251}$ a federal law that facilitates the use of electronic records and signatures in interstate and foreign commerce by ensuring the validity and legal effect of contracts entered into electronically. ${ }^{252}$

There are a host of other laws, but with regard to electronic communications, the Controlling the Assault of Non-Solicited Pornography and Marketing Act (hereafter CAN-SPAM Act) ${ }^{253}$ regulates rules for commercial email, and establishes requirements for commercial messages, gives recipients the right to arrange to stop being emailed and provides for tough penalties for violations. It covers all commercial messages, which it defines as 'any electronic mail message the primary purpose of which is the commercial advertisement or promotion of a commercial product or service, including email that promotes content on commercial websites. ${ }^{254}$ It does not exclude business-to-business email such that any communication must comply with the law. ${ }^{255}$

\section{State Rules}

\subsection{2}

\section{State Laws}

The Uniform Electronic Transactions Act (hereafter UETA) was adopted by the NCCUSL in $1999 .{ }^{256}$ It is an update to the UCC model law adopted by all states as a guide to contract law and business practice, the development, sale, licensing, support and maintenance of computer software and for many other contracts involving information. Its rules are primarily for 'electronic records and electronic signatures relating to transactions' that are not subject to the $\mathrm{UCC}^{257}$ and guarantees that electronic transactions are just as enforceable as their paper counterparts ${ }^{258}$ by providing that 'a contract may not be denied legal effect or enforceability solely because an electronic record was used in its formation. ${ }^{259}$

\footnotetext{
${ }^{251}$ Electronic Signatures in Global and National Commerce Act 15 USC ch. 96, available at http://goo.gl/N3rN3. The Act went into effect in October 2000. Although UETA spells out rules for digital signatures, the federal ESIGN lays out the basis for interstate commerce.

${ }^{252}$ Careful to preserve the underlying consumer protection laws governing consumers' rights to receive certain information in writing, Congress imposed special requirements on businesses that want to use electronic records or signatures in consumer transactions to obtain from consumers electronic consent or confirmation to receive information electronically that a law usually requires to be in writing. Section 101(c)(1)(C)(ii) of the ESIGN Act.

${ }^{253} 15$ USC 7701

${ }^{254}$ Sec 3(2)(A) of the CAN-SPAM Act of 2003 [15 U.S.C. 7701, et seq., Pub. Law No. 108-187], available at http://goo.gl/98JuX.

255 Ibid.

${ }^{256}$ Available at http://goo.gl/Qbtz5.

${ }^{257}$ But they do affect sales transactions under Arts 2 and $2 \mathrm{~A}$ of the UCC.

${ }^{258}$ UETA ss 7 and 9.

${ }^{259}$ Some of the other issues covered under the Act are security procedures, record retention, admissibility of electronic records, time and place of sending and receiving electronic records, and errors in and changes to electronic records. It also
} 


\subsection{3}

\section{Application to MFS}

State and federal e-commerce laws both emulate e-commerce laws in South Africa, Europe and the EU in relation to regularising the use of electronic transactions in transacting insofar as guaranteeing that electronic transactions are just as enforceable as their paper counterparts and electronic signatures have just the same force and effect. They do not however provide any omnibus consumer protection clauses that are features of e-commerce laws in the other jurisdictions. This is left to the laws applicable to the agencies that may somehow have jurisdiction over aspects of MFS. In this regard, this minimises regulatory arbitrage, although the arbitrage is evident elsewhere in state and federal laws in relation to the varying and many times overlapping remits.

\section{Consumer Protection}

\subsection{1}

\section{Overview}

A variety of laws at both the federal or state levels regulate consumer affairs for specific domains. There are a number of federal consumer protection laws that relate to telecommunications ${ }^{260}$ and financial matters.

Most federal consumer protection laws have been enforced by the FTC and the US Department of Justice to now. The FTC is empowered under the FTC Act ${ }^{261}$ to inter alia prevent unfair methods of competition, and unfair or deceptive acts or practices in or affecting commerce; seek monetary redress and other relief for conduct injurious to consumers; prescribe trade regulation rules defining with specificity acts or practices that are unfair or deceptive, and establishing requirements designed to prevent such acts or practices; conduct investigations relating to the organisation, business, practices, and management of entities engaged in commerce; and make reports and legislative recommendations to Congress. It polices unlawful Unfair and Deceptive Acts and Practices (hereafter UDAP), similar to those contained in the South African CPA. Some of the FTC's work is performed or aided by the Bureaus of Consumer Protection, Competition and Economics aided by the Office of General Counsel. ${ }^{262}$ Federally regulated financial institutions have long been subject to UDAP laws by way of the FTCA. ${ }^{263}$ As noted above, it was only with the passing of the Dodd-Frank Act and its creation of the CFPB that the US gained an omnibus consumer protection law

\footnotetext{
allows any law that requires a physical record to be satisfied by an electronic record and that any signature requirement can be met by an electronic signature.

${ }^{260}$ Such as the National Do Not Call Registry, the Communications Act, and the Telephone Consumer Protection Act 47 USC $\$ 227$ of 1991 enacted to curb telemarketing. It has both state and federal application.

26115 USC $\$ \$ 41-58$, as amended.

${ }^{262}$ See FTC (2012) op cit note 29.

${ }^{263}$ As Smith and Shahani describe it, to prevent UDAP, the FTCA requires each bank regulator, including the FDIC, the FRS, the OCC, the OTS and the NCUA to establish a division of consumer affairs to receive consumer complaints and to take appropriate action in response to such actions or practices on the part of the institutions they regulate. See BW Smith and VR Shahani (2008) 'Unfair and Deceptive Acts and Practices: Developments in the Financial Services Industry' Banking Law Journal at 809, available at http://goo.gl/pb4fr.
} 
relating to financial matters. Dodd-Frank deprives the FTC of general authority related to consumer protection for financial service products.

There are also a number of state consumer protection laws which, in relation to financial and communications products, centre round implementations of the model law, the UMSA ${ }^{264}$ and others. Many states also have Departments of Consumer Affairs devoted to regulating certain industries and protecting consumers who use goods and services from those industries. ${ }^{265}$

\subsubsection{Application to MFS}

While there are no federal laws that directly regulate prefunded cards, ${ }^{266}$ the FTCA prohibits unfair and deceptive practices, regardless of the type of payment device involved. ${ }^{267}$ The FTC took action against a seller of prepaid telephone cards to recent immigrants, claiming that the seller failed to provide consumers with the number of minutes they would have available. As the CFPB is still in its infancy, its purview over MFS is not yet determinable.

However, as MFS metamorphose and develop into a robust bank and financial services industry in the US and could possibly have systemic (and manifest consumer protection) implications, the legislative and legal arsenal provided to the CFPB by Dodd-Frank could flesh out its ultimate purview.

\subsection{USA And MFS: Summary And Conclusion}

Despite it being the world's largest and most developed economy with sophisticated financial structures, there is a large base of unbanked, underserved and underbanked in the US that are currently using various types of SVPs in what could be seen as a parallel banking system. MFS is currently in its infancy in the US and what is being considered as rather additive models of MFS where existing open loop systems are accessed by NFC-based phones, where the account is funded by cash, cheque, or debit and credit payment instruments.

The ability to regulate this and to provide cogent consumer protection measures is vastly complicated by the dual nature of the US regulatory system, that is, regulations provided at federal level and the individual state level as well as competing jurisdictions by various state and federal agencies. There have been some limited successes at a homogenised state and federal approach, which has been motivated in part by security and AML concerns. This however is still complicated by the various (and sometimes competing) state and federal regimes relating to money and payment with money-type products as well as simple transfer of value using person-to-person systems. The result is inconsistent treatment of prefunded SV

\footnotetext{
${ }^{264}$ See ch 11, s11.2.4.7.2 above on the Uniform Money Services Act.

${ }^{265}$ For a full list of applicable consumer protection statutes, see http://goo.gl/cebLR.

${ }^{266}$ Except payroll cards and cards where the pooled funds are placed in a FDIC-insured account.

${ }^{267}$ Budnitz (2008a) op cit note 1 .
} 
systems by federal and state prudential agencies like the FDIC, OCC/OTA, and FRB. ${ }^{268}$ Indeed, the converged nature of MFS and that there is no MFS-law, means that any regulation encompasses inter alia telecommunications, banking, payments, AML concerns, and consumer protection. Regulation of analogous SVPs and their non-bank issuers has been an outgrowth of existing regulatory frameworks, consisting mostly of a panoply of regulatory bolt-ons rather than new legislative phenomena.

To the extent that banks are already subject to a prudential regulation, the business of issuing SVPs as emoney has been encompassed by this larger, pre-existing predominantly laissez-faire regulatory framework that embraces 'non-banks' in providing alternative mechanisms for persons to make payments or to obtain currency or cash in exchange for payment instruments. Even so, problems in application and interpretation have led to divergent viewpoints regulatory treatment even at an intra-federal level when confronted with new types of electronic financial services since they do not dovetail into legacy banking laws and traditional notions of the 'business of banking', and deposit-taking. This is compounded by the putative control the states have over their state-wide banks and other services that involve 'money' and nontraditional (non-bank) payment schemes, and the difference in control and scope versus federal law. ${ }^{269}$

Unlike the EU, diversity from and loosening of control by a central body is considered a good thing. Further complicating the nexus is that the nomenclature used throughout these state and federal regimes is somewhat muddled and could possibly give rise to regulatory arbitrage. For example, although prepaid cards and SVCs are now generally - commercially - conflated under the appellation 'prepaid', use of product descriptors by the FCC, UMSA, state MSB statutes, the FTC, FRB, FDIC, and various AML statues somehow all distinguish between the two as being different types of products.

These product-based artificial distinctions, which derive from the FRB-based definitions initially created in 1996, have meant that there is a sense that 'stored value' and 'prepaid' require separate regulatory regimes when ultimately they may simply be incarnations of the mechanisms of prefunding a loadable or nonloadable purse, network based or offline to be used as if they were cash, and so, ultimately, simply describing the same prefunded SV thing. However, steps have been suggested to rectify this issue with proposed new federal rules.

The states have tried to fill this inconsistency somewhat with their own patchwork of light-touch-moneytype UMSA-based safety and soundness laws that touch on MSBs, SVPs and e-money but which are primarily revisions and perfunctory bolt-on extensions of the existing legacy of 'money service' laws that

\footnotetext{
${ }^{268}$ As Ramasastry (2008) op cit note 1 passim points out, the disconnect at a federal (regulatory) level to prefunded purses reflects the fact that there is no primary federal agency in the US that supervises non-bank providers of financial services such as (non-bank) e-money issuers.

${ }^{269}$ See, for example, the instance of PayPal being targeted by states as being a bank for taking deposits and thus requiring a state banking license, versus a circuitous FDIC ruling indicating that PayPal does not take deposits under s3(1) as it is not a bank or savings association because it does not accept (physical) deposits as defined by federal law, which requires institutions to have a banking charter. PayPal, it said, does not have a charter, thus it is not a bank. See T Wolverton (2002) 'FDIC Decides PayPal's No Bank', available at http://goo.gl/RWYQu. However, the FDIC also determined that when PayPal acts as agent for customers and places PayPal customer funds into a 'pool' account held at an insured FDIC member bank, those funds will qualify for FDIC insurance in the event of a failure of a bank at which the funds were placed. This 'passthrough' insurance for customers does not apply to funds that PayPal customers choose to invest in the PayPal Money Market Fund, to liabilities of PayPal itself, nor if PayPal was deemed by the FDIC not to be acting as an agent for its customers. See PayPal's website for comments on FDIC Pass-Through Insurance, available at http://goo.gl/Ra6ey.
} 
usually regulate checks and money transmitters that mostly offer services to unbanked, underserved and underbanked consumers using financially-related but non-traditional products like currency exchanges, check cashing and wire transfers. Basic consumer protections in regard to SVPs would be in respect of rules for fees and expiry dates for the SOV.

Their application though is somewhat generic. The UMSA is the closest the US has to the EU's EMD, although the MSB laws do not require licensing of all aspects of SVP-type product offerings in the way that the catch-all Electronic Money Directive 1/ Electronic Money Directive 2 (hereafter EMD1/EMD2) tend to do. The MSB-laws, though, speak to a similar underlying meta-regulatory conundrum as to whether to treat these SOVs when used in closed or semi-open systems as 'money', or whether to treat them according to their application as payment instruments, or something else. The bolt-ons to these laws attempt a nexus between these bespoke type products and new types of payment instruments like SVP, remittances and emoney type products. Several states for example also took the position that the transfer of money over the Internet or the use of an electronic payment instrument was the equivalent of money transmission in the brick-and-mortar world and hence bolted their SVP laws onto their existing remittance-type state statutes.

Although it also has its inconsistencies and some bolt-ons, the USMA as a model law provides a more consistent and more de novo view of money and payment instruments and processes, for example, it defines money as 'a medium of exchange, whether or not redeemable in money', which would indicate widespread acceptance. This view creates an effective distinction between money and near-money, the former triggering the need generally to be licensed under a state's MSB laws. The SVP's lofty rise to the appellation of money as a store of value, unit of account and means of exchange may have legal implications insofar as the issuers may be considered as banks, although at state level an ELMI-like (hereafter Electronic Money Institution) MSB designation is most likely. Thus bilateral, closed systems do not necessarily fall under these regimes. Even with the UMSA model law, the state bolt-ons across the states that have implemented MSB statutes have been characterised by divergent implementation.

In practice, implementation and the interplay between state and federal laws is still confusing and unnecessarily complex. Indeed, both the type of prefunding method and the type of usage of a SVP becomes relevant to the rubric of laws, regulations and degrees of consumer protections that may become applicable. For example, at the federal level, the most cogent and relevant set of rules that approximate to MFS are those that revolve around treatment of prefunded SVPs and money within the AML, Reg E, Reg Z and FTC schemes. If the purchase of SOV is via a credit card, debit card, or EFT, the SVP purchase itself may be covered under federal regimes like Reg E and Reg Z. However, subsequent purchases of goods and services within the domain of the MNO made with that SOV would then not be covered. This is because the MNO prepaid card purchase with a credit or debit (or even direct EFT transfer from a deposit to the MNO for buying the value) would be seen more as an advance payment for buying MNO services, and not as a purchase of the goods subsequently purchased with that SOV. The situation may change however if the MNO purse is used for general purchases beyond a bilateral ecosystem stricture, such that the MNO SVA 
could be seen as an account or even deposit that would invoke regulatory oversight. ${ }^{270}$ It may also be classed as a payment intermediary, a possible conundrum reflected in a case brought against PayPal. ${ }^{271}$

Further exemptions, but for different reasons, may exist when applying state law. For example, in regard to use of the SVP, if the goods and services are digital (and usable on the phone), they may fall within the goods and services exceptions aimed at 'closed systems', a feature prevalent in many state MSB-type laws. Thus if an MNO for example provides both the payment instrument, and also provides the goods and services that can be bought with the payment instrument, then the system can be said to be fully closed and the goods and services exception would apply. This clarity of purpose is somewhat blurred though when 'information services' are bought by the subscriber in relation to the applicability of telecommunications law to $\mathrm{MFS}^{272}$ where the MNO may merely act as a billing conduit - or financial intermediary as it could be classed in terms of FDIC regulations - for similar third party digital purchases, with incremental amounts drawn off the purse as the micro-transactions take place. Thus if the goods and services are primarily digital goods that can only be telecommunications-based, or more specifically, can only be primarily utilised with the payment instrument itself, then the goods and services exemption in these laws would probably also apply.

This confusing nomenclature at a prudential and product level has been cited as one of the reasons consumer protection is too diverse and complex, with outwardly identical products being treated differently at state and federal level. ${ }^{273}$ The issue of pre-emption also hangs in the air: for example, in relation to giftcard type SVCs that are issued by banks or that are issued by private merchants but underwritten by banks, sellers of these cards may be successful in avoiding federal consumer protection laws by involving entities such as national banks that are regulated by federal law. Under certain circumstances, courts hold that federal law pre-empts state law in this respect. To enhance consistent consumer protection, though, the FTC uses so-called base-line consumer and business protections that are either not variable by the financial institutions or can only be altered to a limited degree which means that no gross variation of consumer protection rights codified in law are allowed at a state level.

Still, with the exception of payroll SVCs, there are currently still no legislatively mandated error resolution procedures under Reg E. Some SVPs offer protections that are similar to Reg E, but these are via persuasive but legally unenforceable card association network rules. ${ }^{274}$ This has the potential for a high

\footnotetext{
${ }^{270}$ Thus if a purse is linked to a deposit account that is used primarily for personal, family, or household use as required by Reg E, then a transfer of funds from that account to the purse would constitute an EFT governed by the EFTA and Reg E such that it should be treated in the same fashion as any other consumer EFT product offered by a bank that maintains an account, such as a telephone bill payment service or a home banking system. However, the omnibus application of the EFTA/Reg E regime to all models is maybe too generic, as the application turns not only on how the purse is funded, but more so on how it is used (as a means of exchange), making the purse issuer a payment intermediary.

${ }^{271}$ PayPal, although acting as a payment intermediary, has not been officially designated as providing an EFT service that would invoke Reg E protections. It is however classed and licensed as a MSB under most state MSB laws, and as an MSB for purposes of federal AML laws.

${ }_{272}$ In relation to the purchase of digital services using Premium Rated SMS (hereafter PSMS) shortcodes, under the Communications Act of 1934 as amended, text messaging and short code provisioning are 'information services', not telecommunications services and both are therefore legally exempt from common carrier regulation.

${ }^{273}$ While some credit and debit cards have the same Visa logo, they offer differing underlying federal consumer protection regimes. That is, rules allocating loss from unauthorised payment, erroneous payment, and the reversibility of payment will vary according to whether payment is made by cheque, credit or debit card, wholesale wire transfer, or letter of credit.

${ }^{274}$ Association rules however do have many error resolution components that mimic Reg E, although they may not necessarily be as generous to a consumer as Reg E and Reg Z.
} 
degree of confusion as consumers who see for example the Visa and MasterCard logos on these cards would probably assume that the cards have the same protections as credit and debit cards carrying identical $\log 0{ }^{275}$ The protections based on how the SVPs are funded and how they are used thus remain the arbiter for state and federal protections.

To posit a more robust financial regulatory regime though in the wake of the Great Recession in the US, the FRB through mandates given in terms of Dodd-Frank, has implemented a number of regulatory changes under its mandate in terms of the TILA and EFTA so as to encourage new payments and to enhance consumer protection. Still, at a payment systems level, the Federal Reserve lacks explicit legal authority to oversee systemically important payments systems: overseeing of payments is instead done via bank supervision - normally done to ensure the protection of depositors - and is spread across the FRS, the FDIC, the OCC, the NCUA, and state supervisory agencies. There is, further, the new CFPB, which may have omnibus ability to regulate most or all forms of MFS that may emerge in the US. As the CFPB is still in its infancy, however, its purview over MFS is not yet determinable but as MFS metamorphoses and develops - as it may - into a robust bank and financial services industry in the US with possibly some systemic and manifest consumer protection implications, the legislative and legal arsenal provided to the CFPB by DoddFrank will flesh out its ultimate purview.

While at one level, this would promote the movement towards a uniform set of laws based on uniform principles, some have suggested that product-level regulation is preferred since this allows federal and state regulators to zone in on certain products a generic approach may miss. Still, as with other jurisdictions, there are other regulatory remits offering protections since use of a mobile device may, tangentially, be in the realm of telecommunications regulation relating to billing systems. There is also the FTCA which prohibits unfair and deceptive practices regardless of the type of payment device. While the nexus to payments may appear tentative, the recourse to any telecommunications and broad consumer laws may have the same or even superior efficacy to payment-specific laws that appear to struggle to offer a comprehensive regulatory and prudential oversight of new payment products under existing regimes.

Thus, while there are only a few federal laws that directly regulate the use of prefunded SVPs, the vast majority of protections derive from state MSB-type safety and soundless laws. Even though there are no federal laws directly related to the consumer problems addressed by the state law, the perimeter of the MSB-type state statutes and thus their application has led to jurisdictional conflicts with federal laws based on federal preemption precepts applying indirectly through the vagaries of the state's rights in terms of the 'commerce clause' in the US constitution. ${ }^{276}$

Insofar as the collateral of federal law may tangentially touch on prefunded purses as to their 'means of exchange', functionality, these are grouped together at a (federal) prudential level under various statutes relating to electronic fund transfers, credit cards and bespoke check laws.

\footnotetext{
${ }^{275}$ Consumer knowledge and assumptions of these cards may be lacking however. Further, PIN-free debit cards effectively mimic PIN-less credit cards, such that they may appear identical to many consumers in their functionality although clearly in most cases the debit card requires a positive balance at purchase to complete a transaction.

${ }^{276}$ See for example PGCC, LLC v Ayotte op cit note 184, and further, Neiman (2010) op cit note 36.
} 
More succinct omnibus AML legislation speaks directly to these new forms of money and payments, while generic consumer protection is offered by the FCC specifically on telecoms and the EFTA regime generally on consumer protection. At a state level, SVPs may be touched by 'Money Service Business' (MSB)-type laws, or gift card regulations, or any applicable EFT laws.

It may be then that those offering new MFS products may have an ambiguous legal status. Consumers seeking legal relief if, for example, they mistakenly transfer money to the wrong recipient may have difficulty finding a legal nexus using existing sets of laws even with their modern SVP-related bolt-ons, where available. However, the relatively laissez-faire attitude by the Federal Reserve to new services bracketed to some extent by regulatory inertia due to partisan views between pro- and anti-regulatory Democrats and Republicans respectively - has allowed an organic growth of e-money and SVP-type services free of regulation and free of restrictions on who may provide what, unlike in South African regulation which specifies who can provide interoperable SVP and e-money. This is similar to the Kenyan case, although this is largely because of a lack of regulation, not necessarily a deliberate policy not to implement legislation that restricts potential providers of new services. The EU, too, has a similar laissezfaire attitude, although because of the need to provide consistency in the EU, this is done through an orderly authorisation and safety and soundness regimes, that is, via the EMD1/2 and the PSD.

In all, the US market is - as it has always been - a breeding ground for innovation and is naturally highly competitive. The federal government has had a relatively hands-off approach to regulating new types of financial systems and innovations unless there were clear systemic and consumer protection considerations that the states or self-regulation were unable or unwilling to address. While the result has been innovation, the effect however has been a patchwork of inconsistent rules and protections.

This panoply may have worked in the past in the framework of easily identifiable financial silos, but with the emergence of more complex and chimerical financial ecosystems in MFS and other financial fields, further coordination in rules between the states and the federal government is seen to be required. Indeed, the (glacial) convergence of state and federal laws relating to AML provisions in respect to SVPs as well as the recent federal CFPB indicates a more coordinated and normative approach to financial regulation is afoot. Regulation is thus manifesting in the US as may be required, but at the same time innovation is not being stifled: competition is manifest.

The overall philosophy generally in the US then is that new regulations are only imposed where absolutely required, and then only on a proportional basis. This can-do regulatory philosophy is one that South African regulators and policy makers, it is submitted, should embrace when approached with considering financial innovations such as MFS and the potential new non-bank entrants to provide it.

If regulations are necessary in South Africa to foster competition and provide for innovation in the financial sector, then the emergence of MFS provides ample reason. The risks are relatively manageable, but the political and policy will must follow. 


\title{
CHAPTER 12
}

\section{SOUTH AFRICA AND MOBILE FINANCIAL SERVICES}

The advent of democracy in South Africa in 1994 accelerated efforts to include all segments of the population in the development process. ${ }^{1}$ The South African economy is classed as a developing country ${ }^{2}$

\begin{abstract}
${ }^{1}$ In South Africa, there are 17.3 million (hereafter mn) economically active people out of a total population of $49 \mathrm{mn}$, of which $62 \%$ are residing in urban areas. The literacy rate of the total population is $86.4 \%$. The GDP per capita is US $\$ 10,700$. See for general economic and financial information on South Africa: United States. Central Intelligence Agency (CIA) (2012) 'Africa: South Africa' in The World FactBook, available http://goo.gl/AFSi; South African Reserve Bank (SARB) (2011f) 'Statistics', available at http://goo.gl/0Ata2; South Africa, Department of Trade and Industry (DTI) (2011) 'Economic Statistics', available at http://goo.gl/oGzis; R Cassim et al (2004) 'A Review of the Changing Composition of the South African Economy: Report Prepared for the 10-year Review Project: The Presidency' Trade and Industrial Policy Strategies (TIPS)', available at http://goo.gl/vLc31; United States, Central Intelligence Agency (CIA) (2011b) 'Field Listing: Distribution of Family Income: GINI Index' in The World Factbook, available at http://goo.gl/nRD4I; TT Mboweni (2009) 'Overview of the South African Economy', available at http://goo.gl/WoV6R; T Dlamini (2009) 'Managing the Crisis: South Africa Country Report', available at http://goo.gl/XAkuR; South African Reserve Bank (SARB) (2008b) 'Financial Stability Review: September 2008', available at http://goo.gl/IEtIA; South African Reserve Bank (SARB) (2011b) 'Financial Stability Review: March 2011', available at http://goo.gl/IjSvo; Deloitte (2012) 'Deloitte on Africa: Banking Regulatory Environment And Supervision In Africa', available at http://goo.gl/TdTKJ..
\end{abstract}

Statues and bills referred to in this chapter include the Alienation of Land Act 68 of 1981 (hereafter Act 68 of 1981); Apportionment of Damages Act 34 of 1956; Banks Act 94 of 1990 (hereafter Banks Act); Banking Act 38 of 1942; Banks Act 23 of 1965; Bills Of Exchange Act 34 Of 1964; Children's Act 38 of 2005; Collective Investment Schemes Control Act 45 of 2002; Companies Act 61 of 1973 (hereafter Act 61 of 1973); Companies Act 71 of 2008 (hereafter Act 71 of 2008); Competition Act 89 of 1998; Constitution of the Republic of South Africa Act 108 1996; Consumer Affairs (Unfair Business Practices) Act of 1988; Consumer Protection Act 68 of 2008 (hereafter CPA); Co-operative Banks Act 40 of 2007; Cooperatives Act 14 of 2005 (hereafter Act 14 of 2005); Currency and Banking Act 31 of 1920; Currency and Exchanges Act 9 of 1933; Custody and Administration of Securities Act 85 of 1992; Electronic Communications Act 36 of 2005 (hereafter ECA); Electronic Communications and Transactions Act 25 of 2002 (hereafter ECTA); Exchequer Act 66 of 1975; Financial Advisory and Intermediaries Services Act 37 of 2002 (hereafter FAIS); Financial Institutions (Investment of Funds) Act 39 of 1984; Financial Institutions (Protection of Funds) Act 28 of 2001 (hereafter Act 28 of 2001); Financial Intelligence Centre Act 38 of 2001 (hereafter FICA); Financial Markets Control Act 55 of 1989; Financial Services Board Act 97 of 1990 ; Financial Supervision of the Road Accident Fund Act 8 of 1993; Friendly Societies Act 25 of 1956 ; Insider Trading Act 135 of 1998; Inspection of Financial Institutions Act 80 of 1998; Long-term Insurance Act 52 of 1998; Merchandise Marks Act of 1941; Microfinance Act 19 of 2006; Mutual Banks Act 124 of 1993 (hereafter Act 124 of 1993)); National Credit Act 34 of 2005 (hereafter NCA); National Gambling Act 7 of 2004; National Gambling Amendment Act 1 of 2008; National Payment System Act 78 of 1998 (hereafter NPSA); National Payment System Amendment Act 22 of 2004 (hereafter NPSAA); Ombud Schemes Act 37 of 2004; Pension Funds Act 24 of 1956; Prevention of Organised Crime Act 121 of 1998 (hereafter POCA); Price Control Act of 1964; Proceeds of Crime and Money Laundering (Prevention) Act; Promotion of Access to Information Act 2 of 2000 (hereafter POAIA); Protection of Constitutional Democracy against Terrorist and Related activities Act 33 of 2004 (hereafter Terrorism Act); Public Finance Management Act 1 of 1999 ; Public Service Act 30 of 1994; Public Service Act Proclamation 103 of 1994; Regulation of Interception of Communications and Provision of Communication-related Information Act 70 of 2002 (hereafter RICA); Regulation of Interception of Communications and Provision of Communication-Related Information Amendment Act 48 of 2008 (hereafter RICA); Sales and Service Matters Act of 1964; Securities Services Act 36 of 2004; Short-term Insurance Act 53 of 1998; Small Claims Court Act 61 of 1984 ; South African Postbank Limited Act 9 of 2010 (hereafter Act 9 of 2010; ; South African Reserve Bank Act 90 of 1989 (hereafter SARB Act); ; Stock Exchanges Control Act 1 of 1985; Supervision of the Financial Institutions Rationalisation Act 32 of 1996; Trade Practices Act of 1976; Trust Property Control Act 57 of 1988 (hereafter Act 57 of 1988). In the EU, Directive 2000/31/EC on Certain Legal Aspects of Information Society Services (hereafter ECD); Directive 2000/46/EC on the Taking up, Pursuit of and Prudential Supervision of the Business of Electronic Money Institutions (hereafter EMD1); Directive 2009/110/EC On The Taking Up, Pursuit And Prudential Supervision Of The Business Of Electronic Money Institutions (hereafter EMD2); and Directive 2007/64/EC on Payment Services in the Internal Market (hereafter PSD). Unless the full title is required by context, the abbreviated forms of these statutes will be used throughout this chapter.

${ }^{2}$ South Africa is also ranked as a Newly Industrialised Country (NIC) alongside India, China, Turkey, Malaysia, Mexico and Brazil. At the end of 2010, South African became a member of the BRICS group of nations. See generally, United Nations 
with a stable competitive structure in the banking sector, low banking levels, a sophisticated payments system at a national and retail level, relatively sound financial regulation, ${ }^{3}$ but there are overriding policy challenges in the form of weaknesses in the economic structure, including wide social inequalities, high unemployment and income inequality. ${ }^{4}$ South Africa has a relatively sophisticated technology sector, with pervasive high speed (broadband) data networks and a robust mobile telecommunications sector that utilises the latest mobile technology.

Much like other countries, South Africa has a tiered banking structure ${ }^{5}$ that reflects the asset size of the bank and the regulatory constraints on a bank's activities. ${ }^{6}$ Tier 1 includes commercial banks and community-based mutual banks regulated by the Banks $\mathrm{Act}^{7}$ and the Mutual Banks Act $^{8}$ respectively. ${ }^{9}$

Tier 2 consists of commercial savings and loans banks and community-based cooperative banks regulated by the Cooperative Banks Act. ${ }^{10}$ A proposed Tier $3^{11}$ consists of commercial savings banks and

(UN) (2010) 'Conference on Trade and Development World Investment Report 2010' at 28; International Monetary Fund (IMF) (2010a) 'IMF Country Report No 10/296', available at http://goo.gl/eO9W3.

${ }^{3}$ IMF (2010a) op cit note 2. For a general view of regulatory exigencies in South Africa, see South Africa Foundation (2003) 'Designing a Regulatory Impact Assessment for South Africa' available at http:/goo.gl/5RzpZ. They conclude that some ten principles of success are needed to guide the design of a regulatory reform regime for South Africa. These are: Integration with independence; Public private partnership; Appropriate authority; Public accountability; High-level political support; Reform embedded in legislation; Clear guidelines; Coordination; Appropriate cost; and Sufficient information. For a specific overview on cost-benefit of regulation in the South African banking ecosystem: C Quiding (2006) 'The cost-benefit of regulation in South African banking', Master's Dissertation, University of Pretoria, available at http://goo.gl/qlt6o, who believes there is a conflict between the objectives of international compliance and social and economic development and that the support of the enabling environment by the regulations is skewed towards the international compliance objective at the expense of the social and economic objectives. I would agree with this assessment, especially in the light of the SARB's later insistence - detailed in ch 12, s12.4.2 titled E-Money in South Africa - that only licensed banks are to be the sole pivot for allowing MFS and e-money issuance in South Africa.

${ }^{4}$ Bizcast (2010) 'S\&P: South Africa Banking Industry Country Risk Assessment Maintained at Group 5' Standard \& Poor, 22 January, available athttp://goo.gl/9LDbs. Southern Africa's 'GINI coefficient', which measures the inequality as a proportion of its theoretical maximum and which ranges from 0 (no inequality) to 1 (complete inequality), was 0.666 in 2008, compared to Kenya at 0.425 and India at 0.368 (2004)). See Presidency of the Republic of South Africa (2009) 'Development Indicators 2009', available at http://goo.gl/RD9Fw.

${ }^{5}$ For an overview of this tiered hierarchy, see Feasibility (2005) 'The Impact of the Dedicated Banks Bill on Access to Financial Services'. For a banking perspective, see N Mashiya (2006) 'Vision on Banking' Presentation to The $3^{\text {rd }}$ International BANKSETA Conference 11 October 2006, Banking Sector Education \& Training Authority, available at http://goo.gl/UsxqA. For a comprehensive historical overview of the emergence of modern banking structures in South Africa, see G Verhoef (2009) 'Concentration and Competition: The Changing Landscape of the Banking Sector in South Africa 1970-2007' South African Journal of Economic History (24)2 157-197. Verhoef details why large banks have what she terms an entrenched 'oligopolistic position' in South Africa and surmises that this arose from political conditions which resulted in nationalistic policies of pre-1994 governments so as to keep South African capital in the country, as well as exchange control and policies regulating foreign ownership of banks which she says assisted these domestic interests with capital to acquire control of the banks

${ }^{6}$ On the relative sizes and capital requirements of the various tiers of South African banks, see PwC (2011) 'Reinforcing Collective Strength And Stability South Africa - Major Banks Analysis', available at http://goo.gl/n2yRz. Comparatively, see in United States where the median size of Tier 1 is US $\$ 112 \mathrm{bn}$, Tier 2 is US $\$ 2$ bn (hereafter bn) and Tier 3 at US $\$ 137 \mathrm{bn}$. See Federal Deposit Insurance Corporation (FDIC) (2009a) 'Banks' Efforts to Serve the Unbanked and Underbanked Report 2009', available at http://goo.gl/rVF5A. See also the regulatory restrictions in Hong Kong on the banking tiers, in Hong Kong Monetary Authority (2011) 'The Three-tier Banking System', available at http://goo.gl/ufRxq. On the capital requirements of banks in relation to the so-called Basle requirements, see ch 4, s4.2 titled Nature of Banking: An Overview.

${ }^{7}$ Act 94 of 1990 op cit note 1.

${ }^{8}$ See the Mutual Banks Act 124 of 1993 op cit note 1. See ch 12, s12.3.5.4 titled Mutual Banks Act.

${ }^{9}$ These tiers relate to the type of products that a license under a regulatory regime may undertake. Tier 2 and 3 licensed banks and deposit-taking companies are restricted in the amounts and terms of deposits they may accept, and only banks may operate current and savings accounts. The tiered structure must be differentiated from the Basle risk requirements for licensed banks as set out by the Bank of International Settlements. Some believe that prepaid cards portend 'second tier' substitutes for bank accounts which do not provide cardholders with the same stability or protections that all consumers expect and deserve.

${ }^{10}$ Act 40 of 2007 op cit note 1. See ch 12, s12.3.5.3 titled Co-operative Banks Act.

${ }^{11}$ On the configuration of the Tier 3 banks, see Mashiya (2006) op cit note 5. 
community-based co-operative banks regulated by the Cooperative Banks Act and the proposed Dedicated Banks Act. ${ }^{12}$

The banking industry in South Africa is the largest component of the financial system. At the end of 2009, there were 31 banks with operating licenses ${ }^{13}$ regulated by the South African Reserve Bank (hereafter SARB). ${ }^{14}$ Four major groups dominate the South African banking sector: ABSA Bank, Standard Bank South Africa (hereafter SBSA), First National Bank (hereafter FNB) and Nedbank. They reportedly hold over $90 \%$ of the market share in competition with a wide range of niche commercial banks. ${ }^{15}$ In May 2003, the National Treasury requested a study on the competitiveness of the South African banking industry and a Task Group was established to undertake this study which resulted in the Competition Commission's enquiry into the banking sector. ${ }^{16}$ The Commission's final report was issued in $2008 .{ }^{17}$

As noted earlier, ${ }^{18} 24 \%$ to $26 \%$ of the South African population is financially excluded. Even though $60 \%$ of adults have a bank account of some sort, this does not mean they use the account since bank charges, lack of transport and the cost of travelling to and from a bank branch may be prohibitive. Even among the banked population, some $29 \%$ do not save or invest at all, indicating that in many cases, banking is mostly a transactional facility. ${ }^{19}$ Remittances ${ }^{20}$ - mostly by non-South African nationals living in South Africa ${ }^{21}$ play a major part in the unbanked economy, with both formal and informal means of transfer taking place. ${ }^{22}$

${ }^{12}$ See ch 12, s12.3.5.5 on the Dedicated Banks Bill.
${ }^{13}$ Excluding two mutual banks.
${ }^{14}$ Currently, some 42 foreign banks have authorised representative offices in South Africa, all of which provide retail and investment banking. Republic of South Africa National Treasury (2010) 'Vision For Financial Inclusion', available at http://goo.gl/HwmxO.

${ }_{15}$ Competition Commission, South Africa (2008b) 'Banking Enquiry Report to the Competition Commissioner by the Enquiry Panel: Executive Overview’, available at http://goo.gl/WDDbY. See ch 12, s12.5 on the Competition Commission Enquiry into Banking and Payments in South Africa below for a discussion of the Commission's findings.

${ }^{16}$ For the reports and the analysis thereto, see inter alia, H Falkena et al (2004a) 'Competition in South African Banking: Task Group Report for the National Treasury and the South African Reserve Bank', available at http://goo.gl/nZeNb; P Hawkins and A Bertoldi (2006) 'The National Payment System and Competition in the Banking Sector: A Report Prepared for the Competition Commission: Executive Summary and Synopsis', Feasibility, available at http://goo.gl/iTymu. On competition (or antitrust) issues in the South African banking and payments sector, see ch 12, s12.5 titled Competition Commission Enquiry into Banking and Payments in South Africa; Competition Commission (2008a) 'Banking Enquiry Report to the Competition Commissioner: Technical Report', available at http://goo.gl/JRWNj; South African Reserve Bank (SARB) (2011d) 'NPSD: Position Paper on Access to the National Payment System', available at http://goo.gl/KDd7W; VA Lawack-Davids (2008) 'Legal and Regulatory Framework Pertaining to the National Payment System (NPS): Peeling the Layers of the Onion' 29(3) Obiter at 453; South African Reserve Bank (SARB) (2007b) 'Position Paper: Bank Models in the National Payment System', January, available at http://goo.gl/JYxkp.

${ }^{17}$ The substance of the report and its background is discussed in ch 12, s12.5. There has, however, been criticism that suggests that the Competition Commission has been unable to force the banks to implement any of its recommendations particularly the lowering of charges on the inter-bank transfer system. See S Mantshantsha (2009) 'SA Banks Outgun Authorities' posted on Fin24, 3 April, available at http://goo.gl/uc9ca.

${ }^{18}$ See ch 2, s2.1 titled Introduction.

${ }^{19}$ Ibid; and Finmark Trust (2007) 'South Africans Shun the Piggy-bank', available at http://goo.gl/2smnV.

${ }^{20}$ See ch 4, s4.8.4.3 titled Remittances.

${ }^{21}$ There is significant anecdotal evidence that most foreigners, including those that have a legal right to work, find it difficult to open a bank account and that many effectively find themselves excluded from appropriate financial products and services. See H Bester, C Hougaard and D Chamberlain (2010) 'Reviewing the Policy Framework for Money Transfers' CENFRI at 16, available at http://goo.gl/zGcmS.

${ }^{22}$ Ibid at 16 indicate that the formal remittance market in South Africa has three models: account-based, non-account based and e-money based (as a variation on either of the previous two). They believe, though, that $50 \%$ of all remittances out of South Africa - especially to neighbouring states - are informal, that is, Informal Value Transfer Systems (IVTS) and thus are not reflected in official statistics. See also S Mbalekwa (2011) The Legal and Regulatory Aspects of International Remittances within the SADC Region. LLM Thesis, Nelson Mandela Metropolitan University, available at http://goo.gl/DKG12. The World Bank says that official outward remittance flows in 2010 were US\$1,16bn, of which US $\$ 1,1 \mathrm{bn}$ related to the compensation of employees and US $\$ 14 \mathrm{~mm}$ of which were migrant transfers. D Ratha, S Mohapatra and A Silwal (2011) 'Migration and Remittances Factbook 2011: South Africa', World Bank: Washington, available at 
Remittances are subject to strict forex controls. ${ }^{23}$ The South African National Treasury has also made Financial Inclusion (hereafter FI) a priority and seeks to:

' $[\mathrm{P}]$ romote and enhance greater access and usage of appropriate financial services and products for all South Africans, especially the currently financially excluded. National Treasury will further strive to ensure that greater FI delivers tangible socioeconomic benefits for all citizens. ${ }^{24}$

Further, a Financial Sector Charter (hereafter FSC) was introduced that required South African retail banks to provide access to suitable retail products and services to the mostly rural-based 'previously-unbankedmass-market' (hereafter PUMM). ${ }^{25}$ As a result, the entry-level Mzansi bank account was introduced in 2004 by the South African banking industry, launched as a collaborative effort by the four largest commercial banks together with the state-owned Postbank. ${ }^{26}$

The government has indicated that it wishes to broaden the inclusiveness of banking facilities, firstly, by transforming existing financial institutions to include a Black Economic Empowerment (hereafter BEE) component, ${ }^{27}$ and secondly, to integrate the unbanked into the banking and payments structure through a mixture of a tiered banking and payments structure as well as initiatives that encourage participation by the poor in the formal banking sector at the commercial bank Tier 1 level.

There are a number of laws and regulations at statutory, self-regulatory and co-regulatory levels that reflect necessary oversight over telecommunications, banking and microfinance, Anti-Money Laundering (hereafter AML), foreign exchange (hereafter forex), consumer protection and electronic commerce (hereafter e-commerce), with some dedicated regulatory agencies to enforce these regulations. The SARB and the Independent Communications Authority of South Africa (hereafter ICASA), for example, have statutory control over the broad financial and telecommunications sectors respectively. The synthesis of all these agencies and the laws and regulations they enforce on a cumulative basis and that affect Mobile Financial Services (hereafter MFS) directly and indirectly is the focus of this Chapter.

http://goo.gl/o2YkT. MNO airtime and other in-kind means of value transfer represent growing forms of IVTS. See in regard to mobile airtime transfer, ch 6, s6.5.4.3 titled Mobile Airtime Transfer.

${ }^{23}$ See ch 12, s12.3.7.5 below on foreign exchange controls (hereafter forex).

${ }^{24}$ Ibid. See also ch 2, s2.2 titled Rationale for MFS, which includes further statistical analysis of the state of FI in South Africa.

${ }^{25}$ J Coetzee (2005) 'Banking the Unbanked in South Africa: The Practical Implications on Branch Banking', available at http://goo.gl/12cFo. For further insight into FI efforts in South Africa, see Bankable Frontier Associates (2010) 'South African Financial Diaries and the Mzansi Initiative: Five Years Later' at 2, available at http://goo.gl/yTpiW. For overviews of FI in South Africa, see HB Falkena (2004b) 'The Access and Stability Objectives of Regulation' Workshop on Tiered Banking Legislation, available at http://goo.gl/Us0cD; M Kirsten (2006) 'Policy Initiatives to Expand Financial Outreach in South Africa', available at http://goo.gl/nZG0H; Feasibility (2005) op cit note 5; H Falkena et al (2001) 'SMES' Access To Finance In South Africa: A Supply-Side Regulatory Review.' The Task Group of the Policy Board for Financial Services and Regulation, at 6, available at http://goo.gl/brdbX; Consultative Group to Assist the Poor (CGAP) (2010c) 'Update on Regulation of Branchless Banking in South Africa January 2010', available at http://goo.gl/IgkwI; P Clyde (2008) 'Targeting the Unbanked: Mzansi at Standard Bank' William Davidson Institute at the University of Michigan, available at http://goo.gl/EENz0; A Schoombee (2004) 'South African Banks and the Unbanked: Progress and Prospects', available at http://goo.gl/62kMk; D Porteous (2008) 'Mobile Phone Banking: Is m-Banking Advancing Access to Basic Banking Services in South Africa?' Finmark Trust, available from http://goo.gl/4a1P2.

${ }^{26}$ Bankable Frontier Associates (2010) op cit note 25. On its uptake amongst South Africans, see M Fisher-French (2012) 'Mzansi Accounts Reach Dead End' Mail and Guardian, available at http://goo.gl/jzUy1

${ }^{27}$ In August 2002, government, business, labour and community representatives committed themselves to the development of a BEE Charter for the financial sector. See S Arora (2007) 'South Africa: Committed to an Inclusive Financial Sector', available at http://goo.gl/LX2GR. 
South Africa though does not have any progressive financial-centric legislation on payments and e-money like the European Union's (hereafter EU's or EU) Electronic Money Directive(s) (hereafter EMD) ${ }^{28}$ and its Payment Service Directive (hereafter PSD) ${ }^{29}$ nor is there a (consumer-facing or retail) payments law.

The effects of financial, AML, e-commerce, consumer protection and telecommunications laws and regulations are discussed below.

\section{MFS Implementations in South Africa}

\subsection{1}

\section{Overview}

According to research by Mobility 2011, 44\% of urban mobile phone users use mobile phone banking compared with $27 \%$ in 2010 , while in smaller centres and towns, $27 \%$ now use cell phone banking. ${ }^{30}$ In total, during 2011, 37\% of South Africans in urban and rural areas aged 16 and younger used mobile phone banking on a regular basis. ${ }^{31}$ There are several MFS incarnations in South Africa ${ }^{32}$ that use the airtimebased Stored Value Account (hereafter SVA) and the Store of Value (hereafter SOV) therein, and fiatbased SVA. Where the airtime SVA is used, this is as noted earlier, primarily to access Wireless Application Service Providers (hereafter WASP) Value Added Services (hereafter VAS). Where the fiatbased SVA is used this is primarily 'additive, ${ }^{33}$ and where a Mobile Network Operator (hereafter MNO) or Mobile Financial Service Provider (hereafter MFSP) have partnered with a licensed bank to provide MFS and VAS-type services. The SARB Guidelines on agents allowed companies such as Wizzit, MTN Banking $^{34}$ and Standard Bank, which have or have had a large agent network, to have agents or 'outlets' to provide limited services. ${ }^{35}$

\subsection{2}

\section{Wireless Application Service Providers VAS}

Wireless Application Service Providers (hereafter WASPs) as noted earlier ${ }^{36}$ may be considered as the first incarnation of a MFS in the form of a mobile payment (hereafter m-payment), albeit in a limited 'walledgarden ${ }^{37}$ setting. Purchases are mainly for VAS using the airtime SVA. The WASP market in South Africa

\footnotetext{
${ }^{28}$ See ch 9, s9.6.3 titled E-Money, Stored Value Laws and Regulations.

${ }^{29}$ Directive 2007/64/EC on Payment Services in the Internal Market. For a discussion thereof, see ch 9, s9.6.2 on the Payment Services Directive.

${ }^{30}$ M Jacks (2011) 'ABSA’s CashSend Boosts Cellphone Banking Usage in SA', available at http://goo.gl/B3596.

${ }^{31}$ Ibid.

${ }^{32}$ See broadly, ch 2, s2.7 titled Current and Future MFS Schemes.

${ }^{33}$ See ch 2, s2.2 titled Introduction, for an introduction to MFS where the terms 'additive' versus 'transformational' banking are explained.

${ }^{34}$ MTN Banking was formed as a Joint Venture (hereafter JV) between MNO MTN and Standard Bank, but in 2008 it ceased acquiring new customers due to market disinterest.

35 Other services are provided by M-pesa, and FNB as described below. See also ch 6 on mobile and MFS commercial models.

${ }^{36}$ See ch 6, s6.5.4.2 on WASP VAS.

${ }^{37}$ See ch 4, s4.8.3.7 titled Ubiquity of Use: Interoperability.
} 
in 2010 was worth some ZAR4 billion (hereafter bn). ${ }^{38}$ The SARB in 2002 banned the use of the airtime SVA for non-VAS (digital) purchases and enforced this again in 2010.

First National Bank (FNB)

FNB has launched a number of products aimed at mobile banking. Its Pay2Cell product allows FNB accountholders to make payments to other FNB clients using only the recipient's cell phone number, with no branch code or account number required. ${ }^{39}$ FNB also offers the eWallet which caters for both the banked and unbanked market for Person-To-Person (hereafter P2P) transfers. ${ }^{40}$ Whilst there is still a possibility of depositing funds in the wrong account if an error is made while entering the numbers to make a deposit, FNB indicate that there is a procedure that can be followed by the depositor to reverse the transaction.

\subsection{4 \\ ABSA Bank}

ABSA Bank is a licensed Bank with a number of innovative mobile banking and remittance solutions. It is also running a trial of Near Field Communication (hereafter NFC) payments. Its CashSend P2P product was launched in 2008 and it enables individual customers to send money from ABSA's mobile phone banking platform to the 5026 ABSA-owned Automated Teller Machines (hereafter ATMs) or from the bank's Internet banking channel to anyone in South Africa, both banked and unbanked. ${ }^{41}$

To withdraw cash at an ABSA ATM, the receiver of the cash only needs to enter a Personal Identification Number (hereafter PIN) which the bank sends via Short Message Service (hereafter SMS) to the customer's mobile phone, along with a secret code that enables the cash withdrawal at the ATM. ${ }^{42}$ Customers can send amounts ranging from ZAR20 to a maximum of ZAR3,000 per day. Free Unstructured Supplementary Service Data (hereafter USSD) sessions are offered to customers using mobile phones to do banking. ${ }^{43}$

\footnotetext{
${ }^{38}$ In 2010, the average monthly amount spent on a WASP transaction on the South African MNOs below ZAR30 for prepaid and below R70 for post-paid users. Author's personal communications with South African MNOs.

${ }^{39}$ Transactional costs are limited to ZAR1,500 per day and are linked to the type of FNB account that the sender has with FNB.

${ }^{40}$ See generally, ch 4, s4.8.4.3 titled Remittances. With the eWallet, an FNB bank account holder can send money to anybody with a mobile phone. The recipient (who does not need a bank account) can withdraw the cash at any FNB ATM. The sender is charged a transaction fee of about ZAR9 and the recipient does not have to pay to get the money. See P Ndzamela (2010a) 'FNB's e-Wallet Grows Tenfold in 2010' Moneyweb, available at http://goo.gl/o7meV. Users of eWallet are said by FNB to be accountholders who paid domestic staff to minimise fraud. For security, users can only send up to ZAR1,000 per day and the wallet can only keep a total of ZAR1,000. The eWallet has a Personal Identification Number (hereafter PIN) code to ensure that if somebody accesses the recipient's phone, they cannot access the money.

${ }^{41}$ See Annex 1, Exhibit I for a schematic of the method of sending value via an ABSA ATM machine to be cashed out by a non-customer recipient who has a mobile phone at an ABSA ATM.

${ }^{42}$ From the launch of CashSend until May 2011, ABSA customers sent over 900,000 transactions to the value of ZAR450mn with an average value of ZAR450 per transaction. Some $34 \%$ of these P2P transactions were sent via ABSA's cell phone channel. Generally speaking, of ABSA's $11.8 \mathrm{mn}$ retail customers, $2.6 \mathrm{mn}$ make use of cell phone banking and $1.3 \mathrm{mn}$ use Internet banking. See Jacks (2011) op cit note 30.

${ }^{43}$ ABSA indicated that of the $2.8 \mathrm{mn}$ of its customers that use mobile phone banking, $1.2 \mathrm{mn}$ use what they call 'cell phone banking light', which is the easier option and can actually be accessed from any mobile phone using USSD and SMS. Moneyweb (2011) 'ABSA and Vodacom Seal Multi-million Rand Deal: Gavin Opperman - CEO, ABSA Retail', available at http://goo.gl/P0A1Y.
} 
As noted earlier, in this prototypical bank-led model, SBSA and its Community Banking Division provides customers with a fully operational bank account and a transactional account that use the mobile banking platform of the MNO MTN. ${ }^{44}$ There are reportedly no account opening or monthly service charge fees. ${ }^{45}$

Clients may transact by cell phone or by linked debit cards provided to them on retailer devices placed with 'retail partners' within communities. ${ }^{46}$

There may or may not be cash-in/cash out facilities using agents, although retail chain stores may in some cases be used for this purpose, over and above earlier simple account openings and Identification Document (hereafter ID) verification.

SBSA also participated with MNO MTN in a Joint Venture called MTN Banking which offered a MTN MobileMoney Account for transactions ${ }^{47}$ and MTN Money Transfer for remittances. ${ }^{48}$ MTN Banking excluded itself from liability for any losses. ${ }^{49}$

\footnotetext{
${ }^{44}$ See MTN's official website at http://www.mtn.co.za. See further on this MFS facility, ch 6, s6.4.2 on the licensed bank MFS model.

${ }^{45}$ On opening an account clients will receive both an MTN SIM card and a Standard Bank branded debit card. The transactional account operates on the MTN banking platform. There is no fee to open an account and no service charges. All transactions within the mobile money 'club' cost ZAR0.50. Clients can also use their linked debit cards on existing banking infrastructure, but here they will face some Mzansi-type fees.

${ }^{46}$ On the use of agents in MFS, see ch 2, s2.5.2; and ch 6, ss6.4.4.3, 6.5.5.4 and 6.6.3.

${ }^{47}$ MTN Banking, which as noted above ceased to acquire new customers in 2008, but still operates some remaining accounts, describes this as a 'transactional account' for paying bills, remittances and buying airtime. The account number is a cell phone number, plus one extra check digit. A magnetic stripe card is issued with the account. Users can make cash deposits at any EasyPay paypoint such as Pick 'n Pay, Shoprite, Checkers, CheckersHyper, Lewis and Foodworld. Users that have not provided their ID details have restrictions on their accounts that include a maximum balance limit of ZAR25,000 and no debits or credits on the account that exceed ZAR5,000 per day. A user can have these restrictions lifted by visiting one of the MTN outlets or any Standard Bank branch, completing the application form and providing a copy of their ID book and recent proof of residential address. Payments to another MobileMoney account, to another bank account, and EasyPay bill payment cost ZAR3.00. All messages sent from a MTN cell phone to bank using MobileMoney are free. See MTN Banking (2011c) 'MTN Money' Transfer: What is MTN Banking?', available at http://goo.gl/fD4bP, which states: 'The sender and/or receiver accepts that he/she uses the Service at his/her own risk. MTN Banking or the Merchant shall not be liable for any loss or damage, delay, non-delivery, non-payment or underpayment of money transferred whether due to the fault, error or omission of MTN Banking and/or its Merchants, for more than the transfer amount and the fee paid by the sender. No liability is accepted for service delays due to causes beyond the control of MTN Banking and/or the Merchants. In no event will MTN Banking and/or its Merchants be responsible for indirect damages.' MTN Banking (2011a) 'MTN Money: Terms and Conditions', available at http://goo.gl/ptxi0.

${ }^{48}$ This does not require a bank account to effect a Money Transfer transaction and it is immediate. A transaction is limited to ZAR1,000 per day per Identity (ID) number and is offered by a number of merchants who offer cash-in/cash out. The monthly transfer/receive limit is ZAR10,000 per sender/receiver. To send money, the following are required: sender's ID book (only valid South African IDs); the receiver's ID number; cash to be sent; transaction fee (currently this is a flat fee of ZAR15.00); statement of source of income, and agreeing to the T\&C. The sender is given an invoice for the transaction which contains the transaction ID number and the token number. To obtain the money, the receiver must provide his ID book (only valid South African IDs); the transaction ID number as obtained from the sender; the token number as obtained from the sender; and must agree to the T\&C. MTN Banking (2011b) 'MTN Money Transfer: Overview', available at http://goo.gl/pKmcJ.

49 'The sender and/or receiver accepts that he/she uses the Service at his/her own risk. MTN Banking or the Merchant shall not be liable for any loss or damage, delay, non-delivery, non-payment or underpayment of money transferred whether due to the fault, error or omission of MTN Banking and/or its Merchants, for more than the transfer amount and the fee paid by the sender. No liability is accepted for service delays due to causes beyond the control of MTN Banking and/or the Merchants. In no event will MTN Banking and/or its Merchants be responsible for indirect damages.' MTN Banking (2011a) op cit note 47.
} 
As noted earlier, in 2010, MNO Vodacom South Africa and licensed bank Nedbank launched the local incarnation of the Kenyan M-pesa MFS system. Vodacom formed a new division called Vodacom Payment Services Pty Ltd (hereafter VPSPL) to operate M-pesa in South Africa.

Users can transact from the M-pesa menu on their cell phone. VPSPL styles itself as a corporate agent of the licensed bank Nedbank. ${ }^{50}$

VPSPL however allows what it terms an 'Outlet' to open up accounts and provide cash-in/cash out services. ${ }^{51}$ The funds are housed in what is termed a 'collateral account' with Nedbank as the licensed bank partner.

\subsection{7}

Wizzit

As described earlier, ${ }^{52}$ Wizzit is a MFSP that targets the unbanked population in South Africa. It operates under the banking license of the South African Bank of Athens as a MFSP and offers an account that lets customers use their mobile phones to make $\mathrm{P} 2 \mathrm{P}$ payments, transfers and pre-paid purchases. ${ }^{53}$

Holders also receive a pre-paid Maestro card. ${ }^{54}$ Wizzit's 'Wizzkids, ${ }^{55}$ may open up accounts ${ }^{56}$ and act essentially as bank agents. ${ }^{57}$

\subsection{8}

\section{UBank}

UBank, a workers' bank formerly known as Teba, launched a mobile banking product aimed at miners that provides basic banking and remittance services. ${ }^{58}$

\footnotetext{
${ }^{50}$ The M-pesa Terms and Conditions (T\&C) define e-money as 'electronic money created and issued by Us (acting as the agent of Nedbank) in the system, which will equate to the deposits'. See Vodacom (2011a) 'M-PESA Terms \& Conditions', available at http://goo.gl/gMotV. See further ch 6, s6.4.3.

${ }_{51}$ In the MNO contract with M-pesa users, the T\&C refer to the outlet providing services.

${ }^{52}$ See ch 6, s6.4.4 titled Licensed-Bank-MFSP Model.

${ }^{53}$ A pilot project by CGAP, launched in 2009, used POS devices in combination with Wizzit's mobile phone banking platform to allow for a mobile banking payment service for the major wholesalers serving more than 500 micro-entrepreneurs - also known as 'spaza' shops - in the township of Motherwell, where three in five people are unbanked; a pilot programme for easy account opening and preferred pricing at Dunns' outlets - a leading South African clothing retailer - used a direct sales model and the South African Post Office for distribution. See Consultative Group to Assist the Poor (CGAP) (2009b) 'South Africa: Mobile Banking Reaches Beyond the City', available at http://goo.gl/Wghca.

${ }^{54}$ The Maestro branded debit card enables users to make purchases, get cash-back at retail outlets and withdraw money at any South African or Maestro-labeled ATM anywhere in the world.

${ }^{55}$ See ch 6, s6.4 on the bank-led MFS model, and Annex 1, Exhibit I on Wizzkids.

${ }^{56}$ Opening an account requires a copy of an identity document only. There are no monthly fees and no minimum balances. See Wizzit's official website at www.wizzit.co.za.

${ }^{57}$ Wizzkids receive annuity income based on the transaction level of account holders. Wizzkids are typically young, lowincome individuals living in the communities from which they recruit their customers.

${ }_{58} \mathrm{P}$ Ndzamela (2010c) 'Proletariat Will Now be Able to Bank at Night', posted on Moneyweb, available at http://goo.gl/XaLyK.
} 


\title{
PART I Money, Banking And Payments Laws, Bodies And Guidelines
}

\author{
The Prudential Landscape for Financial Products and Services in SA
}

12.3.1

Overview

Although there are a number of regulators of financial services ${ }^{59}$ in South Africa, ${ }^{60}$ the SARB acts as the ultimate overseer over the payments and banking sector. ${ }^{61}$

\subsubsection{Financial-related Regulatory and Advisory Bodies in South Africa}

\author{
National Bodies
}

12.3.2.1

South African Reserve Bank (SARB)

\subsection{Overview}

The SARB's power is derived from the general powers of oversight it has been given in terms of s10(1)(c) of the South African Reserve Bank Act. ${ }^{62}$ The current Tier 1 and Tier 2 banks are overseen by the SARB through two distinct regulatory channels for the banking or the payment sectors.

In South Africa, the SARB's primary role is defined in the South African Constitution as being to protect the value of the currency, namely, the Rand. ${ }^{63}$ In that respect, the SARB may have to act as the 'lender of

\footnotetext{
${ }^{59}$ See ch 12, s12.3.2 titled Financial-related Regulatory and Advisory Bodies in South Africa.

${ }^{60}$ For a broad overview of the regulatory ecosystem faced by South African banks and financial institutions, see VA LawackDavids (2011) 'Mind the Gap - Increasing Compliance - Burden and Regulatory Misalignment' 32(2) Obiter 712-730 who found that approximately 149 acts have been promulgated which impact the business sector in general and an additional 53 acts that impact the financial sector specifically. This analysis however does not include any self-regulatory or co-regulatory oversight over the financial and banking sectors, but includes legislation such as the CPA, which has indirect impact. Banks and those participating in the payment system in South Africa have to abide, inter alia, by FAIS op cit note 1, FICA op cit note 1, NCA op cit note 1, POAIA op cit note 1, the Inspection of Financial Institutions Act op cit note 1; NPSA op cit note 1; the Companies Act op cit note 1; the Banks Act op cit note 1; the South African Reserve Bank Act op cit note 1; and the Exchequer Act op cit note 1. For a selection of regulators and other bodies that may have a bearing on MFS, see ch 12 , s12.3.2 titled Financial-related Regulatory and Advisory Bodies in South Africa. For a more general view of regulators, see L Swart and VA Lawack-Davids (2010) 'Understanding the South African Financial Markets: An Overview of the Regulators' 31(3) Obiter 619-637. See Firstrand Group (s.d.) 'Annex 11: Regulatory Framework: Submission to the Competition Commission', available at http://goo.gl/KeKKK, and also FR Malan (1989) 'Legal Aspects of the Regulation of Financial Institutions' 18(4) Tydskrif vir die Suid-Afrikanse Reg at 553. For a discussion of the role of the SARB, see FR Malan and JT Pretorius (2001b) 'The Reserve Bank, Banks, and Clearing Houses in South African Law: Part 1' 13(1) SA Mercantile Law Journal at 35; FR Malan and JT Pretorius (2001c) 'The Reserve Bank, Banks, and Clearing Houses in South African Law: Part 2' 13(2) SA Mercantile Law Journal at 163, and J de Jager (2006) 'The South African Reserve Bank: An Evaluation of the Origin, Evolution and Status of a Central Bank: Part 1' 18 SA Mercantile Law Journal at 159.

${ }^{61}$ The SARB is the fourth-oldest central bank outside Europe. For a historical overview of the SARB, see J Rossouw (2011) 'Selective Reflection on the Institutional Development of the South African Reserve Bank Since 1921' 26 (S1) Economic History of Developing Regions 2011 S3-S20. Although South African banks have sophisticated and well-managed risk management systems and corporate governance structures in place and complies with international bank standards such as Basel I, II, III which detail capital requirements . See ch 4, s4.2 titled the Nature of Banking: An Overview.

${ }^{62}$ SARB Act op cit note 1 . The SARB has the ability to control the management, administration, operation, regulation and supervision of payment, clearing and settlement systems in South Africa, and to provide for connected matters.
} 
last resort' to banks that find themselves in financial difficulty and which do not have funds to pay back depositors or creditor banks. ${ }^{64}$

The National Payment Systems Act (hereafter NPSA) gives the SARB the power to issue what are known as Directives ${ }^{65}$ which may be of a general nature or a remedial nature when required. ${ }^{66}$ It also issues what it terms 'Position Papers, ${ }^{67}$ 'Circulars' and 'Guidance[s]' which although highly persuasive and which are, in large measure, implemented by those to whom they are addressed, they do not appear to have the force of law.

\subsection{Banking Supervision Department}

The Registrar of Banks is part of the Banking Supervision Department (hereafter BSD) of the SARB and has fairly wide regulatory powers regarding a bank which conducts the business of a bank in South Africa, whether it was incorporated in South Africa or whether it is merely a branch office. The BSD has the authority to appoint inspectors to carry out inspections of the affairs of a bank as defined in the Banks Act. Inspectors may also be appointed to ensure that the banks comply with the regulations relating to trust property as well as capital requirements. ${ }^{68}$

The BSD of the SARB regulates deposit-taking ${ }^{69}$ in terms of the Banks Act, ${ }^{70}$ the Mutual Banks Act, ${ }^{71}$ the PostBank $\mathrm{Act}^{72}$ and the Cooperative Banks Act, ${ }^{73}$ ensuring that banks maintain adequate liquidity to meet redemption demands for deposits on hand.

\subsection{National Payment System Department}

For payment systems oversight, the National Payment System Department (hereafter NPSD) of the SARB is mandated by the NPSA ${ }^{74}$ to oversee the management, safety and soundness of the National Payment

63 Constitution of the Republic of South Africa (1996), Chapter 13, Central Bank (ss 223-225), available at http://goo.gl/QAVf5. It must perform its functions independently and without fear, favour or prejudice, but there must be regular consultation between the SARB and the Cabinet member responsible for national financial matters.

${ }^{64}$ See South African Reserve Bank (SARB) (s.d.) 'About Us', available at http://goo.gl/QadS9; and W Goosen, A Pampallis, A van der Merwe (1999) Banking in the New Millenium at 146.

${ }^{65}$ See s12(1) of the NPSA op cit note 1. See further Lawack-Davids (2008) op cit note 16 at 469.

${ }^{66}$ See s12(3) of the NPSA. Contravention of a SARB Directive is an offence in terms of s12 of the NPSA.

${ }^{67}$ The SARB defines a 'Position Paper' as 'stat[ing] the Reserve Bank's position in respect of specific payment system issues. These documents normally contain approaches, procedures and policy matters, which are applicable at a particular time.' See the SARB's Position Papers at http://goo.gl/By2tW. In relation to e-money, three position papers were issued in 1999, 2006 and 2009. A Position Paper on access to the NPS was issued in 2011.

${ }^{68}$ Act 28 of 2001 op cit note 1 . See earlier in ch 7, s7.4 on Trusts, in relation to the potential use of Trust Accounts in MFS in South Africa. Commercial banks in all countries are limited to lending from one borrower and/or a group of inter-related borrowers: a limit is further placed on the amount that can be lent in relation to the capital held. See Deloitte (2012) op cit note 1.

${ }^{69}$ Deposits as defined by s1 of the Act 941990 op cit note 1, as amended.

${ }^{70}$ Act 94 of 1990 op cit note 1

${ }^{71}$ Act 124 of 1993 op cit note 1. See ch 12, s12.3.5.4 titled Mutual Banks.

${ }^{72}$ Act 9 of 2010 op cit note 1 .

${ }^{73}$ The SARB ensures implementation of and compliance with the 25 Core Principles for Effective Banking Supervision issued by the Basel Committee on Banking Supervision and which are required for a supervisory system to be effective.

${ }^{74}$ NPSA, as amended. Postbank is a division of the South African Post Office. It operates under an exclusion provided for in s2(vii) of the Act 94 of 1990 op cit note 1 . 
System (hereafter NPS) ${ }^{75}$ the central hub that links the SARB to participating banks and each other ${ }^{76}$ and which has been described as 'one of the pillars of financial stability' in South Africa. ${ }^{77}$ The NPS is considered a Systematically Important Payment System (hereafter SIPS). ${ }^{78}$

The SARB is required to perform such functions, implement such rules and procedures and, in general, take such steps as may be necessary to establish, conduct, monitor, regulate and supervise payment, clearing or settlement systems. ${ }^{79}$ This oversight domain spans the payment system infrastructure from the prototypical South African Multiple Option System (hereafter SAMOS) ${ }^{80}$ that is at the core of the NPS in South Africa, through to the payment provider providing retail payment services to consumers. ${ }^{81}$ The SARB's designated role is thus that of overseeing systemic-risk and guarding against activities that are or will be contrary to the public interest or to the integrity, effectiveness or security of the payment system. ${ }^{82}$

\subsection{Financial Surveillance Department}

The Financial Surveillance Department is provided with all the powers, functions and duties assigned to and imposed on the Treasury under the Exchange Control Regulations (with certain exceptions) to investigate compliance with exchange controls in South Africa. ${ }^{83}$ The Department is thus responsible for the day-to-day administration of exchange control. ${ }^{84}$

\subsubsection{Policy Board for Financial Services and Regulation}

The Policy Board for Financial Services and Regulation was established in terms of the Policy Board for Financial Services and Regulation Act which advises the Minister of Finance with a view to coordinating the financial regulation policy in respect of the entire financial services sector. ${ }^{85}$

\footnotetext{
${ }^{75}$ The NPSA is mandated to manage, administer, operate, regulate and supervise the payment, clearing and settlement systems of South Africa, and to provide for connected matters.

${ }^{76}$ In South Africa, the NPS is seen as a set of rules, policies, groups, and infrastructure. See further, s12.3.7.3 on the Structure of the NPS.

${ }^{77}$ South African Reserve Bank (SARB) (2007c) 'Understanding the Core Responsibilities of the Bank: To Maintain Price Stability and Financial Market Stability' [Brochure] at 16. The National Payments System usually concerns Large Value Payments, versus Low Value Payments, which may consist of Retail Payments and Micro-Payments, reflecting hierarchies of payments. See further Chapter 12 for a discussion of the payment systems in South Africa. From 2000 to 2008, the total annual value settled in the NPS increased by $112 \%$ to R89tn. See estandardsforum (2011) 'South Africa', available at http://goo.gl/9v2k1.

${ }^{78}$ SARB Act op cit note 1.

${ }^{79}$ See ch 4, s4.8.2.2 titled Payment: The Process of Verification, Clearing, Settlement and Netting.

${ }^{80}$ See ch 12, s12.3.7.4.2 titled activities and Participants in the Core layer of the NPS.

${ }^{81}$ SARB (2006b) 'The National Payment System Framework and Strategy Vision 2010' at 11, available at http://goo.gl/rej7c. The SARB also simultaneously issued on 20 April 2006 its 'Vision 2010' paper outlining the future of the NPS.

${ }^{82}$ This obligation differs from banking regulation since the Reserve Bank, in its role as overseer of the NPS, has as its primary obligation to ensure the functioning of the NPS as a whole rather than just an individual bank, although it is trite that an individual bank failure may ultimately have a systemic influence on the whole NPS. See Falkena et al (2004a) op cit note 16 at 73. For more information on risk-reduction measures implemented by the NPSD, SARB (2000) 'NPS 01/2000- Position Paper on Risk Reduction Measures for Payment Clearing Houses in the NPS,' available at http://goo.gl/GtKXz.

${ }^{83}$ See ch 12, s12.3.7.5 titled Foreign Exchange Controls, and SARB (2011b) op cit note 1.

${ }^{84}$ While the Minister of Finance has also appointed certain banks to Act as Authorised Dealers in foreign exchange, they are not agents for the Financial Surveillance Department, but Act on behalf of their customers.

${ }^{85}$ Act 141 of 1994.
} 
The Financial Intelligence Centre (hereafter FIC) is a separate unit of the National Treasury and it is responsible for anti-money laundering regulation. ${ }^{86}$

\subsubsection{Financial Services Board}

The Financial Services Board (hereafter FSB) ${ }^{87}$ was established in 1990 with the enactment of the Financial Services Board Act (hereafter FSB Act). It regulates and supervises the non-bank part of the financial services industry in relation to financial products and services and associated financial industries such as collective investment schemes, trusts in securities other than property shares, trusts in property shares, Financial Services Providers (hereafter FSP), insider trading, insurers and retirement funds. Although it regulates 'deposits' placed into 'funds' by institutions and consumers, it does not have jurisdiction over banks per se. ${ }^{88}$

\subsubsection{The Office of the Ombud for Financial Service Providers ${ }^{89}$}

The Office of the Ombud for Financial Services Providers (hereafter FAIS Ombud) was established by the Financial Advisory and Intermediary Services Act 37 of 2002 (hereafter FAIS Act). The FAIS Ombud's role is to resolve disputes between financial services providers and their clients in a procedurally fair, informal, economical and expeditious manner. The FAIS Ombud's jurisdiction is limited to violations which occurred on or after 30 September 2004 and to claims not exceeding ZAR800,000. The Ombud's services are free and accessible to all consumers. ${ }^{90}$

\subsubsection{6 \\ The National Consumer Commission And National Consumer Tribunal}

\subsection{National Consumer Commission}

The National Consumer Commission (hereafter NCC) is an enforcement, policy maker and investigative body for consumer protection issues. It was established in terms of s85 of the CPA as an organ of state and as an institution outside public service to enforce the CPA. Its role in banking and payment disputes is limited though, but it may investigate for example, charges for payment and banking services.

\footnotetext{
${ }^{86}$ It operates according to the Financial Intelligence Centre Act (2001). See further ch 12, s12.7 titled Anti-Money Laundering, Terrorist Financing and Customer Due Diligence Laws and Regulations.

${ }^{87}$ See the official website of the Financial Services Board (hereafter FSB) at http://www.fsb.co.za.

${ }^{88}$ The FSB is subject to the general authority of the Minister of Finance. It has broad regulatory authority over the JSE, including SAFCOM, its clearance and settlement subsidiary, STRATE, financial advisors and intermediaries (hereafter FAIS), collective investment scheme (hereafter CIS) operators, pension funds and insurance companies. It has clear authority to perform on site examinations, to require reports and to investigate misconduct and to impose sanctions for violations of applicable laws.

${ }^{89}$ See the official website of the FAIS Ombud (Office of the Ombud for Financial Services Providers) at http://www.faisombud.co.za.

90 The FAIS Ombud was granted the authority in 2005 to Act as Statutory Ombud under the Financial Services Ombud Schemes Act 37 of 2004 (hereafter FSOS Act). This means that the Ombud can deal with complaints against financial institutions which do not fall within the jurisdiction of any other ombud schemes or where there is uncertainty over jurisdiction.
} 


\section{!2.3.2.6.2 National Consumer Tribunal}

The National Consumer Tribunal (hereafter NCT) was established in terms of the National Credit Act (hereafter NCA), and is also an enforcement arm of the Consumer Protection Act (hereafter CPA). ${ }^{91}$ The Tribunal can hear cases of non-compliance with the National Credit Act (hereafter NCA) and CPA, make orders and provide redress to consumers. Consumers and credit providers may appeal to the NCT against any decisions of the National Credit Regulator (hereafter NCR) as well as the National Consumer Commission. Decisions of the Tribunal may be appealed either to a full panel of the Tribunal or to the High Court.

\subsubsection{7}

\section{The National Credit Regulator}

The National Credit Regulator was established as the regulator under the NCA and is responsible for the regulation of the South African credit industry. It is tasked with carrying out education, research, policy development, registration of industry participants, investigation of complaints, and ensuring enforcement of the Act. The Act requires the Regulator to promote the development of an accessible credit market, particularly to address the needs of historically disadvantaged persons, low income persons, and remote, isolated or low density communities. The NCR is also tasked with the registration of credit providers, credit bureaux and debt counsellors, and to enforce compliance with the Act. ${ }^{92}$

\subsubsection{8}

\section{Securities Regulation Panel}

The Securities Regulation Panel ${ }^{93}$ (hereafter SRP) is a regulatory body established in accordance with Chapter XVA of the Companies Act. ${ }^{94}$ Its function is to regulate as it may deem necessary or appropriate, all affected transactions (as defined in s440A of the Act) and schemes, including all proposals which on successful completion will result in affected transactions relating to any public company, or a private company with a value in excess of $\mathrm{R} 5 \mathrm{mn} .^{95}$

\footnotetext{
${ }^{91}$ CPA op cit note 1; NCA op cit note 1. See the National Consumer Tribunal's official website at http://www.thenct.org.za. In terms of s65 of the CPA, application to 'deposits' as contemplated in the Banks Act and Mutual Banks Act are excluded from its application.

${ }^{92}$ For the impact of the Act on FI, see RP Goodwin-Groen (2006) 'The National Credit Act and its Regulations in the Context of Access to Finance in South Africa', available at http://goo.gl/GpuAK.

${ }^{93}$ See the official website of the Securities Regulation Panel (SRP) at http://www.srpanel.co.za.

${ }^{94}$ Act 61 of 1973 op cit note 1.

95 The SRP has been in existence since 1991 and was established in response to mounting concern about unfair business practices. Its purpose is to ensure good business standards and fairness to shareholders. The Panel formulated the Securities and Regulation Code on Takeovers and Mergers which embodies the general principles and rules governing the matters falling within its jurisdiction. The Code has the force of law.
} 


\section{Advisory Boards}

The South African regulatory scheme includes ten statutory advisory boards and four standing committees that provide input to the Minister of Finance, the Department of Trade and Industry (hereafter DTI), the SARB or the FSB on strategic and policy objectives. ${ }^{96}$ The South African regulatory scheme also includes several statutory advisory boards that provide input to the Minister of Finance or FSB on strategic and policy objectives. $^{97}$

\subsubsection{Ombudsman for Banking Services of South Africa}

The Ombudsman for Banking Services of South Africa (hereafter OBSSA) is a 'Section 21' company that aims to resolve individual complaints about banking services and products. ${ }^{98}$ As a self-regulatory body, complaints are judged in accordance with the Code of Banking Practice (hereafter COBP) ${ }^{99}$ According to the OBSSA, any bank customer may lodge a complaint against his or her bank with the OBSSA, provided the OBSSA has jurisdiction, such that only banks that are members of the Banking Association are bound by the COBP. ${ }^{100}$ Entities such as companies, corporations, partnerships and trusts may lodge a complaint if the person making the complaint is authorised to do so and the annual turnover of the business or group of businesses is ZAR5mn or less per year. The OBSSA can assist if the complaint relates to products or services provided by the bank, involves a claim of ZAR1mn or less, arose within 3 years of the complaint. ${ }^{101}$ There are also no guidelines or dispute resolution mechanisms for payments. ${ }^{102}$

\footnotetext{
${ }^{96}$ These include the Policy Board for Financial Services Regulation, the Financial Markets Advisory Board, the Collective Investment Scheme Advisory Committee, the Advisory Committee on Financial Services Providers, and several other committees concerned with other segments of the financial services sector, but not pertinent to the areas covered by the International Organization of Securities Commissions' (hereafter IOSCO) principles. Also a Standing Advisory Committee on Company Law advises the Minister of Trade and Industry on company law matters. International Monetary Fund (IMF) (2010b) 'South Africa: Detailed Assessment of Implementation on IOSCO Principles - Securities Markets', available at http://goo.gl/ULSng. There is also the South African National Payment System Forum (hereafter SANPAY) which consists of relevant government departments and other payment system stakeholder associations/bodies. It provides a forum for discussion and information sharing in respect of payment system developments and policies.

${ }^{97}$ These include the Policy Board for Financial Services Regulation (Policy Board), the Financial Markets Advisory Board, the Collective Investment Scheme Advisory Committee, the Advisory Committee on Financial Services Providers, and several other committees concerned with other segments of the financial services sector, but not pertinent to the areas covered by the IOSCO principles. Also a Standing Advisory Committee on Company Law advises the Minister of Trade and Industry on company law matters. In total there are ten advisory committees and four standing committees that play a role in regulating the financial sector in South Africa.

${ }^{98}$ These are companies that are registered to provide services and do not intend to make, or to be judged by, the profits that they make. These companies are registered in terms of s21 of Act 71 of 2008 op cit note 1 and are often referred to as 'Section 21 Companies'.

99 See Ombudsman for Banking Services of South Africa (OBSSA) (2011) 'The OBS's Jurisdiction', available at http://goo.gl/skLYJ. The COBP is not a statutory code though; it sets out minimum standards that the bank must adhere to in the relationship with a client. The COBP also provides some safeguards to bank clients, including the possibility of refunds in certain cases where loss is caused by the bank. All member banks of the Banking Council are subject to the jurisdiction of the Ombudsman. and which sets out reasonable care criteria it expects of bank clients in dealing with accounts and security thereof. See Banking Association of South Africa (2012) 'Code of banking Practice', available at http://goo.gl/56DMx.For a discussion of the rights and responsibilities of banks and consumers detailed in the COBP, see ch 7, ss7.3.6.5.3 titled The Bank and 7.3.6.5.4 titled Bank Customers, relating to risk allocation. See similarly ch 12, s12.11 titled Consumer Protection and Loss Allocation with Respect to Payment for a comparison of allocation of risk for consumers in multiple jurisdictions.

${ }^{100}$ The governing structure of the OBS consists of a Board of Directors, comprised four independent, non-bankers, three representatives of the banks and an independent chairperson.

${ }^{101}$ The OBSSA does not handle complaints involving a bank's commercial decision about lending or credit, interest rates or bank charges, unless there has been maladministration, or a matter that would more appropriately be dealt with by a court of
} 
Payment providers in the NPS are governed via a self-regulatory umbrella body called the Payment Association of South Africa (hereafter PASA) which in turn controls the various payment stream associations (and member banks) that participate in these payment streams. ${ }^{103}$ PASA has a governing council, an executive office and several strategic, risk and payment clearing house workgroups or committees. ${ }^{104}$ The NPSD has a seat on PASA without voting rights, but not on any of the privately owned payment switches such as BankservAfrica and Share Transactions Totally Electronic (hereafter STRATE). ${ }^{105}$ Access to PASA is however limited by the NPSA although the NPSAA in 2008 nominally broadened accessibility to PASA by allowing what were termed 'designated clearing system participants. $^{106}$

\subsubsection{The NPSSB and NPSOF}

The National Payment System Strategy Body (hereafter NPSSB) is a consultative body where the SARB interacts with various bank and non-bank stakeholders in the NPS, including PASA, the Banking Association of South Africa, the National Treasury, the Payment System Stakeholder Forum (for low value payments), the South African Retailers' Payment Issues Forum (hereafter SARPIF), and the Association of System Operators and Third Party Payors Association. The NPSSB functions in an advisory capacity to the Bank and inputs received are considered in the policy and strategic decisions made by the Bank. The NPSSB has no juristic personality or decision-making powers. ${ }^{107}$

The SARB also saw a need for bank and non-bank stakeholders, in addition to the advisory role, to also have a forum in which to discuss high-level operational matters and provide input to the NPSSB. This role is done via the NPS Operational Forum (hereafter NPSOF).

law or another dispute resolution process, or a matter which is or has been the subject of litigation, subject to certain exceptions.

${ }^{102}$ See however WG Schulze (2004c) 'Smart Cards and e-Money: New Developments Bring New Problems' 16(4) SA Mercantile Law Journal at 711 who justifiably notes that in relation to a SOV where the issuer is not a registered bank, that since the COBP applies only to those registered banks that have consented to its applying to them, it does not he says bind institutions other than banks such that those who 'buy' their SOV units to be placed in a SVA and other private currencies from these institutions will not be able to rely on the Code. This is a rationale for the need for a new law suggested below on retail payments that will include such SOV types. On private currencies, see ch 4, s4.8.4.4.4.1.

${ }^{103}$ The NPSA has as its goal the creation of an environment of collegiality, wherein the SARB remains responsible for the overall safety and soundness of the NPS, while the clearing environment is managed primarily by self-regulatory bodies. The NPSA made provision for this type of payment system management body to manage the affairs of its members in relation to payment instructions, and to Act as a medium of communication with the SARB, government, public bodies, the media and the general public. Although the NPSA was only promulgated in October 1998, the Payment Association of South Africa (PASA) had been formally established on 26 September 1996.

${ }^{104}$ Postbank and Ithala Bank in 2004 became the first two non-bank entities to participate in the NPS following the creation of rules for non-bank participation. They participate via sponsorship agreements with settlement banks lodged with PASA. See PASA's Annual Report for 2004.

105 STRATE is an electronic settlement system for transactions on JSE limited and off-market trades. It enables dematerialisation of equity scrip in a Central Securities Depository (CSD) to facilitate settlement and the transfer of ownership by electronic book entry.

${ }^{106}$ For the implementation thereof, see SARB (2011d) op cit note 16.

107 The NPSSB focuses mainly on strategic payment system-related issues, most importantly those issues that may have a risk-related impact on the NPS and to the participants in the NPS. See generally Ibid 
The Micro Finance Regulatory Council (hereafter MFRC) was established in accordance with the Usury Act Exemption Notice of 1 June 1999. It is a 'Section 21' company and has been recognised as the official and single regulator of all money lending transactions falling within the scope of the Usury Act Exemption Notice. Its primary aim is to promote sustainable growth of the micro-lending industry, to meet the credit needs of the underserved, while ensuring that consumer rights are protected.

Any moneylender who wishes to avail themselves of the benefits of the Usury Act Exemption must register with the MFRC and comply with MFRC rules and the Exemption Notice.

\subsubsection{South African National Payment System Forum (SANPAY)}

The South African National Payment System Forum (hereafter SANPAY) consists of relevant government departments and other payment system stakeholder associations/bodies. It provides a forum for discussion and information sharing of payment system developments and policies

C

Financial-related Regulatory and Advisory Bodies in South Africa

\section{Application to MFS}

12.3.3.1

\section{Comparative Application to MFS in Other Jurisdictions}

A scan of the countries surveyed earlier ${ }^{108}$ reveal that MFS invoke a multi-disciplinary number of regulators. Where there are fiat-based redeemable funds at play - that may or may not amount to a deposit according to municipal law - invariably a financial regulator or overseer will have some jurisdiction, although this may be shared with other agencies. In Kenya, this would be the Central Bank of Kenya (hereafter CBK), in the United States this would be the Office of the Comptroller of the Currency (OCC), the Consumer Financial Protection Bureau (hereafter CFPB), state Money Services Business (hereafter MSB) licensing authorities, the Federal Deposit Insurance Corporation (hereafter FDIC), or the Federal Reserve. In the EU, this may, according to the regime employed and the municipal law, be a national central bank or a specialised agency like the Financial Services Authority (hereafter FSA) in the UK. As the models metamorphose and as more non-banks start participating in taking redeemable funds from the public under regimes like MSB, the European Union's EMD and PSD, there is likely to be a re-evaluation of the hierarchy of regulation needed, if so needed.

${ }^{108}$ See ch 9 on the EU, in particular, ch 9 ss9.6.2 on the PSD, and 9.6.3 on the EMD. See also ch 10 on Kenya; and ch 11 on the US, and in particular, ch 11, 11.2.4.2.2 on the CFPB. 


\subsubsection{2}

Application to MFS in SA

The ability to provide MFS, and the use and storage of the funds for that purpose is because of the narrow regulatory regime in South Africa which focuses only on banks being able to provide these services and hence it is the SARB that has primary jurisdiction over MFS. The SARB has asserted itself in determining even the use of the airtime-based SVA used in WASP-type VAS. Its e-money policy, discussed below, also limits this to licensed banks that have been given consent by the SARB to issue e-money. ${ }^{109}$ In the sphere of consumer protection, the self-regulatory body the OBSSA is the primary arbiter of all retail banking and payments disputes, although where there is credit involved - which in MFS there usually is not as it is primarily prefunded - the NCR and NCT have jurisdiction. In relation to the potential use of trusts for housing MFS funds, the FSB may have jurisdiction over the trusts alongside the SARB.

\subsubsection{Conclusion: Regulatory Bodies}

The range of South African financial-related regulators reflects a spectrum of industry sectors, but does not directly address payment services. At the retail level of intervention, the closest may be OBSSA in relation to banking disputes, although this is a bank-led organisation and does not have jurisdiction over non-banks. There are also no guidelines or dispute resolution mechanisms for payments. ${ }^{110}$ Ultimately, though, at a macro level, the SARB has overall jurisdiction over which payment, banking and e-money schemes may operate.

D

\section{Banking and Payment Laws and Regulations}

12.3.5

Banking Laws and Regulations in South Africa

\subsubsection{Overview}

Under the broad rubric of systemic concerns and protection of user deposits, a number of institutions rising to the 'business of banking' under South African law are regulated by general and intuitional banking laws.

Most banking activity and deposits are regulated primarily by the Banks Act, non-Tier 1 banks via the Cooperative Banks Act, the Mutual Banks Act, and the PostBank Act. ${ }^{111}$ There is also a stalled Dedicated Banks Bill which may have relevance to MFS insofar as it could conceivably allow EU-type Electronic Money Institution (hereafter ELMI) ${ }^{112}$ or Payment Services Providers (hereafter PSPs) to operate in South Africa. ${ }^{113}$

\footnotetext{
${ }^{109}$ See ch 12, s12.4 titled E-Money and Stored Value.

${ }^{110}$ See ch 12, s12.11 titled Consumer Protection and Loss Allocation with Respect to Payments.

${ }^{111}$ Co-operative Banks Act No 40 of 2007. See s12.3.5.5 on the Mutual Banks Act.

${ }^{112}$ See ch 9, s9.6.3 titled E-Money, Stored Value Laws and Regulations in the EU; and the EMD1 op cit note 1.

${ }^{113}$ See ch 12, s12.3.5.5 on the (stalled) Dedicated Banks Bill.
} 
Banks and the business of banking are terms not explicitly defined in the Banks Act, but rather are characterised through functional characteristics, such as whether they accept deposits. ${ }^{114}$

The analysis below looks at whether accepting fiat funds for placing a SOV in the airtime and fiat-based SVAs amount to deposit-taking and as such whether an entity is conducting 'the business of a bank' as defined in the Banks Act.

\subsubsection{2}

\section{Banks Act}

The Banks Act was initially promulgated as the Deposit Taking Institutions Act 94 of 1990 but its name was changed to the Banks Act in $1993^{115}$ and represented the first iteration of legislation in South Africa that defined a 'deposit' directly, with courts relying up to that point on Roman law instances of mutuum. ${ }^{116}$ Only with the Banks Act of 1965 was 'deposit' defined. ${ }^{117}$ The Banks Act does not define a 'bank' per se, using instead a circular definition of a bank as being 'a public company registered as a bank in terms of this Act'. ${ }^{118}$ The Act thus relies more on an entity's financial activities than on its institutional characteristics to determine the perimeter whereby it could be termed a bank, ${ }^{119}$ and being fulfilled, s11 of the Act restricts these banking activities - business of a bank ${ }^{120}$ - to public companies ${ }^{121}$ registered in terms of the Act ${ }^{122}$ and makes contravention thereof an offence. ${ }^{123}$ The Act has specific objective tests for determining whether an entity is effectively conducting the 'business of a bank'. Any entity whose business activities fall within the definition of 'business of a bank' and which satisfy the symbiotic definition of 'deposit' will have to obtain a banking license from the Registrar of Banks, ${ }^{124}$ as well as be subject then to a plethora of financiallinked legislation as well as prudential oversight and liquidity guarantees. ${ }^{125}$ The implications of having to register as a bank include maintaining liquidity requirements with the SARB in terms of its Blue Book, its Vision 2010, the Basle I-III policies, adherence to the soft law of the Banking Council of South Africa's rules and regulations and being subject mutatis mutandis to financial-related legislation.

\footnotetext{
${ }^{114}$ Malan and Faul argue that the Banks Act is more geared towards regulating deposits than it is towards regulating banks. Banks are regulated directly by the Registrar of Banks. See FR Malan and W Faul (1991) 'Introduction to the Deposit-taking Institutions Act 94 of 1990 op cit note 1' Journal of South African Law at 380.

${ }^{115}$ WG Schulze (2001) 'Depositum, Deposit and Deposit-taking Institutions: Birds of a Feather? Not Quite' 13(1) SA Mercantile Law Journal at 79. The first legislation aimed at regulating banks was the Currency and Banking Act of 1920. This was followed by the Banking Act 38 of 1942, followed by the Banks Act 23 of 1965. For a history of banking legislation in South Africa, see A Itzikowitz (1992) 'The Deposit-taking Institutions Act 94 of 1990: Its History and an Overview of its Main Provisions' 4 SA Mercantile Law Journal 170.

${ }^{116}$ Equitable Trust \& Insurance Cp SA Ltd v Registrar of Banks 1957 (2) SA 167 (T).

${ }^{117}$ Schulze (2001) op cit note 115 at 79.

${ }^{118}$ Act 94 of 1990 op cit note 1 at s1(1).

${ }^{119}$ Schulze $(2004 \mathrm{c})$ op cit note 102 at 713.

${ }^{120}$ See ch 12, s12.3.5.2.1 titled Banks Act Test: 'The Business of a Bank'.

${ }^{121}$ Ibid. Section 1(1) of Act 94 of 1990 op cit note 1 defines a bank as 'a public company registered as a bank in terms of this Act'.

${ }^{122}$ Ibid Section 11(1).

${ }^{123}$ Ibid Section 11(2).

${ }^{124}$ The Registrar of Banks is given discretionary powers to grant or refuse an application for issuing banking licenses.

${ }^{125}$ Act 94 of 1990 op cit note 1 at s2(a) allows the definitions of 'the business of a bank' and 'deposit' to be varied by regulation from time to time for the purposes of the application of any of or all the provisions of the Act.
} 
Where the plethora of activities detailed in the Banks Act are exhaustive in assisting in the determination, there is also a common law characterisation of banking that is similarly based on an entity's institutional characteristics. $^{126}$

\subsection{Banks Act Test: 'The Business of a Bank'}

Section 1 of the Banks Act lists the objective criteria that would indicate that an entity is conducting the 'the business of a bank' that would require a banking license. Much of this relates to whether the entity being scrutinised takes deposits as defined by the Act and associated lending activities, or any other activity which the Registrar has declared to be the business of a bank. Similarly, it will also include an analysis of whether the core activities amount to 'the business of a bank'. Both are important criteria that must be satisfied before the Registrar of Banks may deem the entity to be conducting (or proposing to conduct) is that of 'the business of a bank' that would move the Registrar to demand registration as a bank.

'The business of a bank' is defined inter alia as:

(a) the acceptance of deposits from the general public (including persons in the employ of the person so accepting deposits) as a regular feature of the business in question;

(b) the soliciting of or advertising for deposits;

(c) the utilisation of money, or of the interest or other income earned on money, accepted by way of deposit as contemplated in paragraph (a)-

(i) for the granting by any person, acting as lender in his own name or through the medium of a trust or a nominee, of loans to other persons;

(ii) for investment by any person, acting as investor in his own name or through the medium of a trust or a nominee; or

(iii) for the financing, wholly or to any material extent, by any person of any other business activity conducted by him in his own name or through the medium of a trust or a nominee; but does not include:

(aa) the acceptance of a deposit by a person who does not hold himself out as accepting deposits on a regular basis and who has not advertised for or solicited such deposit...'

Section 52 of the Banks Act allows licensed banks to enter into agreements with non-banks, for example, for payment services and for accepting deposits as agents of the licensed bank acting as principal.

\footnotetext{
${ }^{126}$ United Dominions Trust v Kirkwood [1966] 2 QB 431 (CA) (hereafter UDT); N Joachimson v Swiss Bank Corporation [1921] 3 KB 110 (hereafter Joachimson'). See a discussion thereof in relation to common law aspects of banking, at ch 4 , s4.2 on the Nature of Banking: An Overview.
} 
A detailed definition of a deposit is laid out in s1 of the Banks Act. In relation to MFS, it is submitted that the most important sections relevant to the enquiry are sections (a) and (b)(i), the latter relating to advance payments. Section 1(a) defines a deposit as:

\footnotetext{
“"deposit", when used as a noun, means an amount of money paid by one person to another person subject to an agreement in terms of which:
}

(a) an equal amount or any part thereof will be conditionally or unconditionally repaid, either by the person to whom the money has been so paid or by any other person, with or without a premium, on demand or at specified or unspecified dates or in circumstances agreed to by or on behalf of the person making the payment and the person receiving it; and

(b) no interest will be payable on the amount so paid or interest will be payable thereon at specified intervals or otherwise,

notwithstanding that such payment is limited to a fixed amount or that a transferable or non-transferable certificate or other instrument providing for the repayment of such amount mutatis mutandis as contemplated in paragraph (a) or for the payment of interest on such amount mutatis mutandis as contemplated in paragraph (b) is issued in respect of such amount;

but does not include an amount of money (i) paid as an advance, or as part payment, in terms of a contract for the sale, letting and hiring or other provision of movable or immovable property or of services ...'

Further “"deposit”' when used as a verb, or any derivative thereof, has a corresponding meaning., 127

\subsubsection{3}

\section{Co-operative Banks Act}

Cooperatives are essentially credit unions such as group savings and lending schemes and stokvels ${ }^{128}$ whose members are generally from poor communities. ${ }^{129}$ They may provide only savings, or savings and loans. At a statutory level, co-operatives are defined in terms of the Co-operatives $\mathrm{Act}^{130}$ as having members who are of similar occupation or profession or who are employed by a common employer or who are employed within the same business district and have common membership in an association or organisation, including a business, religious, social, co-operative, labour or educational group, or reside within the same

\footnotetext{
${ }^{127}$ What should be highlighted in this definition of 'deposit' are the sets of exclusions in subpar (b)(i) of Act 94 of 1990 op cit note 1 .

${ }^{128}$ Ibid. Act provides for the registration of primary savings co-operative banks, primary savings and loans co-operative banks, and secondary co-operative banks. In the case of co-operatives not registered as Co-operative Banks that meet the criteria, the Act prescribes that such co-operatives must register as Co-operative Banks within 2 months of meeting the criteria.

${ }^{129}$ A wide range of credit and savings associations operating in disadvantaged communities are spoken of loosely as stokvels, based on an Afrikaans terms for co-operative savings groups. See G Coetzee and C Cross (2002) 'The Role of Community Banks in South Africa: Can it Contribute to Improve Access to Financial Services for the Poor?' available at http://goo.gl/ZMJPg.

${ }^{130}$ Act 14 of 2005 op cit note 1. See also the regulations thereto: National Treasury Co-operative Banks Act 2007: Regulations in Terms of Section 86, Government Gazette, No 32357, 1 July 2009, available at http://goo.gl/O0te4; and Cooperative Banks Act Supervisors' Rules, Government Gazette, No 32860, 12 January 2010, available at http://goo.gl/zslse.
} 
defined community or geographical area. The Act provides for the registration of cooperatives as defined so as to allow them to undertake inter alia deposit-taking financial services under a formal prudential regime, albeit with less stringent requirements than those imposed on banking institutions registered in terms of the Banks Act. ${ }^{131}$ There has been some criticism of their viability however. ${ }^{132}$

\subsubsection{Mutual Banks Act ${ }^{133}$}

The Mutual Banks Act was passed in 1993 to formalise mutually-owned banks to provide more competition to and access to banking services. ${ }^{134}$ The Act provides that a Mutual Bank may accept deposits and grant loans, advances or other credit. They also have less stringent capital-adequacy prerequisites than, but similar risk management requirements, to Tier 1 banks. The Act attempts to involve communities in banking by including a provision for local boards for branches of Mutual Banks, the organisation of which must be mutually based rather than equity-based. There are however only two Mutual Banks, GBS Mutual Bank and VBS Mutual Bank. ${ }^{135}$ A 'deposit' in terms of the Mutual Banks Act means a deposit as defined in s1(1) of the Banks Act.

\subsubsection{Dedicated Banks Bill}

The Dedicated Banks Bill is an oft-discussed but manifestly stalled bill that, it is submitted, may suit the majority of potential MFSPs by providing a framework for dedicated entities that simply do savings and payments but that do not necessarily provide credit. Its limited scope, proportional-regulation design is similar to that envisaged in the EU with the genesis of the ELMIs and their activities limited primarily to emoney. ${ }^{136}$ The Bill refers to 'dedicated banks' that are either savings or savings and loans, also known as narrow and core banks respectively. These new entrants would constitute Tier 2 and Tier 3-type banks and would essentially be 'dedicated' to fundamental banking activities such as savings-only or savings and loans rather than provide a plethora of additional services that are characteristic of Tier 1 banks. ${ }^{137}$ The Bill says that potential entrants may apply for licences either to operate 'core banks' or 'narrow banks'. Generally, narrow banks are envisaged as engaging in deposit-taking and payment activities while core banks undertake deposit-taking, effect payments, as well as issue limited categories of low-risk loans. To operate a narrow bank or a deposit-taking bank, an equity capital of ZAR10mn is proposed. It would have to keep $10 \%$ of the deposits in capital reserves. ${ }^{138}$ They will not be allowed to lend and can only generate profits through investing the deposits in short-term safe investments such as the money markets. Presumably their profit will come from overall transaction fees. It proposes that the Core Banks will be

\footnotetext{
${ }^{131}$ Act 14 of 2005 op cit note 1 applies to all incorporated co-operatives registered as Co-operative Banks in terms of the Act as well as to all co-operatives incorporated as such in terms of the Act, which take deposits from the public and which have 200 or more members and which hold deposits of members to the value of ZAR1mn or more. See Cliffe Dekker Hofmeyr (2008) 'Summary of the Provisions of the Co-Operative Banks Act 2008', available at http://goo.gl/K8laz.

${ }^{132}$ S Theobald (2009) 'Sub-species May Prove Endangered' Times Live, 13 September, available at http://goo.gl/q1aBA.

${ }^{133}$ Mutual Banks Act 124 of 1993 op cit note 1, available at http://goo.gl/FQQBd.

${ }^{134}$ Many of its provisions relate back to Act 94 of 1990 op cit note 1.

${ }^{135}$ For an analysis of why these banks have not been a success, see Coetzee and Cross op cit note 128 .

${ }^{136}$ For a copy of the Dedicated Banks Bill, see http://goo.gl/7jC9o.

${ }^{137}$ Feasibility (2005) op cit note 5 at 15.

${ }^{138}$ A Ntingi (2008) 'Small Banks Stand Warned' Fin24, 13 April, available at http://goo.gl/fI7GT.
} 
able to take deposits and lend out about $90 \%$ of the deposits and maintain $10 \%$ capital reserves, but will need to ZAR50mn in initial equity. ${ }^{139}$

\subsubsection{6}

\section{Implications of Registering as a Bank}

Besides the common law implications of doing the 'business of a bank', South Africa's Banks Act imposes a number of duties on licensed banks. The implications of having to register as a bank include the following:

- Maintaining liquidity requirements with the SARB in terms of its Blue Book and its Vision 2010 policies. $^{140}$

- Adhering to Banking Council of South Africa soft-law rules and regulations

- Abiding by other relevant legislation. ${ }^{141}$

\subsubsection{Application to MFS}

\subsection{Comparative Application to MFS in Other Jurisdictions}

There is no definition of a bank per se in EU law: ${ }^{142}$ rather, EU law refers to 'credit institutions' and on the prudential supervision of such institutions insofar as they may provide 'credit'- that is, intermediation. The EU has progressed away from a 'sledge-hammer' approach, that is, in relation to the regulation the concept that the 'business of banking' engenders and introduced enabling legislation that made provision for institutions that undertake only part of the 'business of banking' paradigm that is, payments. Intermediation from user funds - deposits - instead is left to the licensed banks, also known as 'credit institutions'. There are however some safety and soundness regimes in the PSD that prevent the entity from using any user funds for payments in allocation of credit. An application of the regular 'business of banking' rules to new entities would constitute a disproportionate burden on these entities and stifle innovation. This stratification allows the evolution of new business models such as those engendered by MFS. The EU model - based as it is on the ELMI and PSD - appears more additive than transformational.

\footnotetext{
139 The restrictions are said to allow them to provide banking services without much systemic risk, a result of the liquid nature of their assets, and the restriction on high risk loans and investments. See Feasibility (2005) op cit note 5 at 15.

${ }_{140}$ All banks must maintain a minimum reserve balance in an account with the SARB sufficient to cover at least such amounts as may be necessary to comply with the bank's exposure to notes and subsidiary coin liability as well as the percentages determined by the Governor of the SARB. A bank may also have to maintain a special deposit account into which account the bank may have to deposit at least such amounts as may be necessary. See $\operatorname{ss} 10 \mathrm{~A}(1)$ and $10 \mathrm{~A}(3)(\mathrm{a})$ of the SARB Act op cit note 1 .

${ }^{141}$ Other relevant (financial) legislation governing the activities of banks include the Companies Act 61 of 1973 op cit note 1 , the Exchequer Act 66 of 1975, FAIS op cit note 1, FICA op cit note 1, NCA op cit note 1, the Inspection of Financial Institutions Act 80 of 1998; and POAIA op cit note 1. See Lawack-Davids (2011) op cit note 60 passim on the regulatory burden on banking institutions.

${ }^{142}$ See in the EU, ch 9, s9.5.4 on Banking Laws and Regulation. In particular, Directive 2006/48/EC lays down the rules on the taking-up and pursuit of the business of 'credit institutions' as they are termed and on the prudential supervision of such institutions.
} 
In the $\mathrm{US}^{143}$ there is no enabling regulation per se, but rather safety and soundness regimes such as MSBs that relate to consumer protection, although the Federal Reserve and the FDIC have taken steps to ensure that Stored Value Cards (hereafter SVCs) used for payroll payments have underlying assurances of liquidity where those funds are stored by the issuer of the SVC in a pooled account.

In Kenya, ${ }^{144}$ despite an obvious loophole in the definition of deposit that excluded the eponymous M-pesa system from being classed as deposit-taking and thus undertaking the business of banking, alongside the lack of a national payment system act, it was a bold policy move based on social and FI realities alongside the solid business model presented by M-pesa, that allowed the Central Bank of Kenya to effectively ignore the loophole and give its now famous blessing to the roll-out of M-pesa in Kenya. The growth of MFS without adequate oversight may ultimately raise some systemic concerns. ${ }^{145}$

\subsection{Application to MFS in South Africa}

The Banks Act has as one of its the key criteria for defining banking activity, as embodied in s1(a), that the acceptance of deposits from the general public as a regular feature would amount to conducting 'the business of a bank ${ }^{146}$ or the 'business of banking' as it is also commonly known. Deposits will only be socalled if they do not qualify for one of the exemptions to deposit-taking, for example, that they are a category of 'advance payment'. Correspondingly, any activities which do not fall within the definition of the 'business of a bank' or which do not constitute the taking of 'deposits' will mean that registration as a bank in terms of the Banks Act is not required.

Insofar as MFS may amount to the 'business of banking' - and the 'tests' thereto in the Banks Act - from a number of potential actors, our enquiry is framed by a few basic enquiries: whether the funds paid to a nonbank such as an MNO acting as an MFSP via the purchase of prepaid airtime vouchers by subscribers and placed as a SOV in a SVA for use inter alia for telecommunications services and for nontelecommunications third-party services amounts to the 'business of banking'; and secondly, whether the redeemable fiat-based value paid to an MNO by a subscriber and stored in a fiat-based SVA - and the user funds possibly placed with a Tier 1 bank in a pooled master account in the name of a subsidiary trust company ${ }^{147}$ - amounts to deposit-taking and as such, in the current diagnostic regime, amounts to the 'business of banking'. Associated with the former is also the question of whether the agent of the MNO is similarly engaged in deposit-taking. The enquiry may relate to a determination at statute and common law.

The sale of pre-paid airtime by a MNO to a subscriber is usually governed by a contractual provision accepted by the purchaser upon purchase of either the initial SIM access package ${ }^{148}$ and/or the prepaid

\footnotetext{
${ }^{143}$ See ch 11 on the United States of America and MFS.

${ }^{144}$ See ch 10 on Kenya and MFS.

${ }^{145}$ See comments by the Governor of the Central Bank of Kenya, Njuguna Ndung'u, that the rapid expansion of mobile money services in the country came with systemic risks that need to be addressed. See J Mbugua (2011) 'CBK Governor Calls for More Secure Mobile Money Services' Allafrica.com, available at http://goo.gl/4RoQE.

${ }_{146}$ This would, inter alia, necessitate a banking license.

${ }^{147}$ See ch 4, s4.8.4.4.6 titled Pooled Master Accounts.

${ }^{148}$ See ch 5, s5.2.2 titled User Access to Mobile Networks.
} 
recharge voucher which usually specifies that the $\mathrm{MNO}$ and/or the seller of the prepaid airtime, as an agent of the MNO, is not obliged to or will not pay back any amount on demand to the subscriber. As there is then no 'repayment' to speak of in the prepaid ecosystem, the MNO does not conform to subs (a) in relation to the 'business of a bank'.

This satisfies the first leg in exemption from the MNO prepaid (airtime) SOV being defined as a 'deposit'. However, because subs (a) may be purposely frustrated by an entity simply indicating that it will not repay any monies, the exemption also requires that the scheme governed by subs (a) must also conform to subs (b)(i) regarding 'advance payment' for services. The money so given to the entity must thus be used for the consumption of services provided or facilitated by this entity. In the MNO context, if the money flow from the purchaser of prepaid airtime to the MNO amounts to an advance payment for goods and services to be delivered or rendered by the MNO to the subscriber, then subs (b)(i) is satisfied. The sale of prepaid mobile airtime thus ostensibly falls under the exemption in subs (b)(i) which means that the purchase of prepaid vouchers and the storage within an airtime SOV by the MNO of this value is currently not considered a 'deposit' in terms of the Banks Act and as such that they are not considered to be conducting the business of a bank, and as such do not require a banking license. ${ }^{149}$

\section{Banking Agents}

\subsubsection{1}

\section{Overview}

Some licensed banks in South Africa in their 'branchless banking' initiatives, use agents to provide services. In relation to a bank, the Banks Act defines 'agents' (of a bank) as:

'[A] right granted to a person by that bank to receive on its behalf from its clients any deposits, money due to it or applications for loans or advances, or to make payments to such clients on its behalf. ${ }^{150}$

The Act does not explicitly limit the provision of these agent-provided services to physical locations (or branches), but restricts banks from entering into agency agreements to when the bank has provisioned for itself its organisational extensions, purchase of a business, losses, and bad debts. ${ }^{151}$ There may be circumstances where a bank 'outsources' some of its functions to that of an agent. The Banks Act mediates this process, providing the opportunity for banks to grant the right to a person by that bank to receive on its behalf from its clients any deposits, money due to it or applications for loans or advances, or to make payments to such clients on its behalf. The SARB clarified the scope of agents to provide services with a Circular ${ }^{152}$ that deals with outsourcing of those traditional in-house functions performed by banks, such as

\footnotetext{
149 This view may change in the event of new technologies like Near Field Communication (NFC) being used for bidirectional payments that use the phone as a payment instrument. See ch 5, s5.5.6.5 titled Near Field Communication (NFC).

${ }^{150}$ The definition of 'Agency' in s1(1) of the Act 94 of 1990 op cit note 1. See s1(1)(i) of the Mutual Banks Act where 'agency' is defined as 'a right granted to a person by a mutual bank to receive on behalf of such bank from its clients any deposits, money due to it or applications for loans or advances, or to make payments to such clients on its behalf'.

${ }^{151}$ Section 78(1)(f)(i) of Act 94 of 1990 op cit note 1.

152 South African Reserve Bank (SARB) (2004) 'BSD Circular 14/2004: Outsourcing of Functions within Banks', available at http://goo.gl/wB4vN.
} 
treasury management, internal audit and compliance. ${ }^{153}$ While not preventing banks from outsourcing services per se, it does not allow the outsourcing of internal audit and compliance functions except when the BSD gives consent.

\subsubsection{Application to MFS}

\subsection{Comparative Application to MFS in Other Jurisdictions}

In the EU, the $\mathrm{PSD}^{154}$ makes provision for the roles and responsibilities of agents in various scenarios. This may be on an 'agency' or 'outsourcing' basis as provided for in Article 17 of the PSD, but which in the absence of precise demarcations, may amount to the same thing. ${ }^{155}$ In an EU context, will probably manifest as an 'additive' implementation, rather than 'transformational' where there is no bank - or credit institution in EU parlance - to speak of. The MNO may also be an agent of a bank providing payment services on behalf of the PSP, but would in terms of Article 17 of the PSD, need to be authorised. They would then also be subject to the connected liabilities specified in Article 18 of the PSD. ${ }^{156}$ The MNO will also have contractual arrangements with agents that provide the cash-in/cash-out facilities as well as merchants who participate in the MNO scheme. In this scenario, it is still an open question as to who the PSP, agent and outsourcing provider (individually) are.

In the US in relation to the use of agents, there is no restriction per se on their use under the Federal Bank Service Company Act of 1963 (hereafter BSCA) statute. ${ }^{157}$ Depending on their affiliation, some non-bank providers though are subject to supervision via the BSCA whereby financial institutions are required to notify their primary federal regulator in writing of any relationships or contracts they enter into with third parties for provision of certain services to the financial institution. ${ }^{158}$

In Kenya, ${ }^{159}$ in terms of the Banking Act, banks are not allowed to open or change the location of a branch of that bank without the approval of the CBK. A 'branch' means any premises, other than its head office, at which an institution transacts business in or outside. There are also no regulations explicitly governing the outsourcing of functions by banks. Nonbank institutions do not face such restrictions on the use of agents or super-agents if so used. New agent banking regulations allow banks to engage a wide range of retail outlets for transaction handling (cash-in and cash-out) and product promotion (receiving account applications, though applications must be approved by a bank staff member).

\footnotetext{
${ }^{153}$ The SARB's Circular on the outsourcing of bank activities provides general guidance for outsourcing arrangements that may have a bearing on the risk profile of a bank; that may affect the systems and control of a bank; that may be classified as being of strategic importance, and which may have implications for SARB and its supervisory duties.

${ }^{154}$ PSD op cit note 1 .

${ }^{155}$ Art 17(7) of the PSD refers to 'outsourcing of important operational functions' of payment services.

${ }^{156}$ Art 18 of the PSD in respect of liability says that where payment institutions rely on third parties for the performance of operational functions, those payment institutions take reasonable steps to ensure that the requirements of the PSD are complied with and that payment institutions remain fully liable for any acts of their employees, or any agent, branch or entity to which activities are outsourced.

${ }^{157}$ See ch 11, s11.2.3.3 titled Application to MFS.

158 These services include check and deposit sorting and posting, as well as other 'similar functions performed for a depository institution'.

${ }^{159}$ See ch 10, s10.2.4 on use of agents in Kenya.
} 
This paved the way for banks to begin utilising the M-pesa platform and associated network of M-pesa outlets as a channel. M-pesa's 'status' as a non-bank allowed it to create an agent network that approximated the functional characteristic of a bank branch insofar as cash was taken in and given out. By contrast, outsourcing to agents is only approved by CBK on a case-by-case basis. With use of the hybrid M-kheso product a user with dual M-pesa and M-kheso accounts must deposit funds into his M-pesa account via an M-pesa agent, and once confirmation via SMS is received by the user that the deposited funds are available, the user will use the M-pesa interface to transfer funds to the M-kheso account.

\subsection{Application to MFS in South Africa}

The SARB Guidelines on Agents allowed companies such as Wizzit and MTNMoney, ${ }^{160}$ and Standard Bank, which have large 'branchless banking' agent networks, to have agents provide limited services. ${ }^{161}$ In most cases, this was limited to only opening up accounts for new customers. MFSP Wizzit's 'Wizzkids', who open up accounts, are essentially bank agents since Wizzit is reportedly a division of Capitec Bank.

In relation to the provision of fiat money to an agent of a bank or a MFSP acting as the agent to a bank and whether it amounts to a deposit, as noted earlier, ${ }^{162}$ policy considerations dictate whether an agent is taking deposits and time appears to be the arbiter such that if the agent does not immediately credit the bank's account in it being the principal, then the agent could be said to be engaged in deposit-taking. In the incarnation of M-pesa in South Africa launched in 2010, South African MNO Vodacom formed a new division, Vodacom Payment Services (Proprietary) Limited (VPSPL) to operate M-pesa. VPSPL styles itself as a corporate agent of the licensed bank Nedbank. ${ }^{163}$ VPSPL however allows what it terms an 'outlet' to open up accounts and provide cash-in/cash-out services. ${ }^{164}$ The 'outlet' is termed in VPSPL's contract with the outlet as a 'counterparty'. ${ }^{165}$ It indicates that the outlets are independent but are authorised by VPSPL to provide services and are not in partnership with VPSPL. ${ }^{166}$ Further, in line with its contractual rights, VSPL limits its liability in respect of the outlets, to such a degree that, as the agent of the bank, it does not bear any responsibility or liability whatsoever for any wilful or negligent acts or omissions on behalf of the outlets in providing the Services. ${ }^{167}$ The funds that are deposited with an outlet ultimately land up in what is termed a 'collateral account' housed within Nedbank. The user however does not have an account with Nedbank per se although Nedbank is the principal in this instance to its agent VPSPL. The

\footnotetext{
${ }^{160}$ See MTN Banking (2011c) op cit note 47.

${ }^{161}$ See ch 6, ss6.4.2 on the licensed bank MFS Model and 6.4.3 on the hybrid Bank-MNO MFS Model. See ch 6, s6.6.2 titled Types of Transaction.

${ }^{162}$ See ch 12, s12.3.5.7.2 titled Application to MFS in South Africa.

${ }^{163}$ In the M-pesa T\&C, the definition of e-money states that 'electronic money created and issued by Us (acting as the agent of Nedbank) in the system, which will equate to the deposits'. See Vodacom (2011a) op cit note 47.

${ }^{164}$ In the MNO contract with M-pesa users, the T\&C refer to the Outlet providing services.

${ }^{165}$ In the MNO-Outlet agreement, 'counterparty' is defined as 'You, in your capacity as an Outlet, appointed by CPSPL in terms of this agreement'. See Vodacom (2011a) op cit note 50.

${ }^{166}$ Vodacom (2011a) op cit note 50 at s12.2 which deals with the T\&C for M-pesa in South Africa.

${ }^{167}$ Ibid. See also s12.3 of the same T\&C which state that: 'You accept that You use the Services at your own risk. Neither Us, Vodacom, Nedbank, nor any third party shall be liable for any loss of whatsoever nature and howsoever suffered by you, whether arising in contract, delict, statute or otherwise, unless it is directly caused by Our Gross negligence or wilful default. Liability for such Act shall be limited to the amount of the loss that a reasonable person, in Your position, would have suffered. For the avoidance of doubt, any such loss shall exclude indirect, special and/or consequential losses and/or damages'.
} 
user merely has a right to claim e-money funds or the cash par equivalent thereof when he desires. ${ }^{168} \mathrm{At}$ common law then, since the consumer contract is with Vodacom as, in respect of its terminology, the administrator ${ }^{169}$ of the e-money funds presumably issued by Nedbank and where VPSPL is acting as an agent of Nedbank in this respect. Nedbank is thus the principal, VPSPL the agent, and the outlet appears to be a sub-agent of VPSPL.

Generally, the bank has a common law duty of care not to cause damage to its client through negligence which may amount to a delict. ${ }^{170}$ Presumably, and in light of the outsourcing guidelines issued by the SARB, this duty of care relates to the choice of agent and the agent's activities that are in general approved of by the principal at Board level. This would probably extend to the Outlet acting as a Counterparty of VPSPL and as a sub-agent of Nedbank insofar as it takes deposits in Nedbank's name from the public. Issues might arise over how to deal with occasions when agents' actions cause loss to the user, for example, owing to fault on the part of the Outlet/Counterparty when taking cash deposits. What would happen broadly, say, if the funds so deposited with the Outlet somehow did not match what was reflected in the account administered by the VPSPL; or, where a payment instruction from the M-pesa menu was ultimately made to the wrong recipient and/or for the incorrect amount? In the absence of specific statutory payment rules, the common law rules of agency may apply insofar as the outlet is a duly appointed subagent acting in an intermediary capacity, and therefore may serve to protect the user so that the user would be able to recover the deposited amounts, after copious proof thereof, from the VPSPL. ${ }^{171}$

\section{Payment Systems and Governing Frameworks}

\subsubsection{Overview}

The formal, regulated payments system in South Africa is known as the NPS, which broadly comprises technical systems and groups of institutions that allow clearance and settlement of payments like cheques, electronic payment and card payments between banks and other entities providing payment services in the country. ${ }^{172}$ Trillions of Rands cumulatively pass through this system monthly. ${ }^{173}$ There are various strata or layers of payment providers that can operate within the NPS, some more systemically important than

\footnotetext{
${ }^{168}$ E-Money in the agreement T\&C is defined as 'electronic money created and issued by Us (acting as the agent of Nedbank) in the system, which will equate to the deposits'.

${ }^{169}$ Section 2 of the M-pesa Customer Registration agreement defines 'Account' as 'Your e-money account, administered by Us' where 'Us' is VPSPL.

${ }^{170}$ First National Bank of Southern Africa Ltd v Duvenhage 2006 (5) SA 369 (SCA). See ch 7, s7.3.6.5.3 titled The Bank, on allocation of risk with respect to banks and losses. J Moorcroft (2010) 'Negligence of a Bank' Banking Law and Practice at s18.1 on a Bank's Delictual Liability.

${ }^{171}$ See ch 7, s7.2.6.3 on agents. For an analogous view of the role of agents and their role in payment intermediation in the NPS and the liability of the principal for their actions, see Lawack-Davids (2008) op cit note 16 at 461.

${ }^{172}$ The SARB refers to the NPS as facilitating the 'circulation of money, that is, it enables transacting parties to exchange value'. See South African Reserve Bank (SARB) (2011e) 'NPSD: Position Paper on Interoperability' NPS 01/2011 at 2, available at http://goo.gl/gVB09.

${ }^{173}$ The average value settled through SAMOS on a monthly basis was approximately ZAR7.3 trillion (hereafter tn). In October 2008, at the height of the global financial crisis following the collapse of Lehman Brothers, a record settlement of ZAR8.5tn took place. South African Reserve Bank (SARB (2012) 'The Importance and Development of Sound Financial Market Infrastructures to Position South Africa in SADC and Worldwide', available at http://goo.gl/JIEg3. In 2007, it was ZAR2,4tn. D Mitchell (2007) 'Head of the NPSD' cited in The South African Reserve Bank: Understanding the Core Responsibilities of the Bank, SARB, May, at 15.
} 
others. ${ }^{174}$ While all registered banks are allowed to take deposits, not all banks may operate in all facets of the payment domain. ${ }^{175}$ Conversely, a bank may be a payment provider, but a payment provider may not necessarily be a bank. Access to the systemic core where settlement is done is highly restricted to certain classes of banks, and is controlled and governed by sets of laws and regulations and policy decisions, ${ }^{176}$ the primary instrument being the National Payment System Act (hereafter NPSA). ${ }^{177}$ Since payments are primarily made from funds on deposit, the BSD and the NPSD co-operate closely to prevent regulatory arbitrage or duplication of oversight. ${ }^{178}$ The participant in the NPS all must deal in 'money' to participate. Remittances as payments are all subject to strict forex controls.

\subsubsection{National Payment System Act}

\subsection{Background}

The NPSA gives the SARB a mandate to oversee and monitor the payment system via its NPSD. ${ }^{179}$ The rules and principles in the NPSA are based on its 'Blue Book' issued in $1995^{180}$ and an updated policy framework issued in 2006 called 'Vision 2010'. ${ }^{181}$ These contain several risk-reduction measures to be implemented in the retail environment.

\subsection{Scope of the NPSA}

The NPSA's primary object is to provide '...for the management, administration, operation, regulation and supervision of payment, clearing and settlement systems in the Republic of South Africa. ${ }^{182}$

The NPSA defines a payment system as being a system that 'enables payments to be effected or facilitates the circulation of money and includes any instruments and procedures that relate to the system. ${ }^{183}$ It is

\footnotetext{
${ }^{174}$ For a description of the layers, see South African Reserve Bank (SARB) (2006d) 'Vision 2010', s3.5.4 at 12, available at http://goo.gl/rYKVk; Lawack-Davids (2008) op cit note 16; SARB (2011d) op cit note 16; SARB Directive 1/2007 and Directive 2/2007.

${ }^{175}$ For payments, however, only those banks qualifying in terms of the SARB's payment criteria are eligible to clear in their own name and settle in the books of the Bank in their own name.

${ }^{176}$ For competition issues related to this 'closed' nature, see ch 12, s12.5 on the Competition Commission Enquiry into Banking and Payments in South Africa.

${ }_{177}$ NPSA, as amended by the NPS Amendment Act No 22 of 2004 (NPSAA), available at http://goo.gl/YMPFQ.

178 South African Reserve Bank (SARB) (2006c) 'Position Paper on Electronic Money NPS 01/2006', available at http://goo.gl/BYRnG at 12, available at http://goo.gl/rYKVk.

${ }^{179}$ This is done in conjunction with the BSD.

${ }^{180}$ The NPSA derives from events in 1994, when the SARB and the banking and payments industry in South Africa began collaborating on formulating a long-term strategy for the modernisation and development of the domestic payment system. This culminated in the development of a strategic document published by the SARB in 1995 called the 'South African National Payment System Framework and Strategy' document, also known as the 'Blue Book,' as well as the NPSA. The Blue Book defines the NPS as 'a defined group of institutions and of a set of instruments and procedures, used to ensure the circulation of money within a geographic area, usually a country'. See South African Reserve Bank (SARB) (1995) 'Blue Book Overview', available at http://goo.gl/TuzRB; and also TT Mboweni (2006) 'A historical review and a look at the future prospects of the National Payments System in South Africa', available at http://goo.gl/yotEQ.

${ }^{181}$ SARB (2006c) op cit note 178.

${ }^{182}$ See s1 of the NPSA. Section 10(i)(c) of the SARB Act says that the Bank must:
} 
based on 13 fundamental principles that cover all aspects of the payment system from the moment a consumer (the payor) issues an instruction to pay another person, through to the final settlement between banks at the SARB. Banks that are deemed to be at the core of the NPS that provide payment services ${ }^{184}$ to its customers 'should preferably participate in the interbank clearing process under its own name, thereby ensuring that all exposures are visible. ${ }^{185}$ Despite defining a payment system and its species, and being the prototypical legislation for payments, neither the NPSA (nor its later amendment) defines a 'payment' ${ }^{186}$ per se, and rather defines it in terms of an activity that a 'payment' engenders or is an integral component of, for example a 'payment instruction' or 'payment obligation'. The Bank for International Settlements (hereafter BIS) and the European Central Bank (hereafter ECB), as shown earlier, both define payment as 'the transfer of a monetary claim on a party acceptable to the payee. ${ }^{187}$

\subsection{Roles Mandated by the NPSA}

The NPSA has as its goal creation of an environment of collegiality, wherein the SARB remains responsible for the overall safety and soundness of the NPS. Section 1 of the NPSA and s10(i)(c) of the SARB Act says that the SARB must:

'perform such functions, implement such rules and procedures and, in general take such steps as may be necessary to establish, conduct, monitor, regulate and supervise payment, clearing or settlement systems. ${ }^{188}$

Regulations issued under the NPSA apply only to the core settlement bank participants such as the banks, ${ }^{189}$ while other payment providers who do clearing are governed via the self-regulatory umbrella body PASA ${ }^{190}$ which controls the various payment stream associations (and member banks) that participate in the different payment streams. While the NPSD is mandated in terms of the NPSA to oversee the safety

\footnotetext{
${ }^{183}$ The NPSA definition is similar to the definition of a payment system by the BIS which says that it is 'a set of instruments, banking procedures and, typically, an interbank funds transfer system that ensures the effective circulation of money.' In a similar vein, the 'Blue Book' defines the payment system as 'a defined group of institutions and of a set of instruments and procedures, used to ensure the circulation of money within a geographic area, usually a country.' Similarly, a 'payment instruction' is defined as 'an instruction to transfer funds or make a payment', while a 'payment obligation' is defined as 'an indebtedness that is owed by one settlement system participant to another as a result of the clearing of one or more payment instructions'.

${ }^{184}$ At a high level, the SARB in turn defines payment services in the NPS as services whereby a bank enables its clients to: (a) make third-party payments by providing its clients with the means to issue payments to the clients of another bank or the other bank itself, through direct access to their (that is, the bank's clients') bank accounts; (b) receive payments directly into their (the bank's clients') accounts from clients of another bank or the other bank itself; (c) withdraw cash at another bank. SARB (2007b) op cit note 16 passim.

${ }^{185}$ These 'Payment services' provided by banks that enable payors to transfer their claims to a beneficiary at the beneficiary's bank are wholesale payments, and are systemically different to the retail payment services to consumers provided by, for example, payment service providers and retailers that receive money or payments on behalf of a third person such as paying for fixed telephone services or traffic fines. The former, wholesale payments link directly to inter-bank settlement systems and are deemed systemic by the SARB. See Falkena et al (2004a) op cit note 16 at 73.

${ }_{186}$ Again, a payment could have systemic implications if there is gross failure of a participant at the core of the NPS settlement system, SAMOS. See ch 12, s12.3.7.4.2 titled activities and Participants in the Core, on SAMOS.

${ }_{187}$ See the definition of 'payment' provided in European Central Bank (ECB) (2011a) 'Glossary', available at http://goo.gl/gdQYW. Typically, such claims take the form of banknotes or deposit balances and/or a credit arrangement held at a banking institution or at a central bank.

${ }^{188}$ This mandate was extended in the amendment of the NPSA in 2004 when the SARB was given the power to issue directives to any person regarding a payment system or the application of the provisions of the Act.

${ }^{189}$ Except for the SA Postbank which was exempted as a result of political considerations

${ }^{190}$ See ch 12, s12.3.2.11 on the Payments Association of South Africa. The NPSA says that the NPSD must recognise and oversee a payment system management body and, currently, PASA is the only authorised body.
} 
and systemic soundness of the NPS, ${ }^{191}$ since payments are primarily made from funds on deposit, ${ }^{192}$ the BSD and the NPSD need to cooperate closely to prevent regulatory arbitrage or duplication of oversight. ${ }^{193}$ All registered banks are allowed to take deposits, although not all banks may operate in the payment domain. ${ }^{194}$ For example, s52 of the Banks Act allows for non-banks to enter into arrangements with banks that may allow them to offer payment-related services in conjunction with the bank. ${ }^{195}$ The SARB also monitors SIPS developments. ${ }^{196}$ The SARB also monitors non-SIP developments, for example, the effect on the NPS if a component of the NPS such as technology infrastructure fails or is compromised by continued breaches in security. ${ }^{197}$

\subsubsection{Structure of the NPS}

The NPS is said to include the total payment process made up of all the systems, mechanisms, institutions, agreements, procedures, rules and laws that come into play from the moment an end-user, using a payment instrument, issues a payment instruction to pay another person or business, ${ }^{198}$ through the final interbank settlement of transactions in the books of the central bank. ${ }^{199}$ The NPS thus enables transacting parties to exchange value to conduct business efficiently. ${ }^{200}$ The infrastructure in the NPS consists of instruments, systems, applications, networks, payment, clearing and settlement systems.

The various components that are at the heart of the NPS have been categorised in major reports ${ }^{201}$ on the banking and payment sector in South Africa as consisting of:

- The legal and statutory framework, ${ }^{202}$

- Rules, regulations and agreements, ${ }^{203}$

- Payment instruments and payment streams, ${ }^{204}$

- Systems, processes and procedures, ${ }^{205}$

- Technological infrastructure, ${ }^{206}$

- Payment and settlement transactions, ${ }^{207}$

${ }^{191}$ NPSAA op cit note 1.

${ }^{192}$ A bank may be a payment provider, but a payment provider may not necessarily be a bank.

${ }^{193}$ See s3.5.4 of SARB (2006c) op cit note 178 at 12.

${ }^{194}$ For payments, however, only those banks qualifying in terms of the SARB's payment criteria are eligible to clear in their own name and settle in the books of the Bank in their own name.

${ }^{195}$ SARB (2009) 'Position Paper on Electronic Money' available at http://goo.gl/HdH2k, at 7.

${ }^{196}$ Some recent risk-reduction initiatives include the signing of new contractual agreements between the participants of each payment clearing house in the NPS, as well as the introduction of item limits for retail payment streams to a maximum of R5mn to reduce the values being settled in these streams and to encourage high value payments to be processed through the SAMOS system. See ch 12, s12.3.7.4.2 titled activities and Participants in the Core, on SAMOS.

${ }^{197}$ It believes that compromises could seriously threaten the position of a participant in the payment system, and could result in a chain reaction. For example, the fear with e-money is that if operated outside the strictures of the NPS, that it may somehow create this systemic effect on solvent schemes if one or more (unregulated) e-money schemes fail. See the SARB's position on e-money in SARB (2006b) op cit note 81; SARB (2011d) op cit note 16.

${ }^{198}$ A beneficiary.

${ }^{199}$ Mboweni (2009) op cit note 1; and SARB (2011d) op cit note 16 at s2.

${ }^{200}$ As of 2004, the banking industry earned $38 \%$ of its revenue, or ZAR29bn, from payment system-related fees. See Hawkins and Bertoldi (2006) op cit note 16.

${ }^{201}$ Hawkins and Bertoldi (2006) op cit note 16; Lawack-Davids (2008) op cit note 16 passim.

202 acts such as the NPSA and NPS Amendment Act, and the SARB Act.

${ }^{203}$ Such as the self-regulatory rules developed by the PASA.

${ }^{204}$ Such as Electronic Fund Transfers (EFTs).

${ }^{205}$ Such as Information Technology (IT) communication protocols.

${ }^{206}$ Such as SAMOS and the national ATM networks. 
- Banks providing financial intermediation, ${ }^{208}$

- Providers of access to payment-related services, ${ }^{209}$

- End-users of the different products provided by non-bank payment, and Providers. $^{210}$

\subsubsection{Participants in the NPS}

\subsection{Overview}

There are various ways to describe the structure and hierarchical relationships in the NPS. Most of the descriptors refer to a 'core' with 'layers' that may resemble an 'onion'. ${ }^{211}$ These layers are shown in Exhibit A, which is as stylised structure of the NPS showing the five component layers, with a highly regulated inner core followed by participants who are regulated to an ever decreasing extent.

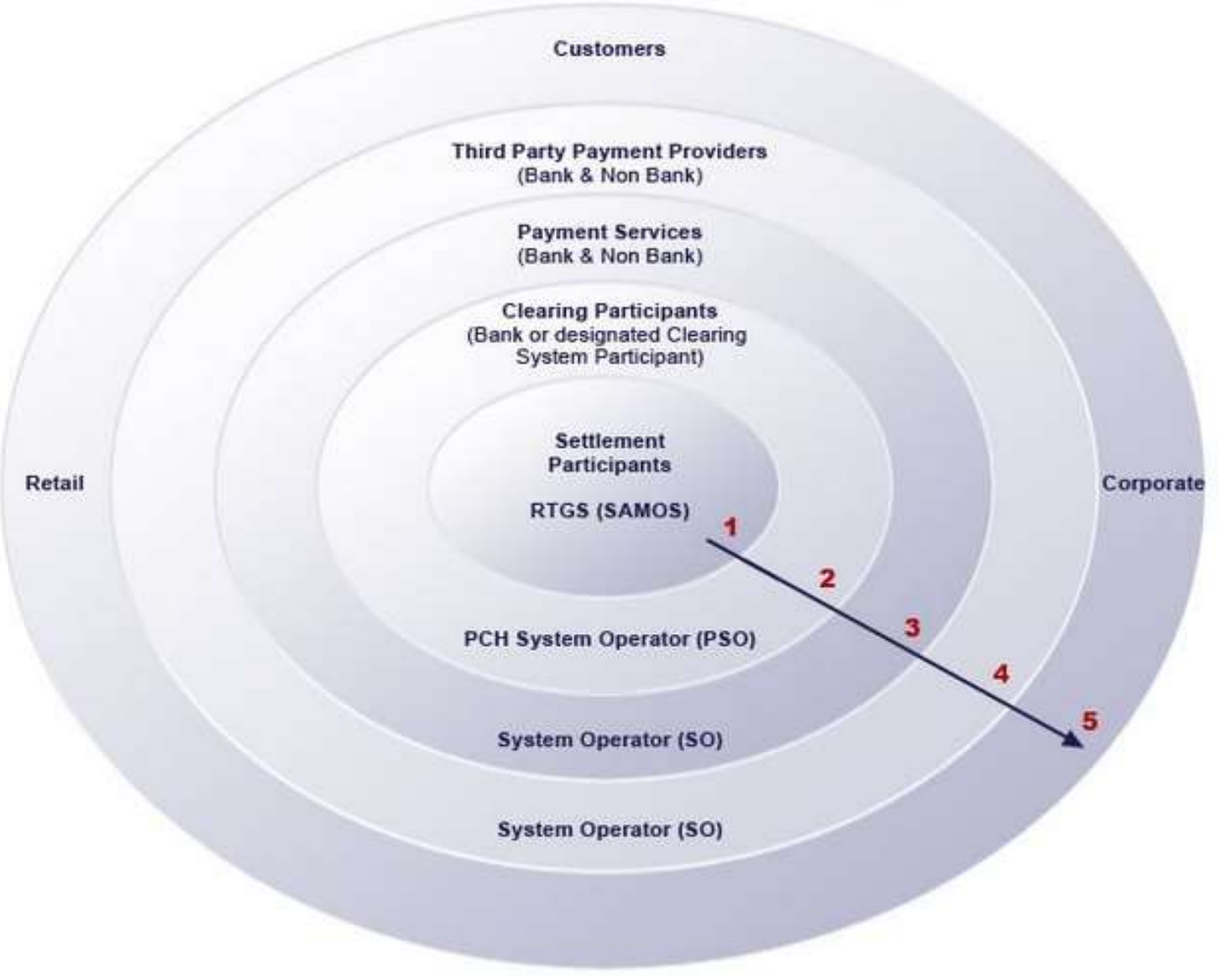

Exhibit A NPS Landscape And Key Role Players ${ }^{212}$

\footnotetext{
${ }^{207}$ Such as EFT transactions through BankservAfrica, as well as high-value transactions through SAMOS.

${ }^{208}$ Such as registered commercial banks.

${ }^{209}$ These include Customer Payment System Providers like EasyPay.

${ }^{210}$ Such as retailers.

${ }^{211}$ Lawack-Davids (2008) op cit note 16.

${ }^{212}$ Graphic is sourced from Payments Association of South Africa (PASA) (2011) 'NPS Landscape: Key Roleplayers,' available at http://goo.gl/Y3auI
} 
There may be said to be five layers, each described below. The core is the common descriptor though, referring to an 'exclusive ${ }^{, 213}$ systemic set of providers who provide mainly settlement activities. ${ }^{214}$

The SARB acts as a settlement bank or a clearing house for the other banks for which it holds cash balances. $^{215}$

The middle and outer layers consist inter alia of registered banks, interbank systems, retail payment providers, buy aid societies, SVCs, and the consumers making payments using cash, credit cards and cheques. $^{216}$

Ultimately then, a payment by a consumer at the extremity of the outer layer will in some way wind its way through relevant participants in the NPS to the (core) point where it has an effect on the daily settlement and clearing processes that SAMOS mediates.

\section{NPS: The Core and Settlement}

\subsection{Activities and Participants in the Core}

The core activity of the NPS is settlement, defined by the NPSA as the 'discharge of settlement obligations, ${ }^{217}$ which is the 'indebtedness that is owed by one settlement system participant to another as a result of one or more settlement instructions'. ${ }^{218}$

Clearance and settlement have been facilitated and given effect by the SARB since September 1921 but the function developed gradually through three stages, namely: the manual system, ${ }^{219}$ the automated system ${ }^{220}$

\footnotetext{
${ }^{213}$ The NPS has been described as a 'privileged banking space' since banks are the only organisations with immediate and unmediated access to official and settlement systems, although there is some non-bank participation in the clearing system. This resulted in the Competition Commission Enquiry, detailed below in ch 12, s12.5 titled the Competition Commission Enquiry into Banking and Payments in South Africa.

214 The formal, core structures in the payments pyramid are considered systemic structures and are constantly under observation by the National Payment System Department (NPSD) of the SARB and the laws and associated regulations that control the NPS reflect this hierarchy and systemic risk. See ch 4, s4.8.1 on systemic risk, and ch 12, s12.3.1 titled Overview, on the SARB's oversight roles; Lawack-Davids (2008) op cit note 16 passim.

${ }^{215}$ Even though the exposure faced by the Reserve Bank from the settlement system is small, the settlement risk has grown significantly due to the growth in trading values.

${ }^{216}$ The mechanics for making these payments include cash, credit cards, cheques, debit orders and credit payments. Falkena et al (2004a) op cit note 16 at 71.

${ }^{217}$ See $\mathrm{s} 1$ of the NPSA as amended by s1(i) of Act 22 of 2004 op cit note 1.

${ }^{218}$ See $\mathrm{s} 1$ of the NPSA as amended by s1(j) of Act 22 of 2004 op cit note 1 while $\mathrm{s} 1$ of the NPSA defines 'settlement instruction' as 'an instruction given to a settlement system by a settlement system participant or by a PCH system operator on behalf of a Reserve Bank settlement system participant to effect settlement'.

${ }^{219}$ The manual system, in operation until 1973, was a system which allowed cheques and other payment instruments, held by the various clearing banks against one another, to be cleared or exchanged in clearing houses, at specified times each business day, by representatives of each of these banks. In centres where the Reserve Bank was represented, the Bank itself provided and facilitated the clearing house operation. Once clearing had taken place and the obligations of the participants had been determined in each centre, these figures were forwarded to a central point where the net obligations were calculated. These net obligations were then processed and the transfers made across the participants' accounts in the books of the SARB, thus effecting settlement.

${ }^{220}$ The second stage started when Bankserv - a centralised clearing bureau, owned and managed by the clearing banks and now known as BankservAfrica - was established in 1973 and the clearing procedures changed considerably. The bulk of the country's cheques and other payment instruments were cleared through the bureau's electronic clearing facilities in Johannesburg, Cape Town, Port Elizabeth and Durban.
} 
and now the current real-time and tightly controlled SAMOS settlement system launched in $1998 .{ }^{221}$ The current regulations allow registered banks to participate in two ways in the NPS, namely, either as direct clearing and settling banks - that is, with direct access to SAMOS - or as a member of a Payment Clearing House $(\mathrm{PCH})^{222}$ without a settlement account. This latter arrangement is referred to as sponsorship ${ }^{223}$ and requires that the member's obligations are settled by another bank under a sponsorship arrangement. ${ }^{224}$ These relationships are negotiated on an individual basis between the bank requiring such a service and the bank providing it. Banks that are members of SAMOS are alongside the SARB at the core of the NPS. The average turnover in payments (excluding cash) in SAMOS for October 2008 for alone was ZAR8.5 trillion (hereafter tn). ${ }^{225}$

\subsection{Regulation of the Core}

The SAMOS system is considered the prototypical 'bank' account ${ }^{226}$ in the country, placed at the base of the pyramid of payment systems and other participants that constitute the NPS. All are deemed systemically critical under BIS SIPS criteria and thus SAMOS membership is limited by the SARB to registered banks with a capital base of at least ZAR1bn. ${ }^{227}$

Section 5(1) of the NPSA requires that settlement must be effected in money or by means of entries passed through the SARB settlement system or a designated settlement system. For systemic risk considerations where an entity in the settlement arrangement may possibility default, the NPSA says that a settlement effected in money or by means of an entry to the credit of the account maintained by a settlement system participant in the Reserve Bank settlement system or a designated settlement system is final and irrevocable and may not be reversed or set aside. ${ }^{228}$ As a further precaution against systemic risk, the SAMOS system rules are that a payment must be initiated by the paying bank rather than the receiving bank, a payment design known as 'credit-push'. ${ }^{229}$ In other words, sufficient funds must be available before the payment can be made.

\footnotetext{
${ }^{221}$ SAMOS mediates on a Real Time Gross Settlement basis (hereafter RTGS), finally and irrevocably single settlements between banks as well as settling obligations arising out of retail payment clearing and the equity and bond markets.

${ }^{222}$ See ch 12, s12.3.7.4.4 titled Activities and Participants in the Second Layer.

${ }^{223}$ Sponsorship can take three forms: sponsorship of the settlement of obligations that stem from clearing; clearing and settling on behalf of a smaller player by a larger player; and technical sponsorship where the smaller bank uses the systems of the larger bank, but clears and settles in its own name.

${ }^{224}$ A number of non-banks have become members of the payment system on a sponsored basis, eg the Postbank, is a sponsored financial institution in the payment system. It has no settlement account at the SARB.

${ }^{225}$ Mboweni (2009) op cit note 1.

${ }^{226}$ Or as the SARB term it, 'The Banker's Bank'. See SARB (2007c) op cit note 77 at 15.

${ }^{227}$ Thus $s 4$ of the NPSA says that only the following may participate in settlement arrangement: the SARB, a bank, a mutual bank, a co-operative bank or a branch of a foreign institution and, in the case where a payment system management body recognised by the Reserve Bank, and such person is a member of the payment system management body so recognised; a designated settlement system operator; or who meet the criteria for participation in the SARB settlement system.

${ }^{228}$ See ss5(1) and (2) of the NPSA op cit note 1. The SARB is cognisant that SAMOS does not totally ameliorate all risks from the payment system as there may yet be banks defaulting, the most recent and prominent being Santam Bank. The SAMOS system however is designed to rapidly isolate the defaulting bank from other solvent participants in SAMOS.

${ }^{229}$ Here, the payor initiates the transfer of funds to the payee. This is in contrast with the system that operated before March 1998 where a cheque, for example, was regarded as a 'debit-pull' instrument, with a payment instruction that required the recipient (or its bank) to collect funds from the remitter, effectively causing the collecting bank to 'pull' the funds through the payment system. See also ch 4, ss4.8.2.3.1 titled High Value Payment Systems; and on debit/credit transfers, 4.8.3.9 titled Payment Flows.
} 


\subsection{Activities and Participants in the Second Layer}

Radiating out from the core is the second layer, the clearing domain. Clearing is defined as 'the exchange of payment instructions' which are defined as 'instruction to transfer funds or make a payment ${ }^{230} \mathrm{~A}$ 'clearing system participant' is defined as a:

'bank, a mutual bank, a co-operative bank, a branch of a foreign institution or designated clearing system participant that clears on behalf of others in a type of sponsorship arrangement. ${ }^{231}$

In effect these are mostly entities such as commercial banks, payment system operators, payment operators, and those providing retail-facing services like the Customer Payment Service Providers (hereafter CPSP) who utilise the infrastructure of banks and payment providers at the core. These may be Payment Clearing Houses System Operators (hereafter PCHSO) ${ }^{232}$ which run the systems which receive, collate and transmit payment messages, or clearing, and push - or 'settle' - the net positions of banks through to SAMOS. BankservAfrica $^{233}$ is the dominant retail PCHSO, clearing more than $90 \%$ of the retail volume. ${ }^{234}$ International PCHSOs like Visa and MasterCard operating in South Africa are subject to the same legislative framework as domestic participants.

Next in the payments hierarchy are the Payment Clearing Houses (hereafter PCHs), which are specific segments of the NPS that service specific payment niches. ${ }^{235} \mathrm{PCH}$ s thus switch payments from one member of a specific PCH to another. There are ATM PCHs, debit card PCHs, credit card PCHs, etc., ${ }^{236}$ and relatively few of the banks with membership of those PCHs serve the retail high-volume segment, because the so-called 'Big Four' banks dominate this $\mathrm{PCH}^{237}$

\footnotetext{
${ }^{230}$ See $\mathrm{s} 1$ of the NPSA.

${ }^{231}$ See $\mathrm{s} 1$ of the NPSA. A 'designated clearing system participant' is defined as a person 'specified in the notice referred to in s6(3)(a) of the NPSA'.

${ }^{232}$ The NPSA defines a Payment Clearing House System Operator (PCHSO) as a legal person that clears on behalf of two or more settlement system participants, that is, banks. This may also include trusts.

${ }^{233}$ BankservAfrica is a PCHSO that is wholly owned by the banks, of which the big banks have a $93 \%$ share.

${ }^{234}$ It mediates retail and wholesale transactions such that when an authorisation request for a payment from a user's credit or debit card is sent by a retailer via his bank (the acquiring bank) to the user's bank (the issuer bank) via BankservAfrica, the issuer bank will transmit an approval code to the retailer. An authorisation is placed against a user's account, after which the money is withdrawn by the banks from the account and placed in a holding account for later settlement.

${ }^{235}$ Membership of each PCH is predicated on meeting monetary, technical and other requirements for that PCH. Registered banks can participate in the NPS either as direct clearing and settling banks with direct access to SAMOS, or as members of a PCH without a settlement account, but with indirect access to SAMOS via a sponsoring bank. Sponsoring requires that the bank's obligations are settled by another bank under a sponsorship agreement.

${ }^{236}$ The 'ATM' PCH Saswitch for example allows an ATM card holder belonging to Saswitch-PCH Bank A to use the ATM of Saswitch-PCH Bank B.

${ }^{237}$ Besides Payment Clearing Houses dealing with PIN-validated electronic debit payment instruments such as Saswitch ATMs, there are also electronic clearing debit payment instrument PCHs (for cheque clearing), the paper credit payment instrument (for deposits on an agency basis), as well as the debit card and credit card PCHs.
} 


\subsection{Regulation of the Second Layer}

While regulations issued under the NPSA apply only to the core NPS participants such as the banks, other payment providers are governed by PASA which in turn controls the various payment stream associations (and member banks) that participate in these payment streams.

iii)

\section{Third Layer}

\subsection{Activities and Participants in the Third Layer}

The third layer consists of providers of payment services either directly by a clearing participant or by means of a System Operator (hereafter SO). The SOs, who may be non-banks, provide the payment instructions electronically, including the delivery to and/or receipt of payment instructions, to two or more persons to allow such persons to make payments and/or to receive the proceeds of payment instructions. ${ }^{238}$

They thus provide technical and information technology services of various kinds to banks and other clients (retailers and non-bank financial intermediaries and other large corporates). ${ }^{239}$ From a retail payment perspective, CPSPs - such as Easypay - provide the technical payment infrastructure that consumers use for paying bills at, for example, Points of Sale (hereafter POS) at retail outlets.

\subsection{Regulation of the Third Layer}

Section 7 of the NPSA says that in relation to 'payments to third persons', 'a person may as a regular feature of its business accept money or payment instructions from any other person for purposes of making payment on behalf of the other person to a third person to whom the payment is due', such as the payment of utility bills. An authorised SO may therefore provide services in respect of payment instructions to two or more of the following entities: banks, mutual banks, registered branches of foreign banks, co-operative banks and designated clearing service providers; Beneficiary Service Providers (hereafter BSP); Payor Service Providers (hereafter PSPr); and clients of banks. ${ }^{240}$

\footnotetext{
${ }^{238}$ Technically, they access BankservAfrica directly, but they do so under the auspices of the clearing banks and are typically not distinguishable from the clearing banks in terms of the instructions they transmit or facilitate. Lawack-Davids (2008) op cit note 16 .

${ }^{239}$ Competition Commission (2008b) op cit note 15 at 444. SOs are non-financial entities that facilitate the back-office solutions for banks for transmission of instructions to BankservAfrica, or who POS devices, who own and deploy ATM machines. Other SOs may be Bureaux that allow submission of, for example, payment instructions.

${ }^{240}$ It is evident from the earlier that the inclusion of the 'designated clearing system participant' would further widen access to this layer of the onion as such clearing system participants would also be able to provide payments to third parties as envisaged in 87 of the NPSA. Further, in terms of Directive $2 / 2007$ issued by the SARB, any person acting as a SO shall, inter alia, not pay such funds from or transfer such funds to its own account; keep separate and distinct the business divisions of the SO from other business divisions; or refrain from providing services which allow the offsetting of mutual obligations by trading partners or persons for whom they are processing payment instructions. South African Reserve Bank (2007a) 'Directive 2/2007 - Directive for Conduct within the National Payment System in Respect of System Operators', available at http://goo.gl/DxPcT.
} 


\subsection{Activities and Participants in the Fourth Layer}

The fourth layer consists of clearing participants and registered non-bank Third Party Payment Providers (hereafter TPPP). There are two types of TPPPs: a BSP and a PSPr. A BSP is a person who accepts money or the proceeds of payment instructions from multiple payors on behalf of a beneficiary as a regular feature of that person's business; while a PSPr is a person who accepts money or the proceeds of payment instructions from a payor to make payment on behalf of that payor to multiple beneficiaries as a regular feature of that person's business. ${ }^{241}$ A PSPr or BSP accepts money or the proceeds of payment instructions from two or more payors, and this process is also known as 'payment intermediation'. The intermediary is required to pay those funds to a third person on behalf of such payor. ${ }^{242}$ These TPPP as intermediaries are usually enabled by a SO that provides the necessary technology but does not accept the funds into their own account for onward payment to another party.

\subsection{Regulation of the Fourth Layer}

Section 7 of the NPSA says that in relation to 'payments to third persons', 'a person may as a regular feature of its business accept money or payment instructions from any other person for purposes of making payment on behalf of the other person to a third person to whom the payment is due', such as the payment of utility bills. ${ }^{243}$ If the intermediary is a settlement system participant, the intermediary's activities will be regulated and supervised in terms of the provisions of the Banks Act or Mutual Banks Act. ${ }^{244}$ All TPPPs need to be registered by a sponsoring clearing participant with PASA. Further, the SARB Directive $2 / 2007^{245}$ provides for conduct, record-keeping and risk-management for BSP and PSPrs and their agents. $^{246}$

v)

Fifth Layer

\subsection{Activities and Participants in the Fifth Layer}

The fifth layer consists of consumers and corporate customers of TPPPs and other non-bank providers of payment services. These may be private payment systems and services on this most outer layer that practically operates outside the perimeter of the NPS (and hence the NPSA). These are primarily non-bank,

\footnotetext{
${ }^{241}$ SARB (2007a) op cit note 240.

${ }^{242}$ Lawack-Davids (2008) op cit note 16 at 461.

${ }^{243}$ Indeed, s7 of the NPSA is one of the main reasons that e-money issuance is limited in South Africa to licensed banks, as a non-bank in the SARB's view can only accept money from someone if - as per s7 - a payment is due. Otherwise that receipt would be deposit-taking, it believes. See further, ch 12, s12.4 titled E-Money and Stored Value.

${ }^{244}$ Lawack-Davids (2008) op cit note 16.

245 SARB (2007a) op cit note 240 .

246 The rules are to inter alia ensure that it is appointed as an agent of each beneficiary when acting as BSP or as an agent of each payor when acting as PSPr; and keep separate and distinct the payment business divisions from the other business divisions in terms of SARB (2007a) op cit note 240.
} 
single-purpose payment services such as prepaid cards for telecommunications use and any other prepaid value that can be seen as advanced payment for goods and services. ${ }^{247}$

\subsection{Rules and Regulations of the Fifth Layer}

There is some regulation here: where a payment intermediary is for example a non-bank performing third party payment services for the public - for example P2P payments like remittances - as a regular feature of its business, this is regulated by s7 of the NPSA relating to payments to third persons.

\subsubsection{Foreign Exchange Controls}

The ability to do P2P remittances and payments is impacted by long standing forex controls that the SARB implemented in the 1960s to control the inflow and outflow of funds from South Africa. ${ }^{248}$

Current forex control legislation revolves around the Exchange Control Regulations, ${ }^{249}$ as well as Orders and Rules ${ }^{250}$ issued in terms of s9 of the Currency and Exchanges Act. ${ }^{251}$ The administration of the forex Regulations is a function of the Treasury, but this has been delegated to the Financial Surveillance Department of the SARB. There is an Exchange Control Manual - first issued by the SARB in 1990 - to assist those authorised dealers in foreign exchange with a general understanding of the purpose, scope and operation of the exchange control system in South Africa and in the Common Monetary Area (hereafter CMA) ${ }^{252}$ The CMA incorporates South Africa, Lesotho, Swaziland and Namibia which forms a single exchange control territory. ${ }^{253}$ Thus transfer of funds from South Africa to other CMA countries does not require the approval of Exchange Control. For remittances outside the CMA the rules differ according to

\footnotetext{
247 These 'advance payments' also Act as an exclusionary trigger for determining whether an entity is taking 'deposits' in terms of the Banks Act. See ch 12, s12.3.5.2.2 titled Deposits.

${ }^{248}$ See generally in relation to forex controls in South Africa, South African Reserve Bank (SARB) (2001) 'NPSD: Position Paper on Common Monetary Area (CMA) Cross-border Payments' Position Paper No 01/2001, available at http://goo.gl/7jsXD; Bester, Hougaard and Chamberlain (2010) op cit note 21; Ratha, Mohapatra and Silwal (2011) op cit note 22; and Mbalekwa (2011) op cit note 22; and South African Reserve Bank (SARB) (2010a) 'NPSD: Position Paper on Common Monetary Area (CMA) Cross-Border Payments', available at http://goo.gl/AdsJg.

${ }^{249}$ Exchange Control Regulations as promulgated by Government Notice R1111 of 1 December 1961 and amended up to Government Notice No R9 in Government Gazette, No 33926, of 14 January 2011. In terms of the Exchange Control Regulations, the control over South Africa's foreign currency reserves, as well as the accruals and spending thereof, is vested in the Treasury. The Treasury is defined as '... in relation to any matter contemplated in these regulations, means the Minister of Finance or an officer in the Department of Finance (National Treasury) who, by virtue of the division of work in that Department, deals with the matter on the authority of the Minister of Finance'.

${ }^{250}$ Orders and Rules as published in Government Notice R1112 of 1 December 1961 and amended up to Government Notice R663 in Government Gazette, No 31153 of 17 June 2008. The Minister of Finance issues Orders and Rules under the Exchange Control Regulations and the current set was published on 1 December 1961, and amended from time to time. The Orders and Rules contain various orders, rules, exemptions, forms and procedural arrangements.

${ }^{251}$ Currency and Exchanges Act 9 of 1933.

${ }^{252}$ The SARB indicates that the exchange control manual merely serves as a general guideline and does not replace or supersede the Exchange Control Regulations, Orders and Rules, nor the norms and policies as applied by the Financial Surveillance Department from time to time. The Financial Surveillance Department of the SARB continuously updates the exchange control manual to reflect current policies and norms. See South African Reserve Bank (SARB) (2011a) 'Exchange Control Manual', available at http://goo.gl/Ekuh5. The complete Exchange Control Manual is available at http://goo.gl/b4CUH.

${ }^{253}$ While each CMA member has its own exchange control regulation and authorities, in terms of the CMA Agreement, their application of exchange control must be at least as strict as that of South Africa. Section D7 of the Exchange Control Manual; and Bank (SARB) (2010a) op cit note 248.
} 
whether someone is a resident or non-resident of South Africa. ${ }^{254}$ Only authorised entities may provide forex services and there are annual limits on amounts South African citizens may remit for their personal purposes out of the country. ${ }^{255}$ These value restrictions appear to be subtly loosening - mainly insofar as how much money may be remitted annually outside South Africa - as South Africa becomes more integrated into the global economy. Non-bank Money Transfer Organisations (hereafter MTOs) however must still cooperate by law with licensed banks as they are the only entitiesauthorised to deal in forex. ${ }^{256}$

Banks and authorised forex dealers must comply with extensive controls and reporting rules where every forex transaction must be categorised and reported according to the Exchange Control Manual. ${ }^{257}$ Insofar as the SARB's Exemption 17 loosens CDD criteria in relation to qualifying accounts and remittance transactions for remittances, it relates primarily to account-based remittances with South Africa and the CMA and does not have a similar liberalising effect on cross-border remittances since Exemption 17 does not apply at all to non-account based cross-border remittances. ${ }^{258}$

\subsubsection{Application to MFS}

\subsection{Comparative Application to MFS in Other Jurisdictions}

To enhance the use of cashless payment facilities in the EU and to promote consumer protection, the EU has implemented a range of progressive laws and regulations that allow for the genesis of new forms of cashless payment instruments and new entrants providing payment services. This includes a raft of clear licensing regimes and designated roles for bodies engaged in supervision and oversight of financial entities, especially those 'non-bank' entities engaged in financial services and payments. The foci are through the EMD and the PSD. The PSD also makes provision for the roles and responsibilities of agents in various scenarios, and for capital requirements such as a payment service provider would have to either segregate user funds or adequately insure them in a separate account.

In Kenya, despite an obvious loophole in the definition of deposit that excluded the eponymous M-pesa system from being classed as a deposit-taking entity and thus undertaking the business of banking, alongside the lack of a national payment system act, it was a bold policy move based on the realities of

\footnotetext{
${ }^{254}$ Section D8 of the Exchange Control Manual defines a resident as 'a person (ie, a natural person, body corporate, foundation, trust or partnership) whether of South African or any other nationality who has taken up residence, is domiciled or registered' in South Africa. A non-resident is a 'person (ie, a natural person or legal entity) whose normal place of residence, domicile or registration is outside the CMA'. Section F3 defines a 'temporary resident' as 'foreign nationals, [who] are, for purposes of exchange control, natural persons of countries outside the CMA who have taken up temporary residence in the Republic excluding those who are purely on temporary visits'. Bester, Hougaard and Chamberlain (2010) op cit note 21 at 17, which points out that documented and undocumented migrants (as opposed to legal migrants) working in South Africa would meet the non-resident definition.

${ }^{255}$ Section F2.2 of the Exchange Control Manual indicates that residents (natural persons) over the age of 18 years may be availed of a single allowance within an overall limit of R1mn per individual per calendar year. Each transaction must be reported.

${ }^{256}$ Authorised forex bureaux have limited authority to buy and sell foreign exchange, which must be for travel-related purposes only.

${ }_{257}$ Bester, Hougaard and Chamberlain (2010) op cit note 21 at 16; CGAP (2010c) op cit note 25 at 12.

${ }^{258}$ Notice R1353 of 2004, published in Government Gazette No 27011, 19 November 2004, available at http://goo.gl/C45CK; and Notice R1354 of 2004, published in Government Gazette No 27011, 19 November 2004, available at http://goo.gl/C45CK. See Bester, Hougaard and Chamberlain (2010) op cit note 21 at 18.
} 
social and FI alongside the solid business model that M-pesa represented, that allowed the CBK to effectively ignore the loophole and give its now famous blessing to the roll-out of M-pesa in Kenya. ${ }^{259} \mathrm{M}$ pesa user funds are kept in a special Trust Account. However, there is a lack of adequate oversight in terms of the growth of MFS which this may ultimately raise some systemic concerns. ${ }^{260}$

In the US in regard to remittances, a proposed rule from the US Financial Crimes Enforcement Network (hereafter FinCEN) would impose the full panoply of Bank Secrecy $\mathrm{Act}^{261}$ requirements on the entity identified as a 'provider of prepaid access' which may provide some oversight over prepaid value transfers that may include MNO airtime transfers where offered. ${ }^{262}$

\subsection{Application to MFS in South Africa}

While participants in the NPS are all in some way (systemically) linked together, as one moves away from the core, however, the NPSA is relevant but becomes less effective. ${ }^{263}$ At the top of the payments pyramid is what one could call an informal, non-systemic environment ${ }^{264}$ where the activities of the participants are effectively, as far as the current environment is concerned, unregulated by any formal payments law. Examples of these entities are those who offer prepaid debit cards or private stored value cards issued by non-banks. Many MFS services related to non-redeemable prepaid SOVs would also fit into this characterisation. ${ }^{265}$ The conduct rules are thus mandated more by self-regulation, albeit empowered by the NPSA and sanctioned by the NPSD. ${ }^{266}$ This prudential dilution is magnified even more as one moves towards participants such as the CPSPs, who provide value-added payment services for customers and firms. There are also no effective rules and regulation for non-bank, single-purpose payment services such as prepaid cards for telecommunications use, or any other prepaid value that can be seen as advanced payment for goods and services. Only the ECTA ${ }^{267}$ and possibly some provisions in the $\mathrm{NCA}^{268}$ with their general provisions around e-commerce and consumer protection, have any relevance to these payment instruments. For the most part however, in relation to financial products, these provisions are ineffective and/or exclude 'financial' products.

The NPSD however wants to fill this prudential 'gap' so that the Department may have oversight over any 'payment system' - which could in theory possibly also include a private payment system with its own

\footnotetext{
${ }^{259}$ See ch 10, s10.2.3.3 titled Application to MFS.

${ }^{260}$ Ibid. In particular, this highlights the separate trust company established by MNO Safaricom for its MFS activities through its subsidiary, M-pesa. This could be a model for the emergence of MFS through new non-bank MFS providers in South Africa.

${ }^{261}$ Bank Secrecy Act 31 USC 1051.

${ }^{262}$ See 'Proposed Rules' (2010) 75(123) Federal Register Monday 28 June 28, available at http://goo.gl/Qh0Hm.

${ }^{263}$ Under current perimeter regulations.

${ }^{264}$ They could be classed as non-systemic because of volumes and relative disembodiment from the payments core, systemic system. This concurs with the BIS determination of 'systemic'.

${ }^{265}$ In many cases, however, especially where there is a private payment system that involves a closed loop system with its own treasury, currency, settlement, clearing and payment instruments, there will not be any participation in the NPS despite potential SARB NPS Directives and the NPSA provisions that relate to similar types of (money-based) payment activities.

${ }_{266}$ See references in the Feasibility study to this 'self-regulation'.

${ }^{267}$ ECTA op cit note 1.

${ }^{268}$ NCA op cit note 1
} 
issuance, treasury, clearing and settlement measures, like an MNO airtime SOV - that they deem systemically important to confidence in the payment system in South Africa as a whole.

Indeed, the NPSAA empowers the NPSD to oversee the use of MNO airtime SOVs, even though a MNO prepaid scheme is ordinarily considered by the SARB to be a single purpose SOV that may not need to be connected to any NPS participants. ${ }^{269}$ To nip any possibility of their interconnection to the NPS and the ringfence their activities however, the SARB in 2002 assessed the nature of the potential 'open' and 'closed loop ${ }^{270}$ use of the mobile airtime SOV and indicated that the use of the airtime based SOV for use with WASP VAS ${ }^{271}$ would be allowed only if digital VAS were being purchased with this SOV; that is, only intangible goods and services could be purchase with this SOV and which had to be consumed on the mobile phone SVA the VAS were purchased with. Any use beyond this prescribed perimeter would mean that the airtime SOV would be considered e-money, which of course under the SARB e-money rules, ${ }^{272}$ may only be issued and operated by a licensed bank. Some WASPs however appeared to test the perimeter of this restriction: in 2010, the SARB stopped companies from marketing short-term prepaid insurance that could be bought using airtime-based SOVs in MNO SVAs.

Insofar as a fiat-based MNO is concerned, SOV may ostensibly be used for P2P transfers. However section 7 of the NPSA ${ }^{273}$ only allows fiat money to be stored in a SOV when payment is due to a third party, such that if nothing is due, then the entity accepting funds as a SOV in a SVA could be seen to be engaged in deposit-taking. That is, if a MFSP takes funds from the public ostensibly for future use for a possible payment-due to a third party, this would be considered deposit-taking since payment is not immediately due. Here time therefore - as with the deposit-taking potential with agents - is again an arbiter of deposittaking.

This payment-due restriction is clearly not applicable to contemporaneous and non- contemporaneous payment activities that characterise WASP VAS when an MFS SVA using an airtime-based SOV is used for these transactions: use of the airtime SOV in this scenario does not appear to fall foul of s7 simply because the airtime SOV is not seen in this context to be (fiat) 'money' per se. ${ }^{274}$

Further, and curiously though, the context of the 'payment-due' criteria of s7 may obliquely act as an enabler of cross-border P2P transfers using the airtime $\mathrm{SOV}^{275}$ simply because these SOVs are not seen to

\footnotetext{
${ }^{269}$ This access (to the NPS) scenario could potentially occur then if a MNO airtime-based SVA is used for single or multipurpose payment services, for example, to buy digital or corporeal goods and services.

${ }^{270}$ See generally on open or closed use, ch 4, s4.8.3.7 titled Ubiquity of Use: Interoperability; and also on SVPs, 4.8.4.4.4.4 titled Open and Closed SVPs.

${ }^{271}$ See ch 6, s6.5.4.2 on WASP VAS.

${ }^{272}$ See ch 12, s12.4 titled E-Money and Stored Value.

${ }^{273}$ NPSA op cit note 1.

${ }^{274}$ Indeed, these types of services appear to fall outside the perimeter of the payments infrastructure (and possibly the NPSA) in South Africa and may mostly, if at all, be governed by either self-regulatory structures, or contract, or both. On the AML implications of these schemes, see further ch 12, s12.7.2 titled Comparative Application to MFS in Other Jurisdictions.

${ }^{275}$ See ch 6, s6.5.4.3 titled Mobile Airtime Transfer. Airtime value can similarly bought and transferred directly P2P from one MNO user in South Africa to a user of its sister MNO in another country, although as yet there are not any MNOs who allow this type of direct P2P transfer from South Africa.
} 
be 'money' - an important trigger, it appears, for s7. ${ }^{276}$ There are no apparent restrictions on these crossborder transfer facilities for non-banks. ${ }^{277}$ By comparison, remittances (transfers) of fiat value using a MFS SVA with a fiat-based $\mathrm{SOV}^{278}$ - the SVA populated by value sourced from, for example, cash or an EFT out of the CMA, would need to be done via banks who would then need to abide by the SARB forex rules. ${ }^{279}$ A restriction would similarly apply to where the SOV is fiat-based e-money in a system operated as it needs to be according to the SARB's rules - by an MNO or MFSP in conjunction with the bank. ${ }^{280}$ The SARB however does allow airtime-based SOV transfers when the airtime of a non-South African MNO is purchased using, to wit, a fiat SOV via a South African bank which then sends the airtime value to the recipient outside South Africa. ${ }^{281}$

The twists and turns though of this policy, based on whether a fiat or non-fiat SOV is used in a SVA, appears then, it is submitted, to signify a significant policy lacuna.

\subsubsection{Conclusion: Payment Systems}

MMOs and MFSPs that may independently offer payment services to the public are restricted within the NPS from operating for their own account and independently, even though they nominally may be members of the NPA. The siren example of s7 relating to the store of funds by an entity for a possible payment amounting to a deposit if the payment is not immediately due calcifies this limited role.

The regime governing whether they are engaging in deposits under the Banks Act, ${ }^{282}$ or falling foul of s7 of the NPSA or even the e-money Position Paper regime, ${ }^{283}$ however, it is submitted, is predicated on a subjective policy consideration: time.

There is another way though: non-bank players - be they system operators, providers of ATM or POS devices, MNOs, MFSP, bureaus, or micro-lenders - are not necessarily interested in doing the main business of a bank, that is, long-term deposit taking and, as such, the risky (but profitable) business of intermediation that could threaten their liquidity and thus introduce systemic risk. ${ }^{284}$ Granted they may introduce some risks but these are entirely manageable through auditing and continued oversight. User funds stored in pooled accounts that act as the source of value for payments could be protected through the use of trust companies and trust accounts, the equivalent of collateral accounts sometimes used to minimise systemic risk generally. ${ }^{285}$ The PSD as a model for a new 'lite' regime that focuses on protecting payment

\footnotetext{
${ }^{276}$ See ch 13 passim for a re-evaluation of money that includes a discussion of whether airtime-based SOVs stored in a MNO SVA amount to money.

${ }^{277}$ Author's personal communications with SARB, cross-border airtime transfer operators, and banks.

${ }^{278}$ See ch 4, s4.8.4.3 titled Remittances; and also ch 6, s6.6.5.5.3.2 titled EFTs and Remittances.

${ }^{279}$ See SARB (2010a) op cit note 248 passim.

${ }^{280}$ On the banks-only e-money regime in operation in South Africa, see ch 12, s12.4.2 titled E-Money in South Africa.

${ }^{281}$ See ch 6, s6.5.4.3 titled Mobile Airtime Transfers, and references to FNB South Africa and their CMA airtime transfer activities therein.

${ }^{282}$ Act 94 of 1990 op cit note 1 .

${ }^{283}$ See ch 12, s12.4 titled E-Money and Stored Value.

${ }^{284}$ Competition Commission (2008a) op cit note 16 at 444, available at http://goo.gl/JRWNj; see also ch 12, s12.5 titled the Competition Commission Enquiry into Banking and Payments in South Africa below.

${ }^{285}$ On pooled master accounts and their use, see ch 4, s4.8.4.4.6. See also ch 7, s7.4 on Trusts and Trust Accounts, and their possible use in MFS and other pooled/master accounts; and ch 10, s10.2.3.3 on the separate trust company established by
} 
systems whilst liberalising the payments market through enabling new entrants such as PSPs without systemic implications, is a salient and successful example. A PSP's ability to access payment networks albeit not those considered systemically important in member states - is also to be welcomed and provides a framework for similar implementations worldwide, including, it is submitted, in South Africa. ${ }^{286}$

\section{E-Money and Stored Value}

In terms of its broad mandate of regulatory and supervisory authority over of the financial system in South Africa, the SARB sees e-money ${ }^{287}$ as a risk that may potentially affect the managing and control of the NPS. As such, it uses its power under the NPSA ${ }^{288}$ to control the issuance, management and use of emoney in South Africa. MFS systems using redeemable - and possibly even some non-redeemable SOVs in SVAs - may fit into the SARB e-money regime.

\subsubsection{1}

\section{Prudential Framework}

The SARB and the legislature have not embraced the e-money legislative framework prevalent in other jurisdictions like the EU as described earlier. ${ }^{289}$ Local efforts have been characterised instead by Position Papers on e-money issued by the SARB that, while not being law per se, have a persuasive effect on potential e-money participants and the broader financial community. Three specific e-money Position Papers have been issued by the NPSD, first in 1999, then an updated, but largely similar version in 2006, and another in 2009. ${ }^{290}$ Each of the Position Papers shows some resemblance to the pre-EMD bank-focused 1990s' approach of Central Banks (hereafter CBs) in Europe, and indeed of the ECB itself since in all three Position Papers the SARB limits e-money issuance to licensed banks. ${ }^{291}$ The SARB's rationale has shifted from the deposit-focused approach of the 1999 Position Paper to one where more payment-centric

Safaricom for its M-pesa activities. This could be a model for the emergence of MFS through new entrants in South Africa. See further also ch 12, s12.3.5.7.2 titled Application to MFS in South Africa; and similarly ch 14, s14.9.4 titled Use Of Trust Accounts and Recommendation 5 therein that recommends the use of trusts and trust accounts for prospective non-bank MFS providers in South Africa.

As was indicated in the Competition Commission Report, simply allowing more non-banks into the system is not enhancing the quality of the system, but allowing more appropriately regulated non-banks in the system is likely to enhance the system. Competition Commission (2008a) op cit note 16 at 444.

${ }^{286}$ See also inter alia, Recommendation 4 in ch 14 , s14.9.3 on a proposed new regulatory regime encapsulated in a PSPL.

${ }^{287}$ See ch 4, s4.8.4. titled Stored Value Products. It is worth mentioning here again that the configuration of a SVP offered to users is that it may contain different types of SVAs, each SVA with its own type of SOV. These SOVs may for example be airtime- or fiat-based, denominated in a UOA of the fiat of the national currency such as the Rand; or some other private UOA, such as airtime minutes respectively. See further Exhibit A in ch 2, s2.1 that highlights these relationships in an MFS setting.

${ }^{288}$ NPSA op cit note 1.

${ }^{289}$ See ch 9, s9.6.3 titled E-Money, Stored Value Laws and Regulations, in the EU.

290 South African Reserve Bank (SARB) (1999) 'Position Paper on Electronic Money - April 1999', available at http://goo.gl/LfPCU; SARB (2006c) op cit note 178; SARB (2009) op cit note 195.

${ }^{291}$ A more stringent approach was taken in 2006, allowing only registered commercial banks with settlement accounts with the SARB to issue e-money. 
approaches are emphasised in the 2006 and 2009 Position Papers. This shift appears to subtly recognise that e-money is less about deposits and savings than it is about a means of payment or transactions.

In the 2006 Position Paper, the perimeter definition of e-money resembled the original EMD1 definition of e-money. ${ }^{292}$ In respect of the 2009 Position Paper, after much lobbying from MNOs and other potential issuers of e-money for a graduated non-bank e-money regime much like that of the EU, the NPSD embarked on a fact-finding mission to determine new policy guidelines around e-money, followed then by intensive stakeholder participation. ${ }^{293}$

However, the resultant 2009 Position Paper retained the status quo introduced in the 1999 and 2006 Position Papers, with the SARB justifying the restriction to licensed banks only on the basis that it believes that issuance involves clearing and settlement. ${ }^{294}$

\title{
12.4.2.2 Issuance and Redemption ${ }^{295}$
}

The 2009 Position Paper indicates that the SARB considers e-money to be a supplement to physical notes and coins. ${ }^{296}$ A new definition of e-money was also provided as being:

\begin{abstract}
'monetary value represented by a claim on the issuer. This money is stored electronically and issued on receipt of funds, is generally accepted as a means of payment by persons other than the issuer and is redeemable for physical cash or a deposit into a bank account on demand.'
\end{abstract}

As per the requirements of the Banks Act, deposits of e-money would have to be held in a separately identifiable e-money account for each holder of e-money and comply with the relevant sections of the Banks Act and its Regulations. ${ }^{297}$ A bank, as the holder of an e-money deposit, must, on demand, redeem the electronic value held on the instrument for central bank currency, and at par. As s52 of the Banks Act allows for non-banks to enter into arrangements or joint ventures ${ }^{298}$ with banks, this allows them to offer payment-related services in conjunction with that bank. ${ }^{299}$

Non-banks are thus limited, in respect of e-money, to providing services as SOs or third-person PSPs in terms of SARB Directives 1 and 2 of 2007 respectively. The modality of e-money as primarily a

\footnotetext{
292 The SARB paper of 2006 defined e-money as being 'Monetary value represented by a claim on the issuer which is stored on an electronic device and which is widely accepted as a means of payment by persons other than the issuer'. See SARB (2006c) op cit note 178 .

${ }^{293}$ Author's personal communication with MNOs and the SARB during the periods 2005-2011.

${ }^{294}$ The SARB further indicates that due to what it sees as a functional intersection between the money received and the ability to possibly do $\mathrm{P} 2 \mathrm{P}$ remittance-type payments with the balances, this is another reason why banks would remain the sole entities legally able to issue e-money.

${ }^{295}$ See in relation to SVPs, ch 4, ss4.8.4.4.5.1 titled The Process of Issuance ; and 4.8.4.4.7 titled Issuers and The Deposit Concept.

${ }^{296}$ SARB (2009) op cit note 195.

${ }^{297}$ SARB (2009) op cit note 195 at 8.

298 The Banks Act at s52(6) defines 'Joint Venture' as 'a contractual arrangement between two or more persons, one or more of whom is a bank or a controlling company, in terms whereof the parties undertake an economic activity that is subject to their joint control'.

${ }^{299}$ Application for such arrangements would be required to be made by the bank concerned to the Registrar of Banks. SARB (2009) op cit note 195 at 8.
} 
transactional payment service thus appears again to be recognised by the SARB. This is the modus that apparently allowed Wizzit ${ }^{300}$ and M-pesa ${ }^{301}$ as non-bank MFS systems to be approved by the SARB.

Generally though, the SARB says it may consider other models of e-money issuance in order to facilitate the development of e-money products and the opportunities that they present on a national and regional basis which are aimed at providing secure payment instruments to the unbanked and rural communities of the Southern African region.

The practical iterations that allow this will, it says, include support for the development of a banking industry vision for electronic substitutes for physical banknotes and coins. ${ }^{302}$

Importantly, too, is that says it will support the development of national standards to enable interoperability of e-money products and devices. ${ }^{303}$

\subsubsection{Interoperability}

In regard to interoperability, ${ }^{304}$ the SARB says that it encourages e-money interoperability between emoney issued by banks (as the only legal issuers of e-money, even in partnership with non-banks). ${ }^{305}$ The SARB though will not support separate and independent 'closed systems' to develop over the long-term, as they say this will lead to payment system inefficiencies.

However, the SARB indicates that it recognises the importance of innovation in the payment system arena and that an over-emphasis of the principle of interoperability, it believes, could lead to less payment system innovation over the longer term.

Therefore, where feasible, it will maintain a balance between interoperability and innovation. ${ }^{306}$

\footnotetext{
${ }^{300}$ See ch 12 , s12.2.7 on Wizzit.

${ }^{301}$ See ch 12, s12.2.6 on Vodacom M-pesa.

302 The term 'banking industry' is significant in its perimeter vision. It may refer to existing banks or the concept of banking in general. However, the SARB says further that it has been cautious not to stifle development and has always maintained that regulation of e-money products and schemes will be applied appropriately as innovation occurs. See SARB (2009) op cit note 195 .

${ }^{303}$ Interoperable systems, it says, lead to the development of large network externalities which will, in the longer term, reduce operational cost and complexity for all customers. If more than one settlement system participant issues e-money, an e-money PCH may be established by PASA to ensure interoperability and appropriate rules for clearing and settlement of similar e-money transactions between these banks.

${ }^{304}$ The principle of interoperability was entrenched by the SARB in the Vision and Strategy document agreed to between the Bank and the commercial banks in 1995 (the Blue Book) as well as its Vision 2010 document. One of the main strategic objectives is to 'enhance and maintain the interoperability and operational effectiveness of the payment system'.

${ }^{305}$ SARB (2009) op cit note 195 at 8; and SARB (2011e) op cit note 172 at 2.

${ }^{306}$ Should more than one settlement system participant introduce a similar new product or methodology, or should the product or methodology reach an expansionary stage, SARB says that consideration should be given to the establishment of a PCH by the PASA to ensure interoperability and appropriate rules for clearing and settlement of the transactions between these banks. SARB (2011e) op cit note 172 at 4.
} 


\subsubsection{1}

\section{Comparative Application to MFS in Other Jurisdictions}

\begin{tabular}{|c|c|c|c|}
\hline EU EMD1 & EU EMD2 & SA SARB 2009 & US UMSA \\
\hline Monetary value & Monetary value & Monetary value & Stored value record \\
\hline $\begin{array}{l}\text { represented by a claim on } \\
\text { the issuer }\end{array}$ & $\begin{array}{c}\text { as represented by a claim on the } \\
\text { issuer }\end{array}$ & $\begin{array}{l}\text { represented by a claim on } \\
\text { the issuer }\end{array}$ & \\
\hline & & money & monetary value \\
\hline $\begin{array}{l}\text { which is stored on an } \\
\text { electronic device and }\end{array}$ & $\begin{array}{l}\text { electronically, including } \\
\text { magnetically, stored }\end{array}$ & stored electronically & \\
\hline issued on receipt of funds & issued on receipt of funds & issued on receipt of funds & \\
\hline \multicolumn{4}{|l|}{$\begin{array}{c}\text { of an amount not less in } \\
\text { value than the monetary } \\
\text { value issued. }\end{array}$} \\
\hline & & is generally & \\
\hline Accepted & accepted & accepted & \\
\hline as a means of payment & $\begin{array}{l}\text { for the purpose of making } \\
\text { payment transactions as defined } \\
\text { in the PSD }\end{array}$ & as a means of payment & $\begin{array}{l}\text { used as a means of } \\
\text { exchange. }\end{array}$ \\
\hline \multirow[t]{4}{*}{$\begin{array}{l}\text { by undertakings other } \\
\text { than the issuer. }\end{array}$} & $\begin{array}{c}\text { by a natural or legal person } \\
\text { other than the electronic money } \\
\text { issuer. }\end{array}$ & $\begin{array}{l}\text { by persons other than the } \\
\text { issuer }\end{array}$ & \\
\hline & & and is redeemable & \\
\hline & & $\begin{array}{c}\text { for physical cash or a } \\
\text { deposit into a bank } \\
\text { account }\end{array}$ & \\
\hline & & on demand. & \\
\hline
\end{tabular}

Exhibit B: Comparisons of e-money definitions in the EU, South Africa and the US.

The South African e-money position can be compared to jurisdictions elsewhere. As Exhibit B shows, there are some nuanced differences between the EU, SA and the US positions.

The EU position is characterised by two Directives that are most applicable to the business models of MFS: the Second Electronic Money Directive (EMD2 op cit note 1) ${ }^{308}$ and the Payment Services Directive (PSD op cit note 1). ${ }^{309}$ The EMD2 provides a legal framework for non-banks to issue e-money, but subject to safety and soundness rules and some (proportionate) capital requirements.

The EMD2 relaxed some restrictions of the first Electronic Money Directive (EMD1 op cit note 1) in so far as the allowed business activities an ELMI - as it was termed in the EMD1 and is still used to some extent $^{310}$ - could participate in and also altered the definition of e-money from the confusing definition in

\footnotetext{
${ }^{307}$ Point 5 of Article 4 of the PSD op cit note 1.

${ }^{308}$ See ch 9, s9.6.3 titled E-Money, Stored Value Laws and Regulations in the EU.

${ }^{309}$ See ch 9, s9.6 2 titled Payment Services Directive.

${ }^{310}$ Ibid. In the EMD2 op cit note 1 and the associated PSD op cit note 1, ELMIs were instead called a 'Financial Institution' (FI).
} 
the EMD1 which had effectively captured airtime-based SOVs as being 'e-money. ${ }^{311}$ The extensive crossreferencing and sharing of many clauses between the PSD and the EMD2, and the categorisation of emoney issuers as PSPs in the PSD, cements a close nexus between the two Directives and indicates that ultimately the business of FIs, as ELMIs were newly termed, relate primarily to enabling and storing value for use in payments.

It however becomes clear from the analysis earlier - and from the contrived nature of the exclusions relating to the EMD2 and PSD in relation to regarding a user's funds as not being a deposit ${ }^{312}$ and for certain types of MNO business models and uses of the airtime or fiat-based SOV as not being subject either to the PSD or EMD2, that the EMD2 and PSD are geared towards more additive models of MFS ${ }^{313}$ where the MNO is not necessarily the primary facilitator of MFS services, instead being more of a partner (or agent in the PSD scheme thereof). When applied to more transformational MFS services ${ }^{314}$ - in particular using both the airtime and fiat-based SOVs housed in SVAs, it is doubtful that the exclusions and contrived notions of how to exclude or include certain business models stand up to the scrutiny of legal certainly.

Although FIs as ELMIs are allowed to distribute electronic money by selling or reselling electronic money products to the public, ${ }^{315}$ providing a means of distributing e-money to customers, or of redeeming electronic money on the request of customers or of 'topping up' customers' e-money products, through natural or legal persons on their behalf, the EMD2, like the EMD1, prohibits them from issuing electronic money through agents. ${ }^{316}$ However, in recognition of their role as PSPs under the PSD, the EMD2 allows EMI to provide payment services as defined in the PSD $^{317}$ through agents and branches, where the conditions in Article 17 of the PSD relating to the use of agents, branches or entities to which their activities are outsourced. The agents must however be registered with the financial institution.

In the $\mathrm{US}^{318}$ unlike the $\mathrm{EU}$, while federal and state law and regulations make copious reference to 'electronic money' and its nomenclature variations, there is no framework per se in federal law that provides guidance as to what could qualify as electronic money. There are however deposit protections for SVPs at the federal level for payroll SVCs, as well as use of these SVPs when they are prefunded using value derived from a debit or credit instrument. At state level, the prefunded SVA's function as a SOV and its associated use for payment is not necessarily treated under two sets of regimes. Instead 46 states group the new products under existing money transmitter or EU EMD-type ${ }^{319}$ MSB statutes, some using the UMSA as a 'model law' guide. ${ }^{320}$ The UMSA does not have a clear definition of 'e-money' per se. Instead the determination as to whether a SVA is subject to a state MSB-type regime is decided by whether its use and the SOV therein rises to a 'stored value' record, that is, 'monetary value' used as a 'means of

\footnotetext{
${ }^{311}$ Indeed, the non-applicability of the EMD2 to these SOVs was explicitly laid out as derogations and in the Preamble. See ch ss9, 9.6 2 titled Payment Services Directive; and 9.6.3 titled E-Money, Stored Value Laws and Regulations in the EU.

312 Ibid for a discussion of this 'carve-out.'

${ }^{313}$ See ch 2, s2.1 on the distinction between 'additive' and 'transformational' MFS.

${ }^{314}$ Ibid.

${ }^{315}$ In terms of Art 3(4) of the EMD2.

316 Art 3(5) of the EMD2.

${ }^{317}$ Listed in the Annex to Directive 2007/64/EC.

${ }^{318}$ See earlier ch 11, s11.2.5 titled E-Money and SVPs in the US.

${ }^{319}$ Ibid. Many are based on the UMSA codified in 2000 and amended in 2004.

${ }^{320}$ Ibid.
} 
exchange'. Implementations relating to prefunded SVCs, money transmission, and prepaid cards have not been uniform though, creating a patchwork of compliance obligations for MSBs. Moreover, there have been jurisdictional conflicts with federal agencies in relation to gift-card type SVCs that are issued by banks or who are issued by private merchants but underwritten by banks.

In Kenya, ${ }^{321}$ there is no specific legal framework for e-money and mobile payments, ${ }^{322}$ but this is being planned. ${ }^{323}$ The CBK had allowed the M-pesa system by special dispensation in 2006, as a loophole in the Banking Act relating to deposits meant that there was a regulatory void.

\subsubsection{Application to MFS in SA}

\subsection{Overview}

A MFS scheme that fits the perimeter definition of e-money will ostensibly come under the jurisdiction of the SARB. In that case, only members of SAMOS may issue e-money. Analysis of the 2009 e-money definition shows the following components are required to fulfil the SARB definition:

- Monetary value

- Represented by a claim on the issuer

- (This) Money

- (which) is stored electronically

- and issued on a receipt of funds

- (which) is generally

- accepted

- as a means of payment

- by persons other than the issuer

- and is redeemable

- for physical cash or a deposit into a bank account

- on demand

To determine whether a scheme fits the criteria for e-money issuance, specific touch-points of the definition are analysed below.

As with the EMD1 definition though, at first brush, this definition is deceptively straightforward. The point of the exercise that follows below is to indicate whether, and if so where, the e-money definition is equivocal and opens up the possibility of regulatory arbitrage and even challenge.

\footnotetext{
${ }^{321}$ See ch 10 on Mobile Financial Services on Kenya. At the time of completion of this study, new e-money guidelines and a national payment system law were in the process of being issued in Kenya.

${ }^{322}$ See on Kenya, ch 10, s10.2.3 titled Banking Laws and Regulation.

323 'CBK Outlines Rules for Electronic Money' (2011) The Star, 21 March, available at http://goo.gl/QDHS8.
} 


\subsubsection{2}

\section{'Monetary Value'}

The SARB indicates that e-money is to be considered as a 'supplement' to physical notes and coins in the long-term. ${ }^{324}$ The logical extrapolation is that any 'monetary value' will immediately translate into the notional currency of e-money use, the most obvious being the Rand as the Unit of Account (hereafter UOA). However, it is not certain that this always applies. For example, a MNO's prepaid airtime SOV may have some notional UOA like airtime minutes or data bytes, but this would not necessarily be described nor applied in terms of currency or as the unit of account of the national currency. ${ }^{325}$ Redeemable fiat-based MFS SOVs though would certainly have 'monetary value'.

\subsubsection{3 'Claim'}

In practice, monetary claims used for e-payments constitute either claims held with commercial or central banks (deposit balances), or e-money. This 'claim', for the most part, also relates to the redeemability (at par) requirement of the SARB's par value requirements. However, redeemability into specie cash is a salient feature of many MFS systems like M-pesa. The alternative redeemability, into a bank deposit account, is thus not essential to the SARB definition of e-money, although, it seems, desirable.

\subsection{Money}

From the discussion earlier, it is not always certain that a monetary value equates to money, nor is it certain that something is 'money'. The current legal view of money is of course that it is a UOA, Means of Exchange (hereafter MOE) and SOV. Each component must be present at least to indicate that something is money. Hence, the nexus between 'monetary value' and 'this money' for the purposes of this component of the e-money definition may be disrupted by the money not being money per se and thus, again for the purposes of this definition, not being a monetary value subject to the definition.

\subsubsection{5 'Stored Electronically'}

It appears that stored value products as well as network, or server-based access products like mobile phones, could meet this definition. The account based nature of the e-money scheme also has implications for its ultimate prudential oversight requirements, specifically whether or not a deposit-taking arrangement is at play. As e-money is purely an electronic product, if the storage mechanism is an account-based server that can additionally allow the e-money to be withdrawn by non-electronic means such as by cheque, this

\footnotetext{
${ }^{324}$ SARB (2009) op cit note 195 at $\mathrm{s} 5$.

${ }^{325}$ As indicated in ch 5, s5.4.2 titled Prepaid Consumer Billing Systems, some MNOs prefer to simplify matters for some prepaid subscribers by denominating the value of a prepaid SOV and the spending power thereof in units of 'minutes', data megabytes available for use, or the number of SMS text messages rather than a notional currency value even though the minutes/SMSs were probably purchased using a notional currency.
} 
would be indicative of the money being a deposit rather than e-money, which would require the scheme to be regulated under a different and stricter prudential banking regime.

\subsection{Issued on a Receipt of Funds}

The 'funds' appellation and nexus to 'money', it appears, relates to fiat funds, but as shown earlier, these funds (as the 'money') may not be 'money'. For example, receipt of funds as a SVP 'currency' that is not in the UOA of the national currency may frustrate the definition. The fact that the e-money is (or must be) redeemable for cash does not matter, since there is no indication that the redeemability (into fiat cash) needs to be at par with the value related to the 'receipt of funds'.

\subsubsection{7 'Generally'}

'Generally' may be interpreted as either widely available in the market sense, or widely accepted in the geographical sense, or a combination of the two. The former would relate to a large number of merchants accepting the e-money as a consideration for purchase of their goods and services, while the latter may mean that the consideration is accepted throughout the country rather than in specific geographical areas. Because it relates to a financial instrument where technical parameters are first required to be available before the consideration can be accepted, 'generally' should not be given a literal meaning, but instead a contextual meaning that is relative to the industries the payment mechanism serves. Thus, in the context of merchants that have the facility available for accepting e-money or its variants, the consideration may be widely accepted by them.

\subsubsection{8 'Accepted as Means of Payment (by Persons other than the Issuer)'}

This clause is arguably the siren mechanism for determining if e-money is at play. As with the EMD1 and to some extent, the EMD2, ${ }^{326}$ it can be surmised that if a reseller-type arrangement is proven in an e-money type transaction, then other undertakings would not be accepting of the value. While the EMD allows emoney to be used as a new means of payment, e-money also has functional characteristics as a payment instrument. This means that it can also depict the type of monetary claim transferred for making a payment in the form of coins or banknotes or units stored on a pre-funded electronic chip card. Thus e-money, like cash, can be considered both as a payment instrument and as a means of payment.

\subsubsection{9 '(Accepted as Means of Payment) by Persons other than the Issuer'}

The clause is meant to differentiate the single purpose use from multi- or general-purpose use of e-money. The former usually prevails where the storage device is only accepted as payment by one merchant (and the issuer), for example, photocopy cards at universities, prepaid phone cards, ski passes, toll tokens, rather than a plethora of merchants. The single-purpose nature of a scheme is usually a dogmatic indication that it

\footnotetext{
${ }^{326}$ This reasoning was applied to exempting MNOs from the provisions of the EMD1. EMD 1 op cit note 1.
} 
is 'not accepted by undertaking other than the issuer'. However, the lines may blur between single and multi-purpose, particularly if the 'single-purpose' schemes suddenly metamorphose into single-purposeplus-one schemes, it becomes increasingly difficult simply to equate single-purpose with an automatic exclusion from the SARB guidelines.

\subsection{0 'Is Redeemable' (for Physical Cash or a Deposit into a Bank Account on Demand)'}

A bank, as the holder of an e-money deposit, must, on demand, redeem the electronic value held on the instrument for central bank currency at par. However, the definition does not indicate a par value redemption where value redeemed could either be more or less than the value initially given to the issuer. Typically in an (ostensibly non-redeemable) MNO airtime SOV, the value could be redeemed through an airtime transfer scheme, where the recipient pays the sender - in cash or via deposit of a value in a bank account - for some or all of the value sent. While the issuer, the MNO, may initially be embarking on an airtime-based scheme that fits the e-money definition, the practical application thereof may amount to emoney. However, while redeemability is specified as a necessity for e-money, it is not certain who must do the redeemability. For example, as indicated earlier, an MFS airtime-based SOV can be used for transactions as a 'currency' for WASP-type digital purchases. The settlement - that is, the ultimate destination for the funds - amount, though, between the MNO and the WASP is usually in fiat currency, and is into the WASP's bank account.

\subsection{1 'For Physical Cash'}

As indicated below, ${ }^{327}$ the fact that the e-money is (or must be) redeemable for cash matters not, since there is no indication that the redeemability (into fiat cash) needs to be at par with the value related to the 'receipt of funds, 328

\subsection{2}

\section{'A Deposit into a Bank Account'}

As indicated below ${ }^{329}$ the fact that the e-money is (or must be) redeemable via a deposit into a bank account similarly does not mean that it needs to be at par with the value related to the 'receipt of funds'.

\subsection{3 'On Demand'}

'On demand' implies that there is liquidity to pay those who have a claim on the issuer. However, it is not certain whether it is necessarily the issuer who should provide the liquidity back to the 'claimant' as there is no 'on-par' requirement in the definition nor a direct categorical indication that the issuer necessarily

\footnotetext{
${ }^{327}$ See ch 12, s12.4.3.2.13 on the 'on demand' component of e-money.

${ }^{328}$ The SARB inadvertently ringfences the need for redeemability at par to banks only at s8 of the Paper: "A bank, as the holder of an e-money deposit, must, on demand, redeem the electronic value held on the instrument for central bank currency, at par'. This criterion is circular: if e-money as a SVP issued by a non-bank can be shown because of drafting inconsistencies to be e-money, then invoking a bank as the only entity that must/can redeem at par renders $s 8$ of the paper nugatory.

${ }^{329}$ See ch 12, s12.4.3.2.13 on the 'on demand' component of e-money.
} 
needs to be the entity redeeming the value. In that case, the scenario detailed below where the value could be redeemed through an airtime transfer scheme is possible: that is, where the recipient pays the sender - in cash or via deposit of a value in a bank account - for some or all of the value sent could ostensibly capture MNO SVAs.

\subsubsection{3}

\section{SARB Actions}

Even though a scheme may not be e-money per se from the e-money definition, the SARB may still step in to regulate hybrid schemes ${ }^{330}$ that effectively equate to e-money insofar as they may be seen to be a deposit, or breach 57 of the NPSA, or which is being used beyond the restriction on walled-garden closed loop use. ${ }^{331}$ As described earlier, this is the way it should be done (see one page earlier), ${ }^{332}$ the SARB has stepped in when it sees the SVA use as ostensibly breaching the perimeter from what could broadly be considered single use to general use. The latter, it believes, would constitute e-money. Policy considerations thus currently inform what e-money may be, not just whether it is considered a deposit in law. The modality of e-money as primarily a transactional payment service appears to be recognised by the SARB ${ }^{333}$ And as noted earlier, ${ }^{334}$ where a SVA is fiat-based in a system operated by a MNO or MFSP in conjunction with a bank, P2P transfers out of the CMA would need to conform to SARB forex rules. ${ }^{335}$

\subsection{4 \\ Conclusion: E-Money}

While the context of the SARB Position Paper on e-money indicates that e-money is only to be issued by licensed banks, the e-money definition used by the SARB does not unequivocally ring fence this institutional restriction and may provide a legal basis for challenge, if it ever came to that. The equivocation in the definition relates primarily to the fact that various components of the definition can be challenged such that the institutional 'restriction' may be bypassed or other entities captured inadvertently in the regime. The examples relating to each component of the SARB e-money definition shown earlier ${ }^{336}$ are there to emphasise the point and to in effect, demonstrate that MFS as a new business model - and thus also because of its overarching simultaneous applicability to varying facets of law and business - continues to frustrate precise legal categorisations.

\footnotetext{
330 'Hybrid' in the sense that it is ostensibly single-purpose, but may have multi-purpose features. An MNO providing a platform for the sale to its prepaid subscriber base of third party (digital) goods and services may fit such a hybrid characterisation.

${ }^{331}$ As indicated earlier at ch 12, s12.3.7.6.2 titled Application to MFS in SA, the SARB has already shut down schemes selling insurance from the airtime SOV.

332 Ibid.

${ }^{333}$ See the discussion in ch 12, s12.4.2.2 titled Issuance and Redemption on issuance of e-money and the references to nonbank participation in that process.

${ }^{334}$ See ch 12, s12.3.7.6.2 titled Application to MFS in SA.

${ }^{335}$ See ch 12, s12.3.7.5 titled Foreign Exchange Controls, on forex rules in South Africa. Further, there appears to be a policy lacuna whereby airtime value is bought and transferred directly P2P from one MNO user in South Africa to a user of its sister MNO in another country - although this is not considered e-money, according to the SARB and its various e-money Position Papers, and thus is not necessarily subject to forex rules.

${ }^{336}$ See on e-money, ch 12, s12.4.3.2 titled Application to MFS in SA.
} 
Indeed, this frustration is demonstrably very similar to the equivocation with the EMD1 when applied to WASP-type services bought with the airtime-based SOV, and which because of drafting inconsistencies, ultimately expanded the institutional perimeter of the EMD1 to - possibly inadvertently - include MNO WASP services. This drafting inconsistency ultimately led to the EMD1's demise and a new definition of e-money in the EMD2. A similar series of changes to the SARB definition of e-money from 1999 to 2009 parallels the tortuous and sometimes contrived goal of trying to match policy to technology evolution. ${ }^{337}$ The problem of course then is that there is a lack of clarity and consistency for planning and commercial purposes.

The equivocations over e-money aside, the larger picture reveals that again the SARB has limited the issuance of e-money to licensed banks despite the implicit indication that it recognises that e-money is less of a savings tool and is positioned more as a payment tool. ${ }^{338}$ Indeed, e-money paper was issued by the NPSD, not the BSD. The focus however is still on allowing only licensed banks, for whom payments are not necessarily their core business. The focus, it is submitted, is misplaced: it should be on facilitating payments and creating an enabling and proportionate regime thereto. The tight nexus created between the EMD2 and the PSD in the EU demonstrates a cogent framework to create a similar regime in South Africa where it could enhance FI. ${ }^{339}$

As noted earlier, the Competition Commission set up an enquiry ${ }^{340}$ to examine certain aspects of competition in retail banking in South Africa. The banking sector is dominated by four large banking groups with strong domestic franchises as well as smaller niche banks. The four major banks together have well over $90 \%$ of the retail market. ${ }^{341}$ This Enquiry followed two earlier reports, first the 2004 Task Group report on Competition in South African banking - also known as the Falkena III report - and the 2006 Feasibility report into competition in banking and the NPS, which also examined competition in the retail banking industry. ${ }^{342}$ Both of these, the reports said, impacted on access to competitive banking services for businesses or individual users. ${ }^{343}$

The Commission report on banking in South Africa pointed to a fundamental need for competition in the banking and payments sector. It was thought that the introduction of more entities at the Tier 2 and Tier 3 levels might provide this competition by providing savings and loans, savings, or simple payment services

\footnotetext{
${ }^{337}$ Indeed, the SARB recognises this in its 2009 Position Paper at s4: 'Although electronic payment technologies have developed significantly since the introduction of the concept of e-money in the early nineties, the regulation thereof is constantly being developed. The Bank, therefore, has been cautious not to stifle development and has always maintained a position that regulation of e-money products and schemes will be applied appropriately as innovation occurs.' SARB (2009) op cit note 195 .

338 'The Bank will continue to assess the benefits [of] new payment innovations ...'. See SARB (2009) op cit note 195 at s2.

${ }^{339}$ See again See also inter alia, Recommendation 4 in ch 14, s14.9.3 on a proposed new regulatory regime encapsulated in a PSPL.

${ }^{340}$ Inquiry in terms of s21 of the Competition Act 89 of 1998.

${ }^{341}$ Competition Commission (2008a) op cit note 16.

342 This raised concerns around access to the payments system by would-be service providers (banks and non-banks) and bank charges for payments transactions.

${ }^{343}$ See op cit note 5 on the reports.
} 
off a prepaid balance. From a payments perspective, the Enquiry revealed that small banks and those institutions that saw themselves as prospective participants in the NPS had a number of concerns such as the costs of entry to the NPS and its different streams, and once in, inadequate representation in various institutional structures and the disadvantages of being a small player in bilateral negotiations of interbank fees.

The Enquiry concluded that 'Big Four' constitute an oligopoly, inter alia, because the banking and payments industry sets high entry barriers through regulatory requirements and high associated costs, and that customers do not fully understand the cost of the products offered and because of customer 'captivity' where they have difficulty in switching providers and which leads to inelastic demand and non-competitive prices. $^{344}$

There were also 28 recommendations made by the Enquiry ${ }^{345}$ that covered the areas of penalty fees, ATM fees, access to the NPS, payment cards and interchange fees. The Enquiry recommended ${ }^{346}$ inter alia that an access regime that includes non-bank providers of payment services should be developed so as to allow for their participation, under effective regulation and supervision, in both clearing and settlement activities in appropriate low-value or retail payment streams that does not threaten the systemic stability; ${ }^{347}$ that the NPSA should be revised to allow for nonbanks to be clearing and (even) settlement participants, and hence members of PASA; and that an independent, objective and transparent regulatory process for determining interchange in the payment card and other relevant payment streams should be put into effect and enforced as soon as practicable. ${ }^{348}$

There has however been criticism that suggests that the Competition Commission was unable to force the banks to implement any of its recommendations particularly the lowering of charges on the inter-bank transfer system. ${ }^{349}$

Further, it appears that the SARB whilst taking cognisance of the need to do so in some manner is not yet ready to open up the NPS to robust non-bank participation. ${ }^{350}$

\footnotetext{
${ }^{344}$ Finmark Trust (2009) 'Finmark Brief: The Banking Enquiry 2009', available at http://goo.gl/pBQrw. Feasibility (2005) op cit note 5 .

${ }^{345}$ The full report is not officially available, although it was leaked to various online media. See M Ashton (2009) 'Bank Report Leak Exposes Tech Flaw' posted on Fin24, 8 January, available at http://goo.gl/GFSWy. A summary of the report and its recommendations was produced by Feasibility and Finmark Trust. See Feasibility (2009) 'The Banking Enquiry 2009', available at http://goo.gl/X02Ms, and Finmark Trust (2009) op cit note 325.

${ }^{346}$ Ibid.

${ }^{347}$ See ch 12, s12.3.2.1 on the South African Reserve Bank (SARB) on the various oversight roles of the SARB. Oversight of the payment system involves individual bank oversight and surveillance, monitoring, analysis, and the implementation of risk-reduction measures.

${ }^{348}$ The inquiry recommended that PASA consider the Australian payment systems model, where there is tiered membership to allow input by non-bank participants. This would give them exposure to policy and regulatory debates and contribute to a greater understanding of what takes place in the 'inner core' of the payments system. Feasibility (2005) op cit note 5.

349 See Mantshantsha (2009) op cit note 17.

${ }^{350}$ SARB (2011e) op cit note 172.
} 
South Africa, like many developing countries, may have a ready-made payment and micro-remittance system available through the use of mobile phone as payment instruments. Some $31 \%$ of the unbanked have a prepaid cell phone and a further $17 \%$ have access to the cell phone of a friend or family member. ${ }^{351}$ With this widely available access medium, a proportional e-money and payment regime that enables micropayments but which is not as onerous as existing payment legislation where applicable, may provide a solution. Overbearing regulation focused more on the traditional banking activities - that is, intermediation - may have the effect of stifling the emergence of schemes that have socio-economic benefits and is not cognisant of the fact that transactional services for payments are now a key element in the relationship between many banks and their customers. ${ }^{352}$ Indeed, the BIS says that existing payment systems may be inadequate for the emerging payment needs of an economy such that initiatives to reform some elements of a national payment system need to be undertaken. Practically this may entail the gradual emergence of a broader range of payment instruments and services as a less strident regulatory regime. The SARB indicates that it takes cognisance of social-policy imperatives such as the Financial Sector Charter to make financial services more accessible to those in the low-income, unbanked and rural communities. Despite these laudable goals and the siren calls for more progressive regulations to allow non-banks to issue emoney-type instruments to service the unbanked, there have been very few cases of e-money issuance in South Africa, even though some schemes largely resemble e-money in function, but still lack the normative characteristics such as par-value redemption. ${ }^{353}$

This impasse is demonstrated in SARB Policy Papers with respect to e-money, which the SARB continues to limit to issuance only by licensed banks despite it implicitly indicating that it recognises that e-money is less of a savings tool and positioned more as a payment tool. ${ }^{354}$ Granted there is a still a cogent need to protect the core of any national payment system and the current legislation and associated regulations that control the NPS reflect this core and the hierarchy and systemic risk. The oversight though appears to be disproportionate to the extent that the crux of the payments system - and the issuance of e-money - is limited to banks. ${ }^{355}$ This focus on limiting new payment instruments - like e-money SVPs - issuance to banks, it is submitted, is misplaced.

Non-banks, as shown in Kenya where the M-pesa MFS system revolutionised the moribund retail banking and payments ecosystem, have the capacity to fundamentally alter the FI imbalance. That said, while the (stalled) Dedicated Banks Bill in South Africa is a welcome start to addressing this need in South Africa, it

\footnotetext{
${ }^{351}$ Clyde (2008) op cit note 25. See also Finmark Trust (2007) op cit note 19 at 5.

${ }^{352}$ P Lowe (2007) 'Non-Banks in the Payments System: A Central Bank Perspective' Federal Reserve Bank of Kansas City Conference on Nonbanks in the Payments System: Innovation, Competition and Risk, Santa Fe, 2-4 May 2007, available at http://goo.gl/Z24tW.

${ }^{353}$ E-bucks.

${ }^{354}$ See s1: 'The Bank will continue to assess the benefits that new payment innovations could provide to the country as a whole'.

355 The Competition Commission report highlights that whilst most non-bank players do not appear to be interested in doing the main business of a bank, it is still possible that they could introduce risks such as fraud and inchoate technical standards into a system. It notes further that this is the crux of the issue, since simply allowing more non-banks into the system is not enhancing the quality of the system, although allowing more appropriately regulated non-banks in the system is likely to enhance the system.
} 
however, it is submitted, maintains an unnecessary focus on the 'business of banking' and the core 'deposit' motif rather than on the evolution of systems that have a fundamentally more transactional and payments foci. The regulatory and policy focus, it is thus submitted, should be on facilitating payments and creating an enabling and proportionate regime thereto, incorporating robust financial consumer protections similar to those in the PSD - and enforced by a body similar to the US's CFPB - that address the reality of widespread financial illiteracy. Fundamental safety and soundness could be addressed by the use of trust bank accounts for safe storage of user funds.

The models for achieving these goals have not only been shown to exist, but to also thrive. For example, the tight nexus created by the EC between the EMD2 and the PSD and its allowing new, non-bank institutions like FIs (ELMIs) and PI to participate proportionality and unfettered - but subject to safety and soundness criteria - in the growing transactional space is a model for a cogent framework to create a similar regime in South Africa where it could enhance FI. Further, the success of M-pesa in provision of MFS, a banking-like facility with a pure transactional focus in Kenya, in fundamentally transforming the banking and payments regime in Kenya, further amplifies the ability to parse this success with a liberated payments regime in South Africa.

12.7

\author{
Anti-Money Laundering, Terrorist Financing and Customer Due Diligence Laws and \\ Regulations $^{356}$
}

12.7.1

Introduction

South Africa has adopted the Financial Action Task Force 40+9 principles (hereafter FATF) on AntiMoney Laundering (hereafter AML) and Counter-Terrorist Financing (hereafter CTF) ${ }^{357}$ These are implemented through Financial Intelligence Centre Act 38 of 2001 (hereafter FICA), the Prevention of Organised Crime Act 121 of 1998 (hereafter POCA), ${ }^{358}$ and the Protection of Constitutional Democracy Against Terrorist and Related Activities (hereafter Terrorist Act) ${ }^{359}$ while Money Laundering is criminalised in $\mathrm{s} 4$ of POCA. ${ }^{360}$

\footnotetext{
${ }^{356}$ For an introduction to these issues, see ch 8, s8.5 earlier on Anti-Money Laundering, Terrorist Financing and Customer Due Diligence Laws and Regulations.

357 Financial action Task Force (FATF) (2009b) 'Methodology for Assessing Compliance with the FATF 40 Recommendations and the FATF 9 Special Recommendations', available at http://goo.gl/UmZIS. These recommendations have become known as the Forty Recommendations which have since been revised a number of times. For an explanation of the AML regimes as they apply to South Africa, see generally L De Koker (2008) 'Money Laundering and Terror Financing Risk Management of Low Risk Financial Products and Services in South Africa', available at http://goo.gl/cCSTQ; and in respect of remittances, Mbalekwa (2011) op cit note 22 at 117. On AML issues in South Africa generally see, J Isern and L De Koker (2009) 'AML/CFT: Strengthening Financial Inclusion and Integrity' 56 CGAP Focus Note, August, available at http://goo.gl/wxyx6; L De Koker (2002) 'Money Laundering in South Africa' ISS, available at http://goo.gl/4TXD5; L De Koker (2010) 'Will RICA's Customer Identification Data Meet Anti-Money Laundering Requirements and Facilitate the Development of Transformational Mobile Banking in South Africa? An Exploratory Note' Finmark Trust, available at http://goo.gl/dtboP; L De Koker (2009) 'The Money Laundering Risk Posed by Low-risk Financial Products in South Africa: Findings and Guidelines; 12(4) Journal of Money Laundering Control 323-339.

${ }^{358}$ FICA op cit note 1 is linked to the POCA op cit note 1, which contains the substantive money laundering offences as well as the Terrorist Act op cit note 1.

${ }^{359}$ Terrorist Act op cit note 1 .

${ }^{360}$ POCA and the Terrorist Act criminalise money laundering and terror financing while FICA requires financial service providers and certain professionals to maintain specific AML/CFT controls. See note 1 for these acts.
} 
AML also overlaps with other common law offences like fraud, forgery and uttering as well as statutory offences such as corruption, but according to De Koker, FICA overrides many of the secrecy and confidentiality obligations in South African law. ${ }^{361}$ This includes any incidentalia ${ }^{362}$ of traditional banking agreements that may be said to exist at common law between banker and client. ${ }^{363}$ No duty of secrecy or confidentiality or any other statutory or common law restriction on the disclosure of information affects any duty of an institution, person or the South African Revenue Service (hereafter SARS) to report or to allow access to information in terms of Chapter 3 Part 3 of FICA. ${ }^{364}$

However, this provision does not apply to the common law right to legal professional privilege as between an attorney and an attorney's client in respect of communications made in confidence. The SARB however sees it as important that in terms of cross-border supervisory standards, that all regulatory authorities in Africa ensure industry alignment and uniform compliance with the FAFT standards. ${ }^{365}$ The 2008 report by the FAFT on South Africa's development of AML/CFT systems described it as 'work in progress'. 366 Many of the issues FICA addresses are based on the FATF recommendations.

The FIC was established under FICA in February 2002. ${ }^{367}$ FICA's aim is to establish a Centre and a Money Laundering Advisory Council to combat money laundering activities; to impose certain duties on institutions and other persons who might be used for money laundering purposes; to amend the POCA, and the Promotion of Access to Information Act, 2000; and to provide for matters connected therewith. ${ }^{368}$

FICA $^{369}$ differentiates between ordinary businesses and so-called 'accountable institutions ${ }^{370}$ and as such the regulatory regime of the FICA imposes KYC record-keeping and reporting obligations on these accountable institutions. ${ }^{371}$ Ordinary businesses are those that are not classified as 'accountable institutions'. ${ }^{372}$ These institutions are compelled by FICA to identify and verify the identities of their

\footnotetext{
${ }^{361}$ De Koker (2002) op cit note 357 passim and on a discussion of $S v$ Dustigar (Case no CC6/2000 (Durban and Coast Local Division) unreported) and $S v$ Caswell (Case no 27/87/98 (Regional Court, Cape Town) unreported, in which seven persons were convicted as accessories after the fact on the strength of their involvement in the laundering of the proceeds of an armed robbery. An eighth accused was convicted on a count of statutory laundering under the POCA. They allowed the abuse of their bank accounts to launder the money and also allowed new accounts to be opened and fixed deposits to be made in their names to launder the money.

${ }^{362}$ See ch 7, s7.2.4 titled Terms of the Contract.

${ }^{363}$ See ch 4, s4.5 titled The Banker-Customer Relationship.

${ }^{364}$ On reporting duties and access to information. See s37(1) of FICA op cit note 1.

365 South Africa contributes to this objective through its participation in the East and Southern African Anti-Money Laundering Group (ESAAMLG) and the Committee of Central Bank Governors (CCBG). See South African Reserve Bank (SARB) (2006a) 'Bank Supervision Department Annual Report 2006: Chapter 2: Current Issues in Banking Supervision', available at http://bit.ly/cOfw2T.

${ }^{366}$ Financial action Task Force (FATF) (2009a) 'Eastern and Southern Africa Anti-Money Laundering Group Mutual Evaluation Report - February 2009', available at http://goo.gl/b9j2L.

${ }^{367}$ Financial Intelligence Centre (FIC) (2001) 'About Us', available at http://goo.gl/1IyAO.

${ }^{368}$ Preamble to FICA op cit note 1

${ }^{369}$ FICA op cit note 1.

${ }^{370}$ Schedule 1 of FICA lists accountable institutions as being inter alia: a financial instrument trader; a person who carries on the 'business of a bank' as defined in the Banks Act; a Mutual Bank per the Mutual Banks Act; a person who carries on a business in respect of which a gambling licence is required to be issued by a provincial licensing authority; a person who carries on the business of dealing in forex; a person who issues, sells or redeems travellers' cheques, money orders or similar instruments; and a person who carries on the business of a money remitter. See note 1 for these acts.

${ }^{371}$ On low risk, see De Koker (2009) op cit note 357 at 323.

372 Section 22 of FICA. It also requires accountable institutions to develop and implement internal rules to facilitate compliance with these obligations. See also De Koker (2008) op cit note 357 at 12 fn 27.
} 
customers, to keep specific records, to report suspicious and other transactions, to train their employees on compliance with the FICA duties and to appoint a compliance officer.

Section 21(1) of FICA ${ }^{373}$ provides that an accountable institution may not establish a business relationship or conclude a single transaction with a customer unless the accountable institution has taken the prescribed steps to, among others, establish and verify the identity of the customer. ${ }^{374}$ Section 22 says the accountable institutions must keep records of the identity of the customer, which includes a record or copy of the documents which the institution had used to verify a person's identity. FICA does not clearly state that a copy of the ID must be made by an accountable institution, but the FIC and OBSSA have said that the most prudent and practical manner to comply with this obligation would be to make and keep a copy of the ID of the client. $^{375}$

Insofar as the FICA KYC requirements for accountable institutions to capture and keep proof of identity and a document showing proof of a residential address may have been too onerous for those in informal settlements or for migrant workers who did not have fixed addresses, the SARB issued additional guidance which relaxed to some extent the requirements. ${ }^{376}$ Aimed primarily at relaxing the requirements for users to adopt the low-cost entry-level national banking product, Mzansi, ${ }^{377}$ the Minister of Finance issued an (expanded) so-called Exemption 17 notice, which revised the AML regulations so as to allow banks to open accounts, subject to balance and transaction limits and only with presentation of only a South African national identity document. ${ }^{378}$ As a consequence, the percentage of banked adults in South Africa increased from $46 \%$ in 2004 to $63 \%$ in $2008 .^{379}$

In relation to Money Laundering (hereafter ML), FICA criminalises this act, which it defines as:

'an activity which has or is likely to have the effect of concealing or disguising the nature, source, location, disposition or movement of the proceeds of unlawful activities or any interest which anyone

\footnotetext{
${ }^{373}$ FICA op cit note 1

${ }^{374}$ The term 'prescribed steps' refers to the procedure for establishing and verifying the identity of a customer which is prescribed in the Money Laundering and Terrorist Financing Control Regulations. Overall the purpose is to ensure that a transaction, or a series of transactions, can be reconstructed to indicate what had transpired and who was involved. See Ombudsman for Banking Services in South Africa and the Financial Intelligence Centre (2009) 'Joint Statement: Clarification on the Obligations of Accountable Institutions on Verifying Client Identities, and Record Keeping Johannesburg, 09 July, 2009', available at http://goo.gl/g0lqD. See also on customer identification procedures, Financial Intelligence Centre (FIC) (2005) 'Guidance Note 3: Guidance for Banks on Customer Identification and Verification and Related Matters', available at http://goo.gl/yZ1jk.

${ }^{375}$ The FIC and the OBSSA indicate that when the record-keeping requirement is read in conjunction with the requirement to establish and verify the identity of a customer, they believe that the use of an ID forms part of the procedure of identifying a customer and thus forms part of the record of the customer's identity to be kept by the institution. CGAP note that this clarification and a 2008 amendment to the FICA giving the FIC the right to levy personal penalties on bank compliance officers for violations of AML/CFT rules, means that some bank officers are erring on the side of safety and following a conservative approach of photocopying documents. This then makes field operations, where a photocopying machine or electricity may not be available, very difficult. See CGAP (2010c) op cit note 25; and De Koker (2010) op cit note 357.

376 The extension to Exemption 17 details are published in Government Gazette No 27011, 19 November 2004. The initial Exemption 17 issued in 2003 was deemed insufficient to cater for a variety of circumstances as inter alia it did not exempt account products with typical debit card functionality because such cards could be used for effectuating transactions in foreign countries, individual accounts that were 'dormant' for 180 days, or certain second-order financial products. See Isern and De Koker op cit note 357; De Koker (2009) op cit note 357 at 331; and CGAP (2010c) op cit note 25 passim.

${ }^{377}$ Isern and De Koker (2009) op cit note 357; and CGAP (2010c) op cit note 25 passim.

378 Ibid

${ }^{379}$ Ibid
} 
has in such proceeds, and includes any activity which constitutes an offence in terms of Section 64 of this Act or Section 4, 5 or 6 of the Prevention Act ...'

The ability to do P2P remittances using either the airtime or fiat-based mobile SOV is also impacted by long-standing forex controls discussed earlier. ${ }^{380}$

\subsection{2}

\section{Comparative Application to MFS in Other Jurisdictions}

In the EU, ${ }^{381}$ the EU Payments Regulation with its incorporation of the FATF Recommendations on wire transfers, effectively projected financial surveillance into the official/formal money transfer business sector. There are also provisions in the PSD where and agents of PSPs will have to abide by AML Directives. In the UK, for example, there are a number of what are termed Money Service Businesses that may engage in Money Transfer, whose regulation is fragmented as responsibilities are split between Her Majesty's Revenue and Customs and the FSA. Notably though, the Regulation on information on the payor accompanying transfers of funds does not apply to transfers of funds carried out via a mobile phone or any other digital device or linked to IT, when the payments are post-paid and insofar as the payment service provider must comply with obligations in the third Money Laundering Directive.

In the US, ${ }^{382}$ the ability of MFS to be used in AML and TF has been raised a number of times and it has also been suggested that new legislation is needed to regulate m-payment service providers that could include requirements that service providers monitor accounts, enhance suspicious activity reporting, require maximum transaction limits, require the registration of prepay cell phones with m-payment, and the development of new, m-payment specific software to detect suspicious activity. At a Federal level, incarnations like prepaid cards and SVC may be impacted by federal AML schemes such as the Uniting and Strengthening America by Providing Appropriate Tools Required to Intercept and Obstruct Terrorism Act (hereafter the PATRIOT Act). It is not clear whether the BSA's reference to 'funds' and 'money' means value in the form of airtime or even airmiles as falling within the statute, nor is it clear whether 'telegraph' is a catch-all phrase that can seamlessly be applied to MNOs. However, there is further clarification provided in relation to designation of other businesses by the Secretary that may be captured by the BSA.

It appears then that an MNO which sends the 'value of the currency or funds' in the form of an equivalent amount of minutes paid for that monetary value may be captured by the definition as requiring reporting to FinCEN, but then only if it is transmitted through a financial agency or institution or an (undefined) electronic funds transfer system. Unlike the transfer of abstract 'value' equivalent of currency as captured by the definition of a money transmitter, an MNO transferring monetary value from an account with monetary value (and not minutes) in terms of this section would be captured by this section for the

\footnotetext{
${ }^{380}$ See ch 12, s12.3.7.5 titled Foreign Exchange Controls.

${ }^{381}$ See on the EU, ch 9, s9.10 titled Anti-Money Laundering, Terrorist Financing and Customer Due Diligence Laws and Regulations.

${ }^{382}$ See on the US, ch 11, s11.3 titled Anti-Money Laundering, Terrorist Financing and Customer Due Diligence Laws and Regulations.
} 
purposes of the Federal AML regime as a money transmitter, even though the MNO is not registered at a state-level as an MSB. Where the funds held by the MNO are in a pooled account in an FDIC-insured financial institution before transfer, then a bank pooling funds for an MNO-based wallet pooling system would also have to do a periodic due diligence of the MNO to check whether the MNO or any other similar entity it is powering/enabling via this funds pool is engaged in money transmission business as defined by Federal statute.

MFS providers like Obopay or PayPal that act as financial intermediaries between subscribers using a mobile phone for transfer may also be captured by the AML regime. A MNO or payment intermediary accepting or selling funds could be captured as being a 'seller or redeemer of traveller's checks, money orders, or stored value' if they sell or redeem such checks or money orders or stored value in an amount greater than US $\$ 1,000$ in currency or monetary or other instruments with any person on any day in one or more transactions. At a Federal level, anyone doing money transfer would necessarily be classified as a MSB under federal AML laws even if the transfer was (pre)funded from a system not captured under the definition of a SVC. An entity need not be registered at a state-level as an MSB to be captured under Federal AML regimes.

Even so, it is not clear whether the value received by the sending MNO would be captured, since it is only the accepting MNO (if in an inter-MNO system) party that can claim a putative exemption for only receiving currency and not the (equivalent) 'value of the currency or funds'. However, policy considerations would mean that this scenario is probably moot, since the Secretary could (and probably would) simply issue new regulations if it felt that m-payments were causing a leak in AML efficacy - even if specie is not used. The ability to do so is mandated in the BSA as well as the enabling Regulations.

In Kenya, the omnibus AML law is The Proceeds of Crime and Anti-Money Laundering Act $^{383}$ which provides mechanisms for detecting and seizing the proceeds of money laundering. Section 45(1) of the Act mandates new KYC requirements in that a reporting institution must take reasonable measures to satisfy itself as to the true identity of any applicant seeking to enter into a business relationship with it or to carry out a transaction or series of transactions with it, by requiring the applicant to produce an official record reasonably capable of establishing the true identity of the applicant. This may include a birth certificate; a national identity card; a driver's license; a passport; or any other official means of identification as may be prescribed. The Registration of Persons Act, CAP 107, requires Kenyan citizens 18 years old and earlier to register with the National Registration Bureau and be issued with a national identity card.

The CBK also issued Agent guidelines ${ }^{384}$ with new criteria for adherence to the AML/KYC law and which specify agent and customer due diligence, KYC and CTF policies and procedures and which includes Agent Due Diligence (hereafter ADD) procedures. The AML/CTF law applies directly to the MFS players and it is up to the MFSP to ensure that their agents apply the AML/CTF law. There are also transactional

\footnotetext{
${ }^{383}$ Proceeds of Crime and Anti-Money Laundering Act 9 of 2009. See further on Kenya, ch 10, s10.3 titled Anti-Money Laundering, Terrorist Financing and Customer Due Diligence Laws and Regulations.

${ }^{384}$ Central Bank of Kenya (2010) ‘CBK/PG/15: Guidelines on Agent Banking', available at http://goo.gl/cs41
} 
limits commensurate with customer's profile. Agents must also report to the institution within twenty-four hours, all suspicious activities that come to the agent's knowledge and not exceed any mandated transactional limits.

\subsection{3}

\section{Application to MFS in South Africa}

The SARB relaxed applicable KYC criteria for MFS with the issuance of Guidance Note 6 in $2008^{385}$ that offered a proportionate risk-based approach to new technologies and channels. The Note allowed banks to open mobile-banking based accounts without having to undertake the face-to-face procedures ordinarily required under Exemption 17. Instead the SARB simply mandated 'account-opening procedure [that] must include adequate steps to verify the identity of the client, including cross-referencing the prospective clients particulars with third-party databases which include information on the names and identity numbers of persons sourced from the Department of Home Affairs such that the ID number is valid and that the prospective client does not appear on a database relating to fraud convictions. ${ }^{386}$

The non face-to-face process would only apply for low-value transactions and debits from accounts which must be to ZAR1,000 per day. ${ }^{387}$ If a client's identity was confirmed through a non face-to-face process and the client wishes to exceed the limit of ZAR1,000 per day, a face-to-face confirmation of the clients' identity would be carried out in accordance with the provisions of Exemption 17. If a client wishes to exceed the limits provided for in Exemption 17, the normal verification process will be applied in relation to all the identity particulars of that client as provided for FICA and the Money Laundering Control Regulations. ${ }^{388}$ De Koker ${ }^{389}$ describes instances where criminals used various methods to open or access the Exemption 17 bank accounts, for example, in the use of so-called ML ghost owners ${ }^{390}$ and mules. ${ }^{391}$ There are however tensions between the Customer Identity Verification (hereafter CIV) processes in FICA and those required for the registration of all mobile users in South Africa, the so-called 'RICA' process in terms of the RICA law. ${ }^{392}$

In relation to the applicability of FICA and POCA to MFS directly, this raises some important issues. FICA refers to 'money' throughout, and requires at $\mathrm{s} 31$ in respect of what it terms 'electronic transfers of money' to or from the Republic, that if an accountable institution through electronic transfer sends or receives

\footnotetext{
385 South African Reserve Bank (SARB) (2008a) 'Guidance Note 6/2008 Issued in Terms of Section 6(5) of the Act 94 of 1990 op cit note 1: Cell-Phone Banking', available at http://goo.gl/qPZzp.

${ }^{386}$ Ibid at ch 2, s2.4 titled Services Available In MFS.

${ }^{387}$ See ch 2, ss 2.5 titled Structure and Participants in MFS Schemes; and 2.6 titled Comparisons with other Systems and Internet E-Commerce.

${ }^{388}$ In addition to the verification process in the account-opening procedure, these accounts must include control measures to prevent a person from opening more than one such account, say by refusal to open subsequent accounts where a particular ID number is already associated with an existing account. A bank must also apply enhanced measures to scrutinise the transaction activity in relation to such an account for the reporting thereof. SARB (2008a) op cit note 384 at s2.3-2.3.

${ }^{389}$ CGAP (2010c) op cit note 25 passim.

${ }^{389}$ Isern and De Koker (2009) op cit note 357 passim; De Koker (2009) op cit note 357 at 331.

${ }^{390}$ In this instance criminals used false identity documents to open accounts in the name of non-existent persons.

${ }^{391}$ Mules are third parties who wittingly or unwittingly allow the use of their accounts by others. This may even take place via coercion. See De Koker (2009) op cit note 357 at 331 reports on an instance where an agent of a bank opened a large number of accounts in the names of persons with whom he was acquainted. He obtained their personal details and opened the accounts without their knowledge or permission.

${ }^{392}$ Colloquially, the process of having registered or registering a SIM card under RICA op cit note 1 is known as 'having 'RICA'd a SIM card' or 'RICA'ing a SIM card.' This is described and compared in ch 12, s12.8.4.2.
} 
money in excess of a prescribed threshold, or on the instruction, of another person, it must, report the transfer to the FIC. Section 56 makes it an offence for an accountable institution to not report this to the FIC. ${ }^{393}$ There are separate reporting requirements for cash. ${ }^{394}$ The crisp issue raised here is that this does not strictly capture the growing airtime transfer (donation) market - formal and informal, national and cross-border - insofar as the airtime-based SOV, as discussed earlier, is not necessarily 'money' and hence falls out the scope of FICA in regard to electronic (fund) transfers.

The issue is better addressed though in POCA which at $\mathrm{s} 2$ defines the receipt of illegal property to be an illegal act. Section 1(xvi) defines 'property' as 'money or any other movable, immovable, corporeal or incorporeal thing and includes any rights, privileges, claims and securities and any interest therein and all proceeds thereto'. This 'incorporeal thing' catchall remedies the use of 'money' in the definition of property, such that this would include airtime-based SOVs. FICA may have to be altered to similarly reflect airtime value as an incorporeal thing that is subject to that Act.

The restricted forex regime has three essential consequences for MFS. ${ }^{395}$ Firstly, on cost as the compliance costs of reporting are passed onto consumers; second, there is a lack of competition in the provision of services as only certain entities are allowed to provide forex services; and third, that there is no capability allowed for branchless provision of these services, at least for fiat-based SVAs. While the SARB investigates allowing certain airtime transfer schemes to operate across borders within the CMA, ${ }^{396}$ in reality, however, entrepreneurs and the malevolents alike have already seized the gap, and transfer airtime voucher numbers and thus their value to neighbouring countries, or, where pan-African MNOs operate they use the same airtime recharging scheme simply by inserting the voucher numbers in plain SMS messages.

\subsection{4}

\section{Conclusion: AML Laws}

While its potential for cost reduction and FI is noted and encouraged, the use of MFS has also been seen as providing an increased risk factor for ML, TF and fraud. MFS has been tagged as being vulnerable to AML and $\mathrm{TF}$ and as such, has in some cases been curtailed in use by limits on daily transfers, the value of transfers and on maximum SVA balances. Most countries base their AML, KYC and CTF laws and regulations on the FATF recommendations, implementing them to varying degrees in their municipal versions. South Africa's implementation is very sporadic and provisions in all these regulations provide for increased data collection, but do not automatically fully 'prevent' terrorists and other criminals from having access to payment systems for moving their funds. Instead, these regulations only serve to establish an audit trail that may be followed once a suspected terrorist or terrorist organisation has been identified. A

\footnotetext{
${ }^{393}$ See also in relation to policy frameworks around remittances, Bester, Hougaard and Chamberlain (2010) op cit note 21 passim.

394 'Cash' is defined as coin and paper money of the Republic or of another country that is designated as legal tender and that circulates as, and is customarily used and accepted as, a medium of exchange in the country of issue.

${ }^{395}$ Some have been identified by CGAP (2010c) op cit note 25 at 13.

${ }^{396}$ See thereto, ch 12, 12.3.7.6.2 titled Application to MFS in South Africa, in relation to the more exotic uses of the airtimebased SOV.
} 
concern is that so-called low-value, high frequency transfers - or 'digital smurfing ${ }^{397}$ - represents a ML threat.

South Africa's Exemption 17 is a welcome enabler of FI. The double-requirements for a RICA and FICAbased registration scheme however may hinder this, especially since the respective CIV procedures are not being aligned. This will require the respective regulatory bodies to coordinate their AML/CT procedures. Any AML laws sounding in money may need to be refined to include value that may not necessarily amount to money, for example, airtime minutes and airmiles, because FICA sounds primarily in money, which may not capture potentially 'non-money' airtime SOVs being transferred nationally and crossborder.

PART II. Additional Statutory Oversight Related To MFS

\section{Overview}

12.8.2

\section{Laws and Regulations}

MFS providers are subject to both hard and soft telecommunications-related regulations. MNOs in South Africa are directly licensed through provisions of the Electronic Communications Act of 2005 (hereafter ECA). ${ }^{398}$ The ECA recognises individual and class licenses, depending on the services provided. This Class scheme is designed, at best, to recognise that the boundaries between telecommunication and broadcasting technologies, for example, is increasingly blurred insofar as a telecommunications provider can through technologies like Digital Video Broadcast - Handheld (hereafter DVB-H) ${ }^{399}$ or Third Generation Mobile Network-based (hereafter 3G) video streaming, also provide a similar broadcasting service. This multifaceted capability is called 'convergence'. The ability though of a telecommunications provider to

\footnotetext{
397 See J Forbes (2007) 'The Convergence of Telecom and Financial Services and its Effects on AML/CFT Wire Remittance Operations', available at http://goo.gl/m4Wdm. For an overview of the range of legislation the 'smurfs' seek to overcome, see RM Bortner (1996) 'Cyberlaundering: Anonymous Digital Cash and Money Laundering', available at http://goo.gl/srveR. 398 ECA op cit note 1. ICASA and the Department of Communication had provided a limited number of individual licenses. The ECA came into effect in July 2006 and repealed the Telecommunications Act 103 of 1996 and the Independent Broadcasting Authority Act 153 of 1993. All licenses issued under the old acts were converted after application to licenses under the ECA. ICASA has issued regulations pursuant to the Act that lay down standard terms of and conditions for licenses - see goo.gl/NCU07. ICASA and the Department of Communication had provided a limited number of individual licenses. In Altech Autopage Cellular (Pty) Ltd v Chairperson of the Council of the Independent Communications Authority of South Africa and Others (20002/08) [2008] ZAGPHC 268 (29 August 2008), the court finally provided clarity for the ongoing confusion as to whether Value Added Network Service (hereafter VANS) license holders may 'self-provide' their own facilities, that is, not being forced to use the facilities of established individual licenses to carry their data and voice traffic. The court held that VANS license holders be provided with individual electronic communications service licenses and individual electronic communications network service licenses and as such could self-provide the data facilities underlying their networks and provide value added services on these services. The exercise of this right will be subject to frequency licensing or lawful use of 'unlicensed' spectrum. Where a licensee wishes to self-provide fixed links this will need to be done within the existing framework inherited from the Telecommunications Act. See D Cull (2008) 'Note on the Altech Judgment', available at http://goo.gl/aOZEe.

399 Digital Video Broadcast-Handheld (DVB-H) is the specification for bringing broadcast services to battery-powered handheld receivers. See the official Mobile TV website available at http://www.dvb-h.org.
} 
provide financial services does not appear to be explicitly catered for, but neither is it implicitly or explicitly excluded from the ostensible bouquets of services a license holder may partake in. ${ }^{400}$

\subsection{3}

\section{Regulators}

\subsubsection{ICASA}

In order to provide telecommunications and broadcasting services in South Africa, an individual or class license must be obtained from the telecommunications regulator ICASA. ${ }^{401}$ Individual licenses are required in respect of services that have a significant impact on socio-economic development such as national or regional telecommunications and broadcasting providers and can only be provided after a call by ICASA for applications. ${ }^{402}$ Class licenses are provided to services and do not have a significant impact on socioeconomic development, and authorisation is usually provided after registration with ICASA. ${ }^{403}$ Within these types of licenses, but usually more at the class level, there may be licenses for electronic communications network services; or broadcasting services; and an electronic communications service license. ${ }^{404}$

Section 2(n) of the ECA mandates ICASA to, among other things, promote the interests of consumers with regard to the price, quality and variety of electronic communications services. Section 69 of the ECA mandates ICASA to prescribe regulations dealing with a Code of Conduct for licensees as well as the enduser and Subscriber Service Charter, the latter dealing with the quality of service issues. ${ }^{405}$ All licensees must clearly communicate billing processes to consumers, end-users or subscribers as well as minimum standards via a Code of Conduct.

\subsubsection{2}

\section{WASPA}

Mobile operators, service providers and WASPs are to a large measure subject to robust self-regulation measures insofar as the prepaid airtime SOV is used for WASP-type MFS under the auspices of the Wireless Application Service Providers' Association (hereafter WASPA). ${ }^{406}$

\footnotetext{
${ }^{400}$ Class licenses are required in respect of services which ICASA considers do not have a significant impact on socioeconomic development. Persons providing services requiring class license authorisation need only register with ICASA, in the prescribed manner, in respect of those services.

${ }^{401}$ See s5(1) of the ECA op cit note 1. ICASA has a limited discretion to exempt certain services from the ECA's licensing requirements.

${ }^{402}$ M Tshesane (2007) 'The Electronic Communications Act: An Overview', available at http://goo.gl/2c4QB.

${ }^{403}$ These individual licenses would make use of voice telephony using numbers from the national numbering plan specified by ICASA, as well as the frequency spectrum allocated to then by ICASA.

${ }^{404}$ See s5(2) of the ECA op cit note 1 . There may be, for example, class electronic communications service (CECS) and class electronic communications networks service (CECNS) licences.

${ }^{405}$ As prescribed by ICASA in Notice 1740 of 2007 published in Government Gazette No 30553, 7 December 2007; see Notice 272 of 2008 published in Government Gazette No 30792, 25 February 2008, available at http://goo.gl/6nvXe.

406 See further on WASPA, ch 6, s6.5.4.2.4 titled Dispute Resolution. See the official website of WASPA at www.waspa.org.za.
} 
In the $\mathrm{EU},{ }^{407}$ the regulatory framework on electronic communications consists of seven Directives and related documents in connection with ICT regulation and is bracketed by the 'Framework Directive' which forms part of the Telecommunications Package designed to recast the existing regulatory framework for telecommunications so as to allow for a flexible regulatory framework capable of responding to new technologies, convergence, and an increasingly competitive market. Recital 10 of the Directive on a common regulatory framework for electronic communications networks and services relates to 'Information Society Services' (hereafter ISS) which would cover a range of MNO services, including MFS-type services. PRS clearly qualify as ISS since there is no specific legislation as yet at EU level relating to PRS. Jurisdiction would be applicable from National Regulatory Authorities (hereafter NRAs) and/or associated co-regulatory or self-regulatory bodies. As far as fiat-based MFS services are concerned, the bearer component of the MFS certainly would be subject to the Directive although it is uncertain which would have overriding jurisdiction: the financial or the telecommunications-based Directives. As with other jurisdictions, unless it is explicitly stated, there will probably be concurrent jurisdiction, setting the stage for elements of regulatory arbitrage. However it is left to individual member states to implement. In the UK, for example, the telecommunications regulator is the Office of Communications (hereafter Ofcom), while in respect of value added and premium rated services, the co-regulatory body is PhonePayPlus.

In the US, ${ }^{408}$ some telecommunication-related laws may apply to MFS, for example, state anti-cramming statutes. There are however some statutory protections that apply in California for unauthorised charges on a phone bill, including a cell phone bill, but only for unauthorised charges and not for disputes about the delivery or quality of goods or services. While there are state consumer laws that oversee certain aspects of consumer protection, if the protection would when be subject at some level to the Consumer Clause of the US Constitution and other Federal Acts, this would mean that the entity offering the product is subject only to Federal law. In those circumstances there may be lacunae in the regulation where there is no Federal law to explicitly cover that product. Insofar as there is no explicit payment/prudential regime, one thinks therefore of state laws around Terms and Conditions (hereafter T\&C) in prepaid wireless cards. The FCC's Truth In Billing (hereafter TIB) may apply here, although it is not clear how a prepaid customer who does not receive a bill would be captured by the statute. Although no Federal law directly regulates stored value cards except payroll cards, the Federal Trade Commission Act (hereafter FTCA) prohibits unfair and deceptive practices, regardless of the type of payment device involved.

In Kenya, ${ }^{409}$ anyone providing MFS services must obtain a license from the Communications Commission of Kenya (hereafter CCK). Telecommunications regulations require that a MNO offer only those

\footnotetext{
${ }^{407}$ See on the EU, ch 9, s9.11 titled Telecommunications Laws and Regulations.

${ }^{408}$ See on the US, ch 11, s11.4 titled Telecommunications Laws and Regulations.

${ }^{409}$ See on Kenya, ch 11, s10.4 titled Telecommunications-related Laws and Regulations.
} 
telecommunication services listed in its license. MFS ostensibly falls under the definition of 'content' and must thus be listed in the license agreement. This listing of services in the MNO license is the most the CCK requires from MNOs engaging in MFS. The primary regulator with respect to a MNO's MFS activities is however still the CBK. When the CCK receives an application for a Content Service Provider license that involves MFS, they inform CBK as a courtesy. However, where the CCK regulations may impact MFS is on the data-protection aspects of the MNO activities.

\subsubsection{2}

\section{Application to MFS in South Africa}

The telecommunications regulator is largely responsible for the telecommunications component of a MNO's services, although the type of service delivered by the MNO may come under scrutiny if it impacts on the quality of service provided by the MNO and the number ranges - for example PSMS shortcodes used for provision of services. ICASA's jurisdiction over consumer matters may clash with the overarching consumer protection legislation in South Africa, the CPA, leading to regulatory arbitrage. ${ }^{410}$ ICASA was also responsible for ensuring that all mobile subscribers in South Africa were registered through the socalled 'RICA' CIV process by 30 June 2011. Those who were not 'RICA'd' by the cut-off date could not access an MNO or any other services including MFS. ${ }^{411}$ Further, the airtime SVA would be inaccessible until that Subscriber Identity Module (hereafter SIM) card was 'RICA'd' which may impact provisions of the CPA on ownership of the airtime SOV.

The FICA and RICA CIV processes meet via MFS. There are continuing concerns though that RICA - and by association, FICA - while ensuring possibly more secure mobile communication facilities, may however harm efforts relating to Financial Inclusion in cutting off access to the mobile networks. The RICA process especially has been criticised since it can be circumvented relatively easily. ${ }^{412}$ Further, both RICA and FICA procedures are based on official South African ID books and similar documents, both of which have been massively compromised by corruption and fraud in their efficacy to provide a true reflection of the

\footnotetext{
${ }^{410}$ See below ch 12, s12.10 titled Consumer Protection Laws; and specifically ch 12, s12.10.2.2.7 titled Jurisdictional Issues between the NCC and Other Regulatory Bodies.

${ }^{411}$ The RICA process was undertaken in terms of s40 of RICA op cit note1, which came into operation on 1 July 2009. It mandated that no SIM card could be used unless it had been 'RICA'd' in terms of RICA. Section 40 sets out the process to be followed and the information to be provided to the MNOs. Section 51(3A) of the RICA criminalises non-compliance with s40. In terms of s51(3B) a person who fails to comply with s40(5) is guilty of an offence and is liable on conviction to a fine (not exceeding ZAR60,000) or to imprisonment for a period not exceeding 12 months. The Department of Communications reported that at the cut-off date, MNO Cell $\mathrm{C}$ had $99 \%$ of their post-paid and $97 \%$ of their prepaid subscribers registered, MTN had $99,5 \%$ of post-paid and $97 \%$ of prepaid subscribers registered and Vodacom had 98,98\% of post-paid and 95,12\% of prepaid subscribers registered. See Department Of Communications (2011) 'Post RICA Campaign Media Briefing', available at http://goo.gl/OghGB.

${ }^{412}$ SIM card resellers exploited an effective loophole in the RICA process which allowed up to 100 SIM cards to be registered to one person, the rationale for this being that users may have multiple mobile devices requiring a SIM card. These resellers sold the SIM cards registered under their names and under the names of other accomplices at a premium to those who did not wish to be identified via RICA, an apparent contravention of s40(5) of the RICA. See Department of Communications (2011) op cit note 389. Further, the ability to almost effortlessly use forged documentation to evade detection is manifest. It simply requires a false ID for the SIM card registration, which is often relatively simple to get in some countries. According to the South African Fraud Prevention Services (SAFPS), impersonation and ID theft are 'a huge problem' and the South African ID document is notoriously easy to forge. See IOL (2008) 'Fake ID Crooks Hoodwink Landlord', available at http://goo.gl/VMYCc; and crime organisations in Bulgaria for example have found ways to beat the SIM registration system introduced at the beginning of 2010 by using false IDs. This is a worldwide issue: see also S Echo (2010) 'Bulgarian Criminals "Beating the System” of Pre-paid SIM Card Registration', available at http://goo.gl/Ojflb.
} 
identity of the holder. ${ }^{413}$ There are also some differences - some would say misalignments - between the FICA process outlined earlier for the registration of users of standard banking products and Exemption 17 products and the RICA process for registration of all mobile users. ${ }^{414}$ De Koker indicates for example in relation to CDD, the two differ in relation to processes for the storing of customer CIV data as well as the quality of such data, particularly in relation to addresses and the type of identifying documents each process requires. ${ }^{415}$ He notes though that while the RICA data is useful in respect of the SARB Guidance 6/2008 on MFS, a bank that wishes to utilise the RICA processes and data remains accountable for the FICA processes and will need to ensure that the CIV processes are sufficiently robust. ${ }^{416}$

\subsubsection{Conclusion: Telecommunications}

MFS is a chimerical service offering which tests the perimeters of the functional versus institutional regulatory approach described earlier ${ }^{417}$ by invoking a number of regulators, agencies, laws and regulations who may - inadvertently or not - have simultaneous and conflicting jurisdiction and applicability. This includes telecommunications regulators who may have simultaneous oversight over MFS, resulting in a potpourri of incompatible laws and regulations, which could be exacerbated by posturing by each agency in 'protecting its turf'. The conflicting criteria for FICA and RICA in relation to MFS reflect this. This is largely a policy and government matter, where the regulators and policy need to coordinate to prevent arbitrage and unnecessary regulation.

\section{Introduction}

Transactions conducted electronically are governed by the Electronic Communications and Transactions Act (hereafter ECTA) ${ }^{418}$ The ECTA attempts, like many similar laws in other national and international jurisdictions, to give effect to many common law contractual provisions to the extent that this promotes transacting with modern technologies. ${ }^{419}$ The overall aim of the ECTA is to remove barriers to, and to promote legal certainty, stability and confidence in, electronic communications and transactions, by promoting technology neutrality in the application of legislation to these transactions.

\footnotetext{
${ }^{413}$ De Koker (2010) op cit note 357 at 17. See also South African Press Association (SAPA) (2010) 'ID Book Designer "Stupid"' posted on News24.com, 23 February, available at http://goo.gl/s2Tyj, in relation to comments on the official ID book launched pre-1994 by the Deputy Home Affairs Minister.

${ }^{414}$ De Koker (2010) op cit note 357 at 17.

${ }^{415}$ RICA allows customers to use a range of alternative official ID documents to verify names and ID numbers, while FICA requires customers to produce primarily the green bar-coded ID book. RICA processes do not capture or store information regarding the type of document that was used to verify these details such that the RICA verification process does not satisfy s22(i) of FICA, which requires that all CIV documents be stored. Further, De Koker notes that FICA requires residential addresses to be recorded and verified, whilst RICA allows a range of other addresses to be captured when a residential address is not available or when a client resides in an informal settlement.

${ }^{416}$ De Koker (2010) op cit note 357 at 16.

${ }^{417}$ See ch 8, s8.3 titled Types of Regulatory Foci.

${ }^{418}$ ECTA op cit note 1. The ECTA was the result of a process initiated by the South African Government in 1999 to establish a formal structure to define, develop, regulate and govern e-commerce in South Africa. See L Michalson (2011) 'Guide to the ECTA 2008', available at http://goo.gl/B8Cct.

${ }^{419}$ The rest of the ECTA pivots around this critical section.
} 
As enabling legislation (for recognition of electronic transactions), the ECTA provides for legal recognitions of transactions done electronically by assigning functional equivalence to paper-based methods such as writing, originality and signatures. ${ }^{420}$ The ECTA thus allowed electronic transactions to have, subject to some exclusions, ${ }^{421}$ the same legal force and effect as paper-based transactions.

Section 11 provides the legal basis, giving legal recognition to what it terms 'data messages', which it says is:

'data generated, sent, received or stored by electronic means and includes voice, where the voice is used in an automated transaction and a stored record. ${ }^{422}$

It then insists that 'information is not without legal force and effect merely on the ground that it is wholly or partly in the form of a data message'. ${ }^{423}$

While it does not define 'electronic transactions', the Act does define the term 'transaction' as being:

'a transaction of either a commercial or non-commercial nature, and includes the provision of information and e-government services. ${ }^{424}$

This $a b$ initio recognition of electronic contracts in the ECTA however does not waive the fundamental common law requirements set forth in the substantive law governing the transaction and as such still requires consideration of the legal barriers that might exist with respect to that type of transaction, as well as any additional requirements for enforceability that might be imposed by law. ${ }^{425}$ Further, the ECTA does not abrogate the common law need for the parties to still satisfy the requirements for a contract, including offer, acceptance, and the inclusion of certain minimum terms. An agreement is reached when two or more parties consent to be bound to each other by contractual obligations. The legislation simply ensures that transactions previously done on paper can now be done electronically. ${ }^{426}$

\footnotetext{
${ }^{420}$ Over 300 pieces of legislation were identified by the Department of Communications in 1999 which were not suitable to the information age as they were strictly paper-based. See Michalson (2011) op cit note 396.

${ }^{421}$ Section 4(4) read with Schedule 2 of the ECTA lists the items not capable of being reduced to electronic form for validity: An agreement for alienation of immovable property as provided for in the Act 68 of 1981 op cit note 1; An agreement for the long-term lease of immovable property in excess of 20 years as provided for in the Act 68 of 1981; The execution, retention and presentation of a will or codicil as defined in the Wills Act 7 of 1953; and the execution of a bill of exchange as defined in the Bills of Exchange Act 34 of 1964.

${ }_{422}$ It specifically includes any Internet messages and e-mail, but is wide enough also to include telefax, fax, SMS on a cell phone and instances where voice is used in conjunction with a voice recognition system on a computer. What is clearly excluded are purely voice messages, such as telephone conversations, including answering machines or voice mail services where messages are stored as voice messages.

${ }^{423}$ Section 11(1) of the ECTA op cit note 1.

${ }^{424}$ Pistorius points out that the definition is problematic since it includes non-commercial transactions, the provision of information and does not expressly exclude unilateral transactions. See T Pistorius (2008) 'The Legal Effect of Input Errors in Automated Transactions: The South African Matrix' 2 Journal of Information, Law \& Technology, available at http://goo.gl/jho0l.

${ }_{425}$ This same caveat is recognised in the CPA under different circumstances.

${ }^{426}$ TJ Smedinghoff (2002) 'The Legal Requirements for Creating Secure and Enforceable Electronic Transactions', available at http://goo.gl/LA7zl.
} 
Chapter VII of the ECTA outlines in detail a number of consumer protection measures intended to maintain a level of protection equal to that which exists for off-line contracts. For example, there are requirements for the conclusion of contracts such as the need for confirmation steps that ostensibly allow users to identify and correct handling mistakes and the acknowledgement of receipt. Service providers must also inform the consumer of different aspects of the online contract. The later CPA defers most of its consumer protection provisions relating to electronic transactions to the ECTA. ${ }^{427}$

\section{Application to MFS}

\subsubsection{Comparative Application to MFS in Other Jurisdictions}

In the $\mathrm{EU},{ }^{428}$ the E-Commerce Directive ${ }^{429}$ (ECD) provides rules for doing business over electronic bearers and for a coherent and appropriate legislative framework it is essential to develop electronic commerce within the EU. It is a horizontal framework directive that applies to all ISS, that is, those provided at a distance and by electronic means, although it only applies to service providers established within a Member State. Similar to the ECTA, it mandates which information is to be provided on a website or similar electronic medium, information that a consumer must have about the steps to take to conclude a contract online, information to provide in online advertising, limits on the potential liability of ISPs for unlawful material which they carry unwittingly, and the national law that will apply to on-line services, codes of conduct, out-of-court dispute settlements, court actions and cooperation between Member States. The ECD does not necessarily trump the existing level of protections from general interest objectives that are set down in existing Community law, including those relating to the level of consumer protection and complements sector-specific financial services legislation, such that the information requirements in the ECD will supplement financial services legislation, such as the PSD. Similarly, there are some derogations in the ECD which fall into general and specific case-by-case categories. The ECD appears to be manifestly applicable to a broad range of MFS, with providers and users alike having to navigate the ECD alongside other applicable provisions such as the PSD. Pertinently, the general derogations in the ECD reflect different legal solutions provided by other general instruments and include certain provisions that are specific to existing Community financial services legislation. These are listed in the Annex to the ECD and in respect of financial transactions, include 'the emission of electronic money by institutions'; the freedom of the parties to choose the law applicable to their contract; contractual obligations concerning consumer contacts; and the permissibility of unsolicited commercial communications by electronic mail.

Of similar import is the Distance Selling Directive that gives a broadly similar set of rights to EU consumers whenever they enter into a contract by distance means, as well as the Distance Marketing of Consumer Financial Services Directive which aims to provide retail customers who deal with financial services firms or buy a product through distance means, with minimum standard information about the firm that they propose to deal with and the product or service being offered and a right to cancel. Here is no

\footnotetext{
427 The general interaction between the CPA and the ECTA in relation to MFS is described earlier in ch 12, s12.10.2.2.6 on the interplay of the CPA with the ECTA.

${ }^{428}$ See on the EU, ch 9, s9.12 titled E-Commerce and Associated Laws.

${ }^{429}$ See ECD op cit note 1.
} 
reference to the Directive and your sentence is too long As an example of the interaction between the ECD, the Distance Marketing Directive (hereafter DMD) and financial services, the UK FSA specifies that inter alia the provider of a financial promotion must include a description of the main features of the product or service; the total price to be paid by the consumer under the contract, including all related fees, charges and expenses or, if this cannot be given, the basis for the calculation of the price; any risks associated with the specific features of the contract; and the name and address or contact point of the person with whom the consumer would enter into a contract. The issue of providing these details on a small mobile screen remains an unsolved issue.

In the US, ${ }^{430}$ the federal Electronic Signatures in Global and National Commerce Act (hereafter ESIGN) facilitates the use of electronic records and signatures in interstate and foreign commerce by ensuring the validity and legal effect of contracts entered into electronically. The Controlling the Assault of NonSolicited Pornography and Marketing Act (hereafter CAN-SPAM Act) regulates rules for commercial email, and establishes requirements for commercial messages and covers all commercial messages. At a state level, the Uniform Electronic Transactions Act (hereafter UETA) is a model law for contract law and business practice, the development, sale, licensing, support and maintenance of computer software and for many other contracts involving information. It rules are primarily for 'electronic records and electronic signatures relating to transactions' and guarantees that electronic transactions are just as enforceable as their paper counterparts. While state and federal e-commerce laws both emulate e-commerce laws in South Africa, Europe and the EU in relation to regularising the use of electronic transactions in transacting insofar as guaranteeing that electronic transactions are just as enforceable as their paper counterparts and that electronic signatures have the same force and effect. They do not however provide any omnibus consumer protection clauses that are features of e-commerce laws in the other jurisdictions. This is left to the laws applicable to the agencies that may somehow have jurisdiction over aspects of MFS. In this regard, this minimises regulatory arbitrage, although the arbitrage is evident elsewhere in state and Federal laws in relation to the varying and many times overlapping remits.

In Kenya ${ }^{431}$ the Kenya Communications (Amendment) Act No 1 of 2009 provides an e-commerce-like set of laws, although it is not under a dedicated and named 'e-commerce' law, rather under the general jurisdiction of the telecommunications regulator, the CCK. It has a plethora of provisions that provide for functional equivalence of electronic messages in respect of their written, paper equivalents. In essence, then, the Act gives recognition to electronic signatures as legally binding, and gives the Minister of Information the power to approve the manner and format of affixing an electronic signature as well as the control of the processes for ensuring the adequate integrity, security, and confidentiality of electronic records or payments. This includes the legal recognition of electronic records; attribution of electronic records, formation and validity of contracts; recognition of parties of electronic messages; acknowledgement of receipt; and legal recognition of electronic signature. The interaction between the $\mathrm{CCK}$ and the $\mathrm{CBK}$ in respect of the enforcement of the e-commerce provisions in the Amendment Act is not clear.

\footnotetext{
${ }^{430}$ See on the US, ch 11, s11.5 titled Electronic Commerce Laws and Regulations.

${ }^{431}$ See on Kenya, ch 10, s10.5 titled Electronic Commerce.
} 


\subsection{Overview}

While the ECTA places South African legislation on par with similar provisions in other jurisdictions, ${ }^{432}$ there are still disparities in the normative applicability of some of the ECTA's provisions, which in a MFS context relate primarily to consumer protection and the provision of information.

While there is only one, non-contextual reference to mobile through the use of the term 'WAP' in the ECTA, the omnibus term 'data message' means that virtually all transactions conducted via mobile are captured by the ECTA. The courts have recognised that SMSs constitute data messages insofar as they provide the basis for the formation or dissolution of contracts. ${ }^{433}$ At this first blush then, mobile transacting appears to fall squarely within this generic definition because it is an electronic means of data transmission over which contracts can be made. However, drafting errors may ameliorate its efficacy, especially in consumer protection. Each instance of applicability and any equivocations of the practical application to MFS are discussed below in relation to inter alia specific provisions on the formation of contracts, and the consumer protection clauses in Chapter VII ${ }^{434}$ of the ECTA.

\section{Contractual Parameters in the ECTA}

\subsection{Legal Capacity}

There are no provisions in the ECTA on contractual capacity. There are however provisions in the omnibus CPA relating to minors and those generally without capacity. ${ }^{435}$ Where both the ECTA and CPA are silent or inchoate on specific aspects of legal capacity, common law precepts would apply.

\subsection{Formation of Contracts by Users Contracting with Electronic Agents}

The majority if not all of the transactions in MFS transactions will be automated and will use computer servers that interact with the user without necessarily any human intervention.

\footnotetext{
${ }^{432}$ Parts of the Act are, to a large extent, based on the EU's Distance Selling Directive (Directive 97/7/EC on the Protection of Consumers in Respect of Distance Contracts) and the ECD op cit note 1; as well as the Canadian Uniform Electronic Commerce Act of 2000; and the US Uniform Electronic Transactions Act (1999). See Pistorius (2008) op cit note 424.

${ }^{433}$ Jafta $v$ Ezemvelo KZN Wildlife [2008] JOL 22096 (LC); for an overview of this case, see D Collier (2008) 'E-Mail and SMS Contracts' 16 Juta's Business Law at 20; and ME Manamela (2011) “"To Meet is to Part": Resignation by SMS Constitutes Notice in Writing as Required by the Basic Conditions of Employment Act: Mafika v SA Broadcasting Corporation Ltd' 23(3) SA Mercantile Law Journal 521-528

${ }^{434}$ Sections 42 to 49 of the ECTA op cit note 1.

${ }^{435}$ See in the context of the CPA, ch 12, s12.10.2.2.1 titled Agreements by Persons Lacking Legal Capacity; and, generally, see ch 7, s7.2.2.5 titled Legal Capacity.
} 
The Act refers to these servers as an 'electronic agent' which, it says, is a:

'computer program or an electronic or other automated means used independently to initiate an action or respond to data messages or performances in whole or in part, in an automated transaction. ${ }^{436}$

Further, s20(a) in relation to automated transactions says that:

'in an automated transaction an agreement may be formed where an electronic agent performs an action required by law for agreement formation.'

And s20(b) says that:

'an agreement may be formed where all parties to a transaction or either one of them uses an electronic agent.'

Attribution of data messages in relation to automated agents is covered by $\mathrm{s} 25(\mathrm{c})$ which says that a data message will be that of the originator if it was sent by an 'information system' programmed by or on behalf of the originator to operate automatically, unless it is proved that the information system did not properly execute such programming. ${ }^{437}$

The 'information system' referred to is defined in s1 of the ECTA as:

'a system for generating, sending, receiving, storing, displaying or otherwise processing data messages and includes the Internet.'

In relation to MFS, this definition of 'information system' is problematic, since technically because of what appear to be drafting errors in the ECTA that vitiate its technology neutrality, there may not, it is submitted, be the necessary nexus between the definition of 'Information System' and mobile technology. As a necessary technical excursus to explain this, 'Internet' is defined in the ECTA as the 'interconnected system of networks that connects computers around the world using the TCP/IP and includes future versions thereof.' TCP/IP, in turn, is defined as 'Transmission Control Protocol/ Internet Protocol used by an information system to connect to the Internet. ${ }^{, 438}$

\footnotetext{
${ }^{436}$ See $\mathrm{s} 1$ of the ECTA. The definition of an electronic agent is based on the US UETA's definition of an electronic agent.

${ }^{437}$ As Pistorius (2008) op cit note 424 points out, s20 conforms to South African common law which recognises automated contract formation through automated means even in the pre-Internet days. At common law, where a message or action is sought to be attributed to a person in court, the person who alleges attribution or who wants to produce a document has to prove that it is authentic. See also VA Lawack-Davids (2000) 'Aspects of Internet Payment Instruments', Unpublished LLD Thesis, University of South Africa at 296; and MCJ Olmesdahl (1984) 'Unheralded Demise of Wolmer versus Rees' 100 South African Law Journal at 545 which deals with contracts concluded by telephone and telex.

${ }^{438}$ See 11 of ECTA. The definition clause provides a degree of 'gold-plating' by specifically including definitions of a range of technologies. For example, 'hyperlink', 'Internet', IP address, 'TCP/IP', 'WAP', 'web page', 'website' and 'World Wide Web'.
} 
The equivocation however is that the Global System for Mobile Communication (hereafter GSM) networks on which the majority of MFS are based use - and as was explained earlier ${ }^{439}$ - what is known as Signalling System 7 (hereafter SS7) instead of TCP/IP as the bearer medium (technology) for transmitting SMS text messages sent along GSMs SS7 data channel, as well as for USSD-based messages sent along the GSM signalling channel. ${ }^{440}$ Use of SS7 as a transport medium/bearer is thus a sine qua non for any connectivity using the GSM network. ${ }^{441}$ The nexus then between an information system and the mobile technologies used in most MFS systems is broken by the use of the terms 'Internet' and 'TCP/IP'. It is submitted that the misdirected technical definition used by the drafters in the ECTA is such that s25(c) may not apply to MFS. The removal of the word 'Internet' may in the definition of 'information system' solve this issue.

In relation to an originator who is not an automated agent, s25(a) says that a data message is attributable to an originator if it was sent by the originator personally, while s25(b) says that a data message will be attributed to the originator if it was sent by a person who had authority to act on the originator's behalf in respect of that data message. Pistorius notes ${ }^{442}$ that ss25(a) and $25(\mathrm{~b})$ are in line with South African common law since had the person referred to in s25(a) not personally transmitted the data message, or had the person referred to in $\mathrm{s} 25$ (b) not been appropriately authorised to act on behalf of the originator, that originator will be able to lead evidence of that the manner in which consent was obtained was 'improper', or more stridently, fraudulent or obtained under duress, such that any agreement concluded on the basis of such misrepresentation could be proven to be void $a b$ initio or to be voidable. ${ }^{443}$ The affected user may be able to mount a case of unjustified enrichment.

\subsubsection{4}

\section{Mistake in Transactions}

Section 20 of the ECTA relates to 'automated transactions' and holds out at s20(e) the possibility that a transaction may be reversed if there is 'material error' on the part of the user, and that four, (weighty) conditions are met: first, that the electronic agent did not provide that person with an opportunity to prevent or correct the error; ${ }^{444}$ that person notifies the other person of the error as soon as practicable after that person has learned of $\mathrm{it}^{445}{ }^{45}$ that person takes reasonable steps, including steps that conform to the other person's instructions to return any performance received, or, if instructed to do so, to destroy that

\footnotetext{
${ }^{439}$ See the discussion earlier in ch 5, s5.2 titled Mobile Network Technologies, on SS7 and its role in GSM-based mobile communications systems.

${ }^{440}$ Unstructured Supplementary Service Data. See the discussion of USSD in ch 5, s5.3.5 on Unstructured Supplementary Service Data (USSD).

${ }^{441}$ TCP/IP however is not a stranger to the GSM world as GPRS and EDGE, described in ch 5, s5.3.2 titled GPRS and EDGE, both use TCP/IP for data transport. Here a TCP/IP-over-SS7 connection would be established. Use of WAP-based phones to connect to a WAP site via GPRS and EDGE cannot ameliorate the ambiguity and inherent uncertainty derived from the use of the term 'web site' in s43(1). The clause, it is submitted, should have referred rather to an information system that may provide goods and services as contemplated in s43(1) which would not necessarily be website-based with its inherent implications that the values are aimed at anything Internet.

${ }^{442}$ Pistorius (2008) op cit note 424.

${ }^{443}$ See further S van der Merwe, L van Huyssteen and M Reinecke (1993) Contract General Principles at 98. See also R Meiring (2004) 'Electronic Transactions' in R Buys (ed) Cyberlaw @ SA: The Law of the Internet in South Africa (2 ${ }^{\text {nd }}$ ed) at 100.

${ }^{444}$ See s20(e)(i).

${ }^{445}$ See s20(e)(ii).
} 
performance; ${ }^{446}$ and that person has not used or received any material benefit or value from any performance received from the other person. ${ }^{447}$

Material error is not defined in the ECTA. However at common law, there may be material mistakes that relate to the terms of the contract such as error in corpora, error in persona, and error in negotio. Error in qualitate - is generally not regarded as material. ${ }^{448}$ Hence a party to an agreement who raises mistake in an MFS transaction to escape contractual liability must prove that not only is the mistake material, but also that it is reasonable, together known as iustus error. ${ }^{449}$ Proof that this mistake is material will not by itself excuse the mistaken party. A unilateral mistake ${ }^{450}$ induced by the seller's innocent misrepresentation does not necessarily void the contract. ${ }^{451} \mathrm{~A}$ mistake is reasonable if accompanied by objective circumstances that make it excusable in the eyes of the law. This may be when the mistake was induced by an unacceptable misrepresentation by the contract-assertor or someone for whose acts he may be liable, and this misrepresentation may be via commission ${ }^{452}$ or omission. ${ }^{453}$ Hence, s20 will only have effect if the user proves the conditions that gave rise to the iustus error and that he took the steps outlined in s20(e) to mitigate and then cancel the error.

Further, s20(e)(i) requirements, it is submitted, are somewhat too dogmatic in the face of some transactions done on the mobile screen where the ability to see all the material aspects of the transactions may be limited. It also does not necessarily allow proper differentiation between keystroke errors, for example the wrong number is keyed in when doing a remittance, or when the user is under the mistaken belief that a click on a link will take him to a non-transactional element of the service. Further, s20's caveat that it will only apply if the user 'made a material error during the creation of a data message' does not immediately seem to allow differentiation between situations where the user made a material error that gave rise to the keystrokes because of faulty information, versus simple but notable keystroke errors. It appears however that s20's exemption will not apply when the error is made not necessarily from a keystroke error, but from wrong information that gave rise to that keystroke input, for example, the wrong account - or phone number in the case of MFS - for a remittance having been given to the user beforehand. Even so, in the case of keystroke error and general contracting through navigation of truncated menus and links on the small Lead Crystal Display (hereafter LCD) screen, the system design and the pivotal information presented to the user must summarise the pivotal aspects of that transaction.

For example, a Wireless Application Protocol (hereafter WAP) link from a WAP push message ${ }^{454}$ sent to a phone may have a link to billable premium rated WASP content surreptitiously embedded in it, such that a user who clicks on that link simply to investigate the contents of that link but who was unaware of the

\footnotetext{
${ }^{446}$ See s20(e)(ii).

${ }^{447}$ See s20(e)(iv).

${ }^{448}$ Trollip v Jordaan 1961 (1) SA 238 (A) (hereafter Trollip); Allen v Sixteen Stirling Investment (Pty) Ltd 19744 SA (D). See also ch 7, s7.2.2.3.1 on mistake (in contracting).

${ }^{449}$ See Van der Merwe, Van Huysteen and Reinecke (1993) op cit note 443 at 33; see ch 7, s7.2.1.3.1 passim on mistake.

${ }^{450}$ The term 'unilateral mistake' has been interpreted as meaning a non-material mistake in motive. See Van der Merwe, Van Huysteen and Reinecke (1993) op cit note 443 at 35.

${ }^{451}$ Trollip op cit note 448.

452 Misleading the contract-denier by a statement or other positive Act.

${ }^{453}$ Failure to correct or remove an incorrect impression existing in the mind of the contract-denier.

${ }^{454}$ See ch 5, s5.5.3.1 titled Wireless Application Protocol.
} 
billing consequences. ${ }^{455}$ That user may not have had the intent to subscribe, yet funds are almost immediately deducted from their airtime SOV. Similarly, there are no protections available to the user if they made a material error, but where they cannot rise to fulfil the conditions in s20(e), for example, that they did have the opportunity to prevent or correct the error, but could not because of faulty information given to them, for example, by the recipient of the transaction. The value is lost to the sender unless he brings a case of unjustified enrichment against the recipient or the owner of the system. Where the user has sent the value, but the recipient is invalid as the putative recipient's number does not exist or where it is suspended pending some administrative issue or past evidence of fraud, but the user complied with all of ss20(ii) to 20(iv), but not with s20(i) as he only learned of the material error (the wrong recipient number) after the remittance transaction was completed, then the user still cannot avail himself of the protection of s20. In that instance, the user would have to prove a case of unjustified enrichment against the system owner or other owner if the sender's system is interoperable with other systems in the same or other countries.

In other words, s20 places such a heavy demonstrative burden on the user, and the practicalities of a MFS transaction may vitiate the ability of the section to have any real effect, and in many instances it may practically be inapplicable to fasten consumer protection on MFS transactions. ${ }^{456}$

Section 43(1) says that a supplier offering goods or services for sale, for hire or for exchange by way of an electronic transaction must make the following information available to consumers on the website where such goods or services are offered and must provide a swathe of information, including: full contact details, description of the goods and services, and minimum duration of the agreement in the case of agreements for the supply of products or services to be performed on an on-going basis or recurrently. ${ }^{457}$ Section $43(3)$

\footnotetext{
${ }^{455}$ The WAP message sent to the phone and which may be designed to look like an SMS message may say simply 'click here to continue', but which then automatically activates a billable and expensive subscription service when clicked on.

${ }^{456}$ For further evidence of the dilution of the consumer protection sections of the ECTA op cit note 1, see Pistorius (2008) op cit note 424, in particular to a comparison of the effect of keystroke errors by consumers and natural persons where it is correctly argued that because of drafting errors in the Act, the protection offered to a natural person that made an error in an automated transaction provided for in s20(e) is at odds with the consumer-protection provisions of s43(2) of the ECTA. These errors are but a host of drafting errors in the ECTA. For errors relating to technical definitions and the implications thereof, see LJ Perlman (2003) 'Application of the South African Electronic Communications and Transactions Act 25 of 2002 to Mobile Commerce' Unpublished LLB dissertation, University of South Africa. For another comprehensive overview of the informational requirements and elements of consumer protection ostensibly offered by the ECTA and possible equivocations in their application, see W Jacobs (2004) 'The Electronic Communications and Transactions Act: Consumer Protection and Internet Contracts' 16(4) SA Mercantile Law Journal 556-56.

${ }^{457}$ In full, s43(1) of the ECTA requires inter alia the following details: the entity's full name and legal status; its physical address; telephone number; its website and email address; membership of any self-regulatory bodies; any code of conduct it subscribes to and access thereto; company registration number and names of office bearers; physical address; description of the main characteristics of the goods or services offered; the full price; the manner of payment; any terms of agreement that will apply to the transaction and how those terms may be accessed, stored and reproduced electronically by consumers; the manner and period within which consumers can access and maintain a full record of the transaction; the return, exchange and refund policy; any ADR codes; the security procedures and privacy policy of the supplier in respect of payment, payment information and personal information, where appropriate; and the rights of consumers in terms of s44 of the ECTA, where applicable.
} 
in turn says that if a supplier fails to comply with the provisions, the consumer may cancel the transaction within 14 days of receiving the goods or services under the transaction. ${ }^{458}$

While the merits of being able to provide the information on a small mobile phone screen are at play, the drafting of this section, it is submitted, negates the entire premise of s43(3) in its reference to the section only being applicable to 'websites'. Technically, a mobile phone using SMS or USSD - the majority of MFS transactions, will not be captured by this provision because of the technical definition of website used in the ECTA as being 'any location on the Internet containing a home page or web page'. Again, as explained per the technical explanation earlier ${ }^{459}$ in relation to the definition of Internet and its use of TCP/IP, the nexus between Internet and mobile technologies utilised in many MFS systems is thus rendered nugatory by the incorrect technical descriptors such that $\$ 43$ may in most cases be of no effect to most MFS transactions.

Nonetheless, insofar as there may be a slight possibility of its future applicability, it appears from the wording of $s 43$ that these $T \& C$ need not actually be explicitly displayed nor sent to the consumer unless specifically requested. At best they must be made explicitly available to the consumer as an active - by clicking on or checking a link of acceptance - and irreconcilable condition for moving on to the next stage of the transaction that the consumer must accept to proceed to the next stage. Or at worst, the consumer be presented with a link to the $T \& C$ that has a passive component insofar as simply continuing to the next (billable) step indicates acceptance of the $\mathrm{T} \& \mathrm{C}$, that, is where viewing the $\mathrm{T} \& \mathrm{C}$ is not a sine qua non for moving on or completing the transaction. This latter view is supported by s11(2) of the ECTA, where information incorporated into an agreement and that is not in the public domain is regarded as having been incorporated into a data message if such information is referred to in a way in which a reasonable person would have noticed the reference thereto and the incorporation thereof. ${ }^{460}$ However, the ECTA does not hint at how the obligatory information in $\mathrm{s} 43$ - or a link to the information supposedly incorporated by reference as alluded to in ss11(1) and (2) of the ECTA - should be displayed or presented if requested by a consumer. This may possibly allow some vendors to 'bury' the most cogent portions of the T\&C - or even burying the only link to the full T\&C - that may adversely affect the consumer's rights in a complex web of interconnected but disparate links. ${ }^{461}$

\footnotetext{
${ }^{458}$ If a transaction is cancelled in terms of $\mathrm{s} 44$, the consumer must return the performance of the supplier or, where applicable, cease using the services performed. The supplier must refund all payments minus the cost of returning goods.

${ }^{459}$ See ch 12, s12.9.2.2.3 titled Formation of Contracts by Users Contracting with Electronic Agents.

${ }^{460}$ Effectively this means that a critical portion of the contract - for example here the T\&C - may have complete legal effect even though any of its actual provisions are not part of any data message being viewed. Perlman (2003) op cit note 456, as well as Jacobs (2004) op cit note 456 who agrees with this assessment.

${ }^{461}$ Surprisingly too, in a polyglot nation of 11 official languages and the fact that this provision is meant to protect the consumer, there is no requirement that the supplier provide the consumer with any of the information in the consumers' requested home language. This however is remedied somewhat by Part D of the CPA in relation to the 'right to information in plain and understandable language'. Section 22(2)(d) of the CPA for example insists on 'notices' - which could mean the $\mathrm{T} \& \mathrm{C}$ - to be in 'plain language' which $\mathrm{s} 22(2)(\mathrm{d})$ further explains can only be so if the 'organization, form and style of the notice, document or visual representation' an ordinary consumer with some experience in the class of goods or services sold could understand it. However, there is a disconnect between the peremptory provision of s22 of the CPA - which ostensibly relates to $\mathrm{T} \& \mathrm{C}$ - and s 23 of the CPA which relates to proper disclosure of the price of goods or services: this is because s23(1)(a) excludes the operation of the consumer protection rules in s23 on pricing display if the provisions of $s 43$ of the ECTA apply. Since in most MFS transactions s43 of the ECTA will apply, s23 is thus excluded and rules relating to formatting and proper display of pricing information are instead left to the practically ineffectual general informational requirement provisions of $\mathrm{s} 43$. This may however be saved by s20(d) relating to automated transactions, where '[a] party interacting with an electronic agent to form an agreement is not bound by the terms of the agreement unless those terms were
} 
The consumer must also be given the opportunity to review the entire transaction, correct mistakes, or withdraw completely if they so want. The ability of the consumer to review, correct any mistakes, and withdraw from the putative transaction before finally placing an order would also indicate that there is an obligation on the supplier to not only introduce this revision facility before conclusion of the contract, but that the supplier should also inform the consumer about the fact that this revision section actually exists. In all, these compulsory conditions are more robust versions of what would normally be called T\&C.

Other than common law presumptions of intent, ability and performance in contracting, ${ }^{462}$ there is no corresponding injunction in the ECTA to the consumer to actually read or access the $\mathrm{T} \& \mathrm{C}$, presumably leaving it to the common law rule of caveat subscriptor for those who do not bother despite having the ability to do so. ${ }^{463}$ It appears then that if a reference to the T\&C (or any other information) within the message is adequate, then it would be the responsibility of the person who has reasonably (my italics) been made aware of the existence of the $\mathrm{T} \& \mathrm{C}$ by way of oblique reference to it to actually make the effort to follow the links (necessarily) provided - if they can be found.

\subsubsection{6}

Storage Requirements

The ECTA specifies a number of practical provisions which revolve around the circumstances in which the supplier must make available to the consumer the method of how the T\&C and the record of the transaction may be accessed, stored and reproduced electronically by consumers. ${ }^{464}$ Section 11(3)b for example says that $\mathrm{T} \& \mathrm{C}$ must be made accessible in a form in which they may be read, stored and retrieved by the other party, whether electronically or as a computer printout - as long as such information is reasonably capable of being reduced to electronic form by the party incorporating it. ${ }^{465}$ However, the practical information insisted on in the remainder of 543 for the laudable purpose of consumer protection would again make its applicability to MFS almost impossible at worst, and extremely difficult at best. Clearly different devices present different characteristics, which affect, in practice, the consumer's position. Indeed, just concerning the broad range of wireless devices, varied capacities are shown in terms of the display size, storage facility, or data processing. The practical conditions that obviate an explicit nexus between the provisions and the mobile environments are thus numerous.

\footnotetext{
capable of being reviewed by a natural person representing that party prior to agreement formation'. This however still does not stop someone from burying the position of the 'reviewable' T\&C. That is, they are available for review, but only if and when the user finds them. This conduct may be remedied possibly by s40 of the CPA relating to the consumer's right to fair and honest trading, and unconscionable conduct that may impact on that - for example, the situation described in s40(2) that it is considered unconscionable in terms of the CPA for a supplier to knowingly take advantage of the fact that a consumer was substantially unable to protect the consumer's own interests because of physical or mental disability, illiteracy, ignorance, inability to understand the language of an agreement, or any other similar factor.

${ }_{462}$ The ECTA does not appear to alter common law provisions for the formation of contract other than provide legal certainty for data, including the sanctioning of the Reception Theory to contracts and the recognition of digital signatures.

${ }_{463}$ See ch 7, s7.2.2.3.1 on mistake (in contracting).

${ }^{464}$ See ECTA op cit note $1 \mathrm{ss} 43(1)(\mathrm{k})$ and $43(1)(\mathrm{m})$ read with $\mathrm{s} 16$.

${ }^{465}$ Ibid s11(3)(a), (b), (c).
} 
In regard to transaction security, there is no requirement to use electronic signatures or advanced electronic signatures specified in the Act. However s43(5) says that the 'supplier' must utilise a payment system that is 'sufficiently secure with reference to accepted technological standards at the time of the transaction and the type of transaction concerned.' Section 43(6) further says that the supplier is also liable for any damage suffered by a consumer due to a failure by the supplier to comply. ${ }^{466}$ However, the term payment system is not defined in the definitions clause, in keeping with the technologically agnostic nature of many of the provisions. The payment system is not likely, though, to always be the NPS, although it could be in relation to those conducting e-commerce - for example banks, TPPPs and BSPs. For MFSPs who are not members of the NPS due to the closed nature of a private SOV system they may use, the payment system - used generically - must be secure. ${ }^{467}$ However, this still leaves open questions of interpretation as to the precise nature of the payment system, especially when a chimera of disparate but interconnected payment systems are involved in facilitating one seamless MFS transaction. ${ }^{468}$ A WASP VAS transaction for example may involve multiple participants, inter alia, an IP, WASP and the MNO. ${ }^{469}$ This creates opportunity for a 'weakest link' scenario, where one of the components of this intricate chain that presents itself to the consumer (and even the supplier) as seamless, creates a security loophole. Loss-allocation rules fastening on whoever was the weakest link may thus come into focus. ${ }^{470}$

\subsubsection{8}

\section{Cooling Off Period Available for Some Services}

Section 44 of the Act allows for a cooling-off period, whereby a consumer has 7 days to cancel a transaction without reason or penalty and obtain a refund. It however does not apply to financial services, including but not limited to, investment services, insurance and reinsurance operations, banking services and operations relating to dealings in securities; auctions; where audio or video recordings or computer software were unsealed by the consumer; for the sale of newspapers, periodicals, magazines and books; for the provision of gaming and lottery services. Nor does it apply to a regulatory authority established in terms of a law if that law prescribes consumer protection provisions in respect of electronic transactions. ${ }^{471}$

\footnotetext{
${ }^{466}$ Supplier in this context is presumed to mean the supplier of goods or services as outlined in the opening paragraph of $s 43$ of the ECTA op cit note 1 .

${ }^{467}$ See SARB (2009) op cit note 195 at 8-9 where the SARB in relation to e-money says that the technology used in e-money must be secure and ensure confidentiality, integrity, authenticity and non-repudiation, and that the security and operational services should meet the requirements of international standard bodies. In particular, see SARB (2008c) 'Position Paper number 02/2008: Interbank Settlement Network Security Architecture', available at http://goo.gl/xZeGA.

${ }^{468}$ The potential security vulnerabilities in mobile systems are outlined in ch 5, s5.7 on the security aspects of mobile technology and its application to MFS.

${ }^{469}$ See ch 6, s6.5.4.2 on WASP VAS.

${ }^{470}$ In a WASP-type VAS transaction, a WASP and the MNO may be acting as a technical service provider to an IP, and may possibly avail themselves of s73 relating to 'mere conduits'. However the fact that both the WASP and IP may share in the IP's profits through so-called out-payments payment settlement and that they must have abided by a recognised Code of Conduct may exclude this possibility. See ch 6, s6.5.4.2 on WASP VAS.

${ }^{471}$ See $s 42(2)$ of the ECTA op cit note 1. It must be noted that the exclusions for application of $s 44$ as cited in s42(2) - whilst relating to goods and services - do not under the categorisation of 'services' therein, cater for the mow ubiquitous business model of WASPs and IPs implemented worldwide, notably subscription services where users pay a daily, weekly or monthly fee for access to services. These access services for example allow for subscribers to obtain unlimited downloads of music to their mobile phones. They represent the majority of income for most WASPs and IPs in South Africa. An important distinction however must be made between access and potential consumption versus actual consumption of, for example,
} 
The South African ECTA was written with technological neutrality in mind, but instead, it is submitted, it is technologically agnostic. It is shown earlier ${ }^{472}$ to have a number of general inconsistencies in application due to incongruous nomenclature and technical definitions and the focus on technologies and events in the time when the ECTA was drafted. Insofar as the CPA defers then to the ECTA, insofar as consumer protection is concerned, this then is a 'circular firing squad' in ameliorating the efficacy of the effect since the ECTA's inconsistencies insofar as it can be shown to apply to mobile render both well-meaning statutes ineffective. Where the ECTA is silent or contradictory, common law remedies are the only remedies available. As Schulze has noted, the ECTA merely provides a general framework for the facilitation and regulation of electronic communications and transactions. ${ }^{473}$ The ECTA requires revisions to make it properly applicable to mobile, which has since become a major portion of the electronic transactions it purports to (want to) regulate.

\section{Consumer Protection Laws}

12.10.1

\section{Overview}

South Africa created a dedicated consumer protection law, the $\mathrm{CPA},{ }^{474}$ to harmonise consumer legislation in South Africa. It consolidates consumer protection provisions from five acts ${ }^{475}$ and also introduces general principles of consumer protection to serve as an overarching governing statement on consumer protection matters in South Africa. ${ }^{476}$

The CPA defines a 'consumer' in respect of any particular goods or services as:

'a person to whom those particular goods or services are marketed in the ordinary course of the supplier's business; (b) a person who has entered into a transaction with a supplier in the ordinary course of the supplier's business, unless the transaction is exempt from the application of this Act by Section 5(2) or in terms of Section 5(3); (c) if the context so requires or permits, a user of those

music, exemplified in Section 42(2)(g) with respect to 'audio recordings' that 'where audio or video recordings or computer software were unsealed by the consumer,' the exemption would not apply.

${ }^{472}$ See for example in ch 12, s12.9.2.2.5 titled Information Requirements for the Validity of a Transaction, detailing inconsistencies in nomenclature usage in the ECTA.

${ }^{473}$ WG Schulze (2004) 'Countermanding an Electronic Funds Transfer: The Supreme Court of Appeal Takes a Second Bite At The Cherry’ 16(4) SA Mercantile Law Journal at 670.

${ }^{474}$ CPA op cit note 1.

475 The CPA cites these as the Consumer Affairs (Unfair Business Practices) Act of 1988, Trade Practices Act of 1976, Sales and Service Matters Act of 1964, Price Control Act of 1964, and Merchandise Marks Act of 1941 (specifically ss2-13, 1617). It also amends some portions of the NCA, the ECTA and the Lotteries Act 57 of 1997.

${ }^{476}$ For a broad overview and commentary on the CPA, see T Naudé (2009) 'The Consumer's Right to Fair, Reasonable and Just Terms under the New Consumer Protection Act in Comparative Perspective' 126(3) South African Law Journal at 505536; T Naude (2007) 'The Use of Black and Grey Lists in Unfair Contract Terms Legislation in Comparative Perspective' 124 South African Law Journal 128; M Gouws (2010) 'A Consumer's Right to Disclosure and Information: Comments on the Plain Language Provisions of the Consumer Protection Act' 22 SA Mercantile Law Journal 79-94 at 81. In relation to contract terms, see R Sharrock (2010) 'Judicial Control of Unfair Contract Terms: The Implications of the Consumer Protection Act' 22 SA Mercantile Law Journal at 295. In relation to financial services, see A Itzikowitz (2010) 'The Impact of the Consumer Protection Act 68 of 2008 on the Business of Banking' Annual Banking Law Update 53-79, at 53. 
particular goods or a recipient or beneficiary of those particular services, irrespective of whether that user, recipient or beneficiary was a party to a transaction concerning the supply of those particular goods or services; and (d) a franchisee in terms of a franchise agreement, to the extent applicable in terms of Section $5(6)(b)$ to (e).'

A business can however also be classed as a 'consumer' when that business has up to around ZAR3mn in 'assets'. 477

The CPA was ostensibly developed 'to prevent exploitation or harm to consumers ${ }^{\text {, }}{ }^{48}$ through a number of mechanisms that include a powerful omnibus NCC to mediate on consumer complaints. ${ }^{479}$ The CPA aims to establish effective mechanisms for enforcement of these consumer rights, prohibit certain conduct and place certain obligations on suppliers of goods or services. ${ }^{480}$ Consumers will in certain instances be allowed to cancel contracts if they are not satisfied with the terms of contract as well as if their contracts will be renewed. ${ }^{481}$ It also imposes the need for good faith in contracts, legislating as it does inter alia unfair, unreasonable or unjust contract terms, ${ }^{482}$ a notice required for certain $\mathrm{T} \& \mathrm{C} ;{ }^{483}$ details of prohibited transactions, agreements, terms or conditions ${ }^{484}$ via regulations, ${ }^{485}$ as has been done in Europe, on what are called black and grey list terms. ${ }^{486}$ Insofar as contracts phrased in language beyond normal literacy that would make it difficult if not impossible for Joe Citizen to understand the import of what they are signing in a contract, the CPA also introduces plain language provisions ${ }^{487}$ that provide the consumer with an added level of comfort when entering into a contract. ${ }^{488}$

In terms of electronic transactions, the CPA mostly defers to - what under the circumstances could be considered inchoate - the consumer protection provisions of the ECTA described earlier. It also allows deference to other sector regulators whose regulations may have similar import to those in the CPA. ${ }^{489}$

\footnotetext{
${ }^{477}$ See SA Government Gazette No 33621, 1110-2010, vol 544 for these asset calculations; available at http://goo.gl/9JgTP

${ }^{478}$ The primary purpose of the CPA is to prevent exploitation or harm to consumers and to promote the social well-being of consumers. South Africa, Department of Trade and Industry (DTI) (2009) 'Media Release: President Motlanthe Approved Consumer Protection Bill 30 April 2009', available at http://goo.gl/EQhEM.

${ }^{479}$ See on the NCC, ch 12, s12.3.2.6.1

${ }^{480}$ DTI (2009) op cit note 478.

${ }^{481} \mathrm{CPA}$ op cit note 1 at $\mathrm{s} 55$ excludes goods bought at auction from the right of return and implied warranty benefits. Common law rights are still available however in these cases.

${ }^{482}$ Ibid s48.

${ }^{483}$ Ibid 449 .

${ }^{484}$ Ibid s51.

${ }^{485}$ Government Gazette No 34180 on Consumer Protection Act (68/2008) Regulations issued 1 April 2011.

${ }^{486}$ For an overview of the use of black and grey lists, see Naude (2007) op cit note 476. As Naude notes, a black list is a list of prohibited terms which are invalid under all circumstances, whereas a grey list is a list of terms which may be unfair, but the final decision depends on the circumstances of the particular case. The German Civil Code contains an extensive black list, while the EC Directive on Unfair Terms in Consumer Contracts 93/13/EEC of 5 April 1993, a minimum-harmonisation Directive, prescribes a minimum level of protection.

${ }^{487}$ Section 50 of the CPA op cit note 1 governing written consumer agreements, requires the agreements to be written in plain and understandable language, while s22(2) indicates that an agreement can be considered to be in plain language if it is reasonable to conclude that an ordinary consumer of the class of persons for whom the agreement is intended, with average literacy skills and minimal experience as a consumer of the relevant goods or services, could be expected to understand. See further ch 8, s8.5 titled Anti-Money Laundering, Terrorist Financing and Customer Due Diligence Laws and Regulations and ch 13, s13.6 titled Legal Characteristics Based on the Claim School on Consumer Protection.

${ }^{488}$ As Gouws notes, if the consumer cannot understand the meaning of technical legal jargon and unpronounceable Latin phrases in the agreement, it is unlikely that the parties have agreed to the terms of the agreement. See Gouws (2010) op cit note 476 at 81 .

${ }^{489}$ The CPA op cit note 1 says in s2(1) that it must be interpreted in a manner that gives effect to the purposes set out in $\mathrm{s} 3$ which include promoting fair business practices and protecting consumers from improper trade practices and deceptive,
} 
Insofar as the CPA may conflict with other legislation, s2(8) of the CPA indicates that if there is an inconsistency between any provision of the CPA and other specified legislation, the provisions of both Acts will apply concurrently to the extent that it is possible to apply and comply with one of the inconsistent provisions without contravening the second. To the extent that this cannot apply, the provision that extends the greater protection to a consumer prevails over the alternative provision. ${ }^{490}$ It also explicitly gives courts the power to ensure fair and just conduct, $T \& \mathrm{C}^{491}$ but has specific reference to interplay with the common law in s2(10), which says that no provision of the CPA should be interpreted as precluding consumers from exercising any rights afforded to them in terms of the common law.

\subsubsection{Application to MFS}

\subsubsection{Comparative Application to MFS in Other Jurisdictions}

In the US, ${ }^{492}$ until recently with the passing of the Dodd-Frank Wall Street Reform and Consumer Protection Act (hereafter the Dodd-Frank Act), there was no omnibus Federal consumer protection law relating to financial services, banking and payments. The new law created the CFPB to oversee aspects of financial protection measures outlined in Dodd-Frank. A variety of laws at both the Federal and state levels usually regulate consumer affairs, but arguably the states have the most robust laws relating to financial consumer protection. There are however a number of state consumer laws, which in relation to financial and communications products, are centred around implementations of the model law, the Uniform Money Services Act (hereafter the UMSA).

Federal consumer protection laws are mainly enforced by the FTC and the US Department of Justice. The FTC polices unfair and deceptive acts and practices by way of the FTC Act. Many states also have Departments of Consumer Affairs devoted to regulating certain industries and protecting consumers who use goods and services from those industries. While there are no federal laws that directly regulate prefunded cards, the FTC Act prohibits unfair and deceptive practices, regardless of the type of payment device involved. With regards to the CFPB, which is still in its infancy, its purview over MFS is not yet determinable. However, as MFS metamorphose and develop into a robust bank and financial services industry in the US and could possibly have systemic and manifest consumer protection implications, the legislative and legal arsenal provided to the CFPB by the Dodd-Frank Act will flesh out its ultimate purview.

misleading, unfair or fraudulent conduct $(\mathrm{s} 3(1)(\mathrm{c})$ and $(\mathrm{d}))$. Section 3(1)(b)(iv) notes that the purpose of the Act is to promote and advance the social and economic welfare of consumers in the country.

${ }^{490}$ However, in relation to National Consumer Protection Institutions detailed in ch 5 of the CPA; s2(8) of the CPA says that if there is an inconsistency between the following acts and the CPA, the acts will prevail over the CPA: Public Finance Management Act 1 of 1999, or the Public Service Act Proclamation No 103 of 1994, the provisions of the Public Finance Management Act 1 of 1999, or of the Public Service Act 30 of 1994.

${ }^{491}$ See 552 of the CPA op cit note 1.

${ }^{492}$ See on the, US ch 11, s11.6 titled Consumer Protection. 
In the EU, ${ }^{493}$ unlike South Africa and Australia which have developed an omnibus consumer protection law, there is no one Consumer Protection law, although the EU has over time developed a vast number of sector-specific laws with consumer protection components that relate to varying spheres of economic activity. As such, it implemented a broad swathe of consumer-facing consumer protection rules and consumers can avail themselves of the rules, while others are out of sight, providing stability in the operation of wholesale financial markets. A number of redress mechanisms have also been developed, many using Alternative Dispute Resolution (hereafter ADR) processes. At a national level, consumer protection even for the same Directive or Regulation may be spread across multiple agencies under which entities jurisdiction falls. Generally, there is the Unfair Commercial Practices Directive which contains general prohibitions on unfair business-to-consumer commercial practices; national consumer laws in a particular country may provide consumers with additional rights that supplement rights provided by EU laws, as well as the protections in the e-commerce directive, the Distance Selling Directive; and the Directive on Distance Marketing of Consumer Financial Services. The European Court of Justice (hereafter ECJ) has ruled that both insurance and banking are particularly sensitive sectors in relation to consumer protection.

The PSD adds to consumer certainty for example on payments in the EU by establishing a modern and harmonised legal framework for payment services by replacing existing national rules in the 27 Member States by a set of provisions applying throughout the single market. A high level of consumer protection is provided for via strict information requirements and the definition of the rights and obligations of the users and providers of payment services. It does not apply however to payments via cash or cheque. The ECD complements the PSD with a range of informational requirements that must be presented to a user for an electronic contract and transaction to be valid. The EC has also established some non-judicial bodies to assist in disputes such as the Network for the Extra-Judicial Settlement of Consumer Disputes (hereafter EEJ-Net) as well as Financial Dispute Resolution Network (hereafter Fin-NET) - similar to the South African OBSSA - which is responsible for handling disputes between consumers and financial services providers like banks. In the sphere of MFS though, the PSD appears to be the most preeminent and relevant consumer protection law applicable.

In Kenya, ${ }^{494}$ there is no specific consumer protection law. In regard to MFS, they are affected directly and indirectly by a number of financial laws that address consumer protection issues. The CBK's 2010 Agent Guidelines however provide direct consumer protection provisions, although these relate more to formalities in the transaction process than any dispute resolution facilities. While the Banking Act allows the CBK to restrict increases in bank charges, it is not certain that MFS services like M-pesa would be subject to these restrictions as there is no licensed bank structure per se to regulate. The CBK however indicates that it requires any provider to have procedures and capacities to handle and resolve complaints timeously and must provide reports to the regulator.

\footnotetext{
${ }^{493}$ See on the EU. ch 9, s9.13 titled Consumer Protection-Type Laws.

${ }^{494}$ See on Kenya, ch 10, s10.6 on Consumer Protection.
} 
Further, the Kenya Information and Communications (Dispute Resolution) Regulations 2010 set out the scope of and guidelines for any disputes between a license holder and a consumer and allows the CCK to resolve disputes between a consumer and a service provider. This may ostensibly bring an MFS service like M-pesa under the jurisdiction of the CCK if there is any dispute as to charges, billing and general loss of value in the prepaid stored value SOV. A particular issue around prepaid billing is raised by the Kenya Information and Communications (Tariff) Regulations 2010 which say inter alia that a licensee shall provide accurate billing information on tariffs to enable customers to verify whether they are billed correctly. Since prepaid mobile access is usually a paperless system at worst, and a web or WAP-based interface for transaction-logging at worst, any MFSP would have to provide an accessible billing system via web or WAP, or if possible, a printout via an agent or at an MNO office.

\subsubsection{Application to MFS in South Africa}

\subsection{Agreements by Persons Lacking Legal Capacity}

Section 39 of the CPA makes provision for issues around agreements with persons lacking legal capacity. Section 39(1) says that an agreement to enter into a transaction, or for the supply of any goods or services, to or at the direction of a consumer is void if the consumer is subject to an order of a competent court holding that person to be mentally unfit and the supplier knew, or could reasonably have determined, that the consumer was the subject of such an order.

In relation to minors, an agreement is voidable at the option of the consumer, if at the time the agreement was made the consumer was an un-emancipated minor; and the agreement was made without the consent of an adult responsible for that minor; and the agreement was not ratified by either an adult responsible for that minor or by the consumer after being emancipated or becoming an adult. For the merchant, this may cause problems as it can be a relatively simple matter for the (major) person ultimately paying for the minor's use or the parent/guardian of that minor to insist that they did not give consent. There is however a 'catch-all-type' proviso in s39(2) insofar as holding the minor culpable for the costs. This would arise if the consumer (as a minor) or any person acting on behalf of the consumer, directly or indirectly, by act or omission induced the supplier to believe that the consumer had an unfettered legal capacity to contract; or attempted to obscure or suppress the fact that the consumer did not have an unfettered legal capacity to contract. Judging from WASPA's reported experience on adjudicating on a minor's use of PRS, ${ }^{495}$ this may pose significant challenges, in relation to minors who transaction either with their own mobile phones, and/or who use their parents' mobile phones and incur charges for the purchase of say WASP-type digital goods and services via premium rated services.

The problem is exacerbated because systems for adult-verification in WASP services and MFS services are generally very weak or non-existent, but which can still bind the owner of the mobile phone for costs incurred by the minor's use. That said, even the regular indication in many WASP services that the service

${ }^{495}$ See generally the official website of WASPA at www.waspa.org.za; and Independent Online (IOL) (2011) 'Control Your Child's Cellphone Use', available at http://goo.gl/C83gJ. 
is for 'adults only' or that the user must 'ensure that they have the bill payor's permission' to incur costs would suffice for s39(2) as the minor - assuming he has the cognitive skills of course - by continuing despite the warning may then bind the bill payor.

This issue is likely to rear its head often, and the ultimate allocation of costs may lie simply on the evidence. It is likely though to be an on-going and significant test of the CPA and the NCC - or any other body tasked with retail payments regulation - to test this provision.

\subsection{Ownership of MFS SOV}

While the CPA is an omnibus consumer protection law, the only direct provisions relating to MFS in the CPA are those relating to prepaid certificates, credits and vouchers.

Section 65(2) relates to the holding of and accounting for consumer's property and states that when a supplier has possession of any prepayment, deposit, or other money, or any other property belonging to or ordinarily under the control of a consumer, the supplier must not treat that property as being the property of the supplier and must exercise the degree of care, diligence and skill that can reasonably be expected of a person responsible for managing any property belonging to another person. Further, that person will be liable to the owner of the property for any loss resulting from a failure to comply. Section 65(1) however says that subs (2) does not apply to a supplier that is a bank, as defined in the Banks Act, ${ }^{496}$ a Mutual bank, as defined in the Mutual Banks Act ${ }^{497}$ or any other financial institution similarly licensed and authorised to conduct business and take deposits from the public in terms of any national legislation. It appears then that the carve-out exclusion embodied in s65(2) would only apply to prepaid redeemable MFS SOV, such that banks holding e-money SOV value may treat those funds as funds belonging to the bank. This view of property rights in stored value comports with common law views on money given to banks, where the bank is said to have an ownership right in the money presented to it, while the depositor has a personal right to claim the value from the bank.

However ss63(3) ${ }^{498}$ and 65(2) $)^{499}$ appear to alter these settled common law provisions around ownership of (stored) values, insofar as they apply to prepaid certificates where there is no licensed bank involvement. ${ }^{500}$ Section 63(3) for example says that any consideration paid by a consumer to a supplier in exchange for a

\footnotetext{
${ }^{496}$ Act 94 of 1990 op cit note 1.

497 Act 124 of 1993 op cit note 1.

${ }^{498}$ See s64(3) of the CPA op cit nte 1 which says that: 'Any consideration paid by a consumer to a supplier in exchange for a prepaid certificate, card, credit, voucher or similar device contemplated in subs(1) is the property of the bearer of that certificate, card, credit, voucher or similar device to the extent that the supplier has not redeemed it in exchange for goods or services, or future access to services.'

${ }_{499}$ Section 65(2) says that when a supplier has possession of any prepayment, deposit, membership fee, or other money, or any other property belonging to or ordinarily under the control of a consumer, the supplier must not treat that property as being the property of the supplier. Section 65(1) however excludes the application of s65(2) from being applicable to a bank, as defined in the Banks Act; a Mutual Bank or any other financial institution that is similarly licensed and authorised to conduct business and take deposits from the public in terms of any national legislation.

500 'Prepaid certificate' is not defined in the CPA although s63(1) says it applies to transactions where a 'supplier accepts consideration from a person in exchange for a prepaid certificate, card, credit, voucher or similar device and expressly or implicitly agrees to provide goods or services to any person who subsequently presents that certificate, card, credit, voucher or similar device, up to the value represented by it, but does not apply with respect to such a device, or the value represented by it, after all of the value of the device has been exchanged for goods, services or future access to services.
} 
prepaid certificate, card, credit, voucher or similar device contemplated in s63(1) of the CPA is the property of the bearer of that certificate, card, credit, voucher or similar device to the extent that the supplier has not redeemed it in exchange for goods or services, or futureaccess to services. ${ }^{501}$ Here then in the scope of s63, the supplier must treat that property as being the property of the bearer - unlike the similar s65(2)(a) and the carve-out for licensed banks provided for in s65(1). ${ }^{502}$ In an MFS context, there would be a distinction between issuance of stored value ${ }^{503}$ versus supply of goods and services ${ }^{504}$ that is facilitated through this issuance. Section 63(3) will only apply however to goods and services supplied by the supplier, expressly or implicitly. ${ }^{505}$

Arguably as the prepaid certificate is effectively only supplied - issued - by an $\mathrm{MNO},{ }^{506}$ the section will only apply to services supplied directly by the MNO to the user, and not where say it is a WASP that directly supplies (a) service to the user, whereby the WASP is simply using the prepaid card supplier - the MNO - as a micro-billing engine for access to the SOV in the prepaid SVA. Further, although 'service' is defined in s1 as being inter alia 'any work or undertaking performed by one person for the direct or indirect benefit of another' ${ }^{507}$ it is not clear whether the act of providing a prepaid certificate and any amounts and allowing another party - the WASP for example - to periodically draw from the airtime-based SVA using micro-billing engines for say the provision of VAS amounts to a 'service' as contemplated in s63(1).

\subsection{Access to Service Facilities}

According to s64(3) of the CPA, if a supplier intends to close a facility to which the supplier has committed to provide future access in terms of an agreement with a consumer to provide any service, without making available a reasonably accessible alternative facility, the supplier must (a) give written notice of that intention to such consumer at least 40 business days before the intended date of closure; and $(b)$ no later than five business days after closing that facility, refund to such consumer the balance of any money belonging to that consumer in terms of this section. ${ }^{508}$

In respect of MFS, s64(3) may have had an impact on subscription service club type facilities funded from the airtime SOV, where there is one offering advertised initially and where at some point the content of the service offering changes because of, for example, a change in business model or content. In the fast moving world of digital content, this switching is very typical.

\footnotetext{
${ }^{501}$ Section 65(2)(b) refers instead to the supplier 'managing' the property on behalf of another.

502 'Bearer' here may have the ordinary meaning ascribed to it, rather than in a negotiable instrument context as it is not certain that the prepaid value - used as a written/printed airtime voucher - could necessarily be negotiated. Rather ownership may pass by simple transfer.

${ }^{503}$ CPA op cit note 1 s63(1)(a)

${ }^{504}$ Ibid s63(1)(b)

${ }^{505}$ Ibid.

506 This presumably will only apply to prepaid airtime SOVs as there is usually no licensed bank involved in the redeemability per se, although commercially licensed banks do sell airtime via ATM machines or on the mobile phone via WAP. Rather, s63(3) in a NFS context is more likely geared towards the MNO as the core issuer (of the stored value) acting as a supplier.

507 CPA s1: Definitions.

${ }^{508}$ Subsection (3)(b), read with the changes required by the context, applies equally.
} 
Thus where a user signs up for a subscription service that is paid for via WASP billing via an Online Billing System (hereafter OBS) engine, that ostensibly provides love poems, then the supplier altering that offering downstream to ringtones would ostensibly adhere to the mandated procedure in s64(3). How practical, measurable and similarly enforceable this will be is open to question.

In relation to prepaid certificates and vouchers that could be used in telecommunications and MFS services, credits and vouchers, $s s 63^{509}$ and $65^{510}$ appear to alter the common law provisions around ownership of values in the prepaid certificate.

\subsection{Liability for Loss of MFS SVP Value}

Section 65 of the CPA deals with the supplier having to hold and account for the consumer's property. Insofar as liability for loss of the MFS SOV in a SVA, s65(2) says that when a supplier has possession of any prepayment, deposit, membership fee, or other money, or any other property belonging to or ordinarily under the control of a consumer, the supplier in the handling, safeguarding and utilisation of that property must not treat that property as being the property of the supplier. Section 65(2)(b) says further that they must exercise the degree of care, diligence and skill that can reasonably be expected of a person responsible

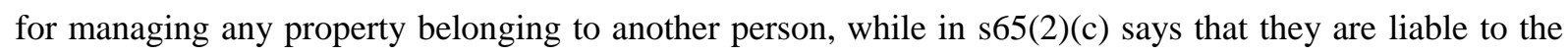
owner of the property for any loss resulting from a failure to comply. Since s65(1) excludes licensed banks and most financial institutions from the provisions of ss65(2), 65(2)(b) and 65(2)(c) would presumably only apply to airtime-based MFS SOVs as it is phrased widely enough to include them.

Section 65(2) however is not clear on what the supplier's perimeter liability may be. It could be for the storage of the value - the 'safeguarding' requirement - such that if the system fails and the value is somehow erased from the records of the supplier, the supplier is liable in terms of s65(2)(c). However it seems the user would have to prove that the supplier did not 'exercise the degree of care, diligence and skill that can reasonably be expected of a person responsible for managing any property belonging to another person.' From what are you quoting and whose emphasis is it? For an ordinary user of a system, this appears to be an enormous burden of proof although in the case of the total loss of value, the burden may be less as it may be a relatively straightforward matter of fact as to the value. In that case the onus would be on the supplier to disprove that the user had any value stored in the system and the extent of that value. However, the burden may shift to the user to show that the supplier 'did not exercise the degree of care, diligence and skill that can reasonably be expected of a person responsible for managing any property belonging to another person.'

\footnotetext{
${ }^{509}$ See s64(3): Any consideration paid by a consumer to a supplier in exchange for a prepaid certificate, card, credit, voucher or similar device contemplated in subs(1) is the property of the bearer of that certificate, card, credit, voucher or similar device to the extent that the supplier has not redeemed it in exchange for goods or services, or future access to services.

${ }^{510}$ Section 65(2): When a supplier has possession of any prepayment, deposit, membership fee, or other money, or any other property belonging to or ordinarily under the control of a consumer, the supplier must not treat that property as being the property of the supplier. Section 65(1) however excludes the application of s65(2) from being applicable to a bank, as defined in Act 94 of 1990 op cit note 1; a mutual bank, as defined in Act 124 of 1993 op cit note 1; or any other financial institution that is similarly licensed and authorised to conduct business and take deposits from the public in terms of any national legislation.
} 
Examples where this may apply are where subscription services run by WASPs and their Information Providers remove value from a user's airtime-based SVA without his knowledge and consent, a problem recognised worldwide. It is particularly problematic in South Africa where most users are prepaid mobile users and do not necessarily have access to any mobile billing information to allow them to check that value is being removed. ${ }^{511}$ The MNO, as the supplier and system operator of the SVA, may in terms of s65(2) be held accountable for not putting systems in place to prevent this where it can be shown that the MNO was previously aware of the problem and had technical or other methods of preventing the issue.

In relation to e-money, the SARB though says that issuers of e-money must ensure that the public are made aware of the conditions of use, the liability of the issuer and what recourse the holder of the e-money would have in relation to the issuer. ${ }^{512}$

\subsection{Enforcement of Rights by Consumers}

The burden of proof for all the issues described earlier may be very high for the subscriber, especially where the subscriber may not have access to billing data so as to source and formulate the problem he may face.

The CPA has a number of provisions where consumers as defined may have some redress though structures established and/or recognised by the Act. Section 66 allows the consumer to resolve any dispute with a supplier by either referring the matter directly to the NCT, if such a direct referral is permitted by the CPA in the case of the particular dispute; or he may refer the matter to the applicable ombudsman with jurisdiction if the supplier is subject to the jurisdiction of any such ombudsman. ${ }^{513}$

Section 69 allows a class of persons identified through and allowed by s4(1)(c) of the $\mathrm{CPA}^{514}$ that may be affected by any of the issues raised in s69 and elsewhere, to enforce their rights. This may give rise to a number of US-style class action lawsuits.

The possibility that Banks and other licensed financial institutions may be subject to an industry ombudsman - such as the OBSSA ${ }^{515}$ - in terms of the CPA is not removed by s69, despite the exclusions embodied in s65(2).

\footnotetext{
${ }^{511}$ The issue is especially prevalent when a prepaid cell phone number is recycled because of non-use or zero balance in the SVA for a period of time specified in the MNO-subscriber agreement. The MNO will after the period of non-use allocate the number to a new user. However, WASP systems may still have the number listed on their systems as being active users of a subscription service, such that when airtime is loaded into the SVA by the new owner, the new owner of that recycled cell phone number is billed for the previous owner's activities without his knowledge and consent. The issue may be solved to some extent with RICA where the owners of mobile numbers must be registered, although this is no panacea.

512 SARB (2009) op cit note 195 at 7.

${ }^{513}$ If the matter does not concern a supplier contemplated in the latter, then the consumer may in terms of s69(3)(c)(i) refer the matter to the applicable industry ombudsman, accredited in terms of s82(6) of the CPA op cit note 1 if the supplier is subject to any such ombudsman. Section 69 also allows consumers to apply to the consumer court of the province with jurisdiction over the matter. Or the consumer may refer the matter to another ADR agent contemplated in s70 of the CPA; or they may file a complaint with the NCC via s71 of the CPA; or approach a court with jurisdiction over the matter, if all other remedies available have been exhausted.

${ }_{514}^{514}$ Ibid at s4(1)(c): 'A person acting as a member of, or in the interest of, a group or class of affected persons.'

${ }^{515}$ See ch 12, s12.3.2.10 on the Ombudsman for Banking Services in South Africa.
} 


\subsection{Interplay of the CPA with the ECTA}

The CPA defers to the consumer protection provisions in a number of instances where the transaction is electronic and falls within the parameters of the Act. In other cases, it defers to provisions of the ECTA, discussed in detail below ${ }^{516}$ and the footnotes therein. For example, ss23(1) and 26(1) of the CPA in relation to the disclosure of the price of goods or services and sales records respectively, ${ }^{517}$ defers to $s 43$ of the ECTA which has some strict informational requirements for suppliers offering goods or services for sale, for hire or for exchange by way of an electronic transaction. ${ }^{518}$ In relation to a consumer's right to a cooling-off period after receiving direct marketing, s16(1) of the CPA says that the section does not apply to a transaction if $\mathrm{s} 44$ of the ECTA relating to the cooling-off period applies to that transaction, that is if the transaction is done electronically. ${ }^{519}$

In relation to a consumer's rights with respect to delivery of goods or supply of services, s19(1) of the CPA says that this section does not apply to a transaction if the performance of that transaction is governed by s46 of the ECTA that deals with when the supplier must perform in terms of an electronic transaction. ${ }^{520}$

\subsection{Jurisdictional Issues Between the NCC and Other Regulatory Bodies}

Whilst the CPA is designed to be an overarching piece of legislation that provides comprehensive protection for consumers across all sectors of the economy, it makes provision at s5(3) for what are known as 'sector regulators' as well as provincial regulatory authorities to handle any consumer-related issues that may be in the regular scope of that sector regulator.

Specifically, s5(3) of the CPA provides that:

'A regulatory authority may apply to the Minister [of Trade and Industry] for an industry-wide exemption from one or more provisions of this Act on the grounds that those provisions overlap or duplicate a regulatory scheme administered by that regulatory authority in terms of -

(a) any other national legislation ...'

Section 5(4) says that after receiving advice from the NCC, the Minister may grant the requested exemption sought, but only to the extent that the sector scheme ensures consumer protection through similar, existing provisions in their respective regulatory framework. The issue however is whether this may set the stage for jurisdictional clashes where the similar provisions do not necessarily provide a higher degree of consumer

\footnotetext{
${ }^{516}$ See ch 12, s12.9.2.2.5 titled Information Requirements for the Validity of a Transaction.

${ }^{517}$ Section 23(1) of the CPA op cit note 1 says that this section does not apply to a transaction if $s 43$ of the ECTA op cit note 1 applies to that transaction.

${ }^{518}$ See the detailed discussion in ch 12, s12.10.2.2.6 on the interplay of the CPA and the ECTA in relation to information requirements for the validity of a transaction.

${ }^{519}$ As indicated earlier at ch 12, s12.9.2.2.8 on the cooling off period available for some services, s42(2)(a) excludes financial services from the cooling off provisions of the ECTA op cit note 1.

${ }_{520}$ In relation to catalogue marketing, s33(1) of the CPA op cit note 1 says that this section does not apply to a transaction if Chapter 7 of the ECTA relating to consumer protection applies to it.
} 
protection than what is envisaged in the CPA, or where there may be a perception that regulatory capture may ameliorate the sector body's efficacy in terms of consumer protection. ${ }^{521}$ In the case of MFS, it is most likely that ICASA could be granted exemption if it applies on behalf of those it licenses. ${ }^{522}$

\subsection{3 \\ Conclusion: Consumer Protection Laws}

The process of ensuring an effective financial consumer protection framework alongside proportional regulation that nurtures innovation requires a comprehensive approach and consultation among various stakeholders to ensure consistency within laws and regulations, with the possibility of a lack of regulatory coordination resulting in a disproportionate amount of, or ineffective, regulation. The need for regulators and their agencies to talk to one another across this converged spectrum becomes manifestly more important, coordination failure needs to be addressed and the resultant swathe of inconsistent laws and regulations that are possibly killing the golden goose and ameliorating consumer protections through regulatory arbitrage. Close coordination is also essential to develop effective oversight and regulatory structures.

Consumer protection regulators are more likely to take a functional approach with a focus on products and services, regardless of which institutions provide these services. A functional approach applies consumer protection to all financial service providers irrespective of their institutional type (ie, bank or nonbank), ensuring a level playing field. But consumer protection agencies often face a challenge taking on the responsibility of financial consumer protection because they lack both knowledge of the financial sector and capacity. In many countries the legal provisions relevant for consumer protection are diffused and largely fragmented throughout multiple pieces of specific or non-specific consumer protection-type legislation. This may be through specific laws relating to consumer protection, or general consumer protection type provisions in (non-financial) sector-specific legislation, such as telecommunications laws relating to the operational characteristics and obligations for example of an MNO. Generally though, there may be a general consumer protection law without explicit reference to financial services, or a consumer protection law with explicit remit for financial services; or consumer protection regulations within the framework of financial sector legislation, or consumer protection clauses in telecommunications and ecommerce type laws.

Even omnibus consumer protection laws may be diluted if circumstances are created for regulatory arbitrage: the CPA for example contains a provision that exempts a sector from full applicability if that sector is regulated - on a statutory, co-regulatory, or self-regulatory basis - with provisions that are similar to those (generically) in the CPA. The dilution may arise if the enforcement of these similar provisions is less than salubrious by the entity tasked with that enforcement, either through general and historical

\footnotetext{
${ }^{521}$ For examples of initial clashes post-implementation of the CPA in relation to mobile services, see R Muller (2011b) 'Vodacom Tells Consumer Commission to Take a Hike' MyBroadband, available at http://goo.gl/TgCrQ; R Muller (2011a) 'Vodacom Downtime: Can You Get Money Back?' MyBroadband, available at http://goo.gl/irgMh; W Knowler (2011) 'Prepaid Airtime - Use it or Lose it for Now' IOL, available at http://goo.gl/XUxGM.

522 Independent Communications Authority of South Africa (ICASA) (2011) 'Media Release: ICASA and National Consumer Commission's Role on Consumer Protection Matters in the Communications Sector', available at http://goo.gl/jxkMK.
} 
inefficiency in enforcing its own regulations possibly because of lack of resources, institutional capacity, its limited enforcement powers, and/or possibly because it may suffer from regulatory capture. ${ }^{523}$

The CPA also defers throughout to the ECTA. This is problematic: the ECTA - a supposedly technologically neutral law - for example was shown earlier ${ }^{524}$ to have a number of general inconsistencies in application due to incongruous nomenclature and definitions and the focus on technologies and events in the time when the ECTA was drafted. Insofar as MFS are concerned they may be considered 'electronic transactions', the CPA is not necessarily geared towards consumer protection issues involved in complex financial transactions done electronically per se, effectively still leaving this to the ECTA and other selfregulatory codes like the OBSSA.

Thus fundamental issues of mistake, coercion, fraud, and other issues that may cause a user unintended financial loss when using either a prepaid airtime-based SOV or are subject to an indirect regime through the ECTA and not the CPA, and where the ECTA is silent or contradictory, common law remedies are the only remedies available.

As Schulze laments, ${ }^{525}$ the ECTA merely provides a general framework for the facilitation and regulation of electronic communications and transactions. There appears therefore to not have been any coordination in first fixing the errors in the ECTA before handing over much of the CPA's (potential) efficacy with regard to electronic transactions - including MFS.

It is submitted that because of the fragmented nature of MFS-applicable regulation and the importance generally in a stable financial system and its impact on growth, that this portends the need ${ }^{526}$ to have a specific payment services Regulator - suggested here as the Payment Services Regulatory Authority (hereafter PSRA) - that enforces provisions of a suggested new Payments Services Provider Law (hereafter PSPL), not national payments systems for which the central banks usually have jurisdiction. ${ }^{527}$

A PSRA would be similar in scope and purpose as the CFPB in the US, implementing and regulating a specific PSPL, much like the PSD in the EU. The PSRA would administer licensing and sound operation of the PSPs and ensure compliance with the consumer protection provisions of the proposed PSPL.

\footnotetext{
${ }^{523}$ See ch 8, s8.2 titled Philosophies Behind Regulation, which discusses regulatory capture.

${ }^{524}$ See ch 12, s12.9.3 titled Conclusion: E-Commerce Laws.

${ }_{525}$ Schulze (2004c) op cit note 102 at 715.

${ }^{526}$ See Recommendation 8 in ch 14, s14.9.7 on the need for a dedicated agency (authority) to regulate consumer payments.

${ }^{527}$ See also inter alia, Recommendation 4 in ch 14, s14.9.3 on a proposed new regulatory regime encapsulated in a PSPL; Recommendation 7 in ch 14, s14.9.6 on the need for a new regulatory regime that codifies consumer and service provider rights in macro retail payments, preferably within the framework of a proposed PSPL; and Recommendation 8 in ch 14 , s14.9.7 on the need for a dedicated agency (authority) to regulate consumer payments.
} 
From the preceding discussions, the investigation of MFS and the available consumer protections and loss allocation rules that could be available to consumers, finds that there is a no comprehensive and available legal and regulatory ecosystem in South Africa that provides for this. This finding then triggered a larger discussion on consumer protections and loss allocation rules in South Africa for non-cash payments generally, ${ }^{528}$ but of course with a corresponding eye on any direct relevance to MFS.

It appears that disparate laws, self-regulatory codes of conduct and procedures, and common law condictiones described earlier point to a weakness in South Africa law and jurisprudence in relation to consumer protection for consumer payments. It is, it is submitted, extremely difficult and especially economically unclear as to how a consumer could wade through the disparate codes, laws and common law remedies to find something that 'fits' their particular circumstance.

Unless they are passionate, financially empowered to pay legal fees to pursue a case, and can assuage the convention of contractual power and informational asymmetry that is invariably stacked against them in pursuit of a solution, they are unlikely to be able to assemble a formidable panoply of remedies that would conceivably ameliorate loss allocation whilst emboldening their rights.

All these risks and equivocations, it is submitted, are amplified by equivocations in understanding whether new emerging, payment systems like to those in MFS amount to 'money,' since then any ability to apply laws, conventions, common law remedies may first need to be clarified. A re-evaluation of money is required - and indeed as a first step in this general process, is initiated ${ }^{529}$ and undertaken ${ }^{530}$ in this study to assist in this clarification.

There is also no one 'payments champion' in South Africa: rather competencies are - primarily due to inconsistent legal drafting ${ }^{531}$ and allocation of regulatory competencies ${ }^{532}$ - spread primarily at an institutional-approach level but sometimes at a functional approach level ${ }^{533}$ according to legislation and convention amongst multiple agencies such as the NCC, the NCT, the OBSSA, ${ }^{534}$ and WASPA.

\footnotetext{
${ }^{528}$ The South African Bills of Exchange Act 56 of 2000 is not necessarily relevant to this discussion as it involves cheques and paper drafts, a fading payment instrument in many parts of the world. The broad issues it encompasses, as well as the common law precepts that surround it may however be very useful in providing guidance on newer and emerging, dematerialised forms of payment.

${ }^{529}$ See ch 3 titled Overview of Money.

${ }^{530}$ See ch 13 titled a Re-Evaluation of Money.

${ }^{531}$ For example, where the CPA defers to - deficient and inconsistent, it appears - provisions in the ECTA in relation to electronic transactions.

${ }^{532}$ For example, in MFS instances, regulatory arbitrage over who should have jurisdiction over transactions conducted over the mobile phone: the SARB NPSD or BSD, the OBSSA, ICASA, NCC, NCT or WASPA.

${ }^{533}$ See ch 8, s8.3 titled Types of Regulation Foci, describing differences between the functional and institutional approaches.

${ }^{534}$ See ch 12, s12.3.2.10 on the OBSSA and the Code of Banking Practice. As noted earlier, it is up to the OBSSA to ultimately determine any compensation, if any, from a loss. The degree of risk or blame, as noted earlier that could be allocated may be mediated by the OBSSA according to the framework of the COBP, statute and the common law.
} 
Nonetheless, the bright-line differences to the existing stark realities risk allocation and consumer protections in 'money' and consumer payments are clear from investigations of inter alia the EU and the USA which, in some cases are admittedly not ideal and clear, present formidable answers to these issues.

The EU, for example, has in the omnibus PSD codified potential and absolute solutions to issues relating to inter alia the circumstances surrounding loss, fraud, theft, proof, and negligence in many non-cash payment environments. ${ }^{535}$

In the USA, the loss and risk allocation rules are spread across a number of statutes, and to some extent, enforcement is spread across multiple agencies. ${ }^{536}$ These rules also depend to a great degree on the type of payment instrument used, such that - while apparently are effective in some specific instances - in aggregate they present a disparate set of rules and remedies for consumer payments. Maximum-loss rules for example and the circumstances that give effect to them provide some comfort to consumers. The overall efficacy of these rules though are in some ways ameliorated, but yet in some ways augmented, by the need to consider whether state or federal rules apply to a particular instance. State rules in aggregate usually apply more localised and stricter consumer protection measures, but their interplay with federal rules via pre-emption often brings the two types into conflict. ${ }^{537}$ Enforcement of payments and SVPs at a federal level appears to fall within the remit of the new CFPB for example is the omnibus financial protection agency that has a distinct focus and remit on consumer payments and SVPs.

In Australia, the new 'ePayments Code' of practice, while not part of the comparative focus of this thesis, is instructive in demonstrating moves towards regulating emerging payment methodologies and thus is included here. ${ }^{538}$ This self-regulatory Code regulates consumer electronic payments that such as those from ATMs, Electronic Fund Transfer at Point of Sale (hereafter EFTPOS), debit and credit card transactions, contactless NFC transactions, ${ }^{539}$ online payments, and internet banking. It includes a tailored set of light touch requirements for low value products (with a maximum balance of AU\$500); a new regime to resolve mistaken internet banking payments; and plain English drafting that is product and technology neutral. ${ }^{540}$

\footnotetext{
${ }^{535}$ See ch 9, s9.6.2.5 titled Transactional Rules and Liability Allocation in the Payment Services Directive. These relate inter alia to Obligations of the Payment Services User (PSU); Obligations of the Payment Services Provider (PSP); Liability Allocation between PSP and its Technical Providers; Loss from Lost or Stolen Instruments; Loss for Transactions Prenotification of Loss/Theft; Loss for Transactions Post-notification of Loss/Theft; Loss for Transactions of 'Offline' Payment Instruments; Loss from Cloned/Forged Payment Instruments; Effect of Gross Negligence by the PSU; Effect of Fraud by the PSU; Effect of Misappropriation of the Payment Instrument (PI) or its Security Features; Burden of Proof for Unauthorised Payments; and Possible Reduction of PSU Liability.

${ }^{536}$ These could include the Federal Trade Commission, and state bodies. See further inter alia ch 11, s11.2.3.2 on the federal overview and ch 11, s11.2.3.4 on the state overview.

${ }^{537}$ See for example issues around preemption of state rules by federal rules, particularly in relation to SVPs.

${ }^{538}$ The new Australian Code, formerly called the 'EFT Code', was launched in July 2011, is described as providing 'a best practice consumer protection regime for electronic payment products.' The Code mandates that all service providers who subscribe to the Code should have implemented its provisions by 20 March 2013. It is regulated by the Australian Securities and Investments Commission (ASIC). Virtually all banks, credit unions and building societies currently subscribed to the old EFT Code along with a number of non-traditional banking service providers. The new epayments Code is available at http://goo.gl/0YX3f.

${ }^{539}$ The NFC component is especially relevant to this study and MFS, although it is more of an additive banking focus than a transformation focus. See ch 5, s5.5.6.5 on Near Field Communications.

${ }^{540}$ On loss allocation, the Code sets out the interplay between payment service providers and consumers. For example, a consumer whose electronic payment account has been hacked into and used by a third party to make purchases without their authorisation will not bear the monetary loss if the account provider is a subscriber to the Code ; a consumer who inadvertently transfers money to the wrong person because they enter the wrong payment details can use the procedures to
} 
South Africa is a developing country whose growth is dependent on a stable financial infrastructure and the ability of its citizens to participate in all aspects of the economy. Lack of access to financial systems limits this growth. The move towards FI has included low-cost banking products like Mzansi, but the most promising is the ability to transact, pay, and do remittances ubiquitously using a mobile phone. Some $31 \%$ of the unbanked have a prepaid cell phone and a further $17 \%$ have access to the mobile phone of a friend or family member.

With this widely available access medium, a proportional prudential regime that enables micro-payments but which is not as onerous as existing payment legislation where applicable, may provide a solution. Since financial exclusion is a reality, there is a need for regulators to balance their objective to protect consumers with the need to expand financial access where the dilemma is more a policy question of how to prudently boost financial access, than as a narrow regulatory concern of how to protect existing consumers. The balance is also between compliance and systemic risk mitigation and expansion of financial access of those at the BOP. The direct cost of complying with regulations however invariably directly impacts the operating expenses of a financial institution.

Possible entrants include Micro Finance Institutions (hereafter MFIs), retailers and MNOs. In the latter two cases, the ability to cross subside their service offerings makes for a compelling business case. Further, for MNOs, there is very little technical infrastructure required to scale up to providing the services contemplated. MFS shows clearly that the nature of banking - the 'business of banking', if it is that - is changing, and with it the lines between traditional bank participants and non-bank participants is becoming blurred. Indeed, transactional banking - rather than pure savings - is now a key element in the relationship between many banks and their customers, but importantly is capable of being offered by non-banks. There is also a blurring of borders between payment instruments.

The SARB indicates that it takes cognisance of social policy imperatives such as the Financial Sector Charter to make financial services more accessible to those in the low-income, unbanked and rural communities. Despite these laudable goals and the siren calls for more progressive regulations to allow non-banks to issue e-money-type instruments to service the unbanked, there have been very few cases of emoney issuance in South Africa, even though some schemes largely resemble e-money in function, but still lack the normative characteristics such as par-value redemption. This impasse is demonstrated in SARB Policy Papers with respect to e-money, which the SARB continues to limit to issuance only by licensed banks despite it implicitly indicating that it recognises that e-money is less of a savings tool and is 
positioned more as a payment and transactional tool. Granted there is a still a cogent need to protect the core of any national payment system and the current legislation and associated regulations that control the NPS reflect this core and the hierarchy and systemic risk. The oversight though appears to be disproportionate to the extent that the crux of the payments system - and the issuance of e-money - is limited to banks. This focus on limiting new payment instruments - such as e-money as a SVP - issuance to banks, it is submitted, is misplaced.

Non-banks, as shown in Kenya where the M-pesa MFS system revolutionised the moribund retail banking and payments ecosystem, have the capacity to alter fundamentally the FI imbalance. Indeed, the progressive policies of the CBK in allowing the then relatively unknown and untested M-pesa MFS system to be introduced into Kenya by the MNO Safaricom in 2006 allowed this to occur. ${ }^{541}$ That said, while the (stalled) Dedicated Banks Bill in South Africa is a welcome start to addressing this need in South Africa, it unnecessarily maintains the focus on the 'business of banking' and the core 'deposit' motif rather than on the evolution of systems that have as its fundamentals, a more transactional and payments foci. The regulatory and policy focus, it is thus submitted, should be on facilitating payments and creating an enabling and proportionate regime thereto, whilst incorporating robust financial consumer protections similar to those in the PSD and enforced by a body similar to the CFBP in the US. Fundamental safety and soundness could be addressed by the use of trust bank accounts for safe storage of user funds. The primary focus, therefore, should be at a high level on how to protect user funds and their use, not necessarily the institution and the instruments involved. ${ }^{542}$

In jurisdictions where an MNO or some MFSP have been given fiat-based redeemable funds from the public for use in a SVA, and where allowed or directed by legislation or the local prudential regulator, the funds have been pooled in what could be called a 'master bank account' the bank account of a separate entity - usually either a separate corporate company or a business trust - that is given responsibility for the safekeeping of user funds. These 'trust' tools are part of the raft of safeguarding measures aimed at ensuring liquidity as part of safety and soundness regimes, aimed at ensuring that customers can ultimately redeem the value placed with the MFSP or MNO, that is, cash out the value provided. It is submitted then that in relation to the provision of fiat-based MFS services in South Africa, that the establishment of trusts to house the 'pool' of funds would be a desirable process that could be made part of the 'bank-lite' or payment provider regime's licensing conditions. The trusts would be under the remit of the FSB.

At a regulatory level then, the current position on a bank-only approach outlined in the SARB's most recent E-money Position Paper $^{543}$ as to who may provide and operate electronic SOVs using fiat values, is too restrictive for a developing economy. This is even more evident when opportunities such as affordable,

\footnotetext{
${ }^{541}$ See ch 10 passim on M-pesa's introduction into Kenya and the CBK's enabling role.

${ }^{542}$ This of course is easier said than done, but co-regulatory bodies like PhonePayPlus in the UK - similar to the selfregulatory WASPA in South Africa - that have evolved micropayment-value-based, and enforced de minimis-aware Codes of Conduct in regard to WASP-type MFS telegraph examples of how stratified, value-based regulations may evolve without derogating from the overall goal of protection of user funds and providing legal certainty for payment services for SVPs in MFS.

${ }^{543}$ See ch 12, s12.4 titled E-Money And Stored Value in South Africa.
} 
manageable, and ubiquitous MFS systems that can be provided by both banks and non-banks present themselves to enhance FI.

It is submitted then that a new 'bank-lite-type' regime - possibly the reintroduction of a revised and appropriately renamed version of the dormant Dedicated Banks draft bill, but preferably rather a new and dedicated PSPL akin to the EMD2 and PSD, so as to emphasise the payments and necessary consumer protection foci.

This PSPL would license and hence would allow specialised PSPs - be they MNOs, WASPs, MFSPs or any other eligible entity licensed as PSPs under the proposed PSPL - to provide Payment Services (PS) and remittances and issue e-money from a SOV akin to the Payment Account (hereafter PA) used in the PSD. ${ }^{544}$ As with the PSD and EMD1/2, the fiat value exchanged for the value should not amount to a deposit per se, although functionally it would serve the same purpose and be redeemable on par and on demand. Time, the apparent subjective arbiter used to determine whether a deposit is at play, would thus be replaced with an objective standard. An associated enabling of agents to act for these new entities, it is submitted, should be part of the new regime.

For safety and soundness reasons, the payments business of a PSP should be ring-fenced to a degree from its primary business via formation of a trust company vehicle which should control the (pooled) funds derived from user prepayment in a special trust bank account. ${ }^{545}$

The PSPs licensed in terms of the proposed PSPL should be allowed access to the NPS to allow for seamless interoperability not just with banks, but with other MFS systems. The degree of access to the various layers of the NPS for any one PSP however would be decided on a case-by-case basis with systemic risk considerations in mind.

In all, this would in essence break the monopoly of licensed banks on use of customer funds without disrupting the financial sector on a systemic basis. ${ }^{546}$

\subsubsection{General Observations on Consumer Protection}

With regard to consumer protection of PS, this was shown earlier to be highly fragmented, even with the omnibus CPA. This equivocation is also highlighted in the varying AML regimes that could apply to MFS, RICA and FICA. The CPA also defers in large measure to the ECTA, which may have direct application to MFS. The ECTA merely provides a general framework for the facilitation and regulation of electronic communications and transactions. The ECTA it was shown however has significant lacunae and

\footnotetext{
${ }^{544}$ This would in essence break the monopoly of licensed banks on use of customer funds.

${ }^{545}$ A formal law recognising them as stand-alone entities able to transact through the NPS may free them from the current forced association with licensed (Tier 1) banks and may reduce associated costs for users.

${ }^{546}$ This is much the same conclusion reached by the Feasibility Study of March 2006 regarding the enquiry into the banking sector in South Africa, and followed subsequently by the Competition Commission enquiry.
} 
inconsistencies in its drafting which significantly dilutes and even negates its efficacy. The ECTA should be amended to fix at the very least the drafting inconsistencies highlighted. The CPA also has provision for deferring regulation to sector regulators - for example ICASA - further diluting its efficacy and setting up the possibility of regulatory arbitrage. Mostly though, the NCC is not a specialised body for financial services. Indeed, from the discussion earlier, there is a cumulative lacuna in oversight as they (together and separately) do not deal with electronic-banking services, 'private currencies', SVPs, SVCs, or e-money per $s e^{547}$

There are thus no legislative-level normative rules applicable to these payment instruments and facilities that could, inter alia, provide guarantees to users that the values embodied in these instruments will be protected in the case of, for example, the insolvency of the issuer. Neither are there any mandated minimum service-level guarantees as to the efficacy of their private payment systems, or concepts as to interoperability and exchange values between 'private currencies'.

It is submitted then that the PSPL also provide for specific consumer protections over both macro and micro retail payments that include EFTs. SVPs and similar prefunded systems that mediate risk-allocation in consumer payments ensure Quality of Service, and provide for the rights and responsibilities of parties. The harmonised PSPL rules would be applied in a symmetrical manner so as to provide some measure of protection to all parties in electronic payments, be it between the payor and the recipient, and between the payor and recipient and their respective financial institutions.

The PSPL should for legal certainty answer some basic questions: ${ }^{.48}$

- Who bears the risk of authorised payments;

- What must be done about claims of error;

- When are payments completed so that they discharge the underlying obligation;

- Can they be reversed;

- And if so, when and how can they be reversed?

While there may be statutory applications to these issues, there may also be tension with the common law at a micro level, although it is submitted that properly devised, elements of the PSPL would in large measure solve the excessively high bar set by each of the condictiones discussed earlier for their use in redress.

Any rules that may be applicable - express or implied - to PS should be removed from the consumer protection provisions of laws such as the ECTA and CPA, and instead consolidated into a framework set of rules in the PSPL.

${ }^{548}$ See ch 12, s12.11 titled Consumer Protection and Loss Allocation with Respect to Payment. 
For enforcement of the PSPL and for licensing of PSP, a specific statutory agency - a Payment Services Regulatory Authority (PSRA) - should be formed to administer the licensing of the PSPs and ensure compliance with the consumer protection provisions of the PSPL.

Regardless of whether a functional, institutional, or single-agency approach is used, the effectiveness can be enhanced by gold-plating the enabling PSPL to clearly define roles, and in particular that it should be given an express mandate on consumer protection issues rather than it being implied. The CFPB in the USA could serve as a model for its operation.

It is accepted though that owing to the de minimis nature of the MNO airtime $\mathrm{SOV}$, for example, there may need to be some off-setting of regulatory oversight at a certain cut off value to a co-regulatory regime, using an entity like WASPA who would have jurisdiction on amounts say under ZAR15,000 and for specific SVP and MFS types. ${ }^{549}$

This would be similar to values allowed to be adjudicated on by Small Claims Courts in South Africa. ${ }^{550}$ Compliance should be enforced through light-touch registration rather than a licensing scheme for these smaller-value SVPs.

\subsubsection{General Observations on Security Aspects}

In regard to AML/KYC, the SARB's Exemption 17 is a welcome enabler of Financial Inclusion. The double-requirements for a RICA and FICA-based registration scheme however may hinder this, especially since the respective CIV procedures are not to be aligned. This will require the respective regulatory bodies to coordinate their AML/CT procedures. Further, transfer of private currencies ${ }^{551}$ like airtime minutes and airmiles may circumvent AML rules if the definitions of what is captured in these AML regimes particularly if they pivot around money - are not correct. FICA ${ }^{552}$ sounds in money, and as such this may not necessarily capture the 'non-money' airtime SOV in regard to national and cross-border transfers.

In all, scaling up to create an omnibus PSPL with specific goals, rules, protections and principles in South Africa alongside a specific agency akin to the $\mathrm{CFPB}^{553}$ in the US for enforcement - either on a statutory or co-regulatory basis based on value - is, it is submitted, desirable in the context of the transformational banking nature of the South African market. ${ }^{55}$

\footnotetext{
${ }^{549}$ The success of WASPA in handling consumer complaints on micro-payments based on WASP VAS using both formal and informal techniques for this purpose, and which is enforced through tightly enforced Code of Conduct indicates the possibility of this approach.

550 Small Claims Court Act 61 of 1984. In terms of notices issued in terms of Sections 15 and 16 of the Act, the maximum (fiat-based) claim that can be adjudicated on ZAR12,000. See Government Notice R985 of 27 October 2010. Most disputes in the VAS domain in South Africa are under ZAR15,000.

${ }^{551}$ On private currencies, see ch 4, s4.8.4.4.4.1.

${ }^{552}$ FICA op cit note 1.

${ }^{553}$ See on the CFPB ch 11, s11.2.4.2.2.

${ }^{554}$ See Recommendation 8 in ch 14, s14.9.7 on the need for a dedicated agency (authority) to regulate consumer payments.
} 


\section{CHAPTER 13}

\section{RE-EVALUATION OF MONEY}

\section{Introduction}

\subsection{1}

\section{Rationale}

The legal nature of money is a topic not often dissected or discussed in any great depth. On the one hand it may, as Keynes blithely put it, be because of the potential 'madness' ${ }^{1}$ the study of money evokes.

Alternatively, as Phandor Eder presciently commented in 1935, it may be for the somewhat more prosaic reason of stability:

'One of the penalties paid for the blessings of stability of the currency is that the law finds itself unprepared for unexpected and revolutionary changes in the monetary system. Money constitutes the most vital part of the substructure of the entire legal system, but when its stability is taken for granted, monetary questions rarely come before the courts and no analysis of underlying legal theories becomes necessary. ${ }^{2}$

Having surveyed the emerging technology, banking and payments landscape and their respective interaction with the common law and statue, the preceding chapters manifestly demonstrate that the rapid commercial adoption of new technologies in the form of Mobile Financial Services-based Stored Value Products (hereafter MFS and SVPs respectively) and associated transaction-based payment facilities by entities such as Mobile Network Operators (hereafter MNOs) and Mobile Financial Service Providers (hereafter MFSPs) which control and service them, challenge the settled views of dealing with matters of money. ${ }^{3}$

At issue is whether these new forms of payment - if they may thus far be so called in contradistinction to money - indeed amount to money. In other words, the transactions-based nature of these and other systems appears to bring about a need for a re-evaluation and understanding of money.

\footnotetext{
${ }^{1}$ JM Keynes (1930) A Treatise on Money at 5.

2 PJ Eder (1935) 'Legal Theories of Money' 20 Cornell Law Quarterly at 52. And as Chung also describes this:
}

'The likely reason such questions are not asked is because the answers seem so well-settled, and money carries with it the appearance (or illusion) of stability.'

JJ Chung (2009) 'Money as Simulacrum: The Legal Nature and Reality of Money' 5 Hastings Business Law Journal at 110.

${ }^{3}$ See ch 3 for a comprehensive introduction to the money-related concepts discussed in this chapter, and specifically therein ss 3.9 on the Orthodox School and 3.10 on the Claim School. See also inter alia ch 2 on an introduction to MFS, and specifically therein Exhibit A in s2.1 demonstrating the relationships and interactions within a SVP used in MFS; also ch 4 on banking and payments, and specifically therein s4.8.4.4 on SVPs and the features, incidences and interactions of its component forms; ch 5 on mobile technology; ch 6 on MFS Models, and specifically therein s6.5.4.2 on the Wireless Application Service Providers (hereafter WASPs). 
It has been suggested, however, that settling on a definition of money that provides legal (and economic) certainty should be held over until technology provides the reason. ${ }^{4}$ The emergence of SVPs generally and MFS specifically provides the trigger, it is submitted, for a re-evaluation of money.

\begin{abstract}
${ }^{4}$ WG Schulze (2004b) 'E-money and Electronic Fund Transfers: A Shortlist of Some of the Unresolved Issues' 16 SA Mercantile Law Journal at 50. Further, on legal aspects relaying to money, see: A Nussbaum, (1950) Money in the Law: National and International; B Geva and M Kianieff (2002) 'Reimagining E-Money: Its Conceptual Unity with other Retail Payment Systems' at 6-7, available at http://goo.gl/QfR4y; C Proctor (2005) Mann on the Legal Aspect of Money 6 ${ }^{\text {th }}$ ed; D Fox (2010b) 'The Case of Mixt Monies: Confirming Nominalism in the Common Law of Monetary Obligations', available at http://goo.gl/lcKOF; D Kreltszheim (2003) 'The Legal Nature of "Electronic Money": Part 1' 14 Journal of Banking and Finance Law and Practice 161; DM Fox (1996) 'Bona Fide Purchase and the Currency of Money' 55 Cambridge LJ 547565; DM Fox (2008) 'Property Rights' in Money; DM Fox (2010a) 'Identification of Money at Common Law' 69 The Cambridge Law Journal 28-30; FA Mann (1992) The Legal Aspect of Money $5^{\text {th }}$ ed; FR Malan, JT Pretorius and SF du Toit (2009) Malan on Bills of Exchange, Cheques and Promissory Notes $5^{\text {th }}$ ed; JM Keynes (1937 repr 1973)The General Theory Of Employment, Interest And Money; JS Rogers (2005) 'The New Old Law of Electronic Money' 58 Southern Methodist University Law Rev 1253-1311, available at http://goo.gl/KetTp; JT Pretorius (2004) 'The Bona Fide Purchaser of a Krugerrand' 16(3) SA Mercantile Law Journal 466-476; R Bollen (2004) 'A Review of the Regulation of Payment Facilities' 11(3) Murdoch University Electronic Journal of Law, available at http://goo.gl/Tsn4j; R Goode (1995) Commercial Law $2^{\text {nd }}$ ed at 490; R Mackenzie (1998) 'Virtual Money, Vanishing Law: Dematerialisation in Electronic Funds Transfer, Financial Wrongs and Doctrinal Makeshifts in English Legal Structures' 2(1) Journal of Money Landering Control; RA Bollen (2005) 'What a Payment Is (And How it Continues to Confuse Lawyers)' 11 Murdoch University Electronic Journal of Law at 190, available at http://goo.gl/y1UOR; RM Goode (1983) Payment Obligations in Commercial and Financial Transactions; RM Goode (2004) Commercial Law 3rd ed; RW Sifers (1997) 'Regulating Electronic Money in Small-Value Payment Systems: Telecommunications Law as a Regulatory Model' 49 Federal Communications Law Journal 701 at 704-705; S Wadsley and GA Penn (2000) The Law Related to Domestic Banking $2^{\text {nd }}$ ed; SF du Toit (2009) 'Die Dematerialisasie Van Geld: In Die Skadu Van Die Sakereg' Tydskrif vir die Suid-Afrikaanse Reg 1; VA Lawack-Davids (2000) 'Legal Aspects of Internet Payment Instruments' Unpublished LLD Thesis, University of South Africa; and WW Hudson (1895) 'Scientific Standard Money' 2(3) Modern Culture 581.
\end{abstract}

Cases and statues cited inter alia include: Miller v Race (1758) 1 Burr 452; Re Charge Card Services Ltd. [1988] 3 All ER 702 (CA); Moss v Hancock [1899] 2 QB 111 (hereafter Moss); United Dominions Trust Ltd v Kirkwood [1966] 2 QB 431 (hereafter UDT); Directive 2000/46/EC on the Taking up, Pursuit of and Prudential Supervision of the Business of Electronic Money Institutions (EMD1); Directive 2009/110/EC On The Taking Up, Pursuit And Prudential Supervision Of The Business Of Electronic Money Institutions (EMD2); and the Consumer Protection Act 68 of 2008 (hereafter CPA).

On anthropological and sociological approaches, see: A Mitchell-Innes (1913) 'What is Money?' The Banking Law Journal, available at http://goo.gl/Ya1Ck; AM Mitchell-Innes (1914) 'The Credit Theory of Money' 31 The Banking Law Journal 151-168, available at http://goo.gl/DXbDJ; D Graeber (2009) 'Debt: The First Five Thousand Years', available at http://goo.gl/glvJs; E Lagerspetz (1984) 'Money as a Social Contract' 17(1) Theory and Decision 1-9; G Ingham (2002) 'New Monetary Spaces?' in Organisation for Economic Co-operation and Development 'The Future of Money', available at http://goo.gl/RTOse; G Ingham (2000) 'Babylonian Madness': On The Historical And Sociological Origins Of Money' 16 in J Smithin (ed) (2000) What Is Money?; J Smithin (ed) (2000) What Is Money?; K Hart (1986) 'Heads or Tails? Two Sides Of The Coin' 21(4) Man at 637-656; K Hart (2005) 'Notes Towards An Anthropology Of Money' 2 Kritikos, available at http://goo.gl/yXXiZ; LR Wray (2010b) 'Keynes's Approach to Money: What can be Recovered?', available from http://goo.gl/7aeUT; and P Pilkington (2011) 'What is Debt? - An Interview with Economic Anthropologist David Graeber', available at http://goo.gl/b86br.

Classic works on money cited in this chapter are: C Menger (1892) 'On the Origin of Money' 2 Economic Journal 239255; FA von Hayek (1976) Denationalisation of Money: An Analysis of the Theory and Practice of Concurrent Currencies; FA Walker (1879) Money in its Relations to Trade and Industry; G Simmel (1900) Philosophie des Geldes $5^{\text {th }}$ ed; G Simmel (2004) The Philosophy of Money $3^{\text {rd }}$ enlarged ed; GF Knapp (1924) The State Theory of Money; JM Keynes (1971) A Treatise on Money; L von Mises (1953) Theory Of Money and Credit, available at http://goo.gl/HnPCx; and WT Newlyn and RP Bootle (1978) Theory of Money $3^{\text {rd }}$ ed.

On electronic money (e-money) and Stored Value Products (SVPs) and their effect, see: A Berentsen (1998) 'Monetary Policy Implications of Digital Money' 51 Kyklos 89-117; B Ely (1996) 'Electronic Money and Monetary Policy: Separating Fact from Fiction' Cato Institute's Conference on The Future of Money in the Information Age, May 23, 1996, available at http://goo.gl/GjgXN; B Lietaer (2001) The Future of Money: Creating New Wealth, Work and a Wiser World; C Costa and P de Grauwe (2001) 'Monetary Policy In A Cashless Society', available at http://goo.gl/3j7q2; C Fullenkamp and SM Nsouli (2004) 'Six Puzzles in Electronic Money and Banking', available at http://goo.gl/b8rwZ; C Goodhart and M Krueger (2001) 'The Impact of Technology on Cash Usage' No 4 Exchange: The Magazine of De La Rue 9-11, available at http://goo.gl/WiWJl; C Holtzhausen and C Monnet (2003) 'Money and Payments: A Modern Perspective', available at http://goo.gl/VdrOo; CAE Goodhart (1989) Money, Information and Uncertainty $2^{\text {nd }}$ ed; CW Herrmann (2007) 'Contemporary Perspectives on Monetary Sovereignty', available at http://goo.gl/HBsOJ; G Papadopoulos (2007) 'Electronic Money and the Possibility of a Cashless Society' at 1, available at http://goo.gl//TFzG; NF Piffaretti (1998) 'A Theoretical Approach to Electronic Money FSES-302', available at http://goo.gl/UDlv1NF; R Bootle (2001) 'The Future of Electronic Money: Why the Nok will not Replace the Dollar' 32(1) The Business Economist 7-15; SA Bell (1998) The Hierarchy of Money Jerome Levy Economics Institute Working Paper No 231, available at http://goo.gl/mNvnx; SW Schmitz (2005) 'Will Central Banks Survive Electronic Money?' prepared for the conference The Future of Payments, Bank of England, London 19-20 May; SW Schmitz (2006) 'eMoney and Monetary Policy: The Role of the Inter-eMoney-Institution Market for 
As was noted by Moini in this regard:

'The accelerating transformation of the payment system due to the impact of Information Technology ... has brought about monetary phenomena and policy issues that cannot be properly analyzed by means of the traditional concepts of monetary economics. ${ }^{5}$

The reasons for such a re-evaluation are manifest: many laws and regulations sound in money, and the actions and rights obtaining to money - in whatever guise - depend on a proper, updated classification of money. ${ }^{6}$

Intimately connected to this enquiry into whether an entity that stores value in a SVP system is engaging in deposit-taking, is the understanding that money lies at the core of the banking ecosystem and a banker is 'one that traffics in "money",7 which may mean 'Bank Money, ${ }^{8}$ and instruments treated as money. ${ }^{9}$

The crisp question that then follows is whether the MFS-based airtime Stored Value Account (hereafter SVA) - as a genus of the SVP family - as offered by MNOs or other similar system operators, and the Store of Value (hereafter SOV) therein can be seen as money such that these operators may be in contravention of banking legislation for engaging in deposit-taking without a requisite banking license. ${ }^{10}$

Settlement Media and the UOA: A Critical Assessment of the Literature' in Schmitz, SW and Wood, GE (eds) Institutional Change in the Payment System and Monetary Policy by Electronic Money Innovations: Implications for Monetary Policy; and T Palley (2001-2002) 'The e-Money Revolution: Challenges and Implications for Monetary Policy' 24 Journal of Post Keynesian Economics at 217-233, available at http://goo.gl/MeGW8.

On macro-economic perspectives, see: BP Pesek and TR Saving (1970) Money, Wealth, And Economic Theory; GA Selgin and LH White (2002a) 'The Future of Fiat Money: A Mengerian Perspective' available at http://goo.gl/MRBhW; HP Minsky (1986) Stabilising an Unstable Economy; J Kutyn (2005) 'Nature of Money'. available at http://goo.gl/5pbSB; K Matthews (2011) 'Lecture Slides for Money, Banking \& Finance' Cardiff University, available at http://goo.gl/arwNn; KL Macintosh (1998) 'How to Encourage Global E-Commerce: The Case for Private Currencies on the Internet' 11 Harvard Journal of Law and Technology 733; LR Wray (1990) Money and Credit in Capitalist Economies: The Endogenous Money Approach; LR Wray (2010) 'Money Levy' Economics Institute Working Paper No 647, available at http://goo.gl/qPn16; M Mellor (2011) 'The Confusing World Of Modern Monetary Theory', available at http://goo.gl/p1Ucr; and M Sawyer 'Money: Means of Payment or Store of Wealth?' (2003) in L-P Rochon and S Rossi Modern Theories of Money: The Nature and Role of Money in Capitalist Economies 3-17.

${ }^{5}$ Moini, M (2001) 'Toward a General Theory of Credit and Money' 14(4) The Review of Austrian Economics 267-317 at 309.

${ }^{6}$ There is also an economic reason: global markets have seen financial innovation and deregulation but this has led to the breakdown in the traditional relationships between the measures of money and economic activity, and as such has raised the issue as to what is meant by money. See Matthews (2011) op cit note 4.

${ }^{7}$ Lord Denning in UDT op cit note 4 at 445, quoting Dr Johnson.

${ }_{9}^{8}$ See ch 3,s3.5.3.3.2 on 'Bank Money', a phrase termed by Keynes.

${ }^{9}$ Wadsley and Penn (2000) op cit note 4 at 92.

${ }^{10}$ The issue also revolves around context: many of these MFS-based fiat and airtime-based SVPs are now used for transactions beyond just those provided by the issuer, for example, financial-type transactions whereby someone can for example buy prepaid funeral insurance with prepaid mobile airtime balances, or enter competitions or buy any other digital goods. In these instances, the value may be less about an advance payment for goods and services - which would mean it does not fall under the 'deposit' exemption prevalent in many legislative frameworks relating to banking licenses - and more about a deposit alongside all the prudential and personal rights implications that obtain. See ch 4, ss 4.4 on deposit taking, and 4.5.3 on licensing. For a graphical representation of the relationships between SVPs, SVAs and UOAs, see Exhibit A in ch 2, s2.1. The configuration and order then is that there is a SVP offered to users which may contain different types of SVAs, each with its own type of SOV denominated in a specific UOA. These SOVs may for example be airtime- or fiat-based, denominated in a UOA of the fiat of the national currency such as the Rand; or some other private UOA, such as airtime minutes respectively. See further ch 4, s4.8.4.4.4.1 titled Private Currencies. On the hierarchy of biological classification, see 'Genus' (s.d.) in Wikipedia: the Free Encyclopedia, available at http://goo.gl/esvju; and for an explanation of its parallel use in this study, see ch 4, s4.8.4.4.2 on SVP Nomenclature. 
While the enquiry that follows relates to SVPs generally, the enquiry is focused specifically on the inherent quality of the mobile airtime-based prepaid SVA as is used in MFS: the crisp issue then is whether a mobile-based prepaid SVA is storing money per se, or if the SOV therein is simply a claim to (Generally Accepted Means of Exchange) ${ }^{11}$ money? This may affect then inter alia rights to and in 'money,' consumer protection measures, and Anti-Money Laundering (hereafter AML) legislation relating to money: if, according to a legal analysis of money, something is not money then could these laws strictly apply and how would they apply? ${ }^{12}$ Similarly, could these values to be interpreted as a Store of Wealth (hereafter SOW)?

While prima facie new electronic forms of money and their core payment functionality may appear to approximate to modern forms of money, lingering questions still remain about whether the nature of money is changing in the light of emerging technology. This again precipitates the need for a reevaluation. It is submitted that the broad goal of such re-evaluation is to attempt to find a basis for consistency in laws sounding in money as well as an equivalence of rights pertaining to money, in whatever form ${ }^{13}$ money may be, whether in corporeal or in emerging incorporeal forms.

This issue was framed by Proctor thus: ${ }^{14}$

'If money is to exist in several different forms, then the law should certainly ensure that the rights of a person who receives "money" are essentially the same, irrespective of the precise form in which that money is received. If new means of payment are to constitute "money", then consistency and the lawyer's respect for precedent demand that these new means must display characteristics which are in most respects similar to the more traditional, physical forms of money.'

It is evident then that as a result of the emergent, hybrid SVAs, there needs to be clarity as to what money is before embarking upon an examination of the legal (and economic) consequences of its (potential) new form. Indeed, a 'new' framing may be necessary to provide a coordinated view of money. ${ }^{15}$

The consequences of a failure to do so was ably outlined by Eder in the context of money the 1930s, but which remains relevant today, that:

\footnotetext{
'No attempt appears to have been made to correlate the special topics to the much broader field of monetary legal theory. Lacking a comprehensive treatment of the whole subject, not alone the bar and the courts, but also the legislative and executive authorities may fall into errors, of language at least, that may tend to distort in unexpected ways the whole legal structure. ${ }^{, 16}$
}

\footnotetext{
${ }^{11}$ See ch 3, s3.5.3.3.1 on the GAME.

${ }^{12}$ See ch 13, s13.8.2.2 titled Specific Legal Effects. See also Mackenzie (1998) op cit note 4, in relation to something of value not being found to be money because of the legal system's inability to deign a new context and role for money due to technological advances, and this may have implications for value not being seen as money laundering.

${ }^{13}$ Even the notion of whether 'form' is the correct descriptor is up for discussion.

${ }^{14}$ Proctor (2005) op cit note 4 at 37-38

15 As Kianieff (2008) op cit note 4 at 14 puts it, the enquiry is whether these new forms are merely (new) payment mechanisms, or are they entirely new forms of money.

${ }^{16}$ Eder (1935) op cit note 3 at 52 .
} 


\subsection{2}

\section{Parameters of the Enquiry}

The context of an enquiry into money devolves from the locus classicus case on money, Moss, ${ }^{17}$ where Darling $\mathrm{J}$ in 1899 described money (and this description is repeated here for convenience) as:

'[T]hat which passes freely from hand to hand throughout the community in final discharge of debts and full payment for commodities, being accepted equally without reference to the character or credit of the person who offers it and without the intention of the person who receives it to consume it or to apply it to any other person other than in turn to tender it to others in discharge of debts or payment for commodities.'

This legal definition of money as adopted by Darling $\mathrm{J}$ in Moss was based on a book published by FA Walker, ${ }^{18}$ which had however been criticised earlier by WW Hudson:

\footnotetext{
'The fault of this definition is that it tells certain things which are true about money without any allusion to the things which make true money. It deals with superficial facts of money, but does not touch the fundamental facts of money at all. It is an entirely worthless definition for purposes of science, although a very good statement of what in general money serves for. ${ }^{19}$
}

As noted earlier, FA Mann ${ }^{20}$ also criticised this definition of money as incorrectly appropriating an economic, functional approach to money rather than determining it to be that which is to settle debts. Despite its apparent inadequacies, the definition in Moss has survived into the modern era.

A putative extrapolation of Moss in relation to an investigation of SVPs generally is suggested by Geva and Kianieff who paraphrase the criteria in Moss to mean that for something - here SVPs - to rise to be money, there must be an enquiry into some direct and incidental features of money such as whether it passes freely from hand to hand; ${ }^{21}$ whether it circulates; ${ }^{22}$ whether it is acceptable to a wide range of creditors (acceptors) $;^{23}$ whether anonymity ${ }^{24}$ is a relevant feature; whether there is no recourse against the offeror; ${ }^{25}$ and whether it confers final discharge of debts. ${ }^{26}$

While they righty discard inter alia $^{27}$ the chattel component - that is, a tangible component -in Mann's definition of money ${ }^{28}$ as being relevant to any enquiry on money, they also say that 'the adoption of the

\footnotetext{
${ }^{17}$ Moss op cit note 4.

${ }^{18}$ Walker (1879) op cit note 4 at 4.

${ }^{19}$ Hudson (1895) op cit note 4 at 581 .

${ }^{20}$ Mann (1992) op cit note 4 at 8. Mann's definition of money, repeated here for convenience, was framed as being:
}

'[A]1l chattels which, issued by authority of law and denominated with reference to a unit of account, are intended to serve as a universal medium of exchange in the state of issue.'

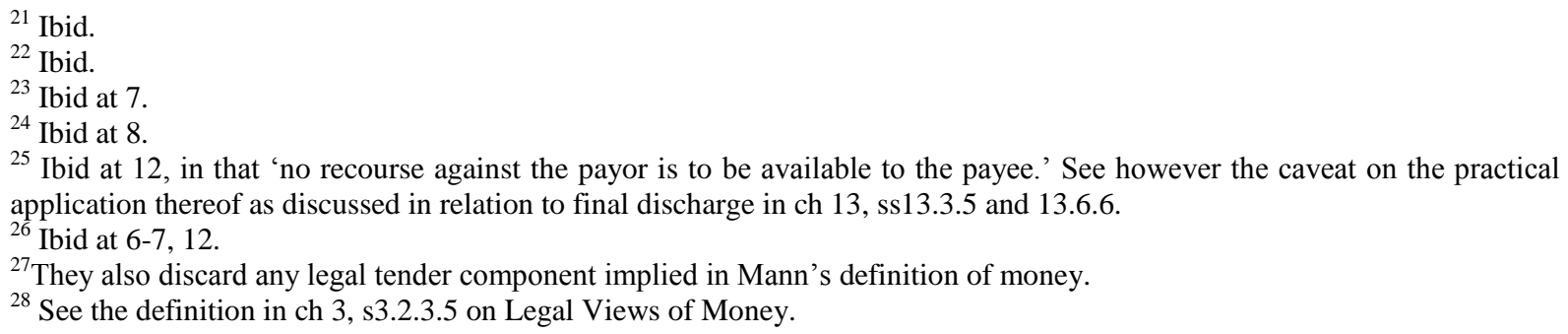


economic definition by Moss v. Hancock appears to [them] to be satisfactory, ${ }^{29}$ but do not define what 'the' refers to. While also seemingly ignoring the implied tangibility-related criteria ${ }^{30}$ in Moss and impact if any thereof, they also appear to imply - misplaced, it is submitted - that their acceptance of 'the economic definition' negates the need for any further enquiry into the true meaning and import of 'the economic definition,' particularly whether or not 'the' economic definition used to analyse SVPs indeed provides any direct nexus to Moss so as to allow emerging SVPs to be legally classed as money.

It is submitted however that any legal enquiry into money must have a focus on the implications of any available economic definitions associated with money. In this instance, the focus should be on which of the most available economic criteria for money could amount not only to the 'the,' but also indeed which of them are best suited to founding a nexus - an 'equivalence' - of emerging SVPs to Moss.

With Moss then as the common law standard bearer in understanding the legal basis for money, the enquiry as to whether SVPs and other emerging intangible forms of value such as MFS-based SOVs can, it is submitted, be properly framed by using Orthodox School and Claim Schools views of money as the basis for an expanded enquiry into the 'economic definition.'

The theoretical basis for each of these two Schools was earlier ${ }^{31}$ comprehensively set out, where it was noted that the Orthodox School has dominated the legal and economic view of money. ${ }^{32}$ It was also noted ${ }^{33}$ that prima facie it appears that the Claim School with its 'tangible-free', debt-based focus and conceptualisation of money appears to provide a better theoretical underpinning for emergent transaction media potentially claiming the mantle of money. ${ }^{34}$

The goal then in this Chapter is a practical application of each of the two Schools to SVPs - particularly those used in MFS - in an equivalence analysis to determine which of the two best provides for an economic underpinning of a legal nexus to Moss. ${ }^{35}$ The equivalence criteria outlined above ${ }^{36}$ to be used in the expanded enquiry relate specifically to tangibility, circulation, acceptance, anonymity, and final discharge. The criteria in each of the economic Schools are also practically applied in the analysis.

\footnotetext{
${ }^{29}$ Geva and Kianieff (2002) op cit note 4 at 6.

${ }^{30}$ In causa, they imply that the definition of money in Moss is ostensibly free of any other similar tangible connotation. This assumption appears to be based on a failure to apply a more cogent analytical enquiry into the wording and context used in Moss - such as the 'tangible' implication of the wording 'hand to hand' and 'to consume it' - and particularly any observation that the economic definition used in Moss was not only of a time where tangible components prevailed as 'money,' but that the criteria for money in Moss themselves seemingly imply the need for some tangibility. This incongruity may, as will be discussed below, possibly be a nugatory factor - depending on the 'economic definition' of money used - in founding an equivalence of SVPs so as to be money when using the criteria in Moss op cit note 4.

${ }^{31}$ See passim ch 3 titled Overview of Money.

${ }^{32}$ See ch 3, s3.9 on the Orthodox School. For an historical exposition of how the common law came to appropriate the Orthodox School, see Mann (1982) op cit note 4 at 1-10.

${ }^{33}$ See ch 3, s3.14 titled Summary and Conclusions.

${ }^{34}$ That these technologies may also be payment systems is comparatively easier to analyse.

${ }^{35}$ It must be noted here that a focus on the Claim School is not just a way to contrive to find a way of assimilating SVPs so as to determine that they amount to money, but as a modest attempt to assay a potential 'fix' for the specific doctrinal dogmas that may arise and to determine (using both Schools) whether fiat-based and airtime based MFS SVPs can amount to money.

${ }^{36}$ That is, whether it passes freely from hand to hand; whether it circulates; whether it confers final discharge of debts; whether there is no recourse against the offeror; whether it is acceptable to a wide range of creditors (acceptors); and whether anonymity is a relevant feature.
} 
A caveat should however be noted in the use in the equivalence enquiry of the "final discharge ${ }^{, 37}$ criterion of Moss - and the extrapolation thereof by Geva and Kianieff as 'no recourse' ${ }^{38}$ - as one of the criteria has some equivocation in practical application. In one sense in relation to a generic SVP, this could mean that no recourse against the payer (in a transaction) is to be available to the payee upon the default of or change to usage rules by the issuer of the SVP's SOV. In another sense, it could also reflect the potential of what could be termed 'adverse title' of payer insofar as there are equivocations in the SVA usage as to whether there is an absolute or conditional right to use the SOV in the SVA.

In WASP Value Added Services-based (hereafter VAS) MFS transactions, for example, this could also manifest in a number of ways. ${ }^{39}$ From a subscriber perspective, this 'adverse title' issue could, affecting both the subscriber and the WASP, relate to the continued existence of the SVA itself, ${ }^{40}$ such that default of the (MNO) issuer ${ }^{41}$ would negate any ability by the payee - the WASP, in this context - to claim any value due. Similarly, the user would not be able to claim value from the MNO in case of default. ${ }^{42}$

In this case final discharge may not occur because the payer (the subscriber) cannot be held accountable by the WASP - as the payee - for the MNO default. Similarly affecting both the subscriber and the WASP is a second issue which revolves around the quality (of use) of the SVA itself by an MNO or by an MFSP's subscribers in transactions and which could impede 'final discharge'.

Seen from a user perspective, this quality impact could arise from expiry of the SVA (thus rendering the SOV void), or by restrictions by the MNO, MFSP or even regulations ${ }^{43}$ on the type (or value) of transactions that can be used. ${ }^{44}$

\footnotetext{
${ }^{37}$ That is the invocation in Moss op cit note 4 for someone to accept the value 'without reference to the character or credit of the person who offers it.'

${ }^{38}$ Geva and Kianieff (2002) op cit note 4 at 12.

${ }^{39}$ The discussion is predicated on a certain conception of the MNO-WASP-Subscriber contractual relationships. Depending on the jurisdiction and the contracts specified in a particular circumstance, the subscriber and the WASP may be deemed to have a direct contractual nexus for payment; in others, the payment by the subscriber is to the MNO, who is said to have the direct relationship with the WASP. See ch 6, s6.5.4.2 on WASP VAS on the (complicated) apparent relationships in the WASP industry. The discussion in this section reflects, rather, a generic viewpoint on these relationships.

${ }^{40}$ Here the MNO, for example, acting as an issuer owes a 'debt' to the mobile subscriber (the payee, in this context) in the circulating rights mélange that is characteristic of EFTs and scriptural values generally

${ }^{41}$ In an MFS WASP VAS sense, say in a scriptural fiat-value 'outpayment' to a WASP by an MNO after a user's VAS transaction.

${ }^{42}$ Ordinarily, when seen as being analogous to a deposit, the MNO subscriber has a personal right to the value in the SVA the for the use of that value, although this common law conception appears to be challenged by s65(2) of the CPA which indicates that the subscriber, rather than the MNO issuer, holds 'ownership' of the SOV. This section does however not apply to a) a bank, a mutual bank, or any other financial institution that is similarly licensed and authorised to conduct business and take deposits from the public in terms of any national legislation. See the discussion on this section in ch 12, s12.10.2.2.2 on Ownership of MFS SOV Value; and also ch 8, s8.7 on an introduction to the CPA; and generally on prepaid SVAs used in MNOs, see ch 5, s5.4.2 titled Prepaid Consumer Billing Systems. See also Exhibit A in ch 2, s2.1.

${ }^{43}$ See for example the restrictions on storage and use mandated by the so-called 'FICA' regulations in South Africa. On FICA, see ch 12, s12.7 on AML and CTF.

${ }^{44}$ Some MNOs have revoked the SOV value in a SVA when users have moved from prepaid to postpaid value, while others have 'mid-stream,' barred users from using their SVA for WASP Premium Rated Services. See for example the reported SMS from South African MNO Cell C to its users that 'From 8 Aug 2012 please recharge with prepaid airtime to pay for content services. These costs will no longer be paid from your Control Chat Top Up airtime. Cell C.' See the consumer reaction thereto at Mybroadband (2012) 'Thread: Control Chat - Recharged Prepaid Airtime Only to Pay for Content Services', available at http://goo.gl/VfQIl. A similar 'quality' equivocation could arise from the stymying of attempts by the WASP to obtain from the MNO a fiat 'outpayment' based on a VAS transaction that debited the subscriber's SVA for that transaction. For example, a State or self-regulatory authority may find mala fides in the transaction and force the MNO to reverse the transaction. Payment would thus not necessarily be made and the SVA would not be debited, or the debit reversed, both with the effect that there is no 'final discharge.' See similarly, Re Charge Card Services Ltd. [1988] 3 All ER
} 
A third issue that would impact the use of the SOV as final payment could also relate to the veracity of the liability of the holder of the SVA in needing to pay for a transaction. The issue arises because the current holder of a SVA - usually linked to a particular mobile phone number - could be using a 'recycled ${ }^{45}$ mobile phone number such that the current owner is billed for VAS subscription services initiated by the previous owner of that phone number. ${ }^{46}$

That said, the focus in the money re-evaluation that follows will be towards the SVP in the form of the MNO-controlled prepaid SVA and the quality of the SOV therein, used in MFS as a potential form of what we may come to call 'mobile money' (hereafter m-money) as it is often commercially known ${ }^{47}$ in so far as being a variant ${ }^{48}$ of electronic money (hereafter e-money). ${ }^{49}$

The enquiry may also generally include other emerging SVPs forms of value such as 'private' social media currencies such as Facebook Credits ${ }^{50}$ as potential replacements for fiat money ${ }^{51}$ and possibly to act as legal tender. ${ }^{52}$

The comparative analysis is not complete without further analysis of the economic and legal impact of these emerging SVPs. This then forms the basis of the discussion of the re-evaluation of money that follows. $^{53}$

702 (CA) at 707 where it was said that 'If it is not honoured, the condition is not satisfied and the liability of the [payor] to pay...remains.'

${ }^{45}$ See the brief discussion in the footnotes to ch 5, s5.2.2. titled User Access to Mobile Networks in relation to the effect of so-called mobile phone number 'recycling' by an MNO, the process whereby an unused mobile phone number is after a time of inactivity allocated to a new owner. As noted earlier, the inactivity causing the recycling could relate to the failure (by the previous owner) to 'recharge' the SVA with mobile airtime SOV such that the SVA had a zero balance for some time. Essentially then and especially in a prepaid mobile airtime ecosystem, some three to six months after the last use, the MNOs will issue a new SIM card for sale and provide the inactive number with that new SIM card.

${ }^{46}$ Ibid. As noted earlier, the current owner is, based on the number in use, thus billed for VAS subscription services initiated by the previous owner who eventually effectively relinquished use on that phone number through inactivity. For the WASP merchant, the adverse title may be of little interest - he may be happy just to do the billing and receive the value from the MNO. See ch 5, s5.4.4.2 on subscription (periodic) billing of VAS by WASPs; and ch 6, s6.5.4.2 on WASPs.

${ }^{47}$ See ch 2, s2.1 titled Introduction.

${ }^{48} \mathrm{New}$ forms of money that we will then analyse include electronic forms of money, e-money, m-money, SVPs, and their relation to new forms of payments. The literature on the topic refers primarily to e-money rather than what is standardised on in this study as a SVP. Thus SVP and e-money are used interchangeably, although in this study e-money, like the MFS-based SVA, is seen as a species of the family SVP. See ch4, s4.8.4.4.2 on SVP nomenclature; and again, Exhibit A in ch 2, s2.1 showing a graphical representation of these taxonomical hierarchies. See also Exhibit A in ch 13, s13.9 below which shows a possible taxonomical hierarchy linking MFS SVPs such as 'm-money' to 'debt.'

${ }_{49}$ To be clear: usually when the existing literature refers to 'e-money', it refers primarily to private e-money, not $\mathrm{CB} /$ government e-money. $\mathrm{CB}$ monetary policy is conducted through open market operations using electronic money for settlements and payments, which allows it to maintain monetary control and achieve its policy goals in the world of government electronic money.

${ }^{50}$ See ch 3, s3.5.3.3.1 on the GAME.

${ }^{51}$ Whether they rise to the legal requirements will be determined, under current guidelines, inter alia by their form; and whether they rise to the economic requirements will require assessing their nature within the theoretical confines of either the Orthodox or Claim School.

${ }^{52}$ In this context, the evident lacunae in our understanding of money precipitated by these emerging technologies is what will be addressed here. In so doing, cognisance will be made of the differences between SVPs which are denominated in the Unit of Account (hereafter UOA) of the Generally Accepted Means of Exchange (hereafter GAME), but which are currently seen more as advance (prepaid) purchases for goods and services, and SVPs that may be similar in the UOA but which are fiat-based and fully redeemable and at par: essentially an electronic representation of the GAME. See ch 13, s13.8.2.2 on legal tender.

${ }^{53}$ The re-evaluation analysis may proceed on one of two tracks. Either the nominalist approach which attaches labels to real world objects; while the empiricist approach attach labels to concepts and then search for the corresponding real world entity. In a manner, the analysis in this chapter proceeds along the Empiricist approach. See Matthews (2011) op cit note 4. 
A.

13.2
Orthodox School View

\section{Core Orthodox School Economic Characteristics}

\section{A Store of Value (SOV)}

A feature of the Orthodox School ${ }^{54}$ view of money is that for something to be money it must somehow have a SOV, or else it presumably would not be accepted by any parties to a transaction.

In the Orthodox School, tangible sense, the 'face value' of the money must be maintained. From the perspective of the SVP-user, the SVP-issuer - which could be the System Operator (hereafter SO) - would need to ensure the unit value stored as a SOV_by the system in the SVA following an input of value by the user ${ }^{55}$ is maintained. ${ }^{56}$

However, in an SVP environment - either as a UOA in the GAME, or as some other private UOA - this ability to maintain the 'face value' may be contestable through contract or other legal or statutory incidents. From a user perspective, for example, the face value may expire after a certain time. ${ }^{57}$ The SVA may thus after that point not have stored anything. Further, from an SVP-issuer perspective, the SVA may have only a limited ability to provide value per se, and may indeed be a liability of sorts: with mobile airtime-based MFS SVAs for example, the unit value stored available to the user may differ from the input (or prefunding) value. ${ }^{58}$

\subsection{2}

\section{Unit of Account (UOA)}

As indicated earlier, ${ }^{59}$ the UOA usually refers to a standard unit in which prices and debts are measured. In the Orthodox School, this is almost always needs to be denominated in the Central Bank (hereafter CB) GAME. ${ }^{60}$

A fiat-based MFS SVA usually uses the UOA denominated by the CB in the State of issue, that is, that of the UOA of the GAME. The mobile airtime-based MFS SVA may similarly use the UOA of the GAME, but invariably this is non-redeemable back into fiat GAME. Or, it may use some other - also non-

\footnotetext{
${ }^{54}$ See ch 3, s3.9 on the Orthodox School.

${ }^{55}$ In a MNO SVA, the (SOV) input value may not be the value the system operator receives, but this is of no concern to the consumer. Note that the SO designation used here is not necessarily the same meaning as is afforded to SO's in a South African payments context. See ch 12, s12.3.7.4.7 titled Regulation of the Third Layer.

${ }^{56}$ Accepting that there may be inflationary or deflationary fluctuations between what is stored and the extent of the capacity of that value to ultimately purchase goods and services or to be interchanged with values in another system.

${ }^{57}$ See ch 5, s5.4.2 titled Prepaid Consumer Billing Systems. Statute however, may override these conditions, for example, the CPA.

${ }^{58}$ In the mobile sector, for example, MNOs may sell prepaid cards in their distribution chain - that is, consisting primarily of distributors and retailers - at a discount to the face value. As the issuer however, the MNO is obliged to provide to the user on demand the full nominal face value of the mobile airtime recharge card. Other than a welcome saving, practically this is of little consequence to the consumer but may be of major financial consequence to the merchant.

${ }^{59}$ See ch 3, s3.9 passim.

${ }^{60}$ See Schmitz (2005) op cit note 4 at 59. In the Claim School, this 'unit' is the most important facet of new money, although the two theories coincide here as both are the descriptors of value.
} 
redeemable - UOA denomination may be characterised as minutes, data sizes or points available for use on a prepaid mobile phone account, or as a 'token' value denominated as per the rules of the SVP scheme.

In relation to the SOV and any potential 'discounting ${ }^{, 61}$ off the trite 'face value' of the SOV by MNOs - or by any other issuers of virtual and similar emerging currencies used in SVPs - this could be seen however as nominally weakening the homogeneity required for the UOA function: if the recipient is unsure of the discounting criteria and surrounding circumstances, he may be disinclined to accept it as money. ${ }^{62}$

In this sense, then, a SVA with a UOA not denominated in the GAME and where the UOA may not necessarily be homogenous, may not necessarily amount to money because, in Simmel's words, it does not amount to a 'stable pole'. 63

\subsection{3}

Role as a Means of Exchange (MOE)

The Means of Exchange (hereafter MOE) is the pivot in the functional, Orthodox School. It represents an asocial $^{64}$ decision to designate one particular item and its perceived intrinsic value as the method of exchanging value using either a real or symbolic backing. ${ }^{65}$

Its role is an incidental function of its role as the GAME, ${ }^{66}$ which as the State-sanctioned MOE ${ }^{67}$ is usually denominated in a fiat UOA. ${ }^{68}$ Most in the Claim School however dismiss the MOE as being an inchoate means to settle debts, that is, by postponing final settlement. By implication however through the associated State Theory of money, if there is no linkage - even ephemerally and peripherally - to the UOA of the GAME, the value is not money. ${ }^{69}$

While there could conceivably be multiple ways of linking emerging currencies and SVPs to the GAME, the overarching principle in this conception is that users will want to continue to ultimately redeem the value in the CB-backed GAME because this is how taxes must be paid. ${ }^{70}$

In this sense, and at least in the Orthodox School view, the value in a mobile airtime-based SVA would not amount to a MOE, while a fiat-based SVA could if the system employed was open and interoperable enough to allow direct redeemability to the GAME. ${ }^{71}$

\footnotetext{
${ }^{61}$ See further, ch 5, s5.2.2 on the value chain generally in mobile telecommunications and discounting by MNO.

${ }^{62}$ Fox (2008) op cit note 4 at 61-62. See also on nominalism, Fox (2010b) op cit note 4.

${ }^{63}$ Simmel (2004) op cit note 1 at 119. See further on this, ch 3, s3.2.4.2.

${ }^{64}$ On the meaning of asocial, see ch 3, s3.2.4.1 titled Issuance And Production. See also Bell (1998) op cit note 4 at 19-21; and Goodhart (1989) op cit note 4 at 26. Compare this to a social, 'personal credit' decision relating to a Means of Payment (hereafter MOP).

${ }^{65}$ The value pivots usually around a value determined by the State for the purpose of exchanging values. See Schmitz (2006) op cit note 4 at 59. See further ch 3, s3.9 on the Orthodox School.

${ }^{66}$ This relates to the finality of macro-economic settlement in CB money as a result of the 'netting' of balances between banks and the CB, usually at the end of a day. See Schmitz (2006) op cit note 4 at 59.

${ }^{67}$ Economists have parlayed scenarios where there is a uniform UOA, but there is no (centralised) GAME, which is heretical of course to the Orthodox School which sees them all as necessarily coincident, completing the virtuous cycle of money.

${ }^{68}$ A MOP by contrast can be seen as a private decision as to how to extinguish debts or claims. See Bell (1998) op cit note 4 at 19 and 21 for a distinction between private and public decisions.

${ }^{69}$ See on the State Theory of money and its relationship to the Societary Theory of money, ch 3, s3.2.4.1 titled Issuance And Production.

${ }^{70}$ Lietaer (2001) op cit note 4 at 19. This is similarly the basis for the State Theory described in ch 3, s3.2.4.1.
} 
However, crucially and additionally, with presumably the only backing of the MOE being the liquidity of the issuer or similar entity, the lack of a tangible backing - real or symbolic - as required by the Orthodox School for something to amount to a money would indicate that that there is no ability to sustain a MOE function, and thus the SVP would thus presumably not amount to money. ${ }^{72}$

\section{Tangibility}

The need in $\mathrm{Moss}^{73}$ for a money to '[pass] freely from hand to hand' and 'not be consumed' strongly implies that it must consist of a tangible thing for it to be able to circulate. ${ }^{74}$ The tangibility aspect also fulfils the Orthodox School need for commodity-backed money. ${ }^{75}$ However it could be argued that tangibility does not necessarily - literally - imply a physical object: it may simply relate to the ability to transfer generally. Hence, for most adherents to the Orthodox School, as noted earlier it is sufficient that there be a symbol of a commodity placed scripturally in an account that in some respect would suffice to meet the tangibility criterion. ${ }^{76}$ Legal and economic fictions allow them to symbolise the GAME.

Overall though, any dogmatic application of a need for a physical item to be tucked away somewhere as the basis for its representation of the intangible GAME in the Orthodox School domain may, even if fictions are employed, not to be enough for MFS SVPs to amount to money.

\subsection{2}

\section{Circulation}

A similar quintessential feature of money relates to its 'circulation,' outlined in $\mathrm{Moss}^{77}$ as being the condition where money 'pass[es] ... freely throughout the community'. ${ }^{78}$

Seen in the context of the additional and associated need for the money to "[pass] freely from hand to hand' in the discussion earlier on tangibility, if a SVP shares this characteristic, this would be a persuasive factor in considering it as money. ${ }^{79}$ Scriptural money would simply be a series of circulating rights. ${ }^{80}$

\footnotetext{
${ }^{71}$ See ch 4, s4.8.3.7 titled Ubiquity of Use

${ }^{72}$ See ch 13, s13.3.1 titled Tangibility.

${ }^{73}$ See ch 3, s3.10 on the Claim School.

${ }^{74}$ This preoccupation with 'form' is how the coincident requirement of 'circulation' arises.

${ }^{75}$ In modern economies, however, it is of course rare for the tangible coin to be used in mercantile transactions, and it might even be disallowed by law.

${ }^{76}$ Ingham (2002) op cit note 4 at 125 . This is after all how many fiat currencies that do not have a physical backing like gold to ostensibly maintain the value and trust. See ch 3, s3.5.3.3.1 on symbolic representations of the GAME.

${ }^{77}$ Moss op cit note 4.

${ }^{78}$ See Moss op cit note 4; and the conflation thereof as 'circulation' in Geva and Kianieff (2002) op cit note 4 at 7.

${ }^{79}$ See Papadopoulos (2007) op cit note 4; and Geva and Kianieff (2002) op cit note 4 at 12 who give the comparative example of a travellers' cheque which 'circulates,' although this circulation feature is throttled since it has to be registered and then signed to be redeemed and payable. Similarly, if there is no circulation then because of these necessities, then there is not likely to be wide acceptance. Also, bank drafts and certified cheques may provide for an absolute discharge of debts, but they do not circulate and thus are not considered to be money. See Geva and Kianieff (2002) op cit note 4 at 13.

${ }^{80}$ Scriptural entries - such as demand deposits and Electronic Fund Transfers (EFTs) - relating to money in current law are however not considered to be money per se. Rather they are simply considered as representing a set of circulating rights and
} 
Hence the determinant of whether a SVP is (acceptable and) in circulation is how easily the value is able to be passed along 'freely' from 'hand to hand' in 'the community', an ability which from the consumer and merchant perspectives respectively, could turn on the redeemability - 'freely' - of the stored or earned value, since anyone who has some value stored may at some stage want to use the value or transform it into something else. ${ }^{81}$

From this perspective and within the Orthodox School domain where tangibility is a totem, the fiat-based SVA is superior - even in a large, national closed-loop environment like M-pesa ${ }^{82}$ where the UOA is that of the GAME - to the limited-use mobile airtime-based SVA in qualifying as money.

\subsection{3 \\ Acceptance}

Intimately related to the requirement in $\mathrm{Moss}^{83}$ for there to be circulation, is how widely accepted that money is. If there is no circulation per se, there is unlikely to be wide acceptance.

Generally, to be considered as money in the Orthodox School domain, it must be widely accepted both by merchant and consumers, by the former as a MOE in the purchase of goods and services - of which there may be an exchange function to settle obligations - and by the latter as a means of storing and subsequently obtaining value. In both cases, the acceptability could be motivated by a subsidiary function of the SOV: the conversion (via redeemability) to the totem of the Orthodox School, the GAME. ${ }^{84}$

Free convertibility - 'redeemability' to the GAME ${ }^{85}$ - may be seen as a subset of acceptance, allowing the value to be used ubiquitously without any impediments or reference ${ }^{86}$ to the "character or credit ${ }^{87}$ of the offeror of the value ${ }^{88}$ However, while the appearance of free convertibility - as a type of redeemability to an equivalent like a cash balance in a demand deposit in a bank may possibly satisfy elements of the necessary characteristics of money in the Orthodox School domain, this indication does not in and of itself mean that it is money.

\footnotetext{
obligations. This movement, however, does not necessarily then rise to the required 'circulation' criterion implied in Moss op cit note 4. See further ch 13, s13.3.3 on circulation; Bollen (2004) op cit note 4; and Kreltszheim (2003) op cit note 4. Compare the legal observations of circulation to Fisher's classic, purely economic view of this requirement, that is, the velocity and volume of money in circulation in a determination of the purchasing power of money, a relationship also known as 'Societary Circulation'. See I Fisher (1909) The Purchasing Power of Money.

${ }^{81}$ The extent of its circulation may affect the value of money. See B Klein (1974) 'The Competitive Supply of money' 6(4) Journal of Money, Credit, and Banking at 436; and Schmitz (2006) op cit note 4 at 17.

${ }^{82}$ See ch10, s10.1 on M-pesa.

${ }^{83}$ Moss op cit note 4.

${ }^{84}$ A nexus to the GAME is core to the Orthodox School.

${ }^{85}$ See ch 13, s13.3.2.

${ }^{86}$ This is of course analogous to the 'holder in due course' or 'bona fide holder for value' criteria for negotiable instruments. See further Malan, Pretorius and Du Toit (2009) op cit note 4 at 11.

${ }^{87}$ That is, the entitlement of the offerer to provide that value.

${ }^{88}$ Thus, although the value may not necessarily have geographic ubiquity of 'acceptance', if there is a redeemability component to it, this may suggest a compatibility, and possibly even an equivalence, to the GAME of the Orthodox School. When the degree of restrictions or limits are not considered to be substantial, free convertibility may arguably support the conclusion that the value is money, even if by itself, the wide acceptability of the SVP value has not been satisfactorily established. Geva and Kianieff (2002) op cit note 4 at 7.
} 
For example, in an MFS environment, there is an impediment in this potential redeemability component. As noted earlier, ${ }^{89}$ when seen from a WASP merchant's perspective of acceptance (and redeemability), MNOs usually take a large percentage of revenue in a digital VAS transaction from a WASP merchant that is far larger than a nominal banking or payments charge, so that the actual redeemable out-payment to the merchant from the retail value is, from a merchant's perspective, far less than the retail value of the transaction paid by the customer. ${ }^{90}$ In this case then, free convertibility of the entire earned value into redeemable scriptural value - if that conversion is possible at all - is not guaranteed. ${ }^{91}$ However, if the extent of the restriction on the use of a mobile airtime SOV or free convertibility thereof is not considered to be substantial, its capability in allowing free convertibility could be persuasive in supporting the determination that the value is money in terms of the Orthodox School.

There are of course a number of other strata that can be used to determine whether the value is acceptable, such as whether it can be determined to what extent the money is being used in a single or multi-purpose context. ${ }^{92}$ But, as noted earlier, value loaded on closed, single-purpose SVPs like (prepaid) telephones and transport cards are usually regarded as advance payment for those specific goods or services as a closedloop currency rather than SVPs as an 'e-money' usually bound in a legislative regime, ${ }^{93}$ although the legislative boundary is sometimes very thin and subjective. ${ }^{94}$

In all, value stored in a multi-purpose, fiat-based, open (interoperable) SVP widely accepted by numerous merchants, with a UOA related to the GAME and redeemable into the GAME is likely to constitute a form of money in terms of an Orthodox School equivalence to Moss, although more in a representative manner. However, a closed loop SVP that is non-redeemable or denominated in the GAME, is unlikely to be considered money in terms of this School's equivalence to Moss.

\subsubsection{Anonymity}

While the 'credit of' motif - and its seemingly tautological relationship to the anonymity criterion implied in Moss - may potentially undermine the anonymity component in founding equivalence to Moss, the focus is on not having any 'reference' to the identity (corpus) per se of the offeror. ${ }^{95}$

From the perspective of a user of MFS SVPs in both fiat and mobile airtime SVA forms, they could be anonymous or identifiable either because of AML statutes ${ }^{96}$ or because of contractual provisions around

\footnotetext{
${ }^{89}$ The so-called 'outpayment'. See ch 6, s6.5.4.2 on WASP 'outpayments'.

${ }^{90}$ However, since credit cards have similar albeit smaller commission structures per transactions. Some credit cards are deferred payment via the provision of pure credit, they do not necessarily serve as money, but rather as a payment instrument with money at its core.

${ }^{91}$ Payment may also be contingent on extraneous factors or other network externalities such as disputes.

${ }^{92}$ Relevant restrictions or limits relating to the use of a SVP may be either geographic, such as being accepted solely in one shopping mall or in one small town, or by reference to the number of participating creditors. See Geva and Kianieff (2002) op cit note 4 .

${ }^{93}$ See for example the EU's first Electronic Money Directive, the EMD1 op cit note 4, where the perimeter of its application was in dispute. The EMD1 was replaced by the EMD2 op cit note 4. See the discussion thereof in ch 9, s9.6.

${ }^{94}$ See for example a dispute in interpretation of the EMD1 where the perimeter of its application was in dispute.

${ }^{95}$ While this anonymity component may have some resonance as a pivot from the fading English Law maxim discussed earlier that money cannot be followed because it has 'no earmark,' which in of itself implies an element of anonymity to it. See further ch 3, s3.12.2 titled Legal Definitions And Theories Relating to money, with its discussion of the 'no earmark' rule
} 
accountholders. In many airtime-based MFS SVA environments though, the relationship is mostly anonymous and usually characterised as an online unaccountable ${ }^{97}$ system that does not identifiably track the user of any SVA once a Subscriber Identity Module card (hereafter SIM card) is issued for use in that MNOs telecommunications-only or MFS-based system. ${ }^{98}$

Despite the difficulties in fulfilling the dogmatic 'no earmark' anonymity criterion in terms of Moss, is not, it is submitted, a major criterion per se for something to be considered as money, and demonstrates the glacial evolution of thinking away from older dogmatic views of money. ${ }^{99}$

Final discharge however could be seen as relevant.

\subsection{5 \\ Final Discharge}

As regards the criterion in Moss $^{100}$ that money must 'effect a final discharge with no recourse to the payer', a money must unequivocally provide for this through a functional quality, the 'Means'. In the Orthodox School domain, this is termed the MOE.

It has been cautioned earlier though that the literature often interchanges the MOE with the MOP in describing this 'means' function. ${ }^{101}$ However, as highlighted earlier in relation to the Orthodox and Claim Schools, ${ }^{102}$ there are significant differences in their effect. For example, if one sees the goal of money as necessary to provide a MOP, that is, to act in a 'final discharge of debts' as described in Moss, ${ }^{103}$ then the GAME it appears may not necessarily fulfill this role since it sometimes signifies inchoate or delayed payment in satisfaction of a debt. ${ }^{104}$ The differences ultimately have a bearing on determining whether or not what the system embodies is indeed, functionally, money.

\footnotetext{
${ }^{96}$ The audit trail may be imposed by law - for example the 'RICA' SIM card registration law in South Africa discussed in ch 12 , s12.7 - to prevent money laundering and transfers between nefarious persons.

${ }^{97}$ See ch 4, s4.8.3.6 titled Accessibility and Tracking of Payments: Online and Offline

${ }^{98}$ This anonymity though is less likely with identifiable SVPs which are characterised by an online accountable motif where the use and user of the SVP can be tracked from the time of issuance. Indeed, as Geva and Kianieff (2002) op cit note 4 at 8 observe regarding the anonymity component, that historically the transition from coins to paper money involved a degree of loss of anonymity, and that in a modern, SVP-type environment, potential recording is by a third party increases the loss of anonymity. However, they say such loss may be a mere question of degree but anonymity may be further eroded such that (loss of) anonymity is 'quite a precarious test' for whether something constitutes money.

${ }^{99}$ Geva and Kianieff also discount its relevance. Ibid at 8 .

${ }^{100}$ Moss op cit note 4.

${ }^{101}$ For a detailed explanation of the functional difference between a MOE and a MOP and the inchoate nature of the MOE, see Sawyer (2003) op cit note 4 at 3-17 passim; and Goodhart (1989) op cit note 4 at 38-44. For a detailed explanation of the functional difference between a MOE and a MOP and the inchoate nature of the MOE, Goodhart (1989) op cit note 4 at 2427, 38-44; Mann (1992) op cit note 4; Nussbaum (1950) op cit note 4; Sawyer (2003) op cit note 4 at 3; Papadopoulos (2007) op cit note 4 passim; Newlyn and Bootle (1978) op cit note 4 passim; and Cesarano (1994) op cit note 4.

${ }^{102}$ See ch 3, ss3.9 on the Orthodox School and 3.10 on the Claim School.

${ }^{103}$ Moss op cit note 4. See also on an intermediate-type step, Goodhart (1989) op cit note 4 at 24-27; and commentary thereto by Papadopoulos (2007) op cit note 4 at 5 .

${ }^{104}$ Thus, when viewing money as providing a MOP to act in a 'final discharge of debts' as described in Moss op cit note 4, then the GAME as a MOE may not necessarily fulfil this role as this may be conditional on some event. For example, the buyer needing to have sufficient funds to pay later or the issuer not going insolvent which may sometimes signify inchoate or delayed payment. If there is a conditional claim, it may not be considered as e/m-money. For a detailed explanation of the functional differences between a MOE, SOV and a MOP and the inchoate nature of the MOE, see inter alia Piffaretti (1998) op cit note 4 at 13; Sawyer (2003) op cit note 4 at 3-5; and Goodhart (1989) op cit note 4 at 24-27.
} 
It may be noted that in relation to MFS SVPs systems, most use the credit-push method such that the ultimate recipient of fiat-based value - for example, the WASP merchant - may not necessarily receive the value unconditionally upon the execution of the transaction. ${ }^{105}$ In the case of an airtime-based MFS SVA specifically, a merchant however may also still have a valid claim against the MNO, for example, as issuer, for payment and settlement, although the extent of the payment may be subject to onerous contractual conditions that may exist between the MNO and the merchant. ${ }^{106}$

In some sense, the delayed and potentially inchoate nature of some MFS systems where there is billing from a mobile airtime-based MFS SVA parallels the inchoate nature of the MOE terms of the Orthodox School, such that there is no 'final discharge'.

\section{Analysis and Application to MFS}

Nobel-winning economist Friedrich Von Hayek, well known for proposing that fiat currencies should be scrapped in favour of private currencies ${ }^{107}$ suggests that it is communities that will best accept their own (private) currency ${ }^{108}$ in a type of 'Societal' approach to money. ${ }^{109}$ In the case of MFS, the acceptability of mobile airtime as a tradable commodity - especially in Africa and Asia - and in settlement of debts and including its use in informal remittances, ${ }^{110}$ is a salient indication that airtime is accepted in many communities as 'currency', but not necessarily as money. ${ }^{111}$

In relation to mobile airtime-based SVA balances these are not backed by any general asset other than the liquidity of the issuer, for example, an MNO. In relation to the Orthodox School however, non-referral or

\footnotetext{
${ }^{105}$ As noted earlier, ultimate payment may even be delayed because of a dispute, for example, over the veracity of billing by a WASP.

${ }^{106}$ For example, a State or regulatory authority may find mala fides in the transaction and force the MNO to reverse the transaction. Payment would thus not be made. For examples of self-regulatory bodies in the mobile sector, see http://www.waspa.org.za and http://www.phonepayplus.org.uk. The fact that a direct debtor-creditor relationship may exist in certain circumstances between the consumer and the merchant may also complicate matters. Further, Goodhart says that emoney cannot be used as a means of final payment in settlement of debts as it is illiquid in that it is not convertible or redeemable to CB assets since it can only be used as what could be termed a 'Means of Transaction,' that is, an asset that is an intermediate claim/asset on the process of completing a transaction. The fact that the MNO is the 'intermediate' step would confirm this view. See Goodhart (1989) op cit note 4 at 24-27; and on a commentary thereto, see Papadopoulos (2007) op cit note 4 at 5 . Similarly, as noted by Wray (2006) op cit note 4 , this view is analogous to the differentiation expounded by Schumpeter who - in a more macro-economic perspective of money - said that a monetary theory of credit that could be a feature of the Orthodox School insofar as it fastens on a fixed quantity of money based on metallic commodities, versus credit that can create money via the deposit multiplier that is the hallmark of fractional banking and endogenous money creation. Thus, any private 'Credit Money' is only a temporary substitute for 'real money' such that final settlement must take place in real money, which is the ultimate UOA, SOV, and MOP. Exchanges, he says, might take place based on credit, but credit expansion is strictly constrained by the quantity of real money. The Credit Theory of money, by contrast, emphasises that credit normally expands to allow economic activity to grow. Because there is a clearing system that cancels claims and debits, credit is not merely a temporary substitute for Real money. While Schumpeter questions the role of money though as MOP, he questions that it is required for most final settlements.

${ }^{107}$ Von Hayek went so far as to propose that governments be removed altogether from the provision of money. This view is the analogue of what was the 'free banking' era, which allowed private monies to compete alongside and equally with State fiat money. Under free banking arrangements, private banks competed against each other to provide the public with currency under a benevolent set of government regulation. See Von Hayek (1976) op cit note 4 at 27; and Macintosh (1998) op cit note 4 at 740.

${ }^{108}$ Von Hayek (1976) op cit note 4 at 63; Macintosh (1998) op cit note 4 at 742 . Whether they will accept it if it is only usable within that community is debatable. See Bootle (2001) op cit note 4 at 10; Schmitz (2006) op cit note 4 at 66; Berentsen (1998) op cit note 4.

${ }^{109}$ See ch 3, s3.2.4.1 on the Societary Theory approach, and similarly Lagerspetz (1984) op cit note 4.

${ }^{110}$ See ch 4, s4.8.4.3 titled Remittances.

${ }^{111}$ See ch 3, s3.6 on a discussion of the differences between currency and money.
} 
non-nexus to the GAME, even in a symbolic capacity, as well as the lack of a tangible reference point would indicate that it is not money. Further, insofar as the UOA does not relate directly to the GAME, as well as the fact that there is commercial discounting of the retail price of the 'face value' of the mobile airtime SOV, would also in terms of the Orthodox School, not allow it to function as a proper SOV, and thus as money.

In relation to this inability to embrace new forms of money, Wray finds a disconnect between the basis of the Orthodox School to the emerging money in that 'on the surface, this appears to be an "evolutionary" approach that recognises human agency in the transformation from barter to fiat money. However, the disconnect is that "the Orthodox economists turn money into a "natural" phenomenon free from essential social relationships.' His analysis suggests that this myopia would obviate the Orthodox School's ability to account for new and emerging forms of money that are not State and material-based. Thus the Orthodox School reinforces a notion that money and monetary relations are inherently impersonal.

Insofar as the further tenet of the Orthodox School and its embrace of the GAME and State Theories, and in particular that non-State (private) values could be an anathema to the State Theory of money, Hart ${ }^{112}$ suggests that the Community Theory of money ${ }^{113}$ as a component of the Societary Theory allows money to be seen as a symbol of something intangible (society), rather than a 'thing' with objective value. ${ }^{114}$

This emphasis on trust between people, leads to the idea that money is a type of 'personal credit' generated by social interaction which creates the opportunity to provide for an alternative to all standard theories of money as an impersonal object. ${ }^{115}$ Money, he concludes, does not require the State: its role in the production of money being eroded, ${ }^{116}$ although clearly not completely ameliorated. ${ }^{117}$ There are a number of outcomes thereof, including the difficulties that this presents to governments and legally.

From a legal perspective then, in the analysis of an equivalence of the Orthodox School to Moss, it appears that the inchoate MOE that is a totemic feature of the Orthodox School flails any equivalence to a 'final discharge.'

The example, in an MFS domain, of the inability to guarantee payment in the GAME or any other MOP ${ }^{118}$ to merchants or WASPs who use the prepaid SOV value in settlement of a transaction with a consumer, is

\footnotetext{
${ }^{112}$ Hart (2000) op cit note 4 at 318.

${ }^{113}$ See a discussion thereof in ch 3, s3.4.1, in particular Hart (2000) op cit note 4; and Lagerspetz (1984) op cit note 4.

${ }^{114}$ New technologies, says Hart, used within decentralised markets have the potential to transform money from an impersonal MOE to 'an act of remembering, a way of keeping track of the exchanges we each enter into.' Hart (2000) op cit note 4 at 234

${ }^{115}$ Hart thus sees instead emerging currencies such as e-money as an SVP increasingly manifesting as this 'personal credit'. Ibid.

${ }^{116}$ But as Dodd (2005) op cit note 4 notes, Hart is not suggesting that money is being re-personalised in all of its forms, rather that while State currency is and will remain the dominant form of money, it is losing its monopoly over the world's monetary system.

${ }^{117}$ ، Any moves towards more personalised forms of money will co-exist with those that are already dominant. A large number of transactions, involving people and institutions around the world, will have the need of a money - or monies - that have wide acceptability both as money-of-account and as money-proper, to use Keynes's terms. At present the dollar and, to a lesser extent, some other national currencies play such a role.' Hart (2000) op cit note 4 at 298.

${ }^{118}$ This is through throttling of the 'outpayment' value payable within the systems of the MNO.
} 
coincident with the 'intermediate step' alluded to by Goodhart and Papadopoulos ${ }^{119}$ which makes payment conditional, that is, similar to the inchoate nature of a MOE. Thus what may be accepted as MOE by a merchant may however not necessarily provide the final MOP to settle the debt. This is in contradistinction to the finality of the payment in a legal sense as unconditional and irrevocable payment for settling of debts and general obligations; and unless there are stricter controls in place for billing from a mobile airtimebased MFS SVP, in terms of the Orthodox School, there is no final discharge and thus it is unlikely to amount to money.

Thus in aggregate, and seen from the Orthodox School view of money when compared to Moss, along with their relative coincidences, the nexus to Moss from an Orthodox School perspective is thus incomplete and the MFS airtime SOV at least is unlikely to amount to money.

Insofar as legal systems continue to interpret Moss in its current form, this at the least, has implications for laws and regulations ${ }^{120}$ as well as processes that sound in money.

\section{B. Claim School View Of Money}

\section{Core Economic Characteristics}

As described earlier, the heterodox Claim School has at its core, the concept advanced inter alia by Knapp and Keynes of 'tokens' denominated in the UOA. ${ }^{121}$ This is simply the chosen description or title of the account, and which is somewhat analogous to the UOA in the Orthodox School insofar as it is a descriptor of the value. The Claim School UOA - also called the 'Money of Account' (MOA) by Keynes - features as a pivot in the Claim School. Answering to this MOA is money, the forms or 'things' which result in a (final) MOP. ${ }^{122}$

In the Claim School view, money is seen as a MOP and not as a MOE that is a feature of the Orthodox School, such that money is largely seen as a species of debt. ${ }^{123}$

\footnotetext{
${ }^{119}$ Goodhart (1989) op cit note 4 at 24-27; and commentary thereto by Papadopoulos (2007) op cit note 4 at 5.

${ }^{120}$ See ch 13, 13.8.2 titled Legal Effects.

${ }^{121}$ Knapp (1924) op cit note 4; Keynes (1971) op cit note 4; Papadopoulos (2007) op cit note 4 says that these tokens, although designated in a particular money or UOA, do not exhaust the identity of money.

${ }^{122}$ Contra a MOE as in the Orthodox School.

${ }^{123}$ While Graeber posits an anthropological basis for money as debt, and Pesek and Saving demonstrating a controversial mathematical model for founding an economic nexus of money to debt, Wray outlined the logical sequence of this theory, quoting in part from Clower in RW Clower (1971) 'Theoretical Foundations1 of Monetary Policy' in Gilbert, JC and Sedgwick, R (eds) Monetary Theory and Monetary Policy in the 1970s: Proceedings of the 1970 Sheffield Seminar on Monetary Theory and Monetary Policy in the 1970s (1970: University of Sheffield):
}

'(1) (M)oney buys goods and goods buy money, but goods do not buy goods.; (2) money is always debt; it cannot be a commodity from the first proposition because, if it were, that would mean that a particular good is buying goods.; (3) Default on debt is possible.'

Wray (2010) op cit note 4; and similarly on the nexus to money and 'debt', Graeber (2011) op cit note 4; Mitchell-Innes (1913) op cit note 4; Mitchell-Innes (1914) op cit note 4; Hart (1986) op cit note 4; Pesek and Saving (1970) op cit note 4 at 112. See further on the taxonomical basis for categorisation 'debt' in relation to 'money', ch 13, 13.5.3.2 titled Means of Payment. 
As noted earlier, ${ }^{124}$ while the SOV is a disputed and some would say relatively benign ${ }^{125}$ feature in terms of the Claim School, it has been suggested ${ }^{126}$ that the SOV here does play a role since otherwise the money would presumably not be accepted by outside parties.

And, as with the issues identified earlier ${ }^{127}$ with respect to SVPs and the discounting of the available 'face value' of the input value, the same concern would be applicable in the Claim School.

Although the SOV - unlike the UOA - is not necessarily a coveted Claim School feature, it nonetheless has some cogent legal import as it relates to the species of legal 'debt' or 'claim' the system issuer of value may have to the holder of that value. In causu, legal consequences relating to SOV depend on the type of system employed, but the SOV feature itself may pivot around the device of substitution of liabilities that is a feature of the law of contract and the law of obligations when applied to banking and payments.

\subsection{2}

\section{Unit Of Account (UOA)}

As noted earlier, ${ }^{128}$ the Claim School assigns its central role not to a MOE function characteristic of the Orthodox School, but to the UOA function - and what Keynes termed the Money of Account (MOA) which is a qualitative measure that is designed to assess the intrinsic, abstract character of money. ${ }^{129}$ Establishment of the UOA is thus a pre-eminent feature of the Claim School view of money, alongside the Claim School feature of money being a MOP for debts and SOV functions. ${ }^{130}$ Use of an 'accounting' system to determine values of money here acts to dematerialise money such that the need for tangibility is removed.

It is possible then for the dematerialised SVP to compete with or even substitute the national UOA, such that (denomination in) the national UOA is not necessarily the ultimate determinant of whether something is money. ${ }^{131}$ Indeed, as noted earlier, ${ }^{132}$ Von Hayek was a proponent of multiple (largely non-fiat)

\footnotetext{
${ }^{124}$ See ch 3, s3.9.2.2 on the Store of Value feature in the Orthodox School, and the discussion therein of the thereof views of Keynes and Wicksell.

${ }^{125}$ In all though, the SOV is comparatively the most benign terminological commonality between the Orthodox and Claim Schools, although strictly speaking there is no commodity per se in the Claim School to store the value since the value would, heretically to Claim School dogma, be stored in a commodity that underlines the (store of) value.

${ }_{126}$ Of the SOVs actual role, a solution to the question of how a money as a promise to pay could function as both a universally acceptable MOP and store of value has, as noted by Ingham (2000) op cit note 4 at 19 , remained intractable within the confines of the theoretical assumptions of real analysis.' He suggests however a solution may be found in associating both as pivotal components of social relations social relations between economic agents and between them and a monetary 'authority'. In his view, that authority may be the State. See similarly the discussion by Wray (2010b) op cit note 4.

${ }^{127}$ See ch 13, s13.2.1 on the SOV use in the Orthodox School.

${ }^{128}$ See ch 3, s3.10.2.1 on UOA in the Claim School.

${ }^{129}$ Keynes (1971) op cit note 4 at 3 said that the 'Money of Account' was 'that in which debts and prices and general purchasing power are expressed (while) money itself is that by delivery of which debts and contracts are discharged.' Thus, the State determined the units of account and the 'MOP,' or the 'thing' which would 'answer' to debts denominated in the UOAs.

${ }^{130}$ Keynes (1937/1973) op cit note 4 passim.

${ }^{131}$ There are a number of ways a new money such as airtime-based MFS money could for example compete with or replace an existing national GAME and its UOA at this level. See further ch 13, s13.8.3.1 titled Overview.

${ }^{132}$ See the analysis and application to MFS described in ch 13, s13.4.
} 
currencies with competing UOAs existing in one economy. ${ }^{133}$ While attractive at the time of conception in an era of national hyperinflation, a more sober assessment would reveal that the challenge arising would be that multiple UOAs would have to be kept by others, which could result in losses as one unit becomes unacceptable or devalued because of the spread between it and other 'GAMEs' denominated in their own specific UOAs. ${ }^{134}$ Similarly, Bootle says that society has a strong interest in operating with only one UOA, that is, one money. ${ }^{135}$ However, being denominated in a national UOA is currently less of a guarantee of acceptability economy-wide than would be its redeemability into the GAME. ${ }^{136}$

Geva and Kianieff, ${ }^{137}$ though, say that the criticism that these types of SVPs may not necessarily provide a distinct UOA should not disqualify them from being candidates for being money, as the UOA could be external to be the money itself. This is a view not dissimilar to the Claim School. Thus, the denomination of a form of a SVP in standard units of a national currency ${ }^{138}$ does not diminish its position as (possibly being) money in its own right.

In this sense, and based mostly on practicalities, mobile airtime-based SVP value when used as a MOP could - if it meets all the other criteria for money - also be generally acceptable as money if it is consistent with a standard national UOA. If denominated in alternative UOAs like minutes or megabytes of data, it will probably only be generally acceptable as money if it is usable and redeemable for services and products other than the community in which it operates. If, however, as in the Claim School variant, the New Monetary Economics (hereafter NME) School, ${ }^{139}$ the UOA is exchangeable in some way, then it may become a MOP via a transfer of wealth, and then, presumably, money. ${ }^{140}$

\footnotetext{
${ }^{133}$ Macintosh (1998) op cit note 4 at 740-742. Although it seemed feasible in an era of hyperinflation of the 1970s when his thesis was mooted, Von Hayek's approach has subsequently been widely criticised as probably engendering a chaotic system in markets that would not know in which monetary unit to quote prices. See Bootle (2001) op cit note 4 at 1-15. Further, even though over time competitive exigencies in markets denominated in alternative UOAs may result in an eventual dominant UOA acting as the GAME, this transition may involve higher prices due to a spread in exchange between the dominant UOA and the alternative types. Schmitz (2006) op cit note 4 at 61 categorises these as the degree of uncertainty, the risk and uncertainty preferences of individuals, resource costs of holding inventory positions in different risky assets (ie not nominally fixed with respect to the GAME) and the related risk and uncertainty, the market structure, potential asymmetries of information amongst traders, and transaction as well as information costs.

${ }^{134}$ Bootle (2001) op cit note 4 at 10 refers to these potential currencies in units of the 'Nok' (named after the mobile phone manufacturer Nokia) and 'Microsofts'. He postulates that eventually people would have to discriminate between the units even within a single jurisdiction.

${ }^{135}$ Ibid. This view is similar to the view of Vaubel who says that a single UOA offered only by government is one of the cornerstones of the public good characteristics associated with money since it allows any individual with money balances denominated in the UOA set by government to be more liquid and less likely to become illiquid. The effect of this is that his potential trading partners will be more likely to be trade with him. See R Vaubel (1984) 'The Government's money Monopoly: Externalities or Natural Monopoly?' 37 Kyklos at 28.

${ }^{136}$ Schmitz (2006) op cit note 4 at 74 says that the model faces a more fundamental critique than its inherent instability, namely that the UOA is not meaningfully defined. He believes that the denomination of particular e-money (as a SVP) is a purely nominalistic exercise or its denomination will be determined by market exchange. In the absence of redeemability, the nominalistic denomination may be arbitrary so that different prices will have to be paid in different electronic monies. If however the denomination of the UOA is determined by market exchange, then he says, each electronic money will serve as a UOA since prices in different electronic monies will differ. Hence, he surmises, in both cases there will be no uniform UOA. See further on nominalistic functions of money from a legal perspective, Fox (2010b) op cit note 4.

${ }^{137}$ Geva and Kianieff (2002) op cit note 4 at 8.

${ }^{138}$ That is, when the GAME reports the stored value in a MNO prepaid balance as the number of Rands, Euros or Dollars, for example.

${ }^{139}$ On NME, see ch 3, s3.10.11.

${ }^{140}$ This is much like airline loyalty points which are redeemable for products and services other than airline flights. MFSbased SVPs thus may again be representative of a SOW rather than a SOV.
} 
The overall observation then is that it will only be money if the transfer (of wealth) capability is ubiquitous throughout a general economy and not limited to a particular scheme or community. However, unlike the Orthodox School criteria for a UOA, there is no 'automatic' disqualification if the UOA is not coincident with the UOA of the GAME: the potential thus exists for a SVP to rise to be deigned as money.

\subsection{3}

\section{'Money'}

As noted earlier, ${ }^{141}$ in relation to the Orthodox School view of money, money has besides its trite SOV function, two simultaneous but functionally indistinguishable roles: that of the MOE and as the 'commodity' or chattel that enables or represents this exchange. Comparatively, the Claim School ${ }^{142}$ separates money into an intermediate ${ }^{143}$ - but not functionally inchoate - item, the 'thing' which then acts as a MOP. ${ }^{144}$ This differentiation, according to the tenets of the Claim School and its variants, provides the basis for a competing system within a jurisdiction whereby the State designates the UOA while the market may evolve a parallel system of numeraire or UOAs. ${ }^{145}$

Thus in an electronic, incorporeal (dematerialised) incarnation of money in SVPs, there exists potential for the multiple UOAs and multiple 'things' that provide the MOP for that money (unit) of account. The MOP may then conceivably rise to be a competitor to - or even replace - the generic GAME as money. ${ }^{146}$

\subsubsection{A 'Thing' as the Money}

Whereas the UOA is the named description or title (for example the Dollar), the money is the 'thing' which answers to the description. ${ }^{147}$ In contradistinction to the dogma of the Orthodox School, the 'thing' here is not necessarily tangible, nor does it necessarily need to be tangible, but it could be. ${ }^{148}$ A broad, account-type system that involves debits and credits - generally, debt - to a SVP would support the notion of personal rights to claim a debt rather than property rights in a tangible thing.

And as noted earlier, ${ }^{149}$ use of a common numéraire or UOA, does not however logically compel the use of a common money in transactions. This means that anything can act as money, for example, loyalty points, mobile airtime minutes or the like. Whether these are accepted generally in an economy would ordinarily be determined by what UOA it is denominated in and whether there is an exchange value between it and other monies answering to the same or other UOAs. The value transferred using the money 'thing' could, according to the extrapolation of the Claim School by the NME School, even be via a

\footnotetext{
${ }^{141}$ See ch 3, s3.9 on the Orthodox School.

${ }^{142}$ See ch 3, s3.10 on the Claim School.

${ }^{143}$ Goodhart (1989) op cit note 4 at 24-27; and commentary thereto by Papadopoulos (2007) op cit note 4 at 5.

144 These latter roles all pivot around the 'UOA' function.

${ }^{145}$ Wray (2010) op cit note 4 at 4.

${ }^{146}$ Models that determine the effect of the parallel use of multiple units of account may sometimes be confused with currency competition.

${ }^{147}$ Keynes (1971) op cit note 4 at 3.

${ }^{148}$ The possibility of embracing 'tangibility' is not to dilute the non-tangibility dogma of the Claim School: it merely means that any tangible item may be one of many alternatives that could constitute the 'thing.'

${ }^{149}$ See ch 3, s3.10.2.2 on money
} 
transfer of wealth such as shares or similar values that satisfy a creditor's need. ${ }^{150}$ Thus unlike the Orthodox School which has its money based on a tangible 'chattel' item or representation thereof, the static fiat GAME, in the Claim School there are no numero clauses of what could provide a MOP. ${ }^{151}$

What this implies then is that legally any 'thing' may satisfy a claim as long as there is implied or actual acceptance thereto by any parties in a transaction. ${ }^{152}$ The pivot, again, is debt.

\subsubsection{Means of Payment (MOP)}

As noted earlier, ${ }^{153}$ the terms MOP and MOE are often used interchangeably in legal and economic literature to describe money. ${ }^{154}$ However, as also copiously indicated, they are respective components of two heterodox and largely incompatible theories of money. ${ }^{155}$

Various models have been employed to determine and explore the differences (and monetary effects) engaged in employing either a MOE versus a MOP. While the MOE is seen as an asocial endeavour ${ }^{156}$ using a tangible thing to which proprietary rights may obtain - to allow value to be provided in exchange for goods and services or the like, a MOP is generally a private (or Societal) decision crafted along the fault lines of how to extinguish debts or claims, ${ }^{157}$ using the meme of a 'two-sided balance sheet' where the issuer 'owes' the holder - acting as creditor - to the issuer of the money ${ }^{158}$ (acting as a MOP). ${ }^{159}$

As such, the core of this Societal relationship ${ }^{160}$ is that of credit (and concomitantly, debt), where money embodies a negotiable claim upon society to receive goods and services of real value in the future in return for it. ${ }^{161}$ In that sense, money is seen as being a debt-relation or a promise to pay that exists between human beings and which cannot be identified independently of its institutional usages since money expresses a social relation. ${ }^{162}$ More specifically, '[m]oney is privately created when one party is willing to go into debt and another is willing to hold that debt ${ }^{3}{ }^{163}$ That is, money could be seen as a form of payment for a debt held by the holder on the issuer.

\footnotetext{
${ }^{150}$ See ch 3, s3.7.2.2 titled Money As A Store Of Wealth.

${ }^{151}$ This too is a feature of personal rights - Hart's 'personal credit' - versus the limited real-right types of right in ownership proper. See Hart (2000) op cit note 4 at 318.

${ }_{152}$ This may relate to the moniker that 'money is what money does'.

${ }^{153}$ See ch 13, s13.3.5 titled Final Discharge.

${ }^{154}$ See for example Newlyn and Bootle (1978) op cit note 4 at 1-3; Goode (1995) op cit note 4 at 490.

${ }^{155}$ In the Claim School, the MOP is seen as a derivative of the UOA.

${ }^{156}$ See ch 3, s3.9 on the Orthodox School.

${ }^{157}$ See ch 3, s3.2.4.1 titled Issuance And Production.

${ }^{158}$ Simmel (1900) op cit note 4 as noted by Hermann (2007) op cit note 4.

${ }^{159}$ Minsky (1986) op cit note 4 at 226-228. See also Bell (1998) op cit note 4 at 19 and 21; and Goode (1983) op cit note 4, at ch 4 passim.

${ }^{160}$ As opposed to the State Theory used by Mann (1992) op cit note 4.

${ }^{161}$ See Simmel (1900) op cit note 4 at 162; and Herrmann (2007) op cit note 4.

162 Bell (1998) op cit note 4 at 19 ; Graeber (2011) op cit note 4.

${ }^{163}$ Wray (1990) op cit note 4 at 14. See also Mitchell-Innes (1913) op cit note 4; Mitchell-Innes (1914); Hart (1986) op cit note 4; and Graeber (2011) op cit note 4 who all equate money to debt.
} 
Functionally, though, as with the broad but trite moniker 'money is what money does', ${ }^{164}$ the same rudimentary - but not necessarily legally accurate - etymological classification can be applied to payments as being determined as being 'what parties agree as payment, is payment'. ${ }^{165}$ Some classifications may include the structural characteristics of a payment, specifically the payment mechanism which facilitates the payment that may, and if the technical design and the legal analysis allow, also embody the payment value itself. The MOP though is thought to be the mechanism of finally settling debts. ${ }^{166}$

However, despite the extensive exposition of the theoretical aspects of money, the discussions may be moot and the concept of money may just coalesce around one aspect: money - at least in its intangible 'form' as a SOV in a SVP - may not hold the primacy as the monolithic entity, but rather as a species of the order 'payment' within the broader class, 'debt'. This characterisation of money as payment thus adopts the Claim School view of money for the purposes of this conflation. Indeed, as indicated by Goode:

\begin{abstract}
'Accordingly, much of the debate on what constitutes money in law is rather sterile and has few implications for the rights of parties to commercial transactions, where payment by bank transfer is the almost universal method of settlement. ... The crucial question, then, is not what constitutes money but what constitutes payment. ${ }^{167}$
\end{abstract}

And as the difference was caustically characterised by the economist Ludwig von Mises:

'The fact that the law regards money only as a means of cancelling outstanding obligations has important consequences for the legal definition of money. What the law understands by money is in fact not the common medium of exchange but the legal medium of payment. It does not come within the scope of the legislator or jurist to define the economic concept of money. 168

Further, in an apparent nod to the evolution of private currencies - which may derive from banks as 'bank money ${ }^{169}$ or otherwise - that may oblige this core role, Goode says:

'Any transfer of value in a form according with the express or implied agreement of the parties constitutes payment, whether or not it is money in the legal sense. The provision of a claim on a bank ... represents by far the most important method of discharging money obligations. ${ }^{170}$

From this discussion, it may said that the Claim School view of money insofar as it allows a theoretical nexus to payment and the use of private currencies - such as airtime-based SVAs in MFS, or emerging private currencies generally - as money that may hold economic value and which may be used legally for

\footnotetext{
${ }^{164}$ The origin of the term is economic and is based on economists who define money in a functional rather than legal way. See Herrmann (2007) op cit note 4 at 9. See also National Council on Economic Education (2011) 'money is What money Does', available at http://goo.gl/Z01ST. The other layman's point of view is that whatever people accept as money is money. The Big Question Team, The Open University (2005) 'What is Money?' 10 January, available at http://goo.gl/1uXb2.

${ }^{165}$ Except of course where patently illegal or contra bona mores. See also Bollen (2005) op cit note 4 at 190.

${ }^{166}$ See ch 13, s13.6.6 titled Final Discharge and use of abstract methods in relation to payments settling debts.

${ }^{167}$ Goode (1995) op cit note 4 at 492. See also a discussion and apparent approval of Goode's summation by Du Toit (2009) op cit note 4.

${ }^{168} \mathrm{~L}$ von Mises (1953) Theory Of money and Credit, available at http://goo.gl//HnPCx

${ }^{169}$ See ch 3, s3.7.2.1 titled Credit Money.

${ }^{170}$ Goode (1995) op cit note 4 at 492.
} 
settling debts, appears as a more cogent basis for re-evaluating money so as to contrive a nexus between the Claim School's general criteria - and that of the current legal view of money as per Moss and its relationship to payments.

It appears again then that the core characteristic of money that allows intangible SVPs such as those used in MFS, but generally also in a payment relationship, is 'debt.'

\section{Introduction}

The preceding discussion has shown that, at an economic level at least, the Claim School appears to demonstrate far better consonance in relation to explaining the emergence of new forms of (dematerialised) money than does the commodity-based Orthodox School.

The next step then is to proceed with an attempt at equilibrating the Claim School with the legal view of money, particularly the discrete legal criteria for money. ${ }^{171}$

\subsubsection{Tangibility}

As noted earlier, unlike the Orthodox School, the MOE and an associated tangible commodity or a symbol $^{172}$ of a tangible commodity are not part of the Claim School's conceptualisation of money.

Seen though in the context of the additional need in Moss $^{173}$ for the money to '[pass] freely from hand to hand', the Claim School partially fulfills this criterion using the 'token' ${ }^{174}$ or 'thing ${ }^{175}$ concept, that may or may not be something tangible. ${ }^{176}$ Further, although it is not entirely necessary when employing the Claim School as the basis for characterising new forms of money, a device similar to that used in the analysis of the tangibility criterion in the Orthodox School view of money, ${ }^{177}$ may similarly be used to find consonance with the implied requirement for tangibility in Moss, legal fictions. ${ }^{178}$ When this legal fiction

\footnotetext{
${ }^{171}$ That is, the need for tangibility, circulation, acceptance, anonymity, and final discharge. See Moss op cit note 4, and Geva and Kianieff (2002) op cit note 4 passim.

${ }^{172}$ Ingham (2002) op cit note 4 at 125.

${ }^{173}$ Moss op cit note 4.

${ }^{174}$ Knapp (1924) op cit note 4 passim.

${ }^{175}$ Keynes (1971) op cit note 4 passim.

${ }^{176}$ It must however be stressed that a tangible item - and tangibility generally - is not a core component of this analysis: it is merely one of the 'things' that be used to validly satisfy a debt. In this sense, the 'thing' may even be the tangible item that Moss op cit note 4 ostensibly implies, or even some abstract thing like a dematerialised scriptural entry into an account describing value. Invariably though in the Claim School view, there is usually no tangible 'thing'. Indeed, some conceptions of the Claim School discount the need for a 'thing' at all, emphasising rather the credit-based, 'bookkeeping' nature of the School. See in this regard, Mellor (2011) op cit note 4 in relation to a discussion on Keynes's use of a 'thing'. Mellor points out for example that even though Keynes is quite clear that money as an accounting mechanism is much more important than the role of money as a (tangible) medium, he still retains a key notion of the tangibility of money in the 'thing' that answers to the MOA/UOA; and generally See ch 3, s3.10.2.1.

${ }^{177}$ See ch 12 , s13.3.1.

${ }^{178}$ That is, just as the legal and financial systems employee a practical, legal fiction to equate bank 'inside money' as (representing) the GAME or legal tender, so too could a legal fiction be employed to equate the 'thing' where it is not
} 
is similarly employed then in the Claim School equalisation with Moss, the tangibility function may thus be satisfied to equilibrate Moss with the Claim School.

Again, this may not be necessary since there is no tangible thing to 'transfer' in the Claim School; only personal rights involved in debt relationships are relevant. This is especially true of the SOVs in fiat-based and airtime-based MFS SVAs, similar to the rights involved in an EFT. ${ }^{179}$

\subsection{3 \\ Circulation}

In relation to the requirement in $M o s s^{180}$ for circulation - to '[pass] freely from hand to hand throughout the community' - for something to be money, when used in both airtime and fiat MFS systems where the value transfer occurs entirely within the electronic payment system, this poses far more difficult issues than the phases of issuance or redemption. ${ }^{181}$

Geva and Kianieff ${ }^{182}$ for example ask how the money can be said to circulate if the value-issuer's obligation is not being directly transferred. They surmise rightly though that this is not a critical issue, as the $\mathrm{CB} \mathrm{GAME}^{183}$ 'circulates' in the same intangible manner as the circulating rights that characterise say EFTs. Importantly, circulation must be viewed not only in the context of actual 'transferability' or concrete assignment, but rather that 'substance ought to be allowed to prevail over form' ${ }^{184}$ This view, it appears, is coincident with the Claim School view that dismisses any need for a tangible item - even necessarily for a representation thereof - to be at the basis for value transfer.

It is self-evident however that in mobile airtime-based MFS SVAs and - unlike most fiat-based MFS systems - there is invariably no interoperability between competing systems to connect to users of another competing MNO or MFSP-based system, such that there is no effective circulation outside the system per $s e$. Value thus only circulates between participants in the closed system, maybe a very large one at that.

The import thereof, specifically whether this is an adverse or nugatory factor in a determination of money, is to be found in the invocation possibly of the Societary Theory of money ${ }^{185}$ associated with some components of the Claim School. Simply put, it becomes a question of availability versus, to some extent, acceptability: if there are 30 million (hereafter $\mathrm{mn}$ ) people on one MNO in a country ('nation') where there may be 50mn mobile users who have the potential to use an (available) MFS payment system, albeit one

tangible with bespoke representations thereof. See ch 3, s3.5.3.2.4.1 on 'Bank Money' and ch 3, s3.7.2 on 'Credit Money', which is considered 'Inside money'. See also ch 3, s3.10.2.2 that discusses Circuitism in relation to bank 'Inside money'.

${ }^{179}$ With EFTs the legal rights are created and extinguished along the transfer chain so as to allow the ultimate payee beneficiary to receive the value from the initiating payor. These transfers are legally recognised as circulation since the CBs deposit obligation is fundamentally the same as that on the banknote so as to be considered as money.

${ }^{180}$ It must 'pass freely throughout the community'. See Moss op cit note 4; and the conflation thereof as 'circulation' in Geva and Kianieff (2002) op cit note 4 at 7.

${ }^{181}$ Rogers (2005) op cit note 4. On money issuance, see ch 3, s3.2.4.1.

${ }^{182}$ Geva and Kianieff (2002) op cit note 4 at 24.

183 That is, CB deposit obligations.

${ }^{184}$ Ibid. On money forms, see ch 3, s3.2.4.2. While the electrons that make up the particular value on an electronic device or in a composite system 'consumed' able to be circulated in toto - instead they are extinguished infinitesimally and reconfigured into new entries. On similarly on how electrons may be 'consumed,' see ch 3, s3.12.2 on Legal Definitions And Theories Relating to money.

${ }^{185}$ See ch 3, s3.2.4.1 on the State Theory of money, which society could mean a nation, the community, or the State. 
which is not accepted by many merchants because of its closed-loop (circulation-type) nature, is this still a nugatory feature of that system in founding something as a money?

It is submitted that this is not: the case of M-pesa in Kenya offered by MNO Safaricom ${ }^{186}$ is instructive, where its non-interoperable (closed circulation-type) nature was of less concern to users who looked at its widespread availability and utility compared to the comparatively limited but widely accepted, where available Automatic Teller Machines (hereafter ATMs), Points of Sale (hereafter POS), Electronic Fund Transfer (hereafter EFT) and banking infrastructures offered by licensed banks. This availability (and ease of use) meant that this society was more inclined to use the M-pesa SOV as money than other societies where the utility of an MFS system may not have been as necessary. ${ }^{187}$

In all then, it could be surmised that circulation is to be viewed in relation to availability, which in this narrow context, trumps general or ubiquitous acceptance. Thus, in relation to the criterion in Moss implying circulation, availability - in relation to fiat-based and airtime-based MFS systems that may or may not use the UOA of the GAME - should satisfy the implied 'circulation' criterion for money.

Acceptance however is of course still an important criterion of Moss to satisfy, as discussed below.

\subsection{4}

\section{Acceptance}

As noted earlier, ${ }^{188}$ the requirement in Moss for the value to be 'accepted equally ... throughout the community' is intimately related to the requirement of circulation, that is how widely the value is available in the community.

As noted earlier in relation to circulation of MFS SVPs, there is some nuanced difference between availability and acceptability. If, in the case of restricted ${ }^{189}$ or limited use products such as MNO airtimebased SVAs or fiat-based MFS SVAs that are generally non-interoperable between MNOs, the value may not be widely accepted beyond the limited number of relationships or payees ${ }^{190}$ for which the MNO allows their SVAs to be used as a source of payment. ${ }^{191}$ The extent of this restriction could be seen as adverse in a determination of determining whether the value is indeed money. ${ }^{192}$ Availability may, quantitatively be on an equal footing if not better footing than acceptability.

\footnotetext{
${ }^{186}$ See generally ch 10 on MFS in Kenya.

${ }^{187}$ Such as in more developed environments that have relatively sophisticated financial, payment and banking infrastructures.

${ }^{188} \mathrm{See}$ ch $13,13.6 .3$ on Circulation in the Orthodox School.

189 One could investigate the extent of geographic use, or participatory use by (some) merchants so as to determine whether it is widely circulated.

${ }^{190}$ Or communities, in Von Hayek's view. See Von Hayek (1976) op cit note 4 at 63.

${ }^{191}$ Acceptance of the value will be assumed when using any mechanism that facilitates the smooth operation of the extinction and corresponding creation of interchangeable obligations accepted in full discharge of debts. Geva and Kianieff (2002) op cit note 4 at 25 .

${ }_{192}$ Relevant restrictions or limits relating to the use of a SVP may be either geographic, such as acceptance being bound solely to one shopping mall or one small town, or numerical, and is based on the number of participating creditors. See Geva and Kianieff (2002) op cit note 4.
} 
In all then, acceptance may be founded by a society - 'the community' ${ }^{193}$ - through ubiquitous circulation and the utility the (money) facility offers. Acceptance, at least in the sense of MFS is, as was also noted earlier, intimately related to circulation and availability. Indeed, in the case of M-pesa MFS system in Kenya, the efficacy and utility of the system so impressed consumers and competitors alike, that availability and acceptability rapidly conflated such that M-pesa operated by MNO Safaricom became ubiquitous throughout Kenya, and even had limited interoperability with some competing banking products although not necessarily at all with its MNO-competitors. ${ }^{194}$

Nonetheless, even if something does not necessarily have geographic ubiquity of acceptance (and availability), but there is a redeemability component ${ }^{195}$ to it, this may be persuasive in suggesting that the value will be accepted by society, however widely framed. ${ }^{196}$

\subsection{5}

\section{Anonymity}

Anonymity seemingly conflicts with the fundamental Claim School tenet ${ }^{197}$ whereby a (traceable) debitcredit 'bookkeeping' system comes into being when money is created. Ordinarily, the use of a debit-credit system would imply knowledge of the identity of the participants. ${ }^{198}$ Thus the 'no earmark' ${ }^{199}$ 'anonymity' rule, again, is fundamentally difficult to employ in many account-type (prepaid) MFS SVP systems as there is usually some audit trail, ${ }^{200}$ be it an innate part of the system, or as part of a legal requirement for AML purposes. ${ }^{201}$ As noted earlier, the 'no earmark' rule as a totem of the anonymity criterion has diminished relevance in any discussion of (incorporeal) money since it is seen to be of little economic relevance in today's world. ${ }^{202}$ Rather, at a basic level, the currency of money is determined as the pivotal feature.

\footnotetext{
${ }^{193}$ This comports with the expansive Societary Theory view of money predominant in the Claim School, in which the community is part of the Society. See the discussion in ch 3, s3.4.2.1 on the State Theory of money, and in particular the expansive view proffered by Hart and Von Hayek in relation to what a society is. In Harts view, it is a nation, communities and the State. Von Hayek suggests that it is communities that will best accept their own (private) currencies. See Von Hayek (1976) op cit note 4 at 63; Macintosh (1998) op cit note 4 at 742. Whether a 'currency' will be accepted if it is only usable within that community is still an open question to some. See the discussion thereto in Bootle (2001) op cit note 4 at 10; and Schmitz (2005a) op cit note 4 at 66.

${ }^{194}$ See further and generally ch 10 on a discussion on MFS in Kenya.

${ }^{195}$ Redeemability or compatibility and almost 'pseudo' equivalence to fiat money - the GAME - although equivalence, in whatever form, however is not in terms of the expansive, Societary Theory view of the Claim School a prerequisite for something to be money.

${ }^{196}$ See ch 3, s3.2.4.1 on issuance.

197 That is, this allows the holder of value for example to have a claim over the issuer of that money for fulfilment of the embodied value when the holder uses the money to, for example, discharge a debt.

${ }^{198}$ In a MFS domain, use of a prepaid SVP SVA will not necessarily require identification of the holder of the SOV presented for payment. Indeed the majority of mobile prepaid SVPs are anonymous even though the electronic tracing mechanism allows indirect identification of the person using the SVA as well as the location in which they use it.

${ }_{199}$ See the discussion of this maxim and the modern conception thereof in see ch 3, s3.12.2 titled Legal Definitions And Theories Relating To money.

${ }^{200}$ A trail of at least the usage, and not necessarily also of the user.

${ }^{201}$ The audit trail may be imposed by law - for example the 'RICA' SIM card registration law in South Africa discussed in ch 12 , s12.7 - to prevent money laundering and transfers between nefarious persons.

${ }^{202}$ See the discussion of this maxim and the modern conception thereof in ch 13, s13.3.4 above. It does however still appear to present a somewhat obstructionist role in matters of determining unjustified enrichment in relation to incorporeal value transfers. On the relevance of the maxim, see also Fox (2008) op cit note 4 at 265-277; on a modern application thereof in a Canadian case, Fox (2010a) op cit note 4 passim. On Unjustified Enrichment, see Du Plessis (2011) op cit note 4 passim; and Visser (2008) op cit note 4 passim.
} 
Insofar as the associated 'credit' of the issuer or user - their 'character - is concerned, since the fundamentals of the Claim School and use of debit-credit nomenclature are abstract to the actual utility of the value, this credit-character conjunction, this then would relate more to informing where a money would be positioned in the hierarchy of money. ${ }^{203}$ Adverse 'credit' then relating to one party may conceivably be an indication that a particular money does not enjoy the same hierarchical position as other 'monies,' and at the extreme may even disqualify something from being a money.

Thus the anonymity criterion, for the purposes of determining whether in terms of the Claim School there is equivalence to Moss, may again be placed aside. ${ }^{204}$

\subsection{6}

\section{Final Discharge}

Insofar as the criterion that money must effect a 'final discharge' so that 'no recourse against the payer is available to the payee, ${ }^{205}$ the MOP component of the Claim School - with its money-as-a-debt (and conversely, credit) for a payment thread - seems well aligned to fulfilling this.

In use of the MOP of the Claim School, 'payment' may be used both as a noun and a verb. When used as a noun, the Claim School employs the bookkeeping metaphor described earlier ${ }^{206}$ to describe new forms of money. Insofar as the corporeal or incorporeal money 'thing' may also embody the value in and of itself, it may then, in the nomenclature of the Claim School, also be the actual link in creating money. ${ }^{207}$

Payment may also be a verb that describes the active and legally inductive process of discharging an obligation through the mechanism of transfer of value from one to another using money. Similarly, Goode says payment is the legal act whereby a 'gift or loan of money [is] offered and accepted in performance of a monetary obligation, ${ }^{208}$ and further, that it constitutes 'any transfer of value in a form according with the express or implied agreement of the parties constitutes payment, whether or not it is money in the legal sense. $^{, 209}$

This comports to some extent with South African law, where the $a c t$ - as a verb - of payment is considered as and required to be a 'bilateral justice act ${ }^{210}$ that requires the cooperation of both the debtor and creditor. It may be argued then in relation to money that the 'bilateral' requirement, if at all necessary in defining or characterising a payment, ${ }^{211}$ could relate only to the functional requirements that facilitate a payment, not

\footnotetext{
${ }^{203}$ See ch 3, s3.2.4.1 on hierarchies of money

${ }^{204}$ See again, Geva and Kianieff (2002) op cit note 4 at 8-9 who reach similar conclusions as to the relevance of anonymity, but based on a limited technology-specific perspective.

${ }^{205}$ Geva and Kianieff (2002) op cit note 4 at 12.

${ }^{206}$ See ch 3, s3.10.1; and ch 13, s13.5.3.2.

${ }^{207}$ The Claim School sees a thing (which may be money) acting as a MOP as being one of the pivotal components in creating money. When someone offers a 'thing' as consideration for an obligation, money is created. The 'thing' can be anything, although in theory even in the Claim School a tangible 'thing' can be used as long as the value of the money is not based on the 'thing'.

${ }^{208}$ Goode (1983) op cit note 4 at 11.

${ }^{209}$ Goode (2004) op cit note 4 at 452.

${ }^{210}$ VolkskasBank BPK v Bankorp (h/a Trustbank) 1991 (3) SA 605 (A). See also Lawack-Davids (2000) op cit note 4 at 10 for a discussion thereof.

${ }^{211}$ It has been discussed previously though that this bilateral requirement may not have consonance with regard to unilateral payments, for example a gift or remittance. See the discussion in ch 7, s7.3.2.1.
} 
the intrinsic, abstract ${ }^{212}$ quality of the method - that is the 'money thing' in Keynes' nomenclature - that comprises the payment. ${ }^{213}$

Linking then the nexus between the intrinsic MOP function of money identified in the Claim School and the general legal characteristic of what constitutes payment, Goodhart says of the extent of the finality when one compares the functional definition of the MOE versus the narrower MOP feature of money, that:

'A MOE includes those assets ... whose transfer to the seller will commonly allow a sale to proceed. The distinction is that when the seller receives a MOE which is not a MOP he will feel that he still has a valid claim for future payment against the buyer, or even more generally against some other group the buyer has provided him with a claim. ${ }^{214}$

A MOP then is in some sense final ${ }^{215}$ while a MOE is not and thus only desirable in an economy where there is an intermediate time dimension, for example, in the provision broadly speaking of 'credit' as in a cheque that is payable at a later time. ${ }^{216}$ The MOP however, whatever the 'thing' is, signifies finality.

In relation to MFS, with most SVPs there is no real credit: everything is primarily prepaid credit-push, and the payments therefrom mostly final. In this sense, the SOVs in MFS SVPs if they were to be considered as money as being a specialised MOP, would alleviate problems of exchange under conditions of uncertainty. ${ }^{217}$ The incorporeal nature of this claim is further reflected by Goode who says that a creditor's right to be paid is purely a personal right, ${ }^{218}$ since he does not own money representing the debt, but instead he is owed money. ${ }^{219}$

The inference then is manifest in these accounts of payments that payment can be achieved by a Societal acceptance of the money 'thing'. Further, if the putative scheme being used to pay for goods and services is used or described as a MOP, this usually embodies a credit-push system where the obligation by the issuer to pay is unconditional, and where the payment so proffered has no recourse (or connection) to the underlying relationship between the issuer nor the buyer. ${ }^{220}$

\footnotetext{
${ }^{212}$ See ch 7, s 7.3.6.7 where the abstract nature of payment in South African law is discussed.

${ }^{213}$ In that respect, one could have recourse to Goode's view of payment as it involves either the transfer of money or the discharge of money obligations but rather a pure exchange of sorts. Where the rights of parties are not fixed by reference to any money sum, Goode takes the view that there is no payment. See Goode (1983) op cit note 412 at 16 . Thus, a 'bilateral act' of payment is not key to an understanding of money per se, but rather remains important only within the context that it is used.

${ }^{214}$ Goodhart (1989) op cit note 4 at 26.

${ }^{215}$ GLS Shackle (1971) '[Discussion Papers on "Theoretical Foundations of Monetary Policy” by RW Clower]' in JC Gilbert and R Sedgwick (eds) Monetary Theory and Monetary Policy in the 1970s: Proceedings of the 1970 Sheffield Seminar on Monetary Theory and Monetary Policy in the 1970s (1970: University of Sheffield) at 32-34.

${ }^{216}$ Goodhart (1989) op cit note 4 at 26-27.

${ }^{217}$ Ibid at 27.

${ }^{218}$ This is, in a way similar to the 'personal credit' concept proffered by Hart in relation to the Societary Theory of money. Hart (2000) op cit note 4 at 318. See also ch 3, s3.11; and 13, s13.4.

${ }^{219}$ Goode (1995) op cit note 4 at 491.

${ }^{220}$ Cash and credit cards generally are payment instruments that provide this finality of payment. See ch 3 , s3.10.3 on final discharge in the Claim School. Fry et al suggest that uncertainty and transaction costs constitute the two prerequisites for a demand for money as a MOP. They say that uncertainty produces a preference for an immediate (final) rather than postponed payment, while transaction costs produce a preference for payment in something that is generally acceptable as a MOP since a number of exchanges (of value) may add to the cost of a transaction. MJ Fry et al (1999) Payment Systems in Global Perspective at 46
} 
Insofar as the SOV in an airtime-based MFS SVAs could be considered to be money, some private money commercial models using their own MOP could in turn and in time become more accepted and so be afforded a promotion amongst the hierarchies of money ${ }^{221}$ by society elevating their MOP function as final settlement. ${ }^{222}$

Taking a slightly different view however is Papadopoulos, ${ }^{223}$ who in contriving a nexus between the two Schools, describes private 'e-money' - as a species of the family SVP - parenthetically in the negative to found the nexus. He appears to adopt the State Theory of money approach, surmising that where private money is not redeemable nor backed by a UOA that is the descriptor of the GAME, it also cannot be a Means of (general) Payment. Nor can it be used as a means of final payment in settlement of debts as it is illiquid - in the sense that it is not convertible or redeemable to CB assets ${ }^{224}$ - since it can only be used as what Goodhart ${ }^{225}$ had alluded to as being a 'Means of Transaction', that is an asset that is an intermediate claim/asset on the process of completing a transaction. ${ }^{226}$ 'E-money', Papadopoulos concludes then, is not a payment instrument. Further, he says that since it fulfils neither the role of GAME nor of MOP that are the essentialia in the ability to behave as and create money in the Orthodox and even Claim Schools respectively, nor is it then money. Rather, he concludes, private (e)money is simply a sale of an issuer's liabilities, that is, a sale of debt. ${ }^{227}$

This circuitous route, even though it is founded in the negative, ultimately sails towards the overriding theme: the provenance that money is a 'debt.'

It appears then that the act of payment must encompass something the recipient - usually the creditor ${ }^{228}$ finds valuable and acceptable before, and if agreed implicitly or otherwise between the parties, the obligation is deemed to be finally extinguished following the final payment. Money as the thing fulfilling the description provided by the UOA and hence acting as the MOP is thought to provide the means to finally discharge these debts. ${ }^{229}$

\footnotetext{
${ }^{221}$ See ch 3, s3.2.4.1 on hierarchies of money.

${ }^{222}$ This promotion within the hierarchies of (accepted) money would allow a particular MOE to approach the status of private money. Ingham for example gives the example of award of 'loyalty credit' for purchases of a range of goods whose suppliers comprise a linked trading network might also operate in a similar way in the production of limited MOP. Ingham (2002) op cit note 4 at 131

${ }_{223}$ Papadopoulos (2007) op cit note 4 at 5 .

${ }^{224}$ Thus although it may fulfil a descriptive 'money of account' function as described by Keynes, it is not money as there is no acceptable asset - a money - that answers to the description of the MOA. See Keynes (1971) op cit note 4 at 3.

${ }^{225}$ Goodhart (1989) op cit note 4 at 26.

${ }^{226}$ In this respect, although it is 'merely' a Means of Transaction, the assets used can be deemed currency. Currency, says Kutyn may be 'anything which either through custom or use is used in trade as a MOE'. Currency serves as a SOV for its owner. Kutyn (2005) op cit note 4 at 2; Ely (1996) op cit note 4.

${ }^{227}$ Papadopoulos (2007) op cit note 4 at 5. For a similar view, see Piffaretti (1998) op cit note 4 at 14.

${ }^{228}$ In an e-money and banking scenario, deposit into a SOV usually creates a presumption that the system operator or bank has an obligation to the 'depositor' for repayment of the value 'deposited'. The depositor takes on the mantle of creditor to the debtor system operator/bank.

${ }^{229}$ For an exposition on the final settlement of debts, see Lietaer (2001) op cit note 4; and Ingham (2002) op cit note 4 at 131. While the MOP is also used in the context of the final settlement of debts, the term 'settlement' is steeped in, and thus suited more to, the macro-economic exercise of settlement between banks and the CB after a day's trading. Settlement in CB money, using a Clearing and Settlement Institution (CSI), ensures finality in an economic sense. For an exposition on final settlement in CB terms, see Schmitz (2006) op cit note 4 at 3 and 59-84, who explains the difference between the two types of 'settlement'. See also ch 4, s4.8.2.2 titled Payment: The Process of Verification, Clearing, Settlement and Netting.
} 
As noted earlier, MFS systems are generally credit-push but may in some cases also be debit pull. Seen in this light, any determination of whether a particular MFS SVA, that provides payment finality as a MOP in the Claim School, may act as money is entirely system dependent. ${ }^{230}$

\section{7}

\section{Analysis and Application to MFS}

It has been shown earlier that the Claim School view of money and its social, 'debt-centric' stance has more than a passing confluence to 'personal' rights than just terminology: it shares the fundamental precepts of obligations whereby money is seen as a series of debt relationships.

Indeed, it may be a better fit in an analysis of new, emerging forms of value deigning to be money and which has legal equivalence with the criteria of Moss.

As to the potential of confluence, Goodhart notes that:

'[My] prevailing judgment [is] that the Chartalist/credit approach is historically valid, while the metallist/Mengerian/mainstream view of money arising as a means of reducing transaction costs is nothing but a pure myth, a fable. ${ }^{, 231}$

And as Goodhart surmises further, referring in part to the bespoke Orthodox School's applicability to new forms of money, that its general approach:

"Tries to turn economic analysis into an "arithmetic problem"... dropping successively social relations, economic history, and the politics of erstwhile "political economy" from the pure, mathematical, but often jejune, core of economic analysis. We need to turn back that tide .....232

Indeed, the use of the 'accounting' system motif in the Claim School to determine values of money appears to trump the Orthodox School and effectively acts to dematerialise money, such that the need in the Orthodox School for tangibility or even a furtive symbolic representation thereof is not only ameliorated, but rejected.

As Janson ${ }^{233}$ then observes as a 'solution':

'[T]he spontaneous character of the high technology activities put the Austrian [Claim] economic thought at the center of the discussion, in particular, the evolutionary approach endorsed by Menger is

\footnotetext{
${ }^{230}$ As Geva and Kianieff (2002) op cit note 4 at 13 note, there is however no general presumption of conditional payment. Further and similarly, see Re Charge Card Services Ltd. [1988] 3 All ER 702 (CA) at 707 where it was said that

'[E]ach method of payment has to be considered in the light of the consequences and other circumstances attending that type of payment.'

${ }^{231}$ Goodhart (2005) at 760.

${ }^{232}$ Ibid at 761 .

${ }^{233}$ Janson (2001) op cit note 4 at 2.
} 
highly consistent with the development pattern exhibited by electronic means of payment (new technologies). ${ }^{234}$

Similarly, Palley ${ }^{235}$ points out that:

'[The] e-money revolution fits naturally into the history of money as told by Austrian economists ... (which) emphasises the endogeneity of the "form" of money which changes in response to technical innovations and market competition ...,236

Using then the Claim School and its variants and in particular the debt relationship emblematic therein, it is possible to disaggregate the payment instrument from the inherent value, such that the modus of payment - the instrument - is relegated to a superfluous artifact: that is, money moves into an emerging technology era happily sans a tangible 'thing' necessary to provide its utility as a final MOP.

As Moini deftly explains this shift:

'Thus money can no longer be viewed as a thing that stands by itself, but rather as a relation that necessarily involves two or more persons. This insight exposes the emptiness of the notion of money as "anything that serves as a medium of exchange.",237

This patently also removes any outstanding nexus to the Orthodox School.

Further, even if the intra-doctrinal objections ${ }^{238}$ in some offshoots of the Claim School are sustained to including a 'thing' acting as a money in non-Orthodox perceptions of money insofar as its inclusion may ideologically pollute the Claim School's pure non-metallic waters, ${ }^{239}$ this matters not: moneys nexus to the Orthodox School is severed, replaced by the Rights, debt-oriented approach emblematic of the Claim School.

Money can then rather be seen in the form of a pure, abstract concept of circulating Rights where debits and credits - to the issuer and holder of the value - are scored in an abstract accounting system.

Given this emerging tectonic shift in the perception of the nature of money, it then becomes possible for the dematerialised MFS SVP to compete with, or even substitute, the national UOA. What may then be termed a 'private' money issuer may, in effect, act as a pseudo $\mathrm{CB}$ with its own private $\mathrm{CB}$, clearing and

\footnotetext{
${ }^{234}$ Ibid. On the economist, Menger, see Menger (1892) op cit note 4, and ch 3, s3.2.4.1 on the State Theory of money.

${ }^{235}$ Palley (2001-2002) op cit note 4 at 1.

${ }^{236}$ The modern variant of the Claim School, NME discussed in ch 3, s3.10.1, also places a premium on computing power and specifically on individuals transferring wealth rather than CB money between one another in settlement of debts. According to this School of thought, developed economies are moving toward a sophisticated barter economy relying on money as a mere UOA: the MOE could then be fully separated from the UOA. See the discussion thereto in Janson (2001) op cit note 4 at 2. Cf Graeber (2011) who ostensibly disputes the conventional timeline of barter being the first type of 'monetary' system that preceded coins and notes.

${ }^{237}$ Moini (2001) op cit note 5 at 271.

${ }^{238}$ See for example Moini (2011) op cit note 5 at 271. This implies, says Moini at 272, that money is not a thing, as suggested by the traditional view, but that money is a definite form of social relation in the sense that its very conception involves rightobligation coupling between persons within the payment community.

${ }^{239}$ That is, in contradistinction to a pure Rights-based two-sided balance sheet of debits and credits sans any 'thing'.
} 
settlement system. ${ }^{240}$ Indeed, a recent patent on 'inside money' was granted in 2007 by the US Patent Office which involves the creation of a virtual $\mathrm{CB} .{ }^{241}$ PayPal, emerging private currencies such as 'Facebook Credits', as well as airtime and fiat-based MFS SVAs offered by MNOs may be additional examples of these new competitive 'private' monetary systems. A SVP, it is suggested then, can be tokentype money acting as a 'thing' whereby an authority or private company designates a UOA. ${ }^{242}$ Thus any item such as airline loyalty airmiles or prepaid mobile airtime could fulfill the role of a MOP in the 'unit' so designated. As an example, prepaid mobile SVA with 100 minutes - minutes being the UOA - stored as the SOV could be considered the equivalent of one fiat or other private currency unit.

With the Claim School established as the cogent description of dematerialised money from an economic and Societary Theory perspective, ${ }^{243}$ the enquiry then moves to a legal determination as whether the Claim School provides for a nexus for MFS SVPs to Moss and its (extrapolated) attributes? ? $^{244}$

In causa, the legal analysis earlier shows that the Claim School approach to money mirrors a MFS SVP's primary role as a legal MOP, both unilaterally and bilaterally. ${ }^{245}$ On the ostensible requirement for tangibility implied in Moss, this is not nugatory to equivalence since legal fictions relating to symbolic, scriptural representation similarly employed in the Orthodox School adequately cater here for dematerialised forms. ${ }^{246}$ While the issue of circulation and acceptance suggests additional potential nugatory factors in equivalence, it is suggested that these too are not necessarily spoilers, since the national availability of these MFS systems - such as the national ubiquity of the eponymous M-pesa MFS system in Kenya - may trump this potential 'handicap.' Similarly, whilst desirable, associated attributes of redeemability into or equivalence with the UOA of the GAME are not, it is submitted, dogmatic requirements for the airtime-based and fiat-based MFS SVA's SOV as a putative qualification for a money, since many types of monies have 'exchange rates' with one another and redeemability may be excluded by contract. ${ }^{247}$ Legal tender is also practically not an overriding factor in any determination. ${ }^{248}$

A potential concern to a determination of universal equivalence however is raised with respect to some iterations of mobile airtime-based MFS, which while generally conforming to the above equivalence

\footnotetext{
${ }^{240}$ Fullenkamp and Nsouli (2004) op cit note 4 at 14. The use of pooled user funds may, however, be restricted by statute as the EMD2 and the Payment Services Directive2007/64/EC (hereafter PSD) specify on use of pooled user funds.

${ }^{241}$ US Patent 7020626 issued on March 28, 2006, to CitiBank. Briefly, the patent involves a transaction network for a synthetic currency, which is commercially designated as Inside money. This synthetic currency acts as an alternative to cash transactions, allowing users of the transaction network to conduct electronic currency transactions in a 24-hour international network creating a virtual CB with near real-time finality of transaction. For a full description, see PatentStorm (2004-2012) 'Inside money', available at http://goo.gl/MgFoY.

${ }^{242}$ Or the UOA in the Orthodox School.

${ }^{243}$ See further from an economic perspective and in relation to economic theory, see inter alia Janson (2001) op cit note 4 at 2; and Palley (2001-2002) op cit note 4 at 1; and Moini (2011) op cit note 5 at 370-271.

${ }^{244}$ The methodology thereto, it may be recalled, was to analyse which of the two Schools if any can be used to legally deign emerging SVPs as money under the specific equivalence criteria for money in terms of Moss op cit note 4 and an extrapolation thereto using the criteria of tangibility, circulation, anonymity, acceptability, and final discharge.

${ }^{245}$ Payment here is used in the context of settlement of a debt and in transfer of value for non-debt purposes, that is, a donation.

${ }^{246}$ The seminal difference between the two Schools remains though that some sort of backing is required in the Orthodox School, a requirement absent in the Claim School.

${ }^{247}$ Redeemability to the GAME is however not a feature of the Claim School.

${ }^{248}$ Importantly, information loaded onto an SOV in an SVA is not meant to imply - although there are cogent indications that this may be the case - that the information loaded is legal tender or anything similar to legal tender, but rather that the information stored implies a right to be paid a sum of money or to be used for payment as money. See Piffaretti (1998) op cit note 4. See further the discussion on implications for legal tender in ch 13, s13.8.2.3.
} 
criteria so as to have the potential to be money, a more dogmatic assessment thereto is hampered by some practical conditional-usage situations and on the type of systems deployed.

Still, from the aggregate equilibration exercise between the Claim School and Moss, it is submitted that the Claim School indeed founds the required nexus to Moss in relation to dematerialised SVPs, providing the pivot to potentially allow intangible values in SVPs to be legally described as money. That this is entirely plausible appears to be supported both from the spectrum of the equilibration analysis and augmented by legal scholarly insight by contemporary and classic legal scholars that appear to venerate the use of forms of the Claim School generally. ${ }^{249}$

In all, while the overriding evidence in the equilibration exercise is that when using the Claim School rather than the Orthodox School view of money as the (economic) basis for the legal analysis, that an ultimate determination of whether a particular MFS SVP that provides payment finality may act as money is largely system dependent. ${ }^{250}$

\section{Overview}

Commentators are somewhat divided ${ }^{251}$ on the 'forms ${ }^{252}$ and the effect of modern forms of money. ${ }^{253}$ Some believe there will be a transition in an evolutionary manner to new permutations and that these new forms of money may have a catastrophic effect on money as we know it today. ${ }^{254}$ Others, however, believe there will be no effect. ${ }^{255}$

Commentaries on potential effects of e-money reached their zenith during the emergence of the internet bubble and hype in the mid- and late 1990s when it was 'certain' that new forms of money driven by technological innovation would arrive and compete with, and even displace it was said, traditional CB money. ${ }^{256}$

\footnotetext{
${ }^{249}$ For a legal perspective on money that adds gravitas to this conceptualisation, see Hudson (1895) op cit note 4; Eder (1935) op cit note 3; Nussbaum (1950) op cit note 4; Schulze (2004b) op cit note 4; see Proctor (2005) op cit note 4; and Fox (2008) op cit note 4 at $44-45$.

${ }^{250}$ The use of MFS SOV may however amount simply to a SOW where the prevailing SOV is not considered robust enough in its link to an acceptable SOV.

${ }^{251}$ Most of the commentaries were on e-money, and very little if any on m-money or its variants.

${ }^{252}$ Even the word 'form' in relation to money is in dispute. See Ingham (2004) op cit note 4 at 76 argues that this is 'a basic category error' that persists from Aristotle's time in the theory and use of metal coins.

${ }^{253}$ For a summary and discussion of these competing views, see Schmitz (2006) op cit note 4 at 62-77.

${ }^{254}$ That is, controlled a by a CB with a uniform UOA and GAME.

${ }^{255}$ See for example Ely (1996) op cit note 4: 'Fundamentally, electronic money is no different than all other forms of money that exist today. Consequently, the monetary policy implications of electronic money are nil.' Ely indicates an important caveat, however, in the federal government's loss of 'seigniorage' income.

${ }^{256}$ Godschalk and Krueger sagely cautioned against exaggerating the actual extent, scope and novelty of these (e-money) developments in H Godschalk and M Krueger (2000) 'Why e-money Still Fails', Third Berlin Internet Economics Workshop at 4 , available at http://goo.gl/rzSZ8. See similarly Bootle (2001) op cit note 4 at 7 who says that:
}

'[T]he world's monetary history makes it clear that there is no necessary reason why a monetary system should be operated by the State, and no reason why the liabilities of the State should necessarily be used as money. Money did not start off that way, so why should it "end up" that way?' 
Since the issuance or existence of e-money have competitive, auxiliary, or even displacement effects, each of these scenarios on the emergence of these SVPs warrants further investigation. ${ }^{257}$ This includes any legal and economic affects.

\section{Legal Effects}

13.8.2.1

\section{Overview}

That the Claim School and its laissez-faire attitude to monetary policies may be gaining ground as the doctrinal match to legal views of money is already evident in the attrition of both economic and legal authorities over new forms of money.

Selgin and White, for example, note that advances in technology are progressively eroding legal restrictions on what may amount to a type of 'business of banking'. ${ }^{258}$ If what is traded, stored or transferred is not fiat money but is, instead, private or 'near' money, then the 'business of banking' as we know it may become moot.

Under these circumstances, an empirical legal and/or economic analysis of whether any dematerialised thing that may amount to money is as much a legal-analytical endeavour as it appears to be a decidedly political affair. ${ }^{259}$

From the discussion earlier, it appears that the continued use of material notions of money - as used in the Orthodox School - will impact on how the law keeps up and adapts to current commercial practices, and thus may equally fail to detect, prevent or punish evolving nefarious and criminal practices such as Money Laundering (ML) and Terrorist Financing (TF). ${ }^{260}$

As noted by Mackenzie, if the perception of money is locked into its historically contingent aspects, legal structures could be marginalised by the superior resources and sophistication of contemporary organised crime, while the ability to 'trace' dematerialised money in electronic systems will depend on an ability to reconceptulise money. ${ }^{261}$

\footnotetext{
${ }^{257}$ Using the permutations enunciated by Schmitz (2006) op cit note 4 at 62-79.

${ }^{258}$ Acting to provide private, 'inside' money, for example, as a SVP like Facebook credits. See Selgin and White (2002a) op cit note 4 at 3 .

${ }^{259}$ Ingham (2002) op cit note 4 at 132 argues that monetary spaces are social and political, in that they cannot be constituted exclusively by the exchange relations of economic agents. In the Claim School, money's exchange abilities do not feature. For an ostensibly political decision on the application of a law, see ch 9, s9.6.3.1 describing the circumstances surrounding the decision in 2006 to exempt MNOs from core provisions of the EMD1 after an enquiry into whether the use of MNObased prepaid SVAs amounted to the use of what was defined in the EMD1 as e-money. Time as a determinant of deposittaking is also a policy issue. EMD1 op cit note 4. See ch 6, s6.4.2.3 titled Use of Agents; and ch 9, s9.3.6.2.4 on the nature of 'time' in relation to a determination of deposit-taking.

${ }^{260}$ Mackenzie (1998) op cit note 4 at 22.

${ }^{261}$ Ibid, at 30.
} 
The use of the Claim School as an alternative conceptualisation of (dematerialised) money may, again it is submitted, ameliorate this effect.

\subsubsection{2}

\section{Specific Legal Effects}

At the level of rights obtaining to a money, the issue is complicated - at least within the confines of South African Roman-Dutch law under review - by the varying regimes that apply when a value (as money) is lost or stolen. In the case of coins and notes, these are seen in terms of real rights of ownership ${ }^{262}$ of corporeals to which the remedy of rei vindicatio ${ }^{263}$ could apply, while with respect to incorporeals such as EFTs and bank deposits, the rights manifest instead as personal rights which sound in the law of obligations and unjust enrichment for which various condictiones are possibly available. ${ }^{264}$

With the hybrid nature of many MFS systems, where then is the line of application of a remedy, if any? ${ }^{265}$ An equivocation ${ }^{266}$ in usability of the appropriate (potential) remedy for some type of loss, augments the previous recommendation ${ }^{267}$ for a Payment Services Provider Law (PSL) that may cover any or many types of potential 'forms' of the value.

\subsubsection{Use as Legal Tender}

From the discussion of the GAME, ${ }^{268}$ a consequence or even prerequisite for SVP species such as e-money or mobile airtime to be considered as the GAME is that they must be legal tender. ${ }^{269}$ While there are numerous forms of payment, not all are considered as legal tender. ${ }^{270}$ But while legal tender is money, (economic) forms of money acting as payment instruments may not necessarily be legal tender. ${ }^{271}$

\footnotetext{
${ }^{262}$ The issue of 'ownership' - described by Honoré as 'the greatest possible interest in a thing which a mature system of law recognises' - come to the fore, but may of course be interpreted narrowly as being only that related to tangible things. It could also be interpreted broadly and in context of applying bespoke principles to emerging forms of hybrid use. AM Honoré (1961) 'Ownership' in AG Guest (ed) Oxford Essays in Jurisprudence 108.

${ }^{263}$ See further ch 3, s3.13 on Money in South African Law.

264 The remedy of the person dispossessed against a mala fide possessor would thus be either via a rei vindicatio or one the condictiones, depending on whether the possessor has acquired ownership of notes and coins. Malan (1977) op cit note 4 at 249. See ch 7, s7.3.6.8 on the Condictiones.

${ }^{265}$ In an example of application to MFS, and specifically the case of a prepaid airtime voucher as used in MFS, the question may be asked as to whether real rights of ownership using the rei vindicatio or one of the condictiones would apply to, for example a scenario where an unused prepaid mobile (airtime) card/voucher with its discernible, visible access code before it was loaded onto the airtime system such that it then became, if it could be framed as such, 'less tangible.' Is then that preloaded access code equivalent to money as with coins and notes and in the context of the longevity of that access code such that one could then possibly apply the rei vindicatio before there is the value becomes 'less tangible' through the trite act of loading the access code into the MNO's or MFSP's MFS system as a SOV?

${ }^{266}$ See the discussion in ch 7, s7.5.2.3 titled Efficacy of Common Law Remedies.

${ }^{267}$ See ch 14, s14.9.3 on Payment Providers, and Recommendation 4.

${ }^{268}$ See on the GAME, ch 3,s3.5.3.3.1

${ }^{269}$ See ch 3, s3.11.3.2.1 above on legal tender.

270 These include cheques, credit cards and debit cards which are considered as merely being the means of transferring fiat money as legal tender.

${ }^{271}$ That said, 'private' money, while not being legal tender, may effectively emulate the features of CB money whilst circulating in payment systems relatively independently of CB fiat money. It may only affect CB money when users, once paid via a private money payment system, want or need to 'cash-in' or 'cash out' into fiat money. See Pretorius (2004) op cit note 4 on whether Krugerrands may be considered as legal tender.
} 
Cash is usually the archetype of legal tender. ${ }^{272}$ However, as indicated earlier, legal tender appears to be becoming a moot issue in an age where money is being transformed from its materialised to a dematerialised state, insofar as money is now primarily represented more by scriptural entries in electronic accounts and instructions on how to store and transfer them than it is by cash or tangible currency. Although taxes, for example, must be paid in legal tender, the State accepts payments in Bank money ${ }^{273}$ Inside money - from taxpayers who use the facilities of their bank since the bank money is perfectly redeemable in the (legal tender) GAME. ${ }^{274}$ Janson $^{275}$ notes that, in general, CB money has a circulation advantage over private money since private 'notes' may not necessarily be legal tender, such that they would not have the same degree of circulation as the GAME would have as legal tender. They would then need to sustain much higher costs of circulation. ${ }^{276}$ With the rising social and maintenance cost of cash however, gradually replacing cash with prepaid stored values becomes very attractive to $\mathrm{CBs}^{277}$ It has also been suggested that illegal economic activities could be reduced by making e-money as a species of SVPs and its equivalents, legal tender. ${ }^{278}$

However, linking 'e-money' as a species of the SVP family to legal tender has up to now been astutely avoided by the EU. The EMD1, ${ }^{279}$ for example, in its definition of e-money specifically says that e-money as a SVP is not legal tender but is rather a 'surrogate for coins and notes', ${ }^{280}$ although in a later sectoral analysis in $2004,{ }^{281}$ appears to confuse the issue by directly giving e-money the status of legal tender. ${ }^{282}$

\footnotetext{
${ }^{272}$ Legal tender is both the ubiquitous 'ordinary' money in circulation that is issued by the State, as well as money that may be lawfully used for the payments of debts and which may not be deemed inadequate by a creditor to whom it is tendered in the proper amount.

${ }^{273}$ See ch 3, s3.7.2.1 on 'Credit Money,' which includes 'Bank Money.'

${ }^{274}$ This nuance is how the legal fiction of inside money representing the GAME arises.

275 Janson (2001) op cit note 4 at p7. This would be true in an analogue method of circulation, but in a digital currency world, it would be more the marketing of the private currency that would incur the expense rather than the digital distribution.

276 The longer the note stays in circulation, the greater the benefits it enjoys such as allowing the issuer to increase its portfolio of loans. Janson (2001) op cit note 4at 7.

${ }^{277}$ The De Nederlandsche Bank, the Dutch Central Bank, says that the social cost of cash amounts to 0.48\% of GDP. Paying larger amounts by debit card could bring down the costs to society, but cost savings would be most pronounced if more payments were made by e-SOVs, irrespective of the specific transaction amount. See De Nederlandsche Bank (2004) The Cost of Payments: Survey on the Costs involved in POS Payment Products, Working Group on Costs of POS Payment Products, National Forum on the Payments System.

${ }^{278}$ M Drehmann, CAE Goodhart and M Krüger (2002) 'The Challenges Facing Currency Usage: Will the Traditional Transaction Medium be Able to Resist Competition from the New Technologies?' 17 Economic Policy 193-227, available at http://goo.gl/T982q.

${ }^{279}$ See on the EMD, ch 9, s9.6.

${ }^{280}$ Recital 3 of the EMD says that e-money is considered an electronic surrogate for coins and banknotes. The German version of the EMD specifically says that that e-money is accepted as a 'MOP by third parties without being legal tender.' Prudentially then, e-money's status as a representation of the GAME is confirmed.

281 'Although it is clear that e-money may not have all the functionality of notes and coins, it's primary purpose is still to be used as legal tender in a payment transaction with a third party.' European Commission (2005a) 'Application of the e-money Directive to Mobile Operators: Guidance Note from the Commission Services', available at http://goo.gl/9iF3U. The EUbased Electronic Money Association (EMA) later decried this statement, saying that the EC was acting 'ultra vires' in respect of its findings, in that it was introducing new objectives for competent legislation as a means of reaching its interpretation'. See http://www.e-ma.org.

${ }^{282}$ In 2000, the Bank for International Settlements (hereafter BIS) canvassed CBs on issuing e-money as legal tender. CBs appear to have lost their initial appetite for doing so. Bank for International Settlements (BIS) (2000) 'Survey of Electronic Money Developments' Committee on Payment and Settlement Systems, available at http://goo.gl/n523M, at 41. The German Bundesbank, for example, indicated that the option of issuing e-money itself should be kept open as a 'last resort', although the conditions that would trigger this option were not revealed. Presumably they are based on known CB concerns about emoney such as costs, safety, legal tender status, risk, and competition or monopoly as well as loss of seigniorage income. Another difference used as a differentiator is that private e-money may not necessarily be backed by one-to-one bank deposits, but are rather claims against commercial players.
} 
There are a number of options for the CB role in SVP schemes. Van Den Hove ${ }^{283}$ for example proposes a number of scenarios for the emergence of e-money as legal tender. ${ }^{284}$ First, the existing fiat currency keeps its current status, implying that it remains legal tender but simultaneously so with e-money; or second, the $\mathrm{CB}$ still issues currency but the currency loses its status as legal tender, or thirdly that currency is abolished altogether. However, making electronic money legal tender need not imply that the CB issues emoney itself. Rather, the $\mathrm{CB}$ could certify the quality of the issue of private money thus rating the money activity, which in effect will give legal tender characteristics to e-money. Thus, if e-money is not yet legal tender, unable to act in final discharge of a debt and requiring the consent of the creditor for its acceptance, this would be yet another indication of its status as the means rather than the end of a payment transaction, that is, the value. ${ }^{285}$ The latter point is somewhat ameliorated by the fluidity or even the complete absence in some jurisdictions of legal tender laws that allow payments by methods other than legal tender where so agreed by the contacting parties. This means that while legal tender is an important definitional component of money - and by extrapolation, e-money - it does not necessarily speak qualitatively to the features of emoney as being money or not. ${ }^{286}$

Herein is a dichotomy: money is not necessarily the same species as 'legal tender', although legal tender is money. ${ }^{287}$ That is because, unless forbidden by statute, parties may agree to forms of payment other than legal tender, so that no adverse inference on the creditor will result. ${ }^{288}$

Contemplation of electronic forms of money being used as legal tender is not welcomed by everyone. Janson $^{289}$ refers to the possible loss of the legal tender monopoly of CBs to a plethora of replacements or analogues as 'science-fiction', while Goodhart and Krueger ${ }^{290}$ feel the need to caution that:

\begin{abstract}
'Electronic money does not have the characteristics of currency. It is not anonymous, and it is not legal tender. Given these special characteristics, the demise of currency at the hands of information technology will not happen, at least not unless an authoritarian government should decree that it must happen. The fact that such a prospect would terrify anyone with the slightest concern for liberty and freedom among people underlines just how important currency usage is for our way of life, including our "bad" behavior.'
\end{abstract}

Indeed there has not exactly been a rush to embrace the concept of e-money as legal tender, although some CBs have warmed to the idea with some having toyed with the idea of issuing e-money as legal tender. ${ }^{291}$

\footnotetext{
283 See L van Hove (2003) 'Making Electronic Money Legal Tender: Pros \& Cons' at 137-171, available at http://goo.gl/mXcNT.

${ }^{284}$ Ibid.

${ }^{285}$ However, if the technological protection measures to ensure uniqueness are in place, the value may, in and of itself, embody the value. See Negotiable Instruments above.

${ }^{286}$ See Geva and Kianieff (2002) op cit note 4 at 10-11.

${ }^{287}$ Kreltszheim (2003) op cit note 4 at 175.

${ }^{288}$ It is only when the creditor, having initially agreed with his debtor to a form of payment in modes other than legal tender (ie fiat coins and notes), may be estopped from subsequently refuting payment has been made when paid in the agreed manner.

${ }^{289}$ Janson (2001) op cit note 4 at 2.

${ }^{290}$ Goodhart and Krueger (2001) op cit note 4.

${ }^{291}$ The Board of Commissioners of Currency in Singapore (BCCS) announced in 2000 that it was to make electronic money legal tender but this does not appear to have been implemented in law. In other moves to promote electronic forms of payment, the Irish National bank recommended that the Irish government should stop issuing or accepting cheques after its
} 
Still, despite these dire warnings and concerns, as noted earlier with respect to a need to determine whether something amounts to legal tender for it to have ubquitous and legal acceptance in a Society, the seminal message is that the import of legal tender is waning in the face of the contemprary primacy of scriptural representations of the GAME as well as generally scriptural representations that characterise emerging forms of value that may amount to money.

\section{Overview}

As the prototypical bank, ${ }^{292}$ the $\mathrm{CB}^{293}$ has a unique position ${ }^{294}$ in the implementation of monetary policy since CB money is the GAME. ${ }^{295}$ The GAME though has, as noted earlier, two incidental functions, that of (uniform) UOA and as the medium of final settlement. ${ }^{296}$

There are three scenarios that may result from SVP species - such as 'm-money' - being seen as money. First a complete replacement of the CB GAME by private UOA and GAME; second, where a CB GAME competes with private UOAs and GAMEs; and third, payment systems with a publicly sanctioned UOA but without a GAME. The permutations also include models ${ }^{297}$ where there are parallel currencies that exist and compete alongside CB GAME money which may have the effect of reducing the demand for CB money; or second, as in Von Hayek's theory of money, the existence of multiple media in competition to

national 'E-Day' on 1 November 2008 to highlight the alternative options for consumers; that the taxi regulator should make it compulsory for all taxis and hackneys to accept payment by debit or credit cards by 1 November 2008; and that the government should levy tax on the inefficient forms of payment instead on the efficient forms. See National Irish Bank (2007a) 'Payments Reform', available at http://goo.gl/qAde5.

${ }^{292}$ See ch 3, s3.5.3.4 on the proto bank concept.

${ }^{293}$ In 1900 there were only 18 countries with CBs. Now well over $90 \%$ of the countries represented at the United Nations have CBs, many from the conversion of colonial currency boards into CBs of independent countries and the creation of new CBs in Eastern and Central Europe in the 1990s. See M King (1999) 'Challenges for Monetary Policy: New And Old' Paper prepared for the Symposium on New Challenges for Monetary Policy sponsored by the Federal Reserve Bank of Kansas City, available at http://goo.gl/z0mRB, and Ingham (2002) op cit note 4 at 126.

${ }^{294}$ The CB is able to manipulate supply and the relative price of the GAME at zero marginal cost. See Schmitz (2006) op cit note 4 at 14.

${ }^{295}$ The CB role in implementation of monetary policy involves inter alia the manipulation of relative price (ie opportunity costs) of medium of final settlement; and the spread of rate of interest on the medium of final settlement and optimal alternative investment such as a money market.

${ }^{296}$ The means of final settlement should not be confused with MOP relating to final discharge of debts. The final settlement relates to the CB settling, or netting, the debts owed by commercial banks to the CB and to each other.

${ }^{297}$ These effects are enumerated inter alia by Schmitz (2006) at 59 in which he classifies the models according to their approach to the institutional structure of the monetary system. First, where the CB GAME is replaced by a private UOA and GAME, there is no pivot in the economy. Any implementation that removes the exclusivity of the CB GAME from the locus of the economy in favour of either other competing 'GAMEs' or no CB GAME whatsoever is heretical to the Orthodox view of money which places the CB GAME at centre stage of the money equilibrium; second, where the CB GAME competes with Private UOAs \& GAMEs; and third, where there is a publicly sanctioned UOA but without a generally accepted MOE (GAME), this conforms to the Chartalist and Von Hayekian view of money that emphasises its UOA features rather than its MOP. 
or even replacing CB money ${ }^{298}$ are available as the UOA and GAME; and third, where there is a publically sanctioned, uniform UOA but without a CB GAME. ${ }^{299}$

At a macro-economic level, some economists believe that the dematerialisation of money into forms such as e-money that create possible alternative MOP may lead to what they term a 'steeper payment pyramid $^{300}$ in the hierarchy of money ${ }^{301}$ where the ratio of CB money to the total value of payments decreases. This, they say, raises concerns about the role of money in general and CB money in particular in the economy-wide payments system. ${ }^{302}$

A swathe of resultant risks ${ }^{303}$ that may appear with the emergence of nascent payment environments that (possibly) bypass the CB's role of fiat money issuer and prudential overseer of banking and payment systems have been identified as: ${ }^{304}$ credit or solvency risk; liquidity risk; market risk; Herstatt (or timegap) risk; ${ }^{305}$ fraud risk; operational risk, and systemic risk. In understanding the potential effect of new forms of money, it is pivotal to sketch the role of the CB in monetary and payment systems as many of the new models tend to impact on its role. ${ }^{306}$

\subsubsection{Macro-economic Consequences}

The evolution of the technical or functional characteristics of electronic forms of money may have economic consequences on monetary theory and financial systems in addition to their legal consequences related to obligations. ${ }^{307}$

In terms of economic consequences, new forms of what may be deemed money - in a MFS sense, in a MFS SVP - may have an effect on CB economic targets and may, at some finite but as yet undeterminable level, have systemic risk implications. ${ }^{308}$ The CB's control over the negotiability of notes outside the banking system may begin to wane if receivers of the SOV in a SVP do not ultimately or even fleetingly redeem their balances' monetary value on their bank accounts, but instead use it to make new

\footnotetext{
${ }^{298}$ CB money producing a UOA (the numeraire) and the GAME as one 'item.'

${ }^{299}$ That is, where the GAME is no longer produced and under the monopoly authority of the CB.

${ }^{300}$ Schmitz (2006) op cit note 4 at 27; Bell (1998) op cit note 4 at 22.

${ }^{301}$ See Bell (1998) op cit note 4; and ch 3, s3.2.4.1 that discusses the hierarchy of money.

${ }^{302}$ Schmitz (2006) op cit note 4 at 27; Bell (1998) op cit note 4 at 22; JM Dykes (1995) 'Digital Cash and the Development of the Apolitical Currency' Paper for MIT 6.805/STS085: Ethics and Law on the Electronic Frontier, available at http://goo.gl/OOVVH; F Shostak (2000) 'Why the Present Monetary System cannot be Reformed' Paper delivered at the Austrian Scholars' Conference, March 25, 2000, Auburn, Alabama USA, available at http://goo.gl/3oMn8 at 5; Fullenkamp and Nsouli (2004) op cit note 4 at 4.

${ }^{303}$ This extensive categorisation is not mutually exclusive.

304 J McAndrews (1997) 'Banking and Payment System Stability in an Electronic Money World' at 7, available at http://goo.gl/VGKOd.

${ }^{305}$ The most well-known example of settlement risk is the failure of a small German bank, BankhausHerstatt. The Herstatt risk is that one party in a foreign exchange trade pays out the currency it sold but does not receive the currency it bought. The failure of BankhausHerstatt in 1974 caused it to default an intra-day forex settlement with other banks. See International Financial Risk Institute (2000) 'Overview: Settlement Risk', available at http://goo.gl/gJSSe.

${ }^{306}$ Holtzhausen and Monnet (2003) op cit note 4 at 8 . They note that while it was their wish to maintain a stable financial environment that was an aim of the establishment of $\mathrm{CBs}$ with a monopoly in note issuance, this was not the only reason. Walter Bagehot, an early writer on monetary policy, they say had argued that the Bank of England's special status was imposed by the government mainly to create an effective way of financing government expenditure, presumably via, inter alia, seigniorage income. See W Bagehot (1873): Lombard Street: A Description of the money Market. See also and Sifers (1997) op cit note 4 at 704-705.

${ }^{307}$ Piffaretti (1998) op cit note 4 at 10

${ }^{308}$ See ch 4.s4.8.1 on systemic risk.
} 
payments, ad infinitum. ${ }^{309}$ A resultant 'decoupling ${ }^{310}$ between CB money and deposit/payment systems may begin to occur, with the possible transformation of money from being predominantly an obligation of a $\mathrm{CB}$, to being that of any other creditworthy (private) issuer. ${ }^{311}$

Indeed Friedman ${ }^{312}$ regards this as the most serious threat to monetary policy efficacy. SVP issuers for example could maintain infinitesimal numbers of distributed accounts that parody CB reserves, but which are kept within the private system instead of having recourse at some 'exit point' to CB money.

While this settlement system is appropriate for large-scale transactions, it is more at the public microtransaction level where a form of currency must be used for day-to-day transactions that macro-economic principles give some pause for thought. Issues such as trust and acceptability are pivotal metrics in determining whether a new form of money will be accepted by consumers.

What will affect this acceptance is inter alia how widely available and how widely accepted the specific money is by merchants, creditors and others as well as the transaction costs associated with that money. ${ }^{313}$

One can assume that the marginal costs of issuing SVP are low, but rather it is the cost - or the spread relative to other monies that is of import in valuations of a money. If that money circulates in a community, and the holders accept its limited acceptability, ${ }^{314}$ then that money is likely to flourish. However, if that money is meant for general use and consumption, users are less likely to want to hold it.

If all monies are issued at par, those with highest acceptance and/or asset backing are likely to flourish, those that do not may wither and an exchange differential between the monies may arise. This is practical incidence of a hierarchy of money. ${ }^{315}$

Using these parameters that act as determinants for the success of a new money in a marketplace, one can then sketch possible prudential implementations to determine which, if any, may find practical and theoretical favour.

\footnotetext{
309 This may be done via transfers of assets (wealth) rather than CB money in a so-called e-settlement. See Palley (20012002) op cit note 4 at 217-233 who says that in times of crisis, the CB would probably be preferred.

${ }^{310}$ Kroszner, for instance, claims that advances made in the payments technologies have already eroded the government monopoly on the issuance of money. See R Kroszner (2001) 'Currency Competition in the Digital Age' quoted in Holtzhausen and Monnet (2003) op cit note 4 at 36.

${ }^{311}$ Geva and Kianieff (2002) op cit note 4 describe the 'decoupling' of the operations of the CB from markets in which financial claims are created and transacted, such as when claims people use in order to execute transactions are no longer restricted to claims backed one-for-one by bank deposits. Rather, they expand to cover claims against commercial players whose issuance is not influenced by the monetary policy of the CB. Geva and Kianieff

${ }^{312}$ C Friedman (2000) 'Decoupling at the Margin: The Threat to Monetary Policy from the Electronic Revolution in Banking' International-Finance 3(2) 211 passim.

${ }^{313}$ Simmel (1900) op cit note 4 observed that money rests upon the trust of individuals who accept it as payment only because they believe that other individuals will accept it in their turn in the future, which at its core is a Societal relationship of credit, embodying a negotiable claim upon society to receive goods and services of real value in the future in return for it. See also Herrmann (2007) op cit note 4 at 2.

${ }_{314}^{314}$ For example, single-use photocopy or mobile airtime prepaid minutes.

${ }^{315}$ On the hierarchy of money, see ch 3, s3.2.2 titled What Could Act As Money?
} 
It has been widely speculated that an overall consequence of this paradigm shift may be the genesis of instability in CB money demand, with consequential detrimental effects on the ability of CBs to formulate, manipulate and conduct monetary policy. ${ }^{316}$ It is speculated that the erosion of demand for banknotes and coins may lead to the shrinkage of the $\mathrm{CB}$ balance sheet and structural liquidity deficit, thereby complicating monetary policy implementation. ${ }^{317}$ The issue then is not whether or not electronic forms of money that ultimately have CB fiat money as redemption should be regulated (as they mostly already are), but whether CBs can continue to achieve their policy goals in a world with private e-money. ${ }^{318}$ Costa and De Grauwe say ${ }^{319}$ that the danger associated with this required transformation of the role of the $\mathrm{CB}$ in a cashless society is that the $\mathrm{CB}$ becomes an agent of the government Treasury, ${ }^{320}$ such that it loses its independence. ${ }^{321}$ The paradox therefore is that the movement towards a cashless society may in fact increase the power of the State over monetary affairs yet again.

\subsubsection{4}

\section{Systemic Risks}

A Group of 10 (hereafter G10) report ${ }^{322}$ identified four concerns regarding (private) e-money as a SVP: transparency; ${ }^{323}$ financial integrity of electronic money issuers; technical security of e-money schemes; and the vulnerability of such schemes to criminal activity. ${ }^{324}$

Similarly, there are issues raised with the emergence of new forms of money supposedly independent of $\mathrm{CB}$ money insofar as the safety of these emerging payment methods and their systemic risk implications in large value payments. ${ }^{325}$ There is also the question as to what extent the new payment technologies, which can constitute a sort of private money, will lead to a reduced demand for CB money in the future.

Systemic risk to a national monetary system or components thereof, ${ }^{326}$ is the risk from a failure of one participant in a transfer system, or in financial markets generally, to meet its required pecuniary obligations to cause a domino effect that causes other participants or financial institutions to be unable to

\footnotetext{
${ }^{316}$ Fullenkamp and Nsouli (2004) op cit note 4 at 24.

317 The demand for banknotes and coins is one of the autonomous and critical factors in forecasting the structural liquidity position for the banking sector.

${ }^{318} \mathrm{CBs}$ use electronic forms of money though at the wholesale level to conduct open market operations. It is unclear why the CB would wish to infringe on the private banks' franchise for providing retail e-money. See Fullenkamp and Nsouli (2004) op cit note 4 at 9 .

${ }^{319}$ Costa and De Grauwe (2001) op cit note 4 at 20, available at http://goo.gl/3j7q2

Thus, they say, the challenge is how to maintain the role of the $\mathrm{CB}$ without increasing the intrusion of politicians

${ }^{320}$ That is, the government finance ministry.

${ }^{321}$ Costa and De Grauwe (2001) op cit note 4 at 19-20: 'We have learned from the monetary history of the last centuries that CBs that are dependent on political institutions often fail in stabilising the price level. As a result, many countries in the world have transformed their CBs into institutions that are independent from the politicians. There is a large consensus today that this transformation is beneficial and that it is necessary to maintain price stability.'

322 Group of Ten (G10) (1997) 'Electronic Money: Consumer Protection, Law Enforcement, Supervisory and Cross Border Issues' Bank for International Settlements, available at http://goo.gl/2PPrn.

${ }^{323}$ Information that allows potential users to make informed choices about the relative merits of electronic money products

${ }^{324}$ See also Macintosh (1998) op cit note 4 at 736

325 There is, however, modern precedent for a non-State body acting as a CB. Just before its handover back to China, the private Hong Kong Bank performed the functions of a CB. See Bootle (2001) op cit note 4 at 12.

${ }^{326}$ See ch 4, s4.8.1 on systemic risk.
} 
meet their own obligations when due, including settlement obligations in a transfer system. ${ }^{327}$ From the prudential, reputational and consumer perspectives, the failure of one brand and its insolvency, or continual compromises in one of more payment system brand may induce the systemic risk that could cause the collapse of initially solvent payment providers.

Systemic failure in an e-money context then could, for example, be the result of the failure of a bank or institution issuing an SVP's SOV or other value to settle its debts with another bank or a financial institution ${ }^{328}$ which then causes liquidity problems. The resultant domino effect may be that other banks may not want to send payments through to it, ${ }^{329}$ further worsening its liquidity position. The cascade may result in multiple failures in banking or financial systems. ${ }^{330}$

Fraud and operational risks in e-money systems have also been identified as being risks of a systemic nature. ${ }^{331}$ From the criminal perspective, the systemic risk arises from the potential transfer of funds by a criminal organisation to other payment systems ad infinitum. ${ }^{332}$

\title{
13.8.3.5 Inflationary Risks
}

Of concern to many monetary authorities is the potential for private money to produce, either glacially or in a spike, inflationary risks that may upset financial stability. The risk is that if the sums involved are not regulated, an inflationary spike or spiral may result. ${ }^{333}$ One way this could potentially happen is if the private money was issued at a discount to its nominal face value. ${ }^{334}$ At a MFS level, this could manifest through situations where value the MNO receives through the wholesale and retail distribution chain that ultimately sells the voucher to an end user will almost certainly be considerably less than - that is, discounted - the value the purchaser of that voucher expects to be able to spend in a commercial transaction, be it buying a ringtone or simply making a call. The MNO thus has a contingent liability on its books corresponding to the face value of a valid and current mobile airtime voucher. ${ }^{335}$

\footnotetext{
${ }^{327}$ Bank for International Settlements (BIS) (1996) 'Implications for CBs of the Development of Electronic Money', available from http://goo.gl/2UxMc at 16 .Such a failure, it is thought, could cause significant liquidity or credit problems and, as a result, may threaten the stability of financial markets - with subsequent effects on the level of economic activity.

${ }^{328}$ For example, as a result of system failure or market perception that caused a run on a bank. See further on Systemically Important Payment Systems (SIPS) below in ch 4, s4.8.1.

${ }^{329}$ See the spectacular failures that triggered the Great Recession, of inter alia of Lehman Brothers, the UK Bank Northern Rock and Bear Stearns. In all these cases, the respective CBs added to liquidity to prevent a meltdown of national financial systems. See 'Northern Rock: The Timeline' (2008) The Independent Wednesday 26 March, available at http://goo.gl/sRSc3; and 'Bear Stearns Cos Inc.' (2008) The New York Times.

${ }^{330}$ See Bootle (2001) op cit note 4 at 13 who says that:
}

\begin{abstract}
'[B]anking systems are interdependent and failures of one institution can easily lead to contagion effects which have ramifications on other parts of the system. Competition is in no way a guarantee against bankruptcy, and the importance of money as a value store and payment mechanism means that governments have a role to prevent issuers defaulting on liabilities. Essentially, any new e-money issuer, or credit-taking institution will need to be regulated in much the same way as existing banks today, as they pose similar risks to consumers. Given these concerns, therefore, the government will regulate to prevent calamity occurring in the new world of e-money. Such regulation will continue to support CB money as the centre of the system.'
\end{abstract}

\footnotetext{
${ }^{331}$ McAndrews (1997) op cit note 4 at 14.

${ }^{332}$ Ibid.

${ }^{333}$ Kohlbach (2004) op cit note 4; Hermann (2007) op cit note 4 at 10 says that although the reasons for inflation are still very poorly understood, some key factors have been identified: an independent $\mathrm{CB}$, low level of conflict between capital and labour and decentralised forms of governments in federal systems.

${ }^{334} \mathrm{As}$ indicated in ch 5, s5.2.2, prepaid mobile airtime vouchers issued by MNOs are often sold at a discount to their face value.

${ }^{335}$ See s35 of the South African Consumer Protection Act 68 of 2008 mandates that the voucher must be valid for 3 years.
} 
The second potential inflationary risk is that which may result from unbridled credit extension. An issuer has four principal ways to make a profit in an SVP system, one of which is to offer the funds received as credit to a third party. Offering credit increases an economy's money supply, which then invariably has an inflationary impact as prices tend to increase. The CB under the threat of increased money supply then usually attempts to 'cool' the national economy by increasing its lending rates to banks in that monetary system. This effect is of course exacerbated if funds available to the user are issued at a discount to the face value of the SOV in the SVA. ${ }^{336}$ In an MFS context, this fear would be largely moot since most MFS implementations do not have any intermediation component, thus reducing risk.

\section{Summary And Conclusions}

New technologies are challenging current conceptions and legal views of money. ${ }^{337}$ It has been the convention in describing money that the value embodied in a money and the modalities of the transfer of that value have been neatly segmented such that one 'component' contains the value and another represents the value as an instrument as a MOE.

New types of payment however may, like a cash note or a coin, be an amalgam, acting not only as a payment instrument but may also embody the value as money within that instrument. That is, that they may act as money and not (just) as a representation of money. In relation specifically to prepaid MFS SVPs under review, the crisp question that arises then is whether they are storing money per se, or if what is stored is simply a claim to (inter alia, GAME) money. The answer to this question will shed light on whether what is stored can be deemed a MOP that finally discharges debts, or whether it is an inchoate MOE.

In that respect, and in relation to the effect of emerging technologies on the concept of money, Moini ${ }^{338}$ notes that:

\footnotetext{
'The emerging digitized payment system is of theoretical interest to the economist because it reveals the nature of the relations between credit and money more transparently than was ever the case with the earlier systems. This provides an opportunity for a fresh start in the investigation of the nature and origin of money.'
}

\footnotetext{
${ }^{336}$ Janson (2001) op cit note 4 at 13 says that:
}

'[I]f electronic money is issued as a consequence of credit, private issuers have incentives to supply additional amounts of electronic money as long as the difference between the interest charged on the credit and the one paid on e-money covers the credit risk premium, the provision of the payment service, and possibly also the cost of refinancing if redeemability is required. Given the low marginal cost of producing electronic money, its issuance could in principle proceed until the interest rate charged on the credit extended for the provision of electronic money is equal to the credit risk premium. This, by lowering the level of interest rates, could in turn endanger the maintenance of price stability.'

${ }^{337}$ The section in answering earlier tentative questions of 'money,' will henceforth use the term money without a parenthesis where it is found to be more definite and applicable.

${ }^{338}$ Moini (2001) op cit note 5 at 309 . 
Similar scholarly tools in law to assist in this 'fresh start' determination are based on common law views of money and payments. They revolve around the definition of money in the locus classicus on money, Moss, as well as in the magisterial works of the legal scholars Francis Mann and to a lesser extent Arthur Nussbaum.

The definition in $M o s s^{339}$ was shown to impute inter alia a scoreboard of (equivalence) features which something of value must possess in order to receive the appellation 'money.' These were extrapolated by Geva and Kianieff ${ }^{340}$ to mean that for something to be money, its features should at a minimum include the ability to pass freely from hand to hand; to circulate; to be for the sole purpose of finally discharging debts; to be acceptable to a wide range of acceptors; to be anonymous; and toeffect a final discharge with no recourse to the payer.

Moss was decided in the $19^{\text {th }}$ century and with an apparent quantitative focus on tangible things that can be the object of money, appears to incorporate elements of the Orthodox School economic view of money with its own tangible (corporeal) focus. Mann's classic definition of money as requiring a 'chattel' component appears to appropriate the Orthodox School's (inchoate) MOE function of money.

The alternative Claim School economic view of money however does not have at its core the requirement for a money to be a tangible item or to have a representation there of that acts as a MOE. Instead it emphasises a UOA - a MOA in economist John Keynes' conception thereof - alongside a pivotal characteristic of being MOP providing a final discharge of debts. The SOV feature is accepted, but it is not pivotal in the Claim School. This qualitative, debt-based approach to money allows any 'thing' to qualify as the money to give gravitas to a UOA. This means that a MFS SOV can be denominated in or described by for example a national currency as the UOA, while available airtime minutes or data megabytes may be the 'thing' that acts as the money. This economic confluence however does not necessarily mean that emerging SVPs amount to money: they of course still have to fulfill most if not all of the criteria in Moss for something to be called money.

In attempts to contrive an equivalence of the totality the requirements for money between those in Moss and in Geva and Kianieff so as to found a nexus to seemingly incompatible modern incorporeal systems such as prepaid MFS-based SVAs used in MFS, the Orthodox School view of money and its insistence on a corporeal asset as its basis, as well as through the inchoate nature of its MOE function, appears then to be deficient in providing this nexus and thus as a legal basis for characterising newer forms of value and payments as money.

Comparatively, the same equivalence exercise when used with the Claim School indicated in aggregate that this School's emphasis on money as being a MOP and a Right (as a debt) appears to be more coincident with the requirement in Moss for the money to act as a 'final discharge' of debts.

\footnotetext{
${ }^{339}$ Moss op cit note 4.

${ }^{340}$ Geva and Kianieff (2002) op cit note 4 passim.
} 
Use of this School is also especially attractive because of its focus on Societal relationships that allow money to be viewed as a series of debt obligations between actors.

Seen in these terms, any payment mechanism can be used as a MOP, but where payment is not unjustifiably delayed, where the contract that specifies the payment type is valid and acceptable within the framework of general contract law, and where no specific law forbids its use. The fact that there is redeemability at par to the GAME may, along with its conformance with other legal and economic criteria for money, also be highly persuasive that it is money. Free convertibility - 'redeemability' - is thus but one of many factors that may have to be taken into account as part of the overall picture of acceptance in cases of restricted $^{341}$ or limited use products like airtime-based MFS SVAs in determining whether they may qualify as money.

Further, a determination then when using the Claim School as the alternative analytical framework for analysing money appears to be that stored value systems have the seminal characteristics of money, but that individual species such as the SOV in an MNO airtime-based SVA may have conditional payment characteristics that may militate against their characterisation as money. On balance though, it is thus possible for dematerialised (incorporeal) electronic MFS SVPs to meet all the 'traditional' common law legal requirements for money outlined in Moss, even if in certain circumstances, that putative money is only used for micro-payments ${ }^{342}$ or may have some other conditionality. ${ }^{343}$ This means that, in terms of a Claim School analysis of money, a determination of whether something is legally money is theoretically possible, but the outcome may be system dependent.

The determination that the Claim School appears to provide a pivotal equivalence for a nexus to Moss provides a context for a conclusion that in terms of an analysis of incorporeal forms of value at least, the current evolutionary journey of money may have reached a doctrinal mismatch between the Orthodox School and common law legal views of money.

Continued use of the Orthodox School to founding equivalence to Moss would buffet against the dogmatism of the theories embedded in the School, meaning that SVPs could not amount to money. This curious result may have implications in, for example, AML laws sounding in money, as well as rights and remedies sounding in or involving money.

The analysis above that formed the basis of the 'fresh start' re-evaluation of money thus shows not what money is - as that is already littered with conceptual potholes created by perennial doctrinal spats - but what money can be, demonstrating also that the use of an alternative economic conception of money via the Claim School and its variants allows it to take 'forms' other than those which are predicated on use of just the Orthodox School.

\footnotetext{
${ }^{341}$ One must also look at geographic use, or participatory use by (some) merchants to determine whether it is (e-)money or not and whether or not it is widely circulated.

${ }^{342}$ The maximum value of payments, though, may be specified by national law, such as a maximum value that may be kept in a SOV at any one time, or the maximum value of a transaction.

${ }^{343}$ Such as the range of goods and services that may be bought, for example, only digital goods and services.
} 
MFS-based SVPs acting as money may take at least one of these forms, likely to be based on a chimera between the Claim-based Von Hayekian and Keynesian economic conceptions of money.

Economic implications of new forms of money include those relating to general macro-economic consequences, systemic effects, inflationary risks, and control by CBs over the issuance of money. While they are significant factors and must be monitored, these factors were not found to be nugatory in the emergence of new forms of money.

Legal effects including the impact of legal tender considerations were also not found to be nugatory as legal tender is a waning practical consideration of money generally. The hybrid nature of many MFS systems was shown to provide an equivocation in a determination of which of the condictiones remedies to use in situations of loss since this was found to be dependent on a determination of whether money is the subject of the enquiry. This augments the previous recommendation for a PSL that may cover any or many types of potential 'forms' of (stored) value.

In all, this Chapter demonstrates that it is plausible to use the Claim School as the legal basis for deigning MFS-based SVPs as a 'complete' money providing for a final discharge of debts.

Money then - at the very least in its intangible 'form' in SVPs as a type of payment instrument - may thus be seen as a species of the order 'payment' within the broader class, 'debt'.

This putative taxonomical hierarchy of all the relationships is shown in Exhibit A.

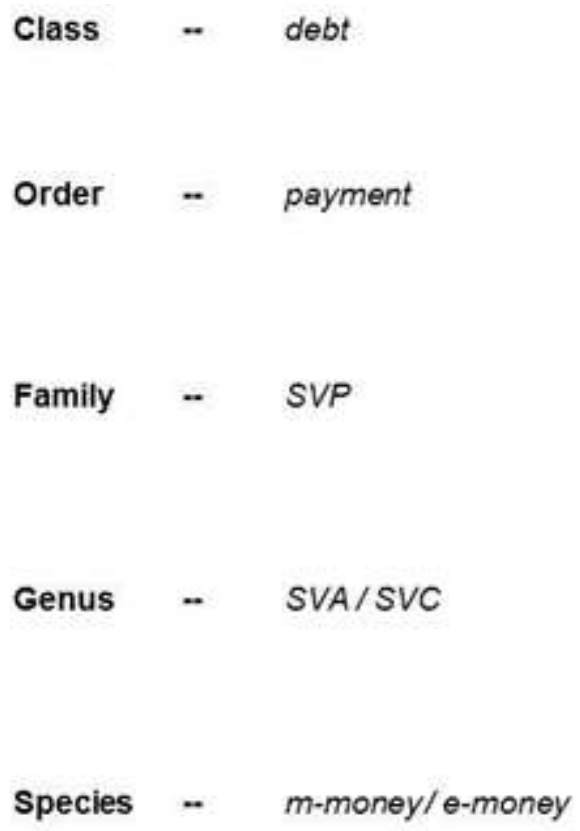

Exhibit A: Possible taxonomical relationships involving money, showing species of money and their relationship to debt. 


\section{CHAPTER 14}

\section{RESEARCH SUMMARIES, CONCLUSIONS AND RECOMMENDATIONS}

The complexity of the questions generally posed to law and policy by technology is the reason why it has been said that:

'[The] challenges technology presents continue to beat even the best legal minds in the world.'

- Justice Michael Kirby, Judge of the High Court of Australia ${ }^{1}$

A. Summaries And Conclusions

14.1 Thesis Summary And General Conclusions

The ability to make payments securely, reliably and efficiently is one of the hallmarks of a modern developed economy. Conversely lack of access to financial services - known as Financial Exclusion (hereafter FE) ${ }^{2}$ - exaggerates the disparities between people, especially those sectors of the population in relatively dire economic straits at the 'Bottom of the Pyramid' (hereafter BOP). ${ }^{3}$ The process of bringing those at the BOP into the financial fold by means of low-cost products and facilities customised to their socio-economic situation and financial literacy is known as Financial Inclusion (hereafter FI). ${ }^{4}$

A seminal development in this process has been the emergence of a new financial ecosystem known as Mobile Financial Services (hereafter MFS) ${ }^{5}$ as an alternative means to provide general financial services to those at the BOP. ${ }^{6}$ MFS uses as its inspiration the relative ubiquity and low cost of entry-level mobile phones and the popular use of prefunded electronic Stores of Value (hereafter SOV) housed in Stored Value Accounts (hereafter SVAs) ${ }^{7}$ operated by Mobile Network Operators (hereafter MNOs) using mobile airtime currency ${ }^{8}$ as a SOV to pay for calls and other similar services. The MFS SVAs may be denominated

\footnotetext{
${ }^{1}$ Comments made by Justice Michael Kirby AC CMG, High Court of Australia, as reported in L Tung (2007) 'Judge: Computer code is more potent than the law' ZDNet, available at http://goo.gl/i3nZ4.

${ }^{2}$ See ch 2, s2.1 titled Introduction.

${ }^{3} \mathrm{FE}$ in South Africa is currently at $24-26 \%$ of the population. See ch 12 , s12.1 titled Overview.

${ }^{4}$ Ibid.

${ }^{5}$ See ch 2, s2.1 titled Introduction to MFS.

${ }^{6}$ See further, ch 2, s2.2 titled The Rationale for MFS.

${ }^{7}$ See ch 4, s4.8.4.4. titled Stored Value Products. Prefunded may also mean 'prepaid,' the latter being of commercial and popular use. The terms are used interchangeably throughout this study, depending titled the context. They both simply mean that users can only use a SVA for transactions if they have placed value in them. No credit ('overdrafts') is given.

${ }^{8}$ Airtime is the value or 'currency' used by MNOs to allow access to their telecommunication facilities. Users will usually prefund (prepay) their airtime SOV by purchasing an 'airtime voucher' or similarly by using some value or denomination in
} 
in the MNO's (private) mobile airtime-based Unit of Account (hereafter UOA) ${ }^{9}$ as well as in a UOA relating to national, fiat-based ${ }^{10}$ currencies such as the Rand or Euro, and may be said to be genera of a family of prefunded electronic Stored Value Products (hereafter SVPs). ${ }^{11}$

There are now over 100 MFS systems operational and in development worldwide ${ }^{12}$ along with a few fledgling entities in South Africa, ${ }^{13}$ many based on the eponymous and hugely successful M-pesa MFS system in Kenya. ${ }^{14}$ Some of these entities may be said to be engaging in mobile commerce (hereafter mcommerce) and allowing mobile payments (hereafter m-payments) for goods and services. Some, depending on their commercial focus and types of SVAs offered to users, may also be said at a commercial level to be engaged in 'mobile banking' (hereafter m-banking) whilst accepting, storing and being general purveyors of what is often termed 'mobile money' (hereafter m-money). ${ }^{15}$ These entities could be licensed banks, non-banks or their respective agents. ${ }^{16}$

The topic is emerging, chimerical, and complex and thus touches on a number of varied but somewhat interconnected technical, commercial, legal, regulatory, economic, and anthropological doctrines and models. Deigning the interconnections, their relative import, and then their cumulative legal and regulatory impact was a major focus of this study, reflected in the diverse range of Problem Statements identified during the course of this research. ${ }^{17}$

This study found ${ }^{18}$ that generally the advent and introduction of these emergent MFS facilities and the nature of the new entrants providing services, has shown the law - and policy-makers - to be unprepared. In particular, the multi-faceted and multi-doctrinal nature of MFS and its transaction-focus as well as the relatively untested nature of new entrants meant that there was either a regulatory void or regulatory arbitrage, with governing regulations either completely absent or unable to efficiently regulate the hybrid systems and concomitant activities which appear to straddle inter alia banking law, ${ }^{19}$ concepts of and the legal nature of money, ${ }^{20}$ payment law, ${ }^{21}$ the law of contract, ${ }^{22}$ and common law views on unjustified enrichment, ${ }^{23}$ Additionally, there was found to be equivocation in application of laws and regulations that may apply directly or indirectly to MFS including those relating to Anti-Money Laundering (hereafter

fiat currency. They may also receive the value via an airtime remittance from another user. The equivalent airtime value is then added electronically for later use by that user. See ch 5, ss5.4 titled Mobile Network Operator (MNO) Billing Systems; and 5.2.2 titled User Access to Mobile Networks that discusses SIM cards and prepaid mobile airtime values.

${ }^{9}$ See ch 3, 3.2.3.4 titled an overview of UOAs.

${ }^{10}$ Fiat is the order of the state. A fiat currency is the notional currency issued by a state in a particular jurisdiction, for example, the South African Rand (hereafter ZAR). See 'Fiat' (2011) Merriam-Webster, available at http://goo.gl/I32Nd.

${ }^{11}$. For stored value and component nomenclature usage and the interaction between them, see ch 4, s4.8.4.4.2. See also ch 2 ,

s2.1 Exhibit A on their interaction in an MFS context.

${ }^{12}$ See further ch 2, s2.7 titled Current and Future MFS Schemes.

${ }^{13}$ See ch 12, s12.2 titled MFS Implementations in South Africa.

${ }^{14}$ See ch 10, s10.1 on M-pesa

15 These appellations often fasten on entities with fiat-based SVAs which may show some similarity in operation to bank accounts.

${ }^{16}$ For pictorial examples of services covered under MFS and discussed in this study, see Exhibits A-J in Annex 1.

${ }^{17}$ On the Problem Statements discussed in this thesis and their genesis, see ch 1, s1.8.

${ }^{18}$ See ch 8 , s8.9 titled Conclusion.

${ }^{19}$ See ch 4, s4.3 titled the common law and banking.

${ }^{20}$ See ch 3, s3.12 titled legal views of money.

${ }^{21}$ See ch 7, s7.3 titled Payments In General.

${ }^{22} \mathrm{Ch} 7, \mathrm{~s} 7.2$ titled Contracts.

${ }^{23}$ Ch 7, s7.3.6.8 titled Actions To Recover Value. There is no general law in South Africa on unjustified enrichment. 
AML),${ }^{24}$ telecommunications, ${ }^{25}$ electronic commerce (hereafter e-commerce), ${ }^{26}$ consumer protection ${ }^{27}$ as well as SVPs, or electronic money (hereafter e-money).

Thereto, this study provides a comprehensive overview of the legal and regulatory aspects of MFS and its incidences, seen from both the service provider's and the consumer's perspectives and makes recommendations ${ }^{28}$ as to how best enable financial-sector development through FI whilst still providing necessary consumer protections and maintaining sound financial policy.

A comparative law analysis approach to the Problem Statements was followed, comparing the situation in South Africa (hereafter SA) ${ }^{29}$ to the European Union (hereafter EU), ${ }^{30}$ Kenya, ${ }^{31}$ and the United States of America (hereafter USA), ${ }^{32}$ each as representative of a mix of developed and developing countries. Each of these jurisdictions was shown to individually provide key legal, regulatory, economic, policy, and commercial lessons and frameworks, that when aggregated as a compendium of Recommendations, ${ }^{33}$ can be seen to telegraph key proposals for the future provision of MFS in SA.

The genesis of the diverse MFS ecosystem under review encapsulates the emergence of the so-called 'branchless banking' paradigm within which the financial and banking needs of those who are at the BOP are served not by a 'bricks 'n mortar' bank branch, but by an electronic replacement or a combination of electronic and human agents who provide what have become known as 'cash-in/cash out' facilities. ${ }^{34} \mathrm{Ab}$ initio, the need arises because traditional 'bricks ' $\mathrm{n}$ mortar' banking facilities are seen to have failed to provide comprehensive FI to those who may be unbanked, underbanked and underserved. ${ }^{35}$

There are a number of MFS configurations highlighted in this study, falling under the broad headings of Bank-Led, ${ }^{36}$ MNO-led, ${ }^{37}$ and Independent MFSP Models. ${ }^{38}$

Examples highlighted include the Licensed Bank Model ${ }^{39}$ the MNO-only model ${ }^{40}$ the Bank-MNO Model $;{ }^{41}$ and the hybrid models. ${ }^{42}$ Where non-banks provide similar services as licensed banks, these MFS

\footnotetext{
${ }^{24}$ See ch 8, s8.5 titled Anti-Money Laundering, Terrorist Financing and Customer Due Diligence Laws and Regulations.

${ }^{25}$ See ch 8, s8.6 titled Telecommunications Laws and Regulations.

${ }^{26}$ See ch 8, s8.7 titled E-Commerce Laws and Regulations.

${ }^{27}$ See ch 8, s8.8 titled Consumer Protection-Type Laws.

${ }^{28}$ See inter alia, Recommendation 4 in ch 14 , s14.9.3 on a proposed new regulatory regime encapsulated in a PSPL; Recommendation 5 titled the use of trust accounts to ring-fence funds stored by non-banks providing transactional services in MFS; Recommendation 6 in ch 14, s14.9.5 titled proposed access to the National Payment System in South Africa by PSPs; Recommendation 7 in ch 14, s14.9.6 titled the need for a new regulatory regime that codifies consumer and service provider rights in macro retail payments, preferably within the framework of a proposed PSPL; and Recommendation 8 in ch 14, s14.9.7 titled the need for a dedicated agency (authority) to regulate consumer payments. Recommendation 8 would be in the form of a proposed Payment Services Regulatory Authority (hereafter PSRA), modelled on the US Consumer Financial Protection Bureau (hereafter CFBP). See further on the CFPB, ch 11, s11.2.4.2.2.

${ }^{29}$ See ch 12 titled SA and MFS.

${ }^{30}$ See ch 9 titled the EU and MFS.

${ }^{31}$ See ch 10 titled Kenya and MFS.

32 See ch 11 titled the USA and MFS.

${ }^{33}$ See ch 14, s14.9 titled Recommendations.

34 These are also known as 'cash-merchants'. See ch 2, 2.5.2 titled Use of Agents.

${ }^{35}$ See ch 2, s2.2 titled The Rationale for MFS.

${ }^{36}$ See ch 6, s6.4.

${ }^{37}$ See ch 6, s6.5

${ }^{38}$ See ch 6, s6.6.

${ }^{39}$ See the licensed bank branchless banking model described in ch 6, s6.4.2.
} 
models are described as 'transformational. ${ }^{43}$ Non-bank entities that provide MFS include MNOs, ${ }^{44}$ Mobile Financial Service Providers (hereafter MFSPs), ${ }^{45}$ and Wireless Application Services Providers (hereafter WASPs) ${ }^{46}$ who usually primarily use the MNOs 'private' (non-fiat) UOA as a source for the payment for Value Added Services (hereafter VAS). ${ }^{47}$ Where licensed banks add a mobile access component to the existing services they offer, ${ }^{48}$ these are described as 'additive'. ${ }^{49}$

The 'transformational' implications of these MFS systems include non-bank entities providing basic banking functions usually ascribed to licensed banks, the use of agents ${ }^{50}$ instead of (bank) branches, the transformation of cash into a SOV in a SVA to be employed by users of MFS systems as a value source for varied types of transactions, such as the payment of bills or the sending of remittances by mobile phone. All these services are available without the customer ever needing to set foot in a bank or bank-like institution. ${ }^{51}$ Others, like WASPs may provide and sell VAS such as digital goods and services. ${ }^{52}$

How to define and regulate these new systems in the midst of FI goals whilst maintaining the systemic fidelity of a nation's financial systems - and the regulatory philosophies ${ }^{53}$ behind the decisions - was framed as the 'regulator's dilemma'. ${ }^{54}$

A particular dilemma was whether the 'm-banking' and 'branchless banking' appellations commercially applied to MFS meant that some types of user funds stored in SVAs by entities engaged in various types of MFS activities and used for transactions could amount to a 'deposit' ${ }^{55}$ such that these entities could be seen to be carrying out the 'business of banking' under domestic regulation - and thus could be seen as 'banks' requiring a banking license.

This study therefore looked at whether according to statute and common law, an MFS entity could, as has been said of banks, be "trafficking in money" ${ }^{56}$ through their acceptance and storage of user funds in various types of MFS SVPs and their component SVAs. Key to this enquiry was the nature and quality of each of the SVAs available for use in MFS, some of which may, as noted earlier, be dominated in specialised UOAs such as mobile 'airtime minutes, ${ }^{57}$ offered by MNOs that usually can only be used for

\footnotetext{
${ }^{40}$ See the MNO-led MFS model described in ch 6, s6.5.

${ }^{41}$ See the bank-MNO MFS model described in ch 6, s6.4.3.

${ }^{42}$ See the independent MFSP model described in ch 6, s6.6.

${ }^{43}$ See ch 2, 2.1 titled Introduction. A 'non-bank' entity would be one which is not licensed as a bank in terms of domestic law.

${ }^{44}$ See ch 6, s6.5 titled MNO-led MFS Model.

${ }^{45}$ See ch 6, s6.6 titled Independent MFSP Model.

${ }^{46}$ See ch 6, s6.5.4.2 titled WASP Value Added Services.

${ }^{47}$ Ibid.

${ }^{48}$ See ch 6, s6.4.2 titled Licensed Bank Branchless Banking Model.

${ }^{49}$ Ibid.

${ }^{50}$ See ch 2, 2.5.2 titled Use of Agents.

${ }^{51}$ Ibid.

${ }^{52}$ See ch 2, s2.6.3 and ch 5, s5.2.3 titled Premium Rated Services.

${ }_{54}^{53}$ See ch 8, s8.2 titled Philosophies behind Regulation.

${ }^{54}$ See ch 8, s8.3 titled Types of Regulation Foci. Put succinctly, this means having to find a proportional regulatory approach to MFS and similar emerging systems through balancing the importance of promoting FI whilst still maintaining financial integrity.

${ }_{56}^{55}$ See ch 4, s4.5.3 titled Application to MFS, and the 'business of banking'.

${ }^{56} \mathrm{Ch} 4$, s4.3.2 titled Characteristics of Banking.

${ }^{57}$ See ch 5, s5.2.2 and ch 6, s6.2 that discuss airtime minutes. These values may or may not be capable of being redeemed back into the national (fiat) currency.
} 
specific transactions within the MNO system, ${ }^{58}$ while others may use value that is redeemable into the UOA of a fiat (national) currency. Other MFS systems may use SVPs that are a hybrid of the two, using two type of SVA. ${ }^{59}$ Each SVA configuration was found to have its own legal, regulatory and associated economic implications and, concomitantly, also possibly provide for incidences that flow from a putative bank-customer relationship. ${ }^{60}$.

This investigation into the quality of the SVAs and their use triggered an important, related investigation into the qualitative nature of a deposit and whether 'money' - being the core element of the traditional deposit - is indeed being 'trafficked' in MFS systems. This is particularly pertinent since, again, commercial appellations regularly fasten the term 'm-money' onto these MFS SVPs, for example, 'm-pesa' in Swahili. ${ }^{61}$

This necessary enquiry into the nature of money and in particular whether these intangible SVPs used in various forms in MFS indeed amount to 'money' revealed that the traditional legal approaches to money have not kept pace with the implications of the emergence of intangible, dematerialised SVPs deigning to be called 'money'. ${ }^{62}$ These traditional approaches are based on the legal criteria for money in the locus classicus, Moss v Hancock ${ }^{63}$ (hereafter Moss) and to some extent on Miller v Race ${ }^{64}$ (hereafter Miller). Moss, decided in 1899, was found to be based on a quantitative, economic view of money termed the Orthodox School. ${ }^{65}$ However when attempting to use the Orthodox School to found a nexus - an 'equivalence' - between the criteria for money detailed in Moss and to SVPs, this School was found to be deficient in this ability. ${ }^{66}$ An alternative economic School, the Claim School, ${ }^{67}$ was found to provide a more cogent nexus for SVPs to Moss insofar as this School pivots around money primarily as a series of debt relations able to provide for finality of payment. This was found to mean that the current evolutionary journey of money may have reached a doctrinal mismatch between the Orthodox School and the common law view of money, necessitating a disaggregation at a legal and economic level of traditional links to the Orthodox School of money in favour of the era-appropriate Claim School. ${ }^{68}$

This finding as well as the use of the Claim School as the alternative analytical framework for identifying 'money' may have implications in, for example, AML laws sounding in 'money,' rights to 'money', or when determining whether 'money' is being used as a deposit. ${ }^{69}$ Further, and even with use of the Claim School as the analytical template, it was also found that while some SVPs have the seminal characteristics

\footnotetext{
${ }^{58}$ See ch 6, s6.5 titled MNO-only MFS Model.

59 Some MFS systems provide two SVA containing two types of SOVs to their users: one redeemable into the fiat currency, while another may be a non-redeemable 'private currency' type. In MFS, the latter is usually the airtime-based SOV. Each SOV type may be commodious for a purpose. See for example the uses detailed in ch 6, s6.3 and in particular, s6.3.3. See also ch 2, s2.1 Exhibit A on their interaction in an MFS context.

${ }^{60} \mathrm{Ch} 4$, s4.5 titled The Banker-Customer Relationship.

${ }^{61} \mathrm{M}$ is for 'mobile,' while 'pesa' is the Swahili word for 'money'.

${ }^{62}$ See ch 3, s3.14 titled Summary and Conclusions

${ }^{63}$ Moss $v$ Hancock [1899] 2 QB 111 (hereafter Moss).

${ }^{64}$ Miller v Race (1758) 1 Burr 452 (hereafter Miller).

${ }^{65}$ See ch 3, s3.9 on the Orthodox School view of money. This School sees money as needing a 'tangible' backing like gold or other precious metals, or a symbolic representation thereof.

${ }^{66}$ See generally ch 13, s13.3 titled Legal Characteristics Based on the Orthodox School, on this equivalence process using the Orthodox School; and ch 13, s13.6 titled Legal Characteristics Based on the Claim School when using the Claim School.

${ }^{67}$ See ch 3, s3.10 on the Claim School view of money.

${ }^{68}$ See ch 3, s3.14 titled Summary and Conclusions.

${ }^{69}$ See ch 13, s13.9 titled Summary and Conclusions.
} 
of money, other individual species such as the mobile airtime-based SVA used to pay for VAS transactions may have conditional payment characteristics that militate against their characterisation as 'money.'

The associated enquiry into the nature of a deposit found that the transient, transactional nature of some MFS systems transforms the core aspect of a 'deposit' from an acceptance of funds - and the subjective time metric used to measure this -into somewhat of a transient source of funds used primarily for transactional payments. ${ }^{70}$ This, it is submitted, telegraphs that the 'business of banking' is becoming so stratified, that the 'deposit' concept as we know it and its nexus to the normally similar core 'intermediation' role in banking may no longer be the pivot around which the 'business of banking' coalesces. This then narrows the 'business of banking' essentially and primarily to that of intermediation and its incidences.

This finding suggests then that value ${ }^{71}$ received by an entity and stored - even if not necessarily transiently - in a SVA for use in transactional (MFS) payments is not a deposit, ${ }^{72}$ suggesting further that the entity involved in the process is not in the "business of banking. ${ }^{73}$ This nuanced shift then begins a possibly necessary disaggregation of the monolithic and venerated 'deposit' from its covalent link to the 'business of banking' such that it becomes the less totemic 'deposit concept' ${ }^{74}$ This, is submitted, would allow a more proportional regime to emerge that is differentiated from the risker aspects of acceptance of user funds: their use for intermediation activities.

The import of this suggests the need for an alternative, proportional-regulation regime policy universe from one that which has been employed for licensed banks engaged in intermediation, to one which focuses instead on the transactional nature of the use of funds and the mainly transient nature of the funds stored in a SVA. ${ }^{75}$ A solution possibly then may be a more coherent framework that focuses, on a proportional risk basis, on the use generally of a SOV for payments. ${ }^{76}$ shifting from and reducing concomitant focus on the value received as being a 'deposit'.

It was recommended thereto that the current bank-only regulatory and policy approach as outlined in the South African Reserve Bank's (hereafter SARB) most recent Position Paper on e-money ${ }^{77}$ as to who may provide and operate electronic SVAs using fiat values, is too restrictive for a developing economy - and even more so where it is manifestly evident that cogent opportunities to enhance FI present themselves in affordable, manageable, and ubiquitous MFS systems that may be provided by both banks and non-banks. ${ }^{78}$ It was recommended thereto that an enabling and proportional 'bank-lite-type' regime should be introduced

\footnotetext{
${ }^{70}$ See ch 4, s4.6 Conclusions; and further ch 4, s4.8.6 Summary and Conclusions.

${ }^{71}$ This may include fiat value.

${ }^{72}$ See ch 4, s4.6 titled Conclusions

${ }^{73}$ Ibid.

${ }_{75}^{74}$ See ch 4, s4.10 titled Summary and Conclusions.

${ }^{75}$ See thereto ch 7, s7.6.3.6; ch 12, ss12.10.3 and 12.12.

${ }^{76}$ See also inter alia, Recommendation 4 in ch 14, s14.9.3 on a proposed new regulatory regime encapsulated in a PSPL;

${ }^{77} \mathrm{Ch} 12$, s12.4 titled E-Money and Stored Value.

${ }^{78}$ See ch 12, s12.2.1 titled General Observations of the Regulatory Structure. It was observed that the relatively progressive policies of the Central Bank of Kenya (hereafter CBK) in allowing the then relatively unknown and untested M-pesa MFS system to be introduced into Kenya by the MNO Safaricom in 2006, albeit in somewhat of a legal and regulatory void, contributed to its massive success and increase in Kenya's FI. See ch 10 passim on M-pesa's introduction into Kenya and the CBK's enabling role thereto.
} 
in SA, ${ }^{79}$ possibly through the re-introduction of a revised and appropriately renamed version of the dormant and draft Dedicated Banks Bill, ${ }^{80}$ but preferably, it is submitted, through the introduction of a new omnibus, payment-focused Payment Services Provider Law (hereafter PSPL) ${ }^{81}$ akin to the EU's omnibus Payment Services Directive ${ }^{82}$ (hereafter PSD) so as to emphasise the payment and transaction focus - and not on the intermediation focus characteristic of licensed banks - of many non-banks and their MFS systems that house SVAs with fiat and private UOAs.

The PSPL would license and authorise specialised Payment Service Providers (hereafter PSPs) - be they MNOs, WASPs, MFSPs or any other eligible entity licensed as PSPs under the proposed PSPL - to provide inter alia Payment Services (hereafter PS) that allow users to make payments for corporeal and incorporeal goods and services; to issue and store e-money in SVAs; ${ }^{83}$ and to provide remittance services. The SVA would be akin to the Payment Account (hereafter PA) allowed for in the PSD, and similarly framed as not necessarily having to rely on or use the facilities, infrastructure and license conditions (and restrictions) of a licensed bank in order to operate it. It was also found however that for considerations of safety and soundness, the PS business of a PSP should be ring-fenced to a degree from its primary business via formation of a special Trust Company vehicle - similar to that employed in Kenya for M-pesa ${ }^{84}$ - which should control and protect the (pooled) funds derived from user prefunding. These pooled funds should be placed in a special trust (bank) account. ${ }^{85}$ Licensed PSPs should also be allowed some access to the National Payment System (hereafter NPS) to allow for seamless interoperability not just with banks, but with other MFS systems. ${ }^{86}$

While relationships embedded within MFS schemes are invariably based on contracts between the participants, the multifaceted nature of MFS schemes means that these relationships may involve inter alia banking, payment and telecommunications contracts. ${ }^{87}$ Payments that characterise the functional transactional aspects of MFS arise from methods of extinguishing obligations formed under the contract, and the nature of the payment were explored. ${ }^{88}$ It was also found that the need at common law for a payment to be 'bilateral' is buffeted by, for example, the unilateral and multilateral mechanism of value transfer that may be employed in MFS. ${ }^{89}$

The potential perfect storm of the conspicuous use of mobile phones in public together with the ability to do financial transactions at high velocity in a context of technical and financial illiteracy has the potential

\footnotetext{
${ }^{79}$ As was inferred from the Competition Commission enquiry into the South African banking sector See further the Competition Commission enquiry into the South African banking sector discussed in ch 12 , s12.5 titled Competition Commission Enquiry Into Banking and Payments in South Africa.

${ }^{80}$ See ch 12, s12.3.5.5.

${ }^{81}$ See inter alia, Recommendation 4 in ch 14, s14.9.3 on a proposed new regulatory regime encapsulated in a PSPL.

${ }^{82}$ See ch 9, s9.6.2 on the Payment Services Directive in the EU.

${ }^{83}$ In South Africa, this is currently limited to licensed banks.

${ }^{84}$ On the use of trust accounts with M-pesa, see ch 10, 10.2.3.3 titled Application to MFS.

${ }^{85} \mathrm{See}$ ch 7, s7.4 titled Trusts in relation to the potential use of trust accounts in MFS in South Africa.

${ }^{86}$ See Recommendation 6 in ch 14, s14.9.5 on proposed access to the National Payment System (hereafter NPS) in South Africa by inter alia PSPs. The degree of access to the various layers of the NPS for any one PSP would be decided on a caseby-case basis with systemic risk considerations in mind.

${ }^{87}$ See inter alia ch 7, s7.2.6.4 titled Application to MFS.

${ }^{88}$ See ch 7, s7.3 titled Payments In General.

${ }^{89}$ See ch 7, s7.3.2.1 titled Overview.
} 
for such hazards as mistake, fraud and duress in MFS transactions. ${ }^{90}$ The imbalances of historical contractual power and the nature of informational asymmetries are tipped in favour of service providers, meaning that additional protections are needed to give new consumers' confidence in the formal financial system and any new innovations. It is also in the interests of institutions - whether structured as a bank or a non-bank - to have an informed and confident clientele. Legal protections and remedies in these cases are in the purview of unjustified enrichment, and legal remedies thereto are limited to the universe of RomanDutch condictiones, ${ }^{91}$ which, it was found, are wholly inadequate and constrained ${ }^{92}$ in the face of MFS and other payment facilities. The enabling regimes for (retail) payment schemes in the EU, ${ }^{93}$ the $\mathrm{US}^{94}$ and Kenya $^{95}$ - and, briefly, emerging rules in Australia $^{96}$ - and their associated loss allocation rules were compared to South Africa. ${ }^{97}$

The EU's PSD in particular was found to present not only a model for an enabling regime for provision of MFS in South Africa, but to provided cogent protections for MFS users ${ }^{98}$ such that they could be incorporated into a PSPL. Similar including loss allocation rules from the US could also be used.

It was also recommended that a specific statutory agency - a proposed Payment Services Regulatory Authority (hereafter PSRA) - should be formed to administer licensing and sound operation of the PSPs and ensure compliance with the consumer protection provisions of the proposed PSPL. ${ }^{99}$ The PSRA could be modeled to some degree on the new Consumer Financial Protection Bureau in the US. ${ }^{100}$

The more affordable and ubiquitous 'transformational' banking paradigm introduces new non-bank actors such as MNOs and MFSPs - into the financial ecosystem. In the transformational 'branchless banking' model, new players replace banks and their branches, while in the additive model, licensed banks augment their existing services with a mobile access component and possibly also agents. MFS systems using redeemable SOVs are mostly additive because of the SARB's policy, although MNOs use non-redeemable mobile airtime 'currency' SOVs. Kenya's eponymous M-pesa MFS system is a global success story,

\footnotetext{
${ }^{90}$ See ch 7, 7.2.2.3 titled Absence of Consensus.

${ }^{91}$ See ch 7, s7.3.6.8 titled Actions to Recover Value on the condictiones.

${ }^{92}$ See ch 7, s7.6 titled Conclusion.

${ }^{93}$ See ch 9, s9.6.2.5 titled Transactional Rules and Liability Allocation in the PSD. These relate inter alia to obligations of the Payment Services User (PSU); obligations of the Payment Services Provider (PSP); liability Allocation between PSP and its technical providers; loss from lost or stolen instruments; loss for transactions pre-notification of loss/theft; loss for transactions post-notification of loss/theft; loss for transactions of 'offline' payment instruments; loss from cloned/forged payment instruments; effect of gross negligence by the PSU; effect of fraud by the PSU; effect of misappropriation of the payment instrument (PI) or its security features; burden of proof for unauthorised payments; and possible reduction of PSU liability.

${ }^{94}$ See further inter alia ch 11, s11.2.3.2 titled the US Federal Overview and ch 11, s11.2.3.4 titled the State Overview.

${ }^{95}$ See ch 10, 10.1 titled Overview.

${ }^{96}$ See ch 12, s12.11 titled Consumer Protection and Loss Allocation with Respect to Payments.

${ }^{97}$ Ibid.

${ }^{98}$ Ibid.

${ }^{99}$ See Recommendation 8 in ch 14, s14.9.7.

${ }^{100}$ See ch 11, s11.2.4.2.2 on the CFPB.
} 
operated by MNO Safaricom as a transformational system using a redeemable SOV that is fiat-based and a mobile airtime-based non-redeemable SOV. M-pesa, which since its launch had 14mn users and 18,000 agents eclipsing bank branches, radically transformed access to financial systems in that country.

\subsection{2 \\ Structure and Participants in MFS Schemes}

The actors in a MFS scheme depend generally on the MFS model, but may include MNOs, licensed banks, Joint Ventures (JVs) between banks and MNOs, third party providers like MFSPs, third party application and content providers like WASPs, third party retail agents - also known as outlets, cash merchants, or correspondents - that are employed by or contracted to banks, MNOs or MFSPs to provide services to customers at the edge of the MFS scheme, and trust companies nominally for housing SOV funds in pooled master accounts.

\subsection{3}

\section{MFS Schemes}

There are broadly three types of MFS schemes and associated commercial models being pursued worldwide, with variations therein: first, a bank only model; second, a MNO-only model; and third, hybrid models consisting of a MNO-bank JV or independent MFSP-bank JV or scheme. ${ }^{101}$ Four representative MFS commercial schemes are discussed in this study. ${ }^{102}$ Many of these schemes are termed 'branchless banking. ${ }^{103}$ At present, the MNO (and some MFSP) models issue two types of SOV: a redeemable fiatbased SOV and a non-redeemable 'virtual' - mostly airtime-based - currency SOV, where the MNO and MFSP act as issuer, treasury, and payment system for clearing and settlement. No credit is thus given to the user, mostly ameliorating fractional banking systemic risks. All the schemes have issues relating to dispute resolution, and the effect of Anti-Money Laundering/Know Your Customer/Customer Due Diligence (hereafter AML/ KYC/ CDD respectively), ${ }^{104}$ telecommunications, e-commerce and consumer protection laws. In almost all the models provided by non-bank actors, the introduction of a human 'agent' is a common 'transformational' factor. ${ }^{105}$ All models have their own commercial strengths and weaknesses and their own sets of legal and regulatory challenges. The common issues revolve around the status of bank agents in 'branchless banking'; dispute resolution; and the effect of AML/KYC/CDD, telecommunications, e-commerce and consumer protection laws. ${ }^{106}$

\footnotetext{
${ }^{101}$ For an exposition of the types of MFS schemes, see ch 6, ss6.3.1 titled MFS Schemes Overview, 6.3.2 titled Licensed Banks MFS Model, 6.3.3 titled the MNO-only MFS Model, 6.3.4 titled the Hybrid MNO-Bank MFS Model and 6.3.5 titled the Independent MFSP Model below relating to the Bank-led, MNO-led, Hybrid Bank-MNO models and Independent MFSP models, respectively.

102 The third, hybrid types may sometimes be classed individually, making four broad types of MFS schemes that are covered in this thesis. The WASP model where Value Added Services (hereafter VAS) are sold and provided to mobile subscribers may be classed within the MNO-only MFS Model. See ch 6, s6.5.4.2 on the WASP VAS model.

${ }^{103}$ See ch 2, s2.3 titled The Scope of MFS for an overview of 'branchless banking'.

${ }^{104}$ Know Your Customer (hereafter KYC); and Customer Due Diligence (hereafter CDD).

${ }^{105}$ See inter alia ch 6, ss6.4.4 titled Use of Agents, 6.5.5 titled Use of the Fiat SVA, and 6.6.3 titled Use of Agents.

${ }^{106}$ See the detailed discussion on these issues in chapter 8 passim.
} 
The bank-only model ${ }^{107}$ employs relatively simple 'additive' access to fiat-based redeemable accounts - or SOV, or wallets, in MFS parlance - with or without the use of agents for cash-in/cash out facilities. The bank operates its MFS services through its domestic banking license, and as such any fiat-based values accepted from the public amount to a deposit subject to domestic banking law. Beyond the common issues, the crisp issues in this model revolve around the policy of conversion of fiat-money to an electronic 'emoney' SOV, the status of bank agents, and dispute resolution.

\subsubsection{MNO-only MFS Model}

The MNO-only model ${ }^{108}$ has the MNO as the core participant: no licensed bank is involved, except to act as the store of the pooled funds on behalf of the MNO or its MFS subsidiary. It may use either a nonredeemable prepaid SOV as the transaction locus, or a combination of a prepaid non-redeemable SOV for MNO airtime-based transactions, plus the provision and use of a 'transformational' redeemable fiat-based SOV, and the use of agents for cash-in/cash out facilities. As the (micro-payment) progenitor of ubiquitous macro-payment MFS, MFS may consist of VAS services using the prepaid airtime SOV for walled garden micro-payment, as well as the more expansive 'transformational' prepaid fiat-based SOV that is redeemable on par and on demand and used for purchase of corporeal and incorporeal goods and services. Existing airtime agents would provide cash-in/cash out facilities. Crisp issues are inter alia whether the funds accepted in the SOV and used for transactions amount to a deposit, whether the MNO is engaged in the 'business of banking', the policy of and the rules around the conversion of fiat-money to an electronic ('e-money') SOV, and the status of its agents.

\subsubsection{Hybrid MNO-Bank MFS Model}

While in some jurisdictions MNOs dominate the transformational MFS landscape and operate without a banking partner, in others regulations and/or commercial imperatives necessitate collaboration with licensed banks in a type of hybrid MFS model. ${ }^{109}$ Users can use either a fiat-based SOV and/or airtime SOV depending on the scheme's rules. The MNO usually has control over the airtime SOV. Crisp issues here are whether the funds accepted and then used for transactions amount to a deposit, whether an entity is engaged in the business of banking, policies and rules on conversion of fiat money to an electronic SOV (emoney) and agent status.

\subsubsection{Independent MFSP Model}

A cited variant of the third 'hybrid model' is the 'independent MFSP' ${ }^{110}$ where this MFSP has no relationship with a MNO but uses any MNO simply as a technology bearer where an MFS software

\footnotetext{
${ }^{107}$ See ch 6, s6.4 titled Licensed Bank-Led Model.

${ }^{108}$ See ch 6, s6.5 titled MNO-led Models.

${ }^{109}$ See ch 6, s6.6 titled Hybrid MFS Models.

${ }^{110}$ Ibid.
} 
application allows access to its system to be added on to compatible phones. No licensed bank may be involved, except to act as the store of the pooled funds on behalf of the MFSP.

The MNO and MFSP's SOV may be non-redeemable and have its own UOA, along with a fiat-based redeemable SOV. Payments may be interoperable with other MFSPs, MNOs, Money Transfer Operators (hereafter MTOs) or banks and any cash-in/cash out facilities may be via agents, MTOs or similar organisation.

Crisp issues in this model pertain to whether funds used for transactions amount to a deposit, whether the entity is acting as a bank, the policy of conversion of fiat money into its SOV, and agent status.

\subsubsection{Banks' Services versus MNO Mobile Financial Services ${ }^{111}$}

Although MFS and traditional banking services share many similarities, both have distinct operational and regulatory differences. Both accept funds from customers who, in a fiat setting and like a regulator expect the funds to be paid back on demand and on par. In a MFS environment, accepting funds is called a cash-in. The MNO or MFSP though will not usually risk customer funds or potential regulatory opprobrium by risking funds through intermediation.

\subsubsection{Use of Pooled Master Accounts ${ }^{112}$}

In many instances consumer funds used to prefund the value in a SVP, e-money or m-money product are placed in what are variously called pooled, master or reservoir accounts with prudentially supervised banks where the system operator and/or a trust is set up by that system operator for safety and soundness reasons.

The holder of the value however may be distinct from the system operator. The consumer may be provided with what may charitably be called a 'pseudo' bank account number.

\subsection{6 \\ Use of Trust Companies ${ }^{113}$}

M-pesa in Kenya created an extra firewall for safety and soundness between the user funds and their ultimate ability to be redeemed at par using a trust account via a special trust company where trustees may safeguard consumer funds placed in a master account.

\footnotetext{
${ }^{111}$ See generally ch 2, s2.6 titled Comparisons with Other Systems and Internet e-Commerce.

${ }^{112}$ See ch 4, ch 4, s4.8.4.4.6 titled Pooled Master Accounts.

${ }^{113}$ See ch 7, s7.4 on Trusts.
} 


\subsection{Payment Methodologies And Characteristics}

\subsubsection{Overview and Nomenclature}

When settling an obligation or making a payment sounding in money, the payment can be effected in various ways, using a number of methodologies, or Means of Payment (hereafter MOP), both tangible and intangible payment methodologies like a prefunded SVA, or Stored Value Card (hereafter SVC). MFS is one of a new class of intangible methods of payment.

\subsubsection{Nomenclature}

The source of funds for payments may be termed an electronic 'purse', or 'wallet,' or SVA, although these may be incarnations and components of the more descriptive term which is used throughout the study, namely, SVP. The MNO-based prepaid airtime value may be seen as a species of SVP where it is the SOV (to wit, the 'money') in a SVA. In this case it may be referred to as an airtime-based SOV, SVA or SVP. Where the value in a SVA is based on a redeemable value using a specific national currency - such as the Rand or Euro - issued by a state via a 'fiat' or decree, this is referred to as a fiat-based, SVA SOV or SVP. E-money is seen as a species of SVP.

\subsubsection{Payment Characteristics}

\section{Tangible Methods of Payment ${ }^{114}$}

These are physical instruments that either embody the value or represent it. Cash is the prototypical tangible payment method with both characteristics, achieved simply by the delivery of coins and banknotes from the payor to the payee. Modern equivalents include negotiable instruments.

\subsubsection{Intangible Methods of Payment ${ }^{115}$}

Intangible payments include Electronic Funds Transfers (hereafter EFTs), debit cards, credit cards, credit transfers and direct debits, and SVPs like e-money. Being almost universally accepted, they may fulfill money's traditional role as a unit of account, store of value and means of exchange or payment.

\subsubsection{Payment Values ${ }^{116}$}

Retail transaction values can be micro- or macro-payments. While there are large value transfer systems (hereafter LVTS) in national payment systems, macro-payments are usually for high-value goods and services and usually involve credit cards, EFTs, cheques or traveler's cheques. Micro-payments can be anything up to R20 or $€ 10$. Most SVP and many MFS transactions are usually micro-payments.

\footnotetext{
${ }^{114}$ See ch 4, s4.8.3.2 titled Tangible Methods of Payment.

${ }^{115}$ See ch 4, s4.8.3.3 titled Intangible Methods of Payment.

${ }^{116}$ See ch 4, s4.8.3.5 titled Value of Payments.
} 


\subsubsection{Accessibility and Tracking of Payments: Online and Offline ${ }^{117}$}

Value can be stored 'offline' as a record on stand-alone payment devices like a SVC, where its loss means catastrophic loss of the available value. Many SVCs, such as transport SOVs, are offline. Value is 'online' when the value 'storage' is remotely stored on a system operator's servers (or 'clouds'), accessed via an access device like a phone. Loss of the access device does not necessarily lead to total loss.

\subsubsection{Interoperability and Ubiquity of Use: Open or Closed ${ }^{118}$}

Closed use systems - or 'walled gardens' - are usually operated by a single issuer such as a MNO, and allow only limited goods, merchants or geographical use.

Interoperability between systems usually depends on commercial and regulatory imperatives. Interoperable, open SVPs issued by Visa and MasterCard are known as General Purpose Reloadable (GPR).

\subsubsection{Security and Reliability of Payments ${ }^{119}$}

Because the mobile phone service is a very public payment instrument, there are special issues in MFS such as the security and reliability of payment and the security of the underlying funds that are of concern to system operators, regulators and users alike as these may undermine general confidence. ${ }^{120}$

\subsection{4}

Payment Methodologies ${ }^{121}$

\subsubsection{Hierarchies ${ }^{122}$}

There is a hierarchy in electronic payments, broadly high value and lower value. The former is usually a national (payment) system, while the latter may include retail payments and possibly even small, 'micropayments' like in MFS and SVPs.

Developed countries usually employ keystone payment systems based on internationally accepted principles developed by Standard Setting Bodies (hereafter SBBs) such as the Bank for International Settlements (hereafter BIS) and its subsidiary, the Committee on Payment and Settlement Systems (hereafter CPSS).

\footnotetext{
${ }^{117}$ See ch 4, s4.8.3.6 titled Accessibility and Tracking of Payment Systems: Online and Offline.

${ }^{118}$ See ch 4, s4.8.3.7 titled Ubiquity of Use: Interoperability.

${ }^{119}$ See ch 4, s4.8.3.8 titled Security and Reliability of Payments.

${ }^{120}$ Specific issues around the security and reliability of payments effected through mobile phones as they relate to MFS are discussed in ch 5, s5.7 titled Security Aspects of Mobile Technology and Application to MFS.

${ }^{121}$ See ch 4, s4.8.4 titled Forms of Payments.

${ }^{122}$ See ch 4, s4.8.4.1 titled Overview titled hierarchies of payments.
} 


\subsubsection{2}

\section{National Payment Systems ${ }^{123}$}

National payment systems are those national systems designed to facilitate payments via national systems, usually through the central bank. These inter-bank LVTS are classed as the apex and as Systemically Important Payment Systems (hereafter SIPS). Access to their core - known in South Africa as the South African Multiple Option Settlement (hereafter SAMOS) - is exclusive, and non-banks are very seldom allowed, if ever, to settle funds in their own name, although they could clear payments. Within this system are those involved in the "clearing' ${ }^{124}$ of payments through exchanging payment instructions between institutions. The values forming part of the clearing must be moved from one account to another, a process known as settlement. ${ }^{125}$ The process whereby one bank settles its obligations against another bank in an exchange of obligations is called 'netting. ${ }^{126}$ Access to the core of a national payment system where settlement is done is considered by the BIS to be systemic and is thus limited to a vetted number of qualified banks.

Clearing on the other hand may be done by banks and vetted non-banks, possibly including non-bank providers like MNOs and MFSPs,

\subsubsection{Retail Funds Transfer ${ }^{127}$}

Next are lower-value, non-SIP retail funds transfer systems that handle a large volume of macro-payments of relatively low value, and which may include tangible and intangible retail payment instruments such as cheques and EFTs.

\subsubsection{Micro-payment Facilities ${ }^{128}$}

A third category, micro-payments, may be walled garden systems that do not interact with a national payment system. They include open and walled garden facilities, for example, MFS systems that use airtime as 'currency' to pay for digital VAS using Premium Rated SMSs.

\subsubsection{Electronic Funds Transfers (EFTs) ${ }^{129}$}

'EFT' colloquially refers to any mechanism or process to transmit funds, or the making of non-cash payments between parties. They are generally done using banks or a national payment system. In a debit EFT, the payee 'pulls' funds from the payor's institution or purse, while in a credit EFT, the payor 'pushes' funds to the payee.

\footnotetext{
${ }^{123}$ Ibid on modern payment systems, instruments and regulation of payments.

${ }^{124}$ See ch 4, s4.8.2.2 Payment: The Process of Verification, Clearing, Settlement and Netting.

${ }^{125}$ Ibid.

126 Ibid.

${ }^{127}$ See ch 4, s4.8.2.4 titled Retail Funds Transfer Systems.

${ }^{128}$ See ch 4, s4.8.2.4.2 titled Low Value Payments: Micro-payments; and ch 4, s4.8.3.5 titled Value of Payments.

${ }^{129}$ See ch 4, s4.8.4.2 titled Electronic Fund Transfers (EFTs) And Similar Systems.
} 
Remittances are flows of value from one individual to another, usually across borders. As a gift or donation, there is not necessarily a payment due to the recipient. MTOs, with or without agents, act as intermediaries. A cross-border remittance from South Africa costs between 15-20\% of the total value sent, which the more affordable MFS process addresses. MNO airtime may also be remitted.

\subsubsection{Stored Value Products ${ }^{131}$}

\subsection{Overview}

An omnibus term to describe the evolution of non-cash stores of value using non-cash-payments may, it is submitted, simply be 'SVP' to describe the family of systems or devices that store value electronically. Variously known also as SVCs, SVAs, e-money, Cybercash, e-wallets, e-purses, Digicash, Cyberbucks, and gift cards, SVA may be a genus, and m-money, MFS and SVC may be the species of the SVP family. Ultimately, it is submitted, they - including MFS - are all 'stored value': it is just the means of access to the value that will differ.

\subsection{Technical and Usage Incarnations ${ }^{132}$}

SVPs may be offline and online, closed or interoperable with other schemes, with value drawn if needed in cash via an agent or ATM. The SVA may be in the fiat currency - but possibly non-redeemable - or in the system operator's private currency UOA. The value chain may consist of the 'issuer' like an MNO or PSP, and holder of the (stored) value purchased; a retailer/agent/distributor selling the SVP to the user, and a bank housing funds from the public in a so-called pooled account.

\subsection{E-money ${ }^{133}$}

E-money is a sub-species of SVP and is usually prefunded. Commercial nomenclature is fuzzy and usually conflates e-money in a MFS setting as 'm-money'. Further, it is submitted, what may be termed 'e-money' usually results from a conflation with electronic forms - or representations - of national (fiat) money. IN many instances, e-money is that which results from a process of regulatory, economic, or legislative intervention and may even in and of itself, also embody the value transferred such that it fulfills common law views of money.

\footnotetext{
${ }^{130}$ See ch 4, s4.8.4.3 titled Remittances.

${ }^{131}$ See ch 4, s4.8.4.4 titled Stored Value Products.

${ }^{132}$ See ch 4, s4.8.4.4.3 titled Technical Aspects.

${ }^{133}$ See ch 4, s4.8.4.4.2 titled Stored Value Nomenclature.
} 
The MNO or MFSP's prefunded online 'wallet' or SVA may contain a SOV that could either be fiat-based money for pure payments and remittances, usually redeemable on-demand and but which may be subject to regulation. Or it may be fiat money 'transformed' into an 'airtime' SOV currency for paying for MNOs' basic services or Premium Rated VAS micro-transactions ${ }^{135}$ in a walled garden ecosystem. Single-purpose private currencies like airtime may not however amount to (e-)money primarily because of their lack of general acceptance in the community or because of conditional payment aspects related to their use as a form of payment.

\subsection{Comparison with other Payment Methodologies, and Internet e-Commerce ${ }^{136}$}

\subsection{Overview ${ }^{137}$}

At a high level, MFS differs from comparable systems like Internet banking or network-based payments as to how services are offered, how devices are used, how value is placed in a SVA; economic funding of the SVA in a SVP; value-chains; methods in transferring value; and the range of services.

\subsection{Technical Comparisons ${ }^{138}$}

Broadly, e-commerce and non-mobile use is primarily associated with PC-based activities which invariably requires the user to have access to computer facilities, be computer and Internet-literate; and usually also to have access to a bank account or debit/credit facility. Transformative and additive MFS-based systems are primarily mobile-based using basic functionality, some using PSMS to pay for VAS.

\subsection{Economic Comparisons ${ }^{139}$}

Non-MFS systems are usually used for macro-payments for goods and services, and for remittances, while MFS are mostly for micro-payments. Compared to par-value deposits in banks, mobile airtime-based SOV incarnations have large distribution costs, discounting the actual value received by a system operator off the available value in a SVA. Other fundamental differences include the source(s) of funding for SOVs in a SVA, and payments, merchant fees, and what can be purchased and where.

\footnotetext{
${ }^{134}$ See ch 4, s4.8.4.4.4.3 titled Mobile-type SVPs.

${ }^{135}$ That is, Premium Rated Services (hereafter PRS).

${ }^{136}$ See ch 2, s2.6 titled Comparisons with other Systems and Internet e-Commerce.

${ }^{137}$ See ch 2, s2.6.1 for Overview.

${ }^{138}$ See ch 2, s2.6.2 titled Technical Comparisons.

${ }^{139}$ See ch 2, s2.6.3 titled Economic Comparisons.
} 


\subsection{Legal and Regulatory Comparisons ${ }^{140}$}

MFS may potentially bring its participants into the purview of banking and payment system regulators, particularly as to whether the use of fiat-based SOVs by MFS schemes amounts to the 'business of banking,' and whether the SOV may be seen as a 'deposit.' These apparent equivocations portend far larger issues in attempts to extrapolate current legal dogma, either in positive law or that derived from common law.

\subsection{5}

\section{Summary And Conclusion}

MFS systems using MNOs for access to users have the ability to be disruptive to traditional forms of payments and banking and as such are seen as being 'transformational' (to an economy), through for example replacing bank branches with 'branchless banking' motifs that include the use of human 'agents' or 'outlets' to provide the equivalent of a human-ATM through cash-in/cash out facilities.

Although the terminology - such as the use of the term m-banking may generally have a banking-based theme - those engaged in MFS are not necessarily banks with appropriate banking licenses. They are instead primarily non-banks, for example MFSPs and MNOs.

Confusing the issue somewhat is that many of the services in MFS are said to approximate 'banking' services although the use of the term 'banking' in commercial marketing material does not necessarily imply or mean that the institution offering those services constitutes a bank or carries out the 'business of a bank' as defined under domestic regulation insofar as domestic regulation may refer to the 'business of banking.'

The issue of the 'deposit' and its role as a seminal pivot in positing an entity's involvement in the 'business of banking' comes to the fore especially when in regard to MNOs, specifically, as to whether the airtimebased SOV used in a general telecommunications setting may be classed as a deposit. Further, the similar storing of user funds by MFSPs, primarily to facilitate remittances and bill payments, also triggers questions of whether the entities may require banking licenses or be regulated within laws and regulations pertaining to national payment systems.

The entry of non-banks into the provision of m-banking has been thought potentially to pose systemic and fraud risks. While these risks are manifest, they are comparatively low since all transactions are usually prefunded, and anti-fraud and proper AML/KYC procedures are in place alongside real-time recordkeeping.

\footnotetext{
${ }^{140}$ See ch 2, s2.6.4 titled Legal and Regulatory Comparisons.
} 


\subsection{1}

\section{Overview}

While MFS and their operating entities are subject to a panoply of regulations of direct or indirect application, due to the evolving nature of MFS business, the scope of this study will look at only the most salient laws and the regulatory philosophies underpinning them.

\subsubsection{Regulatory Foci ${ }^{141}$}

Many of the newest products and services are processed through private networks subject only to private rulemaking from which consumers are excluded. Insofar as the most pertinent of laws and regulations applicable to MFS, this study looks at banking, ${ }^{142}$ payment systems, ${ }^{143}$ contract,${ }^{144}$ payments, ${ }^{145}$ protections at common law, ${ }^{146}$ security laws, ${ }^{147}$ telecommunications laws, ${ }^{148}$ e-commerce laws ${ }^{149}$ and consumer protection laws. ${ }^{150}$ An assessment of whether a SOV is money for legal purposes is also made. ${ }^{151}$

\subsubsection{Philosophies Behind Regulation ${ }^{152}$}

Substantial inequality of one contracting partner may require regulatory intervention using either positive theories of regulation that examine why regulation occurs, while normative theories are based on fixing apparent market failure. Sociological and anthropological aspects and the possible impact of regulation also need to be considered.

\subsubsection{The Regulator's Dilemma and Capture ${ }^{153}$}

Contractual inequality and systemic risk put into sharp relief the 'regulator's dilemma' of balancing the laudable goals of FI with systemic considerations of financial integrity.

Regulators may also be 'captured', meaning that regulated institutions may have inordinate influence on their own regulator.

\footnotetext{
${ }^{141}$ See ch 8, s8.3 titled Types of Regulation Foci.

${ }^{142}$ See ch 4, s4.2 titled the Nature of Banking: An Overview.

${ }^{143}$ See ch 4, ch 4, s4.7 titled the Evolution of Payments.

${ }^{144}$ See ch 7, s7.2 titled Contracts.

${ }^{145}$ See ch 7, s7.3 Payments in General.

${ }^{146}$ For example the common law relating to condictiones and unjustified enrichment.

${ }^{147}$ See ch 8, s 8.5 titled Anti-Money Laundering, Terrorist Financing and Customer Due Diligence Laws and Regulations and chs 9-12 titled the approaches taken by the EU, South Africa, Kenya, and the USA.

${ }^{148}$ See ch 8, s8.6 titled Telecommunications Laws and Regulations, and chs 9-12 on the approaches in the EU, South Africa, Kenya, and the USA.

${ }^{149}$ See ch 8, s 8.7 titled E-Commerce Laws and Regulations, and chs 9-12 on approaches in the EU, South Africa, Kenya, and the USA

${ }^{150}$ See ch 8, s8.8 titled Consumer Protection-Type Laws and chs 9-12 on approaches in the EU, South Africa, Kenya, and the USA.

${ }^{151}$ See chapters 3 and 13 passim on 'money' and its relation to MFS.

${ }^{152}$ See ch 8, s8.2 titled Philosophies behind Regulation.

${ }^{153}$ Ibid.
} 


\subsection{5} Functional versus Institutional Approaches ${ }^{154}$

A functional or institutional approach may be used to ameliorate the regulator's dilemma and regulatory capture.

The functional approach focuses on the service received by the consumer, regardless of the institution providing it, and is usually the remit of an omnibus consumer protection agency, which may however lack capacity and specialised knowledge.

The institutional approach focuses on the institutions providing the financial service, regulated by specialised bodies like the central bank.

\subsubsection{Regulation, Supervision and Oversight ${ }^{155}$}

Banking and payments sectors may be subject to prudential regulation, supervision, and oversight. Prudential (bank and payment) regulation is heuristic - based on SBBs - in nature, invariably enforced by licensing. Associated supervision includes on-site examination, accounting and reporting requirements.

Use of SBB standards - mostly via the CPSS - have been criticised as being ill-suited to developing countries. Oversight is more principle-based, assessing entities doing self- and co-regulation against broad objectives and where necessary, inducing change.

\subsection{7}

\section{Financial Inclusion versus Financial Integrity ${ }^{156}$}

Mandatory implementation of SBB rules may however increase costs beyond which (formal) financial services can be viably offered to the poor.

A need for systemic reliability though underlies the dilemma of how to maintain financial integrity in financial systems without prejudicing local needs and priorities, but whilst promoting FI through innovative and more transaction-focused systems like MFS.

\footnotetext{
154 Ibid.

${ }^{155}$ See ch 8, s8.4.2 titled Regulation, Supervision and Oversight.

${ }^{156} \mathrm{Ibid}$.
} 
Since Financial Exclusion (hereafter FE) is a reality, regulators should balance their objective of protecting consumers with the need to expand financial access.

\section{Conclusion}

The regulator's dilemma, then, is more a policy question of how to prudently boost financial access, than a narrow regulatory concern of how to protect existing consumers.

The balance is also between compliance and systemic risk mitigation and expansion of financial access of those at the BOP.

While a functional or institutional approach may be used, the primary focus should be on how to protect user funds and their use, not necessarily only on the entity employing the service.

\section{Conclusion}

It is thus submitted that in balancing Financial Inclusion versus Financial Integrity, the regulatory and policy focus, should be on facilitating payments and creating a stratified and proportionate enabling regime. 


\section{Issues Of Money And MFS}

'Money is a fundamental concept of the law. There are perhaps few other juridical notions of greater importance.'

- Arthur Nussbaum ${ }^{157}$

\subsection{1}

Overview

The crisp question in respect of MFS-based SOVs - and in particular the airtime-based SOV - is whether what is stored is filigreed money per se, or simply a representation of state-issued fiat money, the latter also known as the Generally Accepted Means of Exchange (hereafter GAME). In the context of MFS, the determination of whether something in a SOV is indeed money may have implications, for example, for AML laws sounding in 'money', rights available in money, and generally those related to financial regulation including whether an entity that ultimately stores the SOV may be engaged in deposit-taking. ${ }^{158}$

\subsection{2}

\section{Concepts of Money}

\subsubsection{1}

What is Money? ${ }^{159}$

Doctrinal contexts determine what is 'money'. Economists for example look at money in terms of purchasing power and macro-economic theories; anthropologists observe community acceptance of money; while lawyers may see money in terms of an ability to settle debts. ${ }^{160}$

\subsubsection{Qualities of Money ${ }^{161}$}

Common themes that characterise money are, firstly, that it is seen as a SOV that is accepted by others because it embodies undiminished and consistent value. Secondly, it is also seen as a UOA, whereby the value of the transfer is homogenous and is accepted as such by all who take it as money and which allows society to compare the values of very dissimilar things so as to lower transaction costs. Thirdly, that others will take it because it is accepted as an independent means or asset used to transfer value from one to another without reference necessarily to what means or asset is actually used to facilitate that exchange. This third feature, depending on the analysis and economic basis of the enquiry, may be termed a MOP or Means of Exchange (hereafter MOE).

\footnotetext{
${ }^{157}$ A Nussbaum (1937) 'Basic Monetary Conceptions in Law' 35(6) Michigan Law Review at 865.

${ }^{158}$ See ch 14, s14.6.3 titled Role of the Deposit in Banking.

${ }^{159}$ See ch 3, s3.2 titled What is Money?

${ }^{160}$ See ch 3, s3.2.3 titled Doctrinal Perspectives titled Money: An Introduction.

${ }^{161}$ See ch 3, s3.2.4 titled Additional Foundational Perspectives Relating to Money.
} 


\subsubsection{3}

What Could Act as Money? ${ }^{162}$

What could be termed money has metamorphosed from seashells to intangible, virtual forms. We may be in another such evolutionary phase, with technology accelerating this change. Forms that in an economic sense could broadly act as money include coins, banknotes, electronically stored scriptural money, Credit Money, Bank Money, wealth money and SVPs. Social agreement to recognise the value a money represents - or is legally endowed with - may allow computer entries to have mercantile value and so be accepted in exchange for goods and services or for the settling of debts, that is, as a standardised MOP or MOE. Is the mobile phone, and its ability to store value and its advertised use for the payment of goods and services, the new 'seashell'?

\subsubsection{Issuance and Production of Money}

\subsection{State versus Societary Theories of Money ${ }^{163}$}

The 'State' of Money theory posits the state as deciding what is valuable through simply declaring what it may accept in payment of taxes. This correlates broadly to 'legal tender' and the GAME. The 'Societary' (or 'Society') theory says money is what a community accepts to extinguish debts, with the State playing, if any, a supporting role in facilitating the acceptance of a 'thing' as money. While they appear mutually exclusive, there is some confluence when using a differentiated concept of 'society' to include three distinct senses, as state, nation and community. Modern forms of money then may be from managed outcome of an interplay between the State and Society (the amorphous) 'markets' to allow for the evolution of private forms of money.

\subsection{Specific Role of the State and Central Bank in Money ${ }^{164}$}

The issuance of fiat currency, determination of legal tender usually through banknotes and coins form part of the parcels of right to monetary sovereignty enjoyed by a state. New potential forms of money may have to navigate the leeways of prudential and state requirements and the apparent vested interests of Central Banks (hereafter CBs) in keeping their monopoly over the issuance of the GAME.

\subsection{Private Money Issuance ${ }^{165}$}

While competitive private banknote issuance preceding the emergence of national central banks has largely disappeared, private commercial money - 'currencies' - may be re-emerging through dematerialised or electronic forms of money and 'Stores of Wealth' (hereafter SOWs) used to exchange value. These operate outside - and compete with - a CB payment system to settle debts.

\footnotetext{
${ }^{162}$ See ch 3, s3.2.2 titled What Could Act as Money?

${ }^{163}$ See ch 3, s3.2.4 titled Additional Foundational Perspectives Relating to Money.

${ }^{164}$ See ch 3, s3.5 titled Role of the State and Central Bank in Money.

${ }^{165}$ See ch 3, s3.4.4.4 titled Private Money Issuance.
} 


\subsection{History of the Analysis ${ }^{166}$}

The vexed question of the nature of money begins with the Greek and Roman philosophers, jurists and legal scholars. Despite apparent doctrinal differences, theories of money and their legality derive from the disparate disciplines of economics, sociology, history, anthropology and law. The legal definition of money is said to be based on the quantitative economic view of money derived from the Orthodox School's economic view of money. The relatively more modern Claim School economic view of money may however provide a compelling, qualitative basis for modern forms of value which could amount to and act as money. Both Schools are contextualised by the State and Societary theories of money regarding the production and issuance of money.

\subsection{Orthodox School ${ }^{167}$}

\subsection{Overview}

The quantitative, functional Orthodox School sees money as having three components: a UOA; a SOV; and a MOE - first identified and named as such by Aristotle - that allows products and services to be acquired because of it.

\subsection{Unit of Account ${ }^{168}$}

The UOA mediates the homogeneity which allows prices and values to be measured consistently against one another, while the SOV function implies that the recipient will obtain the same value from the payors.

\subsection{A Store of Value ${ }^{169}$}

The SOV allows whatever has been received as money to continue to be valuable to others in receipt of it.

\subsection{Means of Exchange $\mathrm{e}^{170}$}

The Means (or Media or Medium) of Exchange (that is, a MOE) allows products and services to be acquired because of it. The MOE is the pivot in this school, and is traditionally based on a tangible 'chattel' - backing like gold or some other valuable item, but practically is implied through the fiction of an incorporeal 'money' - or GAME - being a representation of corporeal money. The MOE may be inchoate, with final settlement being subsidiary to the primary MOE function.

\footnotetext{
${ }^{166}$ See ch 3, s3.8.2 titled History of the Analysis.

${ }^{167}$ See ch 3, s3.9 titled the Orthodox School.

${ }_{168}$ See ch 3, s3.9.2 titled the Components of Orthodox-type Money.

169 Ibid.

170 Ibid.
} 


\subsection{Claim School ${ }^{171}$}

\subsection{Overview}

The competing Claim School of money popularised by the Austrian School of Economics has a qualitative approach to money, emphasising aspects of money as a Claim. Here, something - a 'thing' or 'token' - is declared or accepted as money to settle or pay a debt obligation. Its component parts are a UOA, a 'money', and a MOP, with the emphasis on the UOA. There are variations of this School that emphasise either the State and Societary (Societal) theories.

\subsection{Unit of Account ${ }^{172}$}

The UOA is the pivot in the Claim School, used to describe the intrinsic nature of money. The UOA may be determined by the state (by fiat), with the market or other currencies setting a resultant value equating in value to a UOA set by a non-state actor.

\subsection{3 'Money ${ }^{173}$}

Any 'thing' may qualify as the 'money' to give gravitas to the UOA, be it notes or dematerialised scriptural representations of money.

\subsection{Means of Payment ${ }^{174}$}

In the Claim School, the MOP is seen as money's pivotal characteristic. This may provide an explanation of the characteristics of new forms of non-tangible, dematerialised money and may even be coincident with legal views of money and payments in that they both pivot around debts, obligations and finality of payment - that is, as a payment in final discharge of debts.

\subsubsection{Legal and Regulatory Views of Money}

\subsubsection{Introduction}

Statutory definitions of money are rare. Thus the common law and legal scholars such as Mann and Nussbaum offer the leading legal definitions and interpretations of the essence of money. More accurate (legal) definitions may properly decide the outcome of disputes.

This requires that an appropriate economic theory of money comport with common law views of money.

\footnotetext{
${ }^{171}$ See ch 3, s3.10 on the Claim School.

${ }^{172}$ See ch 3, s3.10.2 titled Components of 'Claim' Money.

${ }^{173}$ Ibid.

${ }^{174}$ Ibid.
} 


\section{PART I. Leading Cases And Works on Money}

\subsubsection{Moss $v$ Hancock H $^{175}$}

Quintessential features required of something for it to be legally considered as money were outlined in the locus classicus, Moss where money was defined as that which:

'... passes freely from hand to hand throughout the community in final discharge of debts and full payment for commodities, being accepted equally without reference to the character or credit of the person who offers it and without the intention of the person who receives it to consume it or apply it to any other use than in turn to tender it to others in discharge of debts or payment of commodities.'

Analysis of Moss shows that it embodies a functional approach to money, as well as an implied requirement for any money to have a corporeal, tangible form to allow it 'to pass from hand to hand.'

A putative extrapolation of Moss in relation to an investigation of SVPs is suggested by Geva and Kianieff ${ }^{176}$ who paraphrase the criteria in Moss to mean that for something - in particular SVPs - to rise to be money, there must be an enquiry into some direct and incidental features of money such as whether it passes freely from hand to hand; whether it circulates; whether it is acceptable to a wide range of creditors (acceptors); whether anonymity is a relevant feature; whether there is no recourse against the offeror; and whether it confers final discharge of debts;

\subsubsection{Miller $v$ Race $^{177}$}

In Miller v Race, money's special character in the law of property was described as 'currency', meaning that it does not follow usual property laws for tangible items that allow the disposed to claim even from a bona fide recipient for value.

This construct though has been thought of as being unfair, but has been followed generally in law in order to facilitate seamless trade.

\footnotetext{
${ }^{175}$ Moss op cit note 20.

${ }^{176}$ B Geva and M Kianieff (2002) 'Reimagining E-Money: Its Conceptual Unity with other Retail Payment Systems', available at http://goo.gl/QfR4y.

${ }^{177}$ Miller op cit note 21 .
} 


\subsubsection{FA Mann on Money ${ }^{178}$}

The nexus between the legal view of money and the Orthodox School was classically framed by FA Mann in his definition of money as requiring what he termed a 'chattel' for something to be legally considered 'money.'

'All chattels which, issued by authority of law and denominated with reference to a unit of account, are intended to serve as a universal medium of exchange in the State of issue.'

Both the Moss and Mann definitions then are coincident with the quantitative, functional approach of the Orthodox School in that they impute a tangibility function based on an exchange value to a commodity or a representation of a commodity.

\section{PART II. Application}

\subsubsection{Legal Tender ${ }^{179}$}

Legal tender usually refers to the ubiquitous 'ordinary' money in circulation issued by the state, but may also mean currency - usually coins and notes issued by a CB - to be lawfully used for payment of debts. It may also be the 'GAME.' It may be one of the qualities used to determine whether something is money, but while all legal tender is money, not all money is legal tender. Cheques, credit cards, debit cards and similar non-cash methods of payment are considered simply as means of transferring fiat money - the GAME - as legal tender. The legal tender status of banknotes - and coins - though as GAME is nowadays of limited practical relevance in the light of electronic and scriptural non-cash transactions.

\subsubsection{Money in South African Law ${ }^{180}$}

Money is not specifically defined in South African law, although there are numerous references to it. While South African courts and legal scholars appear generally ad idem with English law and writers as to its legal nature, they differ insofar as the application of any rights attaching to money and in remedies to reclaim money, especially in relation to intangible forms. Where there is an obligation to pay money, it must ostensibly be in cash using legal tender notes and coins issued by the SARB.

\footnotetext{
${ }^{178}$ FA Mann (1992) The Legal Aspect of Money $\left(5^{\text {th }}\right.$ ed).

${ }^{179}$ See ch 3, s3.12.3.2.1 titled Legal Tender and Fiats.

${ }^{180}$ See ch 3, s3.13 titled Money in South African law.
} 


\subsubsection{7}

Money and Currency ${ }^{181}$

Money is often referred to as 'currency', usually 'a system of money in general use in a particular country.' It may be private or state-derived (fiat), but while money is a form of currency, currency is much broader and tends to engage state control over money issuance, use and money supply. Incarnations include legal tender currency such as Rands or Euros; commercial private currencies such as airtime; as well as complementary currencies and social purpose currencies.

\section{PART III. E-Money}

\subsection{4}

\section{Legal and Regulatory Aspects of E-Money and SVPs}

\subsubsection{1}

\section{Overview}

Electronic money (hereafter e-money) because of its potentially disruptive nature to existing forms of money, control of the state over money issuance, and systemic risk issues, has garnered legal and regulatory attention, although there are very few specific prudential regimes. Rather most authorities have contrived to incorporate it within existing regulatory banking and payment regimes. Similar considerations may apply to 'm-money.'

\subsubsection{European Union ${ }^{182}$}

The EU's first Electronic Money Directive (EMD1) of 2000 created a specific regime for the issuance, use and redeemability of e-money. Owing to faulty definitions relating to the use of MNO airtime SOVs that caused commercial and legal uncertainty, the EMD1 was replaced, some would say repealed, by the EMD2 in 2009. The EMD2 though is rather a subset of the PSD, and both regard e-money as 'an electronic surrogate for coins and banknotes ... to be used for making payments ... and not as means of saving.' Critically, non-bank licensed institutions engaged in e-money - and payments - are not considered to be engaged in deposit-taking if the funds received are 'without delay' exchanged for e-money.

Similarly placing funds for a payment into a 'Payment Account' as the source of value for making payments is not considered deposit-taking.

\footnotetext{
${ }^{181}$ See ch 3, s3.6 titled Money and Currency: General View; and ch 3, s3.12.3.2.2 titled Money as Currency: Legal View. ${ }^{182}$ See ch 9, s9.6.3 titled E-Money, Stored Value Laws and Regulations in the EU. In particular, see ch 9, s9.6.3 on the EMD1 (Directive 2000/46/EC on the Taking up, Pursuit of and Prudential Supervision of the Business of Electronic Money Institutions) and the EMD2 (Directive 2009/110/EC of the European Parliament and of the Council of 16 September 2009 on the taking up, pursuit and prudential supervision of the business of electronic money institutions amending Directives 2005/60/EC and 2006/48/EC and repealing Directive 2000/46/EC)
} 


\subsubsection{3}

Kenya $^{183}$

The success of M-pesa has developed in a regulatory vacuum relating to MFS and banking and payments. Specific e-money regulations though are being developed by the CBK.

\subsubsection{USA}

The US has not embraced a distinct prudential regime for e-money and other SVPs, and employs instead indirect regulation in state and federal law as additions to state cheque and money transmitter laws that equate e-money to money transmission. ${ }^{184}$ The model state Uniform Money Services Act ${ }^{185}$ though is applicable if use rises to a 'stored value' record considered as 'monetary value' and MOE.

Walled gardens may be excluded. Some MFS-based funds transfers may be considered a deposit by the federal FDIC based on the amount of time the value is in an account. ${ }^{186}$

\subsubsection{South Africa ${ }^{187}$}

The SARB has issued e-money 'Position Papers' that, while not being law per se, have a persuasive effect on potential e-money participants and the broader financial community. Three position papers were released in 1999, 2006 and 2009. All three position papers limit e-money issuance and trading to banks.

\subsubsection{6}

\section{Is E-Money Legal Tender? ${ }^{188}$}

While e-money may be denominated in the UOA of a particular jurisdiction, it is not necessarily legal tender. No countries have directly made e-money legal tender, although it may have a status similar to that of a cheque or a scriptural entry in a bank account as a notional representation of the GAME as legal tender.

\subsubsection{Re-evaluation of Money}

Two issues arise in respect of this discussion on money: firstly, is the Orthodox School or Claim School view of money better suited to describing the innate legal characteristics of money? Secondly, in relation to prepaid MFS SVPs, the crisp question that needs to be answered is whether they are storing money per se, or if what is stored is simply a claim to (inter alia, GAME) money.

\footnotetext{
${ }^{183}$ See ch 10, s10.2.3 titled Banking Laws and Regulations in Kenya.

${ }^{184}$ See the discussion in ch 11, s11.2.5 titled E-Money and SVPs in the US.

${ }^{185}$ See ch 11, s11.2.4.7.2 on the Uniform Money Services Act.

${ }^{186}$ See ch 11, s11.2.3.3 titled Application to MFS.

${ }^{187}$ See ch 12, s12.4.2 titled E-Money in South Africa.

${ }^{188}$ See ch 4, s4.8.4.5.8 titled Is E-Money Legal Tender?
} 
Beyond the qualitative differences between the Orthodox and Claim Schools, some quintessential features fundamentally required to reach a nexus to the legal requirements for money in Moss relate to the need for inter alia circulation, acceptance, final discharge, and anonymity.

The analytical course then in a re-evaluation of money is to attempt to provide a modicum of equivalence to each of these 'money-criteria' in relation to the emergent forms of value that deign to be called 'money', particularly by the catalyst in this instance, the MFS SOV as well as other emerging forms of value such as private social media currencies.

\section{Revisiting Problem Statement 1:}

\section{Problem Statement 1}

Whether the MNO airtime-based SOV, fiat and other private currencies used in closed-loop MFS systems legally amount to 'money'? 189

\subsection{Use of Economic Schools in the Assessment}

The use of 'dematerialised' (incorporeal) electronic systems complicates doctrinal analysis by creating a more pronounced gap between the value of money - historically determined and backed by a commodity and its modern, more subsidiary and abstract value as a monetary instrument or 'wealth' money which does not necessarily require recourse to state-issued (fiat) instruments.

Thus when tested against SVP and modern forms of payment mechanisms, the Aristotle-era Orthodox School with its MOE function emphasising an inchoate MOE based on a tangible 'chattel' appears to trigger a doctrinal mismatch insofar as what is instead required is a perspective on the core qualities of money, that is, its abstract intrinsic value.

The Claim School economic view of money offers an alternative, it was found, to provide a qualitative analysis that allows value to be seen as a 'claim' or Right in which something - a 'thing' - declared or accepted as money is as a result of debt relationship and obligation.

Any 'thing' may qualify as the 'money' to give gravitas to the UOA, be it notes or dematerialised scriptural representations of money. This conceptualisation sees money via the Claim School then as a UOA, SOV and a MOP, and also provides gravitas for its application to a legal view of money.

\section{Conclusion}

The Claim School economic view of money is better suited than the Orthodox School as the theoretical pivot in designating a legal basis for money, particularly in relation to assimilating and understanding intangible SOVs such as those used in MFS. ${ }^{190}$

\footnotetext{
${ }^{189}$ See ch 1, s1.8.1 titled MFS and Money.
} 


\subsection{Is a SVP Money?}

The aggregate requirements from Moss and its extrapolation for a 'money' appear to be aligned with that of the Claim School, such that a nexus is established between SVPs and Moss, insofar as both pivot inter alia around money as a 'debt' (or Right), obligations and finality of payment in 'final discharge' of debts.

Seen in these terms, any payment mechanism can be used as a MOP if agreed to by the parties beforehand, where payment is not unjustifiably delayed, where the contract that specifies the payment type is valid and acceptable within the framework of general contract law, and where no specific law forbids its use.

This approach may hold out the titillating prospect of providing the legal basis for new forms of money. Thus, for example, a MFS SVP could be denominated in or described by a national currency as the UOA so that even available airtime minutes or data megabytes may be the 'thing' that acts as the 'money. ${ }^{191}$

This however does not necessarily mean all SVPs amount to 'money'. The determination then when using the Claim School as the alternative analytical framework for analysing 'money' in terms of the common law requirements for money in Moss appears to be that while some SVPs have the seminal characteristics of money, individual species such as MNO airtime SOVs when used to pay for digital goods and services may have conditional payment characteristics that may then militate against this characterisation.

Certain species of SVPs would thus not necessarily amount to 'money,' a finding which may have implications for inter alia AML laws sounding in 'money,' rights sounding in money, and the determination of whether 'money' is being used as a deposit.

However, these conditional aspects may be no more than those currently employed in national or other payment systems to counter fraud or theft. Further, if the conditional nature of the payment is obviated by contract, that is, if there is no conditionality attached to prepayments from a MNO SVA balance, either in the species of payment types allowed by the MNO, or in whether the merchant is guaranteed full near realtime access to the funds from a transaction 'paid' by the MNO subscriber, then MNO balances may act as a MOP and so rise to the appellation of 'money' 'because of the currency of it.'

\section{Conclusion}

Applying legal precepts of money to new non-fiat SVP and MFS systems indicates that some species do not (legally) amount to money. ${ }^{192}$

\footnotetext{
${ }^{190}$ For findings thereto, see ch 3, s3.14 Summary and Conclusions; and ch 13, s13.9 Summary and Conclusions, ch 14, s14.5.4.7 titled Re-evaluation of Money; and specifically ch 14, s14.5.4.7.1 on the use of economic schools in the assessment. ${ }^{191}$ Some believe that the introduction of a 'thing' into a (Claim School) discussion of money is irrelevant, even contradictory and distracting, since they believe that money is in essence simply a Right characterised by a two-sided balance sheet. See ch 13, s13.7 Analysis and Application to MFS.

${ }^{192}$ Ibid.
} 


\subsection{1}

\section{Overview}

The 'transformational banking' motif of MFS may provide analogues to traditional banking services such that the rights and obligations that fasten on banks similarly fasten on MNOs and MFSPs engaged in similar activities.

There are both common law and nominal statutory approaches to determining whether an entity is a bank and whether it is engaged in the 'business of banking'.

\section{PART I. Banking and Deposits}

\subsubsection{Nature of Banking ${ }^{193}$}

Like so many other jurisdictions, South African law has not directly defined the concept of a 'bank'. Rather, statutes use functional attributes to trigger the decision that the entity is engaged in the regulateable 'business of banking'. Where the common law proclaims that a 'bank' is an entity engaged in the 'business of banking', statute provides important detail for this assessment.

The leading case is United Dominions Trust Ltd v Kirkwood (hereafter UDT), ${ }^{194}$ which said that a banker is one who inter alia 'traffics in money' by accepting money from, and collecting cheques for, customers and placing them to their credit.

The fluid nature of banking and these 'triggering' attributes was also noted in Bank of Chettinad v Commissioner of Income Tax, Colombo ${ }^{195}$ and Woods v Martins Bank, ${ }^{196}$ which indicated inter alia that the 'business of banking' must be defined within the context of the era and the country at issue.

\subsubsection{Role of the Deposit in Banking ${ }^{197}$}

One of the most salient if not direct indicators of whether an entity is engaging in the 'business of banking' is whether it takes deposits. This is a functional concept usually associated with and limited by statute with some exceptions - to banks, often exempting 'advance' value received for services to be rendered from being viewed as a deposit. The determination though of whether a deposit could be in existence also involves the time the value may be held by an entity, as well as the nature, scope and salient use of the 'deposit.' Roman-Dutch law sees a deposit as mutuum, a loan for consumption, while the locus classicus

\footnotetext{
${ }^{193}$ See the discussion in ch 4, ss4.2 titled Nature of Banking: An Overview and 4.3 titled The Common Law and Banking.

${ }^{194}$ United Dominions Trust Ltd v Kirkwood (1966) 2 QB 431 (hereafter UDT').

${ }^{195}$ Bank of Chettinad v Commissioner of Income Tax, Colombo [1948] AC 378.

${ }^{196}$ Woods v Martins Bank [1959] 1 QB 55.

${ }^{197}$ See the discussion in ch 4, s4.4 titled Deposits.
} 
Foley v Hill (hereafter Foley) ${ }^{198}$ defined deposit-taking in terms of a debt relationship, whereby, in this case, a bank becomes the owner of the value and the depositor has a corresponding personal right to par, on-demand repayment. Statutory application may clarify the situation. ${ }^{199}$

\subsection{4 'Money' and the Deposit ${ }^{200}$}

Since traditional banking pivots on the concept of 'deposit', the crisp question is at what point does the fiat value provided to an MFS system operator in order for that value to become a SOV ultimately lose its quality as 'money' - if indeed it loses it at all - and if so, can it still be said to be 'money' for the purpose of classifying those who 'traffic' in it as (still) engaging in the 'business of banking'? It is submitted that the degree of 'moneyness' of the value accepted may therefore bring the continued use of the 'deposit' as another pivotal concept in the determination of the 'business of banking' under similar review.

\subsubsection{Banker-Customer Relationship}

A determination as to whether a deposit is in existence will impact on the potential relationships and obligations an entity may then have to its customers and others, specifically whether there is a bankcustomer relationship in existence.

The relationship between bank and customer may be variously characterised as that of a mandate or being sui generis in recognition of the multi-faceted nature of the relationship.

Indeed, Foley also held that a bank has 'superadded obligations' to the customer, which in $N$ Joachimson $v$ Swiss Bank Corporation, ${ }^{201}$ the court said revolved around a number of implied terms of the bankercustomer contract such as that the entity may be acting in the capacity of the customer's agent.

In the case of MFS, the existence of a deposit may be indicative of a bank-customer relationship, although this is not certain. It appears that the nature of these obligations depends on the context, and as such there is still some scholarly dispute as to the relationship, which may be also said to be multi-faceted.

\footnotetext{
${ }^{198}$ Foley $v$ Hill [1848] 2 HLC at 45 (hereafter Foley).

${ }^{199}$ See ch 14, s14.6.6 titled Overview titled statutory application to banking and deposits.

${ }^{200}$ Ibid.

${ }^{201}$ N Joachimson v Swiss Bank Corporation [1921] 3 KB 110 (hereafter Joachimson).
} 


\section{PART II. Statutory Application}

\subsubsection{Overview}

\subsubsection{European Union ${ }^{202}$}

Banks - or 'credit institutions' as they are known in the EU - are regulated through supra-national Directives and Regulations. There are also 'bank-lite' type progressive proportional regulatory regimes such as the EMD2 $2^{203}$ and $\mathrm{PSD}^{204}$ initiated to promote innovative non-paper payment facilities provided by non-banks under specialised licensing regimes that do not allow intermediation: that is, credit. Both incorporate consumer protection and risk-reduction mechanisms. In neither instance are the funds accepted by these entities seen as a deposit if the funds are 'immediately exchanged' for electronic value. ${ }^{205}$

\subsubsection{Kenya ${ }^{206}$}

The Kenyan Banking Act requires those engaged in the 'banking business' to be licensed by the Central Bank of Kenya (CBK). When the M-pesa MFS system was launched in Kenya, it used a loophole in the definition of 'deposit' to avoid being classed as a 'banking business'. M-pesa is run mostly as a payments facility although no payments systems law exists at the time of writing. The CBK insisted though that user funds be placed in a special trust company in a pooled account.

\subsubsection{United States ${ }^{207}$}

The National Bank Act ${ }^{208}$ licenses entities that want a national license to carry on the 'business of banking'. The primary national regulator, the Office of the Comptroller of the Currency says that while deposittaking is an indicator of the 'business of banking', it is an evolving concept alongside technology evolution, such that permissible activities will evolve over time. ${ }^{209}$

The 'business of banking' is not dependent on intermediation. The states require state-licensing and enforce consumer protections. The Uniform Money Services Act (hereafter UMSA) ${ }^{210}$ licenses institutions typically Money Services Businesses - who offer services to the unbanked. ${ }^{211}$

\footnotetext{
${ }^{202}$ See ch 9, s9,5.4 titled Banking Laws and Regulations in the EU.

${ }^{203}$ Directive 2009/110/EC.

${ }^{204}$ Directive 2007/64/EC.

${ }^{205}$ Art 6(2) of EMD2.

${ }^{206}$ See ch 10, s10.2.3 titled Banking Laws and Regulations in Kenya.

${ }^{207}$ See generally ch 11, s11.2 titled The Prudential Landscape for Financial Products and Services, in the US.

${ }^{208}$ National Banking Act of 1864 (ch. 106, 13 Stat. 99).

${ }^{209}$ Office of the Comptroller of the Currency (OCC) (1996) 'Interpretive Letter' No 220, available at http://goo.gl/PILgh; and ch 11, s11.2.4.7 titled Money Service Businesses Laws.

${ }^{210}$ Uniform Money Services Act (2002).

${ }^{211}$ See inter alia ch 11, s11.2.3.1 titled Banking Legislation: Overview; and ch 11, s11.2.4.7 titled Money Service Businesses Laws.
} 
Much like other countries, South Africa has a tiered banking structure reflecting the asset size of the bank and the regulatory constraints on a bank's activities. Tier 1 includes Commercial Banks, regulated by the Banks Act. ${ }^{213}$ Tier 2 consists of Commercial Savings and Loans Banks and community-based Cooperative Banks, regulated by the Cooperative Banks Act. A proposed Tier 3 consists of commercial savings bank, and community-based co-operative banks, regulated by the Cooperative Banks Act and the proposed but stalled Dedicated Banks Act.

The current Tier 1 and Tier 2 banks are overseen through two distinct regulatory streams by the SARB for the banking or the payment sectors, and these two oversight functions approximate to deposits and payments respectively. ${ }^{214}$ The Bank Supervision Department (hereafter BSD) of the SARB regulates deposit-taking in terms of the Banks Act, the Mutual Banks Act, ${ }^{215}$ the PostBank Act, ${ }^{216}$ and the Cooperative Banks Act, ${ }^{217}$ ensuring that banks maintain adequate liquidity to meet redemption demands for deposits on hand. The 'Mzansi' low-cost, entry-level banking product was instituted in 2004 by Tier 1 banks.

\section{PART III. Conclusions}

\subsubsection{Conclusion: Deposit}

\section{Revisiting Problem Statement 2:}

\section{Problem Statement 2}

What is the nature of a deposit, and how does this impact on determining if those engaged in MFS are 'deposit-taking' entities? ${ }^{218}$

The introduction of new entities and their focus on accepting user funds not for intermediation purposes, but primarily and narrowly for transactional payments speaks to the broader issue of (re)defining, at the very least, what may traditionally be considered a 'deposit.' Specifically, it is the subjective policy assessment using 'time' - and not the physical handover of cash - as the metric of whether funds provided to an entity amount to a deposit, and the resultant inconsistency that brings this review.

\footnotetext{
${ }^{212}$ See generally ch 12, s12.1 titled Overview, on the South African financial sector.

${ }^{213}$ Banks Act 94 of 1990.

${ }^{214}$ See ch 12, s12.3.2 titled Financial-related Regulatory and Advisory Bodies in South Africa.

${ }^{215}$ Mutual Banks Act 124 of 1993. See ch 12, s12.3.5.4 titled Mutual Banks Act.

${ }^{216}$ South African Postbank Limited Act 9 of 2010.

${ }^{217}$ Co-operative Banks Act 40 of 2007. See ch 12, s12.3.5.3 titled Cooperative Banks Act.

${ }^{218}$ See ch 1, s1.8.2 titled MFS and the Nature of Banking and Deposits.
} 
It was found ${ }^{219}$ that the nature of a deposit should be less in terms of the narrow covalent bond to the 'business of banking,' but more towards the practical securing of the same personal rights and obligations as Tier 1-type deposits when applied to newer, non-bank commercial entities such as MFSPs, MNOs and retailers. Securing of these 'deposited' funds for safety and soundness reasons could be through these entities holding the pool of user funds in a pooled trust account at a Tier 1 bank. This nuanced shift then begins a possibly necessary disaggregation of the monolithic and venerated 'deposit' from its covalent, credit-related link, to the 'business of banking' such that it becomes the less totemic 'deposit concept'.

\section{Conclusion}

The nature of a deposit is evolving from the strictures of common law conceptions to a more subjective and transactional basis, such that the acceptance and use of funds as a transient SOV for primarily transactional payment purposes - and not intermediation - suggests that funds in these SOVs should not necessarily amount to a deposit. ${ }^{220}$

\subsection{8}

\section{Conclusion: Business of Banking}

\section{Revisiting Problem Statement 3:}

\section{Problem Statement 3}

Is the nature of the 'business of banking' and its traditional trigger by a 'deposit' challenged through the emergence of MFS? ${ }^{221}$

The problem may also be framed as asking whether the 'deposit' as a traditional trigger for the 'business of banking' is still an appropriate metric?

The nature of banking, it was found, ${ }^{222}$ is changing, and with it the lines between traditional bank participants and non-bank participants is becoming blurred.

Deposit-taking and intermediation as the primary focus of banking legislation in most countries in determining whether there is 'business of banking' at play ignores the emergence of activities that revolve primarily around transactional services sourced from a pool of user funds and value-types, and which may be conducted by non-bank entities, even though some of their activities and relationships with customers may resemble those of licensed banks.

\footnotetext{
${ }^{219}$ See ch 4, s4.6 Conclusions; and further ch 4, s4.8.6 Summary and Conclusions; and ch 14, s14.9.2 titled Nature of Banking and Deposits, section A, Recommendations 2 and 3.

${ }^{220}$ See below, ch 14, s14.9.4 Use of Trust Accounts, section A, Recommendation 5).

${ }^{221}$ See ch 1, s1.8.2 titled MFS and the Nature of Banking and Deposits.

${ }^{222}$ See ch 4, s4.8.6 Conclusions.
} 
It appears then that the nature of MFS transforming the core aspect of a 'deposit' into a mere and somewhat transient source of primary use for payments, signifies the 'business of banking' is becoming so stratified that the 'deposit' as we know it and its nexus to the normally similar core 'intermediation' role in banking may no longer be the pivot around which the 'business of banking' coalesces.

This essentially narrows the 'business of banking' to just intermediation such that value received for use in payments - even if not necessarily transient - is not a deposit, meaning too that the entity is not involved in the process of the 'business of banking.'

\section{The conclusion thereto is that:}

\section{Conclusion}

The 'business of banking' is metamorphosing from dated common-law criteria, in that the acceptance of funds used primarily for transactional payment purposes should not necessarily amount to a deposit. This may mean that most MFS activities would not amount to the 'business of banking' and hence should not be subject to the whole gamut of domestic banking regulations. ${ }^{223}$

\section{Revisiting Problem Statement 4:}

\section{Problem Statement 4}

Whether existing general and statutory categorisations and licensing of entities involved in taking value from the public are appropriate, and if so, whether a new categorisation or licensing regime should be considered $?^{224}$

An alternative and proportional 'bank-lite ${ }^{, 25}$ legal and policy universe that focuses more on the transient sourcing of funds and store of value to be used primarily for payments and similar transactions may, it was found, be more appropriate than the full bore and application of the 'business of banking.'

\footnotetext{
${ }^{223}$ For findings and Recommendations thereto, see ch 4, s4.5.3 titled Application to MFS; ch 4, s4.8.6 Summary and Conclusions; ch 14, s14.6.2 titled the Nature of Banking; ch 14, s14.6.3 titled Role of the Deposit in Banking; and ch 14, s14.6.7 titled Conclusion: Deposit; ch 14, s14.6.8 titled Conclusion: Business of Banking; and ch 14, s14.9.2 titled Nature of Banking and Deposits, section A, Recommendations 2 and 3.

${ }^{224}$ See ch 1, s1.8.3 titled the Role and Effect of Payment Regulation.

${ }^{225}$ See ch 12, s12.12 titled South Africa: General Summary and Conclusions.
} 


\title{
Conclusion
}

A new statutory 'bank-lite' regime reflecting the emerging stratified nature of banking, and acceptance and use of user funds may be more appropriate to deal with the emergence of non-

$$
\text { bank actors - such as PSPs - engaged in MFS. }{ }^{226}
$$

14.7

\section{Contractual, Agency and Payment Aspects of MFS}

\section{PART I Contracts}

\subsection{1}

\author{
Nature of a Contract ${ }^{27}$
}

At the core of MFS transactions are incidents relating to contractual formation. The contract may be a multilateral - mostly bilateral - legal act, since two or more persons are usually required. It may however be unilateral, where only one party assumes a duty to perform. Unlike English law, a contract in South Africa does not require consideration for a contract to be valid. Contractual freedom - pacta sunt servanda - is a general principle of contract law, although this is slowly being augmented or even replaced by statutory restrictions. ${ }^{228}$

\subsection{2 \\ Mistake $^{229}$}

At common law, a contractant will be bound unless he can show that the agreement was vitiated by mistake relating to a fact, legal rule, or principle where that facet or rule is material and where the mistake is reasonable, if objective circumstances make it excusable, such as when induced by an unacceptable misrepresentation by the assertor.

A mistake about error in qualitate is generally not material.

\subsection{3}

\section{Duress and Undue Influence ${ }^{230}$}

Contracts formed or performed under duress or undue influence may be voided. Besides duress, there may be impropriety, unconscionability, and abuse of the situation relating to the conduct by a contractant.

\footnotetext{
${ }^{226}$ Ibid. For further findings and Recommendations thereto, ch 14, s14.9.3 titled Payment Providers, section A, Recommendation 4; ch 14, s14.9.4 titled Use of Trust Accounts, section A, Recommendation 5; and ch 14, s14.9.5 Access to the National Payment System, section A, Recommendation 6.

${ }^{227}$ See the discussion in ch 7, s7.2 titled Contracts.

${ }^{228}$ For example ch 12, s12.10 titled Consumer Protection Laws titled the South African Consumer Protection Act; and ch 7, s7.2.4.5 titled Good Faith and Unfair Terms.

${ }^{229}$ See ch 7, s7.2.2.3.1 titled Mistake.

${ }^{230}$ See ch 7, s7.2.2.3.2 titled Duress and Undue Influence.
} 
Misrepresentation and fraud are grounds for rescission of a contract. South African law tends to gravitate towards distinguishing between fraudulent, negligent and innocent (no fault) misrepresentation. While a contract may be voided, surrounding circumstances may yet allocate some risk and loss to the affected party.

\subsection{5}

\section{Discussion}

Despite the principle of pacta sunt servanda or contractual supremacy that permeates our common law, the uneven bargaining and contractual power between users of MFS and the MFSPs - in particular, WASPs may, in the absence of any specific law governing payments and in the light of informational asymmetries, skew the ability of users to enforce any rights or to prevent the imposition of unfair contractual terms.

The harm to the consumer is manifest and immediate in many cases. However, a new and relatively untested Consumer Protection Act may alter the landscape by curbing unfair contract terms.

\section{PART II Agents and the Law of Agency}

$$
\text { Overview }^{232}
$$

MFS copiously uses agents, both human and electronic. The term 'agent' denotes a representative bound by contract with a principal to carry out a mandate and who is also authorised to create, alter or discharge legal relations for the principal. He may appoint 'sub-agents' to act for the principal but still bind the agent. The law of agency is one of a combination of the Roman-Dutch law of contract of mandate and the modern English principles of commercial agency. While there is a large body of law and precedent relating to human agents, there is yet to be any significant testing of variations arising from automated agents.

\section{PART III Payments}

\subsection{7}

\section{Nature of a Payment ${ }^{233}$}

In South African law, a payment - which may be in money - is seen as a performance whereby obligations formed under a valid contract are extinguished, and discharges obligations of a debtor. It is seen as a 'bilateral act' requiring, in the absence of contrary agreement, cooperation of debtor and creditor. Similarly, it has also been held that payment is a bilateral juristic act requiring the meeting of two minds, such that it can be said to be a real agreement by these minds as to the manner in which payment is to be effected.

\footnotetext{
${ }^{231}$ See ch 7, s7.2.2.3.3 titled Fraud and Misrepresentation.

${ }^{232}$ See ch 7, s7.2.6.3 titled Agents generally.

${ }^{233}$ See ch 7, s7.3.4 titled the Nature of Payment.
} 
However, the term 'payment' is, it was found, used inconsistently in South African law when used as a synonym for 'performance' in the law of obligations. ${ }^{234}$

\title{
14.7.8 Allocation of Risk in Contracts and Payments ${ }^{235}$
}

The general principle in allocation of risk is that a reasonable person will take reasonable measures to prevent the occurrence of any foreseeable harm. In financial services generally and banking specifically, a client generally has some broad duties to his banker or financial services provider. This however depends on the nature of the relationship, and the duties are generally limited. In assessing any mitigation, there is a balancing of the reasonable foreseeability of the risk against the social value or utility of the interests served by a defendant's conduct.

The issue of informational asymmetries and contractual power highlighted earlier allocates risk primarily to the user, with arbitration of that allocation left to industry codes created by those with the superior power. With respect also to the highly fragmented nature of consumer protection of payment service generally, this highlights the need, and sets the stage, for the development of an omnibus payments law that incorporates consistent loss allocation rules. ${ }^{236}$

\section{PART IV Conclusions And Discussion}

\subsection{9}

\author{
Conclusion: Payments
}

\section{Revisiting Problem Statement 5:}

\section{Problem Statement 5}

Whether the disembodied nature of MFS and its coincident transaction types challenge the notion in South African law of a payment needing to be 'bilateral'. ${ }^{237}$

In the sphere of payments related to contract and, generally, the need in South African law for a payment to be a 'bilateral juristic act' forms a buttress against evolving commercial realities for which the current conception of payment does not appear to be adequately equipped. In particular, this relates to MFS airtime and fiat-based remittances where there is a unilateral payment and where there is no debt-relationship per

\footnotetext{
${ }^{234}$ See ch 7, s7.3.1 titled Overview, titled payments.

${ }^{235}$ See ch 7, s7.3.6.5 titled Allocation of Risk, Loss and Liability.

${ }^{236}$ See ch 12, s12.11 titled Consumer Protection and Loss Allocation with Respect to Payment.

${ }^{237}$ See ch 1, s1.8.4 titled Nature of the Payment in MFS.
} 
$s e$ between the sender (payor) and the recipient (payee), nor knowledge of the sender. ${ }^{238}$ The payment may be a gift, an anonymous donation or some other non-debt-based reason.

It may also impact on any potential remedies available to the sender and receiver, in that the scenario may be tautological: if the transfer is not a bilateral juristic act, the dogma dictates then that it is not a payment, and as such any remedies based on unjustified enrichment flowing from a payment cannot be used by the wronged party.

Further, the WASP VAS ecosystem also produces some interesting permutations of payment arrangements where the ultimate recipient of the value paid may be split amongst parties, that is, payment can also be multilateral.

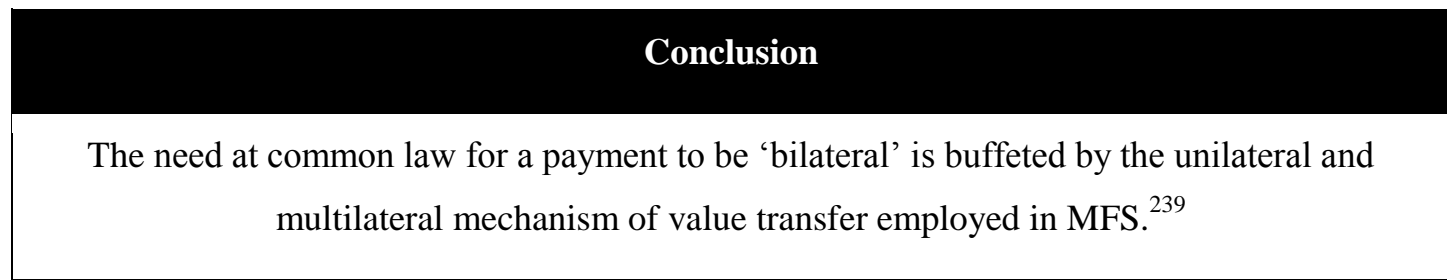

14.7.10

\section{Payment Regulation and Protections}

A

\section{Statutory Payments}

\subsubsection{European Union}

\subsection{Overview}

The Payment Services Directive (hereafter PSD) ${ }^{240}$ applies a range of specific consumer protections and safety and soundness provisions. MNOs who intermediate the sale of ringtones and other VAS from a prepaid airtime SOV are excluded, but are included if they act as an intermediary between a consumer - a Payment Services User (hereafter PSU) and a supplier, although where the instrument develops into a GPR, the exemption no longer applies.

In all, the PSD demonstrates that the focus should be on how to protect user funds and their use, not necessarily the instrument involved.

\footnotetext{
${ }^{238}$ See further the discussion in ch 7, s7.3.2.2 titled Application to MFS.

${ }^{239}$ See ch 7, s7.5 Summary and Conclusions; and ch 14, s14.7.9 titled Conclusion: Payments Revisiting Problem Statement 5; and ch 14, s14.9.10 titled Payment in Law, section A, Recommendation 10.

${ }^{240}$ Directive 2007/64/EC. See the discussion in ch 9, s9.6.2 titled the Payment Services Directive.
} 


\subsection{Specific Consumer Protections ${ }^{241}$}

The PSD provides some of the most progressive and comprehensive protections for users and licensed PSPs alike in dealing with the private law aspects of consumer transactions, specifically the contractual obligations and responsibilities between the PSU and his PSP. It is the first EU law with binding rules on the allocation of loss in both offline and online payments, fastening obligations on the PSU, the PSP and its technical providers alike. Loss allocation and liability rules revolve around loss for transactions postnotification of loss/theft; loss for transactions of 'offline' payment instruments; loss from cloned/forged payment instruments; and the effect of gross negligence by the PSU; effect of fraud by the PSU; effect of misappropriation of the PI or its security features, and rules around who bears the burden of proof for unauthorised payments.

In all, a PSP assumes liability for any failure by other parties in the payment chain up to the account of the payee as well as for any charges and interest which the PSU suffers because of defective execution or nonexecution. There are specific information requirements for low value payment instruments and e-money. For unauthorised payment transactions, a PSP must refund the PS. Damages may be applicable. In regard to protections for micro-payments, these primarily revolve around self- and co-regulatory bodies for WASPtype VAS like PhonePayPlus in the UK and the Ethical Council for Premium Rate Telecommunication Services (hereafter ERS) in Sweden. ${ }^{242}$

\subsubsection{Kenya}

\subsection{Overview}

There is no dedicated payments law in Kenya.

\subsection{Specific Consumer Protections}

Any issues relating to MFS transactions are handled according to contract with MFSPs, guided by an amalgam of indirect, but not easily applicable or effective, provisions of telecommunications law relating to telecommunications billing and CBK rules relating to agents. ${ }^{243}$

\subsubsection{United States}

\subsection{Overview}

At federal level, there is no specific payments law, rather a range of diverse, multi-agency protections through inter alia the Federal Reserve Board (hereafter FRB) and the Federal Trade Commission (hereafter

\footnotetext{
${ }^{241}$ See ch 9, s9.6.2.5.2 titled Liability Allocation and Obligations of the Parties.

${ }^{242}$ See ch 9, s9.11.1 titled Laws and Regulations (telecommunications).

${ }^{243}$ See the discussion in ch 10, s10.6.2 titled Application to MFS.
} 
FTC). There are also evolving omnibus federal protections offered through the new dedicated financial agency, the $\mathrm{CFPB}^{244}$ which is empowered with sweeping rulemaking and enforcement authority. The States are generally the primary front-line regulators of non-traditional financial entities that offer a diverse range of services like cheque cashing, money transmission and foreign exchange to the unbanked. These state laws - for example, the UMSA - may however vary in terms of their scope, licensing and protections.

\subsection{Specific Consumer Protections}

Distinct and separate legal rules and structures exist for each payment type, and legal rights and remedies vary depending upon the 'rails' upon which the payment travels. For example, protections may depend on whether a debit or credit instrument is used, triggering either Federal Regulation E or Regulation Z protections. ${ }^{245}$ Under the Electronic Fund Transfer Act (hereafter EFTA), ${ }^{246}$ the financial institution must promptly investigate any errors and resolve it within 45 days, or re-credit the consumer. Customers may be liable for between US\$50 and US\$500, or the entire amount if they do not follow specified notification criteria for lost/stolen cards. ATMs must have mandatory fee disclosure stickers or screens. The UMSA though, which includes provisions around SVPs by a broad definition of monetary value, complements, and co-exists with, existing state consumer protection laws including fees that Money Services Businesses (hereafter MSBs) can charge and disclosures consumers should see in receipts. ${ }^{247}$ At a self-regulatory level, clearing house rules provide a 60 day window for consumer disputes. ${ }^{248}$

\subsubsection{South Africa}

\subsection{Overview}

The two primary pieces of legislation that have relevance are the Electronic Communications and Transactions Act (hereafter ECTA) ${ }^{249}$ and the Consumer Protection Act (hereafter CPA). ${ }^{250}$

\subsection{Specific Consumer Protections}

While the CPA prevents certain behaviour by suppliers, there is no distinct direction as to what the supplier must do. In the context of MFS and payments, this does not give the user any distinct rights in solving issues of misdirected or fraudulent payment. It was also found that there are conflicts with the ECTA insofar as the CPA defers to its provisions in relation to electronic transactions.

The conflicts, it was found, militate against effective consumer protection for electronic transactions generally, and electronic payments specifically. ${ }^{251}$ The self-regulatory banking Ombudsman, the

\footnotetext{
${ }^{244}$ See ch 11, s11.2.4.2.2 on the CFPB.

${ }^{245}$ See generally ch 11, s11.2.4 titled Payment Systems and Governing Frameworks.

${ }^{246}$ Electronic Fund Transfer Act 15 USC 1601.

${ }^{247}$ See the discussion in ch 11, s 11.2.4.7.2 titled the Uniform Money Services Act.

${ }^{248}$ See ch 11, s11.2.4.2 titled Dodd-Frank Wall Street Reform and Consumer Protection Act.

${ }^{249}$ Electronic Communications and Transactions Act 25 of 2002 (hereafter ECTA). See also ch 12, s12.9 titled E-Commerce Laws.

${ }^{250}$ Consumer Protection Act 68 of 2008. See also ch 12, s12.10 titled Consumer Protection Laws.
} 
Ombudsman for Banking Services in South Africa (hereafter OBSSA), ${ }^{252}$ looks after consumer complaints with regard to bank accounts and EFTs, although the Code of Conduct has no consumer input. Micropayments for WASP-type VAS are enforced by the Wireless Application Service Providers Association (hereafter WASPA), the self-regulatory body for WASP-type VAS. ${ }^{253}$

Redress in the case of mistake, duress and fraud in payments generally fall under the ambit of unjustified enrichment. Methods to this effect however, it was found, are not always available, accessible, obvious or even viable. Specifically, Roman-Dutch condictiones $^{254}$ have been generally employed - insofar as reported cases are concerned - for macro-payments and where there is a capacity for those who have been unjustifiably impoverished to take the matter further after exhausting any protections, if any, offered under the Terms and Conditions (hereafter T\&C) of their provider and any Ombuds-scheme like WASPA or the OBSSA. ${ }^{255}$ Further, these protections apply primarily and more easily to EFTs. Contractual remedies for this then are few, and comparatively weak.

\subsubsection{Conclusion: Payment Consumer Protection}

\section{Revisiting Problem Statement 6:}

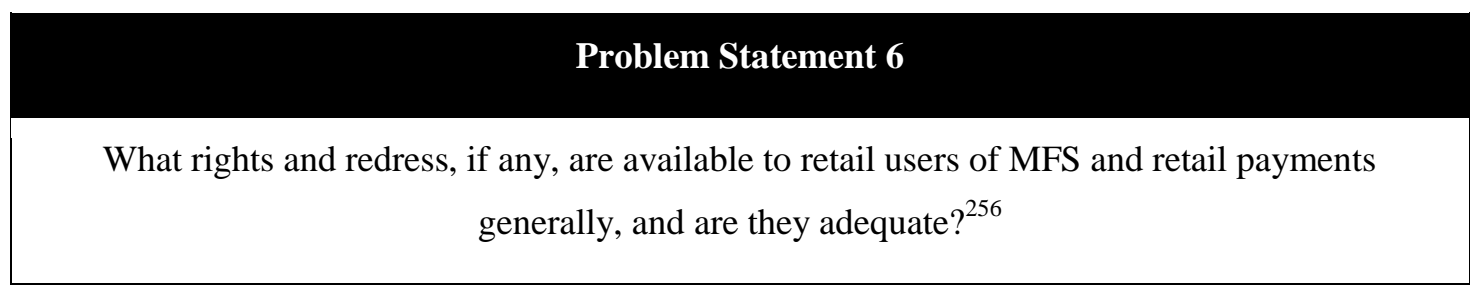

MFS as an evolving ecosystem has some innate customer-facing risks, including its public nature which invites duress and fraud and technical illiteracy which may possibly cause mistakes in transactions. Risk allocation determinations are usually predicated on both parties having access to equivalent information, although informational asymmetry may distort this ability. Thus, it was found, it would be desirable to have legal rules that induce the party with superior information to convey it to the uninformed party or to develop precautionary measures to be utilised.

\footnotetext{
${ }^{251}$ See the detailed discussion in ch 12, s12.10.2.2.6 titled Interplay between the CPA and the ECTA in relation to information requirements for the validity of a transaction. The overall effectiveness of the CPA, ECTA and telecommunications regulatory regimes is negated by deference to the ECTA by the CPA in relation to most electronic transactions; the effective dilution of the CPA through sector-specific derogations of many of its provisions, particularly to the telecommunications regulator ICASA; and inconsistent definitions and application of the ECTA to MFS due to poor drafting,

${ }^{252}$ See ch 12, s 12.3.2.10 on the OBSSA.

${ }^{253}$ See ch 12, s12.8.3.2 on WASPA.

${ }^{254}$ See ch 7, s7.3.6.8 titled Actions to Recover Value, on condictiones.

${ }^{255}$ See ch 12, s 12.3.2.10 titled the OBSSA.

${ }^{256}$ See ch 1, s1.8.5 titled Consumer Rights and Protections in MFS.
} 
Neither the CPA nor the ECTA specifically address mala fide payment, loss and value transfers in any appreciable degree, and loss allocation rules have not been properly established. Ultimately the dispossessed will stay dispossessed because there is no effective statutory assistance.

Use then of the condictiones is possibly available, although the strict confines of their application might, it was found, require further legal resources by the user to argue an expansion of their scope, if at all possible, beyond the context in which the condictio could theoretically be brought. It is unlikely that anyone would engage counsel to fight for a de minimis action invoking the condictio, because first, it is a de minimus and secondly, the condictiones are, it is submitted, too confined to a narrow set of necessary circumstances to be of any general use.

Although it has been demonstrated that the transactional foci of MFS may not necessarily amount to the 'business of banking', and may be more transactional, use could still be made of the principles and aspects of the banker-customer relationship, for example, in allocation of risk.

Issues such as allocation of risk, redress and elements of unjustified enrichment should rather, it is submitted, be addressed by a dedicated PSPL that reflects the nature of MFS and the environment in which these transactions are conducted.

This would of course apply generally across all non-cash payment types. Consumer protections that mediate risk-allocation and Quality of Service (hereafter QOS) in consumer payments should be codified within the PSPL and enforced by a specific agency - the Payment Services Regularity Authority (hereafter PSRA) - that would deal with payment services specifically and to serve as an enforcement arm for the rules and protections in the PSPL.

Regulation, licensing, registration, or oversight over SVPs, private (virtual) currencies, and payments below a certain value may, if needed, be done by an appropriate body under a co-regulatory regime.

Although the genesis and initial role of the US CFPB is primarily on systemic and macro-payment issues and its scope more federal, its broad-based role may serve as a prospective model for a similar agency in South Africa for banking generally, and payments specifically.

As it is still in its infancy, whether the CFPB is able to regulate these new MFS systems effectively remains to be seen. 


\section{Conclusion:}

\section{Conclusion}

Those at the BOP may be affected by informational asymmetries that impact on their ability to avoid risk in cases of mistake, fraud and duress in a payment transaction. Loss allocation rules are also too amorphous. Potential remedies by common law condictiones are constrained to a narrow set of necessary circumstances to be of any general use. The consumer protections in stratified and proportional retail payments regimes like the EU's EMD2 and the PSD are ideally suited to MFS, and could be employed in SA. A financial regulator similar to CFPB in the US should be established under this regime. ${ }^{257}$

\section{Applicability And Impact Of Additional Regulation To MFS}

\subsection{1}

\section{Overview}

The increased efficiencies derived from MFS involve not just financial regulators as the 'usual suspects', but inter alia those relating to implementation of laws and regulations including those relating to AML, telecommunications, e-commerce, and consumer protection. As noted above, these could have further and simultaneous oversight of MFS.

A.

\section{Anti-Money Laundering (AML)}

\subsection{2}

\section{European Union ${ }^{258}$}

EU payments regulation incorporates the international Financial Action Task Force (hereafter FATF) recommendations on EFTs, which effectively projects financial surveillance into the official/formal money transfer business sector.

The PSD also details that agents of PSPs must abide by AML Directives. Application is fragmented though, with regulations on the payor accompanying transfers of funds not applying to transfers of funds using mobile phones. ${ }^{259}$

\footnotetext{
${ }^{257}$ See ch 7, s7.6 Conclusion; ch 12, s12.12 titled South Africa: General Summary and Conclusions; ch 14, s14.7.12 titled Conclusion: Payment Consumer Protection; ch 14, s14.9.6 Payments Law, section A, Recommendation 7; and ch 14, s14.9.7 titled a Payment Services Regulatory Authority, section A, Recommendation 8.

${ }^{258}$ See ch 9, s9.10 titled Anti-Money Laundering, Terrorist Financing, Customer Due Diligence Laws and Regulations.

${ }^{259}$ See inter alia ch 9, s9.10.2 titled Application to MFS.
} 
At federal level, incarnations like prepaid SVC may be impacted by AML laws such as the Patriot Act. It refers to 'funds' and 'money,' possibly then capturing value like airtime or even airmiles. Any potential equivocations are moot since the federal government is empowered to issue new regulations.

\subsubsection{Kenya ${ }^{261}$}

The Proceeds of Crime and Anti-Money Laundering Act $^{262}$ provides mechanisms for detecting and seizing the proceeds of Money Laundering (hereafter ML). CBK-issued guidelines dictate agent adherence to the AML/KYC law, alongside transactional limits that track a customer's risk profile.

14.8.5

South Africa ${ }^{263}$

South Africa has adopted the internal FATF AML principles for AML and CTF, implemented through the Prevention of Organised Crime Act 121 of 1998 (hereafter POCA); the Financial Intelligence Centre Act (hereafter FICA), ${ }^{264}$ and the Protection of Constitutional Democracy Against Terrorist and Related Activities (hereafter Terrorism Act) ${ }^{265}$ while ML is criminalised in s4 of Prevention of Organised Crime Act (hereafter POCA). ${ }^{266}$

FICA overrides many of the secrecy and confidentiality obligations in South African law, including those incidentalia in common law between banker and client. With a refreshingly progressive mindset of proportional risk-based regulation so as to encourage FI, Exemption $17^{267}$ to the AML Regulations allows banks to open accounts with the presentation of only a South African national ID but subject to balance and transaction limits. Further, the SARB relaxed KYC criteria for MFS with the issuance of Guidance Note 6 in 2008 allowing banks to open mobile-banking based accounts without having to undertake face-to-face procedures ordinarily required under Exemption 17. The non face-to-face process would only apply for low-value transactions and debits from accounts up to ZAR1,000 per day. Larger values require face-toface verification.

\footnotetext{
${ }^{260}$ See ch 11, s11.3 titled Anti-Money Laundering, Terrorist Financing and Customer Due Diligence Laws and Regulations in the US.

${ }^{261}$ See ch 10, s10.3 titled Anti-Money Laundering, Terrorist Financing and Customer Due Diligence Laws and Regulations.

${ }^{262}$ Proceeds of Crime and Anti-Money Laundering Act 9 of 2009.

${ }^{263}$ See ch 12, s12.7 titled Anti-Money Laundering, Terrorist Financing and Customer Due Diligence Laws and Regulations.

${ }^{264}$ Financial Intelligence Centre Act 38 of 2001 (hereafter FICA) which is linked to the Prevention of Organised Crime Act

121 of 1998 (hereafter POCA) which in turn contains the substantive money laundering offences as well as the Protection of Constitutional Democracy Against Terrorist and Related Activities Act 33 of 2004 (hereafter POCDATARA).

${ }^{265}$ Act 33 of 2004 op cit note 252.

${ }^{266}$ POCA op cit note 198 and POCDATARA op cit note 198 criminalise money laundering and terror financing, while FICA op cit note 198 requires financial service providers and certain professionals to maintain specific Anti-Money Laundering/Counter Terrorist Financing controls.

${ }^{267}$ Notice R1353 of 2004, published in Government Gazette No 27011, 19 November 2004, available at http://goo.gl/C45CK; and Notice R1354 of 2004, published in Government Gazette No 27011, 19 November 2004, available at http://goo.gl/C45CKon the Financial Intelligence Centre Act (38/2001): Exemption in terms of the Act.
} 
Any AML laws sounding in money may need to be refined to include value that may not necessarily amount to money, for example, airtime minutes and airmiles. In causa, because FICA sounds in money, its scope may not necessarily capture non-money airtime values being transferred nationally and cross-border.

Telecommunications

14.8.7

European Union ${ }^{268}$

There is no specific legislation as yet at EU level relating to PRS. In the UK, in respect of premium rated VAS, the applicable co-regulatory body is PhonePayPlus. As far as fiat-based MFS services, it is not certain which would have overriding jurisdiction: financial or telecommunications-based Directives.

As with other jurisdictions, unless it is explicitly stated, there will probably be concurrent jurisdiction, setting the stage for regulatory arbitrage. ${ }^{269}$

\subsubsection{Kenya $^{270}$}

While the primary regulator with respect to a MNO's MFS activities is the CBK, any entity providing MFS services must also obtain a 'content' license from the telecommunications regulator, the CCK in terms of the Kenya Communications (Amendment) Act. ${ }^{271}$

Additionally, data-protection aspects of the MNO activities are regulated, which may impact on MFS-based bill payments insofar as an ability to share information with credit bureaus. There are also regulations on accurate billing information.

14.8.9

$$
\text { United States }^{272}
$$

Some telecommunication-related laws like state anti-cramming statues may apply, although these may be buffeted by federal pre-emption laws. Although no federal law directly regulates SVPs (except for payroll card versions of SVCs), the Federal Trade Commission $\mathrm{Act}^{273}$ prohibits unfair and deceptive practices, regardless of the type of payment device involved. The Federal Communications Commission's Truth in

\footnotetext{
${ }^{268}$ See ch 9, s9.11 Telecommunications Laws and Regulations, in the EU.

${ }^{269}$ See ch 9, s9.11.2 titled Application to MFS.

${ }^{270}$ See ch 10, s10.4 titled Telecommunications-related Laws and Regulations, in Kenya.

${ }^{271}$ The Kenya Communications (Amendment) Act 1 of 2009, available http://goo.gl/UH891.

${ }^{272}$ See ch 11, s11.4 titled Telecommunications-related Laws and Regulations, in the US.

${ }^{273}$ Federal Trade Commission Act 15 USC $\$ \$ 41-51$.
} 
Billing rules ${ }^{274}$ on bills may apply here, although its application to prepaid customers who do not receive bills is uncertain.

\subsubsection{South Africa ${ }^{275}$}

MFS providers are subject to both hard and soft telecommunications regulations. MNOs in South Africa are directly licensed through provisions of the Electronic Communications $\mathrm{Act}^{276}$ via the telecoms regulator ICASA. The ability though of a telecommunications provider to provide financial services does not appear to be explicitly catered for in licensing regimes, but neither is it implicitly or explicitly excluded. All licensees must clearly communicate billing processes to consumers. At a self-regulatory level, MNOs, service providers and WASPs are to a large measure subject to robust self-regulation measures via WASPA when the airtime-based SOV is used for VAS-type MFS.

\subsubsection{Conclusion}

MFS as a chimerical service offering using licensed telecommunications infrastructure may inadvertently ${ }^{277}$ or not ${ }^{278}$ - includes telecommunications regulators who may have simultaneous oversight over MFS alongside other, for example, financial or consumer protection regulators. With this simultaneous and conflicting jurisdiction and applicability, there is the possibility of coordination failure. This may result in conflicting or incompatible laws and regulations, possibly exacerbated by posturing by each agency through each 'protecting its turf'. The conflicting criteria in FICA and Regulation of Interception of Communications and Provision of Communication-related Information Act 70 of 2002 (hereafter RICA) in South Africa in relation to MFS reflect this. ${ }^{279}$

\section{European Union}

The E-Commerce Directive ${ }^{280}$ (hereafter ECD) provides rules for doing business over electronic bearers and 'Information Society Services', mandating which information is to be provided. It thus appears to be manifestly applicable to a broad range of MFS.

There are however general derogations specific to existing EU financial services legislation, meaning the ECD supplements this legislation.

\footnotetext{
${ }^{274}$ Truth-in-Billing and Billing Format, First Report and Order and Further Notice of Proposed Rulemaking, CC Docket \#98170, 14 FCC Rcd 7492 (1999), available at http://goo.gl/QL8zn.

${ }^{275}$ See ch 12, s12.8 titled Telecommunications-related Laws and Regulations, in South Africa.

${ }^{276}$ Electronic Communications Act 36 of 2005.

277 Telecommunications regulators will by default almost certainly have the bearer portion of a MFS transaction in their remit.

${ }^{278}$ See ch 10, s10.4 titled Telecommunications-related Laws and Regulations, in Kenya, where the telecommunications regulator specifically included types of MFS in its jurisdiction by requiring 'content licenses.'

${ }^{279}$ See ch 12, s12.8.4.2 titled Application to MFS in South Africa.

${ }^{280}$ Directive 2000/31/EC.
} 
14.8.13

Kenya

There is no e-commerce law in Kenya, although the Kenya Communications (Amendment) Act $^{281}$ provides e-commerce-like provisions relating to functional equivalence of electronic messages in respect of their written, paper equivalents. All these could be relevant to MFS, although their application has not yet been tested. $^{282}$

\subsubsection{United States ${ }^{283}$}

The Electronic Signatures in Global and National Commerce Act (hereafter ESIGN) ${ }^{284}$, a federal ecommerce law, facilitates the use of electronic records and signatures in interstate and foreign commerce by ensuring the validity and legal effect of contracts entered into electronically. It does not impact on underlying consumer protection laws governing consumers' rights to receive certain information in writing. The state-based Uniform Electronic Transactions Act (hereafter UETA) similarly guarantees equivalence.

\subsubsection{South Africa ${ }^{285}$}

Transactions conducted electronically are governed by the ECTA. ${ }^{286}$ The ECTA attempts, like many similar laws in other national and international jurisdictions, to give effect to many common law contractual provisions to the extent that this promotes transacting with modern technologies. The overall aim of the ECTA is to remove barriers to (and to promote legal certainty, stability and confidence in) electronic communications and transactions by promoting technology neutrality in the application of legislation to these transactions. It gives legal recognition to data messages and promotes technology neutrality, providing a general framework for the facilitation and regulation of electronic communications and transactions and giving effect to many common law contractual provisions.

While it does not define 'electronic transactions', it defines a 'transaction' as being 'a transaction of either a commercial or non-commercial nature, and includes the provision of information and e-government services'. MFS generally would fit this definition. It also has a number of consumer protection measures which the CPA defers to - intended to maintain the same level of protection as that which exists for offline contracts. In analysis of its application to MFS though, while the ECTA was written with technological neutrality in mind, it is instead somewhat technologically agnostic. It was found ${ }^{287}$ that general inconsistencies in application were the result of incongruous nomenclature and definitions, and the understandable influence of the technologies and events at the time the ECTA was drafted have rendered

\footnotetext{
${ }^{281}$ Act 1 of 2009 op cit note 259 .

${ }^{282}$ See ch 10, s10.4.1 titled The Kenya Communications Amendment Act 1 of 2009.

${ }^{283}$ See ch 11, s11.5 titled Electronic Commerce Laws and Regulations, in the US.

${ }^{284}$ Electronic Signatures in Global and National Commerce Act 15 USC ch. 96.

${ }^{285}$ See ch 12, s12.9 titled E-Commerce Laws, in South Africa.

${ }^{286}$ ECTA op cit note 237.

${ }^{287}$ See inter alia ch 12, ss12.9.3 titled Conclusion: E-Commerce Laws and 12.10.3 titled Conclusion: Consumer Protection Laws.
} 
ECTA and the CPA ineffective with the advent and impact of mobile technology. Where the ECTA is silent or contradictory, common law remedies are the only remedies available.

The ECTA, it is submitted, requires revision to make it properly applicable to developments in mobile technology and its uses, which now form a major portion of the electronic transactions it purports to (want to) regulate.

\title{
Consumer Protection
}

\subsubsection{6}

\author{
European Union ${ }^{288}$
}

The EU does not have an omnibus consumer protection law like that of South Africa, but has sectorspecific protections like the PSD and ECD. The EU though has established minimum consumer protection rules concerning retail financial services, which allow Member States to create stricter rules, as well as non-judicial bodies to assist in financial disputes.

\subsubsection{Kenya}

There is no specific consumer protection law. Instead, MFS issues are directly and indirectly impacted by a number of telecommunications ${ }^{289}$ and financial laws that address consumer protection issues. The Banking $\mathrm{Act}^{290}$ allows the CBK to restrict increases in bank charges, although it is not certain that MFS services like M-pesa would be subject to these restrictions as there is no licensed bank structure per se to regulate. The CBK's agent guidelines specify consumer protection provisions on formalities in the transaction processes. $^{291}$

\subsubsection{United States ${ }^{292}$}

The Dodd-Frank Wall Street Reform and Consumer Protection Act ${ }^{293}$ (colloquially referred to as 'DoddFrank') created an omnibus consumer financial protection law that augments and replaces a variety of consumer protection laws at federal or state levels. Federal consumer protection laws are mainly enforced by the FTC although it cannot investigate banks and credit unions. As noted above, financial protections are offered through the new dedicated federal agency, the CFPB. At state level, the UMSA as a model law enabling a patchwork of light-touch-money-type safety and soundness laws on e-money and SVPs. Divergent interstate implementations however lead to confusion.

\footnotetext{
${ }^{288}$ See ch 9, s9.13 titled Consumer Protection-type Laws in the EU.

${ }^{289}$ For example, Kenya's Act 1 of 2009 op cit note 259. See ch 10, s10.4.1 titled The Kenya Communications Amendment Act 1 of 2009.

${ }^{290}$ Banking Act 1989 Chapter 488.

${ }^{291}$ See ch 10, ss10.3 titled Anti-Money Laundering, Terrorist Financing and Customer Due Diligence Laws and 10.2.4 titled Use of Agents.

${ }^{292}$ See ch 11, s11.6 titled Consumer Protection titled state and federal consumer protection laws and regulations in the US.

${ }^{293}$ Dodd-Frank Wall Street Reform and Consumer Protection Act Pub. Law 111-203, H.R. 4173.
} 
South Africa created a dedicated consumer protection law, the $\mathrm{CPA},{ }^{295}$ to harmonise consumer legislation in South Africa. It consolidates consumer protection provisions from five Acts and also introduces general principles of consumer protection to serve as an overarching governing statement on consumer protection matters in South Africa.

However in terms of electronic transactions, the CPA mostly defers to consumer protection provisions of the ECTA described above. It also allows deference to other sector regulators whose regulations may have similar import to those in the CPA.

The National Consumer Commission (hereafter NCC) enforces the CPA insofar as conflict of laws is concerned, and the CPA will generally apply unless specifically excluded. For electronic transactions, it mostly defers to, it is submitted, inchoate, consumer protection provisions of the ECTA.

The CPA does not preclude consumers from exercising any rights afforded to them in terms of common law, and codifies common law notions of good faith in contract by legislating inter alia unfair, unreasonable or unjust contract terms, notice required for certain terms and conditions; details of prohibited transactions, agreements, terms or conditions while explicitly giving courts the power to ensure fair and just conduct, terms and conditions. ${ }^{296}$

14.8.20

\section{Conclusion: The Regulator's Dilemma}

\section{Revisiting Problem Statement 7:}

\section{Problem Statement 7}

How do regulators militate against the 'dilemma' of promoting Financial Inclusion while protecting financial integrity with regard to MFS, and how does it manifest in regulatory domains relating to telecommunications, e-commerce, consumer protection and AML $?^{297}$

MFS is a chimerical service offering which tests the perimeters of the 'functional' versus 'institutional' approaches to regulation, through the involvement of a number of regulators, agencies, laws and regulations.

\footnotetext{
${ }^{294}$ See ch 12, s12.10 titled Consumer Protection Laws, in South Africa.

${ }^{295}$ Act 68 of 2008 op cit note 238 .

${ }^{296}$ See inter alia ch 12 , ss12.9.3 and 12.10.3.

${ }^{297}$ See ch 1, s1.8.6 titled Role and Effect of Additional Regulatory Oversight of MFS.
} 
They may - inadvertently or not - have simultaneous and conflicting jurisdiction and applicability, ultimately resulting in a potpourri of incompatible laws and regulations and increasing the possibility of regulatory arbitrage. The resultant fragmentation and disproportionate amount of regulation may add to the cost of compliance, and be exacerbated by the 'turf-protecting' posturing of each agency.

There are already examples thereof. Telecommunications regulators may insist on regulating the bearer cost portion of the MFS transaction - for example, SMS costs - as well as modifying an MNO's operating license conditions so as to include MFS provision.

Simultaneous enforcement over MFS by consumer protection agencies with omnibus oversight over consumer protection generally may lead to jurisdictional clashes with sector regulators, such that entities affected may dispute jurisdiction and thus potentially avoid needing to abide by the decisions of either regulator. The need for regulators and their agencies to communicate with one another across this convergent spectrum thus becomes manifestly more important.

Close coordination is essential to develop effective oversight and regulatory structures, as poor coordination and the resultant swathes of inconsistent laws and regulations may result in regulatory arbitrage and an amelioration of consumer protections.

This lack of regulatory coordination again emphasises the need to have a dedicated Regulator - suggested as the PSRA ${ }^{298}$ - that enforces the proposed PSPL. There may however need to be some off-setting of regulatory oversight at a certain cut off value to a co-regulatory regime; using an entity like WASPA that would have jurisdiction on amounts under ZAR15,000 and for specific SVP and MFS types. This would be similar to values allowed to be adjudicated on by Small Claims Courts in South Africa. ${ }^{299}$

Regardless of whether a functional, institutional, or single-agency approach is used, the effectiveness can be enhanced by gold-plating the enabling law to clearly define their roles, and in particular that an agency responsible for financial consumer protection should be given an express mandate on consumer protection issues rather than it being implied and that the single, mandated entity receives and deals with consumer customer complaints and inquiries.

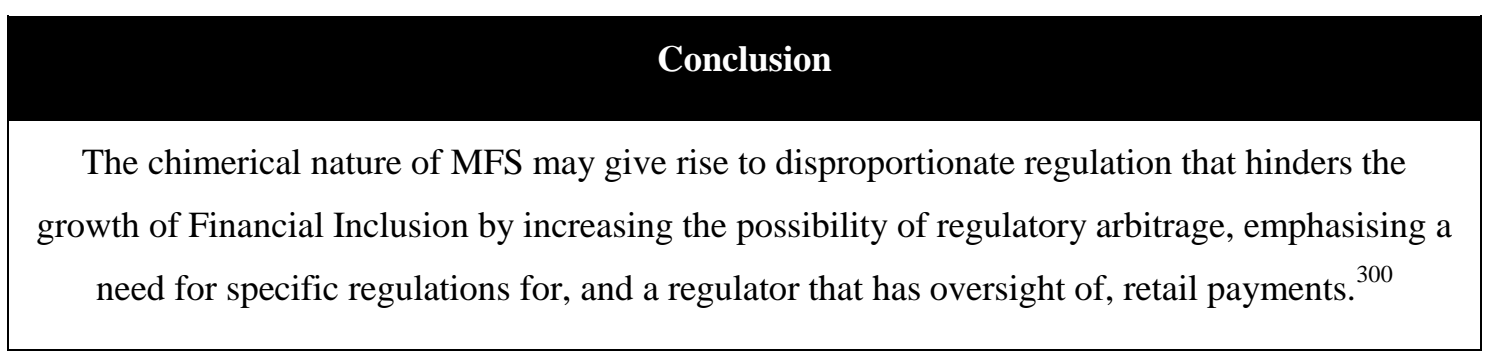

\footnotetext{
${ }^{298}$ See ch 14, s14.9.7 titled Payment Services Regulatory Authority.

${ }^{299}$ Small Claims Court Act 61 of 1984. In terms of notices issued in terms of ss15 and 16 of the Act, the maximum (fiatbased) claim that can be adjudicated titled is ZAR12,000. See Government Notice R985 of 27 October 2010. Most disputes in the VAS domain in South Africa are under ZAR15,000.

${ }^{300}$ See ch 8, s8.9 Conclusion.
} 
Based on the extensive discussions throughout this study in its respective chapters, a summary of the recommendations therein are set out below, some with contextual explanations.

There are eleven recommendations. Details of these recommendations can be found in the respective chapters, and also partly in the conclusions in this Chapter, as well as in Annex 2.

14.9.1

A Recommendation 1

\section{RECOMMENDATION 1}

There is a need for a reassessment of money in law, and for the use of the Claim School's economic view of money in a legal definition of money. ${ }^{301}$

B

Rationale $^{302}$

The Orthodox School's economic view of money on which the legal system bases its treatment of money may not be an appropriate descriptor for modern forms of payments and transactional systems. At issue is the requirement for a commodity backing, and its feature as an inchoate MOE. Use of this School allows many of the electronic payment and stores of value transactional systems to escape (legal) classification as money.

This may have implications inter alia in AML statutes, rights sounding in money, and whether value amounts to a deposit in banking law. It may be appropriate rather to define money using the Claim School theorists' view of money.

The proposed shift in legal emphasis uses the 'Claims' - and Means of Payment feature - that electronic forms of payment and stores of value engender.

\footnotetext{
${ }^{301}$ See ch 14, s14.5.4.7 titled Re-evaluation of Money.

${ }^{302}$ See ch 3, s3.14 Summary and Conclusions; ch 13, s13.9 Summary and Conclusions, and ch 14, s14.5.4.7.1 titled Use of Economic Schools in the Assessment.
} 


\section{RECOMMENDATION 2}

There is a need for a reassessment of the 'deposit concept' generally, and specifically as a metric of the 'business of banking'.

\section{RECOMMENDATION 3}

The acceptance of funds used primarily for transactional payment purposes should not necessarily amount to a deposit.

\section{B. $\quad$ Rationale $^{303}$}

There has traditionally been a covalent nexus between deposit, the business of banking and intermediation, in that the deposit is seen as the source of value for intermediation and triggers the 'business of banking' categorisation. The nature of what banking is, however, is changing, such that deposits - which are really stores of value - are becoming the value sources for transactional platforms, not for intermediation.

Non-bank providers - such as MFSPs - are also able to store this value, but the covalent nexus between deposit and banking creates a theoretical barrier in which these non-banks are classed as doing the business of banking.

If then the provision of user funds to an entity can be regarded as a SOV for special use as a pool of value for transacting rather than a bank-linked 'deposit' that has omnibus use, then the theoretical divide can be bridged.

Thus, in the face of the dematerialisation of money and its new role as a means of payment and store of value, the role of the deposit as the functional pivot around which the business of banking is calibrated should be reviewed.

${ }^{303}$ See ch 4, s4.8.6 titled Nature of the Transaction and Settlement; and ch 14, ss14.6.3 titled the Role of the Deposit in Banking and 14.6.7 titled Conclusion: Deposit: Revisiting Problem Statement 2. 
RECOMMENDATION 4

There is a need for a new regulatory regime that focuses on, and licenses, putative Payment Service Providers.

\section{Rationale $^{304}$}

A balance must be struck between compliance and systemic risk mitigation, and expansion of financial access of those at the BOP. This is characterised by the balancing of Financial Inclusion with Financial Integrity.

Thus a new 'bank-lite-type' payment services regime should be introduced. This may possibly be through the re-introduction of a revised version of the dormant Draft Dedicated Banks Bill, but preferably a Payment Services Provider Law (PSPL) to emphasise the payments focus of many non-banks and MFS systems should be introduced into South Africa.

The PSPL would license and hence would allow specialised Payment Service Providers (PSPs) to provide payment services and remittances from a SOV akin to the Payment Account (PA) used in the PSD. ${ }^{305}$

The fiat value exchanged for the value should not amount to a deposit per se, although functionally it would serve the same purpose and be redeemable on par and on demand. It is submitted that an associated enabling of agents to act for these new entities should be part of the new regime.

\footnotetext{
${ }^{304}$ See ch 7, s7.6 Conclusion in relation to the use of trust accounts for safety and soundness criteria; and ch 14, s14.6.8 Conclusion: Business of Banking; and ch 12, s12.12 titled South Africa: General Summary and Conclusions.

${ }^{305}$ This would in essence break the monopoly of licensed banks on the use of customer funds.
} 
RECOMMENDATION 5

Mandate the use of trust accounts for providers engaged in MFS so as to ring-fence existing business interests and for systemic risk considerations.

B.

\section{Rationale $^{306}$}

For safety and soundness, the business of a PSP should be ring-fenced to a degree from its primary business via formation of a trust company vehicle which should control the (pooled) funds derived from user prepayment in a special trust bank account. The pool of funds should be held in a separate trust account. The Trust should be regulated by the FSB or a similarly empowered body.

\section{RECOMMENDATION 6}

Allow access by licensed PSPs to the SA NPS. ${ }^{307}$

B.

Rationale $^{308}$

Subject to capital requirements and other safety and soundness criteria, MFSPs (as PSPs) should be allowed access to the NPS for clearing and settlement to allow for seamless interoperability not just with banks, but with other MFS systems. In all, this would in essence break the monopoly of licensed banks on the use of customer funds without disrupting the financial sector on a systemic basis.

\footnotetext{
${ }^{306}$ See ch 7, s7.4 titled Trusts, in relation to the potential use of trust accounts in MFS in South Africa; ch 7, s7.6 Conclusion in relation to the use of trust accounts for safety and soundness criteria; ch 12, s12.12 titled South Africa: Chapter General Summary and Conclusions; and ch 14, s14.6.8 Conclusion: Business of Banking.

${ }^{307}$ This should also include MNOs where applicable.

${ }^{308}$ See ch 12, s12.12 titled South Africa: General Summary and Conclusions; and ch 14, s14.6.8 titled Conclusion: Business of Banking.
} 
A.

\title{
Recommendation 7
}

\section{RECOMMENDATION 7}

There is a need for a new regulatory regime that codifies consumer and service provider rights in retail payments.

B.

\section{Rationale $^{309}$}

It is submitted then that the PSPL also provide for specific consumer protections over both macro and some micro retail payments that include EFTs, SVPs and similar prefunded systems. The PSPL would mediate risk-allocation in consumer payments, ensure QOS, and provide for the rights and responsibilities of parties.

The harmonised PSPL rules should be applied in a symmetrical manner so as to provide some measure of protection to all parties in electronic payments, be it between the payor and the recipient, and between the payor and recipient and their respective financial institutions.

Any rules that may be applicable - express or implied - to PS should be removed from the consumer protection provisions of laws such as the ECTA and CPA, and instead consolidated into a framework set of rules in the PSPL.

The PSPL should, for legal certainty, answer some basic questions: who bears the risk of authorised payments; what must be done about claims of error; when are payments completed so that they discharge the underlying obligation; can they be reversed, and if so, when and how can they be reversed?

\subsection{7}

\section{Payments Services Regulatory Authority}

A.

\author{
Recommendation 8
}

\section{RECOMMENDATION 8}

There is a need for a dedicated authority to regulate consumer payments.

${ }^{309}$ See ch 7, s7.5 Summary and Conclusion; and ch 12, s12.12 titled South Africa: Chapter General Summary and Conclusions; and ch 14, s14.7.12 Conclusion: Payment Consumer Protection. 
B.

\section{Rationale $^{310}$}

To enforce the proposed PSPL, a specific statutory agency - a Payment Services Regulatory Authority (hereafter PSRA) - should be formed to administer licensing and sound operation of the PSPs and ensure compliance with the consumer protection provisions of the proposed PSPL. The PSRA should be given an express mandate on consumer protection issues and enforcement rather than it being implied. The CFPB in the USA could serve as a model for its operation.

It is accepted though that owing to the de minimis nature of the MNO airtime-based SOV, for example, there may need to be some off-setting of regulatory oversight at a certain cut off value to a co-regulatory regime, using a self- or co-regulatory entity that would have jurisdiction on amounts under ZAR15,000 and for specific SVP and MFS types.

Compliance should be enforced through a light-touch registration rather than a licensing scheme for these smaller-value SVPs.

14.9.8 Payment In Law

A. Recommendation 9

\section{RECOMMENDATION 9}

There is a need to revisit the need in South African law that a payment needs to be bilateral in order to accommodate, for example, remittances and donations which do not necessarily require the co-operation of the recipient of the payment.

B.

\section{Rationale $^{311}$}

The need at common law for a payment to be 'bilateral' is buffeted by the unilateral and multilateral mechanism of value transfer employed in MFS.

\footnotetext{
${ }^{310}$ See ch 12, ss12.10.3 titled a Payments Services Regulatory Agency, and 12.12 titled South Africa: General Summary and Conclusions; and ch 14, s14.7.11 titled Common Law Protections: Condictiones.

${ }^{311}$ See ch 7, s7.5 titled Summary and Conclusion; and ch 14, s14.7.9 titled Conclusion: Payments: Revisiting Problem Statement 5.
} 
A.

\section{Recommendation 10}

\section{RECOMMENDATION 10}

Changes are required to the Electronic Communications and Transactions Act 25 of 2002 to ensure true technology neutrality.

B.

RATIONALE ${ }^{312}$

Remove the words 'and includes the Internet' in the definition of 'information system' to allow for inclusion of all mobile-related systems.

\subsection{Contribution Of This Study}

The study provides a comprehensive international, inter-doctrinal and sector-level overview of the valencies that may affect the provenance of the evolving domain of Mobile Financial Services (MFS) provided by bank and non-bank entities and delivered by mobile phones to primarily unbanked, underserved and underbanked persons.

This study found ${ }^{313}$ that the introduction of these facilities and the involvement of new entrants in provision of MFS reveal the law to be unprepared.

While the focus of the study is on application to MFS, the varied problem statements identified during the course of the research impact not just on MFS, but also on related systems generally and provide necessary discussion on views of inter alia the entire payments and banking ecosystem and its regulation, and a seminal totem: the nature of money.

The study addresses the 'regulator's dilemma' of how to promote Financial Inclusion whilst maintaining financial integrity at a user and systemic level alike. Similar 'dilemmas' were found to exist across the legal and regulatory regimes surveyed in the European Union, Kenya, the United States of America, and South Africa.

In a discussion of the MFS models identified, each may be regulated by banking, payments, Anti-Money Laundering, telecommunications, e-commerce and consumer protection laws. An array of regulatory arbitrage was found to exist in South African law. Recommendations to address these issues were provided.

\footnotetext{
${ }^{312}$ See ch 12, s12.9.2.2.3 titled Formation of Contracts by Users Contracting with Electronic Agents.

${ }^{313}$ See ch 8, s8.9 titled Conclusion.
} 
In the assessment of whether some funding mechanisms as used for SOVs in MFS are 'deposit-taking' such that an entity could be engaging in the 'business of banking,' a comprehensive survey found that the 'deposit' concept is stratifying insofar as the metric of a deposit may be time-based; that value can be transiently stored; and used only as a funding source for transactions and not necessarily for intermediation purposes. This, it is suggested, necessitates a need for a reassessment of the 'deposit' concept generally, and specifically as a metric of the 'business of banking'. In particular, it was suggested that the acceptance of funds used primarily as a source for transactional payment purposes should not necessarily amount to a deposit.

As many of the evolving MFS models use mobile airtime value as a 'virtual currency,' the impact thereof on law and regulation was undertaken through an extensive evaluation of 'money' using the economic views of money seen in the 'Orthodox School' and 'Claim School,' and specifically questions of whether these stored values may be seen 'money' in law. This type of investigation is rare in legal scholarship. An 'equivalence' analysis revealed that use of the Orthodox School view of money as traditionally founding a nexus to common law view of money does not provide a nexus when applied to emerging intangible systems and values designing to be money.

An alternative and relatively modern theoretical school, the Claim School, however was found to be coincident with legal views of money and payments as it pivots on debts, rights, obligations and finality of payment, views which were found to be largely congruous to the common law legal criteria for money. Further, it was found that while some SVPs have the seminal characteristics of money, other individual species would not amount to 'money' which may impact on laws and rights sounding in 'money.'

Consumer protection for MFS and payments generally through the use of and interaction with current statute, contract, and payment law and specifically the common law condictiones relating to current payments were found to be wanting.

It was found that due to financial literacy and technical concerns, there is inter alia a need for robust and dedicated consumer protection of payment services, to fall under the remit of what this study proposes as a new PSPL for South Africa that licenses non-bank MFS entities acting as PSPs whose primary focus is transactional payments.

The use of trust companies and trust accounts is recommended for safety and soundness for protection of user funds. The potential for a new regulator for payment services - a PSRA - was also investigated and then proposed.

The discussion on payment indicates that MFS challenges the requirement in South African common law for a payment to be 'bilateral.' 


\section{TABLE OF ABBREVIATIONS}

\begin{tabular}{|c|c|}
\hline$€$ & Euros \\
\hline $2 G$ & Second Generation Mobile Network \\
\hline 3G & Third Generation Mobile Network \\
\hline 4G & Fourth Generation Mobile Networks \\
\hline 3GPP & 3rd Generation Partnership Project \\
\hline $3 \mathbf{L 3}$ & The Three Level 3 Committees of the EU \\
\hline 802.11 & WiFi/Wireless LAN specification \\
\hline ABA & Australian Bankers Association \\
\hline $\mathbf{A B C P}$ & Asset-backed commercial paper \\
\hline ACH & Automated Clearing House \\
\hline ACI & Association of Collective Investments \\
\hline ACL & Australian Consumer Law \\
\hline ACMA & Australian Communications and Media Authority \\
\hline AD & Appellate Division \\
\hline ADD & Agent Due Diligence \\
\hline ADI & Authorised Deposit-taking Institution \\
\hline AFI & Alliance for Financial Inclusion \\
\hline AG & Attorney General \\
\hline AGD & Attorney General's Department \\
\hline AIM & Alternative Investment Market \\
\hline ALI & American Law Institute \\
\hline AML & Anti-Money Laundering \\
\hline AMLTF & Anti-Money Laundering Task Force \\
\hline AMTA & Australian Mobile Telecommunications Association \\
\hline APACS & Association for Payment Clearing Services \\
\hline APB & Accounting Policy Board \\
\hline APCA & Australian Payments Clearing Association \\
\hline APPS & Applications \\
\hline APRA & Australian Prudential Regulation Authority \\
\hline APT & Advanced Persistent Threat \\
\hline ARS & Arizona Revised Statues \\
\hline ASA & Advertising Standards Authority \\
\hline ASIC & Australian Securities and Investments Commission \\
\hline ASISA & Association for Savings and Investment in South Africa \\
\hline ATM & Automatic Teller Machine \\
\hline AU\$ & Australian Dollar \\
\hline AUSTRAC & Australian Transaction Reports and Analysis Centre \\
\hline B2B & Business to Business \\
\hline B2C & Business to Consumer \\
\hline BASA & Banking Association of South Africa \\
\hline BBA & British Bankers’ Association \\
\hline BCFP & Consumer Financial Protection Bureau (See also CFPB) \\
\hline BCSB & Banking Code Standards Board \\
\hline
\end{tabular}


BEE

BIC

BIS

BN

BOE

BOP

BRIC

BRICS

BSA

BSA

BSD

BSP

BSS

C2C

CA

CAN-SPAM

CB

CBK

CC

CCK

CDD

CDI

CDL

CDMA

CEBS

CECS

CEIOPS

CESR

CFD

CFPB

CFR

CFT

CGAP

CGO

CHAPS

CIPRO

CIS

CISCA

CIV

CMA

CMO

CMS

COBP

CPA

CPSIPS

CPSP

CPSPS

CPSS

CRB
Black Economic Empowerment shares

Bank Identifier Code

Bank for International Settlements

Billion

Bills of Exchange

Bottom/Base of the Pyramid

Brazil, Russia, India, China

Brazil, Russia, India, China, South Africa

Building Societies Association

Bank Secrecy Act Ch 11 USA???

Bank Supervision Department

Beneficiary Service Providers

Base Station Subsystem

Consumer To Consumer

Communications Alliance

Controlling the Assault of Non-Solicited Pornography And Marketing Act

Central Bank

Central Bank of Kenya

Constitutional Court

Communications Commission of Kenya

Customer Due Diligence

CREST Depository Interest

CREST Depository Limited

Code Division Multiple Access

Committee of European Banking Supervisors

Consumer Electronic Clearing System (Australia)

Committee of European Insurance and Occupational Pensions Supervisors

Committee of European Securities Regulators

Contracts for difference

Consumer Financial Protection Bureau (See also BCFP)

Code of Federal Regulations

Counter Financing of Terrorism

Consultative Group to Assist the Poor

Central Gilts Office

Clearing House Automated Payment System

Companies and Intellectual Property Commission

Collective investment scheme

Collective Investment Schemes Control Act of 2002

Customer Identity Verification

Common Monetary Area

Central Moneymarkets Office

Content Management System

Code of Banking Practice

Consumer Protection Act

Core Principles for Systemically Important Payment Systems

Customer Payment Service Providers

Customer Payment Service Providers

Committee on Payment and Settlement Systems

Credit Reference Bureaus 


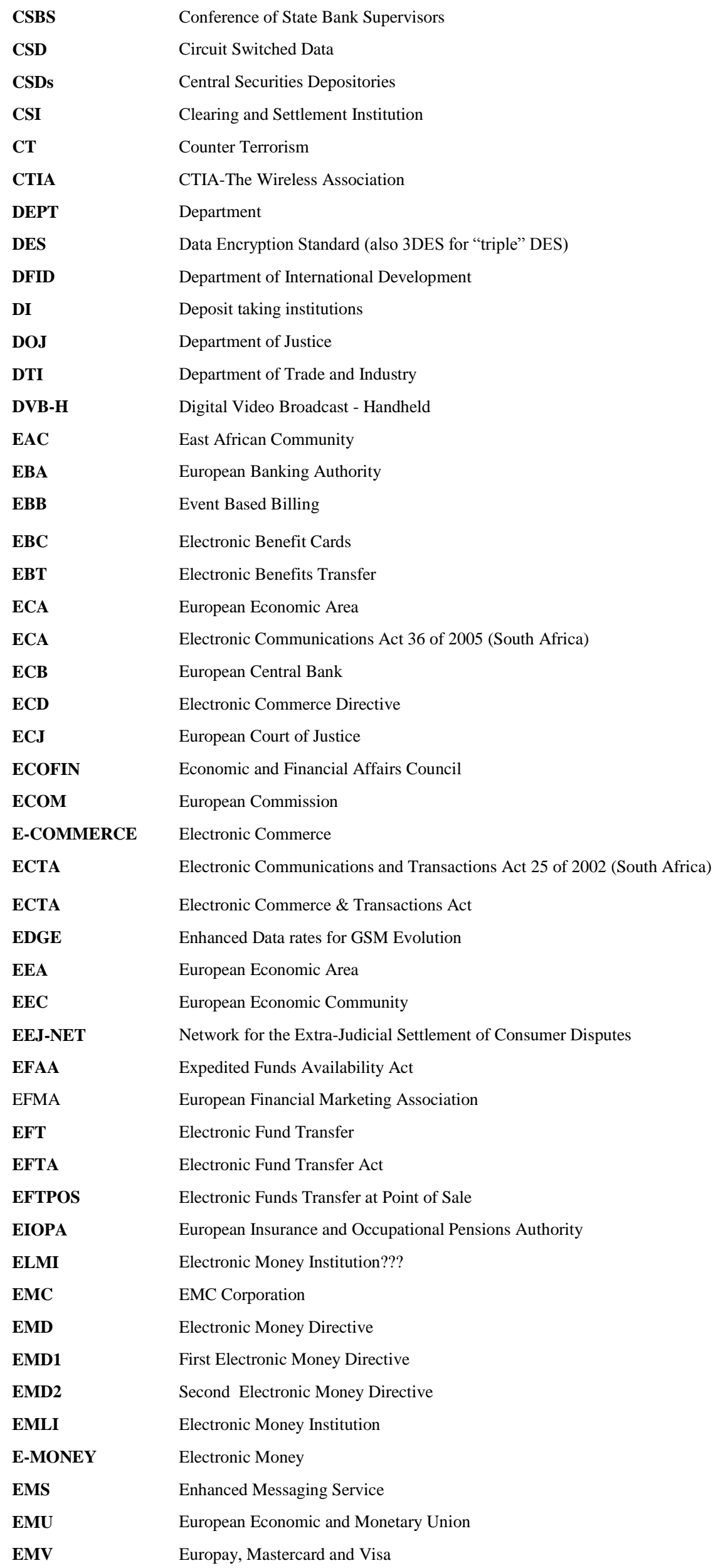


EO

EP

EPC

ESA

ESAS

ESCB

ESFS

E-SIGN

ESMA

ESN

ESRB

EU

EUR

EUROCCP

E-VALUE

EVDO

FAIS

FATF

FCAC

FCBA

FCC

FCRA

FDCPA

FDIA

FDIC

FE

FED

FI

FIC

FICA

FINCEN

FIN-NET

FIPFA

FMIRS

FOS

FRB

FRIP

FRS

FSA

FSAP

FSB

FSD

FS-ISAC

FSMA

FSP

FTC

FTCA
Executive Officer of the FSB

European Parliament

European Payments Council

Exchange Settlement Accounts

European Supervisory Authorities

European System of Central Banks

European System of Financial Supervisors

Electronic Signatures in Global and National Commerce Ac

European Securities and Markets Authority

Electronic Serial Number

European Systemic Risk Board

European Union

Euro

European Central Counterparty

Electronic Value

Evolution-Data Optimized

The Financial Advisory Intermediary Services Act

Financial Action Task Force

Financial Consumer Agency of Canada

Fair Credit Billing Act

Federal Communications Commission

Fair Credit Reporting Act

Fair Debt Collection Practices Act

Federal Deposit Insurance Act

The Federal Deposit Insurance Corporation

Financial Exclusion

Federal Reserve Board

Financial Inclusion

Financial Intelligence Centre

Financial Intelligence Centre Act 38 of 2001 (FICA)

Financial Crimes Enforcement Network

Financial Dispute Resolution Network

Financial Institution (Protection of Funds) Act of 2001

Financial Markets and Insolvency (Settlement Finality) Regulations

Financial Ombudsman Service

Federal Reserve Board

Financial Reporting Investigation Panel

Federal Reserve System

Financial Services Authority

Financial Sector Assessment Program

Financial Services Board

The Financial Stability Department

The Financial Services Information Sharing and Analysis Center

Financial Services and Markets Act

Financial Service Providers

Federal Trade Commission

Federal Trade Commission Act

The Group of Ten (eleven) industrial countries 
G20

G2P

G8

GAME

GAO

GDP

GMCF

GOA

GPR

GPRS

GPS

GRWG

GSM

GSMA

HLR

HM

HMRC

HMT

HSDPA

HSM

HSPA

HSUPA

HSV

HTML

HTTP(S)

IBAN

IBDE

ICASA

ICT

ID

IEMI

IFC

IFIA

IFRS

IMF

IMSI

IOL

IOSCO

IP

IPE

IPR

IRDA

IRS

ISD

ISDN

ISM

ISMA

ISS

The Group of Twenty Finance Ministers and Central Bank Governors

Government to Person

The Group of Eight industrial countries

Generally Accepted Means of Exchange

Government Accountability Office

Gross Domestic Product

Global Mobile Commerce Forum

Government Accountability Office

General Purpose Reloadable

General Packet Radio Service

Global Positioning System

Global Remittances Working Group

Global System for Mobile communications

Global System for Mobile Communications Association

Home Location Register

Her/His Majesty's [UK]

Her Majesty's Revenue and Customs

Her/His Majesty's Treasury [UK]

High Speed Download Packet Access

Hardware Security Module

High Speed Packet Access

High Speed Upload Packet Access

Holder of Stored Value

Hypertext Markup Language

Hypertext Transfer Protocol (s) over Secure Socket Layer

International Bank Account Number

Interbank Data Exchange

Independent Communications Authority of South Africa

Information and Communication Technology

Identifier or Identification

International Mobile Equipment Identity

International Finance Corporation

Inspections of Financial Institutions Act of 1998

International Financial Reporting Standards

International Monetary Fund

International Mobile Subscriber Identity

Independent Online

International Organization of Securities Commissions

Information Provider

International Petroleum Exchange

Intellectual Property Rights

Infrared Data Association

Internal Revenue Service

Investment Services Directive

Integrated Services Digital Network

Industrial Scientific Medical

International Securities Market Association

IT

Information Society Services

Information Technology 


\begin{tabular}{|c|c|}
\hline IVR & Interactive Voice Response \\
\hline IVTS & Informal Value Transfer Systems \\
\hline JMLSG & Joint Money Laundering Steering Group \\
\hline JSE & Johannesburg Stock Exchange \\
\hline $\mathbf{J V}$ & Joint Venture \\
\hline KBA & Kenya Bankers Association \\
\hline KEPSS & Kenya Electronic Payment and Settlement System \\
\hline KSH & Kenyan shillings \\
\hline KYC & know your customer \\
\hline LCH & London Clearing House \\
\hline LIFFE & London International Financial Futures Exchange \\
\hline LISP & Linked Investment Service Providers \\
\hline LME & London Metal Exchange \\
\hline LMI & Low and Moderate Income \\
\hline LSE & London Stock Exchange \\
\hline LSM & Living Standards Measure \\
\hline LTE & Long Term Evolution \\
\hline M-BRIC & Mobile - Brazil, Russia, India, China \\
\hline MAGSTRIPE & Magnetic Stripe \\
\hline M-COMMERCE & Mobile Commerce. \\
\hline MET & Mobile Electronic Transactions \\
\hline MFI & Microfinance Institution \\
\hline MFRC & Micro Finance Regulatory Council \\
\hline MFS & Mobile Financial Services \\
\hline ML & Money Laundering \\
\hline M-MONEY & Mobile Money \\
\hline MMS & Multimedia Messaging Service \\
\hline MMT & Modern Money Theory \\
\hline MMT & Mobile Money Transfer \\
\hline MN & Million \\
\hline MNO & Mobile Network Operator \\
\hline MO & Mobile Originating \\
\hline MOA & Money of Account \\
\hline MOBEY & Mobile Financial Services Forum \\
\hline MOE & Means of Exchange \\
\hline MOIC & Ministry of Information Communication \\
\hline MOP & Means of Payment \\
\hline MOU & Memorandum of Understanding \\
\hline MPRS & Mobile Premium Rated Services \\
\hline MPS & Mobile Premium Rated Services \\
\hline MPSI & Mobile Premium Services Industry Scheme \\
\hline MPSP & Mobile Payment Service Providers \\
\hline MSB & Money Services Business \\
\hline MT & Mobile Terminating \\
\hline MTAN & Mobile Transaction Authentication Number \\
\hline MTN & Mobile Telephone Network \\
\hline MTO & Money Transfer Organizations \\
\hline MTRA & Money Transmitters Regulatory Association \\
\hline MTS & Money Transfer Services \\
\hline
\end{tabular}




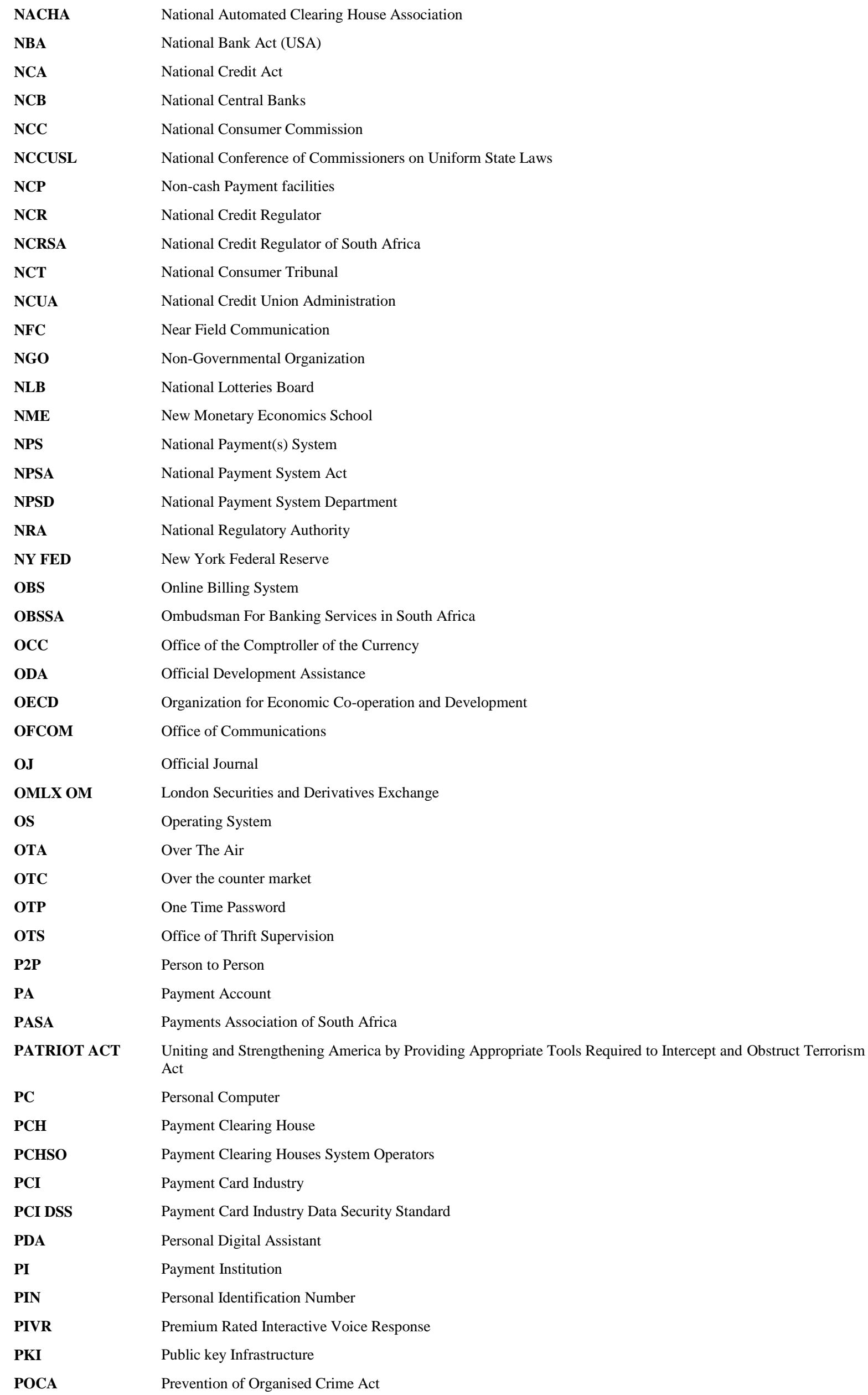




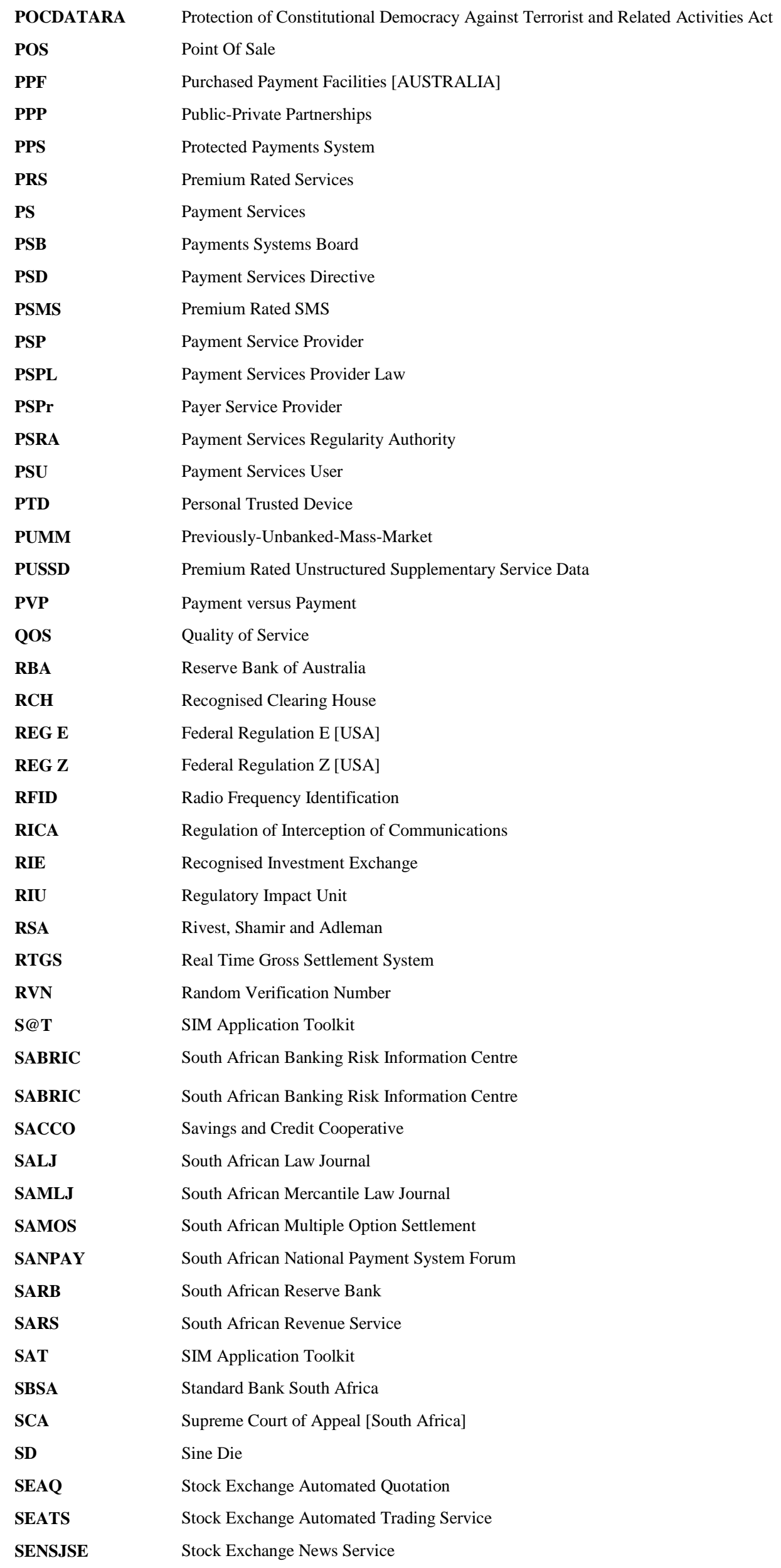


SEPA

SET

SETS

SFD

SIM

SIPS

SLRC

SME

SMME

SMS

SMSC

SO

SOV

sow

SP

SRB

SRO

SS7

SSA

SSAT

SSL

SSL

STK

STRATE

SVA

SVC

SVP

SVRPS

SWIFT

SWIM

T\&C

TAN

TCP/IP

TCPIC

TELCO

TF

THRHR

TIB

TILA

TIO

TISSC

TMLD

TN

TPCA

TPPP

TRANSL

TSP

TSP

UCC
Single Euro Payments Area

Secure Electronic Transactions

Stock Exchange Electronic Trading Service

Settlement Finality Directive

Subscriber Identity Module

Systemically Important Payment Systems

Stock Lending and Repo Committee

Small and Medium Enterprises

Small, Micro and Medium Enterprises

Short Message Service

Short Message Service Centre

System Operator

Store(s) of Value

Store of Wealth

Service Provider

European Systemic Risk Board

Self-regulatory organizations

Signalling System 7

Sub Saharan Africa

Securities Services Act of 2004

Secure Sockets Layer

Secure Sockets Layer

SIM Toolkit

Share Transactions Totally Electronic

Stored Value Account

Stored Value Card

Stored Value Product

Small Value Retail Payments Systems

Society for Worldwide Interbank Financial Telecommunication

The SIM and WIM smartcard

Terms and Conditions

Transaction Authentication Number

Transmission Control Protocol/Internet Protocol

Telecommunications Consumer Protections Industry Code

Telecommunications firm

Terrorist Financing

Tydskrif vir Hedendaagse Romeins Hollandse Reg

Truth-in-Billing

Truth in Lending Act (USA)

Telecommunications Industry Ombudsman

Telephone Information Services Standards Council

Third Money Laundering Directive

Trillion

Trust Property Control Act

Third Party Payment Providers

Translation

Technology Service Providers

Technology Service Provider

Uniform Commercial Code 


\begin{tabular}{|c|c|}
\hline UCITA & Uniform Computer Information Transactions Act \\
\hline UDAP & Unfair and Deceptive Acts and Practices \\
\hline UDAP & Unfair and Deceptive Acts and Practices \\
\hline UETA & Uniform Electronic Transactions Act \\
\hline UK & United Kingdom \\
\hline UI & User Interface \\
\hline UKMTA & UK Money Transmitters Association \\
\hline ULF & Unified Licensing Framework \\
\hline UMSA & Uniform Money Services Act (USA) \\
\hline UMTS & Universal Mobile Telecommunications System \\
\hline UNICTRAL & United Nations Commission on International Trade Law \\
\hline UOA & Unit Of Account \\
\hline URL & Uniform Resource Locator \\
\hline US\$ & United States Dollar \\
\hline USA & United States of America \\
\hline USC & United States Congress \\
\hline USRS & Uncertificated Securities Regulations \\
\hline USSC & United States Supreme Court \\
\hline USSD & Unstructured Supplementary Service Data \\
\hline VAS & Value Added Services \\
\hline VPSPL & Vodacom Payment Services (Proprietary) Limited \\
\hline WAN & Wide Area Network \\
\hline WAP & Wireless Application Protocol \\
\hline WASP & Wireless Application Service Provider \\
\hline WASPA & Wireless Application Service Provider's Association \\
\hline WEF & World Economic Forum \\
\hline WIFI & Wireless Fidelity [See also Wireless LAN[ \\
\hline WIG & Wireless Internet Gateway \\
\hline WIM & WAP Identity Module \\
\hline WIMAX & Worldwide Interoperability for Microwave Access \\
\hline WLAN & Wireless Local Access Network [See WiFi] \\
\hline WML & Wireless Markup Language \\
\hline WPKI & Wireless Public Key Infrastructure \\
\hline WTLS & Wireless Transport Layer Security Protocol \\
\hline WWW & World Wide Web \\
\hline ZAR & South African Rand \\
\hline
\end{tabular}


ANNEX 1

\section{MFS COMMERCIAL EXAMPLES}

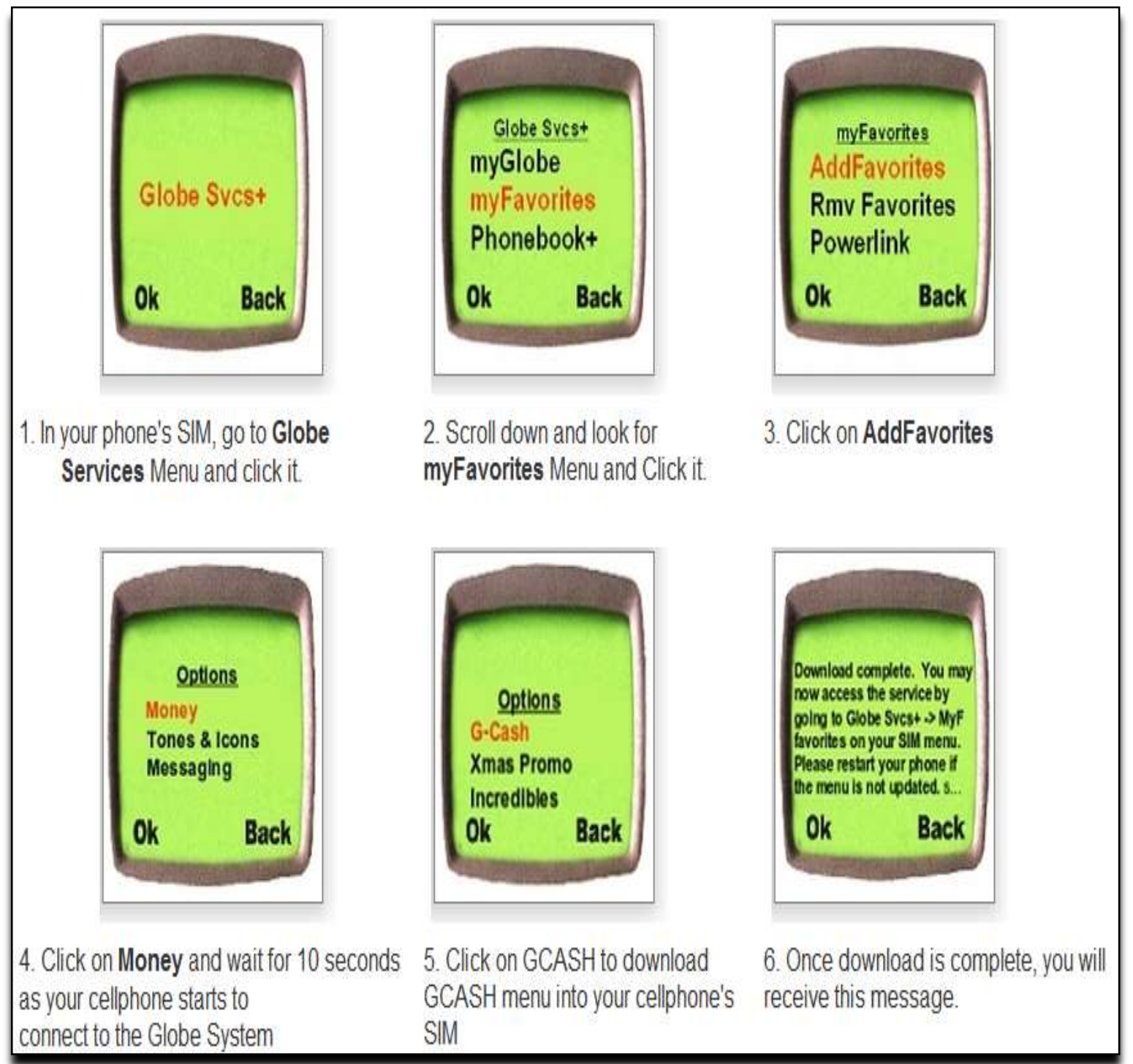

Exhibit A: Method of obtaining a new menu system for a MFS transaction menu using Other-The-Air means. Example is from G-Cash in the Philippines. ${ }^{1}$

\footnotetext{
${ }^{1}$ Mobile Phone Banking and Mobile Commerce Initiative (2011) How do I download the GCASH Menu? Available at http://goo.gl/xUa7O
} 


\section{How to register}

You can register at any m-pesa Ouflet, free. Take your cellphone and ID book and you'll be ready to start using m-pesa in instantly.

Step 1: The Assistant will help you complete a short form

Step 2: The Assistant will register your details on their device

Step 3: You'll receive an SMS with the start PIN

Step 4: Dial *130*7372\#, press the call button to get the m-pesa start up screen and activate your m-pesa Account. Change the start PIN with your own, secret personal 4-digit PIN
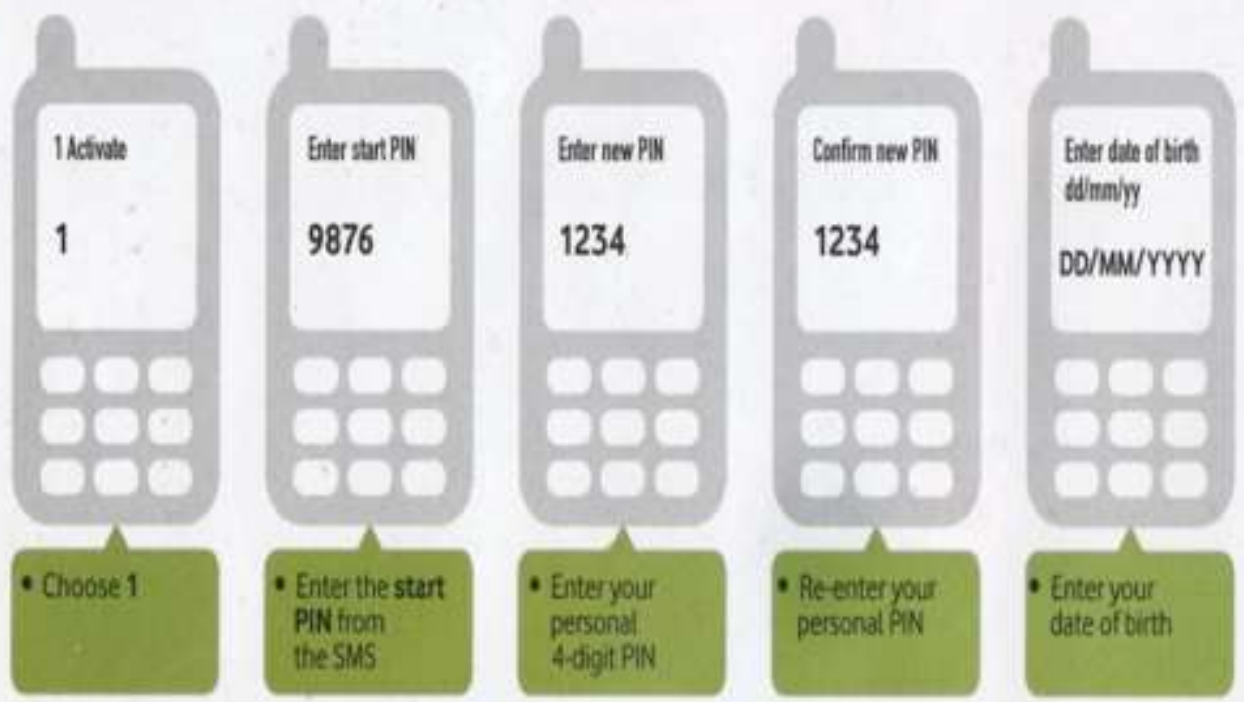

When your m-pesa Account is ready to use, you'll receive an SMS with a secret word. Keep this safe and ready to use when calling customer care. Always use your personal PIN with m-pesa.

Exhibit B: Registration for the use of the "M-pesa"-branded MFS system operated by Vodacom South Africa and Nedbank. ${ }^{2}$ 


\section{Sending money to another person}

Sending money is simple! You can send money to any cellphone user, even if they're not registered for m-pesa, or are on a different mobile network. Dial ${ }^{*} 130 * 7372 \#$ and press the call button to get to the m-pesa menu:
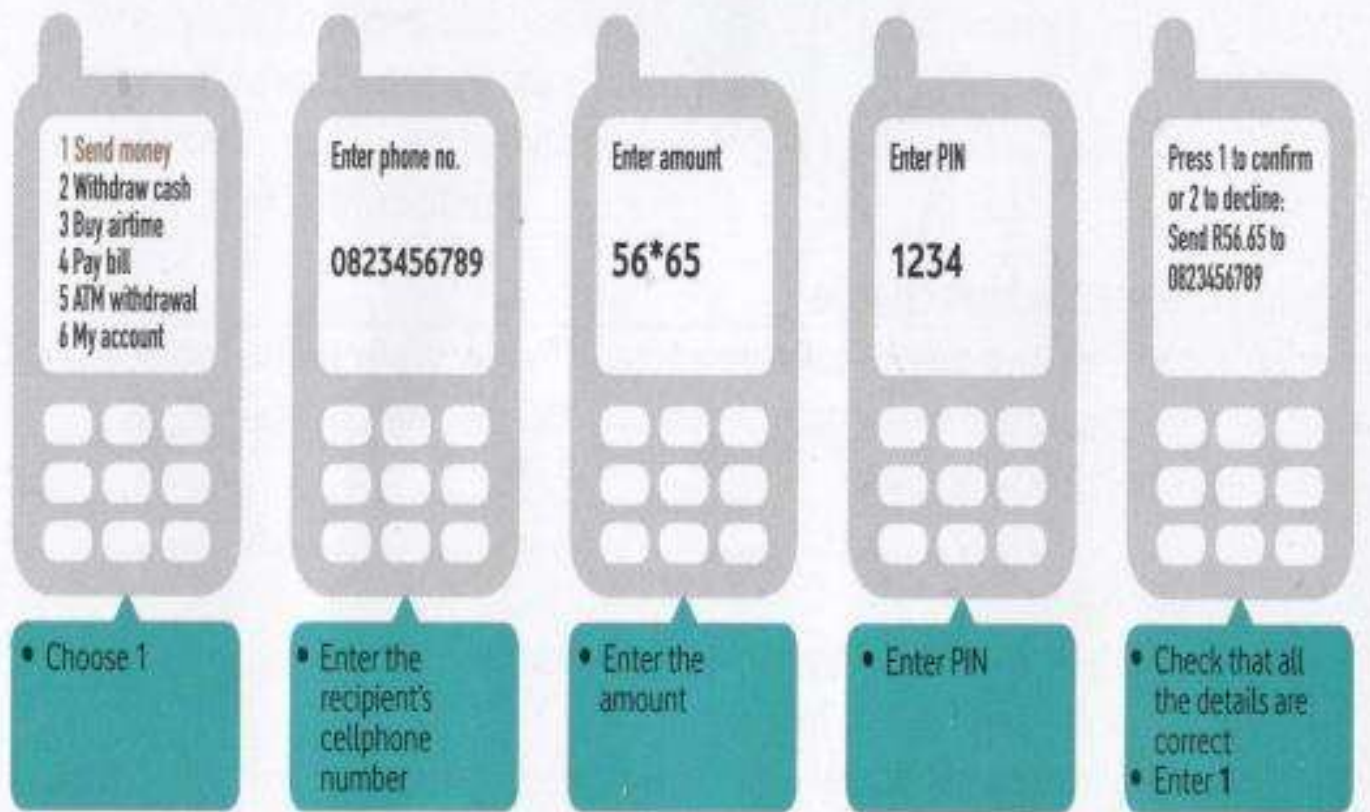

To send Rands + Cents, use the ${ }^{*}$ key as the decimal point, e.g. for R56.65 enter $56^{*} 65$. Make sure you enter the right celllphone number.

You'll both receive an SMS confirming the transfer and your new m-pesa Balance.

Exhibit C: Guide to sending Cash as a remittance to a third party using the " $\mathrm{m}$-pesa"-branded MFS system operated by Vodacom South Africa and licensed bank Nedbank. ${ }^{3}$ 


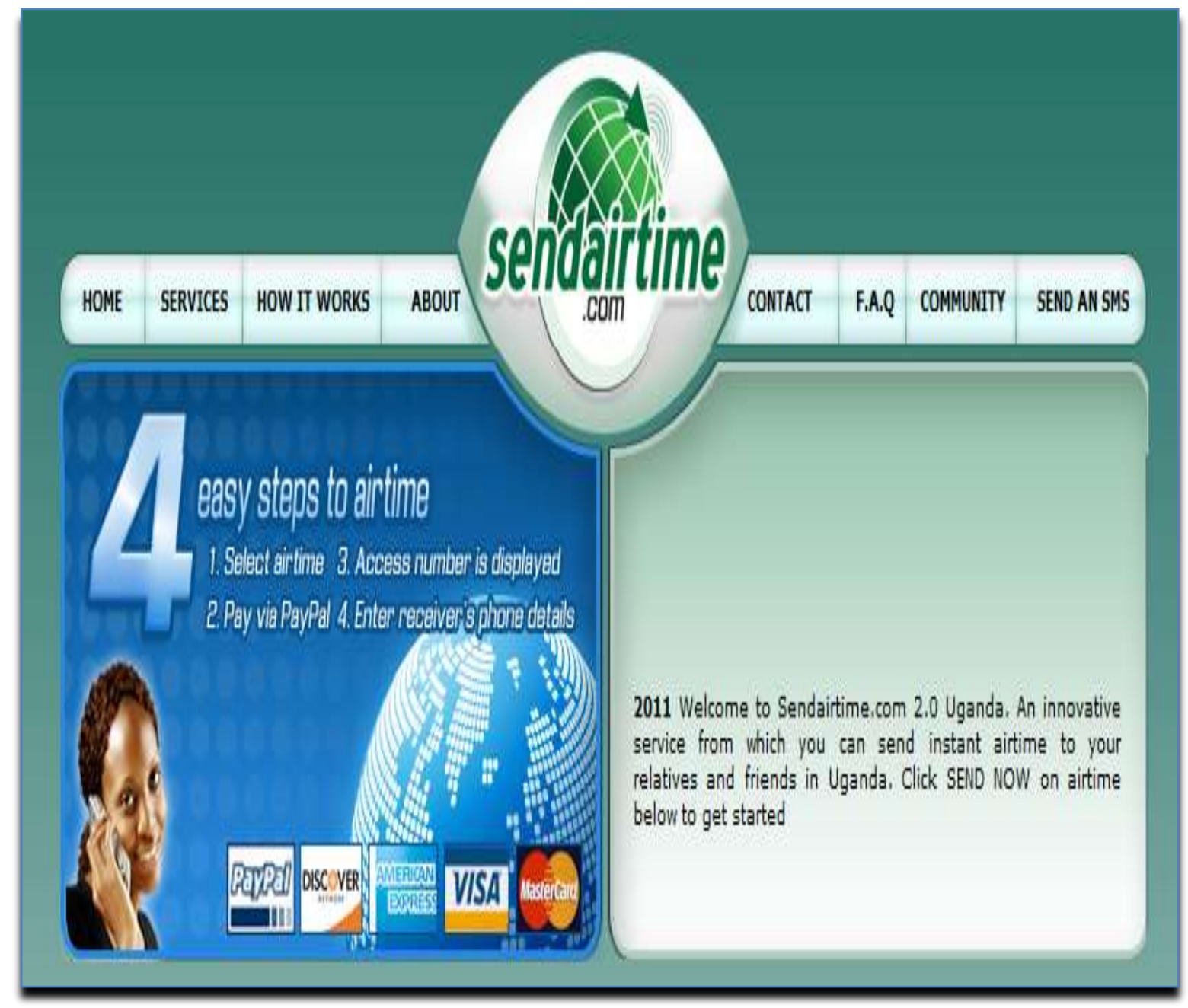

Exhibit D: Facility for buying airtime internationally with a credit card, debit card or Paypal and sending that airtime value to a mobile phone user in Uganda via a system operated by sendairtime.com. ${ }^{4}$ 


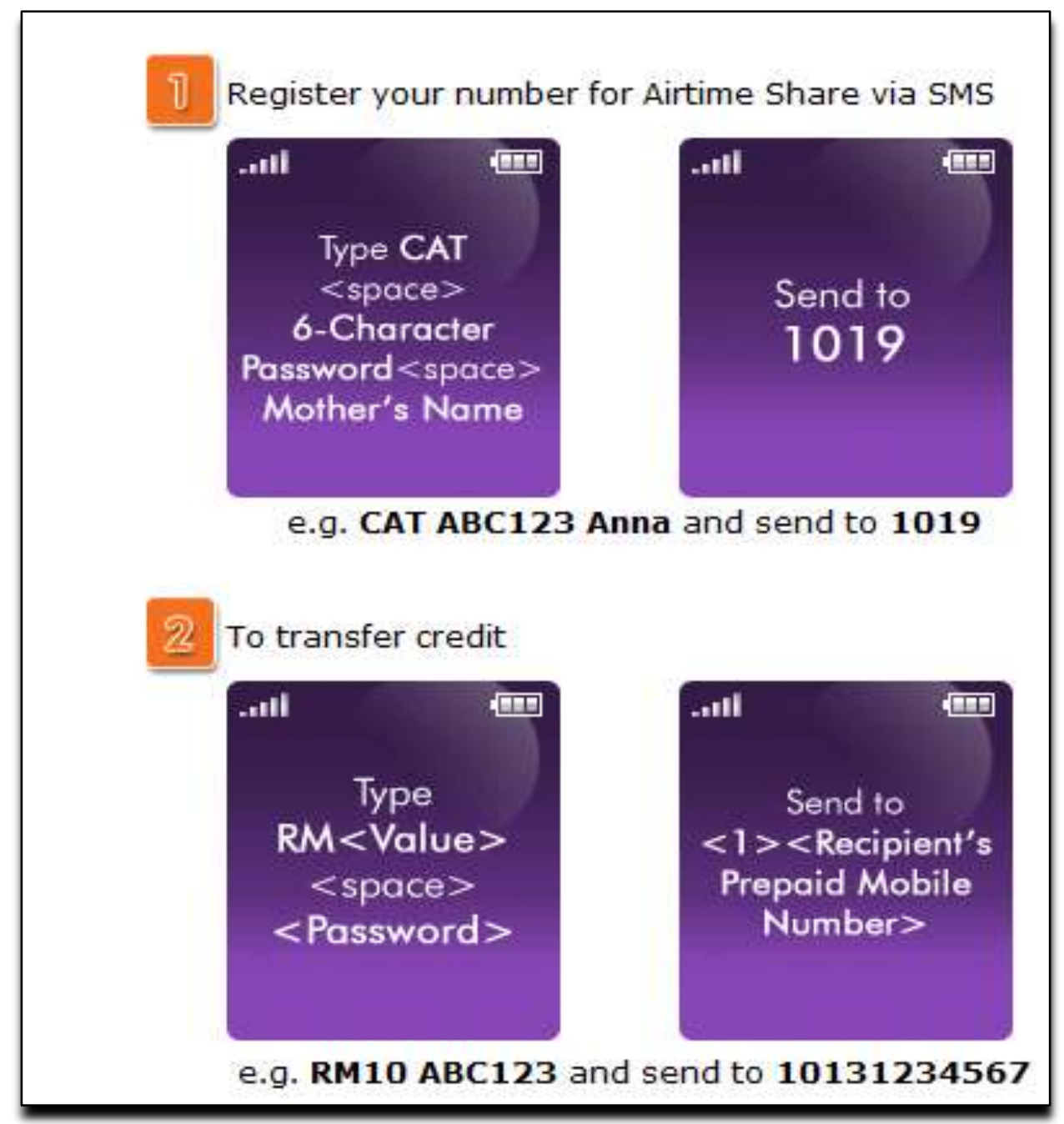

Exhibit E: User instructions for sending airtime via SMS from one person to another using the mobile operator Cellcom. ${ }^{5}$ 


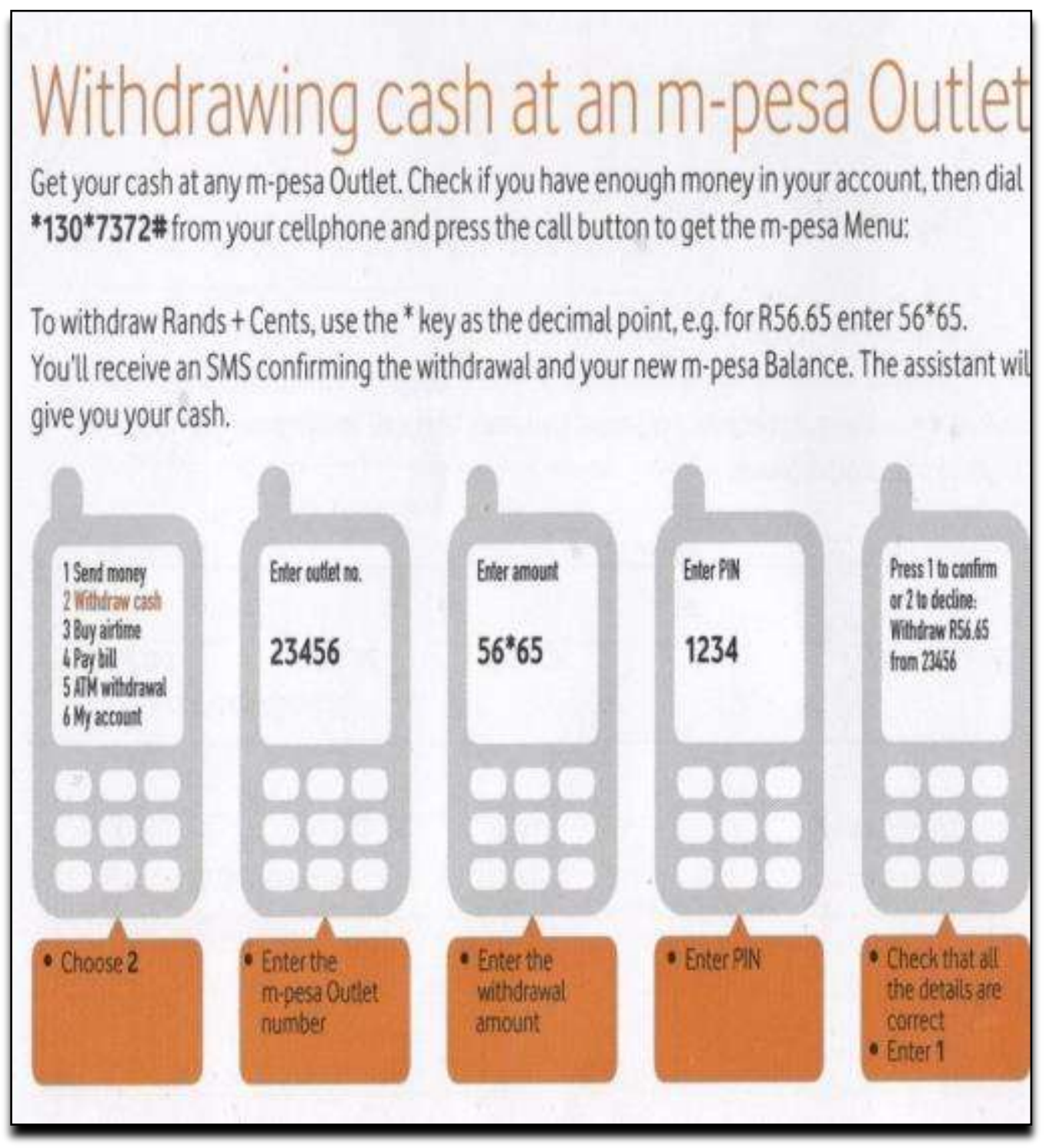

Exhibit F: Guide to withdrawing cash from a (human) Outlet linked to the "m-pesa"-branded MFS system operated by Vodacom South Africa and Nedbank. ${ }^{6}$ 


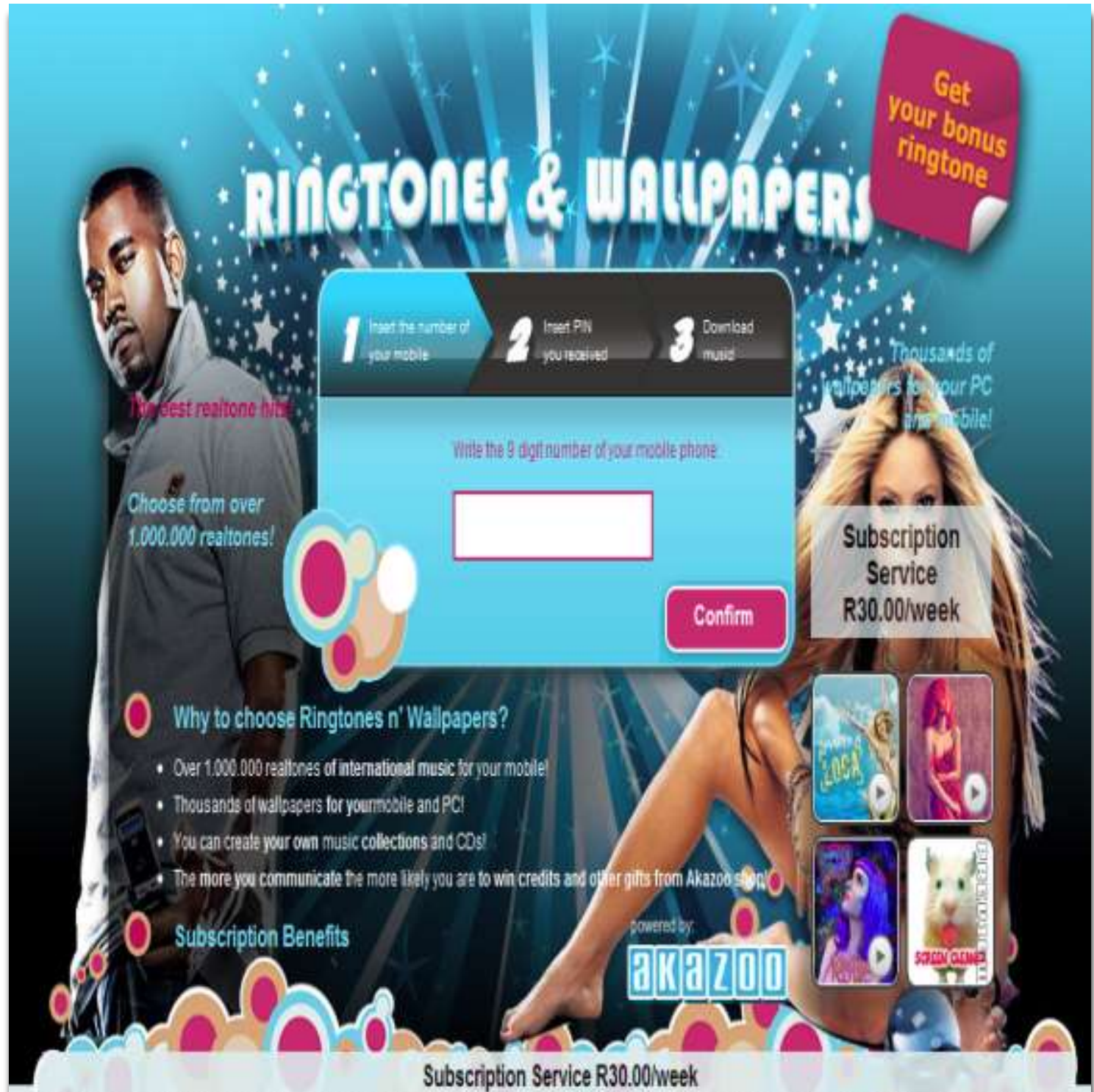

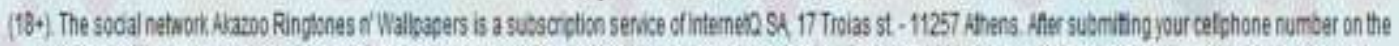

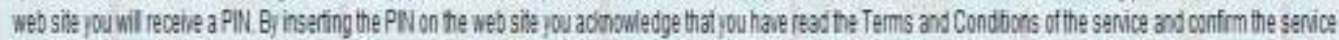

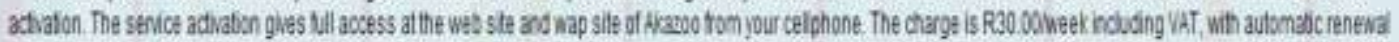

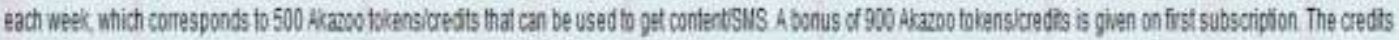

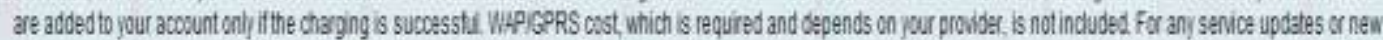

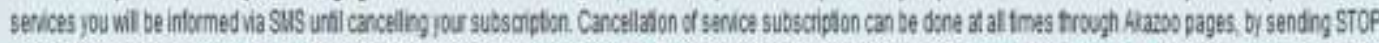

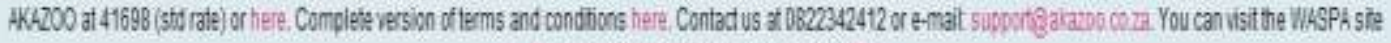

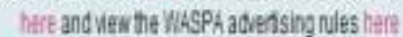

Exhibit G: Example of a South African WASP service selling VAS access to mobile phone ringtones and wallpapers using the subscription services method of billing mobile subscribers. ${ }^{7}$ Billing and payment for this service is done via mobile the airtime-based SOV. 


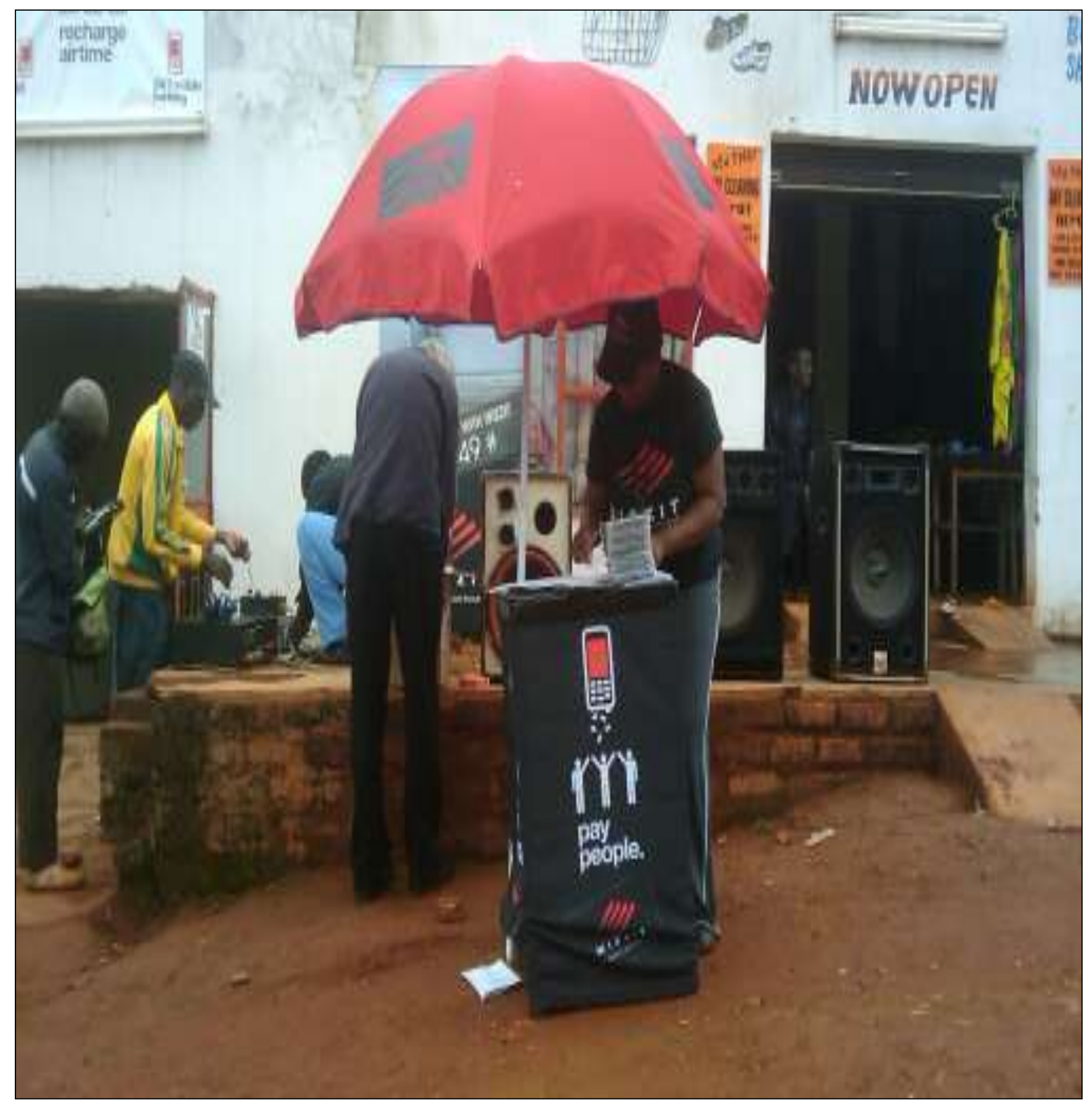

Exhibit H: Wizzit agents - 'Wizzkids' - providing outdoor 'branchless banking' services in a South African township. ${ }^{8}$ 


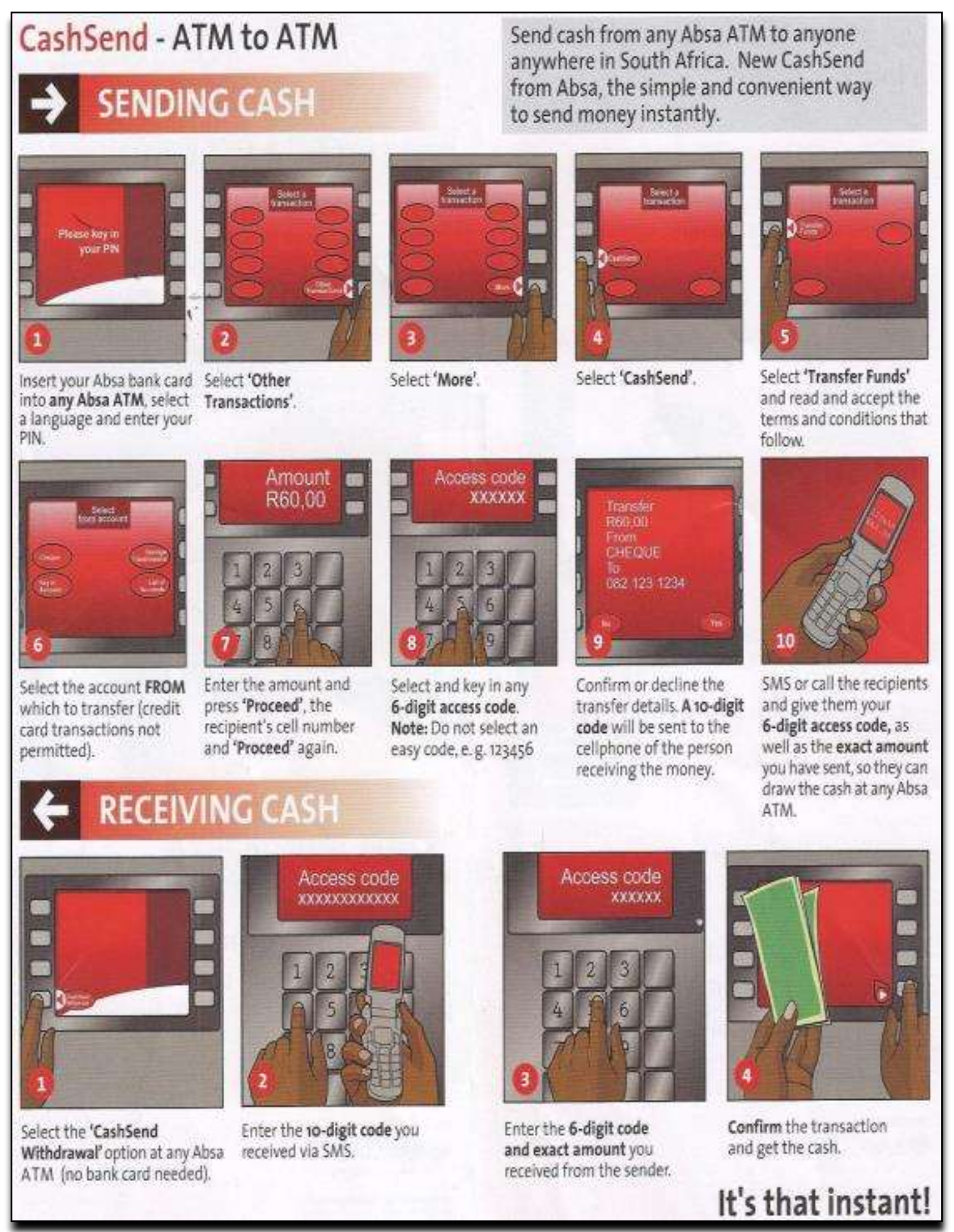

Exhibit I: Schematic of the 'CashSend' method of sending value via an ABSA ATM machine to be cashed out at an ABSA ATM by a non-customer recipient who has a mobile phone. ${ }^{9}$ 


\section{Brighter days with maPESf and KPLC}

How to Pay your Electricity Bill with M-PESA

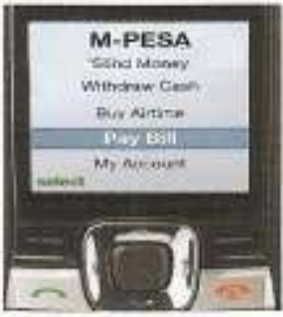

1. Select Pay Bar from

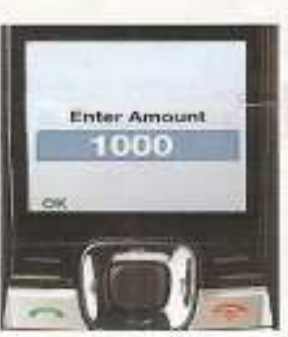

4. Erter the amount yesi wiah and Kahe 35,000 ).

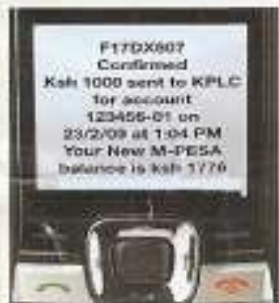

7 . You will moinga a

* contimation sms from

W-PEsA immodintey.

rour kPY o nocount will to

or more detuiles yisit amy $M$

servious outlet countrywide.

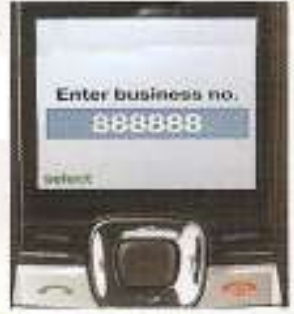

2. Enter the KFLL bumirien number. 8 sagse

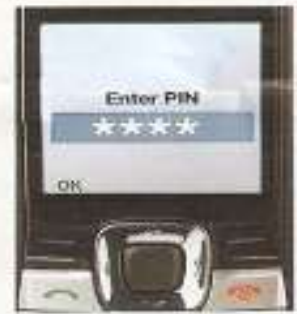

5. Enter your M-PESA per.

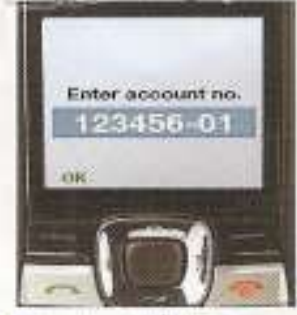

3. Enter the full KPLE mocoun number the

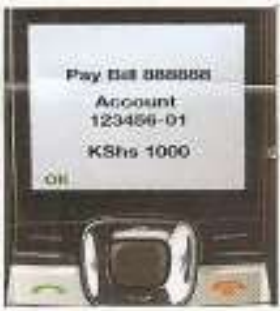

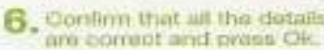

- Sorvice arvaliable to totiatored M-PESA Customero.

- If you sno registared with M-PEEA but do not have the "Pay Bitr, select 'My Actount' In your M-PEsA manta, peloct "Updete Meritu' and the now menu will be sent to your phane at no covs.

- Eneure that yous M-PEsa batance is zutficient to eover

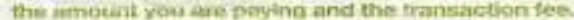

- Pay your hill at least 2 clays befoie your pagment due datis.

- Satarioorn Cintomer Gami Call line 234 FREE from your Eafaricom line.

KPLC Cubtomer Carse: B711 031000/ 07322 111000 0203201000 teharanable eallsa.

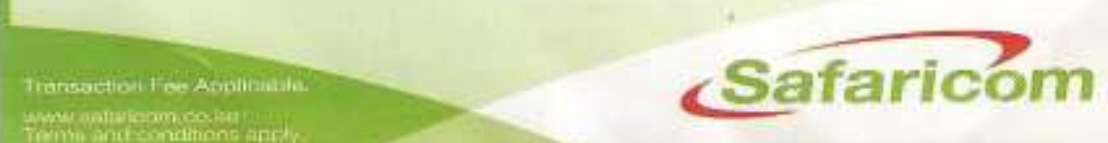

Exhibit J: $\quad$ Schematic of paying an electricity bill using M-pesa in Kenya 


\section{ANNEX 2}

THESIS SUMMARY ${ }^{1}$

\section{A: PROBLEM STATEMENT 1 - Conclusions \& Recommendation}

\section{PROBLEM STATEMENT 1}

Whether the MNO airtime-based SOV, fiat and other private currencies used in closedloop MFS systems legally amount to 'money'?'

\begin{tabular}{|c|} 
CONCLUSIONS \\
\hline $\begin{array}{c}\text { The Claim School economic view of money is better suited than the Orthodox School as the } \\
\text { theoretical pivot in designating a legal basis for money, particularly in relation to assimilating } \\
\text { and understanding intangible SOVs such as those used in MFS. }\end{array}$ \\
\hline Applying legal precepts of money to new non-fiat SVP and MFS systems indicates that some \\
species do not (legally) amount to money. ${ }^{4}$
\end{tabular}

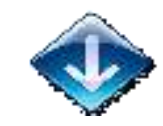

RECOMMENDATION 1

There is a need for a reassessment of money in law, and for the use of the Claim School economic view of money in a legal definition of money. ${ }^{5}$

\footnotetext{
${ }^{1}$ Please note that while each of the 10 Recommendations is numbered, they are not all presented in numerical order but are matched to the relevant problem statement. Some Conclusions make also relate to other problem statements.

${ }^{2}$ See Problem Statement 1 outlined in ch 1, s1.8.1 on MFS and Money

${ }^{3}$ For Conclusions thereto, see ch 3, s3.13 Summary and Conclusions; and ch 13, s13.9 Summary and Conclusions, ch 14, s14.5.4.7 on Reassessment of Money in Law; and specifically ch 14, s14.5.4.7.1 on Use of the Claim School.

${ }^{4}$ Ibid

${ }^{5}$ For recommendations thereto, see ch 14, s14.9.1 on Recommendation: Money in Law (Recommendation 1)
} 


\section{B: $\quad$ PROBLEM STATEMENT 2 - Conclusions \& Recommendation}

\section{PROBLEM STATEMENT 2}

What is the nature of a deposit, and how does this impact on determining if those engaged in MFS are 'deposit-taking' entities?'

CONCLUSIONS
The nature of a deposit is evolving from the strictures of common law conceptions to a more
subjective and transactional basis, such that the acceptance and use of funds as a transient SOV
for primarily transactional payment purposes - and not intermediation - suggests that funds in
these SOVs should not necessarily amount to a deposit. ${ }^{7}$

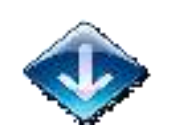

\section{RECOMMENDATION 2}

There is a need for a reassessment of the 'deposit concept' generally, and specifically as a metric of the 'business of banking, 8

\footnotetext{
${ }^{6}$ See Problem Statement 2 outlined in ch 1, s1.8.2 on MFS and the Nature of Banking and Deposits

${ }^{7}$ For Conclusions thereto, see ch 4, s4.8.6 on Summary and Conclusions; ch 14, s14.6.2 on the Nature of Banking; ch 14, s14.6.3 on the Role of the Deposit in Banking; ch 14, s14.6.7 on Conclusion: Deposit; ch 14, s14.6.8 on Conclusions: Business of Banking

${ }^{8}$ For recommendations thereto, ch 14, s14.9.2 on Recommendations: Nature of Banking and Deposits: (Recommendations 2 and 3)
} 


\section{C: $\quad$ PROBLEM STATEMENT 3 - Conclusions \& Recommendation}

\section{PROBLEM STATEMENT 3}

Is the nature of the 'business of banking', and its traditional trigger by a 'deposit' challenged through the emergence of MFS?'

\section{CONCLUSIONS}

The 'business of banking' is metamorphosing from dated common-law criteria, in that the acceptance of funds used primarily for transactional payment purposes should not necessarily amount to a deposit. This may mean that most MFS activities would not amount to the "business

of banking' and hence should not be subject to the whole gamut of domestic banking regulations. ${ }^{10}$

\section{RECOMMENDATION 3}

The acceptance of funds used primarily for transactional payment purposes should not necessarily amount to a deposit. ${ }^{11}$

\footnotetext{
${ }^{9}$ See Problem Statement 3 outlined in ch 1, s1.8.2 on MFS and the Nature of Banking and Deposits

${ }^{10}$ For Conclusions thereto, see ch 4, s4.8.6 on Summary and Conclusions; ch 14, s14.6.2 on the Nature of Banking; ch 14, s14.6.3 on the Role of the Deposit in Banking ; and ch 14, s14.6.7 on Conclusion: Deposit; ch 14, s14.6.8 on Conclusions: Business of Banking;

${ }^{11}$ For recommendations thereto, see ch 14, s14.9.2 on Recommendations: Nature of Banking and Deposits: (Recommendations 2 and 3 )
} 
D: $\quad$ PROBLEM STATEMENT 4 - Conclusions \& Recommendations

\section{PROBLEM STATEMENT 4}

Whether existing general and statutory categorizations and licensing of entities involved in taking value from the public are appropriate, and if so, whether a new categorization or licensing regime should be considered? ${ }^{12}$

A new statutory 'bank-lite' regime - a proposed Payment Service/s Provider Law (PSPL) -
reflecting the emerging stratified nature of banking, and acceptance and use of user funds may be
more appropriate to deal with the emergence of non-bank actors engaged in MFS. ${ }^{13}$

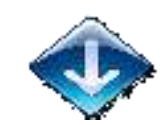

RECOMMENDATION 4

There is a need for a new regulatory regime that focuses on, and licenses, putative Payment Service Providers. $^{14}$

\section{RECOMMENDATION 5}

Mandate use of trust accounts for providers engaged in MFS so as to ring-fence existing business interests and for systemic risk considerations. ${ }^{15}$

\section{RECOMMENDATION 6}

Allow access by licensed PSPs to the SA NPS. ${ }^{16}$

\footnotetext{
${ }^{12}$ See Problem Statement 4 outlined in ch 1, s1.8.3 on the Role and Effect of and Payment Regulation

${ }^{13}$ For Conclusions thereto, see ch 12, s12.12 on South Africa: Chapter General Summary and Conclusions; ch 7, s7.6 Conclusions in relation to the use of trust accounts For safety and soundness criteria; ch 14, s14.6.5 on Access to the South African National Payment System; and ch 14, s14.6.8 Conclusion: Business of Banking.

${ }^{14}$ For recommendations thereto, see ch 14, s14.9.3 on Recommendations: Payment Providers (Recommendation 4).

${ }^{15}$ For recommendations thereto, see ch 14, s14.9.4 Recommendations: Use of Trust Accounts (Recommendation 5).

${ }^{16}$ For recommendations thereto, see ch 14, s14.9.5 Recommendations: Access to NPS (Recommendation 6)
} 


\section{E: $\quad$ PROBLEM STATEMENT 5 - Conclusions \& Recommendation}

\section{PROBLEM STATEMENT 5}

Whether the disembodied nature of MFS and its coincident transaction types challenge the notion in South African law of a payment needing to be 'bilateral'. 17

\section{CONCLUSIONS}

The need at common law for a payment to be 'bilateral' is buffeted by the unilateral and multilateral mechanism of value transfer employed in MFS. ${ }^{18}$

RECOMMENDATION 9
There is a need to revisit the need in South African law for a payment needing to be bilateral in the
light of, for example, remittances and donations which do not necessarily require the cooperation of
the recipient of the payment.

\footnotetext{
${ }^{17}$ See Problem Statement 5 outlined in ch 1, s1.8.4 on the Nature of the Payment in MFS

${ }^{18}$ For Conclusions thereto, see ch 7, s7.5 Conclusions; ch 14, s14.7.9 on Revisiting Problem Statement 5; and ch 14, s14.7.9 on Conclusion: Payments.

${ }^{19}$ For recommendations thereto, see ch 14, s14.9.8 on Recommendations: Payment in Law (Recommendation 9)
} 


\section{F: $\quad$ PROBLEM STATEMENT 6 - Conclusions \& Recommendations}

\section{PROBLEM STATEMENT 6}

What rights and redress, if any, are available to retail users of MFS and retail payments generally, and are they adequate? ${ }^{20}$

\section{(4)}

CONCLUSIONS

Those at the BOP may be affected by informational asymmetries that impact their ability to avoid risk in case of mistake, fraud and duress in a payment transaction. Potential remedies by common law condictiones are too constrained to a narrow set of necessary circumstances to be of any general use. The consumer protections in stratified and proportional retail payments regimes like the EU's EMD2 and the PSD are ideally suited to MFS, and could be employed in SA. A financial regulator similar to the CFPB in the US should be established under this regime. ${ }^{21}$

\section{RECOMMENDATION 7}

There is a need for a new regulatory regime that codifies consumer and service provider rights in retail payments. ${ }^{22}$

\section{RECOMMENDATION 8}

There is a need for a dedicated authority to regulate consumer payments. ${ }^{23}$

\footnotetext{
${ }^{20}$ See Problem Statement 6 outlined in ch 1, s1.8.5 on Consumer Rights and Protections in MFS

${ }^{21}$ For Conclusions thereto, see ch 7, s7.5 Conclusions; ch 12, s12.11 on South Africa: Chapter General Summary And Conclusions; and ch 14, s14.7.12 Conclusion: Payment Consumer Protection

${ }^{22}$ For recommendations thereto, seech 14, s14.9.6 Payments Law (Recommendation 7)

${ }^{23}$ For recommendations thereto, see ch 14, s14.9.7 Payment Regulatory Agency (Recommendation 8)
} 


\section{G: $\quad$ PROBLEM STATEMENT 7 - Conclusions \& Recommendations}

\section{PROBLEM STATEMENT 7}

How do regulators militate the 'dilemma' of promoting Financial Inclusion while protecting financial integrity in regard to MFS, and how does it manifest in regulatory domains relating to telecommunications, e-commerce, consumer protection and AML ${ }^{24}$

\section{CONCLUSIONS}

The chimerical nature of MFS may give rise to disproportionate regulation that hinders the growth of financial inclusion by increasing the possibility of regulatory arbitrage, emphasising a need for specific regulations for, and a regulator that has oversight of, retail payments. ${ }^{25}$

In balancing financial inclusion versus financial integrity, the regulatory and policy focus, should be on facilitating payments and creating a stratified and proportionate enabling regime. ${ }^{26}$

A new statutory 'bank-lite' regime reflecting the emerging stratified nature of banking, and acceptance and use of user funds may be more appropriate to deal with the emergence of non-bank actors engaged in MFS. ${ }^{27}$

\section{RECOMMENDATION 4}

There is a need for a new regulatory regime that focuses on, and licenses, putative Payment Service Providers. ${ }^{28}$

\section{RECOMMENDATION 10}

Changes are required to the Electronic Communications and Transactions Act 28 of 2002 to ensure true technology neutrality. ${ }^{29}$

\footnotetext{
${ }^{24}$ See Problem Statement 7 outlined in ch 1, s1.8.6 on the Role and Effect of Additional Regulatory Oversight of MFS

${ }^{25}$ For Conclusions thereto, see ch 8, s8.9 Conclusions; and ch 14, s14.8.27 Conclusion

${ }^{26}$ For recommendations thereto, see ch 14, s14.9.6 Payments Law (Recommendation 7)

${ }^{27}$ Ibid. For further findings and recommendations thereto, ch 14, s14.9.3 on Payment Service Providers, section A, Recommendation 4; ch 14, s14.9.4 on Use of Trust Accounts, section A, Recommendation 5; and ch 14, s14.9.5 Access to the National Payment System, section A, Recommendation 6.

${ }^{28}$ For recommendations thereto, see ch 14, s14.9.3 on Recommendations: Payment Providers (Recommendation 4).

${ }^{29}$ For recommendations thereto, see ch 14, s14.9.9 on changes to the Electronic Communications and Transactions Act 25 of 2002 (Recommendation 10)
} 
Annex 2: Thesis Summary | 712

BLANK 


\section{TABLE OF LAWS AND REGULATIONS}

\section{A AFGHANISTAN}

\section{$\underline{\text { Regulations }}$}

Islamic Republic of Afghanistan, Da Afghanistan Bank Article (s.d.) 'Article Two: Money Service Providers Regulation', available at http://goo.gl/bLUaG.

\section{B AUSTRALIA}

Trade Practices Amendment (Australian Consumer Law) Act (No 2) 2010

\section{CANADA}

Personal Property Security Act [RSBC 1996] Chapter 359

Uniform Electronic Commerce Act of 2000

\section{EUROPEAN UNION}

\section{$\underline{\text { Directives }}$}

Directive 83/189/EEC on Technical Standards

Directive 93/13/EEC on Unfair Contract Terms

Directive 95/46/EC on Data Protection

Directive 97/5/EC on Cross-border Credit Transfers

Directive 97/7/EC on the Protection of Consumers in Respect of Distance Contracts

Directive 98/26/EC on Settlement Finality in Payment and Securities Settlement Systems

Directive 2000/28/EC on Credit Institutions

Directive 2000/12/EC on the 'Taking up and Pursuit of the Business of Credit Institutions'

Directive 2000/31/EC on Certain Legal Aspects of Information Society Services

Directive 2000/46/EC on the Taking up, Pursuit of and Prudential Supervision of the Business of Electronic Money Institutions

Directive 2001/24/EC on the Reorganization and Winding up of Credit Institutions

Directive 2002/19/EC on Access t Interconnection of, Electronic Communications Networks and Associated Facilities

Directive 2002/20/EC on the Authorisation of Electronic Communications Networks and Service

Directive 2002/21/EC on a Common Regulatory Framework for Electronic Communications Networks and Services 
Directive 2002/22/EC on Universal Service and Users' Rights relating to Electronic Communications Networks and Services

Directive 2002/47/EC on Financial Collateral Arrangements

Directive 2002/58/EC on the Processing of Personal Data and the protection of Privacy in the Electronic Communications Sector

Directive 2002/65/EC on Distance Marketing of Financial Services

Directive 2002/77/EC on Competition In The Markets For Electronic Communication Networks And Services.

Directive 2005/29/EC on Unfair Commercial Practices Directive

Directive 2005/60/EC on the Prevention of the Use of the Financial System for the Purpose of Money Laundering and Terrorist Financing

Directives 2006/48/EC on Capital Requirements

Directive 2006/48/EC on the Taking up and Pursuit of the Business of Credit Institutions (recast)

Directive 2006/49/EC on the Capital Adequacy of Investment Firms and Credit Institutions (recast)

Directive 2007/64/EC on Payment Services in the Internal Market

Directive 2009/110/EC On The Taking Up, Pursuit And Prudential Supervision Of The Business Of Electronic Money Institutions

Directive 2009/111/EC amending Directives 2006/48/EC, 2006/49/EC and 2007/64/EC

Treaty of Rome (1957)

Treaty on the European Union (1993) ['Maastricht']

Treaty of Lisbon (2007), available at http://goo.gl/sRtbV

\section{Decisions, Recommendations and Regulations}

\section{Decisions}

Council Resolution of 25 May 2000 on a Community-wide Network of National Bodies for the Extra-judicial Settlement of Consumer Disputes Official Journal C 155 of 6 June 2000

Decision No 1926/2006/EC on a programme of Community Action in the Field of Consumer Policy for the Years 2007-2013 as of 31 December 2006

Decision 2009/72/EC on setting up a Payment Systems Market Expert Group (PSMEG)

\section{Recommendations}

Recommendation 97/489/EC on Transactions by Electronic Payment Instruments

\section{Regulations}

Regulation (EC) No 2560/2001 on Cross-border Payments in Euro

Regulation (EC) No 1781/2006 of The European Parliament and of The Council of 15 November 2006 on Information on the Payer Accompanying Transfers of Funds 
Regulation (EC) No 924/2009 on Cross-border Payments in the Community

Regulation (EU) No 260/2012 on Technical and Business Requirements for Credit Transfers and Direct Debits in Euro

\section{E KAZAKSTAN}

Law of the Republic of Kazakhstan 'On Payments and Money Transfers’ of 29 June 1998

\section{F KENYA}

The Banking Act 1989, Chapter 488

Central Bank Act 1966, Chapter 481

Kenya Communications Act 2 of 1998

Kenya Information and Communications Act 2 of 1998.

Kenya Communications (Amendment) Act 1 of 2009

Proceeds of Crime and Anti-Money Laundering Act 9 of 2009

\section{$\underline{\text { Regulations }}$}

Central Bank of Kenya (2010) 'CBK/PG/15: Guidelines on Agent Banking'

Kenya Information and Communications (Tariff) Regulations, 2010

\section{G SINGAPORE}

Banking Act of Singapore (Cap 19)

\section{H SOUTH AFRICA}

\section{$\underline{\text { Laws }}$}

Alienation of Land Act 68 of 1981

Apportionment of Damages Act 34 of 1956

Banking Act 38 of 1942

Banks Act 23 of 1965

Banks Act 94 of 1990

Bills Of Exchange Act 34 Of 1964

Children's Act 38 of 2005

Collective Investment Schemes Control Act 45 of 2002 
Companies Act 61 of 1973

Companies Act 71 of 2008

Competition Act 89 of 1998

Constitution of the Republic of South Africa Act 1081996

Consumer Affairs (Unfair Business Practices) Act of 1988

Consumer Protection Act 68 of 2008

Co-operative Banks Act 40 of 2007

Co-operatives Act 14 of 2005.

Currency and Banking Act 31 of 1920

Currency and Exchanges Act 9 of 1933

Custody and Administration of Securities Act 85 of 1992

Electronic Communications Act 36 of 2005

Electronic Communications and Transaction Act 25 of 2002

Exchequer Act 66 of 1975

Films and Publications Act 65 of 1996

Financial Advisory and Intermediaries Services Act 37 of 2002

Financial Institutions (Investment of Funds) Act 39 of 1984

Financial Institutions (Protection of Funds) Act 28 of 2001

Financial Intelligence Centre Act 38 of 2001

Financial Markets Control Act 55 of 1989

Financial Services Board Act 97 of 1990

Financial Supervision of the Road Accident Fund Act 8 of 1993

Friendly Societies Act 25 of 1956

Independent Broadcasting Authority Act 153 of 1993

Insider Trading Act 135 of 1998

Inspection of Financial Institutions Act 80 of 1998

Long-term Insurance Act 52 of 1998

Merchandise Marks Act of 1941

Microfinance Act 19 of 2006

Mutual Banks Act 124 of 1993

National Credit Act 34 of 2005 
National Gambling Act 7 of 2004

National Gambling Amendment Act 1 of 2008

National Payment System Act 78 of 1998

National Payment System Amendment Act 22 of 2004

Ombud Schemes Act 37 of 2004

Pension Funds Act 24 of 1956

Prevention of Organised Crime Act 121 of 1998

Proceeds of Crime and Money Laundering (Prevention) Act

Promotion of Access to Information Act 2 of 2000

Protection of Constitutional Democracy against Terrorist and Related Activities Act 33 of 2004

Public Finance Management Act 1 of 1999

Public Service Act 30 of 1994

Public Service Act Proclamation 103 of 1994

Regulation of Interception of Communications and Provision of Communication-related Information Act 70 of 2002

Regulation of Interception of Communications and Provision of Communication-Related Information Amendment Act 48 of 2008

Sales and Service Matters Act of 1964

Price Control Act of 1964

Securities Services Act 36 of 2004

Short-term Insurance Act 53 of 1998

Small Claims Court Act 61 of 1984

South African Postbank Limited Act 9 of 2010

South African Reserve Bank Act 90 of 1989

Stock Exchanges Control Act 1 of 1985

Supervision of the Financial Institutions Rationalisation Act 32 of 1996

Trade Practices Act of 1976

Telecommunications Act 103 of 1996

Trust Property Control Act 57 OF 1988

\section{$\underline{\text { Regulations }}$}

Regulations 
Co-Operative Banks Act Supervisors' Rules, Government Gazette, No 32860, 12 January 2010, available at http://goo.gl/zslse

Exchange Control Regulations as promulgated by Government Notice R1111 of 1 December 1961 and amended up to Government Notice No R9 in Government Gazette, No 33926, of 14 January 2011

Government Gazette No 34180 on Consumer Protection Act (68/2008)

Regulations issued 1 April 2011.

Government Notice R1112 of 1 December 1961

Government Notice R663 in Government Gazette, No 31153 of 17 June 2008

ICASA in Notice 1740 of 2007 published in Government Gazette No 30553, 7 December 2007

Microfinance (Categorization of Deposit-Taking Microfinance Institutions) Regulations, 2008, available at http://goo.gl/usFVB.

National Treasury Co-Operative Banks Act, 2007: Regulations in Terms of Section 86, Government Gazette, No 32357, 1 July 2009, available at http://goo.gl/O0te4

Notice R1353 of 2004, published in Government Gazette No 27011, 19 November 2004, available at http://goo.gl/C45CK

Notice R1354 of 2004, published in Government Gazette No 27011, 19 November 2004, available at http://goo.gl/C45CK

Notice 211 Of 2009 National Gambling Act (7/2004): Interactive Gambling Regulations: For Written Comments in Government Gazette, no 31956.

Notice 272 of 2008 published in Government Gazette No 30792, 25 February 2008, available at http://goo.gl/6nvXe.

Notice 272 of 2008 published in Government Gazette No 30792, 25 February 2008, available at http://goo.gl/6nvXe.

SA Government Gazette No 33621, 1110-2010, vol 544

\section{SARB Circulars, Directives, Guidance Notes \& Position Papers}

South African Reserve Bank Circulars

South African Reserve Bank (2004) 'BSD Circular 14/2004: Outsourcing of Functions within Banks', available at http://goo.gl/wB4vN.

South African Reserve Bank (2010) Exchange Control Circular No. 11/2010, available at http://goo.gl/4icso

\section{South African Reserve Bank Directives}

South African Reserve Bank (2007) 'Directive 2/2007 - Directive for Conduct within the National Payment System in Respect of System Operators', available at http://goo.gl/DxPcT.

\section{South African Reserve Bank Guidance Note}

South African Reserve Bank (SARB) (2008) 'Guidance Note 6/2008 Issued in Terms of Section 6(5) of the Banks Act, 1990: Cell-Phone Banking', available at http://goo.gl/qPZzp 
South African Reserve Bank Position Papers

South African Reserve Bank (SARB) (1999) 'Position Paper on Electronic Money - April 1999', available at http://goo.gl/LfPCU

South African Reserve Bank (2000) 'NPS 01/2000- Position Paper on Risk Reduction Measures for Payment Clearing Houses in the NPS,' available at http://goo.gl/GtKXz

South African Reserve Bank (SARB) (2006) 'Position Paper on Electronic Money NPS 01/2006', available at http://goo.gl/BYRnG

South African Reserve Bank (SARB) (2007) 'Position Paper: Bank Models in the National Payment System', January, available at http://goo.gl/JYxkp

South African Reserve Bank (2009) ‘Position Paper on Electronic Money’, available at http://goo.gl/HdH2k

South African Reserve Bank (2010) 'Position Paper on Common Monetary Area (CMA) Cross-border Payments' available at http://goo.gl/AdsJg

South African Reserve Bank (2011) 'NPSD: Position Paper on Access to the National Payment System', available at http://goo.gl/KDd7W

South African Reserve Bank (2011) 'NPSD: Position Paper on Interoperability’ NPS 01/2011 at 2, available at http://goo.gl/gVB09

\section{UNITED KINGDOM}

\section{$\underline{\text { Laws }}$}

Banking Act 2009

English Bills of Exchange Act 1882

Financial Services Authority (2009c) Statutory Instruments 2009 No 209

Financial Services and Markets

National Banking Act of 1864 (ch. 106, 13 Stat. 99)?

\section{$\underline{\text { Regulations }}$}

Payment Services Regulations 2009

Financial Services Authority FSA 2001/53 Threshold Conditions (Amendment) Instrument 2001

\section{J UNITED NATIONS}

United Nations (s.d.) 'General Assembly Resolution 51/162: Model Law on Electronic Commerce adopted by the United Nations Commission on International Trade Law (UNCITRAL)', available at http://goo.gl/fODz5 


\section{Federal}

Annunzio-Wylie Anti-Money Laundering Act of 1992

Bank Secrecy Act 31 USC 1051

Bank Secrecy Act Public Law 91-508 1970 [31 USC 5312]

CAN-SPAM Act of 2003 [15 U.S.C. 7701, et seq., Public Law No. 108-187], available at http://goo.gl/98JuX

CFR Part 1005 [BCFP 2012 Final Remittance Rule (Amendment to Regulation E)], available at http://goo.gl/kC8qM

Coinage Act of 1965 Pub.L. 89-81, 79 Stat. 254

Communications Act of 193347 USC

\section{Consumer Credit Protection Act 15 USC $\$ 1601$}

Credit Card Accountability Responsibility and Disclosure Act of 2009, Pub. L. No. 111-24, 123 Stat. 1734 , available at http://goo.gl/Sw7aj

Electronic Fund Transfer Act 15 USC 1601

Electronic Signatures in Global and National Commerce Act. 15 USC ch. 96 available at http://goo.gl/N3rN3

Fair Credit Billing Act 15 USC $\$ 1666$

Federal Trade Commission Act 15 USC $\S \$ 41-51$

International Money Laundering Abatement and Financial Anti-Terrorism Act of 2001, Pub. L. 107-56, 115 Stat. 272, 296-342 (2001) (codified in scattered sections of 31 USCA)

Patriot Act 31 USC, 47 USC, 50 U.S.C.

Telecommunications Act of 1996 [Pub. LA. No. 104-104, 110 Stat. 56 (1996), available at http://goo.gl/RINlp

Telephone Consumer Protection Act 47 USC $\$ 227$ of 1991

The Bank Secrecy Act 12 USC 1951-1959

The Bank Service Company Act of 1962

Truth-in-Billing and Billing Format, First Report and Order and Further Notice of Proposed Rulemaking, CC Docket No. 98-170, 14 FCC Rcd 7492 (1999) (Truth-in-Billing Order and/or Further Notice

Uniform Electronic Transactions Act (1999)

Unlawful Internet Gambling Enforcement Act of 2006, 31 U.S.C. 5361(b)

\section{$\underline{\text { Regulations }}$}

Regulation E

Regulation Z 


\section{$\underline{\text { Opinions And Regulations }}$}

Federal Communications Commission (2007) 'Sec. 64.2401 Truth-in-Billing Requirements' 47 U.S.C. 154, 254(k)

Federal Deposit Insurance Corporation (1996) 'General Counsel's Opinion No. 8: Stored Value Cards', 61 Fed. Reg. 40,490 40,494

Federal Deposit Insurance Corporation (2008) 'General Counsel's Opinion No. 8: Stored Value Cards and Other Non-traditional Access Mechanisms'

IRS (2010) Internal Revenue Notice 2010-94 (December)

Office of the Comptroller of the Currency (OCC) (1996) 'Interpretive Letter' No 220, available at http://goo.gl/PILgh

Office of the Comptroller of the Currency (OCC) (1996) 'Interpretive Letter' No 220, available at http://goo.gl/PILgh

Office of the Comptroller of the Currency (OCC) (1998a) 'Guidance on Electronic Financial Services and Consumer Compliance', available at http://goo.gl/BRLEN.

Office of the Comptroller of the Currency (OCC) (1998b) 'The Report of the Consumer Electronic Payments Task Force', available at http://goo.gl/EtLkt.

Office of the Comptroller of the Currency (OCC) (1999) 'Interpretive Letter' \#855, available at http://goo.gl/hjPS9.

Office of the Comptroller of the Currency (OCC) (2003) 'Conditional Approval' \#568, available at http://goo.gl/OHKzB

Office of the Comptroller of the Currency (OCC) (2008a) 'Activities Permissible for a National Bank', available at http://goo.gl/hFT2Z

Office of the Comptroller of the Currency (OCC) (2008b) 'A Guide to the National Banking System', available at http://goo.gl/4RV1X. For commentary on the US banking system

Office of the Comptroller of the Currency (OCC) (2011) 'National Banks, Thrifts, Credit Unions: Who Regulates Them?', available at http://goo.gl/pXBKo

\section{State}

Florida Money Services Business [ch 69V-560-2008]

New York State Banking Law

Texas Finance Code

Texas Money Services Act of May 26, 2005, 79th Leg., R.S., H.B. 2218, §1

Uniform Commercial Code §4A-201

Uniform Money Services Act (2002)

Uniform Money Services Act (2004) as amended, available at http://goo.gl/wDFHa 


\section{INTERNATIONAL TREATIES}

The Basel II Accord', available at http://goo.gl/5wmGE 


\section{TABLE OF SOUTH AFRICAN CASES}

ABSA Bank Bpk v Janse Van Rensburg 2002 (3) SA 701 (SCA)

African Life Assurance Co Ltd v NBS Bank Ltd 2001 (1) SA 432 (W)

Afrox Healthcare Ltd v Strydom (172/2001) [2002] ZASCA 73

Air-Kel (Edms) Bpk h/a Merkel Motors v Bodenstein en 'n Ander 1980 (3) SA 917 (A)

Alexander NO v Perdicologou 1996 (3) SA 454 (R)

Alfred McAlpine \& Son (Pty) Ltd v Transvaal Provincial Administration 1974 (3) SA 506 (A)

Allen v Sixteen Stirling Investment (Pty) Ltd 1974 (4) SA 164 (D)

Altech Autopage Cellular (Pty) Ltd v Chairperson of the Council of the Independent Communications Authority of South Africa and Others (2002/08) [2008] ZAGPHC 268 (29 August 2008)

B \& H Engineering v First National Bank of Southern Africa Ltd 1993(2) SA 41 (T)

B \& H Engineering v First National Bank of SA Ltd 1995 (2) SA 279 (A)

Bank Windhoek Bpk v Rajie 1994 (1) SA 115 (A)

Barkhuizen v Napier 2007 (5) SA 323 (CC)

Basson v Chilwan 1993 (3) SA 742 (A)

Baylis' Trustee v Cape of Good Hope Bank (1886) 4 SC 442

Be Bop a Lula Manufacturing \& Printing CC v Kingtex Marketing (Pty) Ltd 2008 (3) SA 327 (SCA)

Beningfield v Baxter (1886) LR 12 HL 167

Berzack v Nedcor Bank Ltd 2001- VOL NO SA 410 (A)

BK Tooling (Edms) Bpk v Scope Precision Engineering (Edms) Bpk 1979 (1) SA 391 (A)

Blanche Sadahaw Dhelvi v Devamani Shunmoogun Padayachee case no 2001/19306 6 September 2005 (W)

Brandt v Spies 1960 (4) SA 14 (E)

Braun v Blann and Botha 1984 (2) SA 850 (A)

Bredenkamp v Standard Bank of SA Ltd (599/09) [2010] ZASCA 75

Bredenkamp v Standard Bank (599/09) [2010] ZASCA 75 (27 May 2010)

Breytenbach v Frankel 1913 AD 390

Brisley v Drotsky (432/2000) [2002] ZASCA 35 (28 March 2002)

Broodryk v Smuts 1942 TPD 47

Burg Trailers SA (Pty) Ltd and Another v ABSA Bank Ltd and Others 2004 (1) SA 284 (SCA)

Chubb Fire Security (Pty) Ltd v Greaves 1993 (4) SA 358 (W)

Colman v Dunbar 1933 AD 141

Columbus Joint Venture v ABSA Bank Ltd 2000 (2) SA 490 (W)

Columbus Joint Venture v ABSA Bank Ltd 2002 (1) SA 90 (SCA) 
Commissioner for Inland Revenue v Estate Crewe and Another 1943 AD 656

Commissioner for Inland Revenue v First National Industrial Bank Ltd 1990 (3) SA 641 (A)

Commissioner for Inland Revenue v People's Stores (Walvis Bay) (Pty) Ltd 1990 (2) SA 353 (A)

Commissioner for Inland Revenue v Smollan's Estate 1955 (3) SA 266 (A)

Commissioner of Customs and Excise v Bank of Lisbon International Ltd and another 1994 (1) SA 205 (N)

Commissioner of Customs and Excise v Randles Brothers and Hudson Ltd 1941 AD 369

Commissioner, South African Revenue Service and Another v ABSA Bank Limited \& Another 2003 (2) SA 96 (W)

Commissioner, South African Revenue Service v Brummeria Renaissance (Pty) Ltd [2007] SCA 99 (RSA)

Conradie v Rossouw 1919 AD 279

Conze v Masterbond Participation Trust Managers 1996 (3) SA 786 (C)

Crookes NO and Another $v$ Watson and Others 1956 (1) SA 277 (A)

Dantex Investment Holdings (Pty) Ltd v National Explosives (Pty) Ltd (in liquidation) 1990 (1) SA 736 (A)

David Trust $v$ Aegis Insurance Company Ltd 2000 (3) SA 289 (A)

Davidson v Bonafede 1981 (2) SA 501 (C)

De Freitas v Society of Advocates of Natal and another 2001 (3) SA 750 (SCA)

Deedat \& others $v$ The Master \& others 1995 (2) SA 377 (A)

Diamond v Kernick 1947 (3) SA 69 (A)

Dickens v Daley 1956 (2) SA $11(\mathrm{~N})$

Dickinson Motors (Pty) Ltd v Oberholzer 1952 (1) SA 443 (A)

Diners Club SA (Pty) Ltd v Singh And Another 2004 (3) SA 630 (D)

Double Option Trading 197 (Pty) Ltd v Grimbeek and Another (13703/07) [2009] ZAWCHC 204 (13 August 2009)

Durban's Water Wonderland (Pty) Ltd v Botha 1999 (1) SA 982 (SCA)

Edelstein v Edelstein NO 1952 (3) SA 1 (A)

Efroiken v Simon 1921 CPD 367

Energy Measurements (Pty) Ltd v First National Bank of South Africa Ltd 2001 (3) SA 132 (W)

Equitable Trust and Insurance Co SA Ltd v Registrar of Banks 1957 (2) SA 167 (T)

Estate Ismail v Barclays Bank (DC and O) 1957 (4) SA 17 (T)

Esterhuyse v Selection Cartage (Pty) Ltd 1965 (1) SA 360 (W)

Ex Parte Hulton 1954 (1) SA 460 (C)

Ex Parte Kelly 1942 OPD 265

Ex Parte: Minister of Justice In Re: Nedbank Ltd v Abstein Distributors (Pty) Ltd and Others (240/93) [1995] ZASCA 40

Fakroodeen v Fakroodeen 1971 (3) SA 395 (D)

Faure v Louw (1880) 1 SC 17

Fedgen Insurance Ltd v Bankorp Ltd 1994 (2) SA 339 (W) 
Finestone v Hamburg 1907 TS 629

First National Bank of SA Ltd v Rosenblum 2001 (4) SA 189 (SCA)

First National Bank of Southern Africa Ltd v Duvenhage 2006 (5) SA 369 (SCA)

First National Bank of Southern Africa Ltd v Perry NO and Others 2001 (3) SA 960 (SCA)

Frame v Palmer 1950 (3) SA 340 (C)

Gilbey Distillers and Vintners (Pty) Ltd v ABSA Bank case no 12698/94 (unreported 4 Dec 1998 (C))

Govender v The Standard Bank of South Africa Ltd 1984 (4) SA 392 (C)

Gross and Others v Pentz 1996 (4) SA 617 (SCA)

GS George Consultants and Investments Ltd v Datasys Ltd 1988 (3) SA 726 (W)

Harris v Pieters 1920 AD 644

Hayne \& Co v Kaffrarian Steam Mill Co Ltd 1914 AD 363

Hofer $v$ Kevitt 1998 (1) SA 382 (SCA)

Holscher v ABSA Bank en ' $n$ Ander 1994 (2) SA 667 (T)

Holtzhausen v ABSA Bank 2005 (2) All SA 560 (SCA)

Hoosen v Deedat 1999 (4) SA 425 (SCA)

Indac Electronics (Pty) Ltd v Volkskas Bank Ltd 1992 (1) SA 783 (A)

Jafta v Ezemvelo KZN Wildlife [2008] JOL 22096 (LC)

Jajbhay v Cassim 1939 AD 537

Johannesburg Country Club v Stott 2004 (5) SA 511 (SCA)

Joint Stock Company Varvarinskoye v ABSA Bank Ltd and Others (164/07) [2008] ZASCA 35 (28 March 2008), [2008] 3 All SA 130 (SCA), 2008 (4) SA 287 (SCA)

Jonker v Meester van die Hooggesregshof (88/85) 1986 ZASCA 64 (29 May 1986)

Khan v Naidoo 1989 (3) SA 724 (N)

Kei Brick \& Tile Co (Pty) Ltd v AM Construction 1996 (1) SA 150 (E)

Kergeulen Sealing \& Whaling Co Ltd v CIR 1939 AD 487

Krapohl v Oranje Kooperasie Bpk 1990 (3) SA 848 (A)

Kriel v Terblanche NO 2002 (6) SA 132 (NC)

Kruger v Coetzee 1966 (2) SA 428 (A)

Kwamashu Bakery Ltd v Standard Bank of South Africa Limited 1995 (1) SA 377 (D)

Langford v Moore (1900) 17 SC 1

Law Union and Rock Insurance Co Ltd v Carmichael's Executor 1917 AD 593

Legator McKenna v Shea \& others [2008] ZASCA 144

Levin v Drieprok Properties (Pty) Ltd 1975 (2) SA 397 (A)

Liebenberg v ABSA Bank Limited t/a Volkskas Bank [1998] 1 All SA 303 (C)

Lillicrap, Wassenaar and Partners v Pilkington Brothers (SA) (Pty) Ltd 1985 (1) SA 475 (A) 
Lloyd-Gray Lithographers (Pty) Ltd v Nedcor Bank Ltd t/a Nedbank 1998 (2) SA 667 (W)

Lockie Bros Ltd v Pezaro 1918 WLD 60

Louw v Coetzee 2003 (3) SA 329 (SCA)

Magna Alloys and Research SA (Pty) Ltd v Ellis 1984 (4) SA 874 (A)

Mantra Consulting (Pty) Limited v Valor IT CC and Others (09/35874) [2010] ZAGPJHC 36 (7 April 2010)

Mathews v Williams, Brown and Co (1894) 10 TLR $386(\mathrm{~N})$

McCarthy Retail v Shortdistance Carriers CC 2001 (3) SA 482 (SCA)

Media 24 Ltd v Grobler 2005 (6) SA 328 (SCA)

Miller v Bellville Municipality 1973 (1) SA 914 (C)

Minister of Education v Stuttaford \& Co (Rhodesia) (Pty) Ltd 1980 (4) SA 517 (Z)

Mndi v Malgas 2006 (2) SA $182(\mathrm{E})$

Mondorp Eiendomsagentskap (EDMS) BPK v Kemp en de Beer 1979 (4) SA 74 (A)

Mufamadi v Dorbyl Finance (Pty) Ltd 1996 (1) SA 799 (A)

Mutual and Federal Insurance Co Ltd v Oudtshoorn Municipality 1985 (1) SA 419 (A)

MV Snow Delta: Serva Ship Limited v Discount Tonnage Limited 2000 (4) SA 746 (SCA)

Nashua Mobile (Pty) Ltd v GC Pale CC t/a Invasive Plant Solutions (A3044/2010) [2010] ZAGPJHC 112 (18 November 2010)

Nedbank Ltd v Pestana 2009 (2) SA 189 (SCA)

Nedcor Bank Ltd v ABSA Bank and another 1995 (4) SA 727 (W)

Nissan South Africa (Pty) Ltd V Marnitz NO And Others (Stand 186 Aeroport (Pty) Ltd Intervening) 2005 (1) SA 441 (SCA)

Nortje en ' $n$ Ander v Pool NO 1966 (3) SA (A)

Parker Wood v Swinbourn 1916 NPD 474

Patel v Grobbelaar 1974 (1) SA 532 (A)

Paterson Exhibitions CC v Knights Advertising and Marketing CC 1991 (3) SA 523 (A)

Pestana v Nedbank Ltd 2008 (3) SA 466 (W)

Peterson and Another v ABSA Bank Limited [2011] ZAGPPHC 127, 24067/2010 (27 July 2011)

Pfeiffer v First National Bank of SA Ltd 1998 (3) SA 1018 (A)

Port Elizabeth Municipality v Uitenhage Municipality 1971 (1) SA 724 (A)

Powell v ABSA Bank Ltd (t/a Volkskas Bank) 1998 (2) SA 807 (SEC)

Pratt v First Rand Bank (416/07) [2008] ZASCA 92

Preller v Jordaan 1956 (1) SA 483 (A)

Pretorius v Commissioner for Inland Revenue 1984 (2) SA 619 (T)

$R v$ Gordon 1914 CPD 123

$R v$ Manuel 1953 (4) SA $523(\mathrm{AD})$

$R v$ Solomon 1953 (4) SA 518 (AD) 
Rand Townships Registrar 1945 AD 277

Randfontein Transitional Local Council v ABSA Bank Ltd 2000 (2) SA 1040 (W)

Registrar of Banks $v$ Transafrica Credit and Savings Bank Ltd 1963 (2) SA 687 (C)

Reid Bros (South Africa) v Fischer Bearings Co Ltd 1943 AS 232

Roestof v Cliffe Dekker Hofmeyr Inc (34306/2010) [2011] ZAGPPHC 219 (2012)

Sv Caswell Case no 27/87/98 (Regional Court, Cape Town) unreported

$S$ v Dustigar Case no CC6/2000 (Durban and Coast Local Division) unreported

Sv Gathercole 1964 (1) SA 21 (A)

S v Harper 1991 (1) SA 177 (A)

S v Kearney 1964 (2) SA 495 (A)

S v Kotze 1965 (1) 118 (A)

Sv Van Der Westhuizen (256/2002) [2003] ZAFSHC 27 (30 October 2003)

SA Eagle Insurance Co Ltd v Hartley [1990] ZASCA 106

SA Hyde (Pty) Ltd v Neumann 1970 (4) SA 55 (0)

Saambou-Nasionale Bouvereniging v Friedman 1979 (3) SA 978 (A)

Sackville West v Nourse \& Another 1925 AS 516

Sasfin (Pty) Ltd v Beukes 1989 (1) SA 1 (A)

Schneider \& London v Chapman 1917 TPD 504

SDR Investment Holdings CO (Pty) Ltd and Others v Nedcor Bank Ltd and Another 2007 (4) SA 190 (C)

Shell SA (Pty) Ltd v Corbitt \& Another 1986 (4) SA 523 (C)

Siman \& Co (Pty) Ltd v Barclays National Bank Ltd 1984 (2) SA 888 (A)

SJ Coetzee Inc v Louw 2002 (5) SA 602 (T)

Skead v Colonial Banking \& Trust Co Ltd 1924 TPD 497

South African Railways \& Harbours v National Bank of South Africa Ltd 1924 AD 704

Standard Bank of SAS Ltd v ABSA Bank Ltd 1995 (2) SA 740 (T)

Standard Bank of South Africa Ltd v Oneanate Investments (Pty) Ltd 1995 (4) SA 510 (C)

Standard Bank of South Africa Ltd v Oneanate Investments (In Liquidation) 1998 (1) SA 811 (SCA)

Standard Bank of South Africa Ltd v Peens \& others 2005 (1) SA 315 (SCA)

Strydom v ABSA Bank Bpk 2001 (3) SA 185 (T)

Take and Save Trading CC and Others v Standard Bank of SA Ltd 2004 (4) SA 1 (SCA)

The Firs Investment Ltd v Levy Bros Estates (Pty) Ltd 1984 (2) SA 881 (A)

The Heirs Hiddingh v De Villiers, Denyssen and Others (1887) 5 SC 298

Thorne and Molenaar NNO v Receiver of Revenue, Cape Town 1976 (2) SA 50 (C)

Thoroughbred Breeders' Association v Price Waterhouse 2001 (4) SA 551 (SCA)

Tijmstra v Blunt-MacKenzie NO and Others 2002 (1) SA 459 (T) 
Totalisator Agency Board, OFS v Livanos 1987 (3) SA 283 (W)

Trollip v Jordaan 1961 (1) SA 238 (A)

Trustees, Two Oceans Aquarium Trust v Kantey and Templer (Pty) Ltd 2006 (3) SA 138 (SCA)

Van der Byl \& Co v Solomon (1877) 7 Buch 25

Vereins-Und Westbank AG v Veren Investments and Others (433/2000) [2002] ZASCA 36

Viljoen v Hillier 1904 TS 312

Volkskas Bank BPK v Bankorp (h/a Trustbank) 1991 (3) SA 605 (A)

Wells v South African Alumenite Company 1927 AD 69

Whittal v Alexandria Municipality 1966 (4) SA 297 (E)

Wood v Davies 1934 CPD 250

Willis Faber Enthoven v Receiver of Revenue 1992 (4) SA 202 (A)

Woodhead Plant \& Co v Gunn (1894) 11 SC 4 


\section{TABLE OF FOREIGN CASES}

\section{A AUSTRALIA}

Australian Independent Distributors Ltd v Winter (1964) 112 CLR 443

Australian Prudential Regulation Authority v Siminton (No 6) [2007] FCA 1608

Commissioners of the State Savings Bank of Victoria v Permewan Wright and Co Ltd (1914) 19 CLR 457

Siminton v Australian Prudential Regulation Authority [2008] FCAFC 88

Riedell v Commercial Bank of Australia Ltd 1931 VLR 382

\section{B CANADA}

BMP Global Distribution Inc v Bank of Nova Scotia [2009] SCC 15

Canadian Pioneer Management Ltd et al v Labour Relations Board of Saskatchewan et al [1980] 1 SCR 433

Re Alberta Statutes [1938] SCR 100

Re Bergethaler Waisenamt (No 2) [1949] 1 WWR 323

National Slag v Canadian Imperial Bank of Commerce et al (1982) 140 DLR (3d) 473

\section{ENGLAND}

Anonymous (1676) 1 Mod 215, 86 ER 837 (CP 1676)

A/S Awilco v Fulvia Spa Di Navigazione (The Chikuma) [1981] 1 All ER 652 (HL), [1981] 1 WLR

Balmoral Supermarket Ltd v Bank of New Zealand [1974] 2 Lloyd's LR 164

Banco de Portugal v Waterlow \& Sons [1932] AC 452

Bank of Chettinad v Commissioner of Income Tax, Colombo [1948] AC 378

Barclays Bank v Quincecare [1992] 4 ER 363

Camdex International Ltd v Bank of Zambia [1997] 6 Bank LR 43

Caparo Industries plc v Dickman and Others House of Lords [1990] 2 AC 605

Chambers v Miller (1862) 13 CB (NS) 125, 143 ER 50

Commissioners of Taxation v English, Scottish and Australian Bank [1920] AC 683

Foley v Hill (1848) 2 HL C 28

Great Western Railway Co Ltd v London and County Banking Co Ltd [1901] AC 414

Importers Co Ltd v Westminster Bank [1927] 2 KB 297

Kepitigalla Rubber Estates Ltd v National Bank of India Ltd [1909] 2 KB 1010

Ladbroke v Todd (1914) 30 TLR 433

Langford v Moore (1900) 17 SC 1

Libyan Arab Foreign Bank v Bankers Trust Co (1989) 1 QB 728

Lipkin Gorman v Karpnale (1991) 2 AC 548

London and Harrogate Securities Ltd v Pitts [1976] 1 WLR 1063 
London Joint Stock Bank Ltd v MacMillan and Arthur [1918] 1 AC 777 (HL)

Miller v Race (1758) 1 Burr 452

Moss v Hancock (1899) 2 QB 111

N Joachimson (A Firm Name) v Swiss Bank Corporation [1921] 3 KB 110

Prosperity Ltd v Lloyds Bank Ltd [1923] 39 TLR 372

$R v$ Thompson [1978] ECR 2247

Re Birkbeck Permanent Benefit Building Society [1912] 2 Ch 183

Re Charge Card Services Ltd [1987] Ch 150

Re Shields' Estate [1901] Ir Ch 172

Royal Bank of Scotland v Skinner 1931 SLT 382

Russian Commercial and Industrial Bank [1955] Ch 148

Savory and Co v Lloyd's Bank Ltd (1932) 48 TLR 344 (M)

SCF Finance Co Ltd v Masri (No 3) [1987] 2 WLR 81 CA

Stafford v Henry [1850] 12 Ir Eq 400

Tayeb v HSBC Bank plc [2005] 1 CLC 866

United Dominions Trust Ltd v Kirkwood [1966] 2 QB 431

White $v$ Brown (1883) 4 NLR 88 at 92

Woods v Martins Bank [1959] 1 QB 55

Yuen Kun-Yeu v Attorney-General of Hong Kong 38

D EUROPEAN UNION EUROPEAN COURT OF JUSTICE

Bertrand v Ott 15/78, [1978]

Case 205/84 Commission v Germany [1986] ECR 3755

Case C-222/95 Parodi [1997] ECR I-389

\section{E New Zealand}

$R v$ Wilkinson (13 October 1998, CA 122/98)

\section{F United States Of America}

Assurance of Voluntary Compliance or Discontinuance, In the Matter of: Paypal Inc, A Delaware Corporation, available at http://googl/nVvxe

AT\&T Mobility LLC v Concepcion Et Ux., Slip Opinion \#09-893, available at http://googl/894Qg

Barnett Bank of Marion County, NA v Nelson, 517 US 25, 32 (1996)

First Network Bank v CAPS Inc 2002 WL 485352, (ND Ill 2002)

Micronet, Inc v Indiana Utility Regulatory Commission Indiana Court of Appeals \#93A02- 0603-EX-237 May 10, 2007

Nemser v New York City Transit Authority 530 NYS 2d 493 (NY Sup Ct 1988)

Tracie McFerren v AT\&T Mobility LLC, Case \#08-CV-151322

Watters v Wachovia Bank, NA 127 S Ct 1559 (2007) 


\section{BIBLIOGRAPHY}

3L3AntiMoneyLaunderingTaskForce (2009) 'Compendium Paper on the Supervisory Implementation Practices across EU Member States of the Third Money Laundering Directive [2005/60/EC]' $15^{\text {th }}$ October 2009', available at http://goo.gl/2nwqA

ABA (1997) 'A Commercial Lawyer's Take on the Electronic Purse: An Analysis of Commercial Law Issues Associated with Stored-Value Cards and Electronic Money (Task Force on Stored-Value Cards)' posted on Highbeam Business, 1 February, and originally published in Business Lawyer, available from http://goo.gl/n1b75

ABSA (2011) 'ABSA Bank Cheque Cards', available at http://goo.gl/85vsY

Adams, C (2010) 'The Rise of Complementary Currencies and Corporafinance: E-commerce Driven Competition in the Financial Sector', available at http://goo.gl/Leh2n

African Bank (s.d.) 'African Bank General Terms and Conditions', available at http://goo.gl/Dk893

African Development Bank (2007) 'Bank Group Strategy for the Prevention of Money Laundering and Terrorist Financing in Africa', available from http://goo.gl/bBt6H

Agarwal, S et al (2009) 'The Age of Reason: Financial Decisions over the Life-Cycle with Implications for Regulation', available at http://goo.gl/P7shu

Aglietta, M (2002) 'Whence and Whither Money?' in Organization for Economic Co-operation and Development (OECD) 'The Future of Money', available at http://goo.gl/RTOse

Aite Group (2011) 'The Less-Cash Society: Forecasting Cash Usage in the United States', available at http://goo.gl/pVk2j

Aker, JC and Mbiti, IM (2010) 'Mobile Phones and Economic Development in Africa' 24(3) Journal of Economic Perspectives 207-232

Akindemowo, E (2009) 'Contract, Deposit or E-Value? Reconsidering Stored Value Products for a Modernized Payments Framework' 7(2) DePaul Business and Commercial Law Journal 275-356, available at http://goo.gl/FP297

Akindemowo, E (2010) 'How to Devise U.S. SVP Policy? Prepare to Replace the Deposit Concept', Thomas Jefferson School of Law Research Paper No 1600888

Akindemowo, O (1998) ‘The Fading Rustle, Clink and Jingle: Electronic Value and the Concept of Money' 21(2) University of New South Wales Law Journal 466, available at http://goo.gl/tUz1S

Alaska Division of Corporations, Business Professional Licensing Information (s.d.) 'Money Service Businesses (MSBs)', available at http://goo.gl/NH9Hf

Albers, J (2007) 'Stored Value Cards: Should We Know the Holder?' 11 North Carolina 11 Banking Institute Journal 363 , available at http://goo.gl/56gBb

Alexandre, C, Mas, I and Radcliffe, D (2011) 'Regulating New Banking Models that Can Bring Financial Services to All' 54(3) Challenge Magazine 116-134, available at http://goo.gl/TtoCN

AllAfrica.com (2010) ‘CBK Licenses another Cash Transfer Service Firm', available at http://goo.gl/yVD8U

allBusiness (2007) 'Federal Law Doesn't Bar Telephone “Cramming” Suit, Rules Indiana Court of Appeals', available at http://goo.gl/JORZD

Alliance for Financial Inclusion (AFI) (2010a) 'Case Study: Enabling Mobile Money Transfer: The Central Bank of Kenya's Treatment of M-PESA', available at http://goo.gl/zJXi4

Alliance for Financial Inclusion (AFI) (2010b) 'Consumer Protection: Leveling the Playing Field in Financial Inclusion', available from http://goo.gl/bGeUp

American Association of Retired Persons (AARP), Public Policy Institute (2010) 'Prepaid Cards: Promise and Pitfalls for Consumers', available at http://goo.gl/fMmlg

Analsys Mason (2011) 'Premium Rate Services: International Markets and Regulation: Final Report for PhonepayPlus', available at http://goo.gl/sGQfk

Anderson, R (2007) 'Closing the Phishing Hole: Fraud, Risk and Nonbanks', available at http://goo.gl/LHD8t 
APEC Digital Opportunity Centre (2009) 'Central Bank wants Cashless Society’ [Central Bank of Thailand], 2 November, available at http://goo.gl/dJca0

Apostolik, R, Donohue, C and Went, P (2009) Foundations of Banking Risk: An Overview of Banking, Banking Risks

Arda, A (2004) 'Consulting the European Central Bank: Legal Aspects of the Community and National Authorities' Obligation to Consult the ECB Pursuant to Article 105(4) EC' 1 European Banking and Financial Law Journal 111-152, available at http://goo.gl/HY6ZF

Ardic, OP, Heimann, M and Mylenko, N (2011) 'Access to Financial Services and the Financial Inclusion Agenda around the World: A Cross-Country Analysis with a New Data Set' The World Bank, Financial and Private Sector Development, Financial Access Team of the Consultative Group to Assist the Poor, Policy Research Working Paper No 5537, January, 155, available at http://goo.gl/8EZS3

Ardic, OP, Ibrahim, J and Mylenko, N (2011) 'Consumer Protection Laws and Regulations in Deposit and Loan Services: A Cross-Country Analysis with a New Data Set' World Bank Policy Research Working Paper No 5536, available at http://goo.gl/eD9aa

Arestis, P, McCauley, K and Sawyer, MC (1999) 'From Common Market to EMU: A Historical Perspective of European Economic and Monetary Integration' The Jerome Levy Economics Institute Working Paper No 263, available at http://goo.gl/djvpr

Aristotle (1962) Nicomachean Ethics (350 BC), Book V, translated by M Oswald

Aristotle (1976) The Politics translated by TA Sinclair 41-48, as cited in Geva, B (1987) From Commodity to Currency in Ancient History: On Commerce, Tyranny

Aristotle (350 BCa) Nicomachean Ethics

Aristotle (350 BCb) Politics trans B Jowett, available at http://goo.gl/cHjDy

Arora, A (1987) The Law Relating to Domestic Banking: Banking Law (Vol 1)

Arora, S (2007) 'South Africa: Committed to an Inclusive Financial Sector’, available at http://goo.gl/LX2GR

Ashton, M (2009) 'Bank Report Leak Exposes Tech Flaw' posted on Fin24, 8 January, available at http://goo.gl/GFSWy

Association for Financial Professionals (2005) 'Comment', available at http://goo.gl/nTHMj

Association of E-money Institutions in the Netherlands (2003) 'The Electronic Money Directive: Recapitulation and Outlook: Working Paper for the GTIAD-Meeting of November 27, 2003', available at http://goo.gl/QiG6N

Atkinson, E (1894) 'Discussion of "The Value of Money" by FA Walker' in 9(1) Publications of the American Economic Association 47-56, cited in Tymoigne, E (2006) 'An Inquiry into the Nature of Money: An Alternative to the Functional Approach', California State University, Fresno, Department of Economics, The Levy Economics Institute, Working Paper No 481, 1-35, available at http://goo.gl/mDQQF

Attaway, DA (2007) 'Cracking the Door to State Recovery from Federal Thrifts', 3(1) Seventh Circuit Review 275, available at http://goo.gl/J5kwx

Australian Bankers Association (ABA) (1997) 'A Commercial Lawyer's Take on the Electronic Purse: An Analysis of Commercial Law Issues Associated with Stored-Value Cards and Electronic Money’ Business Lawyer, available from http://goo.gl/n1b75

Australian Banking Industry Ombudsman (2003) 'ABIO Special Bulletin on Electronic Commerce: Emerging Issues in Electronic Banking Disputes’ No 35, available at http://goo.gl/stWMx

Australian Payments Clearing Association (APCA) (2009) 'Competition and Coordination in the Australian Card Payments System', available at http://goo.gl/fNzRI

Australian Securities and Investments Commission (ASIC) (2011) 'ePayments Code', available at http://goo.gl/0YX3f

Avgouleas, E (2008) 'Financial Regulation, Behavioural Finance, and the Global Credit Credit Crisis: In Search of a New Regulatory Model' 3 September, Social Science Research Network, available at

Badenhorst, PJ, Pienaar, JM and Mostert, H (2006) Silberberg \& Schoeman's The Law of Property $5^{\text {th }}$ ed

Bagehot, W (1873) Lombard Street: A Description of the Money Market

Balaban, D (2007) 'Japan's Mobile Wallets Fail to Inspire - Yet' Card Technology, 1 April, available at http://goo.gl/KaOLF 
Balancing Act (2008) 'Bank to Offer Cross-Border Prepaid Airtime in Namibia' 43 News Update, available at http://goo.gl/dXsiB

Ballen, RG and Fox, TA (2008) 'The Role of Private Sector Payment Rules and a Proposed Approach for Evaluating Future Changes to Payments Law' 83(2) Chicago-Kent Law Review 937

Banco de Portugal (s.d.) 'Money in the West of the Iberian Peninsula' , available at http://goo.gl/C6q0a

Banda, LH and Mdwazika, FH (2007) 'Cash and Retail Payment Systems in Developing Countries: Opportunities and Challenges: The Case of Malawi’, available at http://goo.gl/jwAeu

Bångens, L and Söderberg, B (2008) 'Mobile Banking: Financial Services for the Unbanked?', available at http://goo.gl/rmbSJ

Bank for International Settlements (BIS) (1996) 'Implications for Central Banks of the Development of Electronic Money' 120, available at http://goo.gl/TxTnD

Bank for International Settlements (BIS) (1997) 'Real-Time Gross Settlement Systems' Report prepared by the Committee on Payment and Settlement Systems of the Central Banks of the Group of Ten Countries, available at http://goo.gl/OUwkx

Bank for International Settlements (BIS) (2000) 'Survey of Electronic Money Developments' Committee on Payment and Settlement Systems, available at http://goo.gl/n523M

Bank for International Settlements (BIS) (2001) 'Core Principles for Systemically Important Payment Systems', CPSS Publications No 43, January, 1-92, available at http://goo.gl/nxWH3

Bank for International Settlements (BIS) (2011) ‘About BIS’ at http://goo.gl/fll2Q

Bank of Canada (s.d.) 'Seigniorage Revenue', available at http://goo.gl/cEQhq

Bank of England (s.d.) ‘A Brief History of Banknotes’, available at http://goo.gl/oLX3Q

Bank of Japan (2008) ‘Outline of Payment and Settlement Systems, and Market Infrastructures', available at http://goo.gl/

Bankable Frontier Associates (BFA) (2010) 'South African Financial Diaries and the Mzansi Initiative: Five Years Later', available at http://goo.gl/yTpiW

Banking Association of South Africa (2008) 'Overview of the Payments Environment', available at http://goo.gl/JzDVq

'Banks Must Be More Inclusive: Gordhan' (2011), The Citizen, 23 August, available at http://goo.gl/A7abC

Banque De France (2001) 'Recent Developments in the Banque de France's Scoring Method' No 93 Bulletin Digest, available at http://goo.gl/3rpzF

Baptista, P and Heitmann, S (2010) 'Unleashing the Power of Convergence to Advance Mobile Money Ecosystems', available at http://goo.gl/9M1ro

Barr, MS, Mullainathan, S and Shafir, E (2008) 'Behaviorally Informed Financial Services Regulation' New America Foundation, available at http://goo.gl/ZihEc

Barth, JR et al (2010) 'Do Bank Regulation, Supervision and Monitoring Enhance or Impede Bank Efficiency?' 21 March, Social Science Research Network, available at http://goo.gl/2ncNx

Barth, JR, Caprio Jr, G, and Levine, R (2006) Rethinking Bank Regulation: Till Angels Govern

Baxter, IFG (1974) ‘Simple Payment of Money’ 24(1) University of Toronto Law Journal 63-95

BBC Report (British Broadcasting Corporation Report) (1997) 'Brown sets Bank of England Free', available at http://goo.gl/beQZx

BBC Report (British Broadcasting Corporation Report) (1997) 'Brown sets Bank of England Free', available at http://goo.gl/beQZx

'Bear Stearns Cos Inc.' (2008) The New York Times, available at

Beatty, A and Hammond, C (1997) 'Smart Cards: An Australian Perspective' Butterworths Journal of International Banking and Financial Law 312 cited in Effros, RC (2002) 'Electronic Payment Systems: Legal Aspects' 189-208 in Horn, N and Buxbaum, RM (eds) (2002) Legal Issues in Electronic Banking (Studies in Transnational Economic Law, Vol 17) 
Beck, T, Demirgüç-Kunt, A and Levine, R (2007a) 'Finance, Inequality and the Poor' 12(1) Journal of Economic Growth 2749, available at http://goo.gl/0Pkyi

Beck, T, Demirgüç-Kunt, A and Martinez Peria, MS (2007b) 'Reaching Out: Access to and Use of Banking Services Across Countries' 85(1) Journal of Financial Economics 234-266, available at http://goo.g1/5qSSd

Beck, T, Demirgüç-Kunt, A and Martinez Peria, MS (2008) 'Banking Services for Everyone? Barriers to Bank Access and Use around the World,' 22(3) World Bank Economic Review 397-430, available at http://goo.gl/OUSQD

Bell, SA (1998) 'The Hierarchy of Money', The Jerome Levy Economics Institute WP No 231, available at http://goo.gl/mNvnx

Bellis, M (s.d.) ‘The ATM Machine of Luther George Simjian’, available at http://goo.gl/aV5Go

Bendixen, C (1919) Wiihrungspolitik und Geldtheorie im Lichte des Weltkriegs $2^{\text {nd }}$ ed

Benton, MT et al (2007) 'The Boston Fed Study of Consumer Behavior and Payment Choice: A Survey of Federal Reserve System Employees' Public Policy Discussion Paper No. 07-1, Federal Reserve Bank of Boston, available at http://goo.gl/fdAGQ

Berentsen, A (1998) ‘Monetary Policy Implications of Digital Money’ 51 Kyklos 89-117

Bergman, WJ, Johnson, CA and Bliss, RR (2003) 'Netting, Financial Contracts, and Banks: The Economic Implications Research in Financial Services', available at http://goo.gl/uvktt

Berndt, AD, Saunders, SG, and Petzer, DJ (2010) 14(3) 'Readiness for Banking Technologies in Developing Countries' Southern African Business Review 47-76.

Bertelsmann Stiftung (ed) (2010) 'Managing the Crisis: A Comparative Assessment of Economic Governance in 14 Economies', available at http://goo.gl/XAkuR

Bester, H (2010) 'M-PESA: From Kenya to South Africa ...', available at http://goo.gl/plrqM

Bester, H, Hougaard, C and Chamberlain, D (2010) 'Reviewing the Policy Framework for Money Transfers' CENFRI, available at http://goo.gl/zGcmS

Birch, D (2006) 'Low Fat Hazelnut Frappachino on Credit', available at http://goo.gl/EQnPJ

Bizcast (2010) 'S\&P: South Africa Banking Industry Country Risk Assessment Maintained at Group 5' Standard \& Poor, 22 January, available at http://goo.gl/9LDbs

Bleyen, V-A and Van Hove, L (2009) 'Classifying Payment Instruments: A Matryoshka Approach', 28 October, Social Science Research Network, available at http://goo.gl/bz9Eu

Blowers, A (2010) 'Net Neutrality: Ofcom Briefing for Analysts $21^{\text {st }}$ July 2010', available at http://goo.gl/t8j8d

Board of Governors of the Federal Reserve System (2005) 'The Federal Reserve System: Purposes \& Functions' $9^{\text {th }}$ ed, available at http://goo.gl/nHIUh

Board of Governors of the Federal Reserve System (2011) 'Federal Reserve Policy on Payment System Risk', available at http:goo.gl/Thert

Boberg, PQR (1975) ‘Emancipation and the Attainment of Majority' (92) South African Law Journal 183

Boberg, PQR (1984) The Law of Delict: Volume One: Aquilian Liability

Bold, C (2010) 'Tackling Fraud, Money Laundering and Terrorism Financing in Mobile Banking' CGAP Blog, 13 January, available at http://goo.gl/ZgcCB

Bollen, RA (2004) 'A Review of the Regulation of Payment Facilities' 11(3) Murdoch University Electronic Journal of Law, available at http://goo.gl/Tsn $4 \mathrm{j}$

Bollen, RA (2005) 'What a Payment Is (and How it Continues to Confuse Lawyers)' 11 Murdoch University Electronic Journal of Law, available at http://goo.gl/y1UOR

Bollen, RA (2006) 'Time to Modernise the Concept of “Deposit”?' 17(4) Journal of Banking and Finance Law and Practice 283-298

Bollen, RA (2007) 'The History and Operation of International Payment System' 18(27) Journal of Banking and Finance Law and Practice, Social Science Research Network, available at http://goo.gl/J62Gv 
Bollen, RA (2008a) 'Harmonisation of International Payment Services Law: Part 1 (the UNCITRAL Model Law)' 44 Journal of International Banking Law and Regulation, available at http://goo.gl/HiBvA

Bollen, RA (2008b) 'Harmonisation of International Payment Services Law: Part 2 (US Article 4a)' 105 Journal of International Banking Law and Regulation, available at http://goo.gl/dGKtK

Bollen, RA (2008c) 'A Review of Recent Developments in European Payment System Regulation (Including the Proposed Payment Services Directive)' 19 Journal of Banking and Finance Law and Practice 47

Bollen, RA (2009) 'Recent Developments with Banking Services in Developing Countries' Journal of International Banking Law and Regulation 509, Social Science Research Network, available at http://goo.gl/Q1JIx

Bollen, RA (2010) 'Best Practice in the Regulation of Payment Services' Journal of International Banking Law and Regulation 370, Social Science Research Network, available at http://goo.gl/X0acO

Bolt, T (2004) 'Memorandum (to the) Drafting Committee and Observers on Revisions to Uniform Money Services Act', available at http://goo.gl/M4RGl

Bolt T and Ramasastry, A (2000a) 'Memorandum: UMSBA - Matters Relevant to Consideration for Final Approval' 1-9, available at http://goo.gl/i6Cg5

Bolt, T and Ramasastry, A (2000b) 'Questions and Answers about the Uniform Money Services Business Act', available at http://goo.gl/x1oec

Bolt, W and Schmiedel, H (2009) 'SEPA, Efficiency Payment Card Competition' 30 December, ECB Working Paper No 1140, available at http://goo.gl/B2GuZ

Bootle, R (2001) 'The Future of Electronic Money: Why the Nok will not Replace the Dollar' 32(1) The Business Economist 7-15

Bordo, MD (1981) 'The Classical Gold Standard: Some Lessons for Today' Federal Reserve Bank of St Louis Review, May, 2-17, available at http://ideas.repec.org/a/fip/fedlrv/y1981imayp2-17nv.63no.5.html

Bordo, MD (2008) 'Gold Standard' in The Concise Encyclopedia of Economics, Library of Economics and Liberty, available at http://goo.gl/OBJ8

Bortner, RM (1996) ‘Cyberlaundering:Anonymous Digital Cash and Money Laundering', available at http://goo.gl/srveR

Boss, AH (2007) 'The Future of the Uniform Commercial Code Process in an Increasingly International World' 68 Ohio State Law Journal 349 passim, available at http://goo.gl/et5T0

Breyer, S and MacAvoy, PW (1987) 'Regulation and Deregulation' in Eatwell, J, Milgate, M and Newman, P (eds) The New Palgrave: A Dictionary of Economics

Brindle, M, Cox, R and Coleman, R (2004) Law of Bank Payments

Brink, Cohen, Le Roux (s.d.) ‘Collecting Banker's Duty of Care’, available at http://goo.gl/h5pgU

Brix, L and McKee, K (2010) 'Consumer Protection Regulation in Low-access Environments: Opportunities to Promote Responsible Finance’ CGAP Focus Note 60, available at http://goo.gl/r36Pc

Brokelind, C (2000) 'Discussion of Some Legal Issues Raised by the Introduction of the Euro,' available at http://goo.gl/ctmYt

Browne, FX and Cronin, David (1995) 'Payments Technologies, Financial Innovation and Laissez-Faire Banking' 15(1) The Cato Journal, available at http://goo.gl/LiAIh

Buchanan, M (2009) 'The Vile History of Gift Cards and How They Came to Destroy Christmas', available at http://goo.gl/IusYw

Budhram, T (2012) 'Lost, Stolen or Skimmed: Overcoming Credit Card Fraud in South Africa' 40 SA Crime Quarterly 31-37

Budnitz, ME (1997) 'Stored Value Cards and the Consumer: The Need for Regulation'American University Law Review, April, available at http://goo.gl/5Nxe6

Budnitz, ME (2007) '2005-2006 Developments in Payment Systems Law', 3 Journal of Consumer and Commercial Law 116, available at http://goo.gl/Lhp8o

Budnitz, ME (2008a) 'Developments in Payments Law 2008' 12Journal of Consumer \& Commercial Law 2 
Budnitz, ME (2008b) 'Technology as the Driver of Payment System Rules: Will Consumers be Provided Seatbelts and Air Bags?' 83(2) Chicago-Kent Law Review, 909-936 available at http://goo.gl/dj0vi

Bundesverband Deutscher Banken (2007) 'Online Banking Security', available at http://goo.gl/bKK5G at 5

Burger, JC (1990) 'DieRegsaardVan Suid-Afrikaanse Geld’ 2(3) SA Mercantile Law Journal 225-255

Camenisch, JL, Piveteau, J-M and Stadler, MA (1994) 'Security in Electronic Payment Systems' in Bischofberger, WR and Frei, HP (eds) Computer Science Research at UBILAB148-153, available from http://goo.gl/d8qAe

Cameron, E (2002) Honore's South African Law of Trusts $5^{\text {th }}$ ed

Capie, FH, Tsomocos, DP and Wood, GE (2003) 'E-barter Versus Fiat Money: Will Central Banks Survive?' Bank of England Working Paper 197, 1-30, available at http://goo.gl/HXTUr

Caplinger, D (2006) ‘Know Your Numbers: Money Supply’, available at http://goo.gl/Im5Gl

Carruthers, BG and Babb, S (1996) 'The Color of Money and the Nature of Value: Greenbacks and Gold in Post-Bellum America' 101(6) American Journal of Sociology 1556-91

CasinoScamReport.com (2010) 'South Africa's High Court Rules all Online Gambling Illegal', available at http://goo.gl/AEd.Y

Caskey, J, Duran, CR and Solo, TM (2006) 'The Urban Unbanked in Mexico and the United States' World Bank Policy Research Working Paper No 3835, available at http://goo.gl/e2yO9

Cassim, R et al (2004) 'A Review of the Changing Composition of the South African Economy: Report Prepared for the 10year Review Project: The Presidency’ Trade and Industrial Policy Strategies (TIPS), available at http://goo.gl/vLc31

‘CBK Outlines Rules for Electronic Money' (2011) The Star, 21 March, available at http://goo.gl/QDHS8

CellularOnline (1996-2006a) 'What is Bluetooth? [Goodbye Infrared!]', available at http://goo.gl/TjH0O

CellularOnline (1996-2006b) 'What is WiFi?', available at http://goo.gl/berL4

CellularOnline (2011a) ‘Africa', available at http://goo.gl/havhZ

CellularOnline (2011b) 'SIM Toolkit', available at http://goo.gl/rHTL3

CellularOnline (2011c) ‘South African Mobile', available at http://goo.gl/154Ay

CellularOnline (2011d) 'Statistics of Cellular in South Africa', available at http://goo.gl/7B3Af

CellularOnline's home page available at http://goo.gl/ImIYb

Center for Financial Services Innovation (CFSI) (2008) 'The CFSI Underbanked Consumer Study: Underbanked Consumer Overview and Market Segments Fact Sheet', available at http://goo.gl/bV2LZ

Center for Financial Services Innovation (CFSI) (2009) 'A Tool for Getting By or Getting Ahead? Consumers' Views on Prepaid Cards', available at http://goo.gl/fCDLz

Central Bank of Kenya (CBK) (2010) ‘CBK/PG/15: Guidelines on Agent Banking’, available at http://goo.gl/cs41

Central Bank of Kenya (CBK) (2003) 'Payment System in Kenya' at 1, available at http://goo.gl/REmgt

Central Bank of Kenya (CBK) (2009a) 'CBK Mandate', available at http://goo.gl/FnLsy

Central Bank of Kenya (CBK) (2009b) 'Credit Information Sharing to Enhance Financial Sector Development', available at http://goo.gl/DFVQU

Central Bank of Kenya (CBK) (2009c) 'Oversight of Payment System in Kenya: Policy Framework', available at http://goo.gl/OIu0D

Central Bank of Kenya (CBK) (2009d) 'Presentation to the Board of Directors of Domestic Regulators July 2009', available at http://goo.gl/6cK6D

Central Bank of Kenya (CBK) (2011) 'Central Bank of Kenya: Background Information', available at http://goo.gl/FnLsy 
Central Bank of Kenya, Financial Sector Deepening (FSD) (2009e) 'FinAccess National Survey 2009: Dynamics of Kenya's Changing Financial Landscape', June, available at http://goo.gl/ousfU

Cesarano, F (1994) ‘The New Monetary Economics and Keynes’ Theory of Money’ 21(3) Journal of Economic Studies 41

Chakravorti, S (2007) 'Nonbanks and Risk in Retail Payments' Payments and Monetary and Financial Stability Conference, Bank of England/ European Central Bank November 2007, available at http://goo.gl/1ZOR1

Chatain, PL et al (2008) 'Integrity in Mobile Phone Financial Services: Measures for Mitigating Risks from Money Laundering and Terrorist Financing’ World Bank Working Paper No 146, available at http://goo.gl/c6UCV

'Chattel' (2012) in Oxford Dictionaries, available at http://goo.gl/ISQp6

'Check' (2012) in Encyclopaedia Britannica Online Academic Edition, available at http://goo.gl/3AGJr

Cheney, JS (2005) 'Prepaid Card Models: A Study in Diversity’ Federal Reserve Bank of Philadelphia Payment Cards Center Discussion Paper No 05-03, available at http://goo.gl/sJQMS

Cheney, JS (2008) 'An Examination of Mobile Banking and Mobile Payments: Building Adoption as Experience Goods?', available at http://goo.gl/DWiH7

Cherednychenko, OO (2010) 'Full Harmonisation of Retail Financial Services Contract Law in Europe: A Success or a Failure?', available at http://goo.gl/BXRwL

Chipchase, J (2010) 'Mobile Banking: Agents as Mediators' CGAP Blog, available at http://goo.gl/cU8E7

Chorley, RST (1974) Law of Banking $6^{\text {th }}$ ed

Christie, RH (2001) The Law of Contract in South Africa $4^{\text {th }}$ ed

Christie, RH and Bradfield, GB(2011) Christie's The Law of Contract in South Africa $6^{\text {th }}$ ed

Chung, JJ (2009) 'Money as Simulacrum: The Legal Nature and Reality of Money’ 5 Hastings Business Law Journal 109

Citibank (2010) 'Citi Global Transaction Services and the GSMA Host Mobile Money Policy Forum in Africa', available at http://goo.gl/Dsr6v

Citizens Information Board (Ireland) (2011) 'Consumer Rights', posted on Citizens Information, available at http://goo.gl/DGSJP

Claessens, S (2006) 'Access to Financial Services: A Review of the Issues and Public Policy Objectives' 21(2) The World Bank Research Observer 207-240, available at http://goo.gl/2UVq6

Clark, S (2010a) 'All New Nokia Smartphones to come with NFC from 2011' Near Field Communications World web site, $17^{\text {th }}$ June, available athttp://goo.gl/mfGOb

Clark, S (2010b) 'Dutch Banks and Mobile Operators to Launch National NFC Service' Near Field Communications World September 9 th, 2010, available at http://goo.gl/n2yJk

Clark, T (1998) ‘DigiCash Files Chapter 11’ CNET News 4 November, available at http://goo.gl/Zri97

Clarke, R (2008) 'A Risk Assessment Framework for Mobile Payments' Proceedings of the 21st Bled eCommerce Conference, June 2008 63-77, available at http://goo.gl/pjBnr

Cliffe Dekker Hofmeyr (2008) 'Summary of the Provisions of the Co-operative Banks Act 2008', available at http://goo.gl/K8laz

Clower, TW (1971) 'Theoretical Foundations of Monetary Policy' in Gilbert, JC and Sedgwick, R (eds) Monetary Theory and Monetary Policy in the 1970s: Proceedings of the 1970 Sheffield Seminar on Monetary Theory and Monetary Policy in the 1970s (1970: University of Sheffield)

Clyde, P (2008) 'Targeting the Unbanked: Mzansi at Standard Bank' William Davidson Institute at the University of Michigan, available at http://goo.gl/EENz0

CNN (Cable News Network) (1995) 'The ATM is 30 Years Old: How Did We Ever Live Without It?', CNN Technology, 20 September, available at http://goo.gl/scXce

Coase, RH (1960) 'The Problem of Social Cost' 3 Journal of Law and Economics 1-44, available at http://goo.gl/8gerk

'Code of Banking Practice, The' (s.d.) available at http://goo.gl/56DMx 
Coetzee, G and Cross, C (2002) 'The Role of Community Banks in South Africa: Can it Contribute to Improve Access to Financial Services for the Poor?', available at http://goo.gl/ZMJPg

Coetzee, J (2005) 'Banking the Unbanked in South Africa: The Practical Implications on Branch Banking', available at http://goo.gl/12cFo

Coetzee, J (2009) 'Personal or Remote Interaction? Banking the Unbanked in South Africa' 12(4) South African Journal of Economic and Management Sciences 448-461, available at http://www.sajems.org/index.php/sajems/article/view/188

Cohen, BJ (2004) The Future of Money

Cohen-Cole, E (2010) 'Consumer Protection and Regulatory Changes in the Dodd-Frank Bill' NERA Economic Consulting, available at http://goo.gl/2EIP0

'Coin' (2006) in Random House Unabridged Dictionary

Coin Gallery Online, Coin Community Forum (2005-2011) available at http://goo.gl/2BbPC

Collier, D (2008) 'E-Mail and SMS Contracts' 16 Juta's Business Law 20-22

Collins, D (2010) 'Consumer Experience of Branchless Banking' Presentation delivered at Windsor 3 Seminar on Regulating Branchless Banking, Windsor, UK, available at http://goo.gl/nEn5W

Colonial Currency (1998) ‘Introduction to Early Massachusetts Currency’, available at http://goo.gl/xczqG

Commission of the European Communities (2001) 'Communication from the Commission to the Council and the European Parliament on E-Commerce and Financial Services’, Brussels, 07.02.2001, COM(2001) 66 final, available at

Committee of European Banking Supervisors (CEBS) (2009) 'CEBS and CEIOPS Publish Today Ten Principles for the Functioning of Supervisory Colleges', available at http://goo.gl/yQnbo

Committee of Scottish Clearing Banks, The (s.d.) 'The Relationship between Banker and Customer', available at http://goo.gl/VSipP

Committee on Capital Markets Regulation (2009) 'Committee on Capital Markets Regulation Releases Recommendations for Reorganizing U.S. Regulatory Structure', available at http://goo.gl/ZPtGE

Committee on Payment and Settlement Systems (CPSS) (1996) 'Security of Electronic Money', available at http://goo.gl/DhrkY

Committee on Payment and Settlement Systems (CPSS) (2003a) 'A glossary of terms used in payments and settlement systems', available at http://goo.gl/qL7xN

Committee on Payment and Settlement Systems (CPSS) (2003b) 'Red Book - Payment Systems in the United Kingdom', available at http://goo.gl/ndC2B

Committee on Payment and Settlement Systems (CPSS) (2003c) 'The Role of Central Bank Money in Payment Systems,' available at http://goo.gl/qVSck

Committee on Payment and Settlement Systems (CPSS) (2004) 'Survey of Developments in Electronic Money and Internet and Mobile Payments', CPSS Publications No 62, available at http://goo.gl/n01OR

Committee on Payment and Settlement Systems (CPSS) (2005a) 'Central Bank Oversight of Payment and Settlement Systems', available at http://goo.gl/cW8rr

Committee on Payment and Settlement Systems (CPSS) (2005b) 'General Guidance for Payment System Development 2005', available at http://goo.gl/QU7ek

Committee on Payment and Settlement Systems (CPSS) (2007) 'General Principles for International Remittance Services', available at http://goo.gl/mxsnF

Committee on Payment and Settlement Systems (CPSS) and Bank for International Settlements (BIS) (2001) 'Core Principles for Systemically Important Payment Systems', CPSS Publications No 43, January, available at http://goo.gl/nxWH3

Communications Commission of Kenya (CCK) (2011a) 'Market Structure - Telecommunications: Unified Licensing Framework', available at http://goo.gl/bKORK

Communications Commission of Kenya (CCK) (2011b) 'Sector Regulations', available at http://goo.gl/yNHiQ 
Communications Commission of Kenya (CCK) (2011c) 'What We Do', available at http://www.cck.go.ke/about/

Comninos, A et al (2008) 'M-banking the Unbanked' Vol 1 Research ICT Africa, Policy Paper 4, at 6, available at http://goo.gl/UdXks

Competition Commission (2008a) 'Banking Enquiry Report to the Competition Commissioner: Technical Report', available at http://goo.gl/JRWNj

Competition Commission (2008b) 'Banking Enquiry Report to the Competition Commissioner by the Enquiry Panel: Executive Overview', available at http://goo.gl/WDDbY

Conference of State Bank Supervisors (CSBS) (2012) 'What is CSBS?,' available at http://goo.gl/LjWxm

Consultative Group to Assist the Poor (CGAP) (2006) 'Use of Agents in Branchless Banking for the Poor: Rewards, Risks, and Regulation' 38 CGAP Focus Note, available at http://goo.gl/sXHMU

Consultative Group to Assist the Poor (CGAP) (2007) 'Notes on Regulating Branchless Banking in Kenya', CGAP Technology Program, 2 November, 1-19, available at http://goo.gl/1VxlM

Consultative Group to Assist the Poor (CGAP) (2009a) 'Financial Access 2009: Measuring Access to Financial Services around the World' 2, available at http://goo.gl/fuBBy

Consultative Group to Assist the Poor (CGAP) (2009b) 'South Africa: Mobile Banking Reaches beyond the City', available at http://goo.gl/Wghca (check since now a and b)

Consultative Group to Assist the Poor (CGAP) (2010a) 'Financial Access 2010: The State of Financial Inclusion Through the Crisis', available at http://goo.gl/iRSD

Consultative Group to Assist the Poor (CGAP) (2010b) 'Update on Regulation of Branchless Banking in Kenya January 2010', 1-8, available at http://goo.gl/eIZcd

Consultative Group to Assist the Poor (CGAP) (2010c) 'Update on Regulation of Branchless Banking in South Africa January 2010', 1-13, available at http://goo.gl/tBAc1 (CHECK AS NOW A \& b)

Cooper, S (2008) 'NARUSCA v FCC: Federalism, Line Item Billing and the Future of Wireless Consumer Protection' 9(2) Engage: The Journal of the Federalist Society's Practice Groups, available at http://goo.gl/Hw5vg

Cooter, RD and Rubin, EL (1987) ‘A Theory of Loss Allocation for Consumer Payments’ 66(1) Texas Law Review 63-130

Corbett, S (2008) 'Can the Cellphone Help End Global Poverty?' New York Times Magazine, 3 April, available at http://goo.gl/US99k

Cornelius, S (2003) 'The Legal Nature of Payment by Credit Card' 15(2) SA Mercantile Law Journal 153-171

Costa, C and De Grauwe, P (2001) 'Monetary Policy in a Cashless Society', available at http://goo.gl/3j7q2

Cowen, DV and Gering, L (1985) The Law of Negotiable Instruments in South Africa

Cowen, T and Kroszner, R (1987) 'The Development of the New Monetary Economics' 95(3) Journal of Political Economy $567-590$

Crawford, B (1997) 'Is Electronic Money Really Money?' 12 Banking and Finance Law Review 399-424

Crede, A (1995) 'Electronic Commerce and the Banking Industry: The Requirement and Opportunities for New Payment Systems Using the Internet' 1(3) Journal of Computer-Mediated Communication (no pagination), available at http://goo.gl/NkdWC

Cronje, DSP, Olivier, JA and Barnard, AH (1986) The South African Law of Persons and Family Law 2nd ed

Crowe, M, Schuh, S and Stavins, J (2006) 'Consumer Behavior and Payment Choice: A Conference Summary', available at http://goo.gl/TyEux

Cull, D (2008) 'Note on the Altech Judgment', available at http://goo.gl/aOZEe

Cullen International SA and WIK Consult GmbH (2005) 'Final Report for Study on Pan-European Market for Premium Rate Services', 24 June, available at http://goo.gl/mTKnf

'Currency' (s.d.) in Oxford Dictionaries, available at http://goo.gl/z3soH 
Daily Nation (2008) 'Michuki: Probe Cash Transfer', available at http://goo.gl/bhRMj

Dalton, G (1965) 'Primitive Money’ 67(1) American Anthropologist 44-65

Daniel, C (2008) ‘Mobile Payments: A Push Towards a Cashless Society or a Fad?', available athttp://goo.gl/C3BqX

Davies, GA (1994) A History of Money: From Ancient Times to the Present Day

De Jager, J (2006) 'The South African Reserve Bank: An Evaluation of the Origin, Evolution and Status of a Central Bank: Part 1' 18 SA Mercantile Law Journal 159-273

De Jager, J (2010) 'Much Ado about Nothing? Legal Principles on Money, Banks and Their Clients after Joint Stock Company Varvarinskoye v ABSA Bank Ltd' 22 SA Mercantile Law Journal 127-140

De Koker, L (2002) 'Money Laundering in South Africa', Institute for Security Studies, South Africa, 1 September, available at http://goo.gl/4TXD5

De Koker, L (2008) 'Money Laundering and Terror Financing Risk Management of Low Risk Financial Products and Services in South Africa', available at http://goo.gl/cCSTQ

De Koker, L (2009) 'The Money Laundering Risk Posed by Low-risk Financial Products in South Africa: Findings and Guidelines' 12(4) Journal of Money Laundering Control 323-339

De Koker, L (2010) 'Will RICA's Customer Identification Data meet Anti-Money Laundering Requirements and Facilitate the Development of Transformational Mobile Banking in South Africa? An Exploratory Note' Finmark Trust, available at http://goo.gl/dtboP

De Larosière Group, The (2009) 'Report on Financial Supervision in the EU', available at http://goo.gl/CroZY

De Nederlandsche Bank (2004) The Cost of Payments: Survey on the Costs involved in POS Payment Products, Working Group on Costs of POS Payment Products, National Forum on the Payments System

De Vicuña, S (2010) 'An Institutional Theory of Money', in Giovanoli, M and Devos, D International Monetary and Financial Law: The Global Crisis at par 25.01

De Waal, MJ (2000) 'The Core Elements of the Trust: Aspects of the English, Scottish and South African Trusts Compared' 117(3) South African Law Journal 548-571

De Wet, JC and Van Wyk, AH (1992) Kontraktereg en Handelsreg $5^{\text {th }}$ ed

Deloitte (2012) 'Deloitte on Africa: Banking Regulatory Environment And Supervision In Africa', available at http://goo.gl/TdTKJ..

Demirgüç-Kunt, A, Beck, T and Honohan, P (2008) 'Finance for All? Policies and Pitfalls in Expanding Access', available at http://goo.gl/4ILM5

Den Herto, J (1999) ‘General Theories of Regulation', available at http://goo.gl/8QjYD

Department for Business Innovation and Skills (s.d.) 'FAQ’, available at http://bit.ly/ddPuDl

Department of Communications (2011) 'Post RICA Campaign Media Briefing', available at http://goo.gl/OghGB

Department of the Treasury (2010) 'Proposed Rules' 75(123) Federal Register Monday 28 June, available at http://goo.gl/Qh0Hm

'Deposit' (2011) in Oxford Dictionaries, available at http://goo.gl/grsfy

Digital Money Forum (2006) ‘Cashless Country’, available at http://goo.gl/QbzhX

Dew, JK (2009) 'Tying Bank Regulation to Banks' Risk-Return Trade-Offs Following the Financial Crisis: Holding Congress and its Regulatory Apparatus Accountable' Networks Financial Institute Working Paper No 2007-WP-17B, available at http://goo.gl/FXQQr

Dietrick, J (2012) Bad Pennies and Dead Presidents: Money in Modern American Drama, available from http://goo.gl/iUPCf

'Digital' (2011) in Oxford Dictionaries, available at http://goo.gl/ckFyU

Dlamini, T (2009) 'Managing the Crisis: South Africa Country Report', available at http://goo.gl/XAkuR

Dodd, N (1994) The Sociology of Money: Economics, Reason and Contemporary Society 
Dodd, N (2005) 'Laundering “Money”: On the Need for Conceptual Clarity within the Sociology of Money' 46(3) Archives Européennes de Sociologie 387-411

Dodd, N (2007) 'On Simmel's Pure Concept of Money: A Response to Ingham’ 48 European Journal of Sociology 273-294

Dowd, K (1999) 'Too Big to Fail? Long-Term Capital Management and the Federal Reserve' Cato Briefing Paper No 52, available at http://goo.gl/q1n93

Drehmann, M, Goodhart, CAE and Krüger, M (2002) 'The Challenges Facing Currency Usage: Will the Traditional Transaction Medium be Able to Resist Competition from the New Technologies?' 17 Economic Policy 193-227, available at http://goo.gl/T982q

Du Bois, F (2007) Wille's Principles of South African Law $9^{\text {th }}$ ed

Du Plessis, JE (2002) 'Die Regsaard Van Prestasie’ 65(1) Tydskrif vir die Hedendaagse Romeins-Hollandse Reg 59-73

Du Plessis, JE (2011) 'The Cause of Action in Nissan South Africa (Pty) Ltd V Marnitz No(Stand 186 Aeroport (Pty) Ltd Intervening) 2005 (1) SA 441 (SCA)' in Mostert H \& De Waal MJ (eds) Essays in Honour of CG Van der Merwe 1-20

Du Toit, SF (2009) 'Die Dematerialisasie Van Geld: In Die Skadu Van Die Sakereg' 1 Tydskrif vir die Suid-Afrikaanse Reg $1-21$

Duhl, GM (2009) 'International Developments in Consumer Financial Services Law 2007-2008' 64 Business Lawyer (William Mitchell Legal Studies Research Paper No 2009-07), available at http://goo.gl/FqG84

Dwyer, G (1996) 'Wildcat Banking, Banking Panics and Free Banking in the United States' Federal Reserve Bank of Atlanta, available at http://goo.gl/Rdiaf

Dykes, JMM (1995) 'Digital Cash and the Development of the Apolitical Currency Paper for MIT 6.805/STS085: Ethics and Law on the Electronic Frontier', available at http://goo.gl/OOVVH

Dymski, G (2005) 'Banking Strategy and Financial Exclusion: Tracing the Pathways of Globalization' 31 Revista de Economia, 1-29,107-143, Social Science Research Network, available at http://goo.gl/PKb6i

East African Community (EAC) (2011) ‘EAC Quick Facts’, available at http://goo.gl/13zpm

East and Southern African Banking Group (s.d.) 'Factors Leading to the Founding of the SARB', available at http://goo.gl/DgEcC

East Japan Rail Company (s.d.) 'Suica \& N'EX: What is It?', available at http://goo.gl/EnftW

Ebers, M (2004) 'Information and Advising Requirements in the Financial Services Sector: Principles and Peculiarities in EC Law' 8(2) Electronic Journal of Comparative Law, available at http://goo.gl/U6kln

Echo, S (2010) 'Bulgarian Criminals "Beating the System" of Pre-paid SIM Card Registration', available at http://goo.gl/OjfIb

Ecomlink (2010) 'Prepaid Cards and the Underserved', available at http://goo.gl/73iPN

Economicae (s,d.) ‘Keynesian Monetary Theory’, available at http://goo.gl/iPW25

Eder, PJ (1935) ‘Legal Theories of Money’ 20 Cornell Law Quarterly 52

Edozien, J (2008) 'Ending Economic Apartheid', South African New Economics Network, available at http://goo.gl/L9cQZ

Edward Nathan Sonnenbergs (2010) 'Electronic Funds Transfers to SARS?' 126 Integritax Newsletter, posted on MoneyWebTax, 20 April, available at http://goo.gl/zr116

Edwards, R (2009) 'Does Law Follow Money?' 21(1) Bond Law Review 41-64, Article 3, 1-24, available at http://goo.gl/108w3

Effros, RC (2002) Electronic Payment Systems: Legal Aspects in Legal Issues in Electronic Banking

E-Government (2009) 'Kenya: Kenyan Legislators Underscore the Role of e-Transactions Law', available at http://goo.gl/FhtUz

Eisner, MA, Worsham, J and Ringquist, EJ (2000) Contemporary Regulatory Policy

[E]lectronic-payments.co.uk (2011) ‘Electronic Payments Security’, available at http://goo.gl/ASmTM 
Ellinger, EP (1986) 'The Giro System and Electronic Transfers of Funds' Lloyd's Maritime and Commercial Law Quarterly $178-217$

Ellinger, EP, Lomnicka, E and Hooley, A (2006) Ellinger's Modern Banking Law $4^{\text {th }}$ ed

Ellis, H (1934) German Monetary Theory 1905-1933

Ellis, KS (2004) 'Gift Cards/SVCs Overview AFSA SGR Card Subcommittee Legislative Report', available at http://goo.gl/p6JBi

Elsenhuber, U and Schimk, B (2006) 'Payment Institutions: Potential Implications of the New Category of Payment Service Providers for the Austrian Financial Market', available at http://goo.gl/VedWG

Ely, B (1996) 'Electronic Money and Monetary Policy: Separating Fact from Fiction' Cato Institute's Conference on the Future of Money in the Information Age, May 23, 1996, available at http://goo.gl/GjgXN

Equity Bank (2010) 'Orange Money is Launched in Kenya', available at http://goo.gl/OEDBI

Ernst and Young (2009) 'Mobile Money: An Overview for Global Telecommunications Operators', available at http://goo.gl/xAEqS

estandardsforum (2011) 'South Africa', available at http://goo.gl/9v2k1

Europa (2011) ‘Subsidiarity’, in Glossary available at http://goo.gl/J1bJf.

European Banking Association (EBA) (2008) 'Banks Preparing for PSD: A Guide for Bankers on the Payment Services Directive' Version 1.1 November, available at http://goo.gl/mWW5e

European Banking Industry (EBI) (2009) 'Guidance for the Implementation of the Payment Services Directive', available at http://goo.gl/rdbtc

European Central Bank (ECB) (2003) Oversight Standards for Euro Retail Payment Systems, available at http://goo.gl/spzs1

European Central Bank (ECB) (2004) 'Issues Paper for the ECB Conference on 10 November 2004: E-Payments without Frontiers', available at http://goo.gl/TQcLx

European Central Bank (ECB) (2006) 'Opinion of the ECB on a Proposal for a Directive on Payment Services in the Internal Market (ECB/2006/21)’, available at http://goo.gl/8EA5t

European Central Bank (ECB) (2007) 'Nonbanks in the Payments System: European and U.S. Perspectives' Payments System Research Working Paper No PSR WP 07-01 at 62, available athttp://goo.gl/HPOi6

European Central Bank (ECB) (2009a) 'Payment System' Glossary of Terms Related to Payment, Clearing and Settlement Systems, available at http://goo.gl/8E19w

European Central Bank (ECB) (2009b) 'SEPA Brochure 2009', available at http://goo.gl/yt463

European Central Bank (ECB) (2010b) 'Retail Payment Systems', available at http://goo.gl/QM7Xr

European Central Bank (ECB) (2011a) 'Payment' in Payments and Markets Glossary, available at http://goo.gl/gdQYW

European Central Bank (ECB) (2011b) 'Retail Funds Transfer System', available at http://goo.gl/Kap9W

European Central Bank (s.d.) 'Retail Funds Transfer System' in Payments and Markets Glossary, available at http://goo.gl/Kap9W

European Commission (EC) (2001) 'COM/2001/0066 Communication from the Commission to the Council and the European Parliament: E-commerce and Financial Services’, available from http://goo.gl/ITTTw

European Commission (EC) (2003a) 'Communication from the Commission to the Council, the European Parliament and the European Central Bank: Application to Financial Services of Article 3(4) to (6) of the Electronic Commerce Directive' Brussels, 14.05.2003, COM(2003)259 final, available at http://goo.gl/NwUDD

European Commission (EC) (2003b) ‘Comparative Tables of National Rules', available at http://goo.gl/ULYH4

European Commission (EC) (2004) 'Application of the E-Money Directive to Mobile Operators: Consultation Paper of DG Internal Market', 1-18, available at http://goo.gl/U9rcD 
European Commission (EC) (2005a) 'Application of the E-Money Directive to Mobile Operators: Guidance Note from the Commission Services', available at http://goo.gl/9iF3U

European Commission (EC) (2005b) 'How the European Union Works: Your Guide to the EU Institutions', available at http://goo.gl/6f0hY

European Commission (EC) (2006a) 'Application of the E-money Directive to Mobile Operators: Summary of Replies to the Consultation Paper of DG Internal Market', available from http://goo.gl/q0Hcz

European Commission (EC) (2006b) 'Commission Staff Working Document on the Review of the E-Money Directive (2000/46/EC)', available at http://goo.gl/1GuIG

European Commission (EC) (2006c) 'Evaluation of the E-Money Directive (2000/46/EC)', available at http://goo.gl/xBarE

European Commission (EC) (2007a) 'Commission Communicationon the Implementation of the Distance Selling Directive', available at http://goo.gl/wkZSP

European Commission (EC) (2007b) ‘New Legal Framework (NLF) for Payments', available at http://goo.gl/HYNEG

European Commission (EC) (2007c) 'Payment Services Directive: Commission Encourages Swift and Coherent Implementation at National Level', available at http://goo.gl/10A61

European Commission (EC) (2007d) 'Payment Services Directive: Frequently Asked Questions \#23', available at http://goo.gl/rSVr

European Commission (EC) (2008a) 'Consolidated Version of the Treaty on the Functioning of the European Union', available at http://goo.gl/RMvkp

European Commission (EC) (2008b) 'Memorandum of Understanding on Cooperation between the Financial Supervisory Authorities, Central Banks and Finance Ministries of the EU on Cross-Border Financial Stability 2008', available at http://goo.gl/cjwmY

European Commission (EC) (2008c) 'Report on Fraud Regarding Non-cash Means of Payments in the EU: The Implementation of the 2004-2007 EU Action Plan', available at http://goo.gl/nNWZH

European Commission (EC) (2009) 'The EU Compendium Paper on AML supervisory practices' 2 EU AML Info-Letter December, available at http://goo.gl/UzhWB

European Commission (EC) (2010) '2010/C 83/01: Consolidated Versions of the Treaty on EU and the Treaty on the Functioning of the European Union', available at http://goo.gl/Y3UhG

European Commission (EC) (2011a) ‘EC Payments Legislation', available at http://goo.gl/2dhGd

European Commission (EC) (2011b) 'EEJ-Net', available at http://goo.gl/Rs69V

European Commission (EC) (2011c) 'FAQ on the PSD: Question 385', available at http://goo.gl/d5cAw

European Commission (EC) (2011d) 'Financial Services: Additional Legislative Proposal to Complete the Framework for Financial Supervision in Europe', available at http://goo.gl/LqWxC

European Commission (EC) (2011e) 'History of the EU', available at http://goo.gl/4vBN

European Commission (EC) (2011f) 'Information on the Payer Accompanying Transfers of Funds', available at http://goo.gl/NQihO

European Commission (EC) (2011g) ‘Information Society: The Telecoms Reform', available at http://goo.gl/5jSUN

European Commission (EC) (2011h) 'Protection of Consumers' Economic and Legal Interests', available at http://goo.gl/Oz1Ny

European Commission (EC) (2011i) ‘Transposition of the 3rd Anti-Money Laundering Directive: State of Play', available at http://goo.gl/MLJU2

European Commission (EC) (s.d.) 'Application of the e-Money Directive to Mobile Operators: Guidance Note from the Commission Services', available at http://goo.gl/9iF3U

European Commission (EC) (s.d.) 'Legislation', available at http://goo.gl/2dhGd

European Commission (EC) (s.d.) 'New Legal Framework (NLF) for Payments', available at http://goo.gl/HYNEG 
European Commission (EC) Information Society (s.d.) 'The Telecoms Reform', available at http://goo.gl/C6nin

European Court of Justice (ECJ) (2009) 'Press Release No 31/09', available at http://goo.gl/cKmx7

European Financial Marketing Association (EFMA) (2008) 'High Level of Unbanked People in Eastern Europe', available at http://goo.gl/weaWa

European Parliament (2009) 'Commission Proposal for a Regulation on Community Macro-prudential Oversight of the Financial System and Establishing a European Systemic Risk Board (23 September 2009)'

European Union (EU) (2009) 'Commission Proposal for a Regulation on Community Macro-prudential Oversight of the Financial System and Establishing a European Systemic Risk Board (23 September 2009)', available at http://goo.gl/CdPji

European Union (EU) (2011a) 'ESFS Frequently Asked Questions', available at http://goo.gl/BdzfB

European Union (EU) (2011b) ‘EU Institutions and Other Bodies’, available at http://goo.gl/2AbjS

European Union (EU) (2011c) ‘EU Treaties', available at http://goo.gl/ftToi

European Union (EU) (s.d.) 'Summaries of EU Legislation: Fifth Report on the Implementation of the Telecommunications Regulatory Package', available at http://goo.gl/rZHp6

Fahey, E (2011) 'Does The Emperor Have Financial Crisis Clothes? Reflections on the Legal Basis of the European Banking Authority' 74(4) Modern Law Review 581-595, available at http://goo.gl/Ge1C4

Fajfar, M (2004) 'Role and Security of Payment Systems in an Electronic Age' Remarks prepared for IMF Institute Seminar on Current Developments in Monetary and Financial Law, available from http://goo.gl/BPHIs

Falkena, H et al (2001) 'SMES' Access to Finance in South Africa: A Supply-Side Regulatory Review' Task Group of the Policy Board for Financial Services and Regulation, available at http://goo.gl/brdbX

Falkena HB et al (2002) 'Establishing Narrow and Core Banks and their Competitive Impact on Fully Fledged Banks in South Africa' Report of the Task Group of the Policy Board for Financial Services and Regulation

Falkena, H et al (2004a) 'Competition in South African Banking: Task Group Report for the National Treasury and the South African Reserve Bank’, available at http://goo.gl/nZeNb

Falkena, HB (2004b) 'The Access and Stability Objectives of Regulation' Workshop on Tiered Banking Legislation, available at http://goo.gl/Us0cD

Fama, EF (1980) 'Banking in the Theory of Finance' 6 Journal of Monetary Economics 39-57

Fanon, A and Ateya, I (2008) 'Security Issues in M-Banking', available at http://goo.gl/3yEmy

Faul, W (1989) ‘Die “Smart” Kaart: Hoe Werk Dit?’ 1 SA Mercantile Law Journal 381

Feasibility (2005) 'The Impact of the Dedicated Banks Bill on Access to Financial Services', available at http://goo.gl/zvL92

Feasibility (2005) 'The Impact of the Dedicated Banks Bill on Access to Financial Services', available at http://goo.gl/iEizm (Note: Link unavailable since August 2011.)

Feasibility (2006) 'The National Payment System and Competition in the Banking Sector: Report prepared for the Competition Commission: Executive Summary and Synopsis', available at http://goo.gl/iTymu

Feasibility (2009) 'The Banking Enquiry 2009', available at http://goo.gl/X02Ms

Federal Communications Commission (FCC) (s.d.) 'Unauthorized, Misleading, or Deceptive Charges Placed on Your Telephone Bill: “Cramming”' FCC Consumer Facts, available at http://goo.gl/e85hF

Federal Deposit Insurance Corporation (FDIC) (1996) ‘General Counsel’s Opinion No. 8: Stored Value Cards’, 61 Fed. Reg. 40

Federal Deposit Insurance Corporation (FDIC) (2005) 'FIL-24-2005: Statement on MSBs', available at http://goo.gl/21ML4

Federal Deposit Insurance Corporation (FDIC) (2008) 'General Counsel's Opinion No. 8: Stored Value Cards and Other Nontraditional Access Mechanisms’, available at http://goo.gl/IXoI5

Federal Deposit Insurance Corporation (FDIC) (2009a) 'Banks' Efforts to Serve the Unbanked and Underbanked Report 2009', available at http://goo.gl/rVF5A 
Federal Deposit Insurance Corporation (FDIC) (2009b) 'FDIC National Survey of Unbanked and Underbanked Households: Executive Summary', available at http://goo.gl/DRqn1

Federal Deposit Insurance Corporation (FDIC) (2009c) 'National Survey of Unbanked and Underbanked Households December 2009', available at http://goo.gl/DRqn1

Federal Deposit Insurance Corporation (FDIC) (2010) 'FDIC Advisory Committee on Economic Inclusion: Strategic Plan', available at http://goo.gl/098kY

Federal Deposit Insurance Corporation (FDIC) (2011) 'FFIEC Information Technology Examination Handbook', available at http://goo.gl/JQoC5

Federal Financial Institutions Examination Council (s.d.) 'Consumer Affairs Laws and Regulations: Regulation CC', available at http://goo.gl/X1pIv

Federal Reserve Board (FRB) (2004) 'A Summary of the Roundtable Discussion on Stored-Value Cards and Other Prepaid Products', available at http://goo.gl/c79E2

Federal Reserve Board (FRB) (2006) 'Electronic Funds Transfers’, available at http://goo.gl/9zG36

Federal Reserve Education (2011a) ‘Electronic Funds Transfer (EFT)’ Glossary, available athttp://goo.gl/MBf1P

Federal Reserve System (FRS) (2011b) 'The 2010 Federal Reserve System Payments Study: Noncash Payments Trends in the United States: 2006-2009', available at http://goo.gl/HCRMH

Federal Trade Commission (FTC) (2012) ‘About the Federal Trade Commission’, available at http://goo.gl/BFsII

Felsenfeld, C and Bilali, G (2004) 'The Role of the Bank for International Settlements in Shaping the World Financial System’ Fordham School of Law, Pub-Law Research Paper No 44, available at http://goo.gl/FjlT1

Ferguson, N (2008) The Ascent of Money: A Financial History of the World

'Fiat' (2011) in Merriam-Webster, available at http://goo.gl/I32Nd

Figueras, ME and de Subirà, AC (1997) Telematic Currency and Market Strategy, transl by Loti Perella (Chapter 2), available at http://goo.gl/IPjAQ

FinAccess (2009) 'National Survey 2009: Dynamics of Kenya's Changing Financial Landscape', available at http://goo.gl/XtBYS

Financial Action Task Force (FATF) (s.d) 'What is Money Laundering?', FAQ, available at http://goo.gl/wo405

Financial Action Task Force (FATF) (1996) 'FATF-VII Report on Money Laundering Typologies', available at http://goo.gl/hoz02

Financial Action Task Force (FATF) (2001) 'FATF Special Recommendation VII: Wire Transfers,' available at http://goo.gl/RvL5b

Financial Action Task Force (FATF) (2003) 'The 40 Recommendations', available at http://goo.gl/c8e1o

Financial Action Task Force (FATF) (2005) 'Money Laundering and Terrorist Financing Typologies 2004-2005', available at http://goo.gl/5sITY

Financial Action Task Force(FATF) (2009a) 'Eastern and Southern Africa Anti-Money Laundering Group Mutual Evaluation Report: February 2009’, available at http://goo.gl/b9j2L

Financial Action Task Force (FATF) (2009b) 'Methodology for Assessing Compliance with the FATF 40 Recommendations and the FATF 9 Special Recommendations', available at http://goo.gl/UmZIS

Financial Action Task Force (FAFT) (2011) 'What is the FATF?', available at http://goo.gl/PDdiP

Financial Crimes Enforcement Network (FinCEN) (2000) 'A Survey of Electronic Cash, Electronic Banking and Internet Gaming,' available at http://goo.gl/6gkio

Financial Crimes Enforcement Network (FinCEN) (2000) 'Internet Gaming' in A Survey of Electronic Cash, Electronic Banking, and Internet Gaming, 13-14, available at http://goo.gl/ydoeZ

Financial Crimes Enforcement Network (FinCEN) (2003) 'FinCEN Advisory 33: Informal Value Transfer Systems', available at http://goo.gl/HYfks 
Financial Crimes Enforcement Network (FinCEN) (2010) 'Amendment to the Bank Secrecy Act Regulations - Definitions and Other Regulations Relating to Prepaid Access' 75(123) Federal Register, 28 June, 36589-36608, available at http://goo.gl/Qh0Hm

Financial Crimes Enforcement Network (FinCEN) (2010) 'Financial Crimes Enforcement Network; Amendment to the Bank Secrecy Act Regulations - Definitions and Other Regulations Relating to Prepaid Access' 75(123) Federal RegisterJune 28, 36589-36608, available at http://goo.gl/Qh0Hm

Financial Crimes Enforcement Network (FinCEN) (2011) 'Money Services Businesses Home,' available at http://goo.gl/mlwbD

Financial Intelligence Centre (FIC) (2001) ‘About Us’, available at http://goo.gl/1IyAO

Financial Intelligence Centre (FIC) (2005) 'Guidance Note 3: Guidance for Banks on Customer Identification and Verification and Related Matters', available at http://goo.gl/yZ1jk

Financial Management Service (2011) 'US Treasury to "Retire" Paper Check for New Recipients of Social Security and Other Federal Benefits, Saving Taxpayers \$1 Billion,' available at http://goo.gl/9HQfz

Financial Services Authority (FSA) (2005) 'Handbook Release 041 April 2005: Ecommerce Directive', available at http://goo.gl/dM56v

Financial Services Authority (FSA) (2006) 'A Guide to Market Failure Analysis and High Level Cost Benefit Analysis' available at http://goo.gl/kFzus

Financial Services Authority (FSA) (2009a) 'Financial Services Authority (FSA) 2009/19: Perimeter Guidance (Payment Services Scope) Instrument 2009', available at http://goo.gl/f9GqW

Financial Services Authority (2009b) 'Statutory Instruments 2009 No. 209: Financial Services and Markets: The Payment Services Regulations 2009’, available at http://goo.gl/WzEBE

Financial Services Authority (FSA) (2010a) 'The FSA's role under the Payment Services Regulations: Our Approach', available at http://goo.gl/6ulKi

Financial Services Authority (FSA) (2010b) 'Minutes of the First Meeting of the 2EMD Stakeholder Liaison Group held on 22 April 2010’, available at http://goo.gl/0g9Qj

Financial Services Authority (FSA) (2011a) 'E-money Directive', available at http://goo.gl/naM8j

Financial Services Authority (FSA) (2011b) ‘European Supervisory Authorities’, available at http://goo.gl/DL6q8

Financial Services Authority (FSA) (2011c) 'Financial Services Authority Handbook: PERG 15.4 Small Payment Institutions, Agents and Exempt Bodies', available at http://goo.gl/FkL4Q

Financial Services Authority (FSA) (2011d) 'Financial Services Authority (FSA) Handbook: BCOBS Banking Conduct of Business Sourcebook', available at http://goo.gl/PJETH

Financial Services Authority (FSA) (2011e) 'Minutes of the Meeting of the 2EMD Stakeholder Liaison Group', available at http://goo.gl/EbYks

Financial Services Authority (FSA) (2011f) 'The FSA's role under the Electronic Money Regulations 2011: Our Approach,' available at http://goo.gl/7USnQ

Financial Services Authority (FSA) (s.d.) 'FSA 2001/53 Threshold Conditions (Amendment) Instrument 2001, Auth 2.6.2G, , available at http://goo.gl/Jt7Xw

Finextra (2007) ‘Alliance and Leicester Introduces Pre-paid Debit Card for Public Sector’, available at http://goo.gl/zelzr

Finextra (2008) 'US Treasury to Introduce Pre-paid Welfare Card', available at http://goo.gl/07Thy

Finmark Trust (2005) 'FinScope 2005: A Comprehensive Nationwide Survey of Financial Usage in South Africa', available at http://goo.gl/tEycm

Finmark Trust (2007) 'South Africans Shun the Piggy-Bank', available at http://goo.gl/2smnV

Finmark Trust (2009) 'Finmark Brief: The Banking Enquiry 2009', available at http://goo.gl/pBQrw

Finmark Trust (2010) 'FinScope South Africa 2010', available at http://goo.gl/nI7V3

First National Bank (FNB) (2010) ‘Cellphone Banking Terms and Conditions', available at http://goo.gl/S2jM5 
Firstrand Group (s.d.) 'Annex 11: Regulatory Framework: Submission to the Competition Commission', available at http://goo.gl/KeKKK

Fisher, I (1909) 'A Practical Method of Estimating the Velocity of Circulation of Money' 604-605 cited in Morgan, MS (2006) 'Measuring Instruments in Economics and the Velocity of Money' Working Papers on the Nature of Evidence: How Well Do "Facts" Travel? No 13/06, available at http://goo.gl/YaEdH

Fisher, I (1909) The Purchasing Power of Money

Fisher-French, M (2012) 'Mzansi Accounts Reach Dead End' Mail and Guardian, available at http://goo.gl/jzUy1

Fitch, TP (2006) 'EFT' in Dictionary of Banking Terms (Barron's Business Guides) $5^{\text {th }}$ ed

Flismark, B (2010) 'The Payment Services Directive: A Crucial Step Toward Payment Harmonization Across the EU', QFinance, 1-5, available at http://goo.gl/OdcE4

Forbes, J (2007) 'The Convergence of Telecom and Financial Services and its Effects on AML/CFT Wire Remittance Operations', available at http://goo.gl/m4Wdm

Forster, M (2010) ‘The New EU Financial Regulatory Framework', available at http://goo.gl/ejRCZ

Fouché, MA (ed) (2002) Legal Principles of Contracts and Negotiable Instruments $5^{\text {th }}$ ed

Fox, D (1996) 'Bona Fide Purchase and the Currency of Money’ 55 Cambridge Law Journal 547-565

Fox, D (2005) 'Property in Intangible Money’ Society of Legal Scholars Strathclyde Conference 2005

Fox, D (2008) Property Rights in Money

Fox, D (2009) 'Defective Payments of Incorporeal Money in South African and English Law' 4 Tydskrif vir die SuidAfrikaanse Reg 638

Fox, D (2010a) ‘Identification of Money at Common Law’ 69 Cambridge Law Journal 28-30

Fox, D (2010b) 'The Case of Mixt Monies: Confirming Nominalism in the Common Law of Monetary Obligations', available at http://goo.gl/lcKOF

Fraser, BW (1994) 'Central Bank Independence: What Does It Mean?' Talk presented at 20th SEANZA Central Banking Course, Karachi

Friedman, C (2000) 'Decoupling at the Margin: The Threat to Monetary Policy from the Electronic Revolution in Banking' 3(2) International-Finance 211

Friedman, DD (1987) 'Economic Analysis of Law' in The New Palgrave: A Dictionary of Economic Theory and Doctrine, available at http://goo.gl/V4rpL

Friedman, M (1992) Money Mischief: Episodes in Monetary History

Friedman, P (2005) 'Banking the Unbanked: Helping Low-Income Families Build Financial Assets', available at http://goo.gl/GymU1

Friedman, SJ (1984) 'A New Paradigm for Financial Regulation: Getting from Here to There' Pace Law Faculty Publications, Paper 118, available at http://goo.gl/WJkWP

Fritz, S (s.d.) ‘Stockholm’s Banco’, available at http://goo.gl/USmVg

Fry, MJ et al (1999) Payment Systems in Global Perspective

'Fungible' (2011) in Oxford Dictionaries, available at http://goo.gl/bQkaZ

Fullenkamp, C and Nsouli, SM (2004) ‘Six Puzzles in Electronic Money and Banking', available at http://goo.gl/b8rwZ

Furletti, MJ (2004a) 'Prepaid Card Markets and Regulation' Federal Reserve Bank of Philadelphia Payment Cards Center Discussion Paper 04-01, available at http://goo.gl/3eGbi

Furletti, MJ (2004b) 'The Debate Over the National Bank Act and the Pre-emption of State Efforts to Regulate Credit Cards' 77 Temple Law Review, available at http://goo.gl/lfqvk 
Gamboa, LF and Gutierrez, LH (2008) 'Use of Informal Mobile Telephony in Low Income Households in Colombia' Documentos de Trabajo, Facultad de Economía, Universidad del Rosario, No 45, available at http://goo.gl/uDDH3

Gamingzion (2010) 'South Africa ISPs Battle Online Gambling Board', available at http://goo.gl/WMovV

Ganßmann, H (2009) 'Money, Credit and the Structures of Social Action', available at http://goo.gl/n0gl4

Gaus, Gerald (2010) 'Liberalism' in Stanford Encyclopedia of Philosophy, available at http://goo.gl/Z3myh

GCASH (2011a) 'How It Works' available at http://gcash.globe.com.ph/

GCASH (2011b) 'What is GCASH?', available at http://gcash.globe.com.ph/

Gencer, M and Ranck, J (2012) 'Advancing the Dialogue on Mobile Finance and Mobile Health: Country Case Studies,' available from http://goo.gl/0DWLa

'Genus' (s.d.) in Wikipedia: The Free Encyclopedia, available at http://goo.gl/esvju

German Notes (s.d.) 'History of Paper Money', available at http://goo.gl/9ASjt

Geva, B (1987) 'From Commodity to Currency in Ancient History-On Commerce, Tyranny, and the Modern Law of Money' 25 Osgoode Hall Law Journal 115

Geva, B (1989) ‘The EFT Debit Card’ 15 Canadian Business Law Journal 406

Geva, B (1990) 'Payment into a Bank Account' 3 Journal of International Banking Law 108

Geva, B (1993) The Law of Electronic Funds Transfers

Geva, B (2000-2001) 'Legal Aspects Relating to Payment by E-Money: Review of Retail Payment System Fundamentals' 5 Yearbook of International Finance and Economic Law 255

Geva, B (2001) Bank Collections and Payment Transactions: Comparative Study of Legal Aspects

Geva, B (2004) 'The Beneficiary's Bank and Beneficiary Described by Name and Number: Liability Chain and Liability Standard in Wire Transfers (Part 1)' 1 Tydskrif vir die Suid-Afrikaanse Reg 1-19

Geva, B (2007) 'Recent International Developments in the Law of Negotiable Instruments and Payment and Settlement Systems', available at http://goo.gl/MpW9G

Geva, B (2008a) 'Payment Finality and Discharge in Funds Transfers', available at http://goo.gl/jruIS

Geva, B (2008b) 'TARGET2 Transfer of Funds and Harmonization of EU Payment Law' 41(2) Uniform Commercial Code Law Journal 113-145

Geva, B (2009a) ‘The EU Payment Services Directive: An Outsider's View’ 28 Yearbook of European Law 177-215

Geva, B (2009b) 'Payment Transactions Under the EU Payment Services Directive: A US Comparative Perspective' 27(3) Pennsylvania State International Law Review 713-755, available at http://goo.gl/Wj2BB

Geva, B (2010) 'The Harmonization of Payment Services Law in Europe and Uniform and Federal Funds Transfer Legislation in the USA: Which is a Better Model for Reform?' Annual Banking Law Update 22

Geva, B and M Kianieff (2005) 'Reimagining E-Money: Its Conceptual Unity with other Retail Payment Systems' at 2-4, available at http://goo.gl/QfR4y

Gianviti, F (2005) 'Current Legal Aspects of Monetary Sovereignty' 4 Current Developments in Monetary and Financial Law, available at http://goo.gl/wG7Xz

Gill, S and Mclaren, M (2011) 'The Evolution of E-Money in South Africa' 11(7) Without Prejudice 63-64

Gillette, CP and Walt, SD (2008) 'Uniformity and Diversity in Payment Systems’ 83 Chicago-Kent Law Review 499

Gitonga, FK (2010) ‘Kenya', available at http://goo.gl/fvWSy

Gkoutzinis, A (2003) 'Online Financial Services in the European Internal Market and the Implementation of the ECommerce Directive in the UK', available at http://goo.gl/eTadL

Gkoutzinis, AA (2006) Internet Banking and the Law in Europe 
Glajchen, D (2011) A Comparative Analysis of Mobile Phone-Based Payment Services in the United States and South Africa Phd Dissertation, Northcentral University

Global System for Mobile Communications Association (GSMA) (2007) 'Global Money Transfer Pilot Uses Mobile to Benefit Migrant Workers and the Unbanked', available at http://goo.gl/Azkgk

Global System for Mobile Communication Association (GSMA) (2010) 'Mobile Money for the Unbanked: Annual Report 2009', available at http://goo.gl/Alu86

Global System for Mobile Communications Association (GSMA) (2011) ‘GSM Security Algorithms' GSM World, available at http://goo.gl/kQU3a

Global System for Mobile Communications Association (GSMA) (s.d.) 'GSMA Mobile Money for the Unbanked Programme (MMU)', available at http://goo.gl/gxf6S

Glover, GB (2003) The Doctrine of Duress in the Law of Contract and Unjustified Enrichment in South Africa, PhD Thesis, Rhodes University

Glover, GB (2004) 'Metus in the Roman Law of Obligations' (10) Fundamina 31-58

Godschalk, H and Krueger, M (2000) 'Why e-Money Still Fails', Third Berlin Internet Economics Workshop, available at http://goo.gl/rzSZ8

Goldfinger, C (2002) 'Intangible Economy and Electronic Money in the Future of Money’, available at http://goo.gl/LX018

Goode, RM (1983) Payment Obligations in Commercial and Financial Transactions

Goode, RM (1995) Commercial Law $2^{\text {nd }}$ ed

Goode, RM (2004) Commercial Law $3^{\text {rd }}$ ed

Goodhart, CAE (1989) Money, Information and Uncertainty $2^{\text {nd }}$ ed

Goodhart, CAE (2000) 'The Organizational Structure of Banking Supervision' FSI Occasional Papers No 1, November, available at http://goo.gl/rULOC

Goodhart, CAE (2005a) 'Review of Credit and State Theories of Money: The Contributions of A. Mitchell Innes' 37(4) History of Political Economy 759-761

Goodhart, CAE (2005b) 'The Foundations of Macroeconomics: Theoretical Rigour versus Empirical Realism', Paper presented at Louvain-la-Neuve Conference on the History of Economic Thought, 20-22 Jan

Goodhart, CAE. (2009) 'The Continuing Muddles of Monetary Theory: A Steadfast Refusal to Face Facts', 76(1) Economica, 821-830, available at http://goo.gl/ab0bp

Goodhart, CAE and Krueger, M (2001) 'The Impact of Technology on Cash Usage' No 4 Exchange: The Magazine of De La Rue 9-11, available at http://goo.gl/WiWJ1

Goodwin-Groen, RP (2006) 'The National Credit Act and its Regulations in the Context of Access to Finance in South Africa', available at http://goo.gl/GpuAK

Goosen, W, Pampallis, A and Van der Merwe, A (1999) Banking in the NewMillenium

Gorton, GB and Metrick, A (2010) 'Regulating the Shadow Banking System,' available at http://goo.gl/R72bH

Gouverneur, J (1983) Contemporary Capitalism and Marxist Economics

Gouws, M (2010) 'A Consumer's Right to Disclosure and Information: Comments on the Plain Language Provisions of the Consumer Protection Act' 22 SA Mercantile Law Journal 79-94

Grabbe, JO (1999) ‘Smart Cards and Private Currencies’, available at http://goo.gl/CCYJ5

Graeber, D (2009) 'Debt: The First Five Thousand Years' 12 Mute, available at http://goo.gl/Ip7Dl

Graeber, D (2011) Debt: The First 5,000 Years

Grenville, M (2005) 'Crazy Frog Fined and Ordered to Pay Refunds: 160 Characters', available at http://goo.gl/n9g01

Gribov, A (2008) The Institutional Theory of Money: The Essence and Legal Status of Money and Securities, available at http://goo.gl/qMHDc 
Griffith, R and Stephen, F (2000) ‘Electronic Money and Monetary Policy’, available at http://goo.gl/KzdKi

Grossman, RS (2010) Unsettled Account: The Evolution of Banking in the Industrialized World since 1800

Group of Ten (1997) 'Electronic Money: Consumer Protection, Law Enforcement, Supervisory and Cross Border Issues' Bank for International Settlements, available at http://goo.gl/2PPrn

Grundmann, S and Hollering, J (2008) 'EC Financial Services and Contract Law: Developments 2005-2007' 4 European Review of Contract Law 45, available at http://goo.gl/e5PAx

Guest, A (1991) Chalmers on Bills of Exchange

Hahlo, HR (1961) ‘The Trust in South African Law' 78 South African Law Journal 195-208

Hahn, RW (2006) 'Theories of Regulation and Deregulation: A Critical Appraisal' American Economics Association Annual Meeting, available at http://goo.gl/smnWm

Hajenko, V (2008) ““Tell Him He's Dreaming!” - The Constitution, Vanking Business \& The Vibe' Issue 77 Client Information Bulletin, June, available at http://goo.gl/8Mf0j

Haldane, AG, Millard, S, and Saporta, V (2007) The Future of Payment Systems

Hall, RE (1982) 'Monetary Trends in the United States and the United Kingdom: A Review from the Perspective of New Developments in Monetary Economics' 20(4) Journal of Economic Literature 1552-1556

Hannig, A and Jansen, S (2010) 'Financial Inclusion and Financial Stability: Current Policy Issues' ADBI Working Paper No 259, available at http://goo.gl/7U2k3

Haralson, L (2006) 'FRB of St. Louis, Stored-Value Cards: Opportunities, Risks', available athttp://goo.gl/FFwZA

Hardy, D (2006) ‘Regulatory Capture in Banking’ IMF Working Paper, available at http://goo.gl/tRrVU

Hare, JIC (1887) The Law of Contracts repr 2003

Harris, JW (2002) Property and Justice

Harris, SL (2008) 'Introduction to Rethinking Payments Law’ 83 Chicago-Kent Law Review 477

Hart, K (1986) ‘Heads or Tails? Two Sides of the Coin’ 21(4) Man 637-656

Hart, K. (2000) Money in an Unequal World: Keith Hart and his Memory Bank

Hart, K (2005) 'Notes Towards an Anthropology of Money’ 2 Kritikos, available at http://goo.gl/yXXiZ

Hartkamp, AS (2005) Asser's Handleiding tot de Beoefening Van het Nederlands Burgerlijk Recht, Verbintenissenrecht Deel III De Verbintienis uit die Wet

Hartmann, G (1868) Uber Den Rechtlichen Begriff Des Geldes Und Die Rechtliche Natur Von Geldschulden

Hauben, M (s.d.) 'History of ARPANET', available at http://goo.gl/DCsVD

Havenga, P, Havenga, M and Kelbrick, R (2007) General Principles of Commercial Law $6^{\text {th }}$ ed

Hawkins, J (s.d.) 'EFT' in Glossary, Bank for International Settlements (BIS) Papers No 7, available at http://goo.gl/qs4ws

Hawkins, P (2006) 'Financial Access and Financial Stability' Bank for International Settlements (BIS), available at http://goo.gl/HZEjW

Hawkins, P (2009) 'Competition in Banking: The Findings of an Inquiry into the SA Banking Sector and Lessons for Namibia’, available at http://goo.gl/LFZlI

Hawkins, P and Bertoldi, A (2006) 'The National Payment System and Competition in the Banking Sector: A Report Prepared for the Competition Commission: Executive Summary and Synopsis’, Feasibility, available at http://goo.gl/iTymu

Heaton, J and Pretorius, JT (2007) ‘Minors as the Payees of Cheques’ 124 South African Law Journal 112-127

Heffernan, SA (2003) Modern Banking in Theory and Practice

Heffernan, SA (2005) Modern Banking 
Heller, S (2007) 'An Endangered Species: The Increasing Irrelevance of Article 4 of the UCC in an Electronics-Based Payments System’ 40 Loyola of Los Angeles Law Review 513

Help Net Security (2011) 'RSA Hacked, SecurID Users Possibly Affected’, available athttp://goo.gl/QRMBj

Her Majesty's Treasury (HMT) (2009) 'Consultation on the Revision of the E-money Directive and Implementation of the EU Regulation on Cross-border Payments in Euro', available at http://goo.gl/5KdtH

Her Majesty's Revenue and Customs (HMRC) (2011) 'Detailed Guidance,' available at http://goo.gl/e1oGY

Herrmann, CW (2007) 'Contemporary Perspectives on Monetary Sovereignty', European University Institute (EUI) Working Paper RSCAS 2007/28 (Robert Schuman Centre for Advanced Studies), available at http://goo.gl/9VYpc

Heyer, A and Mas, I (2009) 'Seeking Fertile Grounds for Mobile Money’, available at http://goo.gl/anWnt

Hicks, JR (1967) Critical Essays in Monetary Theory, cited in Tymoigne, E (2006) 'An Inquiry into the Nature of Money: An Alternative to the Functional Approach’ Working Paper No 481, available at http://goo.gl/OwpvP

Hillebrand, G (2001) 'What's Wrong with the Uniform Law Process?' 52 Hastings Law Journal 631

Hillebrand, G (2008) 'Before the Grand Rethinking: Five Things to do Today with Payments Law and Ten Principles to Guide New Payments Products and New Payments Law' 83(2) Chicago-Kent Law Review 769

Hlavinka, K and Sullivan, J (2011) 'The Billion Member March: The 2011 COLLOQUY Loyalty Census', available from http://goo.gl/xatFc.

Holland, TE (1896, repr 2006) The Elements of Jurisprudence

Holtzhausen, C and Monnet, C (2003) 'Money and Payments: A Modern Perspective', available at http://goo.gl/VdrOo

Hong Kong Monetary Authority (2011) ‘The Three-tier Banking System', available at http://goo.gl/ufRxq

Honohan, P (2008) 'Cross-Country Variation in Household Access to Financial Services' 32(11) Journal of Banking and Finance 2493-2500, available at http://goo.gl/E0BiF

Honoré, AM (1961) ‘Ownership' in Guest, AG (ed) Oxford Essays in Jurisprudence 108

Hopkins, K (2003) 'The Influence of the Bill of Rights on the Enforcement of Contracts' 19(425) De Rebus at 22-25

Horowitz, MJ (1992) The Transformation of American Law 1870-1960

Hudson, WW (1895) ‘Scientific Standard Money’ 2(3) Modern Culture 581

Huertas, M (2009) 'The Transposition of the Payment Services Directive ('PSD') into UK Domestic Law: Providing a Solution to Overcoming the New Regulatory Challenges that Financial Institutions Will Face', available at http://goo.gl/Fa5Z1

Hughes, N and Lonie, S (2007) 'M-PESA: Mobile Money for the "Unbanked": Turning Mobile phones into 24-Hour Tellers in Kenya', available at http://goo.gl/KQm6O

Hulsmann, JG (2004) ‘Legal Tender Laws and Fractional-Reserve Banking’ 18(3) Journal of Libertarian Studies 33-55

Humphrey, DB et al (2006) 'The Evolution of Payments in Europe, Japan, and the United States: Lessons for Emerging Market Economies', World Bank Policy Research Working Paper No 1676, Social Science Research Network,available at http://goo.gl/qh33a

Hutchison, D (ed) (2009) The Law of Contract in South Africa

ICT Regulation Toolkit (s.d.) ‘Tanzania: The Converged Licensing Framework', available at http://goo.gl/S1oJq

Independent Communications Authority of South Africa (ICASA) (2010) 'Discussion Document: Universal Service and Access Obligations', available at http://goo.gl/f0Q91

Independent Communications Authority of South Africa (ICASA) (2011) 'Media Release: ICASA and National Consumer Commission's Role on Consumer Protection Matters in the Communications Sector', available at http://goo.gl/jxkMK

Independent Online (IOL) (2008) 'Fake ID Crooks Hoodwink Landlord', available at http://goo.gl/9S1vC

Independent Online (IOL) (2011) 'Control Your Child's Cellphone Use', available at http://goo.gl/C83gJ 
Info-Communications Development Authority of Singapore (IDAS) (2010) 'Specification for Contactless e-Purse Application (CEPAS)', available at http://goo.gl/QapJP

Information for Development Program (infoDev) and the International Telecommunication Union (ITU) (2012) 'The EU Regulatory Framework' (Module 3: Authorization of Telecommunication/ ICT Service, s 2.5.1) in ICT Regulation Toolkit available at http://goo.gl/SOpRt

Ingham, G (2002) 'New Monetary Spaces?' in Organization for Economic Co-operation and Development (OECD) 'The Future of Money', available at http://goo.gl/RTOse

Ingham, G (2004) The Nature of Money

Ingham, G (2006) 'Further Reflections on the Ontology of Money: Responses to Lapavitsas and Dodd' 35(2) Economy and Society 259-278

Ingham, G (2007) ‘The Specificity of Money’ 48 European Journal of Sociology 265-272

Institut für Bankinnovation an der Universität Regensburg (2006) 'Secure Payment Methods for E-Government' EGovernment Manual, available at http://goo.gl/LoDdI

Institute of Technology Assessment of the Austrian Academy of Sciences (ITA) (2005) 'Institutional Change in the Payment Systems by Electronic Money Innovations: Implications for Monetary Policy', available at http://goo.gl/Znj3S

Internal Market and Services Directorate General of the European Commission (2003) 'Study on the Security of Payment Products and Systems in the 15 Member States', available at http://goo.gl/zwxdg

International Finance Corporation (IFC) (2007) 'The Next 4billion: Market Size and Business Strategy at the Base of the Pyramid', available at http://goo.gl/sqWhF

International Finance Corporation (IFC) (2010) 'An Analysis of Trends in the Average Total Cost of Migrant Remittance Services', available at http://goo.gl/kAVoS

International Financial Risk Institute (1997) ‘Real-Time Gross Settlement Systems’, available at http://goo.gl/3y5V0

International Financial Risk Institute (2000) ‘Overview: Settlement Risk’, available at http://goo.gl/gJSSe

International Monetary Fund (IMF) (2003) 'Informal Funds Transfer Systems: An Analysis of the Informal Hawala System' International Monetary Fund Occasional Paper No 222, available at http://goo.gl/z3Gth

International Monetary Fund (IMF) (2010a) 'IMF Country Report No 10/296', available at http://goo.gl/eO9W3

International Monetary Fund (IMF) (2010b) 'South Africa: Detailed Assessment of Implementation on IOSCO Principles Securities Markets', available at http://goo.gl/ULSng

International Telecommunication Union (2004) 'Trends in Telecommunication Reform 2004/05: Licensing in an Era of Convergence: Summary’, available at http://goo.gl/aU3MP

IRIN (Integrated Regional Information Networks) News (2008) 'Kenya: Diaspora Clicks in to Keep Kenya Talking', IRIN Humanitarian News and Analysis, 5 January, available at http://goo.gl/cMzrh

Isern, J and De Koker, L (2009) 'AML/CFT: Strengthening Financial Inclusion and Integrity' No 56 CGAP Focus Note, August, available at http://goo.gl/wxyx6

Italian Ministry of Foreign Affairs (2009) 'Rome Road Map for Remittances', available at http://goo.gl/aZgWi

Itzikowitz, A (1992) 'The Deposit-taking Institutions Act 94 of 1990: Its History and an Overview of its Main Provisions' 4 SA Mercantile Law Journal 170

Itzikowitz, A (2010) 'The Impact of the Consumer Protection Act 68 of 2008 on the Business of Banking' Annual Banking Law Update2010: 21 April 2010. Indaba Hotel, Johannesburg 53-79

Ivatury, G and Pickens, M (2006) 'Mobile Phone Banking and Low-Income Customers: Evidence from South Africa', available at http://goo.gl/yWU9d

Ivatury, G, Lyman, TR and Staschen, S (2006) 'Use of Agents in Branchless Banking for the Poor: Rewards, Risks, Regulation’ 38 CGAP Focus Note 1, available at http://goo.gl/sXHMU

Iwai, K (1997) ‘Evolution of Money’, available at http://goo.gl/9kMa7 
Jack, W and Suri, T (2009) 'Mobile Money: The Economics of M-PESA', available at h http://goo.gl/HnS6y

Jack, W, Pulver, C and Tavneet, S (2009) 'M-PESA: The Performance and Impact of M-PESA: Preliminary Evidence from a Household Survey’, Financial Sector Deeping Kenya (FSD Kenya), available from http://goo.gl/TGjwY

Jack, W, Suri, T and Townsend, R (2010) 'Monetary Theory and Electronic Money: Reflections on the Kenyan Experience' 96(1) Economic Quarterly 83-122, available from http://goo.gl/w5jvx

Jacks, M (2011) 'ABSA's CashSend Boosts Cellphone Banking Usage in SA', posted on MobileMoneyAfrica, 5 May, available at http://goo.gl/B3596

Jacob, K (2005) 'Retailers as Financial Services Providers: The Potential and Pitfalls of This Burgeoning Distribution Channel', available at http://goo.gl/U5yug

Jacobs, W (2004) 'The Electronic Communications and Transactions Act: Consumer Protection and Internet Contracts' 16(4) SA Mercantile Law Journal 556-567

Jain, V and Joshi, RC (s.d.) 'Integrating Bluetooth, Biometrics and Smartcards for Personal Identification and Verification', available at http://goo.gl/oiK9N

Janson, N (2001) 'The Development of Electronic Money: Toward the Emergence of Free-Banking?', available at http://goo.gl/ocpDM

Japan’s Corporate News Network (2011) ‘bitWallet Inc.', available at http://goo.gl/eOyOT

Java (2011) 'FAQ: Mobile Java', available at http://goo.gl/LoSFO

Jenkins, SH (2007) 'Contracting Out of the UCC (Introduction)' 40 Loyola of Los Angeles Law Review, available at http://goo.gl/i5KW6

Johannessen, T (2009) 'The SIM Card as a Secure Basis for ID', available at http://goo.gl/7cBSf

Johnston, D and Zimmerman, R (2002) Unjustified Enrichment

Jones, RA (1976) 'The Origin and Development of Media of Exchange' 84(4) Journal of Political Economy 757-775

Jordan, JL (2006) 'Money and Monetary Policy for the Twenty-First Century’, available at http://goo.gl/phJVD

Joubert, J (2006) How Do Trust and Risk Factors Influence the Adoption and Usage of M-commerce by Consumers in South Africa? LLM Thesis, University of Cape Town

Joubert, J and Van Belle, J-P (2009) 'The Importance of Trust and Risk in M-Commerce: A South African Perspective' (Pacific Asia Conference on Information Systems) PACIS 2009 Proceedings, available at http://goo.gl/ckkvQ

Jowett, B (1892) The Dialogues of Plato

Jun, M (2009) 'Prepaid Cards: Second-Tier Bank Account Substitutes: Consumers Union Report', available at http://goo.gl/7fh3V

Kanbur, R (2004) ‘Growth, Inequality and Poverty: Some Hard Questions’, available at http://goo.gl/foReT

Karnani, A (2009) 'The Bottom of the Pyramid Strategy for Reducing Poverty: A Failed Promise' UN DESA Working Paper No 80 , available at http://goo.gl/3iG5L

Kay, J (2009) 'The Slow Drip of Faster Payments' Financial Times, 16 June, available at http://goo.gl/82sO7

Kaye, TS (2008) 'Risk and Predictability in English Common Law: Risk and The Law' in Woodman, G and Klippel, D (eds) Risk and Predictability in English Common Law: Risk and the Law 103, available at http://goo.gl/jSz48

Kearns, D (2008) 'Privaris Releases Bluetooth-supported Portable Biometric Authentication Device: Privaris PlusID 75 Supports Bluetooth for Short Distance Wireless Control' Security Identity Management Alert [Newsletter], January 23, NetworkWorld, available at http://goo.gl/1euHB

Keitel, PL (2008) 'The Laws, Regulations, Guidelines Industry Practices that Protect Consumers Who Use Gift Cards', available at http://goo.gl/Mj6jy

Keitel, PL (2010) 'Electronic Payments and the Consumer-Protection Landscape', available at http://goo.gl/jGRzc 
Keitel, PL (2011) 'Conference Summary: Federal Regulation of the Prepaid Card Industry: Costs, Benefits and Changing Industry Dynamics' Federal Regulation of the Prepaid Card Industry: Costs, Benefits and Changing Industry Dynamics' April 8-9, 2010, a conference sponsored by the Payment Cards Center, available at http://goo.gl/EsJT1

Kelly, M (2001) 'Apportionment of Damages between a Negligent Collecting Bank and a Thief of Cheques: Does the Apportionment of Damages Act Apply?’ 13(3) SA Mercantile Law Journal 509-530.

Kendall, J et al (2011) 'An Emerging Platform: From Money Transfer System to Mobile Money Ecosystem', available at http://goo.gl/khQDt

Kendall, J, Mylenko, N and Ponce, A (2010) 'Measuring Financial Access around the World' Policy Research Working Paper 5253, available at http://goo.gl/p9sf5

Keraan, T (2010) 'Banking the Bottom of the Pyramid', available at http://goo.gl/qRvlm check title

Kerr, A (2006) The Law of Agency $4^{\text {th }}$ ed

Keynes, JM (1924) A Tract on Monetary Reform

Keynes, JM (1937, repr 1973) The General Theory of Employment, Interest and Money reprinted in The Collected Writings of John Maynard Keynes Vol VII cited in Davidson, P (1978) Money and the Real World

Keynes, JM (1964) The General Theory

Keynes, JM (1971) A Treatise on Money

Kianieff, MM (2008) Consumer Retail Online Electronic Payments: Potential Liberation Technology or Source of Despair? $\mathrm{PhD}$ Thesis, York University, available at http://goo.gl/nqKBH

King, M (1999) 'Challenges for Monetary Policy: New And Old' Paper prepared for the Symposium on New Challenges for Monetary Policy sponsored by the Federal Reserve Bank of Kansas City, available at http://goo.gl/z0mRB

King, RG (1983) ‘On the Economics of Private Money’ 12(1) Journal of Monetary Economics 127-158

Kirk, J (2009) 'Investigators Prove Nokia 1100 Online Banking Hack’, available at http://goo.gl/RwvJm

Kirsten, M (2006) 'Policy Initiatives to Expand Financial Outreach in South Africa', available at http://goo.gl/nZG0H

Klein, B (1974) ‘The Competitive Supply of Money’ 6(4) Journal of Money, Credit and Banking 423-453

Klinck, D (1991) ‘Tracing a Trace: The Identity of Money in a Legal Doctrine’ 83(1-2) Semiotica 1

Klopper, P (2007) 'Non-banks in the Dutch Retail Payments System: A Central Bank Perspective', Nonbanks in the Payments System: Innovation, Competition, and Risk: An International Payments Policy Conference sponsored by the Federal Reserve Bank of Kansas City May 2-4, 2007, presented at Session 6 on 4 May, 1-14, available at http://goo.gl/XyHhe

Knapp, GF (1924) The State Theory of Money

Knowler, W (2011) 'Prepaid Airtime: Use it or Lose it for Now' Independent OnLine, available at http://goo.gl/XUxGM

Kohlbach, M (2004) 'Making Sense of Electronic Money' (1) The Journal of Information, Law and Technology (JILT), available at http://goo.gl/R1mxj

Kok, LS (2002) 'Singapore Electronic Legal Tender (SELT): A Proposed Concept' (Chapter 6) in Organisation for Economic Co-operation and Development The Future of Money 147-155, available at http://www.oecd.org/dataoecd/40/31/35391062.pdf

Koppel, SR (2010) 'The Dodd-Frank Act: Remittance Transfers', available at http://goo.gl/snzHa

KPMG (Klynveld Peat Marwick Goerdeler) (2011) 'KPMG Study: "Underserved" Market Represents Opportunity for Banks,' available at http://goo.gl/FHzAj

Kregel, JA (1998) The Past and Future of Banks cited in Tymoigne, E and Wray, LR (2005) 'Money: An Alternative Story', available at http://goo.gl/Mcv4Q

Kreltszheim, D (2003) 'The Legal Nature of “Electronic Money": Part 1' 14 Journal of Banking and Finance Law and Practice 161

Kroszner, R (2001) 'Currency Competition in the Digital Age' cited in Holtzhausen, C and Monnet, C (2003) 'Money and Payments: A Modern Perspective’, available at http://goo.gl/VdrOo 
Krueger, M (2001/2005) ‘Offshore e-Money Issuers and Monetary Policy’, available at http://goo.gl/0Ib6s

Krugel, GT (2007) 'Mobile Banking Technology Options: An Overview of the Different Mobile Banking Technology Options and their Impact on the Mobile Banking Market' FinMark Trust, August, available at http://goo.gl/8eHv7

Krugman, P (2012) End This Depression Now!

Kutyn, J (2005) 'Nature of Money’, available at http://goo.gl/5pbSB

Lacker, JM (1996) 'SVCs: Costly Private Substitutes for Government Currency' Federal Reserve Board of Richmond Economic Quarterly at 1, available at http://goo.gl/OFyQd

Lagerspetz, E (1984) 'Money as a Social Contract' 17(1) Theory and Decision 1-9

Landey, KM (1983) 'Consumer-Cardholder Defenses in Tripartite Credit Card Arrangements: A Battleground for the Beleaguered Bank’ 88 Commercial Law Journal 84

Lanskoy, S (2000) 'The Legal Nature of Electronic Money' 73 Banque de France Bulletin Digest 28

Lascles, D (2000) ‘Europe's New Banks: The “Non-bank” Phenomenon', available at http://goo.gl/QTynJ

Laughlin, J (1919) The Principles of Money $2^{\text {nd }}$ ed

Law, J (1966) Money and Trade Considered

Lawack, VA (1998) 'Electronic Innovations in the Payment Card Industry’ 10(2) SA Mercantile Law Journal 233

Lawack-Davids, VA (2000) Aspects of Internet Payment Instruments, Unpublished LLD Thesis, University of South Africa

Lawack-Davids, VA (2008) 'Legal and Regulatory Framework Pertaining to the National Payment System (NPS): Peeling the Layers of the Onion' 29(3) Obiter 453-471

Lawack-Davids, VA (2011) 'Mind the Gap - Increasing Compliance - Burden and Regulatory Misalignment' 32(3) Obiter $712-720$

Lawack-Davids, VA and Marx, FE (2010) 'Consumer Protection Measures for Erroneous or Unauthorized Internet Payments: Some Lessons from the European Union?' 31(2) Obiter 446-458

Lawrence, WH (2002) 'Understanding Negotiable Instruments and Payments Systems', available from http://goo.gl/dmI2j

Lawson, WJ (1855) The History of Banking: With a Comprehensive Account of the Origin, Rise and Progress of the Banks of England, Ireland and Scotland

Leach, J and Beghin, D (2004) 'The Access Propositions', available at http://goo.gl/2p0qQ

Lee, B-C (2002) 'Regulation in the New Economy' University of Wollongong Department of Economics Working Paper Series 2002 at 1, available at http://goo.gl/WJSkL

Lee, B-C and Longe-Akindemowo, O (1998) 'Regulatory Issues in Electronic Money: A Legal-Economics Analysis', available at http://goo.gl/EwuNO

Lefebvre, P (2003) 'M-Payment Deployment: Paving the Way for an Efficient Mobile Commerce Market' Conference Proceedings Mobile Payment Forum, Dublin, 26 March

'Legal Tender' (1996) in Pocket Legal Dictionary $2^{\text {nd }}$ ed

'Legal Tender' (2012) in Oxford Dictionaries Online, available from http://goo.gl/AKuSH

Legalbrief (2010) ‘Absa Employees in R1.38m Bank Fraud Case’, available from http://goo.gl/LbJYr

Lehrman, S (2007) 'Dialing In: Mobile Phones Target the World's Non-reading Poor' 296(5) Scientific American 30-31

Leinonen, H (2005) 'Liquidity, Risks and Speed in Payment and Settlement Systems: A Simulation Approach', available at http://goo.gl/cgCdj

Lelieveldt, SI (1997) 'How to Regulate Electronic Cash: An Overview of Regulatory Issues and Strategies' 46 American University Law Review at 1163, available at http://goo.gl/RHFTy

Leng, T (2006) 'Legal Effects of Input Errors in e-Contracting’ 22(2) Computer Law \& Security Report 157-164 
Lengalenga, C (2005) 'Some Critical Issues on Informal Value Transfer Systems in Eastern and Southern Africa Anti-Money Laundering Group Member Countries' in International Monetary Fund Regulatory Frameworks for Hawala and other Remittance Systems80-86

'Letter of Credit' (2011) in Encyclopaedia Britannica Online Academic Edition, available at http://goo.gl/oWhmG

Levine, R and Caprio, G (2003) 'Bank Regulation and Supervision: Lessons from a New Database' in Garza, JAM (ed) Macroeconomic Stability, Financial Markets Economic Development, available at http://goo.gl/B1lnm

Lewis, L (2009) 'To Fight Deflation, Abolish Cash: Could Japan Make Reality of “Science Fiction”?' posted on Annuity IQ Financial Insights, 5 July, available at http://goo.gl/7kchj

Leyva, HP (2008) 'M-Payment: A Threat to Anti-Money Laundering' The Vermont Bar Journal, Fall, 1-4, available at http://www.docstoc.com/docs/43553676/M-Payment-A-Threat-to-Anti-Money-Laundering

Liberman, G and Lavine, A (2006) 'Banks vs Thrifts vs Credit Unions: Which Financial Institution Will Work Best for You?’ posted on MarketWatch, 10 July, available at http://goo.gl/YJHID

Lietaer, BA (2001) The Future of Money: Creating New Wealth, Work and a Wiser World

Lietaer, BA (2002) 'The Future of Payment Systems: Unisys Corporation', available at http://goo.gl/mlb1C

Lin, R and Kraus, S (2010) 'Can Automated Agents Proficiently Negotiate with Humans?' 53(1) Communications of the ACM January78-88

Little, AD (2010) 'M-Payments in M-BRIC', available at http://goo.gl/nZTUu

Liu, AT and Mithika, MK (2009) 'Mobile Banking: The Key to Building Credit History for the Poor', available at http://goo.gl/OE4Ra

Locke, J (1690) The Second Treatise Concerning Civil Government, available at http://goo.gl/uu0z

Lotz, J (1997) 'Purchase and Sale' in R Zimmermann and D Visser (eds) Southern Cross: Civil Law and Common Law in South Africa 361

Loubser, MJ (1978) The Theft of Money in South African Law

Loubser, MM and Swart, D (1999) ‘Electronic Money in South African Law’ 10(3) Stellenbosch Law Review 354

Lowe, P (2007) 'Non-Banks in the Payments System: A Central Bank Perspective' Federal Reserve Bank of Kansas City Conference on Nonbanks in the Payments System: Innovation, Competition and Risk, Santa Fe, 2-4 May 2007, available at http://goo.gl/Z24tW

Luo, GY (1999) 'The Evolution of Money as a Medium of Exchange' 23 Journal of Economic Dynamics and Control 415

Lusardi, A and Tufano, P (2008) 'Debt Literacy, Financial Experiences and Overindebtedness' NBER Working Paper No 14808, available at http://goo.gl/NTaEF

Luyat, JJ (2009) 'A Tale of Regulation in the European Union and Japan: Does Characterizing the Business of Stored-Value Cards as a Financial Activity Impact its Development?' 18(3) Pacific Rim Law \& Policy Journal 525-546

Lyman, T (2009) 'Framing the Policy and Regulatory Issues' Windsor II Leadership Seminar on Regulating Transformational Branchless Banking March 9-11, 2009, Windsor, UK, CGAP, Alliance for Financial Inclusion and Department for International Development, available at http://goo.gl/vBjGr

Lyman, TR, Pickens, M and Porteous, D (2008) 'Regulating Transformational Branchless Banking: Mobile Phones and Other Technology to Increase Access to Finance' 43 CGAP Focus Note, January, available at http://goo.gl/0jU4b

Macintosh, KL (1998) 'How to Encourage Global E-Commerce: The Case for Private Currencies on the Internet' 11 Harvard Journal of Law and Technology 733

Mackenzie, R (1998) 'Virtual Money, Vanishing Law: Dematerialisation in Electronic Funds Transfer, Financial Wrongs and Doctrinal Makeshifts in English Legal Structures' 2(1) Journal of Money Landering Control 22

Maclachlan, F (2003) 'Max Weber and the State Theory of Money', available at http://goo.gl/GZDtF

Macleod, HD (1889) The Theory of Credit

Maestro, B (1993) Story of Money 
Mafusire, JM (2010) 'The Zim Dollar is the Zim Dollar Whatever Its International Value: The Problem of Currency Nominalization', available at http://goo.gl/lbdP9

Malaguti, MC (2009) 'The Payment Services Directive: Pitfalls between the Acquis Communautaire and National Implementation' European Credit Research Institute (ECRI) Research Report No 9, available at http://goo.gl/5vR1g

Malan, FR (1977) 'Share Certificates, Money and Negotiability,' 94(3) South African Law Journal 245-256

Malan, FR (1978) 'Professional Responsibility and the Payment and Collection of Cheques' 11 De Jure 326

Malan, FR (1989) 'Legal Aspects of the Regulation of Financial Institutions' 18(4) Tydskrif vir die Suid-Afrikaanse Reg 553567

Malan, FR (1992) 'Price v Neal Revisited’ 25 (3) Acta Juridica 131-147

Malan, FR and Faul, W (1991) 'Introduction to the Deposit-taking Institutions Act 94 of 1990' 7(3) Journal of South African Law 379-388

Malan, FR and JT Pretorius (1994b) ‘Money, Bank Accounts and Tracing’ 10(2) South African Law Journal 387-391

Malan, FR and JT Pretorius (1994c) 'Questions of Negligence and the Collecting Bank: A Brief History of the Bonitas Trilogy’ 6(1) SA Mercantile Law Journal 116-124

Malan, FR and Pretorius, JT (1994a) 'Liability of the Collecting Bank: More Clarity?' 6(2) SA Mercantile Law Journal 218226

Malan, FR and Pretorius, JT (2001a) 'Contemporary Issues in South African Banking Law' 64(2) Tydskrif vir Hedendaagse Romeins-Hollandse Reg 268-288

Malan, FR and Pretorius, JT (2001b) 'The Reserve Bank, Banks Clearing Houses in South African Law: Part 1' 13(1) SA Mercantile Law Journal 35-9

Malan, FR and Pretorius, JT (2001c) 'The Reserve Bank, Banks Clearing Houses in South African Law: Part 2' 13(2) SA Mercantile Law Journal 163-185

Malan, FR and Pretorius, JT (2006) 'Credit Transfers in South African Law (Part 1)' 69(4) Tydkrif vir Hedendaagse Romeins-Hollandse Reg 594-612

Malan, FR, Pretorius, JT and Du Toit, SF (2009) Malan on Bills of Exchange, Cheques and Promissory Notes $5^{\text {th }}$ ed

Manamela, ME (2011) “"To Meet is to Part”: Resignation by SMS Constitutes Notice in Writing as Required by the Basic Conditions of Employment Act: Mafika v SA Broadcasting Corporation Ltd' 23(3) SA Mercantile Law Journal 521-528

Mann RJ (s.d.) ‘Regulating Internet Payment Intermediaries’ 86 Texas Law Review 681-683

Mann, FA (1982) The Legal Aspect of Money: With Special Reference to Comparative Private and Public International Law $4^{\text {th }}$ ed

Mann, FA (1992) The Legal Aspect of Money $5^{\text {th }} \mathrm{ed}$

Mann, RJ (2004) 'Making Sense of Payments Policy in the Information Age' 93 Georgetown Law Journal 633, available at http://goo.gl/E8dKR

Mann, RJ (2008) ‘A Requiem for Sam’s Bank’ 74 Chicago-Kent Law Review 101, available at http://goo.gl/ZzOIX

Mansour, Y (2007) ‘The E-Money Directive and MNOs: Why it All Went Wrong', available at http://goo.gl/ILah2

Mantel, B and McHugh, T (2002) 'Changing E-Payment Payment Networks in the U.S.: The Strategic, Competitive \& Innovative Implications' $2-10$ cited in

Mantshantsha, S (2009) ‘SA Banks Outgun Authorities’ posted on Fin24, 3 April, available at http://goo.gl/uc9ca

Martin, DA (1972) 'The Medium is not the Money’ 6(000002) Journal of Economic Issues 67

Marx, F and Govindjee, A (2007) 'Revisiting the Interpretation of Exemption Clauses: Drifters Adventure Tours CC v Hircock 20072 SA 83 (SCA)’ 28(3) Obiter at 624

Maryland Office of Consumer Protection (2011) 'Money Transmitters,' available at http://goo.gl/I570M 
Mas, I (2008) 'Realizing the Potential of Branchless Banking: Challenges Ahead' 50 CGAP Focus Note, available at http://goo.gl/tsvOy

Mas, I (2009a) ‘The Economics of Branchless Banking’ 4(2) Innovations, available at http://goo.gl/qSXr0

Mas, I (2009b) 'The Utility of Retail Payments in Addressing the Financial Inclusion Gap in Developing Countries' 1 Lydian Payments Journal, available at http://goo.gl/QOK3L

Mas, I (2010a) 'Liquidity Management: Mobile Money’, available at http://goo.gl/Zsks2

Mas, I (2010b) 'M-kheso in Kenya: A New Step for M-PESA and Mobile Banking', available at http://goo.gl/q1KI8

Mas, I (2010c) 'Savings for the Poor: Banking on Mobile Phones' 11(4) World Economics, available at http://goo.gl/cDFcs

Mas, I and Ng'weno, A (2010) ‘Three Keys to M-PESA’s Success: Branding, Channel Management and Pricing', available at http://goo.gl/2AF1V

Mas, I and Radcliffe, D (2010) 'Mobile Payments go Viral: M-PESA in Kenya: Yes Africa Can: Success Stories from a Dynamic Continent, World Bank, August 2010', available at http://goo.gl/mwhxz

Mas, I and Siedek, H (2008) 'Banking through Networks of Retail Agents' 47 CGAP Focus Note, available at http://goo.gl/4XM4w

Mashiya, N (2006) 'Vision on Banking' Presentation to The $3^{\text {rd }}$ International BANKSETA Conference 11 October 2006, Banking Sector Education and Training Authority, available at http://goo.gl/UsxqA

MasterCard Worldwise (2011) 'MasterCard Rules' 7 December, available at http://goo.gl/Ee6Cn

Matthew 25:27 Bible (King James Version), BibleGateway.com, available at http://goo.gl/UjaNg

Matthews, K (2011) 'Lecture Slides for Money, Banking \& Finance' Cardiff University, available at http://goo.gl/arwNn

Mauri, A (2007) 'The Currency Board and the Rise of Banking in East Africa', available at http://goo.gl/IT24r

Mavromati, D (2008) The Law of Payment Services in the EU: The EC Directive on Payment Services in the Internal Market

Mbalekwa, S (2011) The Legal and Regulatory Aspects of International Remittances within the SADC Region, LLM Thesis, Nelson Mandela Metropolitan University, available at http://goo.gl/DKG12

Mboweni, TT (2006) 'A Historical Review and a Look at the Future Prospects of the National Payments System in South Africa' 10th Anniversary Function of the Payment Association of South Africa, available at http://goo.gl/TMLN1

Mboweni, TT (2009) 'Overview of the South African Economy', available at http://goo.gl/WoV6R

Mbugua, J (2011) 'CBK Governor Calls for More Secure Mobile Money Services' Allafrica.com, available at http://goo.gl/4RoQE

McAndrews, J (1997) 'Banking and Payment System Stability in an Electronic Money World', available at http://goo.gl/VGKOd

McCallum, BT (1985) 'Bank Regulation, Accounting Systems of Exchange, and the Unit of Account: A Critical Review' NBER Working Paper No 1572, available at http://goo.gl/HFRho

McEachern, WA (2006) Macroeconomics: A Contemporary Introduction

McFadden, L (2010) ‘How the CARD Act Impacts Gift Cards', Bankrate, available at http://goo.gl/YFko

McGregor, S (2010) 'Safaricom of Kenya Money-Transfer Users Rise to 61\% in July from Year Ago', available at http://goo.gl/DFrW9

McKay, C and Pickens, M (2010a) 'Branchless Banking Pricing Analysis' CGAP Technology Program, available at http://goo.gl/krLf1

McKay, C and Pickens, M (2010b) 'Branchless Banking 2010: Who's Served? At What Price? What's Next?' CGAP Focus Note, available at http://goo.gl/d2bM5

McLennan, JS (2006) ‘Contracting with Business Trusts’ 18 SA Mercantile Law Journal 329

Meadows, A and Williams, A (2001) 'Moneta and the Monuments: Coinage and Politics in Republican Rome' 91 The Journal of Roman Studies 27 
Medhi, I, Cutrell, E and Toyama, K (2010) ‘It’s Not Just Illiteracy’ Microsoft Research, available at http://goo.gl/RKN18

Medhi, I, Ratan, A and Toyama, K (2009) 'Mobile-Banking Adoption and Usage by Low-Literate, Low-Income Users in the Developing World Microsoft Research', available at http://goo.gl/YgOLt

Megrah, M (1961) Paget's Law of Banking $6^{\text {th }}$ ed

Meikle, S (1994) ‘Aristotle on Money’ 39(1) Phronesis 26-44

Meiring, R (2004) 'Electronic Transactions' in Buys, R (ed) Cyberlaw @ SA: The Law of the Internet in South Africa $2^{\text {nd }}$ ed

Meissner, CM (s.d.) ‘Gold Standard Entry’ in Oxford Encyclopedia of Economic History, available at http://goo.gl/TC3D0.

Mellor, M (2011) ‘The Confusing World of Modern Monetary Theory', available at http://goo.gl/p1Ucr

Meltzer, A (2002) ‘Money’, available at http://goo.gl/1vpr3

Menger, C (1871) 'Principles of Economics', available at http://goo.gl/iDjPz

Menger, C (1892) ‘On the Origin of Money’ 2 Economic Journal 239-255

Messori, M (2002) ‘Credit and Money in Schumpeter's Theory’, available at http://goo.gl/ClXhk

Metropolitan Museum of Art (2010) 'Heilbrunn Timeline of Art History', available at http://goo.gl/Ix27C

Mian, AR and Sufi, A (2010) 'The Great Recession: Lessons from Microeconomic Data', available at http://goo.gl/C9aoS

Michalson, L (2011) 'Guide to the ECTA 2008', available at http://goo.gl/B8Cct

Microfinance Opportunities (2005) 'Assessing the Outcomes of Financial Education', available at http://goo.gl/zUpdM

Microfinance Podcast (2010) 'MFP' 126

Migley, JR and Van der Walt, JC (2005) 'Delict' in The Law of South Africa Vol 8 Part $12^{\text {nd }}$ ed

Millard, S and Saporta, V (2005a) 'Central Banks and Payment Systems: Past, Present and Future' Background Paper to the Bank of England Conference on the Future of Payments, 19-20 May 2005, available at http://goo.gl/uqdDC

Millard, S and Saporta, V (2005b) 'The Future of Payments' 19 Bank of England Financial Stability Review 59, available at http://goo.gl/tVDBh

Miller, M et al (2009) 'The Case for Financial Literacy in Developing Countries: Promoting Access to Finance by Empowering Consumers', available at http://goo.gl/nNGLJ

Miller, R, Michalski, W and Stevens, B (2002) 'The Future of Money' in Organization for Economic Co-operation and Development (OECD) (2002) The Future of Money, available at http://goo.gl/Gj9cD

Minsky, HP (1986) Stabilizing an Unstable Economy

Mishkin, S (1989) The Economics of Money, Banking

Mitchell, D (2007) 'Head of the NPSD' cited in South African Reserve Bank (SARB) The South African Reserve Bank: Understanding the Core Responsibilities of the Bank

Mitchell-Innes, A (1913) 'What is Money’ 30 The Banking Law Journal 377-408, available at http://goo.gl/Ya1Ck

Mitchell-Innes, A (1914) 'The Credit Theory of Money‘ The Banking Law Journal 151-168, available at http://goo.gl/DXbDJ

Mobilthinking (2011) 'Fighting Poverty with Mobile Money: Interview with Claudia McKay', Consultative Group to Assist the Poor (CGAP)

Moini, M (2001) 'Toward a General Theory of Credit and Money’ 14(4) The Review of Austrian Economics 267-317

Molatlhwa, O (2012) 'Banks Clients Lost R180m in Fraud Scam’ SowetanLive, available at http://goo.gl/M9U9C

'Money Characteristics' (2012) in AmosWEB Encyclonomic WEB*pedia, available at http://goo.gl/XfxgE

Moneyweb (2011) 'ABSA and Vodacom Seal Multi-million Rand Deal: Gavin Opperman - CEO, ABSA Retail', available at http://goo.gl/P0A1Y 
Moorcroft, J (2010) Banking Law and Practice

Morawczynski, O (2007) 'Innovations in Mobile Banking: The Case of M-PESA' First National Consultative Forum on Microfinance November 12-14, 2007 in Khartoum, Sudan, available at http://goo.gl/NaDX1

Morawczynski, O and Pickens, M (2009) 'Poor People Using Mobile Financial Services: Observations on Customer Usage and Impact from M-PESA' CGAP Brief, available at http://goo.gl/UuQDD

Morgan, JP (2005) 'Legal Implications of SVCs', available at http://goo.gl/U2zex

Mostert, M et al (eds) (2010) The Principles of the Law of Property in South Africa

Mthembu, MA (2010) 'Electronic Funds Transfer: Exploring the Difficulties of Security' (5)4 Journal of International Commercial Law and Technology 201

MTN Banking (2011a) 'MTN Money: Terms and Conditions', available at http://goo.gl/ptxi0

MTN Banking (2011b) 'MTN Money Transfer: Overview', available athttp://goo.gl/pKmcJ

MTN Banking (2011c) ‘MTN Money Transfer: What is MTN Banking?', available at http://goo.gl/fD4bP

Mueller, RS (2010) 'Statement before the House Committee on Appropriations, Subcommittee on Commerce, Justice, Science, and Related Agencies,' available at http://goo.gl/N3vjW

Muir, C (2008) ABSA's Implementation of Mobile Banking as a Value-Added Mobile Business Offering Unpublished LLM Dissertation, University of Johannesburg, available at http://goo.gl/eybSZ

Muller, R (2009) 'This is How SMS Banking Fraudsters Did It' MyBroadband, available at http://goo.gl/DDbEI

Muller, R (2011a) ‘Vodacom Downtime: Can You Get Money Back?’ MyBroadband, available at http://goo.gl/irgMh

Muller, R (2011b) 'Vodacom Tells Consumer Commission to Take a Hike’ MyBroadband, available at http://goo.gl/TgCrQ

Mulliner, C (2009) 'Vulnerability Analysis and Attacks on NFC-enabled Mobile Phones' 1st International Workshop on Sensor Security, available at http://goo.gl/w1gkO

Mundell, R (1998) 'Uses and Abuses of Gresham's Law in the History of Money’, available at http://goo.gl/B63Le

Munir, AB (2004) Internet Banking: Law and Practice

Murray, IB (1962) 'Is a Trust or an Estate a Legal Persona?’ 79 South African Law Journal 37

Mwihia, J and Straziuso, J (2011) 'Kenyans Sending Drought Aid Money by Mobile Phone' The Sydney Morning Herald, 30 August, available at http://goo.gl/72TTZ

Mybroadband (2012) 'Thread: Control Chat - Recharged Prepaid Airtime Only to Pay for Content Services', available at http://goo.gl/VfQIl

Nagarajan, S (2009) 'Impact of Global Financial Crisis on Remittances Flows to Africa' African Development Bank, available at http://goo.gl/uX89K

Nagel, C and Pretorius, JT (2004) 'Countermanding Payment of a Cheque' 67 Tydskrif vir die Hedendagse RomeinsHollandse Reg 641

Nagel, C and Pretorius, JT (2005) 'Cheques: Honour, Dishonour and Re-Honour' 68 Tydskrif vir die Hedendagse RomeinsHollandse Reg 527

Nagel, CJ and Pretorius, JT (2010) 'Taxpayers Beware the SARS Cheque Refund' 73 Journal of Contemporary RomanDutch Law 482, available at http://goo.gl/K74SB

Nanto, DK (1998) ‘The 1997-98 Asian Financial Crisis: CRS Report For Congress', available at http://goo.gl/3F5XZ

Narayan, A (2007) 'Overview of Regulatory Challenges in the Converged Telecommunication/ICT Environment', available at http://goo.gl/32OlY

Natelson, RG (2006) 'The Legal Meaning of "Commerce” in the Commerce Clause' 80(3) St. John's Law Review, available at http://goo.gl/VvcUG

National Archives (s.d.) 'Explanatory Notes for UK Banking Act 2009,' available at http://goo.gl/1ca0H 
National Community Investment Fund (NCIF) (2009) 'Demystifying Prepaid Cards', available at http://goo.gl/giEUb

National Council on Economic Education (2011) 'Money is What Money Does', available at http://goo.gl/Z01ST

National Irish Bank (2007a) 'Payments Reform', available at http://goo.gl/qAde5

National Irish Bank (2007b) 'Pre-Budget Submission', available at http://goo.gl/78jkF

Nativ, S (2007) 'The Demand for Research-Based Policy Alternatives: The Case of Electronic Money in the US and the EU', available at http://goo.gl/2JvSB

Naudé, T (2007) 'The Use of Black and Grey Lists in Unfair Contract Terms Legislation in Comparative Perspective' 124 South African Law Journal 128

Naudé, T (2009) 'The Consumer's Right to Fair, Reasonable and Just Terms under the New Consumer Protection Act in Comparative Perspective' 126(3) South African Law Journal 505-536

Nduati, S (2006) 'Expanding Financial Services to the Poor: The Role of ICT/Regulatory Challenges $9^{\text {th }}$ June 2006', available at http://goo.gl/4dgBW

Ndung'u, M (2009) 'CBK Presentation to the Board of Directors of Domestic Regulators', available at http://goo.gl/KMbKe

Ndzamela, P (2010a) 'FNB's e-Wallet grows tenfold in 2010' posted on Moneyweb, available at http://goo.gl/o7meV

Ndzamela, P (2010b) ‘ More South Africans are Using Financial Products', Finmark Trust, News and Media Releases, New Publications, posted on Moneyweb , available at http://goo.gl/sArpi

Ndzamela, P (2010c) 'Proletariat Will Now be Able to Bank at Night', posted on Moneyweb, available at http://goo.gl/XaLyK

Neely, K and Fonte, E (2010) 'The Future of Plastic', available at http://goo.gl/zmlxL

Neethling, J, Potgieter, JM and Visser, PJ (1989) Law of Delict

Neiman, RH (2010) 'Managing Pre-emption and Oversight in a Modernized Dual Banking System' Bureau of National Affairs Banking Report, available at http://goo.gl/ob5xZ

Nel, J, Boshoff, C and Raleting, T (2012) 'Exploiting the Technology Cluster Effect to Enhance the Adoption of WIG Mobile Banking Among Low-Income Earners' 21(1) Management Dynamics 30-44

Newlyn, WT and Bootle, RP (1978) Theory of Money $3^{\text {rd }}$ ed

Ngugi, B, Pelowski, M and Ogembo, JG (2010) 'M-PESA: A Case Study of the Critical Early Adopters' Role in the Rapid Adoption of Mobile Money Banking in Kenya', available at http://goo.gl/td5rH

Nilsen, R (2012) 'The Power of Debt', available at http://goo.gl/ovxdW

'Northern Rock: The Timeline' (2008) The Independent, Wednesday 26 March, available at http://goo.gl/sRSc3

Ntingi, A (2008) 'Small Banks Stand Warned' Fin24, 13 April, available at http://goo.gl/fI7GT

Ntingi, A (2011) 'Banks Not Keen On Deposit Insurance Plan', available at http://goo.gl/KqdCl.

Ntuyenabo, F (2009) The Legal Foundation of the Independence of Central Banks - A Comparative Study LLM Thesis, University Of South Africa

'Numeraire' (2011) in Investopedia, available at http://goo.gl/9vHGO

'Numeraire' (2011) in Oxford Dictionaries, available at http://goo.gl/fJpci

Nuri, VZ (2002) 'Fractional Reserve Banking as Economic Parasitism: A Scientific, Mathematical, \& Historical Expose, Critique, and Manifesto', available at http://goo.gl/mYQhC

Nussbaum, A (1937) ‘Basic Monetary Conceptions in Law’ 35(6) Michigan Law Review 865

Nussbaum, A (1950) Money in the Law: National and International

Nyaoma, G (2010) 'Mobile Payments Regulatory Framework Perspectives in Kenya', available at http://goo.gl/lDPDl

O’Brien, KJ (2009) 'Cellphone Encryption Code is Divulged' New York Times, available at http://goo.gl/CGYPy 
Obopay Press Release (2008) 'CITI and Obopay Launch Person-To-Person Mobile Payment Pilot Service for Citibank Customers', available at http://goo.gl/GX5yx

O'Connor, SM (1998) 'The De Minimis Exemption of Stored Value Cards From Regulation E: An Invitation to Fraud?' 5 Richmond Journal of Law and Technology 6

Odinga, RO (2009) 'Investing in Women: African Women's Economic Summit 2009', available at http://goo.gl/g8peb

Oelofse, AN (1991) 'Onlangse Ontwikkelings in die Tjekreg' 3 SA Mercantile Law Journal 376

Office of the Comptroller of the Currency (OCC) (1996) 'Interpretive Letter' No 220, available at http://goo.gl/PILgh

Office of the Comptroller of the Currency (OCC) (1998a) 'Guidance on Electronic Financial Services and Consumer Compliance', available at http://goo.gl/BRLEN

Office of the Comptroller of the Currency (OCC) (1998b) 'The Report of the Consumer Electronic Payments Task Force', available at http://goo.gl/EtLkt

Office of the Comptroller of the Currency (OCC) (2003) 'Conditional Approval' \#568, available at http://goo.gl/OHKzB

Office of the Comptroller of the Currency (OCC) (2008a) 'Activities Permissible for a National Bank', available at http://goo.gl/hFT2Z

Office of the Comptroller of the Currency (OCC) (2008b) 'A Guide to the National Banking System', available at http://goo.gl/4RV1X

Office of the Comptroller of the Currency (OCC) (2011) 'National Banks, Thrifts, Credit Unions: Who Regulates Them?', available at http://goo.gl/pXBKo

Office of the Federal Register (1996) 'CFR Parts Affected During May' (Proposed Rules) 61(86) Federal Register, available at http://goo.gl/MCm01

Office of the State Controller (2005) 'Electronic Funds Transfer 101', available at http://goo.gl/RnacC

Olivecronna, K (1957) The Problem of the Monetary Unit

Olivella, M (1992) 'The Power of Money: Monetics against Corruption', available at http://goo.gl/m3aSf

Olivier, L (1998) 'Pitfalls in Creating an Investment Trust' 115 South African Law Journal 519-527

Olmesdahl, MCJ (1984) 'Unheralded Demise of Wolmer versus Rees' 100 South African Law Journal 545

Ombudsman for Banking Services in South Africa (OBSSA) (2008) 'Card Cloning', Bulletin 13, available at http://goo.gl/m7rrB

Ombudsman for Banking Services in South Africa (OBSSA) (2011) 'The OBS's Jurisdiction', available at http://goo.gl/skLYJ

Ombudsman for Banking Services in South Africa and the Financial Intelligence Centre (OBSSA and FIC) (2009) 'Joint Statement: Clarification on the Obligations of Accountable Institutionson Verifying Client Identities Record KeepingJohannesburg, 09 July, 2009', available at http://goo.gl/g0lqD

Organization for Economic Co-operation and Development (OECD) (2002) 'The Future of Money', available at http://goo.gl/5dhqr

Organisation for Economic Co-operation and Development (OECD) (2003) 'Glossary of Terms: EMI', available at http://goo.gl/efR3k

Organisation for Economic Co-operation and Development, Development Co-operation Directorate (2010) 'Development Aid Rose in 2009 and Most Donors will Meet 2010 Aid Targets', available at http://goo.gl/JDSxK

Ostroy, JM and Starr, RM (1990) 'The Transactions Role of Money' in Friedman, BM and Hahn, FH (eds) Handbook of Monetary Economics

Oxford Dictionaries Online, available at http://goo.gl/UHPTl

Palley, T (2001-2002) 'The e-Money Revolution: Challenges and Implications for Monetary Policy' 24 Journal of Post Keynesian Economics 217-233, available at http://goo.gl/MeGW8

Papadopoulos, G (2007) 'Electronic Money and the Possibility of a Cashless Society', available at http://goo.gl/lTFzG 
Paridon, CM (2008) 'New Changes and Challenges: Non-banks in the Payments System', available at http://goo.gl/XV9RQ

Parikh, T et al (2006) 'Mobile Phones and Paper Documents: Evaluating a New Approach for Capturing Microfinance Data in Rural India' ACM Conference on Computer-Human Interaction (CHI), Montreal, Canada, available at http://goo.gl/m635Z

Parkinson, P (2002) 'Reconceptualising the Express Trust' 61(3) Cambridge Law Journal 657

Parrott, D (2010) GSMA Mobile Money Summit 2010: Unleash the Power of Mobile Money Rio de Janeiro, 24 May

Passas, N (2003) 'Informal Value Transfer Systems, Terrorism and Money Laundering: Report to the National Institute of Justice', available at http://goo.gl/8LZHQ

Passas, N (2006) 'Fighting Terror with Error: The Counter-productive Regulation of Informal Value Transfers', available at http://goo.gl/gTZPh

PatentStorm (2004-2012) ‘Inside Money’, available at http://goo.gl/MgFoY

Paths to Learning (2008) 'Community Banking: A Microfinance Unit of the Standard Bank Group South Africa', available athttp://goo.gl/m43LY

Pati, AP (2009) 'Enhancing Financial Inclusion: The Catalytic Role of Self Help Groups' The Management Accountant, available at http://goo.gl/mccjV

Paul, R (2003) 'Bring Back Honest Money Speech to the US House of Representatives, July 25, 2003', available fromhttp://goo.gl/W8TVh

Payment Card Industry (PCI) Security Standards Council home page, available at https://www.pcisecuritystandards.org

Payments Association of South Africa (PASA) (2011) 'NPS Landscape: Key Roleplayers,' available at http://goo.gl/Y3auI

PayPal (1999-2012) 'Purchase Protection from PayPal', available from http://goo.gl/Hktp4

Peachy, D (2010) 'Key Changes in the Second Electronic Money Directive E-Money Stakeholder Liaison Group Meeting 22 April 2010’, available at http://goo.gl/G7aW3

Penn, GA, Shea, AM and Arora, A (1987) The Law Relating to Domestic Banking: Banking Law Vol 1

Perlman, L (2007) 'WASPA: Laying the Foundations for Mobile Money' in Goldstuck, A (ed) The Hitchhiker's Guide to Going Mobile: The South African Handbook of Cellular and Wireless Communication

Perlman, L (2010) 'Mobile Money and Payments Issues: [Aspects of Legal \& Regulatory Issues in Mobile Financial Services in the Developing World]' Mobile Money II Conference, Friday 5 November, 2010, Columbia University, The Columbia Institute for Tele-Information (CITI) at Columbia Business School, available at http://goo.gl/PxViy

Perlman, LJ (2003) Application of the South African Electronic Communications and Transactions Act 25 of 2002 to Mobile Commerce Unpublished LLB dissertation, University of South Africa

Pesek, BP and Saving, TR (1970) Money, Wealth, And Economic Theory

Peterson, B (2006) ‘Money Service Businesses: Meet Your Regulator(s)', available at http://goo.gl/Sr3aA

Philippine Institute for Development Studies (2009) 'Transformational Branchless Banking: Blazing New Trails in Delivering Financial Services' 9(1) Economic Issue of the Day, available at http://goo.gl/oxU76

Pickens, M (2007) ‘When is Mobile Banking not Banking?’, available at http://goo.gl/qfomV

Pickens, M (2008) ‘Airtime as Remittance: Good Deal for the Poor?' CGAP Blog, available at http://goo.gl/2zN5X

Pickens, M (2009a) 'Understanding What Drives Profits for Agents: M-PESA', available at http://goo.gl/lg8g5

Pickens, M (2009b) 'Window on the Unbanked: Mobile Money in the Philippines' CGAP Briefs, available at http://goo.gl/yMGyQ

Pickens, M (2010) 'Building Viable Agent Networks: Brazil and Kenya' CGAP, available at http://goo.gl/pKuos

Pickens, M and McKay, C (2010) 'Branchless Banking 2010: Who's Served? At What Price? What's Next?', available at http://goo.gl/6LL61 
Piffaretti, NF (1998) 'A Theoretical Approach to Electronic Money FSES-302', available at http://goo.gl/UDlv1

Pilkington, P (2011) 'What is Debt? - An Interview with Economic Anthropologist David Graeber', available at http://goo.gl/b86br

Pistorius, T (2008) 'The Legal Effect of Input Errors in Automated Transactions: The South African Matrix' 2 Journal of Information, Law \& Technology, available at http://goo.gl/jho01

Plato Republic, II 371

Plauche, M and Prabaker, M (2010) 'Text-Free User Interfaces' in Association for Computing Machinery (ACM) Conference on Computer Human Interaction, Montreal, Canada, available at http://goo.gl/OGiwC

Porteous, D (2004) 'The Regulator's Dilemma: Opening Space for Innovation and Development in the Financial System' Workshop on Tiered Banking Regulation, Pretoria, 22 November, available at http://goo.gl/9mjG5

Porteous, D (2006a) 'The Enabling Environment for Mobile Banking in Africa', available at http://goo.gl/JDDRn

Porteous, D (2006b) ‘The Regulator’s Dilemma', available via www.finmarktrust.org.za

Porteous, D (2008) 'Mobile Phone Banking: Is m-Banking Advancing Access to Basic Baking Services in South Africa?' Finmark Trust, available from http://goo.gl/4a1P2

Powell, S (2009) ‘Critical Measures to Protect Against Rocketing EFT Fraud Risk’ Without Prejudice December 48-50

Powell, S (2011) 'EFT Fraud and Password Abuse’ Without Prejudice November 43-44

Prahalad, CK (2006) The Fortune at the Bottom of the Pyramid

Presidency of the Republic of South Africa (2009) 'Development Indicators 2009', available at http://goo.gl/RD9Fw

Pretorius, CJ (2011) 'Third Party Fraud Inducing Material Mistake: Slip Knot Investments 777 (Pty) Ltd v Du Toit 20114 SA 72 (SCA)' 14(7) Potchefstroom Electronic Law Journal 187-209

Pretorius, JT (2000) 'More Guidelines on the Negligence of the Collecting Bank' 12(3) SA Mercantile Law Journal 359-368

Pretorius, JT (2002) 'New Bank Accounts and the Collecting Bank’ 14(1) SA Mercantile Law Journal 93-107

Pretorius, JT (2004) 'The Bona Fide Purchaser of a Krugerrand' 16(3) SA Mercantile Law Journal 466-476

Pretorius, JT (2005) ‘The Truncation of Cheques: Novel Developments in America' 13(1) Juta's Business Law 38-43

Pretorius, JT (2008) 'Combining Bank Accounts: The Validity of this Practice Explored' 16(11/12) Juta's Business Law 5154

Pretorius, JT and Van der Bijl, C (2006) 'A New Mode of Forgery: The Rise of Cloned and Washed Cheques'18(2) SA Mercantile Law Journal 196-203

Prior, F and Santomá, J (2010) 'Banking the Unbanked Using Prepaid Platforms and Mobile Telephones' IESE Business School-University of Navarra, Barcelona,. Spain, Working Paper WP-839, January, available at http://goo.gl/NtOKd

Proctor, C (2005) Mann on the Legal Aspect of Money $6^{\text {th }}$ ed

Proctor, C (ed) (2009) Goode on Payment Obligations in Commercial and Financial Transactions

'Proferens' (2012) Oxford Dictionaries, available at http://goo.gl/UHPTl

'Proposed Rules' (2010) 75(123) Federal Register Monday 28 June 28, available at http://goo.gl/Qh0Hm

Public Utility Research Center (2011) ‘Theories of Regulation', available at http://goo.gl/slr9b

PwC (2011) 'Reinforcing Collective Strength And Stability South Africa - Major Banks Analysis', available at http://goo.gl/n2yRz

Quiding, C (2006) The Cost-Benefit of Regulation in South African Banking Unpublished MBA Thesis, Gordon Institute of Business Science, available at http://goo.gl/qlt6o

Radcliffe, D (2010) 'Expanding Customers' Financial Options through Mobile Payment Systems: The Case of Kenya', available at http://goo.gl/6D6YD 
Radhakrishna, G (2009) 'Liability Issues in Internet Banking in Malaysia' 7 Communications of the IBIM 1-7, available at http://goo.gl/4R0Jp

Ramachandran, R (2010) ‘BFSI: Best Practices in Financial Inclusion’, available at http://goo.gl/DhGWU

Ramasastry, A (2000) 'Memorandum to the Cyberpayments Working Group of the Uniform Money Services Business Act Drafting Committee', available at http://goo.gl/E1buF

Ramasastry, A (2005a) 'Do Banks Have a Legal Duty to Notify Customers About Specific Computer Viruses? A Miami Suit Raises the Question' Findlaw, available at http://goo.gl/MMuqA

Ramasastry, A (2005b) 'Non-bank Issuers of Electronic Money: Prudential Regulation in Comparative Perspective' in Current Developments in Monetary and Financial Law International Monetary Fund, available via http://goo.gl/Yzq0O

Ramasastry, A (2008) 'Confusion and Convergence in Consumer Payments: Is Coherence in Error Resolution Appropriate?' 83(2) Chicago-Kent Law Review 813

Rashid, S (2001) ‘Can There Be a Theory of Money?’, available at http://goo.gl/eL7mC

Rasmussen, RK (2002) 'The Uneasy Case against the Uniform Commercial Code' 62(4) Louisiana Law Review, available at http://goo.gl/yRGi1

Rasske, R (2004) 'AML Requirements upon Identifying an MSB’ Bankers Online, available at http://goo.gl/Qphz8

Ratan, AL (2008) 'Using Technology to Deliver Financial Services to Low-income Households: A Preliminary Study of Equity Bank and M-PESA Customers in Kenya' Microsoft Research Technical Report, available at http://goo.gl/oY5wg

Ratha, D et al (2007) 'Remittance Trends 2007' Migration and Development Brief 3, available at http://goo.gl/JVCZ0

Ratha, D, Mohapatra, S and Silwal, A (2011) 'Migration and Remittances Factbook 2011: South Africa', World Bank: Washington, available at http://goo.gl/o2YkT

Ravichandran, K and Alkhathlan, K (2009) 'Financial Inclusion: A Path towards India's Future Economic Growth', available at http://goo.gl/YyGJ5

Reed, C (2010) 'Online and Offline Equivalence: Aspiration and Achievement' 18(3) International Journal of Law and Information Technology 248-273, available at http://goo.gl/EsgXM

Rees, D (2010) 'Money Laundering and Terrorism Financing Risks Posed by Alternative Remittance in Australia' Australian Institute of Criminology, available at http://goo.gl/Fip0H

Reichwein, D and Rosati, S (2007) 'Non-banks in the Payments System: European and US Perspectives', available at http://goo.gl/HPOi6

Republic of South Africa, National Treasury (2010) 'Vision for Financial Inclusion', available at http://goo.gl/NgKrw

Reserve Bank of Australia (s.d.) 'Legal Tender', available at http://goo.gl/xqr1h

Reserve Bank of India (s.d.) 'FAQ', available from http://goo.gl/trb4c

Reserve Bank of New Zealand (s.d.) 'Statement of Principles: Payment System Oversight', available at http://goo.gl/IOx40

Retsinas, NP and Belsky, ES (2005) 'Building Assets, Building Credit: Creating Wealth in Low-Income Communities' 31(1) International Journal of Urban and Regional Research 239-243

Rhine, SLW and Su, S (2005) 'Stored Value Cards as a Method of Electronic Payment for Unbanked Consumers', available at http://goo.gl/h6d0H

Richmond, R (2011) 'Security to Ward off Crime on Phones' New York Times 23 February, available at http://goo.gl/HMcCZ

Rider, BAK (1999) 'The Limits of the Law: An Analysis of the Interrelationship of the Criminal and Civil Law in the Control of Money Laundering' 2 Journal of Money Laundering Control 209

Ritchie, S (2005) 'Will Regulators Burst the Prepaid Bubble?' 9 North Carolina Banking Institute Journal 201-222, available at http://goo.gl/RnXN0

Roberts, P (2011) ‘Threat Post: Zeus Banking Trojan Comes to Android Phones’, available at http://goo.gl/lUeiQ

Robertson, DH (1928, repr and rev 1932) Money $2^{\text {nd }}$ rev ed 
Robertson, J (2010) ‘Hacker Builds \$1,500 Cell-phone Tapping Device’, available at http://goo.gl/EWJW

Rogers, JS (2005) 'The New Old Law of Electronic Money' 58 Southern Methodist University Law Review 1253-1311, available at http://goo.gl/KetTp

Rohling, TA and Tapley, MW (1998) 'Optimal Regulation of Electronic Money: Lessons from the "Free Banking” Era in Australia’ 17(7) Economic Papers 729

Rosenberg, AS (2005) 'Better than Cash? Consumer Protection and the Global Debit Card Deluge' TJSL Public Law Research Paper No 05-04, available at http://goo.gl/4fmN3

Rossouw, J (2011) 'A Selective Reflection on the Institutional Development of the South African Reserve Bank Since 1921' 26(S1) Economic History of Developing Regions S3-S20

Rothbard, MJ (1999) 'A History of Money and Banking in the United States: The Colonial Era to World War II', available at http://goo.gl/peUBs

Royal Mint (s.d.) ‘Legal Tender Guidelines’, available at http://goo.gl/J1U1p

Rubin, E (1991) 'Efficiency, Equity and the Proposed Revision of Articles 3 and 4' 42 Albany Law Review 551

Rubin, PH (s.d) 'Law and Economics', available at http://goo.gl/oSkeq

Rural Finance (2008) 'Knowledge Management’ 9 Newsletter March, available at http://goo.gl/Yidcq

Rutledge, SL (2010) 'Consumer Protection and Financial Literacy: Lessons from Nine Country Studies’ The World Bank, available from http://bit.ly/bYhcII

Sachs, J (2005) The End of Poverty

Safaricom (s.d.) ‘General M-PESA FAQs’, available at http://goo.gl/azEfw.

Safaricom (2011a) 'M-KHESO Frequently Asked Questions', available at http://goo.gl/tXHrR

Savingsadvice.com (2004) 'Man Pays Traffic Ticket with 8,200 Pennies', available at http://goo.gl/UiDZL

Sawyer, M (2003) 'Money: Means of Payment or Store of Wealth?' in Rochon, L-P and Rossi, S Modern Theories of Money: The Nature and Role of Money in Capitalist Economies 3-17

Saxena, A (2009) 'Accelerating Financial Inclusion through Innovative Channels: 10 Obstacles for MFIs Launching Alternative Channels - and What Can Be Done About Them' No 27 InSight, available at http://goo.gl/BwmHj

Schimk, B (2006) 'Payment Institutions: Potential Implications of the New Category of Payment Service Providers for the Austrian Financial Market', available at http://goo.gl/VedWG

Schmitz, SW (2001) 'The Institutional Character of Electronic Money Schemes: Redeemability and the Unit of Account' at 17, available at http://goo.gl/RDx01

Schmitz, SW (2005) 'Will Central Banking Survive Electronic Money?' prepared for the conference The Future of Payments, Bank of England, London 19-20 May

Schmitz, SW (2006) 'eMoney and Monetary Policy: The Role of the Inter-eMoney-Institution Market for Settlement Media and the Unit of Account: A Critical Assessment of the Literature' in Schmitz, SW and Wood, GE (eds) Institutional Change in the Payment System and Monetary Policy by Electronic Money Innovations: Implications for Monetary Policy 93-120

Schmitz, SW and Wood, GE (2006) Institutional Change in the Payments System and Monetary Policy

Schoenblum, JA (2009) Multistate and Multinational Estate Planning Toolkit Media Group

Schoombee, A (2004) 'South African Banks and the Unbanked: Progress and Prospects', available at http://goo.gl/62kMk

Schulze, WG (2001) 'Depositum, Deposit and Deposit-taking Institutions: Birds of a Feather? Not Quite' 13(1) SA Mercantile Law Journal 78-95

Schulze, WG (2002) 'The Sources of South African Banking Law: A Twenty-first Century Perspective (Part 1)' 14(3) SA Mercantile Law Journal 438-461

Schulze, WG (2004a) 'Countermanding an Electronic Funds Transfer: The Supreme Court Takes a Second Bite at the Cherry' 16(4) SA Mercantile Law Journal 667-684 
Schulze, WG (2004b) 'E Money and Electronic Fund Transfers: A Shortlist of Some of the Unresolved Issues' 16(1) SA Mercantile Law Journal 50-66

Schulze, WG (2004c) 'Smart Cards and e-Money: New Developments Bring New Problems' 16(4) SA Mercantile Law Journal 703-715

Schulze, WG (2004d) 'Unauthorized Cash Withdrawals with a Credit Card, and Unfair Contract Terms' 12(3) Juta's Business Law 143-146

Schulze, WG (2005) 'Of Credit Cards, Unauthorised Withdrawals and Fraudulent Credit-Card Users' 17(2) SA Mercantile Law Journal 202-213

Schulze, WG (2006) 'Delictual Liability of a Bank Towards its Client: A New Prominence Given to the Element of Causation: Court Judgement' 22(4) Tydskrif vir die Suid-Afrikaanse Reg 834-839

Schulze, WG (2007) 'Electronic Fund Transfers and the Bank's Right to Reverse a Credit Transfer: One Small Step for Banking Law, One Huge Leap for Banks: Case Comment' 19(3) SA Mercantile Law Journal 379-387

Schulze, WG (2008) 'Electronic Fund Transfers and the Bank's Right to Reverse a Credit Transfer: One Big Step (Backwards) for Banking Law, One Huge Leap (Forward) for Potential Fraud: Pestana v Nedbank (Act One, Scene Two)' 20(2) SA Mercantile Law Journal 290-297

Schulze, WG (2009) 'A Final Curtain Call, but perhaps not the Last Word on the Reversal of Credit Transfers: Nedbank Ltd v Pestana: Case Comments’21(3) SA Mercantile Law Journal 396-404

Schumpeter, JA (1934) The Theory Of Economic Development: An Inquiry Into Profits, Capital, Credit, Interest And The Business Cycle

Schumpeter, JA (1954) History of Economic Analysis

Schumpeter, JA (1970) Das Wesen des Geldes

Scott, H (2007) 'The Requirement of Excusable Mistake in the Context of the Condictio Indebiti: Scottish And South African Law Compared' 124(4) SA Law Journal 827-866

Scott, H and Visser, D (2010) 'The Impact of Legal Culture on the Law of Unjustified Enrichment: The Role of Reasons' at 155, in Bant, E and Harding, M (eds) Exploring Private Law

Security News (2011) 'PIN Pads Hacked at Michaels Stores Nationwide', available at http://goo.gl/CDXYe

Selgin, GA and White, LH (1994) 'How Would the Invisible Hand Handle Money’ 32 Journal of Economic Literature 17181749

Selgin, G and White, LH (2002a) 'The Future of Fiat Money: A Mengerian Perspective', available at http://goo.gl/MRBhW

Selgin, G and White, LH (2002b) ‘Mengerian Perspectives on the Future of Money', available at http://goo.gl/heT1G

Sese, A (2004) 'The Fiduciary Relationship between a Bank and Customers' 4 Shinshu Law Review 185-200 at 189, available from http://goo.gl/Mcnoq

Setsuya, S and Humphrey, DB (1995) 'Transforming Payment Systems: Meeting the Needs of Emerging Market Economies', available at http://goo.gl/cWLvP

Shackle, GLS (1971) '[Discussion Papers on "Theoretical Foundations of Monetary Policy” by RW Clower]' in Gilbert, JC and Sedgwick, R (eds) Monetary Theory and Monetary Policy in the 1970s: Proceedings of the 1970 Sheffield Seminar on Monetary Theory and Monetary Policy in the 1970s (1970: University of Sheffield) 32-34

Sharma, P and Mukhopadhyay, B (2009) 'Reaching a Billion People: The Electronic Payments Solution', available at http://goo.gl/sojbw

Sharrock, RD (2010) 'Judicial Control of Unfair Contract Terms: The Implications of the Consumer Protection Act' 22(3) SA Mercantile Law Journal 295-325

Shaw, J (2000) Law of the EU 3rd ed

Sher, H (1996) 'Trusts in South Africa’2(7) Trusts \& Trustees 11

Sherif, MH (2004) Protocols for Secure Electronic Commerce 
'Shoprite Lashes out at Banks Over System Failures' (2009) Mail and Guardian, 6 Nov, available at http://goo.gl/aUY0F

Shoprite (2011) 'Consumer Services: Money Market', available at http://goo.gl/jLNDJ

Shostak, F (2000) 'Why the Present Monetary System Cannot be Reformed' Paper delivered at the Austrian Scholars' Conference, 25 March, Auburn, Alabama USA, available at http://goo.gl/k315S

Shubik, M (2000) ‘The Theory of Money’ Cowles Foundation Discussion Papers No 1253, available at http://goo.gl/6RmTn

Sifers, RW (1997) 'Regulating Electronic Money in Small-Value Payment Systems: Telecommunications Law as a Regulatory Model' 49 Federal Communications Law Journal 701

Silard, SA (1983) 'Reviewed Work(s): The Legal Aspect of Money: With Special Reference to Comparative Private and Public International Law by FA Mann' 77(3) American Journal of International Law 676-679

Silke, JM (1981) The Law of Agency in South Africa $3^{\text {rd }}$ ed

Simmel, G (1900) Philosophie des Geldes $5^{\text {th }}$ ed

Simmel, G (2004) The Philosophy of Money $3^{\text {rd }}$ enlarged ed

Simon, J (2005) 'Payment Systems Are Different: Shouldn't Their Regulation Be Too?' Paper presented to Federal Reserve Bank of New York Conference Antitrust Activity in Card-Based Payment Systems: Causes and Consequences, 15-16 September, available at http://goo.gl/qOJag

Singh, D (2007) Banking Regulation of UK and US Financial Markets

Singh, S (2008) 'The Social and Cultural Interpretation of Number: A Focus on Remittances as a Currency of Care', available from http://goo.gl/Mmjwf

Skinner, C (2007) The Future Of Banking

Smedinghoff, TJ (1996) Online Law: The SPA's Legal Guide to doing Business on the Internet

Smedinghoff, TJ (2002) 'The Legal Requirements for Creating Secure and Enforceable Electronic Transactions', 30 August, available at http://goo.gl/LA7zl

Smith, A (1776) An Inquiry into the Nature and Causes of the Wealth of Nations Book IV Chapter II

Smith, BW and Shahani, VR (2008) 'Unfair and Deceptive Acts and Practices: Developments in the Financial Services Industry’ Banking Law Journal 809-816, available at http://goo.gl/pb4fr

Smithin, J (2000) What Is Money?

Society for Worldwide Interbank Financial Telecommunication (SWIFT) (2011) 'Oversight of SWIFT,' available at http://goo.gl/AV2yv

Solin, M and Zerzan, A (2010) 'Mobile Money: Methodology for Assessing Money Laundering and Terrorist Financing Risks', available at http://goo.gl/F6vw5

Solomon, LD (1996) Rethinking Our Centralized Monetary System: The Case For A System Of Local Currencies

Sommer, JH (1998) 'Where is a Bank Account?’ 57 Maryland Law Review 1, available at http://goo.gl/or29s

Sommer, JH (2005) ‘Why Should a Legal Scholar Care About Bank Deposits?', available at http://goo.gl/C8ogR

Sommer, JH (2007) 'Why Worry About Bank Deposits’ Unpublished Manuscript

Sommer, JH (2008) ‘Commentary: Where is the Economic Analysis of Payment Law?’ 83 Chicago-Kent Law Review 7511

Sonnekus, JC (2008a) 'Eensydige Terugskryf Van Kliënt se Krediet deur Bank Onregmatig' 2 Tydskrif vir die SuidAfrikaanse Reg 348-354

Sonnekus, JC (2008b) Unjustified Enrichment in South African Law

South Africa Foundation (2003) 'Designing a Regulatory Impact Assessment for South Africa', available at http://goo.gl/5RzpZ

South Africa, Department of Trade and Industry (DTI) (2009) 'Media Release: President Motlanthe Approved Consumer Protection Bill', 30 April, available at http://goo.gl/vjKRo 
South Africa, Department of Trade and Industry (DTI) (2011) ‘Economic Statistics', available at http://goo.gl/oGzis

South African Banking Risk Information Centre (SABRIC) (2010a) 'Phishing Scams Rising in South Africa', July, available at http://goo.gl/3X6aN

South African Banking Risk Information Centre (SABRIC) (2010b) 'SABRIC Announces 2010 Banking Industry Card Fraud Figures', available from http://goo.gl/peT0n

South African National Treasury (2010) 'Vision for Financial Inclusion', available at http://goo.gl/HwmxO

South African Press Association (SAPA) (2010) 'ID Book Designer "Stupid" posted on News24.com, 23 February, available at http://goo.gl/s2Tyj

South African Press Association (SAPA) (2011) 'MTN Launches Mobile Insurance' Times Live, 23 March, available from http://goo.gl/NcA7f

South African Reserve Bank (s.d.) 'History of South African banknotes 1782 to 1920,' available at http://goo.gl/RwR9M

South African Reserve Bank (SARB) (1995) ‘Blue Book Overview', available at http://goo.gl/TuzRB

South African Reserve Bank (SARB) (1999) 'Position Paper on Electronic Money - April 1999', available at http://goo.gl/LfPCU

South African Reserve Bank (SARB) (2001) 'NPSD: Position Paper on Common Monetary Area (CMA) Cross-border Payments' Position Paper No 01/2001, available at http://goo.gl/7jsXD

South African Reserve Bank (SARB) (2004) 'BSD Circular 14/2004: Outsourcing of Functions within Banks,' available at http://goo.gl/BWr81

South African Reserve Bank (SARB) (2006a) 'Bank Supervision Department Annual Report 2006: Chapter 2: Current Issues in Banking Supervision', available at http://bit.ly/cOfw2T

South African Reserve Bank (SARB) (2006b) 'The National Payment System Framework and Strategy: Vision 2010', available at http://goo.gl/rej7c

South African Reserve Bank (SARB) (2006c) 'Position Paper on Electronic Money NPS 01/2006', available at http://goo.gl/BYRnG

South African Reserve Bank (SARB) (2006d) 'Vision 2010', available at http://goo.gl/rYKVk

South African Reserve Bank (2007a) 'Directive 2/2007 - Directive for Conduct within the National Payment System in Respect of System Operators', available at http://goo.gl/DxPcT

South African Reserve Bank (SARB) (2007b) 'Position Paper: Bank Models in the National Payment System', January, available at http://goo.gl/JYxkp

South African Reserve Bank (SARB) (2007c) 'Understanding the Core Responsibilities of the Bank: To Maintain Price Stability and Financial Market Stability’ [Brochure]

South African Reserve Bank (SARB) (2008a) 'Guidance Note 6/2008 Issued in Terms of Section 6(5) of the Banks Act, 1990: Cell-Phone Banking’, available at http://goo.gl/qPZzp

South African Reserve Bank (SARB) (2008b) 'Financial Stability Review: September 2008', available at http://goo.gl/IEtIA

South African Reserve Bank (SARB) (2008c) 'Position Paper number 02/2008: Interbank Settlement Network Security Architecture', available at http://goo.gl/xZeGA

South African Reserve Bank (SARB) (2009) 'Position Paper on Electronic Money', available at http://goo.gl/HdH2k

South African Reserve Bank (SARB) (2010a) 'NPSD: Position Paper on Common Monetary Area (CMA) Cross-Border Payments', available at http://goo.gl/AdsJg

South African Reserve Bank (SARB) (2010b) Personal Communication

South African Reserve Bank (SARB) (2011a) 'Exchange Control Manual’, available at http://goo.gl/Ekuh5

South African Reserve Bank (SARB) (2011b) ‘Financial Stability Review: March 2011', available at http://goo.gl/ljSvo 
South African Reserve Bank (SARB) (2011c) 'Financial Surveillance and Exchange Controls', available at http://goo.gl/xIaHP

South African Reserve Bank (SARB) (2011d) 'NPSD: Position Paper on Access to the National Payment System', available at http://goo.gl/KDd7W

South African Reserve Bank (SARB) (2011e) 'NPSD: Position Paper on Interoperability' NPS 01/2011, available at http://goo.gl/gVB09

South African Reserve Bank (SARB) (2011f) 'Statistics', available at http://goo.gl/0Ata2

South African Reserve Bank (SARB) (2012) 'The Importance and Development of Sound Financial Market Infrastructures to Position South Africa in SADC and Worldwide', available at http://goo.gl/JIEg3

South African Reserve Bank (SARB) (s.d.) ‘About Us', available at http://goo.gl/QadS9

South African Revenue Service (SARS) (2010) 'Reference Guide: Provisional Tax' 10 July

South African Revenue Service (SARS) (2011) 'Make a Payment', available at http://goo.gl/pdrvx

Sprecher Grier Halberstam LLP (s.d.) 'How to Contract Online', available at http://goo.gl/gYveu

Staff Reporter (2009) 'FNB Unveils Cross-border Airtime Top-up Service' Lesotho Times, 30 April, available at http://goo.gl/RzYeb

Standard Bank (2009-2010) Personal Communication to author

Standard Bank (2011) ‘Community Banking’, available at http://goo.gl/VcpKo

Stassen, JC (1978) 'Betaling deur Middel Van 'n Driepartykredietkaart' De Jure 134

Stathopoulos, M (1995) Modern Techniques for Financial Transactions and Their Effects on Currency: General and National Reports

Stavins, J (2006) ‘Consumer Behavior and Payment Choice: A Conference Summary’, available at http://goo.gl/TyEux

Steennot, R (2008) 'Legal Aspects of Credit Transfers and Electronic Payments: A Belgian Perspective' Financial Law Institute Working Paper No 2008-12, available at http://goo.gl/STVJ8

Steennot, R (2010) 'Allocating Liability in Case of Fraudulent use of Electronic Payment Instruments and the Belgian Mobile Payment Instrument Pingping’ Financial Law Institute WP 2010-12, available from http://goo.gl/pDx5X

Stervinou, A (2011) 'The Role of Non-banks in Retail Payments' Regional Payment Systems Workshop - LAC Port of Spain, Trinidad \& Tobago, 08 February 2011, available at http://goo.g1/5x3CZ

Stigler, GJ (1971) 'The Economic Theory of Regulation' 2 Bell Journal of Economics 3-21, available at http://goo.gl/CY63C

Stigler, GJ (1972) 'The Law and Economics of Public Policy: A Plea to the Scholars' 1(1) The Journal of Legal Studies 1-12

Stiglitz, JE (2009) ‘Government Failure vs Market Failure: Principles of Regulation’, available at http://goo.gl/TsVr9 p2

Subbarao, D (2009) 'Retail Payments: Perspectives and Way Forward: Valedictory Address delivered at the Regional Seminar on Payment and Settlement Systems, India', available at http://goo.gl/Voc5a

Sullivan, RJ (2006) 'The Supervisory Framework Surrounding Non-bank Participation in the US Retail Payments System: An Overview' FRS Bank of Kansas City, Payments System Research Working Paper 04-03, available at http://goo.gl/paJwC

Sullivan, RJ and Wang, Z (2007) 'Nonbanks in the Payments System: Innovation, Competition, and Risk - A Conference Summary', Nonbanks in the Payments System: Innovation, Competition, and Risk: An International Payments Policy Conference sponsored by the Federal Reserve Bank of Kansas City May 2-4, 2007, 83-106, available at http://goo.gl/OLB2A

Suri, T and Jack, W (2008) 'The Performance and Impact of M-PESA: Preliminary Evidence from a Household Survey', available from http://goo.gl/TGjwY

Swart, D (2000) 'Online Banking Law and Payment Systems' in Buys, R (2001) Cyberlaw, available at http://goo.gl/5Z2Ms

Swart, L and Lawack-Davids, VA (2010) 'Understanding the South African Financial Markets: An Overview of the Regulators' 31(3) Obiter 619-637

Swart, L and Lawack-Davids, VA (2010) 'Understanding the South African Financial Markets: An Overview of the Regulators' 31(3) Obiter 619-637 
Symonds, EL (1983) ‘The Bank Customer Relationship’ 100 Banking Law Journal 220

Tanner, JC (2005) ‘GSMA Kicks off Emerging Market Push with Sub-\$40 Handset’, available at http://goo.gl/FtDnb

Tarazi, M and Breloff, P (2010) 'Nonbank E-Money Issuers: Regulatory Approaches to Protecting Customer Funds' CGAP FocusNote 63, available from http://goo.gl/Os4AL

Task Force on Stored-Value Cards (1997) 'A Commercial Lawyer's Take on the Electronic Purse: An Analysis of Commercial Law Issues Associated with Stored-Value Cards and Electronic Money’ 52 Business Lawyer 653

Taylor, JB (2007) Global Financial Warriors: The Untold Story of International Finance in the Post-9/11 World

Telco 2.0 (2010) ‘Security Breach at M-PESA: Telco 2.0 Crash Investigation', available at http://goo.gl/ym8Br

‘Terms \& Conditions' (Ts\&Cs) from MNO Vodacom, available at http://goo.gl/nyfyn

Terradas, BA (2003) 'Restrictions on Jurisdiction Clauses in Consumer Contracts within the European Union' Oxford U Comparative L Forum 1, available at http://goo.gl/zL3Cp

Terzi, A (2102) ‘Civilized Money View vs. Monetarist Keynesianism', available at http://goo.g//Hmh6

Teslik, LH (2008) ‘The US Financial Regulatory System’, available at http://goo.gl/RNG17

Thaler, T and Sunstein, C (2003) 'Libertarian Paternalism’ 93(2) The American Economic Review 175-179

The Big Question Team, The Open University (2005) ‘What is Money?' 10 January, available at http://goo.gl/1uXb2

'The Global Credit Crisis: In Search of a New Regulatory Model', available at http://goo.gl/7r7Pt

'The Gold Standard' (s.d.) in Concise Encyclopedia of Economics, available at http://goo.gl/OBJ8

The South African Encyclopedia of Forms and Precedents vol 1 at 396

Theobald, S (2009) 'Sub-species May Prove Endangered’ Times Live, 13 September, available at http://goo.gl/q1aBA

Thinktank (2010) 'Current \& future market for Premium Rate Services: Report prepared for PhonepayPlus', available at http://goo.gl/Wp595

Thomas, JAC (1976) Textbook of Roman Law

Thornton, H (1802) An Enquiry into the Nature of the Paper Credit of Great Britain

T-Mobile (2008) 'Petition for Declaratory Ruling that Text Messages and Short Codes are Title II Services or are Title I Services Subject to Section 202' WT Docket \#08-7 at 2, available at http://goo.gl/VS0pj

Tobin, J (1963) 'Commercial Banks as Creators of Money’ in Carson, D (ed) Banking and Monetary Studies

Tobin, J (1980) 'The Overlapping Generations Model of Fiat Money: Discussion' in Karken, JH and Wallace, N (eds) Models of Monetary Economies

TopBits.com (s.d.) ‘Two Factor Authentication', available at http://goo.gl/3bls5

Total Telecom (2010) 'US Telcos to Unveil Details of Mobile Payment JV',available at http://goo.gl/6soMh

Totsuka, T and Kuyama, A (2010) 'Regulations on Payment-services Business in Japan,' available at http://goo.gl/khO5O

Tshesane, M (2007) 'The Electronic Communications Act: An Overview', available at http://goo.gl/2c4QB

Tung, L (2007) 'Judge: Computer Code is more Potent than the Law', available at http://goo.gl/i3nZ4

Turner, C (2002) European Law: Key Facts

Tyree, A (2000) ‘The Legal Nature of Electronic Money’, available at http://goo.gl/wcLhJ

Tyree, A (2008a) 'The Business of Banking', available at http://goo.gl//D3ep

Tyree, A (2008b) 'Payment by Credit Card', available at http://goo.gl/GomPJ 
UK Department for Business, Innovation and Skills (2010) 'Reducing Regulation Made Simple,' available at http://goo.gl/ABzyj

United Kingdom Remittance Working Group (2007) 'UK Remittance Market Best Practices for the Remittance Industry in the UK' Department of International Development (DFID), available at http://goo.gl/BJMKu

United Kingdom, Department of Trade and Industry (2002) 'A Guide for Business to the Electronic Commerce (EC Directive) Regulations 2002 (SI 2002/2013)’, 31 July, 1-30, available at http://goo.gl/gVLIL

United Nations (UN) (2006) 'Millennium Development Project Report', available at http://goo.gl/hwTgq

United Nations (UN) (2010) Conference on Trade and Development World Investment Report 2010

United Nations Commission on International Trade Law (UNCITRAL) (1992) 'UNCITRAL Model Law on International Credit Transfers', available from http://goo.gl/xf9dg

United States Senate Committee on Banking, Housing, and Urban Affairs (2010) 'Brief Summary of the Dodd-Frank Wall Street Reform and Consumer Protection Act', available at http://goo.gl/XrSh

United States, Central Intelligence Agency (CIA) (2011a) 'The World Factbook: Africa: Kenya', available at http://goo.gl/KYPIq

United States, Central Intelligence Agency (CIA) (2011b) 'Field Listing: Distribution of Family Income: GINI Index' in The World Factbook, available at http://goo.gl/nRD4I

United States, Central Intelligence Agency (CIA) (2012) 'Africa: South Africa' in The World FactBook, available http://goo.gl/AFSi

United States, Department of Justice (2008) 'Digital Currency Business E-Gold Pleads Guilty to Money Laundering and Illegal Money Transmitting Charges', available at http://goo.gl/379zC

United States, Department of State, Bureau of International Narcotics and Law Enforcement (2008) 'International Narcotics Control Strategy Report: Mobile Payments: A Growing Threat', available athttp://goo.gl/XZ5R

United States, Government Accountability Office (US GAO) (1999) 'Electronic Banking: Enhancing Federal Oversight of Internet Banking Activities', available at http://goo.gl/8YYRp

United States, Government Accountability Office (US GAO) (2005) 'Credit Reporting Literacy: Consumers Understood the Basics but Could Benefit from Targeted Educational Efforts’, available at http://goo.gl/sSYZq

United States, Government Accountability Office (US GAO) (2006) 'Credit Cards: Increased Complexity in Rates and Fees Heightens Need for More Effective Disclosures to Consumers’ GAO-06-929, available at http://goo.gl/9AVPe

United States, Government Accountability Office (US GAO) (2010) 'Consumer Finance: Factors Affecting the Financial Literacy of Individuals with Limited English Proficiency’ GAO-10-518, available at http://goo.gl/90Wzk

University of London (s.d.) 'The Nature of Money' in Monetary Economics Lecture Notes

Urban Affairs (2010) 'Brief Summary of the Dodd-Frank Wall Street Reform and Consumer Protection Act', available at http://goo.gl/XrSh

Usher, JA and Guadamuz, A (2008) 'Electronic Money: The European Regulatory Approach (October 17, 2008)' in Edwards, L (ed) The New Legal Framework for E-Commerce in Europe 173-201, available at http://goo.gl/2cKGH

Vakhitov, R and Vakhitov, L (2002-2003) 'The Concept of Money' 1 Review of Central and East European Law 103-118

Van Blokland, A (2005) 'Virtual Wallet Services: The End of the Cash Era' 149 Wireless Watch Newsletter, available at http://goo.gl/GvZBJ

Van den Bogaerde, F and Fourie, LJ (1986) Basic Macro Economics $2^{\text {nd }}$ ed

Van der Bijl, C (2007) ‘The Cloning of Credit Cards: The Dolly of the Electronic Era' 31 Stellenbosch Law Review 331-346

Van der Bijl, C (2009) 'SIM-Card Swapping, Mobile Phone Banking Fraud and RICA 70 of 2002' 21(2) SA Mercantile Law Journal 159-173

Van der Merwe, CG and Du Plessis, JE (2004) Introduction to the Law of South Africa

Van der Merwe, CJ and Seker, R (2004) 'Mobile Phishing' 33 South African Computer Journal 111-112

Van der Merwe, S, Van Huyssteen, L and Reinecke, M (1993) Contract: General Principles 
Van der Walt, AJ and Pienaar, GJ (2010) Introduction to the Law of Property 23-26

Van Hove, L (2003) 'Making Electronic Money Legal Tender: Pros \& Cons', Paper prepared for Economics of the Future: Celebrating 100 Years of Cambridge Economics, University of Cambridge, September 17-19,2003, available at http://goo.gl/mXcNT

Van Jaarsveld, I (2004) 'Following the Money across Cyber Highways: A Herculean Task or International Challenge? Some Thoughts on Money Laundering on the Internet' 16(4) SA Mercantile Law Journal 685-702

Van Rensburg, A, Lotz, JG and Van Rijn, TAR (2004) 'Contract' in WA Joubert (ed) The Law of South Africa $2^{\text {nd }}$ ed Vol 5 Part 1

Vaubel, R (1984) ‘The Government’s Money Monopoly: Externalities or Natural Monopoly?’ 37(1) Kyklos 27-58

Vaubel, R (1990) 'Currency Competition: Free Entry Versus Governmental Legal Monopoly’ in Groenveld, K, Maks, J and Muysken, J (eds) Economic Policy and the Market Process cited in Holtzhausen, C and Monnet, C (2003) 'Money and Payments: A Modern Perspective', available at http://goo.gl/VdrOo

Venture 8 (2007) ‘Frequently Asked Questions and Objections’, available at http://goo.gl/Lns3p

Verhoef, G (2009) 'Concentration and Competition: The Changing Landscape of the Banking Sector in South Africa 19702007' South African Journal of Economic History (24)2 157-197

Visa (2007) 'Rules for Visa Merchants: Card Acceptance and Chargeback Management Guidelines', available at http://goo.gl/xiKmx

Visa (2011) 'Payment Security', available at http://goo.gl/xPqch

Visser, C (1985) 'Banking in the Computer Age: The Allocation of Some of the Risks Arising from the Introduction of Automated Teller Machines’ 102 South African Law Journal 646

Visser, C (1989) 'Evolution of Electronic Payment Systems’ 1(2) SA Mercantile Law Journal 189-207

Visser, C et al (2004) Gibson: South African Mercantile and Company Law $8^{\text {th }}$ ed

Visser, DP (2008) Unjustified Enrichment

Vlcek, W (2006a) 'Development v. Terrorism: Migrant Remittances or Terrorist Financing?', Challenge Working Paper, Work Package 2 - Securitization Beyond Borders: Exceptionalism inside the EU and Impact on Policing Beyond Borders, September, available at http://goo.gl/wYD4o

Vlcek, W (2006b) 'Development vs. Terrorism: Money Transfers and EU Financial Regulations in the UK' 10(2) The British Journal of Politics \& International Relations 286-302 at 288

Vodacom (2011a) 'M-PESA Terms \& Conditions', available at http://goo.gl/gMotV

Vodacom (2011b) 'M-PESA User Guide', available at http://goo.gl/gDRQS

Vodacom South Africa (2007) ‘A Parent's Guide to Cellphones', available at http://goo.gl/WQdxY

Vodafone (2007) 'The Transformational Potential of M-Transactions', available at http://goo.gl/mJGNt

Von Hayek, FA (1937) Monetary Nationalism and International Stability

Von Hayek, FA (1976) Denationalisation of Money: An Analysis of the Theory and Practice of Concurrent Currencies

Von Hayek, FA (1979) 'Toward a Free Market Monetary System' 3(1) Journal of Libertarian Studies, available at http://goo.gl/ic8BH

Von Mises Institute (s.d.) 'Overview Of The Austrian School of Economics', available at http://goo.gl/V2Kle

Von Mises, L (1912) The Theory of Money and Credit, available at http://goo.gl/eMRKU

Von Mises, L (1953) The Theory of Money and Credit

Von Savigny, FK (1851) Das Obligationenrecht ['Law of Contracts'] Vol 1 cited in Mann, FA (1982) The Legal Aspect of Money $4^{\text {th }}$ ed

Wadsley, S and Penn, GA (2000) Law Relating to Domestic Banking $2^{\text {nd }}$ ed 
Walker, FA (1879) Money in its Relation to Trade and Industry

Wanda, BP (2003) 'Agency and Representation' inWA Joubert (ed) The Law of South Africa 2 ${ }^{\text {nd }}$ ed Vol 1

Wanjiku, R (2009) 'Kenya Communications Amendment Act (2009): Progressive or Retrogressive?', available at http://goo.gl/vAP05

Ward, J (2002) 'The Supervisory Approach: A Critique', available at http://goo.gl/pgVaW

Warmoth, A (2002) 'The Economic Crisis of the Commons', available at http://goo.gl/J8wgs

Weinrib, A (1988) 'Information and Property’ 38 University of Toronto Law Journal 117

Weiss, DG (2005) 'Letter to the FDIC', available at http://goo.gl/hvkny

Wicksell, K (1906) Vorlesungen über Nationalökonomie transl by Classen, E (1967) Lectures on Political Economy Vol 2 Money $2^{\text {nd }}$ ed, cited in Kiyotaki, N and Wright, R (1992) 'Acceptability, Means of Payment, and Media of Exchange' 16(3) Federal Reserve Bank of Minneapolis Quarterly Review (no pagination), available at http://goo.gl/ii167

Williams, RC (2001) ‘The Investment of Trust Moneys’ 13(2) SA Mercantile Law Journal 311-315

Willis, N (1981) Banking in South African Law

Wilson, S (2007) ‘What To Do With Your Airmiles', available at http://goo.gl/ij6Ld.

Wilson, T, Howell, N and Sheehan, G (2009) 'Protecting the Most Vulnerable in Consumer Credit Transactions' 32(2) Journal of Consumer Policy 117-140, available at http://goo.gl/rXoPj

Winn, JK (2006) Consumer Protection in the Age of the 'Information Economy'

Winn, JK and Webber, M (2006) 'The Impact of EU Unfair Contract Terms Law on U.S. Business-to-Consumer Internet Merchants' 62 The Business Lawyer, available at http://goo.gl/zqFRJ

Wizzit (s.d.) ‘Terms \& Conditions’, available at http://goo.gl/YcAYJ.

Wizzit (2011) Personal Communication

Wolverton, T (2002) ‘FDIC Decides PayPal's No Bank', available at http://goo.gl/RWYQu

Woodward, SE (1998) 'Regulatory Capture at the U.S. Securities and Exchange Commission' Sand Hill Econometrics Working Paper, available at http://goo.gl/um9Hh

World Bank (2001) World Development Report 2000/2001: Attacking Poverty

World Bank (2010) 'Remittance Prices Worldwide' No 2, November, available at http://goo.gl/m5poF

World Bank (2011a) 'Migration and Remittances Unit: Migration and Development Brief 16 - Outlook for Remittance Flows 2011-13', available at http://goo.gl/SZ17Q

World Bank (2011b) 'Remittance Prices Worldwide: South Africa', available at http://goo.gl/s9rMz

World Economic Forum (2011) The Mobile Financial Services Development Report 2011

World Wide Worx (2012) 'Mobility 2012: The Mobile Consumer in South Africa 2012', available from http://goo.gl/WqVfX.

Wray, LR (1990) Money and Credit in Capitalist Economies: The Endogenous Money Approach

Wray, LR (1998) Understanding Modern Money: The Key to Full Employment and Price Stability

Wray, LR (2001a) 'Money and Inflation' in RPF Holt A New Guide to Post Keynesian Economics

Wray, LR (2001b) 'Understanding Modern Money' Paper presented at the Workshop Understanding Unemployment in Australia, Japan and the USA: A Cross Country Analysis, 10 and 11 December, available at http://goo.gl/mXabr

Wray, LR (2006) 'The Credit Money, State Money, and Endogenous Money Approaches: A Survey and Attempted Integration', available at http://goo.gl/zig59

Wray, LR (2010a) 'Money Levy’ Economics Institute Working Paper No 647, available at http://goo.gl/qPn16 
Wray, LR (2010b) 'Keynes’s Approach to Money: What can be Recovered?', available at http://goo.gl/7aeUT

Wray, LR (2011) 'MMP Blog \#20: Effects of Sovereign Government Budget Deficits on Saving, Reserves and Interest Rates, (continued)' New Economic Perspectives, available at http://goo.gl/j0Eky

Wray, LR (ed) (2004) Credit and State Theories of Money: The Contributions of A. Mitchell Innes (Chapters 2 and 3 written by AM Innes), available at http://goo.gl/PRAlb

Yang, C (2005) ‘Electronic Money and Relevant Legal and Regulatory Issues', available at http://goo.gl/QOGAV

Younkins, EW (2005) ‘Aristotle and Economics', available at http://goo.gl/ptDd4

Zarnowski, CF and McDermott, M (1986) ‘The Non-bank Bank Impasse', available at http://goo.gl/2Tt85

Zazzaro, A (2002) 'How Heterodox is the Heterodoxy of the Monetary Circuit Theory? The Nature of Money and the Microeconomy of the Circuit', available at http://goo.gl/GH9kX

Zelizer, VA (1989) 'The Social Meaning of Money: "Special Monies"” 95(2) American Journal of Sociology 342-377, available at http://goo.gl/4BDpL

Zelizer, VA (1994) The Social Meaning of Money: Paychecks, Poor Relief and Other Currencies

Zelizer, VA (2000) 'Fine Tuning the Zelizer View’ 29(3) Economy and Society 383-9

Zelizer, VA (2007) 'Pasts and Futures of Economic Sociology' 50 American Behavioral Scientist 1056, available at http://goo.gl/93nXO.

Zimmermann, R (1996) The Law of Obligations: Roman Foundations of the Civilian Tradition

Zimmermann, R, Visser, D and Reid, K (2006) Mixed Legal Systems in Comparative Analysis: Property and Obligations in Scotland and South Africa

Zingales, L (2004) 'The Costs and Benefits of Financial Market Regulation' ECGI Law Working Paper No 21/2004, available at http://goo.gl/mgAIf 


\section{INDEX}

ABSA

MFS in SA

12.2.4

ADDITIVE BANKING

MFS

2.2

MFS

MFS

AGENT

As Community Bankers

6.4 .2

Cash Merchants

2.5.2

Due Diligence

10.3.1

Electronic

12.9.2.2.3

Introduction

2.1

MFS

7.2.6.4

Overview

2.5.2

Overview

7.2.6.3

SA

12.3.6

Use In MFS

2.3

Use Of In MFS

AIRTIME TRANSFERS

By Banks

12.3.7.6.2

CMA

12.3.7.6.2

Non-CMA

12.3.7.6.2

MFS

6.5.4.3

ALLOCATION OF FAULT

Mistaken Payment

7.3.6.2

Unauthorised Payments

7.3.6.3

ALLOCATION OF LOSS

Agents

7.3.6.5.6.2

Banks

7.3.6.5.3

Contract vs Delict

7.2.5.2

Customers

7.3.6.5.4

EU: Rules For

9.6.2.5

Generally

7.3.6.5.1

Intermediaries

7.3.6.5.6.3

Non-Banks

7.3.6.5.5

Rules: EU, SA, USA, Kenya

12.11 
ANTI-MONEY LAUNDERING

ARISTOTLE

BANK

BANK MONEY

BANK SUPERVISION DEPARTMENT

BANKING

BANKS ACT 94 Of 1990

Business Of Banking

Deposits

Overview

Tests

Kenya

US

SA

EU
9.5

12.7.1

8.5

9.10

10.3

11.3

12.7

3.4 .2

3.2.3.4

3.9.1

3.9.1

3.2.3.4

3.2.3.4

3.2.4.1

4.5.1

4.5.2

7.3.6.5.3.1

3.7.1

12.3.2.1.2

4.3.1

4.3.2

12.3.5.2.1

12.3.5.2.2

12.3.5

12.3.5.2.1

10.2

11.2

12.3 
BASLE I, II, III

BILATERAL

BILLING

BOTTOM OF PYRAMID

BREACH OF CONTRACT

BUSINESS OF BANKING

CAPACITY

CASH MERCHANTS

CAVEAT SUBSCRIPTOR

CUSTOMER DUE DILGENCE

CENTRAL BANK
Bank Capital Requirements

Juristic Act, Payment

a la carte

5.4 .4 .1

Periodic

Periodic

Postpaid

Prepaid

Definition

Versus Delict

7.2.5.2

Banks Act

Overview

UDT

In MFS

General

MFS

Agents

Contract

7.2.2.31

Overview

SA

Prototypical Bank

Role

3.5.3

11.2.4.2.2

CONSUMER FINANCIAL PROTECTION Overview BUREAU

CHARTAL

Knapp

3.10 .1

CHARTALISM

Knapp

3.10 .1 
Use By FA Mann

3.2 .1

CIRCUITISM

CLAIM SCHOOL

CLEARING

CODE OF BANKING PRACTICE

COMMUNITY BANKERS

COMPETITION COMMISSION

CONDICTIONES

CONSENSUS

CONSUMER PROTECTION

CONSUMER PROTECTION LAWS

CONTRACT
Money

3.7.2.1

Overview

3.10

UOA

3.10.2.1

Definition

4.8.2.2

Overview

7.3.6.5.4

SA

12.3.2.10

SA Banks

12.3.2.10

Standard Bank

6.4 .2

Banks And Payments Enquiry

12.5

Actions To Recover Value

7.3.6.7

MFS

7.3.6.8

Types

7.3.6.8

Contract

CPA

12.10

NCC

12.3.2.6

NCT

12.3.2.6

ECTA

12.9.2.2.5

ECTA

12.9.2.2.5

Kenya

9.13

US

10.6

SA

11.6

EU

12.11

$\begin{array}{ll}\text { Black List, CPA } & 12.10 .1 \\ \text { Consensus } & 7.2 .2 .2 \\ \text { Dissensus } & 7.2 .3 .3 \\ \text { Duress } & 7.2 .2 .3 .2 \\ \text { Formation } & 7.2 .2 \\ \text { Fraud } & 7.2 .2 .3 .3\end{array}$




\section{Grey List, CPA}

Misrepresentation

Mistake, Electronic Transacting

Naturalia

Undue Influence

Unfair Terms

\begin{abstract}
CONSUMER PROTECTION ACT 68 OF 2008
\end{abstract}

CREDIT THEORY

CURRENCY

DATA MESSAGE

DEDICATED BANKS BILL

DEPOSIT

DISPUTE RESOLUTION

DODD- FRANK
Overview

Black List Of Terms

Grey List Of Terms

Interplay With ECTA

Jurisdiction

Prepaid Vouchers

Of Money

Versus Money

ECTA

ECTA And MFS

12.9 .1

7.3.5.2

12.3.5.5

Deposit Concept

4.10

History

4.4.2

Legal \& Economic Effects

4.4.4

Nature

4.4.3

Prudential View

4.4.5

Time-Relation

6.4 .2

9.6.3.2.4

USA

11.2.5.5

OBSSA

12.3.2.10

WASPA

USA

11.2.4.2 
E-COMMERCE LAWS
Kenya

ES

SA

EU

Overview

ACT 36 OF 2005

ELECTRONIC COMMUNICATIONS

AND TRANSACTIONS ACT 25 OF 2002

Overview

Interplay With CPA

12.10

12.10.2.2.6

ELECTRONIC FUNDS TRANSFER

E-MONEY

E-MONEY CONTROL

EXCHANGE CONTROL

FINANCIAL ACTION TASK FORCE

FEDEREAL COMMUNICATONS COMMISSION

FEDERAL DEPOSIT INSURANCE CORPORATION

FEDERAL RESERVE BOARD
4.8.4.2

Types

Intro

Legal Tender

SA

SA Interoperability

Kenya

US

SA

12.4

Airtime Transfer

Overview

Remittances

SARB

Overview

40+9 Principles for AML

SA

Overview

11.2.5.2

Overview

11.2.2.5

Overview

11.2..2.2 
FINANCIAL INTELLIGENCE CENTRE Overview

FINANCIAL EXCLUSION

Definition

2.1

National Treasury

12.1

FINANCIAL INCLUSION

FIRST NATIONAL BANK

FOLEY V HILL

FRACTIONAL BANKING

FRAUD

GAME

GOLD STANDARD

Keynes View Of

3.2.3.4

Use of in Money

HACKING

Malware

5.7.4.4

Man In Middle

5.7.5.3

Overview

5.7 .4

Phishing

5.7.4.1

Spoofing

5.7.4.2

Two-Factor Security

5.7.4.4

Viruses

5.7.4.4

Payment Systems

4.8.2

HIERARCHY

INDEPENDENT COMMUNICATIONS

AUTHORITY OF SOUTH AFRICA
SA

AML

12.8.3.1 
Overview $\quad 2.5 .1$

Remittances

4.8.4.3

Store of Wealth

3.7.2.2

Use In Money Laundering

3.7.2.2

WASPs

6.5.4.2

ECTA And MFS

7.3.5.2

INFORMATION SYSTEM

INSIDE MONEY

Type of

3.13

Banks

3.14

3.5.3.3.2

Of Money, Credit

3.2.3.4

E-Money In SA

12.4.2

SARB

12.4.2.3

SVPs

4.8.4.4.5

WASP

6.5.4.2.3

MFS Usage Statistics

10.1

Money Of Account

View of Gold Standard

View of Money

3.10 .2

Chartalism

3.10 .1

State Theory

3.10 .1

Overview

8.5

SA

12.7.1

Exemption 17

12.7.3

Banking

4.2

E-Money

4.8.4.4.11

Transaction Values

4.8.2.4.1 
MANDATE

MANN, FA

MOBILE FINANCIAL SERVICES

MICROPAYMENTS

MILLER V RACE

MINORS

MISTAKE

MNO

MOBILE COMMERCE

MOBILE MONEY

MOBILE PHONE

MODERN MONEY THEORY

MONEY
Overview

7.2.6.2

Definition Of Money

3.2.3.5

Money Definition

Money Use In Law

Additive Banking

2.2

2.3

2.4

Bank-Led Model

6.4

Compared To E-Commerce

2.5

Definition

2.1

Independent MFSP Model

6.6

MNO-led model

6.5

Overview

4.8.2.4.2

Transaction Values

4.8.3.5

Money As Currency

3.12.2.2

No Earmark

13.3.4

Transacting

7.2.2.5.2

Electronic Transacting

12.9.2.2.4

Security

Introduction

2.1

Use Of Term

2.1

Operating Systems

Overview

3.3

Bank Money

3.7.1

Barter

Claim School 


$\begin{array}{ll}\text { Dematerialised } & 3.2 .2 \\ \text { Dematerialised Forms } & 13.1 \\ \text { Inside Money } & 3.5 .3 .3 \\ & 3.13 \\ \text { Institutional Theory } & 3.2 .3 .4 \\ \text { Mann Definition Of } & 3.2 .3 .5 \\ \text { Means Of Exchange, } & 3.2 .1 \\ \text { Miller } v \text { Race } & 3.12 .2 .2 \\ \text { Money Of Account } & 3.10 .2 . \\ \text { Moss } v \text { Hancock } & 3.2 .3 .5 \\ \text { No Earmark } & 3.12 .2 .2 \\ \text { Orthodox School } & 3.9 \\ \text { Outside Money } & 3.5 .3 .2 \\ \text { Scriptural } & 3.7 .2 \\ \text { Societary Theory } & 3.2 .4 .1 \\ & 13.6 .3 \\ \text { State Theory } & 3.2 .4 .1 \\ \text { Types } & 3.2 .2\end{array}$

MONEY OF ACCOUNT

Claim School

3.10.2.1

13.5

Keynes

3.10.2.1

MONEY TRANSFER ORGANIZATION

Remittances

8.4.2.3.3

MOSS V HANCOCK

Criticism Of Moss's Money

Definition

3.2.3.5

Orthodox school

3.9.1

M-PESA

Kenya

10.1

South Africa

12.2.6

MONEY SERVICE BUSINESSES

US

11.2.4.14

MTN

MTN Banking

12.2.5

NASHUA

Phishing 
NATIONAL CONSUMER TRIBUNAL

NATIONAL PAYMENT SYSTEM

OF 1998

CPSP

NATIONAL PAYMENT SYSTEM

DEPARTMENT

NATIONAL TREASURY

NEDBANK

NETTING

NEAR FIELD COMMUNICATIONS

NEW MONENTARY ECONOMICS

NO EARMARK

NOMINALISM

NUMERAIRE
CPA

Enforcement

CPA

12.3.2.6.2

BSP

12.3.7.4.8

Overview

Structure

TPPP

SA

Payment Due

SA

Financial Inclusion

12.1

12.10.1

12.10.2.2.5

12.3.7.4.6

4.8.2.3.1

12.3.7.3

12.3.7.4.8

12.3.7.2

12.3.7.6.2

12.3.2.1.3

M-pesa

12.2.6

Payment

4.8.2.2

Overview

5.5.6.5

Claim School

3.10 .1

Rule Of Money

13.6.5

3.12.2.2

Miller v Race

13.3.4

3.12.3.2.2

3.5.1

3.5 .1

3.10.2.1 
OMBUDSMAN FOR BANKING SERVICES OF SA

ONE TIME PASSWORD

Security In Transactions

5.7.4.4

ORTHODOX SCHOOL

Vodacom Agents

MFS Agents

Overview

PACTA SUNT SERVANDA

PAYMENTS ASSOCIATION OF SOUTH AFRICA

PAYMENT

PAYMENT SERVICE PROVIDER

Recommendation

PAYMENT SERVICES PROVIDER LAW

Recommendation

Recommendation

AUTHORITY

PAYMENT SYSTEM

PAYMENTS

Abstract Theory

Clearing

Flows

Forms
3.5.3.2

3.7.2.1

14.9.3

7.2.2.2

4.8.2.2

4.8.3.9

13.2.3

13.3.1

12.2.6

6.4.3.3

7.2.1

12.3.2.11

7.3.1

7.3.5

7.3.6.2

7.3.2

7.3.2.1

s14.9.3

14.9 .7

4.8.

4.8.4 
Hierarchy $\quad 4.8 .2$

National Payments

4.8.2.3.1

Netting

4.8.2.2

Offline/Online

4.8.3.6

Participants

4.8.2.3.2

Network-based Payments

4.8.4.4.4.2

Examples

5.7.4.1

Nashua

5.7.4.1

7.3.6.5.6.2

Use Of For SVPs

4.8.4.4.6

Longevity Under CPA

12.10.2.2.2

Exchange Rates

4.8.4.4.4.1

Interoperability

4.8.4.4.4.5

Consumer Protection

8.8

Implementation

8.9

Money Laundering

8.5

Regulatory Domains

8.4.2.3.3

Types

5.4.4.1

VAS

6.5.4.2

WASP

6.5.4.2.1

7.2.2.4

5.3 .4

7.2.2.4

WASP

In Mobile

5.2 .2

112.4 .5

REGULATION E

USA

Functional Approach

Institutional Approach

Philosophy

Proportional 
EFT

FATD

RICA

SA

12.8.4.2

SIM Card

12.8.4.2

SIM Card Registration

RISK

Allocation Of

See also ALLOCATION OF FAULT, and ALLOCATION OF LOSS

SAFARICOM

M-pesa Kenya

2.6

MFS

10.1

SAMOS

SA

12.3.7.4.1

SECURITY

Transaction

12.9.2.2.7

Threats

SELF REGULATION

WASPA

6.5.4.2.4

SETTLEMENT

In Payments

4.8.2.2

SHADOW BANKING

Unbanked

2.1

SIM CARD

$\begin{array}{ll}\text { Mobile Phones } & 12.8 .4 .2 \\ \text { Phishing } & 5.7 .4 .1 \\ \text { Phishing } & 5.5 .3 .2 \\ \text { Phishing } & 5.7 .3 \\ \text { RICA Registration } & 5.7 .4 .1 \\ \text { Swap } & 5.2 .2\end{array}$


SOUTH AFRICAN RESERVE BANK

STORE OF VALUE

SPOOFING

STANDARD BANK

STATE THEORY

STORED VALUE CARDS

STORED VALUE PRODUCTS

SYSTEMIC RISK

TELECOMMUNICATIONS

TELECOMMUNICATIONS LAWS

Overview
BSD
E-Money Position Papers

NPSD

Overview

MFS

Mobile Numbers

Agents

SA

Of Money

In a SVP

As a SVP

Overview

Overview

As Money

Overview

Basic Mobile Services

Kenya

US

SA

EU
12.2.5

3.10 .1

3.2.4.1

3.9.2.3

4.8 .1

9.11

12.3 .2 .1

12.3.2.1.2

12.4

12.3.2.1.3

2.1

13.1

5.7 .4 .2

6.4 .2

2.1

2.2

4.8.4.4

2.1

13.1

10.4

11.4

12.8 
TRANSACTION

TRANSACTION

TRANSFORMATIONAL BANKING

TRUST ACCOUNT

TRUSTS

UBANK

UNIFORM MONEY SERVICES ACT

UNBANKED

UNDERBANKED

UNDERSERVED

UNDUE INFLUENCE

UNIT OF ACCOUNT

UNITED DOMINION TRUST

VALUE ADDED SERVICES

VODACOM

WIRELESS APPLICATION PROTOCOL Use in Mobile; In MFS
7.4

7.4

12.2 .8

11.2.4.15

10.1

Overview

11.1

2.1

2.1

2.1

3.10.2.1

13.5.2

3.9.2.1

13.2.2

4.3.2

6.5.4.2.1

12.2.6 
Debtor-Creditor

Parties To Transaction

Payment \& Settlement

SA

Relationships

Code Of Conduct

MFSP
7.2.2.5.3

7.2.6.4.3

6.5.4.2.2

7.3.2.2.2

6.5.4.2.1

12.8.3.2

12.2.7 